QA: QA

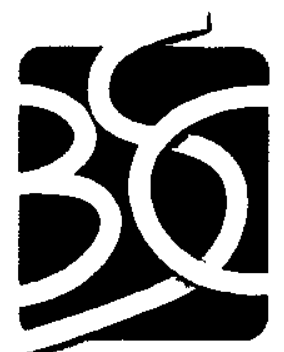

BECHTEL SAIC conpawruc

\title{
Multiscale Thermohydrologic Model
}

ANL-EBS-MD-000049 REV 02

\section{October 2004}

Prepared for:

U.S. Department of Energy

Office of Civilian Radioactive Waste Management

Office of Repository Development

1551 Hillshire Drive

Las Vegas, Nevada 89134-6321

Prepared by:

Bechtel SAIC Company, LLC

1180 Town Center Drive

Las Vegas, Nevada 89144

Under Contract Number

DE-AC28-01RW12101 


\section{DISCLAIMER}

This report was prepared as an account of work sponsored by an agency of the United States Government. Neither the United States Government nor any agency thereof, nor any of their employees, nor any of their contractors, subcontractors or their employees, makes any warranty, express or implied, or assumes any legal liability or responsibility for the accuracy, completeness, or any third party's use or the results of such use of any information, apparatus, product, or process disclosed, or represents that its use would not infringe privately owned rights. Reference herein to any specific commercial product, process, or service by trade name, trademark, manufacturer, or otherwise, does not necessarily constitute or imply its endorsement, recommendation, or favoring by the United States Government or any agency thereof or its contractors or subcontractors. The views and opinions of authors expressed herein do not necessarily state or reflect those of the United States Government or any agency thereof. 
QA: QA

Multiscale Thermohydrologic Model

ANL-EBS-MD-000049 REV 02

October 2004 


\begin{tabular}{|l|l|l|}
\hline OCRWM & MOdEL SignATURE PAGE/CHANGE HiSTORY & Page uii \\
\cline { 2 - 3 } & 1. Total Pages: 606 \\
\hline
\end{tabular}

2. Type of Mathematical Model

$\bigotimes$ Process Model

D Abstraction Model

System Model

Describe Intended Use of Model

This model provides thermohydrologic information and data for other reports supporting License Application. Limitations of the model are that drift seepage during the post-boiling period is not predicted, and the predicted evaporation rate on the drip shield pertains to the case of no dripping on the drip shield.

\section{Title}

Multiscale Thermohydrologic Model

4. Dl (including Rev. No., if applicable)?

ANL-BBS-MD-000049 REV 02

5. Total Appendices

15 (Fifteen)

6. No. of Pages in Each Appendix

I-18, II-6, III-6, IV-26, V-18, VI-6, VII-6, VIII-6, $\mathrm{IX}-14, \mathrm{X}-30, \mathrm{XI}-12, \mathrm{XII}-24, \mathrm{XIII}-32, \mathrm{XIV}-6, \mathrm{XV}-26$

\begin{tabular}{|c|c|c|c|}
\hline & Printed Name & Signature & Date \\
\hline 7. Originator & T. A. Buscheck & & $10 / 11 / 04$ \\
\hline $\begin{array}{l}\text { 8. Independent Technical } \\
\text { Reviewer }\end{array}$ & R. Andrews & & \\
\hline 9. Checker & B. Kirstein & & $10 / 12 / 04$ \\
\hline 10. QER & D. Svalstad & & \\
\hline 11. Responsible ManagertLead & C. Howard & & $1 /$ \\
\hline 12. Responsible Manager & E. Hardin & ELifa & $10 / 12 / 0$ \\
\hline
\end{tabular}

13. Remarks

Brian Mitcheltree checked Sections 4,5, and Appendix IV; Bruce Kirstein checked from the front through Section 3 and Sections 6.3 through 6.5,7 and 8, and Appendices IX and XIII; John Case checked Sections 6 through 6.2, Section 9, and DIRS; Jim Kam checked Appendices I through III, V through VIII, X, XII and XV; Zane Walton checked Appendix XI; Bob Walsh checked Appendix XIV.

Revision 02 addresses CR 79 (elimination of "Technical Information" as a DIRS Input Category), CR 1805 (adequacy of software) and CR 2049 (documentation of model validation). TABLE 4.1-1 CHANGED EQUATIONI NUMEER. Change History

\begin{tabular}{|l|l|}
\hline \multicolumn{1}{|c|}{ 14. Revision No. } & \multicolumn{1}{|c|}{ 15. Description of Change } \\
\hline 00 & $\begin{array}{l}\text { Original issue. Supported TSPA-SR, Rev 00 for the Backfill Case. Used 1.54 } \\
\mathrm{kW} / \mathrm{m} \text { line load. }\end{array}$ \\
\hline
\end{tabular}




\begin{tabular}{|c|c|}
\hline 00 ICN 01 & $\begin{array}{l}\text { This ICN was developed to include the No Backfill Case supporting TSPA-SR } \\
\text { Rev 00 ICN 01. The DTN:SN9908T0872799.004 references were removed. } \\
\text { The data and inputs were referenced to updated DTNs and references, or } \\
\text { entered as assumptions. Revised invert thermal conductivity values and an } \\
\text { adjusted heat load of } 1.45 \mathrm{~kW} / \mathrm{m} \text { were used for the no-backfill case. }\end{array}$ \\
\hline 00 ICN 02 & $\begin{array}{l}\text { This ICN was developed to address the NRC KTI Agreement TEF } 2.9 \text { and } \\
\text { show the influence of drift-scale fracture heterogeneity on TH behavior for the } \\
\text { No Backfill Case. This was accomplished with the use of the 3-D } \\
\text { heterogeneous Line-averaged heat-source Drift-scale TH (LDTH) model, } \\
\text { which was developed for this ICN, and which is completely described in } \\
\text { Section 6.14. The 3-D heterogeneous LDTH model is based on the 2-D } \\
\text { homogeneous LDTH model. The data and inputs were referenced to updated } \\
\text { DTNs and references, or entered as assumptions. Section } 7 \text { has also been } \\
\text { updated to include the conclusions developed from the 3-D heterogeneous } \\
\text { LDTH model. A postprocessor, XLDTH, was developed and used to address } \\
\text { the influence of drift-scale heterogeneity of fracture properties as described } \\
\text { above. This postprocessor is qualified in accordance with the currently } \\
\text { approved version of AP-SI.1Q, Software Management. } \\
\text { Deficiency Report LVMO-00-D-039, Inaccurate Documentation and } \\
\text { Validation of Software Routines and/or Macros, identified software issues that } \\
\text { are addressed in MOL.20010910.0181 (Schreiner, R.L. 2001; Stand Alone } \\
\text { DR-39 package for ANL-EBS-MD-000049, Rev. 00, ICN01, Multiscale } \\
\text { Thermohydrologic Model). Attachment I contains a cross-walk between } \\
\text { attachments in the Stand Alone Package and the attachments formerly } \\
\text { included in this AMR. The Stand Alone package provides additional software } \\
\text { documentation, e.g., source code listings, validation text files, input/output } \\
\text { files and other corrections for routines formerly documented in Attachments I } \\
\text { through XVII and XIX through XX of ICN 01 of this AMR. } \\
\text { Attachment II in this ICN 02 lists files supporting each version of this } \\
\text { document, including the file lists previously documented in Attachment XVIII } \\
\text { of ICN 01. ICN 02 also addresses in Section } 2 \text { the issues and concerns } \\
\text { identified in Deficiency Report BSC-01-D-100, pertaining to control of } \\
\text { electronic information. ICN 02 also addresses NRC KTI agreements pertinent } \\
\text { to this AMR, in Section 1. The following sections have been affected by this } \\
\text { ICN: Section 1, Section 2, Section 3, Section 4, Section 5, Section 6, Section } \\
\text { 7, Section 8, Attachment I and Attachment II }\end{array}$ \\
\hline 01 & Complete revision to support TSPA-LA. \\
\hline
\end{tabular}


Extensive revision to address comments on documentation from Regulatory Integration Team evaluation. Includes major revisions to the following sections: 4.1, 5.3.1.1, 5.3.1.7, 5.4, 6.1.4, and 6.2.1. Some material previously in Section 5 has been moved to Section 4.1. Section 4.1 has been extended to describe the minor modifications to the repository layout that resulted from updates to the related IEDs and to address the properties of the host-rock rubble for the low-probability-seismic collapsed-drift cases.

Sections 6.2.9, 6.2.10, and 6.2.11 have been added to describe the submodels for the low-probability-seismic collapsed-drift cases. Section 6.3.3 has been added to discuss the mass influx in the invert. Section 6.3 .4 has been added to address the influence of parametric uncertainty of percolation flux and hostrock thermal conductivity on near-field and in-drift thermal-hydrologic conditions. Section 6.3.5 is a revised summary of the range of predicted nearfield and in-drift thermal-hydrologic conditions for the TSPA-LA base case. Section 6.3.6 has been added to describe the relationship between dripshield/waste-package relative humidity and temperature at the drift wall. Section 6.3.7 has been added to describe the differences in the in-drift thermalhydrologic conditions between the low-probability seismic collapsed-drift cases and the corresponding nominal intact-drift cases. Section 6.3.7 also includes a seepage analysis for the low-probability-seismic collapsed-drift cases. Section 6.3.8 has been added to compare thermal-hydrologic condition predicted for the TSPA-LA with those predicted for the TSPA-SSPA. Section 6.3.9 has been added to describe the sensitivity (or lack thereof) of near-field and in-drift thermal-hydrologic conditions to host-rock hydrologic-property variability and uncertainty. Section 6.3.10 has been added to describe the sensitivity (or lack thereof) of in-drift thermal-hydrologic conditions to the value of in-drift pseudo permeability. Section 6.3.11 has been added to describe the sensitivity (or lack thereof) of near-field and in-drift thermalhydrologic conditions to invert hydrologic-property variability and uncertainty. Section 6.3.12 has been added to investigate the sensitivity of indrift thermal-hydrologic conditions to uncertainty in ventilation heat-removal efficiency. Section 6.3.13 has been added to describe the relationship between temperature and relative humidity on waste packages.

Added Appendix X: Hydrological Properties for the Intragranular Porosity of the Invert; Appendix XI: Thermoconductivity of the Collapsed Drift Zone; and Appendix XII: Comparison of Percolation Fluxes; Appendix XIII: List of Data Sources for Figures and Tables; and Appendix XIV: Qualification of Unqualified Project Data. 


\begin{tabular}{|l|l|}
\hline & $\begin{array}{l}\text { Revised Sections 7.4.3 and 7.4.4: Comparison of Simulated and Field- } \\
\text { Measurement Temperatures, and Comparison of Simulated and Field- } \\
\text { Measured Saturations in the Matrix; and Appendix VI: LDTH and DDT } \\
\text { Submodel Thermal-Radiation Connection Calculation. Added Section 5.1.4: } \\
\text { Timing of Climate Change Influence on Percolation Flux above Repository; } \\
\text { Section 5.1.5: Water Table Rise; Section 5.3.1.10: Permeability of Host Rock } \\
\text { at Emplacement Drift-Wall Surface; Section 5.3.2.7: Emissivity of } \\
\text { Emplacement Drift Wall; Section 8.4: Yucca Mountain Review Plan Criteria } \\
\text { Assessment; and Appendix XV: Prediction of Relative Humidity in the Invert. }\end{array}$ \\
\hline
\end{tabular}




\section{CONTENTS}

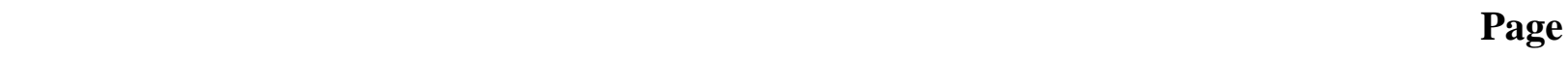

ACRONYMS AND ABBREVIATIONS ...................................................................... xxvii

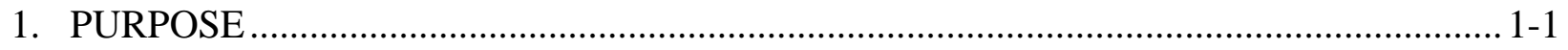

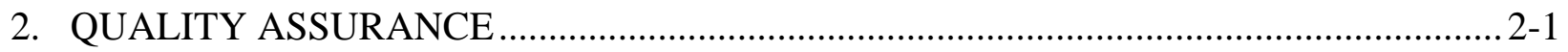

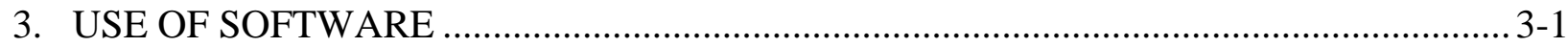

3.1 QUALIFIED SOFTWARE ……………......................................................... 3-1

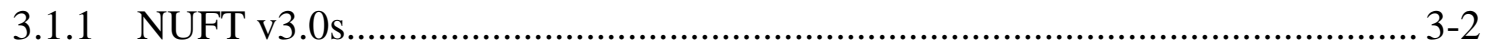

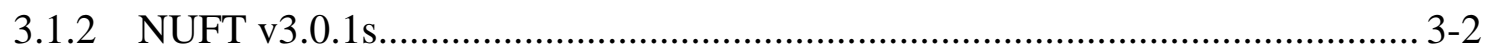

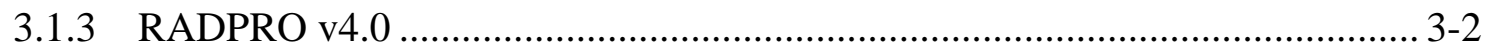

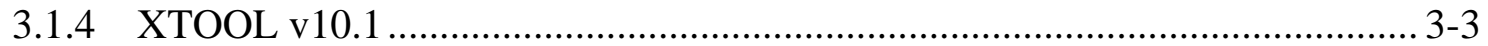

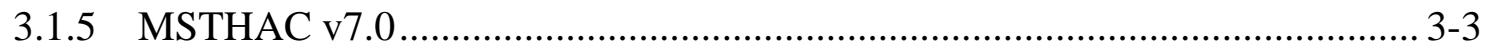

3.1.6 readsUnits v1.0 ……....................................................................... 3-3

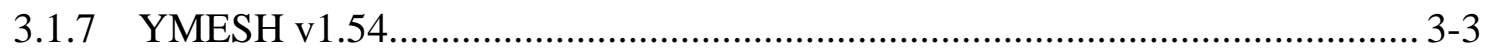

3.1.8 boundary_conditions v1.0............................................................................ 3-4

3.1.9 heatgen_ventTable_emplace v1.0................................................................ 3-4

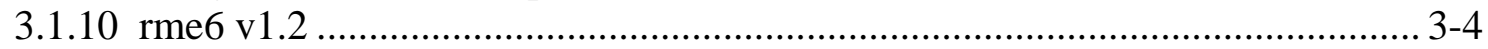

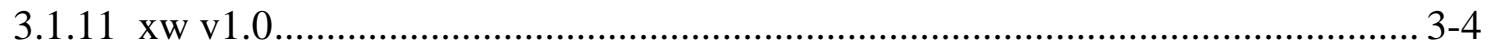

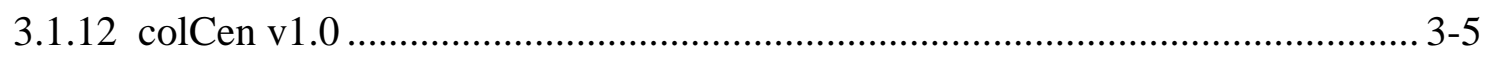

3.1.13 repository_percolation_calculator v1.0.......................................................... 3-5

3.1.14 extractBlocks_EXT v1.0......................................................................... 3-5

3.1.15 Chimney_interpolate v1.0................................................................. 3-5

3.1.16 reformat_EXT_to_TSPA v1.0 ............................................................... 3-6

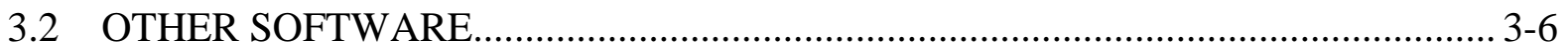

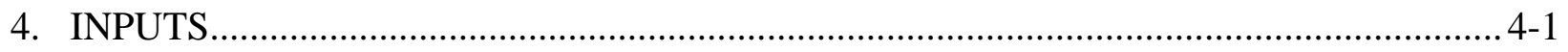

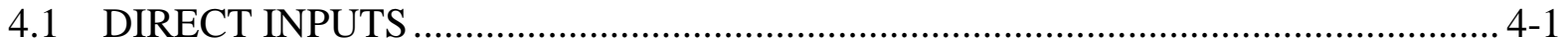

4.1.1 Data, Parameters, and Parameter Uncertainty ……............................................ 4-1

4.1.2 Design Information .................................................................................. 4-1

4.1.3 Direct Inputs for Development of the Properties of Crushed Tuff in the

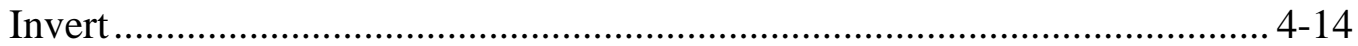

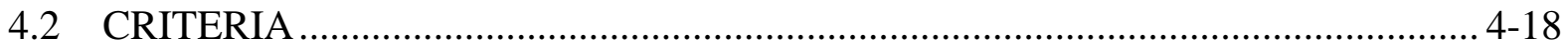

4.2.1 Acceptance Criterion 1 - System Description and Model Integration Are Adequate ................................................................................................ 4-19

4.2.2 Acceptance Criterion 2 - Data Are Sufficient for Model Justification ........... 4-20

4.2.3 Acceptance Criterion 3 - Data Uncertainty Is Characterized and Propagated Through the Model Abstraction.................................................... 4-21

4.2.4 Acceptance Criterion 4 - Model Uncertainty Is Characterized and Propagated Through the Model Abstraction....................................................... 4-21

4.2.5 Acceptance Criterion 5 - Model Abstraction Output Is Supported by Objective Comparisons................................................................................ 4-22

4.3 CODES, STANDARDS, AND REGULATIONS................................................. 4-22 


\section{CONTENTS (Continued)}

Page

4.4 DATA FROM FIELD MEASUREMENTS IN THE LARGE BLOCK TEST AND DRIFT SCALE TEST …..................................................................... 4-22

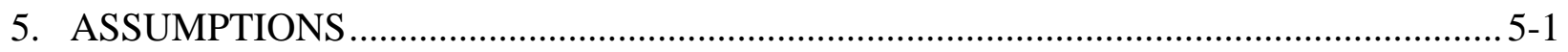

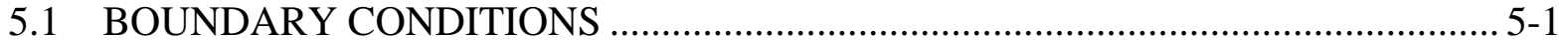

5.1.1 Ground-Surface Relative Humidity …............................................................ 5-1

5.1.2 Ambient Percolation Flux above Repository Horizon.................................... 5-1

5.1.3 Barometric Pressure Fluctuations at the Ground Surface ............................... 5-2

5.1.4 Timing of Climate Change Influence on Percolation Flux above

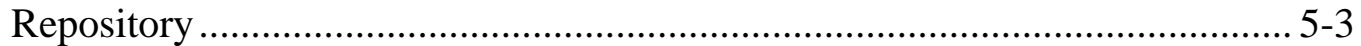

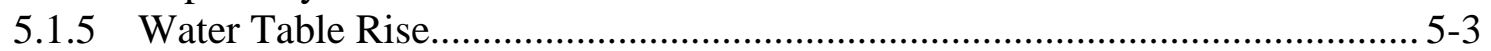

5.2 HEAT FLOW PROCESSES ....................................................................... 5-4

5.2.1 Mountain-Scale Heat Flow ...................................................................... 5-4

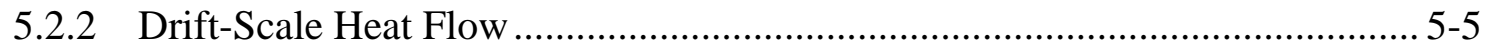

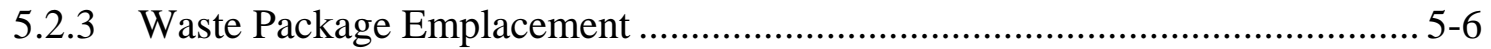

5.3 MATERIAL PROPERTIES ......................................................................... 5-6

5.3.1 Hydrologic Properties .......................................................................... 5-6

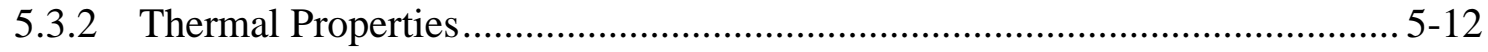

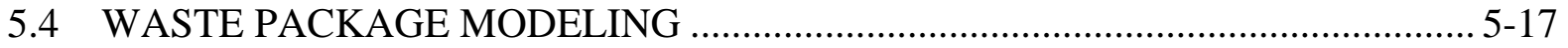

5.4.1 Average Waste Package Diameter ........................................................... 5-17

5.4.2 Waste Package Sequence along Drifts................................................... 5-17

5.5 RELATIVE HUMIDITY IN EMPLACEMENT DRIFTS.................................... 5-18

5.6 CONDENSATE DRAINAGE AROUND EMPLACEMENT DRIFTS .................. 5-19

5.7 GAS- AND LIQUID-PHASE FLOW IN THE LONGITUDINAL DIRECTION ALONG EMPLACEMENT DRIFTS (THE COLD-TRAP EFFECT) ...................... 5-19

5.8 PROPERTIES OF HOST-ROCK RUBBLE FOR LOW-PROBABILITYSEISMIC COLLAPSED-DRIFT SCENARIO................................................ 5-20

5.8.1 Bulk Density of Host-Rock Rubble ...................................................... 5-20

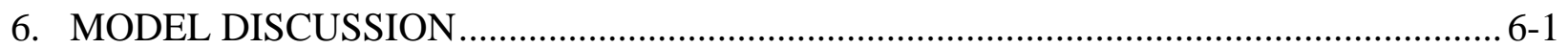

6.1 YUCCA MOUNTAIN THERMOHYDROLOGY CONCEPTUAL MODEL ............ 6-4

6.1.1 Ambient Hydrology and Geology........................................................... 6-4

6.1.2 Incorporating Radioactive Decay Heat .................................................... 6-5

6.1.3 Thermohydrology in the Repository Host Rock ........................................... 6-6

6.1.4 Thermohydrology in Repository Emplacement Drifts ................................ 6-7

6.1.5 Design Factors Influencing Thermohydrology .......................................... 6-9

6.1.6 Natural System Factors Influencing Thermohydrology ............................... 6-10

6.2 THE MULTISCALE THERMOHYDROLOGIC MODELING APPROACH ......... 6-10

6.2.1 Overview of the MSTHM................................................................ 6-10

6.2.2 Incorporating the Unsaturated-Zone Hydrology Model in the MSTHM........ 6-14

6.2.3 Governing Equations for Unsaturated-Zone Thermohydrology .................... 6-17

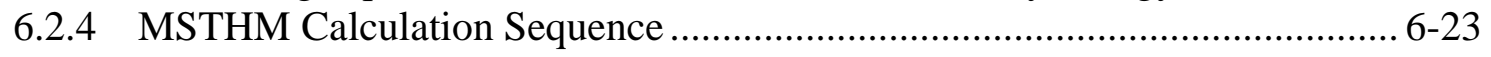

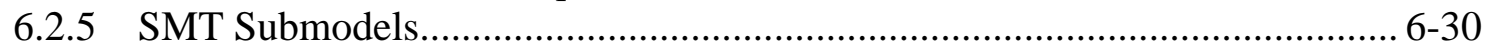




\section{CONTENTS (Continued)}

Page

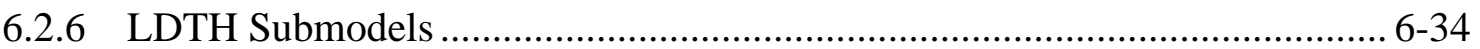

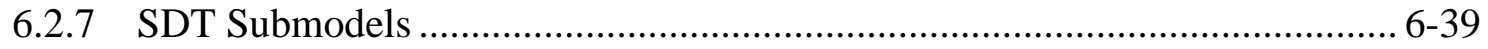

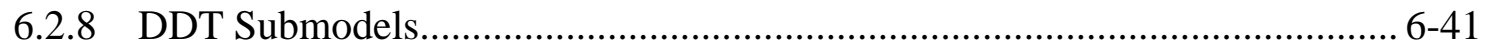

6.2.9 SMT and SDT Submodels for the Low-Probability-Seismic Collapsed-Drift Scenario .............................................................................. 6-46

6.2.10 LDTH Submodels for the Low-Probability-Seismic Collapsed-Drift Scenario.................................................................................................. 6-46

6.2.11 DDT Submodels for the Low-Probability-Seismic Collapsed-Drift

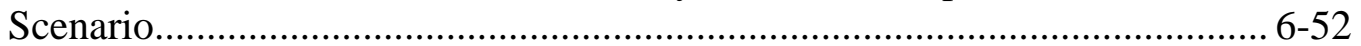

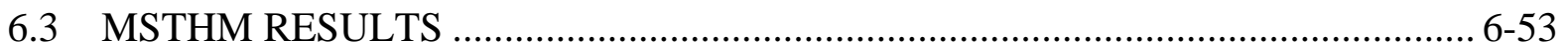

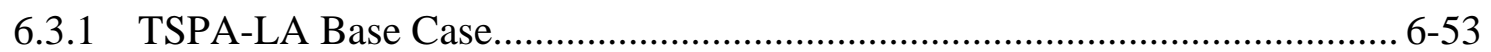

6.3.2 Parameter-Uncertainty-Sensitivity Analyses ................................................ 6-88

6.3.3 Mass Flux in the Invert ........................................................................ 6-117

6.3.4 Combined Influences of Percolation-Flux and Host-Rock Thermal Conductivity Uncertainty on the TSPA-LA Base Case ................................. 6-134

6.3.5 Summary of the Range of Thermal-Hydrologic Conditions for the TSPA-LA Base Case............................................................................. 6-144

6.3.6 Relationship Between Relative Humidity on the Waste Package and Drip Shield and Temperature on the Drift Wall .......................................... 6-146

6.3.7 The Influence of a Low-Probability-Seismic Collapsed-Drift Scenario on In-Drift Thermal-Hydrologic Conditions ...................................................... 6-147

6.3.8 Comparison of Results for the TSPA-LA Base Case with Those for the FY01 Supplemental Science and Performance Analyses (SSPA) ................ 6-155

6.3.9 Influence of Host-Rock Hydrologic-Property Variability and Uncertainty.....

6.3.10 Influence of Pseudo Permeability on In-Drift Temperature and Relative Humidity ................................................................................................ 6-160

6.3.11 Influence of Invert Hydrologic-Property Variability and Uncertainty .......... 6-162

6.3.12 Influence of Ventilation Heat-Removal Efficiency Uncertainty ................... 6-167

6.3.13 Relationship Between Temperature and Relative Humidity on Waste Packages.............................................................................................. 6-168

6.4 COMPARISON AGAINST AN ALTERNATIVE CONCEPTUAL MODEL ....... 6-171

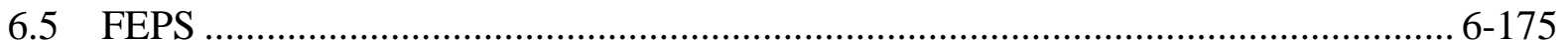

7. MODEL VALIDATION …………………………........................................................

7.1 CONFIDENCE BUILDING DURING MODEL DEVELOPMENT TO ESTABLISH SCIENTIFIC BASIS AND ACCURACY FOR INTENDED USE....... 7-1

7.2 CONFIDENCE BUILDING AFTER MODEL DEVELOPMENT TO SUPPORT THE SCIENTIFIC BASIS OF THE MODEL........................................................... 7-4

7.3 COMPARISON OF NUFT THERMAL-HYDROLOGIC MODEL AGAINST THE LARGE BLOCK TEST ………………………................................................ 7-5

7.3.1 Comparison of Simulated and Field-Measured Temperatures ........................... 7-6 


\section{CONTENTS (Continued)}

Page

7.3.2 Comparison of Simulated and Field-Measured Liquid-Phase Saturations

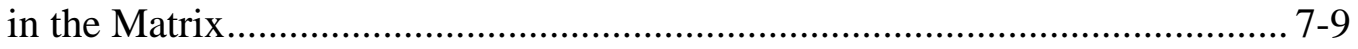

7.3.3 Summary of Model Validation Using LBT Data............................................ 7-9

7.4 VALIDATION OF THE LDTH SUBMODEL USING THE DRIFT SCALE

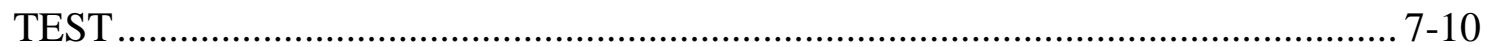

7.4.1 Design and Geometry of the DST ........................................................ 7-10

7.4.2 Description of Three-Dimensional Thermal-Hydrologic Model of the

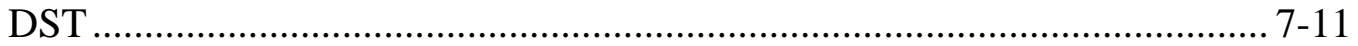

7.4.3 Comparison of Simulated and Field-Measured Temperatures ...................... 7-14

7.4.4 Comparison of Simulated and Field-Measured Liquid-Phase Saturations in the Matrix....................................................................................... 7-31

7.4.5 Summary of Model Validation Using DST Data....................................... 7-39

7.5 COMPARISON OF THE MSTHM RESULTS AGAINST A MONOLITHIC THREE-DIMENSIONAL THERMAL-HYDROLOGIC MODEL .......................... 7-40

7.5.1 Description of the MSTHM Validation Test Case ...................................... 7-40

7.5.2 Results of the MSTHM Validation Test Case ........................................... 7-44

7.5.3 Summary of Three-Drift Repository Validation Test Case ........................... 7-62

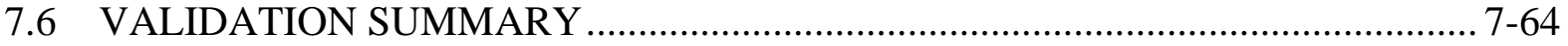

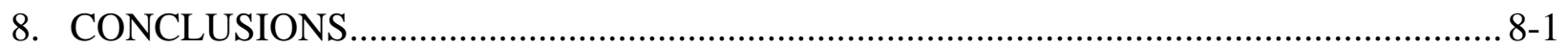

8.1 ANALYSIS AND MODELING CONCLUSIONS ............................................ 8-1

8.2 MODEL VALIDATION, UNCERTAINTIES, AND LIMITATIONS ...................... 8-2

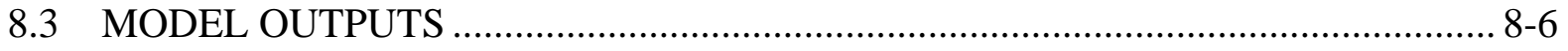

8.4 YUCCA MOUNTAIN REVIEW PLAN CRITERIA ASSESSMENT....................... 8-7

8.4.1 Acceptance Criterion 1 - System Description and Model Integration are Adequate ................................................................................................ 8-8

8.4.2 Acceptance Criterion 2 - Data Are Sufficient for Model Justification .......... 8-12

8.4.3 Acceptance Criterion 3 - Data Uncertainty Is Characterized and Propagated Through the Model Abstraction................................................ 8-13

8.4.4 Acceptance Criterion 4 - Model Uncertainty Is Characterized and Propagated Through the Model Abstraction............................................... 8-15

9. INPUTS AND REFERENCES ........................................................................... $9-1$

9.1 DOCUMENTS CITED .................................................................................... 9-1

9.2 CODES, STANDARDS, REGULATIONS, AND PROCEDURES....................... 9-10

9.3 SOURCE DATA, LISTED BY DATA TRACKING NUMBER ............................ 9-11

9.4 OUTPUT DATA, LISTED BY DATA TRACKING NUMBER ........................... 9-14

9.5 SOFTWARE CODES .............................................................................. 9-16

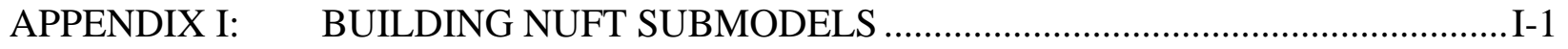

APPENDIX II: $\quad$ BUILDING BOUNDARY CONDITIONS FOR SUBMODELS............... II-1

APPENDIX III: HEAT GENERATION FOR SUBMODELS......................................... III-1 


\section{CONTENTS (Continued)}

Page

APPENDIX IV: BUILDING SUBMODEL MATERIAL PROPERTY FILES .....................IV-1

APPENDIX V: BUILDING SUBMODEL INPUT FILES ………………………............ V-1

APPENDIX VI: LDTH AND DDT SUBMODEL THERMAL-RADIATION

CONNECTION CALCULATION........................................................ VI-1

APPENDIX VII: EXTRACTION / MICRO-ABSTRACTION PROCESS FOR MSTHAC (BUILDING VIRTUAL LDTH AND SDT "CHIMNEY"

SUBMODELS) ……………………………………..........................

APPENDIX VIII: BINNING CALCULATIONS ………................................................. VIII-1

APPENDIX IX: MULTISCALE MODEL APPROACH TO THERMOHYDROLOGY

AT YUCCA MOUNTAIN .....................................................................

APPENDIX X: HYDROLOGIC PROPERTIES FOR THE INTERGRANULAR

POROSITY OF THE INVERT ........................................................... X-1

APPENDIX XI: THERMAL CONDUCTIVITY OF THE COLLAPSED DRIFT ZONE .. XI-1

APPENDIX XII: COMPARISON OF PERCOLATION FLUXES ...........................................

APPENDIX XIII: LIST OF DATA SOURCES FOR FIGURES AND TABLES ................ XIII-1

APPENDIX XIV: QUALIFICATION OF UNQUALIFIED PROJECT DATA.................... XIV-1

APPENDIX XV: PREDICTION OF RH IN THE INVERT ………………………........... XV-1 
INTENTIONALLY LEFT BLANK 


\section{FIGURES}

Page

4-1. Differences Between the Repository Layout Incorporated in the MSTHM for the TSPA-LA, and the Repository Layout Given in the Current IED.

4-2. Complementary Cumulative Distribution Function (CCDF) for Distribution of Host-Rock Percolation Flux in the Superseded Repository Layout and the Current Repository Layout

6-1. Overall Data Flow Diagram for the MSTHM....

6-2. Relationship Between Input Data and Submodels for Three Infiltration-Flux Cases

6.1-1. Repository-Wide Thermal Load Plotted as a Function of Time for the TSPA-LA Design.

6.1-2. Ratio of Relative Humidity $(R H)$ on the Waste Package Surface to Relative Humidity on the Drift-Wall Surface

6.2-1. Geometric Configuration of the Engineered Components Shown for an Average Cross-Section Inside the Emplacement Drifts as Represented in MSTHM

6.2-2. Diagram Showing Drift Spacing, Waste Package Lengths, and Waste Package Spacing in Plan View Considered in MSTHM Calculations for the TSPA-LA Base Case 6-16

6.2-3. Repository Layout Considered in MSTHM Calculations for the TSPA-LA Base Case.

6.2-4. MSTHM Calculation Sequence for a Three-Drift 55-MTU/Acre-Repository Example

6.2-6. Cross-Sectional (Lateral) View of the Numerical Mesh Used in the Vicinity of the Drift for All LDTH Submodels, Including Both the Initialization Runs and the Preclosure and Postclosure Runs

6.2-7. Cross-Sectional (Lateral) View, Perpendicular to Drift Axis, of the Mesh Used in the Preclosure DDT Submodels

6.2-8. Cross-Sectional (Lateral) View, Perpendicular to Drift Axis, of the Mesh Used in the Postclosure DDT Submodels ...

6.2-9. Cross-Sectional (Longitudinal) View, Parallel to Drift Axis, of the Mesh Used in the Preclosure DDT Submodels.

6.2-10. Cross-Sectional (Longitudinal) View, Parallel to Drift Axis, of the Mesh used in the Postclosure DDT Submodels

6.2-11. Cross-sectional (Lateral) View of the LDTH Submodel Mesh Used for the LowProbability-Seismic Collapsed-Drift Scenario.

6.2-12. Cross-Sectional (Lateral) View of the DDT Submodel Mesh Used for the LowProbability-Seismic Collapsed-Drift Scenario.

6.3-1. Distribution of the Four Primary Host-Rock Units Shown for the Repository Layout Considered in MSTHM Calculations for the TSPA-LA Base Case.

6.3-2. Complementary Cumulative Distribution Function (CCDF) for Peak

Temperature on the Drift Wall and Waste Packages....

6.3-3. Contour Map of Peak Waste Package Temperature for the pwr1-2 Waste Package 6-60 


\section{FIGURES (Continued)}

Page

6.3-4. Complementary Cumulative Distribution Functions (CCDFs) for (a) the Time When Boiling at the Drift Wall Ceases and (b) the Maximum Lateral Extent of the Boiling-Point Isotherm $\left(96^{\circ} \mathrm{C}\right)$.....

6.3-5. Contour Map of the Time When Boiling at the Drift Wall Ceases for the pwr1-2 Waste Package

6.3-6. Contour Map of the Maximum Lateral Extent of the Boiling-Point Isotherm $\left(96^{\circ} \mathrm{C}\right)$ from the Drift Centerline for the pwr1-2 Waste Package

6.3-7. Thermal-Hydrologic Conditions for the pwr1-2 Waste Package Plotted for Lower-Bound, Mean, and Upper-Bound Infiltration-Flux Cases at the P2ER8C6 Location in the Tptpul (tsw33) Unit ....

6.3-8. Thermal-Hydrologic Conditions for the pwr1-2 Waste Package Plotted for Lower-Bound, Mean, and Upper-Bound Infiltration-Flux Cases at the P2WR8C8 Location in the Tptpmn (tsw34) Unit

6.3-9. Thermal-Hydrologic Conditions for the pwr1-2 Waste Package Plotted for Lower-Bound, Mean, and Upper-Bound Infiltration-Flux Cases at the P2WR5C10 Location in the Tptpll (tsw35) Unit

6.3-10. Thermal-Hydrologic Conditions for the pwr1-2 Waste Package Plotted for Lower-Bound, Mean, and Upper-Bound Infiltration-Flux Cases at the P3R7C12 Location in the Tptpll (tsw35) Unit

6.3-11. Thermal-Hydrologic Conditions for the pwr1-2 Waste Package Plotted for Lower-Bound, Mean, and Upper-Bound Infiltration-Flux Cases at the P3R8C13 Location in the Tptpln (tsw36) Unit ....

6.3-12. Thermal-Hydrologic Conditions for the Mean Infiltration-Flux Case Plotted for a Range of Waste Packages at the P2ER8C6 Location in the Tptpul (tsw33) Unit .

6.3-13. Thermal-Hydrologic Conditions for the Mean Infiltration-Flux Case Plotted for a Range of Waste Packages at the P2WR8C8 Location in the Tptpmn (tsw34) Unit .

6.3-14. Thermal-Hydrologic Conditions for the Mean Infiltration-Flux Case Plotted for a Range of Waste Packages at the P2WR5C10 Location in the Tptpll (tsw35) Unit ....

6.3-15. Thermal-Hydrologic Conditions for the Mean Infiltration-Flux Case Plotted for a Range of Waste Packages at the P3R7C12 Location in the Tptpll (tsw35) Unit..... 6-80

6.3-16. Thermal-Hydrologic Conditions for the Mean Infiltration-Flux Case Plotted for a Range of Waste Packages at the P3R8C13 Location in the Tptpln (tsw36) Unit.... 6-81

6.3-17. Thermal-Hydrologic Conditions for the Mean Infiltration-Flux Case Plotted for the pwr1-2 Waste Package at the P2ER8C6 Location in the Tptpul (tsw33) Unit..... 6-84

6.3-18. Thermal-Hydrologic Conditions for the Mean Infiltration-Flux Case Plotted for the pwr1-2 Waste Package at the P2WR8C8 Location in the Tptpmn (tsw34) Unit ....

6.3-19. Thermal-Hydrologic Conditions for the Mean Infiltration-Flux Case Plotted for the pwr1-2 Waste Package at the P2WR5C10 Location in the Tptpll (tsw35) Unit ..... 


\section{FIGURES (Continued)}

Page

6.3-20. Thermal-Hydrologic Conditions for the Mean Infiltration-Flux Case Plotted for a Range of Waste Packages at the P3R8C13 Location in the Tptpln (tsw36) Unit.... 6-87

6.3-21. Thermal-Hydrologic Conditions for the pwr1-2 Waste Package Plotted for the Low, Mean, and High Percolation-Flux Cases at the P2ER8C6 Location in the Tptpul (tsw33) Unit

6.3-22. Thermal-Hydrologic Conditions for the pwr1-2 Waste Package Plotted for the Low, Mean, and High Percolation-Flux Cases at the P2WR8C8 Location in the Tptpmn (tsw34) Unit

6.3-23. Thermal-Hydrologic Conditions for the pwr1-2 Waste Package Plotted for the Low, Mean, and High Percolation-Flux Cases at the P2WR5C10 Location in the Tptpll (tsw35) Unit

6.3-24. Thermal-Hydrologic Conditions for the pwr1-2 Waste Package Plotted for the Low, Mean, and High Percolation-Flux Cases at the P3R8C13 Location in the Tptpln (tsw36) Unit.

6.3-25. Thermal-Hydrologic Conditions for the pwr1-2 Waste Package Plotted for the Mean Infiltration-Flux Case at the P2ER8C6 Location in the Tptpul (tsw33) Unit

6.3-26. Thermal-Hydrologic Conditions for the pwr1-2 Waste Package Plotted for the Mean Infiltration-Flux Case at the P2WR8C8 Location in the Tptpmn (tsw34) Unit ......

6.3-27. Thermal-Hydrologic Conditions for the pwr1-2 Waste Package Plotted for the Mean Infiltration-Flux Case at the P2WR5C10 Location in the Tptpll (tsw35) Unit .

6.3-28. Thermal-Hydrologic Conditions for the pwr1-2 Waste Package Plotted for the Mean Infiltration-Flux Case at the P3R8C13 Location in the Tptpln (tsw36) Unit .....

6.3-29. Thermal-Hydrologic Conditions for the pwr1-2 Waste Package Plotted for Three Cases at the P2ER8C6 Location in the Tptpul (tsw33) Unit 6-106

6.3-30. Thermal-Hydrologic Conditions for the pwr1-2 Waste Package Plotted for Three Cases at the P2WR8C8 Location in the Tptpmn (tsw34) Unit.

6.3-31. Thermal-Hydrologic Conditions for the pwr1-2 Waste Package Plotted for Three Cases at the P2WR5C10 Location in the Tptpll (tsw35) Unit ....

6.3-32. Thermal-Hydrologic Conditions for the pwr1-2 Waste Package Plotted for Three Cases at the P3R8C13 Location in the Tptpln (tsw36) Unit

6.3-33. Drip-Shield Temperature (a,b) and Relative Humidity (c,d) for Line-Averaged Heating Conditions Plotted for Four Cases at the P2ER8C6 Location in the Tptpul (tsw33) Unit

6.3-34. Drip-Shield Temperature (a,b) and Relative Humidity (c,d) for Line-Averaged Heating Conditions Plotted for Four Cases at the P2WR8C8 Location in the Tptpmn (tsw34) Unit.

6.3-35. Drip-Shield Temperature (a,b) and Relative Humidity (c,d) for Line-Averaged Heating Conditions Plotted for Four Cases at the P2WR5C10 Location in the Tptpll (tsw35) Unit 


\section{FIGURES (Continued)}

Page

6.3-36. Drip-Shield Temperature (a,b) and Relative Humidity (c,d) for Line-Averaged Heating Conditions Plotted for Four Cases at the P3R8C13 Location in the Tptpln (tsw36) Unit.

6.3-37. Liquid-Phase and Gas-Phase Flux Between the Invert and Adjoining Drift and Host Rock Plotted for the (a) Matrix, (c) Fracture, and (e) Matrix + Fracture Continuum at the P2ER8C6 Location in the Tptpul (tsw33) Unit.

6.3-38. Liquid-Phase and Gas-Phase Flux Between the Upper and Lower Half of the Invert Plotted for the (a) Matrix, (b) Fracture, and (c) Matrix + Fracture Continuum at the P2ER8C6 Location in the Tptpul (tsw33) Unit

6.3-39. Liquid-Phase and Gas-Phase Flux Between the Invert and Adjoining Drift and Host Rock Plotted for the (a) Matrix, (c) Fracture, and (e) Matrix + Fracture Continuum at the P2WR8C8 Location in the Tptpmn (tsw34) Unit

6.3-40. Liquid-Phase and Gas-Phase Flux Between the Upper and Lower Half of the Invert Plotted for the (a) Matrix, (b) Fracture, and (c) Matrix + Fracture Continuum at the P2WR8C8 Location in the Tptpmn (tsw34) Unit.

6.3-41. Liquid-Phase and Gas-Phase Flux Between the Invert and Adjoining Drift and Host Rock Plotted for the (a) Matrix, (c) Fracture, and (e) Matrix + Fracture Continuum at the P2WR5C10 Location in the Tptpll (tsw35) Unit.

6.3-42. Liquid-Phase and Gas-Phase Flux Between the Upper and Lower Half of the Invert Plotted for the (a) Matrix, (b) Fracture, and (c) Matrix + Fracture Continuum at the P2WR5C10 Location in the Tptpll (tsw35) Unit...

6.3-43. Liquid-Phase and Gas-Phase Flux Between the Invert and Adjoining Drift and Host Rock Plotted for the (a) Matrix, (c) Fracture, and (e) Matrix + Fracture Continuum at the P3R8C13 Location in the Tptpln (tsw36) Unit

6.3-44. Liquid-Phase and Gas-Phase Flux Between the Upper and Lower Half of the Invert Plotted for the (a) Matrix, (b) Fracture, and (c) Matrix + Fracture Continuum at the P3R8C13 Location in the Tptpln (tsw36) Unit

6.3-45. Phase Change (a, c, e, and g) in the Matrix and Fracture Continuum and LiquidPhase Flux (b, d, f, h) in the Fracture Continuum Plotted for the Lower Two Gridblocks in the Invert at Four Locations in the Repository

6.3-46. Mass Balance in the Invert Shown by Plotting (a) Liquid-Phase Saturation in the Fracture and Matrix Continuum in the Invert and (b) the Net Accumulated Mass Flux out of the Invert at the P2ER8C6 Location in the Tptpul (tsw33) Unit

6.3-47. Mass Balance in the Invert Shown by Plotting (a) Liquid-Phase Saturation in the Fracture and Matrix Continuum in the Invert and (b) the Net Accumulated Mass Flux out of the Invert at the P2WR8C8 Location in the Tptpmn (tsw34) Unit ........ 6-132

6.3-48. Mass Balance in the Invert Shown by Plotting (a) Liquid-Phase Saturation in the Fracture and Matrix Continuum in the Invert and (b) the Net Accumulated Mass Flux out of the Invert at the P2WR5C10 Location in the Tptpll (tsw35) Unit

6.3-49. Mass Balance in the Invert Shown by Plotting (a) Liquid-Phase Saturation in the Fracture and Matrix Continuum in the Invert and (b) the Net Accumulated Mass Flux out of the Invert at the P3R8C13 Location in the Tptpln (tsw36) Unit. 6-134 


\section{FIGURES (Continued)}

Page

6.3-50. Regrouping of the Three-by-Three Matrix of Infiltration Flux and Host-Rock Thermal Conductivity Cases....

6.3-51. Complementary Cumulative Distribution Function (CCDF) for Peak Temperature on the (a) Drift Wall and on the (b) Waste Packages Plotted for Five Cases

6.3-52. Complementary Cumulative Distribution Functions (CCDF) for (a) the Time When Boiling at the Drift Wall Ceases and (b) the Maximum Lateral Extent of the Boiling-Point Isotherm $\left(96^{\circ} \mathrm{C}\right)$ from the Drift Centerline, Plotted for Five Cases....

6.3-53. Range of Waste Package Temperature and Relative Humidity Histories for all Waste Packages (a, b), for All CSNF Waste Packages (c, d), and for All DHLW Waste Packages (e, f).

6.3-54. The Complementary Cumulative Distribution Function (CCDF) for Relative Humidity on the Drip Shield and Waste Package...

6.3-55. Thermal-Hydrologic Parameters for the "Coolest” Waste Package, the 5 DHLW/DOE SNF-Long (dhlw-l1), Plotted for the Mean Infiltration Flux at the P2WR5C10 Location in the Tptpll (tsw35) Unit

6.3-56. Thermal-Hydrologic Parameters for the "Average” Waste Package, the 44BWR CSNF (bwr1-1), Plotted for the Mean Infiltration Flux at the P2WR5C10 Location in the Tptpll (tsw35) Unit

6.3-57. Thermal-Hydrologic Parameters for the "Hottest" Waste Package, the 21-PWR AP CSNF (pwr1-2), Plotted for the Mean Infiltration Flux at the P2WR5C10 Location in the Tptpll (tsw35) Unit.

6.3-58. Temperature and Relative Humidity at the Drip Shield Crown for the P2WR5C10 Location in the Tptpll (tsw35) Unit, Plotted for the Mean Infiltration Flux and the Low-Probability-Seismic Collapsed Drift with Low- $K_{\text {th }}$ Rubble.....

6.3-59. Thermal-Hydrologic Parameters for the Eight Waste Packages Considered in this Report, Plotted for the Mean Infiltration-Flux Cases at the P3R7C12 Location in the Tptpll (tsw35) Unit, Close to the Repository Center....

6.3-60. Drift-Wall and Drip-Shield Temperature History at the Repository Center for Four Values of Percolation Flux and for the Hydrologic Properties of Each of the Host-Rock Types.

6.3-61. Drift-Wall and Drip-Shield Relative-Humidity History at the Repository Center for Four Values of Percolation Flux and for the Hydrologic Properties of Each of the Host-Rock Types

6.3-62. Drip-Shield Temperature (a) and Relative Humidity (b) at the Repository Center for Different Values of Pseudo Permeability of the Gas-Filled Emplacement Drift Cavity

6.3-63. Invert Liquid-Phase Saturation for the Intragranular Porosity (a) and Temperature (b) at the Repository Center for Invert Gravel Derived from Each of the Indicated Host-Rock Units 


\section{FIGURES (Continued)}

Page

6.3-64. Temperature (a,c,e,g) and Relative Humidity (b,d,f,h) for Various Locations in the Drift at the Repository Center for Invert Gravel Derived from Each of the Indicated Host-Rock Units.

6.3-65. Invert Liquid-Phase Saturation (a) for the Intragranular Porosity, Temperature (b), and Relative Humidity (c) at the Top of the Invert Beneath the Drip Shield at the Repository Center for Different Sets of Hydrologic Parameters for the Intergranular Porosity 6-166

6.3-66. Drip-Shield Temperature (a) and Relative Humidity (b) at the Repository Center for Different Values of Ventilation Heat-Removal Efficiency

6.3-67. Range of Temperature Histories for All Waste Packages, Accounting for Uncertainty of Host-Rock Thermal Conductivity and Percolation Flux

6.3-68. Range of Relative Humidity Histories for All Waste Packages, Accounting for Uncertainty of Host-Rock Thermal Conductivity and Percolation Flux

6.3-69. Range of Temperature vs. Relative Humidity Trajectories for All Waste Packages, During Cooldown, Accounting for Uncertainty in Host-Rock Thermal Conductivity and Percolation Flux.

6.4-1. Comparison of Predicted Temperatures at (a) the Center of the repository and (b) $100 \mathrm{~m}$ from the Edge of the Repository

7.3-1. Comparison of the NUFT-Simulated and Measured Temperatures along Borehole TT1 in the Large Block Test, Given at (a) 30 Days, (b) 100 Days, (c) 200 Days, (d) 300 Days, and (e) 400 Days...

7.3-2. Comparison of the NUFT-Simulated and Measured Liquid-Phase Saturations in the Matrix along Borehole TN3, Given at (a) 100 Days, (c) 365 Days, and (e) 500 Days . 7-8

7.4-1. Plan View of the Drift Scale Test Area $7-11$

7.4-2. Contours of Temperature (for the Base Case) at the End of the Heating Phase, Plotted in (a) Plan View Through a Horizontal Plane at the Elevation of the Wing-Heater Array and (b) for a Vertical Cross-Section Midway along the Heated Drift $(\mathrm{y}=22.9 \mathrm{~m})$ $7-18$

7.4-3. NUFT-Simulated and Measured Temperatures Compared along Borehole 137 (a, c, e) and Borehole 141 (b, d, f) at 175, 365, and 730 Days

7.4-4. $\quad$ NUFT-Simulated and Measured Temperatures Compared along Borehole 137 (a, c, e) and Borehole 141 (b, d, f) at 1,096, 1,500, and 2,005 Days

7.4-5. NUFT-Simulated and Measured Temperatures Compared along Borehole 168 (a, c, e) and Borehole 169 (b, d, f) at 175, 365, and 730 Days

7.4-6. NUFT-Simulated and Measured Temperatures Compared along Borehole 168 (a, c, e) and Borehole 169 (b, d, f) at 1,096, 1,500, and 2,005 Days $7-22$

7.4-7. NUFT-Simulated and Measured Temperatures Compared along Borehole 170 (a, c, e) and Borehole 173 (b, d, f) at 175, 365, and 730 Days $7-23$

7.4-8. $\quad$ NUFT-Simulated and Measured Temperatures Compared along Borehole 170 (a, c, e) and Borehole 173 (b, d, f) at 1,096, 1,500, and 2,005 Days $7-24$

7.4-9. $\quad$ NUFT-Simulated and Measured Temperatures Compared along Borehole 139 (a, c, e) and Borehole 143 (b, d, f) at 175, 365, and 730 Days ..... $7-25$ 


\section{FIGURES (Continued)}

Page

7.4-10. NUFT-Simulated and Measured Temperatures Compared along Borehole 139 (a, c, e) and Borehole 143 (b, d, f) at 1,096, 1,500, and 2,005 Days $7-26$

7.4-11. NUFT-Simulated and Measured Temperatures Compared along Borehole 79 (a, c, e) and Borehole 80 (b, d, f) at 175, 365, and 730 Days .

7.4-12. NUFT-Simulated and Measured Temperatures Compared along Borehole 79 (a, c, e) and Borehole 80 (b, d, f) at 1,096, 1,500, and 2,005 Days

7.4-13. NUFT-Simulated and Measured Temperature Histories Compared at Borehole 133: Sensor 52 (a) and Sensor 23 (b), Borehole 141: Sensor 20 (c), and Borehole 138: Sensor 23 (d)

7.4-14. NUFT-Simulated and Measured Temperature Histories Compared at Borehole 134: Sensor 8 (a), Borehole 144: Sensor 21 (b), Borehole 162: Sensor 26 (c), and Borehole 163: Sensor 24 (d)

7.4-15. NUFT-Simulated and Measured Temperature Histories Compared at Borehole 138: Sensor 3 (a), Borehole 139: Sensor 23 (b), Borehole 144: Sensor 1 (c), and Borehole 164: Sensor 24 (d)

7.4-16 Contours of Liquid-Phase Saturation (for the Base Case) in the Matrix at the End of the Heating Phase, Plotted in (a) Plan View Through a Horizontal Plane at the Elevation of the Wing-Heater Array and (b) for a Vertical Cross-Section Midway along the Heated Drift $(y=22.9 \mathrm{~m})$

7.4-17. NUFT-Simulated and Measured Liquid-Phase Saturations in the Matrix Compared along Borehole 68 at (a) 200 Days, (b) 350 Days, (c) 877 Days, (d) 1,242 Days, (e) 1,510 Days, and (f) 1,917 Days

7.4-18. NUFT-Simulated and Measured Liquid-Phase Saturations in the Matrix Compared along Borehole 79 at (a) 200 Days, (b) 365 Days, (c) 877 Days, (d) 1,242 Days, (e) 1,510 Days, and (f) 1,917 Days

7.4-19. NUFT-Simulated and Measured Liquid-Phase Saturations in the Matrix Compared along Borehole 80 at (a) 200 Days, (b) 365 Days, (c) 877 Days, (d) 1,242 Days, (e) 1,510 Days, and (f) 1,917 Days

7.4-20. NUFT-Simulated Time Histories of (a) Temperature, (b) Liquid-Phase Saturation, and (c) Gas-Phase Pressure in the Matrix, Plotted at Distances of 20 $\mathrm{m}$ and $27 \mathrm{~m}$ from the Collar of Borehole 68.

7.5-1. Drift-Scale Conceptual Schematic Shown for the Model Validation Test Case ........ 7-42

7.5-2. Drift-Wall and Drip-Shield Temperature vs. Time for the (a,b) PWR1, (c,d) DHLW, (e, f) PWR2, and (g, h) BWR Waste Packages at the Center of the Three-Drift Repository Test Case....

7.5-3. Drift-Wall and Drip-Shield Relative Humidity vs. Time for the (a,b) PWR1, (c,d) DHLW, (e, f) PWR2, and (g, h) BWR Waste Packages at the Center of the Three-Drift Repository Test Case.

7.5-4. Drift-Wall Liquid-Phase and Invert Liquid-Phase Saturation vs. Time for the (a, b) PWR1, (c, d) DHLW, (e, f) PWR2, and (g, h) BWR Waste Packages at the Center of the Three-Drift Repository Test Case. 


\section{FIGURES (Continued)}

Page

7.5-5. Drift-Wall and Drip-Shield Temperature vs. Time for the (a, b) PWR1, (c, d) DHLW, (e, f) PWR2, and (g, h) BWR Waste Packages at the Edge of the ThreeDrift Repository Test Case.

7.5-6. Drift-Wall and Drip-Shield Relative Humidity vs. Time for the (a, b) PWR1, (c, d) DHLW, (e, f) PWR2, and (g, h) BWR Waste Packages at the Edge of the Three-Drift Repository Test Case

7.5-7. Drift-Wall Liquid-Phase and Invert Liquid-Phase Saturation vs. Time for the (a, b) PWR1, (c, d) DHLW, (e, f) PWR2, and (g, h) BWR Waste Packages at the Edge of the Three-Drift Repository Test Case

7.5-8. Axial Vapor Flux on the Upstream Side of the Listed Waste Packages at the Edge of the Three-Drift Repository Test Case 


\section{TABLES}

Page

1-1. $\quad$ List of Thermal-Hydrologic Parameters Predicted with the MSTHM .......................... 1-4

1-2. $\quad$ Submodel and Model Types Used in the MSTHM ……........................................... 1-6

1-3. $\quad$ Parameters Used in the MSTHM Methodology .................................................... 1-7

2-1. $\quad$ Engineered Barrier System Components Addressed in This Report, Listed with Corresponding Safety Category (SC) Level ................................................................ 2-1

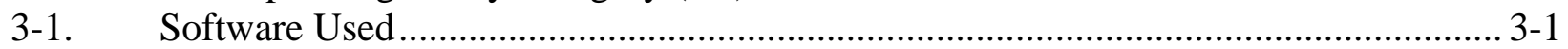

4.1-1. Summary of Input Data and Information Required by the MSTHM............................. 4-2

4.1-2. Changes to the Waste Package and Drip Shield Design Information............................. 4-7

4.1-3. Summary of Current and Superseded IEDs Providing Repository Layout Information ............................................................................................................ 4-11

4.1-4. Summary of Emplacement Panels and Drifts Represented in the SMT Submodel for the Layout in the Superseded IED and the Current IED ....................................... 4-11

4.1-5. Summary of Permeability and Porosity of Various Unconsolidated Materials ........... 4-14

4.1-6. Retention Data for Various Materials ............................................................... 4-15

4.4-1. Source DTNs for Field Measurements Made in the Large Block Test (LBT) ........... 4-22

4.4-2. Source DTNs for Field Measurements Made in the Drift Scale Test (DST)............... 4-24

5.4-1. Summary of Waste Package Types in the Repository Inventory and in the

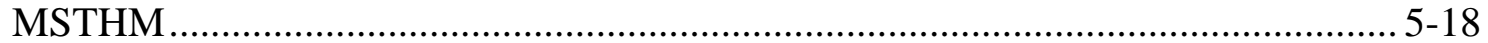

6.1-1. Key Thermal Design Factors and Natural System Parameters Influencing Thermal-Hydrologic Conditions in the Emplacement Drifts and Near-Field Host

Rock.............................................................................................................. 6-10

6.2-1. Summary of Emplacement Panels and Drifts Represented in the SMT Submodel.... 6-32

6.2-2. Hydrologic Property Values for the "Intact” Tptpll (tsw35) Host-Rock Unit and for the Host-Rock Rubble Derived from the Tptpll (tsw35) Unit. .............................. 6-50

6.2-3. Thermal Property Values for the "Intact" Tptpll (tsw35) Host-Rock Unit and for the Host-Rock Rubble Derived from the Tptpll (tsw35) Unit ..................................... 6-51

6.2-4. Thermal Property Values for the "Intact" Tptpll (tsw35) Host-Rock Unit and for the Host-Rock Rubble Derived from the Tptpll (tsw35) Unit. ..................................... 6-53

6.3-1. Initial Liquid-Phase Saturation in the Host Rock at Several Locations in the Repository for Three Infiltration-Flux Cases............................................................... 6-55

6.3-2. Initial Capillary Pressure for the Fracture and Matrix Continuum in the Host

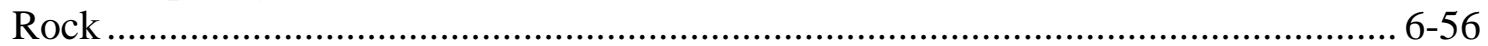

6.3-3. Distribution of the Host-Rock Units as Represented in SMT Submodel for the Emplaced Repository Area (Figure 6.3-1)............................................................... 6-56

6.3-4. Repository-Wide Averaged Percolation Flux Summarized for Lower-Bound, Mean, and Upper-Bound Infiltration-Flux Cases ....................................................... 6-58

6.3-5. Range of Percolation Fluxes for the MSTHM for the Lower-Bound, Mean, and Upper-Bound Infiltration-Flux Cases for the Present-Day Climate ............................ 6-58

6.3-6. Peak Drift-Wall and Waste Package Temperatures for Lower-Bound, Mean, and Upper-Bound Infiltration-Flux Cases ......................................................................... 6-58

6.3-7. Time When Boiling Ceases at the Drift Wall Summarized for Lower-Bound, Mean, and Upper-Bound Infiltration-Flux Cases 6-62 


\section{TABLES (Continued)}

Page

6.3-8. Maximum Lateral Extent of the Boiling-Point Isotherm $\left(96^{\circ} \mathrm{C}\right)$ Summarized for Lower-Bound, Mean, and Upper-Bound Infiltration-Flux Cases................................ 6-62

6.3-9. Percolation Flux for Mean Infiltration-Flux Case for Five Locations Used to Examine Thermal-Hydrologic Conditions in the Repository ...................................... 6-66

6.3-10. Percolation Flux for the Lower and Upper Infiltration-Flux Cases for Five Locations Used to Examine Thermal-Hydrologic Conditions in the Repository ....... 6-66

6.3-11. Range of Peak Temperatures over the Three Infiltration-Flux Cases for the pwr1-2 Waste Package for Five Locations in the Repository.

6.3-12. Range of Time When Boiling at the Drift Wall Ceases over the Three Infiltration-Flux Cases for the pwr1-2 Waste Package for Five Locations in the Repository.....

6.3-13. Summary of Waste Packages Included in the MSTHM Calculations (Figure $6.2-2)$. 6-75

6.3-14. Range of Peak Temperatures from Variability in Waste Package-to-Waste Package Heat Generation for the Mean Infiltration-Flux Case, Summarized for Five Locations in the Repository

6.3-15. Range of Time When Boiling at the Drift Wall Ceases (Resulting from Variability in Waste Package-to-Waste Package Heat Generation) for the Mean Infiltration-Flux Case, Summarized for Five Locations in the Repository

6.3-16. Peak Temperatures in an Alternative MSTHM with Vertically Extended LDTH and SDT Submodels, as Compared with Standard MSTHM Results, for the pwr1-2 at Four Locations in the Repository

6.3-17. Time When Boiling at the Drift Wall Ceases in an Alternative MSTHM with Vertically Extended LDTH and SDT Submodels, as Compared to the Standard MSTHM Results, for the pwr1-2 at Four Locations in the Repository

6.3-18. Potentially Important Parameters to Thermal-Hydrologic Conditions in Emplacement Drifts, Listed for Consideration in the Parameter-Uncertainty Sensitivity Analysis.

6.3-19. Percolation Flux for the Low, Mean, and High Percolation-Flux Cases

Summarized for Four Locations Used to Examine Thermal-Hydrologic Conditions in the Repository

6.3-20. Range of Peak Drift-Wall Temperatures for the pwr1-2 Waste Package (Resulting from Percolation-Flux Uncertainty) Summarized for Four Locations in the Repository.

6.3-21. Range of Peak Waste Package Temperatures for the pwr1-2 Waste Package (Resulting from Percolation-Flux Uncertainty) Summarized for Four Locations in the Repository...

6.3-22. Range of Time When Boiling at the Drift Wall Ceases for the pwr1-2 Waste Package (Resulting from Percolation-Flux Uncertainty) Summarized for Four Locations in the Repository

6.3-23. Wet and Dry Thermal Conductivity Values Used in the Host-Rock Thermal Conductivity Uncertainty Study ..... 


\section{TABLES (Continued)}

Page

6.3-24. Range of Peak Drift-Wall Temperatures for the pwr1-2 Waste Package (Resulting from Thermal Conductivity Uncertainty) Summarized for Four Locations in the Repository

6.3-25. Range of Peak Waste Package Temperatures for the pwr1-2 Waste Package (Resulting from Thermal Conductivity Uncertainty) Summarized for Four Locations in the Repository

6.3-26. Range of Time When Boiling at the Drift Wall Ceases for the pwr1-2 Waste Package (Resulting from Host-Rock Thermal Conductivity Uncertainty) Summarized for Four Locations in the Repository....

6.3-27. Range of Peak Drift-Wall Temperatures for the pwr1-2 Waste Package (Resulting from a Combination of Percolation Flux $Q_{\text {perc }}$ and Thermal Conductivity $K_{\text {th }}$ Uncertainty) Summarized for Four Locations in the Repository .. 6-104

6.3-28. Range of Peak Waste Package Temperatures for the pwr1-2 Waste Package (Resulting from a Combination of Percolation Flux $Q_{\text {perc }}$ and Thermal Conductivity $K_{\text {th }}$ Uncertainty) Summarized for Four Locations in the Repository .. 6-105

6.3-29. Range of Time When Boiling at the Drift Wall Ceases for the pwr1-2 Waste Package (Resulting from a Combination of Percolation Flux $Q_{\text {perc }}$ and Thermal Conductivity $K_{\text {th }}$ Uncertainty) Summarized for Four Locations in the Repository .. 6-105

6.3-30. Range of Peak Drift-Wall Temperatures for the pwr1-2 Waste Package Resulting from Various Combinations of Percolation Flux $Q_{\text {perc }}$ and Thermal Conductivity $K_{\text {th }}$ Uncertainty, Summarized for Four Locations in the Repository .. 6-111

6.3-31. Range of Peak Waste Package Temperatures for the pwr1-2 Waste Package Resulting from Various Combinations of Percolation Flux $Q_{\text {perc }}$ and Thermal Conductivity $K_{\text {th }}$ Uncertainty, Summarized for Four Locations in the Repository .. 6-111

6.3-32. Range of Time When Boiling at the Drift Wall Ceases for the pwr1-2 Waste Package Resulting from Various Combinations of Percolation Flux $Q_{\text {perc }}$ and Thermal Conductivity $K_{\text {th }}$ Uncertainty, Summarized for Four Locations in the Repository....

6.3-33. Peak Values of Liquid-Phase and Gas-Phase Flux for the Matrix and Fracture Continuum Given for $t>50$ Years at Two Different Interfaces

6.3-34. Peak Values of Liquid-Phase and Gas-Phase Flux for the Matrix and Fracture Continuum Given for $t>100$ Years at Two Different Interfaces

6.3-35. Probabilities of the Three Infiltration-Flux Cases

6.3-36. Probabilities of the Combinations of the Three Infiltration-Flux Cases and the Three Host-Rock Thermal Conductivity Cases

6.3-37. Probabilities of the Combinations of the Three Infiltration-Flux Cases and the Three Host-Rock Thermal Conductivity Cases after the Regrouping Shown in Figure 6.3-50

6.3-38. Peak Drift-Wall and Waste Package Temperatures Summarized for Five Cases .... 6-141

6.3-39. Time When Boiling Ceases at the Drift Wall Summarized for Five Cases

6.3-40. Maximum Lateral Extent of the Boiling-Point Isotherm $\left(96^{\circ} \mathrm{C}\right)$ Measured from the Drift Centerline, Summarized for Five Cases. 


\section{TABLES (Continued)}

Page

6.3-41. Relative Humidity on the Drip Shield and Waste Package Corresponding to When the Drift-Wall Temperature is $96^{\circ} \mathrm{C}$ and $100^{\circ} \mathrm{C}$, Summarized for Figure 6.3-54.

6.3-42. Peak Waste Package Temperature for the "Coolest," "Average," and "Hottest" Package for Three Cases at the P2WR5C10 Location in the Tptpll (tsw35) Unit ... 6-152

6.3-43. Time When Boiling on the Waste Package Ceases for the "Coolest," "Average,” and "Hottest" Package for Three Cases at the P2WR5C10 Location in the Tptpll (tsw35) Unit

6.3-44. Summary of Arrival Time at Drip-Shield Crown for Seeps of Varying Magnitude for Low-Probability-Seismic Collapsed-Drift Scenario for the High- $\mathrm{K}_{\text {th }}$ and Low- $\mathrm{K}_{\text {th }}$ Rubble Cases ....

6.3-45. Summary of Temperature at Various Locations in Drift Cross Section, Including Host Rock at Drift Crown, Top and Bottom of Invert Beneath Drip Shield, and Host Rock Below Invert.

6.3-46. Peak Drip-Shield Temperature for Different Values of Ventilation Heat-Removal Efficiency.....

6.5-1. $\quad$ FEPs Addressed by This Report ...................................................................... 6-176

7.4-1. Summary of Thermocouple (RTD) Boreholes Used to Compare Field-Measured Temperatures with NUFT-Simulated Temperatures. ......................................... 7-14

7.4-2. Coordinates of Thermocouple Sensors Used in Figures 7.4-13, 7.4-14, and

7.4-3. $\quad$ NUFT-Simulated (Base-Case) Temperature, Liquid-Phase Saturation, and Gas-Phase Pressure in the Matrix Summarized at 20 and $27 \mathrm{~m}$ from the Collar of Borehole 68.

7.5-1. Design and Operating Parameters Used in MSTHM Validation Test Case .............. 7-41

7.5-2. Waste Package Types Used in the MSTHM Validation Test Case ........................... 7-41

7.5-3. Summary of Peak Temperatures for the Four Waste Package Locations at the Center of the Three-Drift Repository Test Case...

7.5-4. Summary of Time When Boiling Ceases at the Drift Wall for the Four Waste Package Locations at the Center of the Three-Drift Repository Test Case ............... 7-46

7.5-5. Peak Drift-Wall Temperatures Summarized for the Four Waste Package Locations at the Edge of the Three-Drift Repository Test Case....

7.5-6. Peak Drip-Shield Temperatures Summarized for the Four Waste Package Locations at the Edge of the Three-Drift Repository Test Case $7-52$

7.5-7. Drip-Shield Temperature Difference Between the Center and Edge of the ThreeDrift Repository Test Case, Compared for the D/LMTH Model and MSTHM

7.5-8. Summary of Time When Boiling Ceases at the Drift Wall for the Four Waste Package Locations at the Edge of the Three-Drift Repository Test Case.

7.5-9. Summary of Moisture Balance for PWR1 Waste Package in Multiscale Thermal-Hydrologic Model Validation Test Case Summary of Moisture Balance for DOE High-Level Radioactive Waste Package in Multiscale Thermal-Hydrologic Model Validation Test Case ...... 7-61 


\section{TABLES (Continued)}

Page

7.5-11. Summary of Moisture Balance for PWR2 Waste Package in Multiscale Thermal-Hydrologic Model Validation Test Case

7.5-12. Summary of Moisture Balance for BWR Waste Package in Multiscale Thermal-Hydrologic Model Validation Test Case

8-1. Data Tracking Numbers Associated with the Output Produced by This Report ........ 8-16 


\section{INTENTIONALLY LEFT BLANK}




\section{ACRONYMS AND ABBREVIATIONS}

AP

AML

BWR

CR

CSNF

DDT

DHLW

DKM

DMTH

DOE

D/LMTH

DST

DTN

FEP

HLW

IED

LBNL

LBT

LDTH

LMTH

LPD

MSTHAC

MSTHM

MTU

PWR

$R H$

RTD absorber plate (in reference to a PWR waste package type)

areal mass loading (mass of spent nuclear fuel and high-level waste per unit area of heated repository footprint MTU/acre)

boiling water reactor (in reference to a waste package type)

control rod (in reference to a PWR waste package type)

commercial spent nuclear fuel (in reference to a waste package type)

Discrete-heat-source, Drift-scale, Thermal-conduction submodel of the MSTHM (a three-dimensional NUFT submodel)

defense high-level (radioactive) waste

Dual Permeability Model

Discrete-heat-source, Mountain-scale, Thermal-Hydrologic model (result of the MSTHM)

U.S. Department of Energy

Discrete/Line-averaged-heat-source, Mountain-scale, Thermal-Hydrologic

model (a monolithic three-dimensional NUFT model, using a nested mesh)

Drift Scale Test

Data Tracking Number

features, events, and processes

high-level radioactive waste (in reference to a waste package type)

information exchange drawing

Lawrence Berkeley National Laboratory

Large Block (Thermal) Test

Line-averaged-heat-source, Drift-scale, Thermal-Hydrologic submodel of the MSTHM; this submodel is a two-dimensional NUFT submodel

Line-averaged-heat-source, Mountain-scale, Thermal-Hydrologic model (an intermediate result of the MSTHM)

Linear Power Density $(\mathrm{kW} / \mathrm{m})$

Multiscale Thermohydrologic Abstraction Code

Multiscale Thermohydrologic Model

metric tons of uranium (measure of mass of radioactive waste, which is also a measure of the thermal power loading)

pressurized water reactor (in reference to a waste package type)

relative humidity

resistance temperature device (used in the field thermal tests, including the Large Block Test and Drift Scale Test) 
SDT Smeared-heat-source, Drift-scale, Thermal-conduction submodel (a onedimensional NUFT submodel)

SMT Smeared-heat-source, Mountain-scale, Thermal-conduction submodel (this submodel is a three-dimensional NUFT submodel)

SNF spent nuclear fuel

SNL Sandia National Laboratory

SSPA Supplemental Science and Performance Analyses

TSPA Total System Performance Assessment

TSPA-LA Total System Performance Assessment for the License Application

TSPA-SR Total System Performance Assessment for the Site Recommendation

TSPA-VA Total System Performance Assessment for the Viability Assessment

TWP technical work plan

UZ unsaturated zone

WAPDEG waste package degradation (model)

YMP Yucca Mountain Project 


\section{PURPOSE}

The purpose of the multiscale thermohydrologic model (MSTHM) is to predict the possible range of thermal-hydrologic conditions, resulting from uncertainty and variability, in the repository emplacement drifts, including the invert, and in the adjoining host rock for the repository at Yucca Mountain. Thus, the goal is to predict the range of possible thermal-hydrologic conditions across the repository; this is quite different from predicting a single expected thermal-hydrologic response. The MSTHM calculates the following thermal-hydrologic parameters: temperature, relative humidity, liquid-phase saturation, evaporation rate, air-mass fraction, gas-phase pressure, capillary pressure, and liquid- and gas-phase fluxes (Table 1-1). These thermal-hydrologic parameters are required to support Total System Performance Assessment (TSPA) Model/Analysis for the License Application (BSC 2004 [DIRS 168504]). The thermal-hydrologic parameters are determined as a function of position along each of the emplacement drifts and as a function of waste package type. These parameters are determined at various reference locations within the emplacement drifts, including the waste package and drip-shield surfaces and in the invert. The parameters are also determined at various defined locations in the adjoining host rock.

The MSTHM uses data obtained from the data tracking numbers (DTNs) listed in Table 4.1-1. The majority of those DTNs were generated from the following analyses and model reports:

- UZ Flow Model and Submodels (BSC 2004 [DIRS 169861])

- Development of Numerical Grids for UZ Flow and Transport Modeling (BSC 2004 [DIRS 169855])

- Calibrated Properties Model (BSC 2004 [DIRS 169857])

- Thermal Conductivity of the Potential Repository Horizon (BSC 2004 [DIRS 169854])

- Thermal Conductivity of the Non-Repository Lithostratigraphic Layers (BSC 2004 [DIRS 170033])

- Ventilation Model and Analysis Report (BSC 2004 [DIRS 169862])

- Heat Capacity Analysis Report (BSC 2004 [DIRS 170003]).

The MSTHM simulations provide the Total System Performance Assessment for the License Application (TSPA-LA) with the thermal-hydrologic parameters (as a function of time) that influence the evolution of in-drift coupled flow and transport processes. The TSPA-LA then uses those thermal-hydrologic parameters as part of its integrated assessment of the following:

- General corrosion of the waste package

- Localized corrosion of the waste package

- Waste-form degradation

- Radionuclide solubility.

- In-drift seepage evolution and thermal seepage 
- Dust-leachate evolution

- Radionuclide transport in the Engineered Barrier System

Analysis and model reports that are directly downstream of this report include:

- Drift Degradation Analysis

- Evaluation of Features, Events, and Processes (FEP) for the Biosphere Model

- Total System Performance Assessment (TSPA) Model/Analysis for the License Application.

The limitations of the MSTHM include:

- Drift seepage prediction during the post-boiling period is beyond the scope of this report

- The predicted evaporation rate on the drip shield pertains to the case with no dripping on the drip shield.

The MSTHM accounts for three-dimensional drift-scale and mountain-scale heat flow and captures the influence of the key engineering-design parameters and natural system factors affecting thermal-hydrologic conditions in the emplacement drifts and adjoining host rock. The natural system factors include:

- Repository-scale spatial variability of percolation flux above the repository

- Temporal variability of percolation flux (as influenced by climate change)

- Uncertainty in percolation flux (as addressed by the lower-bound, mean, and upper-bound infiltration-flux cases)

- Stratigraphic variation of thermal conductivity

- Stratigraphic variation of bulk rock density and specific heat

- Stratigraphic variation of hydrologic properties of the rock matrix

- Stratigraphic variation of hydrologic properties of fractures

- Variability in overburden thickness.

The engineering-design parameters include:

- Overall areal heat-generation density of the waste inventory, quantified by the average Areal Mass Loading (AML, expressed in metric tons of uranium (MTU) per acre)

- Line-averaged thermal load along emplacement drifts, quantified by the average Lineal Power Density (LPD, expressed in $\mathrm{kW} / \mathrm{m}$ ) 
- Distance between emplacement drifts (also called drift spacing)

- Age of spent-nuclear fuel at time of emplacement

- Repository footprint shape, which influences the evolution of the edge-cooling effect that increases with proximity to the repository edges

- Dimensions of the in-drift design (waste packages, drip shield, and invert)

- Properties of the in-drift engineered barrier system components

- Waste package spacing along the drift (line-load versus point-load spacing)

- Waste package sequencing (particularly with respect to the heat output from the respective waste package types)

- Time- and distance-dependent heat-removal efficiency of preclosure drift ventilation.

The MSTHM (Figure 1-1, Tables 1-2 and 1-3) couples the Smeared-heat-source Drift-scale Thermal-conduction (SDT), Line-average-heat-source Drift-scale Thermal-Hydrologic (LDTH), Discrete-heat-source Drift-scale Thermal-conduction (DDT), and Smeared-heat-source Mountain-scale Thermal-conduction (SMT) submodels such that the flow of water, water vapor, air, and heat through partially saturated fractured porous rock are adequately represented. The relationships between the various submodel and model types are diagrammed in Figure 1-1. The submodel and model types are defined in Table 1-2. All submodels use the Nonisothermal Unsaturated-saturated Flow and Transport (NUFT) simulation code (Nitao 1998 [DIRS 100474]). In addition to being used within the MSTHM itself, the two-dimensional LDTH submodel (Section 6.2.6) is also used as a stand-alone model to conduct sensitivity analyses in this report.

This report provides a description of the MSTHM concept and approach, detailing the software and the routines used in the MSTHM. It describes the inputs to the software and details the specific parameters of that data. It discusses the specific assumptions made in this modeling system and provides the rationale for each assumption. The report includes a description of the MSTHM and the specific submodel components, input-data-preparation and model-building steps, and the MSTHM calculation sequence. Finally, the report includes a discussion of the MSTHM validation in accordance with Technical Work Plan For: Near-Field Environment and Transport In-Drift Heat and Mass Transfer Model and Analysis Reports Integration (BSC 2004 [DIRS 170950]).

Appendix XIII presents a listing of list of data sources for figures and tables in this report. This includes the source DTN, the associated file name, and the software necessary to access the data. An example of accessing data temperature and saturation time history data generated from the MSTHAC v7.0 (Section 3.1.5), using XTOOL v10.1 (Section 3.1.4) is presented in the flow chart in Figure XV-1 in Appendix XV. Note that in accessing the data, it is necessary to download from the YMP server using the Windows Operating System, and then to use File 
Transfer Protocol (FTP) to transfer the files to a Sun Workstation with the Sun OS 5.8 operating system with XTOOL v10.1 software installed.

Table 1-1. List of Thermal-Hydrologic Parameters Predicted with the MSTHM

\begin{tabular}{|c|c|}
\hline Thermal-Hydrologic Parameter & Drift-Scale Location \\
\hline \multirow[t]{8}{*}{ Temperature } & Near-field environment host rock ( $5 \mathrm{~m}$ above crown of drift) \\
\hline & Near-field environment host rock (mid-pillar at repository horizon) \\
\hline & Maximum lateral extent of boiling \\
\hline & Drift wall (perimeter average) \\
\hline & Drip shield (perimeter average) \\
\hline & Drip shield (upper surface) \\
\hline & Waste package (surface average) \\
\hline & Invert (average) \\
\hline \multirow[t]{4}{*}{ Relative humidity } & Drift wall (perimeter average) \\
\hline & Drip shield (perimeter average) \\
\hline & Waste package \\
\hline & Invert (average) \\
\hline \multirow[t]{3}{*}{ Liquid-phase saturation (matrix) } & Drift wall (perimeter average) \\
\hline & Drip shield (perimeter average) \\
\hline & Invert (average) \\
\hline \multirow[t]{8}{*}{ Liquid-phase flux } & Near-field environment host rock ( $5 \mathrm{~m}$ above crown of drift) \\
\hline & Near-field environment host rock ( $3 \mathrm{~m}$ above crown of drift) \\
\hline & Drift wall (upper surface) \\
\hline & Drift wall (lower surface below invert) \\
\hline & Drip shield (crown) \\
\hline & Drip shield (upper surface average) \\
\hline & Drip shield (lower side at the base) \\
\hline & Invert (average) \\
\hline Gas-phase air-mass fraction & Drip shield (perimeter average) \\
\hline Gas-phase pressure & Drip shield (perimeter average) \\
\hline \multirow[t]{4}{*}{ Capillary pressure } & Drip shield (perimeter average) \\
\hline & Invert (average) \\
\hline & Drift wall (crown, in matrix) \\
\hline & Drift wall (crown, in fractures) \\
\hline Gas-phase (water vapor) flux & Drift wall (perimeter average) \\
\hline Gas-phase (air) flux & Drift wall (perimeter average) \\
\hline \multirow[t]{5}{*}{ Evaporation rate } & Drip shield (crown) \\
\hline & Drip shield (perimeter total) \\
\hline & Drift wall (upper surface) \\
\hline & Drift wall (lower surface below invert) \\
\hline & Invert (total) \\
\hline
\end{tabular}

NOTE: The invert relative humidity is not predicted by the MSTHM. It is calculated, using the MathCad spreadsheet described in Appendix XV, based on the MSTHM-predicted temperature and liquidphase saturation in the invert. 
1-D SDT @ N locations \& M AMLs
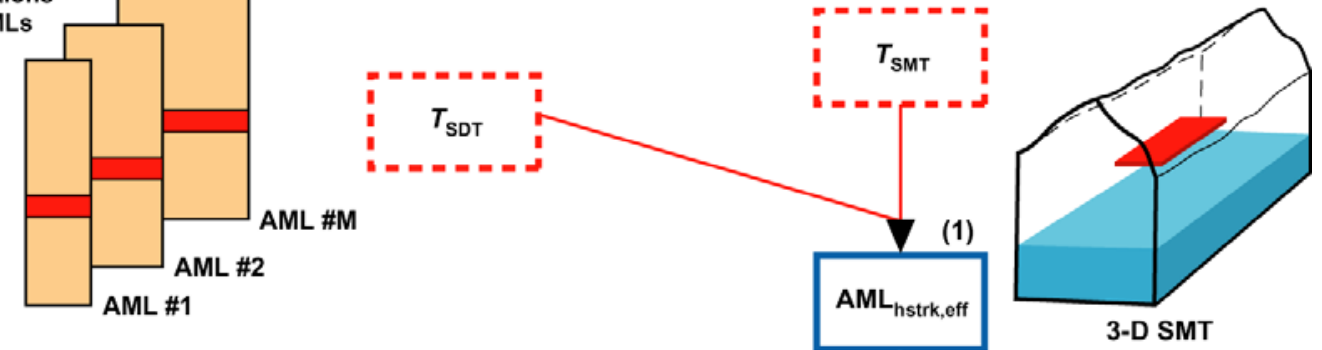

2-D LDTH (a) N locations \& M AMLS
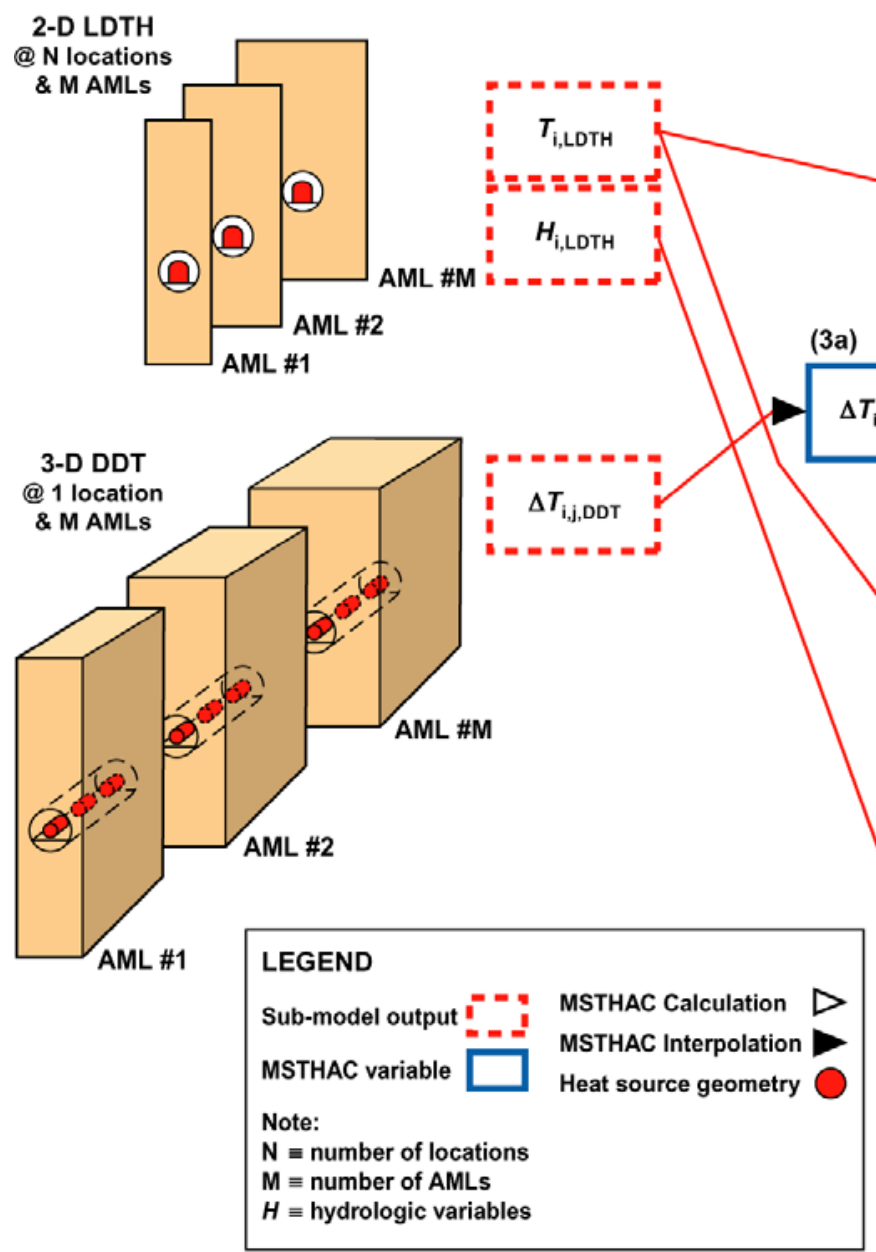

(3a)
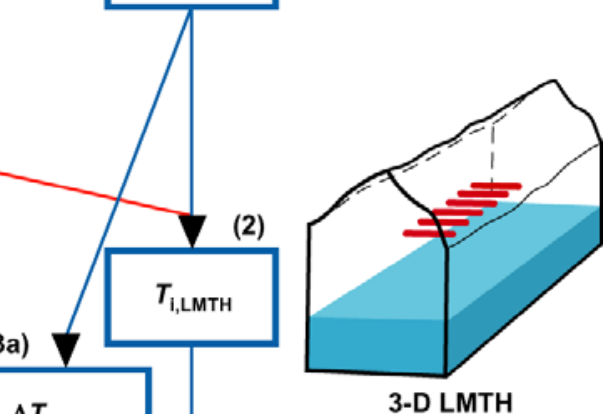

3-D DDT
@ 1 location
\& M AMLs

$T_{\mathrm{i}, \mathrm{j}, \mathrm{DMTH}}$

(3b)

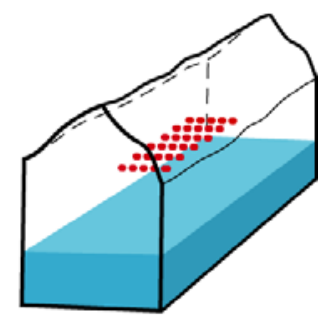

(4)

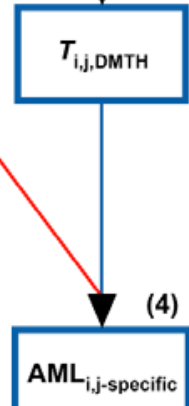

3-D DMTH

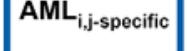

(5)

(6)

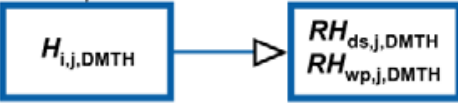

NOTE: SDT-, LDTH-, and DDT-submodel calculations are run with the NUFT code for different AMLs (left side). The SMT-submodel calculation is also run with the NUFT code. The SMT, LMTH and DMTH models are the series of 3-D mountain-scale models of increasing complexity (right side). The MSTHAC code assembles the results of the NUFT submodels in six stages, constructing intermediate parameters (AMLhstrk,eff, $\Delta T_{\mathrm{i}, \mathrm{j}, \mathrm{DMTH}}$, $T_{\mathrm{i}, \mathrm{LMTH}}$ and $\left.\mathrm{AML}_{\mathrm{i}, \mathrm{j} \text {-specific }}\right)$ and final MSTHM parameters $\left(T_{\mathrm{i}, \mathrm{j}, \mathrm{DMTH}}, R H_{\mathrm{i}, \mathrm{j}, \mathrm{DMTH}}\right.$ and $\left.\mathrm{H}_{\mathrm{i}, \mathrm{j}, \mathrm{DMTH}}\right)$ from NUFT submodel output ( $T_{\mathrm{SDT}}, T_{\mathrm{SMT}}, T_{\mathrm{i}, \mathrm{LDTH}}, H_{\mathrm{i}, \mathrm{LDTH}}$ and $\left.\Delta T_{\mathrm{i}, \mathrm{j}, \mathrm{DDT}}\right)$. The submodel and model types are defined in Table 1-2. The parameters are defined in Table 1-3. Note that the four submodels of the MSTHM are the SDT, LDTH, DDT, and SMT submodels. The LMTH model is an intermediate result of the MSTHM and the DMTH model is the final result of the MSTHM.

Figure 1-1. Six Stage Flow Chart Diagram of the MSTHM 
Table 1-2. Submodel and Model Types Used in the MSTHM

\begin{tabular}{|l|l|}
\hline \multicolumn{1}{|c|}{$\begin{array}{c}\text { Submodel I } \\
\text { Model Type }\end{array}$} & \multicolumn{1}{c|}{ Description } \\
\hline MSTHM & Multiscale thermohydrologic model \\
\hline SMT & $\begin{array}{l}\text { Smeared-heat-source, mountain-scale, thermal-conduction: three-dimensional NUFT } \\
\text { submodel }\end{array}$ \\
\hline SDT & Smeared-heat-source, drift-scale, thermal-conduction: one-dimensional NUFT submodel \\
\hline LDTH & $\begin{array}{l}\text { Line-averaged-heat-source, drift-scale, thermal-hydrologic: two-dimensional NUFT } \\
\text { submodel }\end{array}$ \\
\hline DDT & Discrete-heat-source, drift-scale, thermal-conduction: three-dimensional NUFT submodel \\
\hline LMTH & $\begin{array}{l}\text { Line-averaged-heat-source, mountain-scale, thermal-hydrologic model: three-dimensional } \\
\text { MSTHM intermediate result }\end{array}$ \\
\hline DMTH & $\begin{array}{l}\text { Discrete-heat-source, mountain-scale, thermal-hydrologic model: three-dimensional } \\
\text { MSTHM final result }\end{array}$ \\
\hline D/LMTH & $\begin{array}{l}\text { Discrete / line-averaged-heat-source, mountain-scale, thermal-hydrologic model: the } \\
\text { nested-mesh monolithic three-dimensional NUFT model used in the MSTHM validation } \\
\text { (Section 7.5) }\end{array}$ \\
\hline
\end{tabular}

NOTE: The four submodels of the MSTHM are the SDT, LDTH, DDT, and SMT submodels. The LMTH model is an intermediate result of the MSTHM and the DMTH model is the final result of the MSTHM. 
Table 1-3. Parameters Used in the MSTHM Methodology

\begin{tabular}{|c|c|c|}
\hline $\begin{array}{l}\text { Parameter } \\
\text { Name }\end{array}$ & Description & $\begin{array}{l}\text { Stage } \\
\text { (see Figure } \\
\text { 1-1) }\end{array}$ \\
\hline$T_{\mathrm{SDT}}$ & Host-rock temperature output from the one-dimensional SDT submodel. & $\begin{array}{l}\text { Stage } 1 \text { (NUFT } \\
\text { output) }\end{array}$ \\
\hline$T_{\text {SMT }}$ & $\begin{array}{l}\text { Host-rock temperature output from the three-dimensional mountain-scale SMT } \\
\text { submodel. }\end{array}$ & $\begin{array}{l}\text { Stage } 1 \text { (NUFT } \\
\text { output) }\end{array}$ \\
\hline$\Delta T_{\mathrm{i}, \mathrm{j}, \mathrm{DDT}}$ & $\begin{array}{l}\text { Temperature deviation of individual waste package from averaged drift-wall } \\
\text { temperature for reference location i and waste package j. }\end{array}$ & $\begin{array}{l}\text { Stage } 3 a \\
\text { (NUFT output) }\end{array}$ \\
\hline$\Delta T_{\mathrm{i}, \mathrm{j}, \mathrm{DMTH}}$ & $\begin{array}{l}\text { Temperature deviation of individual waste package from averaged drift-wall } \\
\text { temperature for reference location i and waste package j, adjusting for three- } \\
\text { dimensional mountain-scale heat loss. }\end{array}$ & Stages $3 a, 3 b$ \\
\hline$T_{\mathrm{i}, \mathrm{LDTH}}$ & Temperature output from two-dimensional LDTH drift-scale submodel. & $\begin{array}{l}\text { Stages } 2,4 \\
\text { (NUFT output) }\end{array}$ \\
\hline$T_{\mathrm{i}, \mathrm{LMTH}}$ & $\begin{array}{l}\text { Temperature for reference location i adjusted for the three-dimensional mountain } \\
\text { scale heat loss. }\end{array}$ & Stages $2,3 b$ \\
\hline$T_{\mathrm{i}, \mathrm{j}, \mathrm{DMTH}}$ & $\begin{array}{l}\text { Temperature for reference location i and waste package j adjusted for the three- } \\
\text { dimensional mountain-scale heat loss and for waste package variation. }\end{array}$ & Stages $3 b, 4$ \\
\hline$H_{\mathrm{i}, \mathrm{LDTH}}$ & $\begin{array}{l}\text { Set of hydrologic parameters for reference location i. This set includes } R H_{i, L D T H} \\
\text { and } S_{i, L D T H} \text {. }\end{array}$ & $\begin{array}{l}\text { Stage } 5 \text { (NUFT } \\
\text { output) }\end{array}$ \\
\hline$H_{\mathrm{i}, \mathrm{j}, \mathrm{DMTH}}$ & $\begin{array}{l}\text { Set of hydrologic parameters for reference location i and waste package } \mathrm{j} \\
\text { adjusted for three-dimensional mountain-scale heat loss and for waste package } \\
\text { variation. This set includes } R H_{\mathrm{i}, \mathrm{DMMTH}} \text { and } \mathrm{S}_{\mathrm{i}, \mathrm{j}, \mathrm{DMTH}} \text {. }\end{array}$ & Stages 5,6 \\
\hline$R H_{\mathrm{i}, \mathrm{j}, \mathrm{DMTH}}$ & $\begin{array}{l}\text { Relative humidity of the reference location i and waste package } \mathrm{j} \text { for the DMTH } \\
\text { model. }\end{array}$ & Stage 5, 6 \\
\hline$S_{\mathrm{i}, \mathrm{j}, \mathrm{DMTH}}$ & $\begin{array}{l}\text { Liquid-phase saturation of the reference location i and waste package } \mathrm{j} \text { for the } \\
\text { DMTH model. }\end{array}$ & Stage 5,6 \\
\hline $\begin{array}{l}T_{\mathrm{dw}, \mathrm{cav}} \\
R H_{\mathrm{dw}, \mathrm{cav}}\end{array}$ & $\begin{array}{l}\text { Perimeter averages of surfaces adjoining the open cavity outside of the drip } \\
\text { shield only for the DMTH model. }\end{array}$ & Stage 6 \\
\hline $\mathrm{AML}_{\text {hstrk,eff }}$ & $\begin{array}{l}\text { A time-varying parameter that incorporates the influence of three-dimensional } \\
\text { mountain-scale heat-loss (determined by the combined use of the SMT and SDT } \\
\text { submodels) onto the LDTH submodel results. }\end{array}$ & Stages $1,2,3 a$ \\
\hline 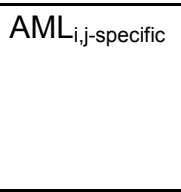 & $\begin{array}{l}\text { A time-varying parameter that combines the influences of waste } \\
\text { package-to-waste package variation (determined by the DDT submodels) and } \\
\text { three-dimensional mountain-scale heat loss (represented by the LMTH-modeled } \\
\text { temperatures), resulting in DMTH-model results for reference location i and } \\
\text { waste package j. }\end{array}$ & Stages 4,5 \\
\hline$P_{\text {sat }}$ & Saturated vapor pressure, which is a function of temperature. & Stage 6 \\
\hline
\end{tabular}

NOTE: $\quad$ Subscript i refers to a reference location in the drift (or host rock); $i=d w$ refers to drift wall, $i=d s$ refers to drip shield, $i=$ in refers to invert, and $i=w p$ refers to waste package. Subscript $\mathrm{j}$ refers to the waste package type, such as $\mathrm{j}=$ DHLW, 21-PWR CSNF, or 44-BWR CSNF. The MSTHM calculation sequence is described in detail in Section 6.2.4. 


\section{INTENTIONALLY LEFT BLANK}




\section{QUALITY ASSURANCE}

The Quality Assurance program applies to the development of this document (BSC 2004 [DIRS 170950], Section 8.1). This document was prepared in accordance with Technical Work Plan for: Near-Field Environment and Transport In-Drift Heat and Mass Transfer Model and Analysis Reports Integration (BSC 2004 [DIRS 170950]), which directs the work identified in work package ARTM02. The technical work plan (TWP) was prepared in accordance with AP-2.27Q, Planning for Science Activities. There were no variances from the planned activities. The methods used to control the electronic management of data are identified in the TWP (BSC 2004 [DIRS 170950], Section 8.4) and were implemented without variance. As directed in the TWP, this document was prepared in accordance with AP-SIII.10Q, Models; LP-SI.11Q-BSC, Software Management; AP-3.15Q, Managing Technical Product Inputs; and reviewed in accordance with AP-2.14Q, Document Review. As needed, unqualified project data is qualified in this document in accordance with AP-SIII.2Q, Qualification of Unqualified Data.

The work scope described in this report has been determined to be subject to the U.S. Department of Energy's (DOE's) Quality Assurance Requirements and Description (DOE 2004 [DIRS 171539]). The work scope of this report involves conducting investigations or analyses of Engineered Barrier System components contained in Q-List (BSC 2004 [DIRS 168361]). Safety Categories for the components are provided in Table 2-1.

Table 2-1. Engineered Barrier System Components Addressed in This Report, Listed with Corresponding Safety Category (SC) Level

\begin{tabular}{|l|c|}
\hline \multicolumn{1}{|c|}{ Engineered Barrier System Component } & Safety Category \\
\hline Drip Shield & SC \\
\hline Drift Invert (Steel) & SC \\
\hline Emplacement Drift Excavated Opening & SC \\
\hline DOE and Commercial Waste Packages & SC \\
\hline
\end{tabular}

Source: BSC 2004 [DIRS 168361].

Furthermore, this report provides analysis of model results supporting performance assessment activities for the Total Systems Performance Assessment for License Application.

This report documents the determination of in-drift thermal-hydrologic conditions that are required by TSPA-LA. It provides in-drift thermal-hydrologic parameters that are important to the performance of the engineered barriers classified in Q-List (BSC 2004 [DIRS 168361]) as "Safety Category" because they are important to waste isolation as defined in AP-2.22Q, Classification Analyses and Maintenance of the Q-List. The results of this report are important to the demonstration of compliance with the postclosure performance objectives prescribed in 10 CFR 63.113. 


\section{INTENTIONALLY LEFT BLANK}




\section{USE OF SOFTWARE}

A complete list of the software and the associated software tracking number is given in Table 3-1.

Table 3-1. Software Used

\begin{tabular}{|c|c|c|c|c|}
\hline Software Name and Version & $\begin{array}{l}\text { Software } \\
\text { Tracking } \\
\text { Number }\end{array}$ & $\begin{array}{c}\text { Software } \\
\text { Qualification } \\
\text { Status }\end{array}$ & $\begin{array}{c}\text { Computers Used to } \\
\text { Run Software (DOE } \\
\text { Property Number) }\end{array}$ & $\begin{array}{c}\text { Sections Where } \\
\text { Software Output } \\
\text { Is Used }^{\mathrm{a}}\end{array}$ \\
\hline NUFT v3.0s & $10088-3.0 s-02$ & Qualified & $\begin{array}{l}\text { 6549273, 6549266, } \\
6700902,6290847, \\
6426406,6290830 \\
6877864,6481320 \\
6290823,6813251 \\
6877857,6524867 \\
6878182,6575968, \\
6274861,6813244 \\
6877840,6549297 \\
\end{array}$ & $\begin{array}{l}6.2,6.3,6.4,7.3 \\
7.5,8.3\end{array}$ \\
\hline NUFT v3.0.1s & $10130-3 \cdot 0.1 \mathrm{~s}-01$ & Qualified & $\begin{array}{l}6700902,6426406 \\
6290830\end{array}$ & $7.4,7.5$ \\
\hline RADPRO v4.0 & $10204-4.0-00$ & Qualified & 6877840,6878182 & $6.2,6.3,8.3$ \\
\hline XTOOL v10.1 & $10208-10.1-00$ & Qualified & 6496843 & $\begin{array}{l}\text { 6.2, } 6.3,6.4,7.3, \\
7.4,7.5\end{array}$ \\
\hline MSTHAC v7.0 & $10419-7.0-00$ & Qualified & $\begin{array}{l}6813251,6290830 \\
6878182\end{array}$ & $6.2,6.3,7.5,8.3$ \\
\hline readsUnits v1.0 & $10602-1.0-00$ & Qualified & 6371317 & $\begin{array}{l}6.2,6.3,7.4,7.5, \\
8.3\end{array}$ \\
\hline YMESH v1.54 & $10172-1.54-00$ & Qualified & $\begin{array}{l}6813251,6813244 \\
6877864,6878182\end{array}$ & $\begin{array}{l}6.2,6.3,7.4,7.5, \\
8.3\end{array}$ \\
\hline boundary_conditions v1.0 & $11042-1.0-00$ & Qualified & 6877840 & $6.3,7.4,8.3$ \\
\hline heatgen_ventTable_emplace v1.0 & $11039-1.0-00$ & Qualified & 6813251 & $6.3,8.3$ \\
\hline rme6 v1.2 & $10617-1.2-00$ & Qualified & 6813251 & $6.3,8.3$ \\
\hline xw v1.0 & $11035-1.0-00$ & Qualified & 6813251 & $6.3,8.3$ \\
\hline colCen v1.0 & $11043-1.0-00$ & Qualified & 6877840 & $6.3,8.3$ \\
\hline $\begin{array}{l}\text { repository_percolation_calculator } \\
\text { v1.0 }\end{array}$ & $11041-1.0-00$ & Qualified & 6813251 & $6.3,8.3$ \\
\hline extractBlocks_EXT v1.0 & $11040-1.0-00$ & Qualified & 6877857 & $6.3,8.3$ \\
\hline Chimney_interpolate v1.0 & $11038-1.0-00$ & Qualified & 6813251,6290830 & $6.3,8.3$ \\
\hline reformat_EXT_to_TSPA v1.0 & $11061-1.0-00$ & Qualified & $\begin{array}{l}6813251,6290830 \\
6878182\end{array}$ & $6.3,8.3$ \\
\hline
\end{tabular}

${ }^{a}$ These are the sections that directly or indirectly utilize the output from the listed software.

\subsection{QUALIFIED SOFTWARE}

The software described in this section is used in the data-flow diagrams (Figures 6-1 and 6-2) of Section 6. The computer software was qualified under procedure AP-SI.2Q, Qualification of Level A Software, before procedure LP-SI.11Q-BSC became effective and is therefore part of the established baseline in accordance with Section 2.0 of LP-SI.11Q-BSC. Because many of these items have to process or produce files consistent with NUFT formats and have been validated for this use, they are the only software appropriate for their tasks. 


\subsubsection{NUFT v3.0s}

NUFT v3.0s (NUFT V3.0s, STN: 10088-3.0s-02 [DIRS 164541]) is baselined as qualified software per LP-SI.11Q-BSC, Software Management, and is used to conduct all of the submodel calculations required by the MSTHM. NUFT v3.0s was obtained from software configuration management and run on Sun workstations with the Sun OS 5.8 operating system. NUFT v3.0s was selected because it solves the governing equations of the mathematical model (Section 6.2), is supported by a suite of special-purpose software that completes implementation of the MSTHM, and imposes no limitations on outputs. As discussed below, the use of NUFT v3.0s for the submodel calculations was within the documented validation range of the software. Therefore, the use of this software was consistent with its intended use.

NUFT v3.0s (and v3.0.1s) is a general-purpose code for simulating mass and heat transport in fractured porous media. Because NUFT is based on the conservation of mass and energy, it is valid for any such calculation, provided the mass- and heat-transport parameters are used within their validation ranges. In other words, what limits the range of validation of NUFT are the mass- and heat-transport-phenomena-related parameters (or constitutive properties), such as thermal conductivity, which affects heat conduction, and permeability, which affects gas- and liquid-phase flow. Thus, if thermal conductivity and permeability are applicable for the range of predicted temperatures, the software (NUFT) is valid for this range. The validation range and limitation of applicability of NUFT is determined by the validation studies conducted in conjunction with the Large Block Test (Section 7.3) and the Drift Scale Test (Section 7.4). Comparisons of the NUFT-predicted temperatures with the measured temperatures in those tests show that NUFT meets the validation requirement described in Technical Work Plan for: Near-Field Environment and Transport In-Drift Heat and Mass Transfer Model and Analysis Reports Integration (BSC 2004 [DIRS 170950]). Because measured temperatures in the Drift Scale Test are as great as $280^{\circ} \mathrm{C}$ in the rock, the validation range of NUFT is up to $280^{\circ} \mathrm{C}$ in the host rock. In Section 6.3.4, which summarizes the range of thermal-hydrologic conditions predicted for the TSPA-LA, it is shown that the maximum peak drift-wall and waste package temperatures are 175.2 and $203.1^{\circ} \mathrm{C}$, respectively (Table 6.3-38). Therefore, NUFT was applied within its validation limits for the TSPA-LA.

\subsubsection{NUFT $\mathbf{~ 3 . 0 . 1 s}$}

NUFT v3.0.1s (NUFT V3.0.1s, STN: 10130-3.0.1s-01 [DIRS 166636]) is baselined as qualified software per LP-SI.11Q-BSC, and is used to conduct all of the nested-mesh model calculations in the model validation exercises for the MSTHM. NUFT v3.0.1s was obtained from software configuration management and run on Sun workstations with the Sun OS 5.8 operating system. NUFT v3.0.1s was selected because nested meshes are a feature of this newer version. Because its use was within the documented validation range of the software (see Section 3.1.1), it was consistent with its intended use.

\subsubsection{RADPRO v4.0}

RADPRO v4.0 (RADPRO V4.0, STN: 10204-4.0-00 [DIRS 164273]) is baselined as qualified software per LP-SI.11Q-BSC, and was obtained from software configuration management and run on a Sun workstation with a SunOS 5.8 (Solaris 8) operating system. RADPRO v4.0 was 
selected because it calculates the radiative heat transfer coefficients in the emplacement drift in accordance with Equation 10 of Section 6.2.3.3 without limitations on its output. Its use was consistent with its intended use and within the documented validation range of the software. Because this software is only used to conduct simple arithmetic functions, it is not applicable to identify validation ranges or limitations of use.

\subsubsection{XTOOL v10.1}

XTOOL v10.1 (XTOOL V10.1, STN: 10208-10.1-00 [DIRS 148638]) is baselined as a qualified software routine per LP-SI.11Q-BSC, and was obtained from software configuration management and run on a Sun workstation with a SunOS 5.6.1 operating system. XTOOL v10.1 is used to generate graphical representations of the results given in the NUFT and MSTHAC v7.0 time-history files (which are files with the suffix: *.ext). XTOOL v10.1 is the only appropriate software for this task. Because this software is only used to generate graphical displays of data, it is not applicable to identify validation ranges or limitations of use.

\subsubsection{MSTHAC v7.0}

MSTHAC v7.0 (MSTHAC V7.0, STN: 10419-7.0-00 [DIRS 164274]) is baselined as qualified software per LP-SI.11Q-BSC, and was obtained from software configuration management and run on a Sun workstation with a SunOS 5.8 (Solaris 8) operating system. MSTHAC v7.0 integrates the results of NUFT submodel calculations to predict the multiscale thermal-hydrologic conditions in the emplacement drifts and adjoining host rock throughout the repository area. MSTHAC v7.0 is the only appropriate software for this task. Because MSTHAC integrates the results of NUFT submodel calculations, its validation range is the same as that described for NUFT v3.0s (Section 3.1.1).

\subsection{6 readsUnits $v 1.0$}

Software routine readsUnits v1.0 (readsUnits V1.0, STN: 10602-1.0-00 [DIRS 164542]) is baselined as qualified software per LP-SI.11Q-BSC, and was obtained from software configuration management and run on a Sun workstation with a SunOS 5.5.1 operating system. This code reads YMESH-generated data describing a stratigraphic column and generates comment lines for NUFT input files that summarize the thicknesses of each of the hydrostratigraphic units (also called UZ model layers) in that column. Software routine readsUnits v1.0 is the only appropriate software for this task. Because this software is only used to generate comment lines in the NUFT input files, it does not influence any model predictions. Therefore, it is not applicable to identify validation ranges or limitations of use.

\subsubsection{YMESH v1.54}

YMESH v1.54 (YMESH v1.54, STN: 10172-1.54-00 [DIRS 163894]) is baselined as qualified software per LP-SI.11Q-BSC, and was obtained from software configuration management and run on a Sun workstation with a SunOS 5.8 (Solaris 8) operating system. YMESH v1.54 is used to generate the thicknesses of the hydrostratigraphic units (also called the UZ model layers) in the various MSTHM submodels based upon the grids from Development of Numerical Grids for UZ Flow and Transport Modeling (BSC 2004 [DIRS 169855]). YMESH v1.54 is the only appropriate software for this task. Because this software is only used to generate numerical grids 
on the basis of geometric relationships, it is not applicable to identify validation ranges or limitations of use.

\subsection{8 boundary_conditions v1.0}

The software routine boundary_conditions v1.0 (boundary_conditions V 1.0, STN: 11042-1.000 [DIRS 164275]) is baselined as qualified software per LP-SI.11Q-BSC, and was obtained from software configuration management and run on a Sun workstation with a SunOS 5.8 (Solaris 8) operating system. The purpose of this routine is to generate upper and lower boundary conditions for the LDTH, SMT, and SDT submodels of the MSTHM (Section 6.2), as well as for other models such as the three-dimensional thermal-hydrologic model for the Drift Scale Test (DST) (Section 7.4). The software routine boundary_conditions v1.0 is the only appropriate software for this task. Because this software is only used to conduct simple interpolations of data, it is not applicable to identify validation ranges or limitations of use.

\subsection{9 heatgen_ventTable_emplace v1.0}

The software routine heatgen_ventTable_emplace v1.0 (heatgen_ventTable_emplace V1.0, STN: 11039-1.0-00 [DIRS 164276]) is baselined as qualified software per LP-SI.11Q-BSC, and was obtained from software configuration management and run on a Sun workstation with a SunOS 5.8 (Solaris 8) operating system. The software routine heatgen_ventTable_emplace v1.0 modifies a heat-generation-rate-versus-time table in two ways. First, it can "age" the heat-generation table by adding a specified number of years to the time entries. Second, it can account for the heat-removal efficiency of ventilation by multiplying the heat-generation-rate values by a specified fraction during the specified ventilation period. The software routine heatgen_ventTable_emplace v1.0 also can incorporate the dependence of the heat-removal efficiency table on distance (along the emplacement drift) from the ventilation inlet. The software routine heatgen_ventTable_emplace v1.0 is the only appropriate software for this task. Because this software is only used to conduct simple arithmetic functions, it is not applicable to identify validation ranges or limitations of use.

\subsubsection{0 rme6 v1.2}

The software routine rme6 v1.2 (rme6 v1.2, STN: 10617-1.2-00 [DIRS 163892]) is baselined as qualified software per LP-SI.11Q-BSC, and was obtained from software configuration management and run on a Sun workstation with a SunOS 5.8 (Solaris 8) operating system. This code converts the grid from Development of Numerical Grids for UZ Flow and Transport Modeling (BSC 2004 [DIRS 169855]) to a format that is readable by YMESH v1.54 (Section 3.1.7). The software routine rme6 v1.2 is the only appropriate software for this task. Because this software is only used to reformat input data for YMESH v1.54, it is not applicable to identify validation ranges or limitations of use.

\subsubsection{1 xw v1.0}

The software routine xw v1.0 (xw V1.0, STN: 11035-1.0-00 [DIRS 164278]) is baselined as qualified software per LP-SI.11Q-BSC, and was obtained from software configuration management and run on a Sun workstation with a SunOS 5.8 (Solaris 8) operating system. The software routine xw v1.0 extends the grid from the three-dimensional unsaturated zone (UZ) 
flow model in the horizontal direction for the purpose of building mountain-scale submodels that extend laterally beyond the grid of the three-dimensional UZ flow model. The software routine $\mathrm{xw}$ v1.0 is the only appropriate software for this task. Because this software is only used to horizontally extend the grid of the three-dimensional UZ flow model, it is not applicable to identify validation ranges or limitations of use.

\subsubsection{2 colCen v1.0}

The software routine colCen v1.0 (colCen V1.0, STN: 11043-1.0-00 [DIRS 164279]) is baselined as qualified software per LP-SI.11Q-BSC, and was obtained from software configuration management and was run on a Sun workstation with a SunOS 5.8 (Solaris 8) operating system. The purpose of colCen v1.0 grid is to determine the gridblock column in the three-dimensional UZ flow model in which a given gridblock column in a MSTHM submodel resides. The software routine colCen v1.0 is the only appropriate software for this task. Because this software is only used to identify the UZ flow-model gridblock column in which a MSTHM submodel resides, it is not applicable to identify validation ranges or limitations of use.

\subsubsection{3 repository_percolation_calculator $\mathbf{v 1 . 0}$}

The software routine repository_percolation_calculator v1.0 (repository_percolation_calculator V1.0, STN: 11041-1.0-00 [DIRS 164280]) is baselined as qualified software per LP-SI.11QBSC, and was obtained from software configuration management and run on a Sun workstation with a SunOS 5.8 (Solaris 8) operating system. The purpose of repository_percolation_calculator v1.0 is to determine the value of percolation flux for each of the LDTH submodels based on the percolation flux map from the three-dimensional UZ flow model. The software routine repository_percolation_calculator v1.0 is the only appropriate software for this task. Because this software is only used to conduct simple arithmetic functions, it is not applicable to identify validation ranges or limitations of use.

\subsubsection{4 extractBlocks_EXT v1.0}

The software routine extractBlocks_EXT v1.0 (extractBlocks_EXT V1.0, STN: 11040-1.0-00 [DIRS 164281]) is baselined as qualified software per LP-SI.11Q-BSC, and was obtained from software configuration management and run on a Sun workstation with a SunOS 5.8 (Solaris 8) operating system. The purpose of extractBlocks_EXT is to determine the effective thermal conductivity for the gridblocks in the drift cavity of an LDTH submodel based on a correlation accounting for the influence of natural convection (Francis et al. 2003 [DIRS 164602], Table 6). The software routine extractBlocks_EXT v1.0 is the only appropriate software for this task. Because this software is only used to conduct simple arithmetic functions, it is not applicable to identify validation ranges or limitations of use.

\subsubsection{Chimney_interpolate v1.0}

The software routine Chimney_interpolate v1.0 (Chimney_interpolate V1.0, STN: 11038-1.0-00 [DIRS 164271]) is baselined as qualified software per LP-SI.11Q-BSC, and was obtained from software configuration management and run on a Sun workstation with a SunOS 5.8 (Solaris 8) operating system. The purpose of Chimney_interpolate is to create a set of virtual SDT and LDTH "chimney" submodels from the 108 "real" chimney submodels (see Appendix VII) for 
more details). The virtual chimney submodels are an input to the MSTHAC v7.0 micro-abstraction process (see Appendix VII for more details). The software routine Chimney_interpolate v1.0 is the only appropriate software for this task. Because this software is only used to conduct simple arithmetic functions, it is not applicable to identify validation ranges or limitations of use.

\subsubsection{6 reformat_EXT_to_TSPA v1.0}

The software routine reformat_EXT_to_TSPA v1.0 (reformat_EXT_to_TSPA V1.0, STN: 11061-1.0-00 [DIRS 164272]) is baselined as qualified software per LP-SI.11Q-BSC, and was obtained from software configuration management and run on a Sun workstation with a SunOS 5.8 (Solaris 8) operating system. The purpose of reformat_EXT_to_TSPA v1.0 is to post-process the micro-abstraction data produced by MSTHAC V7.0 (see Appendix VII for more details). The processing includes finding the typical waste package and location from a set of locations forming a bin and writing an output file in a format specified by the TSPA-LA organization. The software routine reformat_EXT_to_TSPA v1.0 is the only appropriate software for this task. Because this software is only used to reformat MSTHM output data, it is not applicable to identify validation ranges or limitations of use.

\subsection{OTHER SOFTWARE}

Commercial off-the-shelf software was used in the creation of tables and figures shown in this document as well as some data processing.

The figures can be divided into the following types: line plots showing time histories, contour plots showing the variation in some property at a particular point in time for a cross sectional area of interest, plots showing material properties for the repository plan view, and schematic drawings showing repository design parameters.

Contour plots were created using tecplot v9.2-0-3 (09-16-2002).

Plots showing material properties for the repository plan view were created using Matlab v6.1.0.450 release 12.1.

Mathcad 11.2a Professional was used to perform the calculations in Appendices X, XII and XV for developing the hydrologic properties of the invert; for comparing percolation fluxes, and for prediction of RH in the invert, respectively.

Schematic drawings showing repository design information were created using Adobe Illustrator v8.0.

Microsoft Excel 2000 9.0.4402 SR-1 was used to process data for the development of chimney percolation data as detailed in Appendix I.

Numerical results from the use of commercial off-the-shelf software in this report are not dependent on the software used. The documentation of each such use includes sufficient detail to allow an independent reviewer to reproduce or verify the results by visual inspection or hand calculation. 


\section{INPUTS}

\subsection{DIRECT INPUTS}

Data, parameters, design information, and other model/analyses inputs are compiled and presented in Table 4.1-1. There are seven major sections of the table: (1) geometry of the engineered system, (2) geometry of the natural system, (3) properties of the engineered system inside the emplacement drift, (4) properties of the natural system, (5) boundary conditions of the natural system, (6) distribution of percolation flux just below the base of the PTn unit, and (7) waste package heat-generation data and ventilation heat-removal efficiency. The seven sections are further delineated to distinguish separate data, design information, and parameters. The majority of the information compiled in Table 4.1-1, which is direct input, falls into the parameter and design information categories.

In Table 4.1-1, most of the direct inputs to this report are traced to current qualified project data or to qualified data that have been superseded with small changes. One exception is the emissivity range for rock, which is from Incropera and DeWitt's (1996 [DIRS 108184]) advanced textbook for heat and mass transfer. Their range of 0.88 to 0.95 is adapted from sources for hemispherical emissivity of rock at $300 \mathrm{~K}$ and is corroborated by handbook values (Knudsen et al. 1984 [DIRS 170057], pp. 10-51 to 10-52, Table 10-17) for normal emissivity of rough silica and rough fused quartz, which range from 0.80 to 0.93 . Therefore, the information is qualified for its use as emissivities of drift wall and crushed tuff in the MSTHM calculations.

The design of the repository continued to evolve during and after the calculations with the MSTHM. The effects of small changes in the design are discussed in Sections 4.1.2.1 through 4.1.2.8

\subsubsection{Data, Parameters, and Parameter Uncertainty}

The data and parameters required as input for the development of parameter values used in the models/analyses documented in this report are summarized in Table 4.1-1. The following sections of the table include information about parameters: geometry of natural system, invert thermal and hydrologic properties, hydrologic properties of all hydrostratigraphic units (also called UZ model layers), bulk thermal properties of the UZ model layers, and percolation flux below the base of the PTn unit. All of these data were obtained from studies specific to the Yucca Mountain site and are therefore appropriate for use in the MSTHM calculations reported in Section 6.3.

Sections 6.3.2, 6.3.4, and 6.3.0 provide analyses of the impact of uncertainty of key natural system parameters. Sections 6.3.11 and 6.3.12 provide analyses of the impact of uncertainty of key engineered system parameters.

\subsubsection{Design Information}

Other inputs required for the development of parameter values used in the models/analyses documented in this report take the form of design information, often from Interface Exchange Drawings (IEDs). The following sections of Table 4.1-1 include design information: geometry of the engineered system, waste package thermal properties, drip shield thermal properties, 
drift-wall emissivity and waste package heat generation and ventilation heat-removal efficiency. Information from IEDs is appropriate for use in the MSTHM calculations reported in Section 6.3 .

Table 4.1-1. Summary of Input Data and Information Required by the MSTHM

\begin{tabular}{|c|c|c|}
\hline Model Input & Value & Source \\
\hline \multicolumn{3}{|c|}{ Geometry of the Engineered System: Design Information } \\
\hline $\begin{array}{l}\text { Repository emplacement-drift layout } \\
\text { (elevations and end-point coordinates for } \\
\text { each emplacement drift) }\end{array}$ & See IED & BSC 2003 [DIRS 161727] \\
\hline Drift spacing & $81 \mathrm{~m}$ & BSC 2004 [DIRS 168489], Table 1 \\
\hline Waste package spacing & $0.1 \mathrm{~m}$ & BSC 2004 [DIRS 168489], Table 1 \\
\hline Drift diameter & $5.5 \mathrm{~m}$ & BSC 2004 [DIRS 168489], Table 1 \\
\hline $\begin{array}{l}\text { Location of 21-PWR AP WP centerline } \\
\text { above invert }\end{array}$ & $1018 \mathrm{~mm}$ & BSC 2004 [DIRS 167040] \\
\hline Invert height from bottom of drift & $0.806 \mathrm{~m}$ & BSC 2003 [DIRS 164101] \\
\hline 21-PWR AP WP length & $5.165 \mathrm{~m}$ & BSC 2003 [DIRS 165406], Table 1 \\
\hline 21-PWR AP WP diameter & $1.644 \mathrm{~m}$ & BSC 2003 [DIRS 165406], Table 1 \\
\hline 21-PWR CR WP diameter & $1.644 \mathrm{~m}$ & BSC 2003 [DIRS 165406], Table 1 \\
\hline 21-PWR AP WP inner-vessel thickness & $0.0508 \mathrm{~m}$ & BSC 2004 [DIRS 169472], Table 1 \\
\hline 21-PWR AP WP outer-barrier thickness & $0.020 \mathrm{~m}$ & BSC 2004 [DIRS 169472], Table 1 \\
\hline $\begin{array}{l}\text { Nominal quantity of 21-PWR AP waste } \\
\text { packages in LA-design inventory }\end{array}$ & 4299 & BSC 2004 [DIRS 169472], Table 11 \\
\hline $\begin{array}{l}\text { Nominal quantity of 21-PWR CR waste } \\
\text { packages in LA-design inventory }\end{array}$ & 95 & BSC 2004 [DIRS 169472], Table 11 \\
\hline 44-BWR WP length & $5.165 \mathrm{~m}$ & BSC 2003 [DIRS 165406], Table 1 \\
\hline 44-BWR WP diameter & $1.674 \mathrm{~m}$ & BSC 2003 [DIRS 165406], Table 1 \\
\hline 44-BWR WP inner-vessel thickness & $0.0508 \mathrm{~m}$ & BSC 2004 [DIRS 169472], Table 1 \\
\hline 44-BWR WP outer-barrier thickness & $0.020 \mathrm{~m}$ & BSC 2004 [DIRS 169472], Table 1 \\
\hline $\begin{array}{l}\text { Nominal quantity of 44-BWR AP waste } \\
\text { packages in LA-design inventory }\end{array}$ & 2831 & BSC 2004 [DIRS 169472], Table 11 \\
\hline 5 DHLW/DOE SNF-LONG WP length & $5.217 \mathrm{~m}$ & BSC 2003 [DIRS 165406], Table 1 \\
\hline 5 DHLW/DOE SNF-LONG WP diameter & $2.110 \mathrm{~m}$ & BSC 2003 [DIRS 165406], Table 1 \\
\hline $\begin{array}{l}5 \text { DHLW/DOE SNF-LONG WP } \\
\text { inner-vessel thickness }\end{array}$ & $0.0508 \mathrm{~m}$ & BSC 2004 [DIRS 169472], Table 1 \\
\hline $\begin{array}{l}5 \text { DHLW/DOE SNF-LONG WP } \\
\text { outer-barrier thickness }\end{array}$ & $0.0254 \mathrm{~m}$ & BSC 2004 [DIRS 169472], Table 1 \\
\hline $\begin{array}{l}\text { Nominal quantity of } 5 \mathrm{DHLW} / \mathrm{DOE} \\
\text { SNF-LONG waste packages in LA-design } \\
\text { inventory }\end{array}$ & 1406 & BSC 2004 [DIRS 169472] Table 11 \\
\hline 5 DHLW/DOE SNF-SHORT WP length & $3.590 \mathrm{~m}$ & BSC 2003 [DIRS 165406], Table 1 \\
\hline 5 DHLW/DOE SNF-SHORT WP diameter & $2.110 \mathrm{~m}$ & BSC 2003 [DIRS 165406], Table 1 \\
\hline $\begin{array}{l}5 \text { DHLW/DOE SNF-SHORT WP } \\
\text { inner-vessel thickness }\end{array}$ & $0.0508 \mathrm{~m}$ & BSC 2004 [DIRS 169472], Table 1 \\
\hline $\begin{array}{l}5 \text { DHLW/DOE SNF-SHORT WP } \\
\text { outer-barrier thickness }\end{array}$ & $0.0254 \mathrm{~m}$ & BSC 2004 [DIRS 169472], Table 1 \\
\hline $\begin{array}{l}\text { Nominal quantity of } 5 \text { DHLW/DOE } \\
\text { SNF-SHORT waste packages in LA- } \\
\text { design inventory }\end{array}$ & 1147 & BSC 2004 [DIRS 169472], Table 11 \\
\hline Drip-shield length & $6.105 \mathrm{~m}$ & BSC 2003 [DIRS 171024], Sheet 2 \\
\hline Drip-shield width & $2.512 \mathrm{~m}$ & BSC 2003 [DIRS 171024], Sheet 2 \\
\hline
\end{tabular}


Table 4.1-1. Summary of Input Data and Information Required by the MSTHM (Continued)

\begin{tabular}{|c|c|c|}
\hline Model Input & Value & Source \\
\hline Drip-shield thickness (plate-1 or plate-2) & $0.015 \mathrm{~m}$ & BSC 2004 [DIRS 169220], Table 5 \\
\hline $\begin{array}{l}\text { Intersection of drip-shield plate-1 with } \\
\text { drip-shield plate-2 from base/top of invert }\end{array}$ & $1875 \mathrm{~mm}$ & BSC 2003 [DIRS 171024], Sheet 2 \\
\hline $\begin{array}{l}\text { Total nominal quantity of waste package in } \\
\text { LA-design inventory }\end{array}$ & 11,184 & BSC 2004 [DIRS 169472], Table 11 \\
\hline \multicolumn{3}{|c|}{ Geometry of Natural System: Parameters } \\
\hline $\begin{array}{l}\text { Grid of three-dimensional } \\
\text { Unsaturated-Zone Flow and Transport } \\
\text { Model: element/connection file }\end{array}$ & Entire File & $\begin{array}{l}\text { DTN: LB03023DKMGRID.001 [DIRS 162354], } \\
\text { File: Grid_LA_3D.mesh }\end{array}$ \\
\hline $\begin{array}{c}\text { Grid of three-dimensional } \\
\text { Unsaturated-Zone Flow and Transport } \\
\text { Model: vertices file }\end{array}$ & Entire File & $\begin{array}{l}\text { DTN: LB03023DKMGRID.001 [DIRS 162354], } \\
\text { File: grid2002.grd }\end{array}$ \\
\hline \multicolumn{3}{|c|}{$\begin{array}{l}\text { Properties of the Engineered System } \\
\end{array}$} \\
\hline \multicolumn{3}{|c|}{ Invert Thermal and Hydrologic Properties: Parameters } \\
\hline $\begin{array}{l}\text { Intragranular permeability (tswM5, tsw35 } \\
\text { matrix continuum for mean infiltration-flux } \\
\text { property set) }\end{array}$ & $4.48 \times 10^{-18} \mathrm{~m}^{2}$ & DTN: LB0208UZDSCPMI.002 [DIRS 161243] \\
\hline $\begin{array}{l}\text { Porosity of crushed-tuff grains (tswM5, } \\
\text { tsw35 matrix continuum for mean } \\
\text { infiltration-flux property set) }\end{array}$ & 0.131 & DTN: LB0208UZDSCPMI.002 [DIRS 161243] \\
\hline $\begin{array}{l}\text { Intragranular van Genuchten } \alpha \text { (tswM5, } \\
\text { tsw35 matrix continuum for mean } \\
\text { infiltration-flux property set) }\end{array}$ & $1.08 \times 10^{-5} 1 / \mathrm{Pa}$ & DTN: LB0208UZDSCPMI.002 [DIRS 161243] \\
\hline $\begin{array}{l}\text { Intragranular van Genuchten m (tswM5, } \\
\text { tsw35 matrix continuum for mean } \\
\text { infiltration-flux property set) }\end{array}$ & 0.216 & DTN: LB0208UZDSCPMI.002 [DIRS 161243] \\
\hline $\begin{array}{l}\text { Intragranular residual saturation (tswM5, } \\
\text { tsw35 matrix continuum for mean } \\
\text { infiltration-flux property set) }\end{array}$ & 0.12 & DTN: LB0208UZDSCPMI.002 [DIRS 161243] \\
\hline \multicolumn{3}{|c|}{ Invert Thermal and Hydrologic Properties: Data } \\
\hline Bulk Density of 4-10 crushed tuff & $\begin{array}{l}\text { Table IV-8 in } \\
\text { Appendix IV } \\
\end{array}$ & DTN: GS020183351030.001 [DIRS 163107] \\
\hline Specific heat of 4-10 crushed tuff & $\begin{array}{l}\text { Table IV-9 in } \\
\text { Appendix IV }\end{array}$ & DTN: GS000483351030.003 [DIRS 152932] \\
\hline Thermal conductivity of $4-10$ crushed tuff & $\begin{array}{l}\text { Table IV-9 in } \\
\text { Appendix IV }\end{array}$ & DTN: GS000483351030.003 [DIRS 152932] \\
\hline Emissivity (upper invert surface) & 0.88 to 0.95 & $\begin{array}{l}\text { Incropera and DeWitt } 1996 \text { [DIRS 108184], } \\
\text { Table A.11 for Rocks }\end{array}$ \\
\hline $\begin{array}{l}\text { Range in maximum void ratio for } \\
\text { United Soils Classification type SP, } \\
\text { which are poorly graded sands and } \\
\text { gravelly sands. }\end{array}$ & 0.67 to 0.94 & Hilf 1975 [DIRS 169699], Table 7.3, p. 257 \\
\hline \multicolumn{3}{|c|}{ Waste Package Thermal Properties: Design Information } \\
\hline Weight of 21-PWR AP WP & $43,000 \mathrm{~kg}$ & BSC 2003 [DIRS 165406], Table 1 \\
\hline Weight of 44-BWR WP & $43,000 \mathrm{~kg}$ & BSC 2003 [DIRS 165406], Table 1 \\
\hline Weight of 5 DHLW/DOE SNF-SHORT WP & $39,000 \mathrm{~kg}$ & BSC 2003 [DIRS 165406], Table 1 \\
\hline Weight of 5 DHLW/DOE SNF-LONG & $57,000 \mathrm{~kg}$ & BSC 2003 [DIRS 165406], Table 1 \\
\hline $\begin{array}{l}\text { Emissivity of Alloy } 22 \text { (at } \mathrm{T}=650^{\circ} \mathrm{C} \text { ), which } \\
\text { is the outer barrier of the following WPs: } \\
\text { 21-PWR AP, 44-BWR, } 5 \text { DHLW/DOE } \\
\text { SNF-SHORT, } 5 \text { DHLW/DOE SNF-LONG }\end{array}$ & 0.87 & DTN: MO0003RIB00071.000 [DIRS 148850] \\
\hline
\end{tabular}


Table 4.1-1. Summary of Input Data and Information Required by the MSTHM (Continued)

\begin{tabular}{|c|c|c|}
\hline Model Input & Value & Source \\
\hline $\begin{array}{l}\text { Mass density of Alloy } 22 \text { (N06022), which } \\
\text { is the outer barrier of the following WPs: } \\
21-P W R \text { AP, } 44-B W R, 5 \text { DHLW/DOE } \\
\text { SNF-SHORT, } 5 \text { DHLW/DOE SNF-LONG }\end{array}$ & $8690 \mathrm{~kg} / \mathrm{m}^{3}$ & DTN: MO0003RIB00071.000 [DIRS 148850] \\
\hline $\begin{array}{l}\text { Mass density of Stainless Steel Type } 316 \text {, } \\
\text { which is the inner vessel of the following } \\
\text { WPs: 21-PWR AP, 44-BWR, } \\
5 \text { DHLW/DOE SNF-SHORT, } 5 \\
\text { DHLW/DOE SNF-LONG }\end{array}$ & $7.98 \mathrm{~g} / \mathrm{cm}^{3}$ & Table XI of ASTM G 1-90 [DIRS 103515] \\
\hline $\begin{array}{l}\text { Mass density of the internal cylinder of the } \\
\text { 21-PWR AP WP }\end{array}$ & $3495 \mathrm{~kg} / \mathrm{m}^{3}$ & BSC 2004 [DIRS 169990], Table 20 \\
\hline $\begin{array}{l}\text { Mass density of the internal cylinder of the } \\
\text { 44-BWR WP }\end{array}$ & $3342 \mathrm{~kg} / \mathrm{m}^{3}$ & BSC 2004 [DIRS 169990], Table 20 \\
\hline $\begin{array}{l}\text { Mass density of the internal cylinder of the } \\
5 \text { DHLW/DOE SNF-SHORT WP }\end{array}$ & $2175 \mathrm{~kg} / \mathrm{m}^{3}$ & BSC 2004 [DIRS 169990], Table 20 \\
\hline $\begin{array}{l}\text { Mass density of the internal cylinder of the } \\
5 \text { DHLW/DOE SNF-LONG WP }\end{array}$ & $2302 \mathrm{~kg} / \mathrm{m}^{3}$ & BSC 2004 [DIRS 169990], Table 20 \\
\hline $\begin{array}{l}\text { Thermal conductivity of Alloy } 22 \\
\text { (at } T=373.15 \mathrm{~K} \text { ), which is the outer } \\
\text { barrier of the following WPs: } 21-P W R \text { AP, } \\
\text { 44-BWR, } 5 \text { DHLW/DOE SNF-SHORT, } 5 \\
\text { DHLW/DOE SNF-LONG }\end{array}$ & $11.1 \mathrm{~W} / \mathrm{m} \cdot \mathrm{K}$ & $\begin{array}{l}\text { DTN: MO0107TC239938.000 [DIRS 169995], } \\
\text { p. } 13\end{array}$ \\
\hline $\begin{array}{l}\text { Thermal conductivity of Stainless Steel } \\
\text { Type 316, which is the inner vessel of the } \\
\text { following WPs: } 21-P W R \text { AP, 44-BWR, } 5 \\
\text { DHLW/DOE SNF-SHORT, } 5 \text { DHLW/DOE } \\
\text { SNF-LONG }\end{array}$ & $\begin{array}{l}\text { 8.4 BTU/hr-ft- }{ }^{\circ} \mathrm{F} \text { at } \\
200^{\circ} \mathrm{F} \\
\text { 8.7 BTU/hr-ft- }{ }^{\circ} \mathrm{F} \text { at } \\
250^{\circ} \mathrm{F}\end{array}$ & ASME 1995, Section II-D, Table TCD, p. 606 \\
\hline $\begin{array}{l}\text { Thermal diffusivity of Stainless Steel Type } \\
316, \text { which is the inner vessel of the } \\
\text { following WPs: 21-PWR AP, 44-BWR, } 5 \\
\text { DHLW/DOE SNF-SHORT, } 5 \text { DHLW/DOE } \\
\text { SNF-LONG }\end{array}$ & $\begin{array}{l}0.141 \mathrm{ft}^{2} / \mathrm{hr} \text { at } 200^{\circ} \mathrm{F} \\
0.143 \mathrm{ft}^{2} / \mathrm{hr} \text { at } 250^{\circ} \mathrm{F}\end{array}$ & ASME 1995, Section II-D, Table TCD, p. 606 \\
\hline $\begin{array}{l}\text { Thermal conductivity of the internal } \\
\text { cylinder of the following WPs: 21-PWR } \\
\text { AP, 44-BWR, } 5 \text { DHLW/DOE SNF-SHORT, } \\
5 \text { DHLW/DOE SNF-LONG }\end{array}$ & $1.5 \mathrm{~W} / \mathrm{m} \cdot \mathrm{K}$ & BSC 2004 [DIRS 169990], Table 20 \\
\hline $\begin{array}{l}\text { Specific heat of Alloy } 22 \text { (at } T=373.15 \mathrm{~K} \text {, } \\
\text { or } 212^{\circ} \mathrm{F} \text { ), which is the outer barrier of the } \\
\text { following WPs: } 21-P W R \text { AP, } 44-B W R, 5 \\
\text { DHLW/DOE SNF-SHORT, } 5 \text { DHLW/DOE } \\
\text { SNF-LONG }\end{array}$ & $423.0 \mathrm{~J} / \mathrm{kg} \cdot \mathrm{K}$ & $\begin{array}{l}\text { DTN: MO0107TC239938.000 [DIRS 169995], } \\
\text { p. } 13\end{array}$ \\
\hline $\begin{array}{l}\text { Specific heat of the internal cylinder of the } \\
\text { 21-PWR AP WP }\end{array}$ & $378.0 \mathrm{~J} / \mathrm{kg} \cdot \mathrm{K}$ & BSC 2004 [DIRS 169990], Table 20 \\
\hline $\begin{array}{l}\text { Specific heat of the internal cylinder of the } \\
\text { 44-BWR WP }\end{array}$ & $395.0 \mathrm{~J} / \mathrm{kg} \cdot \mathrm{K}$ & BSC 2004 [DIRS 169990], Table 20 \\
\hline $\begin{array}{l}\text { Specific heat of the internal cylinder of the } \\
5 \text { DHLW/DOE SNF-SHORT WP }\end{array}$ & $718.0 \mathrm{~J} / \mathrm{kg} \cdot \mathrm{K}$ & BSC 2004 [DIRS 169990], Table 20 \\
\hline $\begin{array}{l}\text { Specific heat of the internal cylinder of the } \\
5 \text { DHLW/DOE SNF-LONG WP }\end{array}$ & $731.0 \mathrm{~J} / \mathrm{kg} \cdot \mathrm{K}$ & BSC 2004 [DIRS 169990], Table 20 \\
\hline \multicolumn{3}{|c|}{ Drip-Shield Thermal Properties: Design Information } \\
\hline $\begin{array}{l}\text { Nominal weight of drip shield (for a } \\
\text { nominal length of } 5.805 \mathrm{~m} \text { ) }\end{array}$ & $5000 \mathrm{~kg}$ & BSC 2004 [DIRS 169220], Table 1 \\
\hline Mass density of titanium & $0.163 \mathrm{lb} / \mathrm{in}^{3}$ & ASME 1995, Section II-D, Table NF-2, p. 620 \\
\hline
\end{tabular}


Multiscale Thermohydrologic Model

Table 4.1-1. Summary of Input Data and Information Required by the MSTHM (Continued)

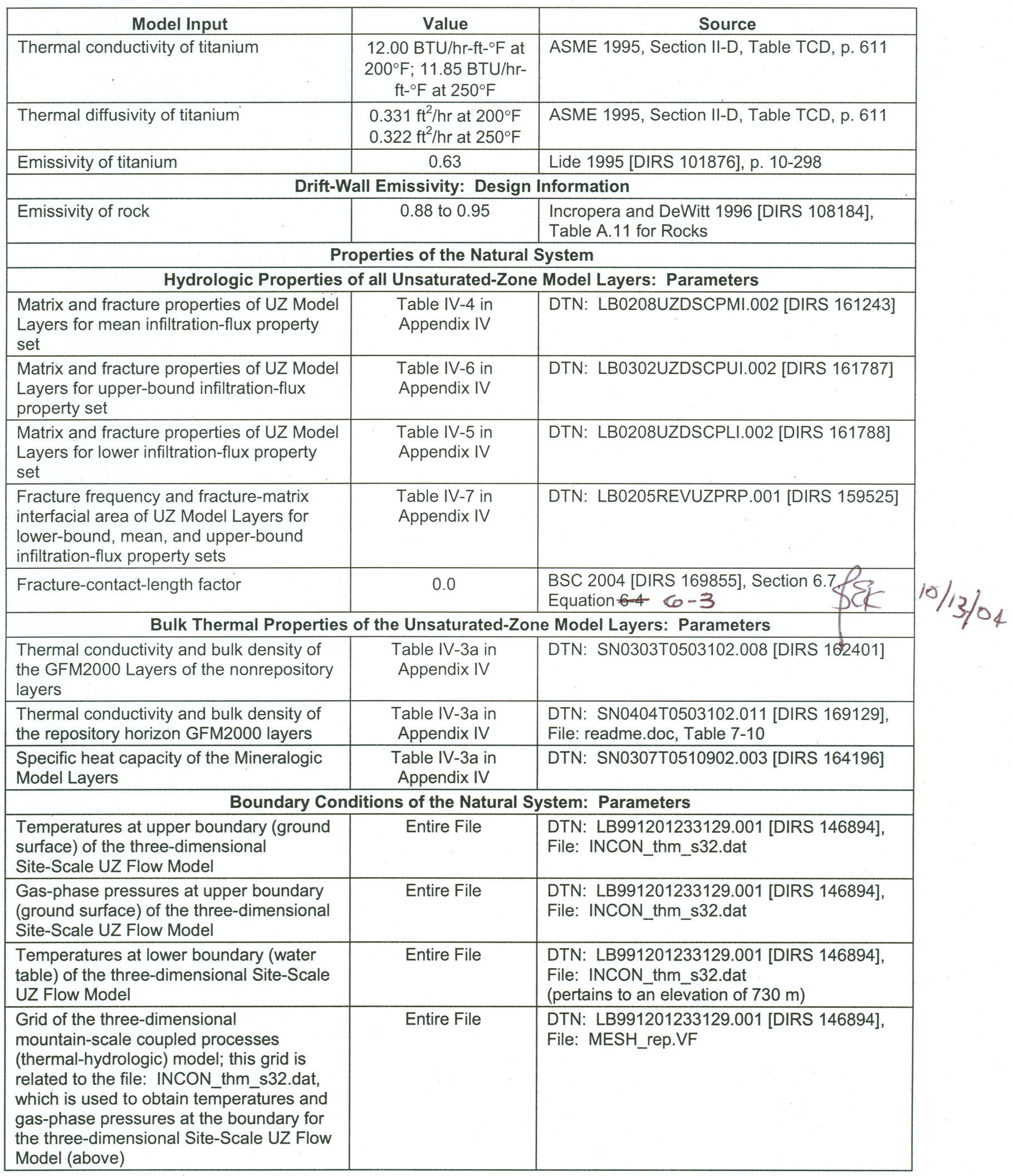


Table 4.1-1. Summary of Input Data and Information Required by the MSTHM (Continued)

\begin{tabular}{|l|c|c|}
\hline \multicolumn{1}{|c|}{ Model Input } & \multicolumn{1}{|c|}{ Value } & \multicolumn{1}{|c|}{ Distribution of Percolation Flux Below PTn Unit: Parameters } \\
\hline \multicolumn{1}{|c|}{ Entire DTN } & DTN: LB0302PTNTSW9I.001 [DIRS 162277] \\
\hline $\begin{array}{l}\text { Percolation Flux from PTn to TSw unit for } \\
\text { mean infiltration-flux case (two- } \\
\text { dimensional map of PTn-to-TSw } \\
\text { percolation flux) }\end{array}$ & \multicolumn{1}{|c|}{} \\
\hline $\begin{array}{l}\text { Percolation Flux from PTn to TSw unit for } \\
\text { upper-bound infiltration-flux case (two- } \\
\text { dimensional map of PTn-to-TSw } \\
\text { percolation flux) }\end{array}$ & Entire DTN & DTN: LB0302PTNTSW9I.001 [DIRS 162277] \\
\hline $\begin{array}{l}\text { Percolation Flux from PTn to TSw unit for } \\
\text { lower-bound infiltration-flux case (two- } \\
\text { dimensional map of PTn-to-TSw } \\
\text { percolation flux) }\end{array}$ & Entire DTN & DTN: LB0302PTNTSW9I.001 [DIRS 162277] \\
\hline $\begin{array}{l}\text { Probabilities of the three infiltration-flux } \\
\text { cases }\end{array}$ & See Table 6.3-35 & BSC 2003 [DIRS 165991], Table 6.3-2 \\
\hline \multicolumn{1}{|c|}{ Waste Package Heat-Generation and Ventilation Heat-Removal Efficiency: Design Information } \\
\hline $\begin{array}{l}\text { Heat-generation rate history for entire } \\
\text { repository }\end{array}$ & See IED & BSC 2004 [DIRS 167369], Table 13 \\
\hline $\begin{array}{l}\text { Average initial heat-generation rate per } \\
\text { meter }\end{array}$ & 1.45 kW/m & BSC 2004 [DIRS 168489], Table 1 \\
\hline $\begin{array}{l}\text { Ventilation-period duration } \\
\text { emplacement }\end{array}$ & BSC 2004 [DIRS 168489], Table 1 \\
\hline Duration of waste package emplacement & 23 years & BSC 2004 [DIRS 168489], Table 1 \\
\hline $\begin{array}{l}\text { Heat-generation rates for each of the } \\
\text { waste package types }\end{array}$ & See IED & BSC 2004 [DIRS 167754], Table 12 \\
\hline $\begin{array}{l}\text { Ventilation heat-removal efficiency as a } \\
\text { function of time and distance from the inlet } \\
\text { of the emplacement drift }\end{array}$ & Entire Worksheet & $\begin{array}{l}\text { DTN: MO0304MWDALACV.000 [DIRS } \\
164551], \text { FILE: ANSYS-LA-coarse.xls, } \\
\text { "Efficiency Data" Worksheet }\end{array}$ \\
\hline
\end{tabular}

${ }^{\text {a }}$ DTN: MO0304MWDALACV.000 [DIRS 164551], which was superseded by DTN: MO0306MWDASLCV.001 [DIRS 165695], is justified for its use in this report, as documented in Appendix XIV.

During the preparation of this report, some of the design information was updated as several information exchange drawings (IEDs) were superseded. These revisions resulted in small changes to the dimensions of the waste packages and drip shield as summarized in Table 4.1-2. For the direct inputs to be justified as they appear in Table 4.1-1, these small changes to the dimensions must insignificantly affect the results of the MSTHM described in this report. The details of this justification are discussed in Sections 4.1.2.1 through 4.1.2.7. 
Table 4.1-2. Changes to the Waste Package and Drip Shield Design Information

\begin{tabular}{|c|c|c|c|c|c|}
\hline \multirow[b]{2}{*}{ Model Input } & \multicolumn{2}{|c|}{ Superseded IED } & \multicolumn{2}{|c|}{ Current IED } & \multirow{2}{*}{$\begin{array}{l}\text { Relative } \\
\text { Change } \\
\text { in Value }\end{array}$} \\
\hline & Value & Source & Value & Source & \\
\hline 21-PWR AP WP length & $5.165 \mathrm{~m}$ & $\begin{array}{l}\text { BSC 2003 [DIRS } \\
\text { 165406], Table } 1\end{array}$ & $5.024 \mathrm{~m}$ & $\begin{array}{l}\text { BSC 2004 [DIRS } \\
\text { 169472], Table } 1\end{array}$ & $-2.7 \%$ \\
\hline 21-PWR AP WP diameter & $1.644 \mathrm{~m}$ & $\begin{array}{l}\text { BSC 2003 [DIRS } \\
\text { 165406], Table } 1\end{array}$ & $1.718 \mathrm{~m}$ & $\begin{array}{l}\text { BSC 2004 [DIRS } \\
\text { 169472], Table } 1\end{array}$ & $+4.5 \%$ \\
\hline 21-PWR CR WP diameter & $1.644 \mathrm{~m}$ & $\begin{array}{l}\text { BSC 2003 [DIRS } \\
\text { 165406], Table } 1\end{array}$ & $1.718 \mathrm{~m}$ & $\begin{array}{l}\text { BSC 2004 [DIRS } \\
\text { 169472], Table } 1\end{array}$ & $+4.5 \%$ \\
\hline Weight of 21-PWR AP & $43,000 \mathrm{~kg}$ & $\begin{array}{l}\text { BSC 2003 [DIRS } \\
\text { 165406], Table } 1\end{array}$ & $41,100 \mathrm{~kg}$ & $\begin{array}{l}\text { BSC 2004 [DIRS } \\
\text { 169472], Table } 1\end{array}$ & $-4.4 \%$ \\
\hline 44-BWR WP length & $5.165 \mathrm{~m}$ & $\begin{array}{l}\text { BSC 2003 [DIRS } \\
\text { 165406], Table } 1\end{array}$ & $5.024 \mathrm{~m}$ & $\begin{array}{l}\text { BSC 2004 [DIRS } \\
\text { 169472], Table } 1\end{array}$ & $-2.7 \%$ \\
\hline 44-BWR WP diameter & $1.674 \mathrm{~m}$ & $\begin{array}{l}\text { BSC 2003 [DIRS } \\
\text { 165406], Table } 1\end{array}$ & $1.756 \mathrm{~m}$ & $\begin{array}{l}\text { BSC 2004 [DIRS } \\
\text { 169472], Table } 1\end{array}$ & $+4.9 \%$ \\
\hline Weight of 44-BWR WP & $43,000 \mathrm{~kg}$ & $\begin{array}{l}\text { BSC 2003 [DIRS } \\
\text { 165406], Table } 1\end{array}$ & $41,700 \mathrm{~kg}$ & $\begin{array}{l}\text { BSC 2004 [DIRS } \\
\text { 169472], Table } 1\end{array}$ & $-3.0 \%$ \\
\hline $\begin{array}{l}5 \text { DHLW/DOE SNF-LONG WP } \\
\text { length }\end{array}$ & $5.217 \mathrm{~m}$ & $\begin{array}{l}\text { BSC 2003 [DIRS } \\
\text { 165406], Table } 1\end{array}$ & $5.059 \mathrm{~m}$ & $\begin{array}{l}\text { BSC 2004 [DIRS } \\
\text { 169472], Table } 1\end{array}$ & $-3.0 \%$ \\
\hline $\begin{array}{l}5 \text { DHLW/DOE SNF-LONG WP } \\
\text { diameter }\end{array}$ & $2.110 \mathrm{~m}$ & $\begin{array}{l}\text { BSC 2003 [DIRS } \\
\text { 165406], Table } 1\end{array}$ & $2.126 \mathrm{~m}$ & $\begin{array}{l}\text { BSC 2004 [DIRS } \\
\text { 169472], Table } 1\end{array}$ & $+0.8 \%$ \\
\hline $\begin{array}{l}\text { Weight of } 5 \text { DHLW/DOE } \\
\text { SNF-LONG }\end{array}$ & $57,000 \mathrm{~kg}$ & $\begin{array}{l}\text { BSC 2003 [DIRS } \\
\text { 165406], Table } 1\end{array}$ & $53,100 \mathrm{~kg}$ & $\begin{array}{l}\text { BSC 2004 [DIRS } \\
\text { 169472], Table } 1\end{array}$ & $-6.8 \%$ \\
\hline $\begin{array}{l}5 \text { DHLW/DOE SNF-SHORT } \\
\text { length }\end{array}$ & $3.590 \mathrm{~m}$ & $\begin{array}{l}\text { BSC 2003 [DIRS } \\
\text { 165406], Table } 1\end{array}$ & $3.453 \mathrm{~m}$ & $\begin{array}{l}\text { BSC 2004 [DIRS } \\
\text { 169472], Table } 1\end{array}$ & $-3.8 \%$ \\
\hline $\begin{array}{l}5 \text { DHLW/DOE SNF-SHORT } \\
\text { diameter }\end{array}$ & $2.110 \mathrm{~m}$ & $\begin{array}{l}\text { BSC 2003 [DIRS } \\
\text { 165406], Table } 1\end{array}$ & $2.126 \mathrm{~m}$ & $\begin{array}{l}\text { BSC 2004 [DIRS } \\
\text { 169472], Table } 1\end{array}$ & $+0.8 \%$ \\
\hline $\begin{array}{l}\text { Weight of } 5 \text { DHLW/DOE } \\
\text { SNF-SHORT }\end{array}$ & $39,000 \mathrm{~kg}$ & $\begin{array}{l}\text { BSC 2003 [DIRS } \\
\text { 165406], Table } 1\end{array}$ & $36,100 \mathrm{~kg}$ & $\begin{array}{l}\text { BSC 2004 [DIRS } \\
\text { 169472], Table } 1\end{array}$ & $-7.4 \%$ \\
\hline Drip-shield length & $6.105 \mathrm{~m}$ & $\begin{array}{l}\text { BSC 2003 [DIRS } \\
171024], \text { Sheet } 2 \\
\end{array}$ & $5.805 \mathrm{~m}$ & $\begin{array}{l}\text { BSC 2004 [DIRS } \\
\text { 169220], Table } 1 \\
\end{array}$ & $-4.9 \%$ \\
\hline Drip-shield width & $2.512 \mathrm{~m}$ & $\begin{array}{l}\text { BSC 2003 [DIRS } \\
\text { 171024], Sheet } 2\end{array}$ & $2.533 \mathrm{~m}$ & $\begin{array}{l}\text { BSC 2004 [DIRS } \\
\text { 169220], Table } 1\end{array}$ & $+0.8 \%$ \\
\hline $\begin{array}{l}\text { Intersection of drip-shield plate-1 } \\
\text { with drip-shield plate-2 from } \\
\text { base/top of invert }\end{array}$ & $1875 \mathrm{~mm}$ & $\begin{array}{l}\text { BSC 2003 [DIRS } \\
171024] \text {, Sheet } 2\end{array}$ & $1891 \mathrm{~mm}$ & $\begin{array}{l}\text { BSC 2004 [DIRS } \\
168067]\end{array}$ & $+0.9 \%$ \\
\hline $\begin{array}{l}\text { Location of 21-PWR AP } \\
\text { centerline above invert }\end{array}$ & $1018 \mathrm{~mm}$ & $\begin{array}{l}\text { BSC 2004 [DIRS } \\
167040], \text { Figure } 1 \\
\end{array}$ & $1050.9 \mathrm{~mm}$ & $\begin{array}{l}\text { BSC 2004 [DIRS } \\
\text { 168489], Figure } 1\end{array}$ & $+3.2 \%$ \\
\hline
\end{tabular}

$\mathrm{AP}=$ Absorber Plate, $\mathrm{CR}=$ Control Rods.

\subsubsection{Waste Package Lengths}

As summarized in Table 4.1-2, the differences in waste package lengths between those used in this report, which are obtained from the superseded IED (BSC 2003 [DIRS 165406]), and those listed in the current IED (BSC 2004 [DIRS 169472]) are small, ranging from -2.7 to -3.8 percent. Waste package lengths are used only in the DDT submodel. The DDT submodel is primarily used for two purposes: (1) calculating the temperature difference between the waste package and drip shield and (2) calculating the longitudinal temperature variations along the drift axis. If the slightly shorter waste package lengths given in the current IED (BSC 2004 [DIRS 169472]) were employed in the MSTHM calculations for this report, it would only result in 
slightly less longitudinal temperature and relative humidity variation along the drift axis. This small reduction in longitudinal variability is insignificant compared to the range of temperature and relative humidity that results from the influence of parametric variability and uncertainty, which is discussed in Section 6.3. Therefore, the waste package lengths from the superseded IED are suitable for use in the MSTHM calculations reported in Section 6.3.

\subsubsection{Waste Package Diameters}

As summarized in Table 4.1-2, the differences in waste package diameters between those used in this report, which are obtained from the superseded IED (BSC 2003 [DIRS 165406]), and those listed in the current IED (BSC 2004 [DIRS 169472]) are small, ranging from +0.8 to +4.9 percent. Waste package diameters are used only in the DDT submodel. The DDT submodel is only used for two purposes: (1) calculating the temperature difference between the waste package and drip shield and (2) calculating the longitudinal temperature variations along the drift axis. If the slightly wider waste package diameters given in the current IED (BSC 2004 [DIRS 169472]) were employed in the MSTHM calculations for this report, it would only result in facilitating slightly better thermal-radiative heat transfer between the ends of the waste packages, thereby resulting in slightly less longitudinal temperature and relative humidity variations along the drift axis. If the slightly wider waste package diameters were employed in the MSTHM calculations for this report, it would also have the effect of slightly decreasing the temperature difference between the waste package and drip shield. The very small reductions in longitudinal temperature variability and in waste package-to-drip-shield temperature difference are insignificant compared to the range of temperature and relative humidity that results from the influence of parametric variability and uncertainty, which is discussed in Section 6.3. Therefore, the waste package diameters from the superseded IED are suitable for use in the MSTHM calculations reported in Section 6.3.

\subsubsection{Waste Package Weights}

As summarized in Table 4.1-2, the differences in waste package weights between those used in this report, which are obtained from the superseded IED (BSC 2003 [DIRS 165406]), and those listed in the current IED (BSC 2004 [DIRS 169472]) are small, ranging from -3.0 to -7.4 percent. Waste package weights are used only in the LDTH and DDT submodels. The weight of the waste package, multiplied by the waste package-specific heat capacity, is the heat capacity of the waste package. The only manner in which the waste package heat capacity affects the MSTHM results is by influencing the time required for heat transfer from the waste packages to the drift wall to reach a quasi-steady-state condition. Because this quasi-steady-state condition is established much earlier than when peak waste package, drip-shield, and drift-wall temperatures occur, it has an insignificant effect on peak temperatures. If the slightly lower waste package weights given in the current IED (BSC 2004 [DIRS 169472]) were employed in the MSTHM calculations for this report, they would only result in allowing heat transfer from the waste package to the drift wall reaching the quasi-steady-state condition slightly earlier. Furthermore, because the weight of the waste package is much less than that of the surrounding host rock, the waste package heat capacity per unit length of drift is much less than that of the surrounding host rock. As discussed in Section 6.3.2, parametric uncertainty of the host-rock heat capacity has an insignificant influence on MSTHM predictions of temperature and relative humidity. Therefore, 
the waste package weights from the superseded IED are suitable for use in the MSTHM calculations reported in Section 6.3.

\subsubsection{Drip Shield Length}

As summarized in Table 4.1-2, the difference in drip-shield length between that used in this report, which is obtained from the superseded IED (BSC 2003 [DIRS 171024]), and that listed in the current IED (BSC 2004 [DIRS 169220]) is small ( -4.9 percent). The only use of the drip-shield length, in conjunction with the drip-shield weight, is to determine the drip-shield weight per unit length of drift in the LDTH submodels and to determine the drip-shield mass density in the DDT submodels. The weight of the drip shield, multiplied by the specific heat capacity, affects the heat capacity of the drip shield. The only manner in which the drip-shield heat capacity affects the MSTHM results is by influencing the time required for heat transfer from the waste package to the drift wall to reach a quasi-steady-state condition. Because this quasi-steady-state condition is established much earlier than when peak waste package, drip-shield, and drift-wall temperatures occur, it has an insignificant effect on peak temperatures. If the slightly shorter drip-shield lengths given in the current IED (BSC 2004 [DIRS 169220]) were employed in the MSTHM calculations for this report, it would result in a slightly larger weight per unit length of drift, thereby causing a slight increase in heat capacity for the drip shield. The weight of the drip shield per unit length is much less than that of the waste packages. Therefore, the time required for heat transfer from the waste package to the drift wall reaching the quasi-steady-state condition would be insignificantly affected by this small change in drip-shield heat capacity. Furthermore, because the weight of the drip shield is much less than that of the surrounding host rock, the drip-shield heat capacity per unit length of drift is very much less than that of the surrounding host rock. As discussed in Section 6.3.2, parametric uncertainty of the host-rock heat capacity has an insignificant influence on MSTHM predictions of temperature and relative humidity. Therefore, the drip shield length from the superseded IED is suitable for use in the MSTHM calculations reported in Section 6.3.

\subsubsection{Drip Shield Width}

As summarized in Table 4.1-2, the difference in drip-shield width between that used in this report, which is obtained from the superseded IED (BSC 2003 [DIRS 171024]), and that listed in the current IED (BSC 2004 [DIRS 169220]) is extremely small (+0.8 percent). The only use of the drip-shield width is in the LDTH and DDT submodels, where it primarily affects the drip-shield surface area. In the LDTH submodels, it influences thermal-radiative heat transfer between the drip shield and other surfaces inside the drift cavity. In the DDT submodels (Figure 6.2-8) it influences thermal-radiative heat transfer between the waste package and underside of the drip shield and between the outside of the drip shield and the other surfaces inside the drift cavity. Thermal-radiative heat transfer is extremely efficient, driven by the difference of temperature to the fourth power of the respective surfaces. A very small ( 0.8 percent) difference in surface area of the drip-shield will have an insignificant effect on the temperature differences within the drift. Therefore, the difference in drip-shield width, which influences drip-shield surface area, has an insignificant effect on temperature or relative humidity predicted by the MSTHM, which is discussed in Section 6.3. Given the manner in which the DDT submodel approximates the geometry of the drip shield (Figure 6.2-8), the 0.8 percent change in drip-shield width is insignificant. Moreover, because the DDT submodel representation of the drip shield 
was done to conserve the drip-shield weight per unit length of drift, any change in drip-shield width, however large or small, will not affect the heat capacity of the drip shield per unit length of drift. Therefore, the drip shield width from the superseded IED is suitable for use in the MSTHM calculations reported in Section 6.3.

\subsubsection{Intersection of Drip-Shield Plate-1 with Drip-Shield Plate-2 from Base/Top of Invert}

As summarized in Table 4.1-2, the difference in the intersection of drip shield plate-1 with drip shield plate-2 between that used in this report, which is obtained from the superseded IED (BSC 2003 [DIRS 171024]), and that listed in the current IED (BSC 2004 [DIRS 168067]) is extremely small (+0.9 percent). The only use of this value is in the LDTH submodels, where it affects the point at which the sloping portion of the drip shield meets the vertical sides of the drip shield (see Figure 6.2-6). Relative to the coarse approximation of the drip-shield shape in the LDTH submodel, this small change in where the sloping portion of the drip shield meets the vertical sides of the drip shield is insignificant. The primary manner in which the shape of the drip shield affects in-drift thermal-hydrologic behavior is by affecting the surface area from which thermal-radiative heat transfer occurs from the drip shield to the drift-wall and upper-invert surfaces. Changing where the sloping and vertical portions of the drip shield intersect does not change the surface area of the drip shield as it is represented in the LDTH submodel. Therefore, thermal-radiative heat transfer from the drip shield to the drift-wall and upper-invert surfaces is unaffected by this change. Consequently, the intersection location from the superseded IED is suitable for use in the MSTHM calculations reported in Section 6.3.

\subsubsection{Location of 21-PWR AP Waste Package Centerline Above the Invert}

As summarized in Table 4.1-2, the difference in the location of the 21-PWR AP WP centerline above the invert between that used in this report, which is obtained from the superseded IED (BSC 2004 [DIRS 167040]), and that given in the current IED (BSC 2004 [DIRS 168489]) is small (+3.2 percent). The only use of this dimension is in the DDT submodels, where it determines the position of the waste package above the invert (see Figures 6.2.7 through 6.2.10). Because the purpose of the MSTHM is to predict postclosure thermal-hydrologic conditions, the only manner in which this dimension affects results from the MSTHM is in how it influences radiative heat transfer between the waste package and drip shield. This radiative heat transfer is the primary factor influencing the temperature difference between the waste package and drip shield. Given the geometric approximation of the waste package and drip shield (see Figure 6.2.8) this small (3.2 percent) difference in the location of the waste package above the invert has an insignificant influence on the predicted temperature difference between the waste package and drip shield. Consequently, it also has an insignificant influence on the predicted thermal-hydrologic conditions within the emplacement drifts. Given the manner in which the DDT submodel approximates the geometry of the waste package and drip shield (Figure 6.2-8), this small change in vertical positioning of the waste package is insignificant. Therefore, the location of the centerline from the superseded IED is suitable for use in the MSTHM calculations reported in Section 6.3. 


\subsubsection{Repository Layout}

During the preparation of this report, the repository layout information was updated as several IEDs were superseded (Table 4.1-3), causing small changes to the repository layout (Table 4.1-4 and Figure 4-1). Specifically, endpoint coordinates of emplacement drifts were updated in the current IED, resulting in the following changes:

1. Elimination of the northernmost drift in Panel P3W, formerly called Panel P2W.

2. Small reductions in the length of several emplacement drifts, particularly in the southern end of Panel 4, formerly called Panel 3 (Figure 4-1). Note that the minor reductions in drift length in Panel 1 and in Panel 3E, formerly called Panel 2E, are too small to appear in Figure 4-1.

3. Addition of two emplacement drifts in Panel P2, formerly called Panel P4.

As evident in Figure 4-1, the changes in the repository layout are small, justifying the use of the superseded IED in the MSTHM calculations reported in Section 6.3.

Table 4.1-3. Summary of Current and Superseded IEDs Providing Repository Layout Information

\begin{tabular}{|l|c|c|}
\hline \multicolumn{1}{|c|}{ Model Input } & Superseded IED & Current IED \\
\hline $\begin{array}{l}\text { Repository emplacement-drift layout (elevations } \\
\text { and end-point coordinates for each emplacement } \\
\text { drift) }\end{array}$ & BSC 2003 [DIRS 161727] & BSC 2004 [DIRS 164519] \\
\hline Available emplacement drift lengths & Not Available ${ }^{\mathrm{a}}$ & BSC 2004 [DIRS 170202] \\
\hline Invert height above drift & $0.806 \mathrm{~m}$ & 2 ' 10" (0.8636 m) \\
(BSC 2004 [DIRS 169503])
\end{tabular}

${ }^{a}$ The footnote labeled ** in BSC 2004 [DIRS 170202] states that this information was not available for the superseded repository layout.

Table 4.1-4. Summary of Emplacement Panels and Drifts Represented in the SMT Submodel for the Layout in the Superseded IED and the Current IED

\begin{tabular}{|c|c|c|c|c|c|c|}
\hline \multicolumn{2}{|c|}{ Panel } & \multicolumn{2}{|c|}{ Number of drifts } & \multirow[b]{2}{*}{ Number of gridblocks } & \multirow{2}{*}{$\begin{array}{l}\text { Modeled drift length } \\
(\mathrm{m})\end{array}$} & \multirow[t]{2}{*}{ Current drift length $(m)$} \\
\hline Old & New & Old & New & & & \\
\hline 1 & 1 & 8 & 8 & 206 & 4,120 & 4092 \\
\hline $2 \mathrm{E}$ & $3 E$ & 19 & 19 & 545 & 10,900 & 10,728 \\
\hline $2 W$ & $3 \mathbf{W}$ & 23 & 22 & 689 & 13,780 & 13,272 \\
\hline 3 & 4 & 30 & 30 & 877 & 17,540 & 17,003 \\
\hline 5 & 2 & $15^{a}$ & $17^{\mathrm{a}}$ & 557 & 11,140 & 12,506 \\
\hline \multicolumn{2}{|c|}{ Total } & 95 & 96 & 2874 & 57,480 & 57,601 \\
\hline
\end{tabular}

a Panel 5 (2) has a total of 27 drifts; the 15 (17) northernmost drifts are used in the TSPA-LA base case.

NOTES: The superseded (old) IED is presented in BSC 2003 [DIRS 161727]; the current (new) IED is presented in BSC 2004 [DIRS 170202]). Note that the layout for the superseded IED is also described in Table 6.2-1.

Each of the heated gridblocks represents a 20 -m interval along the emplacement drift. 


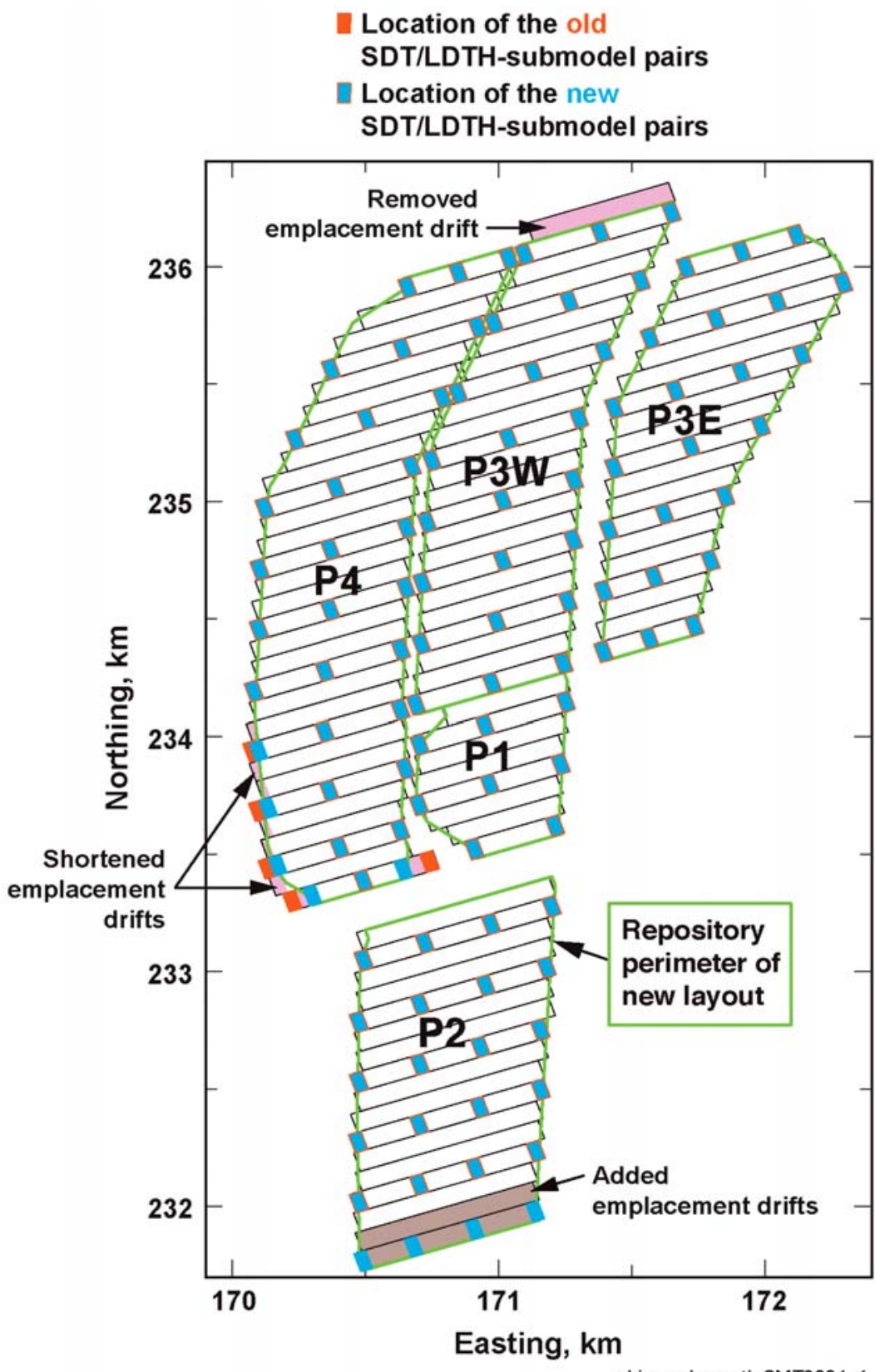

Source: See Table XIII-1.

NOTE: The repository layout incorporated in the MSTHM for the TSPA-LA (Figure 6.2-3) is based on the IED presented in Repository Design, Repository/PA IED Subsurface Facilities (BSC 2003 [DIRS 161727]). This IED has been superceded by the IED presented in D\&E / PA/C IED Subsurface Facilities (BSC 2004 [DIRS 164519]). The LDTH-SDT submodel locations shown in blue are those that have been either moved or added relative to Figure 6.2-3; those shown in orange are those used in the MSTHM for the TSPA-LA, and also correspond to those shown in Figure 6.2-3. Note that the minor reductions in drift length in Panel 1 and in Panel 3E, formerly called Panel 2E, are too small to be apparent at the scale of this diagram. The outline of the repository perimeter corresponds to the end-point coordinates of the heated portions of the emplacement drifts as given in D\&E / PA/C IED Subsurface Facilities (BSC 2004 [DIRS 164519]).

Figure 4-1. Differences Between the Repository Layout Incorporated in the MSTHM for the TSPA-LA, and the Repository Layout Given in the Current IED 
Figure 4-1 clearly shows that the superseded and current repository layouts are very similar. The only areas where the two layouts do not coincide are (1) the northernmost drift of Panel P3W, which was formerly called Panel P2W, (2) the southwestern edge and southeastern corner of Panel 4, which was formerly called Panel 3, and (3) the two southernmost drifts in Panel 2, formerly called Panel P5, of the current repository layout (BSC 2004 [DIRS 164519]). These two southernmost drifts, which have a total length of $1400 \mathrm{~m}$, were added to make up for the length of emplacement drifts that were removed from the superseded layout (BSC 2003 [DIRS 161727]). Dividing $1400 \mathrm{~m}$ by the total length of emplacement drift in the new repository layout (57,600 $\mathrm{m}$ ) gives the percentage (2.4 percent) of the new repository area that lies outside of the superseded repository layout. Therefore, 97.6 percent of the new repository layout coincides with that of the superseded repository layout.

An important natural-system parameter influencing in-drift and near-field thermal-hydrologic conditions is the host-rock percolation flux. Figure 4-2 shows that the distribution of host-rock percolation flux over the repository area is very similar for the superseded and current repository layouts for all three climate states: (1) present-day, (2) monsoonal, and (3) glacial. Therefore, the repository layout from the superseded IEDs is suitable for use in the MSTHM calculations reported in Section 6.3.

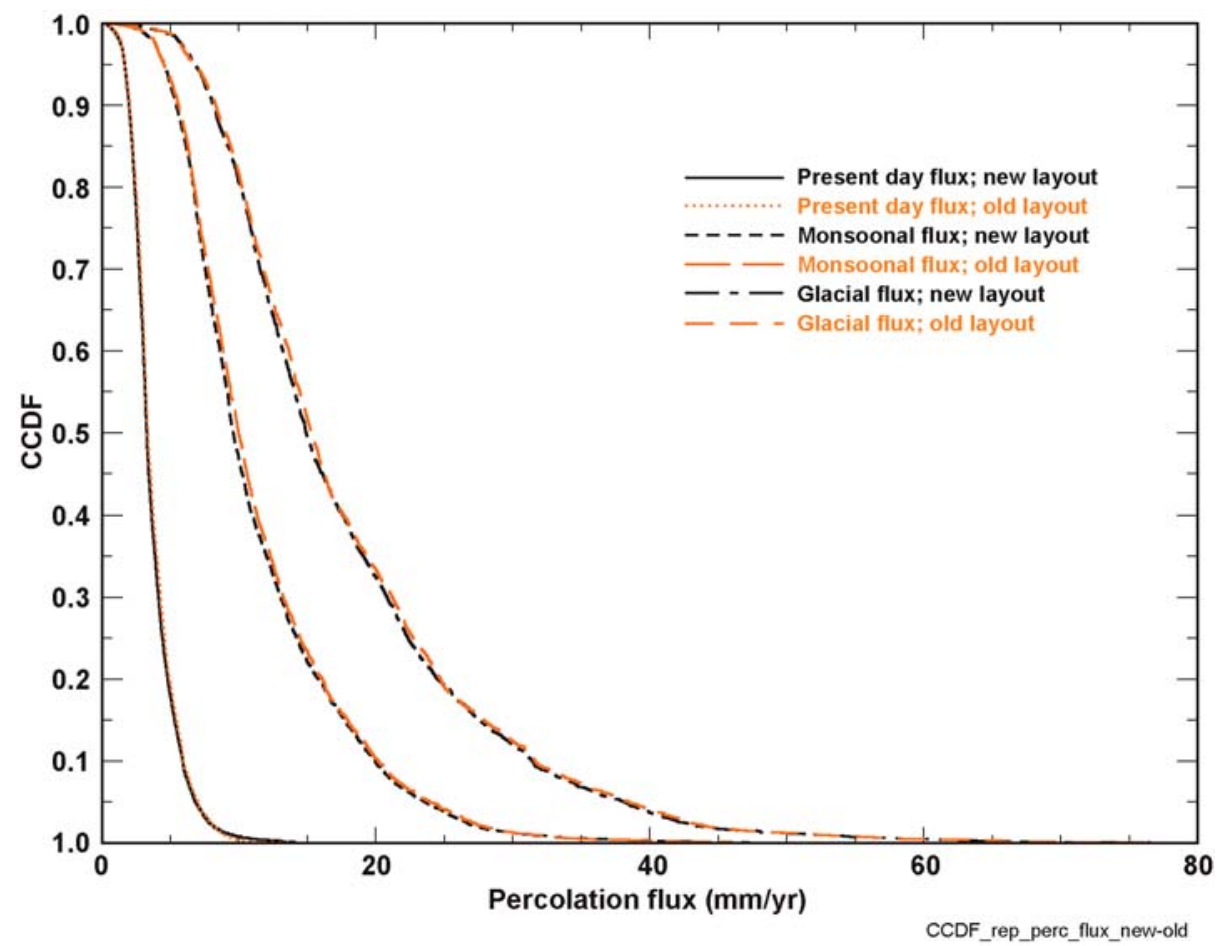

Source: See Table XIII-1.

NOTE: $\quad$ CCDF is given for the present-day, monsoonal, and glacial climates. The superceded repository layout is presented in Repository Design, Repository/PA IED Subsurface Facilities (BSC 2003 [DIRS 161727]). The current repository layout is presented in D\&E / PA/C IED Subsurface Facilities (BSC 2004 [DIRS 164519]).

Figure 4-2. Complementary Cumulative Distribution Function (CCDF) for Distribution of Host-Rock Percolation Flux in the Superseded Repository Layout and the Current Repository Layout 


\subsubsection{Direct Inputs for Development of the Properties of Crushed Tuff in the Invert}

Appendix X presents an analysis that produces retention and flow parameters for the invert. The input for that analysis includes the permeability, porosity, and retention data for volcanic sand, fine sand, glass beads and Touchet Silt Loam (DTN: MO0307SPAUSFPD.000 [DIRS 164436]). Table 4.1-5 presents the permeability data $(\mathrm{k})$ and the porosity data $(\phi)$ of these unconsolidated materials. Table 4.1-6 presents the retention data for the same materials.

Table 4.1-5. Summary of Permeability and Porosity of Various Unconsolidated Materials

\begin{tabular}{|l|c|c|c|c|}
\hline \multicolumn{1}{|c|}{ Material $^{\text {a }}$} & Porosity & $\begin{array}{c}\text { Value } \\
(-)\end{array}$ & $\begin{array}{c}\text { Intrinsic Permeability } \\
\left(\mathbf{m}^{2}\right)\end{array}$ & $\begin{array}{c}\text { Value } \\
\left(\mathbf{m}^{2}\right)\end{array}$ \\
\hline Volcanic Sand & $\phi_{\mathrm{vs}}$ & 0.351 & $\mathrm{k}_{\mathrm{vs}}$ & $1.80 \mathrm{E}-11$ \\
\hline Fine Sand & $\phi_{\mathrm{fs}}$ & 0.377 & $\mathrm{k}_{\mathrm{fs}}$ & $2.50 \mathrm{E}-12$ \\
\hline Glass Beads & $\phi_{\mathrm{gb}}$ & 0.37 & $\mathrm{k}_{\mathrm{gb}}$ & $6.30 \mathrm{E}-12$ \\
\hline Touchet Silt Loam & $\phi_{\mathrm{ts}}$ & 0.485 & $\mathrm{k}_{\mathrm{ts}}$ & $6.00 \mathrm{E}-13$ \\
\hline
\end{tabular}

DTN: MO0307SPAUSFPD.000 [DIRS 164436].

${ }^{\text {a }}$ See Section 6.4 for a description of these materials.

In addition to DTN: MO0307SPAUSFPD.000 [DIRS 164436], the development in Appendix X uses the following direct inputs:

- A value of 2 for the ratio of the capillary rise of water to the capillary rise of the hydrocarbon liquid used for the measurements (Brooks and Corey 1964 [DIRS 156915]).

- The Kozeny-Carman equation as Equation X.52 (Bear 1972 [DIRS 156269], p. 166).

- Porosity of poorly graded sands in the loose state (see below).

- Properties of water (see below).

These inputs are justified for this use in three ways. First, the data, and curve-fits to the data, for various size particles are corroborated by parallel calculations using the Campbell retention relation for the same size particles (BSC 2003 [DIRS 170881]).

The retention relationships developed by the Campbell method show the same characteristics as the nondimensionalized van Genuchten method based upon the Leverett Equation (Leverett 1941 [DIRS 100588]). The results show that as particle size is increased, water retention is reduced. Note that the NUFT dual continuum analyses presented in Advection versus Diffusion in the Invert (BSC 2003 [DIRS 170881]) were conducted over the range of moisture potentials anticipated for the repository using both the nondimensionalized van Genuchten and the Campbell retention constitutive relationships. In both instances, it was determined that intergranular porosity did not cause water retention. For this reason, the use of nondimensionalized van Genuchten parameters as direct input in this report is corroborated. 
Table 4.1-6. Retention Data for Various Materials

\begin{tabular}{|c|c|c|c|c|c|c|c|c|c|c|c|}
\hline \multicolumn{3}{|c|}{ Volcanic Sand } & \multicolumn{3}{|c|}{ Fine Sand } & \multicolumn{3}{|c|}{ Glass Beads } & \multicolumn{3}{|c|}{ Touchet Silt Loam } \\
\hline Saturation & $\begin{array}{c}\text { Capillary } \\
\text { Rise(cm) } \\
\text { Hydrocarbon }\end{array}$ & $\begin{array}{c}\text { Capillary } \\
\text { Rise }(\mathrm{cm}) \\
\text { Water }\end{array}$ & Saturation & $\begin{array}{c}\text { Capillary } \\
\text { Rise }(\mathrm{cm}) \\
\text { Hydrocarbon }\end{array}$ & $\begin{array}{c}\text { Capillary } \\
\text { Rise }(\mathrm{cm}) \\
\text { Water }\end{array}$ & Saturation & $\begin{array}{c}\text { Capillary } \\
\text { Rise }(\mathrm{cm}) \\
\text { Hydrocarbon }\end{array}$ & $\begin{array}{c}\text { Capillary } \\
\text { Rise }(\mathrm{cm}) \\
\text { Water }\end{array}$ & Saturation & $\begin{array}{c}\text { Capillary } \\
\text { Rise }(\mathrm{cm}) \\
\text { Hydrocarbon }\end{array}$ & $\begin{array}{c}\text { Capillary } \\
\text { Rise(cm) } \\
\text { Water }\end{array}$ \\
\hline 0.99 & 12 & 24 & 0.99 & 12.8 & 25.6 & 0.995 & 5.9 & 11.8 & 0.998 & 32.8 & 65.6 \\
\hline 0.986 & 13.5 & 27 & 0.98 & 27.8 & 55.6 & 0.989 & 11.8 & 23.6 & 0.995 & 42.8 & 85.6 \\
\hline 0.98 & 14.5 & 29 & 0.962 & 30.8 & 61.6 & 0.985 & 17.8 & 35.6 & 0.992 & 52.8 & 105.6 \\
\hline 0.974 & 15.5 & 31 & 0.95 & 31.8 & 63.6 & 0.98 & 23.8 & 47.6 & 0.984 & 62.8 & 125.6 \\
\hline 0.948 & 16 & 32 & 0.926 & 34.8 & 69.6 & 0.971 & 26.9 & 53.8 & 0.978 & 67.8 & 135.6 \\
\hline 0.895 & 17 & 34 & 0.901 & 36.8 & 73.6 & 0.938 & 28.8 & 57.6 & 0.967 & 72.5 & 145 \\
\hline 0.875 & 17.2 & 34.4 & 0.855 & 39.8 & 79.6 & 0.912 & 29.3 & 58.6 & 0.946 & 77.8 & 155.6 \\
\hline 0.638 & 21 & 42 & 0.788 & 42.8 & 85.6 & 0.764 & 30.4 & 60.8 & 0.892 & 82.3 & 164.6 \\
\hline 0.479 & 24.8 & 49.6 & 0.716 & 45.8 & 91.6 & 0.681 & 31 & 62 & 0.821 & 87.7 & 175.4 \\
\hline 0.277 & 36.9 & 73.8 & 0.627 & 48.8 & 97.6 & 0.579 & 32.1 & 64.2 & 0.719 & 97.8 & 195.6 \\
\hline 0.188 & 67.7 & 135.4 & 0.503 & 52.8 & 105.6 & 0.465 & 32.7 & 65.4 & 0.641 & 107.6 & 215.2 \\
\hline 0.158 & 136.6 & 273.2 & 0.393 & 57.7 & 115.4 & 0.337 & 33.9 & 67.8 & 0.562 & 123 & 246 \\
\hline - & - & - & 0.314 & 64.8 & 129.6 & 0.269 & 35.7 & 71.4 & 0.492 & 142.6 & 285.2 \\
\hline - & - & - & 0.273 & 71.7 & 143.4 & 0.19 & 39 & 78 & 0.424 & 177 & 354 \\
\hline - & - & - & 0.262 & 74.4 & 148.8 & 0.13 & 43.8 & 87.6 & 0.383 & 207.2 & 414.4 \\
\hline - & - & - & 0.217 & 92.1 & 184.2 & 0.099 & 53.5 & 107 & - & - & - \\
\hline - & - & - & 0.174 & 150.1 & 300.2 & 0.097 & 150.4 & 300.8 & - & - & - \\
\hline
\end{tabular}

DTN: MO0307SPAUSFPD.000 [DIRS 164436]. 
Second, the use of nondimensionalized constitutive relationships is corroborated by unsaturated flow measurements as reported in Advection versus Diffusion in the Invert (BSC 2003 [DIRS 170881], Section 6.8.3). The measurement results indicate that the intergranular porosity was free of water.

Finally, the sources of the inputs are individually justified. The value for the ratio of capillary rise of water to the capillary rise of the hydrocarbon is an estimate that is included in the original report of the qualified data. Van Genuchten (1980 [DIRS 100610]) used the same factor in his analysis. All three authors are prominent soil scientists whose work is widely recognized.

The Kozeny-Carman equation is corroborated by a similar form in a handbook (Winterkorn and Fang 1975 [DIRS 169700], p. 106, Eq. 2.19).

\section{Porosity of Poorly Graded Sands in the Loose State}

In a handbook, Hilf (1975 [DIRS 169699], Table 7.3, p. 257) reports a range in the maximum void ratio $(e)$ of 0.67 to 0.94 for the Unified Soils Classification System type SP, which is for poorly graded sands and gravelly sands with little to no fines (Hilf 1975 [DIRS 169699], p. 84). The corresponding porosity $(\phi)$ can be calculated using the handbook formula that relates the void ratio to porosity (Kaviany 1998 [DIRS 170520], p. 9.76):

$$
e=\frac{\phi}{1-\phi}
$$

where

$$
\begin{array}{ll}
e= & \text { void ratio and } \\
\phi= & \text { porosity }
\end{array}
$$

Solving for $\phi$ in terms of $e$ :

$$
\phi=\frac{e}{1+e}
$$

For the range of void ratios for SP materials, the corresponding range for intergranular porosity is 0.40 to 0.48 . A value of 0.45 is selected for the intergranular porosity of the crushed tuff gravel in the invert because it is near the middle of this range.

\section{Properties of Water}

The properties of water at ambient temperature are given by Incropera and DeWitt (1996 [DIRS 108184]). The water density ( $\rho$ ) equals approximately $1000 \mathrm{~kg} / \mathrm{m}^{3}$ and the absolute viscosity $(\mu)$ equals $8.935 \times 10^{-4} \mathrm{~N} \cdot \mathrm{s} /\left(\mathrm{m}^{2}\right)$. The surface tension of water equals $72 \mathrm{dynes} / \mathrm{cm}$. These values are corroborated by handbook values from Liley et al. (1984 [DIRS 146851], pp. 3-75 and 3-238) by interpolation to $25^{\circ} \mathrm{C}$. Using MathCad 11.2a, the interpolation proceeds as follows: 
Convert the temperature to Kelvin from Celsius:

$$
25^{\circ} \mathrm{C}+273.15=298.15 \mathrm{~K}
$$

The density of water given by Liley et al. (1984 [DIRS 146851], Table 3-38) is $997.045 \mathrm{~kg} / \mathrm{m}^{3}$. Use $1,000 \mathrm{~kg} / \mathrm{m}^{3}$ for purposes of illustrating hydraulic conductivity versus moisture potential relationships, as in Attachment X. Liley et al. (1984 [DIRS 146851], Table 3-302) list the following values of viscosity and surface tension:

$$
i:=0 . .1
$$

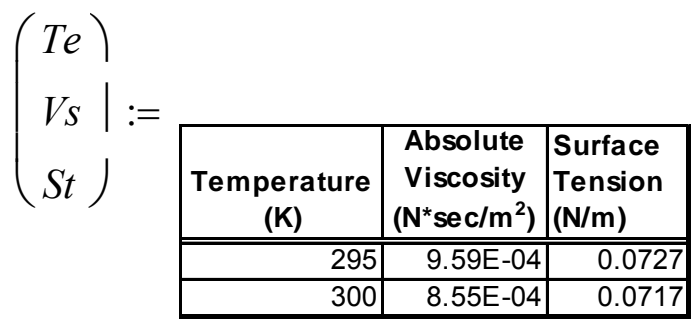

Add units for purposes of interpolation:

$$
\begin{gathered}
\text { Temperature }_{i}:=T_{i} \cdot K \\
\text { Viscosity }_{i}:=V s_{i} \cdot\left(N \cdot \frac{s e c}{m^{2}}\right) \\
\text { Surface_Tension }_{i}:=S t_{i} \cdot \frac{N}{m}
\end{gathered}
$$

Perform a linear interpolation on this data for a temperature of $25^{\circ} \mathrm{C}$ or $298.15 \mathrm{~K}$ :

$$
\text { linterp }(\text { Temperature, Viscosity, } 298.15 \cdot K)=8.94 \times 10^{-4} \frac{N \cdot \mathrm{sec}}{m^{2}}
$$

$$
\text { linterp (Temperature, Surface Tension, 298.15 } K)=72.1 \frac{d y n e}{\mathrm{~cm}}
$$

The properties listed above are used for analysis of moisture retention and hydraulic conductivity relationships for the intergranular porosity of the invert in Appendix $X$. The ambient temperature of $25^{\circ} \mathrm{C}$ is consistent with the temperature used in the analysis of the Brooks and Corey moisture retention measurements presented in Appendix X. This analysis, which applies the ambient temperature value, is used only to illustrate the relationship of unsaturated hydraulic conductivity to moisture potential of the intergranular porosity of the invert. The NUFT code uses van Genuchten moisture retention and relative permeability relationships that are independent of temperature; however, NUFT accounts for the temperature dependence of the fluid properties in the thermal-hydrologic simulations. 


\section{Adjustment for Fluid Density for the Height of Capillary Rise}

The Brooks and Corey retention data presented in Appendix X used hydrocarbon as the fluid. The data in Appendix $\mathrm{X}$ are adjusted to account for the difference between water and the hydrocarbon fluid. According to Brooks and Corey (1964 [DIRS 156915], Equation 17, p. 9), the capillary rise of water was about twice that of the hydrocarbon used in the measurements. This relationship is justified for the intended use in that it is established fact that the capillary rise or retention equals the capillary pressure divided by the density of the fluid.

\section{Qualification of the Use of Information from Fetter}

The referenced source by Fetter (1993 [DIRS 102009]) on the topics of the theory supporting analytical equations for steady-state unsaturated flow in porous medium and the use of the van Genuchten relation was reviewed by the following individuals: J.M. Bahr at the University of Wisconsin - Madison; R.A. Griffin at the University of Alabama; J.I. Hoffman at Eastern Washington University; M. Th. van Genuchten at the U.S. Department of Agriculture Salinity Laboratory; S. Kornder at the James River Paper Company; G. Sposito at the University of California - Berkeley; N. Valkenburg at Geraghty and Miller, Inc.; and P. Wierenga at the University of Arizona. Noting that the information of interest from Fetter pertains to unsaturated flow and the van Genuchten relation, and the fact that this source was reviewed by Martinus Th. van Genuchten, among others, the source is considered reliable for its intended use. The extent to which this source of information addresses the supporting analytical equations for steady-state unsaturated flow in porous medium and the use of the van Genuchten relation is considered adequate because these topics were extensively reviewed, as documented here.

\subsection{CRITERIA}

Project Requirements Document (Canori and Leitner 2003 [DIRS 166275]) contains three criteria that are relevant to the work documented in this report. They are:

1. PRD-002/T-014 Performance Objectives for the Geologic Repository After Permanent Closure; see 10 CFR 63.113 [DIRS 156605] for compete requirement text.

2. PRD-002/T-015 Requirements for Performance Assessment; see 10 CFR 63.114 for compete requirement text.

3. PRD-002/T-016 Requirements for Multiple Barriers; see 10 CFR 63.115 for compete requirement text.

Work described in this document will support these requirements, but more specific criteria exist in Yucca Mountain Review Plan, Final Report (Yucca Mountain Review Plan) (NRC 2003 [DIRS 163274]). Selected Yucca Mountain Review Plan acceptance criteria are presented to supplement or clarify the Project Requirements Document citation.

Technical Work Plan for: Near-Field Environment In-Drift Heat and Mass Transfer Model and Analysis Reports Integration (BSC 2004 [DIRS 170950], Section 3.2) identifies the applicable acceptance criteria for this model report. Because this model report predicts results that directly or indirectly pertain to quantity of water contacting engineered barriers and waste forms, the 
following Yucca Mountain Review Plan acceptance criteria, based on meeting the requirements of 10 CFR 63.114(a)-(c) and (e)-(g) [DIRS 156605]), were identified as applicable to this technical product (NRC 2003 [DIRS 163274], Section 2.2.1.3.3.3). As discussed in Section 8.4, several parts of the criteria are not included because they are not relevant to this model report. Section 8.4 discusses the contents of this report as they relate to the acceptance criteria.

\subsubsection{Acceptance Criterion 1 - System Description and Model Integration Are Adequate}

(1) Total system performance assessment adequately incorporates important design features, physical phenomena, and couplings, and uses consistent and appropriate assumptions throughout the quantity and chemistry of water contacting engineered barriers and waste forms abstraction process;

(2) The abstraction of the quantity and chemistry of water contacting engineered barriers and waste forms uses assumptions, technical bases, data, and models, that are appropriate and consistent with other related U.S. Department of Energy abstractions. For example, the assumptions used for the quantity and chemistry of water contacting engineered barriers and waste forms are consistent with the abstractions of "Degradation of Engineered Barriers" (Section 2.2.1.3.1); "Mechanical Disruption of Engineered Barriers (Section 2.2.1.3.2); "Radionuclide Release Rates and Solubility Limits" (Section 2.2.1.3.4); “Climate and Infiltration” (Section 2.2.1.3.5); and "Flow Paths in the Unsaturated Zone” (Section 2.2.1.3.6). The descriptions and technical bases provide transparent and traceable support for the abstraction of quantity and chemistry of water contacting engineered barriers and waste forms;

(3) Important design features, such as waste package design and material selection, backfill, drip shield, ground support, thermal loading strategy, and degradation processes, are adequate to determine the initial and boundary conditions for calculations of the quantity and chemistry of water contacting engineered barriers and waste forms;

(4) Spatial and temporal abstractions appropriately address physical couplings (thermalhydrologic-mechanical-chemical). For example, the U.S. Department of Energy evaluates the potential for focusing of water flow into drifts, caused by coupled thermal-hydrologic-mechanical-chemical processes;

(5) Sufficient technical bases and justification are provided for total system performance assessment assumptions and approximations for modeling coupled thermalhydrologic-mechanical-chemical effects on seepage and flow, the waste package chemical environment, and the chemical environment for radionuclide release. The effects of distribution of flow on the amount of water contacting the engineered barriers and waste forms are consistently addressed, in all relevant abstractions;

(6) The expected ranges of environmental conditions within the waste package emplacement drifts, inside the breached waste packages, and contacting the waste forms and their evolution with time are identified. These ranges may be developed to include: (i) the effects of the drip shield and backfill on the quantity and chemistry of 
waster (e.g., the potential for condensate formation and dripping from the underside of the shield); (ii) conditions that promote corrosion of engineered barriers and degradation of waste forms; (iii) irregular wet and dry cycles; (iv) gamma-radiolysis; and (v) size and distribution of penetrations of engineered barriers;

(7) The model abstraction for quantity and chemistry of water contacting engineered barriers and waste forms is consistent with the detailed information on engineered barrier design and other engineered features. For example, consistency is demonstrated for: (i) dimensionality of the abstractions; (ii) various design features and site characteristics; and (iii) alternative conceptual approaches. Analyses are adequate to demonstrate that no deleterious effects are caused by design or site features that the U.S. Department of Energy does not take into account in this abstraction;

(8) Adequate technical bases are provided, including activities such as independent modeling, laboratory or field data, or sensitivity studies, for inclusion of any thermalhydrologic-mechanical-chemical couplings and features, events, and processes;

(9) Performance-affecting processes that have been observed in thermal-hydrologic tests and experiments are included into the performance assessment. For example, the U.S. Department of Energy either demonstrates that liquid water will not reflux into the underground facility or incorporates refluxing water into the performance assessment calculation, and bounds the potential adverse effects of alteration of the hydraulic pathway that result from refluxing water;

(12) Guidance in NUREG-1297 (Altman et al. 1988 [DIRS 103597] and NUREG-1298 (Altman et al. 1988 [DIRS 103750]), or other acceptable approaches, is followed.

\subsubsection{Acceptance Criterion 2 - Data Are Sufficient for Model Justification}

(1) Geological, hydrological, and geochemical values used in the license application are adequately justified. Adequate description of how the data were used, interpreted, and appropriately synthesized into the parameters is provided;

(2) Sufficient data were collected on the characteristics of the natural system and engineered materials to establish initial and boundary conditions for conceptual models of thermal-hydrological-mechanical-chemical coupled processes, that affect seepage and flow and the engineered barriers chemical environment;

(3) Thermo-hydrologic tests were designed and conducted with the explicit objectives of observing thermal-hydrologic processes for the temperature ranges expected for repository conditions and making measurements for mathematical models. Data are sufficient to verify that thermal-hydrologic conceptual models address important thermal-hydrologic phenomena;

(4) Sufficient information to formulate the conceptual approach(es) for analyzing water contact with the drip shield, engineered barriers, and waste forms is provided. 


\subsubsection{Acceptance Criterion 3-Data Uncertainty Is Characterized and Propagated Through the Model Abstraction}

(1) Models use parameter values, assumed ranges, probability distributions, and bounding assumptions that are technically defensible, reasonably account for uncertainties and variabilities, and do not result in an under-representation of the risk estimate;

(2) Parameter values, assumed ranges, probability distributions, and bounding assumptions used in the total system performance assessment calculations of quantity and chemistry of water contacting engineered barriers and waste forms are technically defensible and reasonable, based on data from the Yucca Mountain region (e.g., results from large block and drift-scale heater and niche tests), and a combination of techniques that may include laboratory experiments, field measurements, natural analog research, and process-level modeling studies;

(3) Input values used in the total system performance assessment calculations of quantity and chemistry of water contacting engineered barriers (e.g., drip shield and waste package) are consistent with the initial and boundary conditions and the assumptions of the conceptual models and design concepts for the Yucca Mountain site. Correlations between input values are appropriately established in the U.S. Department of Energy total system performance assessment. Parameters used to define initial conditions, boundary conditions, and computational domain in sensitivity analyses involving coupled thermal-hydrologic-mechanical-chemical effects on seepage and flow, the waste package chemical environment, and the chemical environment for radionuclide release, are consistent with available data. Reasonable or conservative ranges of parameters or functional relations are established;

(4) Adequate representation of uncertainties in the characteristics of the natural system and engineered materials is provided in parameter development for conceptual models, process-level models, and alternative conceptual models. DOE may constrain these uncertainties using sensitivity analyses or conservative limits. For example, DOE demonstrates how parameters used to describe flow through the EBS bound the effects of backfill and excavation-induced changes;

\subsubsection{Acceptance Criterion 4-Model Uncertainty Is Characterized and Propagated Through the Model Abstraction}

(1) Alternative modeling approaches of features, events, and processes are considered and are consistent with available data and current scientific understanding, and the results and limitations are appropriately considered in the abstraction;

(2) Alternative modeling approaches are considered and the selected modeling approach is consistent with available data and current scientific understanding. A description that includes a discussion of alternative modeling approaches not considered in the final analysis and the limitations and uncertainties of the chosen model is provided;

(3) Consideration of conceptual model uncertainty is consistent with available site characterization data, laboratory experiments, field measurements, natural analog 
information and process-level modeling studies; and the treatment of conceptual model uncertainty does not result in an under-representation of the risk estimate;

(4) Adequate consideration is given to effects of thermal-hydrologic-mechanical-chemical coupled processes in the assessment of alternative conceptual models. These effects may include: (i) thermal-hydrologic effects on gas, water, and mineral chemistry; (ii) effects of microbial processes on the engineered barrier chemical environment and the chemical environment for radionuclide release; (iii) changes in water chemistry that may result from the release of corrosion products from the engineered barriers and interactions between engineered materials and ground water; and (iv) changes in boundary conditions (e.g., drift shape and size) and hydrologic properties, relating to the response of the geomechanical system to thermal loading.

\subsubsection{Acceptance Criterion 5-Model Abstraction Output Is Supported by Objective Comparisons}

No subcriteria are applicable to this report.

\subsection{CODES, STANDARDS, AND REGULATIONS}

This report was prepared to comply with 10 CFR Part 63 [DIRS 156605], the U.S. Nuclear Regulatory Commission rule on high-level radioactive waste. Subparts of this rule that are applicable to data include Subpart E, Section 114 (Requirements for Performance Assessment). The subpart applicable to models is also outlined in Subpart E Section 114. The subparts applicable to features, events, and processes (FEPs) are 10 CFR 63.114(d), (e), and (f) [DIRS 156605]. Standard Practice for Preparing, Cleaning, and Evaluating Corrosion Test Specimens (ASTM G 1-90 [DIRS 103515]) was also used in preparing this report, as was Section II of 1995 ASME Boiler and Pressure Vessel Code (ASME 1995 [DIRS 108417]).

\subsection{DATA FROM FIELD MEASUREMENTS IN THE LARGE BLOCK TEST AND DRIFT SCALE TEST}

The source DTNs for the field measurements in the Large Block Test (LBT) are listed in Table 4.4-1. These DTNs are used for model validation purposes only and are not direct input to the MSTHM. The source DTNs for the field measurements in the Drift Scale Test (DST) are listed in Table 4.4-2.

Table 4.4-1. Source DTNs for Field Measurements Made in the Large Block Test (LBT)

\begin{tabular}{|l|l|l|}
\hline Model Input & \multicolumn{1}{|c|}{ Value } & \multicolumn{1}{c|}{ Source } \\
\hline Heater power history & $\begin{array}{l}\text { Heater power input for each of 5 heater boreholes; power } \\
\text { history read from 7 tables; table name and time range as } \\
\text { follows: }\end{array}$ & $\begin{array}{l}\text { DTN: LL980918904244.074 } \\
\text { [DIRS 135872] }\end{array}$ \\
& - S98461_018 2/27/1997-4/30/1997 & \\
& - S98461_0195/1/1997-7/31/1997 & \\
& - S98461_020 8/1/1997-10/31/1997 & \\
& - S98461_021 11/1/1997-1/20/1998 & \\
\hline
\end{tabular}


Table 4.4-1. Source DTNs for Field Measurements Made in the Large Block Test (LBT) (Continued)

\begin{tabular}{|c|c|c|}
\hline Model Input & Value & Source \\
\hline $\begin{array}{l}\text { Top surface boundary } \\
\text { temperature controlled } \\
\text { by heat exchanger }\end{array}$ & $\begin{array}{l}\text { Temperature averaged from } 4 \text { RTDs, TNE-1, TNW-1,TSE1- } \\
\text { 1, and TSW-1; table name and time range as follows: } \\
\text { - S98461_022 2/27/1997-4/30/1997 } \\
\text { - S98461_023 5/1/1997-7/31/1997 } \\
\text { - S98461_024 8/1/1997-10/24/1997 } \\
\text { - S98461_025 10/25/1997-12/31/1997 } \\
\text { - S98461_026 1/1/1998-3/31/1998 } \\
\text { - S98461_027 4/1/1998-6/30/1998 } \\
\text { - S98461_028 7/1/1998-9/16/1998 }\end{array}$ & $\begin{array}{l}\text { DTN: LL980918904244.074 } \\
\text { [DIRS 135872] }\end{array}$ \\
\hline $\begin{array}{l}\text { Snapshots of rock } \\
\text { temperature profile } \\
\text { along Borehole TT1 }\end{array}$ & $\begin{array}{l}\text { Temperature profile along Borehole TT1 at five different } \\
\text { times. Given below are table (or file) name, elapsed time in } \\
\text { hours (h), and the range of row numbers that contain the } \\
\text { data for each time. } \\
\begin{array}{ll}\text { S98461_033 } 719.8 \mathrm{~h} & 1-41136 \\
\text { S98461_034 } 2399.6 \mathrm{~h} & 1-159235 \\
\text { S98461_035 } 4800.13 \mathrm{~h} & 1-149893 \\
\text { S98461_029 } 7200.03 \mathrm{~h} & 1-90950 \\
\text { S98461_031 } 9600.22 \mathrm{~h} & 1-98329 \\
\end{array}\end{array}$ & $\begin{array}{l}\text { DTN: LL980918904244.074 } \\
\text { [DIRS 135872] }\end{array}$ \\
\hline $\begin{array}{l}\text { Initial volumetric water } \\
\text { content from neutron } \\
\text { measurements }\end{array}$ & $\begin{array}{l}\text { Initial water content obtained from average of values } \\
\text { measured along Borehole TN3 prior to heating; data from } \\
\text { file at row numbers } 1-159\end{array}$ & $\begin{array}{l}\text { DTN: LL980919304244.075 } \\
\text { [DIRS 145099] }\end{array}$ \\
\hline $\begin{array}{l}\text { Volumetric water } \\
\text { content from neutron } \\
\text { measurements }\end{array}$ & $\begin{array}{l}\text { Rock water content profile along Borehole TN3 at } 103 \mathrm{~d} \text {, } \\
361 \mathrm{~d} \text {, and } 501 \mathrm{~d} \text {; data from file at row numbers } 2200- \\
2254 \text { for } 103 \mathrm{~d}, 2365-2419 \text { for } 361 \mathrm{~d} \text {, and } 2585-2639 \text { for } \\
501 \mathrm{~d}\end{array}$ & $\begin{array}{l}\text { DTN: LL980919304244.075 } \\
\text { [DIRS 145099] }\end{array}$ \\
\hline $\begin{array}{l}\text { Air temperature: } \\
1 / 1 / 1997- \\
12 / 31 / 1997\end{array}$ & $\begin{array}{l}\text { Bureau of Land Management Site } 8 \text { temperature data used } \\
\text { in boundary conditions. Data under table name } \\
\text { S04010_001, and parameter name Temperature. Data in } \\
\text { Microsoft Access folder Met1997t.mdb, in table S008_97t. } \\
\text { The Julian day number is in Column } 3(1-365) \text {, time of day } \\
\text { in Column } 4(\mathrm{hr}, \mathrm{min}) \text { and temperature in Column } 8\left({ }^{\circ} \mathrm{C}\right) .\end{array}$ & $\begin{array}{l}\text { DTN: MO0312SEPQ1997.001 } \\
\text { [DIRS 167116] }\end{array}$ \\
\hline $\begin{array}{l}\text { Air temperature: } \\
1 / 1 / 1998-3 / 31 / 1998\end{array}$ & $\begin{array}{l}\text { Bureau of Land Management Site } 8 \text { temperature data used } \\
\text { in boundary conditions. MOL.19990315.0065 Data file: } \\
\text { 1q98b_sr.txt. The site number is in Column } 1 \text { (used only } \\
\text { Site } 8 \text { data), Julian day number in Column } 3(1-365) \text {, time of } \\
\text { day in Column } 4(\mathrm{hr}) \text { and temperature in Column } 7(\mathrm{~K}) \text {. }\end{array}$ & $\begin{array}{l}\text { DTN: MO98METDATA114.000 } \\
\text { [DIRS 165702] }\end{array}$ \\
\hline $\begin{array}{l}\text { Air temperature: } \\
4 / 1 / 1998-6 / 30 / 1998\end{array}$ & $\begin{array}{l}\text { Bureau of Land Management Site } 8 \text { temperature data used } \\
\text { in boundary conditions. Data file: } 2 \text { q98a_sr.txt } \\
\text { (MOL.19990323.0416). The site number is in Column } 1 \\
\text { (used only Site } 8 \text { data), Julian day number in Column } 3 \text { (1- } \\
\text { 365), time of day in Column } 4 \text { (hr) and temperature in } \\
\text { Column } 7 \text { (K). }\end{array}$ & $\begin{array}{l}\text { DTN: MO98METDATA117.000 } \\
\text { [DIRS 165705] }\end{array}$ \\
\hline $\begin{array}{l}\text { Air temperature: } \\
\text { 7/1/1998 - 9/30/1998 }\end{array}$ & $\begin{array}{l}\text { Bureau of Land Management Site } 8 \text { temperature data used } \\
\text { in boundary conditions. Data file: } 3 q 98 \text { sr.txt } \\
\text { (MOL.19990105.0204). The site number is in Column } 1 \\
\text { (used only Site } 8 \text { data), Julian day number in Column } 3 \text { (1- } \\
\text { 365), time of day in Column } 4 \text { (hr) and temperature in } \\
\text { Column } 7 \text { (K). }\end{array}$ & $\begin{array}{l}\text { DTN: MO98METDATA120.000 } \\
\text { [DIRS 165706] }\end{array}$ \\
\hline $\begin{array}{l}\text { Drift-scale calibrated } \\
\text { one-dimensional } \\
\text { property set, FY99: } \\
\text { Base-case infiltration }\end{array}$ & Entire DTN. & $\begin{array}{l}\text { DTN: LB990861233129.001 } \\
\text { [DIRS 110226] }\end{array}$ \\
\hline
\end{tabular}

NOTE: Also listed is one of the data sets used in the thermal-hydrologic model calculations of the LBT. Note that these DTNs are used for validation purposes only. 
Table 4.4-2. Source DTNs for Field Measurements Made in the Drift Scale Test (DST)

\begin{tabular}{|c|c|c|}
\hline Model Input & Value & Source \\
\hline $\begin{array}{l}\text { As-built locations of boreholes, } \\
\text { sensors, and heaters }\end{array}$ & $\begin{array}{l}\text { Location of temperature sensors in Table } \\
\text { S00085_001; locations of temperature and } \\
\text { neutron boreholes and heaters in Table } \\
\text { S00085_002 }\end{array}$ & $\begin{array}{l}\text { DTN: MO0002ABBLSLDS.000 } \\
\text { [DIRS 147304] }\end{array}$ \\
\hline $\begin{array}{l}\text { Heater power and sensor } \\
\text { temperatures: November } 7 \\
1997 \text { - May 31, } 1998\end{array}$ & $\begin{array}{l}\text { Floor heater and wing heater power in Table } \\
\text { S98349_001; Table names and time intervals } \\
\text { for temperatures are as follows: } \\
\text { - S98349_004 } 11 / 7 / 1997-11 / 30 / 1997 \\
\text { - S98349_005 } 12 / 1 / 1997-12 / 31 / 1997 \\
\text { - S98349_006 } 1 / 1 / 1998-1 / 31 / 1998 \\
\text { - S98349_007 } 2 / 1 / 1998-2 / 28 / 1998 \\
\text { - S98349_008 } 3 / 1 / 1998-3 / 31 / 1998 \\
\text { - S98349_009 } 4 / 1 / 1998-4 / 30 / 1998 \\
\text { - S98349_010 } 5 / 1 / 1998-5 / 31 / 1998\end{array}$ & $\begin{array}{l}\text { DTN: MO9807DSTSET01.000 } \\
\text { [DIRS 113644] }\end{array}$ \\
\hline $\begin{array}{l}\text { Heater power and sensor } \\
\text { temperatures: June 1, } 1998- \\
\text { August 31, } 1998\end{array}$ & $\begin{array}{l}\text { Floor heater and wing heater power in Table } \\
\text { S99012_001; Table names and time intervals } \\
\text { for temperatures are as follows: } \\
\text { - S99012_004 6/1/1998 - 6/30/1998 } \\
\text { - S99012_005 } 7 / 1 / 1998-7 / 31 / 1998 \\
\text { - S99012_006 8/1/1998-8/31/1998 }\end{array}$ & $\begin{array}{l}\text { DTN: MO9810DSTSET02.000 } \\
\text { [DIRS 113662] }\end{array}$ \\
\hline $\begin{array}{l}\text { Heater power and sensor } \\
\text { temperatures: September } 1 \text {, } \\
1998 \text { - May 31, } 1999\end{array}$ & $\begin{array}{l}\text { Floor heater and wing heater power in Table } \\
\text { S99304_010; Table names and time intervals } \\
\text { for temperatures are as follows: } \\
\text { - S99304_001 } 9 / 1 / 1998-9 / 30 / 1998 \\
\text { - } \quad \text { S99304_002 } 10 / 1 / 1998-10 / 31 / 1998 \\
\text { - S99304_003 } 11 / 1 / 1998-11 / 30 / 1998 \\
\text { - S99304_004 } 12 / 1 / 1998-12 / 30 / 1998 \\
\text { - S99304_005 } 1 / 1 / 1999-1 / 31 / 1999 \\
\text { - S99304_006 } 2 / 1 / 1999-2 / 28 / 1999 \\
\text { - S99304_007 } 3 / 1 / 1999-3 / 30 / 1999 \\
\text { - S99304_008 } 4 / 1 / 1999-4 / 29 / 1999 \\
\text { - S99304_009 } 5 / 1 / 1999-5 / 31 / 1999\end{array}$ & $\begin{array}{l}\text { DTN: MO9906DSTSET03.000 } \\
\text { [DIRS 113673] }\end{array}$ \\
\hline $\begin{array}{l}\text { Heater power and sensor } \\
\text { temperatures: June 1, } 1999- \\
\text { October } 31,1999\end{array}$ & $\begin{array}{l}\text { Floor heater and wing heater power in Table } \\
\text { S00044_001; Table names and time intervals } \\
\text { for temperatures are as follows: } \\
\text { - S00044_004 } 6 / 1 / 1999-6 / 30 / 1999 \\
\text { - S00044_005 } 7 / 1 / 1999-7 / 31 / 1999 \\
\text { - S00044_006 } 8 / 1 / 1999-8 / 31 / 1999 \\
\text { - S00044_007 } 9 / 1 / 1999-9 / 30 / 1999 \\
\text { - S00044_008 } 10 / 1 / 1999-10 / 31 / 1999\end{array}$ & $\begin{array}{l}\text { DTN: MO0001SEPDSTPC.000 } \\
\text { [DIRS 153836] }\end{array}$ \\
\hline $\begin{array}{l}\text { Heater power and sensor } \\
\text { temperatures: November } 1 \text {, } \\
1999 \text { - May 31, } 2000\end{array}$ & $\begin{array}{l}\text { Floor heater and wing heater power in Table } \\
\text { S00327_009; Table names and time intervals } \\
\text { for temperatures are as follows: } \\
\text { - S00327_002 } 1 / 1 / 2000-1 / 31 / 2000 \\
\text { - S00327_003 } 2 / 1 / 2000-2 / 29 / 2000 \\
\text { - S00327_004 } 3 / 1 / 2000-3 / 31 / 2000 \\
\text { - S00327_005 } 4 / 1 / 2000-4 / 30 / 2000 \\
\text { - S00327_006 } 5 / 1 / 2000-5 / 31 / 2000 \\
\text { - S00327_007 } 11 / 1 / 1999-11 / 30 / 1999 \\
\text { - S00327_008 } 12 / 1 / 1999-12 / 31 / 1999\end{array}$ & $\begin{array}{l}\text { DTN: MO0007SEPDSTPC.001 } \\
\text { [DIRS 153707] }\end{array}$ \\
\hline $\begin{array}{l}\text { Sensor temperatures: January } \\
15,2002 \text { - June } 30,2002\end{array}$ & $\begin{array}{l}\text { Data obtained from text files: } \\
\text { TDIF_009_0201_2.txt, TDIF_009_0202.txt, } \\
\text { TDIF_009_0203.txt, TDIF_009_0204.txt, } \\
\text { TDIF_009_0205.txt, and TDIF_009_0206.txt }\end{array}$ & $\begin{array}{l}\text { DTN: MO0208SEPDSTTD.001 } \\
\text { [DIRS 161767] }\end{array}$ \\
\hline
\end{tabular}


Table 4.4-2. Source DTNs for Field Measurements Made in the Drift Scale Test (DST) (Continued)

\begin{tabular}{|c|c|c|}
\hline Model Input & Value & Source \\
\hline $\begin{array}{l}\text { Heater power and sensor } \\
\text { temperatures: June 1, } 2000- \\
\text { November } 30,2000\end{array}$ & $\begin{array}{l}\text { Floor heater and wing heater power in Table } \\
\text { S00468_002; Table names and time intervals } \\
\text { for temperatures are as follows: } \\
\text { - S00468_003 } 10 / 1 / 2000-10 / 31 / 2000 \\
\text { - S00468_004 } 6 / 1 / 2000-6 / 30 / 2000 \\
\text { - S00468_005 } 9 / 1 / 2000-9 / 30 / 2000 \\
\text { - S00468_006 } 8 / 1 / 2000-8 / 31 / 2000 \\
\text { - S00468_007 } 7 / 1 / 2000-7 / 31 / 2000 \\
\text { - S00468_008 } 11 / 1 / 2000-11 / 30 / 2000\end{array}$ & $\begin{array}{l}\text { DTN: MO0012SEPDSTPC.002 } \\
\text { [DIRS 153708] }\end{array}$ \\
\hline $\begin{array}{l}\text { Heater power and sensor } \\
\text { temperatures: December } 1 \text {, } \\
2000 \text { - May 31, } 2001\end{array}$ & $\begin{array}{l}\text { Floor heater and wing heater power in Table } \\
\text { S01100_002; Table names and time intervals } \\
\text { for temperatures are as follows: } \\
\text { - S01100_004 } 12 / 1 / 2000-12 / 31 / 2000 \\
\text { - S01100_005 } 1 / 1 / 2001-1 / 31 / 2001 \\
\text { - S01100_006 } 2 / 1 / 2001-2 / 28 / 2001 \\
\text { - S01100_007 } 3 / 1 / 2001-3 / 31 / 2001 \\
\text { - S01100_008 } 4 / 1 / 2001-4 / 30 / 2001 \\
\text { - S01100_009 } 5 / 1 / 2001-5 / 31 / 2001\end{array}$ & $\begin{array}{l}\text { DTN: MO0107SEPDSTPC.003 } \\
\text { [DIRS 158321] }\end{array}$ \\
\hline $\begin{array}{l}\text { Heater power and sensor } \\
\text { temperatures: June 1, } 2001- \\
\text { January } 14,2002\end{array}$ & $\begin{array}{l}\text { Floor heater and wing heater power in Table } \\
\text { S02060_010; Table names and time intervals } \\
\text { for temperatures are as follows: } \\
\text { - S02060_001 } 6 / 1 / 2001-6 / 30 / 2001 \\
\text { - S02060_002 } 7 / 1 / 2001-7 / 31 / 2001 \\
\text { - S02060_003 } 8 / 1 / 2001-8 / 31 / 2001 \\
\text { - S02060_004 } 9 / 1 / 2001-9 / 30 / 2001 \\
\text { - S02060_005 } 10 / 1 / 2001-10 / 31 / 2001 \\
\text { - S02060_006 } 11 / 1 / 2001-11 / 30 / 2001 \\
\text { - S02060_007 } 12 / 1 / 2001-12 / 31 / 2001 \\
\text { - S02060_008 } 1 / 1 / 2002-1 / 14 / 2002\end{array}$ & $\begin{array}{l}\text { DTN: MO0202SEPDSTTV.001 } \\
\text { [DIRS 158320] }\end{array}$ \\
\hline $\begin{array}{l}\text { Sensor temperatures: July 1, } \\
2002 \text { - December 31, } 2002\end{array}$ & $\begin{array}{l}\text { Data obtained from text files: } \\
\text { TDIF_010_0207.txt, TDIF_010_0208.txt, } \\
\text { TDIF_010_0209.txt, TDIF_010_0210.txt, } \\
\text { TDIF_010_0211.txt, and TDIF_010_0212.txt }\end{array}$ & $\begin{array}{l}\text { DTN: MO0303SEPDSTTM.000 } \\
\text { [DIRS 165698] }\end{array}$ \\
\hline $\begin{array}{l}\text { Sensor temperatures: January } 1 \text {, } \\
2003 \text { - June } 30,2003\end{array}$ & $\begin{array}{l}\text { Data obtained from text files: } \\
\text { TDIF_011_0306.txt, TDIF_011_0302.txt, } \\
\text { TDIF_011_0303.txt, TDIF_011_0304.txt, } \\
\text { TDIF_011_0305.txt, and TDIF_011_0301.txt }\end{array}$ & $\begin{array}{l}\text { DTN: MO0307SEPDST31.000 } \\
\text { [DIRS 165699] }\end{array}$ \\
\hline $\begin{array}{l}\text { Water content in rock from } \\
\text { neutron measurements: August } \\
1997 \text { - May } 2002\end{array}$ & $\begin{array}{l}\text { Following are the neutron boreholes and files } \\
\text { that supply the water content data: } \\
\begin{array}{lll}\text { - } & \text { Borehole } 68 & \text { File N10hv.xls } \\
\text { - } & \text { Borehole } 79 & \text { File N11hxv.xls } \\
\text { - } & \text { Borehole } 80 & \text { File N12hxv.xls } \\
\end{array}\end{array}$ & $\begin{array}{l}\text { DTN: LL020710223142.024 } \\
\text { [DIRS 159551] }\end{array}$ \\
\hline $\begin{array}{l}\text { Water content in rock from } \\
\text { neutron measurements: January } \\
2003 \text { - May } 2003\end{array}$ & $\begin{array}{l}\text { Following are the neutron boreholes and files } \\
\text { that supply the water content data: } \\
\begin{array}{lll}\text { - } & \text { Borehole } 68 & \text { File TD100307.xls } \\
\text { - } & \text { Borehole 79 } & \text { File TD110307.xls } \\
\text { - } & \text { Borehole } 80 & \text { File TD120307.xls } \\
\end{array}\end{array}$ & $\begin{array}{l}\text { DTN: LL030709023122.032 } \\
\text { [DIRS 165701] }\end{array}$ \\
\hline $\begin{array}{l}\text { Temperatures and gas-phase } \\
\text { pressures at upper boundary } \\
\text { (ground surface) and lower } \\
\text { boundary (water table) of the } \\
\text { three-dimensional Site-Scale UZ } \\
\text { Flow Model (Table 4.1-1) }\end{array}$ & $\begin{array}{l}\text { Files: INCON_thm_s32.dat and } \\
\text { MESH_rep.VF }\end{array}$ & $\begin{array}{l}\text { DTN: LB991201233129.001 } \\
\text { [DIRS 146894] }\end{array}$ \\
\hline
\end{tabular}

NOTE: These DTNs are used for validation purposes only. 
INTENTIONALLY LEFT BLANK 


\section{ASSUMPTIONS}

\subsection{BOUNDARY CONDITIONS}

\subsubsection{Ground-Surface Relative Humidity}

Assumption: The relative humidity at the ground surface above the repository is assumed to be 100 percent.

Rationale: The liquid-phase flux distribution applied at the upper boundary of the LDTH submodels of the MSTHM is the percolation-flux distribution (from the base of the PTn unit into the top of the TSw sequence of units) calculated by UZ Flow Models and Submodels (BSC 2004 [DIRS 169861]). Note that the three-dimensional UZ flow model accounts for the influence of evapotranspiration in the soil zone on net infiltration flux at Yucca Mountain by virtue of the fact that it is addressed in the net infiltration-flux distribution applied at the top of the three-dimensional UZ flow model. A relative humidity of 100 percent is applied at the atmosphere boundary at the top of the MSTHM to ensure that the PTn-to-TSw percolation flux is neither significantly diminished nor increased by virtue of gas-phase moisture flux at the top of the MSTHM. To verify that the PTn-to-TSw percolation flux is neither significantly diminished nor increased, the ambient present-day percolation flux above the repository horizon was compared to the PTn-to-TSw percolation flux, which is imposed at the upper boundary in the LDTH submodels (Section 6.2.6). It was found that the differences between the imposed PTn-to-TSw percolation flux at the upper boundary and the percolation flux above the repository horizon never exceed $3.61 \times 10^{-4} \mathrm{~mm} / \mathrm{yr}$ for the mean infiltration-flux case. For example, the percolation flux above the repository is $3.11 \times 10^{-5} \mathrm{~mm} / \mathrm{yr}$ greater than the imposed PTn-to-TSw percolation flux for the LDTH submodel location with the lowest present-day PTn-to-TSw percolation flux; because this difference is only 0.01 percent of the PTn-to-TSw percolation flux, which is $0.23 \mathrm{~mm} / \mathrm{yr}$, it is insignificant. The percolation flux above the repository is $3.61 \times 10^{-4} \mathrm{~mm} / \mathrm{yr}$ greater than the imposed PTn-to-TSw percolation flux for the LDTH submodel location with the highest present-day PTn-to-TSw percolation flux; because this difference is only 0.003 percent of the PTn-to-TSw percolation flux, which is $13.8 \mathrm{~mm} / \mathrm{yr}$, it is insignificant. Note that these small differences are positive; that is to say that imposing a relative humidity of 100 percent at the ground surface slightly increases the moisture flux above the repository horizon (by the very small quantities given above) compared to the imposed liquid-phase flux at the top of the LDTH submodel.

Confirmation Status: Because this assumption is justified, it does not require further confirmation.

Use in the Model: This assumption affects all LDTH submodels, and is used in Sections 6.2, 6.3, 6.4, 7.4, and 7.5.

\subsubsection{Ambient Percolation Flux above Repository Horizon}

Assumption: The ambient percolation-flux distribution above the repository horizon is assumed to be unaffected by mountain-scale repository-heat-driven thermal-hydrologic effects until it reaches the boiling condensation zones surrounding the emplacement drifts. Moreover, between 
the base of the PTn UZ model layers and the repository horizon, ambient percolation flux is assumed to be one-dimensional vertically downward with no lateral diversion caused by layering or heterogeneity in the hydrologic-property distributions. Therefore, the percolation-flux distribution above the repository horizon is taken to be the percolation-flux distribution from the PTn to the upper TSw UZ model layer unit (also called the PTn-to-TSw percolation flux) that is predicted by UZ Flow Models and Submodels (BSC 2004 [DIRS 169861]).

Rationale: The influence of subboiling evaporation has an insignificant effect on the magnitude or direction of liquid-phase flux. Moreover, the LDTH submodels already account for the influence of subboiling evaporation within the confines of the two-dimensional LDTH-submodel geometry. Fracturing within the sequence of UZ model layer units between the PTn and the repository horizon is dense and ubiquitous (BSC 2004 [DIRS 169857]), which is not conducive to laterally diverting gravity-driven ambient percolation; thus, percolation within this interval is vertically downward. The denseness of the fracture spacing is evident in the data on fracture frequency (DTN: LB0205REVUZPRP.001 [DIRS 159525]). As is discussed in Section 6.1 of Calibrated Properties Model (BSC 2004 [DIRS 169857]), heterogeneity of hydrologic properties (including fracture spacing) is treated as a function of geologic layering; thus, any one geologic layer has homogeneous properties throughout the grid derived from UZ Flow Models and Submodels (BSC 2004 [DIRS 169861]), as well as throughout the MSTHM.

Confirmation Status: Because this assumption is justified, it does not require further confirmation.

Use in the Model: Section 6.2.6.6 describes the use of the PTn-to-TSw percolation flux in the MSTHM LDTH submodels. This assumption is used in Sections 6.2, 6.3, and 7.5.

\subsubsection{Barometric Pressure Fluctuations at the Ground Surface}

Assumption: Barometric (i.e., gas-phase) pressure fluctuations at the ground surface above the repository are assumed to be insignificant. Consequently, the gas-phase pressure at the ground surface is held constant (i.e., does not fluctuate with time) in all thermal-hydrologic models.

Rationale: The magnitude of gas-phase pressure fluctuations resulting from barometric pumping is small compared to the gas-phase pressure gradients resulting from (1) forced convective cooling of emplacement drifts during the preclosure ventilation period and (2) repository-heatdriven boiling during the postclosure period. Moreover, barometric pumping is not a significant contributor to the removal of water vapor from emplacement drifts and the adjoining host rock, compared to the effect of drift ventilation during the preclosure period and the effect of boiling during the postclosure period.

Confirmation Status: Because this assumption is justified, it does not require further confirmation.

Use in the Model: This assumption is used in Sections 6.3, 6.4, 7.3, 7.4, and 7.5. 


\subsubsection{Timing of Climate Change Influence on Percolation Flux above Repository}

Assumption: For representing percolation flux above the repository, the transition from present-day to monsoonal climate is assumed to occur 600 years after emplacement and the transition from monsoonal to glacial transition climate is assumed to occur 2,000 years after emplacement.

Rationale: Section 6.6.1 and Table 6-1 of Future Climate Analysis (BSC 2004 [DIRS 170002]) give a range of duration for the transition from the present day to the monsoonal climate of 400 to 600 years, and a range of duration for the transition from the monsoonal to the glacial transition climate of 900 to 1,400 years. Thus, the minimum times for the timing of the climate transitions are 400 and 1,300 years, respectively. The maximum times for the timing of the climate transitions are 600 and 2,000 years, which is what is assumed in this report, as well as in all other thermal-hydrologic models supporting TSPA-LA, such as Mountain-Scale Coupled Processes (TH/THC/THM) Models (BSC 2004 [DIRS 169866] and Drift-Scale Coupled Processes (DST and TH Seepage) Models (BSC 2004 [DIRS 170338]). Because peak repository temperatures are predicted to occur within 15 to 20 years after closure (Section 6.3.2), the timing of the first climate transition (400 to 600 years) has no effect on peak temperatures. Because the majority of waste package locations in the repository are predicted to cool down below boiling (at the drift wall) prior to 1,300 years (Figure 6.3-52 and Table 6.3-37), the timing of the second climate transition (1,300 to 2,000 years) will have an insignificant effect on the majority of the waste package locations in the repository. The only locations potentially affected by this assumption are those in regions of low percolation flux, close to the center of the repository. Even for those situations, the influence of this assumption is not expected to be significant, compared to the influences of host-rock thermal conductivity uncertainty and percolation-flux uncertainty.

Confirmation Status: Because this assumption is justified, it does not require further confirmation.

Use in the Model: This assumption is used in Sections 6.3 and 7.5.

\subsubsection{Water Table Rise}

Assumption: The influence of water table rise, which results from future (wetter) climates, is assumed to have an insignificant effect on thermal-hydrologic conditions in the emplacement drifts and adjacent host rock. Thus, the influence of water table rise is assumed to have an insignificant effect on temperature and relative humidity in the emplacement drifts.

Rationale: A rise in the water table of 100 to $120 \mathrm{~m}$ for the glacial-transition climate is predicted in Section 6.6.3 of UZ Flow Models and Submodels (BSC 2004 [DIRS 169861]). This change in water table elevation is small compared to the average distance between the repository horizon and the water table, which is on the order of $300 \mathrm{~m}$. With regards to the thermal-hydrologic response in the repository, the primary potential influence of this change is to cause a small increase in liquid-phase saturation in the lower 100 to $120 \mathrm{~m}$ of the unsaturated zone, causing a small change in the thermal conductivity in that vertical interval. Heat flow in that vertical interval, which is dominated by thermal conduction, will experience an insignificant change as a 
result of this small increase in liquid-phase saturation, causing an insignificant change in predicted repository temperatures. The other potential influence of water table rise is to increase the relative humidity in the host rock under ambient conditions. Because ambient relative humidity is already close to unity under the present-day climate, any increases resulting from a future (wetter) climate will be insignificant.

Confirmation Status: Because this assumption is justified, it does not require further confirmation.

Use in the Model: This assumption is used in Sections 6.3, 6.4, and 7.5.

\subsection{HEAT FLOW PROCESSES}

\subsubsection{Mountain-Scale Heat Flow}

Assumption: The following assumption only applies to the SMT submodels (Section 6.2.5). For the SMT submodels, differences in temperature that arise as a result of proximity to the repository edges are assumed to be governed by thermal conduction in the rock. This assumption is equivalent to saying that convective heat transfer mechanisms (notably, buoyant gas-phase convection and the heat-pipe effect) have an insignificant influence on lateral mountain-scale heat flow at Yucca Mountain. This assumption tends to preserve temperature differences that arise as a result of differences in proximity to the repository edges. This assumption allows mountain-scale heat flow to be represented using thermal-conduction models. This assumption is applied to the SMT submodels.

Rationale: The bulk permeability $k_{\mathrm{b}}$ of much of the unsaturated zone is much less than the threshold $k_{\mathrm{b}}$ value at which buoyant gas-phase convection begins to significantly influence heat flow (Buscheck and Nitao 1994 [DIRS 130561]); therefore, heat flow is dominated by heat conduction. Mountain-Scale Coupled Processes (TH/THC/THM) (BSC 2004 [DIRS 169866], Section 6.3) documents a three-dimensional mountain-scale thermal-hydrologic model that is similar in scale to the SMT submodel in the MSTHM. The vertical temperature profile of the mountain-scale thermal-hydrologic model (Figure 6.3.1-6 of BSC 2004 [DIRS 169866]) is indicative of conduction-dominated heat flow. Moreover, the primary role of the SMT submodel in the MSTHM methodology is to predict the rate at which the edge-cooling effect propagates inward from the repository edges toward the repository center. Mountain-scale buoyant gas-phase convection has an insignificant effect on controlling the rate at which the edge-cooling effect propagates in toward the center of the repository. This assumption is also justified because it tends to preserve temperature differences that arise as a result of differences in proximity to the repository edges.

Confirmation Status: Because this assumption is justified, it does not require further confirmation.

Use in the Model: This assumption is used in the MSTHM calculations in Sections 6.3, 6.4, and 7.5. 


\subsubsection{Drift-Scale Heat Flow}

Assumption: The following assumption only applies to the DDT submodels. For the DDT submodels, the influence of repository-scale thermal conductivity variability and drift-scale buoyant gas-phase convection within the host rock are assumed to have an insignificant influence on waste package-to-waste package temperature deviations along the emplacement drifts. This assumption allows the MSTHM methodology to rely upon only one set of DDT submodel calculations conducted at a single LDTH-SDT submodel location.

Rationale: During the preclosure period, thermal radiation between the waste package and drift wall controls the longitudinal temperature deviations along the emplacement drift in the DDT submodels. During the postclosure period, thermal radiation between the waste package and drip shield and between the drip shield and drift wall control the temperature deviations along the emplacement drift. Heat flow in the longitudinal direction in the host rock (both by conduction and convection) plays a much smaller role in attenuating waste package-to-waste package temperature variations along the drift wall than does thermal radiation in the drift (Hardin 1998 [DIRS 100350], Section 3.7.5.4).

The DDT submodel is only used for two purposes: (1) calculating the temperature difference between the waste package and drip shield, and (2) calculating the longitudinal temperature variations along the drift axis. Neither of these quantities is significantly influenced by the thermal conductivity in the host rock (or in any of the other UZ model layers). Therefore, it is not necessary to run the DDT submodels at multiple locations because the only potential benefit would be to capture the influence of the local thermal conductivity values, which is relatively unimportant with regards to the two quantities that the DDT submodel is required to predict. Convective heat transfer driven by thermal-hydrologic behavior in the host rock has little effect on longitudinal temperature variation in the drift. In other words, thermal-hydrologic processes in the host rock do not contribute significantly to equalization of axial temperature variations in the drift. Therefore, the conduction-only DDT submodel adequately represents longitudinal temperature deviations in the drifts or adjoining host rock (relative to line-average-heat-source conditions). This assumption is also justified because it tends to preserve temperature variability along the drifts.

Drift-scale latent heat and convective heat transport by seeping water are included in the MSTHM methodology because these effects are fully addressed by the LDTH submodels. Section 6.2.1 outlines the MSTHM approach and the thermal-hydrologic processes accounted for by the model.

Confirmation Status: Because this assumption is justified, it does not require further confirmation.

Use in the Model: This assumption is used in the MSTHM calculations in Sections 6.2.8, 6.3, 6.4, and 7.5. 


\subsubsection{Waste Package Emplacement}

Assumption: The assumption is made that the entire waste package inventory of the repository is emplaced at the same time.

Rationale: The heat-generation-rate-versus-time tables (BSC 2004 [DIRS 167369]) for the entire waste package inventory, as well as for the individual waste package types (BSC 2004 [DIRS 167754]), were effectively developed for a single time of emplacement and therefore, do not represent how the heat-generation-rate tables may vary for the inventory and respective waste package types during the 23-year emplacement period. Therefore, this assumption is consistent with the heat-generation-rate-versus-time tables. The 50-year ventilation duration is the minimum time that any waste package location in the repository will experience ventilation. For a sequential emplacement repository analysis with all waste packages assumed to be the same years out of reactor at the time of emplacement, packages emplaced at the beginning of the 23-year period would experience higher peak temperatures relative to those emplaced at the end of the emplacement period. The assumption that all waste packages are emplaced simultaneously at 50 years results in an analysis that bounds peak temperatures compared to an analysis that accounts for sequential emplacement after a minimum 50-year ventilation period. Thus, this assumption requires a minimum 50-year ventilation period in order to bound peak temperatures.

Confirmation Status: Because this assumption is justified, it does not require further confirmation.

Use in the Model: This assumption is applied to all submodels, and is used in the MSTHM calculations in Sections 6.3, 6.4, and 7.5.

\subsection{MATERIAL PROPERTIES}

\subsubsection{Hydrologic Properties}

\subsubsection{Permeability of the Drip Shield and Waste Package for the MSTHM}

Assumption: The drip shield and waste packages are assumed to be impermeable to liquid-phase flow for the entire duration of the MSTHM simulation. The drip-shield is not impermeable to gas-phase flow.

Rationale: Because it is not the purpose of the MSTHM model to predict the consequences of seepage onto (or through) the waste package, the assumption that the drip-shield and waste package are impermeable to liquid-phase flow does not affect the intended purpose of the MSTHM. The drip shield will have joints where the drip-shield segments meet. The joints between the drip-shield segments allow the transport (by advection and binary diffusion) of gas (air plus water vapor) between the inside and outside of the drip shield. Note that the assumption of the continuity of $P_{\mathrm{v}}$ across the drip shield is also used in In-Drift Natural Convection and Condensation (BSC 2004 [DIRS 164327], Section 5.3.6), the calculations from which are used as bounding cases only for TSPA-LA. 
Confirmation Status: Because this assumption is justified, it does not require further confirmation.

Use in the Model: This assumption is used in Section 6.3.

\subsubsection{Hydrologic Properties of the Intragranular Porosity in the Invert Materials}

Assumption: The hydrologic properties of the intragranular porosity of the invert materials are assumed to be the same as those of the matrix of the host rock. Because the Tptpll (tsw35) unit is the host-rock unit for 75.1 percent of the repository area as modeled in the MSTHM (Table 6.3-3), it is assumed that matrix properties of the tsw35 unit are applicable to the crushed-tuff invert for the entire repository area. The ratio of the surface area of the crushed tuff grains divided by the connection length into the grains is assumed to be $1 \times 10^{5}$ for the intragranular porosity. These assumptions are used in all LDTH submodels (Sections 6.2.6 and 6.3).

Rationale: The invert is composed of crushed-tuff gravel, which is derived from the host rock. The dual-permeability model (DKM) is applied to represent flow in crushed-tuff gravel, with flow within the tuff grains (called the intragranular porosity) corresponding to flow in the matrix continuum of the DKM, and flow around the tuff grains (called the intergranular porosity) corresponding to flow in the fracture continuum of the DKM. Therefore, it is reasonable to assume that the hydrologic properties of the intragranular porosity are the same as those for the matrix of the predominant host-rock unit. Applying the intact host-rock matrix properties to the intragranular porosity of the invert implies that there is no reduction in the rewetting rate of the invert by virtue of limited rock-to-grain or grain-to-grain contact area. The limited contact area will not prevent the crushed-tuff grains from eventually attaining capillary-pressure equilibrium with the adjoining host rock. When the drift wall has rewet to ambient liquid-phase saturation, relative humidity at the drift wall will be very high ( $>99$ percent). The crushed-tuff grains in the invert cannot remain dry when exposed to a high-relative humidity environment. However, the limited rock-to-grain (and grain-to-grain) contact area may impede the rate at which rewetting allows the invert to attain capillary-pressure equilibrium with the adjoining host rock. Thus, there is some uncertainty about the time required for the invert to rewet to ambient liquid-phase saturation conditions. The fact that the crushed-tuff invert could be derived from material from the other three host-rock units (Tptpll, Tptpmn, and Tptpln) is also a source of uncertainty with respect to the time required for the invert to rewet to ambient liquid-phase saturation conditions.

The assumption that the ratio of the surface area of crushed-tuff grains divided by the connection length into the grains is equal to $1 \times 10^{5}$ affects the disequilibrium between the intergranular porosity and the intergranular porosity. For 3-mm-diameter grains and 45 percent intergranular porosity that apply to the invert (Table 4.1-2), this ratio is $7.33 \times 10^{5}$. Using a value of $1 \times 10^{5}$, which is a ratio smaller than $7.33 \times 10^{5}$, is appropriate because it is unlikely that all of the grain surfaces will be wetted as water drains through the intergranular porosity.

Section 6.3-11 discusses a sensitivity analysis of thermal-hydrological conditions in the invert to hydrologic properties of the intragranular porosity of the crushed-tuff gravel. Figure 6.3-63 plots the liquid-phase saturation for the intragranular porosity and the temperature averaged over the invert. Four different cases are considered, with each case utilizing the matrix properties from each of the respective host-rock units: Tptpul (tsw33), Tptpmn (tsw34), Tptpll (tsw35), and 
Tptpln (tsw36). Invert temperature is insensitive to the hydrologic properties of the intragranular porosity (Figure 6.3-63b). Liquid-phase saturation is also insensitive to hydrologic properties of the intragranular porosity (Figure 6.3-63a). Figure 6.3-64 plots temperature and relative humidity at different locations in the drift, including the host rock at crown of the drift and below the invert, and at the top and bottom of the invert beneath the drip shield for crushed-tuff gravel derived from each of the host-rock units, respectively. Both temperature and relative humidity at those locations are insensitive to hydrologic properties of the intragranular porosity. This lack of sensitivity justifies this assumption.

Confirmation Status: Because these assumptions are considered to be adequate, they do not require further confirmation.

Use in the Model: This assumption is used in Section 6.3.

\subsubsection{Hydrologic Properties for the Concrete Invert in the Drift Scale Test}

Assumption: The hydrologic properties for the Tptpmn (tsw34) host rock in the Drift Scale Test (DST) are assumed to be applicable to the concrete invert in the Heated Drift of the DST.

Rationale: Hydrologic properties for the concrete invert were not measured and are not readily available from the literature. Because the invert comprises such a small volume relative to the thermally perturbed volume of the host rock in the DST, this assumption is justified.

Confirmation Status: Because this assumption is justified, it does not require further confirmation.

Use in the Model: This assumption is used in Section 7.4.

\subsubsection{Fracture Permeability of the Host Rock in the Wing-Heater Array of the Drift Scale Test}

Assumption: The boreholes that contain the wing heaters in the Drift Scale Test (DST) are not explicitly represented in the DST thermal-hydrologic models. The boreholes, which intersect the Heated Drift are not sealed and provide preferential conduits for gas flow. It is assumed that increasing the fracture permeability by a factor of 1,000, in the lateral (horizontal) direction, for the wing-heater array (Figures 7.4-2 and 7.4-16) adequately represents the influence of the wing-heater boreholes as preferential conduits to gas flow. Note that the lateral direction is parallel to the axis of the wing-heater boreholes. Note also that for the interval between the wing heaters and the Heated Drift the fracture permeability is also increased by a factor of 1,000 in the lateral (horizontal) direction.

Rationale: The wing-heater arrays consist of 50 open boreholes (with 25 boreholes located on each side of the Heated Drift) that function as preferential conduits (in the lateral direction) to gas flow within the boiling and dryout zones of the DST. The effect on thermal-hydrologic behavior is to provide a means of relieving gas-phase pressure buildup in the center of the boiling zone and to allow some of the water vapor generated in that zone to enter the Heated Drift and exit through the leaky bulkhead. A thousand-fold increase in lateral fracture permeability effectively eliminates resistance to gas flow from the wing-heater array into the 
Heated Drift. In Section 7.4, it is found that modeled temperatures and liquid-phase saturations are weakly dependent on whether water vapor leaves the DST through the bulkhead. It should be noted that much of this water vapor entered in the Heated Drift from the wing-heater array. Therefore, the assumption for fracture permeability in the wing-heater array is justified in light of its small impact on modeled thermal-hydrologic behavior in the DST.

Confirmation Status: Because this assumption is justified, it does not require further confirmation.

Use in the Model: This assumption is used in Section 7.4.

\subsubsection{Permeability of the Bulkhead in the Drift Scale Test}

Assumption: The bulkhead in the Drift Scale Test (DST) is assumed to be extremely permeable, with a permeability one-tenth that of the open drift. This assumption is made because the bulkhead is not sealed and because it contains several openings between the hot and cold side of the bulkhead.

Rationale: Drift-Scale Coupled Processes (DST and TH Seepage) Models (BSC 2004 [DIRS 170338], Section 7.4.4) discusses how the bulkhead functions as an open boundary for gas-phase flow. In Section 7.4, it is found that modeled temperatures and liquid-phase saturations are weakly dependent on whether water vapor leaves the DST through the bulkhead. Therefore, the assumption for the permeability of the bulkhead is justified in light of its small impact on modeled thermal-hydrologic behavior in the DST.

Confirmation Status: Because this assumption is justified, it does not require further confirmation.

Use in the Model: This assumption is used in Section 7.4.

\subsubsection{Permeability of the Bulkhead in the Three-Dimensional Monolithic Thermal-Hydrologic Model Used in the MSTHM Validation Test Case}

Assumption: The nested-mesh three-dimensional monolithic thermal-hydrologic model, which is called the D/LMTH model and used in the MSTHM validation test case (Section 7.5), has a leaky bulkhead located just beyond the last waste package at the edge of the drift. It is assumed that this bulkhead is leaky, with the same bulk permeability as that of the adjoining fractured rock mass.

Rationale: The influence of an extremely leaky bulkhead on the DST thermal-hydrologic model results is investigated in Section 7.4, where it is found that modeled temperatures and liquid-phase saturations are weakly dependent on whether water vapor leaves the DST through the bulkhead. Therefore, the permeability of the bulkhead in the DST has a small impact on modeled thermal-hydrologic behavior in the DST. Because the thermally perturbed (boiling) zone of the DST is in closer proximity to the bulkhead than it will be for most of the interval of most emplacement drifts in the repository, the impact of the bulkhead on predicted thermal-hydrologic conditions along emplacement drifts will be no greater than that demonstrated for the DST in Section 7.4. Therefore, the assumed permeability of the bulkhead 
in the three-dimensional monolithic D/LMTH model does not play a significant role in thermal-hydrologic behavior predicted in that model; thus, this assumption is justified.

Confirmation Status: Because this assumption is justified, it does not require further confirmation.

Use in the Model: This assumption is used in Section 7.5.

\subsubsection{Pseudo Permeability of the Gas-Filled Cavities Inside the Emplacement Drifts in the LDTH Submodels}

Assumption: The gas-filled cavity between the drip shield and drift wall is represented as a porous media with 100 percent porosity and a very large value of pseudo permeability of $1.0 \times 10^{-8} \mathrm{~m}^{2}$.

Rationale: The value for permeability $\left(1.0 \times 10^{-8} \mathrm{~m}^{2}\right)$ for the gas-filled cavity in the emplacement drifts is much larger than the bulk permeability (which is nearly the same as the fracture permeability in Table IV-4) of the four host-rock units $\left(7.8 \times 10^{-13}, 3.3 \times 10^{-13}\right.$, $9.1 \times 10^{-13}$, and $1.3 \times 10^{-12} \mathrm{~m}^{2}$ for the tsw33, tsw34, tsw35, and tsw36, respectively). The effective permeability is large enough so that it does not impede advective gas-phase flow within the emplacement drifts. Because the LDTH submodel, in principle, allows natural convection to occur within the drift cavity, a possible concern is whether the in-drift convective cooling effect, together with the use of the effective thermal conductivity for the drift cavity, will over-account for the magnitude of in-drift convective cooling. Section 6.3.10 discusses a sensitivity analysis of in-drift pseudo permeability. Figure 6.3-62 plots drip-shield temperature and relative humidity for six different values of in-drift pseudo permeability, ranging over six orders of magnitude. Over this six order of magnitude range, the value of in-drift pseudo permeability has an insignificant influence on in-drift temperature and relative humidity. The range in peak dripshield temperature is $150.9^{\circ} \mathrm{C}$ to $151.1^{\circ} \mathrm{C}$ for these cases. Clearly, there is no over-accounting of convective cooling in the LDTH submodels that support the MSTHM calculations in this report. Therefore, the approach of using an effective thermal conductivity for the drift cavity and a value of pseudo permeability of $1.0 \times 10^{-8} \mathrm{~m}^{2}$ is reasonable and appropriate in the LDTH submodels.

Confirmation Status: Because this assumption is considered to be adequate, it does not require further confirmation.

Use in the Model: This assumption is used in Sections 6.3, 6.4, 7.4, and 7.5.

\subsubsection{Permeability of the Intergranular Porosity of the Invert Materials}

Assumption: The permeability of the intergranular porosity of the crushed-tuff invert is $1.0 \times 10^{-9} \mathrm{~m}^{2}$, which is between the permeability values for the $0.317-\mathrm{mm}$ particle size $\left(1.681 \times 10^{-10} \mathrm{~m}^{2}\right)$ and for the 3-mm particle size $\left(1.511 \times 10^{-8} \mathrm{~m}^{2}\right)$ from Table X-7 of Appendix $\mathrm{X}$.

Rationale: The potential range of values for the permeability of the intergranular porosity of the crushed-tuff invert (Table X-7 of Appendix X) has little effect on thermal-hydrologic conditions 
in the invert for two reasons. The first reason relates to liquid-phase flow. An inspection of the LDTH submodel output related to the MSTHM base-case calculations for the TSPA-LA shows that the intergranular porosity remains dry for all but the initial one-to-two years of the postclosure period. During the first year or two following the end of the ventilation period, boiling and condensation within the invert results in a very small amount of condensate drainage at the base of the invert. After this condensate has drained and the invert has become dry as a result of boiling, the intergranular porosity is completely dry (i.e., 100 percent gas-filled). Therefore, liquid-phase flow in the intergranular porosity does not occur after the brief period of condensate drainage. The second reason relates to gas-phase flow. The value for permeability (of $1.0 \times 10^{-9} \mathrm{~m}^{2}$ ) for the intergranular porosity of the crushed-tuff invert is much larger than the bulk permeability (which is nearly the same as the fracture permeability in Table IV-4) of the four host-rock units $\left(7.8 \times 10^{-13}, 3.3 \times 10^{-13}, 9.1 \times 10^{-13}\right.$, and $1.3 \times 10^{-12} \mathrm{~m}^{2}$ for the tsw33, tsw34, tsw35, and tsw36, respectively). The effective permeability is large enough that it does not impede advective gas-phase flow within the emplacement drifts.

Section 6.3-11 discusses a sensitivity analysis of thermal-hydrological conditions in the invert to hydrologic properties of the intergranular porosity of the crushed-tuff gravel. Figure 6.3-65 plots the liquid-phase saturation for the intragranular porosity, temperature, and relative humidity at the top of the invert beneath the drip shield for five different sets of hydrologic properties for the intergranular porosity. Temperature, liquid-phase saturation, and relative humidity are all insensitive to the hydrologic properties of the intergranular porosity. This lack of sensitivity justifies this assumption.

Confirmation Status: Because this assumption is considered to be adequate, it does not require further confirmation.

Use in the Model: This assumption is used in Section 6.3.

\subsubsection{Tortuosity Factor for Binary Gas-Phase Diffusion}

Assumption: Appropriate values for the tortuosity factor are selected for the matrix and fracture continuum on the basis of the parameter range given by de Marsily (1986 [DIRS 100439], p. 233), which ranges from a value of 0.1 for clays to 0.7 for sands. A value of 0.2 is estimated for the matrix continuum because the pore sizes for the matrix are closer to that of clays than to that of sands. A value of 0.7 is assumed for the fracture continuum because the effective pore sizes for fractures are similar to those of sands.

Rationale: The tortuosity factor is used for determining the binary gas-phase diffusion of air and water vapor. Binary gas-phase diffusion is insignificant to the MSTHM results because its influence is primarily confined to being an insignificant impact on heat flow, compared to the impact of conductive and convective heat flow (Buscheck and Nitao 1994 [DIRS 130561], pp. 15 to 16). Therefore, exact quantification of the tortuosity factor is not required; instead appropriate values are taken from the literature, as discussed above. A value of tortuosity factor of 0.2 is selected for the rock matrix because the pore sizes of the matrix are similar to those of clay, which has a value for tortuosity factor of 0.1 . The tortuosity factor is set to 0.7 for the fractures, which corresponds to the highest value reported by de Marsily (1986 [DIRS 100439]), which corresponds to the value for sand. Binary gas-phase diffusion is further modified for the 
fracture-to-fracture connections by multiplication of the tortuosity factor by the fracture porosity of the bulk rock (Buscheck and Nitao 1994 [DIRS 130561], Equation 8). This operation yields the appropriate value for fracture-to-fracture interconnection area. Similarly, binary gas-phase diffusion is modified for the matrix-to-matrix connections by multiplication of the tortuosity factor by the matrix porosity of the bulk rock. This operation yields the appropriate value for the matrix-to-matrix interconnection area.

Confirmation Status: Because this assumption is considered to be adequate, it does not require further confirmation.

Use in the Model: This assumption is used in Sections 6.3, 7.3, 7.4, and 7.5.

\subsubsection{Permeability of Host Rock at Emplacement Drift Wall}

Assumption: The permeability of the host rock at the drift-wall surface is assumed to be unaffected by the presence of Bernold-style surface sheets, which are described by Michel (1999 [DIRS 163054]), Ground Control for Emplacement Drifts for LA (BSC 2004 [DIRS 170292]), and Longevity of Emplacement Drift Ground Support Materials for LA (BSC 2003 [DIRS 165425]). Thus, it is assumed that the drift wall can be treated as an uncovered surface, with unimpeded gas- and liquid-phase flow between the host rock and drift cavity.

Rationale: Bernold-style surface sheets (Michel 1999 [DIRS 163054]) are bolted tightly to the drift wall to provide ground control for emplacement drifts, as described in Ground Control for Emplacement Drifts for LA (BSC 2004 [DIRS 170292]) and Longevity of Emplacement Drift Ground Support Materials for LA (BSC 2003 [DIRS 165425]). The Bernold-style surface sheets are perforated and corrugated to provide air circulation with the drift cavity (BSC 2004 [DIRS 170292], Section 6.3.1.2; BSC 2003 [DIRS 165425], Section 6.3.2). Therefore, it is reasonable to assume that the Bernold surface sheets have an insignificant influence on the permeability of the host rock at the emplacement drift-wall surface.

Confirmation Status: Because this assumption is justified, it does not require further confirmation.

Use in the Model: This assumption is used in Sections 6.3, 6.4, and 7.5.

\subsubsection{Thermal Properties}

\subsubsection{Thermal Conductivity in SDT, DDT, and SMT Submodels}

Assumption: The thermal conductivity data is provided for both dry and wet conditions. The conduction-only submodels (SDT, DDT, and SMT submodels in Section 6.2) cannot explicitly represent the influence of liquid-phase saturation on thermal conductivity. Since the rock is generally much closer to being fully saturated than being completely dry, the wet value of thermal conductivity are applied to all conduction-only submodels. This assumption has an insignificant effect on the results of the MSTHM.

Rationale: This assumption must be judged in light of how the MSTHM combines the results of four families of submodels: SDT, DDT, SMT, and LDTH. The MSTHM methodology (see 
Figure 1-1, Table 1-1, Table 1-2, Table 1-3, Section 6.2.4, and Appendix IX) accounts for the influence of thermal-hydrologic processes (including liquid-phase saturation changes) on the temperature distribution around and inside the emplacement drifts. Thus the MSTHM fully accounts for the significant liquid-saturation dependence of thermal conductivity as it is affected by rock dryout and condensation buildup (if any). The LDTH submodels also represent the influence of the ambient liquid-phase saturation distribution, which is consistent with that of the three-dimensional UZ flow model, on drift-scale heat flow. It is also important to note that the zone for which the dry thermal conductivity is applicable is confined to a narrow cylindrically shaped dryout zone with a radius generally no greater than $10 \mathrm{~m}$ for the mean infiltration-flux case (Figure 6.3-4b). The primary influence of the narrow zone of decreased thermal conductivity is on temperature buildup in the immediate vicinity of the emplacement drifts; this influence is fully captured in the finely gridded LDTH submodels of the MSTHM, which account for the liquid-phase saturation dependence of thermal conductivity. While significantly affecting the drift-scale temperature gradients around the drifts, this narrow region of reduced thermal conductivity has a no influence on mountain-scale heat flow. Because the volume of reduced thermal conductivity around the drifts is so small, compared to the scale at which mountain-scale heat flow occurs, it has an insignificant influence on mountain-scale heat flow. For the purposes of the SDT, SMT, and DDT submodels, the approximation is made that ambient liquid-phase saturation is 100 percent. The difference in thermal conductivity between a liquid-phase saturation of 90 percent (which is prevalent in the host-rock units) and 100 percent is small in comparison to parametric uncertainty of thermal conductivity (Section 6.3.2.2). Moreover, the LDTH submodel utilizes the ambient liquid-phase saturation values in determining thermal conductivity; thus, for drift-scale heat flow the MSTHM fully accounts for the ambient liquid-phase saturation conditions.

As for the validity of this assumption in the DDT submodel, it should be noted that the DDT submodel is only used for two purposes: (1) calculating the temperature difference between the waste package and drip shield and (2) calculating the longitudinal temperature variations along the drift axis. Neither of these quantities is influenced by whether wet or dry thermal conductivity is applied in the host rock.

Section 7.5 describes the comparison between the MSTHM and a corresponding three-dimensional monolithic thermal-hydrologic model of the same three-drift system. The good agreement between the MSTHM and the corresponding monolithic thermal-hydrologic model attests to the validity of this approach, as well as justifying the appropriateness of the assumption of the thermal conductivity used in the SDT, SMT, and DDT submodels.

Confirmation Status: Because this assumption is justified, it does not require further confirmation.

Use in the Model: This assumption is used in the MSTHM calculations in Sections 6.3 and 7.5.

\subsubsection{SMT Submodel Saturated-Zone Thermal Properties}

Assumption: The SMT submodel (Section 6.2.5) is the only submodel that explicitly represents the saturated zone. An assumption is made that the saturated zone is composed of a material with average thermal properties, including thermal conductivity, mass density, and specific heat 
capacity. The averaging is accomplished by determining area-weighting factors for each of the model layers from the UZ model that occur at the water table, which is the base of the grid from UZ Flow Models and Submodels (BSC 2004 [DIRS 169861]).

Rationale: The range in thermal properties of the units occurring at the water table is relatively narrow, and because the saturated zone is far enough away from the repository horizon (on the order of $300 \mathrm{~m}$ ), the results of the MSTHM are insensitive to the averaging scheme selected for the thermal properties of the saturated zone.

Confirmation Status: Because the output of the MSTHM is not sensitive to this assumption, the assumption is justified and does not require further confirmation.

Use in the Model: This assumption is used in the MSTHM calculations in Sections 6.3 and 7.5.

\subsubsection{Thermal Conductivity and Mass Density for the Dual-Permeability Model}

Assumption: The dual-permeability model (DKM) is comprises a fracture and matrix continuum. It is necessary to apportion the bulk thermal property values to the fracture and matrix continua. The values of thermal conductivity $K_{\text {th }}$ and mass density $\rho$ are apportioned to the fracture and matrix from the values for the bulk rock mass, based on the fracture porosity $\phi_{\text {frac }}$ by the following relationships:

$$
\begin{aligned}
& K_{\text {th,frac }}=K_{\text {th,bulk }} \times\left(\phi_{\text {frac }}\right) \\
& K_{\text {th,mat }}=K_{\text {th,bulk }} \times\left(1-\phi_{\text {frac }}\right) \\
& \rho_{\text {frac }}=\rho_{\text {bulk }} \times\left(\phi_{\text {frac }}\right) \\
& \rho_{\text {mat }}=\rho_{\text {bulk }} \times\left(1-\phi_{\text {frac }}\right)
\end{aligned}
$$

The apportioning of fracture and matrix values of $K_{\text {th }}$ and $\rho$ is shown in Table IV-3b in Appendix IV. This assumption is used in the MSTHM calculations in Sections 6.3 and 7.5.

Rationale: This approach conserves the total value of thermal conductivity and the total value of mass density. Therefore, the total conductive heat flow is the same as a single continuum with the same total value of thermal conductivity. Similarly, during the transient (heat-up) period, the correct mass density of the rock mass is honored. This method is only used in the LDTH submodels.

Confirmation Status: Because this assumption is justified, it does not require further confirmation.

Use in the Model: This assumption is used in Sections 6.2.6, 6.3, and 7.5. 


\subsubsection{Thermal Properties of the Lumped Drip-Shield/Waste Package Heat Source in the LDTH Submodels}

Assumption: The drip shield and waste package are represented as a lumped monolithic heat source in the LDTH submodels with thermal property values that are an average of the respective values for the waste package and drip shield. The mass density, specific heat, and thermal conductivity of the lumped monolithic heat source are a mass-weighted average of the respective waste package and drip-shield values.

Rationale: The purpose of the LDTH submodel within the context of the MSTHM (Section 6.2.4) does not require that the LDTH submodel provide a description of the temperature or hydrological effects inside the drip shield; thus, this assumption is justified.

Confirmation Status: Because this assumption is justified, it does not require further confirmation.

Use in the Model: This assumption is used in the MSTHM calculations in Sections 6.2.6, 6.3, and 7.5.

\subsubsection{Thermal Properties for the Concrete Invert in the Drift Scale Test}

Assumption: The thermal properties for the Tptpmn (tsw34) host rock in the Drift Scale Test (DST) are assumed to be applicable to the concrete invert in the Heated Drift of the DST. It is noted that the TSPA-LA design does not include a concrete liner.

Rationale: Because the invert comprises such a small volume relative to the thermally perturbed volume of the host rock in the DST (Figures 7.4-2 and 7.4-16) this assumption has an insignificant effect on thermal-hydrologic behavior in the DST; therefore, this assumption is justified. Moreover, the comparison between observed and simulated behavior in the DST is limited to the host rock, wherein the assumption about invert properties have an insignificant effect.

Confirmation Status: Because this assumption is justified, it does not require further confirmation.

Use in the Model: This assumption is used in Section 7.4.

\subsubsection{Thermal Conductivity and Thickness of the Bulkhead in the Drift Scale Test}

Assumption: The bulkhead in the Drift Scale Test is assumed to have a very large value of thermal conductivity $\left(5.5 \mathrm{~W} / \mathrm{m}^{\circ} \mathrm{C}\right)$ and a thickness of $0.12 \mathrm{~m}$; thus, the thermal conductance of the bulkhead is assumed to be approximately $46 \mathrm{~W} / \mathrm{m}^{2 \circ} \mathrm{C}$.

Rationale: As described in Drift-Scale Test As-Built Report (CRWMS M\&O 1998 [DIRS 111115]), the bulkhead in the Drift Scale Test (DST) consists of a complex mix of steel, glass, and fiberglass. The thermal conductance of the bulkhead is assumed to be very large because portions of the bulkhead (such as the glass window) are not insulated and because the bulkhead is penetrated by a large array of metal conduit containing instrument cables and power lines. 
Moreover, during the DST, the fiberglass insulation became extremely wet as a result of the condensation of water vapor that was passing through the bulkhead. The total effect of these conditions results in a large value of thermal conductance for the bulkhead that is very difficult to quantify. In Section 7.4, it is found that modeled temperatures and liquid-phase saturations are weakly dependent on whether water vapor leaves the DST through the bulkhead. In Section 7.4, it is also found that the heat loss through the bulkhead resulting from the convection of water vapor is much larger than the heat loss resulting from thermal conduction. Therefore, the assumption for the thermal conductance of the bulkhead is justified in light of its small impact on modeled thermal-hydrologic behavior in the DST.

Confirmation Status: Because this assumption is justified, it does not require further confirmation.

Use in the Model: This assumption is used in Section 7.4.

\subsubsection{Emissivity of Emplacement Drift Wall}

Assumption: The emissivity at the drift-wall surface is assumed to be unaffected by the presence of Bernold-style surface sheets, which are described by Michel (1999 [DIRS 163054]), Ground Control for Emplacement Drifts for LA (BSC 2004 [DIRS 170292]), and Longevity of Emplacement Drift Ground Support Materials for LA (BSC 2003 [DIRS 165425]). Thus, it is assumed that the drift wall can be treated as an uncovered surface, with an emissivity value of 0.9, which is the value for rock given by Incropera and DeWitt (1996 [DIRS 108184], Table A.11).

Rationale: Bernold-style surface sheets (Michel 1999 [DIRS 163054]) are rock bolted tightly to the drift wall to provide ground control for emplacement drifts, as described in Ground Control for Emplacement Drifts for LA (BSC 2004 [DIRS 170292]) and Longevity of Emplacement Drift Ground Support Materials for LA (BSC 2003 [DIRS 165425]). Because the Bernold surface sheets are in good mechanical contact with the surrounding rock, they are in reasonable thermal contact with the host rock as well. Thus, with respect to heat transfer in the drift, the influence of the Bernold surface sheets is to modify the value of emissivity at the drift-wall surface, compared to the value for exposed rock, as is described in Appendix VI. The Bernold-style surface sheets are a Type 316 stainless steel, which has an emissivity range of 0.52 to 0.66 (McAdams 1954 [DIRS 161435]). The value of effective emissivity $\varepsilon_{\text {eff }}$ between the drip shield and drift-wall surface is affected by this change in emissivity at the drift wall surface. For the emissivity range of 0.52 to 0.66 for Type 316 stainless steel, the value of $\varepsilon_{\text {eff }}$ between the drip shield and drift wall is reduced by 6.8 to 15.5 percent, compared to value of $\varepsilon_{\text {eff }}$ used in the MSTHM predictions used in TSPA-LA (Appendix VI). Because thermal radiation depends on the difference of the respective temperatures each raised to the fourth power (Eq. VI-4), the influence of a 6.8 to 15.5 percent reduction in the value of $\varepsilon_{\text {eff }}$ is small. When peak temperatures occur at the drift wall and drip shield (about 20 years after closure), reducing $\varepsilon_{\text {eff }}$ by 6.8 to 15.5 percent results in a drip-shield temperature increase of 0.9 to $2.3^{\circ} \mathrm{C}$, with an increase of $1.5^{\circ} \mathrm{C}$ for the average case (Appendix VI). The influence of reducing $\varepsilon_{\text {eff }}$ by 6.8 to 15.5 percent on temperature decreases during cooldown after temperatures have peaked. These changes in temperature are insignificant compared to the influence of host-rock thermal conductivity uncertainty and percolation-flux 
uncertainty. Therefore, it is reasonable to assume the Bernold surface sheets have an insignificant influence on heat transfer within the drift.

Confirmation Status: Because this assumption is justified, it does not require further confirmation.

Use in the Model: This assumption is used in Sections 6.3 and 6.4.

\subsection{WASTE PACKAGE MODELING}

\subsubsection{Average Waste Package Diameter}

Assumption: The waste package outer diameter is 1.644 meters, which is the diameter of the 21-PWR AP waste package (Table 4.1-2). This value is taken as the average diameter for the waste packages emplaced over the entire repository. This information is used only in the DDT submodels (Section 6.2.8).

Rationale: This assumption only influences two aspects of the MSTHM: (1) the temperature difference between the waste package and drip shield and (2) the waste package-to-waste package variation of this temperature difference. Note that this temperature difference depends on the waste package heat output. The 21-PWR AP waste packages, 21-PWR CR waste packages, and 44-BWR AP waste packages, comprising the majority of waste packages with an appreciable heat output, have diameters of $1.644,1.644$, and 1.674 meters, respectively (Table 4.1-2) which are very close to the value of 1.644 meters in the DDT submodels. Table 11 of D\&E /PA/C IED Typical Waste Package Components Assembly (2) (BSC 2004 [DIRS 169472]) gives the nominal quantities of the various waste package types for the TSPA-LA design, including 4,299 21-PWR AP waste packages, 95 21-PWR CR waste packages, 2,831 44-BWR AP waste packages, and 11,184 total waste packages. Thus, these waste packages comprise a large portion (64.6 percent) of the waste package inventory in the TSPA-LA design. Waste packages that deviate more from a value of 1.644 meters, such as the 24-BWR 1.318-m-diameter AP waste packages and the 5-DHLW/DOE-SNF 2.110-m-diameter co-disposal waste packages (Table 4.1-2), generate much less heat and also comprise a relatively small portion of the overall waste package inventory (BSC 2004 [DIRS 169472], Table 11). Therefore, 1.644 meters is very close to the actual diameter for the majority of waste packages in the overall inventory and is also very close to the diameter of the waste packages generating an appreciable temperature difference between the waste package and drip shield.

Confirmation Status: On the basis of the rationale given above, this assumption is justified and does not require further confirmation.

Use in the Model: This assumption is used in Sections 6.2.8, 6.3, and 7.5.

\subsubsection{Waste Package Sequence along Drifts}

Assumption: The waste package sequence given in Figure 6.2-2 is assumed to be applicable over all emplacement drifts. Thus, this sequence is assumed to be representative of waste package-towaste package heat output variability throughout the entire repository. The use of this sequence is equivalent to assuming that defense high-level waste (DHLW) waste packages, which produce 
much less heat than commercial spent nuclear fuel (CSNF) waste packages, will not be grouped together. In other words, DHLW waste packages will always be placed adjacent to CSNF waste packages.

Rationale: Table 5.4-1 lists the nominal number of waste packages for the repository inventory. Table 5.4-1 also lists the waste packages of the assumed sequence in the MSTHM calculations. The waste packages in the assumed sequence in the MSTHM cover 86.7 percent of the total inventory. Moreover, the percentages of each of the respective waste package types in the MSTHM are similar to the corresponding percentages in the repository inventory. Therefore, the waste package sequence assumed in all of the MSTHM calculations is representative of the inventory of waste packages in the repository.

Table 5.4-1. Summary of Waste Package Types in the Repository Inventory and in the MSTHM

\begin{tabular}{|c|c|c|c|c|}
\hline Waste Package Type & $\begin{array}{c}\text { Nominal } \\
\text { Number in } \\
\text { Inventory }^{\mathbf{a}}\end{array}$ & $\begin{array}{c}\text { Nominal } \\
\text { Percentage } \\
\text { of Inventory }\end{array}$ & $\begin{array}{c}\text { Number } \\
\text { Represented } \\
\text { in } \text { MSTHM }^{\mathbf{b}}\end{array}$ & $\begin{array}{c}\text { Percentage of } \\
\text { Waste Packages } \\
\text { Represented in } \\
\text { MSTHM }\end{array}$ \\
\hline 21-PWR AP & 4299 & $38.4 \%$ & 2.5 & $35.7 \%$ \\
\hline 44-BWR AP & 2831 & $25.4 \%$ & 2.5 & $35.7 \%$ \\
\hline 5 DHLWIDOE SNF LONG & 1406 & $12.6 \%$ & 1 & $14.3 \%$ \\
\hline $\begin{array}{c}\text { Total Number of 21-PWR AP, 44-BWR AP, } \\
\text { 5 DHLW/DOE SNF LONG, 5 DHLW/DOE } \\
\text { SNF-SHORT }\end{array}$ & 1147 & $10.3 \%$ & 1 & $14.3 \%$ \\
\hline Total Inventory & 11,184 & $86.7 \%$ & 7 & $100 \%$ \\
\hline
\end{tabular}

a Source: BSC 2004 [DIRS 169472 ], Table 11.

b See Figure 6.2-2 and Table 6.3-13.

Confirmation Status: On the basis of the rationale given above, this assumption is justified and does not require further confirmation.

Use in the Model: This assumption is used in Sections 6.2.8 and 6.3.

\subsection{RELATIVE HUMIDITY IN EMPLACEMENT DRIFTS}

Assumption: For the purposes of calculating relative humidity $(R H)$ on the drip shield and on the waste package the assumption is made that the partial pressure of water vapor $P_{\mathrm{v}}$ in the drift is uniform and the same as that on the drift-wall surface at a given location. This is the equivalent of saying that the absolute humidity in the drift is the same as that on the drift wall.

Rationale: This assumption recognizes that the gas in the drift (which consists of air and water vapor) is well mixed as a result turbulent mixing (driven by buoyant gas-phase convection) and binary vapor diffusion of air and water. This mixing causes the absolute humidity to be uniform inside the emplacement drift at a given location along the drift. This assumption is validated in Section 7.5 by virtue of the good agreement between the MSTHM predictions of relative humidity in the drift and those of the corresponding three-dimensional monolithic thermal-hydrologic model, which does not make this assumption about relative humidity in emplacement drifts. 
Confirmation Status: Because this assumption is justified, it does not require further confirmation.

Use in the Model: This assumption is used in Sections 6.2.4, 6.3, 6.4, and 7.5.

\subsection{CONDENSATE DRAINAGE AROUND EMPLACEMENT DRIFTS}

Assumption: Condensate that drains around the boiling zone surrounding an individual drift is assumed not to cross the vertical midplanes, which lie between that drift and the adjoining emplacement drifts (note that these vertical midplanes are $40.5 \mathrm{~m}$ away (which is half the 81-m drift spacing) from the centerline of each drift). This assumption is implied with the use of the two-dimensional LDTH submodels (Section 6.2.6), which have adiabatic, no-fluid-flow boundaries on either side of the LDTH submodels.

Rationale: The boiling zones surrounding each emplacement drift are relatively narrow. As discussed in Section 6.3.1.1, the maximum lateral extent of boiling relative to the centerline of the emplacement drift is always much smaller than the half-drift spacing for the TSPA-LA design. Therefore, the majority of the host rock between emplacement drifts always remains below the boiling point, thereby enabling condensate and percolation flux to continuously drain between emplacement drifts. Fracturing within the sequence of UZ model layer units at the repository horizon is dense and ubiquitous (BSC 2004 [DIRS 169857]), which is not conducive to laterally diverting condensate drainage; thus, condensate drainage is extremely unlikely to cross the vertical midplane separating emplacement drifts.

Confirmation Status: Because this assumption is justified, it does not require further confirmation.

Use in the Model: This assumption is used in Sections 6.2.8, 6.3 and 7.5.

\subsection{GAS- AND LIQUID-PHASE FLOW IN THE LONGITUDINAL DIRECTION ALONG EMPLACEMENT DRIFTS (THE COLD-TRAP EFFECT)}

Assumption: Gas- and liquid-phase flow in the longitudinal direction along drifts is assumed to have an insignificant effect on all MSTHM predictions. This is equivalent to saying that the cold-trap effect does not play a significant role in the evolution of the temperature, relative humidity, and liquid-phase saturation histories within the emplacement drifts, as well as in the adjoining host rock. At the repository scale, the cold-trap effect involves the flow of water vapor from the hotter intervals of emplacement drifts (typically closer to the center of the repository) to cooler intervals (typically located closer to the edges of the repository) where this water vapor condenses. In principal, the cold-trap effect results in the transport of heat and moisture from hotter to cooler intervals of the emplacement drift. For all MSTHM predictions, it is assumed that heat and moisture transport in the longitudinal direction along emplacement drifts do not significantly affect thermal-hydrologic conditions along (and adjacent to) emplacement drifts. Thus, it is assumed that heat flow along the drifts is dominated by thermal radiation and that within the invert there is no capillary wicking of moisture in the longitudinal direction.

Rationale: This assumption is tested in Section 7.5, where the MSTHM is compared against a corresponding three-dimensional monolithic thermal-hydrologic model in which gas- and 
liquid-phase flow (i.e., the cold-trap effect) is allowed to occur along the emplacement drift, subject to limitations of porous media models. For the waste packages at the center of the repository, the MSTHM calculations are found to agree closely with those of the three-dimensional monolithic thermal-hydrologic model, with the differences between the two models being much smaller than the range of thermal-hydrologic conditions arising from parametric uncertainty. For the waste packages at the outer edge of the repository, the differences between the MSTHM predictions and those of the corresponding three-dimensional monolithic thermal-hydrologic model are larger than at the center of the repository. These differences, however, are still smaller than the range of thermal-hydrologic conditions arising from parametric uncertainty. The results of the validation study in Section 7.5 demonstrate that the MSTHM methodology (which includes the assumption of insignificant gas- and liquid-phase flow in the longitudinal direction along drifts) is validated for its intended purpose of predicting thermal-hydrologic conditions in emplacement drifts and in the adjoining host rock. Thus, this assumption is also justified.

Confirmation Status: Because this assumption is justified, it does not require further confirmation.

Use in the Model: This assumption is used in Sections 6.3 and 6.4, and is tested in Section 7.5.

\subsection{PROPERTIES OF HOST-ROCK RUBBLE FOR LOW-PROBABILITY-SEISMIC COLLAPSED-DRIFT SCENARIO}

\subsubsection{Bulk Density of Host-Rock Rubble}

In setting up the LDTH and DDT submodels (Sections 6.2.10 and 6.2.11) to represent the lowprobability-seismic collapsed-drift scenario, a value of $1850 \mathrm{~kg} / \mathrm{m}^{3}$ was used for the rubble bulk density in the LDTH submodels (Table 6.2-3), while a rubble bulk density of $1608 \mathrm{~kg} / \mathrm{m}^{3}$ was used in the DDT submodels (Table 6.2-4). The bulk density of the intact Tptpll (tsw35) host rock is $1980 \mathrm{~kg} / \mathrm{m}^{3}$ (Tables IV-3b and IV-3c of Appendix IV). Using a bulk factor of 0.231 (Section 6.2.10.2) and a bulk density of $1980 \mathrm{~kg} / \mathrm{m}^{3}$ for the intact host rock, results in a rubble bulk density of $1608 \mathrm{~kg} / \mathrm{m}^{3}$. To assess whether this small difference in bulk density is significant, the LDTH submodel was rerun for the case where the rubble bulk density is 1608 $\mathrm{kg} / \mathrm{m}^{3}$, so that it could be compared to the case where the rubble bulk density is $1850 \mathrm{~kg} / \mathrm{m}^{3}$. As is evident in Figure 6.3-58, which plots the temperature and relative humidity at the crown of the drip shield for the low- $K_{\mathrm{th}}$ rubble, the influence of rubble bulk density is insignificant over the range of 1608 to $1850 \mathrm{~kg} / \mathrm{m}^{3}$. Therefore the following assumption can be made.

Assumption: The use of a bulk density value of $1850 \mathrm{~kg} / \mathrm{m}^{3}$ for the host-rock rubble in the LDTH submodels for the low-probability-seismic collapsed-drift scenario gives the same MSTHM results that would have been produced if a bulk density value of $1608 \mathrm{~kg} / \mathrm{m}^{3}$ had been used in the LDTH submodels for this scenario.

Rationale: Because steady-state heat flow conditions are quickly established within the rubble, temperature and relative humidity in the drift (Figure 6.3-58) are insensitive to the range in bulk rubble density $\left(1680\right.$ to $1850 \mathrm{~kg} / \mathrm{m}^{3}$ ) considered in Section 6.3.7. Therefore, the MSTHM 
calculations for the low-probability-seismic collapsed-drift scenario are insensitive to the choice of rubble bulk density $\left(1850 \mathrm{~kg} / \mathrm{m}^{3}\right.$ versus $\left.1608 \mathrm{~kg} / \mathrm{m}^{3}\right)$.

Confirmation Status: Based on the rationale given above, this assumption is justified and does not require further confirmation.

Use in the Model: This assumption is used in Section 6.3.7. 


\section{INTENTIONALLY LEFT BLANK}




\section{MODEL DISCUSSION}

This section of the model report describes the multiscale thermohydrologic model (MSTHM), including a discussion about its conceptual framework and how the MSTHM methodology implements that framework. The MSTHM is implemented in several input-data-processing and submodel-building steps (Figures 6-1 and 6-2). The four major steps are (1) submodel input-file preparation, (2) execution of the four submodel families with the use of the NUFT v3.0s code (Section 3.1.1), (3) execution of MSTHAC v7.0 (Section 3.1.5), and (4) binning and postprocessing (i.e., graphics preparation) of the output from MSTHAC v7.0. The overall organization of Section 6 is as follows:

- Section 6.1 presents the scientific framework for Yucca Mountain thermohydrology, beginning with an overview of the ambient hydrological system. This is followed by a discussion of radioactive-decay-heat-driven thermal-hydrologic behavior within the repository emplacement drifts and in the adjoining repository host rock.

- Section 6.2 describes the MSTHM approach. Before discussing the details of the MSTHM approach, this section presents the governing equations that are solved by the NUFT v3.0s and v3.0.1s codes to represent the coupled flow of water, water vapor, air, and heat at the drift scale and to represent heat flow at the mountain scale. This is followed by a detailed description of the four families of MSTHM submodels, which are run with the NUFT code, and the manner in which the Multiscale Thermohydrologic Model Abstraction Code (MSTHAC v7.0) integrates the results from those four families of submodels.

- Section 6.3 presents the results of the MSTHM for the lower-bound, mean, and upper-bound infiltration-flux cases with mean host-rock thermal conductivity; for the lower-bound infiltration-flux case with low host-rock thermal conductivity; and for the upper-bound infiltration-flux case with high host-rock thermal conductivity. This section also covers the sensitivity analysis of parameter uncertainty.

- Section 6.4 describes a study that compares the results of the MSTHM against those of a corresponding alternative conceptual model.

Before continuing, it is important to distinguish between the MSTHM and the Multiscale Thermohydrologic Abstraction Code (MSTHAC v7.0). The MSTHM is the process-level model itself, which consists of four families of submodel types (Section 6.2.4) that are run using the thermal-hydrologic simulation code NUFT v3.0s (Section 3.1.1) and the software that integrates the results of those submodel families. The integrating software used in this report is MSTHAC v7.0 (Section 3.1.5). There were no supporting and corroborating data or product outputs used in the development of this model.

The MSTHM predictions supporting the TSPA-LA utilize assumptions described in Sections 5.1.1, 5.1.2, 5.1.3, 5.1.4, 5.1.5, 5.2.1, 5.2.2, 5.2.3, 5.3.1.1, 5.3.1.2, 5.3.1.7, 5.3.1.8, 5.3.1.9, 5.3.1.10, 5.3.2.1, 5.3.2.2, 5.3.2.3, 5.3.2.4, 5.3.2.7, 5.4.1, 5.4.2, 5.5, 5.6, 5.7, and 5.8.1. 


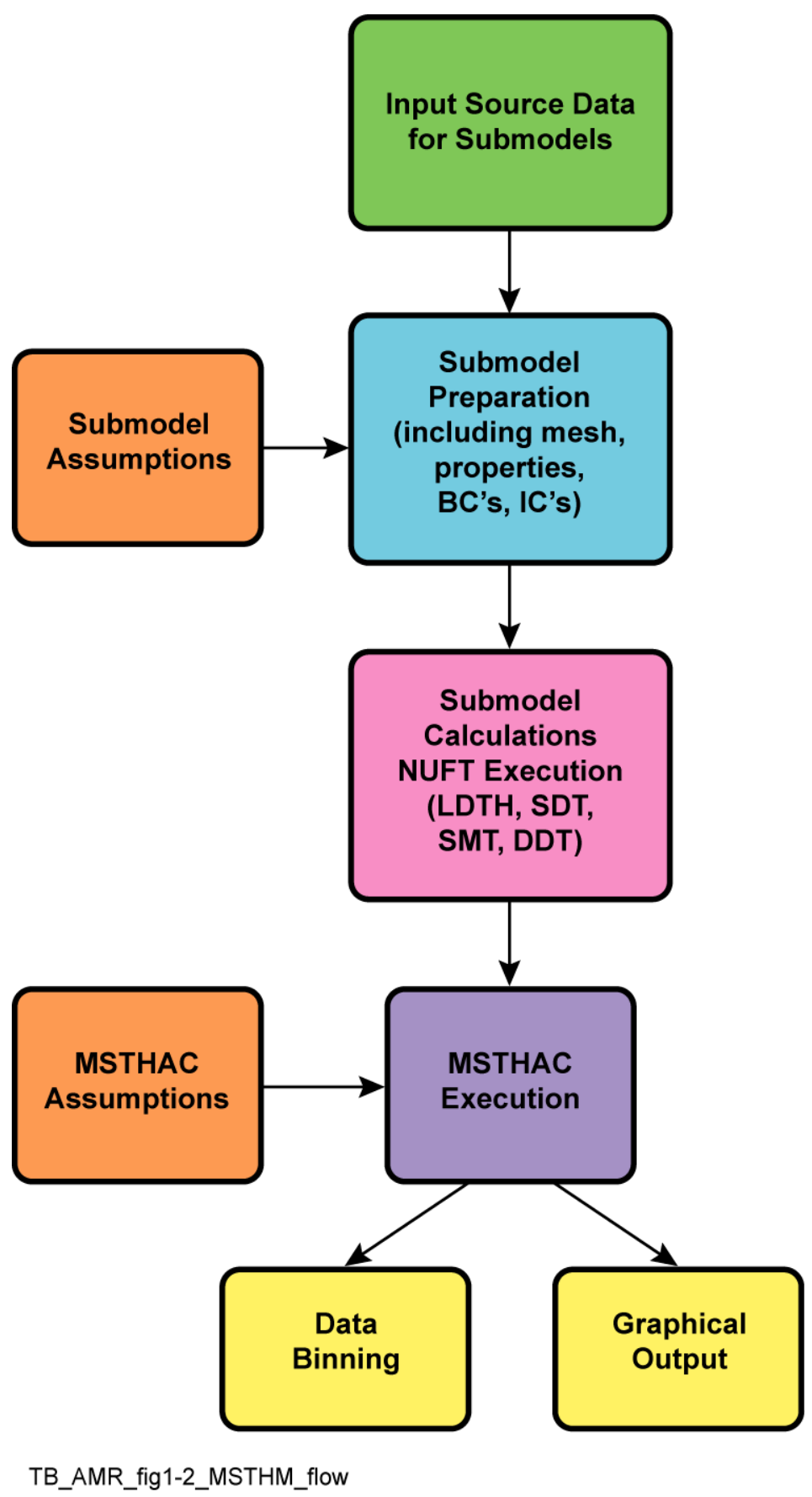

NOTE: $B C=$ boundary conditions; $I C=$ initial conditions.

Figure 6-1. Overall Data Flow Diagram for the MSTHM 


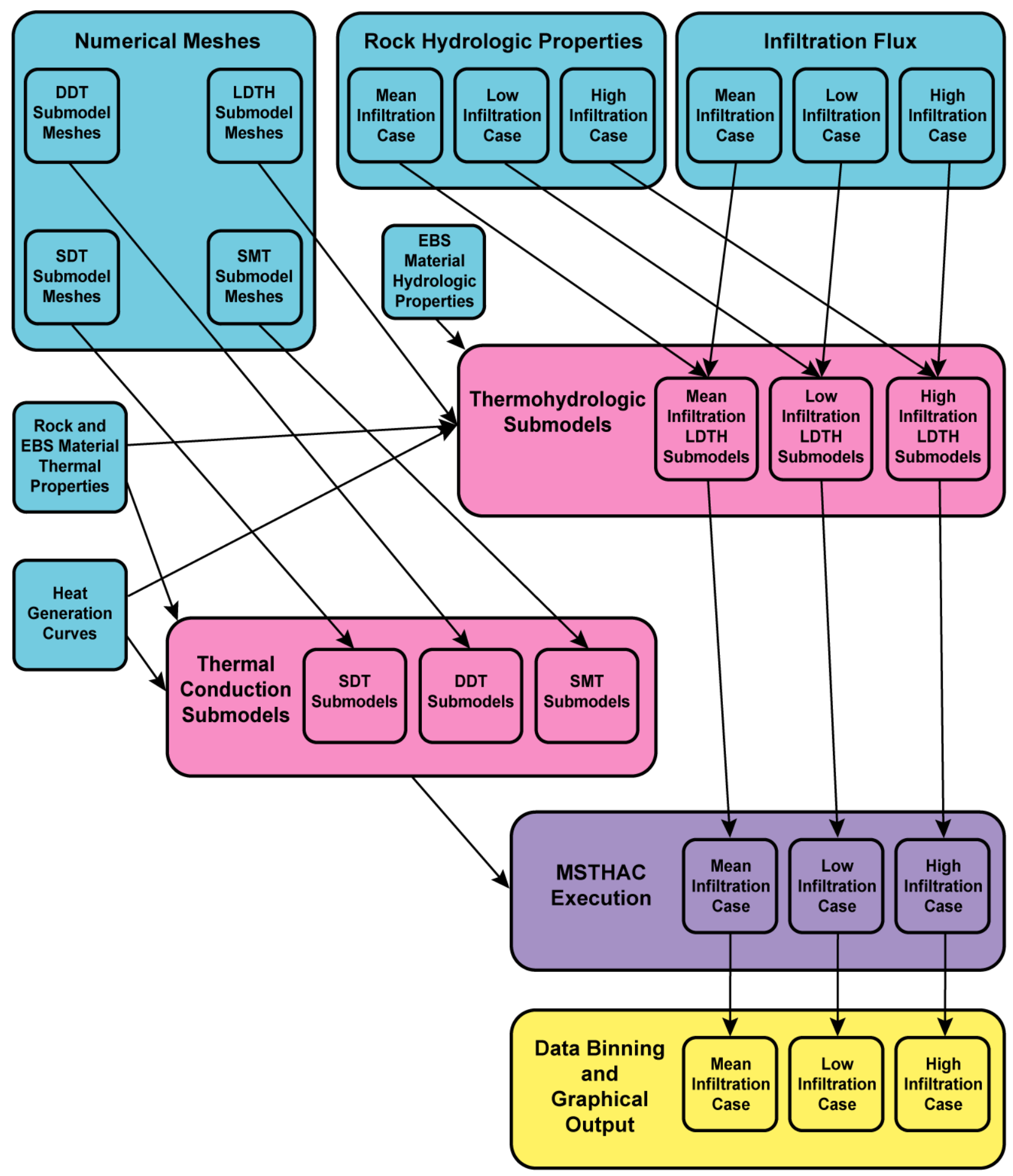

TB_AMR_fig1-3_MSTHM_flow2

Figure 6-2. Relationship Between Input Data and Submodels for Three Infiltration-Flux Cases 


\subsection{YUCCA MOUNTAIN THERMOHYDROLOGY CONCEPTUAL MODEL}

The role of the movement of water and heat within the repository is treated by the study of thermohydrology, which combines the more traditional fields of hydrology and heat transfer. The physical domain that this model report is primarily concerned with is the unsaturated zone of Yucca Mountain that lies above the groundwater table. The geology of Yucca Mountain consists of several sequences of welded and nonwelded volcanic rocks, and the main hydrologic concern is with the movement of liquid water, originating from rainfall and snowmelt (Section 6.1.1). The thermal component of this model is concerned with the movement of liquid water driven by radioactive decay heat from emplaced waste and its effect on temperature and relative humidity (Section 6.1.2). When examining thermal-hydrologic phenomena, there are two distinct regions of concern: (1) the near-field host rock, and (2) within the repository emplacement drifts. The thermal-hydrologic phenomena associated with the host rock primarily involve boiling of water and re-wetting as heating diminishes with time (Section 6.1.3), while the thermal-hydrologic phenomena within the emplacement drift is associated with boiling, evaporation and condensation of water on the waste packages, drip shield, and drift wall (Section 6.1.4). Several factors can influence thermal-hydrologic phenomena, either through the design of the repository (e.g., the average areal-heat-density of the emplaced waste, as discussed in Section 6.1.5), or through the description of the natural system (e.g., percolation flux and thermal conductivity, as discussed in Section 6.1.5).

\subsubsection{Ambient Hydrology and Geology}

Yucca Mountain is composed of several sequences of volcanic tuffs deposited as ash flow sheets about 13 million years ago. Some units are completely devitrified and welded, while others are vitric or partially vitric with various degrees of welding. Some are also zeolitized to varying degrees. In general, the more welded units are more densely fractured. Hydrogeologic units, referred to as UZ-model layers in the grid developed by UZ Flow Models and Submodels (BSC 2004 [DIRS 169861], Section 6.1.1), are defined primarily based on the degree of welding (Montazer and Wilson 1984 [DIRS 100161], p. 8). From the ground surface to the water table, these units are generally referred to as Tiva Canyon welded (TCw), Paintbrush nonwelded (PTn), Topopah Spring welded (TSw), Calico Hills nonwelded (CHn) and Crater Flat (Cfu). More details about the layering in the UZ are found in Table 6-11 of Development of Numerical Grids for UZ Flow and Transport Modeling (BSC 2004 [DIRS 169855]).

Most of the total fluid storage capacity of the welded units at Yucca Mountain is contained in the matrix pores of this rock. The permeability in the rock matrix in these units, however, is low, so fractures are the primary conduits for large-scale flow of water, air, and water vapor in these units. In some of the nonwelded units, fracturing is much less extensive, and the rock matrix is more permeable than in the welded units, causing gas and liquid-phase fluid flow to occur predominantly through the rock matrix.

The climate at Yucca Mountain is arid to semiarid, with infiltration from rainfall and snowmelt. Field data show that water that infiltrates at the ground surface percolates mostly vertically downward to the water table $700 \mathrm{~m}$ beneath the surface, with some degree of lateral diversion and the occasional occurrence of perched or semiperched aquifers (Flint et al. 2001 [DIRS 156351]). Note that under ambient conditions, the relative humidity $(R H)$ in the 
unsaturated zone at the elevation of the repository is very high with relative humidity generally above 99 percent (Buscheck et al. 2002 [DIRS 160749]).

\subsubsection{Incorporating Radioactive Decay Heat}

The repository is located in the unsaturated zone in the TSw hydrostratigraphic unit along a very gently dipping plane, approximately midway between the ground surface and the water table. The repository will accommodate the emplacement of spent nuclear fuel from commercial nuclear power plants and solidified high-level waste. The repository-wide thermal load declines exponentially with time, continuing for tens of thousands of years because of the very long half-life of many of the radionuclides (Figure 6.1-1).

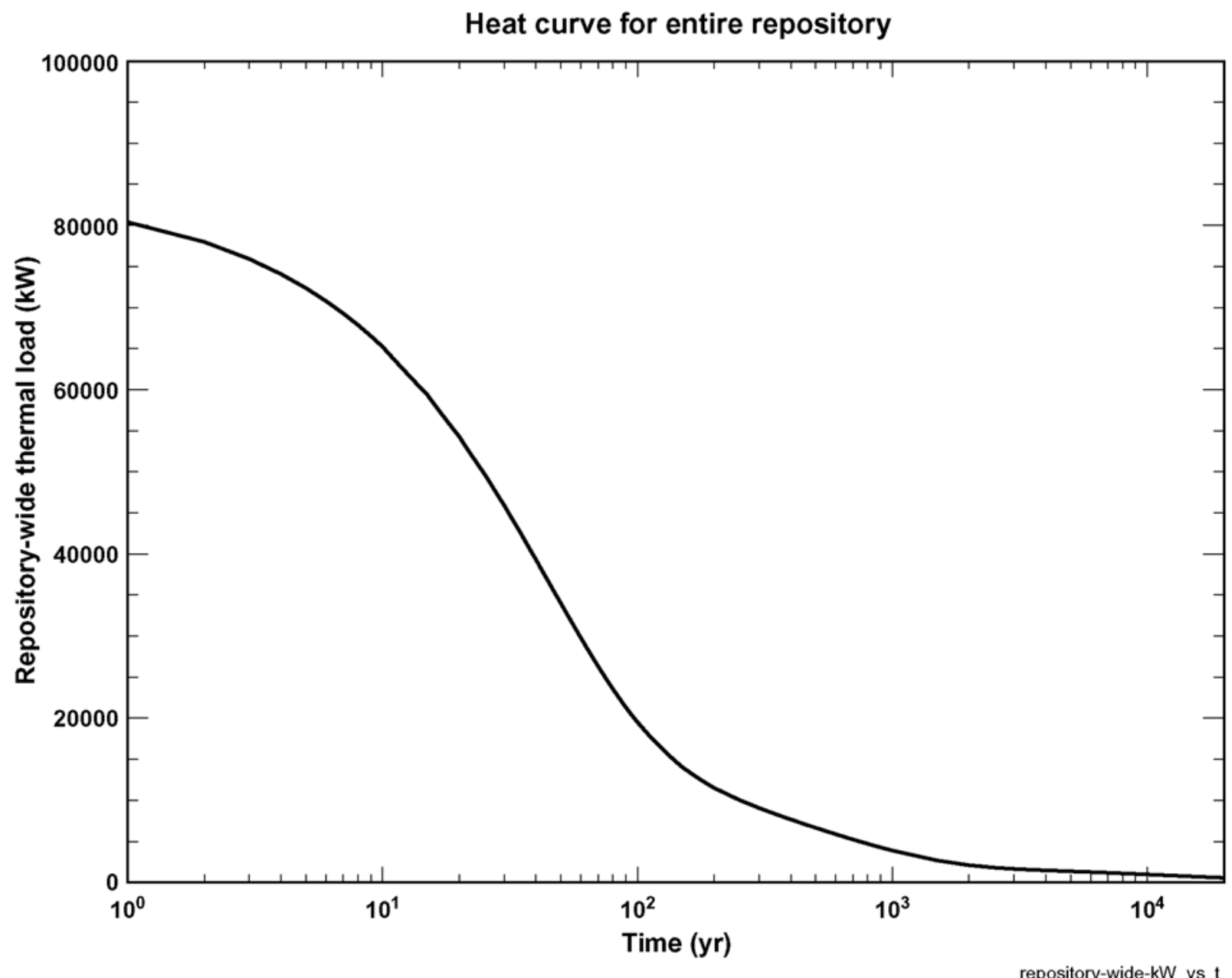

NOTE: The total repository heat load divided by the total length of emplacement drift in the repository $(57.48 \mathrm{~km})$ is equal to the line-averaged heat load. At the time of emplacement $(0 \mathrm{yr})$ the total repository heat load is $83,300 \mathrm{~kW}$, resulting in an initial line-averaged heat load of $1.45 \mathrm{~kW} / \mathrm{m}$. It is important to note that this is a semilog plot. At the time that this plot begins (1 year), the total repository heat load is $80,400 \mathrm{~kW}$. This is the total thermal load represented in the SMT submodel (Section 6.2.5), using the information from BSC 2004 [DIRS 167369], Table 13.

Figure 6.1-1. Repository-Wide Thermal Load Plotted as a Function of Time for the TSPA-LA Design.

After the emplacement of heat-generating nuclear waste, the thermally driven flow of water vapor away from the heat source causes a redistribution of the pore fluids in the rock. Water in 
the matrix pores evaporates, creating zones of rock dryout (with liquid-phase saturation substantially less than ambient values) around the emplacement drifts. This water vapor is driven (primarily in fractures) away from the heat source in the emplacement drifts to where cooler temperatures cause it to condense, forming condensation zones outside of the dryout zones. The reduction in liquid-phase saturation causes a reduction in relative humidity in both the near-field host rock as well as in the emplacement drifts. Heat pipes can result from the countercurrent flow of water vapor and liquid water between the dryout and condensation zones. The magnitude of the liquid flux in a heat pipe can greatly exceed the magnitude of ambient liquid-phase fluxes. As the heat pulse decays, the system gradually rewets, returning to ambient (humid) preheating conditions.

\subsubsection{Thermohydrology in the Repository Host Rock}

In the host rock, local thermal-hydrologic behavior is dominated by whether a location is inside or outside of the zone of boiling temperatures, $96^{\circ} \mathrm{C}$ (Buscheck et al. 2002 [DIRS 160749]) at the elevation of the repository horizon at Yucca Mountain approximately 1,100 $\mathrm{m}$ above mean sea level. Although evaporation, vapor flow (away from the heat source), and condensation occur at below-boiling temperatures, the thermally driven vaporization rates and vapor fluxes in the repository horizon are generally not great enough to result in significant dryout (and relative humidity reduction) in the rock unless temperatures are well above the boiling point.

The boiling zone evolves with time. Because most of the decay heat is removed with the ventilation air, temperatures are not high enough to allow boiling to occur during the preclosure (ventilation) period. However, because the ventilation air has a much lower relative humidity than ambient conditions in the host rock, some dryout will occur during the preclosure (ventilation) period. At the onset of the postclosure period when ventilation stops, a dryout zone caused by boiling-to-above-boiling temperatures forms in the rock immediately encircling each individual emplacement drift. Within this dryout zone, vaporization prevents liquid-phase flow. Moreover, capillary diversion will continue to divert liquid flow away from the drift opening, even after temperatures have dropped below the boiling point. As thermal output wanes, the dryout zones shrink, and the extent of dryout eventually retreats back to the drift wall (Section 6.2.2.1 of BSC 2004 [DIRS 170338]). Dryout zones around adjacent emplacement drifts never coalesce; they always remain distinct and separate.

Whether or not the boiling zones around adjacent drifts coalesce is important because it affects condensate drainage between drifts. If the repository (thermal) design does not result in coalescence of boiling zones, condensate drains continuously between the emplacement drifts. As discussed in Section 6.3.1.1, the maximum lateral extent of boiling relative to the centerline of the emplacement drift is always much smaller than the half-drift spacing for the TSPA-LA repository (thermal) design. Therefore, much of the host rock between emplacement drifts always remains below the boiling point, enabling condensate and percolation flux to continuously drain between emplacement drifts. Accordingly, the "cap" of accumulated condensate above the emplacement drifts is of very limited spatial extent. Variation in the spatial extent and duration of the boiling zone along the drift axis may also be important. Nonuniformity in boiling conditions along the drift axis (resulting from waste package-to-waste package variability in heat output) causes longitudinal variability in the radial extent and duration of boiling, and may promote seepage and/or condensation in the vicinity of cooler waste packages. The end-to-end waste package spacing (with 10-cm gaps separating waste packages) 
(Table 4.1-2) used in the TSPA-LA repository design limits this longitudinal variability (Section 6.3.1.2).

\subsubsection{Thermohydrology in Repository Emplacement Drifts}

The TSPA-LA repository design includes 1.6-to 2.1-m-diameter (on average) waste packages constructed of corrosion-resistant materials, which are overlain by upside down, U-shaped, corrosion-resistant metallic barriers called drip shields. Both the waste packages and drip shields are supported on an invert made of granular material on the floor of the drift. The configuration of these engineered components influences thermohydrologic behavior within the emplacement drifts.

Two important factors influence the local thermohydrologic conditions in the emplacement drifts. The first is whether temperature at the drift wall is above the boiling point, which controls the relative humidity in the near-field host rock and the potential for water seeping into the drift. The second is the temperature difference between the waste package and drift wall, which determines the relative humidity on the surfaces of the drip shield and waste package (Figure 6.1-2). Specifically, the temperature difference between the waste package (or drip-shield) surface and the drift wall determines how much lower the relative humidity is on the waste package (or drip-shield) surface, compared to that on the drift wall. Note that the ratio of relative humidity on the waste package to relative humidity on the drift wall for a given temperature difference between these two surfaces decreases as the absolute temperature on the waste package increases during heating. Because of the edge-cooling effect, waste packages located closer to the repository edges cool down more quickly than those located closer to the repository center. Consequently, relative humidity reduction for waste packages located closer to the repository edges can be greater than for those located closer to the repository center.

Thermal-hydrologic behavior in and around emplacement drifts is easily described by three fundamental processes:

1. Heat flow-Occurs within emplacement drifts primarily by thermal radiation, and in the adjoining host rock, primarily by thermal conduction. Host-rock thermal conductivity is the key natural-system parameter determining the magnitude of temperature buildup in the host rock.

2. Host-rock dryout-Is driven by temperature buildup, resulting in evaporation (at the boiling point), which lowers the liquid-phase saturation in the host rock, thereby lowering the relative humidity in the host rock and in the emplacement drifts. The extent of dryout depends on the extent and duration of boiling conditions in the host rock, which depend on the magnitude of temperature buildup.

3. Host-rock rewetting-Primarily occurs as a result of gravity-driven percolation in fractures, with capillary-driven imbibition into the adjoining matrix. The rate of rewetting is controlled by the local percolation flux, except in regions of very low percolation flux (less than approximately $0.1 \mathrm{~mm} / \mathrm{yr}$ ), where modeling analyses show it is controlled by capillary-driven imbibition of water from the surrounding rock into the dryout zone, through the rock matrix. 


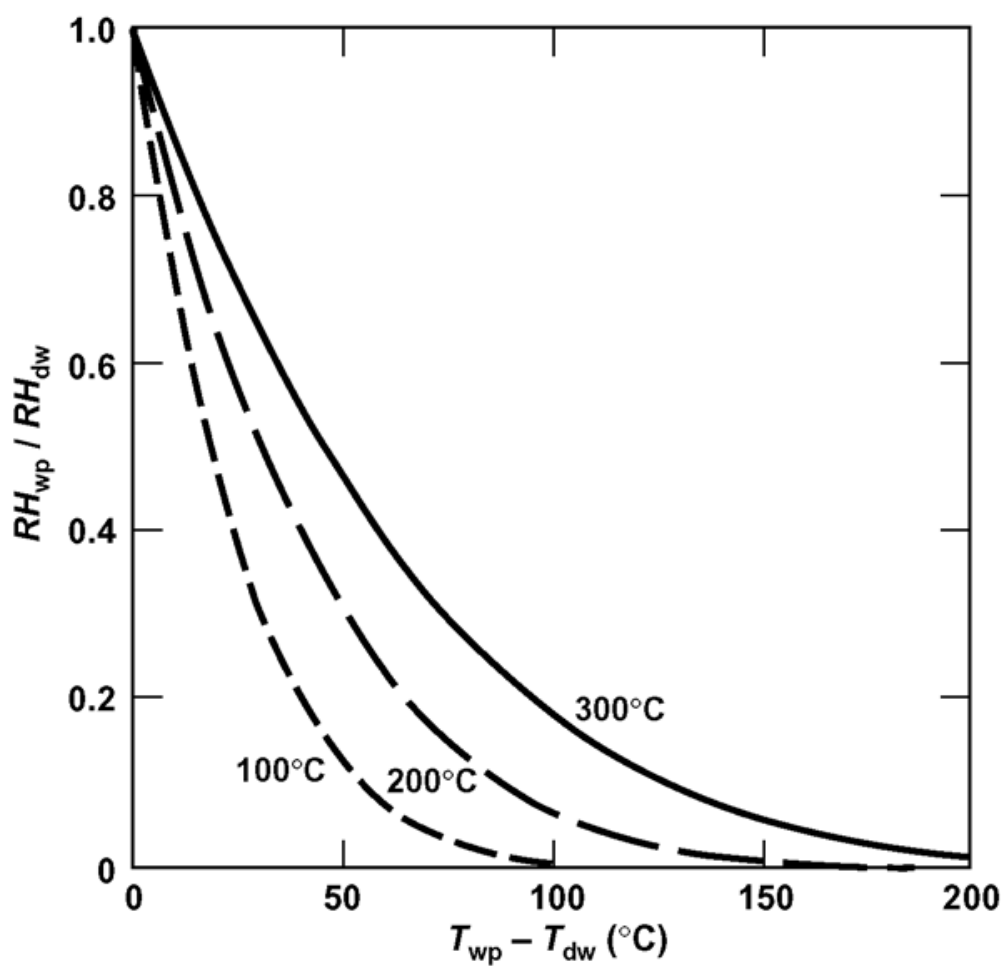

Source: See Table XIII-1.

NOTE: The ratio of relative humidity $(\mathrm{RH})$ on the waste package surface to relative humidity on the drift-wall surface versus the temperature difference between these surfaces is plotted for three different temperatures (taken to be the average of the drift wall and waste package temperatures).

Figure 6.1-2. Ratio of Relative Humidity $(\mathrm{RH})$ on the Waste Package Surface to Relative Humidity on the Drift-Wall Surface

The processes of dryout and rewetting are opposing. Net host-rock dryout, which is the balance between dryout and rewetting, is greatest in regions with a combination of low host-rock thermal conductivity (which facilitates greater temperature buildup) and low local percolation flux (which facilitates slower rewetting). Net host-rock dryout is least in regions with a combination of high host-rock thermal conductivity (which facilitates smaller temperature buildup) and high local percolation flux (which facilitates faster rewetting).

The temperature at the drift wall is controlled by the temperature buildup in the host rock, which is controlled by the local heating conditions and the host-rock thermal conductivity. The relative humidity at the drift wall is controlled by the reduction in liquid-phase saturation that results from boiling and rock dryout. The relative humidity at the drift wall controls relative humidity conditions within the drift; relative humidity in the drift can be no greater than it is at the drift wall. This is true because the absolute humidity within the drift is uniform or nearly so. Heat transfer between engineered components (such as the waste package and drip shield) and the drift wall determines the temperature difference between the waste package and drift wall. This temperature difference controls the reduction in relative humidity on the waste package, relative to that on the drift wall. The drip shield, which lies between the waste package and drift wall, functions as a thermal-radiation shield, which increases this temperature difference. The temperature difference between the waste package and the drift wall is greatest immediately after closure, and slowly decreases with time. 
During the preclosure period (nominally 50 years), waste package heat output starts at the maximum, but the emplacement drifts are ventilated to remove most of the heat. Waste package temperatures are elevated, and some packages may approach $100^{\circ} \mathrm{C}$ immediately after emplacement (subject to control by ventilation). However, the warming of ventilation air ensures that preclosure conditions are dry (e.g., less than $20 \%$ relative humidity), especially where in-drift temperatures are greatest.

At permanent closure, ventilation ceases and the drift-wall rock temperature is initially below boiling, but increases sharply, with temperature peaking within about 20 years. Waste package temperatures follow the evolution of the local drift-wall temperature, but are as much as 10 to $20^{\circ} \mathrm{C}$ warmer at the time when waste package temperatures peak, because of thermal resistance across the drip shield and the in-drift air spaces. This temperature difference approaches zero with time, as the heat output declines. The maximum postclosure temperature of a waste package at any location is determined by the history of heat output, the resistance to dissipation of heat in the host rock, heat transfer from the waste package to the drift wall, and the relationship to other nearby heat sources.

\subsubsection{Design Factors Influencing Thermohydrology}

There are many thermal design parameters that can affect thermohydrologic behavior in an underground nuclear waste repository (Table 6.1-1). These include the average areal-heat-generation density of the waste inventory over the heated repository footprint, and the average lineal-heat-generation density along the drifts (called the line-averaged thermal load). For a given waste inventory, these two parameters constrain the distance between drifts and the size of the required repository footprint.

Other engineering parameters include the placement of the repository horizon relative to the ground surface and the local hydrostratigraphy. The depth of the repository below the ground surface (overburden thickness) translates into the thickness of insulating rock between the repository and the ground surface, which acts like a heat sink. In-drift configuration, including most notably the presence or absence of backfill in the emplacement drifts, and the properties of any in-drift materials are also important to thermohydrology.

Waste package spacing affects the degree of nonuniformity of heating conditions along the axis of the drift. Individual waste packages are cylindrical in shape and 3.5 to $5.1 \mathrm{~m}$ long (Table 4.1-2). If waste packages are spaced far apart from each other along the drift ("point-load" waste package spacing), heating conditions along the drift are less uniform. For waste packages spaced nearly end-to-end ("line-load" waste package spacing), and which is the TSPA-LA repository design, adjacent waste packages couple and share their heat output more effectively, acting more like a uniform line source of heat. Line-load waste package spacing results in more uniform, and persistent rock dryout around the drifts and more efficient condensate shedding between drifts than does point-load waste package spacing with the same overall areal-heat-generation density. Point-load waste package spacing results in less uniform rock dryout around the drifts and less uniform thermohydrologic conditions along the drifts (Buscheck et al. 1999 [DIRS 145972]; Buscheck et al. (2002) [DIRS 160749]). 
Table 6.1-1. Key Thermal Design Factors and Natural System Parameters Influencing Thermal-Hydrologic Conditions in the Emplacement Drifts and Near-Field Host Rock.

\begin{tabular}{|c|c|}
\hline Engineering Design Factors & Natural System Parameters \\
\hline $\begin{array}{l}\text { - Overall areal-heat-generation density of waste } \\
\text { inventory } \\
\text { - Line-averaged thermal load along drifts } \\
\text { - Distance between emplacement drifts } \\
\text { - } \text { Age of spent nuclear fuel at time of emplacement } \\
\text { - Location of repository horizon with respect to } \\
\text { stratigraphy } \\
\text { - Overburden thickness (depth of repository below } \\
\text { - } \text { ground surface) } \\
\text { - } \text { Repository footprint } \\
\text { - Waste package spacing (line load versus point load) } \\
\text { - Duration and heat-removal efficiency of drift } \\
\text { - } \text { In-drift design and materials }\end{array}$ & $\begin{array}{l}\text { - Percolation flux above the repository horizon } \\
\text { - } \quad \text { Thermal conductivity (particularly for host-rock units) } \\
\text { - Bulk rock density and specific heat } \\
\text { - Matrix imbibition } \\
\text { - Capillary wicking in fractures }\end{array}$ \\
\hline
\end{tabular}

\subsubsection{Natural System Factors Influencing Thermohydrology}

Important natural system factors that affect the thermal-hydrologic environment include thermal properties of the repository host rock, hydrologic properties of the host rock, and the magnitude and spatial and temporal distribution of the percolation flux above the repository horizon (Table 6.1-1). Of these factors, the host-rock thermal conductivity and percolation flux above the repository horizon are the most important.

\subsection{THE MULTISCALE THERMOHYDROLOGIC MODELING APPROACH}

\subsubsection{Overview of the MSTHM}

The multiscale thermohydrologic model simulates nonisothermal, multiphase-flow in fractured porous rock of variable liquid-phase saturation and thermal radiation and convection in open cavities. The motivation behind the multiscale modeling approach is the need for a modeling tool that simultaneously accounts for relevant features, events, and processes (FEPs) that occur at a scale of a few tens of centimeters around individual waste packages and emplacement drifts and also at the scale of the mountain. A single numerical model is not used because it requires too large a computational cost to be a viable simulation tool. Note that performance assessment requires the ability to conduct multiple realizations. The multiscale modeling approach was used to model more than 20 different realizations for Total System Performance Assessment-Viability Assessment (TSPA-VA) Analyses Technical Basis Document (CRWMS M\&O 1998 [DIRS 108000], Chapter 3). The approach was also used to model fourteen alternative repository designs during the license application design selection process (Buscheck 1999 [DIRS 130078]) and in six different realizations for Total System Performance Assessment for the Site Recommendation (CRWMS M\&O 2000 [DIRS 153246], Section 3.3.3) and six different realizations for FY 01 Supplemental Science and Performance Analyses, Volume 1: Scientific Bases and Analyses (BSC 2001 [DIRS 155950], Section 5). The following description is a brief overview; a detailed description of the MSTHM is found in Section 6.2.4. 
The multiscale approach breaks the solution of thermal-hydrologic modeling at Yucca Mountain into smaller pieces by varying dimensionality requirements (one-, two-, or three-dimensional) as needed for detail. The approach further subdivides the problem into thermal and thermal-hydrologic submodels. By subdividing the problem into more tractable pieces, the DOE can use efficient thermal-conduction/radiation submodels to address the three-dimensional nature of the heated repository footprint and mountain-scale heat flow as well as the three-dimensional geometric details of the in-drift engineered components, waste package-to-waste package heat-generation variability, and drift-scale heat flow. Two-dimensional thermal-hydrologic models, which are more efficient than three-dimensional thermal-hydrologic models, are used to model all thermal-hydrologic parameters in detail within the emplacement drifts and in the adjoining host rock.

Thermohydrologic behavior is directly simulated for an "average" waste package using a two-dimensional drift-scale cross section for a variety of areal-heat-generation densities at numerous locations throughout the repository footprint. In these simulations, the flow of liquid and gas (water vapor and air) through variably saturated fractured porous media is represented with a dual-permeability model of flow interaction between the fractures and rock matrix. This model accounts for two-phase behavior (i.e., evaporation, boiling, and condensation). Open drifts are modeled as porous media with very high permeability and porosity. The influence of buoyant gas-phase (natural) convection in the drift on heat flow is approximated with the use of an effective thermal conductivity for the gas-filled drift cavity that is based on a correlation (Francis et al. 2003 [DIRS 164602], Table 6). The model represents the processes of thermal conduction and convection in rock, and thermal conduction, convection, and radiation in the open cavities in the emplacement drifts.

The primary purpose of the multiscale thermohydrologic model is to predict the evolution of thermal-hydrologic conditions within emplacement drifts. To accomplish this it is necessary to predict thermal-hydrologic conditions in the adjoining host rock. As discussed in Section 6.1.4, thermal-hydrologic behavior in and around emplacement drifts can be simply broken down to three fundamental processes: (1) heat flow, (2) host-rock dryout, and (3) host-rock rewetting. A key principle utilized by the multiscale thermal-hydrologic model approach is that mountain-scale heat flow is dominated by thermal conduction. A second key principle is that heat flow within the drift is dominated by thermal radiation and that the influence of natural convection on heat flow within the drift can be approximated with an effective thermal conductivity. To summarize, the multiscale thermal-hydrologic model must represent the following processes:

1. Heat flow within the drift-The range of heat output generated by various waste package types and the delivery of that heat to the drift wall.

2. Mountain-scale heat flow-Conduction of heat throughout the mountain, from the ground surface down to a sufficient depth, which includes the entire unsaturated zone plus the upper portion (1000 $\mathrm{m}$ ) of the saturated zone.

3. Drift-scale heat flow in the host rock-Heat flow (primarily by conduction, but also convection) occurring in variably saturated, fractured porous rock. Because thermal conductivity depends on liquid-phase saturation, it is necessary to capture the influence of host-rock dryout and rewetting. 
4. Host-rock dryout and rewetting-Temperature buildup and cooldown in the host rock, as well as the magnitude of liquid-phase flux that enters the dryout zone (primarily resulting from gravity-driven percolation flux), influence the spatial and temporal extent of dryout.

The multiscale thermohydrologic model consists of four different submodel types, described in detail in Section 6.2.4, which collectively represent all four of these processes. Two of the submodel types (SMT and DDT) are three-dimensional in order to represent mountain-scale heat flow, which occurs by conduction, and to represent heat flow within the drifts, which occurs by conduction, radiation, and convection, and which is approximated with an effective thermal conductivity.

Two-dimensional drift-scale thermal-hydrologic submodels are used to predict drift-scale heat flow, dryout, and rewetting in the host rock; these models also predicts heat flow within the drift and how that heat flow influences relative humidity within the drift. One-dimensional drift-scale thermal-conduction models are used to relate the temperature predicted by the two-dimensional drift-scale thermal-hydrologic submodels with the temperatures predicted by the threedimensional mountain-scale thermal-conduction submodel.

It is important to note that drift-scale thermal-hydrologic models are bounded on all four sides by insulated impermeable boundaries that prevent any heat or mass (gas- and liquid-phase) flow across these boundaries. As in the mountain-scale submodel, drift-scale submodels have an upper and lower boundary with specified boundary conditions. Thus, heat and mass flow can leave the drift-scale submodels at the upper and lower boundary. Because of the insulated lateral and longitudinal boundaries, drift-scale models cannot (directly) represent the influence of three-dimensional mountain-scale heat flow. There are several possible options for incorporating the influence of three-dimensional mountain-scale heat flow into the results of drift-scale submodels, including: (1) specifying time-dependent temperature boundary conditions, which are obtained from the three-dimensional mountain-scale submodel, at the sides of the drift-scale submodels, and (2) specifying time-dependent heat flux, which is determined from the three-dimensional mountain-scale submodel, out of the sides of the drift-scale submodels. Because it is computationally feasible, the multiscale thermal-hydrologic model uses the second approach, as is conceptually explained below, and which is described in detail in Section 6.2.4.

The multiscale thermal-hydrologic model implements the time-dependent heat flux at the lateral boundaries of the drift-scale thermal-hydrologic submodels in an empirical fashion. For a repository of theoretically infinite lateral and longitudinal extent, there would be no mountain-scale heat flow in the lateral and longitudinal directions. Consequently, drift-scale submodels could take advantage of symmetry by utilizing insulated lateral and longitudinal boundaries and closely predict the temperature evolution. These models could utilize an insulated boundary along the center axis of the drift and an insulated boundary at the mid-pillar location, which is $40.5 \mathrm{~m}$ from the drift centerline. Because the repository system is of finite lateral and longitudinal extent, three-dimensional mountain-scale heat flow causes heat to cross the lateral and longitudinal boundaries in the drift-scale submodels. The multiscale thermohydrologic model approximates this heat loss by allowing heat to leave the lateral boundary in the drift-scale submodels, which is $40.5 \mathrm{~m}$ away from the centerline of the drift, in a manner that is consistent with three-dimensional mountain-scale heat flow. This is accomplished by comparing temperatures predicted by the three-dimensional mountain-scale submodel with 
those predicted by equivalent one-dimensional drift-scale submodels to adjust the lateral dimension of the drift-scale submodels so that the temperature predicted by the drift-scale submodel matches that of the mountain-scale submodel at each timestep. This adjustment process results in an effective drift spacing, which gradually increases with time, just as the lateral and longitudinal heat loss grows with time. Note that the description in Section 6.2.4 utilizes an effective areal mass loading, which has a one-to-one equivalence to the effective drift spacing. Thus, an effective drift spacing of $81 \mathrm{~m}$ corresponds to an effective areal mass loading of 55 MTU/acre, while an effective drift spacing of $162 \mathrm{~m}$ corresponds to an effective areal mass loading of about 27 MTU/acre. The gradually increasing drift spacing allows the appropriate quantity of heat to leave the physical lateral boundary (with time). This time-dependent drift spacing is then applied to the two-dimensional drift-scale thermal-hydrologic submodels, so that the influence of three-dimensional mountain-scale heat flow is appropriately represented in those submodels.

After the effective drift spacing is incorporated into the two-dimensional drift-scale thermohydrologic submodels, the intermediate results represent a repository that is uniformly heated with a repository-wide average thermal load per unit length. To incorporate the influence of nonuniform heating conditions along drifts (resulting from waste package-to-waste package variability in heat output), three-dimensional drift-scale submodels are used to determine the local temperature deviations relative to those arising from line-averaged heating conditions. These temperature deviations are added to the line-averaged results to determine temperature conditions that incorporate both the influence of three-dimensional mountain-scale heat flow and three-dimensional drift-scale heat flow. Thus, the effective drift spacing (and the corresponding equivalent effective areal mass loading) is adjusted to account for local temperature deviations, as well as for three-dimensional mountain-scale heat flow. The adjusted effective areal mass loading is applied to the two-dimensional drift-scale thermal-hydrologic submodels to determine all hydrologic parameters of interest throughout the repository.

The process of adding the results from three-dimensional thermal submodels to those from two-dimensional thermohydrologic submodels relies on the assumption (Section 5.2.1) that three-dimensional convective heat and mass transfer in the host rock do not influence longitudinal temperature variability along the drift axis. Moreover, the multiscale model approach assumes (Sections 5.2.2 and 5.6) that mountain-scale movement of water and water vapor along the drift axes or between drifts is insignificant. Thus, fluid flow and convection are mostly confined to a two-dimensional vertical cross section orthogonal to the drift axis, with insignificant fluid flow across the vertical midplane in the rock pillar between the drifts. These assumptions are justified by the model validation study documented in Section 7.5, where it was found that the influence of longitudinal vapor transport along the drift has an insignificant influence on in-drift thermal-hydrologic conditions compared to the influence of parametric uncertainty. The thermal-hydrologic multiscale model also neglects any changes in rock properties due to three-way or four-way coupled thermohydrologic-chemical-mechanical processes (Manteufel et al. 1993 [DIRS 100776]) and neglects the influence of dissolved solutes on the thermohydrologic properties of water.

The thermal-hydrologic multiscale modeling approach considers the influence of the following parameters as a function of geographic location in the repository: local stratigraphy, overburden thickness (i.e., distance between the repository and ground surface, which varies by approximately $150 \mathrm{~m}$ across the repository), thermal boundary conditions, and percolation flux. 
It also considers the influence of the proximity to the edge of the repository, which is important because a waste package close to the repository edge will cool more quickly than one at the repository center. As discussed in Section 5.2.1, it is assumed that the differences in temperature that arise as a result of proximity to the repository edges are governed by thermal conduction in the rock. This assumption is equivalent to saying that convective heat transfer mechanisms have an insignificant influence on lateral mountain-scale heat flow at Yucca Mountain. These mechanisms (notably, buoyant gas-phase convection and the heat pipe effect) are included in the two-dimensional thermal-hydrologic (drift-scale) submodels of the MSTHM. The assumption of conduction dominance at the mountain scale bounds temperature differences that arise from differences in proximity to the repository edges, which captures the full range of boiling-period duration across the repository.

The MSTHM represents all possible waste packages emplaced in the repository by four major types: CSNF from pressurized-water reactors (PWRs), CSNF from boiling-water reactors (BWRs), high-level radioactive waste (HLW), and DOE-owned spent nuclear fuel. The relevant point here is that the heat-generation-rate-versus-time relationships for these four waste package types are different. The model considers a waste package sequence (Figure 6.2-2) that results in eight distinct local heating conditions for waste packages. For example, the model distinguishes between a BWR placed between a PWR and a HLW and a BWR placed between two PWRs. As discussed in Section 5.2.2, it is assumed that the differences in temperature between relatively hotter and cooler waste package locations are governed by thermal conduction in the host rock and emplacement drift and thermal radiation in the open cavities in the drift. This assumption is equivalent to saying that convective heat transfer mechanisms (notably, buoyant gas-phase convection) do not significantly contribute to the attenuation of temperature variations along the axis of the drift. However, the influence of buoyant gas-phase convection is represented in the vertical plane perpendicular to the drift axis. This assumption bounds temperature variability along the drifts.

To implement this multiscale approach, a modeling system has been developed that is called the MSTHM, which is described in detail in Section 6.2.4. The following discussion begins with the unsaturated zone hydrology model on which the natural system aspects of the MSTHM are based, followed by a detailed discussion of the governing equations that are used in all the MSTHM simulations.

\subsubsection{Incorporating the Unsaturated-Zone Hydrology Model in the MSTHM}

The MSTHM uses the representation of the unsaturated zone developed in UZ Flow Models and Submodels (BSC 2004 [DIRS 169861]). From Development of Numerical Grids for UZ Flow and Transport Modeling (BSC 2004 [DIRS 169855]), a three-dimensional definition of hydrostratigraphic units (called UZ-model layers) is incorporated in the MSTHM, including position of the water table and surface topography; thermohydrologic properties for these units; and model boundary conditions. The model includes 36 UZ-model layers, each of which is considered to be homogeneous with respect to thermal and hydrologic properties. These hydrologic properties are determined through an inverse modeling approach constrained by site hydrologic data; the assumption is made that important heterogeneity is captured by the detailed stratification (Bandurraga and Bodvarsson 1999 [DIRS 103949]). The thermal properties are determined based on laboratory and field measurements (BSC 2004 [DIRS 169854]; BSC 2004 [DIRS 170033]). 
The MSTHM also incorporates the conceptualization for flow through unsaturated fractured porous rock at Yucca Mountain from the Lawrence Berkeley National Laboratory (LBNL) unsaturated-zone hydrology model. The current conceptual model is based on a dual-permeability representation of overlapping fracture and matrix continua, modified from the traditional approach such that only a portion of connected fractures actively conduct liquid water (Liu et al. 1998 [DIRS 105729]), a portion which depends on liquid-phase saturation in the fractures.

The next step in building the MSTHM involves the addition of the repository emplacement drifts and the engineered components inside those drifts to the unsaturated zone hydrology model discussed above. The geometric configuration of the engineered components inside the drifts used in the MSTHM calculations in support of the TSPA-LA base case is shown in Figures 6.2-1 and 6.2-2.

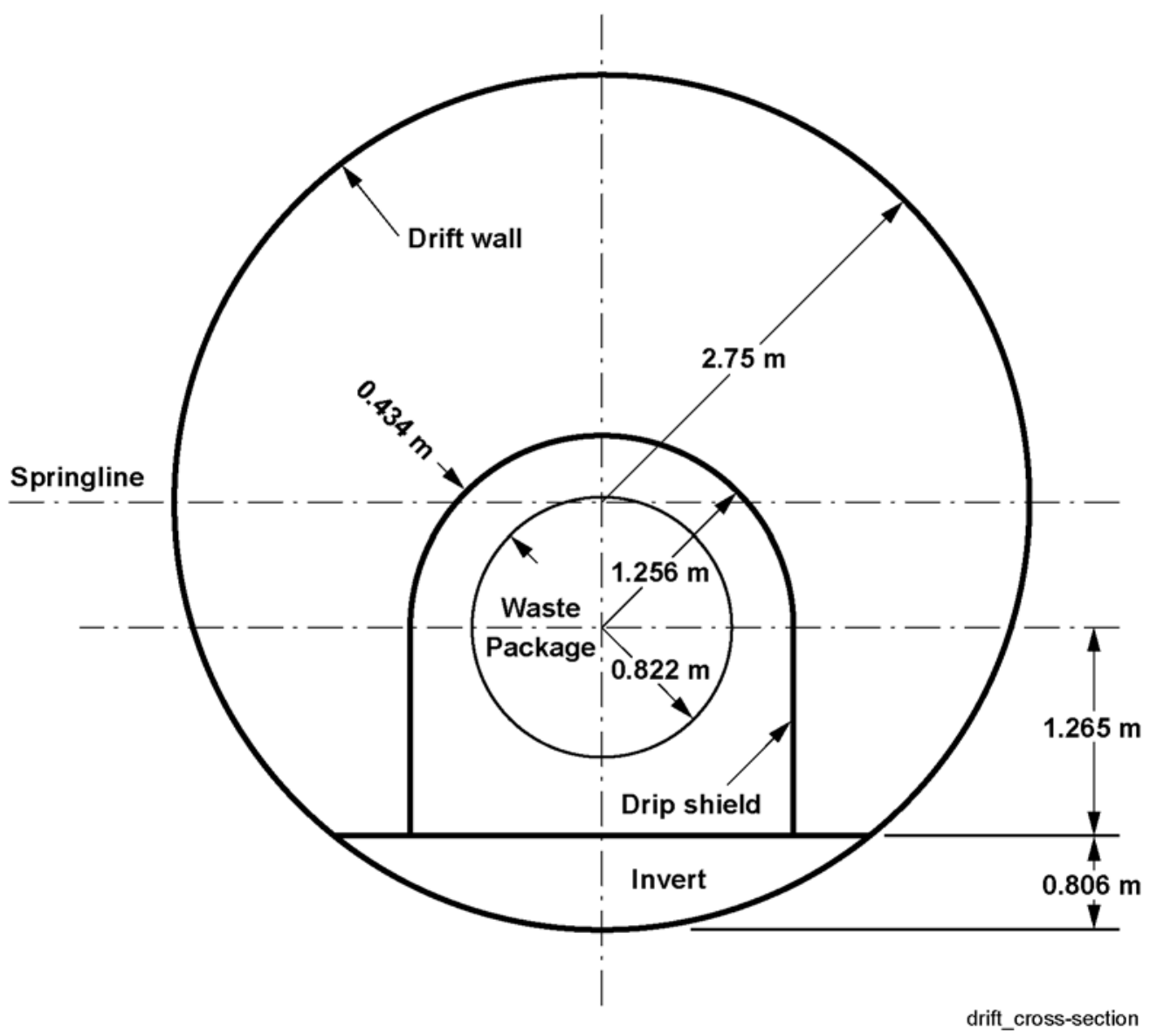

Source: BSC 2003 [DIRS 164101], Figure 2, for invert depth; BSC 2004 [DIRS 168489], Figure 1, for drift diameter.

NOTE: Average waste package diameter is obtained from assumption in Section 5.4.1. Drip-shield width is from BSC 2003 [DIRS 171024], Sheet 2. Location of waste package centerline above invert is from BSC 2004 [DIRS 167040].

Figure 6.2-1. Geometric Configuration of the Engineered Components Shown for an Average Cross-Section Inside the Emplacement Drifts as Represented in MSTHM 


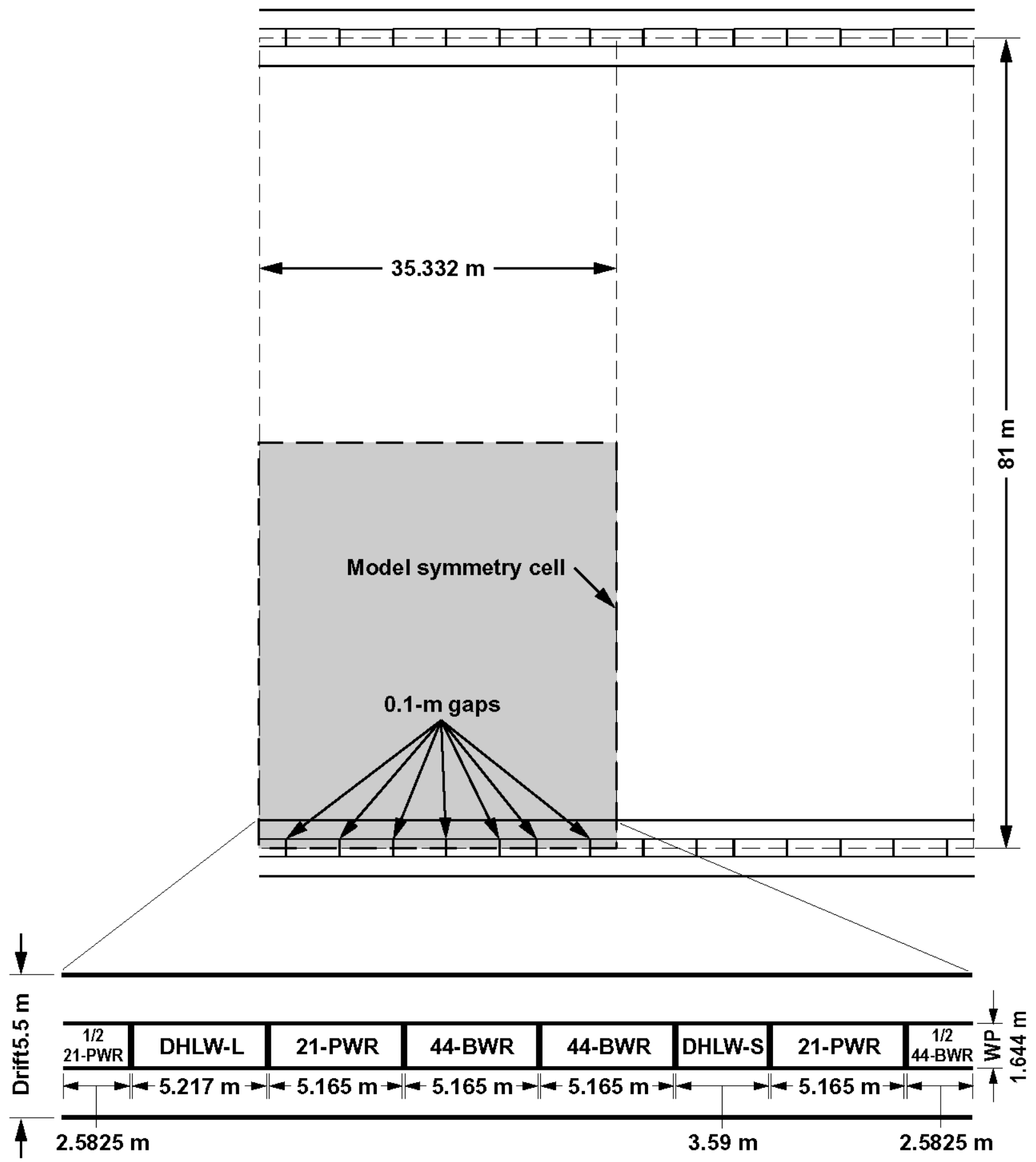

NOTE: Average waste package diameter is obtained from assumption in Section 5.4.1. Waste package lengths are obtained from BSC 2003 [DIRS 165406], Table 1. The names of the respective waste packages (21-PWR, 44-BWR, etc.) used in the DDT submodel are shown above for each waste package.

Figure 6.2-2. Diagram Showing Drift Spacing, Waste Package Lengths, and Waste Package Spacing in Plan View Considered in MSTHM Calculations for the TSPA-LA Base Case 


\subsubsection{Governing Equations for Unsaturated-Zone Thermohydrology}

This section describes the theoretical basis for the NUFT software, which solves the governing equations. Section 3 lists versions of NUFT that are qualified software and are used in the MSTHM. The theoretical basis is repeated here for background.

\subsubsection{Mass-Balance Equation for Thermal-Hydrologic Models}

All thermal-hydrologic models in this report solve the mass-balance equation for air, water, and energy components for liquid- and gas-fluid phases and a nondeformable solid. The mass-balance equation for the air and water components is:

$$
\frac{\partial}{\partial t} \sum_{\varsigma} \phi \rho_{\varsigma} S_{\varsigma} \omega_{\varsigma}^{\beta}=-\sum_{\varsigma} \nabla \cdot \phi \rho_{\varsigma} S_{\varsigma}\left(\omega_{\varsigma}^{\beta} \mathbf{V}_{\varsigma}+\mathbf{J}_{\varsigma}^{\beta}\right)
$$

where $t$ is time, the superscript $\beta$ denotes a component (e.g., air and water), the subscript $\varsigma$ denotes fluid phases (e.g., liquid and gas), $\phi$ is porosity, $\rho_{\varsigma}$ is density of phase $\varsigma, S_{\zeta}$ is saturation

of a $\varsigma$ phase, $\omega_{\varsigma}^{\beta}$ denotes mass fraction of $\beta$ component in phase $\varsigma, \mathbf{V}_{\varsigma}$ is velocity vector for $\varsigma$ phase advection, and $\mathbf{J}_{\varsigma}^{\beta}$ is combined diffusive and dispersive flux tensor, which can be further given by Fick’s law (Cho 1998 [DIRS 160802], p. 1.3, Equation 1-7):

$$
\mathbf{J}_{\varsigma}^{\beta}=-D_{\varsigma}^{\beta} \nabla \omega_{\varsigma}^{\beta}
$$

$D_{\varsigma}^{\beta}$ is combined diffusion and dispersion coefficient for $\beta$ component in $\varsigma$ phase. Darcy's law gives the advective flux vector (Nitao 2000 [DIRS 159883]):

$$
S_{\varsigma} \phi \mathbf{V}_{\varsigma}=-\frac{k_{\varsigma}\left(S_{\varsigma}\right)}{\mu_{\varsigma}}\left(\nabla p_{\varsigma}+\rho_{\varsigma} g \nabla z\right)
$$

where $k_{\varsigma}$ is the permeability function, $\mu_{\varsigma}$ is phase viscosity, $p_{\varsigma}$ is phase pressure, $g$ is gravitational acceleration, and $z$ denotes distance in the vertical direction. The capillary pressure relationship is given by:

$$
p_{\alpha}=p_{g}-p_{c}
$$

and $p_{c}$ is the retention pressure function. In addition to the mass balance equation, there are the constraints:

$$
\sum_{\beta} \omega_{\varsigma}^{\beta}=1 \text { and } \sum_{\varsigma} S_{\varsigma}=1
$$


Local thermodynamic equilibrium is assumed between all phases. Partitioning of components between phases is expressed in terms of partitioning coefficients:

$$
n_{\varsigma}^{\beta}=K_{\varsigma, \xi}^{\beta} n_{\xi}^{\beta}
$$

where $n_{\varsigma}^{\beta}$ is the mole fraction and $K_{\varsigma, \xi}^{\beta}$ is the partitioning coefficient between phase $\varsigma$ and phase $\xi$. For predicting the partitioning of water between the aqueous phases, the model includes the "vapor pressure lowering" effect based on the Kelvin law:

$$
R H=\frac{P_{v}}{P_{s a t}(T)}=\exp \left(\frac{M P_{c}}{\rho R T}\right)
$$

where $R H$ is relative humidity, $P_{\mathrm{v}}$ is partial pressure of water vapor, $P_{\text {sat }}(T)$ is the saturated vapor pressure from the steam tables, based on the local temperature $T, M$ is the molecular weight of water, $P_{\mathrm{c}}$ is capillary pressure, $\rho$ is the density of water $R$ is the Gas Constant, and $T$ is temperature.

\subsubsection{Energy Balance Equation for Thermal-Hydrologic Models}

For all thermal-hydrologic models and submodels in this report, the energy balance equation is:

$$
\frac{\partial}{\partial t}\left[\sum_{\varsigma} \phi \rho_{\varsigma} u_{\varsigma} S_{\varsigma}+(1-\phi) \rho_{s} C_{p}\left(T-T_{\text {ref }}\right)\right]=\sum_{\beta} \sum_{\varsigma}\left[\nabla \cdot \phi h_{\varsigma}^{\beta} \rho_{\varsigma} S_{\varsigma}\left(\omega_{\varsigma}^{\beta} \mathbf{V}_{\varsigma}+\mathbf{J}_{\alpha}^{\gamma}\right)\right]+\nabla \cdot K_{H} \nabla T
$$

where $T$ denotes temperature, $T_{r e f}$ is reference temperature, $u_{\varsigma}$ is specific internal energy, $\rho_{S}$ is solid density, $C_{p}$ is specific heat of solid, $h_{\varsigma}^{\beta}$ is partial specific enthalpy, and $K_{H}$ is thermal conductivity. Note that thermal conductivity is a function of liquid-phase saturation $S$, varying linearly from a "dry" value of $K_{H}(S=0.0)$ to a "wet" value of $K_{H}(S=1.0)$. Where thermal radiation is included to couple grid blocks within the numerical model, a classical radiation term can be added to the right hand side of Equation 8, to represent the conceptual basis for radiative heat transfer.

It is noted that it is possible to use either a specific internal energy accumulation term or a specific enthalpy accumulation term for the fluid phases of Equation 8. Transport Phenomena (Bird et al. 1960 [DIRS 103524]) discusses the validity of either approach. The justification for the use of specific internal energy in the accumulation term of the fluid phases in the NUFT code is discussed in detail in Section 6.2.3.6.

The balance equations (1) and (8) are discretized in space using the integrated finite difference method and discretized in time using the fully implicit backward Euler method. The resulting nonlinear system of equations is solved at each time step using the Newton-Raphson method.

\subsubsection{Radiative Heat Transfer}

Where relevant, models, such as the LDTH and DDT submodels (Sections 6.2.6 and 6.2.8), include radiative heat transfer in the energy balance model for the open cavities within the 
repository drifts in which waste packages are emplaced. In this case, the surfaces of the drift wall and waste package are subdivided into surface elements, each of which is mapped to a computational volume element. Radiative heat flux is calculated for connections between each pair of surface elements using temperatures from the corresponding volume element. The net radiative heat transferred between two model nodes is calculated from the Stefan-Boltzmann law (Cho 1998 [DIRS 160802]):

$$
Q=c\left(T_{1}^{4}-T_{2}^{4}\right)
$$

where $T_{1}$ is the absolute temperature of the radiator, $T_{2}$ is the absolute temperature of the receiver, and $c$ is a coefficient defined by:

$$
c=A F \varepsilon \sigma
$$

where $A$ is the area of the radiating surface element, $F$ is the radiative view factor (Holman 1990 [DIRS 106052]), $\varepsilon$ is emissivity, and $\sigma$ is the Stefan-Boltzmann constant.

\subsubsection{Energy Balance Equations for Thermal-Conduction-Only Models}

For all thermal-conduction models in this report, the energy balance is written:

$$
(1-\phi) \rho_{s} C_{p} \frac{\partial T}{\partial t}=\nabla \cdot K_{H} \nabla T
$$

where $\phi$ is porosity, $\rho_{s}$ is solid density, $C_{p}$ is specific heat of solid, and $K_{H}$ is thermal conductivity. For thermal-conduction-only models, thermal conductivity is not a function of liquid-phase saturation.

\subsubsection{Dual-Permeability and Active-Fracture Models}

All thermal-hydrologic models in this report utilize a dual-permeability approach in which the fracture and matrix systems are treated as two separate continua with a complete set of balance equations and computational grid for each continuum. Each continuum has coupling terms for mass and energy fluxes between the two continua. These terms have the general form:

$$
q_{\text {exchange }}=a \kappa \Delta u / L \text {, }
$$

where $q_{\text {exchange }}$ is flux of mass or energy per unit bulk volume, $\Delta u$ is the difference in pressure or temperature between the continua, and $\kappa$ is a transfer coefficient. The coefficient $\kappa$ for advective flux is of the form $K k_{r} / \mu$, where $K$ is saturated permeability, and $k_{r}$ is relative permeability. For diffusive mass flux of a phase, $\kappa$ is equal to the apparent diffusion coefficient $D_{\text {app }}=\phi S \tau D$, where $\tau$ is tortuosity factor, and $D$ is the free diffusion coefficient. For energy flux, $\kappa$ is the bulk thermal conductivity $K_{H}$. In the conventional dual-permeability approach, $a$ is the surface area of the fracture walls per unit bulk volume, and $L$ is the average distance between centers of the matrix elements, which is proportional to the fracture spacing. Also used is an active-fracture model modification to the traditional dual-permeability approach in which $a$ and 
$L$ are modified to account for inactive fractures (or portions of fractures) as suggested by Liu et al. (1998 [DIRS 105729]).

Specifically, $a$ is multiplied by $S_{e}$, and $L$ is multiplied by $S_{e}^{-\gamma}$, where:

$$
S_{e}=\frac{S_{f}-S_{r}}{S_{\max }-S_{r}}
$$

and $S_{r}$ and $\mathrm{S}_{\max }$ are residual and maximum liquid-phase fracture saturations, respectively, while $S_{f}$ is the fracture saturation.

The relationships between permeability, saturation, and capillary pressure described in Equations 14 and 15 are described by the formulations of van Genuchten (1980 [DIRS 100610]) and Mualem (1976 [DIRS 100599]), modified to account for the active fracture model by the parameter $\gamma$ which has a value between 0 and 1 ( 0 if all fractures are active).

The relative permeability for the liquid phase is given by:

$$
k_{r l}=S_{e}^{(1+\gamma) / 2}\left[1.0-\left(1.0-S_{e}^{(1-\gamma) / m}\right)^{m}\right]^{2}
$$

It is assumed that $k_{r l}+k_{r g}=1$; the subscripts " $l$ " and " $g$ " refer to the liquid and gas phases, respectively. The capillary pressure is given by:

$$
p_{c}=\frac{1}{\alpha}\left(S_{e}^{\frac{\gamma-1}{m}}-1\right)^{\frac{1}{n}}
$$

where $\alpha$ is a curve-fitting parameter (units of inverse pressure), $n$ is a dimensionless curve-fitting parameter, and $m=1-1 / n$.

The parameters used in this model are functions of pressure $p$, temperature $T$, mass fraction $\omega$, and/or saturation $S$ as follows: $\rho_{\alpha}(p, T, \omega), D_{\alpha}^{\gamma}(p, T), \mu_{\alpha}(p, T, \omega), K_{\alpha \beta}^{\gamma}(p, T, S), u_{\alpha}(p, T, \omega)$, $h_{\alpha}^{\gamma}(p, T), k_{\alpha}(S), \tau_{\alpha}(S)$, and $p_{c}(S, T)$.

\subsubsection{Formulation of Energy Balance Equation for Thermal-Hydrologic Models}

It is possible to formulate the energy balance equation (Equation 8) using either specific internal energy (u) or specific enthalpy (h) in the fluid-phase accumulation terms inside the time derivative. Numerical models for subsurface flow and transport have formulated the equation of energy for multicomponent systems both using enthalpy (e.g., Manteufel et al. 1993 [DIRS 100776]; Pollock 1986 [DIRS 164747]) and using specific internal energy (e.g., Lichtner and Walton 1994 [DIRS 152609]; Nitao 1998 [DIRS 100474]). Bird et al. (1960 [DIRS 103524], Table 18.3-1, p. 562) demonstrate that both formulations are valid, as follows: 


$$
\begin{gathered}
\rho \frac{D}{D t} h=-(\nabla \cdot q)+\frac{D p}{D t}-(\boldsymbol{\tau}: \nabla \mathbf{v})+\sum_{i=1}^{n}\left(\mathbf{j}_{i} \cdot \mathbf{g}_{i}\right) \\
\rho \frac{D}{D t} u=-(\nabla \cdot q)-(\boldsymbol{\pi}: \nabla \mathbf{v})+\sum_{i=1}^{n}\left(\mathbf{j}_{i} \mathbf{g}_{i}\right)
\end{gathered}
$$

One may note the fact that specific enthalpy of evaporation $\left(h_{\text {evap }}\right)$ is greater than the specific internal energy of evaporation ( $u_{\text {evap }}$ ) because the specific enthalpy includes a compressible work term. For example, at standard atmospheric pressure $(101.3 \mathrm{kPa}), h_{\text {evap }}=2,257 \mathrm{~kJ} / \mathrm{kg}$ while $u_{\text {evap }}=2088 \mathrm{~kJ} / \mathrm{kg}$, a difference of approximately 8 percent (Keenan et al. 1969 [DIRS 134666]). Such a difference is crucial when considering a simplified batch system (i.e., zero-dimensional reactor). In such simplified cases, one must consider different approaches to the system (i.e., approaching the problem as a closed system versus approaching the problem as an open system). The partial differential equation formulation as represented by Bird et al. (1960 [DIRS 103524], p. 566, Equation 18.4-2) in Equations 16 and 17 incorporates multidimensional transient processes, however. Both the enthalpy formulation (Equation 16) and the internal energy formulation (Equation 17) result in equivalent solutions.

The energy-balance equation in NUFT is based on the derivation of Equation 17, which is the internal energy formulation of the energy equation for $n$ species. Expanding the total derivative on the left-hand side of Equation 17 and incorporating the continuity equation, Equation 17 can be rewritten as:

$$
\frac{\partial}{\partial t}(\rho u)+\nabla \cdot(\rho u \mathbf{v})=-(\nabla \cdot q)-(\boldsymbol{\pi}: \nabla \mathbf{v})+\sum_{i=1}^{n}\left(\mathbf{j}_{i} \cdot \mathbf{g}_{i}\right)
$$

The thermal energy flux $q$ is composed of three terms (Bird et al. 1960 [DIRS 103524], Equation 18.4-2, p. 566):

$$
q=-k \nabla T-\sum_{i=1}^{n} h_{i} \rho D_{i} \nabla \omega_{i}+q^{(\mathbf{x})}
$$

representing, respectively, thermal conduction, species diffusion enthalpy transport, and the Dufour energy flux. Note that according to Bird et al. (1960 [DIRS 103524]), the Dufour energy flux is of minor importance and is therefore typically neglected. Incorporating Equation 19 (less the Dufour energy flux) into Equation 18 and noting that gravitational work (the last term in Equation 18) is zero (Nitao 2000 [DIRS 159883]), results in the simplified equation:

$$
\frac{\partial}{\partial t}(\rho u)+\nabla \cdot(\rho u \mathbf{v})=\left(\nabla \cdot\left[k \nabla T+\sum_{i=1}^{n} h_{i} \rho D_{i} \nabla \omega_{i}\right]\right)-(\boldsymbol{\pi}: \nabla \mathbf{v})
$$

The stress tensor $\pi$ is related to the viscous shear tensor and pressure as follows:

$$
\pi=\tau+p I
$$


Incorporating Equation 21 into the last term of Equation 20 and noting that $p \nabla \cdot \boldsymbol{v}=\nabla \cdot(p v)-\boldsymbol{v} \cdot \nabla p$, Equation 20 can be rewritten as:

$$
\frac{\partial}{\partial t}(\rho u)+\nabla \cdot(\rho u \mathbf{v})=\left(\nabla \cdot\left[k \nabla T+\sum_{i=1}^{n} h_{i} \rho D_{i} \nabla \omega_{i}\right]\right)-(\tau: \nabla \mathbf{v})-\nabla \cdot(p \mathbf{v})+\mathbf{v} \cdot \nabla p
$$

As discussed by Nitao (2000 [DIRS 159883]), both the viscous dissipation term $(\tau: \nabla \boldsymbol{v})$ and the pressure gradient term $(\boldsymbol{v} \cdot \nabla p)$ are typically neglected in Equation 22 because these terms are small compared to other terms. Estimates of the approximate potential error incurred by neglecting these two terms are discussed below. The third term on the right-hand side of Equation 22 can be incorporated into the second term on the left-hand side resulting in a convective enthalpy term. This results in the energy equation as it is employed in the NUFT code:

$$
\frac{\partial}{\partial t}(\rho u)+\nabla \cdot(\rho h \mathbf{v})=\left(\nabla \cdot\left[k \nabla T+\sum_{i=1}^{n} h_{i} \rho D_{i} \nabla \omega_{i}\right]\right)
$$

For a more rigorous mathematical development of Equation 23 from Equation 17, see Documentation of the Thermal Energy Balance Equation Used in the USNT Module of the NUFT Flow and Transport Code (Nitao 2000 [DIRS 159883]). Note that the above equations apply only at the "pore level" and not at the porous medium, or macroscopic, level. Nitao (2000 [DIRS 159883]) also discusses the method used to derive the porous medium energy balance equation by volume averaging the pore level equations.

It is possible to estimate the error incurred by neglecting the viscous dissipation term $(\tau: \nabla v)$ in Equation 22 by considering the maximum error that could occur for a thermal-hydrologic model calculation using the NUFT code. Nitao (2000 [DIRS 159883]) estimates that the maximum error caused by neglecting this term would occur during infiltration through the rock fractures. The maximum possible error in temperature at the repository for a high infiltration of $100 \mathrm{~mm} / \mathrm{yr}$ would be $\Delta T \sim 0.3^{\circ} \mathrm{C}$.

The largest potential source of error lies in neglecting the pressure gradient term in Equation 22. Note that this assumption does not mean that a constant pressure is assumed-only that this particular term in the energy equation is neglected. In fact, pressure is a variable in all of the remaining terms in Equation 22 where it appears. It is possible to estimate the maximum potential error incurred by neglecting the heat gradient term $(v \cdot \nabla p)$ by comparing it to the convective enthalpy term $(\nabla \cdot(\rho h \mathbf{v}))$. The greatest pressure would occur in the host rock immediately adjacent to the drift wall during a boiling event. As an example, consider a maximum drift-wall temperature of $140^{\circ} \mathrm{C}$ as estimated for the higher-temperature operating mode conditions analyzed in FY 01 Supplemental Science and Performance Analyses, Volume 1: Scientific Bases and Analyses (BSC 2001 [DIRS 155950], Figure 5.4.1-2). Such a temperature would result in a $P_{\text {sat }}$ of $361 \mathrm{kPa}$. The results of the supplemental analyses indicate that such a drift-wall temperature incurs a relative humidity of 30 percent; thus, the pressure can be estimated as approximately $120 \mathrm{kPa}$. The extreme downstream temperature and pressure at the 
repository level would be about $96^{\circ} \mathrm{C}$ and $84.5 \mathrm{kPa}$. If the ratio of $(v \cdot \nabla p) / \nabla(\rho h v)$ is approximated as $\Delta p / \Delta\left(\rho_{\text {sat }} h_{\text {sat }}\right)$ then the maximum difference is $(120 \mathrm{kPa}-84.5$ $\mathrm{kPa}) /\left(1.12 \mathrm{~kg} / \mathrm{m}^{3} \times 2,706 \mathrm{~kJ} / \mathrm{kg}-0.353 \mathrm{~kg} / \mathrm{m}^{3} \times 2,652 \mathrm{~kJ} / \mathrm{kg}\right)$ or about 2 percent. Note that this is a conservative error estimate for this particular problem; the estimate neglects thermal conduction as an energy transport mechanism and thus exaggerates the potential error of this scenario where heat flow is dominated by thermal conduction. Hence, is concluded that neglecting the pressure gradient in Equation 22 would result in a maximum error of less than 2 percent for a short time over only the small region of host rock adjacent to drift wall, where boiling of pore water occurs. Neglecting the influence of viscous dissipation and the pressure gradient in the energy equation is therefore acceptable.

\subsubsection{MSTHM Calculation Sequence}

The MSTHM consists of four submodel types (Figure 1-1, Tables 1-2 and 1-3), all of which are run using the NUFT v3.0s code (Nitao 1998 [DIRS 100474], Section 3.1.1). For this report, the LDTH and SDT submodels (Sections 6.2.6 and 6.2.7) are run at 108 geographic locations distributed uniformly over the repository area (Figure 6.2-3); these submodels use the stratigraphy, overburden thickness, thermal-hydrologic boundary conditions, and percolation fluxes appropriate for each location. At each of those 108 geographic locations, the LDTH and SDT submodel calculations are conducted at different values of thermal loading, which can be quantified by the Areal Mass Loading (AML). Note that AML is expressed in terms of metric tons of uranium per acre. For the current repository design, the initial Lineal Power Density (LPD) is $1.45 \mathrm{~kW} / \mathrm{m}$ (BSC 2004 [DIRS 168489], Table 1), which for a drift spacing of $81 \mathrm{~m}$ (BSC 2004 [DIRS 168489], Table 1) corresponds to an areal power density of $17.9 \mathrm{~W} / \mathrm{m}^{2}$. The repository has 57,480.2 m of emplacement drift (Table 6.2-1), which corresponds to a heated repository footprint of 4,655,896 $\mathrm{m}^{2}$ (57,480.2 $\mathrm{m}$ of drift multiplied by an 81-m drift spacing, which is 1150 acres). From Table 6.2-1 it can be seen that the SMT submodel represents the repository as having 57,480 m of emplacement drift. For a 63,000 MTU inventory of commercial spent nuclear fuel (CSNF) waste packages, this corresponds to an AML of 54.76 MTU/acre (63,000 MTU divided by 1150 acres). Therefore, 1 MTU/acre is equivalent to 0.327 $\mathrm{W} / \mathrm{m}^{2}$ at the time of emplacement for the TSPA-LA design. The modeled AML is obtained by virtue of the selected drift spacing in the submodel.

Section 7.5 describes a MSTHM validation test case, also reported by Buscheck et al. (2003 [DIRS 164638]), in which the MSTHM and a corresponding monolithic thermohydrologic model are used to predict the thermohydrologic behavior of a three-drift repository test case, which is a scaled-down version of the repository. The following description of the MSTHM calculation sequence also pertains specifically to that test case, which utilizes six modeled AMLs: 66, 55, 37, 27, 14, and 7 MTU/acre. Because of the very small heated footprint of the three-drift repository test case, the influence of the edge-cooling effect occurs faster and with greater magnitude than is applicable to repository heating conditions, which requires that the LDTH-SDT submodel pairs be run at six different AMLs, rather than at just four (as is typically done for a full-scale repository example). An AML of 55 MTU/acre corresponds to 81-m drift spacing, while $27 \mathrm{MTU} / \mathrm{acre}$ corresponds to 162-m drift spacing. The emplaced AML for the repository is $55 \mathrm{MTU} /$ acre for a total repository-wide heat load of 70,000 MTU (Canori and Leitner 2003 [DIRS 166275], p. 3-95). The modeled AMLs that are less than the emplaced AML account for the evolving influence of the edge-cooling effect (i.e., waste package locations close to the repository edges cool faster than those at the center). The modeled AML that is 
higher than the emplaced AML accounts for hotter-than-average waste package thermal-loading conditions. The LDTH submodel domain is a two-dimensional drift-scale cross-section extending down from the ground surface to the water table. The LDTH submodels are the only submodels to include coupled thermal-hydrologic processes; these submodels assume a heat-generation history that is effectively that of the entire waste package inventory line-averaged over the total length of emplacement drifts in the repository.

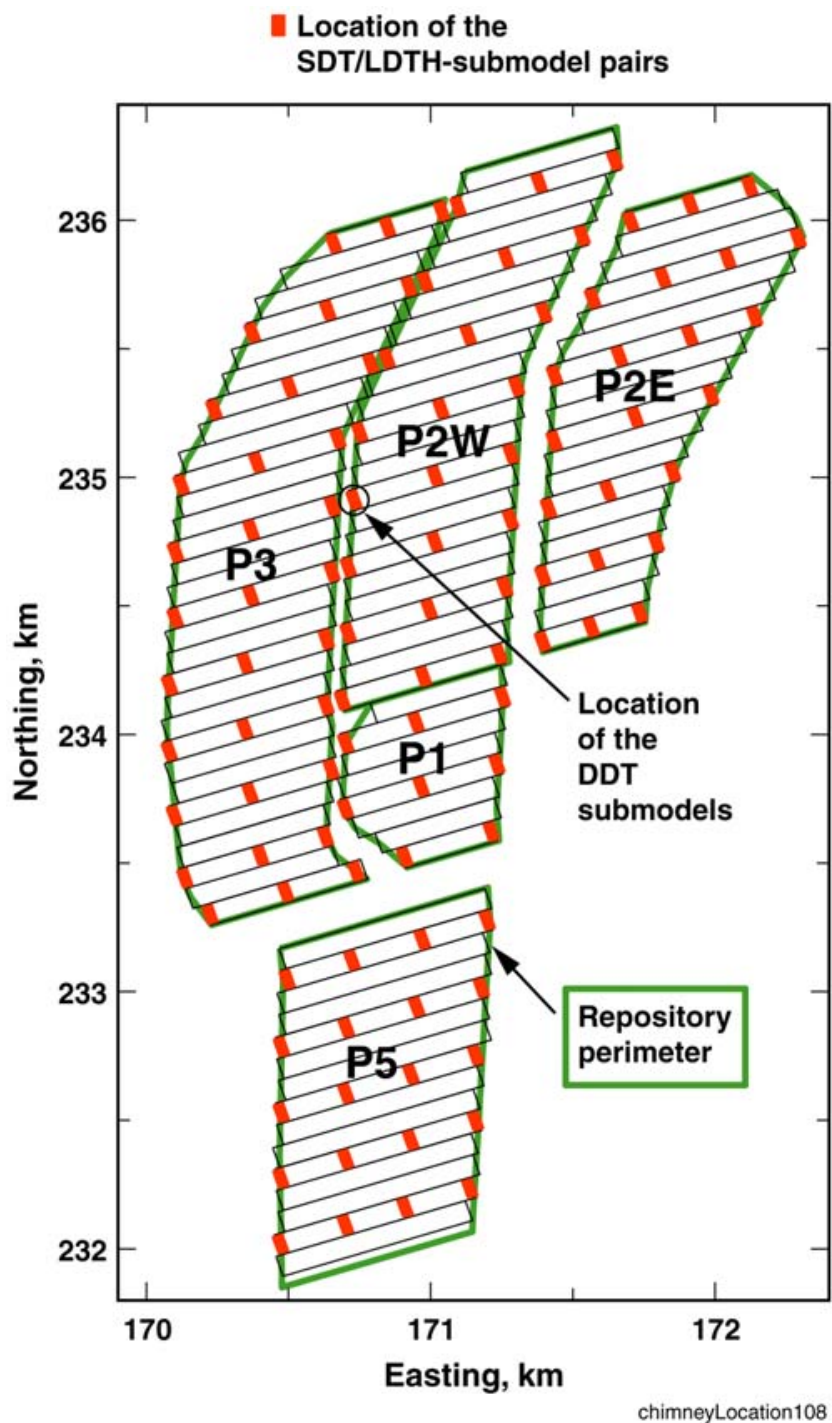

Source: See Table XIII-1.

NOTE: Nevada State Northing and Easting coordinates are given in kilometers. The subhorizontal lines depict the rows of gridblocks in the SMT submodel that represent each of the emplacement drifts. The rectangles correspond to the locations of LDTH-SDT submodel pairs. A total of 108 LDTH-SDT submodel locations are used in the TSPA-LA base case. The outline of the repository perimeter corresponds to the end-point coordinates of the heated portions of the emplacement drifts as given in the IED presented in Repository Design, Repository/PA IED Subsurface Facilities (BSC 2003 [DIRS 161727]). The MSTHM representation of the heated repository footprint closely matches the end-point coordinates of the repository layout. This layout has been slightly revised as shown in Figure 4-1, which is based on the end-point coordinates given in the IED presented in D\&E / PA/C IED Subsurface Facilities (BSC 2004 [DIRS 164519]). Note that the Panel numbers have changed in the revised layout, as shown in Figure 4-1.

Figure 6.2-3. Repository Layout Considered in MSTHM Calculations for the TSPA-LA Base Case 
The three-dimensional SMT submodel, which simulates conductive heat flow from a heat source smeared over the repository area, represents the heated footprint of the repository and allows for consideration of edge-cooling effects and the influence of the varying overburden thickness above the repository. For this example, originally by Buscheck et al. (2003 [DIRS 164638]), the linear power density is $1.35 \mathrm{~kW} / \mathrm{m}$. Note that this linear power density is different from that being analyzed for the TSPA-LA (Section 6.3). The SMT submodel assumes a heat-generation history that is areally averaged for the entire waste package inventory over the entire heated footprint of the repository. The one-dimensional SDT submodels are run at the same 108 geographic locations as the two-dimensional LDTH submodels such that every LDTH submodel is paired to a corresponding SDT submodel. The SDT submodels utilize the same heat-generation history as the LDTH submodels except that heat is smeared over the repository plane in the SDT submodels.

The fundamental concept in the MSTHM is that the results from the two-dimensional LDTH submodels can be modified to account for the influence of three-dimensional mountain-scale heat flow as well as for local deviations arising from waste package-to-waste package variability in heat output. Output from the SMT submodel, together with the LDTH-SDT submodel pairs, is integrated to create the LMTH model (Figure 1-1). The DDT submodel is then used to further modify the LMTH model to account for waste package-specific deviations from average waste package behavior. For this report, the DDT submodels represent eight different waste packages, which fall in two major categories: commercial spent nuclear fuel (CSNF) waste packages, which include pressurized water reactor (PWR) and boiling water reactor (BWR) waste packages; and defense high-level waste (DHLW) waste packages. Four different waste package types are used in the model validation study: PWR1, PWR2, DHLW and BWR (Table 7.3-2). DDT submodel temperature variations are superimposed on LMTH model temperatures to generate the temperatures of the final discrete-heat-source mountain-scale thermal-hydrologic (DMTH) model (Figure 1-1, Tables 1-2 and 1-3).

For the MSTHM analysis of the repository, after all of the submodels have been run using the NUFT code, LDTH and SDT submodel results are spatially interpolated from the geographic locations (a total of 108 for the TSPA-LA MSTHM) to all of the repository subdomains in the SMT submodel (2,874 for the TSPA-LA MSTHM). This approximates running the LDTH-SDT submodel pairs at all repository subdomains in the SMT submodel.

The MSTHM calculation sequence to obtain temperature, relative humidity, and liquid-phase saturation is shown in Figures 6.2-4 and 6.2-5 and is divided into the six stages of Figure 1-1. While this analysis pertains to the three-drift repository model validation test case (Section 7.5), it also illustrates the MSTHM calculation sequence for each of the repository subdomains. The six calculation stages conceptually illustrated in Figure 1-1 are discussed in detail below. 
(a)

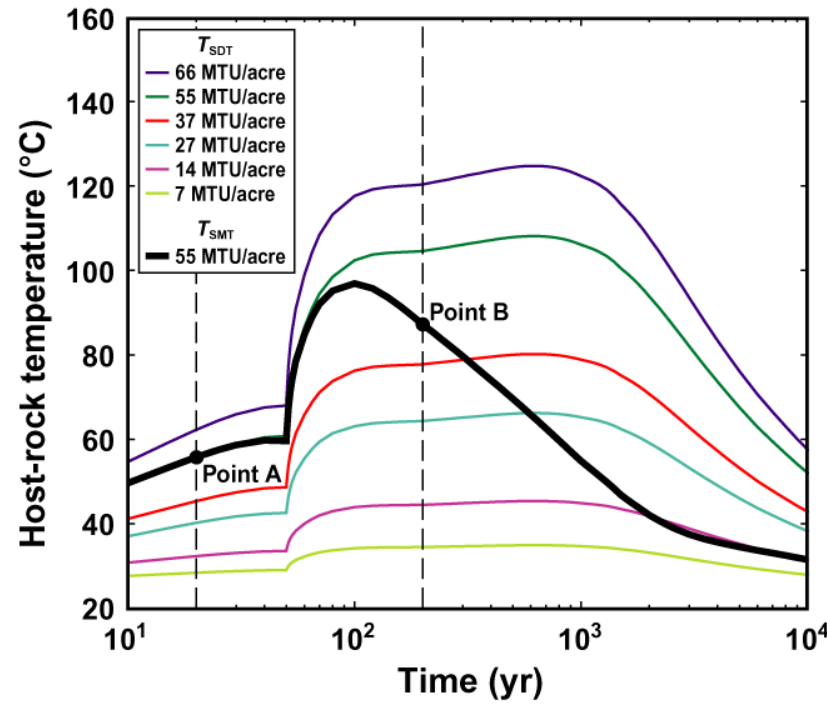

(c)

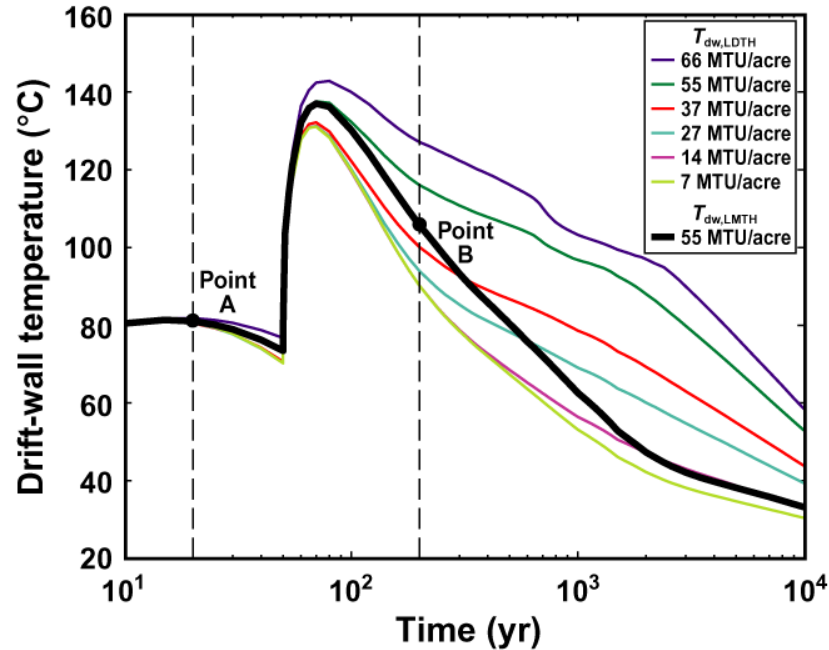

(b)

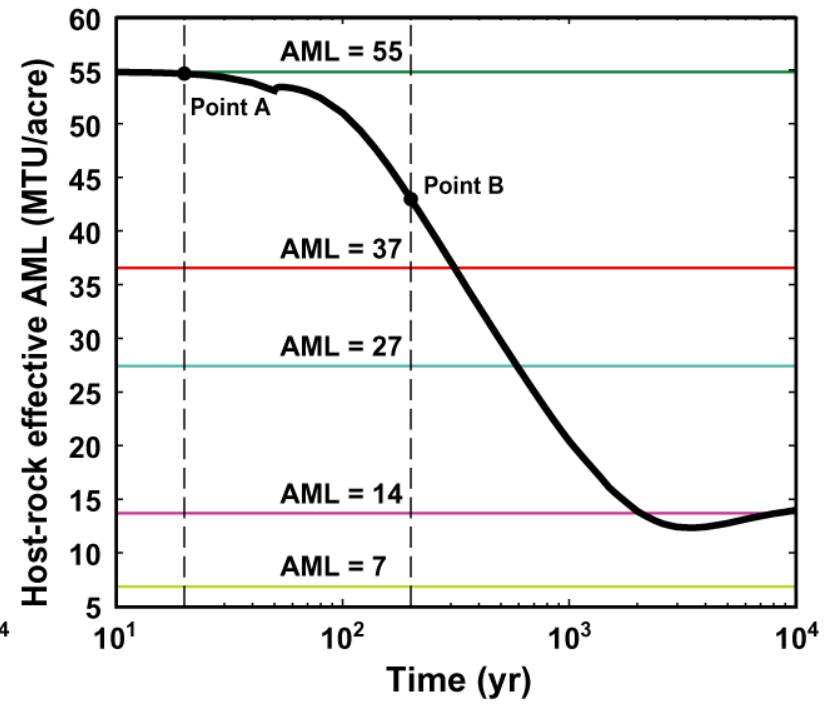

(d)

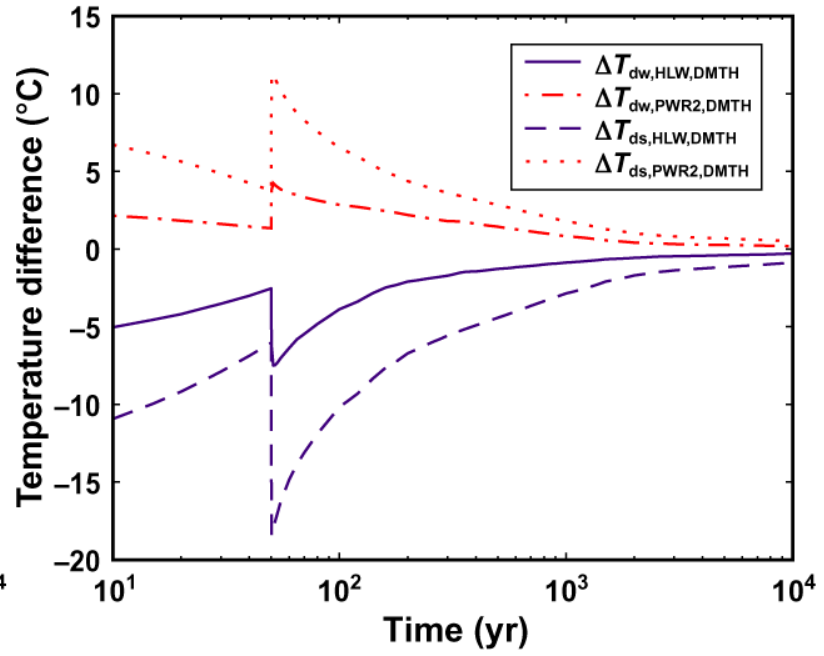

NOTE: (a) Host-rock temperature $T_{\mathrm{SDT}}$ vs. time calculated for the six listed AMLs; also plotted is $T_{\mathrm{SMT}}$ vs. time calculated at the repository center. Because the SDT and SMT submodels use smeared heat sources, the SDT and SMT host-rock temperatures are averaged temperatures for the repository horizon (from pillar mid-point to pillar mid-point) at a given drift location. (b) Host-rock effective AML (AML hstrk,eff) vs. time calculated at the repository center. (c) Drift-wall temperature vs. time calculated for the six listed AMLs; also plotted is $T_{\mathrm{dw}, \mathrm{LMTH}}$ vs. time determined at the repository center. (d) Temperature difference $\Delta T_{\mathrm{dw}, \mathrm{D}, \mathrm{DMTH}}$ between the local and the axially averaged $T_{\mathrm{dw}, \mathrm{LMTH}}$ calculated using the six DDT submodels and interpolated on the basis of AML hstrk,eff Vs. time (Figure 6.2-4b) for the HLW and PWR2 waste packages; also plotted are the corresponding temperature deviations $\Delta T_{\mathrm{ds}, \mathrm{j}, \mathrm{DMTH}}$ between the local drip-shield temperature and the axially averaged $T_{\mathrm{ds}, L \mathrm{LMH}}$.

Figure 6.2-4. MSTHM Calculation Sequence for a Three-Drift 55-MTU/Acre-Repository Example 
(a)

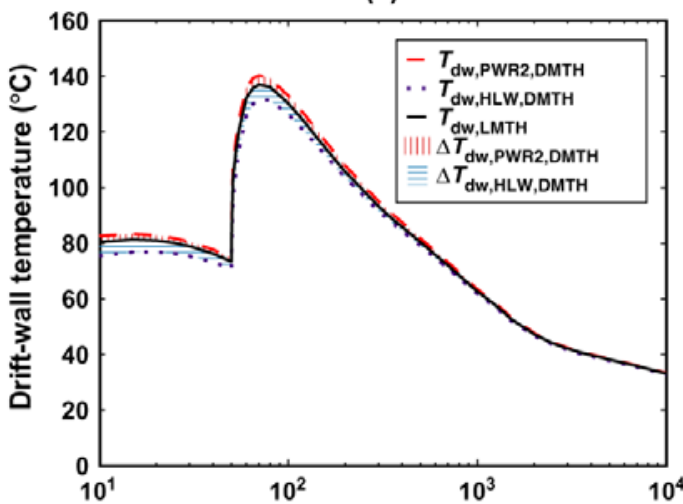

(c)

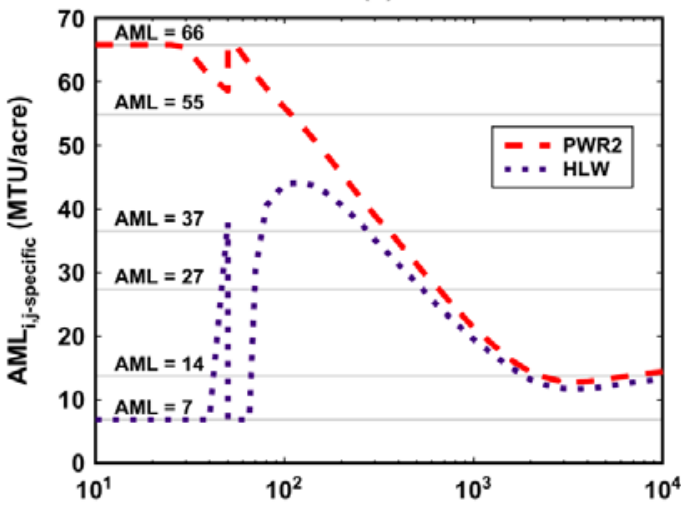

(e)

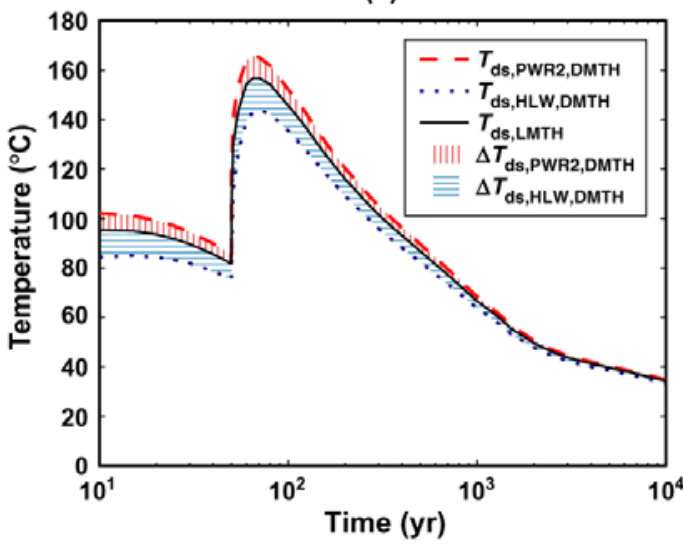

(b)

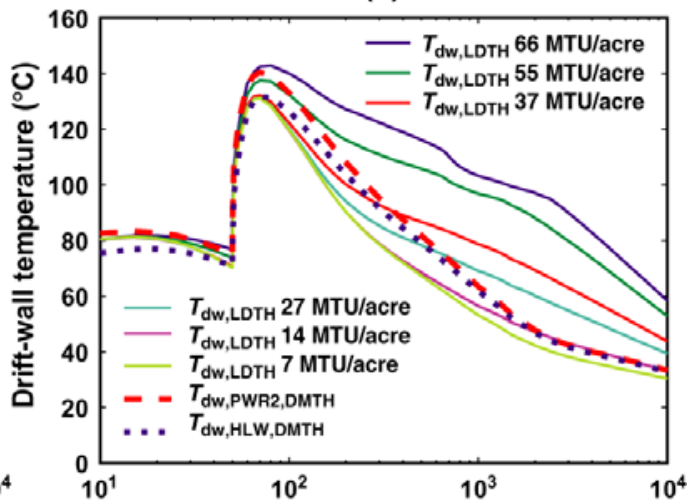

(d)

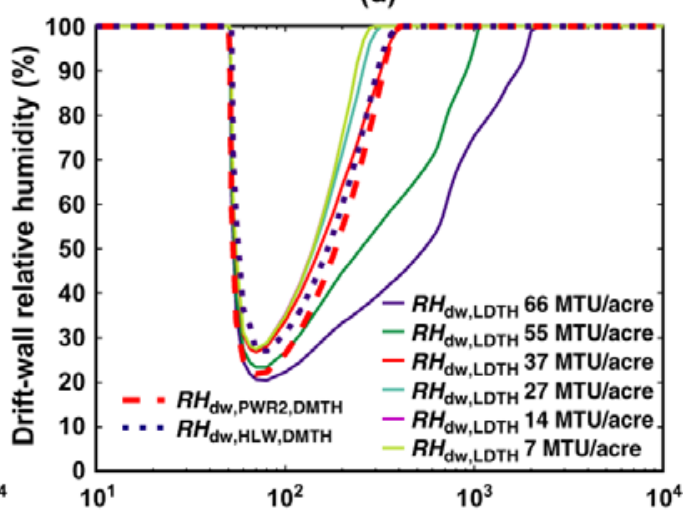

(f)

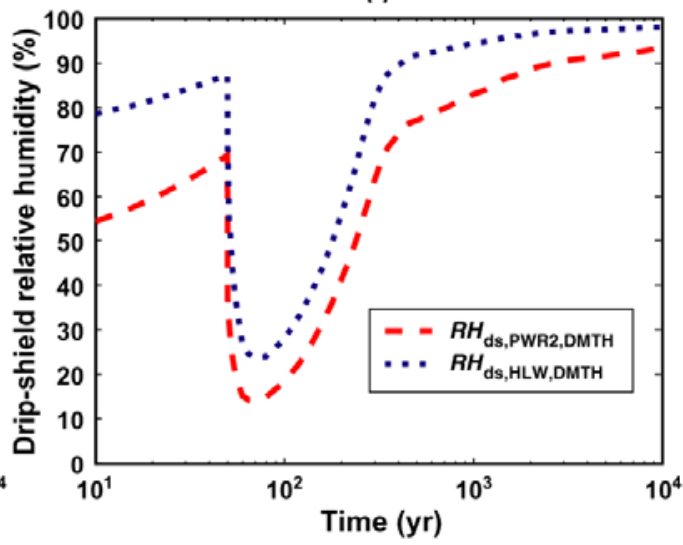

NOTE: (a) $T_{\mathrm{dw}, \mathrm{j}, \mathrm{DMTH}}$ vs. time for the HLW and PWR2 waste packages at the repository center; also plotted is $T_{\mathrm{dw}, L M T H}$ vs. time at the repository center (Figure 6.2-4c). (b) $T_{\mathrm{dw}, \mathrm{LDTH}}$ vs. time calculated for the six listed AMLs; also plotted is $T_{\mathrm{dw}, \mathrm{j}, \mathrm{DMTH}}$ vs. time for the HLW and PWR2 waste packages at the repository center. (c)

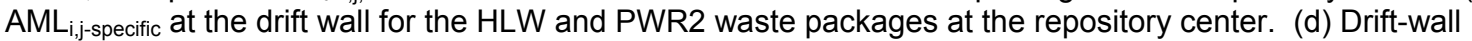
relative humidity $\mathrm{RH}_{\mathrm{dw}, \text { LDTH }}$ vs. time calculated for the six listed AMLs; also plotted is $R H_{\mathrm{dw}, \mathrm{j}, \mathrm{DMTH}}$ vs. time for the HLW and PWR2 waste packages at the repository center, which is determined on the basis of $A M L_{i, j-s p e c i f i c ~}$ vs. time for the respective waste packages. (e) $T_{\text {ds,j,DMTH }}$ vs. time for the HLW and PWR2 waste packages at the repository center; also plotted is $T_{\mathrm{ds}, \mathrm{LMTH}}$ Vs. time at the repository center. (f) $R H_{\mathrm{ds}, \mathrm{j}, \mathrm{DMTH}} \mathrm{Vs}$. time for the HLW and PWR2 waste packages.

Figure 6.2-5. MSTHM-Calculation Sequence (Continued) 
STAGE 1-The first calculation stage generates the host-rock effective AML, referred to as $A M L_{h s t r k, e f f}$. The $A M L_{h s t r k, e f f}$ is generated at each repository subdomain in the following manner:

1. First, the repository subdomain's host-rock temperature history simulated by the three-dimensional SMT submodel is compared with temperature histories simulated by the one-dimensional SDT submodels for a range of heat loading conditions (e.g., for 55 MTU/acre, for 46 MTU/acre, etc.). Note that because the SDT and SMT submodels use smeared heat sources, the SDT and SMT host-rock temperatures are averaged temperatures for the repository horizon (from pillar centerline to pillar centerline) at a given location.

2. Second, the value of $A M L_{h s t r k, e f f}$ at any given time is the AML that a one-dimensional SDT submodel would have to use in order to match the three-dimensional SMT modeled temperature at that location. By using the $A M L_{h s t r k, e f f}$, the influence of three-dimensional mountain-scale heat flow is imposed on the two-dimensional LDTH submodels discussed in Stage 2. As an example, Figure 6.2-4a-c illustrates how the concept of the AML $\mathrm{h}_{\mathrm{hstrk}, \mathrm{eff}}$ is used to account for three-dimensional mountain-scale heat flow. The host-rock temperature $T_{\mathrm{SMT}}$ calculated by the three-dimensional SMT submodel is compared with temperatures $T_{\mathrm{SDT}}$ calculated by the family of AML-dependent SDT submodels (Figure 6.2-4a). For each timestep, AML hstrk,eff (Figure 6.2-4b) is obtained by interpolating for $T_{\mathrm{SMT}}$ among the family of AML-dependent $T_{\mathrm{SDT}}$ curves. For example, Point $\mathrm{A}$, which is at 20 years, finds the $T_{\mathrm{SMT}}$ to be virtually the same as $T_{\mathrm{SDT}}$ for $55 \mathrm{MTU} / \mathrm{acre}$, thus yielding an AML $\mathrm{L}_{\mathrm{hstrk}, \text { eff }}$ of 55 MTU/acre at 20 years. Point B, which is at 200 years, finds $T_{\text {SMT }}$ lying between $T_{\mathrm{SDT}}$ for 55 and $37 \mathrm{MTU} / \mathrm{acre}$; linear interpolation between $T_{\mathrm{SMT}}$ and the two $T_{\mathrm{SDT}}$

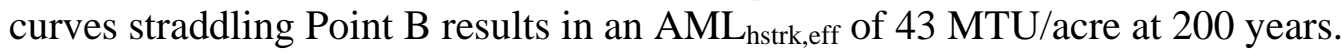

Initially, $T_{\mathrm{SMT}}$ at the center of this three-drift repository test case corresponds exactly to $T_{\mathrm{SDT}}$ calculated by the 55-MTU/acre SDT submodel because there has been no thermal communication between the center and edge of the repository. Thus, AML $L_{\text {hstrkeff }}$ is the emplaced AML of 55 MTU/acre for early time (Figure 6.2-4b). Because of the relatively small size of the repository in this example (which corresponds to the MSTHM validation test problem described in Section 7.5), it takes only 50 years to establish thermal communication between the center and edge of the repository. Thus, the edge-cooling effect begins to influence the repository center at about 50 years, causing $T_{\mathrm{SMT}}$ to begin a steady decline relative to the family of AML-dependent $T_{\mathrm{SDT}}$ curves. This relative decline in $T_{\mathrm{SMT}}$ (Figure 6.2-4a) results in a corresponding steady decline in host-rock effective AML (Figure 6.2-4b).

STAGE 2-This stage generates the three-dimensional LMTH-model (Table 1-2) temperatures at each of the repository subdomains; it does not address the influence of waste package-to-waste package variability in heat output. The LMTH-model drift-wall temperature $T_{\mathrm{dw}, \mathrm{LMTH}}$ is

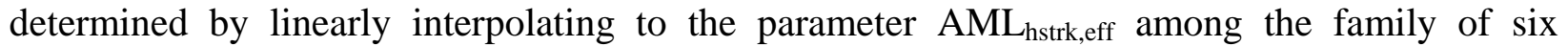
AML-dependent LDTH submodel drift-wall temperature $T_{\mathrm{dw}, \mathrm{LDTH}}$ curves. Returning to the example discussed in Stage 1 and examining Figure 6.2-4c, the AML $L_{\mathrm{hstrk}, \text { eff }}$ is 55 MTU/acre at Point A ( $t=20$ years), and thus $T_{\mathrm{dw}, \mathrm{LMTH}}$ is equal to $T_{\mathrm{dw}, \mathrm{LDTH}}$ for $55 \mathrm{MTU} / \mathrm{acre}$, which is about $81^{\circ} \mathrm{C}$. At Point B $(t=200$ years $)$, the AML $\mathrm{Astrk}_{\text {,eff }}$ is $43 \mathrm{MTU} / \mathrm{acre}$, and thus an interpolated value of $T_{\mathrm{dw}, \mathrm{LMTH}}$ of $105^{\circ} \mathrm{C}$ is determined, which is between $T_{\mathrm{dw}, \mathrm{LDTH}}$ for $55 \mathrm{MTU} / \mathrm{acre}\left(115^{\circ} \mathrm{C}\right)$ and $T_{\mathrm{dw}, \mathrm{LDTH}}$ for $37 \mathrm{MTU} / \mathrm{acre}\left(100^{\circ} \mathrm{C}\right)$. The process of using AML $\mathrm{h}_{\mathrm{hstrk}, \mathrm{eff}}$ to generate LMTH-model 
temperatures is repeated for invert temperatures $T_{\mathrm{in, \textrm {LMTH }}}$, for drip-shield temperatures Tds, LMTH, and for temperatures at various reference locations in the host rock. LMTH-model temperatures are determined for each of the repository subdomains. It is important to note that the LDTH and DDT submodels include the mechanism of thermal-radiative heat transfer between the waste package, drip-shield, invert, and drift-wall surfaces. Because thermal-radiative heat transfer is proportional to the temperature difference between two surfaces raised to the fourth power (i.e., $T_{1}{ }^{4}-T_{2}{ }^{4}$ ), it is dependent on temperature differences within the drifts, as well as on the absolute temperature (history) in the drifts. Consequently, a DDT submodel, which is run at only one AML, cannot address the manner in which thermal-radiative heat transfer is dependent on absolute temperature (history). To address this issue, DDT submodels are run at a variety of AMLs so that thermal-radiative heat transfer incorporates the influence of the temperature differences, as well as the influence of the absolute temperature in the drift, all as a function of time. Because the DDT submodels are run for at least four different AMLs that cover a wide range of temperature histories, interpolations between the respective DDT submodels are performed over small enough temperature-history ranges that piecewise linear interpolation adequately characterizes the underlying nonlinear process of thermal-radiative heat transfer.

STAGE 3-After LMTH-model temperatures have been determined at all reference locations (except for on the waste package) and for all repository subdomains, the next stage in the MSTHM process is to build the DMTH-model (Table 1-2) by incorporating the influence of waste package-to-waste package variability in heat output obtained from the family of DDT submodels. For each DDT submodel, the local deviation from an axially averaged temperature (i.e., averaged along the axis of the drift) is determined for each of the four waste package types (PWR1, PWR2, BWR, and HLW) for a variety of reference locations (e.g., drift wall, drip shield, invert, etc.). This local deviation is the difference between the local temperature of interest (e.g., the drift-wall temperature) and the corresponding axially averaged temperature. For example, local temperature deviations are computed for the drift wall $\left(\Delta T_{\mathrm{dw}, \mathrm{jDDT}}\right)$ and for the drip shield $\left(\Delta T_{\mathrm{ds}, \mathrm{j}, \mathrm{DDT}}\right)$. These temperature deviations are then interpolated as a function of the $\mathrm{AML}_{\mathrm{hstrk}, \text { eff }}$ in the same manner as $T_{\mathrm{i}, \mathrm{LDTH}}$ is interpolated to determine $T_{\mathrm{i}, \mathrm{LMTH}}$, as discussed in Stage 2. This is done to determine a temperature deviation accounting for the evolving influence of the edge-cooling effect at that repository subdomain. Computed temperature deviations for the drift wall and drip shield ( $\Delta T_{\mathrm{dw}, \mathrm{j}, \mathrm{DMTH}}$ and $\left.\Delta T_{\mathrm{ds}, \mathrm{j}, \mathrm{DMTH}}\right)$ are illustrated in Figure 6.2-4d. The DMTH-model values of drift wall temperature $\left(T_{\mathrm{dw}, \mathrm{j}, \mathrm{DMTH}}\right.$, Figure 6.2-5a) are determined by adding $\Delta T_{\mathrm{dw}, \mathrm{j}, \mathrm{DMTH}}$ (Figure 6.2-4d) to $T_{\mathrm{dw}, \mathrm{LMTH}}$ (Figure 6.2-4c). Note that the DMTH-model values of drip-shield temperature $T_{\mathrm{ds}, \mathrm{j}, \mathrm{DMTH}}$ are similarly determined by adding $\Delta T_{\mathrm{ds}, \mathrm{j}, \mathrm{DMTH}}$ to $T_{\mathrm{ds}, \mathrm{LMTH}}$ (Figure 6.2-5e).

STAGE 4-The parameter $A M L_{i, j-s p e c i f i c ~}$ accounts for axial variations due to waste package sequencing and waste package-to-waste package variability in heat output and is necessary for the calculation of all hydrologic parameters in the DMTH-model. The parameter AML $\mathrm{L}_{\mathrm{i}, \mathrm{j} \text {-specific }}$ is generated in much the same manner as the parameter $A M L_{h s t r k, e f f}$ in Stage 1. A number of values

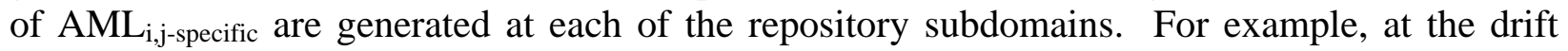

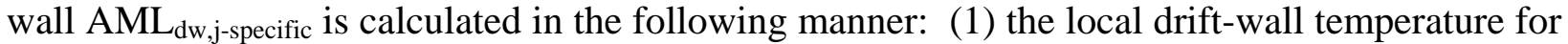
a specific waste package $T_{\mathrm{dw}, \mathrm{j}, \mathrm{DMTH}}$ is compared to the family of AML-dependent $\mathrm{T}_{\mathrm{dw}, \mathrm{LDTH}}$ curves (Figure 6.2-5b); (2) the value of $A M L_{d w, j-s p e c i f i c ~}$ at any given time is the AML that an LDTH submodel would have to be to match the three-dimensional DMTH-model result. Figure 6.2-5c

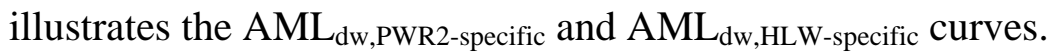




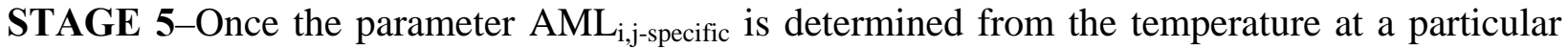
repository subdomain and a reference/waste package-specific location, it is possible to determine the corresponding hydrologic parameters, using output from the family of AML-dependent LDTH submodels. Note that the hydrologic parameters from the LDTH submodels are collectively referred to as $\mathrm{H}_{\mathrm{i}, \mathrm{j}, \mathrm{LMTH}}$ in Figure 1-1 and Table 1-3. For example, $R H_{\mathrm{dw}, \mathrm{j}, \mathrm{DMTH}}$ is obtained by linear interpolation for each timestep, using the $A M L_{d w, j-s p e c i f i c ~}$ and the family of AML-dependent $R H_{\mathrm{dw}, \mathrm{LDTH}}$ curves (Figure 6.2-5d). The value of $R H_{\mathrm{dw}, \mathrm{j}, \mathrm{DMTH}}$ accounts for both the reference/waste package-specific deviations in local temperature and for the influence of three-dimensional mountain-scale heat flow at that particular repository subdomain. With the exception of drip-shield relative humidity $R H_{\mathrm{ds}, \mathrm{j}, \mathrm{DMTH}}$ and waste package relative humidity $R H_{\mathrm{wp}, \mathrm{j}, \mathrm{DMTH}}$, all other hydrologic parameters are calculated in a similar manner to $R H_{\mathrm{dw}, \mathrm{j}, \mathrm{DMTH}}$.

STAGE 6-The relative humidity on the drip shield and waste package $\left(R H_{\mathrm{ds}, \mathrm{j}, \mathrm{DMTH}}\right.$ and $\left.R H_{\mathrm{wp}, \mathrm{j}, \mathrm{DMTH}}\right)$ is determined by relating thermal-hydrologic parameters that were determined by the DMTH model. The drip-shield relative humidity, $R H_{\mathrm{ds}, \mathrm{j}, \mathrm{DMTH}}$ is obtained by the following relation:

$$
R H_{d s, j, D M T H}=R H_{d w, c a v} \frac{P_{s a t}\left(T_{d w, c a v}\right)}{P_{s a t}\left(T_{d s, j, D M T H}\right)}
$$

Here $R H_{\mathrm{ds}, \mathrm{j}, \mathrm{DMTH}}$ and $T_{\mathrm{ds}, \mathrm{j}, \mathrm{DMTH}}$ are the perimeter-averaged relative humidity and temperature on the drip shield, $R H_{\mathrm{dw} \text {,cav }}$ and $T_{\mathrm{dw} \text {,cav }}$ are the perimeter-averaged relative humidity and temperature on the drift wall and invert surfaces that adjoin the open drift cavity outside of the drip shield, and $P_{\text {sat }}$ is the saturated vapor pressure. The waste package relative humidity $R H_{\mathrm{wp}, \mathrm{j} \text {,DMTH }}$ is calculated in an analogous manner. The relationship for the $R H_{\mathrm{wp}, \mathrm{j}, \mathrm{DMTH}}$ utilizes the manner in which gas-phase mixing at the drip-shield joints allows the continuity of the partial pressure of water vapor $P_{\mathrm{v}}$ between the outside and inside of the drip shield. As discussed in Section 5.3.1.1, the joints in the drip shield allow the transport (by advection and binary diffusion) of gas (air plus water vapor) across the drip shield, which allows the continuity of $P_{\mathrm{v}}$ across the drip shield. Note that the assumption of the continuity of $P_{\mathrm{v}}$ across the drip shield is also used as a bounding case in In-Drift Natural Convection and Condensation (BSC 2004 [DIRS 164327], Section 5.3.6). From a heat-transfer perspective, the drip shield functions like a thermal-radiation shield (between the waste package and the drift wall) that causes the waste package to be hotter than it would have been without the presence of the drip shield. Figure 6.2-5f illustrates $R H_{\mathrm{ds}, \mathrm{j}, \mathrm{DMTH}}$ at two waste package locations at the center of the repository.

\subsubsection{SMT Submodels}

The three-dimensional SMT submodel is used to determine the repository-scale variations in host-rock temperature $(T)$ resulting from the heat output from the entire inventory of 70,000 MTU of waste, including 63,000 MTU of commercial spent nuclear fuel (CSNF) and 7,000 MTU of other nuclear waste (Canori and Leitner 2003 [DIRS 166275], p. 3-95). The SMT submodel includes the influence of mountain-scale thermal-property stratigraphic variation, the edge-cooling effect, which results from lateral heat loss at the repository edges, and the overburden-thickness distribution. Overburden thickness is defined to be the depth of the repository horizon below the ground surface. The SMT submodel domain extends from the ground surface to $1,000 \mathrm{~m}$ below the present-day water table and the lateral (adiabatic) 
boundaries are far enough away from the repository that they do not affect repository temperatures. The temperature $1,000 \mathrm{~m}$ below the water table is estimated by extrapolation using the software routine boundary_conditions v1.0 (Section 3.1.8).

The SMT submodel is a conduction-only calculation that does not require separate validation in this report. The reason they do not require validation is that they are conduction-only calculations that utilize standard scientific methods (e.g., Fourier's Law) to perform the calculations. Moreover, validation testing of the NUFT v3.0s code included conduction-only test problems (bmrk002 and verif02), which are described in the Validation Test Plan for NUFT 3.0s (LLNL 2002 [DIRS 170259]; LLNL 2000 [DIRS 170258]).

\subsubsection{SMT Submodel Mesh}

The actual and modeled repository footprints (Figure 6.2-3) cover nearly identical areas of approximately $4.656 \mathrm{~km}^{2}$, which is based on the modeled length of drifts (Table 6.2-1) multiplied by the 81-m drift spacing. The repository footprint corresponds to the area that is heated by the smeared-heat-source representation of heat generation from waste packages. The areal distribution of gridblocks in the repository area of the SMT submodel is shown in Figure 6.2-3. The SMT submodel discretely represents each emplacement panel (Panels 1, 2E, 2W, 3, and 5) as well as each emplacement drift by using rows of heated gridblocks that are $20 \mathrm{~m}$ in the longitudinal direction, $81 \mathrm{~m}$ perpendicular to the drift axis, and 6-m thick in the vertical direction. The 6-m-thickness of the smeared heat source in the SMT submodel is consistent with that of the SDT submodel discussed in Section 6.2.7. There are 2,874 20-m intervals along the 95 emplacement drifts in the SMT submodel. The actual total heated length of emplacement drift in the repository is $57,480.2 \mathrm{~m}$; the modeled length of emplacement drifts is $57,480.0 \mathrm{~m}$. Table 6.2-1 lists the actual and modeled lengths of heated emplacement drifts in each of the panels. The heated length of each emplacement drift is obtained from the end-point coordinates (BSC 2003 [DIRS 161727]).

The SMT submodel mesh is constructed so that boundary effects have an insignificant influence on the predicted temperatures near the repository. This is accomplished by extending the lateral boundaries at least $1,000 \mathrm{~m}$ beyond the repository edges and by extending the lower boundary $1,000 \mathrm{~m}$ below the water table.

The software routine YMESH v1.54 (Section 3.1.7) is used to generate the SMT submodel mesh file so that it is consistent with the three-dimensional distribution of UZ model layers in the site-scale UZ flow and transport model (DTN: LB03023DKMGRID.001 [DIRS 162354]) as described in Table 11 of Development of Numerical Grids for UZ Flow and Transport Modeling (BSC 2004 [DIRS 169855]). The process of building the SMT submodel mesh is described in Appendix I. Note that the lower boundary (corresponding to the water table) of the threedimensional site-scale UZ flow model is a gently sloping surface. It is also noted that the output from the previous version of the site-scale UZ flow model (DTN: LB990701233129.001 [DIRS 106785]) had a horizontal lower boundary at an elevation of $730 \mathrm{~m}$, which was based on an assumption that the water table was horizontal. 
Table 6.2-1. Summary of Emplacement Panels and Drifts Represented in the SMT Submodel

\begin{tabular}{|c|c|c|c|c|}
\hline Panel & $\begin{array}{c}\text { Total heated drift } \\
\text { length } \\
(\mathbf{m})^{\mathbf{a}}\end{array}$ & $\begin{array}{c}\text { Number of } \\
\text { emplacement }_{\text {drifts }^{\mathbf{a}}}\end{array}$ & $\begin{array}{c}\text { Number of heated } \\
\text { gridblocks }^{\mathbf{b}}\end{array}$ & $\begin{array}{c}\text { Total modeled } \\
\text { length of drifts }_{(\mathbf{m})^{\mathbf{c}}}\end{array}$ \\
\hline $\mathbf{1}$ & $4,100.4$ & 8 & 206 & $4,120.0$ \\
\hline $\mathbf{2 E}$ & $10,882.0$ & 19 & 545 & $10,900.0$ \\
\hline $\mathbf{2 W}$ & $13,845.1$ & 23 & 689 & $13,780.0$ \\
\hline $\mathbf{3}$ & $17,493.6$ & 30 & 877 & $17,540.0$ \\
\hline $\mathbf{5}$ & $11,159.1$ & $15^{\mathbf{d}}$ & 557 & $11,140.0$ \\
\hline $\begin{array}{c}\text { Entire } \\
\text { repository }\end{array}$ & $57,480.2$ & 95 & 2874 & $57,480.0$ \\
\hline
\end{tabular}

${ }^{a}$ Total heated drift lengths for each panel and for the entire repository, as well as the number of emplacement drifts, are determined from the endpoint coordinates in BSC 2003 [DIRS 161727].

${ }^{b}$ Each of the heated gridblocks represents a $20-m$ interval along the emplacement drift.

c Total length of drifts as represented in the SMT submodel, as well as in the MSTHM.

${ }^{d}$ Panel 5 has a total of 27 drifts; the 15 northernmost drifts are emplaced in the TSPA-LA base case.

The 2,874 gridblocks in the SMT submodel are the 2,874 locations for which the MSTHM provides thermal-hydrologic output. Because each of these 2,874 locations is represented by a gridblock that is 20-m-long in the axial direction along the drift, they can each contain approximately four waste packages. The MSTHM uses the DDT submodel (Section 6.2.8) to discretely represent the thermal-hydrologic conditions for a wide range of waste packages, ranging from those that have low heat-generation rates (e.g., DHLW waste packages) to those that have high heat-generation rates (e.g., 21-PWR CSNF waste packages). The DDT submodel discretely represents eight waste packages, including three 21-PWR CSNF waste packages, three 44-BWR CSNF waste packages, and two DHLW waste packages. The MSTHM is constructed to provide thermal-hydrologic parameter histories (e.g., temperature and relative humidity) for each one of those eight waste packages at all 2,874 locations in the repository, which results in a total of 22,992 sets of thermal-hydrologic parameter histories. This number of sets is greater than the number of waste packages that could be emplaced in 57,480 m of emplacement drifts. The extra thermal-hydrologic parameter sets are provided to address uncertainty concerning the actual emplaced sequencing of waste packages. In other words, it cannot be known a priori what the actual emplaced waste package sequencing will be. The 22,992 sets of thermal-hydrologic parameter histories are provided for multiple scenarios, such as lower-bound, mean, and upper-bound infiltration-flux cases to allow downstream process models to sample from a broad set of thermohydrologic conditions that encompasses the influence of various sources of uncertainty.

\subsubsection{SMT Submodel Boundary Conditions}

The SMT submodel domain extends from the ground surface to $1,000 \mathrm{~m}$ below the present-day water table. The lateral boundaries, which are adiabatic boundaries, are at least $1,000 \mathrm{~m}$ from the repository edges, which is far enough away from the repository so that they do not affect thermal behavior in the repository. The temperature at the ground surface is based on ground-surface temperatures from the three-dimensional UZ flow model (DTN: LB991201233129.001 [DIRS 146894], File INCON_thm_s32.dat), which is based on a correlation of temperature versus elevation. 
The temperature at the lower boundary of the model domain is extrapolated vertically from the temperature gradient at the (sloping) water table of the current site-scale UZ flow model. The temperature at the sloping water is interpolated, based on the temperature at an elevation of $730 \mathrm{~m}$, which was the water table in the previous three-dimensional UZ flow model, and the ground-surface temperature. Both the ground-surface temperature distribution and the (730-m-elevation) water-table temperature distribution are found in DTN: LB991201233129.001 [DIRS 146894], File INCON_thm_s32.dat. Appendix II describes the process of generating boundary temperatures for the SMT submodels, as well as for the other submodels.

Note that since the boundary conditions were determined for the SMT submodel, a new source of boundary conditions has been made available in Mountain-Scale Coupled Processes (TH/THC/THM) Models (BSC 2004 [DIRS 169866]). The temperature boundary conditions can be extracted from the INCON block of file: th_v16.dat of DTN: LB0310MTSCLTH3.001 [DIRS 170270]. As discussed in Appendix I, these updated boundary conditions result in insignificant differences in temperatures at both the upper boundary (the ground surface) and the lower boundary (the water table), compared to those obtained in this report from file: INCON_thm_s32.dat of DTN: LB991201233129.001 [DIRS 146894].

\subsubsection{SMT Submodel Heat-Generation Rates}

The heat-generation rate for the SMT submodel is in the form of a heat-generation-rate-versus-time table, which is part of the SMT submodel NUFT-input file. For the TSPA-LA base case there is an assumption that all waste packages are simultaneously emplaced (Section 5.2.3). Thus, heating starts at the same time for the entire repository represented in the SMT submodel. The heat-removal efficiency of drift ventilation is represented by the reduction of the net heat-generation rate during the preclosure period. It is important to note that the heat-removal efficiency depends on the distance from the ventilation inlet and it also varies with time (Table III-1 of Appendix III). Thus, the effective heat-generation rate along an emplacement drift depends on the distance from the edge of that drift during the preclosure period. The heat-removal effect of drift ventilation is incorporated into the heat-generation-rate-versus-time tables for the heated repository blocks, using the software routine heatgen_vent_emplace v1.0 (Section 3.1.9). For the postclosure period, the same heatgeneration-rate-versus-time table is applied to the entire repository because drift ventilation has ceased and the effective heat-generation rate is the full nominal rate. Appendix III describes the process of generating heat-generation-rate-versus-time tables for the SMT submodel, as well as for the other submodels.

\subsubsection{SMT Submodel Material Properties}

Because the SMT submodel is a thermal-conduction model, it only requires thermal properties, which are contained in the SMT submodel NUFT-input files.

The SMT submodel uses bulk thermal properties consistent with the SDT submodel (Section 6.2.7). These properties are based on Table IV-3a in Appendix IV and the assumption of using the wet thermal conductivity as discussed in Section 5.3.2.1. 
Where saturated zone thermal properties are required the thermal properties are a weighted average of UZ model layers as discussed in Section 5.3.2.2. The averaging is accomplished by determining area-weighting factors for each of the UZ model layers that occur at the water table, which is the lower boundary of the three-dimensional site-scale UZ flow model. The process of building the SMT submodel material property files is described in Appendix IV.

\subsubsection{SMT Submodel Simulations}

The initialization of the SMT submodel is accomplished by running the SMT submodel with no repository thermal load until a steady-state temperature distribution is achieved. Only one SMT submodel simulation is required to represent the preclosure and postclosure period. This simulation is run for 20,000 years after closure of the repository. The process of building the SMT submodel input files is described in Appendix V.

\subsubsection{LDTH Submodels}

The two-dimensional LDTH submodels use the dual-permeability method, modified with the active-fracture concept, to represent two-phase heat and fluid flow in the fractured porous rock. The LDTH submodels are run at the 108 drift-scale-submodel locations (Figure 6.2-3) and for 4 different values of modeled AML (14, 27, 55, and 66 MTU/acre). Representing the influence of edge-cooling effects requires that most of the LDTH submodel runs use a modeled AML that is less than the actual AML of the repository.

In addition to their use as a submodel within the MSTHM methodology, the two-dimensional LDTH submodels are also used as stand-alone models to conduct sensitivity analyses in this report (e.g., Section 6.3.9). Thus, the LDTH submodel is validated against the Drift Scale Test in Section 7.4.

The NUFT code is used to model flow through a fractured porous media in the LDTH submodels. The key NUFT options that are required for LDTH simulations include the dual-permeability and the active-fracture concept. These NUFT options are required to be consistent with the hydrologic property set (DTN: LB0208UZDSCPMI.002 [DIRS 161243]) used in the MSTHM calculations supporting the TSPA-LA.

The DKM conceptualizes the fractured rock as having two interacting materials, one representing the matrix and one representing the fractures. The interaction between the fractures and the matrix is explicitly calculated from the local temperature and pressure differences, thus allowing transient behavior to be predicted.

The active fracture concept accounts for the contact area between the fracture and the matrix, as well as the frequency of fractures. The concept is that fracture flow only occurs through some of the fractures. The flux through a fracture increases with liquid-phase saturation; thereby focusing flow through a portion of the fractures (i.e., through active fractures), which results in faster pathways for liquid-phase flux through the mountain.

The natural system hydrologic properties in the calibrated drift-scale hydrologic property set (DTN: LB0208UZDSCPMI.002 [DIRS 161243]) were calibrated in Calibrated Properties Model (BSC 2004 [DIRS 169857]), using an inverse modeling technique that assumes the use of 
the DKM and the active-fracture concept. Both the DKM and active-fracture concept are implemented in NUFT as options.

\subsubsection{LDTH Submodel Locations}

The LDTH submodel locations are shown in Figure 6.2-3, and represent repository-scale variability of thermal properties, hydrologic properties, percolation flux, and overburden thickness.

\subsubsection{LDTH Submodel Mesh}

The cross-sectional (lateral) dimensions of the drift for the postclosure period are shown in Figure 6.2-1; these dimensions were used to build the numerical meshes of the LDTH submodels (Figure 6.2-6). The same mesh is used for the initialization submodel runs, which establish steady-state conditions for the time of emplacement and the submodel runs for the preclosure and postclosure periods. The process of building the LDTH submodel input files is described in Appendix V.

The numerical mesh for the LDTH submodel (Figure 6.2-6) assumes that the drip shield and waste package are lumped as a monolithic heat source. This lumped approximation of the drip shield and waste package allows for the representation of thermal-hydrologic behavior down to the surface of the drip shield. This lumped heat source is $1 \mathrm{~m}$ in the longitudinal direction along the drift axis (as it is in the smeared heat source in the SDT submodel discussed in Section 6.2.7). This lumped representation for the waste package and drip shield is applied during both the preclosure period and the postclosure period. Note that the drip shield is emplaced at the very end of the preclosure period. For the preclosure period, this lumped approximation of the drip shield and waste package in the LDTH submodel is corrected by the manner in which the preclosure DDT submodel (Figure 6.2-7), which accounts for the actual dimensions of the waste package (without the presence of the drip shield), is applied in the MSTHAC methodology (Section 6.2.4). The postclosure DDT submodel (Figure 6.2-8), which accounts for the actual waste package and drip-shield dimensions (including the correct dimensions of the gap between the waste package and drip shield), is applied in the MSTHAC methodology (Section 6.2.4) to represent thermohydrologic behavior between the drip shield and waste package. 


\section{LDTH submodel}

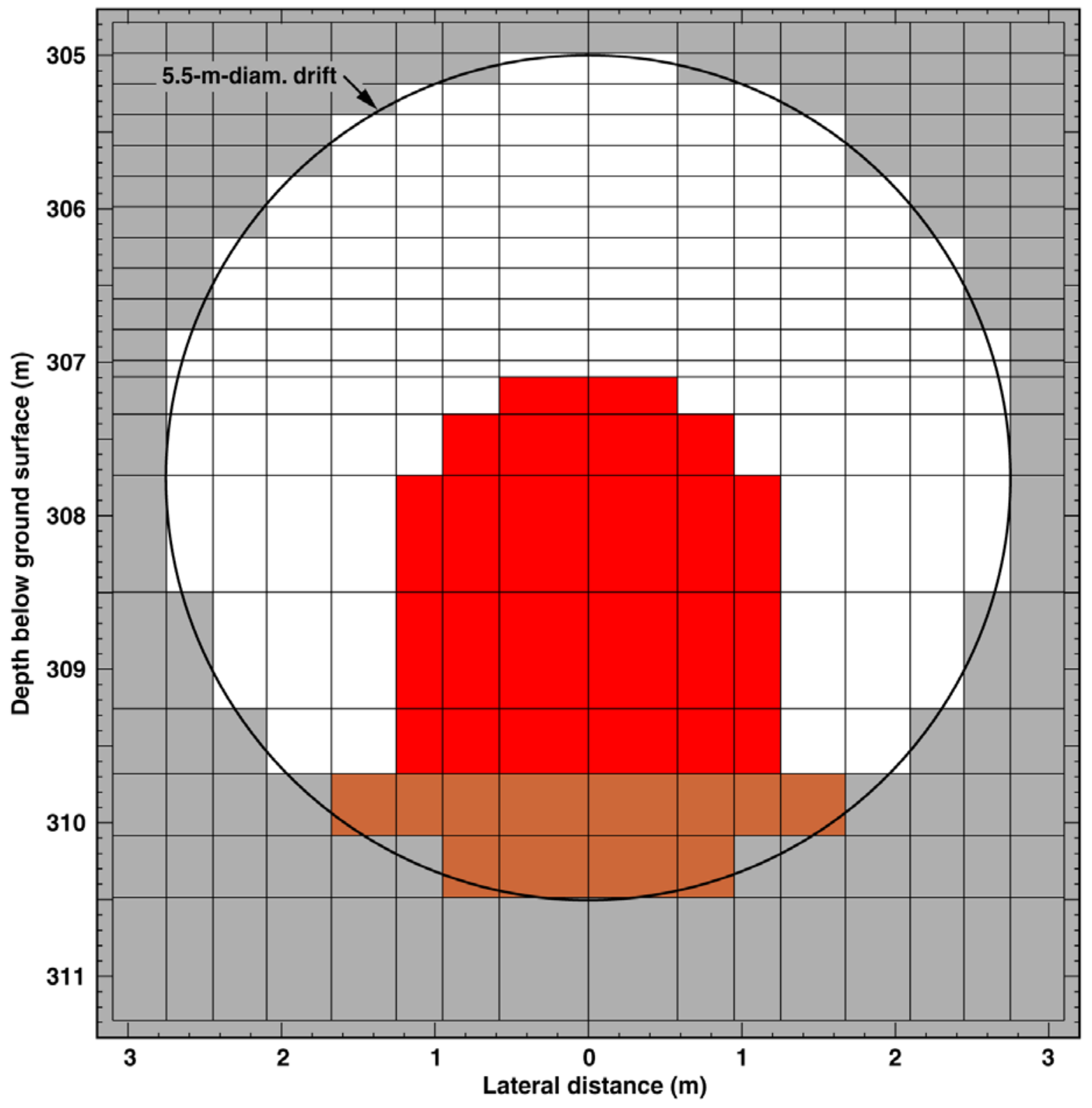

Tptpll (tsw35) host rock

$\square$ Air gap

Lumped drip-shield/waste-package heat source

Crushed tuff invert (Tptpll gravel)

P2WR5C10-LDTH55-01_mesh_xz

Source: See Table XIII-1.

NOTE: This illustrates just a portion of the mesh. The entire model extends laterally $40.5 \mathrm{~m}$ (the mid-pillar centerline) and extends from the ground surface to the water table.

Figure 6.2-6. Cross-Sectional (Lateral) View of the Numerical Mesh Used in the Vicinity of the Drift for All LDTH Submodels, Including Both the Initialization Runs and the Preclosure and Postclosure Runs 


\subsubsection{LDTH Submodel Boundary Conditions}

Because the LDTH submodels are for a symmetry cell between the vertical plane down the center of the drift and the vertical midplane between drifts, the lateral boundaries are adiabatic and no-mass-flow boundaries. The LDTH submodels require temperature, pressure, and gas-phase air-mass fraction at the upper boundary, which represents the ground surface, and at the lower boundary, which represents the water table. The upper boundary also requires the enthalpy associated with the infiltration flux at the top of the model. Note that the enthalpy is determined from the temperature of the upper boundary.

Both the upper and lower boundaries have constant conditions with time. Note that the process of calculating air-mass fraction at the ground surface utilizes the assumption that the atmosphere is at 100 percent relative humidity (Section 5.1.1). The process of adding the boundary conditions to the LDTH submodels is described in Appendix II.

Note that since the boundary conditions were determined for the LDTH submodels, a new source of boundary condition has been made available in Mountain-Scale Coupled Processes (TH/THC/THM) Models (BSC 2004 [DIRS 169866]). The temperature and gas-phase-pressure boundary conditions can be extracted from the INCON block of file: th_v16.dat of DTN: LB0310MTSCLTH3.001 [DIRS 170270]. As discussed in Appendix I, these updated boundary conditions result in insignificant differences in temperatures and gas-phase pressures at both the upper boundary (the ground surface) and the lower boundary (the water table) compared to those obtained in this report from file: INCON_thm_s32.dat of DTN: LB991201233129.001 [DIRS 146894].

\subsubsection{LDTH Submodel Heat-Generation Rates}

The heat-generation rates for the LDTH submodels are in the form of heat-generation-rate-versus-time tables located in NUFT include files. Because any given LDTH submodel covers the same model domain (including the same area in plan view) as the corresponding SDT submodel, the LDTH and corresponding SDT submodel use the same heat-generation-rate-versus-time tables. The drip shield and waste package are lumped as a monolithic heat source. The heat-removal efficiency of drift ventilation is represented by the reduction of the net heat-generation rate during the preclosure period. The heat-removal efficiency depends on the distance from the ventilation inlet and also varies with time. Thus, the effective heat-generation rate along an emplacement drift depends on the distance from the edge of that drift during the preclosure period. The heat-removal effect of drift ventilation is incorporated into the heat-generation-rate-versus-time tables for a given LDTH-SDT submodel location, using the software routine heatgen_ventTable_emplace v1.0 (Section 3.1.9). For the postclosure period, the same heat-generation-rate-versus-time table is applied to all LDTH-SDT submodel locations because drift ventilation has ceased and the effective heat-generation rate is the full nominal rate at all locations. The input files for the LDTH submodels involve assumptions described in Sections 5.1.1, 5.1.2, 5.1.3, 5.1.4, 5.1.5, 5.3.1.1, 5.3.1.2, 5.3.1.7, 5.3.1.8, 5.3.1.9, 5.3.1.10, 5.3.2.3, 5.3.2.4, and 5.3.2.7. Appendix III describes the process of generating heat-generation-rate-versus-time tables for the LDTH submodels. 


\subsubsection{LDTH Submodel Material Properties}

Material properties are read into the LDTH submodel NUFT-input files as "include" files for the natural system properties and for the engineered barrier system properties inside the emplacement drifts.

One hydrologic property set, called the modified-mean infiltration-flux hydrologic property set (dkm-afc-1Dds-mc-mi-04), is used to conduct the LDTH submodel calculations for lower-bound, mean, and upper-bound infiltration-flux cases. The modified-mean infiltration-flux property set is the same as the mean infiltration-flux property set (DTN: LB0208UZDSCPMI.002 [DIRS 161243]), with the one modification being that the van Genuchten fracture alpha in the Tptpul (tsw33) is set to be the same $\left(1.02 \times 10^{-4} \mathrm{~Pa}^{-1}\right.$ ) as that in the Tptpll (tsw35) unit (Table IV-4 in Appendix IV). The file dkm-afc-EBS-mi-03 gives the thermal and hydrologic properties of the materials inside the emplacement drift. The thermal properties inside the emplacement drifts, such as the drip shield composed of titanium and invert composed of crushed tuff, are given in Table 4.1-2. The thermal properties inside the drifts also include the emissivity values of the surfaces. Note that a value of 0.9 is used for the emissivity of the rock and invert surfaces in the drift, which is obtained from Incropera and DeWitt's (1996 [DIRS 108184]) advanced textbook for heat and mass transfer. The engineered barrier system thermal properties also include the use of an effective thermal conductivity for the gas-filled drift cavity that is based on a correlation (Francis et al. 2003 [DIRS 164602], Table 6) accounting for the influence of natural convection, which is described in Appendix I. It should be noted that the correlations for the in-drift effective thermal conductivity, which were obtained from Table 6 of Francis et al. (2003 [DIRS 164602]), have been updated in In-Drift Natural Convection and Condensation (BSC 2004 [DIRS 164327], Table 6.4.7-3), resulting in small changes to the coefficients. As evident in Figure I-1 of Appendix I, the small changes to the coefficients result in insignificant changes to the in-drift effective thermal conductivity. The gas-filled cavity between the drip shield and drift wall is represented as a porous medium with 100 percent porosity and a permeability of $1 \times 10^{-8} \mathrm{~m}^{2}$ (Section 5.3.1.7). Because the dual-permeability method is used, it is necessary to partition the gas-filled cavity into the matrix and fracture continua. This partitioning, which is taken to be 50 percent matrix continuum and 50 percent fracture continuum, has an insignificant on flow because of conditions in these respective continua are in equilibrium within the gas-filled drift. The input files are associated with the assumptions described in Sections 5.1.1, 5.1.2, 5.2.3, 5.3.1.1, 5.3.1.2, 5.3.1.7, 5.3.1.8, 5.3.2.3, and 5.3.2.4. The process of generating the LDTH submodel material properties files is described in Appendix IV. The input files require the assumptions described in Sections 5.1.1, 5.1.2, 5.2.3, 5.3.1.1, 5.3.1.2, 5.3.1.7, 5.3.1.8, 5.3.2.3, and 5.3.2.4. The process of generating the LDTH submodel material properties files is described in Appendix IV.

\subsubsection{LDTH Submodel Percolation Flux}

The liquid-phase flux is specified at the upper boundary of the LDTH submodels. For the TSPA-LA base case, the upper-boundary liquid-phase flux corresponds to the distribution of percolation flux just below the base of the PTn unit (also called the PTn-to-TSw percolation flux); these data are generated by the three-dimensional UZ flow model for the three climate states: present-day, monsoonal, and glacial-transition. Thus, the MSTHM includes the influence of lateral diversion in the PTn as represented in the three-dimensional UZ flow model. 
The PTn-to-TSw percolation flux is provided for the present-day, monsoonal, and glacial-transition climates for lower-bound, mean, and upper-bound infiltration-flux cases (DTN: LB0302PTNTSW9I.001 [DIRS 162277]), resulting in nine files. The software routine repository_percolation_calculator v1.0 (Section 3.1.13) is used to determine the percolation flux at each of the 108 LDTH-SDT submodel locations (Figure 6.2-3) in Panels 1, 2E, 2W, 3, and 5. The process of generating LDTH submodel percolation-flux boundary conditions is described in Appendix I. Appendix XII describes a comparison of the percolation-flux distribution implemented in the MSTHM compared to the PTn-to-TSw percolation-flux distribution from DTN: LB0302PTNTSW9I.001 [DIRS 162277]. As is evident in Figures XII-3 through XII-11, the percolation flux implemented in the MSTHM corresponds closely with that from DTN: LB0302PTNTSW9I.001 [DIRS 162277] for all three climate states and for all three infiltration-flux cases.

\subsubsection{LDTH Submodel Simulations}

The LDTH submodel is the only submodel type that has to be run for each of the three infiltration-flux cases (lower-bound, mean, and upper-bound). The simulations for the other three submodel types are applicable to all infiltration-flux cases.

Each LDTH submodel set for a given infiltration-flux case consists of 432 simulations, which comes from 108 drift-scale-submodel locations (Section 6.3.1) and 4 AML values run at each location $(108 \times 4=432)$. The process of building the LDTH submodel input files is described in Appendix I.

\subsubsection{SDT Submodels}

The one-dimensional smeared-heat-source drift-scale thermal-conduction (SDT) submodels are run in parallel with the LDTH submodels at the same 108 locations and for the same AMLs $(14,27,55$, and $66 \mathrm{MTU} / \mathrm{acre})$. These submodels are required to obtain functional relationships between "line-averaged" temperatures predicted by the LDTH submodel and the "smeared" host-rock temperatures predicted by the SDT submodel.

The SDT submodels are conduction-only calculations that do not require separate validation in this report. The reason they do not require validation is that they are conduction-only calculations that utilize standard scientific methods (e.g., Fourier's Law) to perform the calculations. Moreover, validation testing of the NUFT v3.0s code included conduction-only test problems (bmrk002 and verif02), which are described in the Validation Test Plan for NUFT 3.0s (LLNL 2002 [DIRS 170259]; LLNL 2000 [DIRS 170258]).

\subsubsection{SDT Submodel Locations}

The SDT submodels are run at the same 108 drift-scale-submodel locations (Figure 6.2-3) as the LDTH submodel (Section 6.2.6.1).

\subsubsection{SDT Submodel Mesh}

The SDT submodels use the same vertical discretization of gridblocks as is used in the SMT submodels (Section 6.2.5). The manner in which the LDTH-SDT temperature relationships are developed and used to modify SMT-predicted host-rock temperatures (Section 6.2.4) requires 
consistency between how vertical heat flow is modeled in the respective SDT and SMT submodels, including consistency in the vertical gridblock discretization in the respective submodels.

\subsubsection{SDT Submodel Boundary Conditions}

The SDT submodel boundary temperature conditions are the same as the corresponding LDTH submodel (Section 6.2.6.3). Consistent upper and lower boundary temperatures ensure self-consistency with respect to how the LDTH and SDT submodels are used to generate LDTH-temperature versus SDT-temperature relationships and how these relationships are used in the MSTHAC v7.0 methodology to correct SMT-predicted temperatures to LMTH conditions (Section 6.2.4).

Because the SDT submodels are for a symmetry cell between the vertical plane down the center of the drift and the vertical midplane between drifts, the lateral boundaries are adiabatic and no-mass-flow boundaries. The SDT submodels require temperature at the upper boundary, which represents the ground surface, and the lower boundary, which represents the water table. Both boundaries have constant temperature conditions with time. The process for generating SDT submodel boundary conditions is described in Appendix II.

Note that since the boundary conditions were determined for the SDT submodels, a new source of boundary condition has been made available from the Mountain-Scale Coupled Processes (TH/THC/THM) Models (BSC 2004 [DIRS 169866). The temperature boundary conditions can be extracted from the INCON block of file: th_v16.dat of DTN: LB0310MTSCLTH3.001 [DIRS 170270]. As discussed in Appendix I, these updated boundary conditions result in insignificant differences in temperatures at both the upper boundary (the ground surface) and the lower boundary (the water table), compared to those obtained in this report from file: INCON_thm_s32.dat of DTN: LB991201233129.001 [DIRS 146894].

\subsubsection{SDT Submodel Heat-Generation Rates}

Because any given SDT submodel represents the same model domain (including the same area in plan view) as the corresponding LDTH submodel, the SDT and corresponding LDTH submodel use the same heat-generation rate-versus-time table (Section 6.2.6.4). Appendix III describes the process of generating heat-generation-rate-versus-time tables for the SDT submodels. The heat generation is smeared over a gridblock that is 6-m thick in the vertical direction (as it is in the SMT submodel, discussed in Section 6.2.5), $1 \mathrm{~m}$ in the longitudinal direction along the drift axis (as it is in the LDTH submodels, discussed in Section 6.2.6), and which extends from the drift centerline to the midpillar location between drifts.

\subsubsection{SDT Submodel Material Properties}

Because the SDT submodel is a conduction-only model, the material properties only involve thermal properties. Material properties are read into the SDT submodel NUFT-input files as "include" files for the natural system thermal properties. The SDT submodel uses the same thermal properties (for the UZ model layers) that are used in the SMT submodel (Section 6.2.5.4). The material properties of the SDT submodels utilize assumptions described in Section 5.3.2.1. The process of building the SDT submodel material-property file is described in Appendix IV. 


\subsubsection{SDT Submodel Simulations}

Each SDT submodel set consists of 432 simulations that come from 108 LDTH-SDT submodel locations (Figure 6.2-3) and 4 AML values run at each location $(108 \times 4=432)$. The process of building the SDT submodel input files is described in Appendix V.

\subsubsection{DDT Submodels}

The three-dimensional DDT submodel is used to account for waste package-specific heat output and for thermal radiation between all waste package and drift surfaces to determine waste package-specific deviations (relative to line-averaged-heat-source conditions) in temperatures in the drift and adjoining host rock. For the preclosure and postclosure periods, thermal radiation between the waste package and drift surfaces controls the longitudinal temperature deviations along the drift. The values of thermal conductivity or convective heat-flow processes in the host rock play a minor role on the magnitude of longitudinal temperature deviations along the drift (Hardin 1998 [DIRS 100350], Section 3.7.5.4). This allows an MSTHM calculation to only require a set of DDT submodel calculations conducted at a single location in the repository. The P2WR5C10 LDTH-SDT submodel location is located in Panel 2W, which is located in the approximate center of the repository (Figures 6.2-3 and 6.3-1). The nomenclature R5C10 refers to the row and column of this drift-scale submodel location within the lattice of drift-scale submodel locations (Figure 6.2-3). This location was selected because the repository horizon at that location is in the middle of the Tptpll (tsw35 UZ model layer), which is the predominant host-rock type in the repository, and because the overburden thickness at that location is close to the average for the repository. The DDT submodels utilize assumptions described in Sections 5.2.2, 5.2.3, 5.3.2.1, and 5.4.

The DDT submodels are conduction-only calculations that do not require separate validation in this report. The reason they do not require validation is that they are conduction-only calculations that utilize standard scientific methods (e.g., Fourier's Law) to perform the calculations. Moreover, validation testing of the NUFT v3.0s code included conduction-only test problems (bmrk002 and verif02), which are described in the Validation Test Plan for NUFT 3.0s (LLNL 2002 [DIRS 170259]; LLNL 2000 [DIRS 170258]). The DDT submodel represents thermal radiation inside the emplacement drifts and also represents the influence of natural convective heat flow in the drifts through the use of an equivalent thermal conductivity that is based on a correlation given by Francis et al. (2003 [DIRS 164602], Table 6) (Section 6.2.8.5). Thus, the DDT does not model natural convection in the drift; it only uses a correlation derived elsewhere as indicated. The software qualifications of NUFT v3.0s and NUFT v3.0.1s include test problems that demonstrate the validity of NUFT in modeling a one-dimensional thermal conduction problem (bmrk 002), a three-dimensional thermal conduction problem (verif02), and a three-dimensional thermal radiation problem (verif03) (LLNL 2002 [DIRS 170259]; LLNL 2000 [DIRS 170258]).

\subsubsection{DDT Submodel Locations}

The P2WR5C10 LDTH-SDT submodel location, which is in the center of the repository, located in Panel 2W (Figures 6.2-3 and 6.3-1), is used for all DDT submodel calculations. 


\subsubsection{DDT Submodel Mesh}

The lateral and longitudinal dimensions of the drift for the preclosure and postclosure periods are shown in Figures 6.2-1 and 6.2-2, respectively. Note that the drip shield (Figure 6.2-1) is not present during the preclosure ventilation period. These dimensions were used to build the numerical meshes of the DDT submodels. The cross-section view of the mesh is shown in Figures 6.2-7 and 6.2-8 for the preclosure and postclosure periods, respectively. The longitudinal view of the mesh is shown in Figures 6.2-9 and 6.2-10 for the preclosure and postclosure periods, respectively. The DDT submodel utilizes symmetry in all four directions: (1) about the vertical midplane down the center of the drift, (2) the vertical midplane down the center of the rock pillar between drifts, (3) the vertical plane that is orthogonal to and intersects the "one-half" 21-PWR waste package, and (4) the vertical plane that is orthogonal to and intersects the "one-half" 44-BWR waste package (Figure 6.2-2). Thermal radiation is represented between all surfaces in the drift. From a heat-transfer perspective, the drip shield functions like a thermal-radiation shield (between the waste package and the drift wall) that causes the waste package to be hotter than it would have been without the presence of the drip shield. The increased temperature difference between the waste package and the drift wall reduces the relative humidity on the waste package in a fashion that is analogous to that given in Equation 24 (Section 6.2.4) for the drip shield itself.

\subsubsection{DDT Submodel Boundary Conditions}

The temperature boundary conditions for the DDT submodels are the same as those for the SDT submodel at the P2WR5C10 LDTH-SDT submodel location (Figures 6.2-3 and 6.3-1), which is in the center of the repository, located in Panel 2W. The DDT submodel temperature boundary conditions are the same as the corresponding LDTH submodel.

Because the DDT submodels are for a symmetry cell between the vertical plane down the center of the drift and the vertical midplane between drifts, the lateral boundaries are adiabatic and no-mass-flow boundaries. The DDT submodels require temperature at the upper boundary, which represents the ground surface, and at the lower boundary, which represents the water table. Both boundaries have constant temperature conditions with time. The process for generating DDT submodel boundary conditions is described in Appendix II.

\subsubsection{DDT Submodel Heat-Generation Rates}

Heat-generation-rate-versus-time tables are required for the 8 different waste packages represented in the DDT submodels (Figure 6.2-2), which are read into the DDT submodel NUFT-input files as "include" files. The heat-generation-rate-versus-time tables utilize the assumption described in Section 5.2.3. During the preclosure period, the DDT submodel has the same heat-removal-efficiency-versus-time table that is applicable to the P2WR5C10 LDTH-SDT submodel location (Figures 6.2-3 and 6.3-1). Note that the heat-removal-efficiency-versus-time tables are derived from DTN: MO0304MWDALACV.000 [DIRS 164551]. Appendix III describes the process of generating heat-generation-rate-versus-time tables for the DDT submodel, as well as for the other submodels. 


\section{Pre-closure DDT submodel}

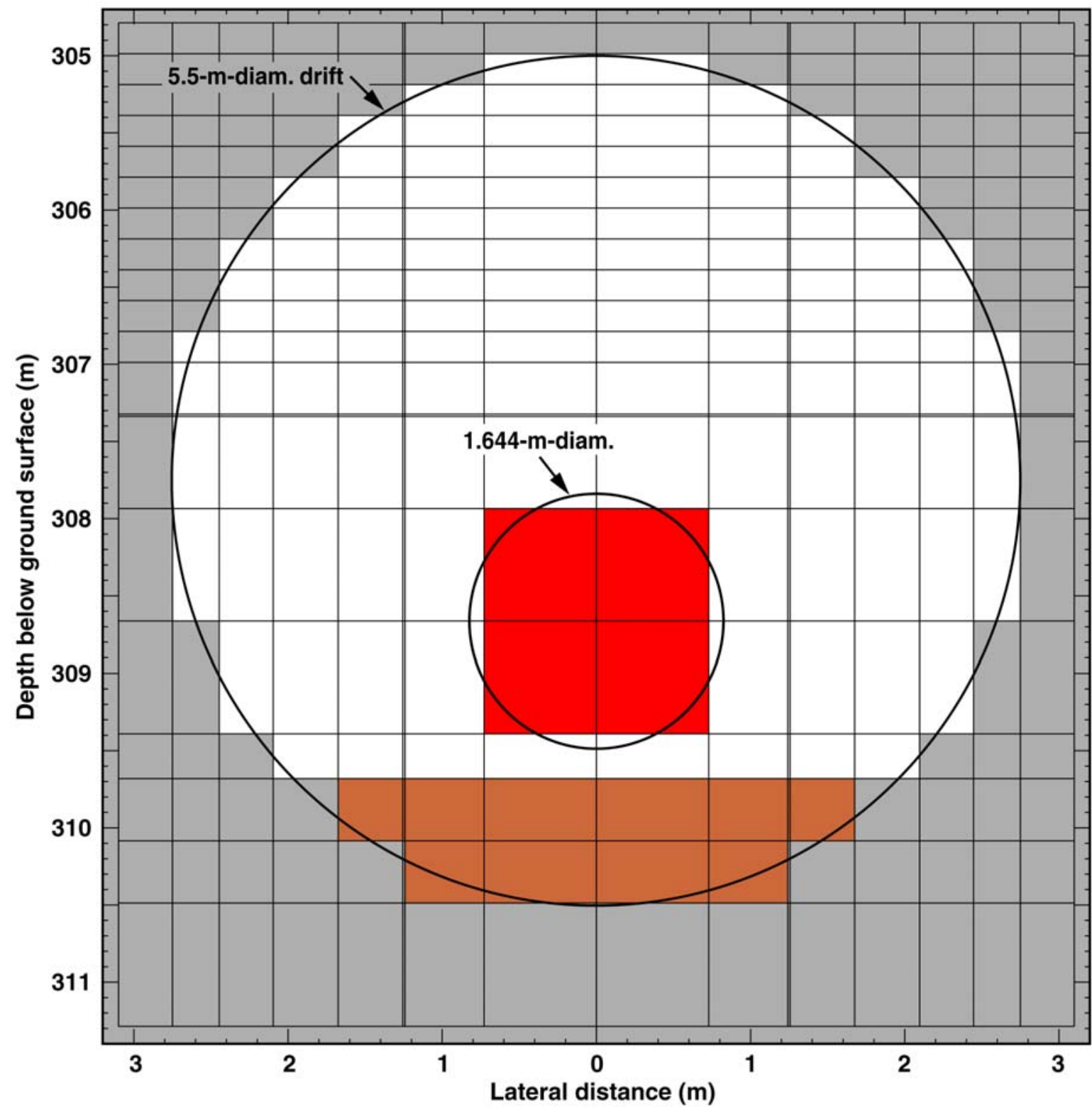

Tptpll (tsw35) host rock

Air gap

Waste package

Crushed tuff invert (Tptpll gravel)

P2WR5C10-DDT55-01v_mesh_xz

Source: See Table XIII-1.

NOTE: This illustrates just a portion of the mesh. The entire model extends laterally $40.5 \mathrm{~m}$ (the mid-pillar centerline) and extends from the ground surface to the water table.

Figure 6.2-7. Cross-Sectional (Lateral) View, Perpendicular to Drift Axis, of the Mesh Used in the Preclosure DDT Submodels 


\section{Post-closure DDT submodel}
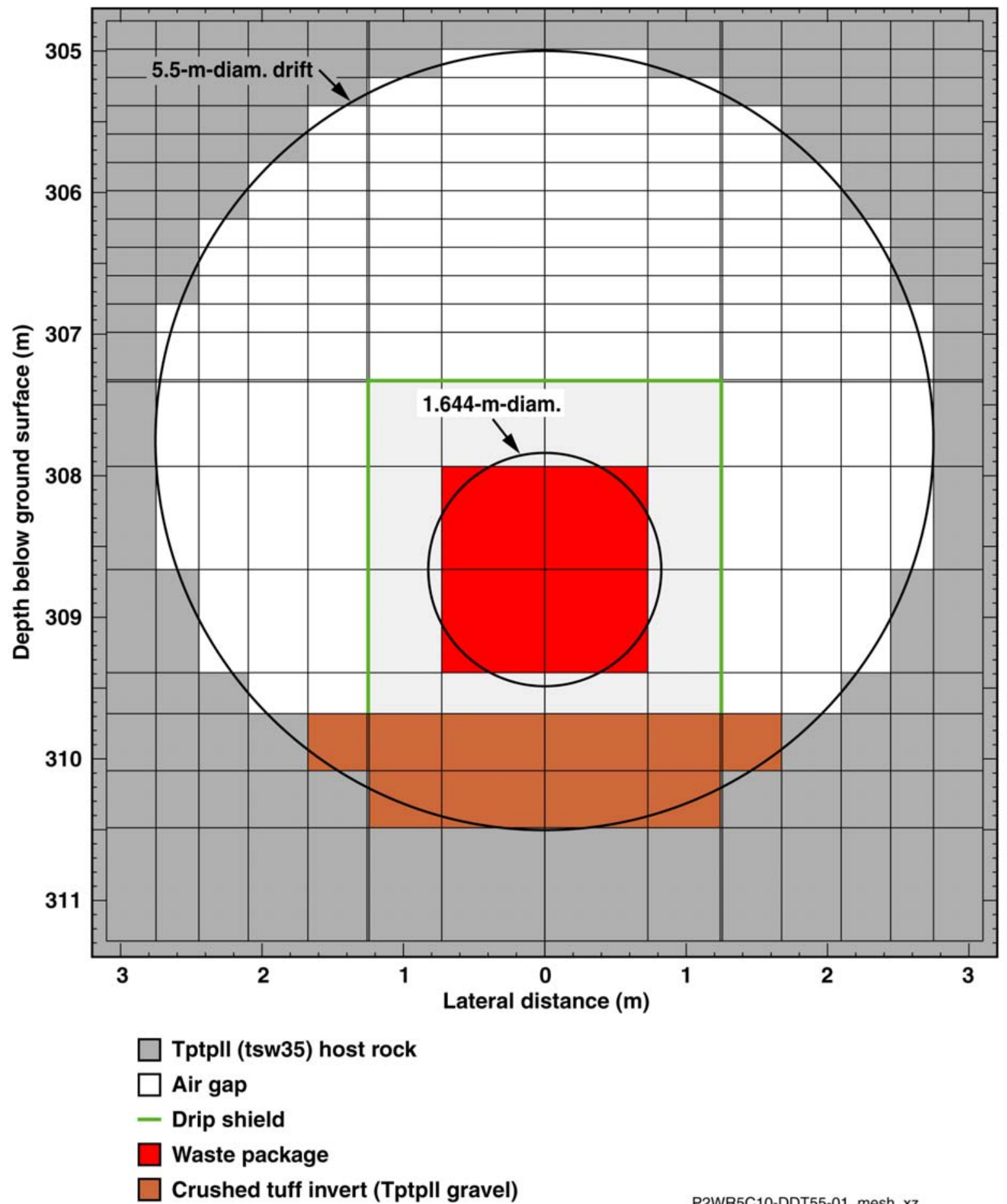

P2WR5C10-DDT55-01_mesh_xz

Source: See Table XIII-1.

NOTE: This illustrates just a portion of the mesh. The entire model extends laterally $40.5 \mathrm{~m}$ (the mid-pillar centerline) and extends from the ground surface to the water table.

Figure 6.2-8. Cross-Sectional (Lateral) View, Perpendicular to Drift Axis, of the Mesh Used in the Postclosure DDT Submodels 


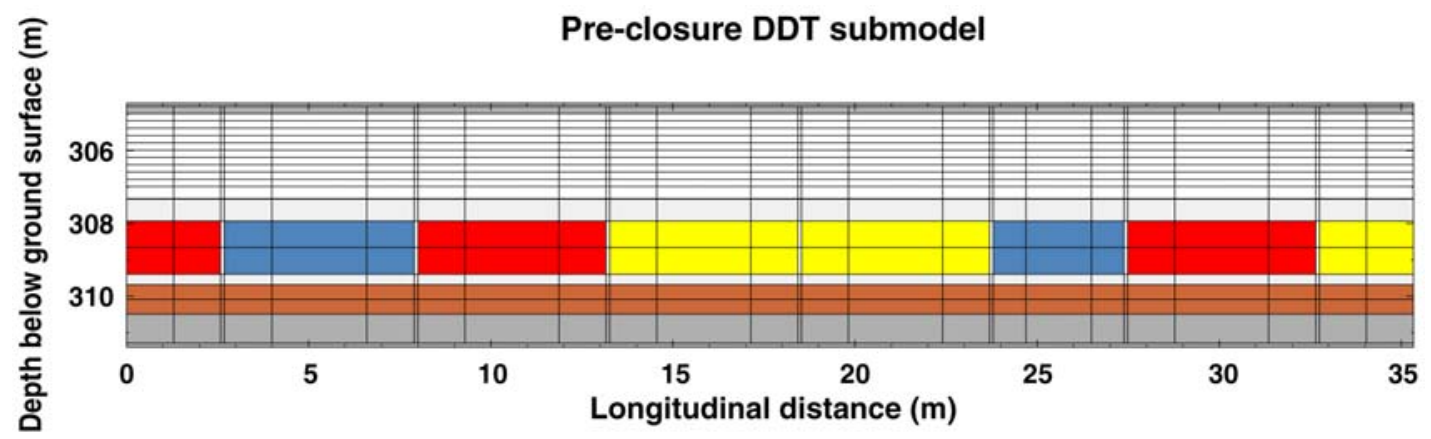

Tptpll (tsw35) host rock

Air gap

21-PWR AP CSNF WP

5 DHLW/DOE SNF WP

44-BWR CSNF WP

Crushed tuff invert (Tptpll gravel)

P2WR5C10-DDT55-01v_mesh_yz

Source: See Table XIII-1.

NOTE: $\quad$ WP = waste package. This illustrates just a portion of the mesh. The entire model extends laterally 40.5 $\mathrm{m}$ (the mid-pillar centerline) and extends from the ground surface to the water table.

Figure 6.2-9. Cross-Sectional (Longitudinal) View, Parallel to Drift Axis, of the Mesh Used in the Preclosure DDT Submodels

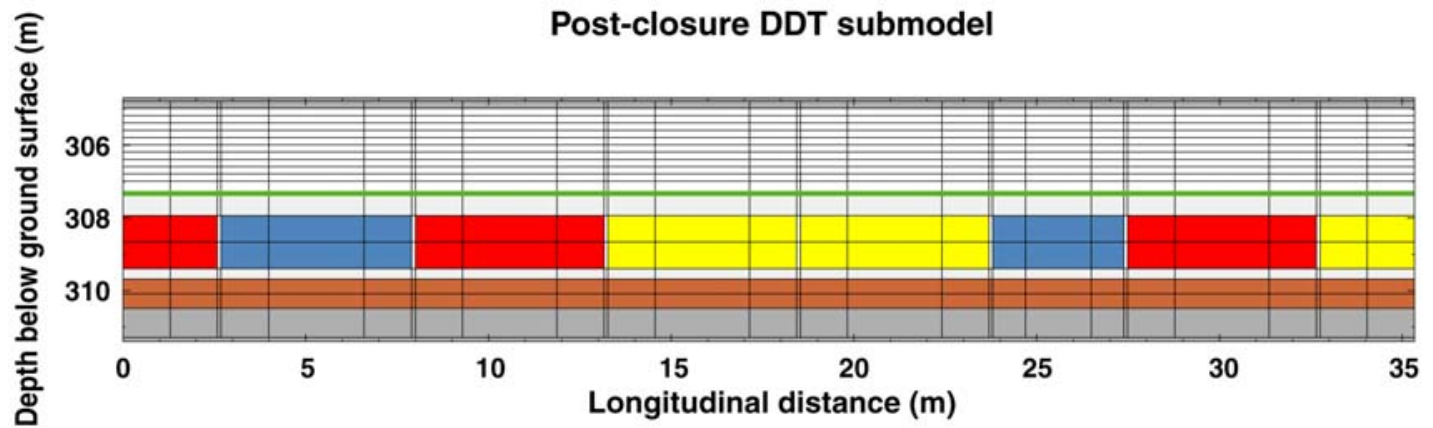

Tptpll (tsw35) host rock

Air gap

- Drip shield

21-PWR AP CSNF WP

5 DHLW/DOE SNF WP

44-BWR CSNF WP

Crushed tuff invert (Tptpll gravel)

P2WR5C10-DDT55-01_mesh_yz

Source: See Table XIII-1.

NOTE: $\quad$ WP $=$ waste package. This illustrates just a portion of the mesh. The entire model extends laterally 40.5 $\mathrm{m}$ (the mid-pillar centerline) and extends from the ground surface to the water table.

Figure 6.2-10. Cross-Sectional (Longitudinal) View, Parallel to Drift Axis, of the Mesh used in the Postclosure DDT Submodels 


\subsubsection{DDT Submodel Material Properties}

Because the DDT submodel is a thermal-conduction/radiation-only model (i.e., does not represent hydrologic processes), the material properties only involve thermal properties. Material properties are read into the SDT submodel NUFT-input files as "include" files for the natural system thermal properties. The DDT submodel uses the same thermal properties (for the UZ model layers) that are used in the SMT and SDT submodels (Sections 6.2.5.4 and 6.2.7.5). The DDT submodels also use thermal properties of the engineered barrier system components, such as the drip shield, invert, and respective waste packages (Table 4.1-2). The thermal properties of the engineered barrier system components include the emissivity values of the surfaces within the emplacement drifts. The engineered barrier system thermal properties also include the use of an effective thermal conductivity for the air in the drift cavity that is based on a correlation (Francis et al. 2003 [DIRS 164602], Table 6) accounting for the influence of natural convection, which is described in Appendix I. It should be noted that the correlations for the in-drift effective thermal conductivity, which were obtained from Table 6 of Francis et al (2003 [DIRS 164602]), have been updated in In-Drift Natural Convection and Condensation (BSC 2004 [DIRS 164327], Table 6.4.7-3), resulting in very small changes to the coefficients. As evident in Figure I-1 of Appendix I, the small changes to the coefficients result in insignificant changes to the in-drift effective thermal conductivity. The material properties of the DDT submodels utilize assumptions described in Section 5.3.2.1. The process of building the DDT submodel material-property file is described in Appendix IV.

\subsubsection{DDT Submodel Simulations}

A single set of DDT submodel simulations (for modeled AMLs of 14, 27, 55, and 66 MTU/acre) was conducted for this report at the P2WR5C10 LDTH-SDT submodel location (Figures 6.2-3 and 6.3-1). This set of DDT submodel simulations is used in all three (lower-bound, mean, and upper-bound) infiltration-flux cases. The process of building the DDT submodel NUFT-input files is described in Appendix V.

\subsubsection{SMT and SDT Submodels for the Low-Probability-Seismic Collapsed-Drift Scenario}

For the low-probability-seismic collapsed-drift scenario, no changes are required for the SMT submodel. Therefore, the description of the SMT submodel (Section 6.2.5) is applicable. For the collapsed-drift scenario, no changes are required for the SDT submodels. Therefore, the description of the SDT submodels (Section 6.2.7) is applicable. The SDT submodel location is the P2WR5C10 LDTH-SDT submodel location (Figures 6.2-3 and 6.3-1). A single set of SDT submodel simulations (for modeled AMLs of 14, 27, 55, and 66 MTU/acre) was utilized.

\subsubsection{LDTH Submodels for the Low-Probability-Seismic Collapsed-Drift Scenario}

For the low-probability-seismic collapsed-drift scenario, two changes need to be implemented in the LDTH submodels. First, the geometry of the drift is changed to account for the host-rock rubble that fills the drift from the outer surface of the drip shield to the intact host-rock. Second, thermal-hydrologic properties are required for the host-rock rubble. The implementation of these changes is described in the following sections. The boundary conditions, heat-generation rates, and percolation-flux values are the same as those used in the corresponding MSTHM 
calculations for the intact drift (i.e., nominal) case. Two thermal conductivity $K_{\text {th }}$ cases are considered: (1) high- $K_{\text {th }}$ host-rock rubble and (2) low- $K_{\text {th }}$ host-rock rubble.

\subsubsection{LDTH Submodel Location}

The LDTH submodel location is the P2WR5C10 LDTH-SDT submodel location (Figures 6.2-3 and 6.3-1). Two sets of LDTH submodel simulations (for modeled AMLs of 14, 27, 55, and 66 MTU/acre) are conducted for two different host-rock rubble thermal conductivity cases. This location was selected because it is representative of a typical location in the predominant host-rock unit (Tptpll), close to the center of the repository area, and because the local percolation-flux values (Table 6.3-9) are close to the repository-wide averages for the present-day, monsoonal, and glacial climates (Table 6.3-4).

\subsubsection{LDTH Submodel Mesh}

The low-probability-seismic scenario causes collapse of the drift opening, which is represented by a circular profile with a diameter of $11 \mathrm{~m}$. The resulting host-rock rubble completely fills the modified drift opening, from the outer surface of the drip shield out to the modified "drift wall," as shown in Figures 6.2-11 and 6.2-12 of this report, and in Section 6.4.3.4 of Abstraction of Drift Seepage (BSC 2004 [DIRS 169131]). A schematic of the collapsed-drift scenario is also given in Figure 6.4-22 of Abstraction of Drift Seepage (BSC 2004 [DIRS 169131]). The cross-sectional (lateral) geometry of the drift for the collapsed drift is represented in the LDTH submodel mesh, which is shown in Figure 6.2-11. Note that the cross-sectional geometries of the drip shield and invert remain the same. Note that this mesh is used for both the preclosure and postclosure periods.

The bulking factor is obtained from the LDTH submodel mesh (Figure 6.2-11) as follows. The bulking factor is a measure of the additional volume that the host-rock rubble occupies (after it collapses into and completely fills the previously open drift cavity) compared to the volume it occupied while it was intact host rock. Thus, the bulking factor is a relative measure of how much "bulkier" the host-rock rubble is (when it falls into and fills the drift cavity) than the original intact host rock that it was derived from. Note that the host-rock rubble also completely fills the volume that the intact host rock originally occupied. The bulking factor is equal to the cross-sectional area of the previously open drift cavity, which is the area of the blue region that lies inside of the dashed line in Figure 6.2-11 (and which is shown in white in Figure 6.2-6), divided by the cross-sectional area of the host-rock rubble zone outside of the original 5.5-mdiameter drift (which is the area of the blue region that lies outside of the dashed line in Figure 6.2-11). On the basis of the LDTH submodel mesh (Figure 6.2-11), the bulking factor is equal to 0.231 . Thus, the volume of host-rock rubble zone is 23.1 percent larger than the original volume of the intact host rock from which the rubble was derived. 


\section{LDTH Submodel}

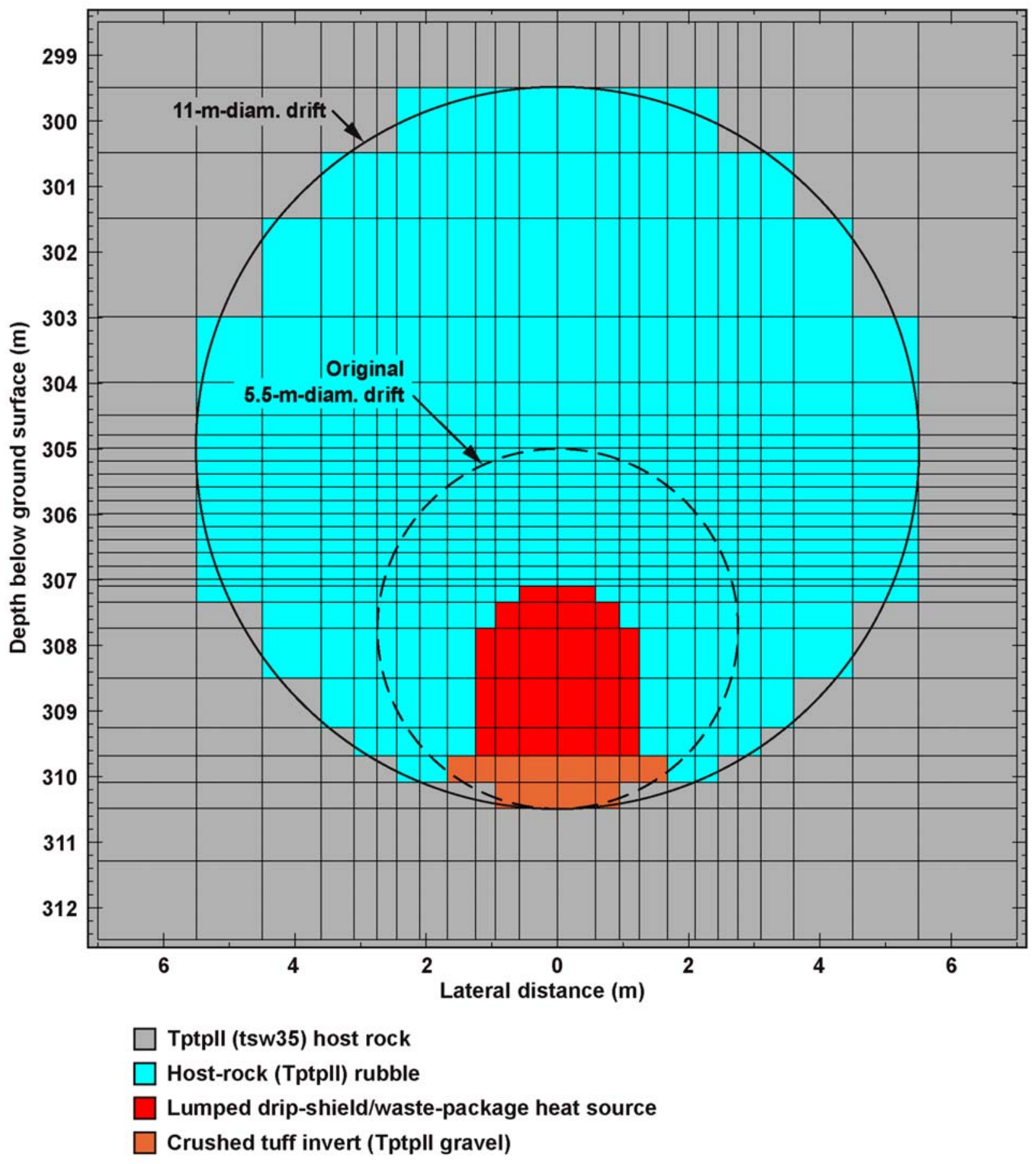

P2WR5C10-LDTH55-mi-mkt-14

Source: See Table XIII-1.

NOTE: This mesh is used for the preclosure and postclosure periods. The figure illustrates just a portion of the mesh. The entire model extends laterally $40.5 \mathrm{~m}$ (the mid-pillar centerline) and extends from the ground surface to the water table.

Figure 6.2-11. Cross-sectional (Lateral) View of the LDTH Submodel Mesh Used for the LowProbability-Seismic Collapsed-Drift Scenario 


\section{Post-Closure DDT Submodel}

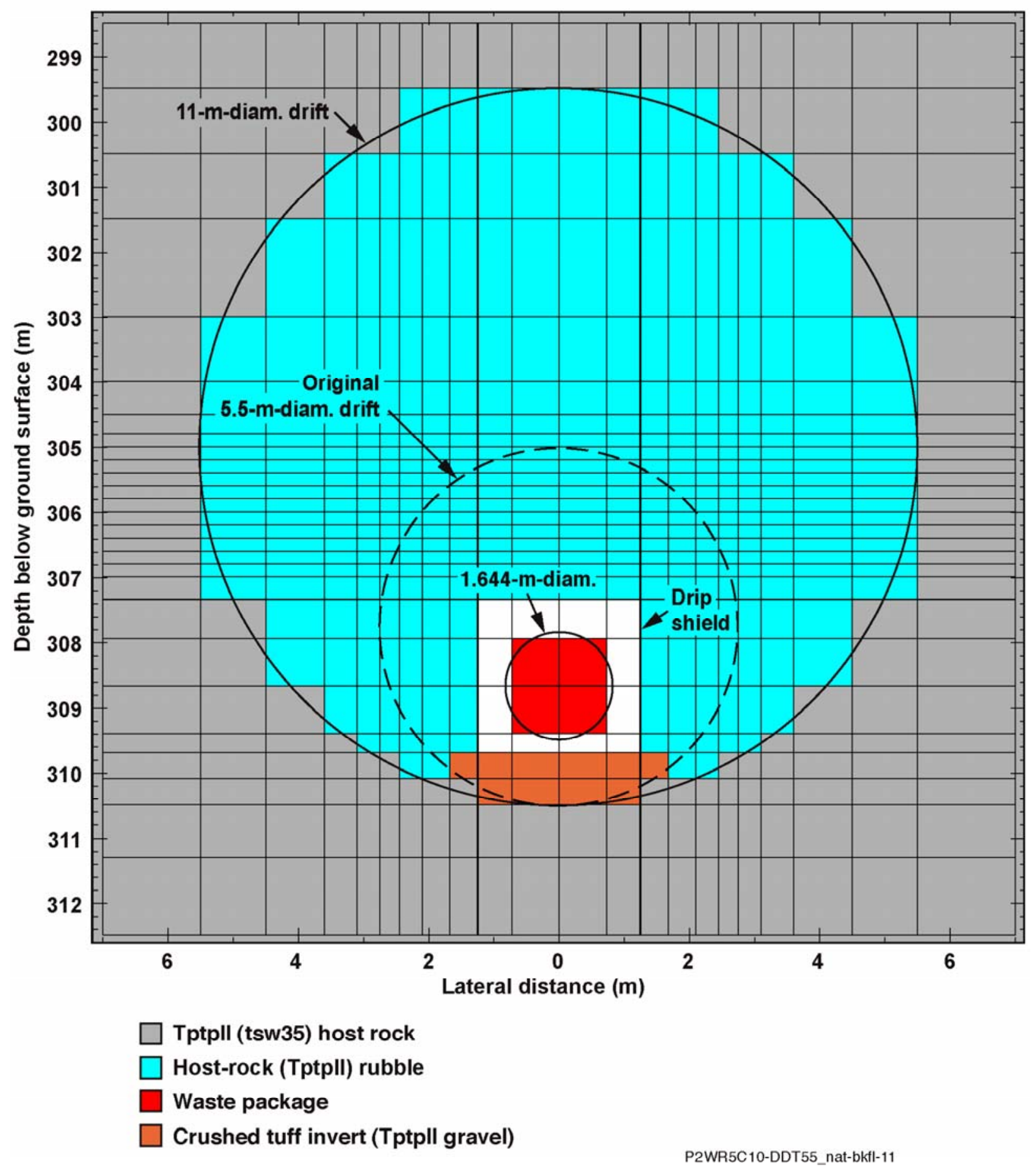

Source: See Table XIII-1.

NOTE: This mesh is used for the preclosure and postclosure periods.

Figure 6.2-12. Cross-Sectional (Lateral) View of the DDT Submodel Mesh Used for the Low-ProbabilitySeismic Collapsed-Drift Scenario 


\subsubsection{LDTH Submodel Host-Rock Rubble Thermal-Hydrologic Properties}

The thermal-hydrologic properties of the host-rock rubble are derived from those of the Tptpll (tsw35) unit, which is the host-rock unit at the P2WR5C10 LDTH-SDT submodel location (Figures 6.2-3 and 6.3-1). The hydrologic properties of the host-rock rubble are modified from those of the intact host rock (Table 6.2-2) in a manner that is analogous to what is done to the crushed-tuff invert. The only matrix-continuum hydrologic parameters that are modified from the intact host-rock values are the matrix porosity and matrix permeability; these two parameters are reduced to account for the decreased density of the host-rock rubble by multiplying the intact-host-rock values by $1 /(1+\mathrm{BF})$, where BF is the bulking factor. The bulk grain density and bulk thermal conductivity (Table 6.2-3) are also reduced to account for the decreased density of the host-rock rubble by multiplying the intact-host-rock values by $1 /(1+\mathrm{BF})$. This value of bulk thermal conductivity $K_{\text {th }}$ is applied to the high- $K_{\text {th }}$ case because it implicitly incorporates parallel thermal conductors (versus series thermal conductors). Thus, the solid portion of the host-rock rubble is effectively lined up in parallel with the void portion of the rubble.

The low- $K_{\text {th }}$ case is intended to account for the thermal-contact resistance between blocks of the rubble. Because the thermal conductivity of the solid portion of the rubble is much greater than that of the air-filled voids, the vast majority of thermal conduction occurs in the solid portion. The geometry of the rubble causes a "bottle-necking" effect at the point where the rock blocks contact each other. The values of $K_{\text {th }}$ for the low- $K_{\text {th }}$ case are half of those of the high- $K_{\text {th }}$ case to account for thermal-contact resistance at the bottlenecks. Thermal radiative heat transfer also contributes to heat transfer within the air-filled voids. The relative contribution of radiative heat transfer depends on the size of the rock blocks and voids, with larger voids facilitating more efficient thermal-radiative heat transfer than smaller voids. For large block (and void) sizes, thermal-radiative heat transfer will mitigate the influence of the bottlenecking effect, which will make the high- $K_{\text {th }}$ case applicable. For small block (and void) sizes, the low- $K_{\text {th }}$ case will be applicable. Neither the high- $K_{\text {th }}$ case nor low- $K_{\text {th }}$ case is more or less likely to be the appropriate value to be applied for effective thermal conductivity of the host-rock rubble. As a result of this argument, each alternative, the high- and low- $K_{\text {th }}$ cases, can be assigned the same probability (of 50 percent).

Table 6.2-2. Hydrologic Property Values for the "Intact" Tptpll (tsw35) Host-Rock Unit and for the Host-Rock Rubble Derived from the Tptpll (tsw35) Unit.

\begin{tabular}{|c|c|c|c|}
\hline Property & $\begin{array}{c}\text { Intact Host-Rock } \\
\text { Property Value }\end{array}$ & $\begin{array}{c}\text { Host-Rock Rubble Property } \\
\text { Value }\end{array}$ & $\begin{array}{c}\text { Basis for Rubble Property } \\
\text { Value }\end{array}$ \\
\hline Matrix porosity & 0.131 & 0.1065 & Intact Value $\times 1 /(1+\mathrm{BF})$ \\
\hline Fracture porosity & $9.6 \times 10^{-3}$ & 0.187 & $1-1 /(1+\mathrm{BF})$ \\
\hline Matrix permeability & $4.48 \times 10^{-18} \mathrm{~m}^{2}$ & $3.6393 \times 10^{-18} \mathrm{~m}^{2}$ & Intact Value $\times 1 /(1+\mathrm{BF})$ \\
\hline Fracture permeability & $9.10 \times 10^{-13} \mathrm{~m}^{2}$ & $1.0 \times 10^{-10} \mathrm{~m}^{2}$ & $\begin{array}{c}\text { Assumption } 2 \text { of Section } 5 \text { of } \\
\text { BSC 2004 [DIRS 169131] }\end{array}$ \\
\hline $\begin{array}{c}\text { Fracture van Genuchten } \\
\text { alpha }\end{array}$ & $1.02 \times 10^{-4} \mathrm{~Pa}^{-1}$ & $0.01 \mathrm{~Pa}^{-1}$ & $\begin{array}{c}\text { Assumption } 1 \text { of Section } 5 \text { of } \\
\text { BSC 2004 [DIRS 169131] }\end{array}$ \\
\hline
\end{tabular}

NOTES: Intact host-rock property values for the Tptpll (tsw35) unit are obtained from Table IV-4 and IV-5 in Appendix IV.

The only property values listed are those for which the intact and rubble values differ. All other property values for the intact host rock and host-rock rubble are the same. 
Table 6.2-3. Thermal Property Values for the "Intact" Tptpll (tsw35) Host-Rock Unit and for the Host-Rock Rubble Derived from the Tptpll (tsw35) Unit

\begin{tabular}{|c|c|c|c|}
\hline Property & $\begin{array}{l}\text { Intact Host-Rock } \\
\text { Property Value }\end{array}$ & $\begin{array}{l}\text { Host-Rock Rubble Property } \\
\text { Value }\end{array}$ & $\begin{array}{l}\text { Basis for Rubble Property } \\
\text { Value }\end{array}$ \\
\hline Bulk density & $1980 \mathrm{~kg} / \mathrm{m}^{\mathrm{a}}$ & $1850.0 \mathrm{~kg} / \mathrm{m}^{\mathrm{a}}$ & Assumption, Section 5.8 .1 \\
\hline $\begin{array}{l}\text { Bulk density of matrix } \\
\text { continuum }\end{array}$ & $\begin{array}{l}\text { Not used or } \\
\text { determined }\end{array}$ & $1831.5 \mathrm{~kg} / \mathrm{m}^{\mathrm{a}}$ & 99 percent of bulk rubble value \\
\hline $\begin{array}{c}\text { Bulk density of fracture } \\
\text { continuum }\end{array}$ & $\begin{array}{l}\text { Not used or } \\
\text { determined }\end{array}$ & $18.5 \mathrm{~kg} / \mathrm{m}^{\mathrm{a}}$ & 1 percent of bulk rubble value \\
\hline $\begin{array}{l}\text { Grain density of matrix } \\
\text { continuum }\end{array}$ & $2258.11 \mathrm{~kg} / \mathrm{m}^{\mathrm{a}}$ & $2049.8 \mathrm{~kg} / \mathrm{m}^{\mathrm{a}}$ & $\begin{array}{c}\text { Bulk matrix density } /\left(1-\phi_{m}\right), \\
\text { where } \phi_{m}=0.1065(\text { Table } 6.2-2)\end{array}$ \\
\hline $\begin{array}{c}\text { Grain density of fracture } \\
\text { continuum }\end{array}$ & $21.89 \mathrm{~kg} / \mathrm{m}^{\mathrm{a}}$ & $22.76 \mathrm{~kg} / \mathrm{m}^{\mathrm{a}}$ & $\begin{array}{l}\left.\text { Bulk fracture density/( } 1-\phi_{\mathrm{f}}\right) \text {, } \\
\text { where } \phi_{\mathrm{f}}=0.187(\text { Table6.2-2) }\end{array}$ \\
\hline $\begin{array}{l}\text { Bulk dry thermal } \\
\text { conductivity }\end{array}$ & $1.28 \mathrm{~W} / \mathrm{m}-\mathrm{K}$ & $\begin{array}{l}1.0 \mathrm{~W} / \mathrm{m}-\mathrm{K}\left(\text { High- } K_{\text {th }} \text { case }\right)^{\mathrm{b}} \\
0.5 \mathrm{~W} / \mathrm{m}-\mathrm{K}\left(\text { Low- } K_{\text {th }} \text { case }\right)\end{array}$ & $\begin{array}{l}\text { Intact Value } \times 1 /(1+\mathrm{BF}) \\
\left(\text { High- } K_{\text {th }} \text { rubble value }\right) / 2\end{array}$ \\
\hline $\begin{array}{l}\text { Bulk wet thermal } \\
\text { conductivity }\end{array}$ & $1.89 \mathrm{~W} / \mathrm{m}-\mathrm{K}$ & $\begin{array}{l}1.515 \mathrm{~W} / \mathrm{m}-\mathrm{K}\left(\text { High- } K_{\text {th }} \text { case }\right)^{\mathrm{a}} \\
0.7575 \mathrm{~W} / \mathrm{m}-\mathrm{K}\left(\text { Low }-K_{\text {th }} \text { case }\right)\end{array}$ & $\begin{array}{l}\text { Intact Value } \times 1 /(1+\mathrm{BF}) \\
\left(\text { High- } K_{\text {th }} \text { rubble value }\right) / 2\end{array}$ \\
\hline $\begin{array}{l}\text { Dry thermal conductivity } \\
\text { of matrix continuum }\end{array}$ & $1.268 \mathrm{~W} / \mathrm{m}-\mathrm{K}$ & $\begin{array}{l}0.99 \mathrm{~W} / \mathrm{m}-\mathrm{K}\left(\text { High- } K_{\text {th }} \text { case }\right) \\
0.495 \mathrm{~W} / \mathrm{m}-\mathrm{K}\left(\text { Low }-K_{\text {th }} \text { case }\right)\end{array}$ & 99 percent of bulk rubble value \\
\hline $\begin{array}{l}\text { Dry thermal conductivity } \\
\text { of fracture continuum }\end{array}$ & $1.23 \times 10^{-2} \mathrm{~W} / \mathrm{m}-\mathrm{K}$ & $\begin{array}{l}0.01 \mathrm{~W} / \mathrm{m}-\mathrm{K}\left(\text { High- } K_{\text {th }} \text { case }\right) \\
0.005 \mathrm{~W} / \mathrm{m}-\mathrm{K}\left(\text { Low- } K_{\text {th }} \text { case }\right)\end{array}$ & 1 percent of bulk rubble value \\
\hline $\begin{array}{l}\text { Wet thermal conductivity } \\
\text { of matrix continuum }\end{array}$ & $1.872 \mathrm{~W} / \mathrm{m}-\mathrm{K}$ & $\begin{array}{l}1.5 \mathrm{~W} / \mathrm{m}-\mathrm{K}\left(\text { High- } K_{\text {th }} \text { case }\right) \\
0.75 \mathrm{~W} / \mathrm{m}-\mathrm{K}\left(\text { Low }-K_{\text {th }} \text { case }\right)\end{array}$ & 99 percent of bulk rubble value \\
\hline $\begin{array}{l}\text { Wet thermal conductivity } \\
\text { of fracture continuum }\end{array}$ & $1.81 \times 10^{-2} \mathrm{~W} / \mathrm{m}-\mathrm{K}$ & $\begin{array}{l}0.015 \mathrm{~W} / \mathrm{m}-\mathrm{K}\left(\text { High- } K_{\text {th }} \text { case }\right) \\
0.0075 \mathrm{~W} / \mathrm{m}-\mathrm{K}\left(\text { Low }-K_{\text {th }} \text { case }\right)\end{array}$ & 1 percent of bulk rubble value \\
\hline Bulk density & $1980.0 \mathrm{~kg} / \mathrm{m}^{\mathrm{a}}$ & $\begin{array}{c}1608.0 \mathrm{~kg} / \mathrm{m}^{\mathrm{a}} \\
\text { (sensitivity case: Figure 6.3-58) }\end{array}$ & Intact Value $\times 1 /(1+B F)$ \\
\hline $\begin{array}{l}\text { Bulk density of matrix } \\
\text { continuum }\end{array}$ & $\begin{array}{l}\text { Not used or } \\
\text { determined }\end{array}$ & $\begin{array}{c}1591.9 \mathrm{~kg} / \mathrm{m}^{\mathrm{a}} \\
\text { (sensitivity case: Figure 6.3-58) }\end{array}$ & 99 percent of bulk rubble value \\
\hline $\begin{array}{l}\text { Bulk density of fracture } \\
\text { continuum }\end{array}$ & $\begin{array}{l}\text { Not used or } \\
\text { determined }\end{array}$ & $\begin{array}{c}16.1 \mathrm{~kg} / \mathrm{m}^{\mathrm{a}} \\
\text { (sensitivity case: Figure 6.3-58) }\end{array}$ & 1 percent of bulk rubble value \\
\hline $\begin{array}{l}\text { Grain density of matrix } \\
\text { continuum }\end{array}$ & $2258.11 \mathrm{~kg} / \mathrm{m}^{\mathrm{a}}$ & $\begin{array}{c}1781.6 \mathrm{~kg} / \mathrm{m}^{\mathrm{a}} \\
\text { (sensitivity case: Figure 6.3-58) }\end{array}$ & $\begin{array}{c}\text { Bulk matrix density } /\left(1-\phi_{m}\right) \\
\text { where } \phi_{m}=0.1065(\text { Table } 6.2-2)\end{array}$ \\
\hline $\begin{array}{l}\text { Grain density of fracture } \\
\text { continuum }\end{array}$ & $21.89 \mathrm{~kg} / \mathrm{m}^{\mathrm{a}}$ & $\begin{array}{c}19.8 \mathrm{~kg} / \mathrm{m}^{\mathrm{a}} \\
\text { (sensitivity case: Figure 6.3-58) }\end{array}$ & $\begin{array}{c}\left.\text { Bulk fracture density/(1- } \phi_{f}\right) \\
\text { where } \phi_{f}=0.187 \text { (Table 6.2-2) }\end{array}$ \\
\hline
\end{tabular}

${ }^{a}$ Value is close to, but slightly less than, the value obtained from the Intact Value $\times 1 /(1+B F)$, in order to be consistent with the slight reduction made to the dry $K_{\text {th }}$ value, which was rounded down.

b This value is rounded down slightly.

NOTE: Intact host-rock property values are obtained from Table IV-3b in Appendix IV. The only property values listed are those for which the intact and rubble values differ. All other property values for the intact host rock and host-rock rubble are the same. Note that $\phi_{m}$ and $\phi_{f}$ are matrix-continuum and fracture-continuum porosity, respectively.

Appendix XI corroborates estimates of the effective dry bulk thermal conductivity of the host-rock rubble in the collapsed drift on the basis of the Kunii and Smith relationship (Kunii and Smith 1960 [DIRS 153166], Equation 8). On the basis of that assessment, a mean value of 0.81 $\mathrm{W} / \mathrm{m}^{\circ} \mathrm{C}$ is determined for the dry bulk thermal conductivity, with a range of 0.57 to $1.05 \mathrm{~W} / \mathrm{m}^{\circ} \mathrm{C}$. The low end of this range $\left(0.57 \mathrm{~W} / \mathrm{m}^{\circ} \mathrm{C}\right)$ is very close to the dry bulk thermal conductivity value 
of $0.5 \mathrm{~W} / \mathrm{m}^{\circ} \mathrm{C}$ used in low- $K_{\text {th }}$ case. The high end of this range $\left(1.05 \mathrm{~W} / \mathrm{m}^{\circ} \mathrm{C}\right)$ is very close to the dry bulk thermal conductivity value of $1.0 \mathrm{~W} / \mathrm{m}^{\circ} \mathrm{C}$ used in the high- $K_{\text {th }}$ case.

The fracture-continuum porosity of the rubble does not include the small contribution of the fracture porosity, which is $9.6 \times 10^{-3}$ for the Tptpll (tsw35) unit (Table IV-4 of Appendix IV), that was present in the intact rock (prior to its collapse into the drift). The fracture-continuum permeability and van Genuchten alpha parameter are taken from Section 6.4.3.4 of Abstraction of Drift Seepage (BSC 2004 [DIRS 169131]). The fracture-continuum permeability is $10^{-10} \mathrm{~m}^{2}$ (about two orders of magnitude larger than that of the intact Tptpll host rock). The fracture-continuum van Genuchten alpha is $0.01 \mathrm{~Pa}^{-1}$. The bulk density and bulk thermal conductivity of the host-rock rubble are partitioned between the fracture and matrix continuum in the exactly same fashion, and for the same reasons, as is done for the crushed-tuff invert material (see Appendix IV). Thus, 99 percent of the bulk density and bulk thermal conductivity are partitioned to the matrix continuum and 1 percent is partitioned to the fracture continuum. This partitioning is done because the majority of the thermal mass in the rubble resides in the matrix continuum.

\subsubsection{DDT Submodels for the Low-Probability-Seismic Collapsed-Drift Scenario}

For the collapsed-drift scenario, two changes need to be implemented in the DDT submodels. First, the geometry of the drift is changed to account for the host-rock rubble that fills the drift from the outer surface of the drip shield to the intact host-rock. Second, thermal properties are required for the host-rock rubble. The implementation of these changes is described in the following sections. The boundary conditions and heat-generation rates are the same as those used in the corresponding MSTHM calculations for the intact drift (i.e., nominal) case. Two thermal conductivity $K_{\text {th }}$ cases are considered: (1) high- $K_{\text {th }}$ host-rock rubble and (2) low- $K_{\text {th }}$ host-rock rubble.

\subsubsection{DDT Submodel Location}

The DDT submodel location is the P2WR5C10 LDTH-SDT submodel location (Figures 6.2-3 and 6.3-1). Two sets of LDTH submodel simulations (for modeled AMLs of 14, 27, 55, and 66 MTU/acre) are conducted for two different host-rock rubble thermal conductivity cases.

\subsubsection{DDT Submodel Mesh}

The low-probability-seismic scenario causes collapse of the drift opening, which is represented by a circular profile with a diameter of $11 \mathrm{~m}$ (see Section 6.2.10.2). The resulting host-rock rubble completely fills the modified drift opening, from the outer surface of the drip shield out to the modified "drift wall," which now has a diameter of $11 \mathrm{~m}$. The cross-sectional (lateral) geometry of the drift for the collapsed drift is represented in the DDT submodel mesh as is shown in Figure 6.2-12. Note that the cross-sectional geometries of the drip shield, waste package, and invert remain the same.

\subsubsection{DDT Submodel Host-Rock Rubble Thermal Properties}

The thermal properties of the host-rock rubble (Table 6.2-4) are derived from those of the Tptpll (tsw35) unit, which is the host-rock unit at the P2WR5C10 LDTH-SDT submodel location (Figures 6.2-3 and 6.3-1). Just as is done for the LDTH submodels, the bulk grain density and 
bulk thermal conductivity are reduced to account for the decreased density of the host-rock rubble by multiplying the intact-host-rock values by $1 /(1+\mathrm{BF})$. The DDT submodels use the same bulk grain density as is used in the LDTH submodels for the high- $K_{\text {th }}$ and low- $K_{\text {th }}$ host-rock rubble cases. For thermal conductivity, the DDT submodels use the bulk dry thermal conductivity that is used in the LDTH submodels for the high- $K_{\text {th }}$ and low- $K_{\text {th }}$ host-rock rubble cases, respectively. The dry value of bulk thermal conductivity is used because the DDT submodels are primarily used to predict longitudinal variability in temperature along the axis of the drift. The longitudinal variability is greatest when peak temperatures occur, which is when the majority of the rubble is dry as a result of boiling. Much of the rubble remains relatively dry throughout the majority of the simulation period of 20,050 years; therefore, the dry value of thermal conductivity for the rubble is a reasonable choice.

Table 6.2-4. Thermal Property Values for the "Intact" Tptpll (tsw35) Host-Rock Unit and for the Host-Rock Rubble Derived from the Tptpll (tsw35) Unit.

\begin{tabular}{|c|c|c|c|}
\hline Property & $\begin{array}{c}\text { Intact Host-Rock } \\
\text { Property Value }\end{array}$ & $\begin{array}{c}\text { Host-Rock Rubble Property } \\
\text { Value }\end{array}$ & $\begin{array}{c}\text { Basis for Rubble Property } \\
\text { Value }\end{array}$ \\
\hline Bulk density & $1980 \mathrm{~kg} / \mathrm{m}^{3}$ & $1608 \mathrm{~kg} / \mathrm{m}^{3}$ & Intact Value $\times 1 /(1+\mathrm{BF})$ \\
\hline Bulk grain density & $2280 \mathrm{~kg} / \mathrm{m}^{3}$ & $1850 \mathrm{~kg} / \mathrm{m}^{3}$ & $\begin{array}{c}\text { Bulk density } /\left(1-\phi_{\mathrm{m}}\right), \mathrm{where} \\
\phi_{\mathrm{m}}=0.131^{\mathrm{a}}\end{array}$ \\
\hline $\begin{array}{c}\text { Bulk dry thermal } \\
\text { conductivity }\end{array}$ & $1.28 \mathrm{~W} / \mathrm{m}-\mathrm{K}$ & $\begin{array}{c}1.0 \mathrm{~W} / \mathrm{m}-\mathrm{K}\left(\text { High- } K_{\text {th }} \text { case) }\right. \\
0.5 \mathrm{~W} / \mathrm{m}-\mathrm{K} \text { (Low- } K_{\text {th }} \text { case) }\end{array}$ & $\begin{array}{c}\text { Intact Value } \times 1 /(1+\mathrm{BF}) \\
\left.\text { (High- } K_{\text {th }} \text { rubble value }\right) / 2\end{array}$ \\
\hline
\end{tabular}

a A porosity value of 0.131 only affects the relationship between bulk density and bulk grain density applied to the DDT submodel. It has no other influence on the DDT submodel.

NOTE: Intact host-rock property values are obtained from Table IV-3b in Appendix IV. The only property values listed are those for which the intact and rubble values differ. All other property values for the intact host rock and host-rock rubble are the same.

\subsection{MSTHM RESULTS}

\subsubsection{TSPA-LA Base Case}

This section discusses the MSTHM calculations that were conducted for the TSPA-LA base case. As was done for the Total System Performance Assessment for the Site Recommendation (called the TSPA-SR), the base case consists of three infiltration-flux cases: lower-bound, mean, and upper-bound infiltration-flux cases for three climate states: present-day, monsoonal, and glacial-transition. Past MSTHM calculations directly used the infiltration maps for these three cases with the underlying assumption being that there is no lateral attenuation of infiltration in the PTn unit (or in any other unit above the repository); thus, percolation above the repository occurs strictly as one-dimensional vertical downward flow. For the TSPA-LA base case, the upper-boundary liquid-phase flux in the MSTHM corresponds to the distribution of percolation flux just below the base of the PTn unit; these data (Table 4.1-1) are generated for the three climate states: present-day, monsoonal, and glacial-transition. Thus, the TSPA-LA base-case MSTHM accounts for the influence of lateral diversion in the PTn as represented in the three-dimensional UZ flow model.

Previous MSTHM calculations (such as those in support of the TSPA-SR) used different hydrologic property sets for each of the infiltration-flux cases; thus, lower-bound, mean, and upper-bound one-dimensional drift-scale hydrologic property sets were applied to their 
respective infiltration-flux cases. For this study it was found that only one hydrologic property set (called the modified-mean infiltration-flux property set) is needed for conducting MSTHM calculations for the three infiltration-flux cases. Abstraction of Drift Seepage (BSC 2004 [DIRS 169131], Section 6.6.3) addresses the van Genuchten fracture alpha and permeability distributions for the Tptpul (tsw33) and Tptpln (tsw36) units. It is noted by this reference that the Tptpul (tsw33) unit is hydrogeologically similar to the Tptpll (tsw35) unit; furthermore, it is stated that the two units with lithophysal cavities in the rock (the Tptpul and Tptpll units) should have similar hydrogeological characteristics. The modified-mean infiltration-flux property set is the same as the mean infiltration-flux property set (DTN: LB0208UZDSCPMI.002 [DIRS 161243]) with the one modification being that the van Genuchten fracture alpha in the Tptpul (tsw33) is set to be the same $\left(1.021 \times 10^{-4} \mathrm{~Pa}^{-1}\right.$ ) as that in the Tptpll (tsw35) unit (see Table IV-4, Appendix IV). This is consistent with the observation in Abstraction of Drift Seepage (BSC 2004 [DIRS 169131], Section 6.6.3) that the Tptpul and Tptll are hydrologically similar. As discussed below, this one modification also produces a consistent contrast in capillary pressure between the matrix and fracture continuum for all four host-rock units.

For this study, it was found that the application of the modified-mean infiltration-flux property set to lower-bound, mean, and upper-bound infiltration-flux cases produces uniform calculated host-rock liquid-phase saturation for the three infiltration-flux cases. It was also found that host-rock liquid-phase saturation consistently increases (slightly) with increasing percolation flux. The purpose for conducting lower-bound, mean, and upper-bound infiltration-flux cases with the MSTHM is to address the influence of percolation-flux uncertainty on thermal-hydrologic conditions within emplacement drifts and in the adjoining host rock. In conducting a sensitivity study to a particular parameter (in this case, percolation flux), it is preferred to vary only one parameter at a time. Table 6.3-1 lists the initial (ambient) liquid-phase saturation in the host rock (immediately above the crown of the emplacement drift) for lower-bound, mean, and upper-bound infiltration-flux cases when the modified-mean drift-scale hydrologic property set is applied to the MSTHM. Table 6.3-1 shows that the use of the modified-mean infiltration-flux property set results in similar initial liquid-phase saturation at a given location for lower-bound, mean, and upper-bound infiltration-flux cases.

Table 6.3-2 lists the initial (ambient) capillary pressure in the fracture and matrix continuum of the host rock for the same locations given in Table 6.3-1. The mean infiltration-flux property set produces very small values of capillary pressures in the fracture continuum for locations where the host rock is the Tptpul (tsw33) unit; these small values of fracture capillary pressure are much smaller than they are for regions of the repository where the host rock is not the Tptpul (tsw33) unit (i.e., where the local host-rock unit is either Tptpmn (tsw34), Tptpll (tsw35), or Tptpln (tsw36)). Moreover, the mean infiltration-flux property set produces a large (order of magnitude) contrast in capillary pressure between the matrix and fracture continuum in the Tptpul (tsw33) unit, whereas the contrast in capillary pressure is much smaller for the other three host-rock units: Tptpmn, Tptpll, and Tptpln. The modified-mean infiltration-flux property set produces fracture capillary pressures in the Tptpul unit that are consistent with those in the rest of the repository (i.e., in regions where the host rock is either Tptpmn, Tptpll, or Tptpln). Moreover, for all four host-rock units, the modified-mean infiltration-flux property set produces a consistent contrast in capillary pressure between the matrix and fracture continuum, which is generally on the order of a factor of two throughout most of the repository area, with the only exception being in the Tptpln unit where the contrast is larger (about a factor of six). 
Table 6.3-3 and Figure 6.3-1 show the distribution of host-rock units over the repository area. The majority of the repository area (81.1 percent) is in the two units (Tptpll and Tptpul) with lithophysal cavities. Most of the remainder of the repository area (where waste is to be emplaced) is in the nonlithophysal units (Tptpmn and Tptpln) with a small percentage (1.6 percent) being in fault zones. These areas are based on Development of Numerical Grids for UZ Flow and Transport Modeling (BSC 2004 [DIRS 169855]).

Table 6.3-1. Initial Liquid-Phase Saturation in the Host Rock at Several Locations in the Repository for Three Infiltration-Flux Cases

\begin{tabular}{|l|l|l|l|c|c|c|}
\hline \multirow{2}{*}{$\begin{array}{c}\text { LDTH-SDT } \\
\text { submodel } \\
\text { Iocation }\end{array}$} & Host-Rock unit & $\begin{array}{c}\text { Easting } \\
(\mathbf{m})\end{array}$ & $\begin{array}{c}\text { Novada State } \\
\text { Coordinates }\end{array}$ & \multicolumn{2}{c|}{$\begin{array}{c}\text { Initial Liquid-Phase Saturation } \\
\text { in the Host Rock (\%) }\end{array}$} \\
\cline { 2 - 7 } & & $\begin{array}{c}\text { Lower-Bound } \\
\text { Infiltration- } \\
\text { Flux Case }\end{array}$ & $\begin{array}{c}\text { Mean } \\
\text { Infiltration- } \\
\text { Flux Case }\end{array}$ & $\begin{array}{c}\text { Upper-Bound } \\
\text { Infiltration- } \\
\text { Flux Case }\end{array}$ \\
\hline P2ER4C4 & Tptpul (tsw33) & 172138.9 & 235625.9 & 96.4 & 96.4 & 96.9 \\
\hline P2ER5C5 & Tptpul (tsw33) & 171985.7 & 235320.6 & 95.5 & 95.6 & 95.8 \\
\hline P2ER6C6 & Tptpul (tsw33) & 171623.3 & 234947.4 & 95.4 & 95.5 & 95.7 \\
\hline P2ER8C7 & Tptpul (tsw33) & 171393.1 & 234361.5 & 94.0 & 97.2 & 97.3 \\
\hline P2ER8C6 & Tptpul (tsw33) & 171564.3 & 234417.2 & 90.5 & 95.6 & 95.7 \\
\hline P2ER8C5 & Tptpul (tsw33) & 171735.5 & 234472.8 & 93.6 & 97.4 & $97.3^{\text {a }}$ \\
\hline P2ER7C6 & Tptpul (tsw33) & 171584.3 & 234679.2 & 93.0 & 96.5 & $96.3^{\text {a }}$ \\
\hline P2ER7C5 & Tptpul (tsw33) & 171793.5 & 234747.2 & 95.1 & 95.2 & 95.3 \\
\hline P2ER6C5 & Tptpul (tsw33) & 171851.6 & 235021.5 & 93.6 & 95.5 & 95.6 \\
\hline P2ER3C4 & Tptpmn (tsw34) & 172292.1 & 235931.1 & 97.5 & 97.8 & 98.0 \\
\hline P2ER2C5 & Tptpll (tsw35) & 172121.9 & 236131.4 & 92.0 & 92.0 & 92.1 \\
\hline P2WR1C8 & Tptpll (tsw35) & 171647.4 & 236232.7 & 94.0 & 94.0 & 94.1 \\
\hline P3R1C11 & Tptpll (tsw35) & 171038.7 & 236034.9 & 94.6 & 94.6 & 94.7 \\
\hline P3R8C13 & Tptpln (tsw36) & 170080.6 & 233935.1 & 98.6 & 98.7 & 98.7 \\
\hline
\end{tabular}

Source: See Table XIII-2.

a The value of percolation flux for the upper-bound infiltration-flux case is less than that for the mean infiltration-flux case at this particular location.

NOTE: The initial (ambient) liquid-phase saturation in the host rock (prior to waste emplacement) is obtained by applying the modified-mean infiltration-flux property set to the MSTHM. 
Table 6.3-2. Initial Capillary Pressure for the Fracture and Matrix Continuum in the Host Rock

\begin{tabular}{|l|l|c|c|c|c|}
\hline \multirow{2}{*}{$\begin{array}{c}\text { LDTH-SDT } \\
\text { submodel } \\
\text { location }\end{array}$} & Host-Rock Unit & \multicolumn{2}{|c|}{$\begin{array}{c}\text { Fracture capillary pressure } \\
\mathbf{P a}\end{array}$} & $\begin{array}{c}\text { Matrix capillary pressure } \\
\text { (Pa) }\end{array}$ \\
\cline { 3 - 6 } & $\begin{array}{c}\text { Mean Infiltration- } \\
\text { Flux Property Set }\end{array}$ & $\begin{array}{c}\text { Modified-Mean } \\
\text { Infiltration-Flux } \\
\text { Property Set }\end{array}$ & $\begin{array}{c}\text { Modified-Mean } \\
\text { Mean Infiltration- } \\
\text { Flux Property Set }\end{array}$ & $\begin{array}{c}\text { Infiltration-Flux } \\
\text { Property set }\end{array}$ \\
\hline P2ER4C4 & Tptpul (tsw33) & $1.46 \times 10^{3}$ & $2.28 \times 10^{4}$ & $3.23 \times 10^{4}$ & $4.27 \times 10^{4}$ \\
\hline P2ER5C5 & Tptpul (tsw33) & $1.46 \times 10^{3}$ & $2.28 \times 10^{4}$ & $4.51 \times 10^{4}$ & $5.06 \times 10^{4}$ \\
\hline P2ER6C6 & Tptpul (tsw33) & $1.46 \times 10^{3}$ & $2.27 \times 10^{4}$ & $4.38 \times 10^{4}$ & $5.18 \times 10^{4}$ \\
\hline P2ER8C7 & Tptpul (tsw33) & $1.45 \times 10^{3}$ & $2.27 \times 10^{4}$ & $2.03 \times 10^{4}$ & $3.50 \times 10^{4}$ \\
\hline P2ER8C6 & Tptpul (tsw33) & $1.45 \times 10^{3}$ & $2.26 \times 10^{4}$ & $4.51 \times 10^{4}$ & $5.09 \times 10^{4}$ \\
\hline P2ER8C5 & Tptpul (tsw33) & $1.47 \times 10^{3}$ & $2.29 \times 10^{4}$ & $3.14 \times 10^{4}$ & $3.34 \times 10^{4}$ \\
\hline P2ER7C6 & Tptpul (tsw33) & $1.43 \times 10^{3}$ & $2.22 \times 10^{4}$ & $3.46 \times 10^{4}$ & $4.25 \times 10^{4}$ \\
\hline P2ER7C5 & Tptpul (tsw33) & $1.46 \times 10^{3}$ & $2.28 \times 10^{4}$ & $5.34 \times 10^{4}$ & $5.43 \times 10^{4}$ \\
\hline P2ER6C5 & Tptpul (tsw33) & $1.47 \times 10^{3}$ & $2.30 \times 10^{4}$ & $4.55 \times 10^{4}$ & $5.13 \times 10^{4}$ \\
\hline P2ER3C4 & Tptpmn (tsw34) & $2.22 \times 10^{4}$ & $2.22 \times 10^{4}$ & $2.32 \times 10^{4}$ & $2.32 \times 10^{4}$ \\
\hline P2ER2C5 & Tptpll (tsw35) & $2.40 \times 10^{4}$ & $2.40 \times 10^{4}$ & $5.78 \times 10^{4}$ & $5.78 \times 10^{4}$ \\
\hline P2WR1C8 & Tptpll (tsw35) & $2.44 \times 10^{4}$ & $2.44 \times 10^{4}$ & $4.37 \times 10^{4}$ & $4.37 \times 10^{4}$ \\
\hline P3R1C11 & Tptpll (tsw35) & $2.44 \times 10^{4}$ & $2.44 \times 10^{4}$ & $3.95 \times 10^{4}$ & $3.95 \times 10^{4}$ \\
\hline P3R8C13 & Tptpln (tsw36) & $3.32 \times 10^{3}$ & $3.32 \times 10^{3}$ & $1.94 \times 10^{4}$ & $1.94 \times 10^{4}$ \\
\hline
\end{tabular}

Source: See Table XIII-2.

NOTE: The initial (ambient) capillary pressure for the fracture and matrix continuum in the host rock (prior to waste emplacement) is obtained by applying the mean and the modified-mean infiltration-flux property set to the MSTHM. Note that values are listed for the same locations given in Table 6.3-1.

Table 6.3-3. Distribution of the Host-Rock Units as Represented in SMT Submodel for the Emplaced Repository Area (Figure 6.3-1)

\begin{tabular}{|l|l|c|c|c|}
\hline $\begin{array}{c}\text { Lithostratigraphic } \\
\text { Unit }\end{array}$ & \multicolumn{1}{|c|}{$\begin{array}{c}\text { Uz Model } \\
\text { Layer Unit }\end{array}$} & $\begin{array}{c}\text { Length of } \\
\text { Emplacement } \\
\text { Drift } \mathbf{( m )}\end{array}$ & $\begin{array}{c}\text { Area } \\
\left.\mathbf{( k m}^{\mathbf{2}}\right)\end{array}$ & $\begin{array}{c}\text { Percentage of } \\
\text { Repository Area }\end{array}$ \\
\hline Tptpul & tsw33 & 3,460 & 0.2803 & $6.0 \%$ \\
\hline Tptpmn & tsw34 & 9,260 & 0.7501 & $16.1 \%$ \\
\hline Tptpll & tsw35 & 43,160 & 3.4960 & $75.1 \%$ \\
\hline Tptpln & tsw36 & 660 & 0.0535 & $1.2 \%$ \\
\hline Fault zone & tswfl & 940 & 0.0761 & $1.6 \%$ \\
\hline Total & N/A & 57,480 & 4.6559 & $100 \%$ \\
\hline
\end{tabular}

NOTE: The values of emplacement-drift length and area are as they are represented in the SMT submodel (Section 6.2.5). In the SMT submodel, the represented lengths of the emplacement drifts are based on information from BSC 2003 [DIRS 161727]; the distribution of host-rock units (with respect to the UZ model layers) is consistent with the grid in DTN: LB03023DKMGRID.001 [DIRS 162354]. 


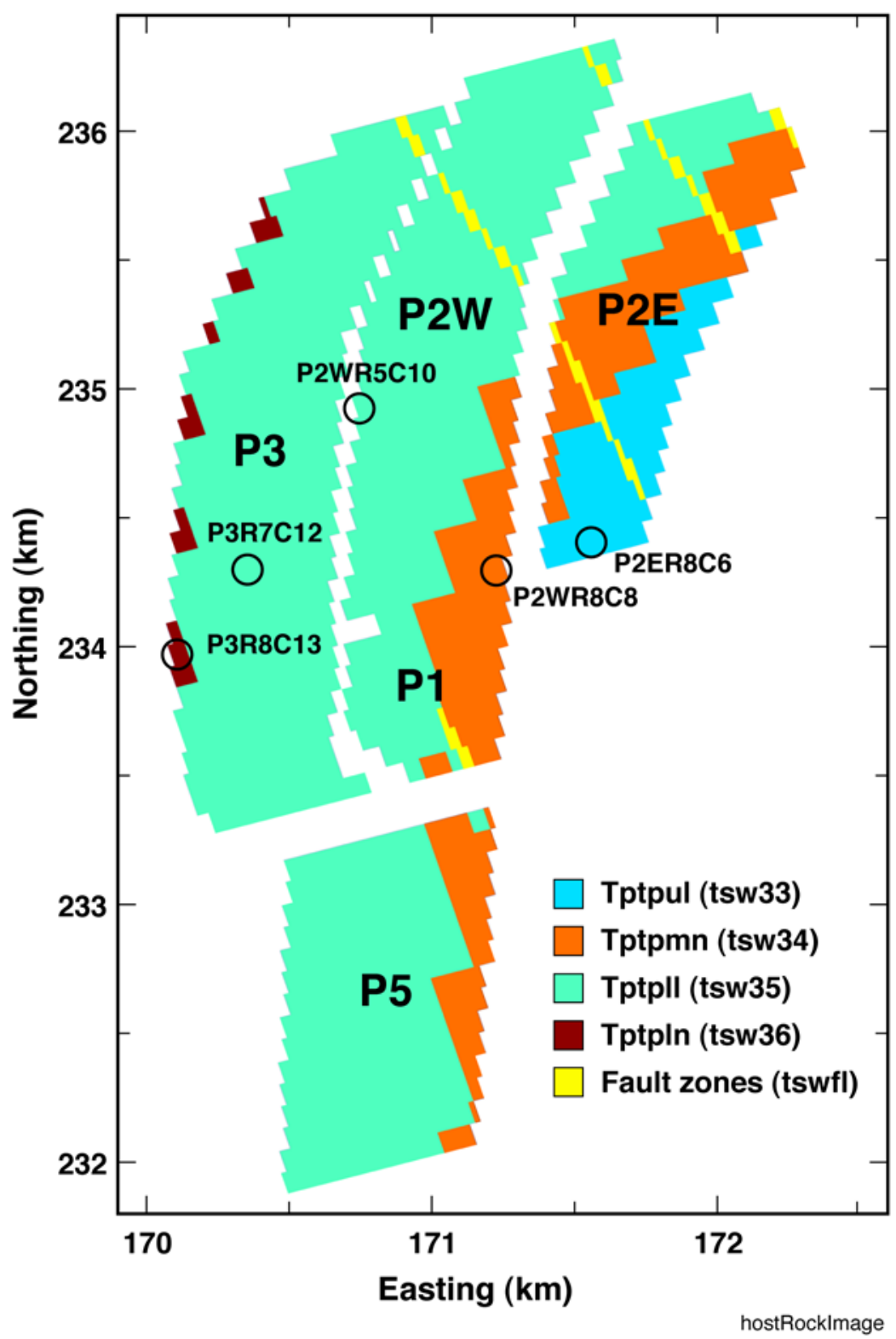

Source: See Table XIII-1.

NOTE: Note that tswfl stands for fault zone. Also shown are the five representative locations that were selected to examine thermal-hydrologic conditions in the four primary host-rock units.

Figure 6.3-1. Distribution of the Four Primary Host-Rock Units Shown for the Repository Layout Considered in MSTHM Calculations for the TSPA-LA Base Case

\subsubsection{Lower-Bound, Mean, and Upper-Bound Infiltration-Flux Cases}

The repository-wide averaged percolation flux for the three climate states (present-day, monsoonal, and glacial-transition) is summarized in Table 6.3-4 for the lower-bound, mean, and upper-bound infiltration-flux cases. Table 6.3-5 summarizes the range of percolation flux for the present-day climate for the lower-bound, mean, and upper-bound infiltration-flux cases. Figure 6.3-2 gives the complementary cumulative distribution function for the peak temperature on the drift wall and on waste packages; these complementary cumulative distribution functions are for 
all waste packages over the entire repository area. Table 6.3-6 gives the coolest, median, and hottest peak drift-wall and waste package temperatures for the three infiltration-flux cases. The spatial extent and duration of dryout of the host rock increase with decreasing percolation flux. Because the thermal conductivity of dry rock is less than that of wet rock, peak temperatures increase with decreasing percolation flux. The sensitivity of peak temperature to percolation flux is strongest at either end of the complementary cumulative distribution function distributions. The differences between the mean and lower-bound infiltration-flux cases are greatest for the hottest waste package locations. The differences between the mean and upper-bound infiltration-flux cases are greatest for the coolest waste package locations. In general, the sensitivity of peak temperature to percolation flux is stronger for the hottest waste package locations.

Table 6.3-4. Repository-Wide Averaged Percolation Flux Summarized for Lower-Bound, Mean, and Upper-Bound Infiltration-Flux Cases

\begin{tabular}{|l|c|c|c|}
\hline \multirow{2}{*}{ Infiltration-Flux Case } & \multicolumn{2}{|c|}{ Repository-Wide Averaged Percolation Flux (mm/yr) } \\
\cline { 2 - 4 } & $\begin{array}{c}\text { Present-Day } \\
\text { (0 years }<\boldsymbol{t}<\mathbf{6 0 0} \text { years) }\end{array}$ & $\begin{array}{c}\text { Monsoonal } \\
(\mathbf{6 0 0} \text { years }<\boldsymbol{t}<\mathbf{2 , 0 0 0} \text { years) }\end{array}$ & $\begin{array}{c}\text { Glacial-Transition } \\
(\mathbf{2}, \mathbf{0 0 0} \text { years }<\boldsymbol{t} \text { ) }\end{array}$ \\
\hline Lower & 0.41 & 4.23 & 1.95 \\
\hline Mean & 3.77 & 11.15 & 17.29 \\
\hline Upper & 10.84 & 19.48 & 34.35 \\
\hline
\end{tabular}

NOTE: These averages are based on averaging the percolation data from DTN: LB0302PTNTSW9I.001 [DIRS 162277] over the heated repository footprint represented in the SMT submodel, as described in Appendix I.

Table 6.3-5. Range of Percolation Fluxes for the MSTHM for the Lower-Bound, Mean, and Upper-Bound Infiltration-Flux Cases for the Present-Day Climate

\begin{tabular}{|l|c|c|c|}
\hline \multirow{2}{*}{} & \multicolumn{3}{|c|}{ Percolation flux (mm/yr) } \\
\cline { 2 - 4 } & Lower infiltration-flux case & Mean infiltration-flux case & Upper infiltration-flux case \\
\hline Lowest value & $2.8 \times 10^{-5}$ & 0.24 & 1.12 \\
\hline Mean value & 0.41 & 3.77 & 10.84 \\
\hline Highest value & 2.20 & 13.74 & 36.18 \\
\hline
\end{tabular}

DTN: LL030808623122.036.

Table 6.3-6. Peak Drift-Wall and Waste Package Temperatures for Lower-Bound, Mean, and Upper-Bound Infiltration-Flux Cases

\begin{tabular}{|c|c|c|c|c|c|c|}
\hline \multirow{2}{*}{$\begin{array}{l}\text { Infiltration- } \\
\text { Flux Case }\end{array}$} & \multicolumn{3}{|c|}{$\begin{array}{c}\text { Peak Drift-Wall Temperature } \\
\left({ }^{\circ} \mathrm{C}\right)\end{array}$} & \multicolumn{3}{|c|}{$\begin{array}{l}\text { Peak Waste Package Temperature } \\
\left({ }^{\circ} \mathrm{C}\right)\end{array}$} \\
\hline & Coolest & Median & Hottest & Coolest & Median & Hottest \\
\hline Lower & 105.7 & 135.4 & 154.8 & 116.3 & 156.0 & 182.9 \\
\hline Mean & 105.0 & 133.0 & 144.2 & 115.6 & 153.3 & 172.0 \\
\hline Upper & 98.6 & 131.6 & 142.5 & 108.6 & 152.1 & 170.8 \\
\hline
\end{tabular}

NOTE: These values are based on Figure 6.3-2. 


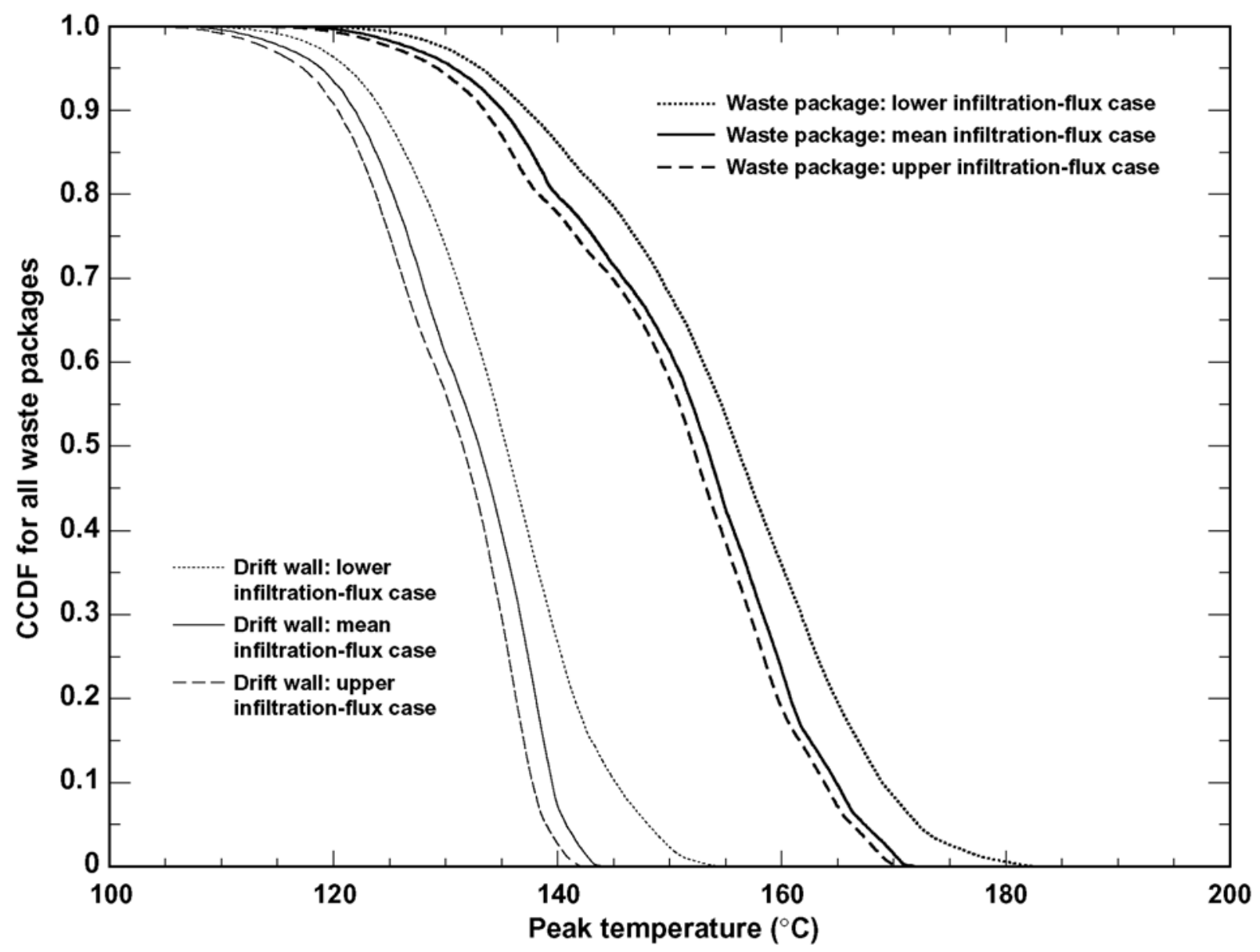

CCDF-Tpeak-dw-wp_li_mi_ui

Source: See Table XIII-1.

NOTE: $\quad$ CCDF is plotted for lower-bound, mean, and upper-bound infiltration-flux cases.

Figure 6.3-2. Complementary Cumulative Distribution Function (CCDF) for Peak Temperature on the Drift Wall and Waste Packages

Figure 6.3-3, which is the contour map of peak waste package temperature for PWR waste packages, illustrates how peak temperatures increase with distance from the repository edges. There are two reasons for this relationship. First, the edge-cooling effect, which results from lateral heat loss at the repository edges, is strongest for locations close to the edge of the repository. Second, the direction of the ventilation-air flow is from the ventilation inlets located at the repository edges in towards the ventilation outlets, which are generally located close to the center of the repository. Table III-1 of Appendix III, which lists the net available heat-generation fraction as a function of time and distance from the ventilation inlet (DTN: MO0304MWDALACV.000 [DIRS 164551]), shows that heat-removal efficiency (resulting from ventilation of emplacement drifts) decreases with distance from the ventilation inlet. Thus, locations closer to the repository edge receive more of the ventilation cooling effect than locations closer to the repository center. One slight variation of this trend is in Panel 5 where the ventilation inlet is on the eastern edge and the ventilation outlet is on the western edge. Figure 6.3-3 shows that peak temperatures on the eastern side of Panel 5 (where the heat-removal efficiency is greatest) are slightly lower than on the western side (where the heat-removal efficiency is least). 


\section{Peak waste-package temperature for the pwr1-2 (21-PWR AP CSNF) waste package \\ Mean infiltration-flux case}

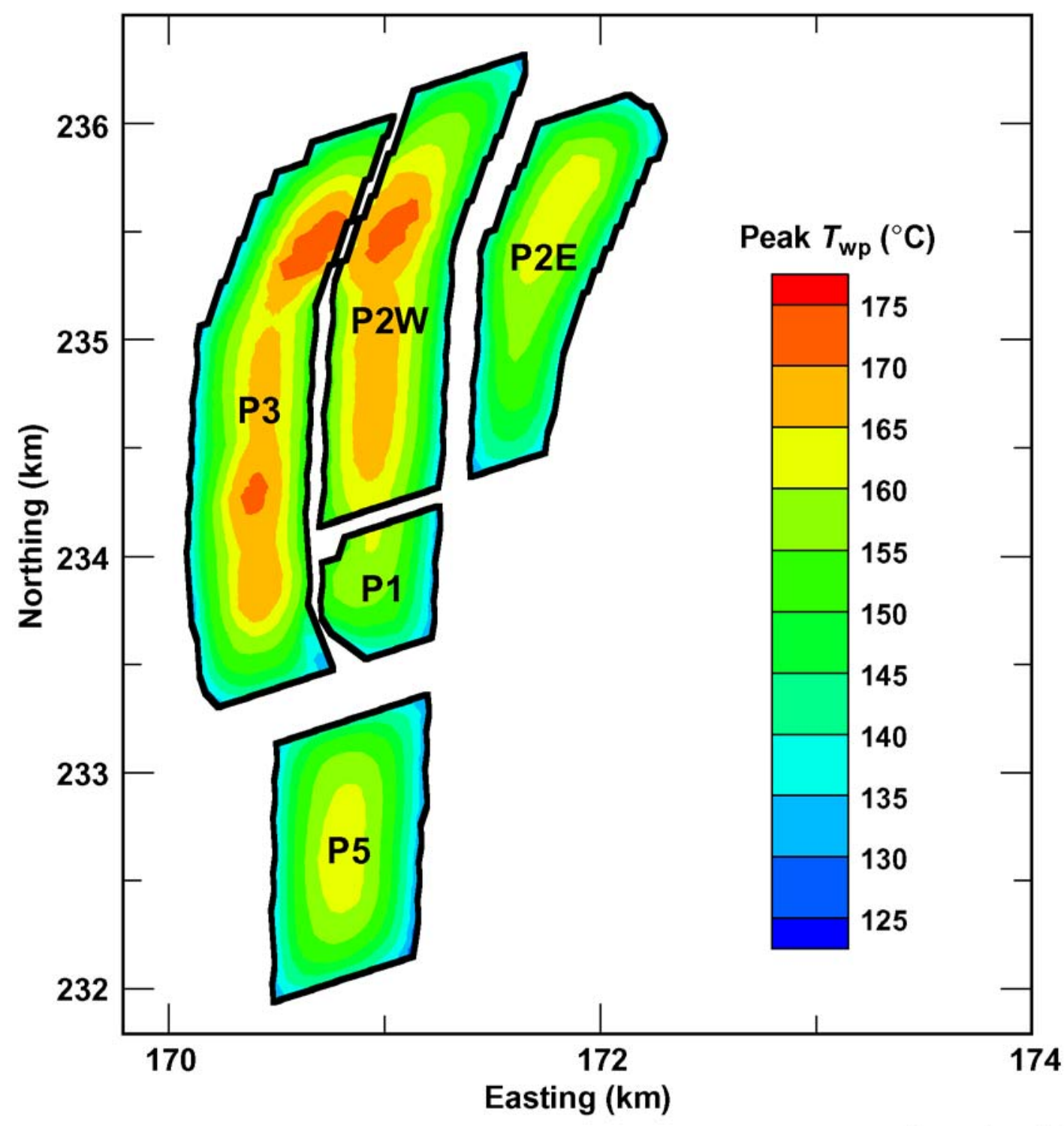

Twp_peak_pwr1-2

Source: See Table XIII-1.

NOTE: $\quad$ This contour map is plotted over the repository area for the mean infiltration-flux case. The pwr1-2 (21-PWR AP CSNF) waste package is the hottest package in the sequence (Table 6.3-13).

Figure 6.3-3. Contour Map of Peak Waste Package Temperature for the pwr1-2 Waste Package 
Figure 6.3-4a and Table 6.3-7 give the complementary cumulative distribution function for the time when boiling at the drift wall ceases for lower-bound, mean, and upper-bound infiltration-flux cases; these complementary cumulative distribution functions are for all waste package locations throughout the repository area. Note that at the repository horizon, which ranges in elevation ranging from about 1038 to $1092 \mathrm{~m}$, the boiling temperature is approximately $96^{\circ} \mathrm{C}$. The boiling-period duration is a useful thermohydrologic parameter because seepage into the drift is predicted not to occur during this period in Section 6.3.2 of Abstraction of Drift Seepage (BSC 2004 [DIRS 169131]). As was the case for peak temperatures, the boiling-period duration increases with decreasing percolation flux. Figure 6.3-5, which is a contour map of the time when boiling at the drift wall ceases for a PWR CSNF waste package for the mean infiltration-flux case, clearly shows that the boiling-period duration increases strongly with distance from the repository edges. The sensitivity of boiling-period duration to percolation flux is greatest for those locations with the longest boiling-period duration, which correspond to locations furthest away from the repository edges where differences in the spatial (and temporal) extent of rock dryout (resulting from differences in percolation flux) have more time to develop. There is a strong relationship between boiling-period duration and the spatial (and temporal) extent of rock dryout. Areas with low percolation flux will have a greater spatial extent of dryout, increasing the volume of rock in which the dry (low) value of thermal conductivity pertains, which enhances the temperature rise around the drifts. The enhanced temperature rise around the drift has the effect of extending the duration of boiling. Areas with high percolation flux will have a smaller spatial (and temporal) extent of rock dryout, decreasing the volume of rock in which the dry (low) value of thermal conductivity pertains, which reduces the temperature rise around the drifts. This reduced temperature rise around the drifts has the effect of shortening the duration of boiling.

Figure 6.3-4b and Table 6.3-8 give the complementary cumulative distribution function for the maximum lateral extent of the boiling-point isotherm for lower-bound, mean, and upper-bound infiltration-flux cases. Note that the lateral extent of the boiling-point isotherm approximately corresponds to the lateral extent of the dryout zone. As was the case for the peak temperatures and boiling-period duration, the maximum lateral extent of boiling increases with decreasing percolation flux. Figure 6.3-6 is a contour map of the maximum lateral extent of boiling (and dryout) for a PWR CSNF waste package. It is apparent that the maximum lateral extent of boiling increases with distance from the repository edges. Areas with low percolation flux will have a greater spatial extent of dryout, increasing the volume of rock in which the dry (low) value of thermal conductivity pertains, which enhances the temperature rise around the drifts. This enhanced temperature rise has the effect of increasing the volume of rock dryout around the drifts. Areas with high percolation flux will have a smaller spatial (and temporal) extent of rock dryout, decreasing the volume of rock to which the dry (low) value of thermal conductivity pertains, which reduces the temperature rise around the drifts. This reduced temperature rise around the drifts has the effect of limiting the volume of rock dryout around the drifts.

It is important to note that the lateral extent of boiling is always much smaller than the half spacing between emplacement drifts. Therefore, the majority of the host rock between emplacement drifts always remains below the boiling point, thereby enabling condensate and percolation flux to continuously drain between emplacement drifts. 
Table 6.3-7. Time When Boiling Ceases at the Drift Wall Summarized for Lower-Bound, Mean, and Upper-Bound Infiltration-Flux Cases

\begin{tabular}{|l|c|c|c|c|c|c|c|}
\hline \multirow{2}{*}{$\begin{array}{c}\text { Infiltration- } \\
\text { flux case }\end{array}$} & \multicolumn{7}{|c|}{ Time when boiling at the drift wall ceases } \\
\cline { 2 - 8 } (years) & Shortest & $\begin{array}{c}\text { 10th } \\
\text { Percentile }\end{array}$ & $\begin{array}{c}\text { 30th } \\
\text { Percentile }\end{array}$ & Median & $\begin{array}{c}\text { 70th } \\
\text { Percentile }\end{array}$ & $\begin{array}{c}\text { 90th } \\
\text { Percentile }\end{array}$ & Longest \\
\hline Lower & 130.2 & 349.9 & 630.9 & 859.6 & $1,122.5$ & $1,453.3$ & $1,734.6$ \\
\hline Mean & 127.2 & 297.5 & 535.8 & 721.0 & 870.6 & $1,006.5$ & $1,356.0$ \\
\hline Upper & 97.7 & 267.7 & 471.6 & 643.7 & 768.6 & 887.2 & $1,162.9$ \\
\hline
\end{tabular}

NOTE: These values are based on data plotted in Figure 6.3-4a.

Table 6.3-8. Maximum Lateral Extent of the Boiling-Point Isotherm $\left(96^{\circ} \mathrm{C}\right)$ Summarized for LowerBound, Mean, and Upper-Bound Infiltration-Flux Cases

\begin{tabular}{|l|c|c|c|c|c|c|c|}
\hline \multirow{2}{*}{$\begin{array}{c}\text { Infiltration- } \\
\text { flux case }\end{array}$} & Least & $\begin{array}{c}\text { 10th } \\
\text { Percentile }\end{array}$ & $\begin{array}{c}\text { 30th } \\
\text { Percentile }\end{array}$ & Median & $\begin{array}{c}\text { 70th } \\
\text { Percentile }\end{array}$ & $\begin{array}{c}\text { 90th } \\
\text { Percentile }\end{array}$ & Greatest \\
\hline Lower & 5.6 & 7.1 & 7.9 & 8.4 & 9.4 & 12.3 & 17.8 \\
\hline Mean & 5.3 & 6.7 & 7.5 & 7.9 & 8.2 & 8.7 & 9.9 \\
\hline Upper & 5.1 & 6.5 & 7.3 & 7.7 & 7.9 & 8.1 & 9.0 \\
\hline
\end{tabular}

NOTE: These values are based on data plotted in Figure 6.3-4b. The maximum lateral extent of the boiling-point isotherm, which is measured from the center of the emplacement drift, approximately corresponds to the maximum lateral extent of dryout. 

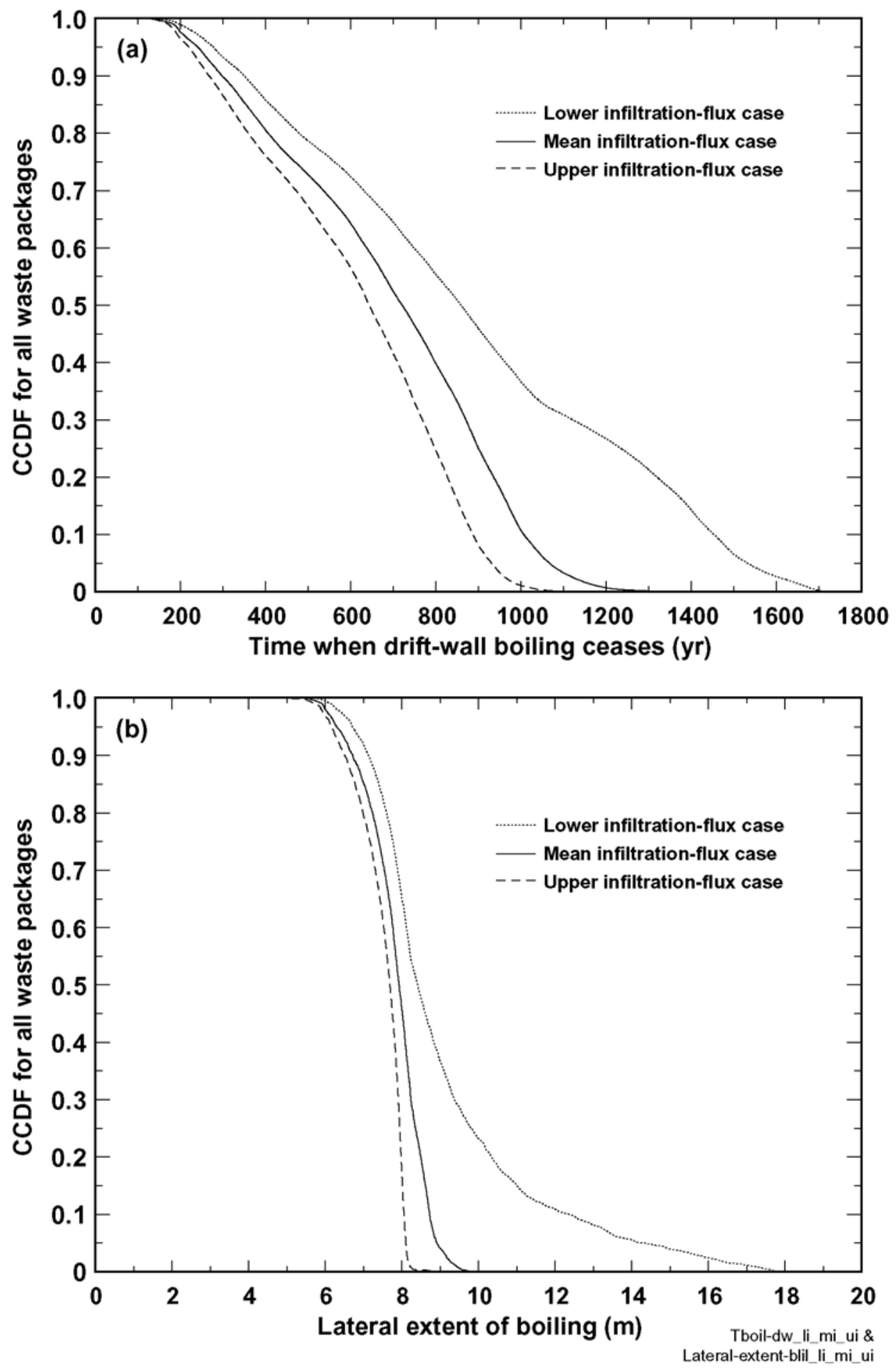

Source: See Table XIII-1.

NOTE: CCDFs are plotted for the lower-bound, mean, and upper-bound infiltration-flux cases. The maximum lateral extent of the boiling-point isotherm, which is measured from the center of the emplacement drift, approximately corresponds to the maximum lateral extent of the dryout zone.

Figure 6.3-4. Complementary Cumulative Distribution Functions (CCDFs) for (a) the Time When Boiling at the Drift Wall Ceases and (b) the Maximum Lateral Extent of the Boiling-Point Isotherm $\left(96^{\circ} \mathrm{C}\right)$ 


\section{Time when drift-wall boiling ceases for the pwr1-2 (21-PWR AP CSNF) waste package \\ Mean infiltration-flux case}

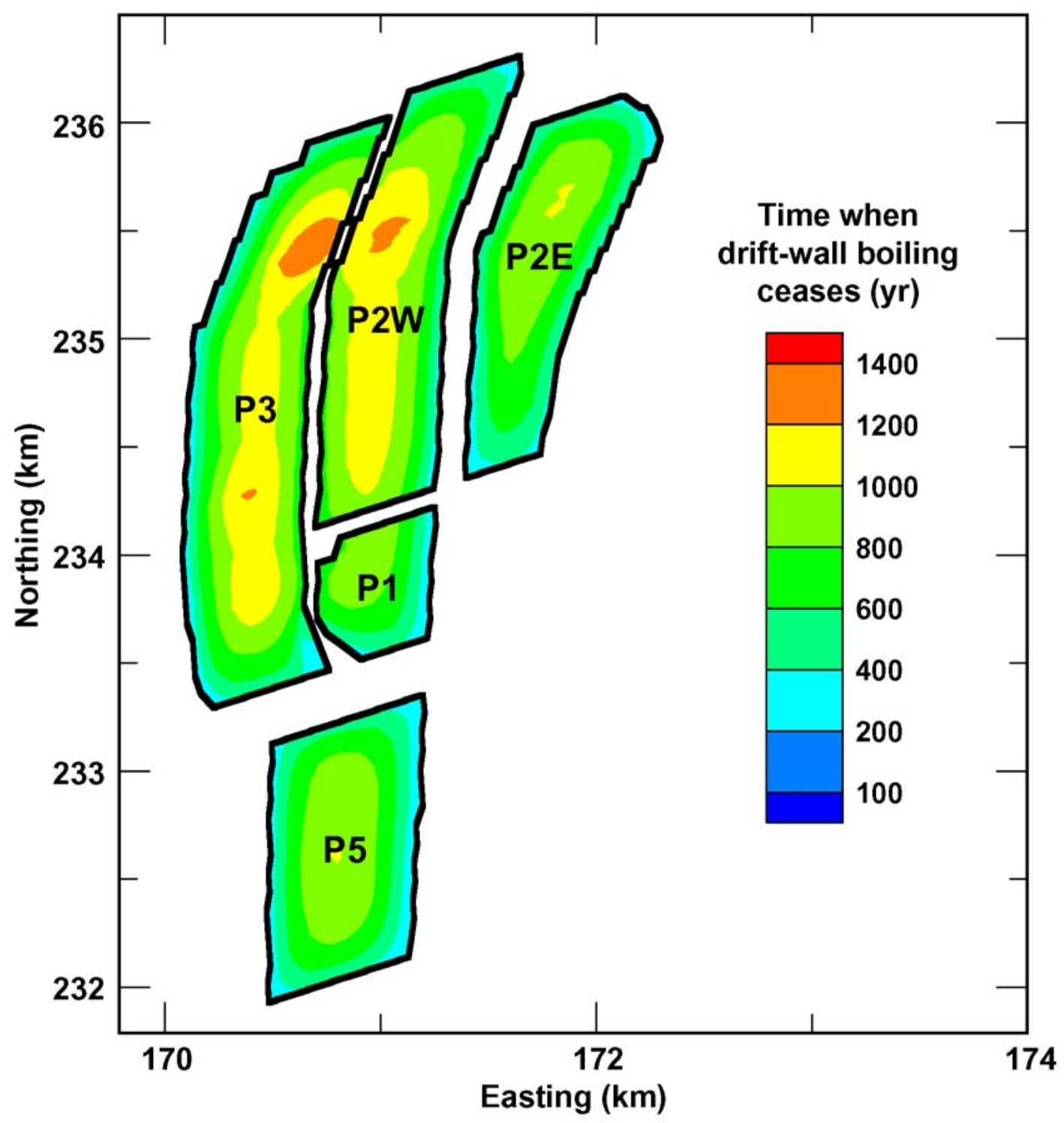

Tdw_boil_dura_pwr1-2

Source: See Table XIII-1.

NOTE: This contour map is plotted over the repository area for the mean infiltration-flux case. The pwr1-2 (21-PWR AP CSNF) waste package is the hottest package in the sequence (Figure 6.2-2).

Figure 6.3-5. Contour Map of the Time When Boiling at the Drift Wall Ceases for the pwr1-2 Waste Package 


\section{Lateral extent of boiling-point isotherm for the pwr1-2 (21-PWR AP CSNF) waste package \\ Mean infiltration-flux case}

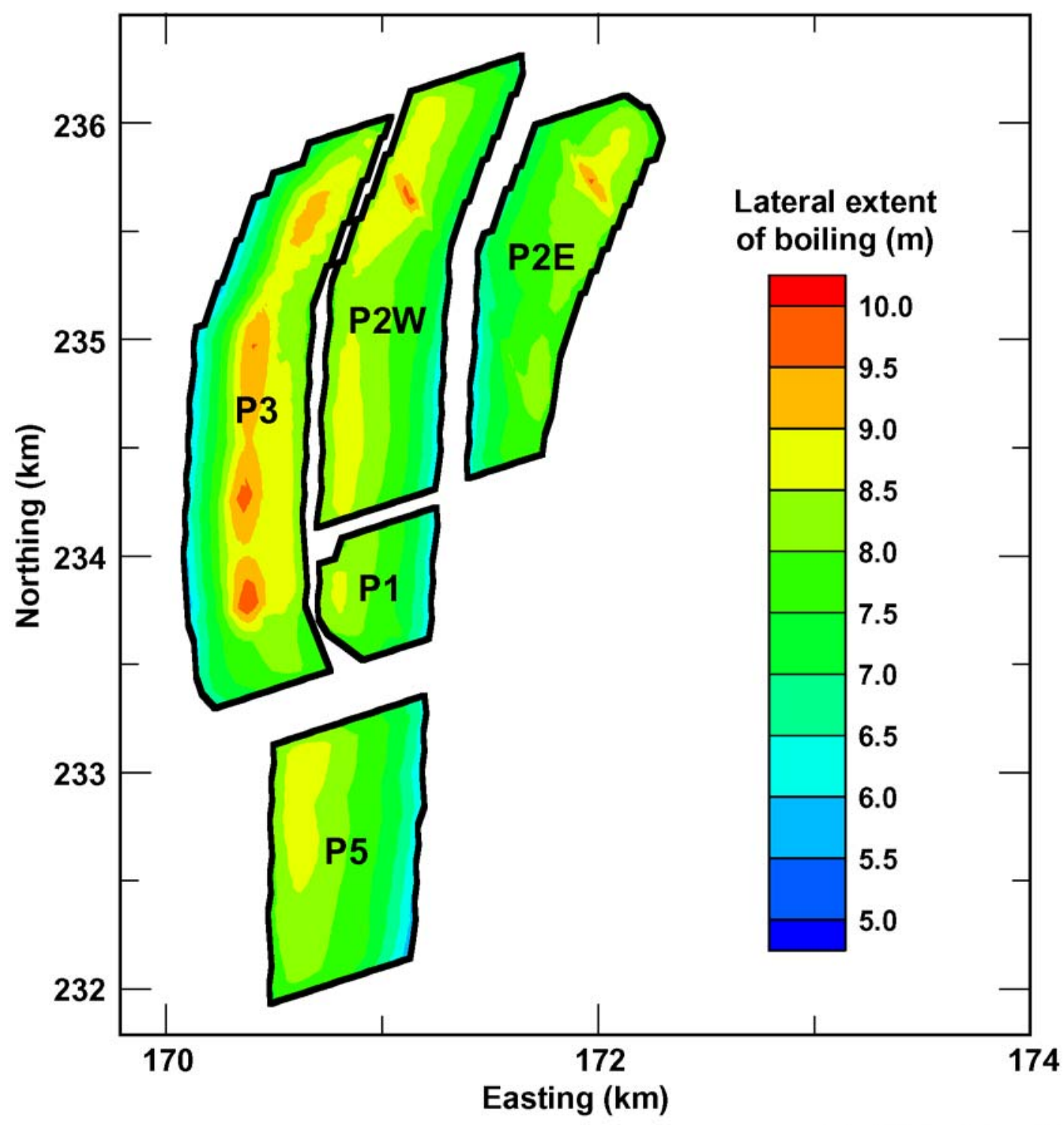

Lateral_Tboil_extent_pwr1-2

Source: See Table XIII-1.

NOTE This contour map is plotted over the repository area for the mean infiltration-flux case. The pwr1-2 (21-PWR AP CSNF) waste package is the hottest package in the sequence (Table 6.3-13). The maximum lateral extent of the boiling-point isotherm, which is measured from the center of the emplacement drift, approximately corresponds to the maximum lateral extent of dryout.

Figure 6.3-6. Contour Map of the Maximum Lateral Extent of the Boiling-Point Isotherm $\left(96^{\circ} \mathrm{C}\right)$ from the Drift Centerline for the pwr1-2 Waste Package 
For the purpose of examining the details of thermal-hydrologic behavior in emplacement drifts, five locations were chosen that cover all four of the host-rock units (Tables 6.3-9, 6.3-10 and Figure 6.3-1). Four of these locations (P2ER8C6, P2WR8C8, P2WR5C10, and P3R8C13) were chosen because their respective values of percolation flux are close to the repository-wide averages (Table 6.3-4). The fifth location (P3R7C12) was chosen because it has close to the longest boiling-period duration over the entire repository area; note that this location is in a region of low percolation flux, which is a major contributing factor to its very long boiling-period duration. Time histories of drift-wall temperature and liquid-phase saturation, waste package temperature and relative humidity, and invert liquid-phase saturation are plotted (Figures 6.3-7 through 6.3-11) for these five locations (Figure 6.3-1). Tables 6.3-9 and 6.3-10 summarize the relationship between percolation flux and infiltration-flux case for the five locations and three climate states. Using Tables 6.3-9 and 6.3-10 as a guide, the influence of percolation flux on peak temperatures is summarized in Table 6.3-11 for the five locations. The influence of percolation flux on the duration of boiling is summarized in Table 6.3-12, which gives the time when boiling at the drift wall ceases.

Table 6.3-9. Percolation Flux for Mean Infiltration-Flux Case for Five Locations Used to Examine Thermal-Hydrologic Conditions in the Repository

\begin{tabular}{|l|l|l|l|l|c|c|}
\hline \multirow{2}{*}{$\begin{array}{c}\text { LDTH-SDT } \\
\text { submodel } \\
\text { location }\end{array}$} & Host-rock unit & \multicolumn{2}{|c|}{ Nevada State Coordinates } & \multicolumn{2}{|c|}{$\begin{array}{c}\text { Percolation flux for the mean infiltration- } \\
\text { flux case (mm/yr) }\end{array}$} \\
\cline { 2 - 8 } & & & & & \multicolumn{2}{c}{$\begin{array}{c}\text { Glacial- } \\
\text { transition }\end{array}$} \\
\hline P2ER8C6 & Tptpul (tsw33) & 171564.3 & 234417.3 & 5.41 & 11.70 & 23.03 \\
\hline P2WR8C8 & Tptpmn (tsw34) & 171240.9 & 234312.1 & 4.47 & 10.45 & 15.65 \\
\hline P2WR5C10 & Tptpll (tsw35) & 170730.3 & 234912.7 & 4.71 & 14.60 & 22.07 \\
\hline P3R7C12 & Tptpll (tsw35) & 170347.9 & 234277.5 & 0.86 & 3.43 & 6.32 \\
\hline P3R8C13 & Tptpln (tsw36) & 170080.6 & 233935.1 & 7.07 & 21.95 & 31.66 \\
\hline
\end{tabular}

NOTE: $\quad$ See Figure 6.3-1 for locations. The percolation flux is obtained from DTN: LB0302PTNTSW9I.001 [DIRS 162277], as discussed in Appendix I of this report.

Table 6.3-10. Percolation Flux for the Lower and Upper Infiltration-Flux Cases for Five Locations Used to Examine Thermal-Hydrologic Conditions in the Repository

\begin{tabular}{|l|c|c|c|c|c|c|}
\hline \multirow{2}{*}{$\begin{array}{c}\text { LDTH-SDT } \\
\text { submodel } \\
\text { location }\end{array}$} & \multicolumn{2}{|c|}{$\begin{array}{c}\text { Percolation Flux for the Lower-Bound } \\
\text { Infiltration-Flux Case (mm/yr) }\end{array}$} & \multicolumn{2}{c|}{$\begin{array}{c}\text { Percolation Flux for the Upper-Bound } \\
\text { Infiltration-Flux Case (mm/yr) }\end{array}$} \\
\cline { 2 - 7 } & Present-day & Monsoonal & $\begin{array}{c}\text { Glacial- } \\
\text { transition }\end{array}$ & Present-day & Monsoonal & $\begin{array}{c}\text { Glacial- } \\
\text { transition }\end{array}$ \\
\hline P2ER8C6 & $6.331 \times 10^{-2}$ & 3.57 & 1.79 & 7.22 & 14.11 & 34.53 \\
\hline P2WR8C8 & $2.621 \times 10^{-3}$ & 3.44 & 1.31 & 7.31 & 12.51 & 22.14 \\
\hline P2WR5C10 & $2.261 \times 10^{-3}$ & 5.58 & 2.02 & 15.22 & 26.12 & 43.60 \\
\hline P3R7C12 & $1.081 \times 10^{-4}$ & 0.91 & 0.12 & 6.76 & 12.82 & 24.28 \\
\hline P3R8C13 & 0.36 & 6.66 & 3.69 & 16.57 & 33.64 & 54.99 \\
\hline
\end{tabular}

NOTE See Figure 6.3-1 for locations. The percolation flux is obtained from DTN: LB0302PTNTSW9I.001 [DIRS 162277], as discussed in Appendix I of this report. 
Table 6.3-11. Range of Peak Temperatures over the Three Infiltration-Flux Cases for the pwr1-2 Waste Package for Five Locations in the Repository

\begin{tabular}{|c|l|c|c|c|c|c|c|c|c|}
\hline $\begin{array}{c}\text { LDTH-SDT } \\
\text { submodel } \\
\text { location }\end{array}$ & \multirow{2}{*}{$\begin{array}{c}\text { Host-rock } \\
\text { unit }\end{array}$} & \multicolumn{4}{|c|}{$\begin{array}{c}\text { Peak Drift-Wall Temperature } \\
\text { ( } \mathrm{C} \text { () }\end{array}$} & \multicolumn{3}{c|}{ Peak Waste Package Temperature } \\
\cline { 2 - 10 } & & Lower & Mean & Upper & Range & Lower & Mean & Upper & Range \\
\hline P2ER8C6 & $\begin{array}{l}\text { Tptpul } \\
\text { (tsw33) }\end{array}$ & 138.2 & 135.5 & 135.2 & 3.0 & 165.8 & 163.2 & 163.5 & 2.3 \\
\hline P2WR8C8 & $\begin{array}{l}\text { Tptpmn } \\
\text { (tsw34) }\end{array}$ & 127.4 & 123.0 & 122.3 & 5.1 & 154.8 & 150.6 & 150.8 & 4.0 \\
\hline P2WR5C10 & $\begin{array}{l}\text { Tptpll } \\
\text { (tsw35) }\end{array}$ & 149.3 & 141.5 & 139.6 & 9.7 & 177.8 & 169.4 & 168.2 & 9.6 \\
\hline P3R7C12 & $\begin{array}{l}\text { Tptpll } \\
\text { (tsw35) }\end{array}$ & 148.9 & 140.0 & 138.7 & 10.2 & 176.6 & 167.3 & 166.5 & 10.1 \\
\hline P3R8C13 & $\begin{array}{l}\text { Tptpln } \\
\text { (tsw36) }\end{array}$ & 121.4 & 120.5 & 118.8 & 2.6 & 149.2 & 148.2 & 147.4 & 1.8 \\
\hline
\end{tabular}

NOTE: $\quad$ See Figure 6.3-1 for locations. These values are based on data plotted in Figures 6.3-7 through 6.3-11.

Table 6.3-12. Range of Time When Boiling at the Drift Wall Ceases over the Three Infiltration-Flux Cases for the pwr1-2 Waste Package for Five Locations in the Repository

\begin{tabular}{|l|l|c|c|c|c|c|}
\hline \multirow{2}{*}{$\begin{array}{c}\text { LDTH-SDT } \\
\text { submodel } \\
\text { location }\end{array}$} & \multirow{2}{*}{$\begin{array}{c}\text { Host-rock } \\
\text { unit }\end{array}$} & \multicolumn{5}{|c|}{ Time When Boiling at the Drift Wall Ceases for Three Infiltration-flux cases } \\
\cline { 3 - 7 } & & \multicolumn{2}{|c|}{$\begin{array}{l}\text { Lears) } \\
\text { Upper }\end{array}$} & Range & Range $^{\mathbf{a}}$ \\
\hline P2ER8C6 & $\begin{array}{l}\text { Tptpul } \\
\text { (tsw33) }\end{array}$ & 425.3 & 365.6 & 359.8 & 65.5 & $16.7 \%$ \\
\hline P2WR8C8 & $\begin{array}{l}\text { Tptpmn } \\
\text { (tsw34) }\end{array}$ & 298.8 & 221.0 & 213.1 & 85.7 & $33.5 \%$ \\
\hline P2WR5C10 & Tptpll (tsw35) & $1,230.7$ & 686.1 & 540.4 & 690.3 & $78.0 \%$ \\
\hline P3R7C12 & Tptpll (tsw35) & $1,592.3$ & $1,200.1$ & $1,030.9$ & 561.4 & $42.8 \%$ \\
\hline P3R8C13 & $\begin{array}{l}\text { Tptpln } \\
\text { (tsw36) }\end{array}$ & 242.3 & 218.8 & 199.2 & 43.1 & $19.5 \%$ \\
\hline
\end{tabular}

${ }^{a}$ The range (\%) is the range (years) divided by the average time when drift-wall boiling ceases [(shortest + longest)/2].

NOTE: See Figure 6.3-1 for locations. These values are based on data plotted in Figures 6.3-7 through 6.3-11. 

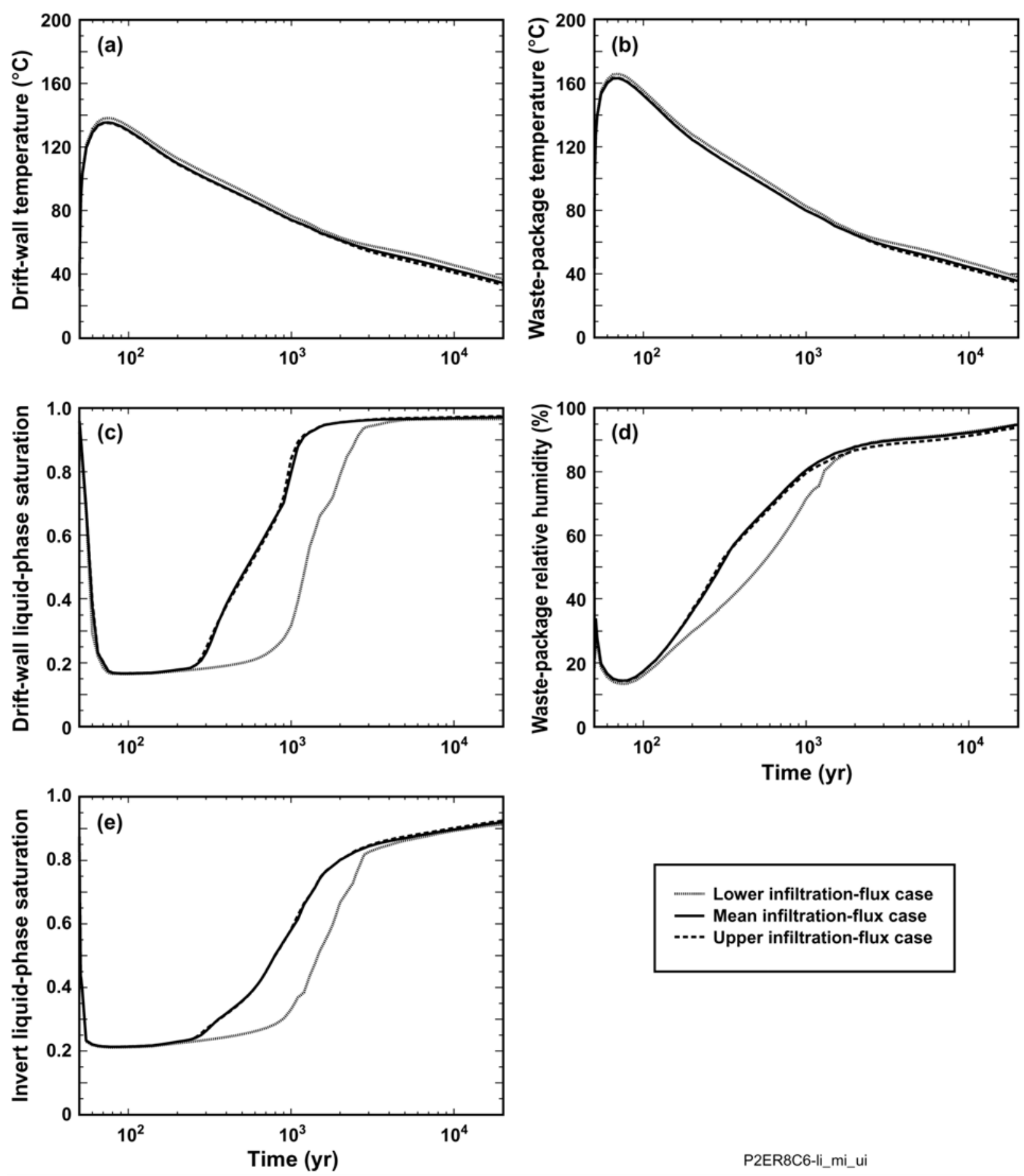

P2ER8C6-li_mi_ui

Source: See Table XIII-1.

NOTE: $\quad$ See Figure 6.3-1 for location. The plotted thermal-hydrologic parameters are (a) drift-wall temperature, (b) waste package temperature, (c) drift-wall liquid-phase saturation, (d) waste package relative humidity, and (e) invert liquid-phase saturation. The pwr1-2 (21-PWR AP CSNF) waste package is the hottest waste package in the sequence (Figure 6.2-2).

Figure 6.3-7. Thermal-Hydrologic Conditions for the pwr1-2 Waste Package Plotted for Lower-Bound, Mean, and Upper-Bound Infiltration-Flux Cases at the P2ER8C6 Location in the Tptpul (tsw33) Unit 

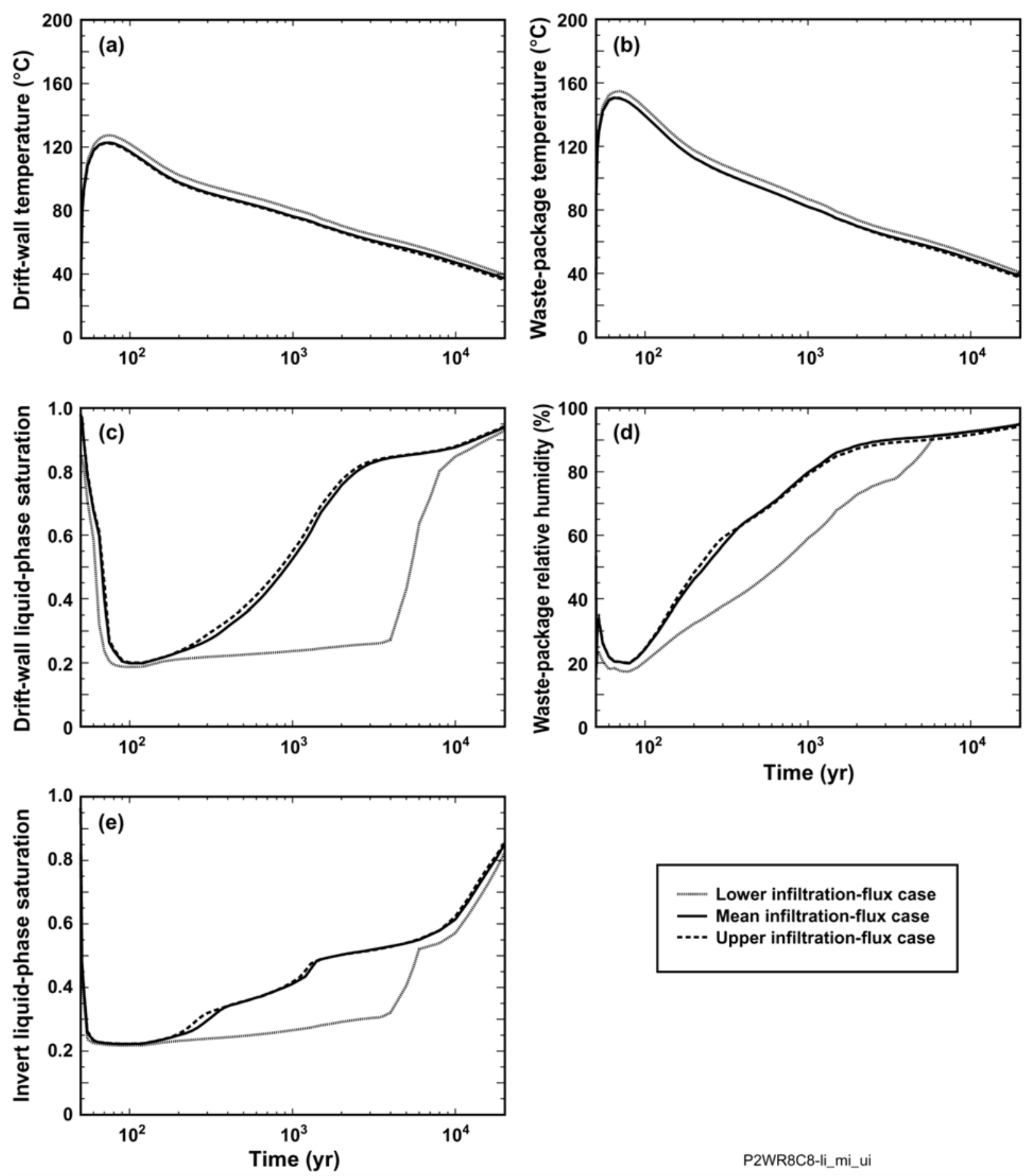

Source: See Table XIII-1.

NOTE: $\quad$ See Figure 6.3-1 for location. The plotted thermal-hydrologic parameters are (a) drift-wall temperature, (b) waste package temperature, (c) drift-wall liquid-phase saturation, (d) waste package relative humidity, and (e) invert liquid-phase saturation. The pwr1-2 (21-PWR AP CSNF) waste package is the hottest waste package in the sequence (Figure 6.2-2).

Figure 6.3-8. Thermal-Hydrologic Conditions for the pwr1-2 Waste Package Plotted for Lower-Bound, Mean, and Upper-Bound Infiltration-Flux Cases at the P2WR8C8 Location in the Tptpmn (tsw34) Unit 

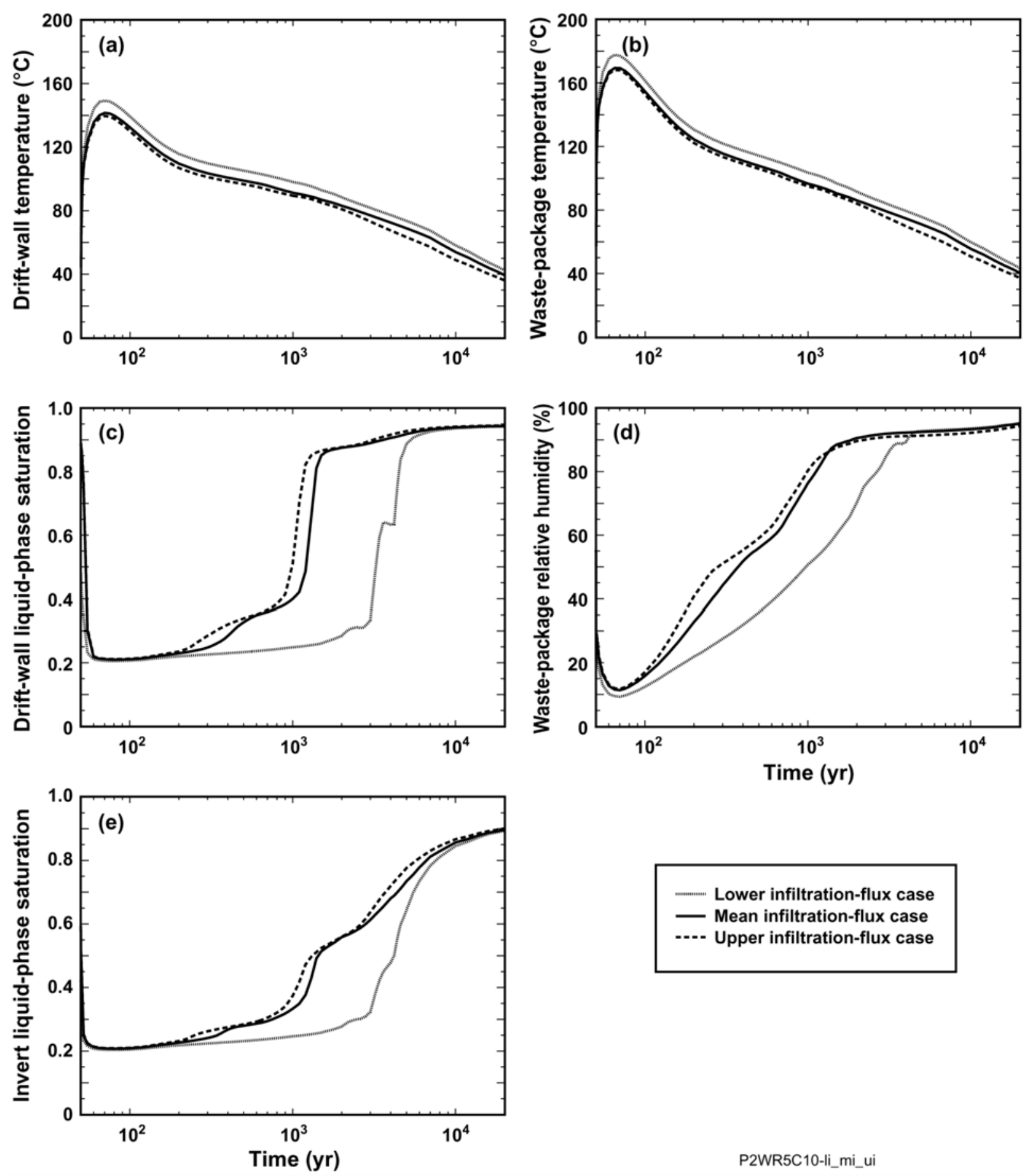

P2WR5C10-li_mi_ui

Source: See Table XIII-1.

NOTE: $\quad$ See Figure 6.3-1 for location. The plotted thermal-hydrologic parameters are (a) drift-wall temperature, (b) waste package temperature, (c) drift-wall liquid-phase saturation, (d) waste package relative humidity, and (e) invert liquid-phase saturation. The pwr1-2 (21-PWR AP CSNF) waste package is the hottest waste package in the sequence (Figure 6.2-2).

Figure 6.3-9. Thermal-Hydrologic Conditions for the pwr1-2 Waste Package Plotted for Lower-Bound, Mean, and Upper-Bound Infiltration-Flux Cases at the P2WR5C10 Location in the Tptpll (tsw35) Unit 

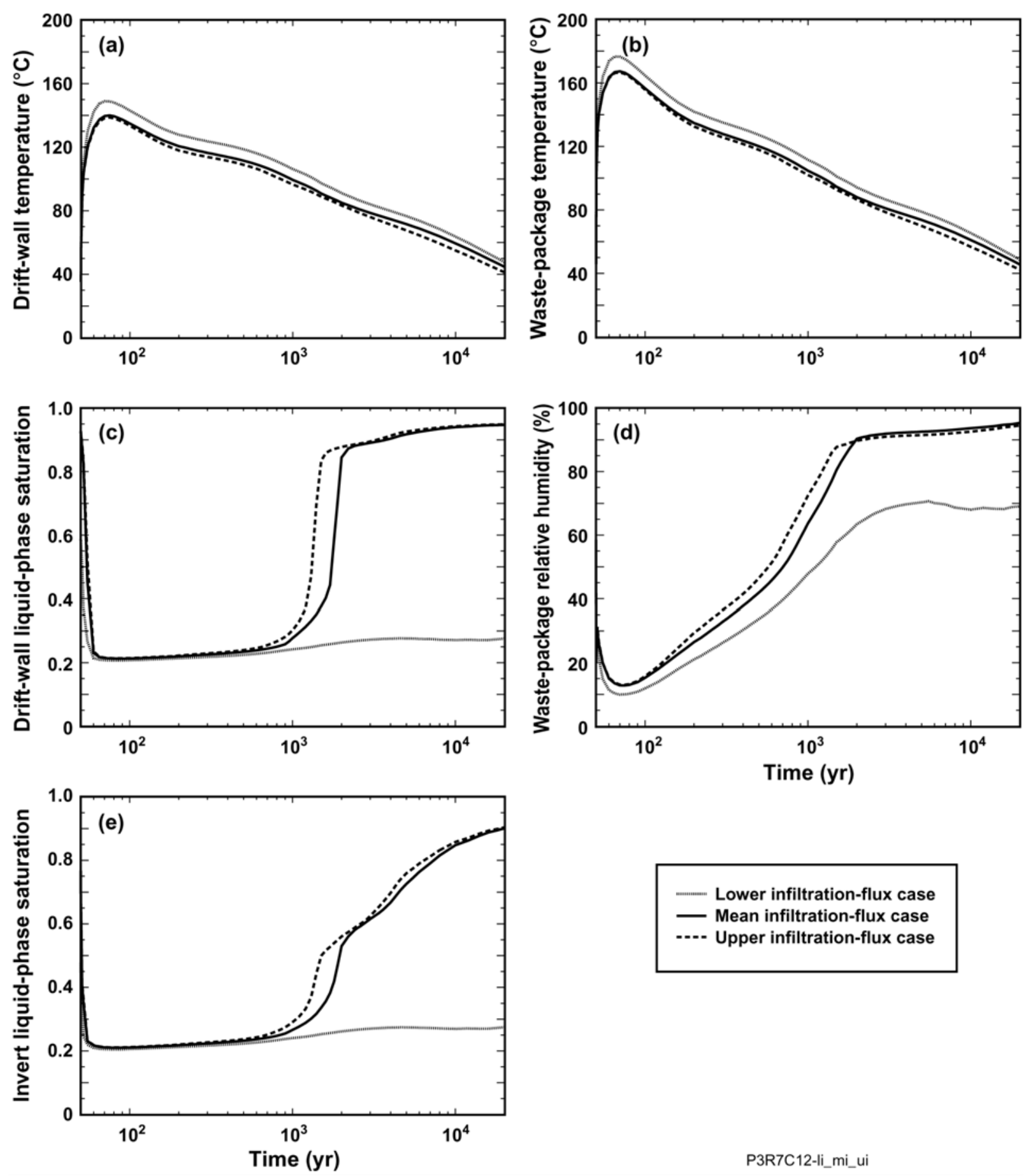

P3R7C12-li_mi_ui

Source: See Table XIII-1.

NOTE: $\quad$ See Figure 6.3-1 for location. The plotted thermal-hydrologic parameters are (a) drift-wall temperature, (b) waste package temperature, (c) drift-wall liquid-phase saturation, (d) waste package relative humidity, and (e) invert liquid-phase saturation. The pwr1-2 (21-PWR AP CSNF) waste package is the hottest waste package in the sequence (Figure 6.2-2).

Figure 6.3-10. Thermal-Hydrologic Conditions for the pwr1-2 Waste Package Plotted for Lower-Bound, Mean, and Upper-Bound Infiltration-Flux Cases at the P3R7C12 Location in the Tptpll (tsw35) Unit 

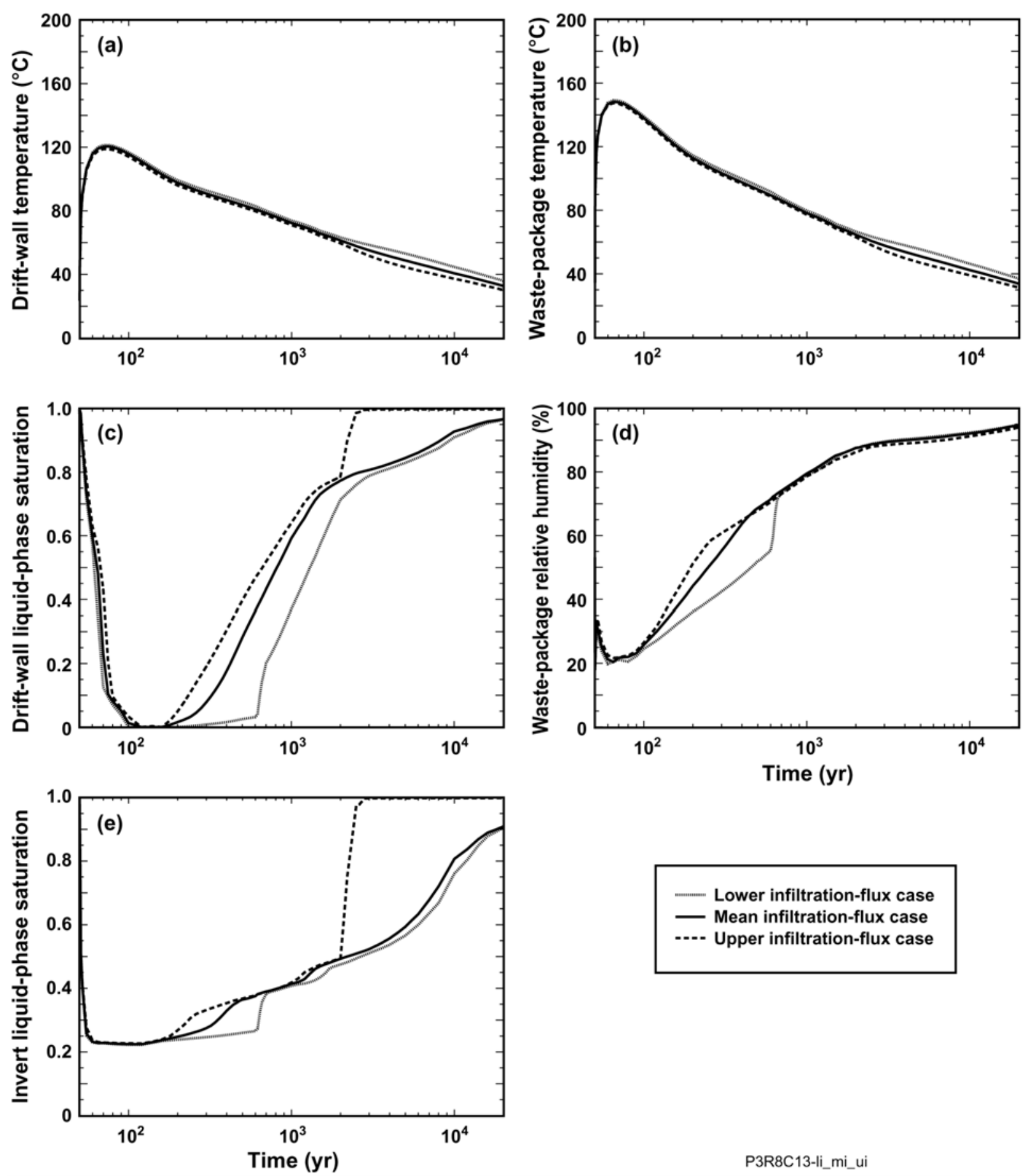

P3R8C13-li_mi_ui

Source: See Table XIII-1.

NOTE: $\quad$ See Figure 6.3-1 for location. The plotted thermal-hydrologic parameters are (a) drift-wall temperature, (b) waste package temperature, (c) drift-wall liquid-phase saturation, (d) waste package relative humidity, and (e) invert liquid-phase saturation. The pwr1-2 (21-PWR AP CSNF) waste package is the hottest waste package in the sequence (Figure 6.2-2).

Figure 6.3-11. Thermal-Hydrologic Conditions for the pwr1-2 Waste Package Plotted for Lower-Bound, Mean, and Upper-Bound Infiltration-Flux Cases at the P3R8C13 Location in the Tptpln (tsw36) Unit 
The influence of percolation flux on peak temperature is about the same for the waste package as it is for the drift wall (Table 6.3-11). The range of peak temperatures (from lower-bound to upper-bound infiltration-flux case) is slightly less for the waste package than it is for the drift wall. The reason for this relationship is that the effectiveness of thermal radiation increases slightly with temperature; consequently, the difference in peak temperature between the waste package and drift wall decreases slightly with increasing peak drift-wall temperature. Because the thermal conductivity of the rock is less for the lithophysal units (Tptpul and Tptpll) than it is for the nonlithophysal units (Tptpmn and Tptpln), peak temperatures are greater in the lithophysal units than in the nonlithophysal units.

The influence of percolation flux on the duration of boiling at the drift wall is greater for the locations (P2WR5C10 and P3R7C12) further from the repository edges than for those closer to the repository edges (P2ER8C6, P2WR8C8, and P3R8C13). Because location P2WR8C8 (located on the eastern edge of Panel 2W) receives some heat from the southern portion of Panel $2 \mathrm{E}$, its boiling duration is somewhat greater than it is for the other two "edge" locations (P2ER8C6 and P3R8C13). Locations away from the repository edges have longer boiling durations that allow more time for the differences in rock dryout between lower and higher percolation fluxes to develop. There is a strong relationship between boiling-period duration and the spatial (and temporal) extent of rock dryout. Areas with low percolation flux will have a greater spatial extent of dryout, increasing the volume of rock in which the dry (low) value of thermal conductivity pertains, which enhances the temperature rise around the drifts. The enhanced temperature rise around the drift has the effect of extending the duration of boiling. Areas with high percolation flux will have a smaller spatial (and temporal) extent of rock dryout, decreasing the volume of rock in which the dry (low) value of thermal conductivity pertains, which reduces the temperature rise around the drifts. This reduced temperature rise around the drifts has the effect of shortening the duration of boiling.

The influence of percolation flux on dryout/rewetting is illustrated by the drift-wall and invert liquid-phase saturation histories (Figures 6.3-7c, 6.3-7e, 6.3-8c, 6.3-8e, 6.3-9c, 6.3-9e, 6.3-10c, 6.3-10e, 6.3-11c, and 6.3-11e). Locations P2ER8C6 and P2WR8C8 have small differences in dryout/rewetting between the upper-bound and mean infiltration-flux cases (Figures 6.3-7c, 6.3-7e, 6.3-8c, and 6.3-8e), while having larger differences between the lower-bound and mean infiltration-flux cases. Location P2WR5C10 has moderate differences in dryout/rewetting between the upper-bound and mean infiltration-flux cases (Figures 6.3-9c and 6.3-9e), while having larger differences between the lower-bound and mean infiltration-flux cases. Tables 6.3-9 and 6.3-10 show that location P2WR5C10 has larger differences in percolation flux between the lower-bound, mean, and upper-bound infiltration cases than do locations P2ER8C6 and P2WR8C8; consequently, location P2WR5C10 shows a greater sensitivity to the infiltration-flux case. Tables 6.3-9 and 6.3-10 show that location P3R7C12 has larger differences in percolation flux between the lower-bound, mean, and upper-bound infiltration-flux cases than does location P2WR5C10; thus, location P3R7C12 (Figures 6.3-10c and 6.3-10e) has larger differences in dryout/rewetting between the upper-bound and mean infiltration-flux cases than does location P2WR5C10 (Figures 6.3-9c and 6.3-9e). Location P3R7C12 has substantial differences in dryout/rewetting between the lower-bound and mean infiltration-flux cases, with the lower-bound infiltration-flux case remaining at low liquid-phase saturation beyond 20,000 years (Figures 6.3-10c and 6.3-10e). Location P3R8C13 has larger differences in dryout/rewetting between the upper-bound and mean infiltration-flux cases (Figures 6.3-11c and 6.3-11e) and between the lower-bound and mean infiltration-flux cases. 
The influence of percolation flux on waste package relative humidity histories is similar to its influence on dryout/rewetting (Figures 6.3-7d, 6.3-8d, 6.3-9d, 6.3-10d, and 6.3-11d). Locations P2ER8C6 and P2WR8C8 have small differences in waste package relative humidity history between the upper-bound and mean infiltration-flux cases (Figures 6.3-7d and 6.3-8d), while having larger differences between the lower-bound and mean infiltration-flux cases. Location P2WR5C10 has moderate differences in waste package relative humidity history between the upper-bound and mean infiltration-flux cases (Figure 6.3-9d), while having larger differences between the lower-bound and mean infiltration-flux cases. Location P3R7C12 has moderate differences in waste package relative humidity history between the upper-bound and mean infiltration-flux cases (Figure 6.3-10d), while having substantial differences between the lower-bound and mean infiltration-flux cases. Location P3R8C13 has small differences in waste package relative humidity history between the upper-bound and mean infiltration-flux case (Figure 6.3-11d); moderate differences between the lower-bound and mean infiltration-flux cases persist for about 700 years. With the exception of location P3R7C12, differences in waste package relative humidity history among the infiltration-flux cases generally diminish within one to several thousand years.

\subsubsection{Influence of Waste Package-to-Waste Package Heat-Generation Variability}

This section investigates the influence of waste package-to-waste package heat-generation variability on thermal-hydrologic conditions in the emplacement drifts. The eight different waste packages considered in all of the MSTHM calculations (Figure 6.2-2) are summarized in Table 6.3-13. Time histories of drift-wall temperature and liquid-phase saturation, waste package temperature and relative humidity, and invert liquid-phase saturation are plotted (Figures 6.3-12 through 6.3-16) for three of these waste packages (dhlw-l1, bwr1-1, and pwr1-2) for the five locations discussed in the previous section (see Figure 6.3-1 for locations). Note that these three waste packages include the coolest and hottest in the waste package sequence considered. The influence of waste package-to-waste package heat-generation variability on peak temperatures is summarized in Table 6.3-14 for the five locations. The influence of waste package-to-waste package heat-generation variability on the duration of boiling is summarized in Table 6.3-15, which gives the time when boiling at the drift wall ceases. 
Table 6.3-13. Summary of Waste Packages Included in the MSTHM Calculations (Figure 6.2-2)

\begin{tabular}{|c|c|c|c|c|}
\hline $\begin{array}{l}\text { Waste } \\
\text { Package } \\
\text { Name in } \\
\text { MSTHM }\end{array}$ & Waste Package type & $\begin{array}{l}\text { Length in } \\
\text { Model (m) }\end{array}$ & $\begin{array}{l}\text { Initial Heat- } \\
\text { Generation } \\
\text { Rate (kW) }\end{array}$ & $\begin{array}{c}\text { Notes } \\
\text { (based on MSTHM output temperatures } \\
\text { and heat output) }\end{array}$ \\
\hline pwr1-1 & $\begin{array}{l}\text { 21-PWR AP CSNF } \\
1 / 221-P W R \text { AP }\end{array}$ & 2.5825 & $5.764^{\mathrm{a}}$ & $\begin{array}{l}\text { Half waste package in model; coolest } \\
\text { PWR waste package in sequence, but } \\
\text { "average" PWR waste package with } \\
\text { respect to heat output }\end{array}$ \\
\hline dhlw-I1 & $\begin{array}{l}5 \text { DHLW/DOE SNF-LONG } \\
5-H L W L O N G\end{array}$ & 5.217 & 0.990 & $\begin{array}{l}\text { Coolest waste package in sequence with } \\
\text { the lowest heat output }\end{array}$ \\
\hline pwr2-1 & $\begin{array}{l}\text { 21-PWR AP CSNF } \\
\text { 21-PWR AP (HOT) }\end{array}$ & 5.165 & 11.800 & $\begin{array}{l}\text { "Average" PWR waste package in } \\
\text { sequence with respect to temperatures, } \\
\text { but highest heat output in sequence }\end{array}$ \\
\hline bwr1-1 & $\begin{array}{l}\text { 44-BWR CSNF } \\
\text { 44-BWR AP }\end{array}$ & 5.165 & 7.377 & $\begin{array}{l}\text { Hottest BWR waste package in sequence, } \\
\text { but "average" BWR waste package with } \\
\text { respect to heat output }\end{array}$ \\
\hline bwr2-1 & $\begin{array}{l}\text { 44-BWR CSNF } \\
\text { 44-BWR ADJESTED }\end{array}$ & 5.165 & 7.100 & "Oldest" BWR waste package in sequence \\
\hline dhlw-s1 & $\begin{array}{l}5 \text { DHLW/DOE SNF-SHORT } \\
\text { 5-HLW SHORT }\end{array}$ & 3.59 & 2.983 & $\begin{array}{l}\text { Hottest DHLW waste package in } \\
\text { sequence }\end{array}$ \\
\hline pwr1-2 & $\begin{array}{l}\text { 21-PWR AP CSNF } \\
21-P W R \text { AP }\end{array}$ & 5.165 & 11.528 & $\begin{array}{l}\text { "Hottest" waste package in sequence, but } \\
\text { average PWR waste package with respect } \\
\text { to heat output }\end{array}$ \\
\hline bwr1-2 & $\begin{array}{l}\text { 44-BWR CSNF } \\
1 / 244-B W R \text { AP }\end{array}$ & 2.5825 & $3.689^{a}$ & $\begin{array}{l}\text { Half waste package in model; coolest } \\
\text { BWR waste package in sequence, but } \\
\text { "average" BWR waste package with } \\
\text { respect to heat output }\end{array}$ \\
\hline
\end{tabular}

a These values represent the heat-generation rate for a half waste package.

NOTES: Waste packages included in Figures 6.3-12 through 6.3-16 are shown in bold. Names of waste package types as they appear in BSC 2004 [DIRS 167754] are shown in italics.

Waste package lengths are based on information from BSC 2003 [DIRS 165406], Table 1. Heat generation rates are based on information from BSC 2004 [DIRS 167754], Table 12. The heat generation rates used in the MSTHM calculations are based on the first 25,000 years of entries in Table 12 of BSC 2004 [DIRS 167754]. Heat generation values for 20,050 years, which corresponds to the end of the MSTHM simulations, are linearly interpolated between the values for 20,000 years and 25,000 years from Table 12 of BSC 2004 [DIRS 167754].

Table 6.3-14. Range of Peak Temperatures from Variability in Waste Package-to-Waste Package Heat Generation for the Mean Infiltration-Flux Case, Summarized for Five Locations in the Repository

\begin{tabular}{|l|l|c|c|c|c|c|c|}
\hline \multirow{2}{*}{$\begin{array}{c}\text { LDTH-SDT } \\
\text { Submodel } \\
\text { Location }\end{array}$} & \multicolumn{2}{|c|}{} & \multicolumn{4}{|c|}{$\begin{array}{c}\text { Peak Waste Package } \\
\text { Temperature ( }{ }^{\circ} \text { C) }\end{array}$} \\
\cline { 3 - 8 } & Host-Rock Unit & Lowest & Highest & Range & Lowest & Highest & Range \\
\hline P2ER8C6 & Tptpul (tsw33) & 122.3 & 135.5 & 13.2 & 132.0 & 163.2 & 31.2 \\
\hline P2WR8C8 & Tptpmn (tsw34) & 109.7 & 123.0 & 13.3 & 118.9 & 150.6 & 31.7 \\
\hline P2WR5C10 & Tptpll (tsw35) & 126.8 & 140.8 & 14.0 & 136.7 & 168.8 & 32.1 \\
\hline P3R7C12 & Tptpll (tsw35) & 126.8 & 140.0 & 13.2 & 136.3 & 167.3 & 31.0 \\
\hline P3R8C13 & Tptpln (tsw36) & 106.6 & 120.2 & 13.6 & 116.1 & 148.2 & 32.1 \\
\hline
\end{tabular}

NOTE: $\quad$ See Figure 6.3-1 for locations. These values are based on data plotted in Figures 6.3-7 through 6.3-16. 
Table 6.3-15. Range of Time When Boiling at the Drift Wall Ceases (Resulting from Variability in Waste Package-to-Waste Package Heat Generation) for the Mean Infiltration-Flux Case, Summarized for Five Locations in the Repository

\begin{tabular}{|l|l|c|c|c|c|}
\hline \multirow{2}{*}{$\begin{array}{c}\text { LDTH-SDT } \\
\text { Submodel } \\
\text { Location }\end{array}$} & \multirow{2}{*}{ Host-Rock Unit } & \multicolumn{5}{|c|}{ Time When Boiling at the Drift Wall Ceases } \\
\cline { 3 - 6 } (years)
\end{tabular}

${ }^{\mathrm{a}}$ The range (\%) is the range (years) divided by the average time when drift-wall boiling ceases [(shortest + longest)/2].

NOTE: See Figure 6.3-1 for locations.

The influence of waste package-to-waste package heat-generation variability on peak drift-wall temperatures is virtually the same for all five locations (Table 6.3-14); similarly, the influence of heat-generation variability on peak waste package temperatures is virtually the same for all five locations. The range of peak drift-wall temperatures is less than the range of peak waste package temperatures. Thermal radiation in the drift is an efficient heat-transfer mechanism for limiting the extent of temperature variability along the axis of the drift. The influence of heat-generation variability on boiling duration varies among the five locations (Table 6.3-15). The greatest degree of boiling-duration variability is at location P2WR5C10, while location P3R7C12 has the least degree of boiling-duration variability.

The influence of heat-generation variability on dryout/rewetting is illustrated by the drift-wall and invert liquid-phase saturation histories (Figures 6.3-12c, 6.3-12e, 6.3-13c, 6.3-13e, 6.3-14c, 6.3-14e, 6.3-15c, 6.3-15e, 6.3-16c, and 6.3-16e). Dryout/rewetting at locations P2ER8C6, P2WR8C8, and P3R8C13 (Figures 6.3-12c 6.3-12e, 6.3-13c, 6.3-13e, 6.3-16c, and 6.3-16e), which are close to the repository edges, exhibit more sensitivity to heat-generation variability than at locations P2WR5C10 and P3R7C12 (Figures 6.3-14c, 6.3-14e, 6.3-15c, and 6.3-15e), which are farther away from the repository edges. Note that location P3R7C12 has by far the least degree of dryout/rewetting variability. For all locations, the invert exhibits less dryout/rewetting variability than the drift wall. 

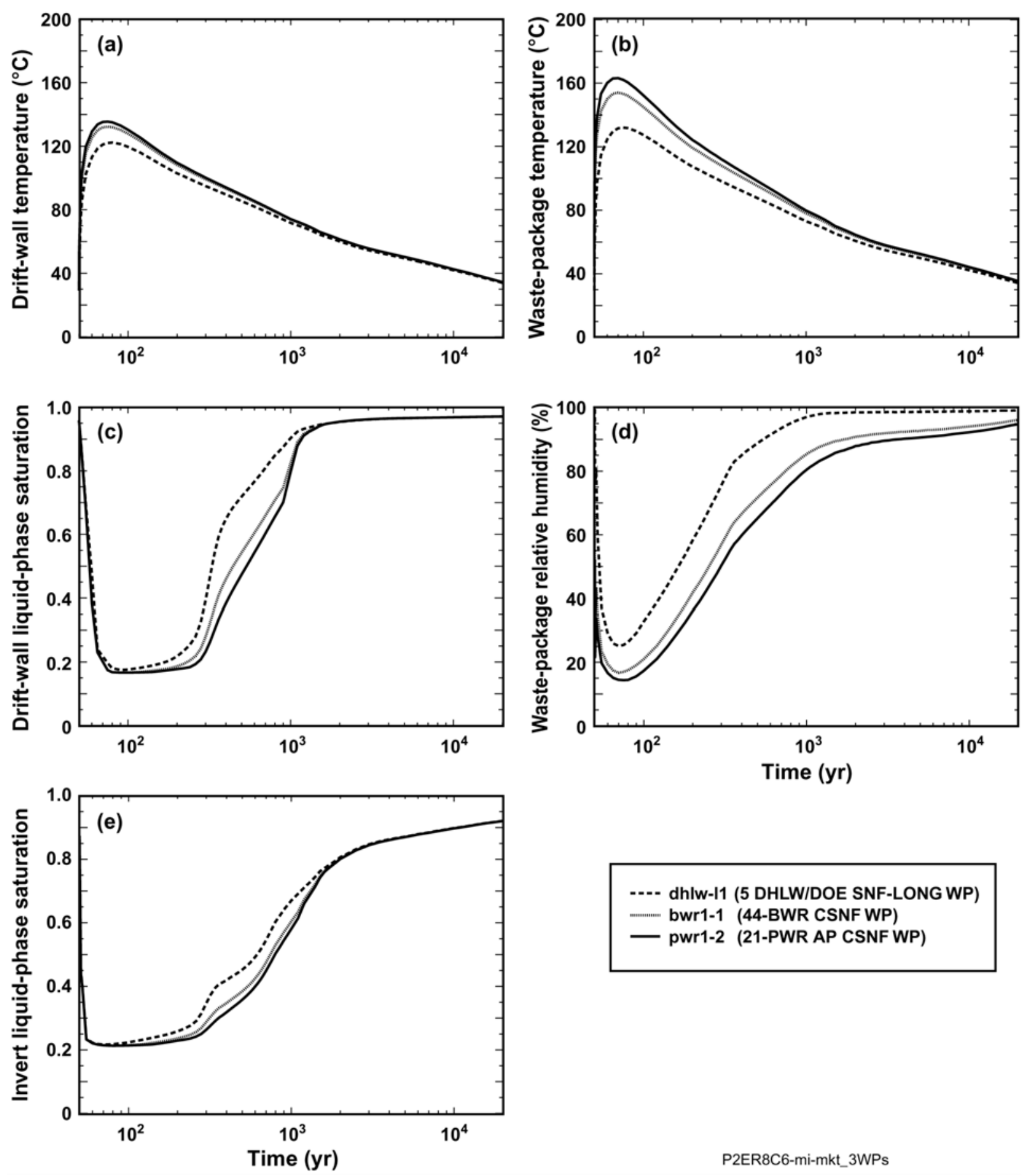

P2ER8C6-mi-mkt_3WPs

Source: See Table XIII-1.

NOTE: $\quad$ See Figure 6.3-1 for location. The plotted thermal-hydrologic parameters are (a) drift-wall temperature, (b) waste package temperature, (c) drift-wall liquid-phase saturation, (d) waste package relative humidity, and (e) invert liquid-phase saturation. These waste packages bracket the entire range of temperature at this location.

Figure 6.3-12. Thermal-Hydrologic Conditions for the Mean Infiltration-Flux Case Plotted for a Range of Waste Packages at the P2ER8C6 Location in the Tptpul (tsw33) Unit 

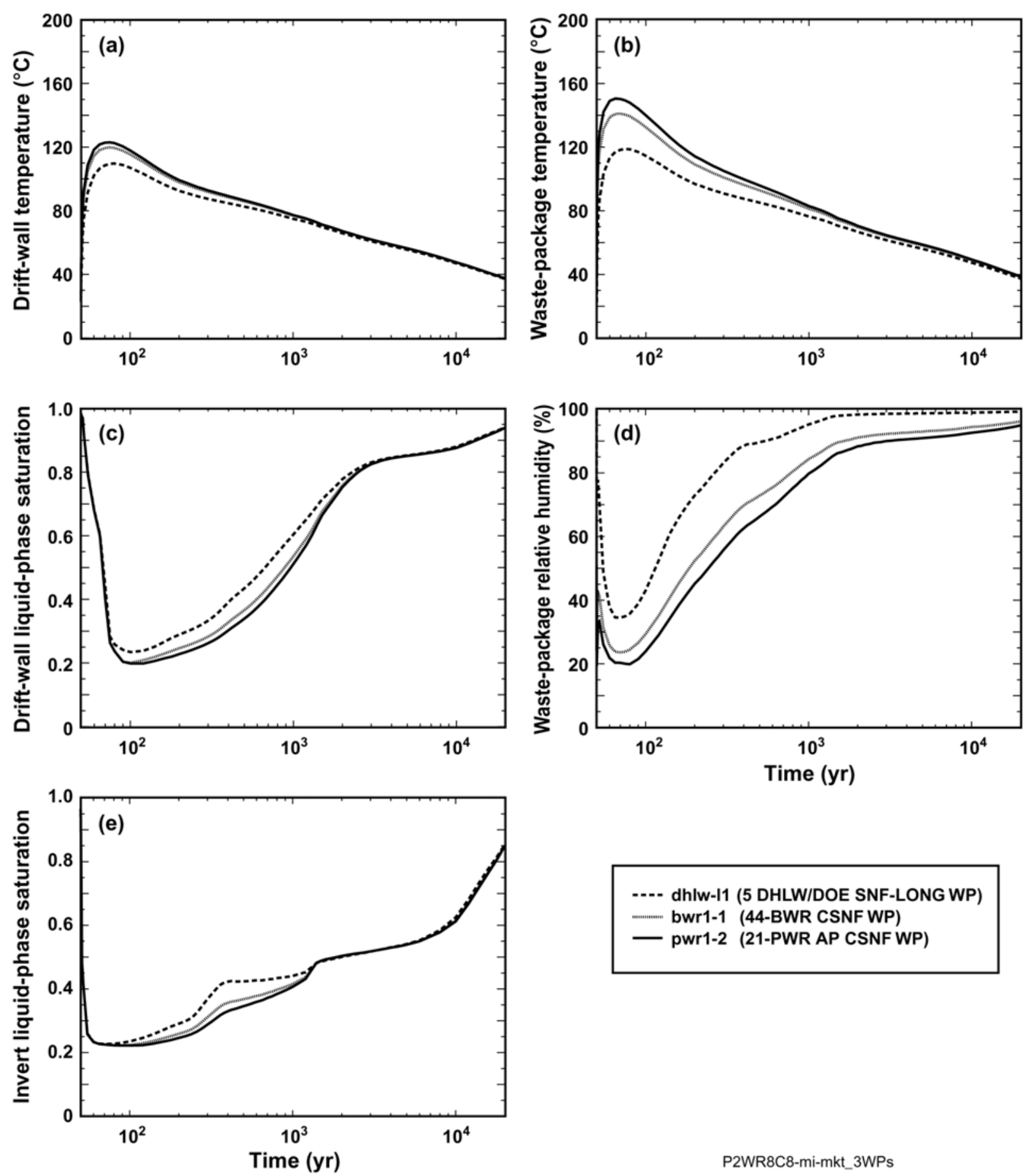

Source: See Table XIII-1.

NOTE: $\quad$ WP = waste package. See Figure 6.3-1 for location. The plotted thermal-hydrologic parameters are (a) drift-wall temperature, (b) waste package temperature, (c) drift-wall liquid-phase saturation, (d) waste package relative humidity, and (e) invert liquid-phase saturation. These waste packages bracket the entire range of temperature at this location.

Figure 6.3-13. Thermal-Hydrologic Conditions for the Mean Infiltration-Flux Case Plotted for a Range of Waste Packages at the P2WR8C8 Location in the Tptpmn (tsw34) Unit 

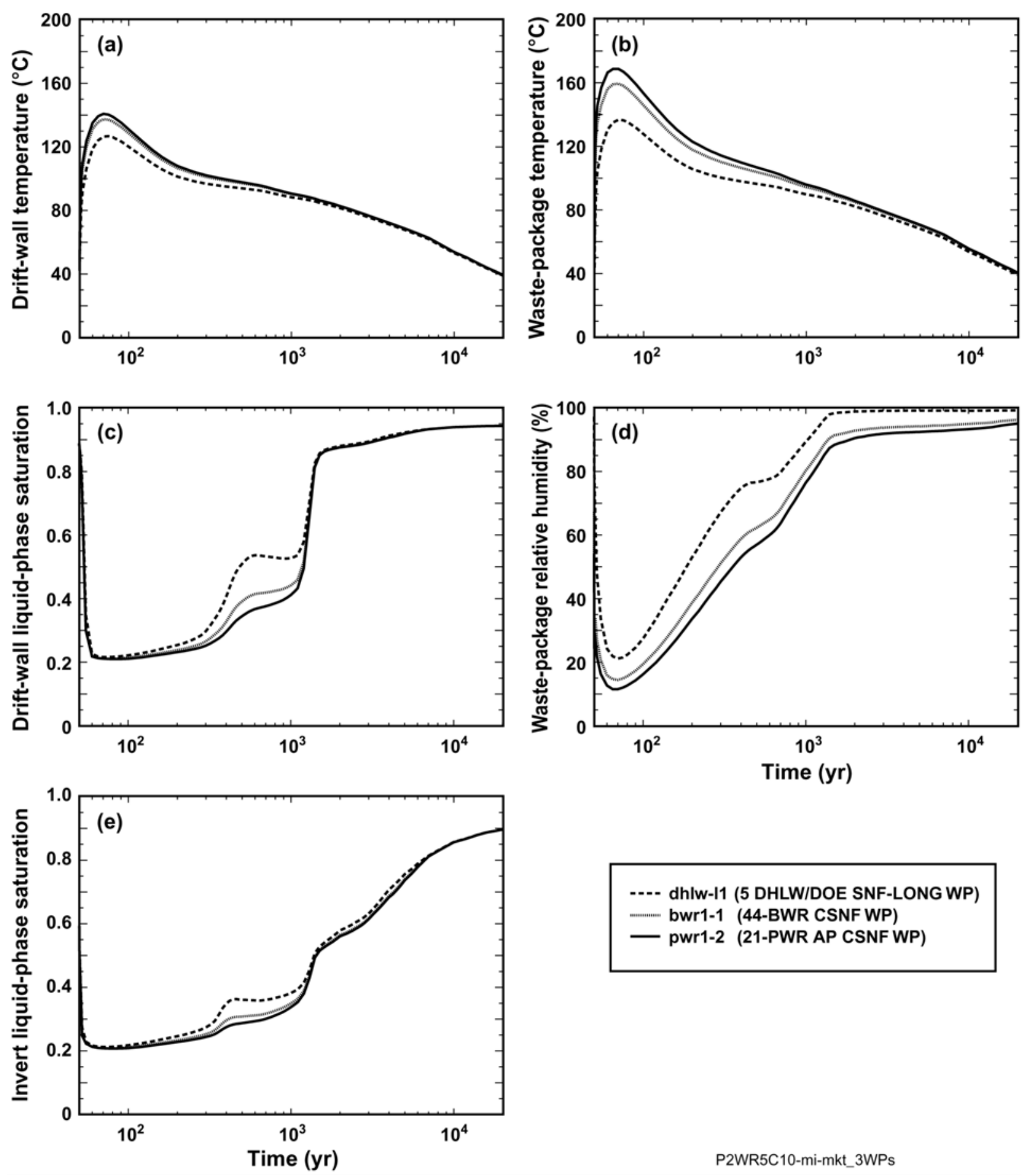

P2WR5C10-mi-mkt_3WPs

Source: See Table XIII-1.

NOTE: $\quad$ WP = waste package. See Figure 6.3-1 for location. The plotted thermal-hydrologic parameters are (a) drift-wall temperature, (b) waste package temperature, (c) drift-wall liquid-phase saturation, (d) waste package relative humidity, and (e) invert liquid-phase saturation. These waste packages bracket the entire range of temperature at this location.

Figure 6.3-14. Thermal-Hydrologic Conditions for the Mean Infiltration-Flux Case Plotted for a Range of Waste Packages at the P2WR5C10 Location in the Tptpll (tsw35) Unit 

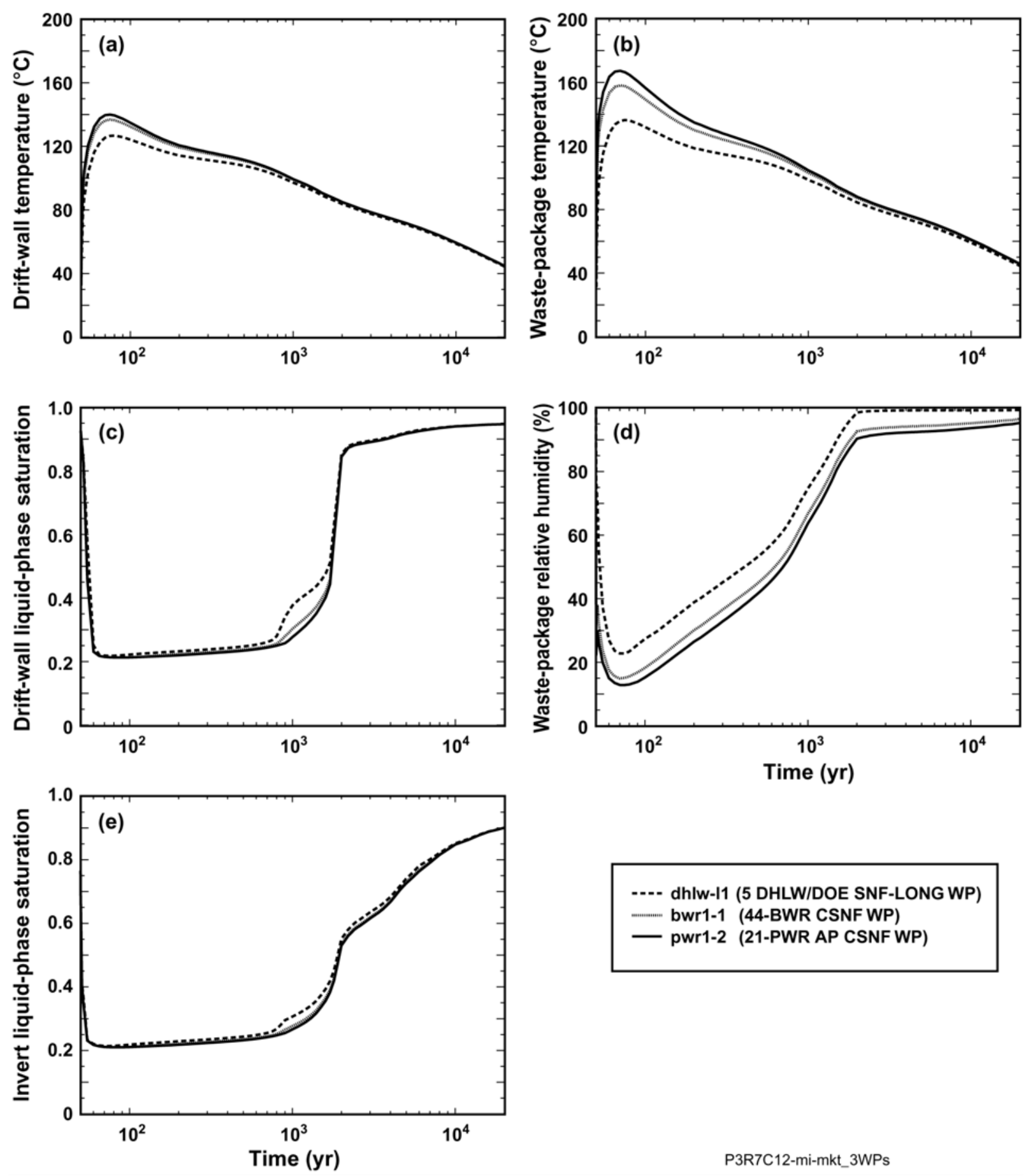

P3R7C12-mi-mkt_3WPs

Source: See Table XIII-1.

NOTE: $\quad$ WP = waste package. See Figure 6.3-1 for location. The plotted thermal-hydrologic parameters are (a) drift-wall temperature, (b) waste package temperature, (c) drift-wall liquid-phase saturation, (d) waste package relative humidity, and (e) invert liquid-phase saturation. These waste packages bracket the entire range of temperature at this location.

Figure 6.3-15. Thermal-Hydrologic Conditions for the Mean Infiltration-Flux Case Plotted for a Range of Waste Packages at the P3R7C12 Location in the Tptpll (tsw35) Unit 

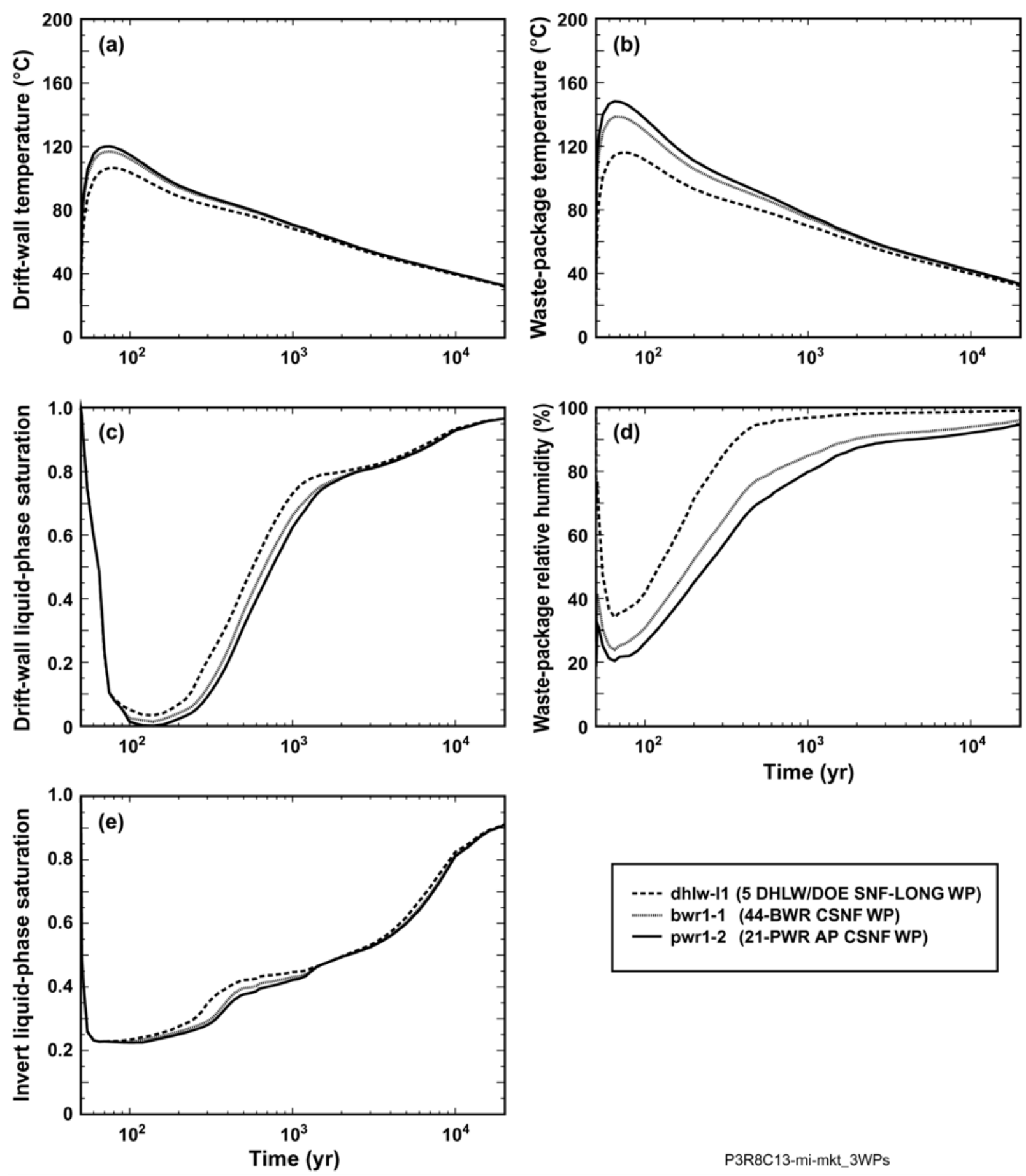

P3R8C13-mi-mkt_3WPs

Source: See Table XIII-1.

NOTE: $\quad$ WP = waste package. See Figure 6.3-1 for location. The plotted thermal-hydrologic parameters are (a) drift-wall temperature, (b) waste package temperature, (c) drift-wall liquid-phase saturation, (d) waste package relative humidity, and (e) invert liquid-phase saturation. These waste packages bracket the entire range of temperature at this location.

Figure 6.3-16. Thermal-Hydrologic Conditions for the Mean Infiltration-Flux Case Plotted for a Range of Waste Packages at the P3R8C13 Location in the Tptpln (tsw36) Unit 
The influence of heat-generation variability on waste package relative humidity variability is similar to the influence on dryout/rewetting. Because the relative humidity at the drift wall depends on the liquid-phase saturation and temperature, the variability of drift-wall relative humidity is similar to that of drift-wall liquid-phase saturation. Relative humidity at a given waste package depends on two factors. The first is the adjacent drift-wall relative humidity. The second factor is the temperature difference between the waste package and adjoining drift-wall surface; relative humidity reduction (relative to the adjacent drift wall) depends on this temperature difference (Section 6.1.4). Waste packages with higher heat-generation rates result in a greater relative humidity reduction, for longer times, than those with lower heat-generation rates. The large difference in heat-generation rate between the coolest and hottest waste packages results in a large difference in the respective relative humidity histories.

From a heat-transfer perspective, the drip shield functions like a thermal-radiation shield (between the waste package and the drift wall) that causes the waste package to be hotter than it would without the presence of the drip shield. The increased temperature difference between the waste package and the drift wall reduces the relative humidity on the waste package. For waste packages with higher heat-generation rates (i.e., the pwr1-2 waste package in Figure 6.3-16), the influence of the thermal-radiation shield on waste package temperature and relative humidity is much greater than it is for waste packages with lower heat-generation rates (i.e., the dhlw-l1 waste package in Figure 6.3-16). This effect is exhibited by comparing the range in drift-wall temperatures (Figure 6.3-16a) with the range in waste package temperatures (Figure 6.3-16b). The larger range in waste package temperatures, compared to the corresponding range in drift-wall temperatures, results in a wide range in waste package relative humidities (Figure 6.3-16d).

\subsubsection{Alternative MSTHM with Vertically Extended LDTH/SDT Submodels}

The standard MSTHM utilizes LDTH and SDT submodels that have a constant-temperature boundary at the water table. To test an alternative approach, MSTHM calculations were conducted with vertically extended LDTH and SDT submodels. In these submodels, the lower boundary of the LDTH and SDT submodels is set 1,000 m below the water table (as is done in the SMT submodel). A series of initialization runs are conducted with the SDT submodel where the lower boundary temperature is iteratively adjusted until the temperature at the water table is equal to that of the SDT submodel with the lower boundary at the water table. The vertically extended SDT submodel is then run with the appropriate heat-generation-rate-versus-time table and the temperature at the water table is saved as output. The water-table temperature history is then applied as the lower boundary temperature (at the water table) in the corresponding LDTH submodel. Applying the SDT submodel water-table temperature history to the lower (water-table) boundary of the LDTH submodel is equivalent to having extended the LDTH submodel 1,000 m below the water table. This alternative MSTHM approach, with vertically extended LDTH and SDT submodels, was applied to four of the five locations (Figure 6.3-1) discussed in previous sections. The alternative MSTHM approach is compared to the standard MSTHM approach in Figures 6.3-17 through 6.3-20. Overall, the two approaches predict nearly the same thermal-hydrologic conditions at the four locations. The small differences between the two approaches occur only at later time (e.g., Figures 6.3-19a, 6.3-19b, 6.3-20a, 6.3-20b, 6.3-20c, and 6.3-20e). At early time, the two approaches predict virtually identical thermal-hydrologic conditions. Peak temperatures (Table 6.3-16) are exactly the same for the two approaches and the duration of boiling (Table 6.3-17) is nearly the same for the two 
approaches. Waste package relative humidity is virtually the same for all time (Figures 6.3-17d, 6.3-18d, 6.3-19d, and 6.3-20d). The alternative MSTHM approach is applied to the low percolation-flux cases described in Sections 6.3.2.1 and 6.3.2.3.

Table 6.3-16. Peak Temperatures in an Alternative MSTHM with Vertically Extended LDTH and SDT Submodels, as Compared with Standard MSTHM Results, for the pwr1-2 at Four Locations in the Repository

\begin{tabular}{|c|c|c|c|c|c|c|c|}
\hline \multirow{2}{*}{$\begin{array}{c}\text { LDTH-SDT } \\
\text { Submodel } \\
\text { Location }\end{array}$} & \multirow[b]{2}{*}{$\begin{array}{c}\text { Host-Rock } \\
\text { Unit } \\
\end{array}$} & \multicolumn{3}{|c|}{$\begin{array}{c}\text { Peak Drift-Wall Temperature } \\
\left({ }^{\circ} \mathrm{C}\right)\end{array}$} & \multicolumn{3}{|c|}{$\begin{array}{l}\text { Peak Waste Package Temperature } \\
\left({ }^{\circ} \mathrm{C}\right)\end{array}$} \\
\hline & & $\begin{array}{l}\text { Standard } \\
\text { MSTHM }\end{array}$ & $\begin{array}{c}\text { Alternative } \\
\text { MSTHM }\end{array}$ & Difference & $\begin{array}{l}\text { Standard } \\
\text { MSTHM }\end{array}$ & $\begin{array}{c}\text { Alternative } \\
\text { MSTHM }\end{array}$ & Difference \\
\hline P2ER8C6 & $\begin{array}{l}\text { Tptpul } \\
\text { (tsw33) }\end{array}$ & 135.5 & 135.5 & 0.0 & 163.2 & 163.2 & 0.0 \\
\hline P2WR8C8 & $\begin{array}{l}\text { Tptpmn } \\
\text { (tsw34) }\end{array}$ & 123.0 & 123.0 & 0.0 & 150.6 & 150.6 & 0.0 \\
\hline P2WR5C10 & $\begin{array}{l}\text { Tptpll } \\
\text { (tsw35) }\end{array}$ & 140.8 & 140.8 & 0.0 & 168.8 & 168.8 & 0.0 \\
\hline P3R8C13 & $\begin{array}{l}\text { Tptpln } \\
\text { (tsw36) }\end{array}$ & 120.2 & 120.2 & 0.0 & 148.2 & 148.2 & 0.0 \\
\hline
\end{tabular}

NOTE: $\quad$ See Figure 6.3-1 for locations. These values are based on data plotted in Figures 6.3-17 through 6.320.

Table 6.3-17. Time When Boiling at the Drift Wall Ceases in an Alternative MSTHM with Vertically Extended LDTH and SDT Submodels, as Compared to the Standard MSTHM Results, for the pwr1-2 at Four Locations in the Repository

\begin{tabular}{|l|l|c|c|c|c|}
\hline \multirow{2}{*}{$\begin{array}{c}\text { LDTH-SDT } \\
\text { Submodel } \\
\text { Location }\end{array}$} & Host-Rock Unit & \multicolumn{4}{|c|}{$\begin{array}{c}\text { Time When Boiling at the Drift Wall Ceases } \\
\text { (years) }\end{array}$} \\
\cline { 2 - 6 } & $\begin{array}{c}\text { Standard } \\
\text { MSTHM }\end{array}$ & $\begin{array}{c}\text { Alternative } \\
\text { MSTHM }\end{array}$ & Difference & Range $^{\text {a }}$ \\
\hline P2ER8C6 & Tptpul (tsw33) & 364.8 & 364.9 & 0.1 & $0.027 \%$ \\
\hline P2WR8C8 & Tptpmn (tsw34) & 242.8 & 242.6 & -0.2 & $0.082 \%$ \\
\hline P2WR5C10 & Tptpll (tsw35) & 623.0 & 622.0 & -1.0 & $0.161 \%$ \\
\hline P3R8C13 & Tptpln (tsw36) & 195.2 & 195.1 & -0.1 & $0.051 \%$ \\
\hline
\end{tabular}

a The range (\%) is the range (years) divided by the average time when drift-wall boiling ceases [(shortest + longest)/2].

NOTE: $\quad$ See Figure 6.3-1 for locations. These values are based on data plotted in Figures 6.3-17 through 6.3-20. 

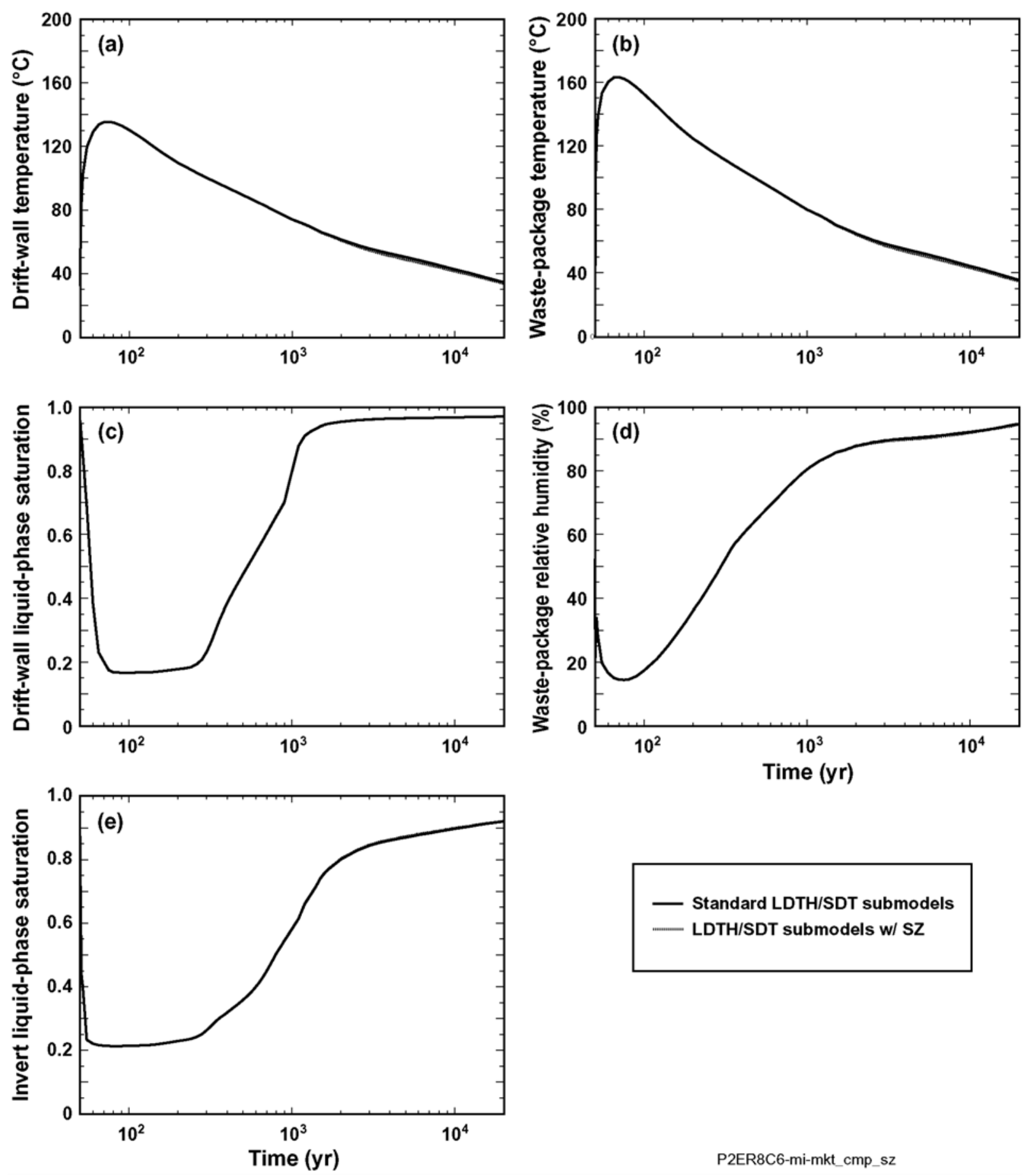

P2ER8C6-mi-mkt_cmp_sz

Source: See Table XIII-1.

NOTE: $\quad$ SZ = saturated zone. See Figure 6.3-1 for location. The plotted thermal-hydrologic parameters are (a) drift-wall temperature, (b) waste package temperature, (c) drift-wall liquid-phase saturation, (d) waste package relative humidity, and (e) invert liquid-phase saturation. The standard MSTHM calculation is compared with an alternative MSTHM calculation in which the LDTH and SDT submodels are vertically extended to include the upper $1 \mathrm{~km}$ of the saturated zone.

Figure 6.3-17. Thermal-Hydrologic Conditions for the Mean Infiltration-Flux Case Plotted for the pwr1-2 Waste Package at the P2ER8C6 Location in the Tptpul (tsw33) Unit 

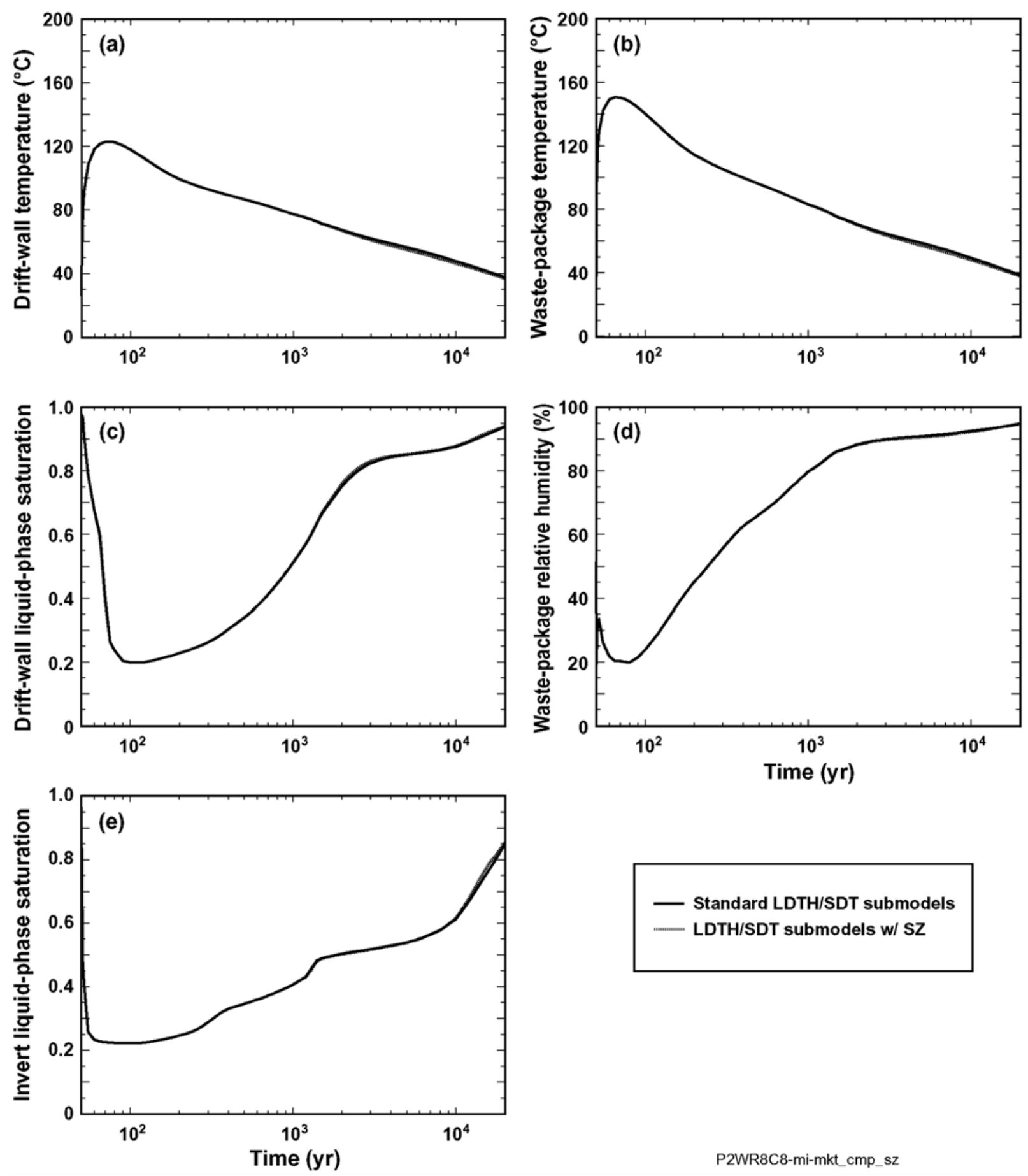

Source: See Table XIII-1.

NOTE: $\quad S Z$ = saturated zone. See Figure 6.3-1 for location. The plotted thermal-hydrologic parameters are (a) drift-wall temperature, (b) waste package temperature, (c) drift-wall liquid-phase saturation, (d) waste package relative humidity, and (e) invert liquid-phase saturation. The standard MSTHM calculation is compared with an alternative MSTHM calculation in which the LDTH and SDT submodels are vertically extended to include the upper $1 \mathrm{~km}$ of the saturated zone.

Figure 6.3-18. Thermal-Hydrologic Conditions for the Mean Infiltration-Flux Case Plotted for the pwr1-2 Waste Package at the P2WR8C8 Location in the Tptpmn (tsw34) Unit 

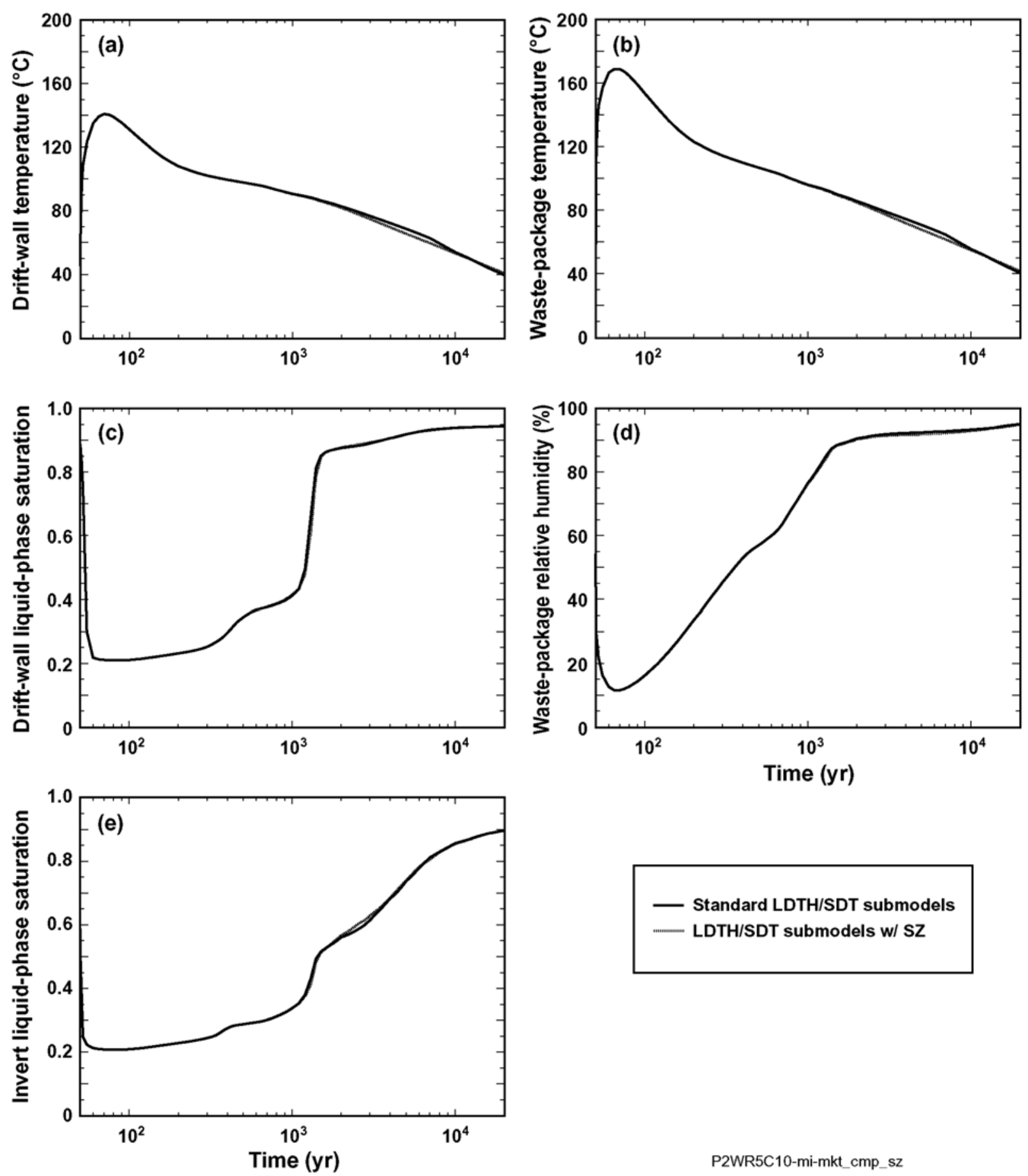

Time (yr)

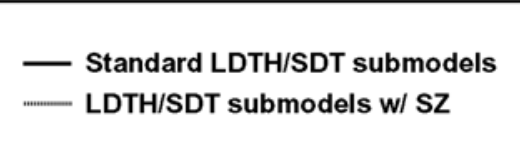

P2WR5C10-mi-mkt_cmp_sz

Source: See Table XIII-1.

NOTE: $\quad S Z$ = saturated zone. See Figure 6.3-1 for location. The plotted thermal-hydrologic parameters are (a) drift-wall temperature, (b) waste package temperature, (c) drift-wall liquid-phase saturation, (d) waste package relative humidity, and (e) invert liquid-phase saturation. The standard MSTHM calculation is compared with an alternative MSTHM calculation in which the LDTH and SDT submodels are vertically extended to include the upper $1 \mathrm{~km}$ of the saturated zone.

Figure 6.3-19. Thermal-Hydrologic Conditions for the Mean Infiltration-Flux Case Plotted for the pwr1-2 Waste Package at the P2WR5C10 Location in the Tptpll (tsw35) Unit 

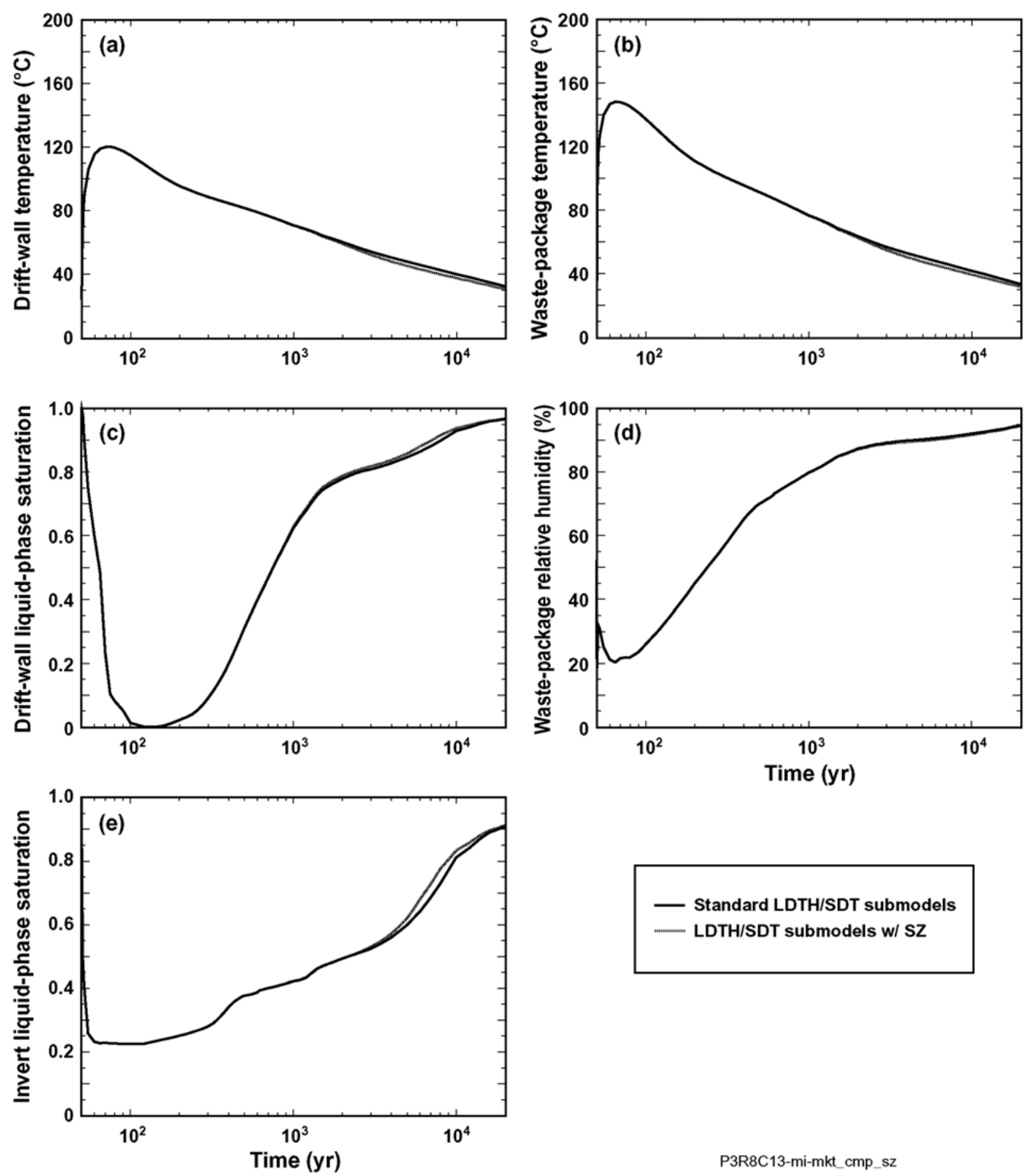

Time (yr)

P3R8C13-mi-mkt_cmp_sz

Source: See Table XIII-1.

NOTE: $\quad$ SZ = saturated zone. See Figure 6.3-1 for location). The plotted thermal-hydrologic parameters are (a) drift-wall temperature, (b) waste package temperature, (c) drift-wall liquid-phase saturation, (d) waste package relative humidity, and (e) invert liquid-phase saturation. The standard MSTHM calculation is compared with an alternative MSTHM calculation in which the LDTH and SDT submodels are vertically extended to include the upper $1 \mathrm{~km}$ of the saturated zone.

Figure 6.3-20. Thermal-Hydrologic Conditions for the Mean Infiltration-Flux Case Plotted for a Range of Waste Packages at the P3R8C13 Location in the Tptpln (tsw36) Unit 


\subsubsection{Parameter-Uncertainty-Sensitivity Analyses}

For MSTHM predictions of thermal-hydrologic conditions within the emplacement drifts and in the adjoining host rock, the key uncertainty parameters (Table 6.3-18) fall into three categories: (1) thermal properties, (2) hydrologic properties, and (3) percolation flux. For thermal and hydrologic properties, the primary focus is the properties of the host rock and of the materials within the emplacement drifts and the ambient percolation flux at the repository horizon.

The primary thermal properties are heat capacity and thermal conductivity. From past analyses, it is known that host-rock heat capacity has an insignificant effect on the thermal-hydrologic response in the drifts and adjacent host rock. This is corroborated by Section 5.3.1.4.10 of FY 01 Supplemental Science and Performance Analyses, Volume 1: Scientific Bases and Analyses (BSC 2001 [DIRS 155950]). Similarly, the insensitivity to invert thermal conductivity, within its range of uncertainty, is corroborated by Section 5.3.1.4.10 of that report. Note that the host-rock thermal conductivity was found to be a significant parameter (BSC 2001 [DIRS 155950], Section 5.3.1.4.8); consequently, it is addressed in Sections 6.3.2.2 and 6.3.2.3 of this report.

The primary hydrologic property of interest is the bulk permeability of the host rock, which is primarily affected by the permeability of the fracture network. A sensitivity study of host-rock bulk permeability (BSC 2001 [DIRS 155950], Section 5.3.1.4.7) found the influence to be primarily confined to temperature. Host-rock bulk permeability was found to modestly influence peak temperatures and boiling-period duration. In Section 6.3.9 of this report, temperature and relative humidity were found to be insensitive to a range of host-rock bulk permeability. The influence of coupled thermal-hydrologic-mechanical coupling on permeability is investigated for the Tptpmn (tsw34) and Tptpll (tsw35) host-rock units in Drift Scale THM Model (BSC 2004 [DIRS 169864]). There it was found that thermal stresses alter the host-rock permeability in the vertical and horizontal directions. However, these thermal-stress-induced changes in host-rock permeability were concluded to have a small influence on dryout and rewetting (BSC 2004 [DIRS 169864], Section 8.1). Because the effect of host-rock bulk permeability on temperature and relative humidity is insignificant, compared to that of host-rock thermal conductivity uncertainty (which is addressed in Sections 6.3.2.2 and 6.3.2.3), it is unnecessary to further investigate the influence of bulk-permeability uncertainty in this report.

Percolation-flux uncertainty at the repository horizon can result from at least two sources. The first source is the uncertainty concerning the magnitude of infiltration flux, which is addressed by way of lower-bound, mean, and upper-bound infiltration flux cases in Section 6.3.1.1.

The second source of percolation-flux uncertainty concerns the possibility of flow focusing in the UZ model layers between the base of the PTn sequence of units and the repository horizon. The liquid-phase flux distribution applied at the upper boundary of the LDTH submodels of the MSTHM is the percolation-flux distribution (from the base of the PTn unit into the top of the TSw sequence of units) calculated by UZ Flow Models and Submodels (BSC 2004 [DIRS 169861]). Flow focusing is the term used to denote the potential concentration of percolation flux from the large-scale average distribution of percolation flux, as simulated by the relatively coarsely gridded three-dimensional UZ flow model, to the drift scale, as simulated by the MSTHM and by Drift-Scale Coupled Processes (DST and TH Seepage) Models (BSC 2004 [DIRS 170338]). The impact of flow focusing of ambient percolation flux at the repository horizon is addressed in Sections 6.3.2.1 and 6.3.2.3. 
Table 6.3-18. Potentially Important Parameters to Thermal-Hydrologic Conditions in Emplacement Drifts, Listed for Consideration in the Parameter-Uncertainty Sensitivity Analysis.

\begin{tabular}{|l|l|l|l|}
\hline \multicolumn{1}{|c|}{ Parameter } & \multicolumn{1}{|c|}{$\begin{array}{c}\text { Previous Parameter- } \\
\text { Uncertainty-Sensitivity } \\
\text { Analyses }\end{array}$} & \multicolumn{1}{|c|}{$\begin{array}{c}\text { Importance to In-drift } \\
\text { Thermal-Hydrologic } \\
\text { Conditions }\end{array}$} & $\begin{array}{l}\text { Parameter Uncertainty- } \\
\text { Sensitivity Analyses in } \\
\text { This Report }\end{array}$ \\
\hline $\begin{array}{l}\text { Host-rock heat } \\
\text { capacity (which } \\
\text { includes influence } \\
\text { of specific heat } \\
\text { and bulk density) }\end{array}$ & $\begin{array}{l}\text { BSC 2001 [DIRS 155950], } \\
\text { Section 5.3.1.4.10 }\end{array}$ & Insignificant & None \\
\hline $\begin{array}{l}\text { Host-rock thermal } \\
\text { conductivity }\end{array}$ & $\begin{array}{l}\text { BSC 2001 [DIRS 155950], } \\
\text { Section 5.3.1.4.8 }\end{array}$ & Important & $\begin{array}{l}\text { Sections 6.3.2.2 and } \\
6.3 .2 .3\end{array}$ \\
\hline $\begin{array}{l}\text { Invert thermal } \\
\text { conductivity }\end{array}$ & $\begin{array}{l}\text { BSC 2001 [DIRS 155950], } \\
\text { Section 5.3.1.4.10 }\end{array}$ & Insignificant & None \\
\hline $\begin{array}{l}\text { Host-rock bulk } \\
\text { permeability }\end{array}$ & $\begin{array}{l}\text { BSC 2001 [DIRS 155950], } \\
\text { Section 5.3.1.4.7 }\end{array}$ & $\begin{array}{l}\text { Minor influence on temperature, } \\
\text { small compared to that of host } \\
\text { rock thermal conductivity } \\
\text { uncertainty (Sections 6.3.2.2 and } \\
6.3 .2 .3)\end{array}$ & None \\
\hline Percolation flux & $\begin{array}{l}\text { BSC 2001 [DIRS 158204], } \\
\text { Sections 6.11 and 6.12 }\end{array}$ & Important & $\begin{array}{l}\text { Sections 6.3.1.1, 6.3.2.1, } \\
\text { and 6.3.2.3 }\end{array}$ \\
\hline
\end{tabular}

\subsubsection{Percolation-Flux Uncertainty at the Repository Horizon, Including the Influence of Flow Focusing}

Between the base of the PTn unit and the repository horizon, ambient percolation flux is assumed to be vertically downward with neither lateral diversion nor flow focusing caused by layering or heterogeneity in the hydrologic-property distributions. Section 6.2.1.4 of Drift-Scale Coupled Processes (DST and TH Seepage) Models (BSC 2004 [DIRS 170338]) discusses the need to address the potential for flow focusing of percolation flux in the hydrogeologic units above the repository horizon. Flow focusing is the term used to denote the potential concentration of percolation flux from the large-scale distribution of percolation flux, as simulated by the relatively coarsely gridded three-dimensional UZ flow model, to the drift scale, as simulated by the MSTHM and by Drift-Scale Coupled Processes (DST and TH Seepage) Models (BSC 2004 [DIRS 170338]). Stochastic modeling analyses discussed in Section 4.3.2 of FY 01 Supplemental Science and Performance Analyses, Volume 1: Scientific Bases and Analyses (BSC 2001 [DIRS 155950]), using a two-dimensional, finely gridded vertical cross section of the unsaturated zone, resulted in maximum flow-focusing factors between 5 and 6 . In Section 6.2.2.2.4 of Drift-Scale Coupled Processes (DST and TH Seepage) Models (BSC 2004 [DIRS 170338]) flow-focusing factors of 5 and 10 were considered in the sensitivity study to percolation flux, resulting in percolation fluxes of 30, 80, and $125 \mathrm{~mm} / \mathrm{yr}$ for the present-day, monsoonal, and glacial-transition climate states, respectively.

Table 6.3-19 summarizes the percolation fluxes for the low and high percolation-flux cases considered in this study. To better discern the influence of the local host-rock unit on thermal-hydrologic behavior, it was decided to use the same value of present-day percolation flux (25 mm/yr) for the high percolation-flux case at all four locations, thus resulting in an effective flow focusing factor of close to 5 at all locations. To obtain the monsoonal and glacial-transition high percolation-flux values at a given location (Table 6.3-19), the 
corresponding percolation flux values in Table 6.3-9 are multiplied by the corresponding factor. Note that the present-day, monsoonal, and glacial-transition high percolation-flux values are similar to those used in Section 6.2.2.2.4 of Drift-Scale Coupled Processes (DST and TH Seepage) Models (BSC 2004 [DIRS 170338]) for the case with a factor of 5 (that case used percolation flux values of 30,80 , and $125 \mathrm{~mm} / \mathrm{yr}$ for the three climate states, respectively).

The low percolation-flux case in Table 6.3-19 corresponds to the possibility of a region of the repository experiencing "flow defocusing," which is the opposite of "flow focusing." Thus, for flow focusing to be able to occur in one region of the repository, it is necessary for adjoining regions to receive less percolation flux than would have occurred without flow focusing. To discern the influence of the local host-rock unit on thermal-hydrologic behavior, it was decided to apply the same value $(0.025 \mathrm{~mm} / \mathrm{yr})$ to all four locations. Because the low percolation-flux cases are meant to correspond to regions that are, in effect, shielded from significant percolation flux, regardless of the magnitude of repository-wide percolation flux, it was decided to use the same small value of percolation flux for all (three) climate states. Thus, this “defocusing” effect persists during all (three) climate states. It is noted that the low percolation-flux cases considered in this section correspond to persistently small flux values, thereby allowing the dryout and temperature effects of low percolation flux to develop. Note that values of present-day percolation flux vary by a factor of 1,000 between the low and high percolation-flux cases.

Table 6.3-19. Percolation Flux for the Low, Mean, and High Percolation-Flux Cases Summarized for Four Locations Used to Examine Thermal-Hydrologic Conditions in the Repository

\begin{tabular}{|c|c|c|c|c|c|c|c|}
\hline \multirow[b]{2}{*}{$\begin{array}{l}\text { LDTH-SDT } \\
\text { Submodel } \\
\text { Location }\end{array}$} & \multicolumn{3}{|c|}{$\begin{array}{c}\text { Percolation Flux for the Low } \\
\text { Percolation-Flux (defocused flow) } \\
\text { Case (mm/yr) }\end{array}$} & \multicolumn{4}{|c|}{$\begin{array}{l}\text { Percolation Flux for the High Percolation-Flux } \\
\text { (focused flow) Case (mm/yr) }\end{array}$} \\
\hline & $\begin{array}{l}\text { Present- } \\
\text { Day }\end{array}$ & Monsoonal & $\begin{array}{c}\text { Glacial- } \\
\text { Transition }\end{array}$ & $\begin{array}{l}\text { Present- } \\
\text { Day }\end{array}$ & Monsoonal $^{\mathrm{a}}$ & $\begin{array}{l}\text { Glacial- } \\
\text { Transition }^{a}\end{array}$ & $\begin{array}{l}\text { Effective } \\
\text { Focus } \\
\text { Factor }^{b}\end{array}$ \\
\hline P2ER8C6 & 0.025 & 0.025 & 0.025 & 25.00 & 54.04 & 106.3 & 4.62 \\
\hline P2WR8C8 & 0.025 & 0.025 & 0.025 & 25.00 & 58.41 & 87.47 & 5.59 \\
\hline P2WR5C10 & 0.025 & 0.025 & 0.025 & 25.00 & 77.49 & 117.18 & 5.31 \\
\hline P3R8C13 & 0.025 & 0.025 & 0.025 & 25.00 & 77.57 & 111.89 & 3.54 \\
\hline
\end{tabular}

${ }^{\mathrm{a}}$ The monsoonal and glacial-transition percolation flux values for the high percolation-flux case are obtained by multiplying the corresponding percolation flux values in Table 6.3-9 by the effective focus factor for that location.

b The effective focus factor is obtained by dividing $25.00 \mathrm{~mm} / \mathrm{yr}$ by the present-day percolation flux listed for the given location in Table 6.3-9.

NOTE: $\quad$ See Figure 6.2-2 for locations. Values for the mean percolation-flux case are given in Table 6.3-9.

The influence of percolation-flux uncertainty on thermohydrologic behavior at four locations (P2ER8C6, P2WR8C8, P2WR5C10, and P3R8C13) in the repository (see Figure 6.3-1 for locations) is shown in time histories of drift-wall temperature and liquid-phase saturation, waste package temperature and relative humidity, and invert liquid-phase saturation (Figures 6.3-21 through 6.3-24) for a 21-PWR AP CSNF waste package. Percolation-flux uncertainty is seen to have a small influence on peak drift-wall temperature (Table 6.3-20) and on peak waste package temperature (Table 6.3-21). Peak drift-wall temperatures only vary by 3.7 to 5.2 percent and peak waste package temperatures only vary by 2.9 to 4.3 percent for a 1,000-fold range of percolation flux. Compared to its influence on peak temperatures, percolation-flux uncertainty has a much stronger influence on the duration of boiling (Table 6.3-22). The sensitivity of 
boiling-period duration to percolation-flux uncertainty is greatest for those locations with the longest boiling-period duration, which correspond to locations near the center of the repository where the extent of rock dryout has more time to develop. Thus locations P2ER8C6 and P3R8C13, which are at the repository edges have the smallest sensitivity to percolation-flux uncertainty, while location P2WR5C10, which is close to the center of the repository, has the greatest sensitivity.

Percolation-flux uncertainty has a strong influence on dryout/rewetting behavior, as shown in the drift-wall and invert liquid-phase saturation histories (Figures 6.3-21c, 6.3-21e, 6.3.22c, 6.3.22e, 6.3-23c, 6.3-23e, 6.3-24c, and 6.3-24e). Similarly, it also has a strong influence on the waste package relative humidity histories (Figures 6.3-21d, 6.3-22d, 6.3-23d, and 6.3-24d). Because the relative humidity at the drift wall depends on the liquid-phase saturation (as well as on temperature) at the drift wall, the variability of drift-wall relative humidity is similar to that of drift-wall liquid-phase saturation. Relative humidity on a given waste package depends on relative humidity at the adjacent drift wall. The large differences in drift-wall liquid-phase saturation histories (between the low and high percolation-flux cases) result in large differences in waste package relative humidity histories between the flux cases.

Table 6.3-20. $\quad$ Range of Peak Drift-Wall Temperatures for the pwr1-2 Waste Package (Resulting from Percolation-Flux Uncertainty) Summarized for Four Locations in the Repository

\begin{tabular}{|l|l|c|c|c|c|c|}
\hline & & \multicolumn{4}{|c|}{ Peak Drift-Wall Temperature ( ${ }^{\circ} \mathbf{C}$ ) } \\
\cline { 3 - 7 } $\begin{array}{c}\text { LDTH-SDT } \\
\begin{array}{c}\text { Submodel } \\
\text { Location }\end{array}\end{array}$ & $\begin{array}{c}\text { Host-Rock } \\
\text { Unit }\end{array}$ & $\begin{array}{c}\text { Low } \\
\text { Percolation } \\
\text { Flux }\end{array}$ & $\begin{array}{c}\text { Mean } \\
\text { Percolation } \\
\text { Flux }\end{array}$ & $\begin{array}{c}\text { High } \\
\text { Percolation } \\
\text { Flux }\end{array}$ & $\begin{array}{c}\text { Low to High } \\
\text { Range }\end{array}$ & $\begin{array}{c}\text { Low to High } \\
\text { Range }^{\mathbf{a}}\end{array}$ \\
\hline P2ER8C6 & Tptpul (tsw33) & 138.9 & 135.5 & 131.9 & 7.0 & $5.2 \%$ \\
\hline P2WR8C8 & Tptpmn (tsw34) & 124.5 & 123.0 & 119.4 & 5.1 & $4.2 \%$ \\
\hline P2WR5C10 & Tptpll (tsw35) & 144.1 & 140.8 & 137.2 & 6.9 & $4.9 \%$ \\
\hline P3R8C13 & Tptpln (tsw36) & 121.9 & 120.2 & 117.5 & 4.4 & $3.7 \%$ \\
\hline
\end{tabular}

a The range $(\%)$ is the range $\left({ }^{\circ} \mathrm{C}\right)$ divided by the peak drift-wall temperature $[($ low + high $) / 2]$.

NOTE: $\quad$ See Figure 6.3-1 for locations. The pwr1-2 (21-PWR AP CSNF) waste package is the hottest waste package in the sequence (Figure 6.2-2). These values are based on data plotted in Figures 6.3-21 through 6.3-29.

Table 6.3-21. $\quad$ Range of Peak Waste Package Temperatures for the pwr1-2 Waste Package (Resulting from Percolation-Flux Uncertainty) Summarized for Four Locations in the Repository

\begin{tabular}{|l|l|c|c|c|c|c|}
\hline \multirow{2}{*}{$\begin{array}{c}\text { LDTH-SDT } \\
\begin{array}{c}\text { Submodel } \\
\text { Location }\end{array}\end{array}$} & $\begin{array}{c}\text { Host-Rock } \\
\text { Unit }\end{array}$ & $\begin{array}{c}\text { Low } \\
\text { Percolation } \\
\text { Flux }\end{array}$ & $\begin{array}{c}\text { Mean } \\
\text { Percolation } \\
\text { Flux }\end{array}$ & $\begin{array}{c}\text { High } \\
\text { Percolation } \\
\text { Flux }\end{array}$ & $\begin{array}{c}\text { Low to High } \\
\text { Range }\end{array}$ & $\begin{array}{c}\text { Low to High } \\
\text { Range }^{\mathbf{a}}\end{array}$ \\
\hline P2ER8C6 & Tptpul (tsw33) & 166.5 & 163.2 & 159.5 & 7.0 & $4.3 \%$ \\
\hline P2WR8C8 & Tptpmn (tsw34) & 151.7 & 150.6 & 147.4 & 4.3 & $2.9 \%$ \\
\hline P2WR5C10 & Tptpll (tsw35) & 172.4 & 168.8 & 165.4 & 7.0 & $4.1 \%$ \\
\hline P3R8C13 & Tptpln (tsw36) & 149.9 & 148.2 & 145.9 & 4.0 & $2.7 \%$ \\
\hline
\end{tabular}

a The range $(\%)$ is the range $\left({ }^{\circ} \mathrm{C}\right)$ divided by the peak drift-wall temperature $[($ low + high $) / 2]$.

NOTE: $\quad$ See Figure 6.3-1 for locations. The pwr1-2 (21-PWR AP CSNF) waste package is the hottest waste package in the sequence (Figure 6.2-2). These values are based on data plotted in Figures 6.3-21 through 6.3-29. 
Table 6.3-22. Range of Time When Boiling at the Drift Wall Ceases for the pwr1-2 Waste Package (Resulting from Percolation-Flux Uncertainty) Summarized for Four Locations in the Repository

\begin{tabular}{|l|l|c|c|c|c|c|}
\hline \multirow{2}{*}{$\begin{array}{c}\text { LDTH-SDT } \\
\text { Submodel } \\
\text { Location }\end{array}$} & $\begin{array}{c}\text { Host-Rock } \\
\text { Unit }\end{array}$ & $\begin{array}{c}\text { Low } \\
\text { Percolation } \\
\text { Flux }\end{array}$ & $\begin{array}{c}\text { Mean } \\
\text { Percolation } \\
\text { Flux }\end{array}$ & $\begin{array}{c}\text { High } \\
\text { Percolation } \\
\text { Flux }\end{array}$ & $\begin{array}{c}\text { Low to High } \\
\text { Range }\end{array}$ & $\begin{array}{c}\text { Low to High } \\
\text { Range }^{\mathbf{a}}\end{array}$ \\
\hline P2ER8C6 & Tptpul (tsw33) & 438.1 & 364.8 & 313.3 & 124.8 & $33.2 \%$ \\
\hline P2WR8C8 & Tptpmn (tsw34) & 286.1 & 242.8 & 197.7 & 88.4 & $36.5 \%$ \\
\hline P2WR5C10 & Tptpll (tsw35) & 896.9 & 623.0 & 385.4 & 484.5 & $75.6 \%$ \\
\hline P3R8C13 & Tptpln (tsw36) & 224.2 & 195.2 & 175.2 & 49.0 & $24.5 \%$ \\
\hline
\end{tabular}

a The range $(\%)$ is the range (years) divided by the average time when drift-wall boiling ceases [(shortest + longest)/2].

NOTE: $\quad$ See Figure 6.3-1 for locations. The pwr1-2 (21-PWR AP CSNF) waste package is the hottest waste package in the sequence (Figure 6.2-2). These values are based on data plotted in Figures 6.3-21 through 6.3-29. 

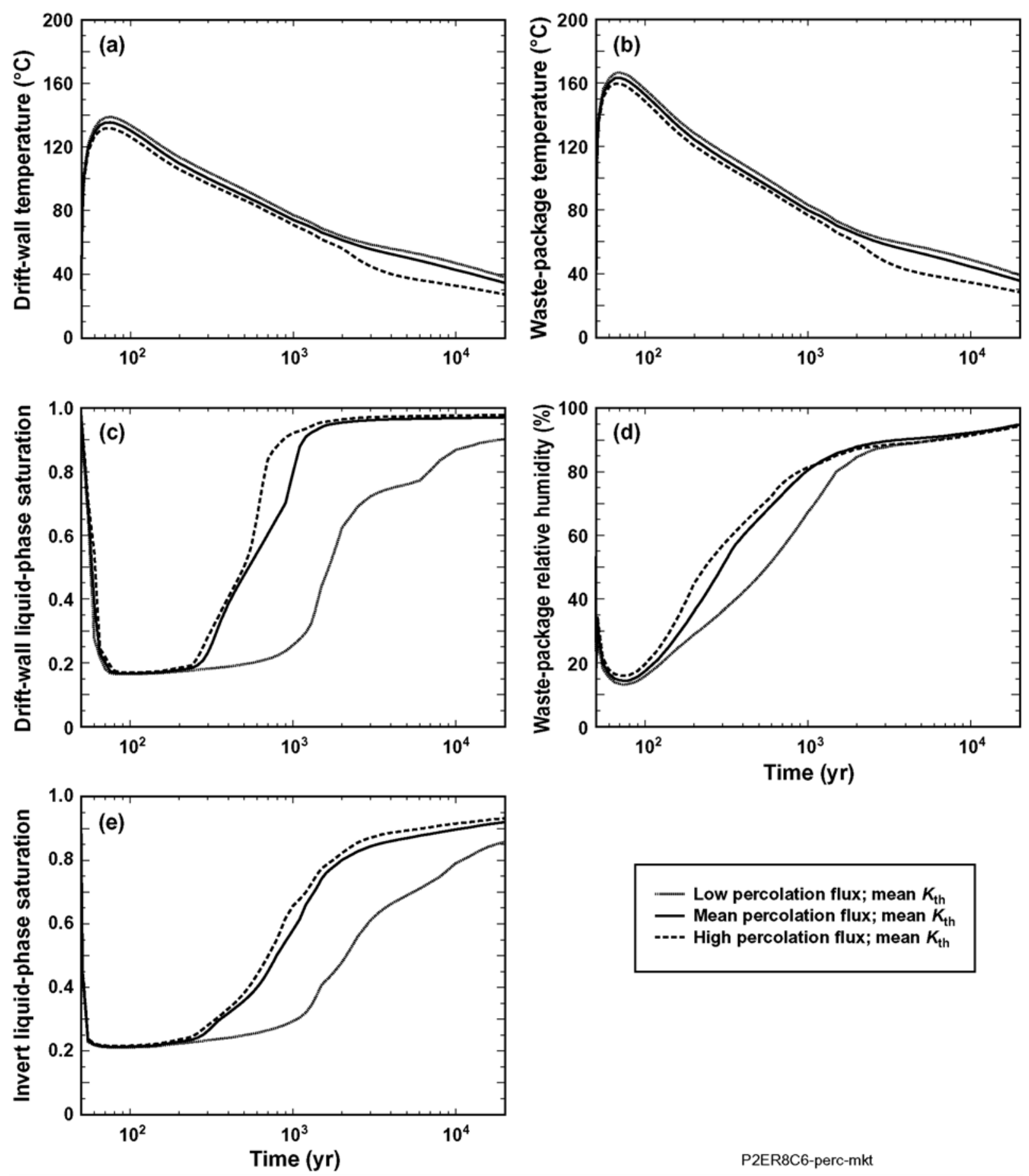

2ER86-perc-mkt

Source: See Table XIII-1.

NOTE: $\quad$ See Figure 6.3-1 for location. The plotted thermal-hydrologic parameters are (a) drift-wall temperature, (b) waste package temperature, (c) drift-wall liquid-phase saturation, (d) waste package relative humidity, and (e) invert liquid-phase saturation. The pwr1-2 (21-PWR AP CSNF) waste package is the hottest waste package in the sequence (Figure 6.2-2).

Figure 6.3-21. Thermal-Hydrologic Conditions for the pwr1-2 Waste Package Plotted for the Low, Mean, and High Percolation-Flux Cases at the P2ER8C6 Location in the Tptpul (tsw33) Unit 

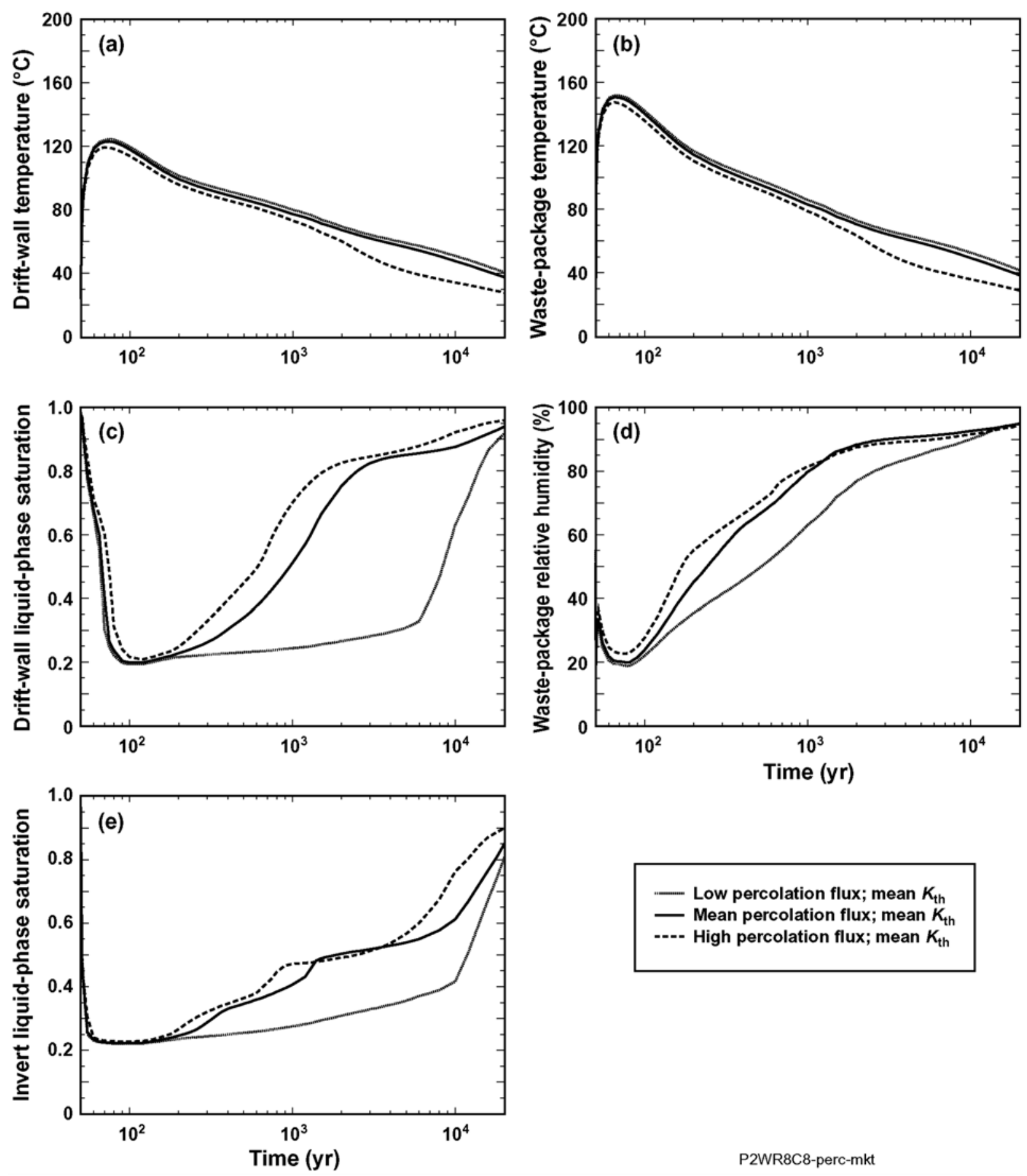

P2WR8C8-perc-mkt

Source: See Table XIII-1.

NOTE: $\quad$ See Figure 6.3-1 for location. The plotted thermal-hydrologic parameters are (a) drift-wall temperature, (b) waste package temperature, (c) drift-wall liquid-phase saturation, (d) waste package relative humidity, and (e) invert liquid-phase saturation. The pwr1-2 (21-PWR AP CSNF) waste package is the hottest waste package in the sequence (Figure 6.2-2).

Figure 6.3-22. Thermal-Hydrologic Conditions for the pwr1-2 Waste Package Plotted for the Low, Mean, and High Percolation-Flux Cases at the P2WR8C8 Location in the Tptpmn (tsw34) Unit 

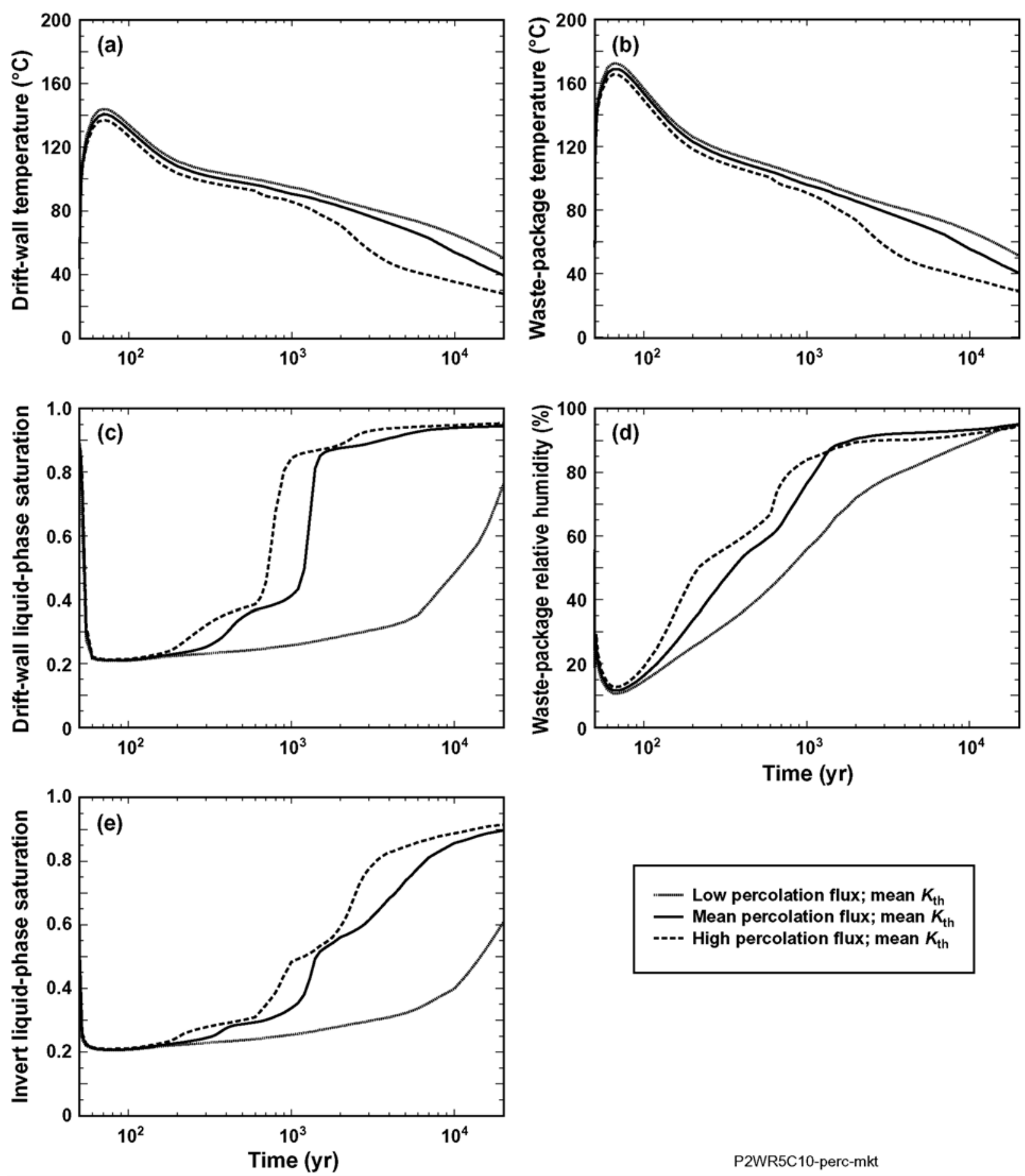

P2WR5C10-perc-mkt

Source: See Table XIII-1.

NOTE: $\quad$ See Figure 6.3-1 for location. The plotted thermal-hydrologic parameters are (a) drift-wall temperature, (b) waste package temperature, (c) drift-wall liquid-phase saturation, (d) waste package relative humidity, and (e) invert liquid-phase saturation. The pwr1-2 (21-PWR AP CSNF) waste package is the hottest waste package in the sequence (Figure 6.2-2).

Figure 6.3-23. Thermal-Hydrologic Conditions for the pwr1-2 Waste Package Plotted for the Low, Mean, and High Percolation-Flux Cases at the P2WR5C10 Location in the Tptpll (tsw35) Unit 

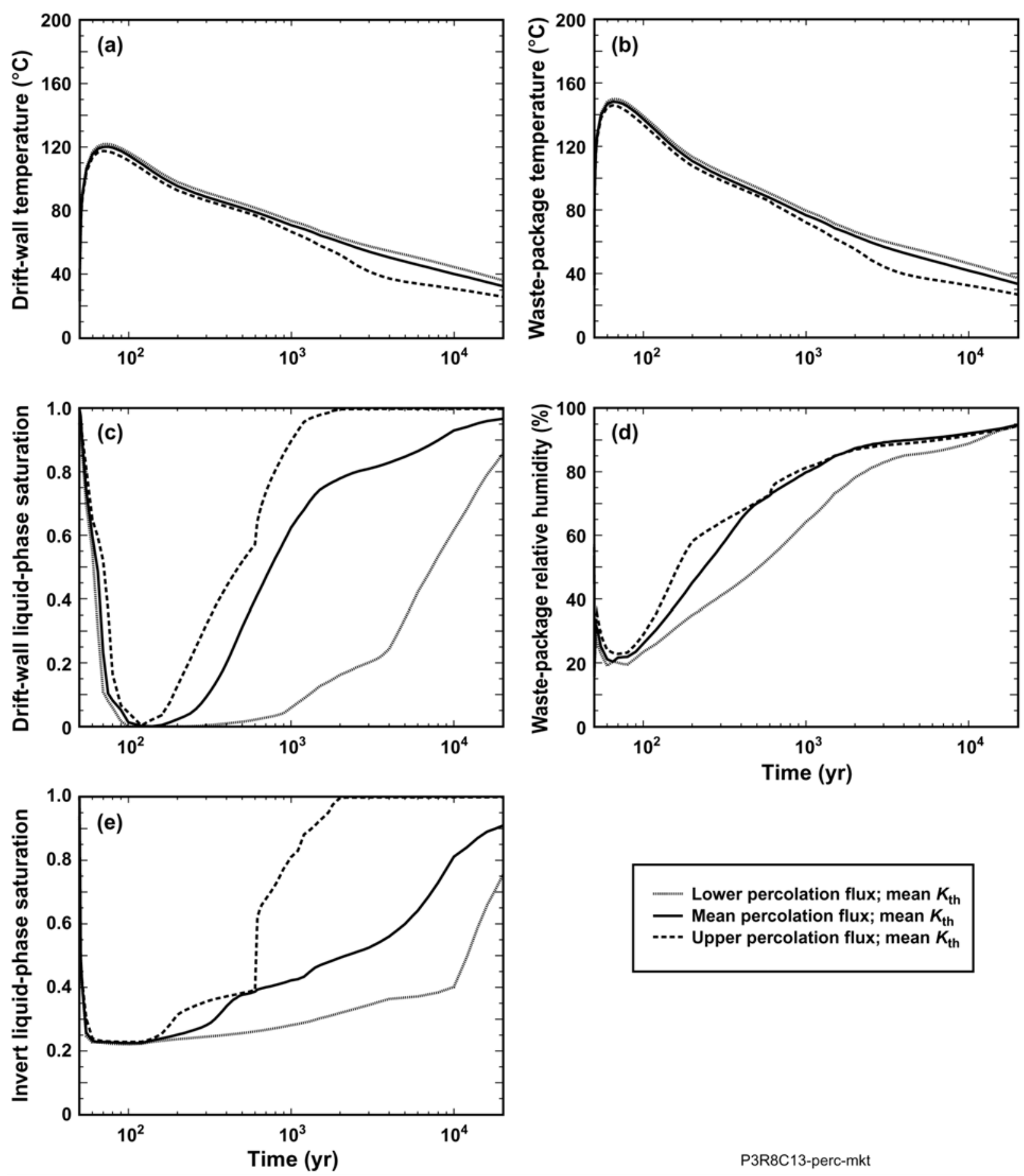

Source: See Table XIII-1.

NOTE: $\quad$ See Figure 6.3-1 for location. The plotted thermal-hydrologic parameters are (a) drift-wall temperature, (b) waste package temperature, (c) drift-wall liquid-phase saturation, (d) waste package relative humidity, and (e) invert liquid-phase saturation. The pwr1-2 (21-PWR AP CSNF) waste package is the hottest waste package in the sequence (Figure 6.2-2).

Figure 6.3-24. Thermal-Hydrologic Conditions for the pwr1-2 Waste Package Plotted for the Low, Mean, and High Percolation-Flux Cases at the P3R8C13 Location in the Tptpln (tsw36) Unit 


\subsubsection{Host-Rock Thermal Conductivity Uncertainty}

The sensitivity of thermal-hydrologic behavior to host-rock thermal conductivity uncertainty is addressed for ranges that extend approximately \pm 1 standard deviation about the mean value (Table 6.3-23). The thermal conductivity data from Table 7-10 of DTN: SN0404T0503102.011 [DIRS 169129] (File: readme.doc) are used to determine the ranges for the wet and dry thermal conductivity values for the four host-rock units. Note that the mean values of $K_{\text {th }}$ of the Tptpul (tsw33) unit are slightly different from those in Table 7-10 of DTN: SN0404T0503102.011 [DIRS 169129] (File: readme.doc). To be consistent with the other thermal-hydrologic models, such as those in Drift-Scale Coupled Processes (DST and TH Seepage) Models (BSC 2004 [DIRS 170338]), $K_{\text {th }}$ for the Tptpul (tsw33) unit is computed as a straight arithmetic average of $K_{\text {th }}$ for the Tptpul from Table 7-10 of DTN: SN0404T0503102.011 [DIRS 169129] (File: readme.doc) and the $K_{\text {th }}$ of the Tptrl from DTN: SN0303T0503102.008 [DIRS 162401] (row 66). This averaging for the Tptpul (tsw33) unit is also applied to the other thermal properties to be consistent with Drift-Scale Coupled Processes (DST and TH Seepage) Models (BSC 2004 [DIRS 170338]), which computes the thermal properties (including $K_{\text {th }}$ ) of the Tptpul (tsw33) unit to be the average of the thermal properties of the Tptpul from Table 7-10 of DTN: SN0404T0503102.011 [DIRS 169129] (File: readme.doc) and the thermal properties of the Tptrl unit from DTN: SN0303T0503102.008 [DIRS 162401] (row 66).

For all locations, host-rock thermal conductivity uncertainty has a strong influence on peak temperatures (Table 6.3-25) and on boiling duration (Table 6.3-26), with the influence being stronger for locations closer to the repository center. Thus, the P2WR5C10 location, which is located close to the center of the repository, has the widest range (114.3 percent) of the time when boiling at the drift wall ceases. Locations P2ER8C6 and P3R8C13, which are at the edge of the repository, have somewhat smaller ranges (65.2 percent and 75.4 percent, respectively) of the time when boiling ceases at the drift wall.

Host-rock thermal conductivity uncertainty has a strong influence on dryout/rewetting behavior for the first 1,000 to 2,000 years, as shown in the drift-wall and invert liquid-phase saturation histories (Figures 6.3-25c, 6.3-25e, 6.3.26c, 6.3.26e, 6.3-27c, 6.3-27e, 6.3-28c, and 6.3-28e). Similarly, host-rock thermal conductivity uncertainty also has a strong influence on the waste package relative humidity histories for the first one- to two-thousand years (Figures 6.3-21d, 6.3-22d, 6.3-23d, and 6.3-24d). 
Table 6.3-23. Wet and Dry Thermal Conductivity Values Used in the Host-Rock Thermal Conductivity Uncertainty Study

\begin{tabular}{|c|c|c|c|c|c|c|}
\hline \multirow{2}{*}{$\begin{array}{c}\text { Host-Rock } \\
\text { Unit }\end{array}$} & \multicolumn{2}{|c|}{ Dry Thermal Conductivity $\left(\mathrm{W} / \mathbf{m}^{\circ} \mathbf{C}\right)$} & \multicolumn{3}{|c|}{ Wet Thermal Conductivity $\left(\mathrm{W} / \mathrm{m}^{\circ} \mathbf{C}\right)$} \\
\cline { 2 - 7 } & Low & Mean & High & Low & Mean & High \\
\hline Tptpul (tsw33) & 0.9842 & 1.24 & 1.4958 & 1.5405 & 1.79 & 2.0395 \\
\hline Tptpmn (tsw34) & 1.1544 & 1.42 & 1.6856 & 1.8188 & 2.07 & 2.3212 \\
\hline Tptpll (tsw35) & 1.0286 & 1.28 & 1.5314 & 1.6415 & 1.89 & 2.1385 \\
\hline Tptpln (tsw36) & 1.2056 & 1.49 & 1.7744 & 1.8624 & 2.13 & 2.3976 \\
\hline
\end{tabular}

NOTE: Low, mean, and high thermal conductivity cases are considered for ranges that extend approximately \pm 1 standard deviation about the mean value. With the exception of the mean values of $K_{\text {th }}$ for the Tptpul (tsw33) unit, these values are taken from Table 7-10 of DTN: SN0404T0503102.011 [DIRS 169129] (File: readme.doc). The mean values of $K_{\text {th }}$ for the Tptpul (tsw33) unit are a straight arithmetic averages of the mean $K_{\text {th }}$ values for the Tptpul from Table 7-10 of DTN: SN0404T0503102.011 [DIRS 169129] (File: readme.doc) and the mean $K_{\text {th }}$ of the Tptrl from DTN: SN0303T0503102.008 [DIRS 162401] (row 66). Also note that Table IV-3a in Appendix IV lists $K_{\text {th }}$ for the Tptpul unit from Table 7-10 of DTN: SN0404T0503102.011 [DIRS 169129] (File: readme.doc) and $K_{\text {th }}$ for the Tptrl unit from DTN: SN0303T0503102.008 [DIRS 162401]. The standard deviations for the Tptpul (tsw33) in Table 7-10 of DTN: SN0404T0503102.011 [DIRS 169129] (File: readme.doc) are divided by the corresponding mean $K_{\text {th }}$ values to obtain the percentage differences for plus and minus one standard deviation. These percentages are then applied to the arithmetic-averaged mean $K_{\text {th }}$ for the Tptpul (tsw33) unit to obtain the plus and minus one-standard-deviation values of $K_{\text {th }}$ for the Tptpul (tsw33) unit.

Table 6.3-24. $\quad$ Range of Peak Drift-Wall Temperatures for the pwr1-2 Waste Package (Resulting from Thermal Conductivity Uncertainty) Summarized for Four Locations in the Repository

\begin{tabular}{|l|l|c|c|c|c|c|}
\hline \multirow{2}{*}{$\begin{array}{c}\text { LDTH-SDT } \\
\text { Submodel } \\
\text { Location }\end{array}$} & Host-Rock Unit & $\begin{array}{c}\text { Low Thermal } \\
\text { Conductivity }\end{array}$ & $\begin{array}{c}\text { Mean Thermal } \\
\text { Conductivity }\end{array}$ & $\begin{array}{c}\text { High Thermal } \\
\text { Conductivity }\end{array}$ & $\begin{array}{c}\text { Low to High } \\
\text { Range }\end{array}$ & $\begin{array}{c}\text { Low to High } \\
\text { Range }^{\mathrm{a}}\end{array}$ \\
\hline P2ER8C6 & Tptpul (tsw33) & 153.3 & 135.5 & 123.2 & 30.1 & $21.8 \%$ \\
\hline P2WR8C8 & Tptpmn (tsw34) & 136.5 & 123.0 & 113.8 & 22.7 & $18.1 \%$ \\
\hline P2WR5C10 & Tptpll (tsw35) & 158.9 & 140.8 & 127.4 & 31.5 & $22.0 \%$ \\
\hline P3R8C13 & Tptpln (tsw36) & 132.7 & 120.2 & 110.8 & 21.9 & $18.0 \%$ \\
\hline
\end{tabular}

a The range $(\%)$ is the range $\left({ }^{\circ} \mathrm{C}\right)$ divided by the peak drift-wall temperature $[($ low + high $) / 2]$.

NOTE: $\quad$ See Figure 6.3-1 for locations. The pwr1-2 (21-PWR AP CSNF) waste package is the hottest waste package in the sequence (Figure 6.2-2). Low, mean, and high thermal conductivity cases are considered for a range of plus and minus one standard deviation about the mean value. These values are based on data plotted in Figures 6.3-25 through 6.3-28. 
Table 6.3-25. Range of Peak Waste Package Temperatures for the pwr1-2 Waste Package (Resulting from Thermal Conductivity Uncertainty) Summarized for Four Locations in the Repository

\begin{tabular}{|l|l|c|c|c|c|c|}
\hline \multirow{2}{*}{$\begin{array}{c}\text { LDTH-SDT } \\
\text { Submodel } \\
\text { Location }\end{array}$} & $\begin{array}{c}\text { Host-Rock } \\
\text { Unit }\end{array}$ & $\begin{array}{c}\text { Low Thermal } \\
\text { Conductivity }\end{array}$ & $\begin{array}{c}\text { Mean } \\
\text { Thermal } \\
\text { Conductivity }\end{array}$ & $\begin{array}{c}\text { High } \\
\text { Thermal } \\
\text { Conductivity }\end{array}$ & $\begin{array}{c}\text { Low to High } \\
\text { Range }\end{array}$ & $\begin{array}{c}\text { Low to High } \\
\text { Range* }\end{array}$ \\
\hline P2ER8C6 & $\begin{array}{l}\text { Tptpul } \\
\text { (tsw33) }\end{array}$ & 181.2 & 163.2 & 151.4 & 29.8 & $17.9 \%$ \\
\hline P2WR8C8 & $\begin{array}{l}\text { Tptpmn } \\
\text { (tsw34) }\end{array}$ & 163.8 & 150.6 & 141.9 & 21.9 & $14.3 \%$ \\
\hline P2WR5C10 & Tptpll (tsw35) & 187.2 & 168.8 & 155.8 & 31.4 & $18.3 \%$ \\
\hline P3R8C13 & $\begin{array}{l}\text { Tptpln } \\
\text { (tsw36) }\end{array}$ & 160.6 & 148.2 & 139.2 & 21.4 & $14.3 \%$ \\
\hline
\end{tabular}

${ }^{a}$ The range $(\%)$ is the range $\left({ }^{\circ} \mathrm{C}\right)$ divided by the peak drift-wall temperature $[($ low + high $) / 2]$.

NOTE: $\quad$ See Figure 6.3-1 for locations. The pwr1-2 (21-PWR AP CSNF) waste package is the hottest waste package in the sequence (Figure 6.2-2). Low, mean, and high thermal conductivity cases are considered for a range of plus and minus one standard deviation about the mean value. These values are based on data plotted in Figures 6.3-25 through 6.3-28.

Table 6.3-26. Range of Time When Boiling at the Drift Wall Ceases for the pwr1-2 Waste Package (Resulting from Host-Rock Thermal Conductivity Uncertainty) Summarized for Four Locations in the Repository

\begin{tabular}{|l|l|c|c|c|c|c|}
\hline \multirow{2}{*}{$\begin{array}{c}\text { LDTH-SDT } \\
\text { Submodel } \\
\text { Location }\end{array}$} & \multicolumn{1}{|c|}{$\begin{array}{c}\text { Tost-Rock } \\
\text { Unit }\end{array}$} & $\begin{array}{l}\text { Low Thermal } \\
\text { Conductivity }\end{array}$ & $\begin{array}{c}\text { Mean } \\
\text { Thermal } \\
\text { Conductivity }\end{array}$ & $\begin{array}{c}\text { High } \\
\text { Thermal } \\
\text { Conductivity }\end{array}$ & $\begin{array}{c}\text { Low to High } \\
\text { Range }\end{array}$ & $\begin{array}{c}\text { Low to High } \\
\text { Range }\end{array}$ \\
\hline P2ER8C6 & $\begin{array}{l}\text { Tptpul } \\
\text { (tsw33) }\end{array}$ & 508.9 & 364.8 & 258.9 & 250.0 & $65.2 \%$ \\
\hline P2WR8C8 & $\begin{array}{l}\text { Tptpmn } \\
\text { (tsw34) }\end{array}$ & 412.8 & 242.8 & 163.8 & 249.0 & $86.4 \%$ \\
\hline P2WR5C10 & Tptpll (tsw35) & 963.8 & 623.0 & 263.0 & 700.8 & $114.3 \%$ \\
\hline P3R8C13 & $\begin{array}{l}\text { Tptpln } \\
\text { (tsw36) }\end{array}$ & 309.0 & 195.2 & 139.8 & 169.2 & $75.4 \%$ \\
\hline
\end{tabular}

${ }^{a}$ The range $(\%)$ is the range (years) divided by the average time when drift-wall boiling ceases [(shortest + longest)/2].

NOTE: $\quad$ See Figure 6.3-1 for locations. The pwr1-2 (21-PWR AP CSNF) waste package is the hottest waste package in the sequence (Figure 6.2-2). Low, mean, and high thermal conductivity cases are considered for a range of plus and minus one standard deviation about the mean value. These values are based on data plotted in Figures 6.3-25 through 6.3-28. 

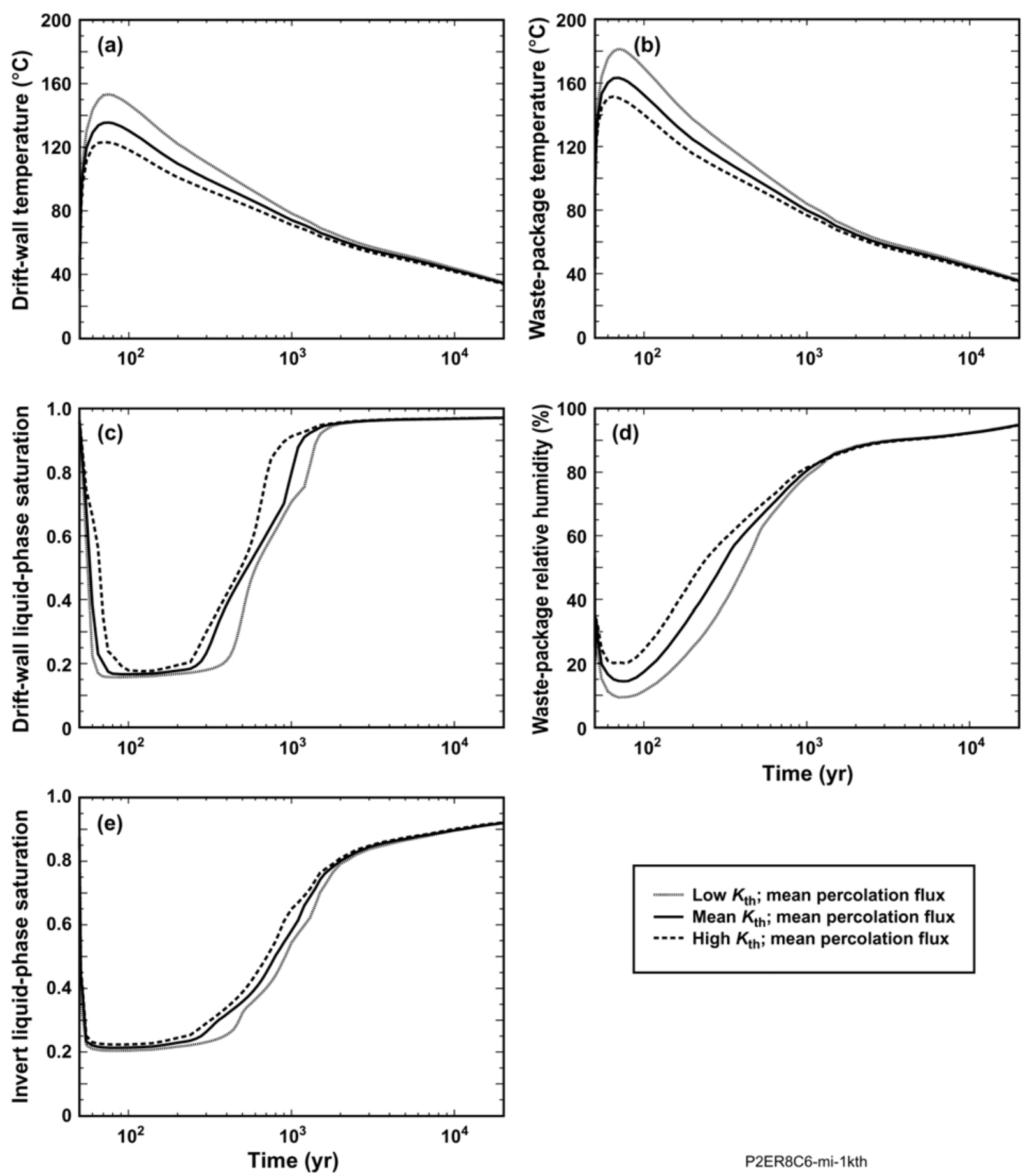

P2ER8C6-mi-1kth

Source: See Table XIII-1.

NOTE: $\quad$ See Figure 6.3-1 for location. Low, mean, and high thermal conductivity cases are considered for a range of plus and minus one standard deviation about the mean value. The plotted thermal-hydrologic parameters are (a) drift-wall temperature, (b) waste package temperature, (c) drift-wall liquid-phase saturation, (d) waste package relative humidity, and (e) invert liquid-phase saturation. The pwr1-2 (21-PWR AP CSNF) waste package is the hottest waste package in the sequence (Figure 6.2-2).

Figure 6.3-25. Thermal-Hydrologic Conditions for the pwr1-2 Waste Package Plotted for the Mean Infiltration-Flux Case at the P2ER8C6 Location in the Tptpul (tsw33) Unit 

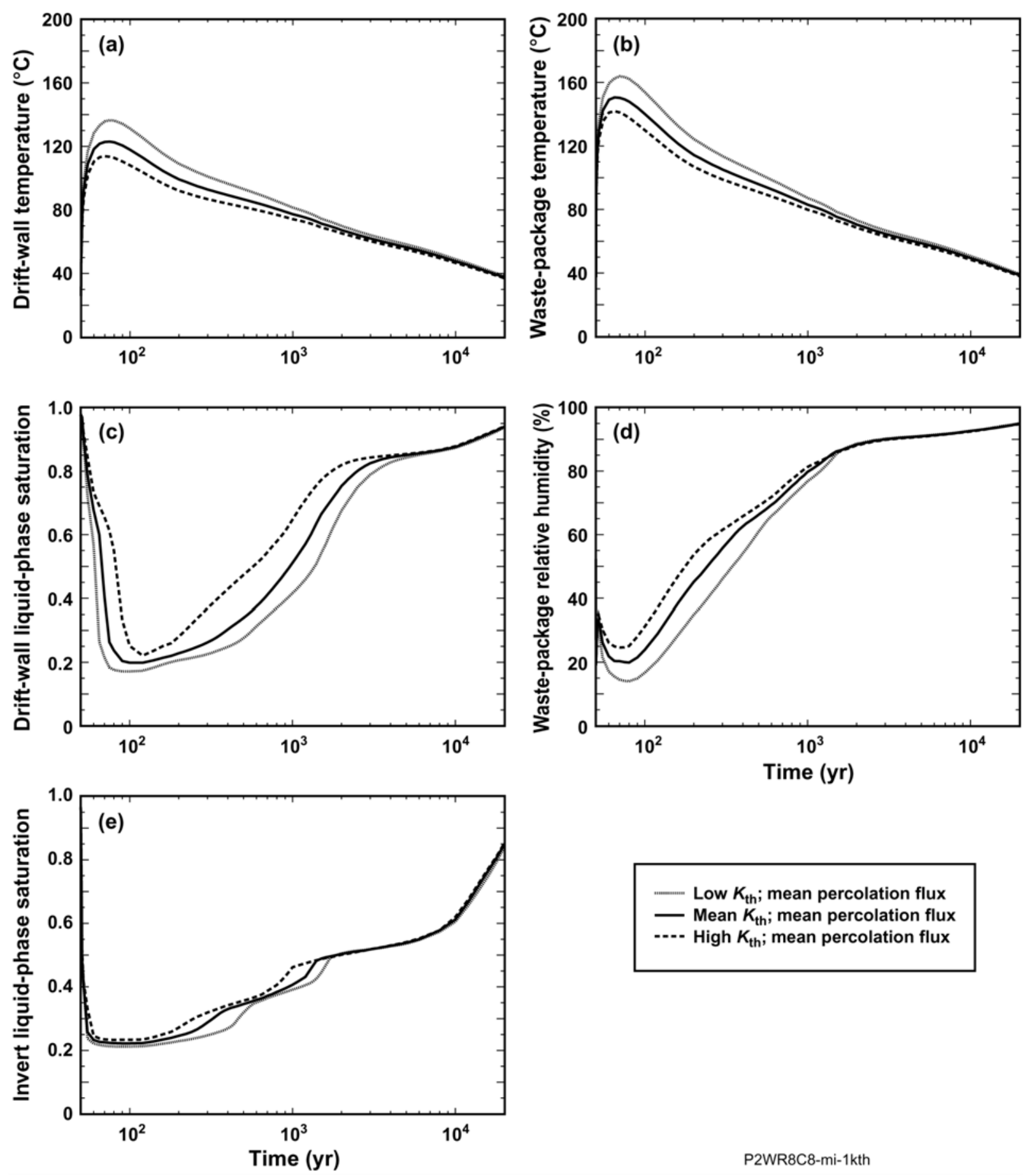

P2WR8C8-mi-1kth

Source: See Table XIII-1.

NOTE: $\quad$ See Figure 6.3-1 for location. Low, mean, and high thermal conductivity cases are considered range of plus and minus one standard deviation about the mean value. The plotted thermal-hydrologic parameters are (a) drift-wall temperature, (b) waste package temperature, (c) drift-wall liquid-phase saturation, (d) waste package relative humidity, and (e) invert liquid-phase saturation. The pwr1-2 (21-PWR AP CSNF) waste package is the hottest waste package in the sequence (Figure 6.2-2).

Figure 6.3-26. Thermal-Hydrologic Conditions for the pwr1-2 Waste Package Plotted for the Mean Infiltration-Flux Case at the P2WR8C8 Location in the Tptpmn (tsw34) Unit 

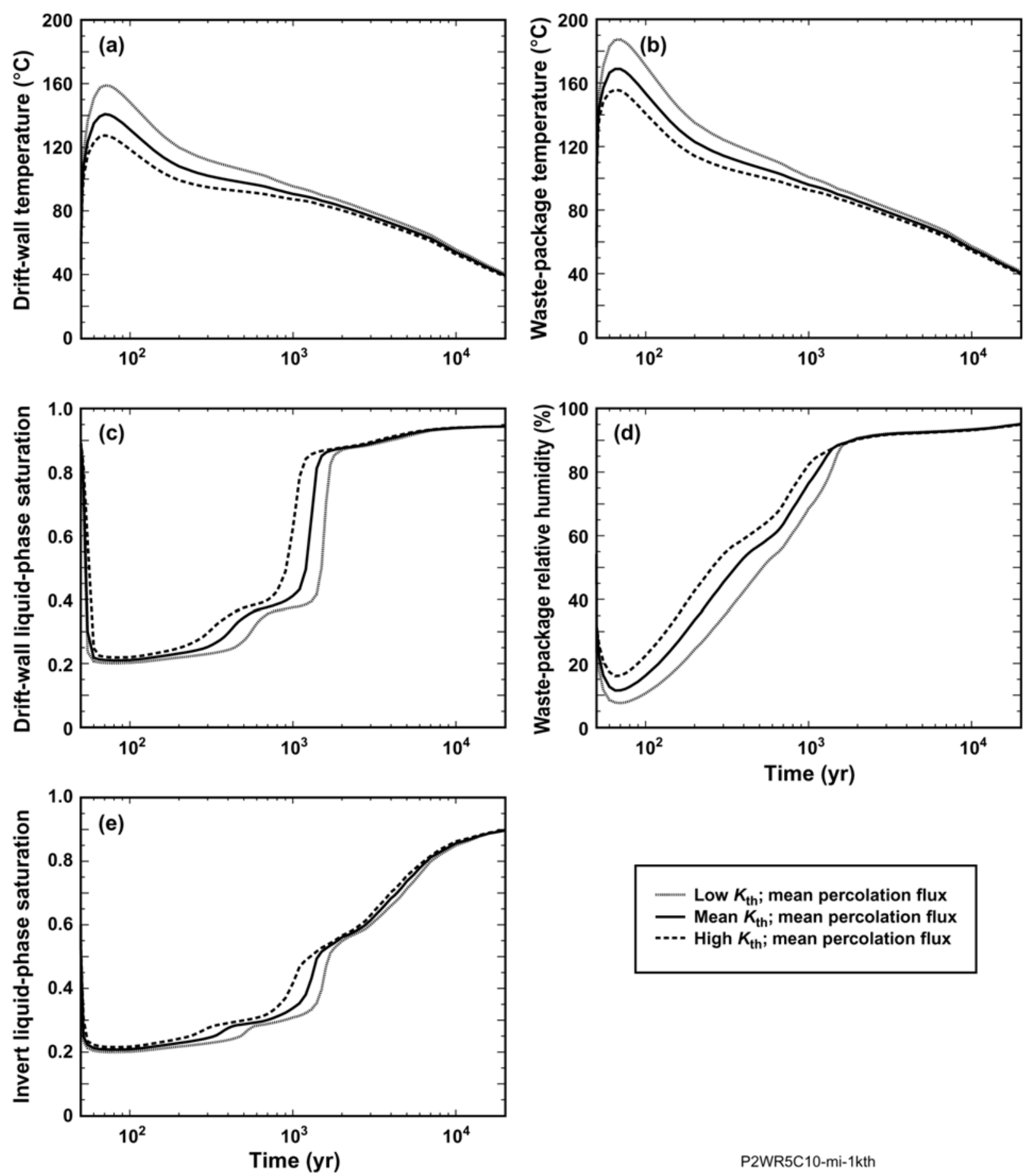

P2WR5C10-mi-1kth

Source: See Table XIII-1.

NOTE: $\quad$ See Figure 6.3-1 for location. Low, mean, and high thermal conductivity cases are considered for a range of plus and minus one standard deviation about the mean value. The plotted thermal-hydrologic parameters are (a) drift-wall temperature, (b) waste package temperature, (c) drift-wall liquid-phase saturation, (d) waste package relative humidity, and (e) invert liquid-phase saturation. The pwr1-2 (21-PWR AP CSNF) waste package is the hottest waste package in the sequence (Figure 6.2-2).

Figure 6.3-27. Thermal-Hydrologic Conditions for the pwr1-2 Waste Package Plotted for the Mean Infiltration-Flux Case at the P2WR5C10 Location in the Tptpll (tsw35) Unit 

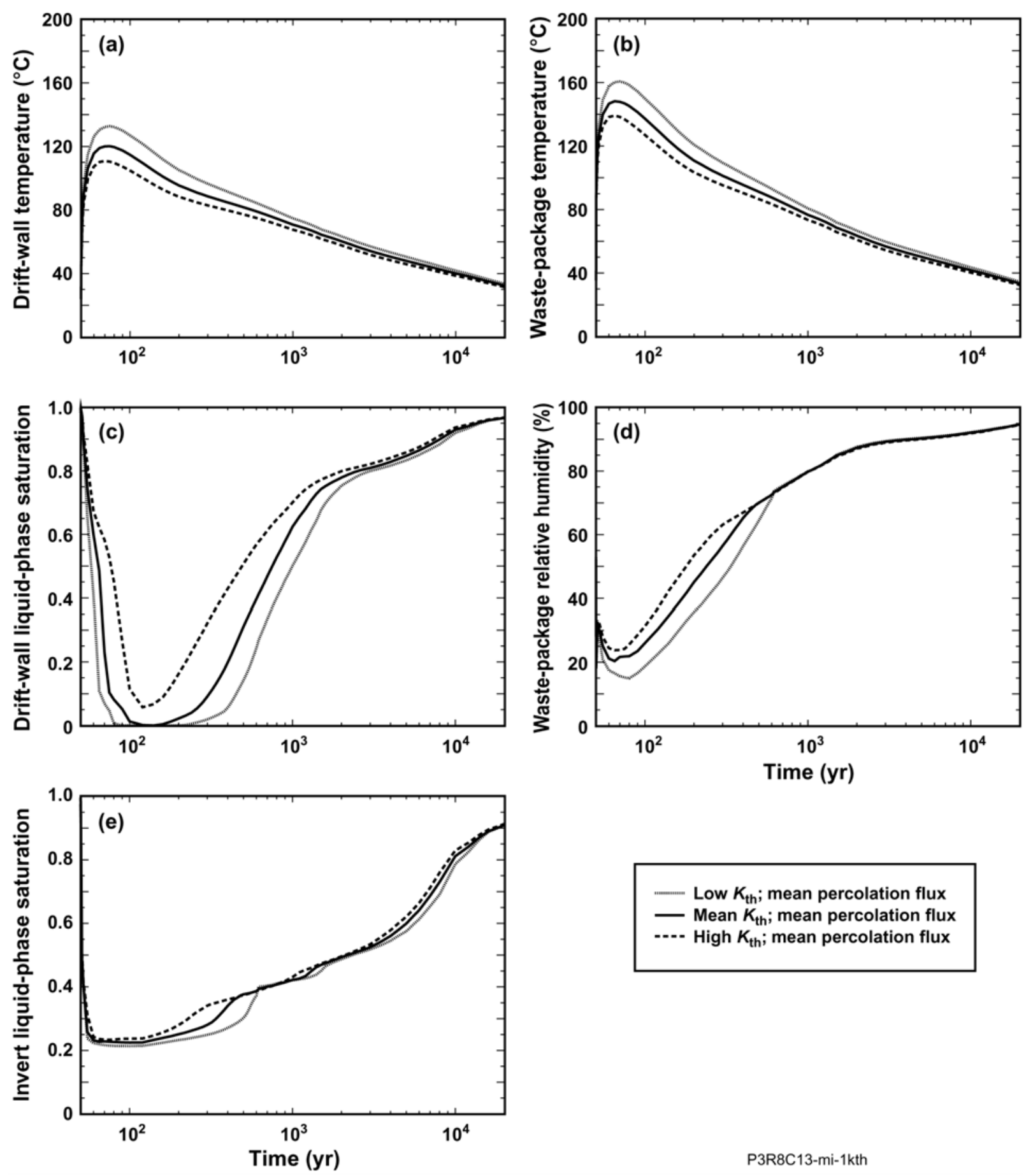

P3R8C13-mi-1kth

Source: See Table XIII-1.

NOTE: $\quad$ See Figure 6.3-1 for location. Low, mean, and high thermal conductivity cases are considered for a range of plus and minus one standard deviation about the mean value. The plotted thermal-hydrologic parameters are (a) drift-wall temperature, (b) waste package temperature, (c) drift-wall liquid-phase saturation, (d) waste package relative humidity, and (e) invert liquid-phase saturation. The pwr1-2 (21-PWR AP CSNF) waste package is the hottest waste package in the sequence (Figure 6.2-2).

Figure 6.3-28. Thermal-Hydrologic Conditions for the pwr1-2 Waste Package Plotted for the Mean Infiltration-Flux Case at the P3R8C13 Location in the Tptpln (tsw36) Unit 


\subsubsection{Combined Influence of Percolation Flux and Host-Rock Thermal Conductivity Uncertainty, Including the Influence of Flow Focusing}

In this section, the combined influence of percolation-flux uncertainty and host-rock thermal conductivity uncertainty on thermal-hydrologic behavior at four locations (P2ER8C6, P2WR8C8, P2WR5C10, and P3R8C13) in the repository (Figure 6.3-1) is shown in time histories of drift-wall temperature and liquid-phase saturation, waste package temperature and relative humidity, and invert liquid-phase saturation (Figures 6.3-29 through 6.3-32) for a 21-PWR AP CSNF waste package. Three cases are considered: (1) low percolation flux and low host-rock thermal conductivity, (2) mean percolation flux and mean host rock thermal conductivity, and (3) high percolation flux and high host-rock thermal conductivity. The values of present-day, monsoonal, and glacial-transition percolation flux values for the low and high percolation-flux cases are summarized in Table 6.3-19; the mean percolation flux values are summarized in Table 6.3-9. The values of dry and wet host-rock thermal conductivity for the low, mean, and high thermal conductivity cases are summarized in Table 6.3-23. Note that the values of percolation flux for these cases are the same as those considered in Section 6.3.2.1 and that the values of host-rock thermal conductivity are the same as those considered in Section 6.3.2.2. Low percolation flux and low host-rock thermal conductivity both result in higher peak temperatures and longer boiling durations. High percolation flux and high host-rock thermal conductivity both result in lower peak temperatures and shorter boiling durations. The range of peak drift-wall and waste package temperatures that result from the two extreme combinations of percolation flux and thermal conductivity are summarized in Tables 6.3-27 and 6.3-28, respectively; the range of the time when boiling on the drift wall ceases is summarized in Table 6.3-29.

Table 6.3-27. Range of Peak Drift-Wall Temperatures for the pwr1-2 Waste Package (Resulting from a Combination of Percolation Flux $Q_{\text {perc }}$ and Thermal Conductivity $K_{\text {th }}$ Uncertainty) Summarized for Four Locations in the Repository

\begin{tabular}{|c|c|c|c|c|c|c|}
\hline \multirow{2}{*}{$\begin{array}{l}\text { LDTH-SDT } \\
\text { Submodel } \\
\text { Location }\end{array}$} & \multirow[b]{2}{*}{$\begin{array}{c}\text { Host-Rock } \\
\text { Unit }\end{array}$} & \multicolumn{5}{|c|}{ Peak Drift-Wall Temperature $\left({ }^{\circ} \mathrm{C}\right)$} \\
\hline & & $\begin{array}{l}\text { Low } Q_{\text {perc }} \\
\text { Low } K_{\text {th }}\end{array}$ & $\begin{array}{c}\text { Mean } Q_{\text {perc }} \\
\text { Mean } K_{\text {th }}\end{array}$ & $\begin{array}{c}\text { High } Q_{\text {perc }} \\
\text { High } K_{\text {th }}\end{array}$ & $\begin{array}{c}\text { Low to High } \\
\text { Range }\end{array}$ & $\begin{array}{c}\text { Low to High } \\
\text { Range }^{\mathrm{a}}\end{array}$ \\
\hline P2ER8C6 & Tptpul (tsw33) & 156.9 & 135.5 & 120.4 & 36.5 & $26.3 \%$ \\
\hline P2WR8C8 & Tptpmn (tsw34) & 138.0 & 123.0 & 111.4 & 26.6 & $21.3 \%$ \\
\hline P2WR5C10 & Tptpll (tsw35) & 162.8 & 140.8 & 124.5 & 38.3 & $26.7 \%$ \\
\hline P3R8C13 & Tptpln (tsw36) & 136.1 & 120.2 & 108.8 & 27.3 & $22.3 \%$ \\
\hline
\end{tabular}

a The range $(\%)$ is the range $\left({ }^{\circ} \mathrm{C}\right)$ divided by the peak drift-wall temperature $[($ low + high $) / 2]$.

NOTE: $\quad$ See Figure 6.3-1 for locations. The pwr1-2 (21-PWR AP CSNF) waste package is the hottest waste package in the sequence (Figure 6.2-2). Low, mean, and high thermal conductivity cases are considered for a range of plus and minus one standard deviation about the mean. 
Table 6.3-28. Range of Peak Waste Package Temperatures for the pwr1-2 Waste Package (Resulting from a Combination of Percolation Flux $Q_{\text {perc }}$ and Thermal Conductivity $K_{\text {th }}$ Uncertainty) Summarized for Four Locations in the Repository

\begin{tabular}{|l|l|c|c|c|c|c|}
\hline \multirow{2}{*}{$\begin{array}{c}\text { LDTH-SDT } \\
\begin{array}{c}\text { Submodel } \\
\text { Location }\end{array}\end{array}$} & $\begin{array}{c}\text { Host-Rock } \\
\text { Unit }\end{array}$ & $\begin{array}{c}\text { Low } \mathbf{Q}_{\text {perc }} \\
\text { Low } \boldsymbol{K}_{\text {th }}\end{array}$ & $\begin{array}{c}\text { Mean } \mathbf{Q}_{\text {perc }} \\
\text { Mean } \boldsymbol{K}_{\text {th }}\end{array}$ & $\begin{array}{c}\text { High } \mathbf{Q}_{\text {perc }} \\
\text { High } \boldsymbol{K}_{\text {th }}\end{array}$ & $\begin{array}{c}\text { Low to High } \\
\text { Range }\end{array}$ & $\begin{array}{c}\text { Low to High } \\
\text { Range }^{\mathrm{a}}\end{array}$ \\
\cline { 3 - 7 } P2ER8C6 & Tptpul (tsw33) & 185.1 & 163.2 & 148.7 & 36.4 & $21.8 \%$ \\
\hline P2WR8C8 & Tptpmn (tsw34) & 165.4 & 150.6 & 139.5 & 25.9 & $17.0 \%$ \\
\hline P2WR5C10 & Tptpll (tsw35) & 191.0 & 168.8 & 152.7 & 38.3 & $22.3 \%$ \\
\hline P3R8C13 & Tptpln (tsw36) & 163.9 & 148.2 & 137.3 & 26.6 & $17.7 \%$ \\
\hline
\end{tabular}

a The range $(\%)$ is the range $\left({ }^{\circ} \mathrm{C}\right)$ divided by the peak drift-wall temperature $[($ low + high $) / 2]$.

NOTE: See Figure 6.3-1 for locations. The pwr1-2 (21-PWR AP CSNF) waste package is the hottest waste package in the sequence (Figure 6.2-2). Low, mean, and high thermal conductivity cases are considered for a range of plus and minus one standard deviation about the mean

Table 6.3-29. Range of Time When Boiling at the Drift Wall Ceases for the pwr1-2 Waste Package (Resulting from a Combination of Percolation Flux $Q_{\text {perc }}$ and Thermal Conductivity $K_{\text {th }}$ Uncertainty) Summarized for Four Locations in the Repository

\begin{tabular}{|l|l|c|c|c|c|c|}
\hline \multirow{2}{*}{$\begin{array}{c}\text { LDTH-SDT } \\
\begin{array}{c}\text { Submodel } \\
\text { Location }\end{array}\end{array}$} & Host-Rock Unit & $\begin{array}{c}\text { Tow } \boldsymbol{Q}_{\text {perc }} \\
\text { Low } \boldsymbol{K}_{\text {th }}\end{array}$ & $\begin{array}{c}\text { Mean } \boldsymbol{Q}_{\text {perc }} \\
\text { Mean } \boldsymbol{K}_{\text {th }}\end{array}$ & $\begin{array}{c}\text { High } \boldsymbol{Q}_{\text {perc }} \\
\text { High } \boldsymbol{K}_{\text {th }}\end{array}$ & $\begin{array}{c}\text { Low to High } \\
\text { Range }\end{array}$ & $\begin{array}{c}\text { Low to High } \\
\text { Range* }\end{array}$ \\
\cline { 2 - 7 } P2ER8C6 & Tptpul (tsw33) & 615.5 & 364.8 & 222.5 & 393.0 & $93.8 \%$ \\
\hline P2WR8C8 & Tptpmn (tsw34) & 514.1 & 242.8 & 144.7 & 369.4 & $112.1 \%$ \\
\hline P2WR5C10 & Tptpll (tsw35) & $1,415.8$ & 623.0 & 207.4 & $1,208.4$ & $148.9 \%$ \\
\hline P3R8C13 & Tptpln (tsw36) & 377.2 & 195.2 & 129.8 & 247.4 & $97.6 \%$ \\
\hline
\end{tabular}

a The range (\%) is the range (years) divided by the average time when drift-wall boiling ceases [(shortest + longest)/2].

NOTE: $\quad$ See Figure 6.3-1 for location. The pwr1-2 (21-PWR AP CSNF) waste package is the hottest waste package in the sequence (Figure 6.2-2). Low, mean, and high thermal conductivity cases are considered for a range of plus and minus one standard deviation about the mean. 

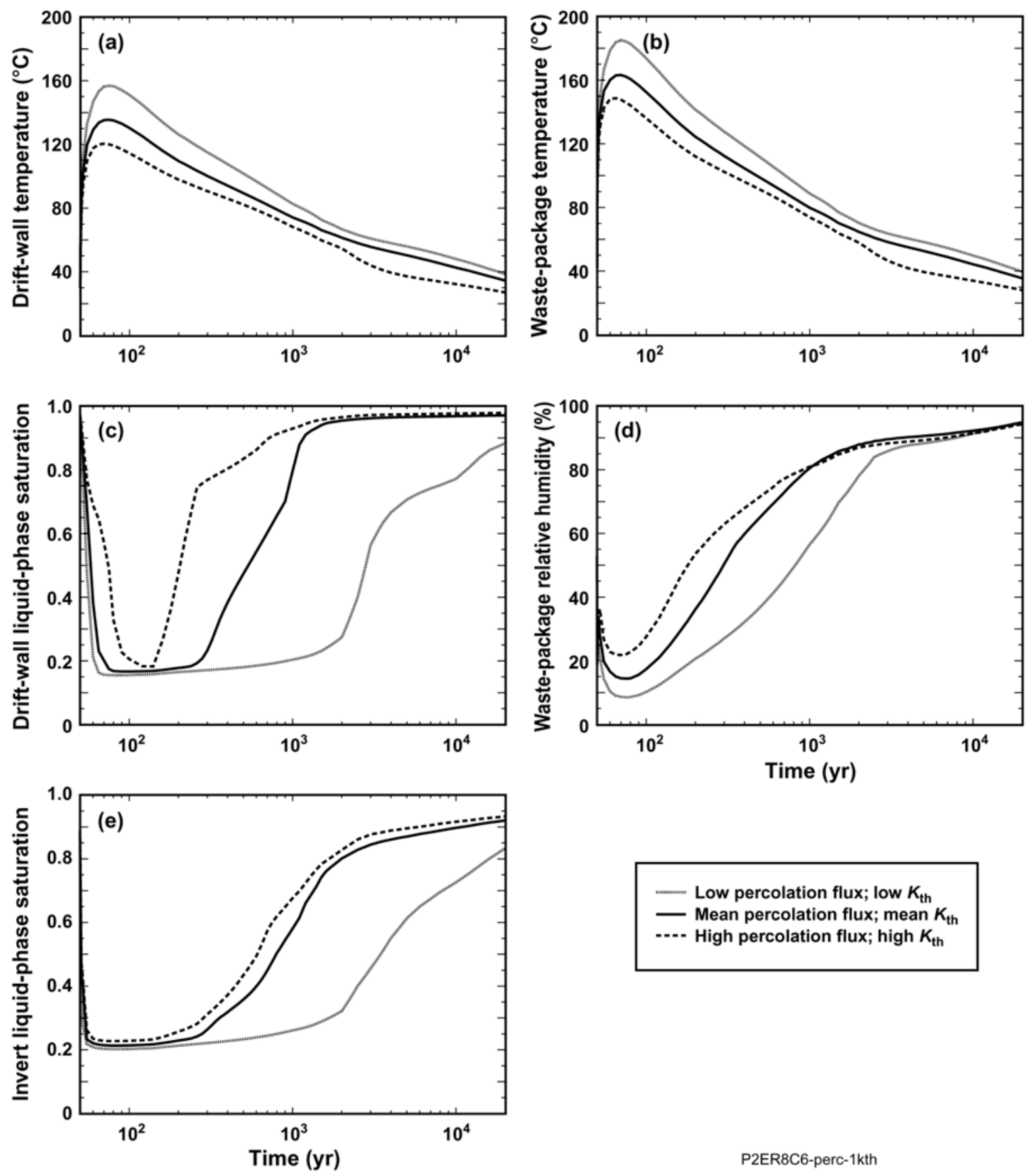

Source: See Table XIII-1.

NOTE: See Figure 6.3-1 for location. These cases are: (1) low percolation flux and low thermal conductivity, (2) mean percolation flux and mean thermal conductivity, and (3) high percolation flux and high thermal conductivity, where the thermal conductivity is varied by plus and minus one standard deviation about the mean. The plotted thermal-hydrologic parameters are (a) drift-wall temperature, (b) waste package temperature, (c) drift-wall liquid-phase saturation, (d) waste package relative humidity, and (e) invert liquid-phase saturation. The pwr1-2 (21-PWR AP CSNF) waste package is the hottest waste package in the sequence (Figure 6.2-2).

Figure 6.3-29. Thermal-Hydrologic Conditions for the pwr1-2 Waste Package Plotted for Three Cases at the P2ER8C6 Location in the Tptpul (tsw33) Unit 

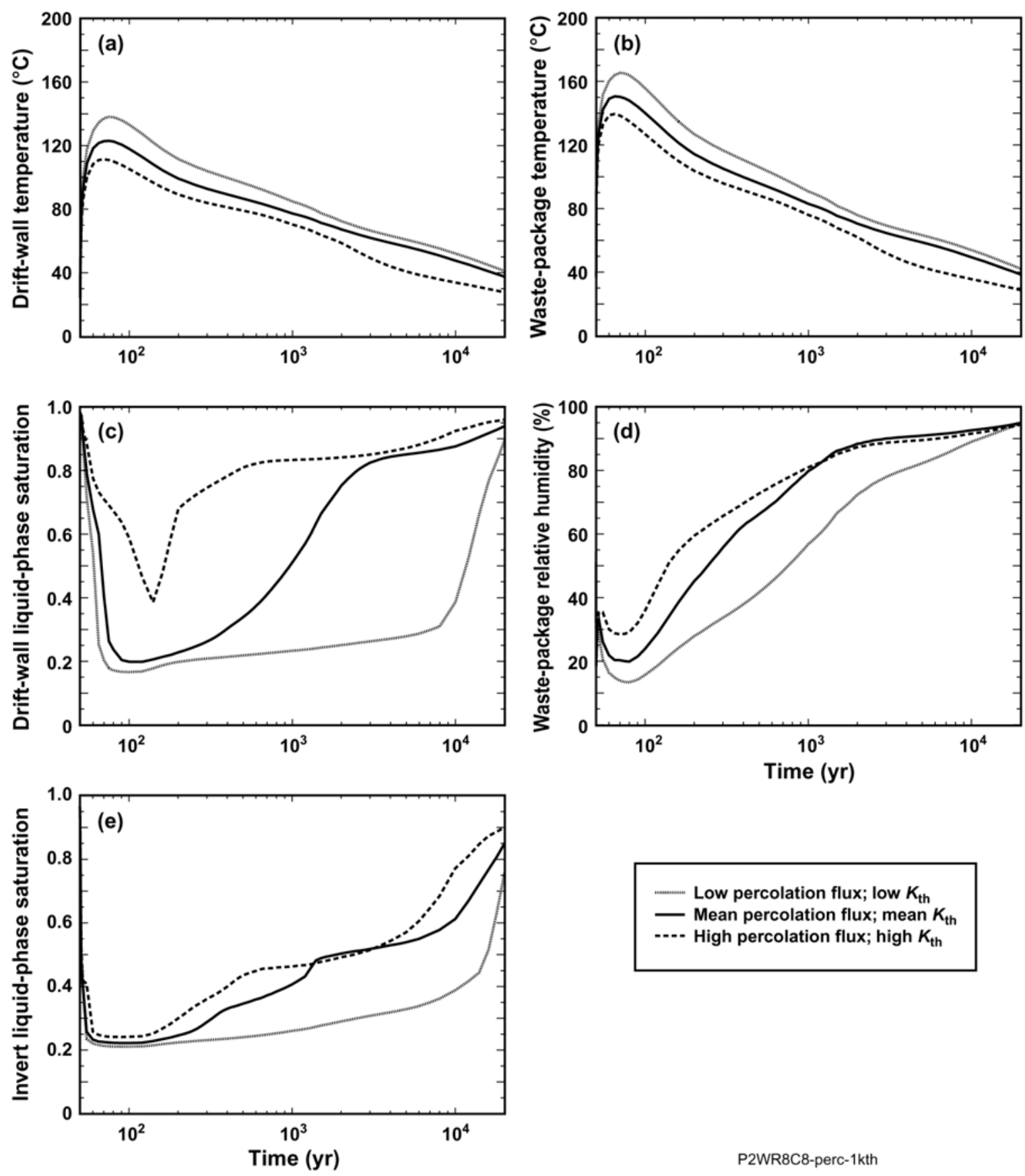

P2WR8C8-perc-1kth

Source: See Table XIII-1.

NOTE: See Figure 6.3-1 for location. These cases are: (1) low percolation flux and low thermal conductivity, (2) mean percolation flux and mean thermal conductivity, and (3) high percolation flux and high thermal conductivity, where the thermal conductivity is varied by plus and minus one standard deviation about the mean. The plotted thermal-hydrologic parameters are (a) drift-wall temperature, (b) waste package temperature, (c) drift-wall liquid-phase saturation, (d) waste package relative humidity, and (e) invert liquid-phase saturation. The pwr1-2 (21-PWR AP CSNF) waste package is the hottest waste package in the sequence (Figure 6.2-2).

Figure 6.3-30. Thermal-Hydrologic Conditions for the pwr1-2 Waste Package Plotted for Three Cases at the P2WR8C8 Location in the Tptpmn (tsw34) Unit 

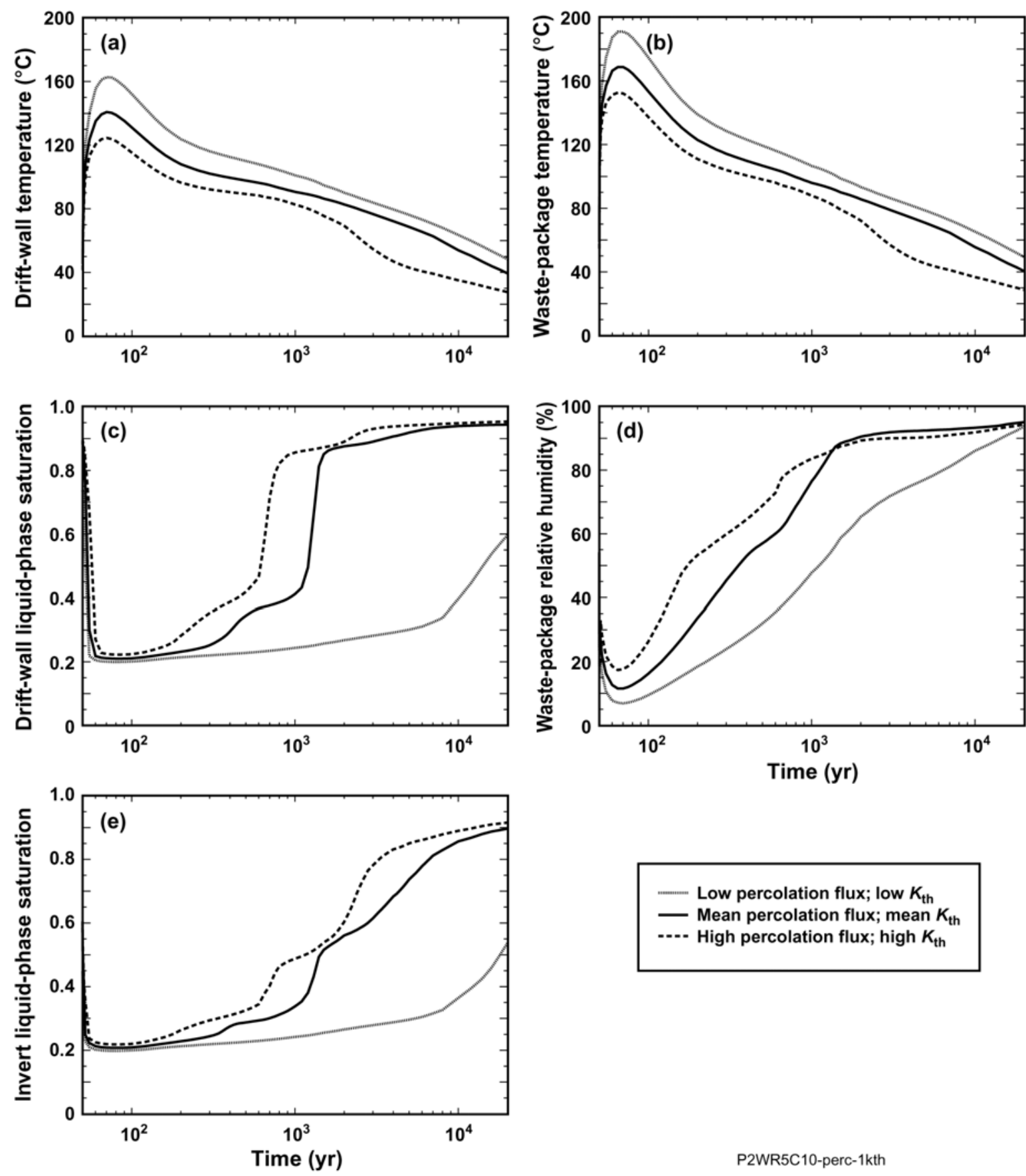

P2WR5C10-perc-1kth

Source: See Table XIII-1.

NOTE: See Figure 6.3-1 for location. These cases are: (1) low percolation flux and low thermal conductivity, (2) mean percolation flux and mean thermal conductivity, and (3) high percolation flux and high thermal conductivity, where the thermal conductivity is varied by plus and minus one standard deviation about the mean. The plotted thermal-hydrologic parameters are (a) drift-wall temperature, (b) waste package temperature, (c) drift-wall liquid-phase saturation, (d) waste package relative humidity, and (e) invert liquid-phase saturation. The pwr1-2 (21-PWR AP CSNF) waste package is the hottest waste package in the sequence (Figure 6.2-2).

Figure 6.3-31. Thermal-Hydrologic Conditions for the pwr1-2 Waste Package Plotted for Three Cases at the P2WR5C10 Location in the Tptpll (tsw35) Unit 

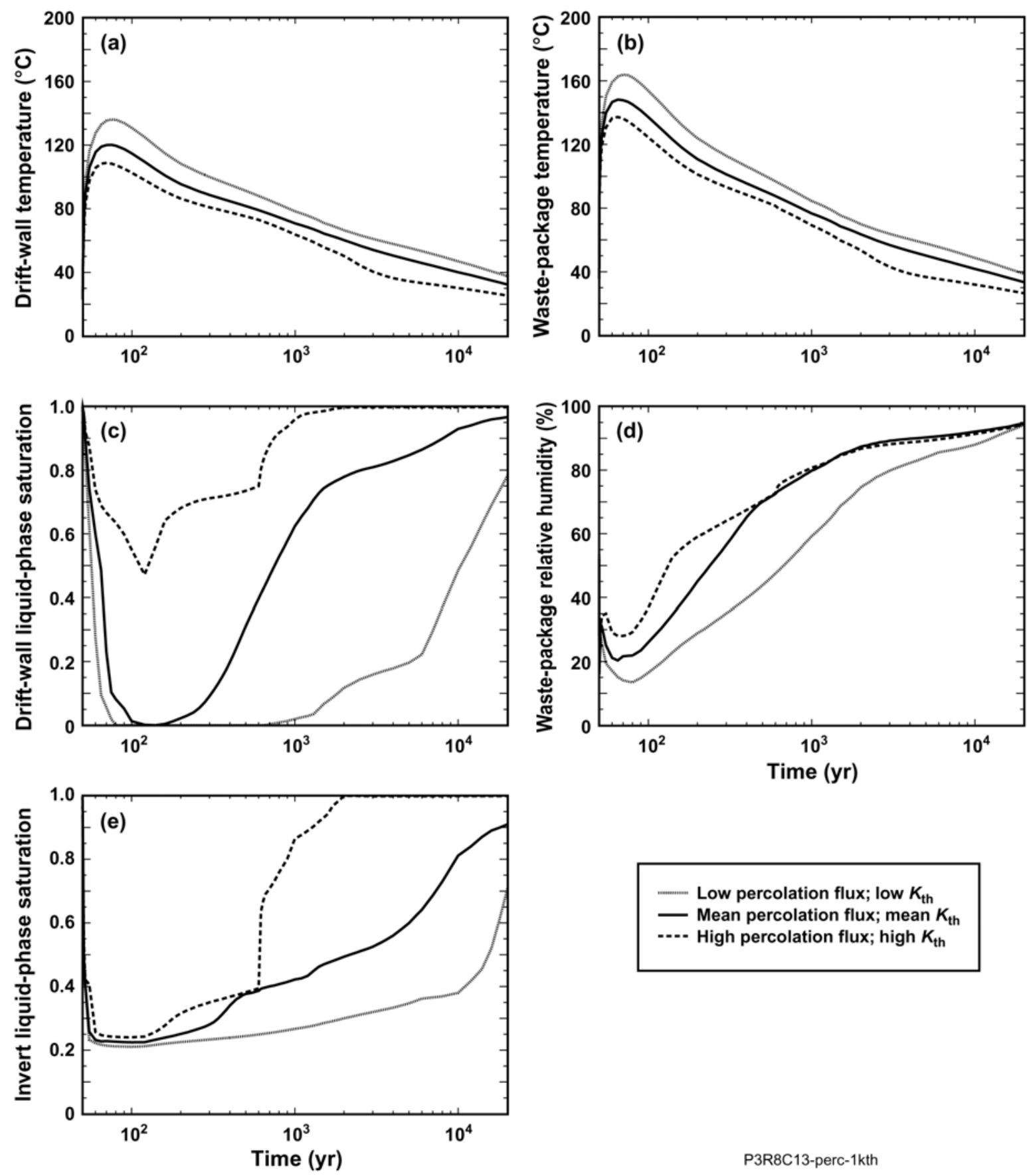

P3R8C13-perc-1kth

Source: See Table XIII-1.

NOTE: See Figure 6.3-1 for location. These cases are: (1) low percolation flux and low thermal conductivity, (2) mean percolation flux and mean thermal conductivity, and (3) high percolation flux and high thermal conductivity, where the thermal conductivity is varied by plus and minus one standard deviation about the mean. The plotted thermal-hydrologic parameters are (a) drift-wall temperature, (b) waste package temperature, (c) drift-wall liquid-phase saturation, (d) waste package relative humidity, and (e) invert liquid-phase saturation. The pwr1-2 (21-PWR AP CSNF) waste package is the hottest waste package in the sequence (Figure 6.2-2).

Figure 6.3-32. Thermal-Hydrologic Conditions for the pwr1-2 Waste Package Plotted for Three Cases at the P3R8C13 Location in the Tptpln (tsw36) Unit 
An important question to ask is whether the combined influence of percolation-flux uncertainty and host-rock thermal conductivity on peak temperatures is simply the sum of the individual contributions to peak-temperature uncertainty. Table 6.3-30 compares the ranges of peak temperatures resulting from (1) percolation-flux uncertainty, (2) host-rock thermal conductivity uncertainty, and (3) a combination of percolation flux and host-rock thermal conductivity uncertainty; Table 6.3-31 makes the same comparison for peak waste package temperatures. Adding the range of peak temperatures resulting from percolation-flux uncertainty to those from host-rock thermal conductivity uncertainty, the results are nearly identical to the range of peak temperatures resulting from the combination of percolation-flux uncertainty and host-rock thermal conductivity. Taking location P2WR5C10 in Table 6.3-30 as an example: adding the peak-temperature range resulting from percolation-flux uncertainty $\left(6.9^{\circ} \mathrm{C}\right)$ to that resulting from host-rock thermal conductivity uncertainty $\left(31.5^{\circ} \mathrm{C}\right)$ yields a total of $38.4^{\circ} \mathrm{C}$, which is close to the peak-temperature range $\left(38.3^{\circ} \mathrm{C}\right)$ that results when the influences of percolation flux and host-rock thermal conductivity uncertainty are combined.

A related question is whether the combined influence of percolation-flux uncertainty and host-rock thermal conductivity on boiling duration is simply the sum of the individual contributions to boiling-duration uncertainty. Table 6.3-32 compares the ranges of the time when boiling at the drift wall ceases resulting from (1) percolation-flux uncertainty, (2) host-rock thermal conductivity uncertainty, and (3) the combination of percolation flux and host-rock thermal conductivity uncertainty. Adding the range of time when drift-wall boiling ends resulting from percolation-flux uncertainty to that from host-rock thermal conductivity uncertainty is nearly equal to the range of boiling duration resulting from the combination of percolation-flux uncertainty and host-rock thermal conductivity uncertainty. Taking location P2WR5C10 in Table 6.3-32 as an example, adding the range of the time when boiling at the drift wall ceases resulting from percolation-flux uncertainty (484.5 years) to that resulting from host-rock thermal conductivity uncertainty (700.8 years), yields $1,185.3$ years, which is similar to the range $(1,208.4$ years) that results when the influences of percolation flux and host-rock thermal conductivity uncertainty are combined. In general, the range resulting from the combined uncertainties is always slightly greater than the sum of the individual contributions to boiling-duration uncertainty. 
Table 6.3-30. Range of Peak Drift-Wall Temperatures for the pwr1-2 Waste Package Resulting from Various Combinations of Percolation Flux $Q_{\text {perc }}$ and Thermal Conductivity $K_{\text {th }}$ Uncertainty, Summarized for Four Locations in the Repository

\begin{tabular}{|c|c|c|c|c|c|c|c|}
\hline \multirow{2}{*}{$\begin{array}{l}\text { LDTH-SDT } \\
\text { Submodel } \\
\text { Location }\end{array}$} & \multirow[b]{2}{*}{$\begin{array}{c}\text { Host-Rock } \\
\text { Unit }\end{array}$} & \multicolumn{2}{|c|}{$\begin{array}{c}\text { Influence of } \\
\text { Percolation- } \\
\text { Flux } \\
\text { Uncertainty on } \\
\text { Peak Drift-Wall } \\
\text { Temperature } \\
\end{array}$} & \multicolumn{2}{|c|}{$\begin{array}{l}\text { Influence of Host- } \\
\text { Rock Thermal } \\
\text { Conductivity } \\
\text { Uncertainty on Peak } \\
\text { Drift-Wall Temperature }\end{array}$} & \multicolumn{2}{|c|}{$\begin{array}{c}\text { Influence of Combined } \\
\text { Percolation Flux and Host- } \\
\text { Rock Thermal Conductivity } \\
\text { Uncertainty on Peak Drift- } \\
\text { Wall Temperature }\end{array}$} \\
\hline & & $\begin{array}{l}\text { Range } \\
\left({ }^{\circ} \mathrm{C}\right)\end{array}$ & $\begin{array}{c}\text { Range } \\
(\%)\end{array}$ & $\begin{array}{l}\text { Range } \\
\left({ }^{\circ} \mathrm{C}\right)\end{array}$ & $\begin{array}{l}\text { Range } \\
(\%)\end{array}$ & $\begin{array}{l}\text { Range } \\
\left({ }^{\circ} \mathrm{C}\right)\end{array}$ & $\begin{array}{l}\text { Range } \\
\text { (\%) }\end{array}$ \\
\hline P2ER8C6 & Tptpul (tsw33) & 7.0 & $5.2 \%$ & 30.1 & $21.8 \%$ & 36.5 & $26.3 \%$ \\
\hline P2WR8C8 & Tptpmn (tsw34) & 5.1 & $4.2 \%$ & 22.7 & $18.1 \%$ & 26.6 & $21.3 \%$ \\
\hline P2WR5C10 & Tptpll (tsw35) & 6.9 & $4.9 \%$ & 31.5 & $22.0 \%$ & 38.3 & $26.7 \%$ \\
\hline P3R8C13 & Tptpln (tsw36) & 4.4 & $3.7 \%$ & 21.9 & $18.0 \%$ & 27.3 & $22.3 \%$ \\
\hline
\end{tabular}

NOTE: $\quad$ See Figure 6.3-1 for locations. The pwr1-2 (21-PWR AP CSNF) waste package is the hottest waste package in the sequence (Figure 6.2-2). These values summarize Tables 6.3-20 through 6.3-29.

Table 6.3-31. Range of Peak Waste Package Temperatures for the pwr1-2 Waste Package Resulting from Various Combinations of Percolation Flux $Q_{\text {perc }}$ and Thermal Conductivity $K_{\text {th }}$ Uncertainty, Summarized for Four Locations in the Repository

\begin{tabular}{|c|c|c|c|c|c|c|c|}
\hline \multirow{2}{*}{$\begin{array}{l}\text { LDTH-SDT } \\
\text { Submodel } \\
\text { Location }\end{array}$} & \multirow[b]{2}{*}{ Host-Rock Unit } & \multicolumn{2}{|c|}{$\begin{array}{c}\text { Influence of } \\
\text { Percolation-Flux } \\
\text { Uncertainty on Peak } \\
\text { Waste Package } \\
\text { Temperature } \\
\end{array}$} & \multicolumn{2}{|c|}{$\begin{array}{l}\text { Influence of Host-Rock } \\
\text { Thermal Conductivity } \\
\text { Uncertainty on Peak } \\
\text { Waste Package } \\
\text { Temperature }\end{array}$} & \multicolumn{2}{|c|}{$\begin{array}{c}\text { Influence of Combined } \\
\text { Percolation Flux and Host- } \\
\text { Rock Thermal Conductivity } \\
\text { Uncertainty on Peak Waste } \\
\text { Package Temperature }\end{array}$} \\
\hline & & $\begin{array}{c}\text { Range } \\
\left({ }^{\circ} \mathrm{C}\right)\end{array}$ & $\begin{array}{c}\text { Range } \\
(\%)\end{array}$ & $\begin{array}{c}\text { Range } \\
\left({ }^{\circ} \mathrm{C}\right)\end{array}$ & $\begin{array}{c}\text { Range } \\
(\%)\end{array}$ & $\begin{array}{c}\text { Range } \\
\left({ }^{\circ} \mathrm{C}\right)\end{array}$ & $\begin{array}{c}\text { Range } \\
\text { (\%) }\end{array}$ \\
\hline P2ER8C6 & Tptpul (tsw33) & 7.0 & $4.3 \%$ & 29.8 & $17.9 \%$ & 36.4 & $21.8 \%$ \\
\hline P2WR8C8 & Tptpmn (tsw34) & 4.3 & $2.9 \%$ & 21.9 & $14.3 \%$ & 25.9 & $17.0 \%$ \\
\hline P2WR5C10 & Tptpll (tsw35) & 7.0 & $4.1 \%$ & 31.4 & $18.3 \%$ & 38.3 & $22.3 \%$ \\
\hline P3R8C13 & Tptpln (tsw36) & 4.0 & $2.7 \%$ & 21.4 & $14.3 \%$ & 26.6 & $17.7 \%$ \\
\hline
\end{tabular}

NOTE: $\quad$ See Figure 6.3-1 for locations. The pwr1-2 (21-PWR AP CSNF) waste package is the hottest waste package in the sequence (Figure 6.2-2).

The combined influence of percolation-flux uncertainty and host-rock thermal conductivity uncertainty on dryout/rewetting is illustrated by the drift-wall and invert liquid-phase saturation histories (Figures 6.3-29c, 6.3-29e, 6.3-30c, 6.3-30e, 6.3-31c, 6.3-31e, 6.3-32c, and 6.3-32e). The time for liquid-phase saturation to rewet back to ambient values ranges by two orders of magnitude for these cases. The combined influence of percolation-flux uncertainty and host-rock thermal conductivity uncertainty on waste package relative humidity histories is shown in Figures 6.3-29d, 6.3-30d, 6.3-31d, and 6.3-32d. Because of the contribution of the temperature difference between the waste package and the drift wall on relative humidity reduction on waste packages, the combined influence of percolation flux and host-rock thermal conductivity uncertainty on waste package relative humidity, while evident, is not as strong as for liquid-phase saturation histories. 
Table 6.3-32. Range of Time When Boiling at the Drift Wall Ceases for the pwr1-2 Waste Package Resulting from Various Combinations of Percolation Flux $Q_{\text {perc }}$ and Thermal Conductivity $K_{\text {th }}$ Uncertainty, Summarized for Four Locations in the Repository

\begin{tabular}{|c|c|c|c|c|c|c|c|}
\hline \multirow{2}{*}{$\begin{array}{l}\text { LDTH-SDT } \\
\text { Submodel } \\
\text { Location }\end{array}$} & \multirow[b]{2}{*}{ Host-Rock Unit } & \multicolumn{2}{|c|}{$\begin{array}{c}\text { Influence of } \\
\text { Percolation-Flux } \\
\text { Uncertainty on } \\
\text { Time When } \\
\text { Boiling at the } \\
\text { Drift Wall Ceases }\end{array}$} & \multicolumn{2}{|c|}{$\begin{array}{c}\text { Influence of } \\
\text { Host-Rock Thermal } \\
\text { Conductivity } \\
\text { Uncertainty on Time } \\
\text { When Boiling at the } \\
\text { Drift Wall Ceases }\end{array}$} & \multicolumn{2}{|c|}{$\begin{array}{l}\text { Influence of Combined } \\
\text { Percolation Flux and Host- } \\
\text { Rock Thermal } \\
\text { Conductivity Uncertainty } \\
\text { on Time When Boiling at } \\
\text { the Drift Wall Ceases }\end{array}$} \\
\hline & & $\begin{array}{l}\text { Range } \\
\text { (years) }\end{array}$ & $\begin{array}{c}\text { Range } \\
(\%)\end{array}$ & $\begin{array}{l}\text { Range } \\
\text { (years) }\end{array}$ & $\begin{array}{l}\text { Range } \\
(\%)\end{array}$ & $\begin{array}{l}\text { Range } \\
\text { (years) }\end{array}$ & $\begin{array}{l}\text { Range } \\
\text { (\%) }\end{array}$ \\
\hline P2ER8C6 & Tptpul (tsw33) & 124.8 & $33.2 \%$ & 250.0 & $65.2 \%$ & 393.0 & $93.8 \%$ \\
\hline P2WR8C8 & Tptpmn (tsw34) & 88.4 & $36.5 \%$ & 249.0 & $86.4 \%$ & 369.4 & $112.1 \%$ \\
\hline P2WR5C10 & Tptpll (tsw35) & 484.5 & $75.6 \%$ & 700.8 & $114.3 \%$ & $1,208.4$ & $148.9 \%$ \\
\hline P3R8C13 & Tptpln (tsw36) & 49.0 & $24.5 \%$ & 169.2 & $75.4 \%$ & 247.4 & $97.6 \%$ \\
\hline
\end{tabular}

\subsubsection{Influence of Hydrologic-Property Uncertainty on In-Drift Temperature and Relative Humidity}

The primary purpose of this section is to help determine whether it is necessary to propagate hydrologic-property uncertainty in the MSTHM calculations for TSPA-LA. The primary hydrologic property of interest is the bulk permeability of the host rock; this parameter is primarily affected by the permeability of the fracture network. As discussed in Section 6.3.2, a sensitivity study (BSC 2001 [DIRS 155950], Section 5.3.1.4.7) found that host-rock bulk permeability has a minor influence on peak temperatures and boiling-period duration. Therefore, host-rock bulk permeability uncertainty does not need to be propagated in the MSTHM calculations for TSPA-LA. In this section, the influence of hydrologic-property uncertainty is further addressed by investigating the impact of utilizing various hydrologic-property sets that have differing values of matrix and fracture properties in the four host-rock units (Tptpul, Tptpmn, Tptpll, and Tptpln).

The influence of hydrologic-property uncertainty on in-drift temperature and relative humidity at four locations (P2ER8C6, P2WR8C8, P2WR5C10, and P3R8C13) in the repository (Figure 6.3-1) is illustrated in time histories of drip-shield temperature and relative humidity (Figures 6.3-33 through 6.3-36). These time histories were generated with the use of the LDTH submodel (Section 6.2.6), which is the primary thermal-hydrologic submodel in the MSTHM family of submodels. Because the LDTH submodel is the only MSTHM submodel that uses hydrologic-property information as input, it is reasonable to use the results of the LDTH submodel to investigate the degree of sensitivity of in-drift temperature and relative humidity to hydrologic-property uncertainty. The LDTH submodel calculations in this section were conducted for an Areal Mass Loading (AML) of $55 \mathrm{MTU} / \mathrm{acre}$. Thus, these results correspond to line-average heat-generation conditions for a repository location far enough away from the repository edges not to be influenced by the edge-cooling effect. For these four locations in the repository, four different cases are investigated: (1) lower-bound infiltration-flux case with lower-bound infiltration-flux property set, (DTN: LB0208UZDSCPLI.002 [DIRS 161788]), (2) lower-bound infiltration-flux case with modified-mean infiltration-flux property set, (3) upper-bound infiltration-flux case with upper-bound infiltration-flux property set 
(DTN: LB0302UZDSCPUI.002 [DIRS 161787]), and (4) upper-bound infiltration-flux case with modified-mean infiltration-flux property set. The modified-mean infiltration-flux property set is used in all of the MSTHM calculations discussed in Sections 6.3.2.1 through 6.3.2.3 and in Section 6.3.3. These pairs of cases were chosen to be able to discern the influence of hydrologic properties on in-drift temperature and relative humidity. Because temperature and relative humidity on the drip shield are key measures of in-drift thermal-hydrologic conditions, this section focuses on those parameters.
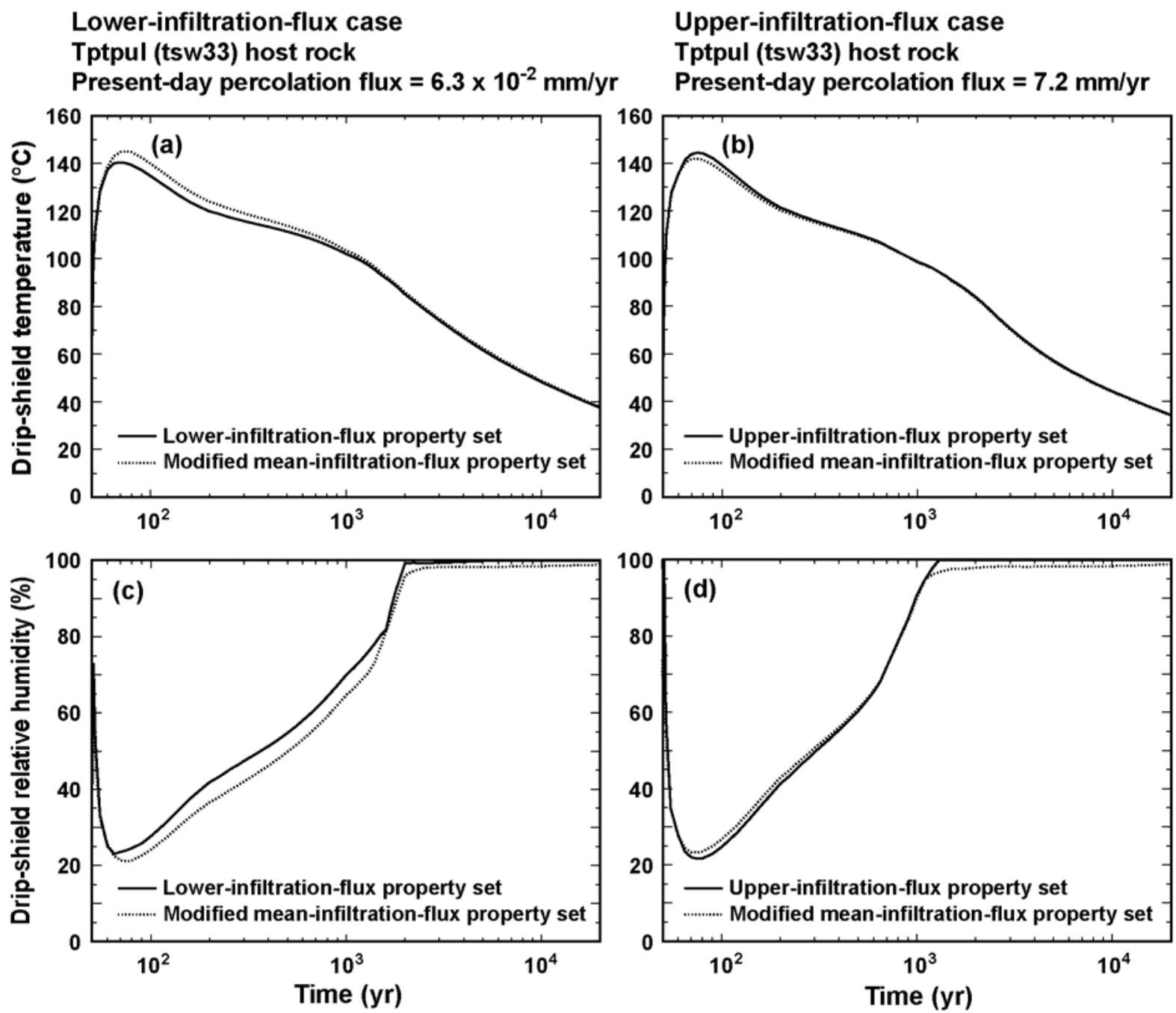

P2ER8C6_LDTH55propSet4pk

Source: See Table XIII-1.

NOTE: See Figure 6.3-1 for location. The four cases are: (1) lower-bound infiltration-flux case with lower-bound infiltration-flux property set, (2) lower-bound infiltration-flux case with modified-mean infiltration-flux property set, (3) upper-bound infiltration-flux case with upper-bound infiltration-flux property set, and (4) upper-bound infiltration-flux case with modified-mean infiltration-flux property set.

Figure 6.3-33. Drip-Shield Temperature $(a, b)$ and Relative Humidity $(c, d)$ for Line-Averaged Heating Conditions Plotted for Four Cases at the P2ER8C6 Location in the Tptpul (tsw33) Unit 

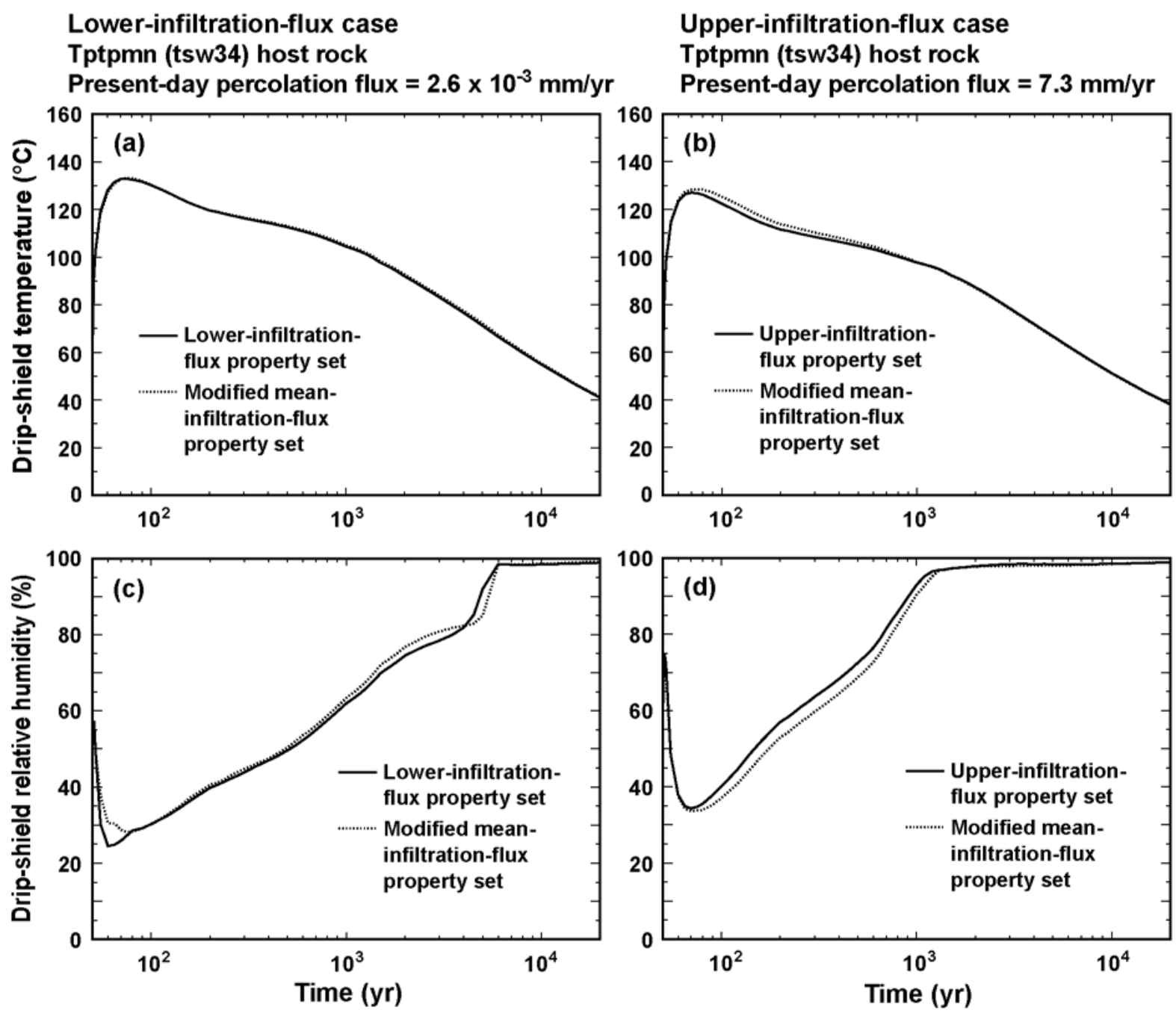

P2WR8C8_LDTH55propSet4pk

Source: See Table XIII-1.

NOTE: $\quad$ See Figure 6.3-1 for location. The four cases are: (1) lower-bound infiltration-flux case with lower-bound infiltration-flux property set, (2) lower-bound infiltration-flux case with modified-mean infiltration-flux property set, (3) upper-bound infiltration-flux case with upper-bound infiltration-flux property set, and (4) upper-bound infiltration-flux case with modified-mean infiltration-flux property set.

Figure 6.3-34. Drip-Shield Temperature $(a, b)$ and Relative Humidity $(c, d)$ for Line-Averaged Heating Conditions Plotted for Four Cases at the P2WR8C8 Location in the Tptpmn (tsw34) Unit 

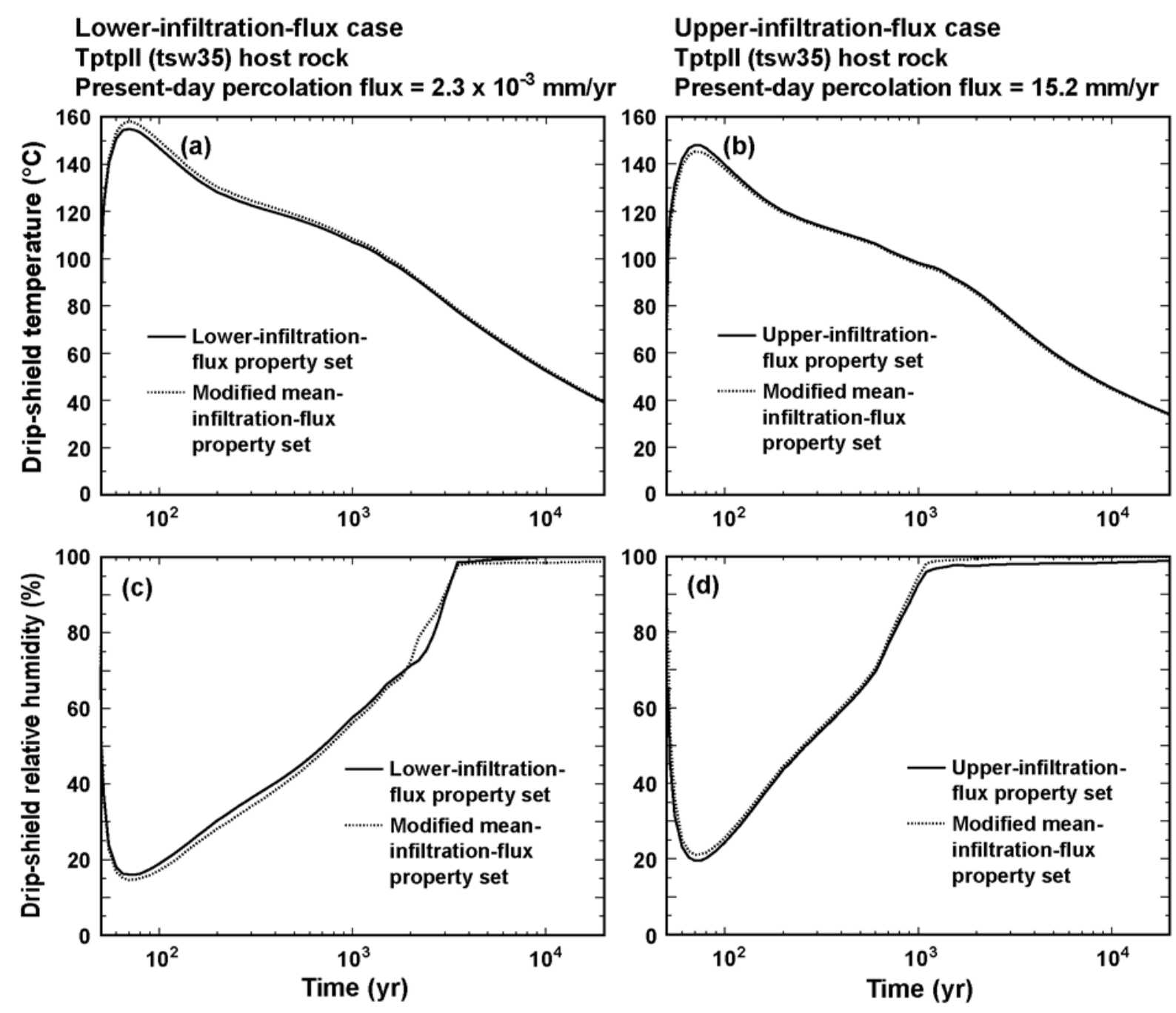

P2WR5C10_LDTH55propSet4pk

Source: See Table XIII-1.

NOTE: See Figure 6.3-1 for location. The four cases are: (1) lower-bound infiltration-flux case with lower-bound infiltration-flux property set, (2) lower-bound infiltration-flux case with modified-mean infiltration-flux property set, (3) upper-bound infiltration-flux case with upper-bound infiltration-flux property set, and (4) upper-bound infiltration-flux case with modified-mean infiltration-flux property set.

Figure 6.3-35. Drip-Shield Temperature $(a, b)$ and Relative Humidity $(c, d)$ for Line-Averaged Heating Conditions Plotted for Four Cases at the P2WR5C10 Location in the Tptpll (tsw35) Unit 
Lower-infiltration-flux case

Tptpln (tsw36) host rock

Present-day percolation flux $=0.36 \mathrm{~mm} / \mathrm{yr}$
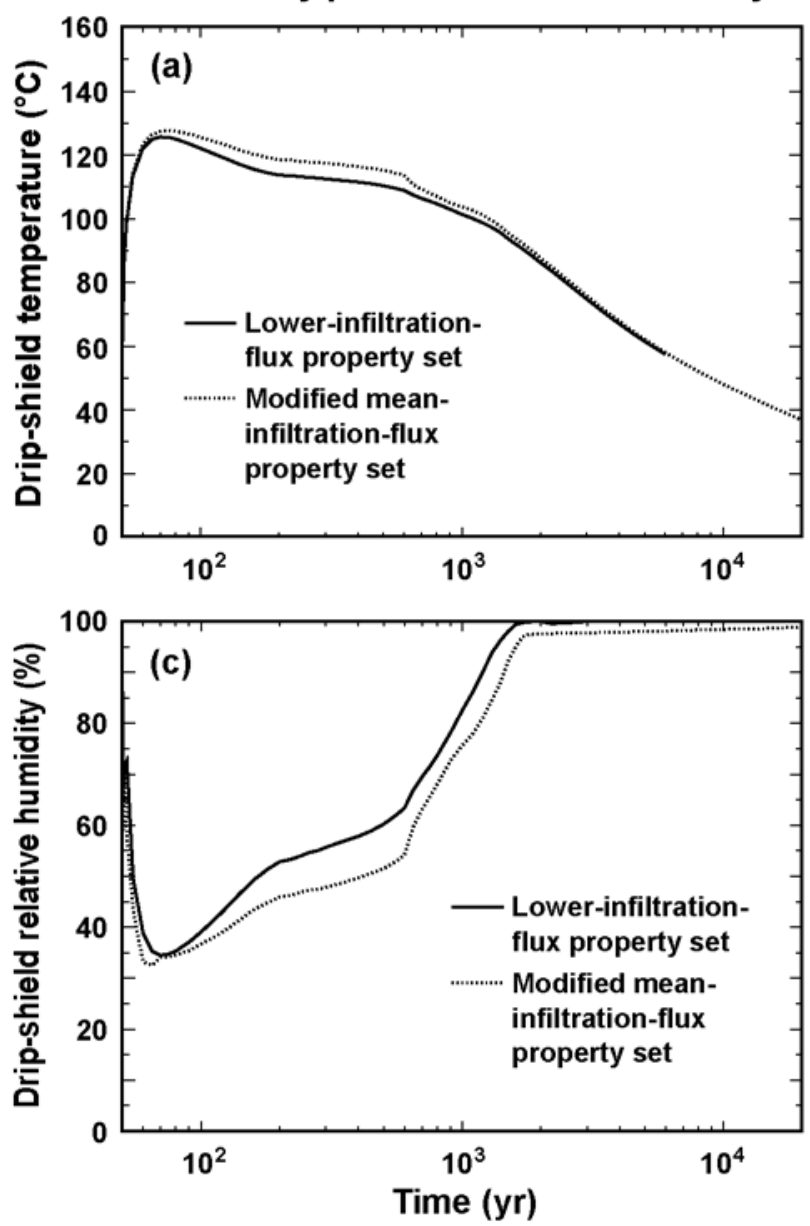

Upper-infiltration-flux case Tptpln (tsw36) host rock Present-day percolation flux $=16.6 \mathrm{~mm} / \mathrm{yr}$
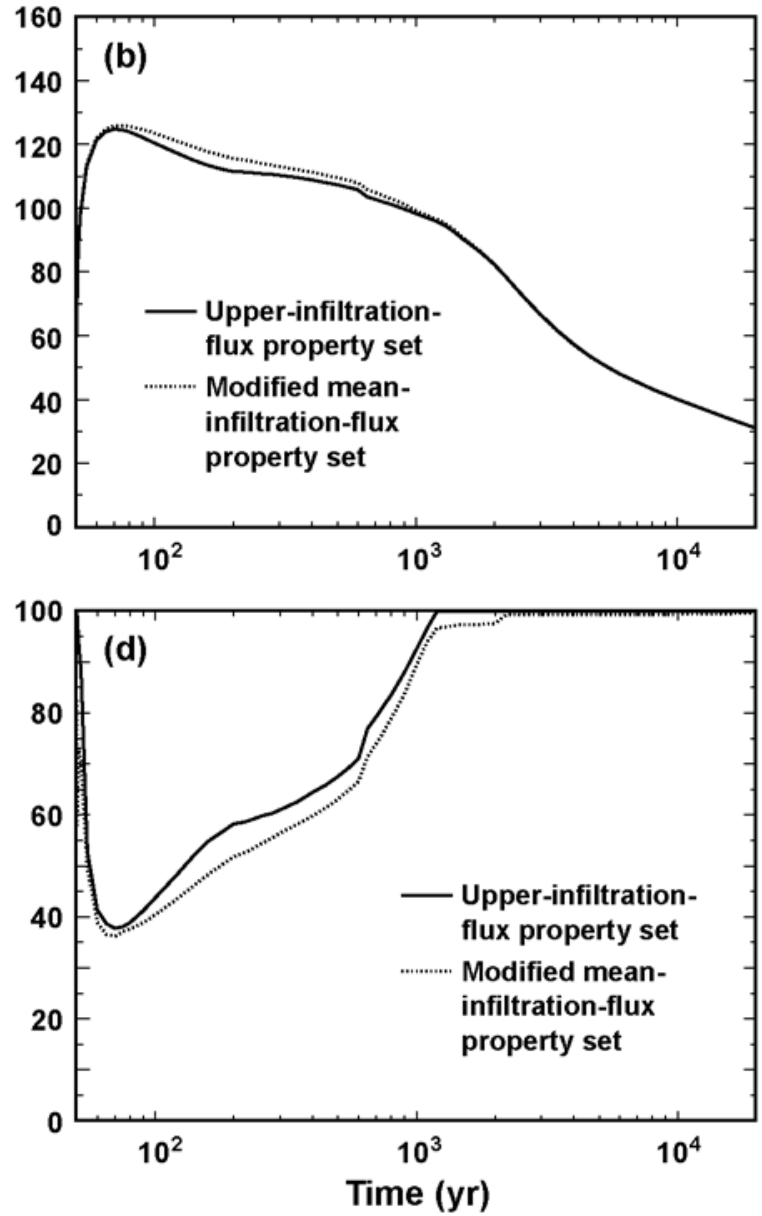

P3R8C13_LDTH55propSet4pk

Source: See Table XIII-1.

NOTE: See Figure 6.3-1 for location. The four cases are: (1) lower-bound infiltration-flux case with lower-bound infiltration-flux property set, (2) lower-bound infiltration-flux case with modified-mean infiltration-flux property set, (3) upper-bound infiltration-flux case with upper-bound infiltration-flux property set, and (4) upper-bound infiltration-flux case with modified mean infiltration-flux property set.

Figure 6.3-36. Drip-Shield Temperature $(a, b)$ and Relative Humidity $(c, d)$ for Line-Averaged Heating Conditions Plotted for Four Cases at the P3R8C13 Location in the Tptpln (tsw36) Unit 
Figures 6.3-33 through 6.3-36 indicate that in-drift temperature and relative humidity are insensitive to hydrologic-property uncertainty. For drifts located in the Tptpul (tsw33) unit (Figure 6.3-33) and the Tptpmn (tsw34) unit (Figure 6.3-34), which comprise 6.0 percent and 16.1 percent of the repository area, respectively (Table 6.3-3), drip-shield temperature and relative humidity are weakly sensitive to hydrologic properties. For drifts located in the Tptpll (tsw35) unit (Figure 6.3-35), which comprise 75.1 percent of the repository area (Table 6.3-3), drip-shield temperature and relative humidity are insensitive to hydrologic properties. For drifts located in the Tptpln (tsw36) unit (Figure 6.3-36), which comprise only 1.6 percent of the repository area (Table 6.3-3), drip-shield temperature and relative humidity are relatively insensitive to hydrologic properties. The results support the conclusion that hydrologic-property uncertainty does not need to be propagated in the MSTHM calculations of in-drift temperature and relative humidity.

\subsubsection{Mass Flux in the Invert}

The primary purpose of this section is to examine gas- and liquid-phase mass fluxes in the invert, including fluxes into and out of the invert, as well as fluxes within the invert. Time histories of gas- and liquid-phase flux and of liquid-phase saturation are provided in Figures 6.3-37 through 6.3-44 for four locations (P2ER8C6, P2WR8C8, P2WR5C10, and P3R8C13) in the repository (Figure 6.3-1). Figure 6.3-45 plots the phase change (with positive and negative phase change corresponding to evaporation and condensation, respectively) and the liquid-phase flux for the lower half of the invert. These four locations were chosen because they cover all four of the host-rock units in the repository and because their respective values of percolation flux are relatively close to the repository-wide averages (Tables 6.3-4, 6.3-5, and 6.3-9). These time histories were generated with the use of the LDTH submodel (Section 6.2.6), which is the primary thermal-hydrologic submodel in the MSTHM family of submodels. The LDTH submodel calculations in this section were conducted for an Areal Mass Loading (AML) of 55 MTU/acre. Thus, these results correspond to line-average heat-generation conditions for a repository location far enough away from the repository edges not to be influenced by the edge-cooling effect.

Figure 6.3-37 plots liquid-phase and gas-phase fluxes between the invert and the adjoining drift and host rock, as well as plotting the liquid-phase saturation in the invert, for the P2ER8C6 location, which is in the Tptpul (tsw33) unit. Figures 6.3-38 plots liquid- and gas-phase fluxes between the upper and lower halves of the invert. Table 6.3-33 provides the peak values of liquid-phase and gas-phase fluxes after 50 years, while Table 6.3-34 provides the peak values after 100 years. These figures and tables show there are three distinctive time periods with respect to mass flux, dryout, and rewetting of the invert, which are:

1. Initial period of strong dryout, when the strong gas-phase flux of water vapor (in the fracture continuum) out of the invert dominates the return capillary-driven liquid-phase flux (in the matrix continuum). Thus, refluxing (i.e., the countercurrent flow of water vapor and liquid water) is quite pronounced during this period. Gas- and liquid-phase fluxes rapidly increase and decrease during this period. At the very beginning of the initial dryout period, condensation is strong in the lower half of the invert (Figure 6.3-45), which lasts until the boiling front passes through the bottom of the invert and into the underlying host rock. Liquid-phase flux (in the fracture continuum) drains from the bottom of the invert to the underlying host rock. Thus, liquid-phase drainage in the 
fracture continuum contributes significantly to the initial dryout of the invert. The source of this liquid-phase drainage is condensation of water vapor that boiled in the upper portion of the invert and was driven downward to the lower portion of the invert. By the end of the initial dryout period the liquid-phase saturation in the invert has attained its minimum value.

2. Period of sustained dryout, when the dryout front is in the host rock beyond the drift wall. During this period, the liquid-phase saturation remains close to its minimum value and mass fluxes within the invert, as well as at its interface with the adjoining drift and with the host rock, are essentially zero.

3. Period of rewetting, when the return capillary-driven liquid-phase flux (in the matrix continuum) dominates the outward flux of water vapor (in the fracture continuum). Gasand liquid-phase fluxes gradually increase and decrease during this period. Liquid-phase flux (in the fracture continuum) drains from the bottom of the invert to the underlying host rock. The source of this liquid-phase drainage flux (which is of a much smaller magnitude than during the initial dryout period) is the condensation of water vapor that boiled in the upper portion of the invert and was driven downward to the lower portion of the invert (Figures 6.3-45a and 6.3-45b). Refluxing, both within the invert as well as at the interface with the host rock, is strong during this period.

Figures 6.3-39 and 6.3-40 for the P2WR8C8 location, which is in the Tptpmn (tsw34) host-rock unit, are qualitatively similar to Figures 6.3-37 and 6.3-38; however, the magnitudes of the gasand liquid-phase fluxes associated with refluxing are much less during the rewetting period (Table 6.3-34). Moreover, the P2WR8C8 location experiences no liquid-phase drainage in the fracture continuum during the rewetting period (Figure 6.3-45d).

Figures 6.3-41 and 6.3-42 for the P2WR5C10 location, which is in the Tptpll (tsw35) host-rock unit, are also qualitatively similar to Figures 6.3-37 and 6.3-38; however, the magnitude of the gas- and liquid-phase fluxes associated with refluxing is somewhat less during the rewetting period (Table 6.3-34). Moreover, the P2WR5C10 location experiences a much smaller liquid-phase drainage flux in the fracture continuum during the rewetting than the P2ER8C6 location (compare Figure 6.3-45f with Figure 6.3-45b).

Figures 6.3-43 and 6.3-44 for the P3R8C13 location, which is in the Tptpln (tsw36) host-rock unit, are qualitatively similar to Figures 6.3-37 and 6.3-38; however, the magnitude of the gasand liquid-phase fluxes associated with refluxing is much less during the rewetting period (Table 6.3-34). Moreover, the P3R8C13 location experiences no liquid-phase drainage in the fracture continuum during the rewetting period (Figure 6.3-45h). 

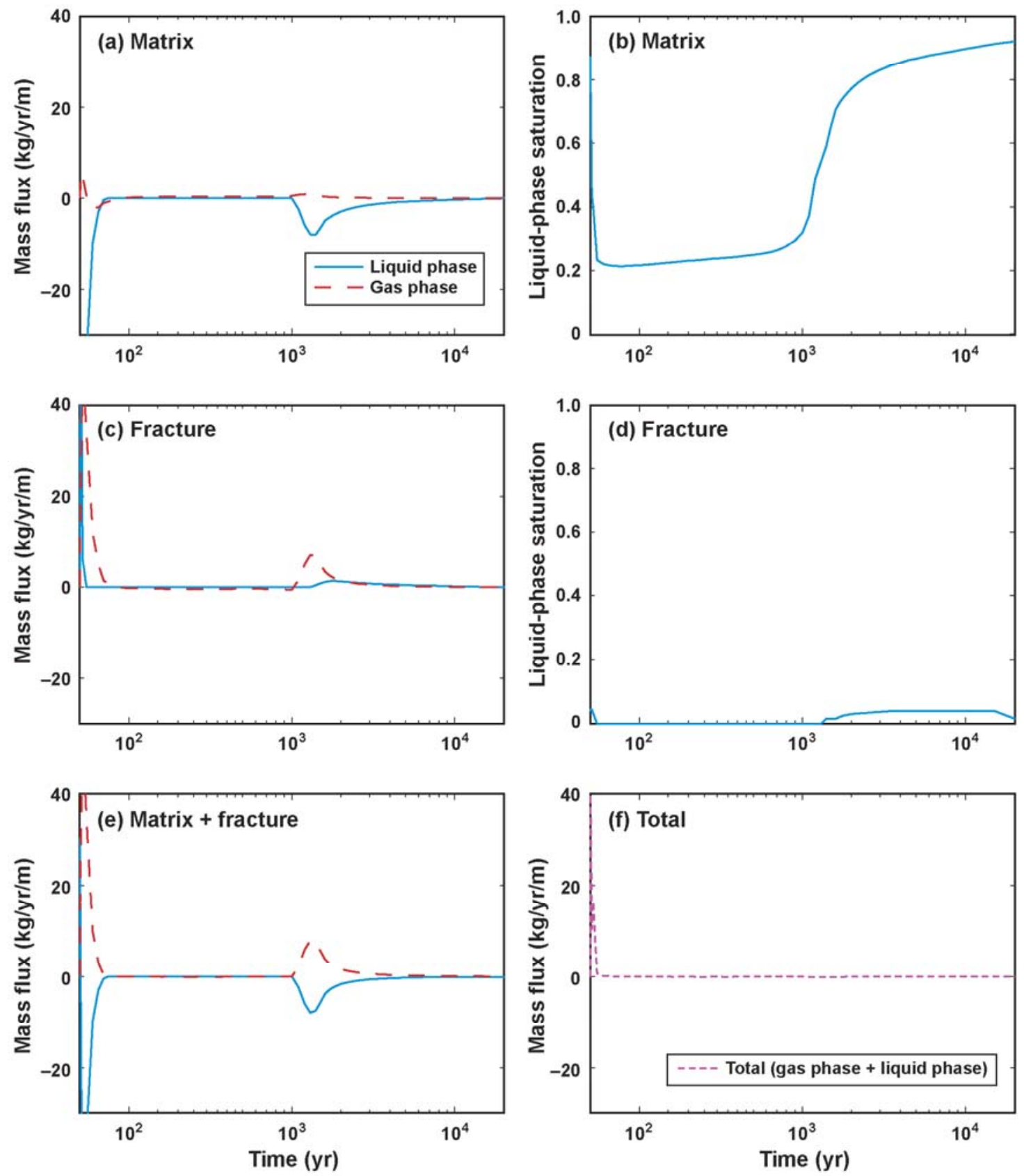

P2ER8C6 inv-hostrock+drift_flux3

Source: See Table XIII-1.

NOTE: $\quad$ See Figure 6.3-1 for location. Also plotted is (f) the total (gas-phase + liquid-phase) mass flux for the matrix + fracture continua. A positive value of mass flux corresponds to flux out of the invert. Also plotted is the liquid-phase saturation for the (b) matrix and (d) fracture continuum. These fluxes are the result of line-averaged heating conditions.

Figure 6.3-37. Liquid-Phase and Gas-Phase Flux Between the Invert and Adjoining Drift and Host Rock Plotted for the (a) Matrix, (c) Fracture, and (e) Matrix + Fracture Continuum at the P2ER8C6 Location in the Tptpul (tsw33) Unit 

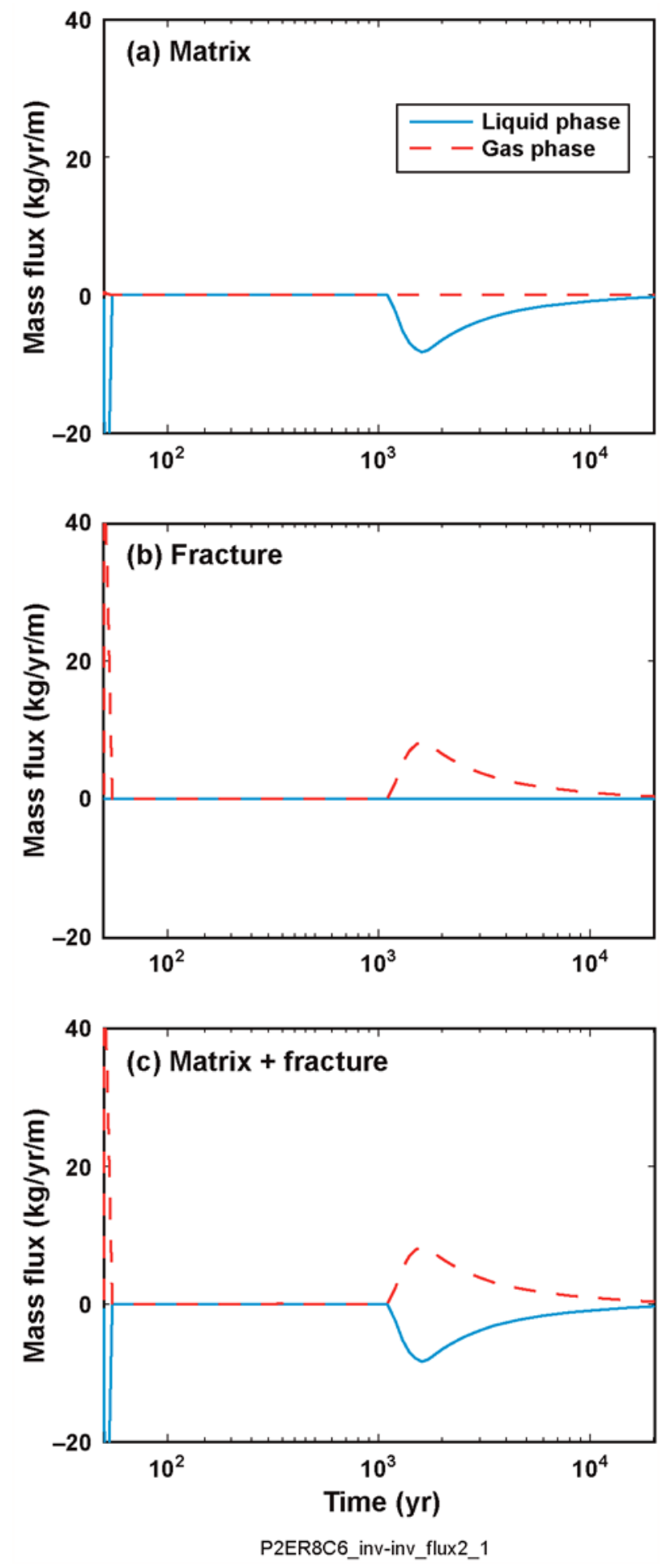

Source: See Table XIII-1.

NOTE: See Figure 6.3-1 for location. A positive value of mass flux corresponds to vertically downward flow. These fluxes are the result of line-averaged heating conditions.

Figure 6.3-38. Liquid-Phase and Gas-Phase Flux Between the Upper and Lower Half of the Invert Plotted for the (a) Matrix, (b) Fracture, and (c) Matrix + Fracture Continuum at the P2ER8C6 Location in the Tptpul (tsw33) Unit 

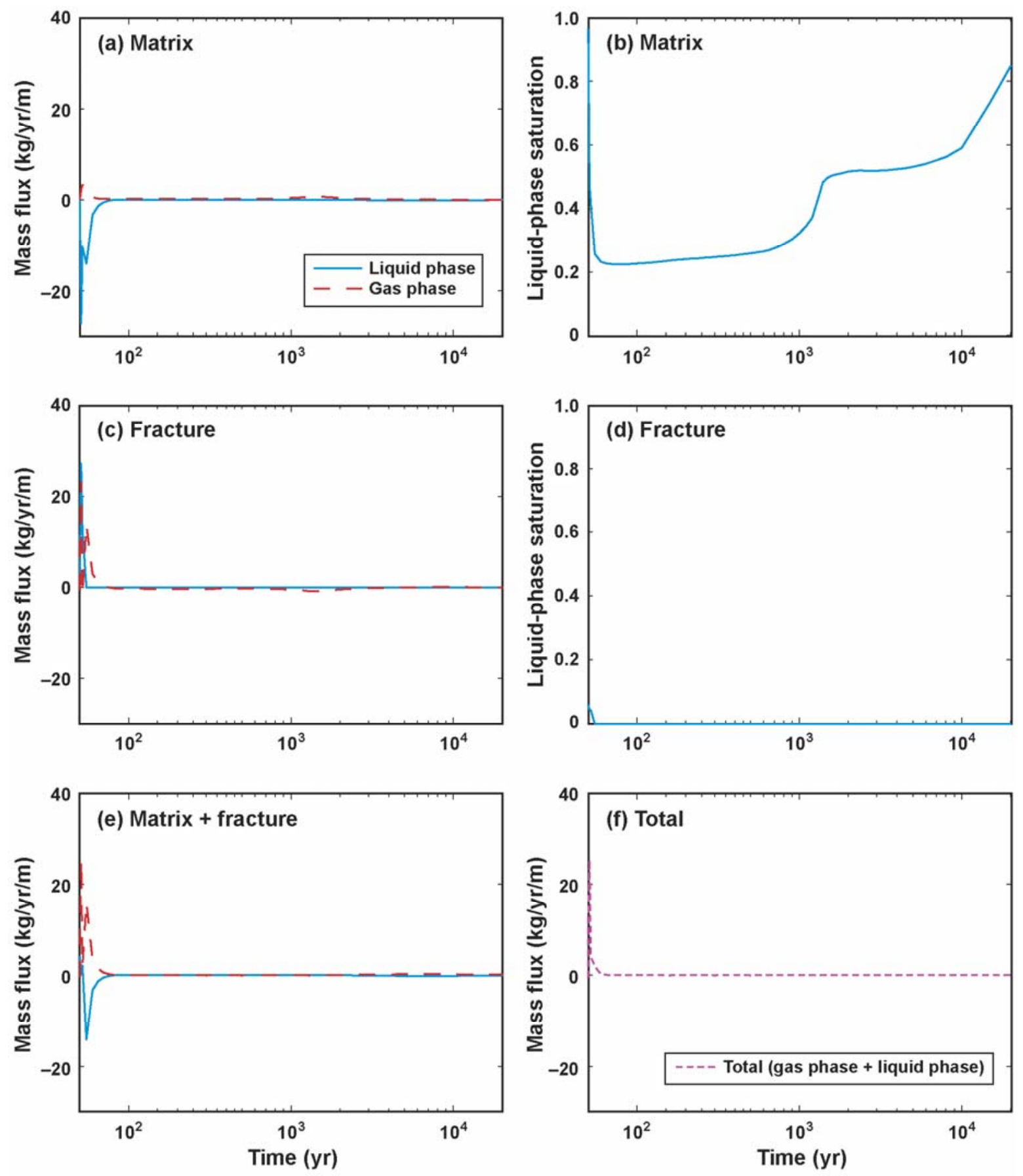

P2WR8C8_inv-hostrock+drift_flux3

Source: See Table XIII-1.

NOTE: See Figure 6.3-1 for location. Also plotted is (f) the total (gas-phase + liquid-phase) mass flux for the matrix + fracture continua. A positive value of mass flux corresponds to flux out of the invert. Also plotted is the liquid-phase saturation for the (b) matrix and (d) fracture continuum. These fluxes are the result of line-averaged heating conditions.

Figure 6.3-39. Liquid-Phase and Gas-Phase Flux Between the Invert and Adjoining Drift and Host Rock Plotted for the (a) Matrix, (c) Fracture, and (e) Matrix + Fracture Continuum at the P2WR8C8 Location in the Tptpmn (tsw34) Unit 

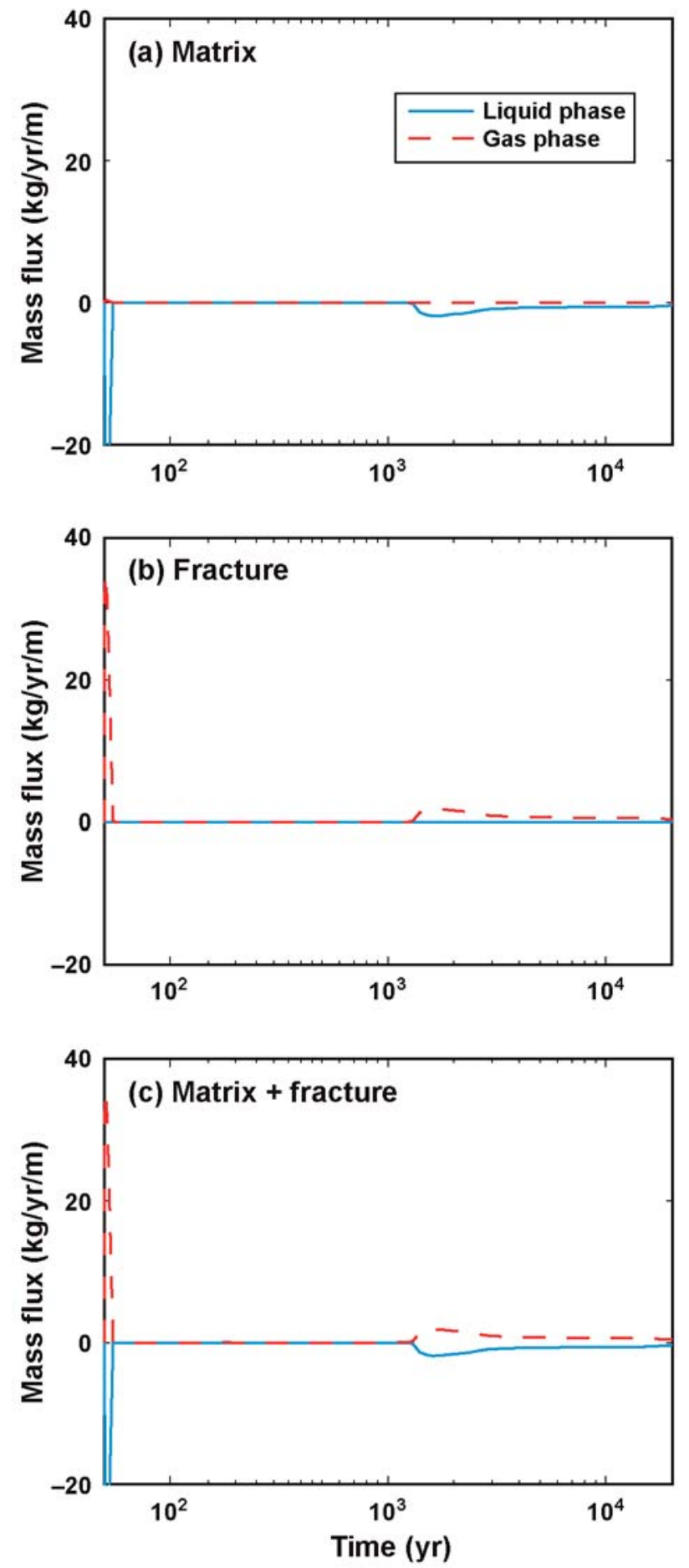

P2WR8C8_inv-inv_flux2_1

Source: See Table XIII-1.

NOTE: See Figure 6.3-1 for location. A positive value of mass flux corresponds to vertically downward flow. These fluxes are the result of line-averaged heating conditions.

Figure 6.3-40. Liquid-Phase and Gas-Phase Flux Between the Upper and Lower Half of the Invert Plotted for the (a) Matrix, (b) Fracture, and (c) Matrix + Fracture Continuum at the P2WR8C8 Location in the Tptpmn (tsw34) Unit 

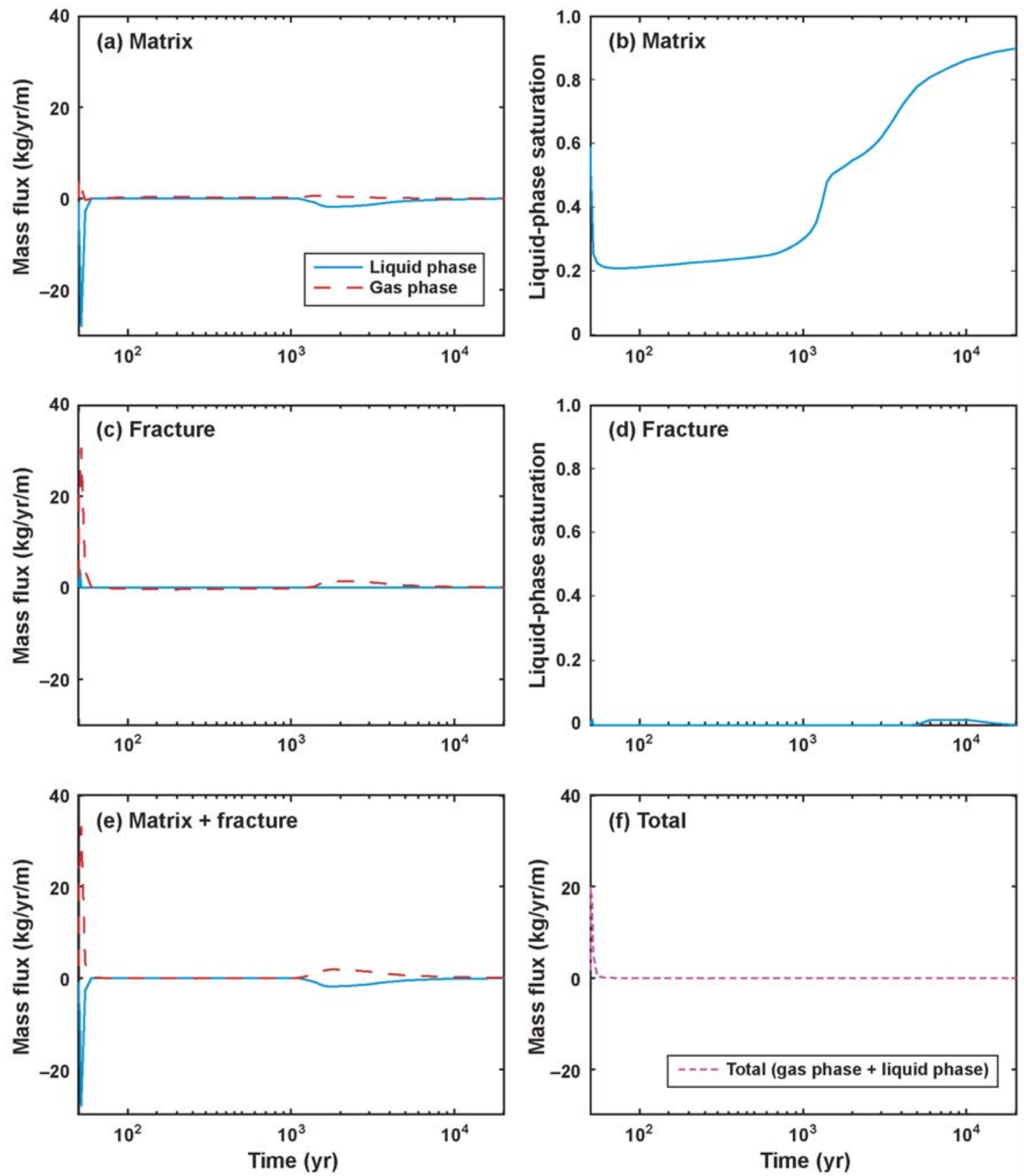

P2WR5C10_inv-hostrock+drift_flux3

Source: See Table XIII-1.

NOTE: $\quad$ See Figure 6.3-1 for location. Also plotted is (f) the total (gas-phase + liquid-phase) mass flux for the matrix + fracture continua. A positive value of mass flux corresponds to flux out of the invert. Also plotted is the liquid-phase saturation for the (b) matrix and (d) fracture continuum. These fluxes are the result of line-averaged heating conditions.

Figure 6.3-41. Liquid-Phase and Gas-Phase Flux Between the Invert and Adjoining Drift and Host Rock Plotted for the (a) Matrix, (c) Fracture, and (e) Matrix + Fracture Continuum at the P2WR5C10 Location in the Tptpll (tsw35) Unit 

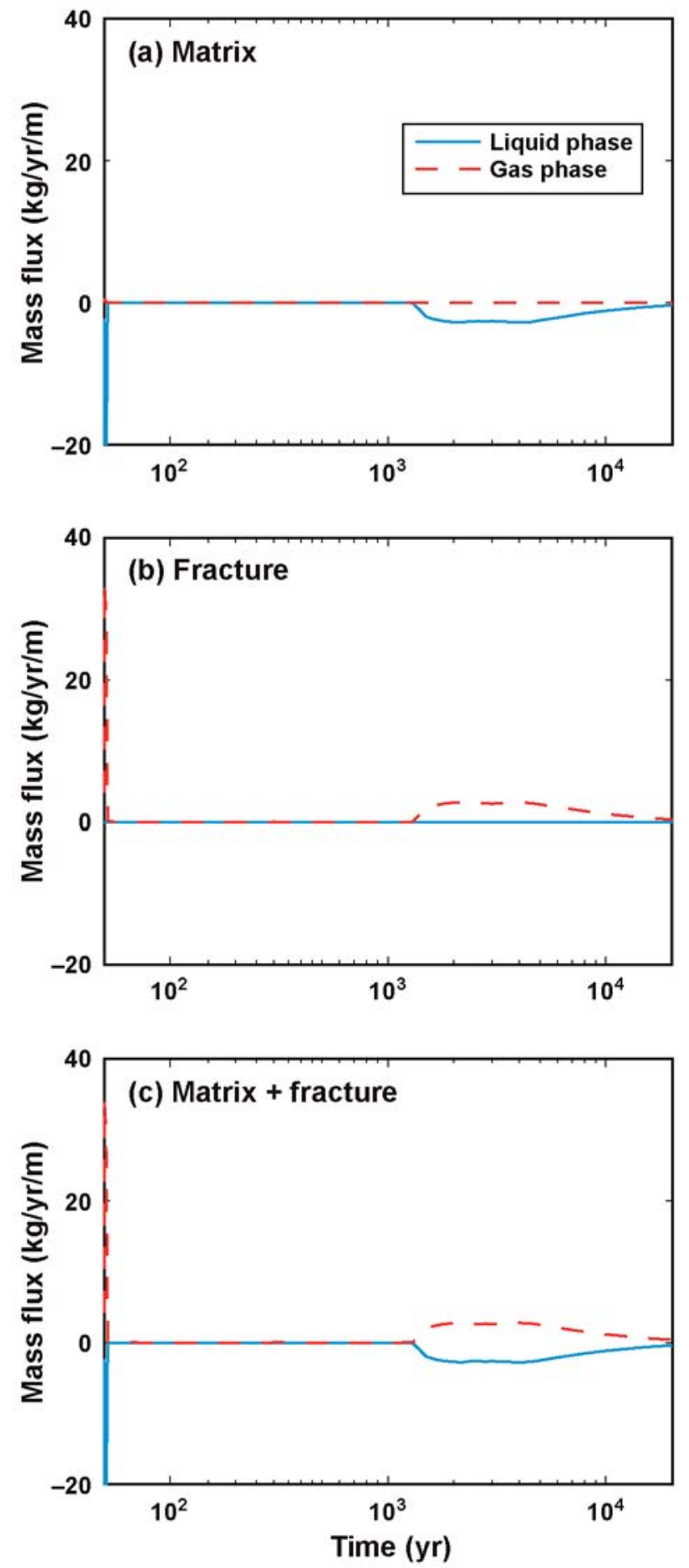

P2WR5C10_inv-inv_flux2_1

Source: See Table XIII-1.

NOTE: See Figure 6.3-1 for location. A positive value of mass flux corresponds to vertically downward flow. These fluxes are the result of line-averaged heating conditions.

Figure 6.3-42. Liquid-Phase and Gas-Phase Flux Between the Upper and Lower Half of the Invert Plotted for the (a) Matrix, (b) Fracture, and (c) Matrix + Fracture Continuum at the P2WR5C10 Location in the Tptpll (tsw35) Unit 

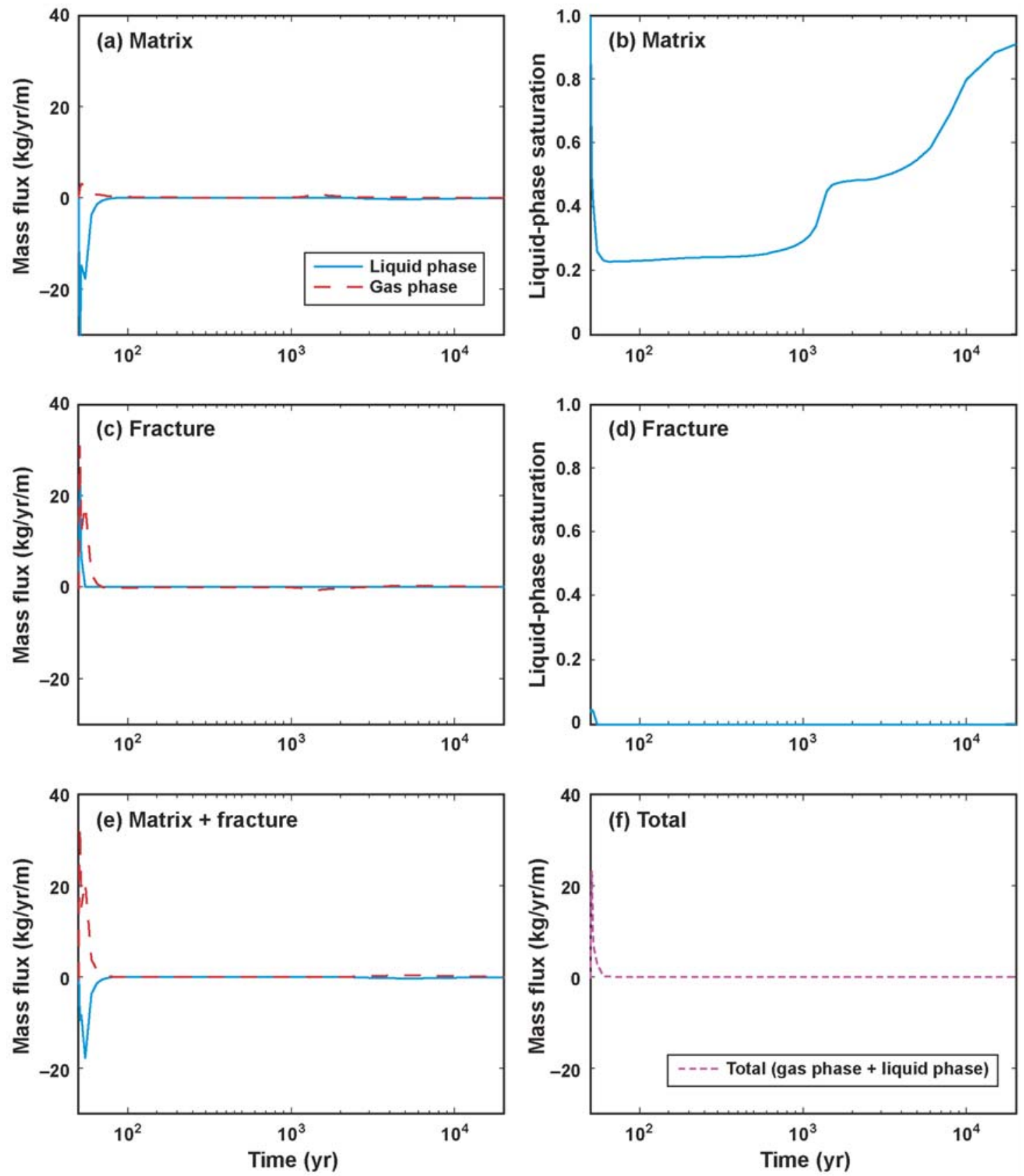

P3R8C13 inv-hostrock+drift flux3

Source: See Table XIII-1.

NOTE: $\quad$ See Figure 6.3-1 for location. Also plotted is (f) the total (gas-phase + liquid-phase) mass flux for the matrix + fracture continua. A positive value of mass flux corresponds to flux out of the invert. Liquidphase saturation for the (b) matrix and (d) fracture continuum is also plotted. These fluxes are the result of line-averaged heating conditions.

Figure 6.3-43. Liquid-Phase and Gas-Phase Flux Between the Invert and Adjoining Drift and Host Rock Plotted for the (a) Matrix, (c) Fracture, and (e) Matrix + Fracture Continuum at the P3R8C13 Location in the Tptpln (tsw36) Unit 

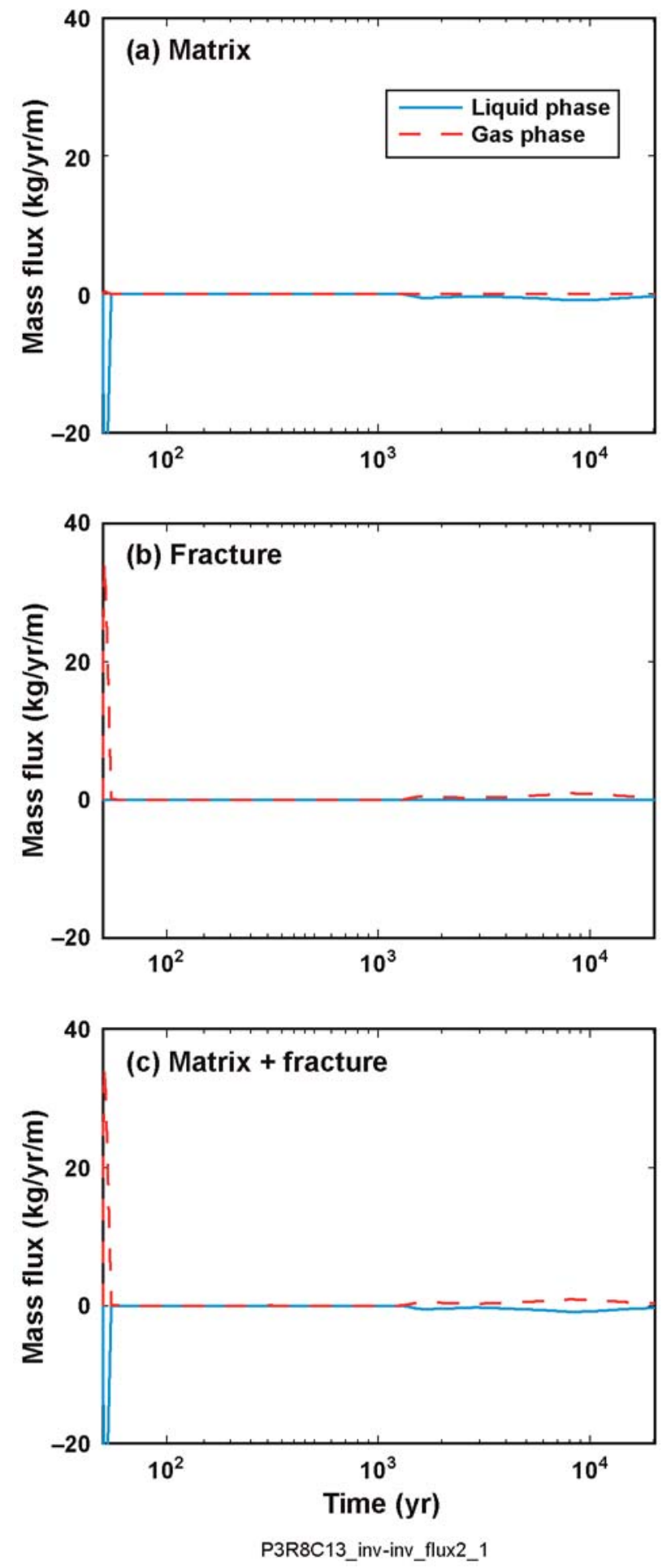

Source: See Table XIII-1.

NOTE: See Figure 6.3-1 for location. A positive value of mass flux corresponds to vertically downward flow. These fluxes are the result of line-averaged heating conditions.

Figure 6.3-44. Liquid-Phase and Gas-Phase Flux Between the Upper and Lower Half of the Invert Plotted for the (a) Matrix, (b) Fracture, and (c) Matrix + Fracture Continuum at the P3R8C13 Location in the Tptpln (tsw36) Unit 
Table 6.3-33. Peak Values of Liquid-Phase and Gas-Phase Flux for the Matrix and Fracture Continuum Given for $t>50$ Years at Two Different Interfaces

\begin{tabular}{|c|c|c|c|c|c|c|c|}
\hline \multirow{3}{*}{$\begin{array}{c}\text { LDTH } \\
\text { Submodel } \\
\text { Location } \\
\text { (Host-Rock } \\
\text { Unit) }\end{array}$} & \multirow[b]{3}{*}{ Interface } & \multicolumn{6}{|c|}{ Mass Flux (kg/yr/m) } \\
\hline & & \multicolumn{2}{|c|}{ Matrix } & \multicolumn{2}{|c|}{ Fracture } & \multicolumn{2}{|c|}{ Matrix + Fracture } \\
\hline & & $\begin{array}{l}\text { Liquid- } \\
\text { Phase }\end{array}$ & $\begin{array}{c}\text { Gas- } \\
\text { Phase }\end{array}$ & $\begin{array}{c}\text { Liquid- } \\
\text { Phase }\end{array}$ & $\begin{array}{l}\text { Gas- } \\
\text { Phase }\end{array}$ & $\begin{array}{c}\text { Liquid- } \\
\text { Phase }\end{array}$ & $\begin{array}{l}\text { Gas- } \\
\text { Phase }\end{array}$ \\
\hline \multirow{2}{*}{$\begin{array}{l}\text { P2ER8C6 } \\
\text { Tptpul } \\
\text { (tsw33) }\end{array}$} & $\begin{array}{l}\text { Invert to drift } \\
+ \text { host rock }\end{array}$ & -74.18 & 5.57 & 49.92 & 48.95 & -37.15 & 53.73 \\
\hline & $\begin{array}{l}\text { Upper to } \\
\text { lower invert }\end{array}$ & -40.77 & 0.33 & 0.00 & 47.96 & -40.77 & 48.29 \\
\hline \multirow{2}{*}{$\begin{array}{l}\text { P2WR8C8 } \\
\text { Tptpmn } \\
\text { (tsw34) }\end{array}$} & $\begin{array}{l}\text { Invert to drift } \\
+ \text { host rock }\end{array}$ & -27.25 & 3.25 & 27.29 & 23.19 & -14.11 & 25.36 \\
\hline & $\begin{array}{l}\text { Upper to } \\
\text { lower invert }\end{array}$ & -35.06 & 0.40 & 0.00 & 35.02 & -35.06 & 35.41 \\
\hline \multirow{2}{*}{$\begin{array}{l}\text { P2WR5C10 } \\
\text { Tptpll } \\
\text { (tsw33) }\end{array}$} & $\begin{array}{l}\text { Invert to drift } \\
+ \text { host rock }\end{array}$ & -28.07 & 4.47 & 3.93 & 30.57 & -28.07 & 33.09 \\
\hline & $\begin{array}{l}\text { Upper to } \\
\text { lower invert }\end{array}$ & -30.05 & 0.46 & 0.00 & 33.94 & -30.05 & 34.41 \\
\hline \multirow{2}{*}{$\begin{array}{l}\text { P3R8C13 } \\
\text { Tptpln } \\
\text { (tsw36) }\end{array}$} & $\begin{array}{l}\text { Invert to drift } \\
+ \text { host rock }\end{array}$ & -34.31 & 3.09 & 24.78 & 30.87 & -17.77 & 32.92 \\
\hline & $\begin{array}{l}\text { Upper to } \\
\text { lower invert }\end{array}$ & -34.66 & 0.42 & 0.00 & 34.42 & -34.66 & 34.84 \\
\hline
\end{tabular}

NOTE: Values are given for $t>50$ years at two different interfaces, including (1) between the invert and the adjoining drift and host rock and (2) between the upper and lower halves of the invert. The mass fluxes are given for four typical locations in the repository. These fluxes, which are the result of line-averaged heating conditions, are given in $\mathrm{kg} / \mathrm{yr}$ per meter of drift. Because peak mass fluxes can occur at different times for the matrix and fracture, the sum of the peak matrix and fracture fluxes may not be equal to the peak matrix + fracture flux. These values are based on data plotted in Figures 6.3-37, 6.3-39, 6.3-41 and 6.3-43. 
Table 6.3-34. Peak Values of Liquid-Phase and Gas-Phase Flux for the Matrix and Fracture Continuum Given for $t>100$ Years at Two Different Interfaces

\begin{tabular}{|l|l|l|l|l|l|l|l|}
\hline \multirow{2}{*}{$\begin{array}{c}\text { LDTH } \\
\text { Submodel } \\
\text { Location } \\
\text { (Host-Rock } \\
\text { Unit) }\end{array}$} & \multicolumn{6}{|c|}{\begin{tabular}{c} 
Mass Flux (kg/yr/m) \\
\cline { 3 - 8 }
\end{tabular}} & \multicolumn{2}{|c|}{ Interface } & $\begin{array}{c}\text { Liquid- } \\
\text { Phase }\end{array}$ & $\begin{array}{c}\text { Gas- } \\
\text { Phase }\end{array}$ & $\begin{array}{c}\text { Liquid- } \\
\text { Phase }\end{array}$ & $\begin{array}{c}\text { Gas- } \\
\text { Phase }\end{array}$ & $\begin{array}{c}\text { Liquid- } \\
\text { Phase }\end{array}$ & $\begin{array}{c}\text { Gas- } \\
\text { Phase }\end{array}$ \\
\cline { 3 - 8 } & $\begin{array}{l}\text { Invert to drift + } \\
\text { P2ER8C6 } \\
\text { Tptpul } \\
\text { (tsw33) }\end{array}$ & -8.04 & 0.88 & 1.39 & 7.08 & -7.97 & 7.91 \\
\cline { 2 - 8 } & $\begin{array}{l}\text { Upper to lower } \\
\text { invert }\end{array}$ & -8.34 & 0.04 & 0.00 & 8.30 & -8.34 & 8.33 \\
\hline \multirow{2}{*}{$\begin{array}{l}\text { P2WR8C8 } \\
\text { Tptpmn } \\
\text { (tsw34) }\end{array}$} & $\begin{array}{l}\text { Invert to drift + } \\
\text { host rock }\end{array}$ & -0.18 & 0.76 & 0.00 & -0.79 & -0.18 & 0.18 \\
\cline { 2 - 8 } & $\begin{array}{l}\text { Upper to lower } \\
\text { invert }\end{array}$ & -1.89 & -0.03 & 0.00 & 1.89 & -1.89 & 1.89 \\
\hline \multirow{2}{*}{$\begin{array}{l}\text { P2WR5C10 } \\
\text { Tptpll } \\
\text { (tsw33) }\end{array}$} & $\begin{array}{l}\text { Invert to drift + } \\
\text { host rock }\end{array}$ & -1.87 & 0.62 & 0.02 & 1.42 & -1.87 & 1.84 \\
\cline { 2 - 8 } & $\begin{array}{l}\text { Upper to lower } \\
\text { invert }\end{array}$ & -2.77 & 0.03 & 0.00 & 2.75 & -2.77 & 2.77 \\
\hline \multirow{2}{*}{$\begin{array}{l}\text { P3R8C13 } \\
\text { Tptpln } \\
\text { (tsw36) }\end{array}$} & $\begin{array}{l}\text { Invert to drift + } \\
\text { host rock }\end{array}$ & -0.31 & 0.66 & 0.00 & -0.69 & -0.31 & 0.31 \\
\cline { 2 - 8 } & $\begin{array}{l}\text { Upper to lower } \\
\text { invert }\end{array}$ & -0.91 & 0.02 & 0.00 & 0.90 & -0.91 & 0.91 \\
\hline
\end{tabular}

NOTE: $\quad$ Values are given for $t>100$ years at two different interfaces, including (1) between the invert and the adjoining drift and host rock and (2) between the upper and lower halves of the invert. The mass fluxes are given for four typical locations in the repository. These fluxes, which are the result of line-averaged heating conditions, are given in $\mathrm{kg} / \mathrm{yr}$ per meter of drift. Because the peak mass fluxes can occur at different times for the matrix and fracture, the sum of the peak matrix and fracture fluxes may not be equal to the peak matrix + fracture flux. These values are based on data plotted in Figures 6.3-37, 6.3-39, 6.3-41 and 6.3-43. 

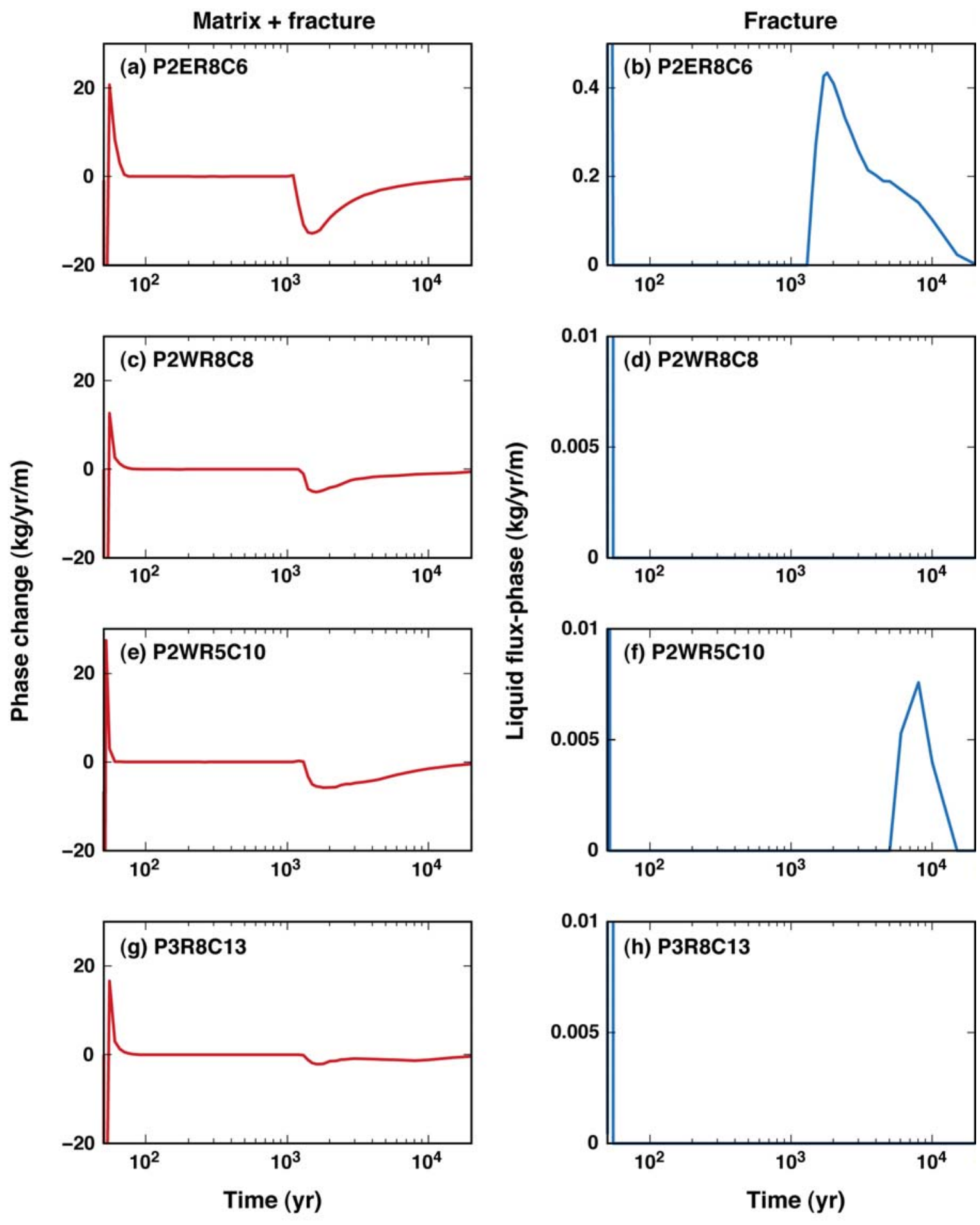

Source: See Table XIII-1.

NOTE: $\quad$ The locations (P2ER8C6, P2WR8C8, P2WR5C10, and P3R8C13) are shown in Figure 6.3-1. Positive values of phase change correspond to evaporation, while negative values correspond to condensation.

Figure 6.3-45. Phase Change (a, c, e, and g) in the Matrix and Fracture Continuum and Liquid-Phase Flux (b, d, f, h) in the Fracture Continuum Plotted for the Lower Two Gridblocks in the Invert at Four Locations in the Repository 
As discussed above, during the rewetting period the return capillary-driven liquid-phase flux (in the matrix continuum) is greater than the outward gas-phase flux of water vapor (in the matrix and fracture continuum) leaving the invert. The total (or net) mass flux of water (liquid-phase plus gas-phase) is plotted in Figures 6.3-37f, 6.3-39f, 6.3-41f, and 6.3-43f. During the rewetting period, the magnitude of this net mass flux is a small negative value (which is too small to be readily apparent in these figures), indicating that mass is returning to the invert. To clearly demonstrate that water is returning to the invert during the rewetting period, and that a mass balance of water is achieved in the invert, the net accumulated mass flux of water out of the invert is plotted in Figures 6.3-46 through 6.3-49; these figures also plot the liquid-phase saturation history in the invert. Note that this rewetting process occurs over a very long period, while the initial dryout process occurred over a very short period at the beginning of the postclosure period $(t>50 \mathrm{yr})$. Note also that all time histories are plotted with a logarithmic time scale. During the initial dryout period, the liquid-phase saturation (very quickly) reaches its minimum value just as the net accumulated mass flux out of the invert has reached its maximum value. During the sustained dryout period, the liquid-phase saturation in the invert remains nearly constant, just as the net accumulated mass flux out of the invert remains nearly constant. During the rewetting period, the liquid-phase saturation in the invert gradually rises, just as the net accumulated mass flux out of the invert gradually declines. 

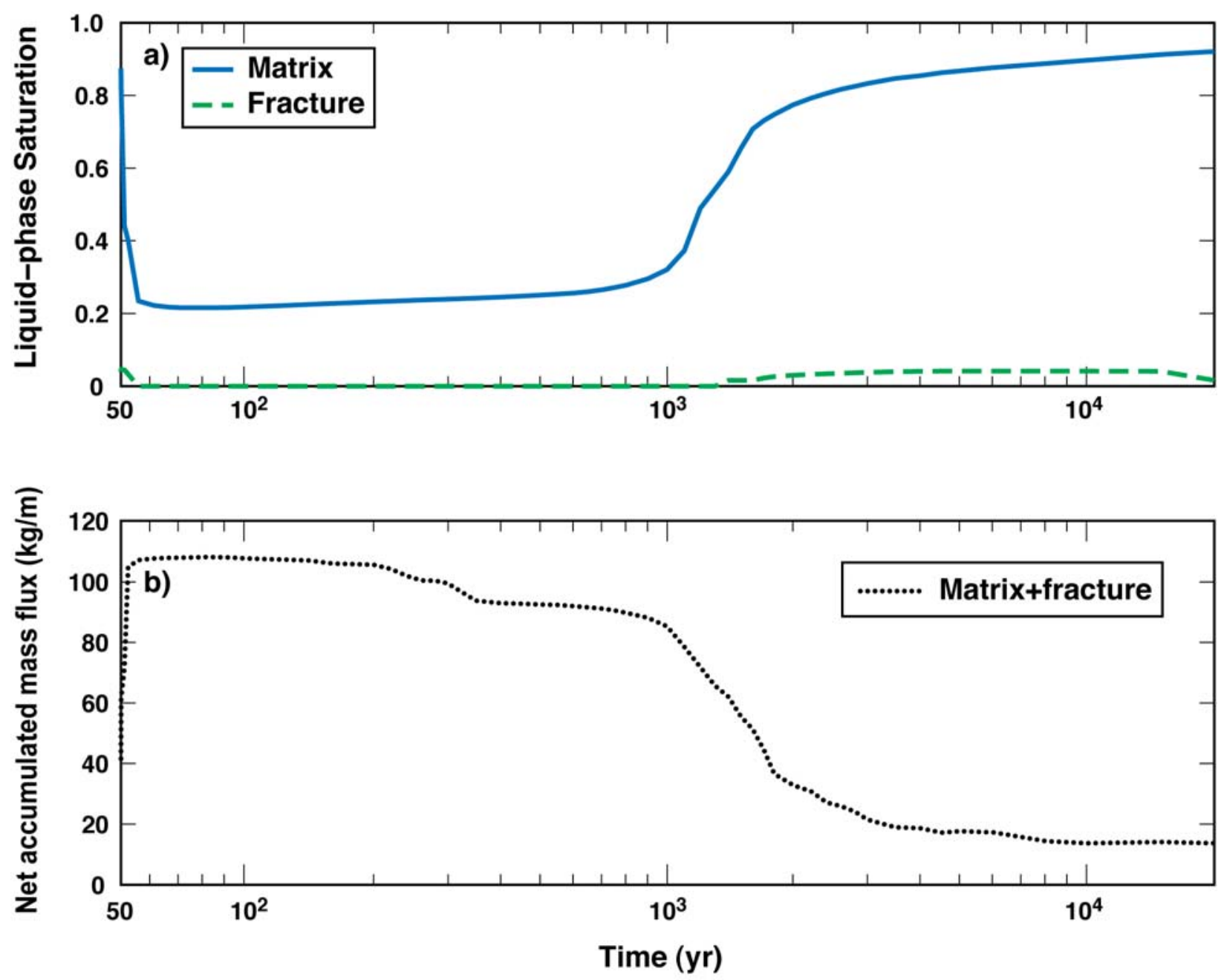

Source: See Table XIII-1.

NOTE: See Figure 6.3-1 for location. Increasing net accumulated mass flux indicates drying, while decreasing net accumulated mass flux indicates rewetting.

Figure 6.3-46. Mass Balance in the Invert Shown by Plotting (a) Liquid-Phase Saturation in the Fracture and Matrix Continuum in the Invert and (b) the Net Accumulated Mass Flux out of the Invert at the P2ER8C6 Location in the Tptpul (tsw33) Unit 

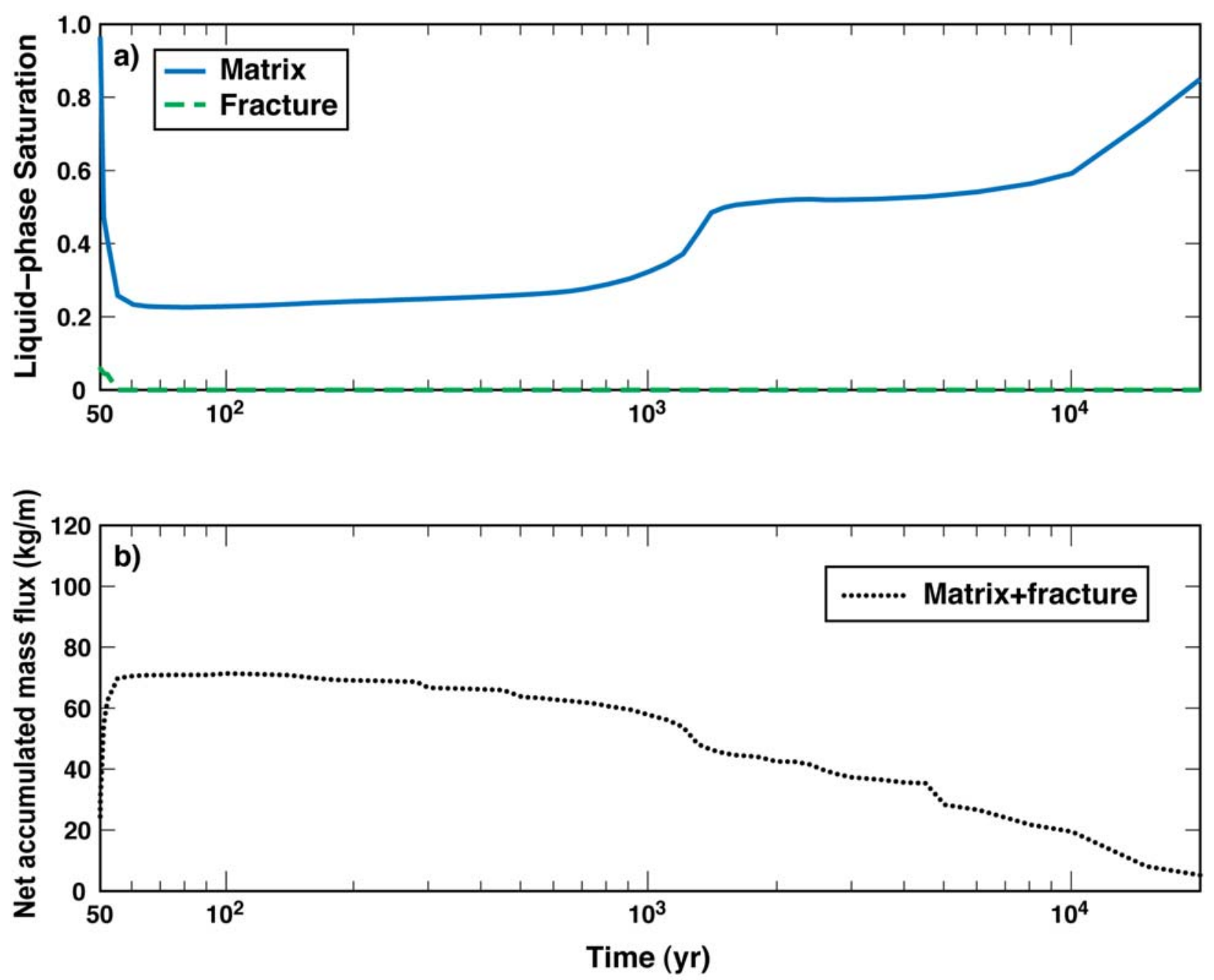

P2WR8C8-accumulatedFlux.tif

Source: See Table XIII-1.

NOTE: $\quad$ See Figure 6.3-1 for location. Increasing net accumulated mass flux indicates drying, while decreasing net accumulated mass flux indicates rewetting.

Figure 6.3-47. Mass Balance in the Invert Shown by Plotting (a) Liquid-Phase Saturation in the Fracture and Matrix Continuum in the Invert and (b) the Net Accumulated Mass Flux out of the Invert at the P2WR8C8 Location in the Tptpmn (tsw34) Unit 

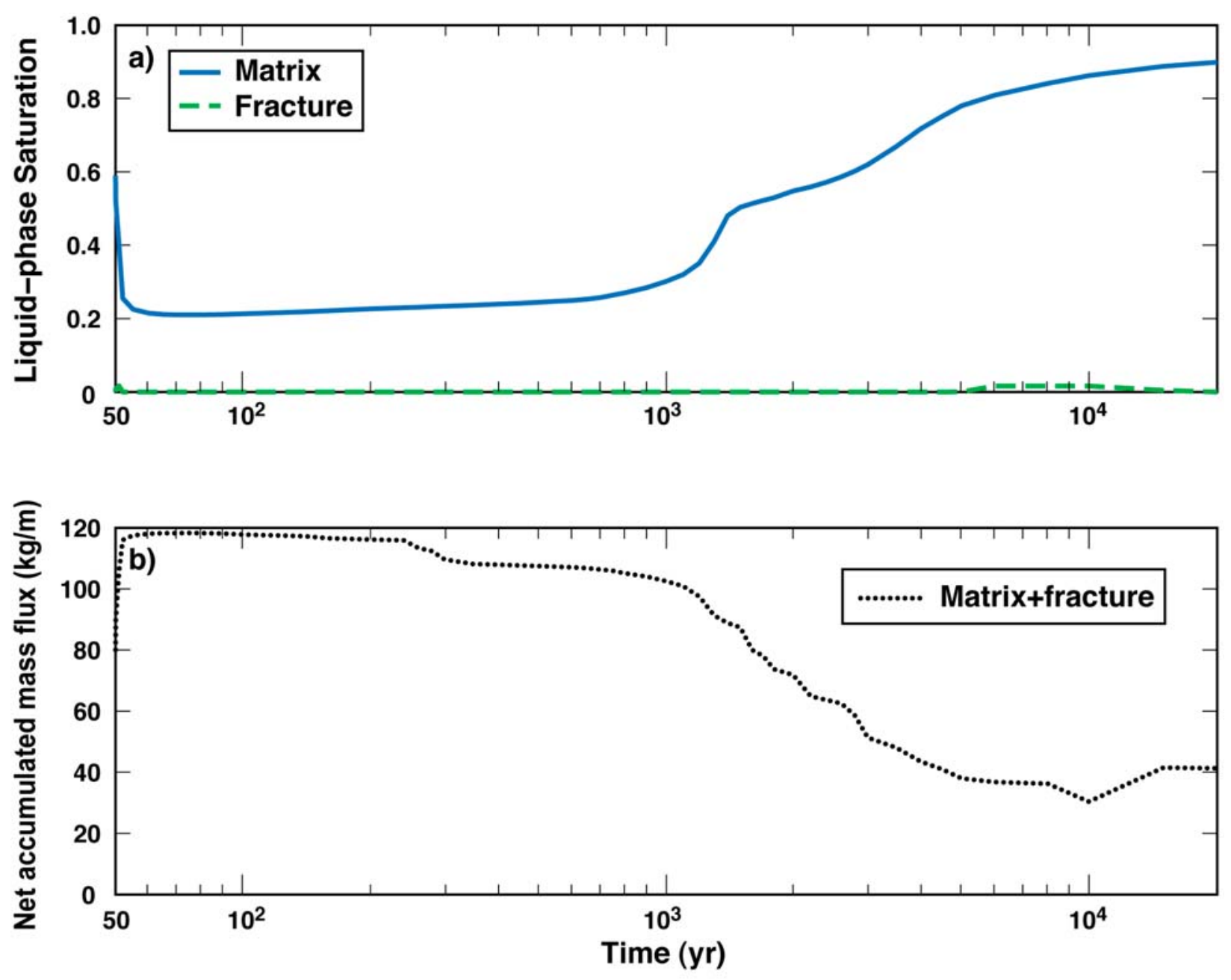

Source: See Table XIII-1.

NOTE: See Figure 6.3-1 for location. Increasing net accumulated mass flux indicates drying, while decreasing net accumulated mass flux indicates rewetting.

Figure 6.3-48. Mass Balance in the Invert Shown by Plotting (a) Liquid-Phase Saturation in the Fracture and Matrix Continuum in the Invert and (b) the Net Accumulated Mass Flux out of the Invert at the P2WR5C10 Location in the Tptpll (tsw35) Unit 

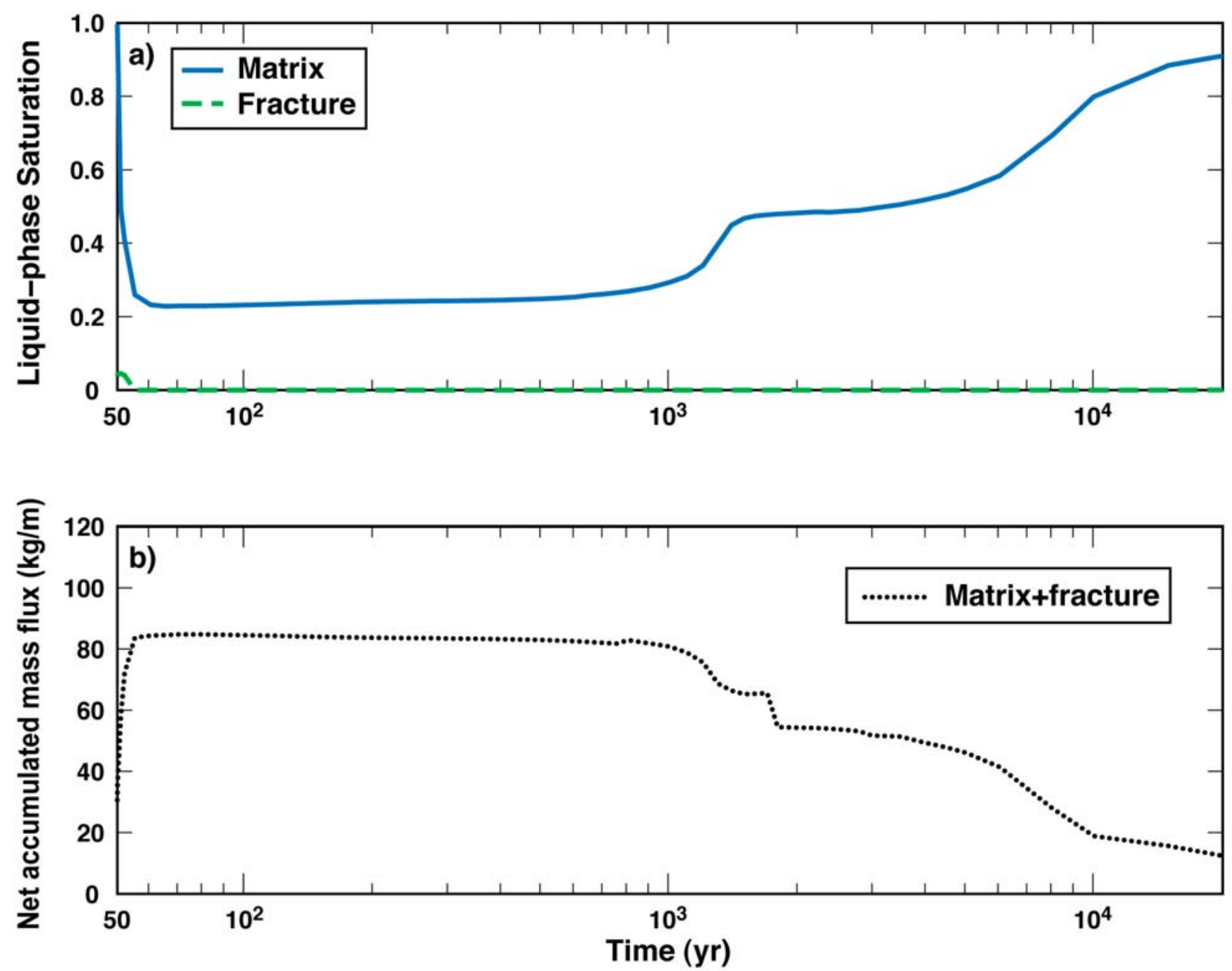

P3R8C13-accumulatedFlux.tif

Source: See Table XIII-1.

NOTE: $\quad$ See Figure 6.3-1 for location. Increasing net accumulated mass flux indicates drying, while decreasing net accumulated mass flux indicates rewetting.

Figure 6.3-49. Mass Balance in the Invert Shown by Plotting (a) Liquid-Phase Saturation in the Fracture and Matrix Continuum in the Invert and (b) the Net Accumulated Mass Flux out of the Invert at the P3R8C13 Location in the Tptpln (tsw36) Unit

\subsubsection{Combined Influences of Percolation-Flux and Host-Rock Thermal Conductivity Uncertainty on the TSPA-LA Base Case}

The purpose of this section is to combine the analyses discussed in Sections 6.3.1.1 and 6.3.2.2. Section 6.3.2.2 describes a sensitivity analysis of the influence of host-rock thermal conductivity uncertainty on thermal-hydrologic behavior in the repository. The analysis in Section 6.3.2.2 was conducted at four locations in the repository (Figure 6.3-1), which cover all four of the host-rock units (Table 6.3-3). This analysis does not explicitly address thermal-hydrologic behavior across the entire repository. These four repository locations (P2ER8C6, P2WR8C8, P2WR5C10, and P3R8C13) were selected because their respective values of percolation flux are relatively close to the repository-wide averages for the mean infiltration-flux case (Tables 6.3-4, 6.3-5, and 6.3-9). Section 6.3.1.1 describes the MSTHM TSPA-LA base-case calculations of the 
entire repository for the three infiltration-flux cases (lower, mean, and upper). Thus, Section 6.3.1.1 addresses the influence of percolation-flux uncertainty on the MSTHM TSPA-LA base-case calculations for the entire repository. The purpose of this subsection (Section 6.3.4) is to address the combined influences of percolation-flux and host-rock thermal conductivity uncertainty on the MSTHM TSPA-LA base-case calculations for the entire repository.

As discussed in Section 6.3.2, the two most significant sources of uncertainty for the output of the MSTHM are host-rock thermal conductivity and percolation flux. Percolation-flux uncertainty is addressed in Section 6.3.1.1 of this report with the use of the three infiltration-flux cases, which are called the lower-, mean, and upper-bound infiltration-flux cases (Table 6.3-4). The three cases in Section 6.3.1.1 use the mean thermal conductivity values (Table 6.3-23) for the four host-rock units (also called repository units), as well as for all of the non-repository units. The probabilities of the three infiltration-flux cases are provided in Table 6.3-35, which is based on Table 6.3-2 of Section 6.3.2 of Analysis of Infiltration Uncertainty (BSC 2003 [DIRS 165991]), excluding the contingency area. The sensitivity of thermohydrologic behavior to host-rock thermal conductivity uncertainty is addressed for approximately \pm 1 standard deviation about the mean values (Table 6.3-23).

Table 6.3-35. Probabilities of the Three Infiltration-Flux Cases

\begin{tabular}{|l|l|}
\hline Infiltration-Flux Case & \multicolumn{1}{|c|}{ Probability } \\
\hline Lower & 0.24 \\
\hline Mean & 0.41 \\
\hline Upper & 0.35 \\
\hline Total & 1.00 \\
\hline
\end{tabular}

Source: Table 6.3-2 of BSC 2003 [DIRS 165991].

The three host-rock thermal conductivity cases, which are called the low-, mean, and highthermal conductivity cases, are used to address parametric uncertainty. The guidelines for TSPA-LA define certain types of uncertainty (BSC 2002 [DIRS 158794], Section 4.1). Variability, also referred to as aleatory uncertainty, arises due to natural randomness or heterogeneity. This first type of uncertainty cannot be reduced through further testing and data collection; it can only be better characterized. Thus, aleatory uncertainty is also referred to as irreducible uncertainty. The second type of uncertainty, which is referred to as epistemic uncertainty, arises from lack of knowledge about a parameter because the data are limited or there are alternative interpretations of the available data. This second type of uncertainty is also called reducible uncertainty because the state of knowledge can be improved with further testing or data collection.

Section 6.2.4 describes the manner in which the MSTHM combines the results from the four submodel types. The SMT submodel (Section 6.2.5) is used to determine the repository-scale variations in host-rock temperature as affected by the mountain-scale thermal-property distribution, the overburden-thickness distribution, and the edge-cooling effect, which is strongly affected by the overall shape of the repository area. The LDTH submodels (Section 6.2.6) are used to determine the influence of local conditions on thermal-hydrologic behavior, including percolation flux and the thermal and hydrologic properties of the local host-rock unit. Percolation-flux uncertainty is incorporated in only the LDTH submodels. In the same fashion, 
host-rock thermal conductivity uncertainty is also incorporated in only the LDTH submodels. The SMT submodel does not incorporate host-rock thermal conductivity uncertainty because it would only potentially influence the rate at which the edge-cooling effect propagates from the edges towards the central region of the repository. At the scale at which the edge-cooling effect propagates, the natural randomness of host-rock thermal conductivity distribution tends to average out, allowing, in effect, the mean thermal conductivity values to control the rate at which the edge-cooling effective propagates in those respective units. Note that for the low-thermal conductivity case, $K_{\text {th }}$ is equal to the mean minus one standard deviation for all of the host-rock units. Similarly, for the high-thermal conductivity case, $K_{\text {th }}$ is equal to the mean plus one standard deviation for all of the host-rock units: (1) Tptpul (tsw33), (2) Tptpmn (tsw34), (3) Tptpll (tsw35), and (4) Tptpln (tsw36 and tsw37).

In Thermal Conductivity of the Potential Repository Horizon (BSC 2004 [DIRS 169854]), fifty equally likely sets of three-dimensional thermal conductivity fields (or realizations) are generated for the four host-rock units. Each field has a mean thermal conductivity, $\mu_{\mathrm{ij}}$, and a standard deviation, $\sigma_{\mathrm{ij}}$, for local variability in thermal conductivity (e.g., see Figure 6-31 of BSC 2004 [DIRS 169854]), where $i=1,2,3,4$ corresponds to the four host-rock units and $j=1,2, \ldots$, 50 corresponds to the fifty fields (or realizations). Values for

$$
\mu_{i}=\frac{1}{50} \sum_{j=1}^{50} \mu_{i j}
$$

and

$$
\sigma_{i}=\frac{\sigma_{i, 15}+\sigma_{i, 30}+\sigma_{i, 45}}{3}
$$

are reported in Table 7-10 of DTN: SN0404T0503102.011 [DIRS 169129] (File: readme.doc). The quantity $\sigma_{\mathrm{i}}$ is a reasonable estimator of drift-scale variability and uncertainty, and is appropriate for use in the LDTH submodels.

Calculations performed using $\mu_{\mathrm{i}}-\sigma_{\mathrm{i}}, \mu_{\mathrm{i}}$, and $\mu_{\mathrm{i}}+\sigma_{\mathrm{i}}$ (Table 6.3-20) raise the question concerning how much weight (i.e., probability in the epistemic sense) should be applied to these three hostrock thermal conductivity cases. Probability distributions for $\mu_{\mathrm{ij}}$ for the fifty fields are presented in Thermal Conductivity of the Potential Repository Horizon (e.g., see lower right plot in Figure 6-31 of BSC 2004 [DIRS 169854]). These distributions are very narrow, with $\mu_{\mathrm{i}} \pm \sigma_{\mathrm{i}}$ tending to be close to the extremes of the presented distributions. As presented by Thermal Conductivity of the Potential Repository Horizon (BSC 2004 [DIRS 169854]), the distributions for $\mu_{\mathrm{i}}$, probably underestimate the uncertainty in $\mu_{\mathrm{i}}$ (i.e., the value for a single effective thermal conductivity to be used over an entire host-rock unit) because they are based only on the fifty fields generated without including potential epistemic uncertainties, such as (1) those associated with the quality of the observational data underlying the generation of the fields, (2) those associated with the model used in determining thermal conductivity values, and (3) the appropriateness of the geostatistical model used in the generation of the thermal conductivity fields. 
Therefore, neither $\mu_{\mathrm{i}}-\sigma_{\mathrm{i}}$ nor $\mu_{\mathrm{i}}+\sigma_{\mathrm{i}}$ represents extreme or unlikely values for the appropriate effective (i.e., spatially averaged) thermal conductivity values to be applied to the respective host-rock units in the LDTH submodels. Furthermore, neither $\mu_{\mathrm{i}}-\sigma_{\mathrm{i}}$ nor $\mu_{\mathrm{i}}+\sigma_{\mathrm{i}}$ is more or less likely than $\mu_{\mathrm{i}}$ to be the appropriate value to be applied for effective thermal conductivity in the host-rock units in the LDTH submodels. As a result of this argument, each alternative $\left(\mu_{\mathrm{i}}-\sigma_{\mathrm{i}}\right.$, $\mu_{\mathrm{i}}$, and $\mu_{\mathrm{i}}+\sigma_{\mathrm{i}}$ ) can be assigned the same probability (i.e., one in three), which is shown in Table 6.3-36.

Combining the probabilities of the three infiltration-flux cases (Table 6.3-35) and the equal (one in three) probabilities of the three host-rock thermal conductivity cases results in a three-by-three matrix of nine percolation-flux host-rock thermal conductivity cases provided in Table 6.3-36. Repository-wide MSTHM calculations were conducted for five of these nine cases, including the three infiltration-flux cases conducted with the mean thermal conductivity values (Section 6.3.1.1), as well as the two cases with the extreme combinations of percolation flux and host-rock thermal conductivity: (1) the lower-bound infiltration-flux, low host-rock thermal conductivity case, and (2) the upper-bound infiltration-flux, high host-rock thermal conductivity case. The four cases for which repository-wide calculations were not conducted are shown in italics in Table 6.3-36.

Table 6.3-36. Probabilities of the Combinations of the Three Infiltration-Flux Cases and the Three Host-Rock Thermal Conductivity Cases

\begin{tabular}{|c|c|c|c|c|}
\hline \multirow[b]{3}{*}{ Infiltration-Flux Case } & \multicolumn{4}{|c|}{ Probability } \\
\hline & \multicolumn{4}{|c|}{ Host-Rock Thermal Conductivity Case } \\
\hline & All & $\begin{array}{c}\text { Low } \\
\text { (Mean - } 1 \text { SD) }\end{array}$ & Mean & $\begin{array}{c}\text { High } \\
\text { (Mean + 1 SD) } \\
\end{array}$ \\
\hline All & 1.0000 & 0.33333 & 0.33333 & 0.33333 \\
\hline Lower & 0.2400 & 0.08000 & 0.08000 & 0.08000 \\
\hline Mean & 0.4100 & 0.13667 & 0.13667 & 0.13667 \\
\hline Upper & 0.3500 & 0.11666 & 0.11666 & 0.11666 \\
\hline
\end{tabular}

Figure 6.3-50 outlines how the four cases for which repository-wide MSTHM calculations were not made (shown in italics in Table 6.3-36) are addressed by the other five cases. First, as was shown in Sections 6.3.2.1 and 6.3.2.2, low percolation flux and low host-rock thermal conductivity affect thermal-hydrologic behavior in a similar fashion, which is to create hotter drier conditions in the adjoining host rock, and high percolation flux and high host-rock thermal conductivity affect thermal-hydrologic behavior similarly, by creating cooler, less dry conditions in the adjoining host rock. Accordingly, there are two cases for which percolation flux and hostrock thermal conductivity have opposing effects: (1) the lower-bound infiltration-flux case with high host-rock thermal conductivity and (2) the upper-bound infiltration-flux case with low host-rock thermal conductivity. For both of these cases, the effects of percolation flux and host-rock thermal conductivity tend to be mutually canceling and the net effect is equivalent to having the mean infiltration-flux case with mean host-rock thermal conductivity. These two cases appear in the upper right and lower left corners of Figure 6.3-50. The arrows from the upper right and lower left corners that point to the center of Figure 6.3-50 are depicting how the mean infiltration-flux case with mean host-rock thermal conductivity is the "surrogate" case for these two "corner" cases. Thus, the probabilities (Table 6.3-36) for the lower-bound 
infiltration-flux case with high host-rock thermal conductivity (0.08000) and for the upper-bound infiltration flux with low thermal conductivity (0.11666) are added to that of the mean infiltration-flux case with mean host-rock thermal conductivity (0.13667), resulting in a combined probability of 0.33333 , as shown in Table 6.3-37.

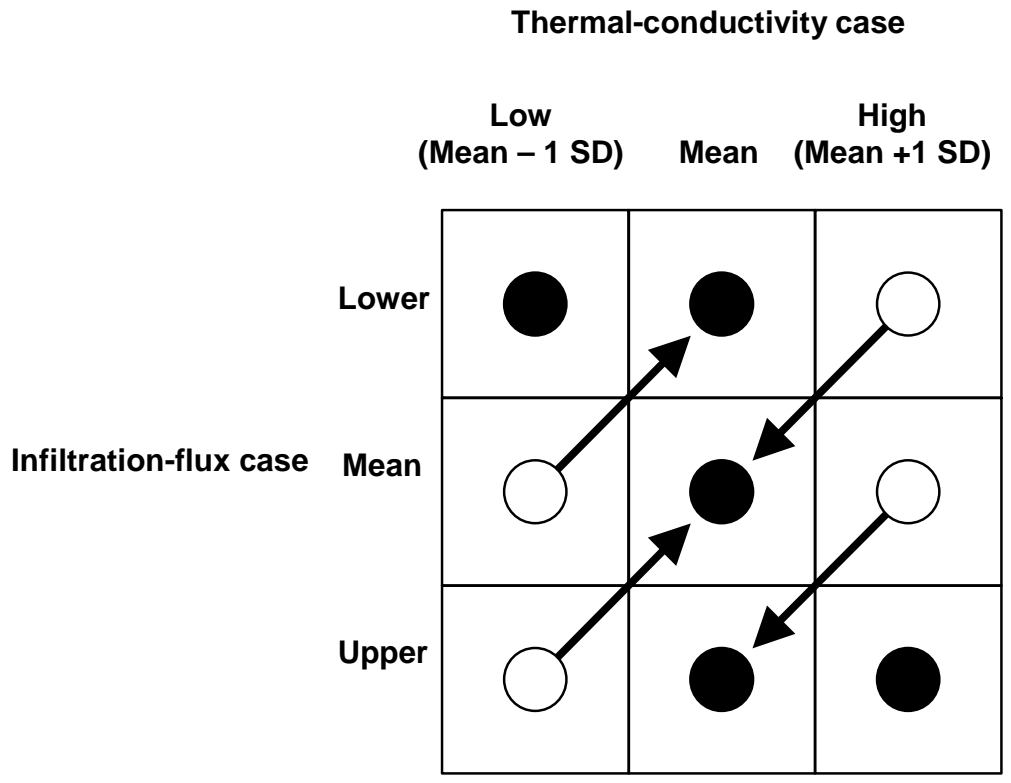

NOTES: The open circles correspond to the cases for which repository-wide MSTHM calculations were not conducted. The filled circles correspond to the cases for which repository-wide MSTHM calculations have been conducted.

Figure 6.3-50. Regrouping of the Three-by-Three Matrix of Infiltration Flux and Host-Rock Thermal Conductivity Cases

Table 6.3-37. Probabilities of the Combinations of the Three Infiltration-Flux Cases and the Three Host-Rock Thermal Conductivity Cases after the Regrouping Shown in Figure 6.3-50

\begin{tabular}{|l|c|c|c|c|}
\hline \multirow{2}{*}{\begin{tabular}{c}
\multirow{2}{*}{$\begin{array}{c}\text { Infiltration-Flux } \\
\text { Case }\end{array}$} \\
\cline { 2 - 5 }
\end{tabular}} & \multicolumn{4}{|c|}{ Host-Rock Thermal Conductivity Case } \\
\cline { 2 - 5 } & All & $\begin{array}{c}\text { Low } \\
\text { (Mean - 1 SD) }\end{array}$ & Mean & $\begin{array}{c}\text { High } \\
\text { (Mean + 1 SD) }\end{array}$ \\
\hline All & 1.0000 & 0.33333 & 0.33333 & 0.33333 \\
\hline Lower & 0.2400 & 0.08000 & 0.21667 & \\
\hline Mean & 0.4100 & & 0.33333 & \\
\hline Upper & 0.3500 & & 0.25334 & 0.11666 \\
\hline
\end{tabular}

NOTE: SD stands for standard deviation.

As discussed above, low percolation flux and low host-rock thermal conductivity affect thermal-hydrologic behavior in a similar fashion, which is to promote hotter drier conditions in the adjoining host rock. Accordingly, the lower-bound infiltration-flux case with mean host-rock thermal conductivity is the "surrogate" case for the mean infiltration-flux case with low hostrock thermal conductivity. This substitution is depicted in Figure 6.3-50 by the arrow pointing from the left column in the middle row to the middle column in the upper row. Thus, the probability (Table 6.3-36) for the mean infiltration-flux case with low host-rock thermal conductivity (0.13667) is added to that of the lower-bound infiltration-flux case with mean host- 
rock thermal conductivity $(0.08000)$, resulting in a combined probability of 0.21667 , as shown in Table 6.3-37.

As discussed above, high percolation flux and high host-rock thermal conductivity affect thermal-hydrologic behavior in a similar fashion, which is to promote cooler, less dry conditions in the adjoining host rock. Accordingly, the upper-bound infiltration-flux case with mean host-rock thermal conductivity is the "surrogate" case for the mean infiltration-flux case with high host-rock thermal conductivity. This substitution is depicted in Figure 6.3-50 by the arrow pointing from the right column in the middle row to the middle column in the lower row. Thus, the probability (Table 6.3-36) for the mean infiltration-flux case with high host-rock thermal conductivity (0.13667) is added to that of the upper-bound infiltration-flux case with mean host-rock thermal conductivity (0.11666), resulting in a combined probability of 0.25334 , as shown in Table 6.3-37.

Figure 6.3-51 gives the complementary cumulative distribution function (CCDF) for the peak temperature on the drift wall and on waste packages for the five infiltration-flux/host-rock thermal conductivity cases; these CCDFs are for all waste packages over the entire repository area. Table 6.3-38 gives the coolest, median, and hottest peak drift-wall and waste package temperatures for these five cases. Because there are 2874 locations in the MSTHM (Table 6.2-1) and eight different waste packages that are represented at each location, there are a total of 22,992 waste package histories provided in each of the five cases for which repository-wide MSTHM calculations were conducted. For the upper-bound infiltration-flux case with high host-rock thermal conductivity, there are 22 waste package histories for which the peak drift-wall temperature is less than the boiling point $\left(96^{\circ} \mathrm{C}\right)$. These 22 histories represent 0.10 percent of the 22,992 histories in that case. Because that case has a probability of 0.11666 (Table 6.3-37), these 22 waste package histories are representative of only 0.01 percent of all waste packages in the repository. Thus, for a total of 11,184 waste packages in the repository (Table 4.1-2), there is a probability of 1.0 that a single waste package will never experience boiling at the drift wall. For the lower-bound infiltration-flux case with low host-rock thermal conductivity, there are 106 waste package histories for which the peak waste package temperature is greater than $200^{\circ} \mathrm{C}$. Because the probability of this case is 0.08000 , these 106 histories are representative of only 0.04 percent of all waste packages in the repository. Thus, for a total of 11,184 waste packages in the repository (Table 4.1-2), only four waste packages are predicted to have a peak temperature in excess of $200^{\circ} \mathrm{C}$. 

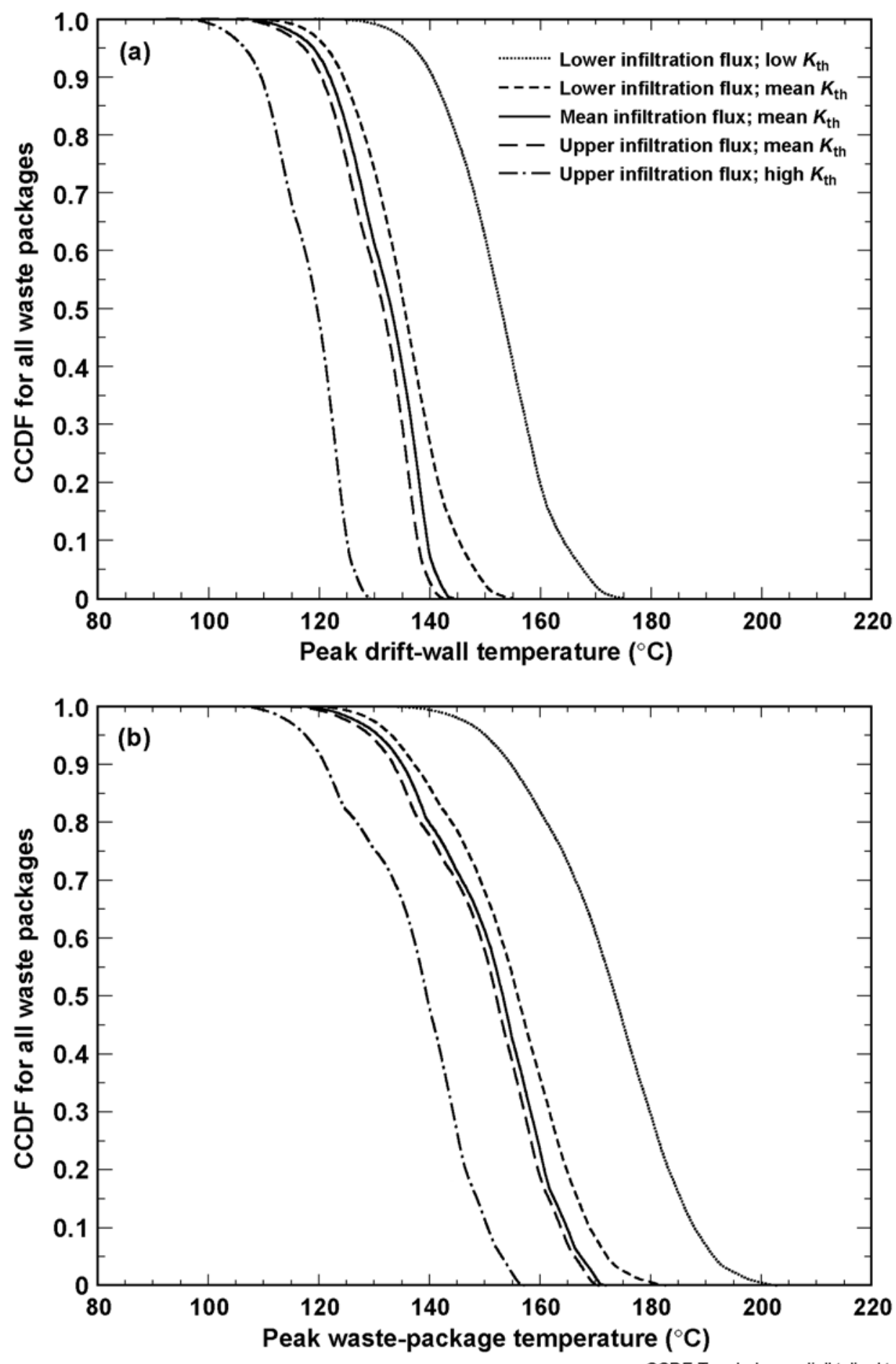

Source: See Table XIII-1.

NOTE: These five cases cover the range of percolation-flux and host-rock thermal conductivity uncertainty addressed in this report.

Figure 6.3-51. Complementary Cumulative Distribution Function (CCDF) for Peak Temperature on the (a) Drift Wall and on the (b) Waste Packages Plotted for Five Cases 
Table 6.3-38. Peak Drift-Wall and Waste Package Temperatures Summarized for Five Cases

\begin{tabular}{|c|c|c|c|c|c|c|}
\hline \multirow[b]{2}{*}{ Case } & \multicolumn{3}{|c|}{$\begin{array}{c}\text { Peak Drift-Wall Temperature } \\
\left({ }^{\circ} \mathrm{C}\right)\end{array}$} & \multicolumn{3}{|c|}{$\begin{array}{l}\text { Peak Waste Package Temperature } \\
\left({ }^{\circ} \mathrm{C}\right)\end{array}$} \\
\hline & Coolest & Median & Hottest & Coolest & Median & Hottest \\
\hline $\begin{array}{l}\text { Lower-bound infiltration-flux, } \\
\text { low thermal conductivity }\end{array}$ & 119.1 & 152.9 & 175.2 & 130.1 & 173.6 & 203.1 \\
\hline $\begin{array}{l}\text { Lower-bound infiltration-flux, } \\
\text { mean thermal conductivity }\end{array}$ & 105.7 & 135.4 & 154.8 & 116.3 & 156.0 & 182.9 \\
\hline $\begin{array}{l}\text { Mean infiltration-flux, mean } \\
\text { thermal conductivity }\end{array}$ & 105.0 & 133.0 & 144.2 & 115.6 & 153.3 & 172.0 \\
\hline $\begin{array}{l}\text { Upper-bound infiltration-flux, } \\
\text { mean thermal conductivity }\end{array}$ & 98.6 & 131.6 & 142.5 & 108.6 & 152.1 & 170.8 \\
\hline $\begin{array}{l}\text { Upper-bound infiltration-flux, } \\
\text { high thermal conductivity }\end{array}$ & 92.3 & 119.6 & 129.3 & 102.0 & 139.5 & 157.2 \\
\hline
\end{tabular}

NOTE: These cases cover the range of percolation-flux and host-rock thermal conductivity uncertainty addressed in this report. This table is based on Figure 6.3-51. These values are data plotted in Figure 6.3-51.

Figure 6.3-52a and Table 6.3-39 give the complementary cumulative distribution function (CCDF) for the time when boiling at the drift wall ceases for the five infiltration-flux host-rock thermal conductivity cases; these CCDFs are for all waste package locations throughout the repository area. As was the case for peak temperatures, the boiling period duration increases with decreasing percolation flux and with decreasing host-rock thermal conductivity. The median waste package experiences boiling at the drift wall for 721 years, and there is a broad range of duration of boiling at the drift wall. There is a probability of less than 1.0 that a single waste package will never experience boiling at the drift, while the waste package at the hottest, driest location in the repository may experience boiling at the drift wall for up to 2,176 years. Figure 6.3-52b and Table 6.3-40 provide the complementary cumulative distribution function (CCDF) for the maximum lateral extent of the boiling point isotherm for the five cases. As was the case for the peak temperatures and boiling period duration, the maximum lateral extent of boiling increases with decreasing percolation flux and with decreasing host-rock thermal conductivity. The median waste package has a maximum lateral extent of boiling of $7.9 \mathrm{~m}$, which is $5.15 \mathrm{~m}$ beyond the springline of the drift. There is a probability of less than 1.0 that a single waste package will never experience boiling in the host rock, while the waste package at the hottest, driest location in the repository may have a maximum lateral extent of boiling of 27.9 $\mathrm{m}$, which represents 69 percent of the lateral extent between the emplacement drift centerline and the midplane in the center of the rock pillar between drifts. For the lower-bound infiltration-flux, low host-rock-thermal conductivity case, 10 percent of the waste package histories have a maximum lateral extent of boiling that exceeds $19 \mathrm{~m}$. Because the probability of this case is 0.08000 (Table 6.3-37), this is representative of 0.8 percent of the waste packages in the repository. Thus, for a total of 11,184 waste packages in the repository (Table 4.1-2), 89 waste packages are expected to have a maximum lateral extent of boiling that exceeds $19 \mathrm{~m}$. 

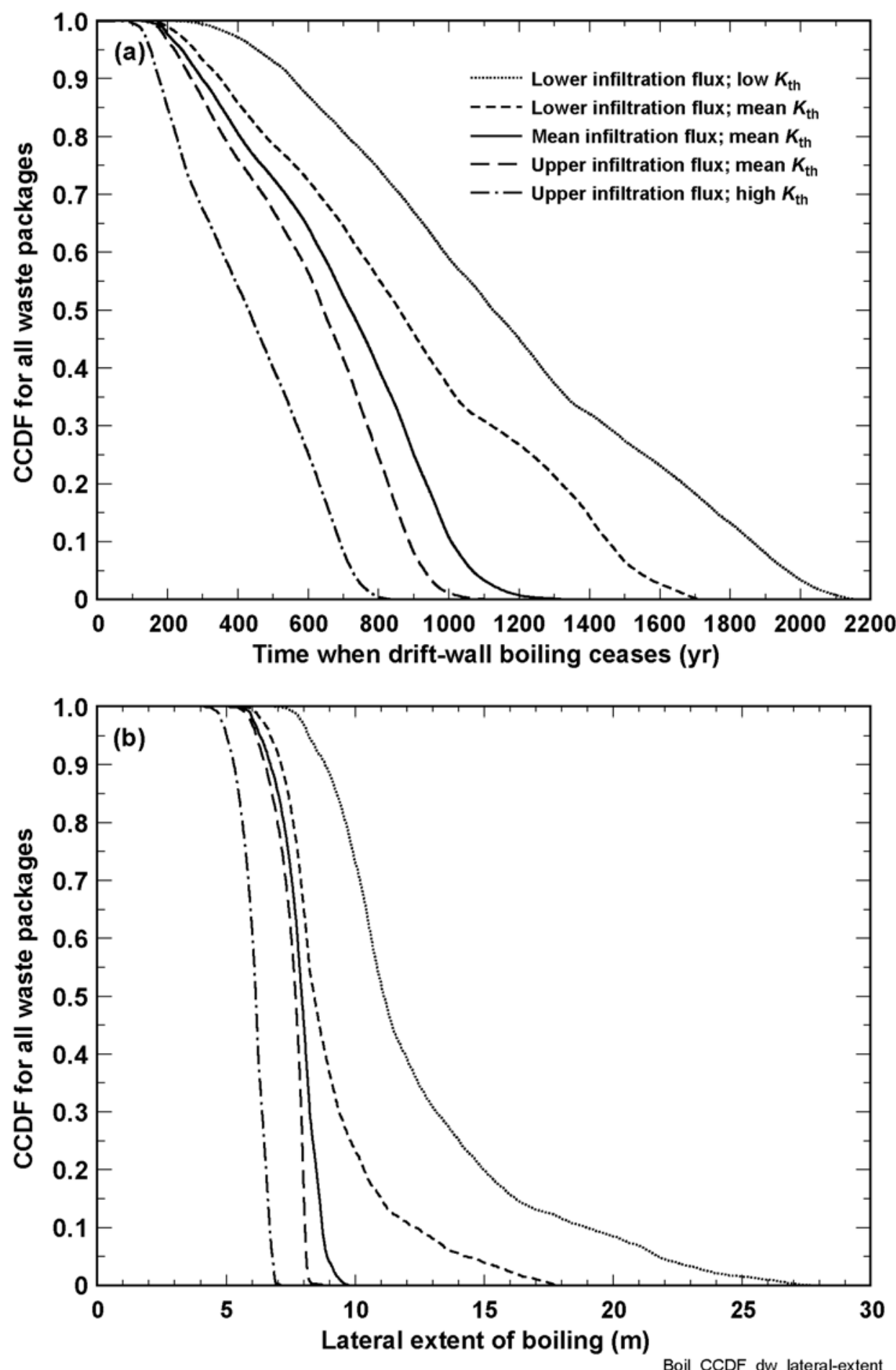

Source: See Table XIII-1.

NOTE: These five cases cover the range of percolation-flux and host-rock thermal conductivity uncertainty addressed in this report.

Figure 6.3-52. Complementary Cumulative Distribution Functions (CCDF) for (a) the Time When Boiling at the Drift Wall Ceases and (b) the Maximum Lateral Extent of the Boiling-Point Isotherm $\left(96^{\circ} \mathrm{C}\right)$ from the Drift Centerline, Plotted for Five Cases 
Table 6.3-39. Time When Boiling Ceases at the Drift Wall Summarized for Five Cases

\begin{tabular}{|l|c|c|c|c|c|c|c|}
\hline \multirow{2}{*}{$\begin{array}{l}\text { Infiltration-Flux, Host- } \\
\text { Rock Thermal } \\
\text { Conductivity Case }\end{array}$} & \multicolumn{7}{|c|}{ Time When Boiling at the Drift Wall Ceases } \\
(years) & Shortest & $\begin{array}{c}\mathbf{1 0} \\
\text { Percentile }\end{array}$ & $\begin{array}{c}\mathbf{3 0} \\
\text { Percentile }\end{array}$ & Median & $\begin{array}{c}\mathbf{7 0} \\
\text { Percentile }\end{array}$ & $\begin{array}{c}\text { 90 } \\
\text { Percentile }\end{array}$ & Longest \\
\hline $\begin{array}{l}\text { Lower-bound infiltration- } \\
\text { flux, low thermal } \\
\text { conductivity }\end{array}$ & 192.6 & 555.3 & 861.6 & 1125.4 & 1447.4 & 1862.7 & 2176.5 \\
\hline $\begin{array}{l}\text { Lower-bound infiltration- } \\
\text { flux, mean thermal } \\
\text { conductivity }\end{array}$ & 130.2 & 349.9 & 630.9 & 859.6 & 1122.5 & 1453.3 & 1734.6 \\
\hline $\begin{array}{l}\text { Mean infiltration-flux, } \\
\text { mean thermal conductivity }\end{array}$ & 127.2 & 297.5 & 535.8 & 721.0 & 870.6 & 1006.5 & 1356.0 \\
\hline $\begin{array}{l}\text { Upper-bound infiltration- } \\
\text { flux, mean thermal } \\
\text { conductivity }\end{array}$ & 97.7 & 267.7 & 471.6 & 643.7 & 768.6 & 887.2 & 1162.9 \\
\hline $\begin{array}{l}\text { Upper-bound infiltration- } \\
\text { flux, high thermal } \\
\text { conductivity }\end{array}$ & $\mathrm{NA}^{\mathrm{a}}$ & 175.7 & 281.6 & 430.4 & 568.9 & 689.5 & 859.5 \\
\hline
\end{tabular}

${ }^{\text {a }} 22$ out of 22,992 waste package/location combinations (or 0.1 percent of the total) never experience boiling at the drift wall.

NOTE: These cases cover the range of percolation-flux and host-rock thermal conductivity uncertainty addressed in this report. This table is based on data plotted in Figure 6.3-52a.

Table 6.3-40. Maximum Lateral Extent of the Boiling-Point Isotherm $\left(96^{\circ} \mathrm{C}\right)$ Measured from the Drift Centerline, Summarized for Five Cases

\begin{tabular}{|l|c|c|c|c|c|c|c|}
\hline \multirow{2}{*}{$\begin{array}{l}\text { Infiltration-Flux, Host- } \\
\text { Rock Thermal } \\
\text { Conductivity Case }\end{array}$} & \multicolumn{7}{|c|}{ Maximum Lateral Extent of Boiling $\left(\boldsymbol{T}>\mathbf{9 6} \mathbf{\circ}^{\circ} \mathbf{C}\right)$} \\
\cline { 2 - 8 } & Least & $\begin{array}{c}\mathbf{1 0} \\
\text { Percentile }\end{array}$ & $\begin{array}{c}\mathbf{3 0} \\
\text { Percentile }\end{array}$ & Median & $\begin{array}{c}\mathbf{7 0} \\
\text { Percentile }\end{array}$ & $\begin{array}{c}\mathbf{9 0} \\
\text { Percentile }\end{array}$ & Greatest \\
\hline $\begin{array}{l}\text { Lower-bound infiltration- } \\
\text { flux, low thermal } \\
\text { conductivity }\end{array}$ & 6.9 & 8.8 & 10.2 & 11.1 & 13.2 & 19.0 & 27.9 \\
\hline $\begin{array}{l}\text { Lower-bound infiltration- } \\
\text { flux, mean thermal } \\
\text { conductivity }\end{array}$ & 5.6 & 7.1 & 7.9 & 8.4 & 9.4 & 12.3 & 17.8 \\
\hline $\begin{array}{l}\text { Mean infiltration-flux, } \\
\text { mean thermal conductivity }\end{array}$ & 5.3 & 6.7 & 7.5 & 7.9 & 8.2 & 8.7 & 9.9 \\
\hline $\begin{array}{l}\text { Upper-bound infiltration- } \\
\text { flux, mean thermal } \\
\text { conductivity }\end{array}$ & 5.1 & 6.5 & 7.3 & 7.7 & 7.9 & 8.1 & 9.0 \\
\hline $\begin{array}{l}\text { Upper-bound infiltration- } \\
\text { flux, high thermal } \\
\text { conductivity }\end{array}$ & $4.1^{\mathrm{a}}$ & 5.3 & 5.9 & 6.1 & 6.4 & 6.7 & 7.2 \\
\hline
\end{tabular}

${ }^{\mathrm{a}} 22$ out of 22,992 waste package/location combinations (or 0.1 percent of the total) never experience boiling at the drift wall; therefore, for those locations, the lateral extent of boiling is inside the emplacement drift.

NOTE: These cases cover the range of percolation-flux and host-rock thermal conductivity uncertainty addressed in this report. This table is based on data plotted in Figure 6.3-52b. 


\subsubsection{Summary of the Range of Thermal-Hydrologic Conditions for the TSPA-LA Base Case}

In Section 6.3, the ranges of thermal-hydrologic conditions across the repository are described for the five infiltration-flux host-rock thermal conductivity cases addressed in this report (Table 6.3-37). Figure 6.3-53 gives the corresponding ranges of temperature and relative-humidity histories for all waste packages. The plots in Figure 6.3-53, sometimes referred to as "horsetail" plots, also break down the ranges in temperature and relative-humidity histories into CSNF and DHLW groupings. The peak temperatures are predicted to be $203.1^{\circ} \mathrm{C}$ and $189.4^{\circ} \mathrm{C}$ for the hottest CSNF and DHLW waste packages, respectively. The peak temperatures are predicted to be $107.7^{\circ} \mathrm{C}$ and $102.0^{\circ} \mathrm{C}$ for the coolest CSNF and DHLW waste packages, respectively. Table 6.3-39 shows that the predicted range in the time when boiling at the drift wall ceases ranges from no boiling to 2176.5 years. The ranges in thermohydrologic conditions shown in Figure 6.3-53 incorporate the influence of percolation-flux uncertainty, as it is represented in the lower, mean, and upper infiltration-flux cases. The ranges in thermohydrologic conditions shown in Figure 6.3-53 also incorporate the influence of host-rock thermal conductivity uncertainty. 
(a) All waste packages

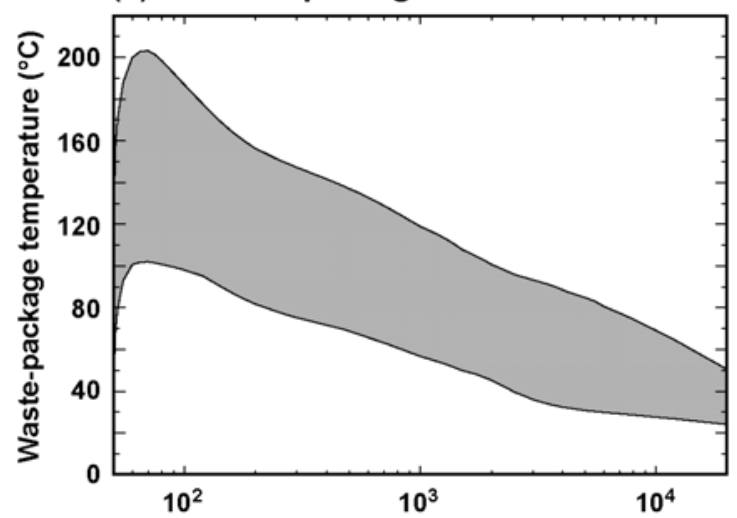

(c) All CSNF waste packages

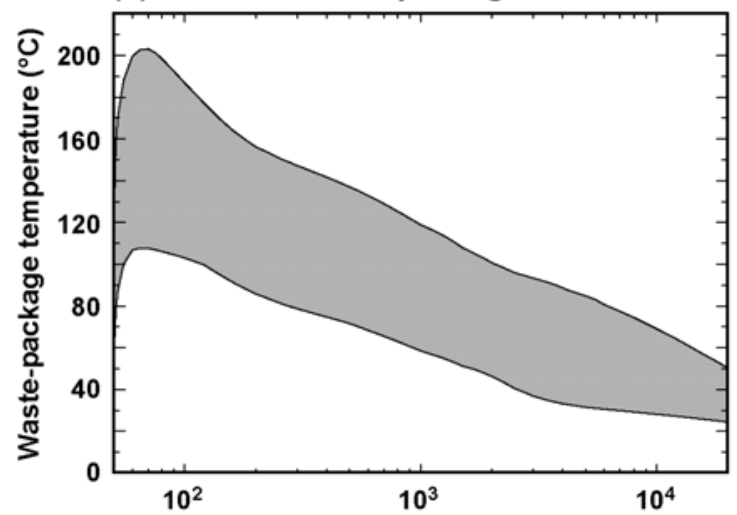

(e) All DHLW waste packages

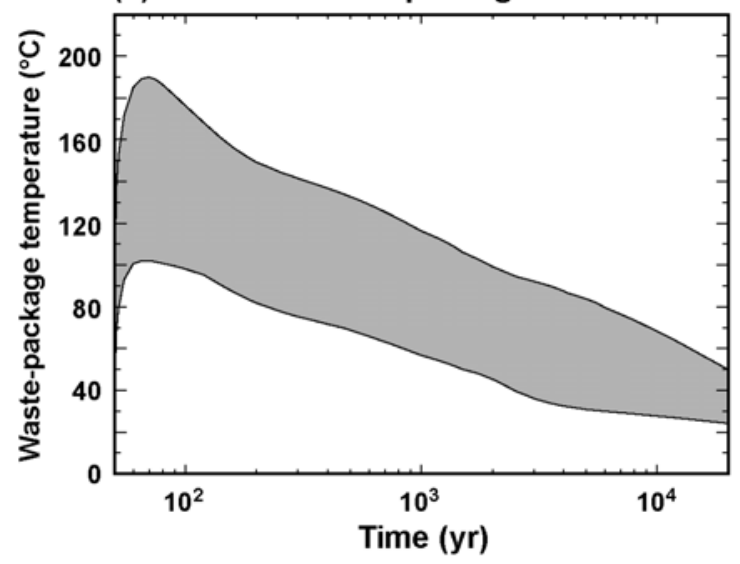

Source: See Table XIII-1.

NOTE: $\quad$ The ranges include the five cases listed in Table 6.3-37: (1) lower infiltration-flux, low thermal conductivity case, (2) lower infiltration-flux, mean thermal conductivity case, (3) mean infiltration-flux, mean thermal conductivity case, (4) upper infiltration-flux, mean thermal conductivity case, and (5) upper infiltration-flux, high thermal conductivity case.

Figure 6.3-53. Range of Waste Package Temperature and Relative Humidity Histories for all Waste

Packages $(a, b)$, for All CSNF Waste Packages (c, d), and for All DHLW Waste Packages $(\mathrm{e}, \mathrm{f})$ (b) All waste packages

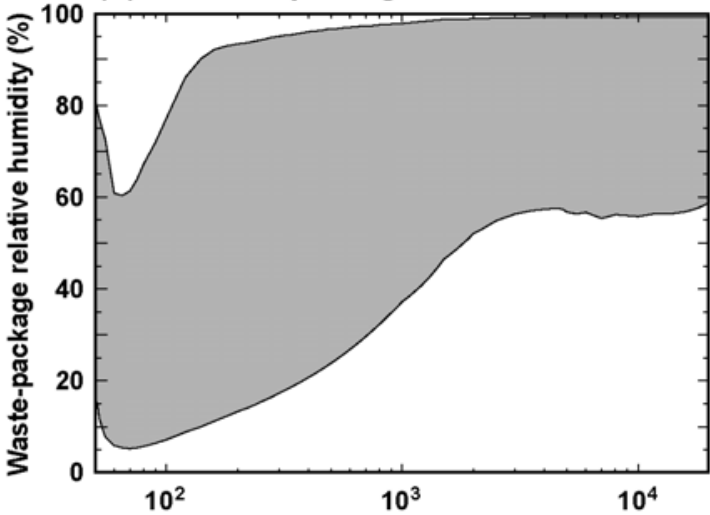

(d) All CSNF waste packages

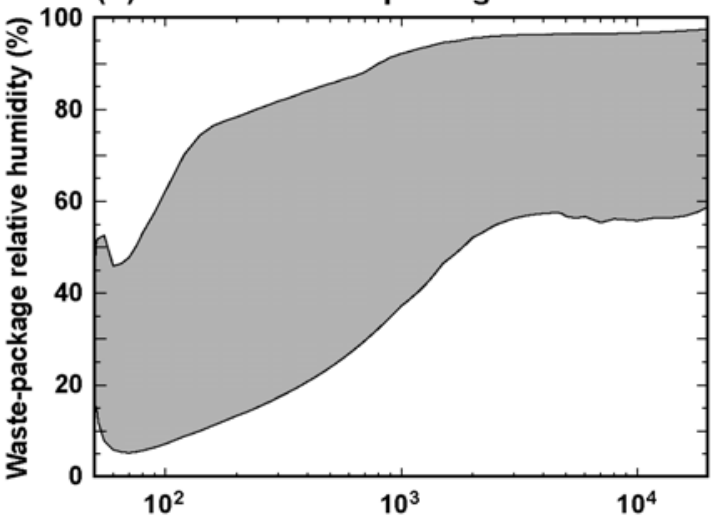

(f) All DHLW waste packages

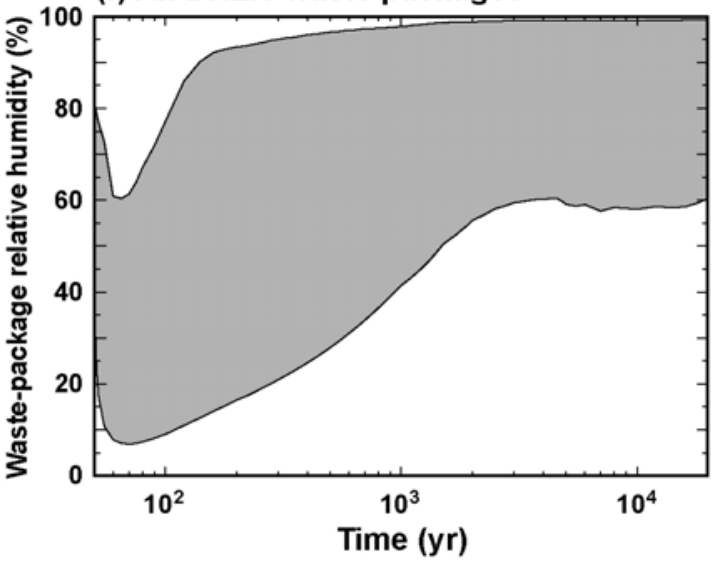

T\&RH_all_CSNF_DHLW_horsetail 


\subsubsection{Relationship Between Relative Humidity on the Waste Package and Drip Shield and Temperature on the Drift Wall}

For the purpose of conducting in-drift geochemical analyses, it is useful to extract thermal-hydrologic output that quantifies the relationship between when boiling conditions cease at the drift wall (and when seepage can potentially commence) and the corresponding relative humidity on the drip-shield and waste package surfaces. Note that the boiling temperature at the repository horizon is $96^{\circ} \mathrm{C}$. Figure 6.3-54 is a plot of the complementary cumulative distribution function (CCDF) of the relative humidity on the drip shield and waste package that corresponds to when the drift-wall temperature is $96^{\circ} \mathrm{C}$. Figure 6.3-54 also plots the CCDF of drip-shield and waste package relative humidity that corresponds to when the drift-wall temperature is $100^{\circ} \mathrm{C}$. Note that in Section 6.5.2.2 of Abstraction of Drift Seepage (BSC 2004 [DIRS 169131]), it is recommended that a threshold temperature of $100^{\circ} \mathrm{C}$, which is higher than the nominal boiling point of $96^{\circ} \mathrm{C}$, be used to define the duration of boiling for abstraction of drift seepage for intact drifts. Note also that the CCDF plots in Figure 6.3-54 account for the influence of parametric uncertainty of host-rock thermal conductivity and percolation flux as is discussed in Section 6.3.4. The probabilities of the five infiltration-flux/host-rock thermal conductivity cases, summarized in Table 6.3-37, were utilized as weighting factors for those respective cases. Table 6.3-41 summarizes the data given in Figure 6.3-54.

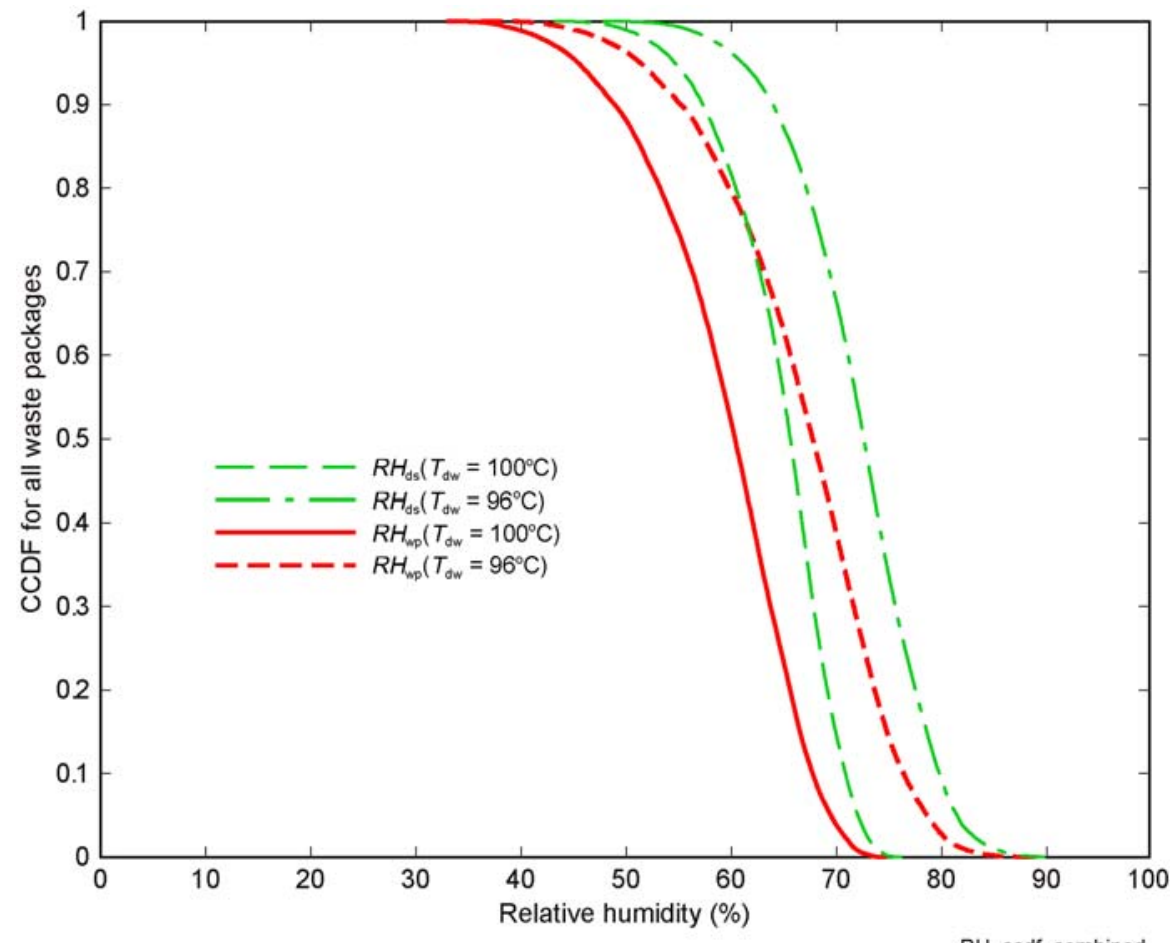

Source: See Table XIII-1.

NOTE: The CCDF corresponds to when the drift-wall temperature is $96^{\circ} \mathrm{C}$ and $100^{\circ} \mathrm{C}$. These plots account for the five infiltration-flux/host-rock thermal conductivity cases discussed in Section 6.3.4, using the probabilities summarized in Table 6.3-37.

Figure 6.3-54. The Complementary Cumulative Distribution Function (CCDF) for Relative Humidity on the Drip Shield and Waste Package 
Table 6.3-41. Relative Humidity on the Drip Shield and Waste Package Corresponding to When the Drift-Wall Temperature is $96^{\circ} \mathrm{C}$ and $100^{\circ} \mathrm{C}$, Summarized for Figure $6.3-54$.

\begin{tabular}{|c|c|c|c|c|c|c|}
\hline \multirow{2}{*}{$\begin{array}{c}\text { Drift-wall } \\
\text { temperature } \\
\left({ }^{\circ} \mathrm{C}\right)\end{array}$} & \multicolumn{3}{|c|}{ Drip-shield relative humidity (\%) } & \multicolumn{3}{c|}{ Waste package relative humidity (\%) } \\
\cline { 2 - 7 } & Lowest & Median & Highest & Lowest & Median & Highest \\
\hline 96 & 47.76 & 72.61 & 89.76 & 36.19 & 67.32 & 88.62 \\
\hline 100 & 43.08 & 65.62 & 76.20 & 32.92 & 60.36 & 74.60 \\
\hline
\end{tabular}

\subsubsection{The Influence of a Low-Probability-Seismic Collapsed-Drift Scenario on In-Drift Thermal-Hydrologic Conditions}

The influence of a low-probability-seismic collapsed-drift scenario on in-drift thermal-hydrologic conditions is considered for the P2WR5C10 location, which is a typical location at the center of the repository. Throughout Section 6.3, the P2WR5C10 location (see Figure 6.3-1 for location) is used for examining the sensitivity of thermal-hydrologic conditions in emplacement drifts to various sources of uncertainty and variability. This location is representative of a typical location in the predominant host-rock unit, which is the Tptpll (tsw35) unit, close to the center of the repository area, and because the local percolation-flux values (Table 6.3-9) are close to the repository averages for the present-day, monsoonal, and glacial climates (Table 6.3-4) for the mean infiltration-flux case.

Sections 6.2.9, 6.2.10, and 6.2.11 describe the changes to the MSTHM submodels that are required to model the influence of drift collapse. Although a full MSTHM calculation involves submodels located at 108 locations spread across the entire repository (Figure 6.2-3), it is only necessary to conduct a MSTHM calculation at a single repository location for the purpose of analyzing the influence of drift collapse on in-drift thermal-hydrologic conditions. The reasoning for this is that the purpose of this section (Section 6.3.7) is to generate tables of "deltas," which are the differences between the thermal-hydrologic results for the case with drift collapse and those for the intact (nominal) case with no drift collapse. These differences, such as the temperature difference (or delta), are entirely dependent on the modified material properties within the emplacement drifts. In other words, the differences are insensitive to the local hostrock unit or local percolation flux. Because of this lack of sensitivity to conditions outside of the drift, these calculated differences (or deltas) can then be applied to the MSTHM results of the five nominal cases with no drift collapse, which are summarized in Table 6.3-37. These differences (deltas) are determined for the eight different waste packages addressed by the MSTHM (Figure 6.2-2 and Table 6.3-13).

The low-probability-seismic scenario causes severe shaking that fails the host rock (breaking it into rubbelized blocks) out to a diameter of $11 \mathrm{~m}$. This scenario is shown in Figure 139f of Drift Degradation Analysis (BSC 2004 [DIRS 166107]). The result of this is a host-rock rubble zone that extends from the outer surface of the drip shield out to the "modified" drift wall, which is the interface between rubbelized host rock and intact host rock. A schematic of this case is given in Figure 6.4-22 of Abstraction of Drift Seepage (BSC 2004 [DIRS 169131]). The key uncertainty influencing in-drift thermal-hydrologic conditions is the effective thermal conductivity $K_{\text {th }}$ of the host-rock rubble. Two $K_{\text {th }}$ cases are considered to address this uncertainty: (1) high- $K_{\text {th }}$ case and (2) low- $K_{\text {th }}$ case. On the basis of the discussion in Section 6.2.10.3, the high- and low- $K_{\text {th }}$ cases are assigned the same probability (of 50 percent). 


\subsubsection{In-Drift Thermal-Hydrologic Conditions for the High and Low Thermal Conductivity Rubble Cases with Total Drift Collapse}

Figures 6.3-55, 6.3-56, and 6.3-57 show the influence of drift collapse, out to a diameter of $11 \mathrm{~m}$, on in-drift thermal-hydrologic conditions for the coolest, average, and hottest waste packages, respectively. These three waste packages are the dhlw-l1, bwr1-1, and pwr1-2 waste packages in Table 6.3-13 and in Figure 6.2-2. Table 6.3-42 summarizes the peak waste package temperatures for the same three waste packages, while Table 6.3-43 summarizes the time when boiling on the waste package ceases for these waste packages. For both the high- and low- $K_{\text {th }}$ cases, the host-rock rubble functions as an insulator that increases the temperature rise on the drip shield (not shown in the figures) and on the waste packages (Figure 6.3-55a, Figure 6.3-56a, and Figure 6.3-57a), as well as in the invert (Figure 6.3-55b, Figure 6.3-56b, and Figure 6.3-57b). The increase in temperature rise, compared to the intact (nominal) case, resulting from drift collapse is about twice as great for the low- $K_{\text {th }}$ case as it is for the high- $K_{\text {th }}$, which is consistent with $K_{\text {th }}$ for the low- $K_{\text {th }}$ case being half of that for the high- $K_{\text {th }}$ case (Table 6.3-23).

The insulating effect of the host-rock rubble substantially extends the duration of boiling conditions on the waste packages (Table 6.3-43). The increase in waste package boiling duration is about twice as great for the low- $K_{\text {th }}$ case as it is for the high- $K_{\text {th }}$ case. Higher temperatures and extended boiling duration in the drift have the effect of substantially extending the period of reduced liquid-phase saturation in the invert (Figure 6.3-55d, Figure 6.3-56d, and Figure 6.3-57d). The liquid-phase saturation in the matrix continuum of the host-rock rubble also remains low for a greatly extended period (Figure 6.3-55e, Figure 6.3-56e, and Figure 6.3-57e). Higher temperatures and extended boiling duration in the drift also substantially extend the period of reduced relative humidity on the drip-shield humidity (not shown in figure) and on the waste package (Figure 6.3-55c, Figure 6.3-56c, and Figure 6.3-57c). 

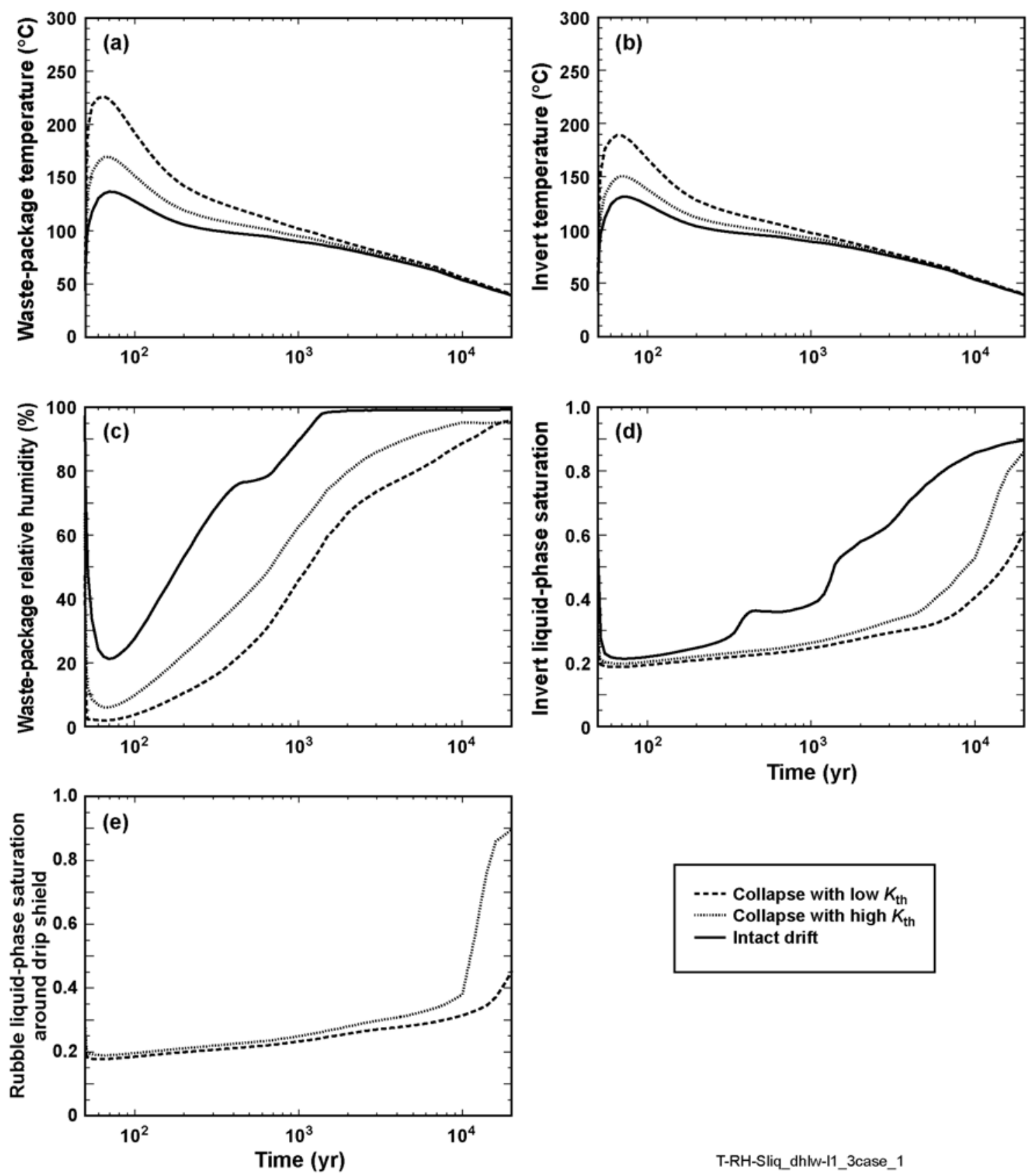

T-RH-Sliq_dhlw-I1_3case_1

Source: See Table XIII-1.

NOTE: $\quad$ See Figure 6.3-1 for location. The cases are: (1) intact-drift (nominal) case, (2) low-probability-seismic collapsed drift with high- $K_{\text {th }}$ host-rock rubble, and (3) low-probability-seismic collapsed drift with low- $K_{\text {th }}$ rubble. The plotted parameters are (a) waste package temperature, (b) invert temperature, (c) waste package relative humidity, (d) invert liquid-phase saturation, and (e) matrix liquid-phase saturation of the rubble surrounding the drip shield.

Figure 6.3-55. Thermal-Hydrologic Parameters for the "Coolest" Waste Package, the 5 DHLW/DOE SNFLong (dhlw-I1), Plotted for the Mean Infiltration Flux at the P2WR5C10 Location in the Tptpll (tsw35) Unit 

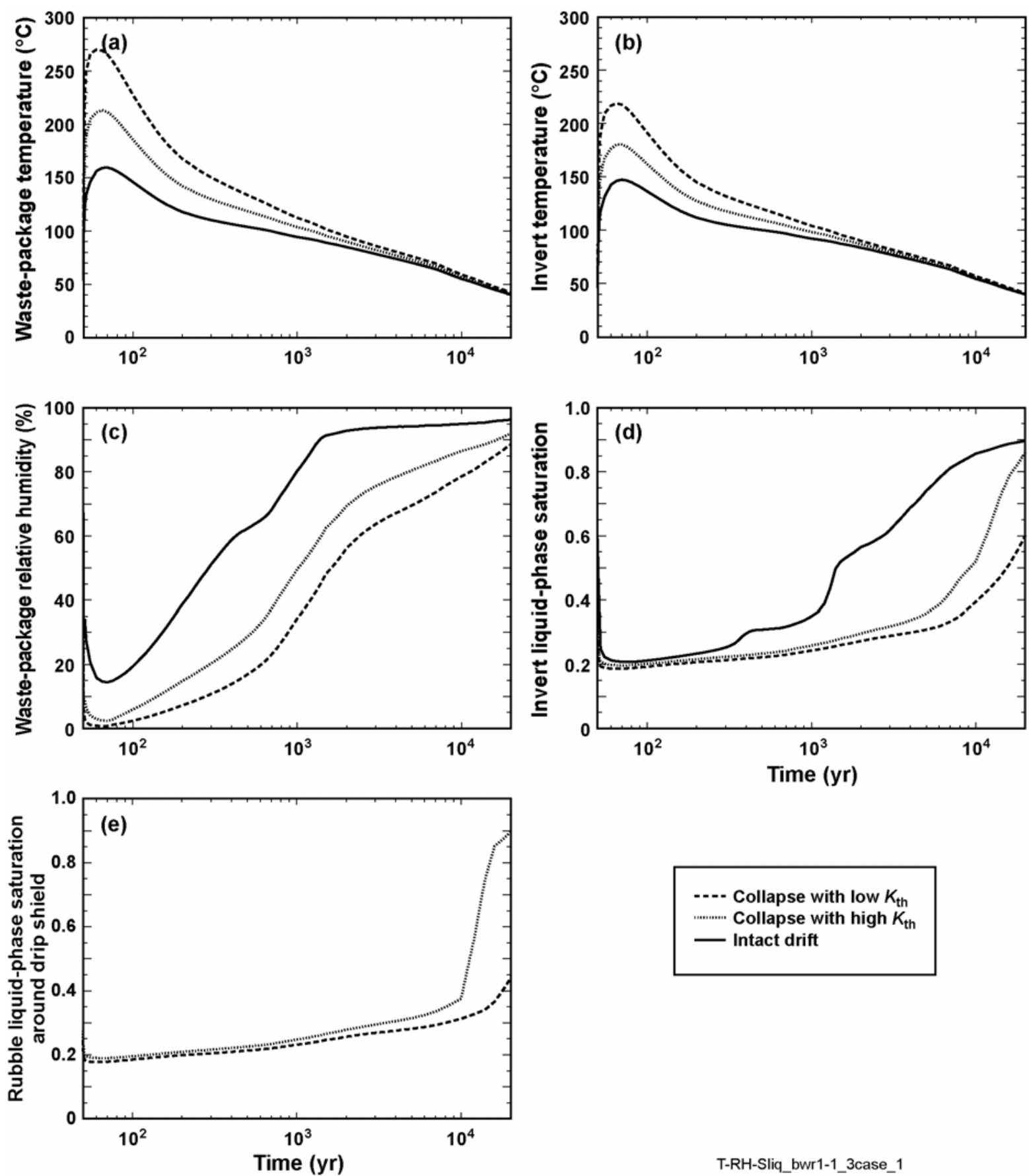

Source: See Table XIII-1.

NOTE: $\quad$ See Figure 6.3-1 for location. The cases are: (1) intact-drift (nominal) case, (2) low-probability-seismic collapsed drift with high- $K_{\text {th }}$ host-rock rubble, and (3) low-probability-seismic collapsed drift with low- $K_{\text {th }}$ rubble. The plotted parameters are (a) waste package temperature, (b) invert temperature, (c) waste package relative humidity, (d) invert liquid-phase saturation, and (e) matrix liquid-phase saturation of the rubble surrounding the drip shield.

Figure 6.3-56. Thermal-Hydrologic Parameters for the "Average" Waste Package, the 44-BWR CSNF (bwr1-1), Plotted for the Mean Infiltration Flux at the P2WR5C10 Location in the Tptpll (tsw35) Unit 

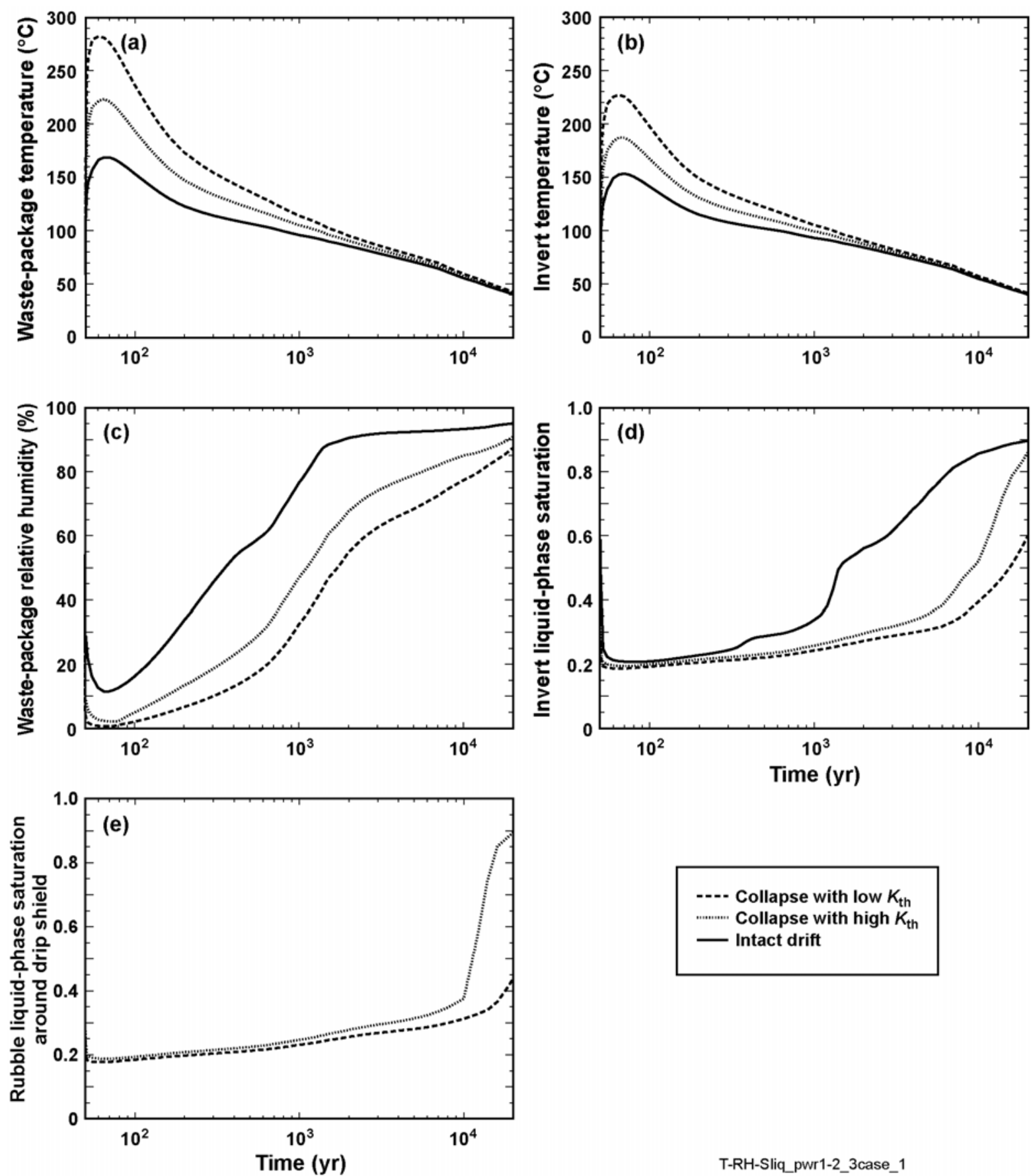

Source: See Table XIII-1.

NOTE: $\quad$ See Figure 6.3-1 for location. The cases are: (1) intact-drift (nominal) case, (2) low-probability-seismic collapsed drift with high- $K_{\text {th }}$ host-rock rubble, and (3) low-probability-seismic collapsed drift with low- $K_{\text {th }}$ rubble. The plotted parameters are (a) waste package temperature, (b) invert temperature, (c) waste package relative humidity, (d) invert liquid-phase saturation, and (e) matrix liquid-phase saturation of the rubble surrounding the drip shield.

Figure 6.3-57. Thermal-Hydrologic Parameters for the "Hottest" Waste Package, the 21-PWR AP CSNF (pwr1-2), Plotted for the Mean Infiltration Flux at the P2WR5C10 Location in the Tptpll (tsw35) Unit. 
Table 6.3-42. Peak Waste Package Temperature for the "Coolest," "Average," and "Hottest" Package for Three Cases at the P2WR5C10 Location in the Tptpll (tsw35) Unit

\begin{tabular}{|c|c|c|c|}
\hline \multirow[t]{2}{*}{ Waste Package Type } & \multicolumn{3}{|c|}{$\begin{array}{l}\text { Peak Waste Package Temperature } \\
\qquad\left({ }^{\circ} \mathrm{C}\right)\end{array}$} \\
\hline & $\begin{array}{l}\text { Intact-drift (nominal) } \\
\text { case }\end{array}$ & $\begin{array}{l}\text { Collapsed Drift with } \\
\text { High- } K_{\text {th }} \text { Rubble } \\
\end{array}$ & $\begin{array}{l}\text { Collapsed Drift with } \\
\text { Low- } K_{\text {th }} \text { Rubble }\end{array}$ \\
\hline $\begin{array}{c}\text { Coolest Waste Package } \\
5 \text { DHLW/DOE SNF-Long (dhlw-l1) WP }\end{array}$ & 136.7 & 169.3 & 225.9 \\
\hline $\begin{array}{c}\text { Average Waste Package } \\
\text { 44-BWR CSNF (bwr1-1) WP }\end{array}$ & 159.5 & 213.2 & 270.0 \\
\hline $\begin{array}{c}\text { Hottest Waste Package } \\
\text { 21-PWR AP CSNF (pwr1-2) WP }\end{array}$ & 168.8 & 223.4 & 282.2 \\
\hline
\end{tabular}

NOTES: See Figure 6.3-1 for location of the Tptpll. The location of the waste packages is given in Figure 6.2-2 and their characteristics listed in Table 6.3-13.

Cases are evaluated for the mean infiltration flux. The cases are: (1) intact-drift (nominal) case, (2) lowprobability-seismic collapsed drift with high- $K_{\text {th }}$ host-rock rubble, and (3) low-probability-seismic collapsed drift with low- $K_{\text {th }}$ host-rock rubble.

Table 6.3-43. Time When Boiling on the Waste Package Ceases for the "Coolest," "Average," and "Hottest" Package for Three Cases at the P2WR5C10 Location in the Tptpll (tsw35) Unit

\begin{tabular}{|c|c|c|c|}
\hline \multirow[t]{2}{*}{ Waste Package Type } & \multicolumn{3}{|c|}{$\begin{array}{l}\text { Time When Boiling on the Waste Package Ceases } \\
\qquad(\mathrm{yr})\end{array}$} \\
\hline & $\begin{array}{c}\text { Intact Drift (Nominal) } \\
\text { Case }\end{array}$ & $\begin{array}{l}\text { Collapsed Drift with } \\
\text { High- } K_{\text {th }} \text { Rubble }\end{array}$ & $\begin{array}{l}\text { Collapsed Drift with } \\
\text { Low- } K_{\text {th }} \text { Rubble }\end{array}$ \\
\hline $\begin{array}{c}\text { Coolest Waste Package } \\
5 \text { DHLW/DOE SNF-Long (dhlw-I1) WP }\end{array}$ & 527.8 & 912.6 & 1368.9 \\
\hline $\begin{array}{c}\text { Average Waste Package } \\
\text { 44-BWR CSNF (bwr1-1) WP }\end{array}$ & 888.2 & 1466.0 & 1898.7 \\
\hline $\begin{array}{l}\text { Hottest Waste Package } \\
\text { 21-PWR AP CSNF (pwr1-2) WP }\end{array}$ & 995.0 & 1527.1 & 1947.2 \\
\hline
\end{tabular}

NOTES: See Figure 6.3-1 for location of the Tptpll. The location of the waste packages is given in Figure 6.2-2 and their characteristics listed in Table 6.3-13.

Cases are evaluated for the mean infiltration flux. The cases are: (1) intact-drift (nominal) case, (2) lowprobability-seismic collapsed drift with high- $K_{\text {th }}$ host-rock rubble, and (3) low-probability-seismic collapsed drift with low- $K_{\text {th }}$ rubble.

\subsubsection{Influence of Bulk Density of Rubble on Thermal-Hydrologic Conditions for Low-Probability-Seismic Collapsed-Drift Scenario}

As is discussed in Section 6.2.10.3, the rubble bulk density value used in the LDTH submodels $\left(1850 \mathrm{~kg} / \mathrm{m}^{3}\right)$ is greater than the value used in the DDT submodels $\left(1608 \mathrm{~kg} / \mathrm{m}^{3}\right)$. Note that a rubble bulk density value of $1608 \mathrm{~kg} / \mathrm{m}^{3}$ is the value that corresponds to a bulking factor of 0.231 and a bulk density of $1980 \mathrm{~kg} / \mathrm{m}^{3}$ (see Table IV-3b and IV-3c of Appendix IV) for the intact Tptpll (tsw35) host-rock unit. To assess whether this difference in bulk density is significant, the LDTH submodel was rerun for the case where the rubble bulk density is $1608 \mathrm{~kg} / \mathrm{m}^{3}$, so that it could be compared to the case where the rubble bulk density is $1850 \mathrm{~kg} / \mathrm{m}^{3}$. As is evident in Figure 6.3-58, which plots the temperature and relative humidity at the crown of the drip shield for the low- $K_{\text {th }}$ rubble, the influence of rubble bulk density over this range of 1608 to $1850 \mathrm{~kg} / \mathrm{m}^{3}$ is insignificant. Because steady-state heat flow conditions are quickly established within the 
rubble, temperature and relative humidity in the drift are insensitive to the bulk density value of the rubble. Therefore, the MSTHM calculations are insensitive to the choice of rubble bulk density $\left(1850 \mathrm{~kg} / \mathrm{m}^{3}\right.$ versus $\left.1608 \mathrm{~kg} / \mathrm{m}^{3}\right)$.
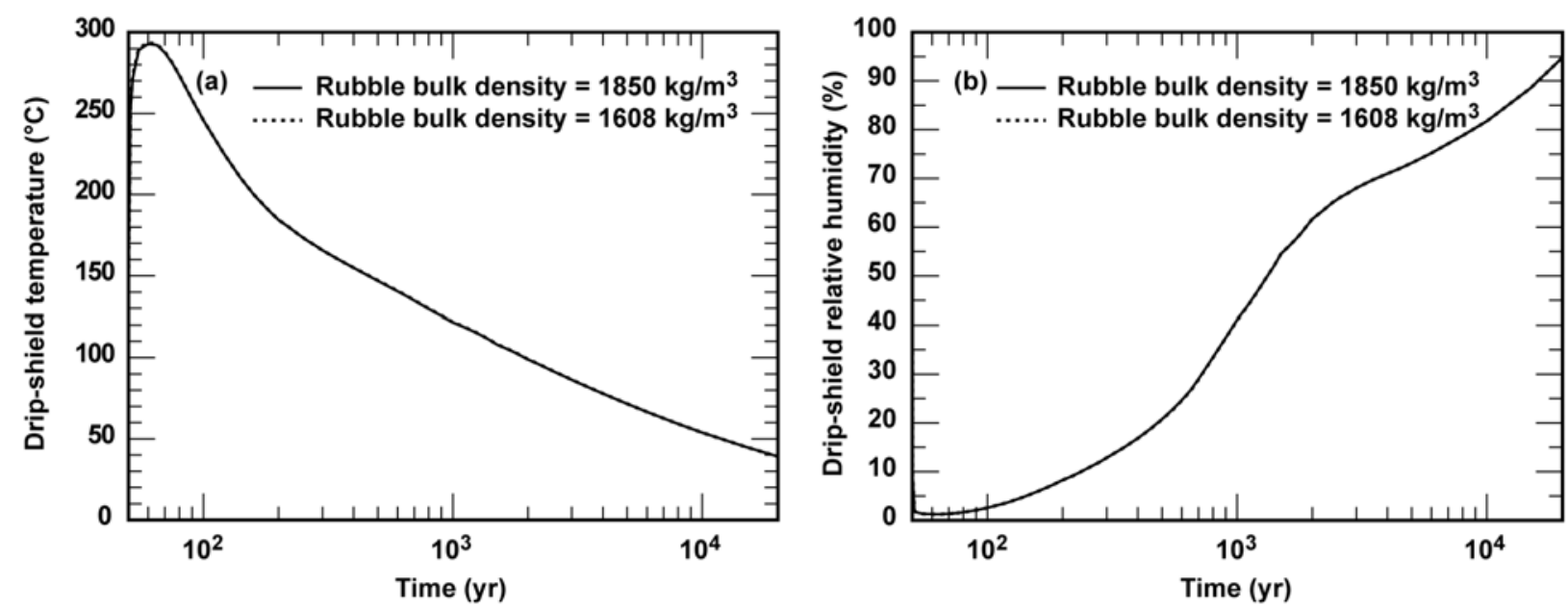

Source: See Table XIII-1.

NOTE: See Figure 6.3-1 for location. Two cases for bulk density of the host-rock rubble are considered, including: (1) bulk density $=1850 \mathrm{~kg} / \mathrm{m}^{3}$ and (2) bulk density $=1608 \mathrm{~kg} / \mathrm{m}^{3}$. Because these plots are from an LDTH submodel, they are representative of line-averaged heating conditions.

Figure 6.3-58. Temperature and Relative Humidity at the Drip Shield Crown for the P2WR5C10 Location in the Tptpll (tsw35) Unit, Plotted for the Mean Infiltration Flux and the Low-ProbabilitySeismic Collapsed Drift with Low- $K_{\text {th }}$ Rubble

\subsubsection{Influence of Seepage on the High and Low Thermal Conductivity Rubble Cases with Total Drift Collapse}

This section describes a sensitivity study of the potential influence of seepage on the high- and low- $K_{\text {th }}$ rubble cases that are discussed in Section 6.3.7.1. Note that the results presented in Section 6.3.7.1 are obtained by executing the full MSTHM methodology executed at a specific location in the repository (location P2WR5C10 in Figure 6.3-1). The seepage analysis in this section (Section 6.3.7.3) is conducted using the LDTH submodel at the P2WR5C10 location conducted for an AML of 55 MTU/acre. Thus, the results in this section are not full MSTHM results. However, the results of the seepage analysis in this section are representative of line-averaged heating conditions at the P2WR5C10 location, which is close to the repository center (i.e., relatively distant from the repository edges).

The seepage analysis is conducted by specifying a seep at the top of the rubble for selected seep magnitudes of 100, 300, 1000, and 10,000 liter/yr/WP, which represents a broad range of possible conditions. In order not to artificially heat or cool the model by virtue of this specified seepage flux, the seep has a specified enthalpy history, which causes the seep temperature history to be consistent with the local temperature history that would have occurred in the absence of the seep. To account for the residual dryout effects resulting from drift ventilation, the seep is turned on at 65 years, which is 15 years after closure. 
Table 6.3-44 summarizes the time that the seep arrives at the crown of the drip shield for the high- and low- $K_{\text {th }}$ rubble cases and for four seep magnitudes. Also summarized is the range in waste package temperatures that occur at the time that the seep arrives at the drip-shield crown based upon the corresponding MSTHM calculations conducted in Section 6.3.7.1. Note that the range of temperatures corresponds to the eight different waste packages that are represented by the MSTHM (see Table 6.3-13). Because the temperatures are taken from the MSTHM calculations that did not incorporate the seeps, the cooling effect of the seep is not included in the waste package temperature ranges in Table 6.3-44. Thus, the listed waste package temperatures are somewhat higher than would occur if the cooling effect of the seep had been included.

Table 6.3-44. Summary of Arrival Time at Drip-Shield Crown for Seeps of Varying Magnitude for LowProbability-Seismic Collapsed-Drift Scenario for the High- $\mathrm{K}_{\mathrm{th}}$ and Low- $\mathrm{K}_{\mathrm{th}}$ Rubble Cases

\begin{tabular}{|c|c|c|c|c|}
\hline $\begin{array}{c}\text { Seep Magnitude } \\
\text { (liter/yr/WP) }\end{array}$ & \multicolumn{2}{|c|}{ High- $\boldsymbol{K}_{\text {th }}$ Rubble } & \multicolumn{2}{c|}{ Low- $\boldsymbol{K}_{\text {th }}$ Rubble } \\
\cline { 2 - 5 } & $\begin{array}{c}\text { Arrival Time at } \\
\text { Drip-Shield Crown } \\
(\mathbf{y r})\end{array}$ & $\begin{array}{c}\text { Waste Package } \\
\text { Temperature Range } \\
\left({ }^{\circ} \mathbf{C}\right)\end{array}$ & $\begin{array}{c}\text { Arrival Time at } \\
\text { Drip-Shield Crown } \\
(\mathbf{y r})\end{array}$ & $\begin{array}{c}\text { Waste Package } \\
\text { Temperature Range } \\
\left({ }^{\circ} \mathrm{C}\right)\end{array}$ \\
\hline $\mathbf{1 0 0}$ & 10,000 & $54.1-57.2$ & 15,000 & $46.7-49.5$ \\
\hline $\mathbf{3 0 0}$ & 5000 & $69.3-73.4$ & 8000 & $61.7-65.7$ \\
\hline $\mathbf{1 0 0 0}$ & 2800 & $79.1-84.0$ & 4000 & $75.6-80.8$ \\
\hline $\mathbf{1 0 , 0 0 0}$ & 1400 & $90.3-98.3$ & 1500 & $93.7-102.4$ \\
\hline
\end{tabular}

DTN: LL040404423122.045.

NOTE: Waste package temperature ranges are obtained from full MSTHM results at the P2WR5C10 location (see Figure 6.3-1 for location).

As discussed in Section 6.3.7.1, because the rubble has a lower thermal conductivity than the adjoining host rock, and because the nominal case of no drift collapse involves thermal radiation, which is a highly efficient mode of heat transfer, the introduction of rubble has a strong insulating effect. The insulating effect of the rubble substantially extends the duration of the boiling period on the waste packages (Table 6.3-43). The increase in waste package boiling duration is about twice as great for the low- $K_{\text {th }}$ case as it is for the high- $K_{\text {th }}$ case. The liquidphase saturation in the matrix continuum of the host-rock rubble remains low for a greatly extended period (Figure 6.3-55e, Figure 6.3-56e, and Figure 6.3-57e). The low liquid-phase saturation substantially reduces the relative humidity in the rubble.

The extended boiling duration and extended duration of reduced relative humidity in the rubble greatly extend the time that seeps can be completely evaporated in the rubble. Thus, a seep of 100 liter/yr/WP requires 10,000 and 15,000 years to reach the crown of the drip shield for the high- and low- $K_{\text {th }}$ rubble cases, respectively. Waste package temperatures have declined substantially by the time that a 100-liter/yr/WP seep reaches the drip shield. A seep of 1000 liter/yr/WP requires 2800 and $4000 \mathrm{yr}$ to reach the crown of the drip shield for the high- and low- $K_{\text {th }}$ rubble cases, respectively. Waste package temperatures have declined to well below the boiling point by the time a 1000-liter/yr/WP seep reaches the crown of the drip shield. It requires a seep of 10,000 liter/yr/WP to reach the crown of the drip shield while some (but not all) of the waste packages are above the boiling point. Had the cooling effect of the seep on the waste package temperatures been included, it is likely that all of waste package temperatures for the 10,000-liter/yr/WP seep would also have been below the boiling point. 


\subsubsection{Comparison of Results for the TSPA-LA Base Case with Those for the FY01 Supplemental Science and Performance Analyses (SSPA)}

This section gives a brief comparison between the thermal-hydrologic conditions predicted for the TSPA-LA base case with those predicted for the FY 01 Supplemental Science and Performance Analyses, Volume 1: Scientific Bases and Analyses (Section 5.4.1 of BSC 2001 [DIRS 155950]). Figure 6.3-59 plots the thermal-hydrologic parameters for all eight waste packages considered in both the TSPA-LA and the SSPA. The LDTH submodel location P3R7C12 was chosen because it is very close to the location used to plot the thermal-hydrologic parameters in Figure 5.4.1-7 of the FY 01 Supplemental Science and Performance Analyses, Volume 1: Scientific Bases and Analyses (Section 5.4.1 of BSC 2001 [DIRS 155950]). This location was chosen because it is close to the geographic center of the repository and because it is the Tptpll (tsw35), which is the host-rock unit for 75.1 percent of the repository area (Table 6.3-2). Note that this comparison is for the mean infiltration-flux case. Note also that the MSTHM calculations for the SSPA were for a period of 1,000,000 years, while the MSTHM calculations for the TSPA-LA are for a period of 20,050 years. The same time axis is used in Figure 6.3-59 as in Figure 5.4.1-7 (Section 5.4.1 of BSC 2001 [DIRS 155950]) to provide a more consistent basis for comparing the history plots of thermal-hydrologic conditions. The legend in Figure 6.3-59 utilizes the same waste package names used in Figure 5.4.1-7 (Section 5.4.1 of BSC 2001 [DIRS 155950]), as well as providing the waste package names (e.g., pwr1-1) used in the TSPA-LA (see Table 6.3-13).

Peak waste package temperatures at the repository center in the MSTHM calculations for the SSPA, as given in Figure 5.4.1-7 (Section 5.4.1 of BSC 2001 [DIRS 155950]), range from 152.3 to $180.1^{\circ} \mathrm{C}$. Peak waste package temperatures at the repository center in the MSTHM calculations for the TSPA-LA base case, as given in Figure 6.3-59, range from 136.3 to $167.3^{\circ} \mathrm{C}$. Thus, for this location in the repository, and for the mean infiltration-flux case, peak waste package temperatures are 12 to $16^{\circ} \mathrm{C}$ lower for the TSPA-LA than for the SSPA. There are two primary causes for the TSPA-LA temperatures being lower than they are in the SSPA. The first is differences in the heat-removal efficiency that was applied to the respective models during the preclosure ventilation period. The MSTHM calculations for the SSPA used a constant heatremoval efficiency of 70 percent (Section 5.3.2.4.1 of BSC 2001 [DIRS 155950]). The MSTHM calculations for the TSPA-LA use a time-varying heat-removal efficiency (DTN: MO0304MWDALACV.000 [DIRS 164551]). Thus, in-drift temperatures are lower at the onset of the postclosure period for the TSPA-LA MSTHM calculations than they are for the SSPA MSTHM calculations. The second reason for the lower TSPA-LA temperatures is the approximation of the influence of natural convection on heat transfer in the drift. The TSPA-LA MSTHM calculations use an effective thermal conductivity for the gas-filled drift cavity that is based on a correlation (Francis et al. 2003 [DIRS 164602], Table 6) that more realistically accounts for the in-drift geometry than the approximation used in the SSPA MSTHM calculations (CRWMS M\&O 2001 [DIRS 153410]). It should be noted that the correlations for the in-drift effective thermal conductivity, which were obtained from Table 6 of Francis et al (2003 [DIRS 164602]), have been updated in In-Drift Natural Convection and Condensation (BSC 2004 [DIRS 164327], Table 6.4.7-3), resulting in very small changes to the coefficients. As evident in Figure I-1 of Appendix I, the small changes to the coefficients result in insignificant changes to the in-drift effective thermal conductivity. The in-drift convective heat transfer approximation for the TSPA-LA MSTHM results in more efficient heat transfer (by 
natural convection), which lowers the temperature difference between the waste package and drift wall; the lower temperature difference results in lower waste package temperatures.
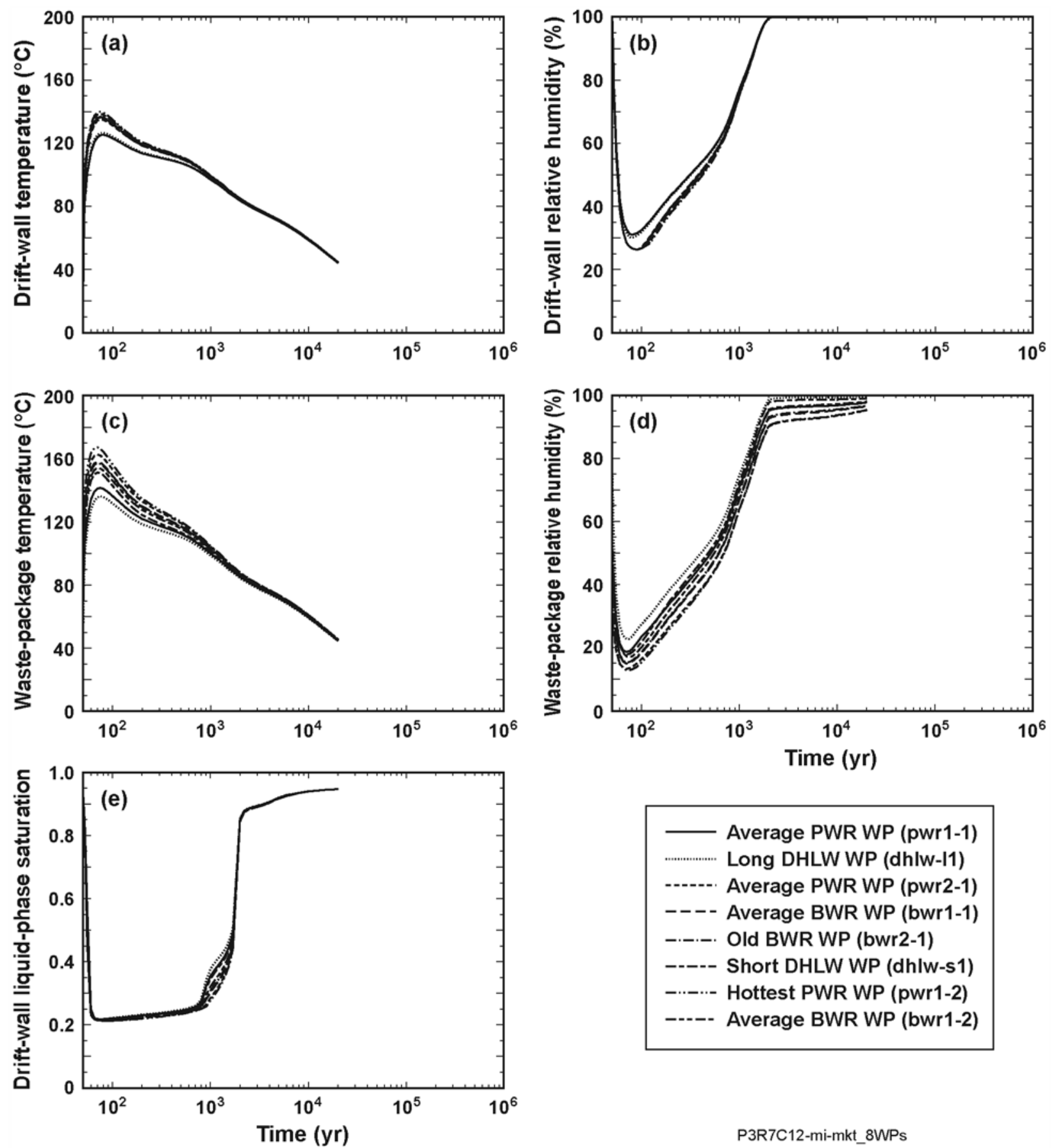

Source: See Table XIII-1.

NOTE: The plotted thermal-hydrologic parameters are (a) drift-wall temperature, (b) drift-wall relative humidity, (c) waste package temperature, (d) waste package relative humidity, and (e) drift-wall liquid-phase saturation. The waste package names (in parentheses) are given in Figure 6.2-2 and in Table 6.3-13.

Figure 6.3-59. Thermal-Hydrologic Parameters for the Eight Waste Packages Considered in this Report, Plotted for the Mean Infiltration-Flux Cases at the P3R7C12 Location in the Tptpll (tsw35) Unit, Close to the Repository Center 


\subsubsection{Influence of Host-Rock Hydrologic-Property Variability and Uncertainty}

The multiscale thermal-hydrologic model addresses repository-scale variability of hydrologic properties. A sensitivity study of hydrologic-property variability, described below, for the four host-rock types (Tptpul, Tptpmn, Tptpll, and Tptpln) demonstrates that multiscale thermohydrologic model-simulated in-drift and near-field thermal-hydrologic conditions are insensitive to differences in the hydrologic property values for these respective host-rock units. The reason for this lack of sensitivity is provided at the end of this section (6.3.9).

Figure 6.3-60 gives the drift-wall and drip-shield temperature histories at a typical location at the center of the repository for percolation flux values ranging from 0.1 to $10 \mathrm{~mm} / \mathrm{yr}$. Figure 6.3-61 gives the corresponding drift-wall and drip-shield relative humidity histories for this location. This location (P2WR5C10 in Figure 6.3-1) happens to be in the Tptpll host-rock unit, which is the predominant host-rock type in the repository (Table 6.3-3). For the purpose of showing the influence of hydrologic-property variability, model calculations were made using the lineaveraged-heat-source drift-scale thermal-hydrologic (LDTH) submodel (Section 6.2.6) applying the hydrologic property values for each of the host-rock types (Tptpul, Tptpmn, Tptpll, and Tptpln), respectively. For a percolation flux of $0.1 \mathrm{~mm} / \mathrm{yr}$ or greater, temperature is insensitive to hydrologic properties (Figures 6.3-60a to 6.3-60f). For a percolation flux of $0.01 \mathrm{~mm} / \mathrm{yr}$, hydrologic properties exert a minor influence on temperature (Figures 6.3-60g and 6.3-60h). For a percolation flux of $1 \mathrm{~mm} / \mathrm{yr}$ or greater, relative humidity is insensitive to hydrologic properties (Figures 6.3-61a to 6.3-61d). For a percolation flux of $0.1 \mathrm{~mm} / \mathrm{yr}$ or less, hydrologic properties exert a minor influence on relative humidity (Figures 6.3-61e to 6.3-61h).

The influence that hydrologic properties exert on temperature and relative humidity is insignificant for two reasons. First, it is insignificant compared to the influence of host-rock thermal conductivity and percolation flux, as evident in Figures 6.3-51 and 6.3-61. Second, the percolation flux range for which hydrologic properties exert some influence (equal to or less than $0.1 \mathrm{~mm} / \mathrm{yr}$ ) constitutes a small portion of the repository for the three climate states (present-day, monsoonal, and glacial), as is evident in Figure 4-2.

The lack of sensitivity of in-drift and near-field temperature and relative humidity to hydrologic properties can be understood by considering the key processes and factors governing thermal-hydrologic behavior in and around emplacement drifts. Thermal-hydrologic behavior in and around emplacement drifts consists of three fundamental processes:

1. Heat Flow-Occurs in emplacement drifts, primarily by thermal radiation, and in the adjoining host rock, primarily by thermal conduction. Consequently, host-rock thermal conductivity is the key natural-system parameter determining the magnitude of temperature buildup in the host rock.

2. Host-Rock Dryout-Is driven by temperature buildup, resulting in evaporation (boiling), which lowers the liquid-phase saturation in the host rock, thereby lowering the relative humidity in the host rock and in the emplacement drifts.

3. Host-Rock Rewetting-Primarily occurs as a result of gravity-driven percolation in fractures, with capillary-driven imbibition into the adjoining matrix. The rate of rewetting is controlled by the local percolation flux except in regions of very low 
percolation flux (less than approximately $0.1 \mathrm{~mm} / \mathrm{yr}$ ), where it is controlled by capillary-driven imbibition in the matrix. The approximate percolation-flux threshold of $0.1 \mathrm{~mm} / \mathrm{yr}$ is obtained by observing the sensitivity of temperature (Figure 6.3-60) and relative humidity (Figure 6.3-61) to percolation flux, which is discussed above
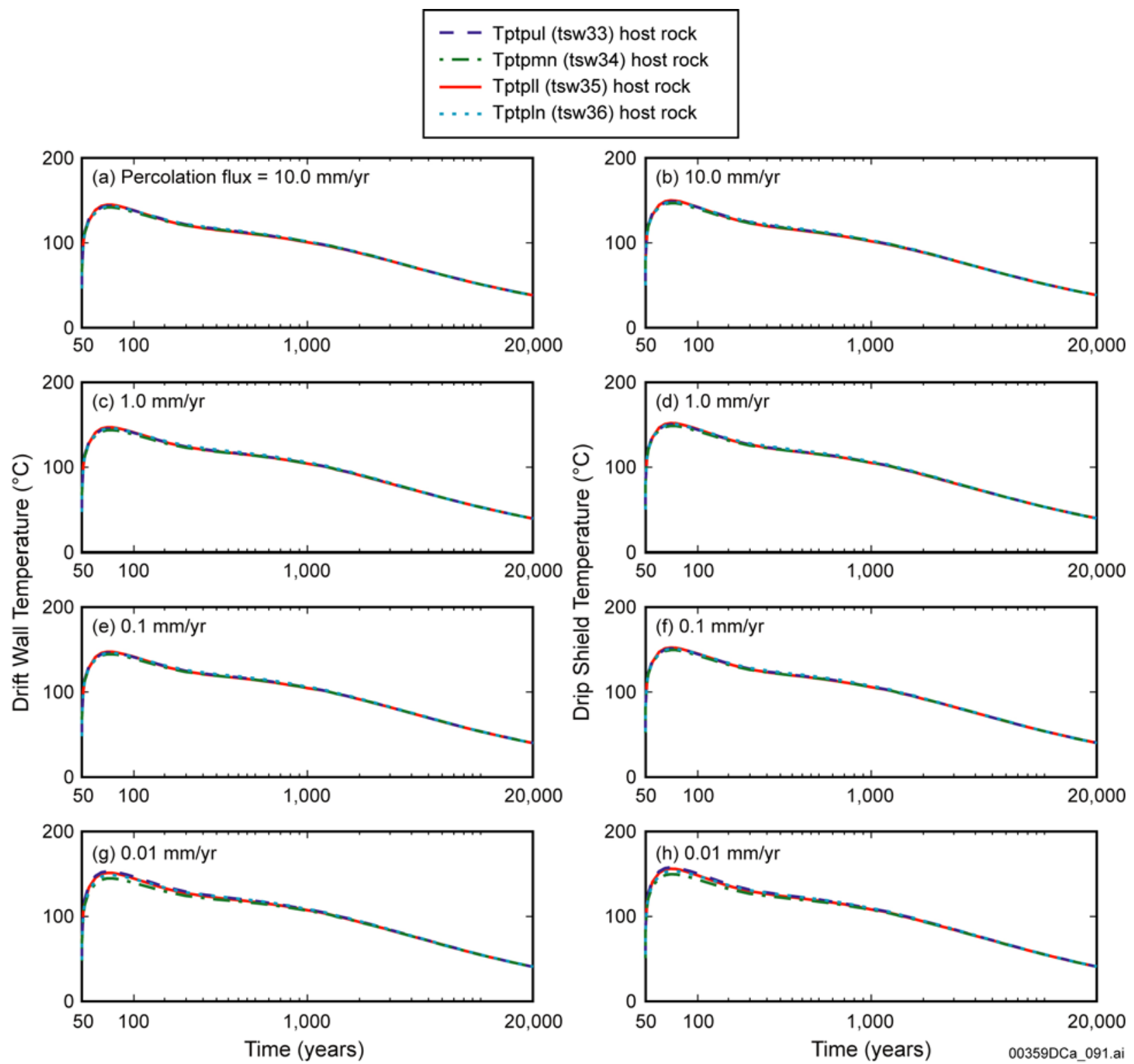

Source: See Table XIII-1.

NOTE: The temperature histories are calculated by the LDTH submodel of the multiscale thermohydrologic model (Section 6.2.6). These temperature histories are calculated for a location close to the center of the repository (the P2WR5C10 location shown Figure 6.3-1). All cases use the thermal properties, including the mean thermal conductivity, of the Tptpll host-rock unit (Table 6.3-23).

Figure 6.3-60. Drift-Wall and Drip-Shield Temperature History at the Repository Center for Four Values of Percolation Flux and for the Hydrologic Properties of Each of the Host-Rock Types 


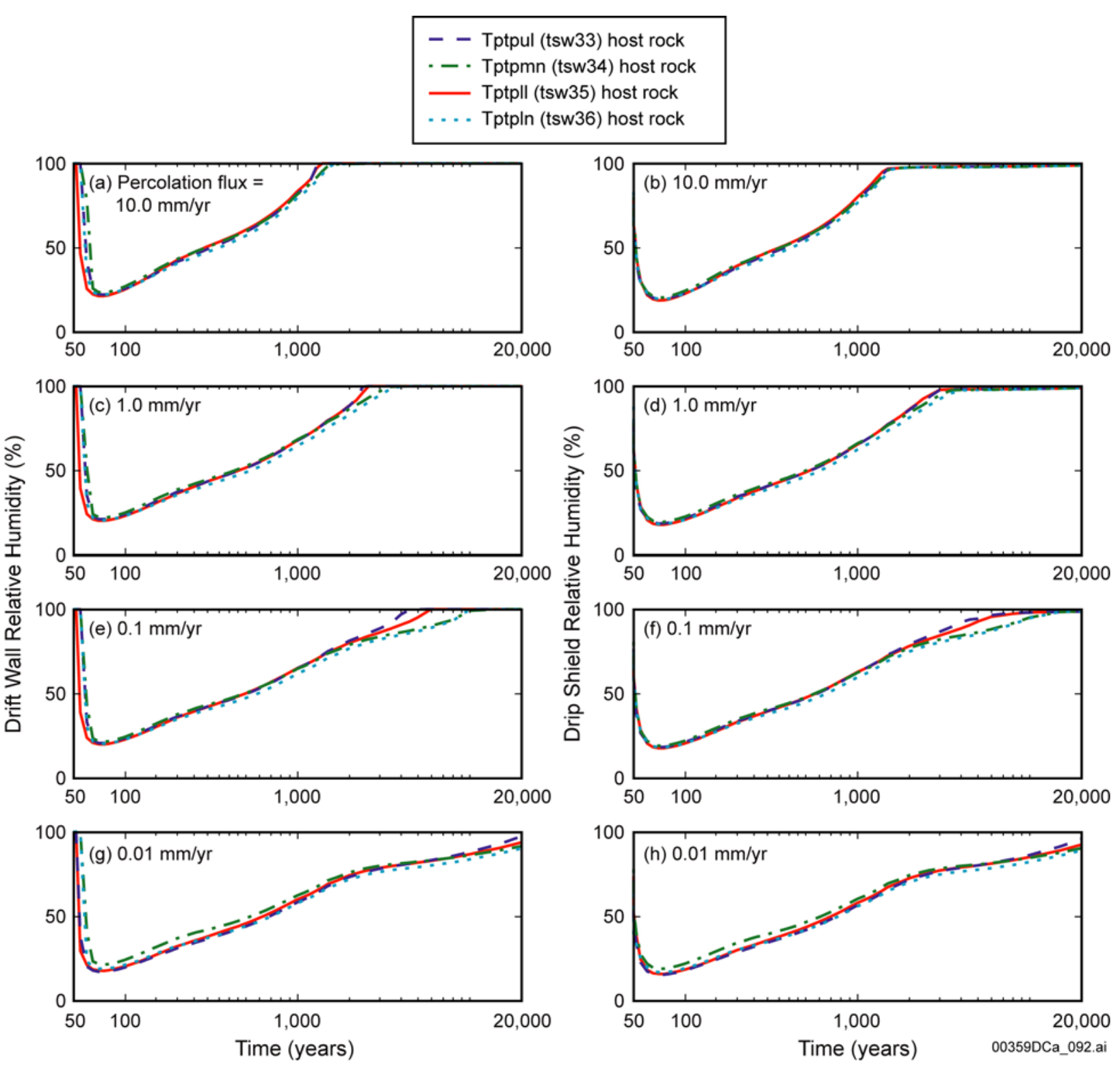

Source: See Table XIII-1.

NOTE: The relative-humidity histories are calculated by the LDTH submodel of the multiscale thermal-hydrologic model (Section 6.2.6). These relative-humidity histories are calculated for a location close to the center of the repository (the P2WR5C10 location shown Figure 6.3-1). All cases use the thermal properties, including the mean thermal conductivity, of the Tptpll host-rock unit (Table 6.3-23).

Figure 6.3-61. Drift-Wall and Drip-Shield Relative-Humidity History at the Repository Center for Four Values of Percolation Flux and for the Hydrologic Properties of Each of the Host-Rock Types

For the range of host-rock hydrologic properties of the four host-rock units, vapor flow from the boiling to the condensation zone essentially occurs in an unthrottled (i.e., unrestricted) fashion. Permeability in the fractures and matrix and fracture spacing is always sufficiently large to result in a (insignificantly) small gas-phase pressure buildup with respect to boiling. Consequently, the gas-phase pressure buildup is small enough to not throttle (i.e., restrict) the rate at which boiling occurs and the resulting vapor flux from the boiling zone to the condensation zone. Thus, the 
range in hydrologic properties for the host rock does not result in differences in the rate at which boiling occurs in the host rock.

For the range of host-rock hydrologic properties of the four host-rock units, the contribution of buoyant gas-phase convection to overall heat flow is small compared to that of thermal convection. Thus, the range in host-rock thermal-hydrologic properties of the four host-rock types does not result in differences in the temperature buildup in the host rock, as is evident in Figure 6.3-60.

For the range of hydrologic properties of the four host-rock units, fracture permeability is sufficiently large and fractures are sufficiently well connected to allow gravity-driven drainage of percolation to occur in an unrestricted fashion. Thus, percolation flux, not fracture permeability, is the rate-limiting quantity governing the magnitude of gravity-driven liquid-phase flow to the boiling-dryout zone. One important caveat to this generalization relates to flow focusing, which arises due to heterogeneity in fracture permeability. The influence of flow focusing is addressed by including areal variability of percolation flux, which results in a broad range of percolation flux over the repository footprint (Table 6.3-5), and by including uncertainty, as is addressed in the lower, mean, and upper infiltration-flux cases (Table 6.3-4). Thus, the manner in which hydrologic properties primarily affect rewetting (and, thus, net dryout) behavior is related to the manner in which those properties affect capillary-driven flow, which primarily occurs as imbibition in the matrix.

For the range of host-rock hydrologic properties of the four host-rock units, capillary-driven imbibition always results in a rewetting magnitude that is effectively less than approximately $0.1 \mathrm{~mm} / \mathrm{yr}$. Accordingly, only in regions with very low percolation flux (less than $0.1 \mathrm{~mm} / \mathrm{yr}$ ) do the hydrologic properties exert a small but insignificant influence on dryout and rewetting behavior in the host rock, as is evident in Figure 6.3-61. For areas of the repository with a local percolation flux greater than $0.1 \mathrm{~mm} / \mathrm{yr}$ (which is the vast majority of the repository area for all three climate states, as shown in Figure 4-2), differences in host-rock hydrologic properties exert an insignificant influence on dryout and rewetting behavior. Even in areas with low percolation flux, the influence of hydrologic properties on dryout and rewetting behavior is small compared to that of host-rock thermal conductivity and percolation flux, as is evident in Figures 6.3-50 and 6.3-51.

\subsubsection{Influence of Pseudo Permeability on In-Drift Temperature and Relative Humidity}

Although the emplacement drift is an open cavity rather than a porous media, the vast majority of simulations of in-drift and near-field thermal-hydrologic conditions use porous-media flow and transport simulators, such as NUFT (Nitao 1998 [DIRS 100474]) and TOUGH2 (Pruess et al. 1999 [DIRS 160778]), which necessitates treating the drift cavity as a porous media with a large permeability and 100 percent porosity. Because the drift cavity is not a porous medium, the permeability of the drift cavity is called pseudo permeability. A value of pseudo permeability of $1 \times 10^{-8} \mathrm{~m}^{2}$ is used in all of the LDTH submodels used to support all MSTHM calculations in this report. It is important that the value of pseudo permeability is at least as large as that of the bulk permeability of the fractured host rock. In that way, the value of pseudo permeability will not impede advective gas-phase flow within the drift cavity, particularly as it relates to buoyant gas-phase convection (also called natural convection) cells that develop in the adjoining host rock. 
As demonstrated below, the porous medium approach with pseudo permeability does not represent the influence of buoyant gas-phase convection (also called natural convection) on heat transfer within the emplacement drift. To represent the influence of natural convection on heat transfer within the drift, an effective thermal conductivity for the gas-filled drift cavity is used. This effective thermal conductivity is based on a correlation (Francis et al. 2003 [DIRS 164602], Table 6) accounting for the influence of natural convection, which is described in Appendix I. It should be noted that the correlations for the in-drift effective thermal conductivity, which were obtained from Table 6 of Francis et al. (2003 [DIRS 164602]), have been updated in In-Drift Natural Convection and Condensation (BSC 2004 [DIRS 164327], Table 6.4.7-3), resulting in small changes to the coefficients. As evident in Figure I-1 of Appendix I, the small changes to the coefficients result in insignificant changes to the in-drift effective thermal conductivity. The effective conductivity approach is used both in the DDT submodels (Section 6.2.8) and in the LDTH submodels (Section 6.2.6). Because the LDTH submodel allows natural convection to occur within the drift cavity, a concern is whether the in-drift convective cooling effect, together with the use of the effective thermal conductivity for the drift cavity, will over-account for the magnitude of in-drift convective cooling.

Figure 6.3-62 plots drip-shield temperature and relative humidity for six different values of in-drift pseudo permeability, ranging over six orders of magnitude. The largest value of in-drift pseudo permeability considered is $1 \times 10^{-6} \mathrm{~m}^{2}$, which is two orders of magnitude larger than the value used in all MSTHM calculations. The smallest value of in-drift pseudo permeability is $1 \mathrm{x}$ $10^{-12} \mathrm{~m}^{2}$, which is four orders of magnitude smaller than the value used in all MSTHM calculations; it is also of the same order of the fracture permeability of the host rock. Over this range, the value of in-drift pseudo permeability has an insignificant effect on in-drift temperature and relative humidity. The range in peak drip-shield temperature is $150.9^{\circ} \mathrm{C}$ to $151.1^{\circ} \mathrm{C}$ for these cases. Clearly, there is no over-accounting of convective cooling in the LDTH submodels that support the MSTHM calculations in this report. Therefore, the approach of using an effective thermal conductivity for the drift cavity is reasonable and appropriate in the LDTH submodels. 

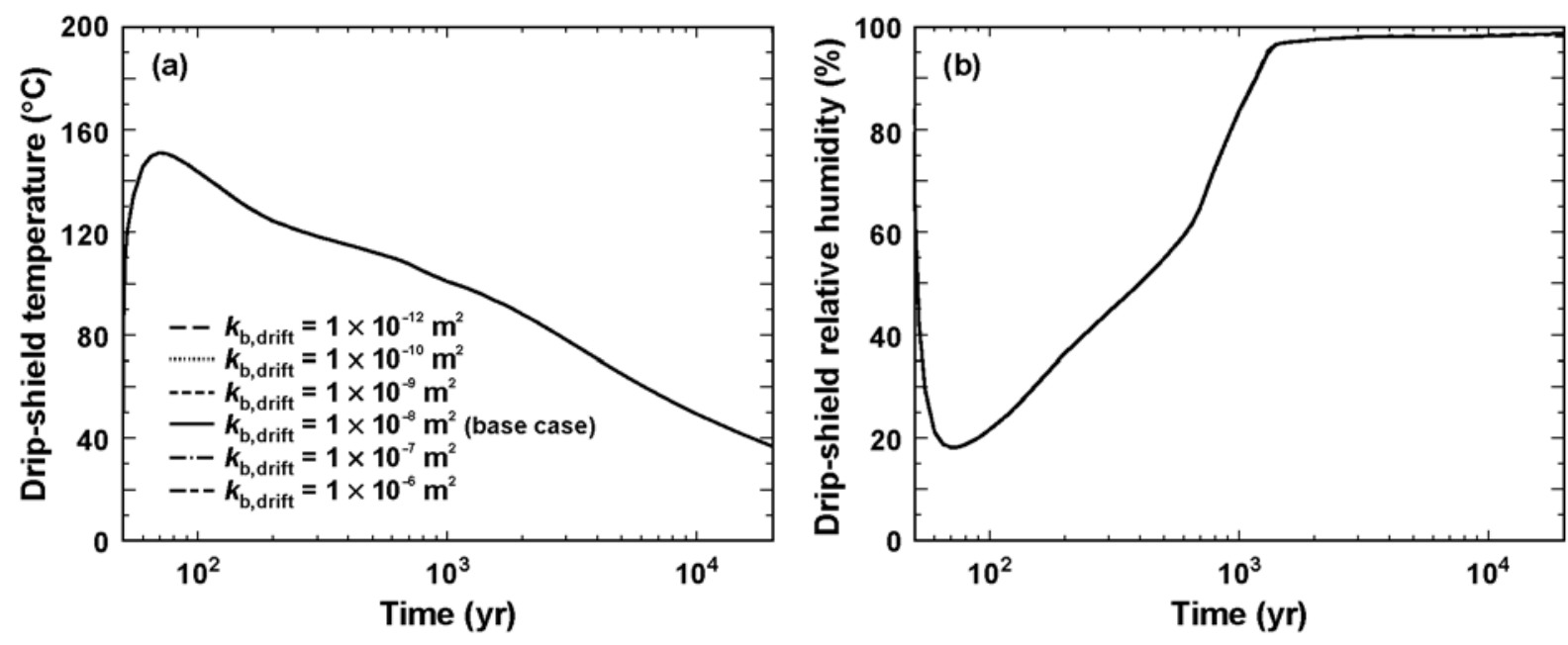

Tds-RHds_allkb

Source: See Table XIII-1.

NOTE: Temperature and relative-humidity histories are calculated by the LDTH submodel (Section 6.2.6) for an AML of $55 \mathrm{MTU} /$ acre and for a location close to the center of the repository (the P2WR5C10 location shown Figure 6.3-1) for the mean infiltration-flux case with mean host-rock thermal conductivity.

Figure 6.3-62. Drip-Shield Temperature (a) and Relative Humidity (b) at the Repository Center for Different Values of Pseudo Permeability of the Gas-Filled Emplacement Drift Cavity

\subsubsection{Influence of Invert Hydrologic-Property Variability and Uncertainty}

All of the MSTHM calculations in this report utilized a single hydrologic property set for the crushed-tuff gravel invert. The dual-permeability model (DKM) is applied to represent flow in crushed-tuff gravel, with flow within the tuff grains (called the intragranular porosity) corresponding to flow in the matrix continuum of the DKM and flow around the tuff grains (called the intergranular porosity) corresponding to flow in the fracture continuum of the DKM. As discussed in Section 5.3.1.2, the hydrologic properties of the intragranular porosity are assumed to be the same as the intact properties for the Tptpll (tsw35) host-rock unit. As discussed in Section 5.3.1.8, the hydrologic properties of the intergranular porosity are taken from case 2 (3-mm particle size) from Table X-7 of Appendix X, with the one modification that the permeability is taken to be $1.0 \times 10^{-9} \mathrm{~m}^{2}$, which is between the values for case 1 , which has a $0.317-\mathrm{mm}$ particle size $\left(1.681 \times 10^{-10} \mathrm{~m}^{2}\right)$ and for case 2 , which has a 3 -mm particle size $\left(1.511 \times 10^{-8} \mathrm{~m}^{2}\right)$ from Table X-7 of Appendix X. Thus, the base case MSTHM calculations used a modified case 2 intergranular-porosity hydrologic property set. The purpose of this section (Section 6.3-11) is to demonstrate the sensitivity (or lack thereof) of thermal-hydrologic conditions in the invert to intragranular properties (as represented by the matrix properties of the four host-rock units) and to intergranular properties (as represented by the cases 1 through 4 in Table X-7 of Appendix X, as well as the modified case 2).

Figure 6.3-63 plots the liquid-phase saturation for the intragranular porosity and the temperature averaged over the invert. Four different cases are considered, with each case utilizing the matrix properties from each of the respective host-rock units: Tptpul (tsw33), Tptpmn (tsw34), Tptpll (tsw35), and Tptpln (tsw36). All four cases utilize the modified case 2 intergranular properties discussed above. Invert temperature is insensitive to the hydrologic properties of the intragranular porosity (Figure 6.3-63b). Liquid-phase saturation is also insensitive to hydrologic 
properties of the intragranular porosity (Figure 6.3-63a), and also justifies not propagating invert hydrologic-property through the MSTHM calculations supporting TSPA-LA. Rewetting proceeds similarly in the two lithophysal units (Tptpul and Tptpll), and also in the two nonlithophysal units (Tptpmn and Tptpln). Because the matrix permeability is smaller in the nonlithophysal units than in the lithophysal units, rewetting proceeds somewhat more slowly in the nonlithophysal units than in the lithophysal units.

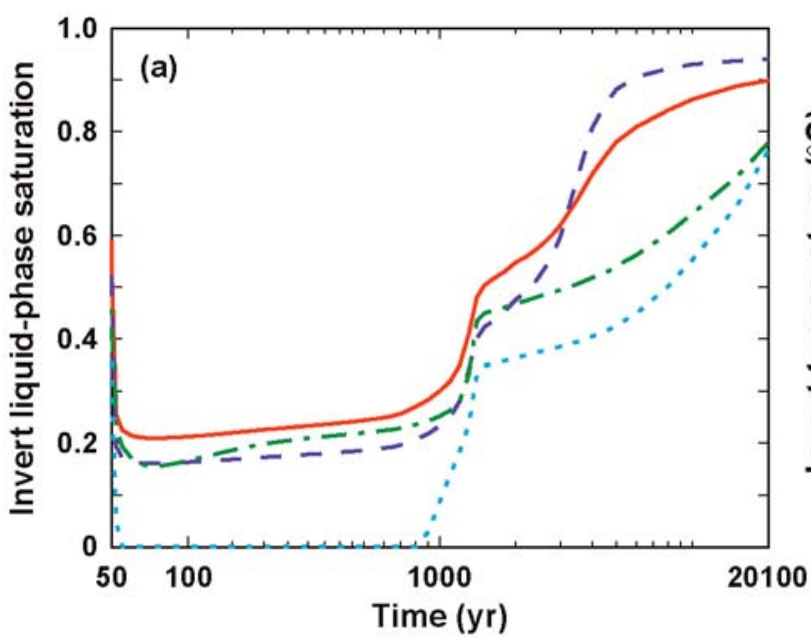

Source: See Table XIII-1.

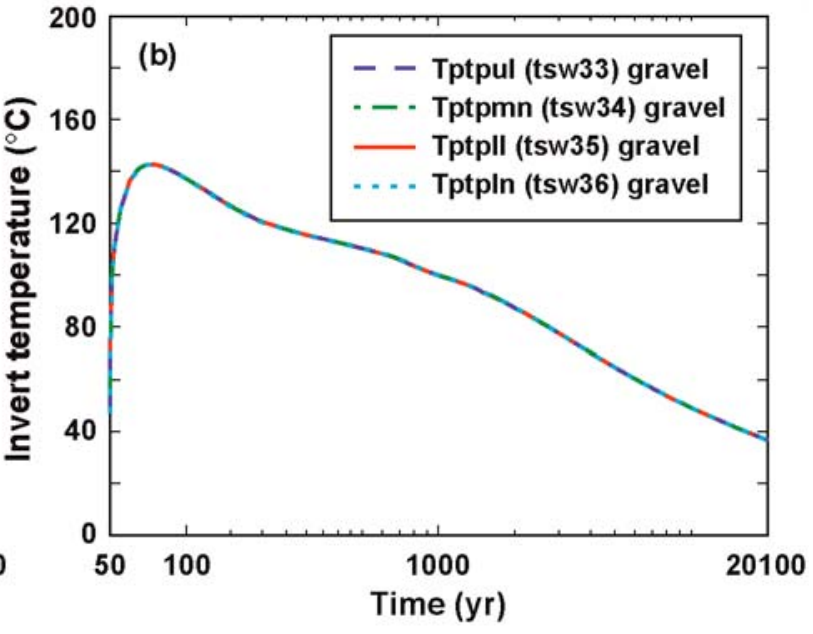

T_Sliq_invP2WR5C10_33-36

NOTE: Invert liquid-phase saturation and temperature histories are calculated by the LDTH submodel (Section 6.2.6) for an AML of $55 \mathrm{MTU} /$ acre and for a location close to the center of the repository (the P2WR5C10 location shown Figure 6.3-1) for the mean infiltration-flux case with mean host-rock thermal conductivity.

Figure 6.3-63. Invert Liquid-Phase Saturation for the Intragranular Porosity (a) and Temperature (b) at the Repository Center for Invert Gravel Derived from Each of the Indicated Host-Rock Units

Figure 6.3-64 plots temperature and relative humidity at different locations in the drift, including the host rock at the crown of the drift and below the invert, and at the top and bottom of the invert beneath the drip shield for crushed-tuff gravel derived from each of the host-rock units, respectively. Both temperature and relative humidity at those locations are insensitive to hydrologic properties of the intragranular porosity. This lack of sensitivity justifies the assumption discussed in Section 5.3.1.2. The small thermal conductivity in the invert results in a large vertical temperature gradient in the invert. This large temperature gradient results in a large relative-humidity gradient in the invert. Consequently, the top of the invert beneath the drip shield always has a much lower relative humidity than any location around the drift wall. As seen in Figure 6.3-64, this relationship (that relative humidity is always less at the top of the invert than at the drift wall) holds for all four of the crushed-tuff gravels (Tptpul, Tptpmn, Tptpll, and Tptpln). 

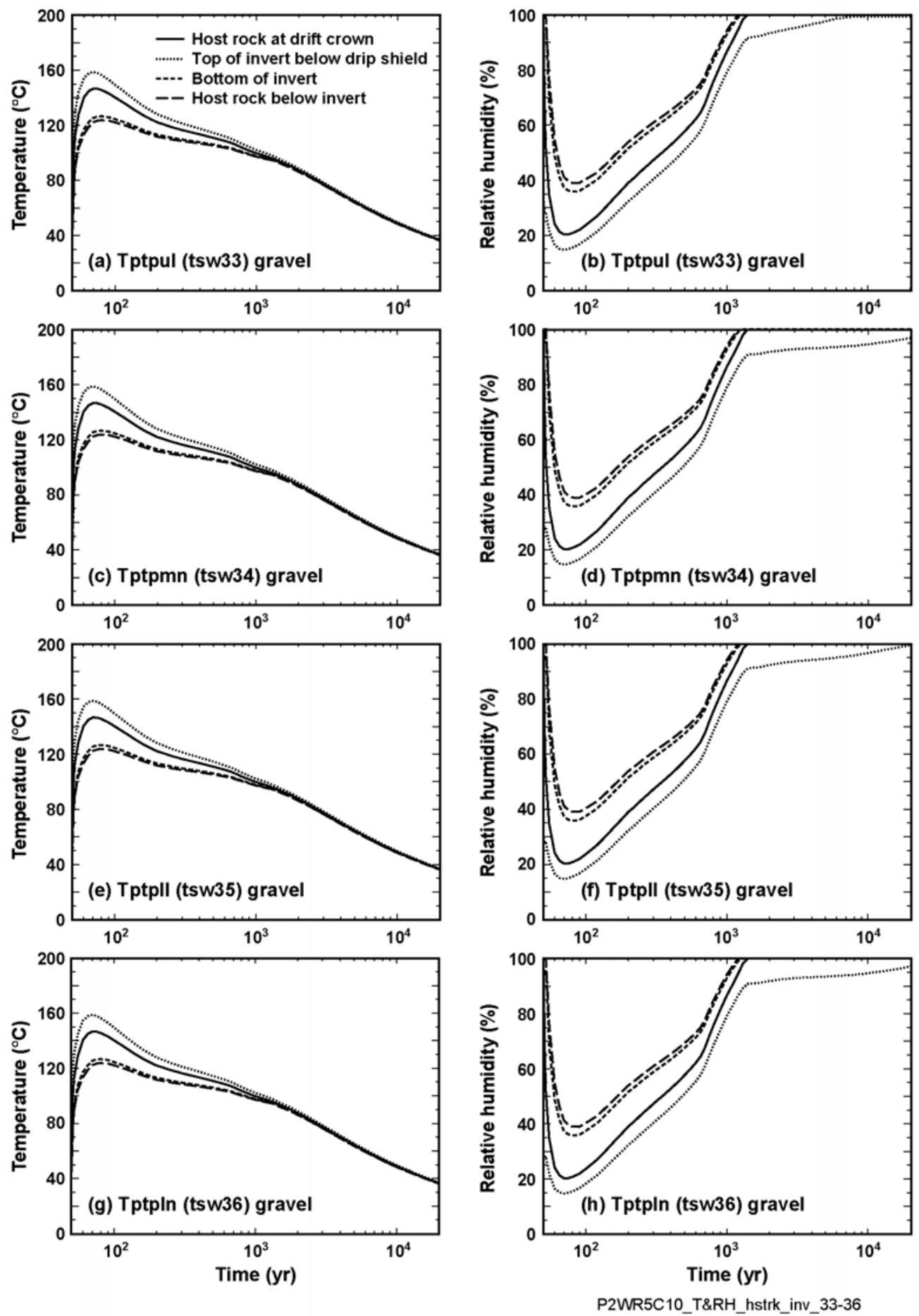

Source: See Table XIII-1.

NOTE: Temperature and relative humidity histories are calculated by the LDTH submodel (Section 6.2.6) for an AML of $55 \mathrm{MTU} / \mathrm{acre}$ and for a location close to the center of the repository (the P2WR5C10 location shown Figure 6.3-1) for the mean infiltration-flux case with mean host-rock thermal conductivity.

Figure 6.3-64. Temperature $(\mathrm{a}, \mathrm{c}, \mathrm{e}, \mathrm{g})$ and Relative Humidity $(\mathrm{b}, \mathrm{d}, \mathrm{f}, \mathrm{h})$ for Various Locations in the Drift at the Repository Center for Invert Gravel Derived from Each of the Indicated Host-Rock Units 
Table 6.3-45 lists the temperatures at the drift crown, drip-shield crown, top and bottom of the invert beneath the drip shield, and in the host rock below the invert. It is important to note that the temperature difference between the top and bottom of the invert is always greater than the temperature difference between the top of the invert and drip-shield crown. This observation has important implications for the consequences of the flux of water vapor longitudinally along the drift axis from hotter to cooler locations where it will condense. For any given drift cross section, the coolest and most humid location is always at the bottom of the invert. Therefore, water vapor that is transported longitudinally along the drift axis will have a greater tendency to condense at the bottom of the invert, where it is coolest and most humid. Moreover, much of the water vapor created by virtue of evaporation at the top of the invert will move downward by advection and binary gas-phase diffusion to the bottom of the invert (or into the host rock below), where it will condense.

Table 6.3-45. Summary of Temperature at Various Locations in Drift Cross Section, Including Host Rock at Drift Crown, Top and Bottom of Invert Beneath Drip Shield, and Host Rock Below Invert

\begin{tabular}{|c|c|c|c|c|c|}
\hline \multirow{2}{*}{$\begin{array}{c}\text { Time } \\
(y r)\end{array}$} & \multicolumn{5}{|c|}{ Temperature $\left({ }^{\circ} \mathrm{C}\right)$} \\
\hline & $\begin{array}{l}\text { Host Rock at } \\
\text { Drift Crown }\end{array}$ & $\begin{array}{l}\text { Crown of Drip } \\
\text { Shield }^{b}\end{array}$ & $\begin{array}{l}\text { Top of Invert } \\
\text { Beneath Drip } \\
\text { Shield }^{\mathrm{a}}\end{array}$ & $\begin{array}{l}\text { Bottom of } \\
\text { Invert Beneath } \\
\text { Drip Shield }^{\mathrm{a}}\end{array}$ & $\begin{array}{c}\text { Host Rock } \\
\text { Below Invert }^{\mathrm{a}}\end{array}$ \\
\hline 70. & 146.6 & 152.2 & 158.7 & 125.5 & 122.3 \\
\hline 100. & 140.1 & 144.2 & 149.3 & 124.4 & 122.1 \\
\hline 1000. & 99.7 & 100.9 & 102.1 & 97.7 & 97.2 \\
\hline 2000. & 87.3 & 88.0 & 88.7 & 86.5 & 86.2 \\
\hline 5000. & 64.5 & 64.9 & 65.4 & 63.9 & 63.8 \\
\hline 10,000 . & 49.0 & 49.3 & 49.7 & 48.6 & 48.5 \\
\hline 20,050 & 36.5 & 36.7 & 37.0 & 36.3 & 36.2 \\
\hline
\end{tabular}

a Temperatures correspond to Figure 6.3-64e.

b Temperatures obtained by applying the temperature difference between top of invert and crown of invert calculated using the DDT submodel.

Figure 6.3-65 plots the liquid-phase saturation for the intragranular porosity, temperature, and relative humidity at the top of the invert beneath the drip shield for five different sets of hydrologic properties for the intergranular porosity discussed above. Temperature, liquid-phase saturation, and relative humidity are all insensitive to the hydrologic properties of the intergranular porosity. This lack of sensitivity justifies the assumption discussed in Section 5.3.1.8. This lack of sensitivity also justifies not propagating invert hydrologic-property uncertainty through the MSTHM calculations supporting TSPA-LA. 

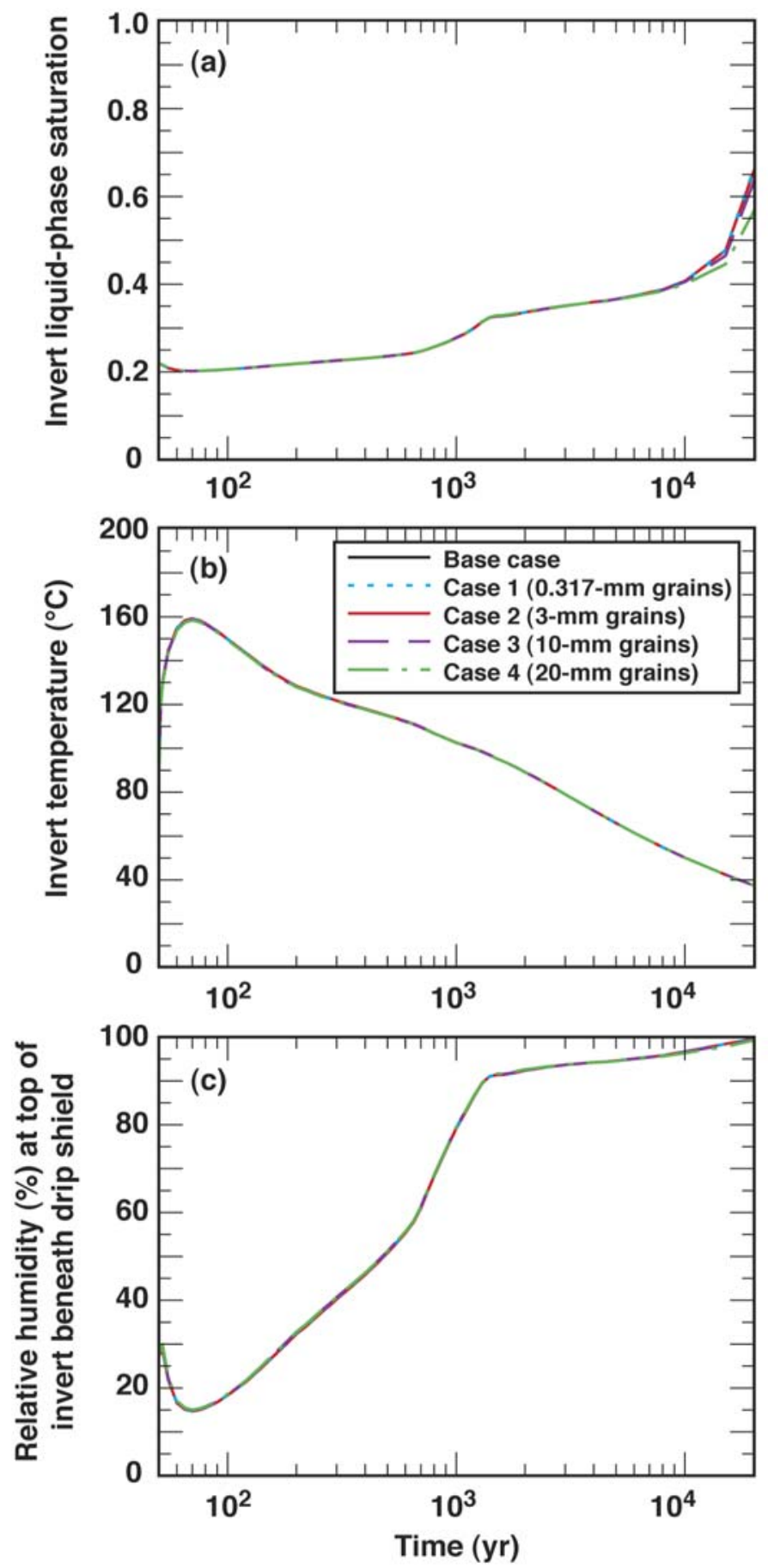

T-S-RH_inv_P2WR5C10_all-intergran

Source: See Table XIII-1.

NOTE: Liquid-phase saturation, temperature and relative humidity histories are calculated by the LDTH submodel (Section 6.2.6) for an AML of $55 \mathrm{MTU} /$ acre and for a location close to the center of the repository (the P2WR5C10 location shown Figure 6.3-1) for the mean infiltration-flux case with mean host-rock thermal conductivity.

Figure 6.3-65. Invert Liquid-Phase Saturation (a) for the Intragranular Porosity, Temperature (b), and Relative Humidity (c) at the Top of the Invert Beneath the Drip Shield at the Repository Center for Different Sets of Hydrologic Parameters for the Intergranular Porosity 


\subsubsection{Influence of Ventilation Heat-Removal Efficiency Uncertainty}

All MSTHM calculations in this report utilize the distance- and time-dependent ventilation heat-removal efficiency tables from DTN: MO0304MWDALACV.000 [DIRS 164551]. This section (Section 6.3-12) investigates the potential impact of uncertainty in ventilation heat-removal efficiency on in-drift thermal-hydrologic conditions. Five heat-removal efficiency cases are considered for a location close to the center of the repository, which is the P2WR5C10 location (see Figure 6.3-3 for location). These calculations use the LDTH submodel (Section 6.2.6) for an AML of 55 MTU/acre. The five cases include the base case, which applied a time-dependent heat-removal efficiency table from DTN: MO0304MWDALACV.000 [DIRS 164551]. The other four cases apply a constant heat-removal efficiency (i.e., constant during the 50-year ventilation period) for values of 70, 80, 90, and 100 percent efficiency. Note that the case with 100 percent efficiency is a hypothetical limiting case, which is equivalent to the surface storage of waste packages during the entire 50-year preclosure period. Figure 6.3-66 plots drip-shield temperature and relative humidity for these five cases. Note that the drip-shield temperature and relative-humidity temperatures for the base case lie between those of the 80- and 90-percent efficiency cases. Based on linear interpolation of peak drip-shield temperature (Table 6.3-45), the base case has an effective constant heat-removal efficiency of 83 percent.
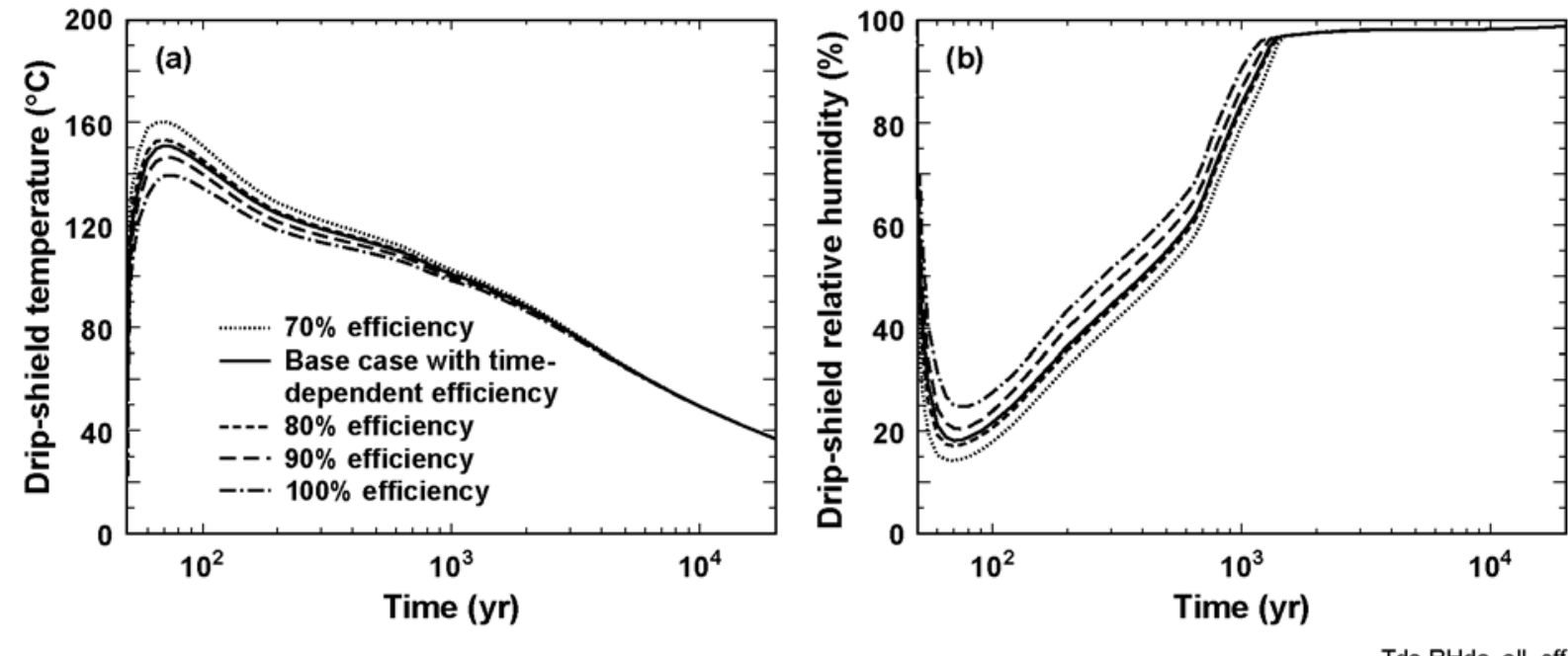

Source: See Table XIII-1.

NOTE: Temperature and relative humidity histories are calculated by the LDTH submodel (Section 6.2.6) for an AML of 55 MTU/acre and for a location close to the center of the repository (the P2WR5C10 location shown Figure 6.3-1) for the mean infiltration-flux case with mean host-rock thermal conductivity.

Figure 6.3-66. Drip-Shield Temperature (a) and Relative Humidity (b) at the Repository Center for Different Values of Ventilation Heat-Removal Efficiency 
Table 6.3-46. Peak Drip-Shield Temperature for Different Values of Ventilation Heat-Removal Efficiency

\begin{tabular}{|c|c|c|}
\hline $\begin{array}{c}\text { Ventilation Heat-Removal } \\
\text { Efficiency } \\
\text { (\%) }\end{array}$ & $\begin{array}{c}\text { Peak Drip-Shield Temperature } \\
\mathbf{( C}^{\mathbf{0}}\end{array}$ & $\begin{array}{c}\text { Peak Drip-Shield Temperature } \\
\text { Compared to Base Case } \\
\mathbf{( C}^{\mathbf{0}} \mathbf{)}\end{array}$ \\
\hline $\mathbf{7 0}$ & 160.4 & 9.4 \\
\hline $\mathbf{8 0}$ & 153.2 & 2.2 \\
\hline Base Case & 151.0 & 0.0 \\
\hline $\mathbf{9 0}$ & 146.3 & -4.7 \\
\hline $\mathbf{1 0 0}$ & 139.3 & -11.7 \\
\hline
\end{tabular}

NOTE: Drip-shield temperatures correspond to Figure 6.3-66.

Over the range of heat-removal efficiency of 70 to 100 percent, the range in the in-drift temperature and relative humidity conditions is less than that resulting from parametric uncertainty of percolation flux and host-rock thermal conductivity (Tables 6.3-27 through 6.3-29 and Figure 6.3-31). Moreover, the impact of the differences arising as a result of proximity to the repository edge, together with the impact of parametric uncertainty (Figure 6.3-53) is much greater than that arising from uncertainty in ventilation heat-removal efficiency. Therefore, uncertainty in ventilation heat-removal efficiency does not need to be propagated through the MSTHM results supporting the TSPA-LA.

\subsubsection{Relationship Between Temperature and Relative Humidity on Waste Packages}

Figure 6.3-67 plots the range of temperature histories for all waste packages across the repository, accounting for the influence of parametric uncertainty of host-rock thermal conductivity and percolation flux above the repository. Note that a comprehensive discussion of the influence of parametric uncertainty on in-drift and near-field thermal-hydrologic conditions is given in Section 6.2.4. Figure 6.3-68 plots the corresponding range of waste package relative humidity histories across the repository. Figure 6.3-69 plots the corresponding range of temperature versus relative humidity trajectories, during cooldown (i.e., after the waste package temperature has peaked). Also plotted on these three figures are histories and trajectories for three distinct waste packages, including (1) a cool DHLW waste package close to the edge of the repository, (2) an average BWR waste package at the center of the repository, and (3) a hot PWR waste package at the edge of the repository. The temperature versus relative humidity trajectories are important to the evolution of the chemical environment on waste packages. 


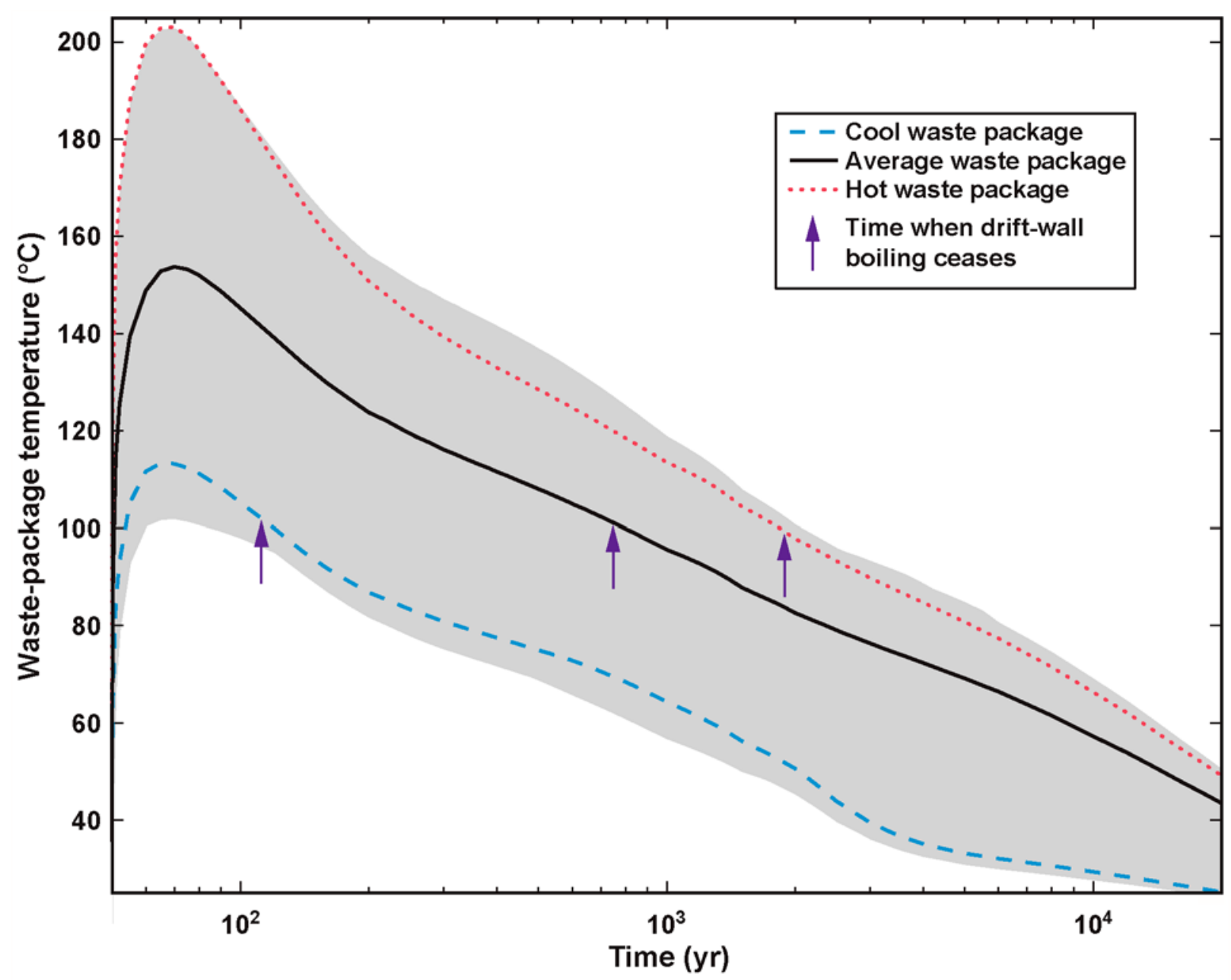

Twp_his_3WPs_env

Source: See Table XIII-1.

NOTE: $\quad$ Also plotted are the temperature histories of three distinct waste packages, including (1) a cool DHLW waste package at the edge of the repository, (2) an average BWR waste package at the center of the repository, and (3) a hot PWR waste package at the center of the repository. The upward arrows indicate the time when boiling ceases at the drift wall. The range of waste package temperature histories is the same as that given in Figure 6.3-53a.

Figure 6.3-67. Range of Temperature Histories for All Waste Packages, Accounting for Uncertainty of Host-Rock Thermal Conductivity and Percolation Flux 


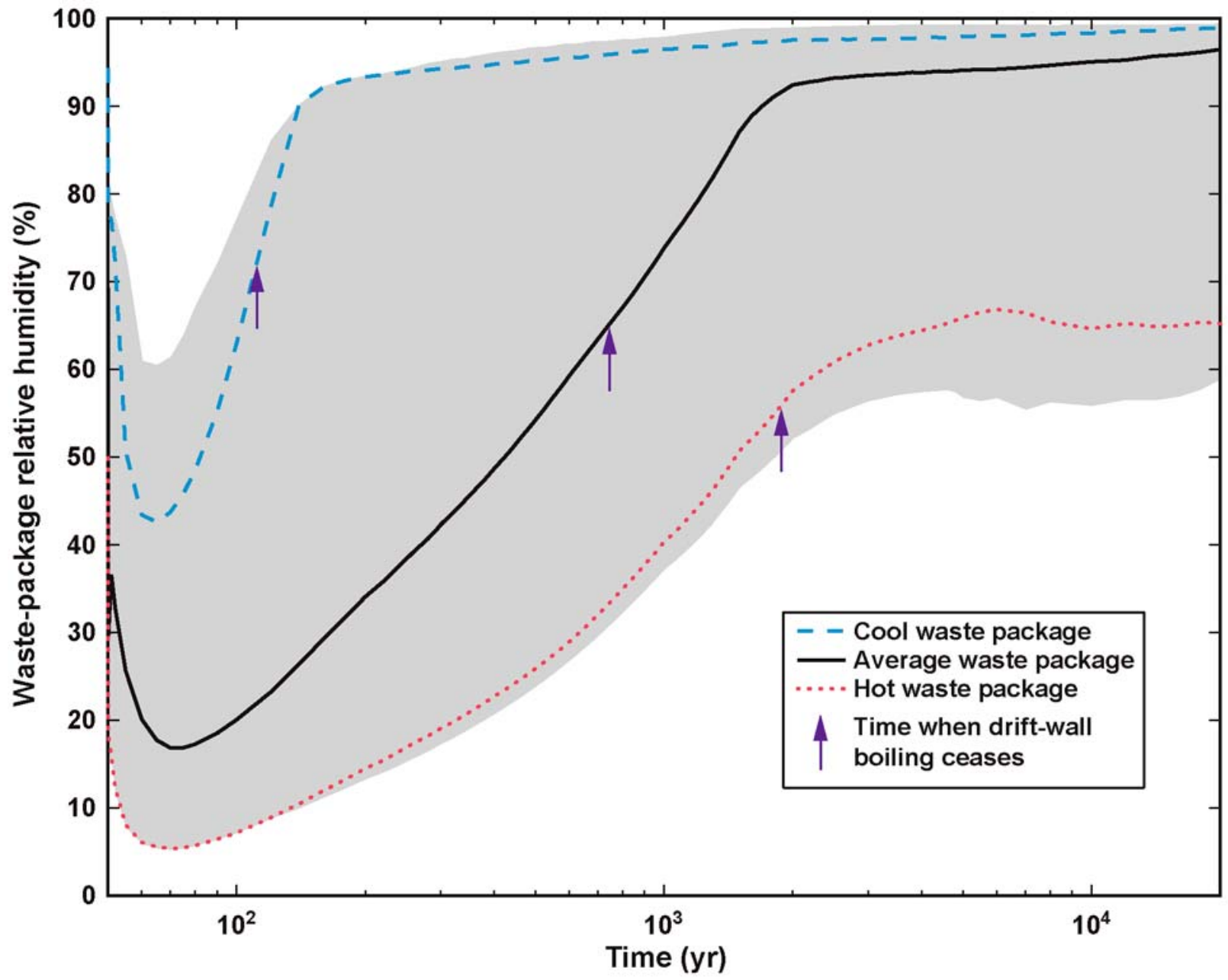

RHwp_his_3WPs_env

Source: See Table XIII-1.

NOTE: $\quad$ Also plotted are the relative-humidity histories of three distinct waste packages, including (1) a cool DHLW waste package at the edge of the repository, (2) an average BWR waste package at the center of the repository, and (3) a hot PWR waste package at the center of the repository. The upward arrows indicate the time when boiling ceases at the drift wall. The range in waste package relative-humidity histories is the same as that given in Figure 6.3-53b.

Figure 6.3-68. Range of Relative Humidity Histories for All Waste Packages, Accounting for Uncertainty of Host-Rock Thermal Conductivity and Percolation Flux 


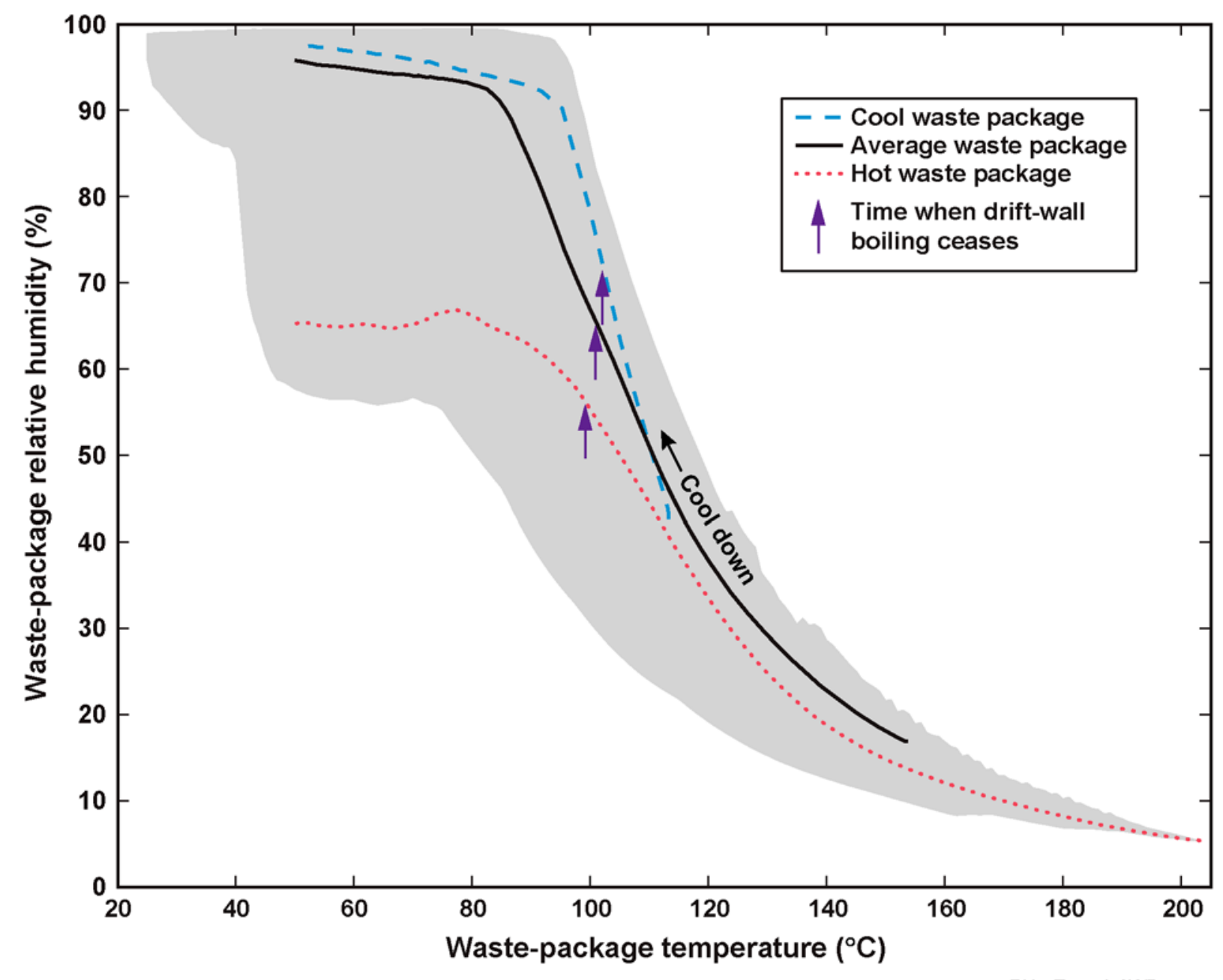

Source: See Table XIII-1.

NOTE: $\quad$ Also plotted are the temperature versus relative-humidity trajectories, during cooldown, of three distinct waste packages, including (1) a cool DHLW waste package at the edge of the repository, (2) an average BWR waste package at the center of the repository, and (3) a hot PWR waste package at the center of the repository. The upward arrows indicate the time when boiling ceases at the drift wall.

Figure 6.3-69. Range of Temperature vs. Relative Humidity Trajectories for All Waste Packages, During Cooldown, Accounting for Uncertainty in Host-Rock Thermal Conductivity and Percolation Flux

\subsection{COMPARISON AGAINST AN ALTERNATIVE CONCEPTUAL MODEL}

An alternative conceptual model to the MSTHM is a mountain-scale thermal-hydrologic model developed by LBNL (Haukwa et al. 1998 [DIRS 117826]). The LBNL model is a monolithic thermal-hydrologic model. Note that the three-drift repository MSTHM model validation test case (Section 7.5) also used a monolithic thermal-hydrologic model to compare against the MSTHM. There is an important distinction between how the monolithic thermal-hydrologic model was used in Section 7.5 and how the LBNL monolithic thermal-hydrologic model is being used in this section (Section 6.4). In Section 7.5, the MSTHM and monolithic thermal-hydrologic model representation of the model validation test problem are essentially equivalent in a number of important respects, including (1) gridblock discretization at the drift 
scale, (2) heat-generation-rate-versus-time tables, (3) representation of in-drift heat-flow processes, and (4) hydrologic and thermal properties used in the respective models. In Section 6.4, the MSTHM and corresponding LBNL thermal-hydrologic model were similar, but not identical in any of these aspects. As discussed below, the LBNL thermal-hydrologic model used (1) coarser grid discretization at the drift scale than the MSTHM, (2) a line-averaged approximation of the heat-generation-rate-versus-time table (whereas the MSTHM represented the waste packages as discrete heat sources), and (3) a lumped heat source that filled the entire cross section of the emplacement drift.

Before discussing the comparison study between the MSTHM and an alternative conceptual model, it is noted that there are several differences between the version of the MSTHM used at the time of this comparison study (Buscheck et al. 1998 [DIRS 148521]) and the version of the MSTHM used to support TSPA-LA (as described in this report). These differences fall under the following categories.

1. Repository layout: As seen in comparing Figure 6.2-3 with Figures 5.1, 5.2, and 6.1 of BSC 2001 [DIRS 158204], both the repository layout and the MSTHM representation of the layout have changed. The current version of the MSTHM utilizes 108 drift-scale submodel locations, while the previous version of the MSTHM utilizes 31 locations. The current version explicitly represents each emplacement drift, while the previous version does not.

2. Drift ventilation: The current version of the MSTHM represents how heat-removal efficiency from drift ventilation varies as a function of time and distance along each of the emplacement drifts, given in DTN: MO0304MWDALACV.000 [DIRS 164551], while the previous version used a single value of heat-removal efficiency for the entire repository, which is held constant during the preclosure ventilation period.

3. Percolation flux: The current version of the MSTHM represents the influence of lateral diversion in the PTn by using the percolation-flux distribution (from the base of the PTn unit into the top of the TSw sequence of units) calculated by UZ Flow Models and Submodels (BSC 2004 [DIRS 169861]). Because the previous version used the infiltration maps at the ground surface from DTN: GS000308311221.005 [DIRS 147613], it did not represent the influence of lateral diversion in the PTn.

Because these differences also pertain to the alternative conceptual model, they do not affect the usefulness of the comparison between the MSTHM and that model.

Figure 6.4-1 compares the drift-wall temperature predicted by the MSTHM (Buscheck et al. 1998 [DIRS 148521]) with those predicted by an east-west cross-sectional mountain-scale thermal-hydrologic model (Haukwa et al. 1998 [DIRS 117826]). Because the east-west thermal-hydrologic model does not predict in-drift thermal-hydrologic conditions and because relative humidity and liquid-phase saturation was not provided from that model, the comparison is restricted to predictions of drift-wall temperatures by the respective modeling approaches. 
(a) repository center at $14 \mathrm{c3}$ location

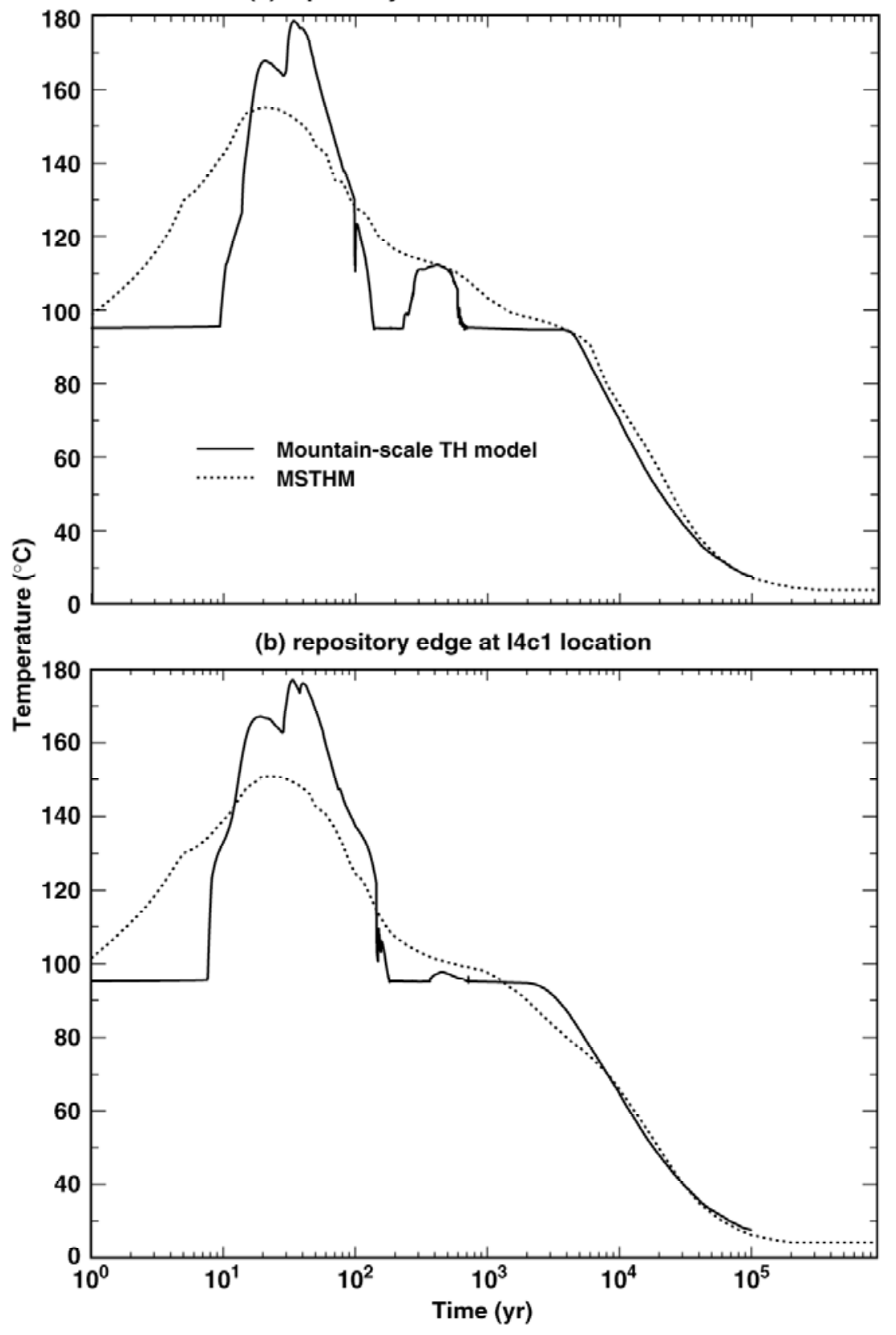

NOTE: This comparison of predicted temperatures at (a) center of the repository (14c3 location in Buscheck et al. 1998 [DIRS 148521], Table 2-2) and (b) $100 \mathrm{~m}$ from the edge of the repository (I4c1 location) is run for the 12/97 TSPA-VA base-case I1 $\times 1 \alpha_{\mathrm{f}, \text { mean }}$ parameter set, where the symbol I stands for the nominal infiltration flux $q_{\text {inf }}$ map (average $q_{\text {inf }}=7.8 \mathrm{~mm} / \mathrm{yr}$ ) for the present-day climate and the parameter $\alpha_{\mathrm{f}}$ is the van Genuchten "alpha" parameter for fractures. The MSTHM is used to predict drift-wall temperature adjacent to an "average" 21-PWR medium-heat CSNF waste package. The east-west cross-sectional mountain-scale thermal-hydrologic model (Haukwa et al. 1998 [DIRS 117826]) is used to predict the drift temperature, which is averaged over the cross section of the drift, arising from a line-averaged heat-source representation of waste package decay heat.

Figure 6.4-1. Comparison of Predicted Temperatures at (a) the Center of the Repository and (b) $100 \mathrm{~m}$ from the Edge of the Repository 
Before discussing the differences in the temperatures predicted by the two approaches (Figure 6.4-1), it is important to discuss the differences in the models. The temperature predicted by the MSTHM is the perimeter-averaged drift-wall temperature adjacent to an "average" 21-PWR medium-heat CSNF waste package. MSTHM discretely represents the decay-heat source from individual waste packages; therefore, some of the drift-wall locations are hotter than that shown in Figure 6.4-1, while some are considerably cooler. The drift-wall gridblocks over which the temperature is averaged extend $0.5 \mathrm{~m}$ into the host rock surrounding the drift. The temperature prediction in the east-west cross-sectional mountain-scale thermal-hydrologic model is for a gridblock that occupies the entire cross section of the drift; therefore, it is a lumped representation of the drift temperature. Moreover, because the east-west cross-sectional mountain-scale model uses a line-averaged heat source, it axially smears out the differences between "hot" and “cold” waste package locations along the drift.

Another difference between the modeling approaches concerns the mountain-scale dimensionality. The MSTHM represents three-dimensional mountain-scale heat flow for the entire extent of the heated repository footprint, while the east-west cross-sectional mountain-scale thermal-hydrologic model has a reflected boundary at the east-west midpoint of the repository. Thus, the east-west model assumes that the overburden thickness of the entire repository area can be approximated with the overburden thickness between the western repository boundary and the midpoint of the repository. Because the eastern half of the repository has much less overburden thickness than the western half, this east-west symmetry approximation effectively over represents the effective overburden thickness for the eastern half of the repository. The cross-sectional geometry of the east-west mountain-scale model implicitly assumes that mountain-scale heat loss in the north-south dimension is insignificant, which is a reasonable assumption given the large north-south dimension of the repository.

Another difference between the two modeling approaches concerns the areal power density applied in the respective models. The initial areal power density in the MSTHM is 92.3 $\mathrm{kW} / \mathrm{acre}$, while it is $99.4 \mathrm{~kW} / \mathrm{acre}$ in the east-west cross-sectional mountain-scale model. Thus, the east-west model has a 7.7 percent larger areal power density than does the MSTHM (Buscheck et al. 1998 [DIRS 148521], p. 3-10).

At the center of the repository (the 14c3 location in Buscheck et al. 1998 [DIRS 148521], Table 2-2) the respective modeling approaches predict almost an identical duration of boiling (Figure 6.4-1a). At the edge repository location, which is $100 \mathrm{~m}$ from the western edge of the repository in the MSTHM (the 14c1 location in Buscheck et al. 1998 [DIRS 148521], Table 2-2), the east-west cross-sectional mountain-scale model predicts a longer duration of boiling than does the MSTHM (Figure 6.4-1b). One reason for this difference is that the east-west model representation of the heated repository footprint extends slightly further to the west than in the MSTHM.

During the postboiling period, the temperatures predicted by the respective modeling approaches are in good agreement. During the early time heat-up period, the coarse (lateral and axial) grid-block spacing in the east-west cross-sectional mountain-scale model does not capture the rapid drift-wall temperature rise that the more finely gridded MSTHM predicts. Because of the coarse lateral grid-block spacing in the east-west model, it smears out the lateral temperature gradient between the drift and the mid-pillar location. Therefore, it tends to overpredict the temperature at the mid-pillar location and thereby prevent condensate from shedding between 
drifts. The fine lateral grid-block spacing in the MSTHM captures the influence that the lateral temperature gradient has on allowing condensate to shed between drifts. The tendency for the east-west cross-sectional mountain-scale model to underrepresent condensate shedding results in a more substantial condensate buildup above the repository horizon. Also, the line-averaged heat-source approximation smears out differences in temperature between otherwise "hot" and "cold" waste package locations and thereby preventing condensate from breaking through "cold" waste package locations along the drift. Altogether, the underprediction of condensate shedding between drifts and condensate breakthrough at "cold" waste package locations causes the east-west cross-sectional mountain-scale model to build up more condensate above the repository horizon that leads to episodic heat-pipe behavior. This episodic behavior is exhibited by the rapid decline from superheated conditions to heat-pipe conditions (Figure 6.4-1a) and the rapid rise once again to superheated conditions at about 400 years. Notice that during the second superheated period predicted by the east-west model, the temperature climbs to be almost exactly that predicted by the MSTHM.

Given the differences between the MSTHM and the east-west cross-sectional mountain-scale model, the agreement between the two models is adequate. Moreover, the differences in predicted temperatures between the MSTHM and the east-west cross-sectional mountain-scale model are within the range of temperature differences resulting from parametric uncertainty (Tables 6.3-30 and 6.3-31). Therefore, the impact of conceptual-model uncertainty is no larger than that of parametric uncertainty. On the basis of this comparison, it is determined that the MSTHM is validated for its intended use.

\subsection{FEPS}

The development of a comprehensive list of features, events, and processes (FEPs) potentially relevant to postclosure performance of the Yucca Mountain repository is an ongoing, iterative process based on site-specific information, design, and regulations. The approach for developing an initial list of FEPs in support of TSPA-SR (CRWMS M\&O 2000 [DIRS 153246]) was documented in The Development of Information Catalogued in REV00 of the YMP FEP Database (BSC 2001 [DIRS 154365]). The initial FEP list contained 328 FEPs, of which 176 were included in the TSPA-SR models (CRWMS M\&O 2000 [DIRS 153246], Tables B-9 to B-17). To support TSPA-LA, the FEP list was re-evaluated in accordance with The Enhanced Plan for Features, Events, and Processes (FEPs) at Yucca Mountain (BSC 2002 [DIRS 158966], Section 3.2). Table 6.5-1 provides a listing of FEPs. 
Table 6.5-1. FEPs Addressed by This Report

\begin{tabular}{|c|c|c|}
\hline FEP & Name & Section Where Disposition is Addressed \\
\hline 2.1.06.06.0A & $\begin{array}{l}\text { Effects of drip } \\
\text { shield on flow }\end{array}$ & 6.3 \\
\hline 2.1.08.03.0A & $\begin{array}{l}\text { Repository dry-out } \\
\text { due to waste heat }\end{array}$ & 6.3 \\
\hline 2.1.08.04.0A & $\begin{array}{l}\text { Condensation } \\
\text { forms on roofs of } \\
\text { drifts (drift-scale } \\
\text { cold traps) }\end{array}$ & 7.5 and 6.3 \\
\hline 2.1.08.04.0B & $\begin{array}{l}\text { Condensation } \\
\text { forms at repository } \\
\text { edges (repository- } \\
\text { scale cold traps) }\end{array}$ & 7.5 \\
\hline 2.1.08.05.0A & Flow through invert & 6.3 \\
\hline 2.1.08.06.0A & $\begin{array}{l}\text { Capillary effects } \\
\text { (wicking) in EBS }\end{array}$ & 6.3 \\
\hline 2.1.08.11.0A & $\begin{array}{l}\text { Repository } \\
\text { resaturation due to } \\
\text { waste cooling }\end{array}$ & 6.3 \\
\hline 2.1.11.01.0A & $\begin{array}{l}\text { Heat generation in } \\
\text { EBS }\end{array}$ & 6.3 \\
\hline 2.1.11.02.0A & $\begin{array}{l}\text { Non-uniform heat } \\
\text { distribution in EBS }\end{array}$ & 6.3 \\
\hline 2.1.11.09.0A & $\begin{array}{l}\text { Thermal effects on } \\
\text { flow in the EBS }\end{array}$ & 6.3 and 7.5 \\
\hline
\end{tabular}




\section{MODEL VALIDATION}

AP-SIII.10Q requires that TSPA model components be validated for their intended purpose and stated limitations, and to the level of confidence required by a component's relative importance to the performance of the repository. Section 1 of this report provides the intended use of the MSTHM and the model limitations.

The governing technical work plan (BSC 2004 [DIRS 170950], Section 2.3.2) identifies Level II as the appropriate level of validation for the MSTHM. The appropriateness of Level II is based on the position that the outputs of this model are judged to be of moderate importance because they may impact TSPA dose results and are therefore used for demonstration of regulatory compliance.

\subsection{CONFIDENCE BUILDING DURING MODEL DEVELOPMENT TO ESTABLISH SCIENTIFIC BASIS AND ACCURACY FOR INTENDED USE}

In accordance with AP-2.27Q, Planning for Science Activities, Level II validation includes a discussion of model development. In particular, this report documents decisions implemented during model development that build confidence and verify that a reasonable, credible technical approach using scientific and engineering principles was taken. The development of the model is documented in accordance with the requirements of Section 5.3.2(b) of AP-SIII.10Q and Attachment 3 of AP-2.27Q. The development of the multiscale thermohydrologic model has been conducted according to these criteria, as follows:

1. Selection of input parameters and/or input data, and a discussion of how the selection process builds confidence in the model. [AP-SIII.10Q 5.3.2(b) (1) and AP-2.27Q Attachment 3 Level I (a)]

The inputs to the multiscale thermohydrologic model have all been obtained from controlled sources. All data for the natural system are from studies specific to the site (Section 4.1.1). All design information is from IEDs (Section 4.1.2). Section 4.1 includes a discussion about selection of input and design parameters. The input data and information and their sources are summarized in Table 4.1-1. Table 4.1-2 summarizes changes to the waste package and drip shield information that occurred during model development. The details of the relative impacts of these changes are discussed in sections 4.1.2.1 through 4.1.2.7. Additional discussion of material properties used, including the rationale for use, are contained in Section 5.3.

2. Description of calibration activities, and/or initial boundary condition runs, and/or run convergences, simulation conditions set up to span the range of intended use and avoid inconsistent outputs, and a discussion of how the activity or activities build confidence in the model. Inclusion of a discussion of impacts of any non-convergence runs[AP-SIII.10Q 5.3.2(b)(2) and AP-2.27Q Attachment 3 Level I (e)].

Initial and boundary conditions for the MSTHM calculations of repository performance are based on inputs from other project documents (Section 4.1) and the assumptions are documented in Section 5. Descriptions of design features are documented in IEDs. Predicted efficiency of the ventilation system is documented in Ventilation Model and Analysis Report (BSC 2004 [DIRS 169862]). Surface and water table conditions are 
documented in Mountain-Scale Coupled Processes (TH/THC/THM) (BSC 2004 [DIRS 169866]). Percolation fluxes are documented in UZ Flow Models and Submodels (BSC 2004 [DIRS 169861]). These inputs were sufficient to define complete initial and boundary conditions for the MSTHM submodels which can be found in Sections 6.2.5, 6.2.6, 6.2.7, and 6.2.8. Additional simulation cases were set up to cover the low probability seismic collapsed-drift scenario in Sections 6.2.9, 6.2.10, and 6.2.11. Results are presented in Section 6.3. The MSTHM addresses the three-dimensional spatial and temporal (e.g., percolation flux and ventilation heat-removal efficiency) distribution of natural-system parameters, boundary conditions, and design information that influence the thermal-hydrologic response throughout the repository, which assures consistency of the MSTHM outputs. The MSTHM predictions have been thoroughly inspected, as displayed in plots and tables throughout Section 6.3, and thoroughly tested, by way of sensitivity analyses documented in Section 6.3, to assure the reasonableness and appropriateness of the MSTHM outputs.

3. Discussion of the impacts of uncertainties to the model results including how the model results represent the range of possible outcomes consistent with important uncertainties.[AP-SIII.10Q 5.3.2(b)(3) and AP-2.27Q Attachment 3 Level 1 (d) and (f)].

Discussion of model uncertainties and their impacts on model results are provided in Section 6.3.1 which discusses the TSPA-LA base case, Section 6.3.4 which discusses the combined influences of percolation-flux and host-rock thermal conductivity uncertainty, and Section 6.3.7 which discusses the influence of a low-probability-seismic collapsed-drift scenario on in-drift thermal-hydrologic conditions relative to the TSPA-LA base case.

4. Formulation of defensible assumptions and simplifications. [AP-2.27Q Attachment 3 Level I (b)].

Discussion of assumptions and simplifications are provided in Sections 5, 6.1, and 6.2. Additional discussion of simplifications can be found in Appendix IX.

5. Consistency with physical principles, such as conservation of mass, energy, and momentum. [AP-2.27Q Attachment 3 Level I (c)]

Consistency with physical principles is demonstrated by the conceptual and mathematical formulations for the mass and energy balance equations in Section 6.2.3 and the selection and use of the NUFT code based on those physical principles.

The purpose of the MSTHM plays a key role in its validation. The purpose of the MSTHM is to predict the possible range of thermal-hydrologic conditions, resulting from uncertainty and variability, in the repository emplacement drifts, and in the adjoining host rock for the repository at Yucca Mountain. Thus, the goal is to predict the range of possible thermal-hydrologic responses across the repository; this is quite different from predicting a single expected thermal-hydrologic response. This range in thermal-hydrologic conditions must capture the influence of the key processes and conditions, including the uncertainty and variability associated with those processes and conditions. Thus, the influence of conceptual-model 
uncertainty must be judged relative to the influence of parametric uncertainty on the range of predicted thermal-hydrologic responses.

The propagation of parametric uncertainty in the MSTHM addresses the two key natural system parameters: host-rock thermal conductivity and percolation flux. A sensitivity study of the influence of hydrologic-property uncertainty supports the conclusion that hydrologic-property uncertainty does not need to be propagated in the MSTHM calculations of in-drift temperature and relative humidity. The propagation of percolation-flux uncertainty and host-rock thermal conductivity uncertainty on repository-wide MSTHM output is captured with five infiltration-flux host-rock thermal conductivity cases (Table 6.3-37). For these five data sets, the range in peak drift-wall temperature is from $92.3^{\circ} \mathrm{C}$ to $175.2^{\circ} \mathrm{C}$, with a median drift-wall temperature of $133.0^{\circ} \mathrm{C}$; the range in peak waste package temperature is from $102.0^{\circ} \mathrm{C}$ to $203.1^{\circ} \mathrm{C}$, with a median waste package temperature of $153.3^{\circ} \mathrm{C}$ (Table $6.3-38$ ). These five cases also result in a wide range of waste package relative-humidity histories as is shown in Figure 6.3-53. For the five infiltration-flux host-rock thermal conductivity cases, the time when drift-wall boiling ceases ranges from no boiling to 2,176.5 years, with a median time of 721.0 years (Table 6.3-39). The percentage of waste packages that may experience no boiling at the drift wall is extremely low $(0.01 \%$ of all waste packages in the repository).

The validation of the MSTHM involves the validation of both the MSTHM methodology and the submodels, or components, used in the MSTHM. Note that all MSTHM submodels (called the SDT, SMT and DDT submodels) are executed with the NUFT v3.0s code (Section 3.1.1). Because the SDT, SMT and DDT submodels are conduction-only calculations, which utilize standard scientific methods (e.g., Fourier's Law) to perform the calculations, they do not require separate validation in this report in the manner that is applied to the LDTH submodel. Moreover, the SDT, SMT, and DDT submodels are never applied as "stand-alone" models for analysis, as is the case for the LDTH submodel (e.g., Section 6.3.9). It should be noted that validation testing of the NUFT v3.0s code included conduction-only test problems (bmrk002 and verif02), which are described in the Validation Test Plan for NUFT 3.0s (LLNL 2002 [DIRS 170259]; LLNL 2000 [DIRS 170258]). These conduction-only test problems are sufficient to validate the usage of the conduction-only submodels in the MSTHM. In Section 7.5, the MSTHM is validated as a whole. However, it would be inappropriate to validate the individual components (or submodels) of the MSTHM as independent entities in Section 7.5 because they do not function as independent entities within the MSTHM methodology. The LDTH submodel is validated in Section 7.4 against the Drift Scale Test, because it is sometimes applied in this report as a "stand-alone" model to conduct sensitivity analyses (e.g., see Section 6.3.9).

The manner in which the MSTHM utilizes the SDT, SMT, and DDT submodels is justified and further described in Sections 5.3.2.1 and 6.2.4. The DDT submodel represents thermal radiation inside the emplacement drifts and also represents the influence of natural convective heat flow in the drifts through the use of an equivalent thermal conductivity that is based on a correlation given by Francis et al. (2003 [DIRS 164602], Table 6) (Section 6.2.8.5). Thus, the DDT does not model natural convection in the drift; it uses a correlation derived elsewhere as indicated. The software qualifications of NUFT v3.0s and NUFT v3.0.1s include test problems that demonstrate the validity of NUFT in modeling a one-dimensional thermal-conduction problem (bmrk 002), a three-dimensional thermal-conduction problem (verif02), and a three-dimensional thermal-radiation problem (verif03) (LLNL 2002 [DIRS 170259]; LLNL 2000 [DIRS 170258]). 
The NUFT code uses an industry-standard finite-difference method that solves the mass balance of water and air and an energy balance.

\subsection{CONFIDENCE BUILDING AFTER MODEL DEVELOPMENT TO SUPPORT THE SCIENTIFIC BASIS OF THE MODEL}

Level II validation must include at least one postdevelopment method described in Paragraph 5.3.2c of AP-SIII.10Q. The governing TWP (BSC 2004 [DIRS 170950], Section 2.3.3) describes two such activities. One is a corroboration of model results with data acquired from the Drift Scale Test (DST).

The other validation method is a comparison to a validation case, consisting of a porous-medium simulation of multiple emplacement drifts and the rock surrounding them. The validation case utilizes an alternative model, which is a monolithic three-dimensional thermohydrologic model. The results from the alternative model are compared with those from an implementation of the MSTHM methodology specifically pertaining to the validation case. The locations for comparison include the repository center and the repository edge.

In addition to the postdevelopment validation activities listed in the TWP, this section reports two other confidence-building comparisons. One is a comparison of results against the Large Block Test (LBT). The other is a comparison of MSTHM results against alternative numerical models. All of these comparisons are summarized in the following list and described in greater detail throughout the remainder of this section:

- Comparison of NUFT LDTH submodel results against the Large Block TestThermal Tests Thermal-Hydrological Analyses/Model Report (CRWMS M\&O 2000 [DIRS 146921], Section 6.2.4) documents the comparison of NUFT thermal-hydrologic model calculations against measurements made in the Large Block Test. This confidence-building activity supplements the activities required by the TWP and therefore has no specific validation criterion. The difference between the modeled and field-measured thermal-hydrologic behavior is compared with the impact of parameter uncertainty on thermal-hydrologic behavior. A summary of this comparison is given in Section 7.3. The NUFT thermal-hydrologic model used in this confidence-building study is a three-dimensional equivalent to the two-dimensional LDTH submodels (Section 6.2.6) used in the MSTHM. These thermal-hydrologic calculations used NUFT v3.0s (Section 3.1.1). The sources of the test data are listed in Table 4.4-1.

- Comparison of NUFT LDTH submodel results against the Drift Scale TestSection 7.4 documents the comparison of NUFT thermal-hydrologic model calculations against measurements made in the Drift Scale Test. The adequacy of the agreement between the modeled and field-measured thermal-hydrologic behavior is judged in light of the impact of parameter uncertainty on thermal-hydrologic behavior. The NUFT thermal-hydrologic model used in this validation study is a three-dimensional equivalent to the two-dimensional LDTH submodels (Section 6.2.6) used in the MSTHM. These thermal-hydrologic calculations used NUFT v3.0.1s (Section 3.1.2), which is essentially identical to NUFT v3.0s except that NUFT v3.0.1s is able to address nested-mesh problems having a large number of nests, while NUFT v3.0s can handle nested meshes with two nests. One validation criterion for this comparison is that temperature changes 
should agree within 30 percent for the heating phase (BSC 2004 [DIRS 170950], Section 2.2.5). The 30-percent validation criterion for temperature rise (above ambient) is consistent with the magnitude of the influence of the parametric uncertainty of host-rock thermal conductivity and percolation flux on temperature. As shown in Table 6.3-30, the combined influence of host-rock thermal conductivity uncertainty and percolation-flux uncertainty causes the rise in peak drift-wall temperature (above ambient) to vary by about 30 percent. Differences greater than 30 percent may be accepted if they resulted from short-term or localized transients in the test conditions, or from instrument response. Another criterion is that matrix liquid saturation trends should be qualitatively the same with respect to location and direction. Table 4-9 lists the sources for results of the Drift Scale Test.

- Comparison of the MSTHM results against a monolithic three-dimensional thermal-hydrologic model-Using a three-drift repository test case (which is a scaled-down version of the repository), the validity of the MSTHM approach is demonstrated by comparing the results of the MSTHM against a corresponding monolithic three-dimensional thermal-hydrologic model that uses a nested mesh. This validation test case is similar to that reported by Buscheck et al. (2003 [DIRS 164638]). A summary of this comparison is given in Section 7.5. For this comparison, NUFT v3.0s is used for the MSTHM calculations, while NUFT v3.0.1s is used in the corresponding monolithic three-dimensional thermal-hydrologic model that uses a nested mesh. The validation criterion for this comparison is based on the maximum model-to-model differences for changes in temperature or relative humidity at either of the two representative locations (representing the repository center and edge), at any time during the simulation. The criterion is that each maximum difference must be smaller than a range of uncertainty in the relevant parameter. The pertinent range of uncertainty is the range in the results generated by the MSTHM for ranges of percolation flux and host rock thermal conductivity in full-repository simulations (BSC 2004 [DIRS 170950], Section 2.2.5). These results are propagated to TSPA (BSC 2004 [DIRS 170950], Section 2.2.4).

- Comparison of MSTHM results against alternative numerical models-Buscheck et al. (1998 [DIRS 148521]) document a comparison between the results of the MSTHM against a three-dimensional east-west cross-sectional mountain-scale thermal-hydrologic model developed at Lawrence Berkeley National Laboratory (Haukwa et al. 1998 [DIRS 117826]). This confidence-building activity is another supplement to the activities required by the TWP; there are no specific validation criteria for this comparison. The difference between the model results is compared with the impact of parameter uncertainty on thermal-hydrologic behavior. A brief summary of this comparison is given in Section 6.4.

\subsection{COMPARISON OF NUFT THERMAL-HYDROLOGIC MODEL AGAINST THE LARGE BLOCK TEST}

The NUFT thermal-hydrologic model used to model the Large Block Test (LBT) is described in Section 6.1.4 of Thermal Tests Thermal-Hydrological Analyses/Model Report (CRWMS M\&O 2000 [DIRS 146921]). The NUFT thermohydrologic model used in this confidence-building study is a three-dimensional equivalent to the two-dimensional LDTH submodels (Section 6.2.6) 
used in the MSTHM. As in the case of the Drift-Scale Test (DST), the LBT was located in the Tptpmn (tsw34) unit. In the LBT, a block of excavated rock ( $3 \mathrm{~m}$ by $3 \mathrm{~m}$ by $4.5 \mathrm{~m}$ ) was heated for one year with five heaters placed in an array of horizontal boreholes $2.75 \mathrm{~m}$ from the top of the block. Temperatures were constantly monitored during the test, while liquid-phase saturations were measured on a regular basis. The source DTN for the heater power history is listed in Table 4.4-1. Note that location-specific thermal or hydrologic property data were not available for the LBT. As described below, two different data sets were used to model the LBT, including that used in the TSPA-SR base-case MSTHM calculations and that used in the TSPA-LA base-case MSTHM calculations (which are described in this report).

\subsubsection{Comparison of Simulated and Field-Measured Temperatures}

Figure 7.3-1 shows the NUFT-simulated versus measured temperature profile along Borehole TT1 at five times from 30 to 400 days. The source DTNs for all field measurements of temperatures are listed in Table 4.4-1. Because the LBT is in the Tptpmn (tsw34) unit, the NUFT thermal-hydrologic models apply the thermal and hydrologic properties for that unit. Two cases are considered: (1) the mean infiltration-flux hydrologic property set used in the TSPA-SR base-case MSTHM calculations (BSC 2001 [DIRS 158204]) and (2) the modified-mean infiltration-flux hydrologic property set used in the TSPA-LA base-case MSTHM calculations. The source of the mean infiltration-flux hydrologic property set used in the TSPA-SR base-case MSTHM calculations is DTN: LB990861233129.001 [DIRS 110226], Table 4.4-1. For the Tptpmn (tsw34) unit, the modified-mean infiltration-flux property set used in the TSPA-LA base-case MSTHM calculations is the same mean infiltration-flux property set (DTN: LB0208UZDSCPMI.002 [DIRS 161243]). Both the TSPA-SR and TSPA-LA cases are in good agreement with the field-measured temperature data. However, both cases predict slightly higher temperatures than the field-measured values, with the TSPA-LA case resulting in the highest temperatures. As is discussed below, the primary cause for the higher simulated temperatures for the TSPA-LA case is the large gas-phase pressure buildup in the matrix (Figure 7.3-2b, d, and f). 

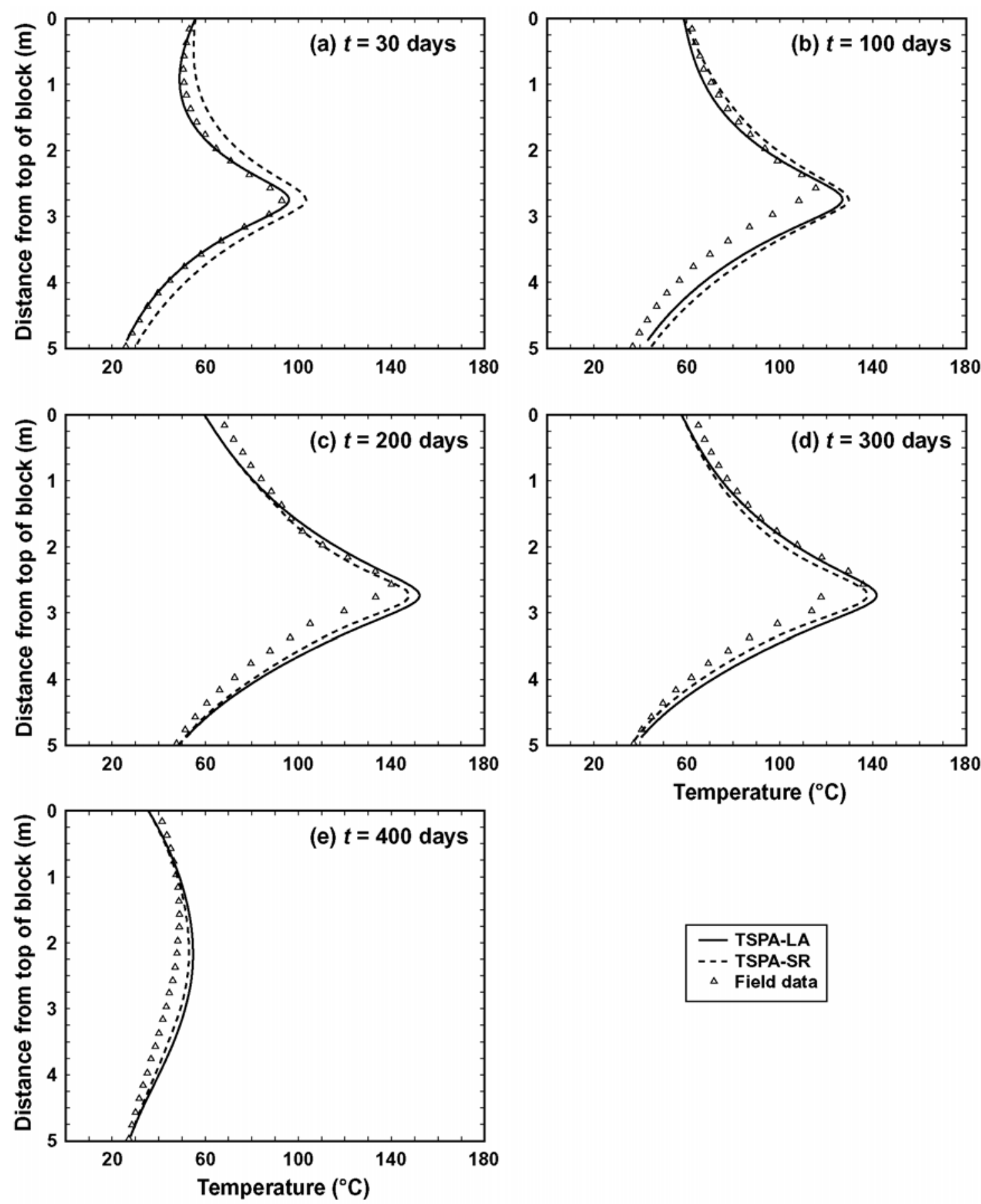

T30-400d_compare

Source: See Table XIII-1.

NOTE: The NUFT simulations include two cases. The TSPA-LA case uses the modified-mean infiltration-flux hydrologic property values for the Tptpmn (tsw34) unit that are used in the MSTHM calculations for the TSPA-LA base case (Section 6.3). Note that for the Tptpmn (tsw34) unit, the mean and modified-mean property sets (discussed in Section 6.3.1) are the same. The TSPA-SR case uses the mean infiltrationflux property values for the Tptpmn (tsw34) unit that are used in the MSTHM calculations for the TSPA-SR base case (BSC 2001 [DIRS 158204]).

Figure 7.3-1. Comparison of the NUFT-Simulated and Measured Temperatures along Borehole TT1 in the Large Block Test, Given at (a) 30 Days, (b) 100 Days, (c) 200 Days, (d) 300 Days, and (e) 400 Days 

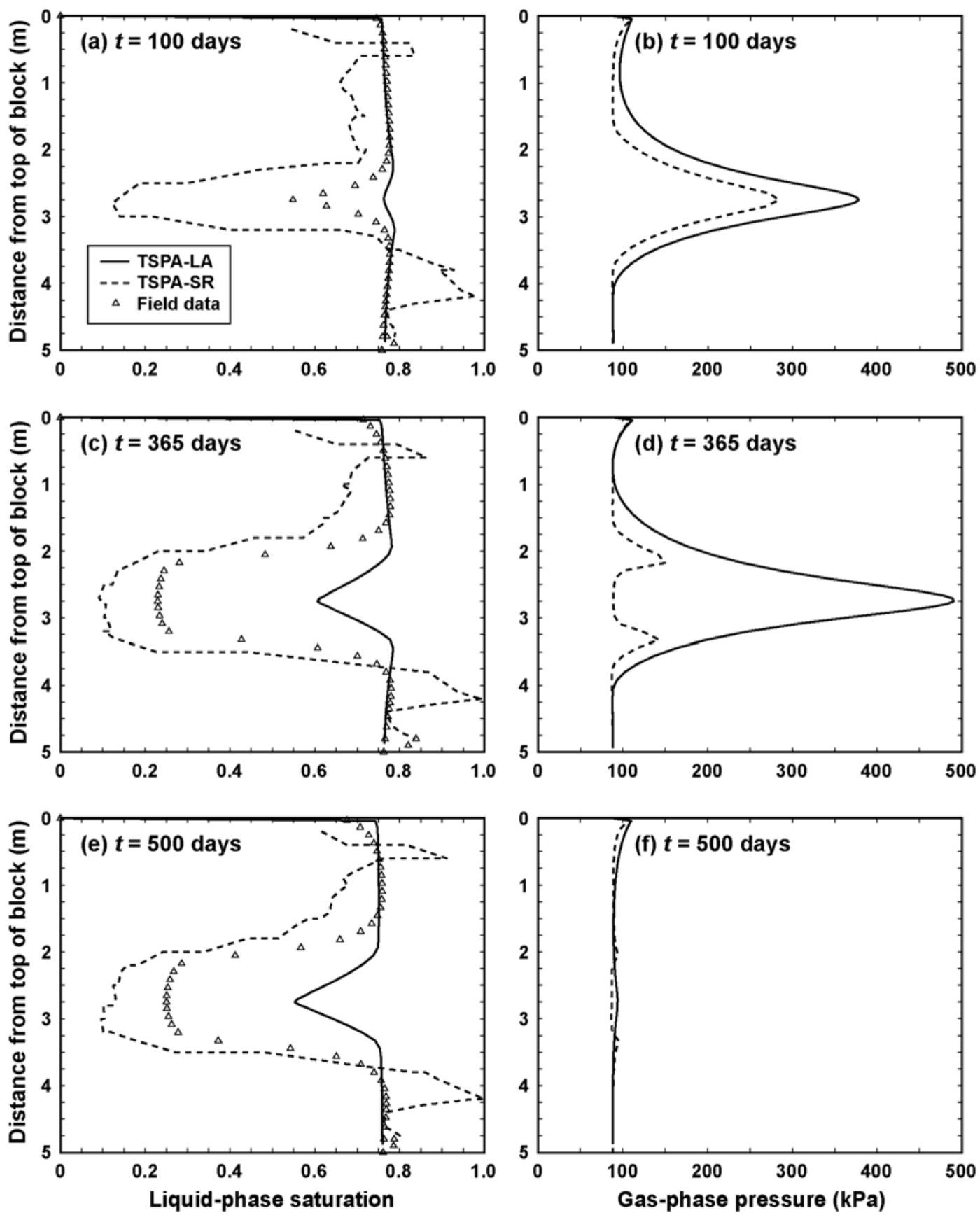

S\&P100-500d_compare

Source: See Table XIII-1.

NOTE: The NUFT-simulated gas-phase pressures in the matrix are also plotted at (b) 100 days, (d) 365 days, and (f) 500 days. Note that there are no field measurements of gas-phase pressure in the matrix. The NUFT simulations include two cases. The TSPA-LA case uses the modified-mean infiltration-flux hydrologic property values for the Tptpmn (tsw34) unit that are used in the MSTHM calculations for the TSPA-LA base case (Section 6.3). Note that for the Tptpmn (tsw34) unit, the mean and modified-mean property sets (discussed in Section 6.3.1) are the same. The TSPA-SR case uses the mean infiltration-flux property values for the Tptpmn (tsw34) unit that are used in the MSTHM calculations for the TSPA-SR base case.

Figure 7.3-2. Comparison of the NUFT-Simulated and Measured Liquid-Phase Saturations in the Matrix along Borehole TN3, Given at (a) 100 Days, (c) 365 Days, and (e) 500 Days 


\subsubsection{Comparison of Simulated and Field-Measured Liquid-Phase Saturations in the Matrix}

Figure 7.3-2 shows the NUFT-simulated and measured liquid-phase saturation profile along TN3, which is a vertical borehole used for neutron probe measurements of water content. Note that the liquid-phase saturations discussed in this section apply to the matrix, rather than to the fractures. The source DTNs for all liquid-phase saturation measurements are listed in Table 4.4-1. Figure 7.3-2 also shows the NUFT-simulated gas-phase pressures in the matrix; note that there are no field measurements of gas-phase pressure in the matrix. At 100 days, the NUFT simulation for the TSPA-SR case shows a well-developed dryout zone, while the TSPA-LA case shows almost no dryout. An important distinction between these two cases is that the matrix permeability for the TSPA-SR case is 23 times greater than it is for the TSPA-LA case. The small matrix permeability in the TSPA-LA case causes more gas-phase pressure buildup, which drives the saturation (or boiling) temperature to be higher, thereby throttling the rate of vaporization and rock dryout. The difference in gas-phase pressure buildup is pronounced at 365 days (Figure 7.3-2d), which causes a large difference in the dryout zones for these two cases (Figure 7.3-2c). The simulated dryout zone for the TSPA-SR case is in close agreement with the measured dryout zone, which in the TSPA-LA case results in little dryout. At 365 days the gas-phase pressure nearly reaches 5 atm for the TSPA-LA case, while for the TSPA-SR case it is less than 1.5 atm (Figure 7.3-2d). Notice that the TSPA-SR case produces two zones of increased gas-phase pressure with each zone corresponding to the boiling zones above and below the heater horizon.

Although the NUFT-simulated dryout lags behind the LBT-observed dryout for the TSPA-LA case, this is not adverse to model confidence. The reason this is not adverse to model confidence is that rock dryout predicted for repository heating conditions is much slower, occurring over much longer time frames than that applicable to the LBT. Consequently, although there may be some lag in predicting dryout under repository conditions in regions of the repository where the Tptpmn (tsw34) unit is the local host-rock unit, it cannot be nearly as great as that illustrated for the LBT conditions, and the long-term MSTHM-predicted saturation histories should closely correspond to those applicable to repository heating conditions.

A comparison of the field-measured liquid-phase saturations at 365 days (when heating ceased) and at 500 days (Figure 7.3-2c and e) indicate that rewetting of the dryout zone in the LBT progresses at a slow rate. Similarly, a comparison of the NUFT-simulated liquid-phase saturations for 365 and 500 days indicates that rewetting progresses at a slow rate. Therefore, the NUFT thermal-hydrologic model, for both the TSPA-SR and TSPA-LA hydrologic property sets, provides a valid representation of rewetting behavior observed in the LBT.

\subsubsection{Summary of Model Validation Using LBT Data}

The good agreement between the NUFT-simulated and measured temperatures demonstrates that the thermal conductivity values in the TSPA-SR and TSPA-LA property sets are appropriate. Moreover, this agreement demonstrates that the NUFT thermal-hydrologic model provides a valid representation of heat flow in the LBT. The differences between the predicted and field-measured temperatures are well within the relative impact of parametric uncertainty (Tables 6.3-30 and 6.3-31). The agreement between the simulated and measured dryout behavior demonstrates that the NUFT thermal-hydrologic model provides a valid representation of dryout 
behavior for the TSPA-SR hydrologic property set. The NUFT thermal-hydrologic model, using both the TSPA-SR and TSPA-LA hydrologic property sets, also provides a valid representation of rewetting behavior observed in the LBT. The cause for the differences between the NUFT-simulated dryout (using the TSPA-LA hydrologic property set) and the measured dryout data is well understood and does not affect the conclusion that the NUFT thermal-hydrologic model of the LBT provides a valid representation of dryout behavior.

\subsection{VALIDATION OF THE LDTH SUBMODEL USING THE DRIFT SCALE TEST}

The three-dimensional thermal-hydrologic model of the Drift-Scale Test (DST) is a three-dimensional equivalent of the two-dimensional LDTH submodels (Section 6.2.6) used in the MSTHM. Both the three-dimensional thermal-hydrologic model of the DST and the two-dimensional LDTH submodel use the NUFT code. Both models use the same (lateral) cross-sectional approximation of the emplacement (or heater) drift and both use the same grid refinement within the drift and in the near-field host rock. Both models use the same representation of thermal-radiative heat transfer in the drift. They both use the same effective thermal conductivity approach to representing the influence of natural convective heat flow in the drifts, which is based on a correlation by Francis et al. (2003 [DIRS 164602], Table 6) (Section 6.2.8.5). Both models use the same thermal and hydrologic property set. Both models use the same boundary conditions at the ground surface and at the water table. The only difference between the three-dimensional thermal-hydrologic model of the DST and the two-dimensional LDTH submodel is the dimensionality of the respective models. Therefore, the validation of the three-dimensional thermal-hydrologic model of the DST is equivalent to validating the two-dimensional LDTH submodels in the MSTHM.

\subsubsection{Design and Geometry of the DST}

The DST is the largest (and longest duration) in situ heater test of its kind (Figure 7.4-1). At the center of the DST is the Heated Drift, which is $47.5-\mathrm{m}$ long with a $5.0-\mathrm{m}$ diameter (similar to the 5.5-m-diameter emplacement drifts in the repository). The thermal load comes from two kinds of heat sources. The Heated Drift has nine waste package-sized heat sources. Emanating from either side of the Heated Drift are 50 horizontal boreholes (25 on each side), containing "wing heaters" that provide additional heating to simulate (in an accelerated fashion) the influence of heating from neighboring emplacement drifts. Each wing heater is composed of two 4.44-m-long segments separated by a $0.66-\mathrm{m}$ gap. The outside of each wing heater is $14 \mathrm{~m}$ from the centerline of the heater drift, while the inside of each wing heater is $4.46 \mathrm{~m}$ from the centerline. The "hot" side of the Heated Drift is separated from the cold side with a thermally insulated bulkhead. The DST heating began on December 3, 1997 and continued for 1,503 days (4.1 years) until January 14, 2002. The DST is now in the cooldown phase and continues to be monitored. The source DTN for the heater power history is listed in Table 4.4-2.

The purpose of large-scale thermal testing at Yucca Mountain is discussed in Section II.E of Thermal-Hydrological Analysis of Large-Scale Thermal Tests in the Exploratory Studies Facility at Yucca Mountain (Buscheck and Nitao 1995 [DIRS 100657]). Sections II.F and II.G of that report discuss the rationale and criteria for the design of large-scale thermal tests. A thermal-hydrologic modeling study (Buscheck and Nitao 1995 [DIRS 100657], Section IV) helped determine the recommended size and duration of the DST. A comprehensive description of the design and geometry of the DST is documented in Sections 7.2.1 and 7.2.2 of Drift-Scale 
Coupled Processes (DST and TH Seepage) Models (BSC 2004 [DIRS 170338]). Section 7.4 of that report gives a detailed and discussion of a thermal-hydrologic model validation study, similar to the results presented below.

\section{Plan View}

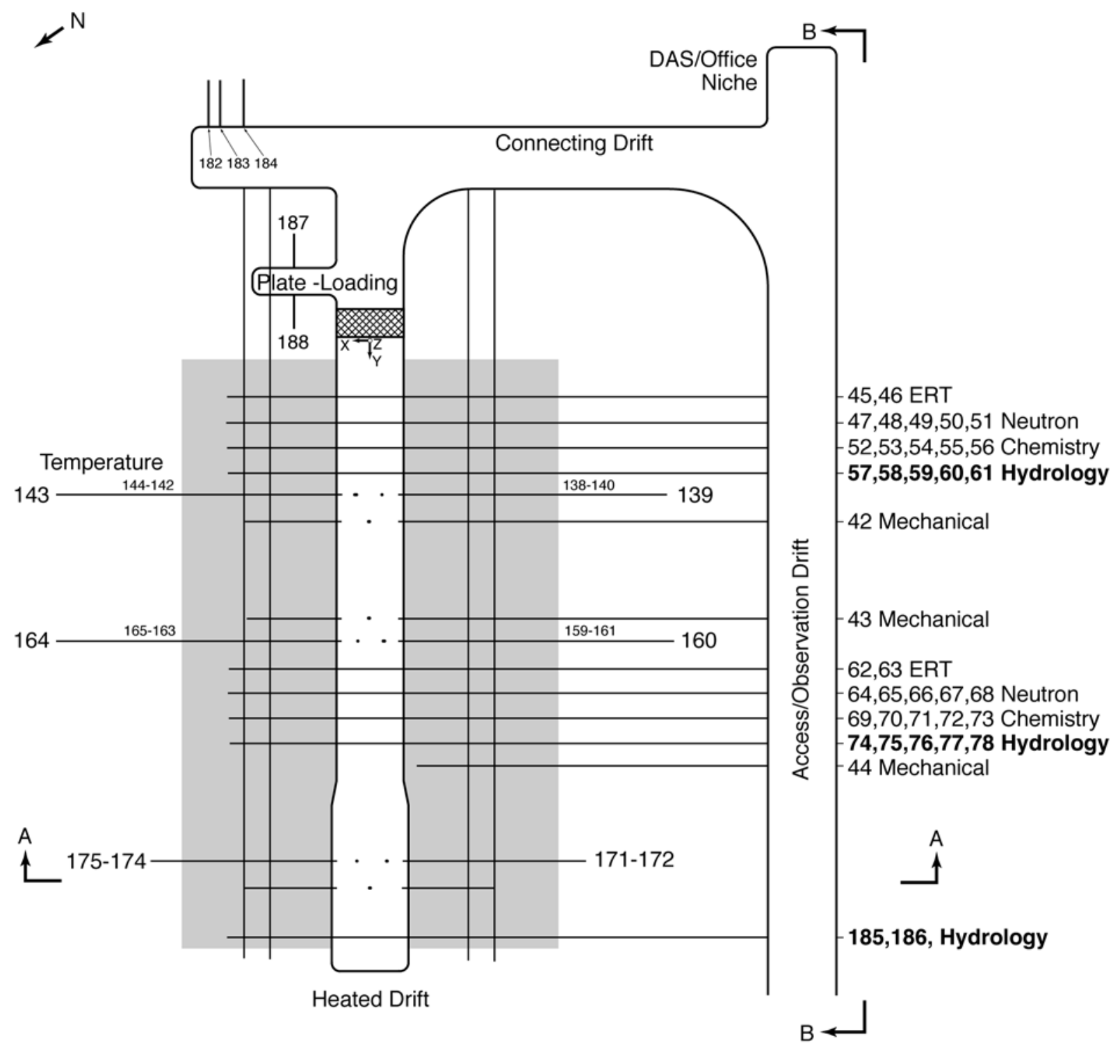

XBD9706-02489.ILR

Source: BSC 2004 [DIRS 170338], Figure 7.2.1-1.

NOTE: The bulkhead is shown as the cross-hatched region, adjacent to the Plate-Loading Niche.

Figure 7.4-1. Plan View of the Drift Scale Test Area

\subsubsection{Description of Three-Dimensional Thermal-Hydrologic Model of the DST}

The model is designed to accurately represent the test domain and the processes governing heat and mass transport in the system. The test geometry, including the dimensions of the 
stratigraphic units from the water table to the ground surface, is adequately represented in this full three-dimensional model. Fracture and matrix interaction is handled using the dual-permeability model employing the active-fracture concept. The thermal-hydrologic simulation code NUFT v3.0.1s (Section 3.1.2) is used because of its ability to handle nested meshes containing many levels of nesting. The model handles heat transfer by conduction, convection, and radiation. The simulation time is 6 years, which includes the 4.1-year heating phase, and 1.9 years of the ongoing cooldown phase.

The thicknesses of hydrogeologic units in the model were obtained by using the software routine YMESH v1.54 (Section 3.1.7) to extract a profile of the units located at the origin of the DST field coordinate system, E171432, N234060 (CRWMS M\&O 1998 [DIRS 111115]). The model extends from the ground surface to the water table $576 \mathrm{~m}$ below the surface, $278 \mathrm{~m}$ in the $\mathrm{x}$-direction, and $478 \mathrm{~m}$ in the y-direction. The center of the bulkhead is located at elevation $1,053 \mathrm{~m}, 253 \mathrm{~m}$ below the ground surface, and $323 \mathrm{~m}$ above the water table. The test configuration geometry allows use of a half-symmetry model since the test is approximately symmetrical about the axis of the Heated Drift. The Connecting Drift, Access Observation Drift, and Plate-Loading Niche are not included in the model. Field data show that these structures have limited effect on the thermal-hydrologic response of the system within a radius of about 25 $\mathrm{m}$ from the Heated Drift.

The half-symmetry model has x-coordinate origin at the center of the bulkhead, and $\mathrm{x}$ positive in the direction away from the access drift (Northward). The y-coordinate axis is parallel to the axis of the Heated Drift with origin $215.9 \mathrm{~m}$ from the bulkhead, and positive in a general westerly direction. The z-direction is positive downward, with origin at the ground surface $252.9 \mathrm{~m}$ above the center of the bulkhead. The root mesh contains four levels of nesting, permitting sufficiently fine discretization in the Heated Drift and wing heater areas, while limiting memory requirements and computation time for the relatively large model. Element dimension varies from $6 \mathrm{~cm}$ in the bulkhead to tens of meters away from the heated areas of the test. The model has a total of 58,258 active elements, 29,129 elements in each of the two continua.

The origin of field coordinates is located at the center of the cold side of the bulkhead that separates the Heated Drift from an unheated and ventilated section of the drift. The y-axis extends from the origin through the bulkhead towards the back end of the Heated Drift (positive to west). $\mathrm{X}$ is positive in a direction away from the access drift (approximately north) and $\mathrm{z}$ is positive downward. The origin of field coordinates is located at approximately $(0,216,253)$ with respect to the computational mesh.

The Heated Drift section in the $\mathrm{x}-\mathrm{z}$ plane is stair-stepped to approximate the 5-m diameter circular drift using a rectangular Cartesian coordinate system. The surface of the invert is $1.3 \mathrm{~m}$ below the center of the drift. Since no thermal and hydrologic properties are available for the invert, material properties of the host rock, Tptpmn (tsw34), are assumed to be applicable to the invert for the DST thermal-hydrologic calculation (Sections 5.3.1.3 and 5.3.2.5).

The nine cylindrical heaters along the Heated Drift are modeled as having a square cross section with area equal to that of the 1.7-m diameter of the cylinder. There are no gaps between the heaters in the model; however, the thermal influence of the gaps is represented by removing conductive heat transfer between the ends of the heaters and by adding thermal-radiative heat 
transfer between the ends of the heaters. Thermal-radiative heat transfer between heater and rock wall elements and across rock wall elements is handled in the model. No fluid flow between canisters is permitted. Wing heater arrays are treated as a separate smeared heat sources.

\subsubsection{Wing-Heater Arrays}

Because the wing-heater boreholes are open to the Heated Drift and because they reside in the area of intensive boiling they are preferential conduits for the flow of water vapor into the Heated Drift. Once the water vapor enters the Heated Drift it then tends to flow towards and through the leaky bulkhead. The NUFT thermal-hydrologic model of the DST does not discretely represent the wing-heater boreholes. However, it is important to include the influence of the wing-heater boreholes on the preferential flow of water vapor. To include the influence of these conduits, the fracture permeability is treated as being anisotropic over the volume of rock occupied by the wing-heater boreholes. The fracture permeability in the x-direction (which is lateral to the Heated Drift axis) is increased by a factor of 1,000 relative to the value of fracture permeability for the Tptpmn (tsw34) unit (Section 5.3.1.4).

\subsubsection{Bulkhead}

The bulkhead, which separates the hot and cold sides of the Heated Drift, is treated as being highly permeable (Section 5.3.1.5). This was necessary because gas-phase pressure measurements across the bulkhead suggest that the structure acts as a partially open boundary that allows substantial vapor loss from the Heated Drift. As described in Drift Scale Test As-Built Report (CRWMS M\&O 1998 [DIRS 111115]), the bulkhead consists of a complex mix of steel, glass, and fiberglass insulation. As described in Section 5.3.2.6, the bulkhead in the Drift Scale Test is assumed to have a very large value of thermal conductivity $\left(5.5 \mathrm{~W} / \mathrm{m}^{\circ} \mathrm{C}\right)$ and a thickness of $0.12 \mathrm{~m}$; thus, the thermal conductance of the bulkhead is equal to $45.83 \mathrm{~W} / \mathrm{m}^{2 \circ} \mathrm{C}$. This assumption is made because portions of the bulkhead (such as the glass window) are not insulated and because the bulkhead is penetrated by a large array of metal conduit containing instrument cables and power lines.

\subsubsection{Initial and Boundary Conditions}

One-dimensional initialization models with the stratigraphic profile developed from the software routine YMESH v1.54 (Section 3.1.7) were used to establish initial conditions for the full three-dimensional models. Boundary conditions were obtained using the software routine boundary_conditions v1.0 (Section 3.1.8), a code developed for calculating boundary conditions for multiscale submodels based on location. For the present-day climate of the mean infiltrationflux case the local percolation flux is $5.922 \mathrm{~mm} / \mathrm{yr}$ at location of the bulkhead. This percolation flux is obtained for the P1-UB26@r\#83:43:1 location in the MSTHM. Note that this nomenclature is related to the naming convection in the SMT submodel, with P1 standing for Panel 1, UB26 pertaining to the $26^{\text {th }}$ drift in the SMT submodel, and r\#83:43:1 corresponding to the numerical mesh in the SMT submodel. The ground surface and water table boundary conditions at this location were obtained from the software routine boundary_conditions v1.0 (Section 3.1.8). Surface boundary parameters calculated were temperature, pressure, air mass fraction, and specific enthalpy of water. Water table parameters were temperature and pressure.

The simulation time used for one-dimensional initialization run is $1.0 \times 10^{9}$ years, which is more 
than enough time for the model to reach steady state. The initialization process is equivalent to that of the LDTH submodels.

\subsubsection{Comparison of Simulated and Field-Measured Temperatures}

Temperatures are monitored in the DST area on a continuous basis by resistance temperature device (RTD) sensors along 28 boreholes; thus, the boreholes containing the thermocouples are called RTD boreholes. The source DTNs for all field measurements of temperatures in the DST are listed in Table 4.4-2. The spatial layout of the 28 RTD boreholes is shown in Figure 7.2.2-1 of Drift-Scale Coupled Processes (DST and TH Seepage) Models (BSC 2004 [DIRS 170338]). For the purpose of comparison with the simulated temperatures, a daily temperature value is taken at 00:00 Greenwich Mean Time. Table 7.4-1 summarizes the RTD boreholes that were used to compare against the NUFT-simulated temperatures. The RTD boreholes fall into four categories. The first three categories consist of RTD boreholes that lie within vertical planes that are orthogonal to the HD axis, including those oriented (1) vertically, (2) laterally, and (3) at a $45^{\circ}$ angle. The fourth category consists of RTD boreholes oriented in the longitudinal direction, which is parallel to the HD axis. The NUFT simulations considered three cases. The base case represents the bulkhead as being thermally insulated and permeable, thereby being leaky to gas flow. The sealed bulkhead case represents the bulkhead as being thermally insulated and impermeable, thereby allowing no gas flow across it. The high thermal conductivity $K_{\text {th }}$ case is the same as the base case with $K_{\text {th }}$ being one standard deviation above the mean, based on Table 7-10 of DTN: SN0404T0503102.011 [DIRS 169129] (File: ReadMe Summery.doc).

Table 7.4-1. Summary of Thermocouple (RTD) Boreholes Used to Compare Field-Measured Temperatures with NUFT-Simulated Temperatures.

\begin{tabular}{|l|l|l|c|c|c|}
\hline $\begin{array}{c}\text { Borehole } \\
\text { Number }\end{array}$ & \multicolumn{1}{|c|}{ Figure } & \multicolumn{1}{|c|}{ Orientation } & $\begin{array}{c}\text { Collar X } \\
\text { Coordinate }\end{array}$ & $\begin{array}{c}\text { Collar Y } \\
\text { Coordinate }\end{array}$ & $\begin{array}{c}\text { Collar Z } \\
\text { Coordinate }\end{array}$ \\
\hline 137 & $7.4-3,7.4-4$ & Vertical above HD (+Z) & 0.775 & 11.918 & 2.510 \\
\hline 141 & $7.4-3,7.4-4$ & Vertical below HD (-Z) & 0.764 & 11.893 & -1.637 \\
\hline 168 & $7.4-5,7.4-6$ & Vertical above HD (+Z) & -0.071 & 31.952 & 2.451 \\
\hline 169 & $7.4-5,7.4-6$ & Vertical below HD (-Z) & -0.003 & 32.007 & -1.629 \\
\hline 170 & $7.4-7,7.4-8$ & Vertical above HD (+Z) & 0.751 & 39.306 & 2.488 \\
\hline 173 & $7.4-7,7.4-8$ & Vertical below HD (-Z) & 0.758 & 39.324 & -1.623 \\
\hline 139 & $7.4-9,7.4-10$ & Lateral (-X) & -2.569 & 11.891 & -0.017 \\
\hline 143 & $7.4-9,7.4-10$ & Lateral (+X) & 2.665 & 11.890 & -0.008 \\
\hline 79 & $7.4-11,7.4-12$ & Longitudinal (+Y) & 9.460 & -11.022 & 3.752 \\
\hline 80 & $7.4-11,7.4-12$ & Longitudinal (+Y) & -9.486 & -11.059 & 3.228 \\
\hline
\end{tabular}

NOTE: $\quad H D=$ Heated Drift. The indicated orientation is relative to the Heated Drift. The source of the coordinates is given in Tables S00085_001 and S00085_002 of DTN: MO0002ABBLSLDS.000 [DIRS 147304].

Figure 7.4-2 shows the temperature contours just prior to the end of the heating phase $(1,500$ days) in plan view through a plane at the elevation of the wing-heater array and for a vertical cross-section midway along the length of the Heated Drift. Note that the heaters are turned off at 1,503 days. Notice also that the highest temperatures are located close to the wing heaters and that the temperature contours are vertically symmetrical about the heater horizon, which indicates that heat flow there is dominated by heat conduction. Because the bulk permeability $k_{\mathrm{b}}$ of the DST area is less than the threshold $k_{\mathrm{b}}$ value at which buoyant gas-phase convection begins 
to significantly influence heat flow (Buscheck and Nitao 1994 [DIRS 130561], pp. 8 to 12), heat flow in the subboiling region is dominated by heat conduction.

Figures 7.4-3 through 7.4-8 compare NUFT-simulated temperatures (for three cases) with measured temperatures along vertically oriented RTD boreholes. Figures 7.4-9 and 7.4-10 compare NUFT-simulated temperatures (for the three cases) with measured temperatures along horizontal (lateral) RTD boreholes. Figures 7.4-13 through 7.4-16 compare NUFT-simulated temperature histories (for the three cases) with measured temperature histories. Table 7.4-2 summarizes the information for the thermocouple sensors used to compare NUFT-simulated and field-measured temperature histories.

Table 7.4-2. Coordinates of Thermocouple Sensors Used in Figures 7.4-13, 7.4-14, and 7.4-15

\begin{tabular}{|c|c|c|c|c|c|}
\hline Borehole & Sensor & Figure & X Coordinate & Y Coordinate & Z Coordinate \\
\hline 133 & 52 & $7.4-13$ & 0.85 & 2.81 & 17.85 \\
\hline 133 & 23 & $7.4-13$ & 0.79 & 2.77 & 9.12 \\
\hline 141 & 20 & $7.4-13$ & 0.70 & 11.94 & -8.87 \\
\hline 138 & 23 & $7.4-13$ & -6.39 & 11.77 & 6.36 \\
\hline 134 & 8 & $7.4-14$ & 0.73 & 2.74 & -3.13 \\
\hline 144 & 21 & $7.4-14$ & 6.31 & 11.96 & 6.27 \\
\hline 162 & 26 & $7.4-14$ & 0.79 & 22.9 & -8.85 \\
\hline 163 & 24 & $7.4-14$ & 6.39 & 22.72 & -6.49 \\
\hline 138 & 3 & $7.4-15$ & -2.15 & 11.88 & 2.12 \\
\hline 139 & 23 & $7.4-15$ & -8.9 & 11.91 & 0.04 \\
\hline 144 & 1 & $7.4-15$ & 2.07 & 11.92 & 2.04 \\
\hline 164 & 24 & $7.4-15$ & 9.01 & 22.77 & 0.11 \\
\hline
\end{tabular}

Source: CRWMS M\&O 1998 [DIRS 111115].

NOTE: $\quad$ The source of the coordinates is given in the top of Table 4.4-2.

It is noted that these comparisons are made for the NUFT simulations that applied the modified-mean infiltration-flux hydrologic-property set (Section 6.3.1). In Section 7.4.4 of Drift-Scale Coupled Processes (DST and TH Seepage) Models (BSC 2004 [DIRS 170338]), comparisons are made for thermal-hydrologic simulations for two property sets. The first set is the DS/AFM-UZ02-MEAN property set (BSC 2004 [DIRS 170338]), also known as the calibrated hydrologic property set, which is equivalent to the modified-mean infiltration-flux hydrologic-property set in the Tptpmn (tsw34), Tptpll (tsw35), and Tptpln (tsw36) units, as discussed in Section 6.3.1. The second set is the site-specific DKM-TT99 property set that was developed specifically for the DST (BSC 2001 [DIRS 157330]). An important difference between these two property sets is that the value of matrix permeability of the Tptpmn (tsw34) unit in the site-specific property set is 70 times larger than that of the calibrated property set. Another difference is that the calibrated property uses the Active Fracture Model (AFM), described in Liu et al. (1998 [DIRS 105729]), while the site-specific set does not use the AFM. As evident in Section 7.4.4 of Drift-Scale Coupled Processes (DST and TH Seepage) Models (BSC 2004 [DIRS 170338]), differences between these respective property sets affect above-boiling temperatures and rock dryout, which are discussed below. Several general observations are made about the temperature comparisons in the vertical RTD boreholes. 
- NUFT-simulated temperatures are higher than the measured temperatures in the zone where temperatures exceed $96^{\circ} \mathrm{C}$. In Section 7.4.4.1 of Drift-Scale Coupled Processes (DST and TH Seepage) Models (BSC 2004 [DIRS 170338]), it was found that the site-specific property set resulted in lower simulated temperatures for the above-boiling region than those resulting from the calibrated hydrologic property set (which is the same as that used in NUFT DST TH simulations). Figures 7.4.4.1-1 and 7.4.4.1-2 of Drift-Scale Coupled Processes (DST and TH Seepage) Models (2004 [DIRS 170338]) show differences in simulated temperature of up to $20^{\circ} \mathrm{C}$ in the above-boiling region between these two property sets. Results from Section 7.4.4.1 of Drift-Scale Coupled Processes (DST and TH Seepage) Models (BSC 2004 [DIRS 170338]) show that better agreement is obtained between simulated and measured temperatures in the above-boiling region when the site-specific property set is used.

- NUFT-simulated temperatures agree fairly well with measured temperatures for the lower temperature range (less than $80^{\circ} \mathrm{C}$ ) during the heating phase. This is consistent with Figures 7.4.4.1-1 and 7.4.4.1-2 of Drift-Scale Coupled Processes (DST and TH Seepage) Models (2004 [DIRS 170338]), which show small differences in simulated temperatures in the below-boiling region between the calibrated and site-specific property sets, together with Figures 7.4.3.1-1, 7.4.3.1-2, and 7.4.3.1-3 of Drift-Scale Coupled Processes (DST and TH Seepage) Models (2004 [DIRS 170338]), which show close agreement between measured and simulated temperatures, with the use of the site-specific property set.

- The high- $K_{\text {th }}$ case, which results in the lowest NUFT-simulated temperatures, is in best agreement with the measured temperatures during both the heating and cooldown phases.

- The sealed-bulkhead case results in slightly higher NUFT-simulated temperatures than the base case (which had a leaky bulkhead). The influence of the leaky bulkhead on simulated temperatures is less than that resulting from a one standard-deviation range in thermal conductivity (which is evident in the temperature differences between the high- $K_{\text {th }}$ case and the base case).

- For the vertical RTD boreholes (Figures 7.4-3 through 7.4-8), "plateau" behavior in temperature close to $96^{\circ} \mathrm{C}$ develops in virtually all of the measured temperature profiles. However, it appears in only a few of the NUFT-simulated temperature profiles, occurring at times later than observed in the field. This effect is associated with the use of the calibrated hydrologic property set and the low value of matrix permeability, which results in a large gas-phase pressure buildup in the matrix that increases the saturation (boiling) temperature. This is consistent with Figure 7.4.4.1-2 of Drift-Scale Coupled Processes (DST and TH Seepage) Models (BSC 2004 [DIRS 170338]). The impact of the large gas-phase pressure buildup is discussed in more detail in Section 7.4.4 of this report.

- At early time (175, 365, and 730 days) for the lateral RTD boreholes (Figure 7.4-9), the NUFT-simulated temperature profiles exhibit more plateau behavior than the measured temperature profiles within the zone of likely condensate shedding.

- At later time (1,096 and 1,500 days) for the lateral RTD boreholes (Figure 7.4-10), the plateau behavior in temperature close to $96^{\circ} \mathrm{C}$ appears in measured temperature profiles. 
The NUFT-temperature profiles exhibit plateau behavior at much higher temperatures. This effect is associated with the use of the calibrated hydrologic property set and the low value of matrix permeability, which results in a large gas-phase pressure buildup in the matrix that increases the saturation (boiling) temperature. High gas-phase pressures in the matrix throttle (i.e., restrict) both vaporization and rock dryout rates. This is consistent with Section 7.4.4 of Drift-Scale Coupled Processes (DST and TH Seepage) Models (BSC 2004 [DIRS 170338]). The impact of the large gas-phase pressure buildup is discussed in more detail in Section 7.4.4 in this report.

- For all boreholes, measured temperatures indicate a more rapid cooldown than NUFT-simulated cooldown. This effect is associated with the use of the calibrated hydrologic properties and the low value of matrix permeability.

- For distances greater than $12 \mathrm{~m}$ from the borehole collar for the lateral RTD boreholes (Figures 7.4-10e and 7.4-10f), there is a pronounced "scattering" of the measured temperature profile during the cooldown phase, which is indicative of either RTD failure or of preferential condensate drainage down fractures into the boreholes, resulting in local convective cooling. Note that the outer portions of Boreholes 139 and 143 are located in the intervals where condensate shedding is most likely to occur.

- At early time (175 and 365 days) for (longitudinal) Boreholes 79 and 80 (Figures 7.4-11 and 7.4-12), NUFT-simulated temperatures agree closely with the measured temperatures. Good temperature agreement persists in Borehole 79 throughout the heating phase.

- At later time (730, 1,096, and 1,500 days) for (longitudinal) Borehole 80 (Figures 7.4-11 and 7.4-12), NUFT-simulated temperatures are higher than measured temperatures for the interval of 15 to $50 \mathrm{~m}$ from the borehole collar. For the interval of 0 to $15 \mathrm{~m}$ from the borehole collar, measured temperatures are higher than NUFT-simulated temperatures. The measured-temperature profile suggests vapor migration towards the borehole collar, where it condenses, with associated heat transfer along the borehole. This effect removes the latent heat of evaporation from the interval of 15 to $50 \mathrm{~m}$ from the borehole collar and deposits this latent heat along the interval 0 to $15 \mathrm{~m}$.

- For (longitudinal) Boreholes 79 and 80 (Figures 7.4-11 and 7.4-12), scattering of the measured temperature profile during the cooldown phase is indicative of either RTD failures or of preferential condensate drainage down fractures into the boreholes, resulting in local convective cooling. Note that Boreholes 79 and 80 are located in a region where condensate shedding is more likely to occur.

It is important to note that the simulated large gas-phase pressure rise in the rock matrix, as discussed above, is transient and that temperature rise and dryout in the DST are accelerated, compared to those predicted for repository heating conditions. Peak temperatures in the DST occurred within 4 years, while peak temperatures require approximately 15 years to occur for repository heating conditions (e.g., Figure 6.3-23). In Section 6.3.9, which describes a sensitivity analysis of the influence of hydrologic properties on the in-drift thermal-hydrologic response, it is found that temperature (peak temperatures and boiling-period duration) and relative humidity are insensitive to the differences in the hydrologic properties for the four 
host-rock units. Although matrix permeability varies by a factor of 37 over the four host-rock units, there is an insignificant influence on predicted thermal-hydrologic responses. Differences in simulated temperatures for the DST arising from differences in the value of matrix permeability are therefore not applicable to temperatures predicted by the MSTHM for repository heating conditions. Thus, although matrix permeability is seen to have a noticeable affect on temperatures simulated for the DST, it does not significantly affect repository temperature evolution predicted by thermal-hydrologic models supporting TSPA-LA.

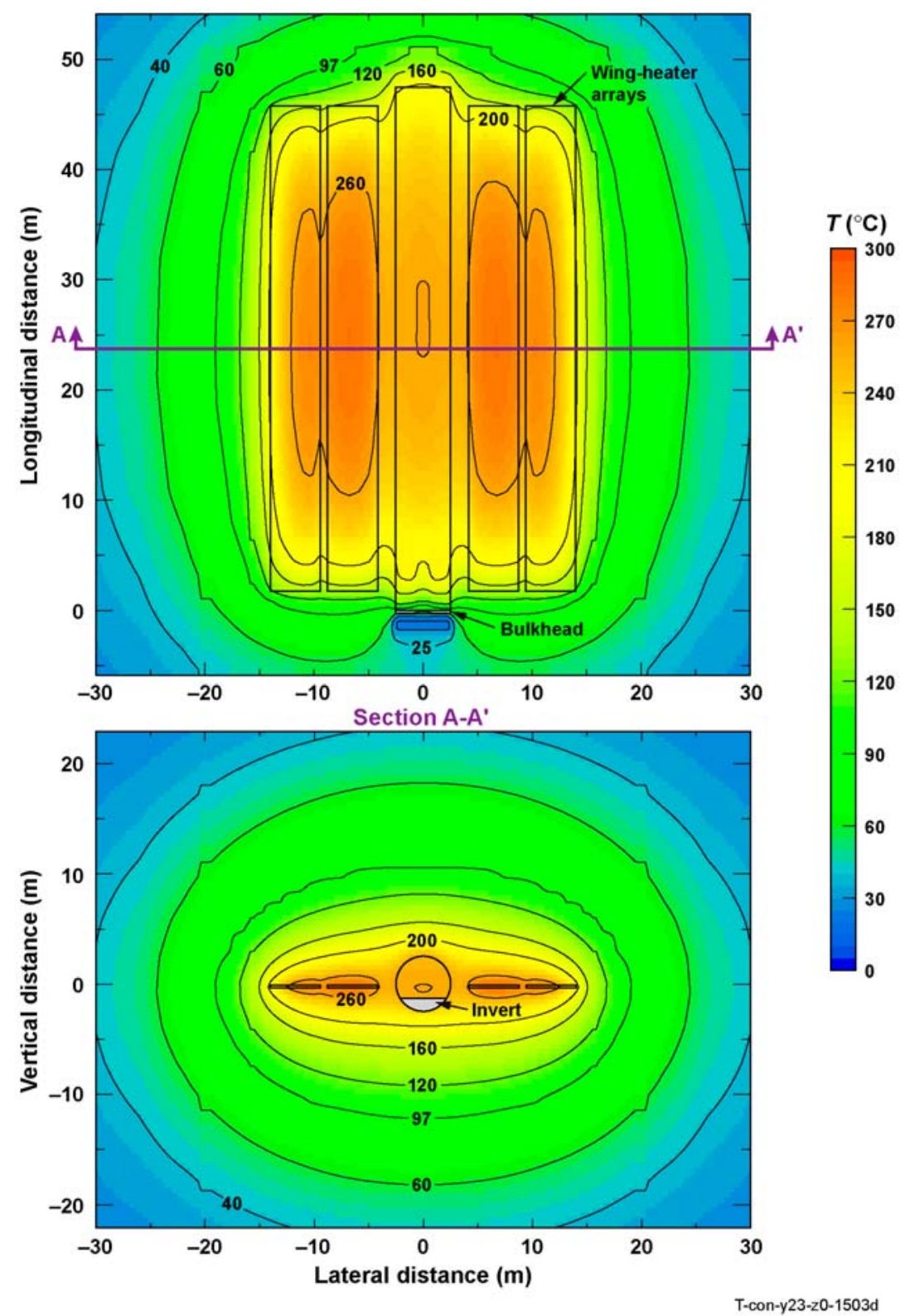

Source: See Table XIII-1.

NOTE: Heaters are turned off at 1,503 days, ending the heating phase.

Figure 7.4-2. Contours of Temperature (for the Base Case) at the End of the Heating Phase, Plotted in (a) Plan View Through a Horizontal Plane at the Elevation of the Wing-Heater Array and (b) for a Vertical Cross-Section Midway along the Heated Drift $(y=22.9 \mathrm{~m})$ 
Borehole 137
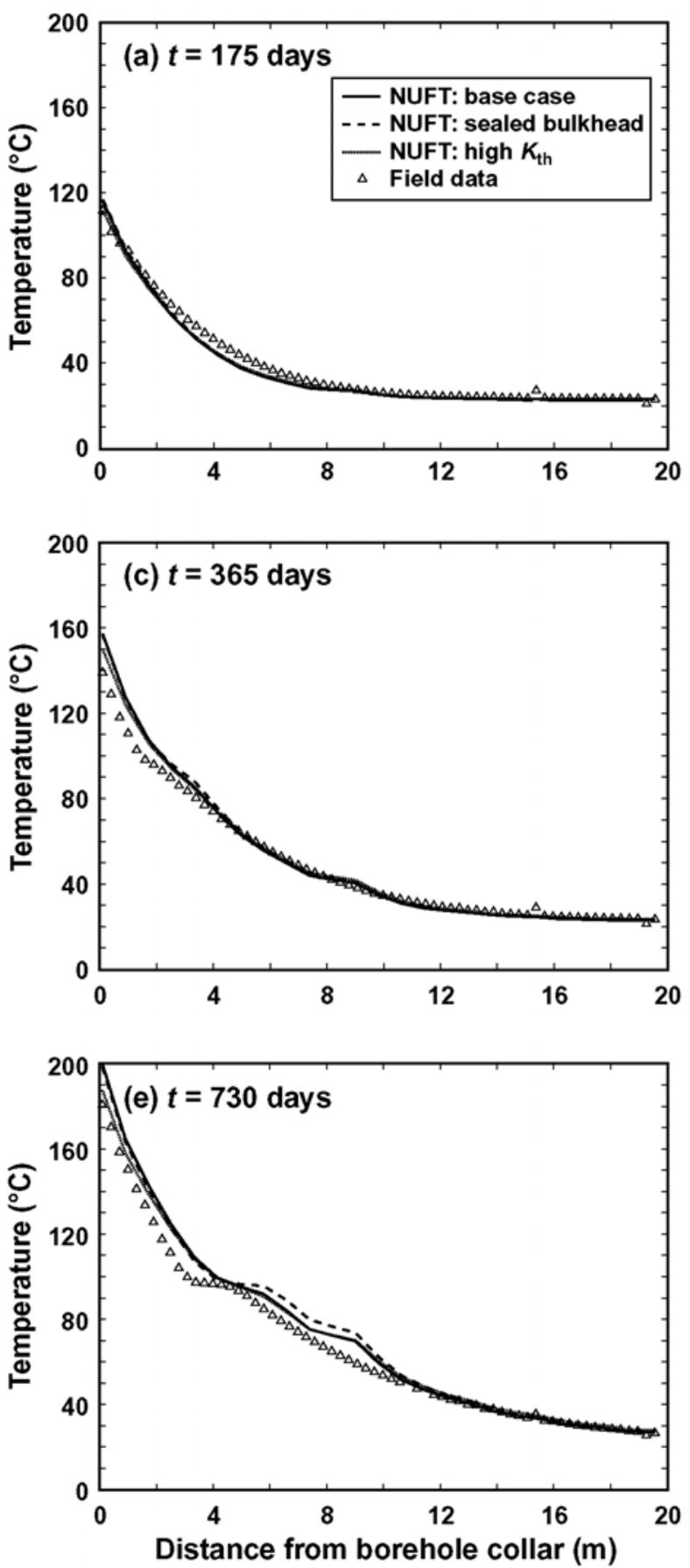

Borehole 141
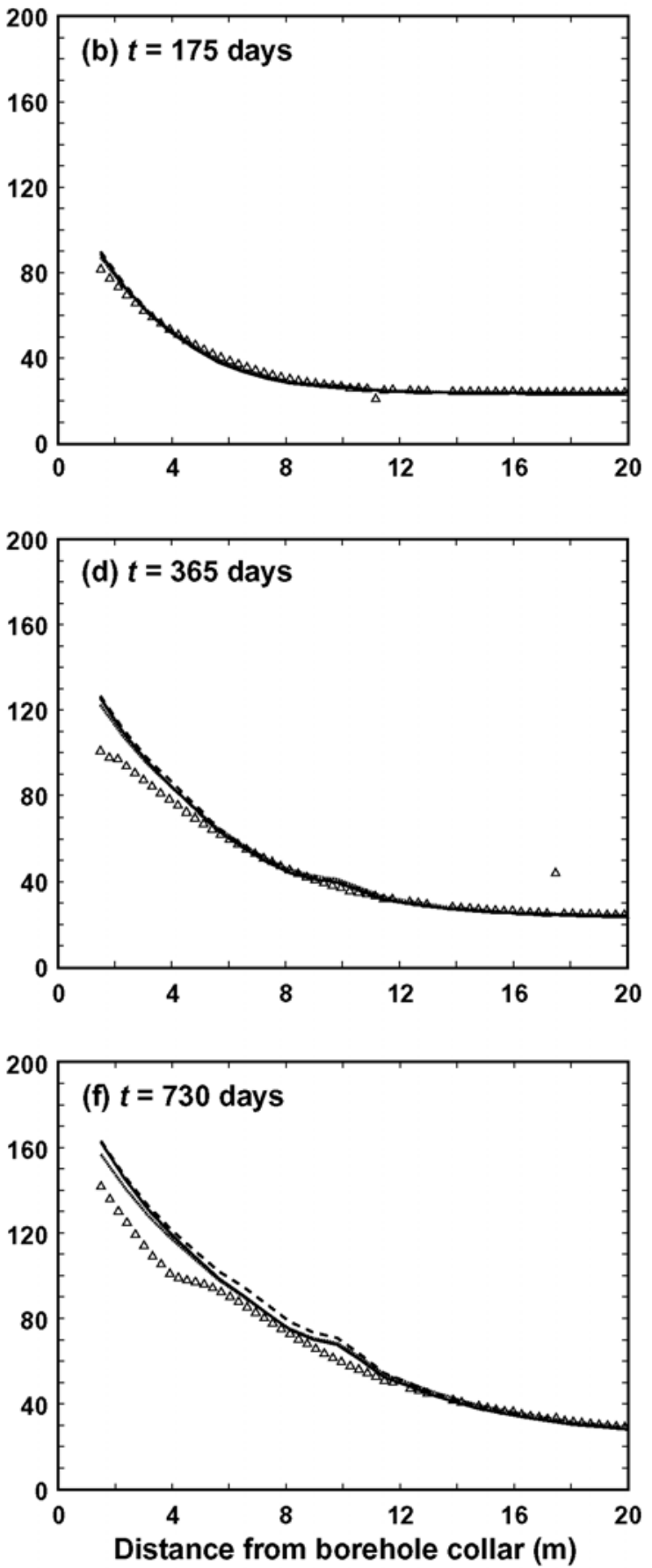

ss-137-141 175-730d

Source: See Table XIII-1.

NOTE: The NUFT simulations are for the three indicated cases. The base case represents gas leakage through the bulkhead, while the sealed-bulkhead case does not allow gas leakage through the bulkhead. The high- $K_{\text {th }}$ case is the same as the base case except with the host-rock thermal conductivity $K_{\text {th }}$ being one standard deviation higher than the mean.

Figure 7.4-3. NUFT-Simulated and Measured Temperatures Compared along Borehole 137 (a, c, e) and Borehole 141 (b, d, f) at 175, 365, and 730 Days 
Borehole 137
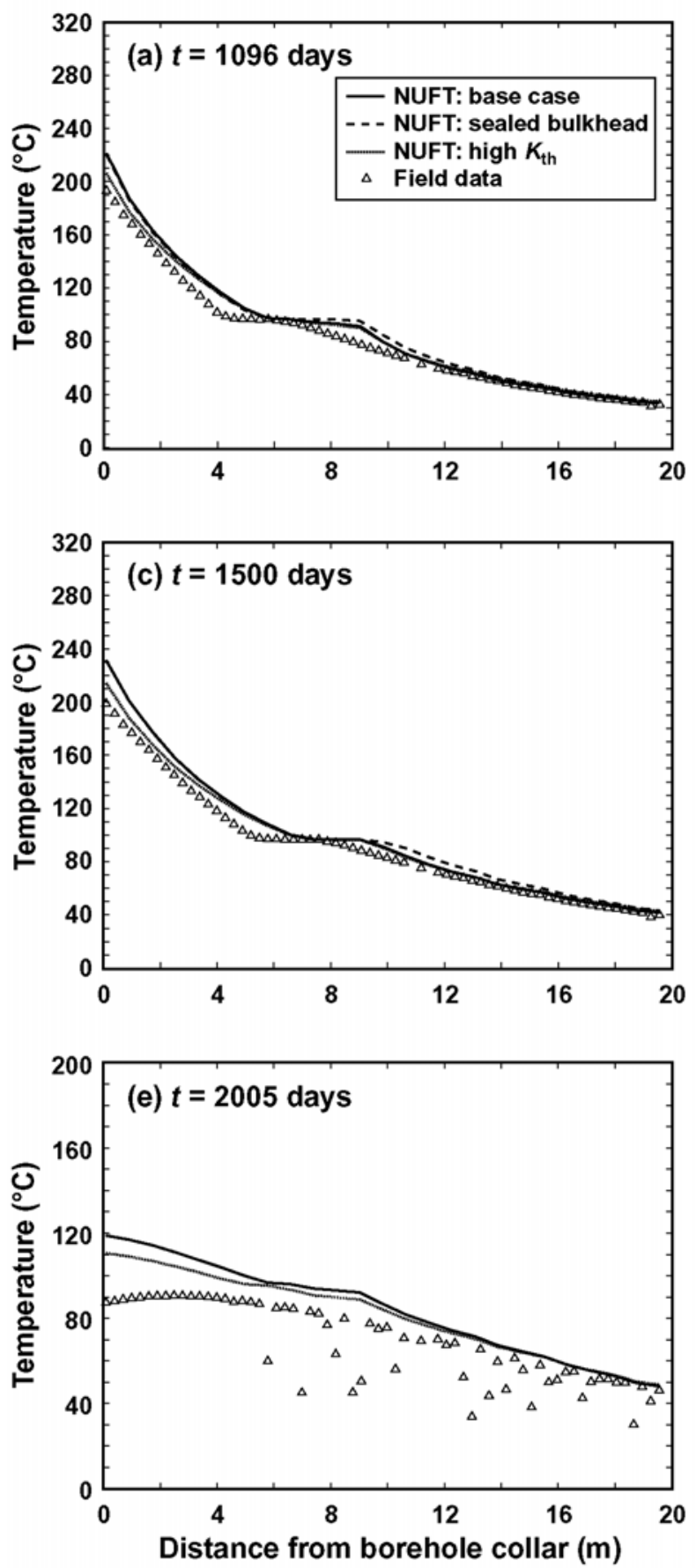

Borehole 141
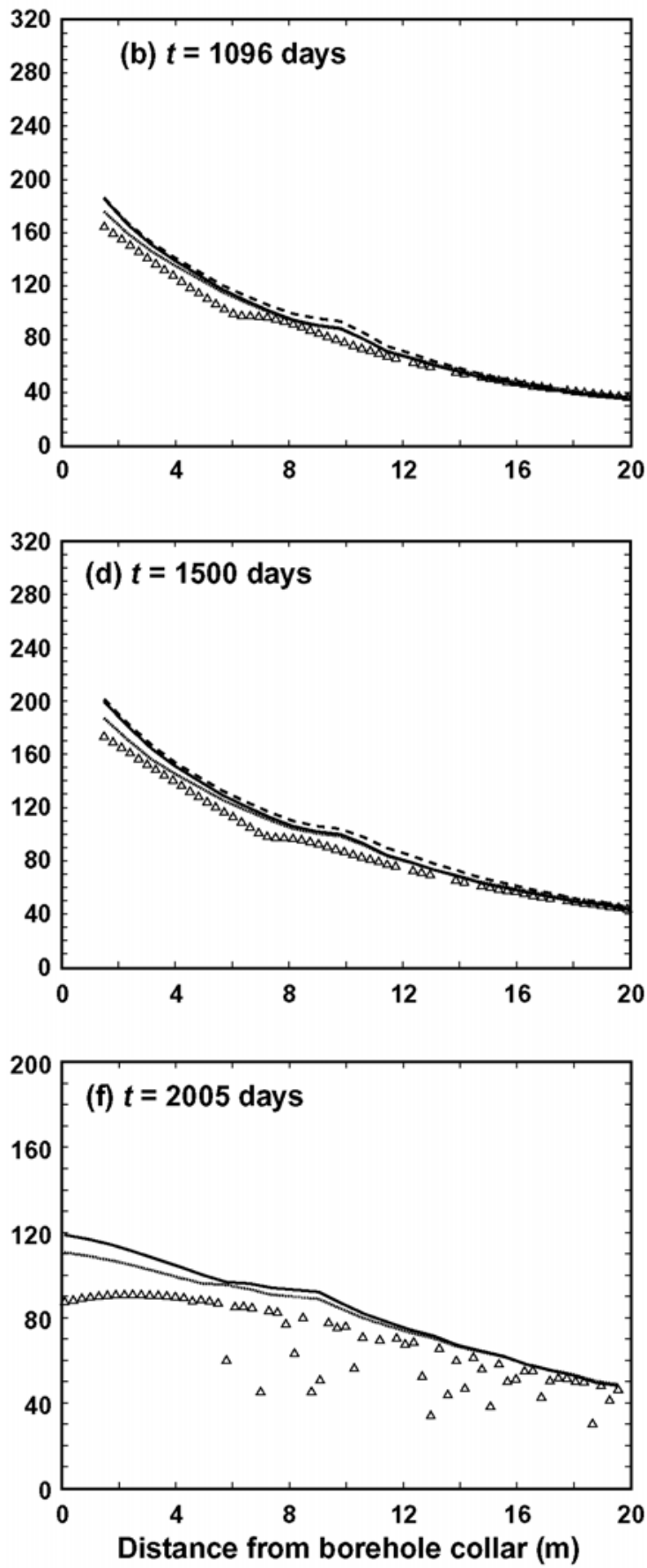

ss-137-141_1096-2005d

Source: See Table XIII-1.

NOTE: The NUFT simulations are for the three indicated cases. The base case represents gas leakage through the bulkhead, while the sealed-bulkhead case does not allow gas leakage through the bulkhead. The high- $K_{\text {th }}$ case is the same as the base case except with the host-rock thermal conductivity $K_{\text {th }}$ being one standard deviation higher than the mean. Note that the heaters are turned off at 1,503 days.

Figure 7.4-4. NUFT-Simulated and Measured Temperatures Compared along Borehole $137(\mathrm{a}, \mathrm{c}, \mathrm{e})$ and Borehole 141 (b, d, f) at 1,096, 1,500, and 2,005 Days 
Borehole 168
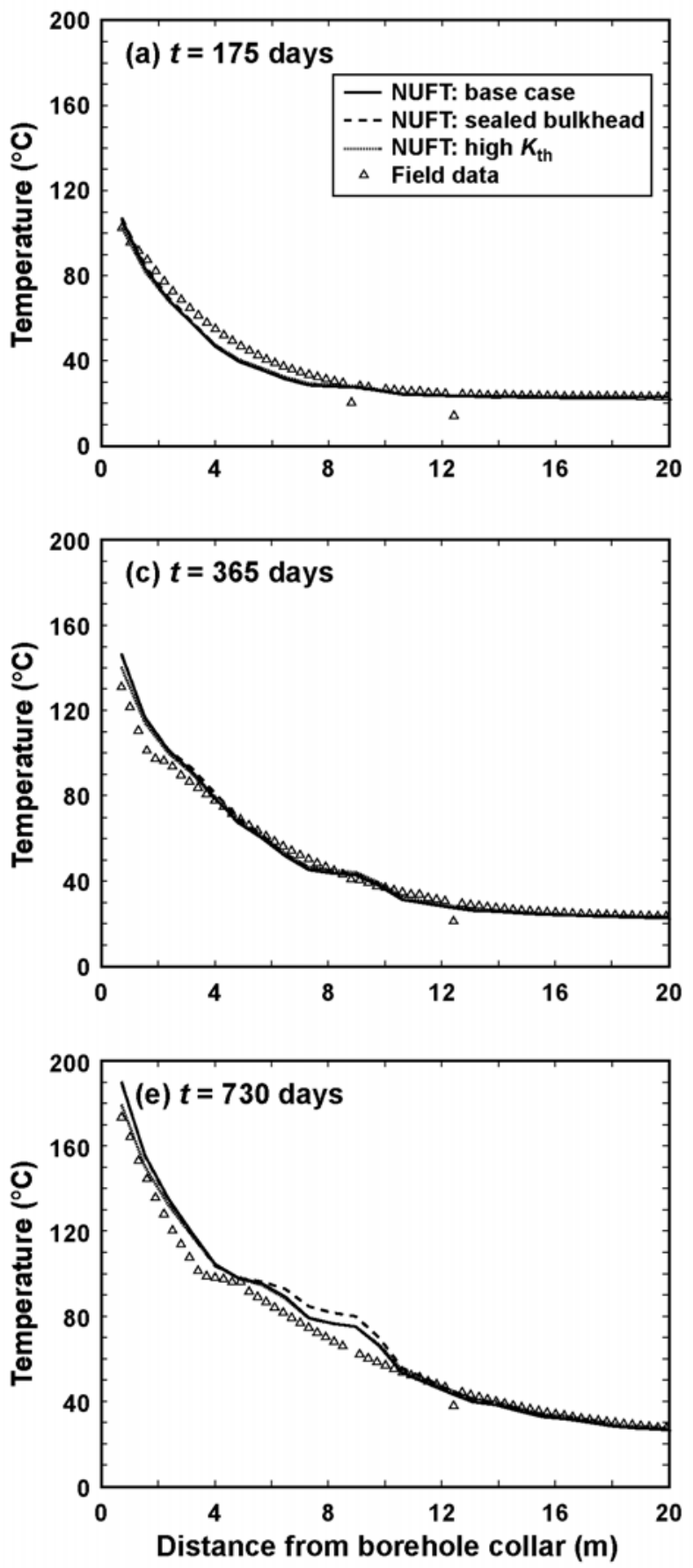

Borehole 169
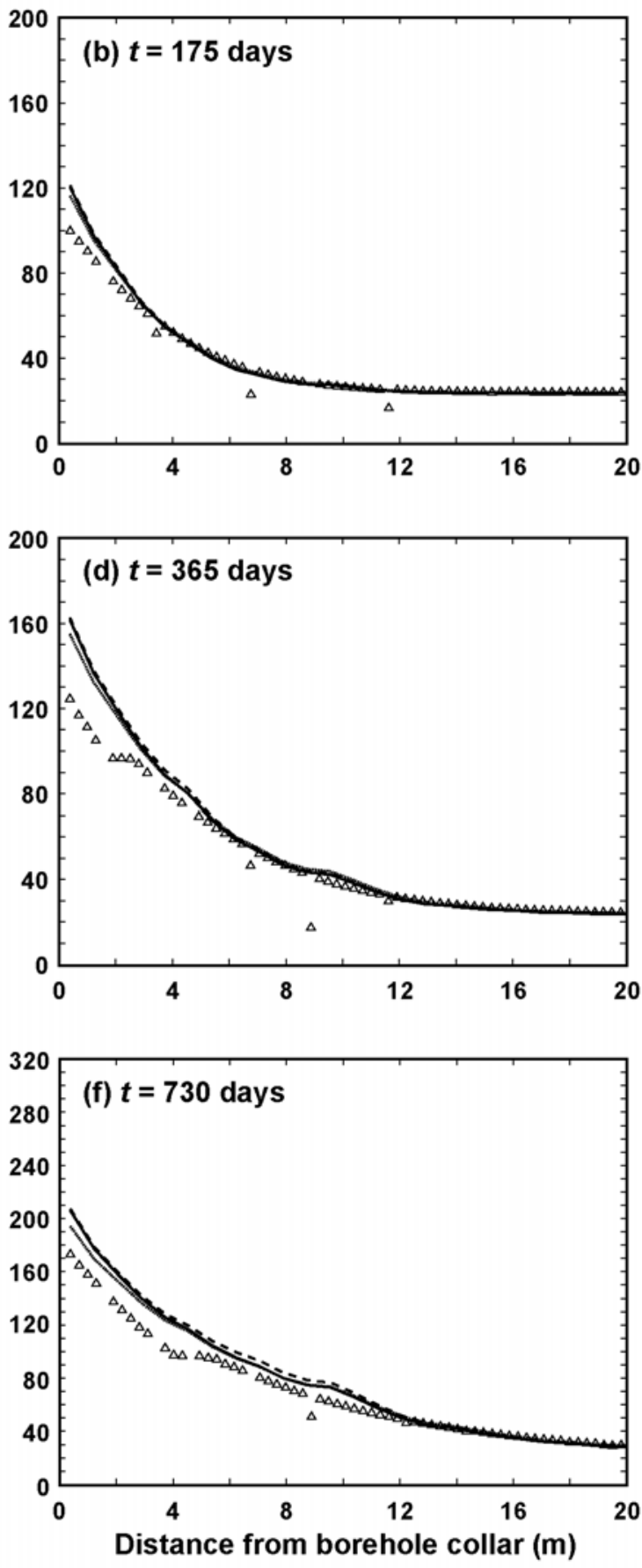

ss-168-169_175-730d

Source: See Table XIII-1.

NOTE: The NUFT simulations are for the three indicated cases. The base case represents gas leakage through the bulkhead, while the sealed-bulkhead case does not allow gas leakage through the bulkhead. The high- $K_{\text {th }}$ case is the same as the base case except with the host-rock thermal conductivity $K_{\text {th }}$ being one standard deviation higher than the mean.

Figure 7.4-5. NUFT-Simulated and Measured Temperatures Compared along Borehole $168(\mathrm{a}, \mathrm{c}, \mathrm{e})$ and Borehole 169 (b, d, f) at 175, 365, and 730 Days 
Borehole 168
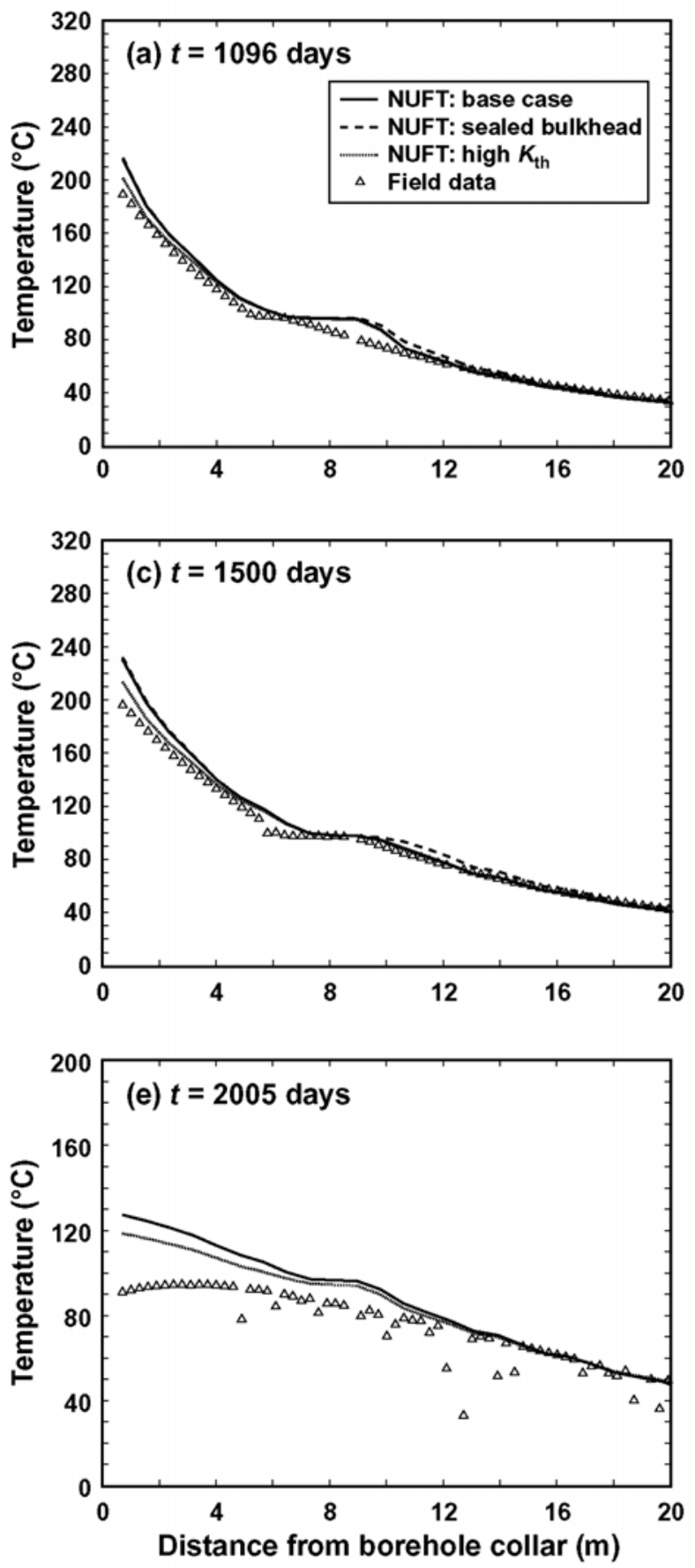

Borehole 169
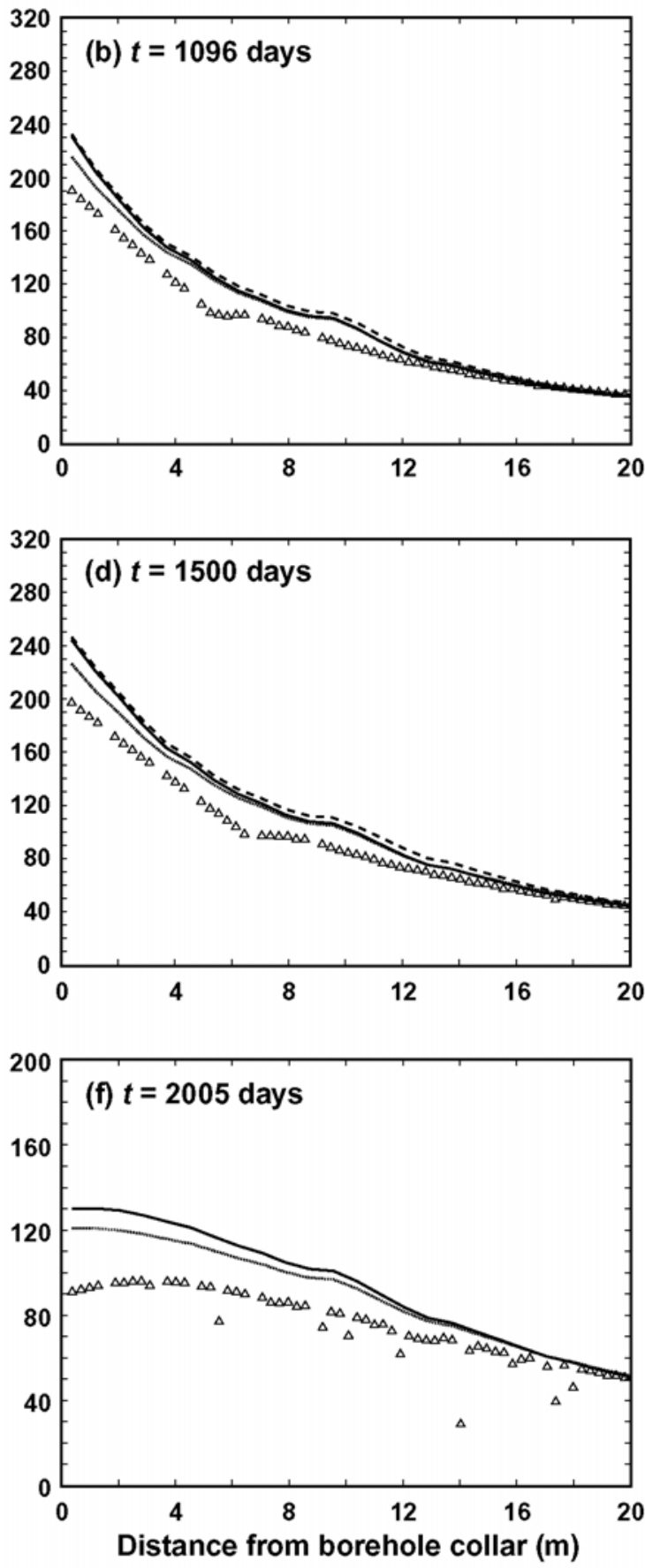

168-169_1096-2005d

Source: See Table XIII-1.

NOTE: The NUFT simulations are for the three cases. The base case represents gas leakage through the bulkhead, while the sealed-bulkhead case does not allow gas leakage through the bulkhead. The high-Kth case is the same as the base case except with the host-rock thermal conductivity $K_{\text {th }}$ being one standard deviation higher than the mean. Note that the heaters are turned off at 1,503 days.

Figure 7.4-6. NUFT-Simulated and Measured Temperatures Compared along Borehole $168(\mathrm{a}, \mathrm{c}, \mathrm{e})$ and Borehole 169 (b, d, f) at 1,096, 1,500, and 2,005 Days 
Borehole 170
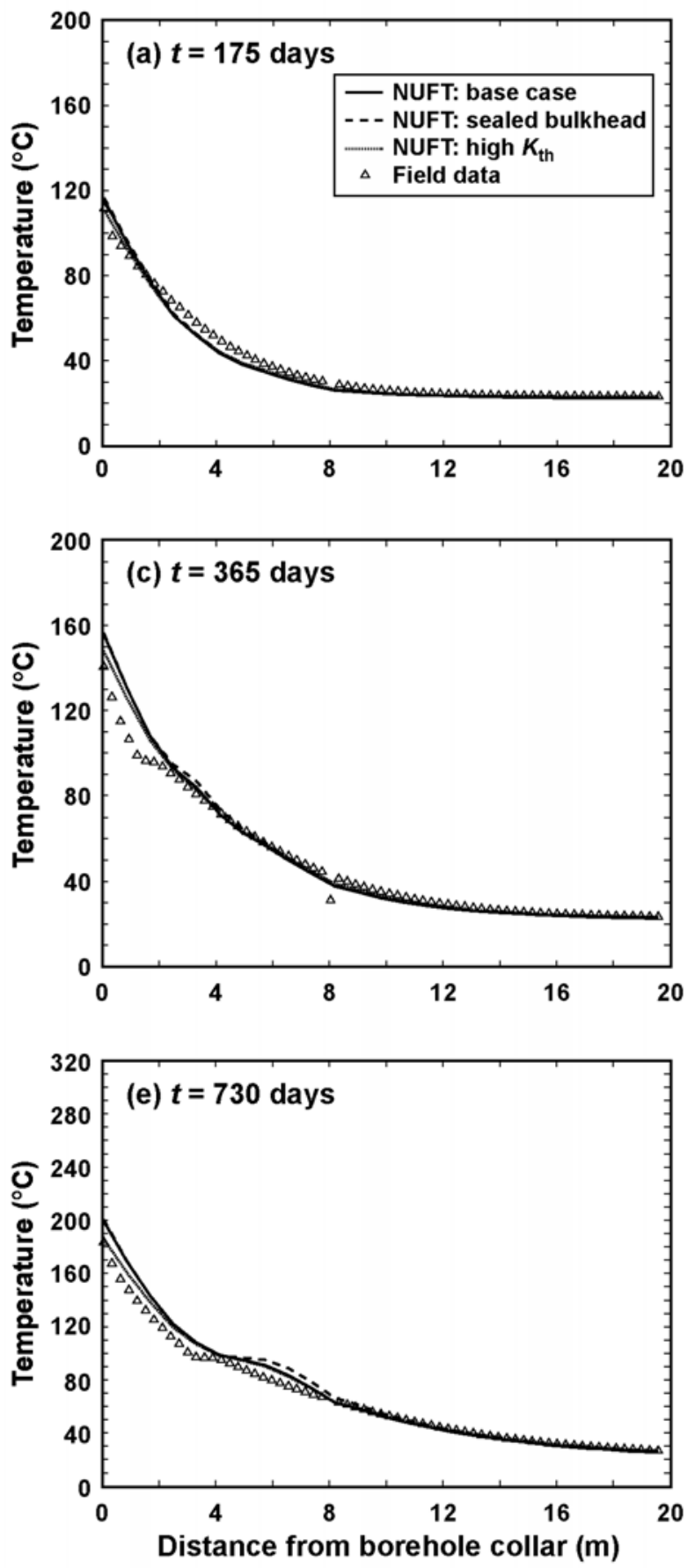

Borehole 173
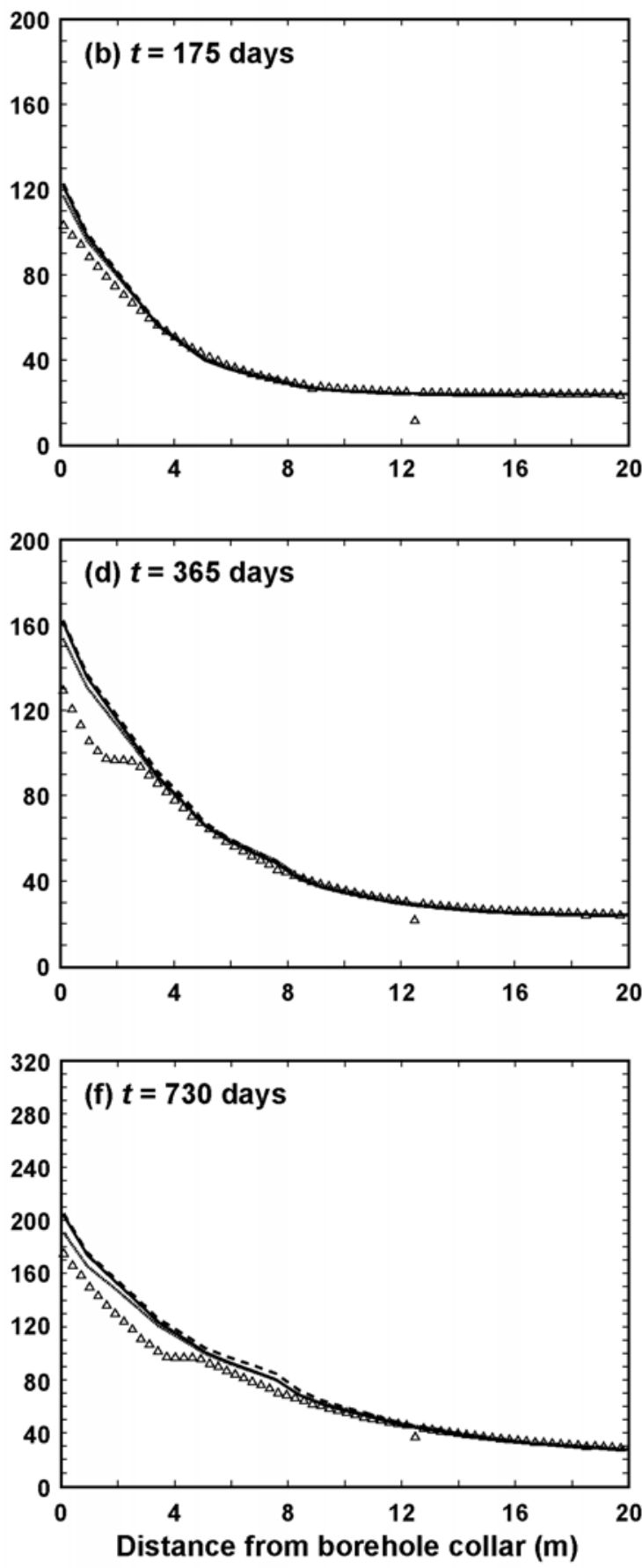

ss-170-173_175-730d

Source: See Table XIII-1.

NOTE: The NUFT simulations are for the three indicated cases. The base case represents gas leakage through the bulkhead, while the sealed-bulkhead case does not allow gas leakage through the bulkhead. The high- $K_{\text {th }}$ case is the same as the base case except with the host-rock thermal conductivity $K_{\text {th }}$ being one standard deviation higher than the mean.

Figure 7.4-7. NUFT-Simulated and Measured Temperatures Compared along Borehole $170(\mathrm{a}, \mathrm{c}, \mathrm{e})$ and Borehole 173 (b, d, f) at 175, 365, and 730 Days 
Borehole 170
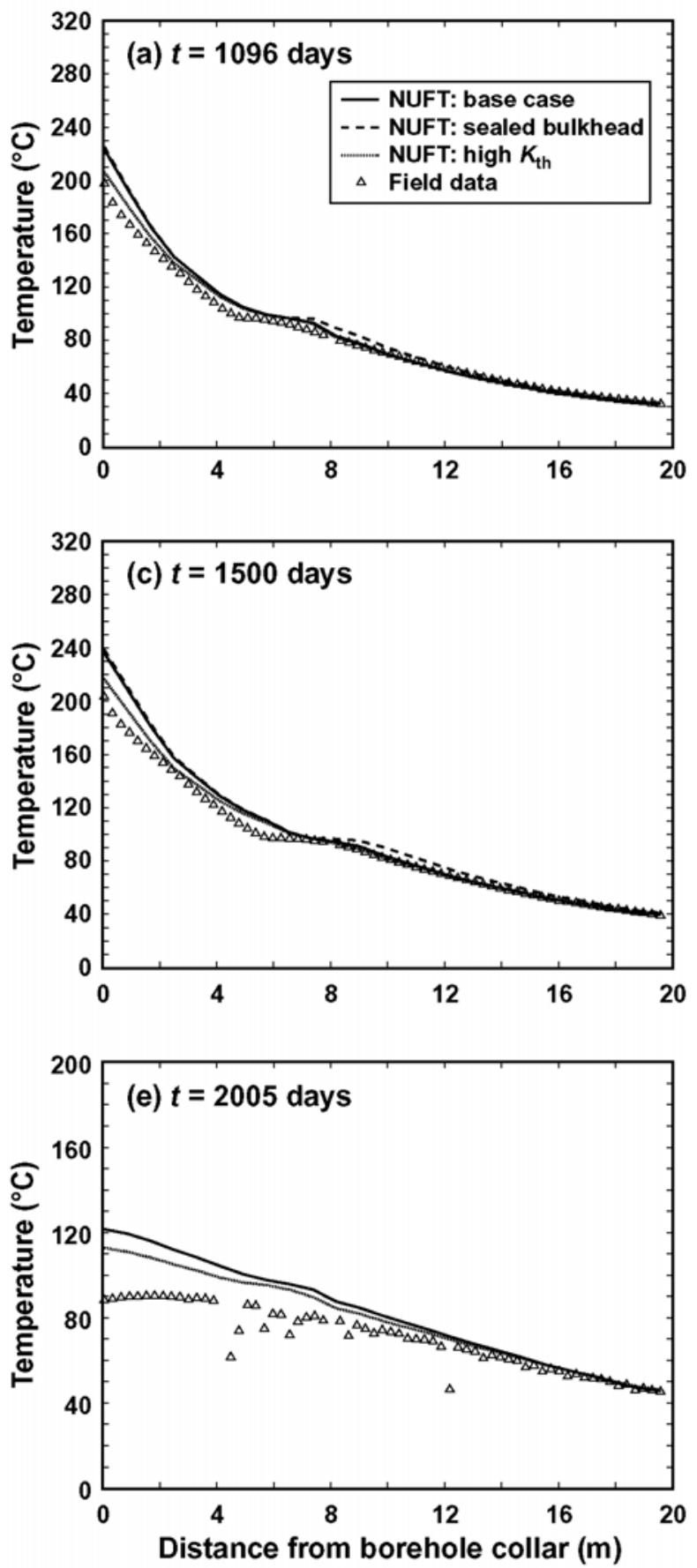

Borehole 173
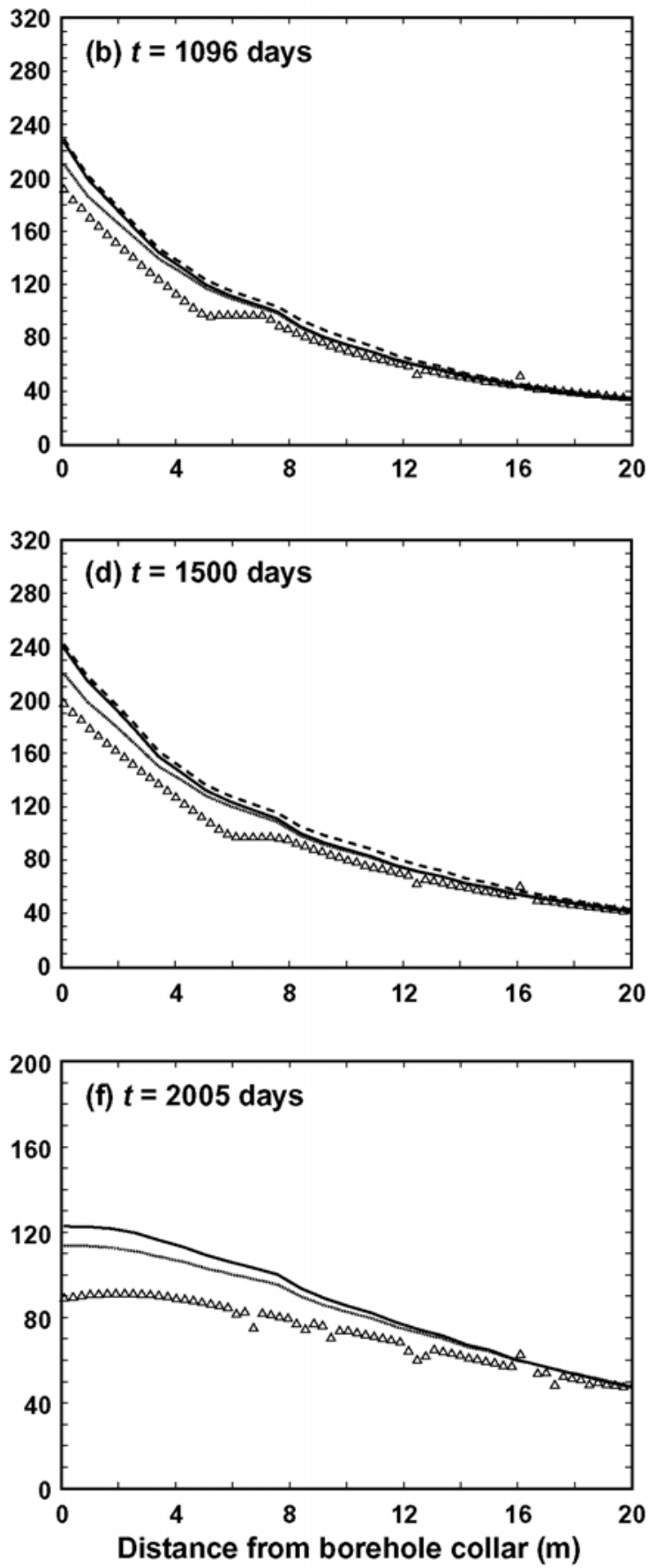

170-173_1096-2005d

Source: See Table XIII-1.

NOTE: The NUFT simulations are for the three indicated cases. The base case represents gas leakage through the bulkhead, while the sealed bulkhead case does not allow gas leakage through the bulkhead. The high- $K_{\text {th }}$ case is the same as the base case except with the host-rock thermal conductivity $K_{\text {th }}$ being one standard deviation higher than the mean. Note that the heaters are turned off at 1,503 days.

Figure 7.4-8. NUFT-Simulated and Measured Temperatures Compared along Borehole $170(\mathrm{a}, \mathrm{c}, \mathrm{e})$ and Borehole 173 (b, d, f) at 1,096, 1,500, and 2,005 Days 
Borehole 139
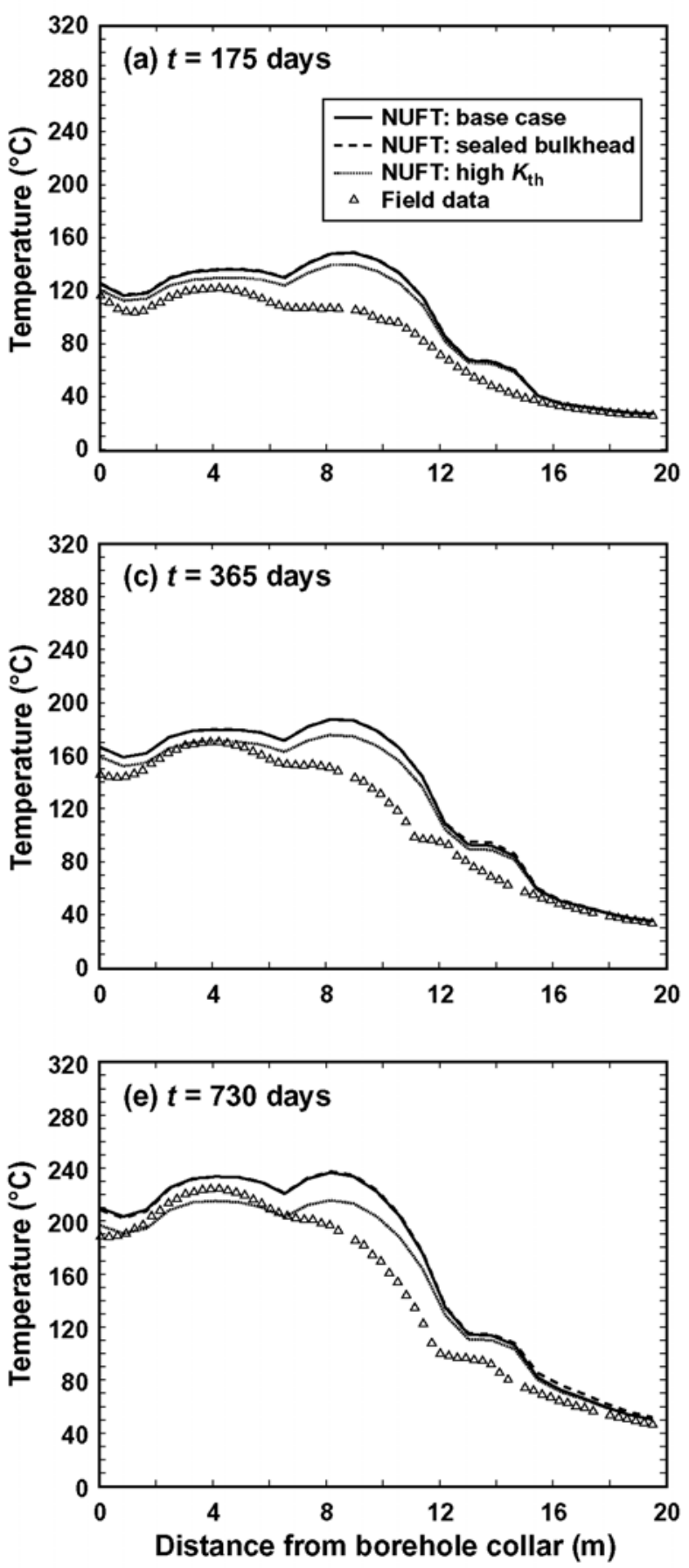

Borehole 143
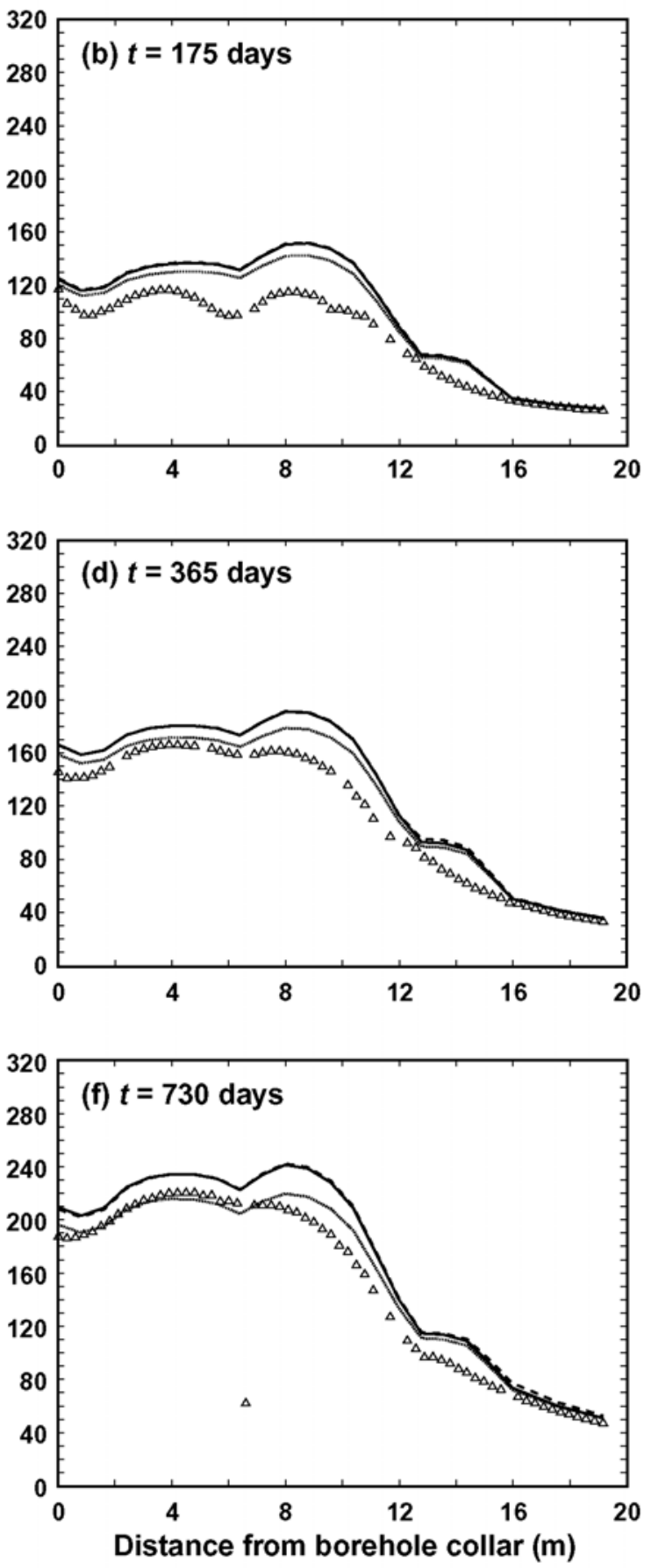

ss-139-143_175-730d

Source: See Table XIII-1.

NOTE: The NUFT simulations are for the three indicated cases. The base case represents gas leakage through the bulkhead, while the sealed-bulkhead case does not allow gas leakage through the bulkhead. The high- $K_{\text {th }}$ case is the same as the base case except with the host-rock thermal conductivity $K_{\text {th }}$ being one standard deviation higher than the mean.

Figure 7.4-9. NUFT-Simulated and Measured Temperatures Compared along Borehole $139(\mathrm{a}, \mathrm{c}, \mathrm{e})$ and Borehole $143(b, d, f)$ at 175, 365, and 730 Days 
Borehole 139
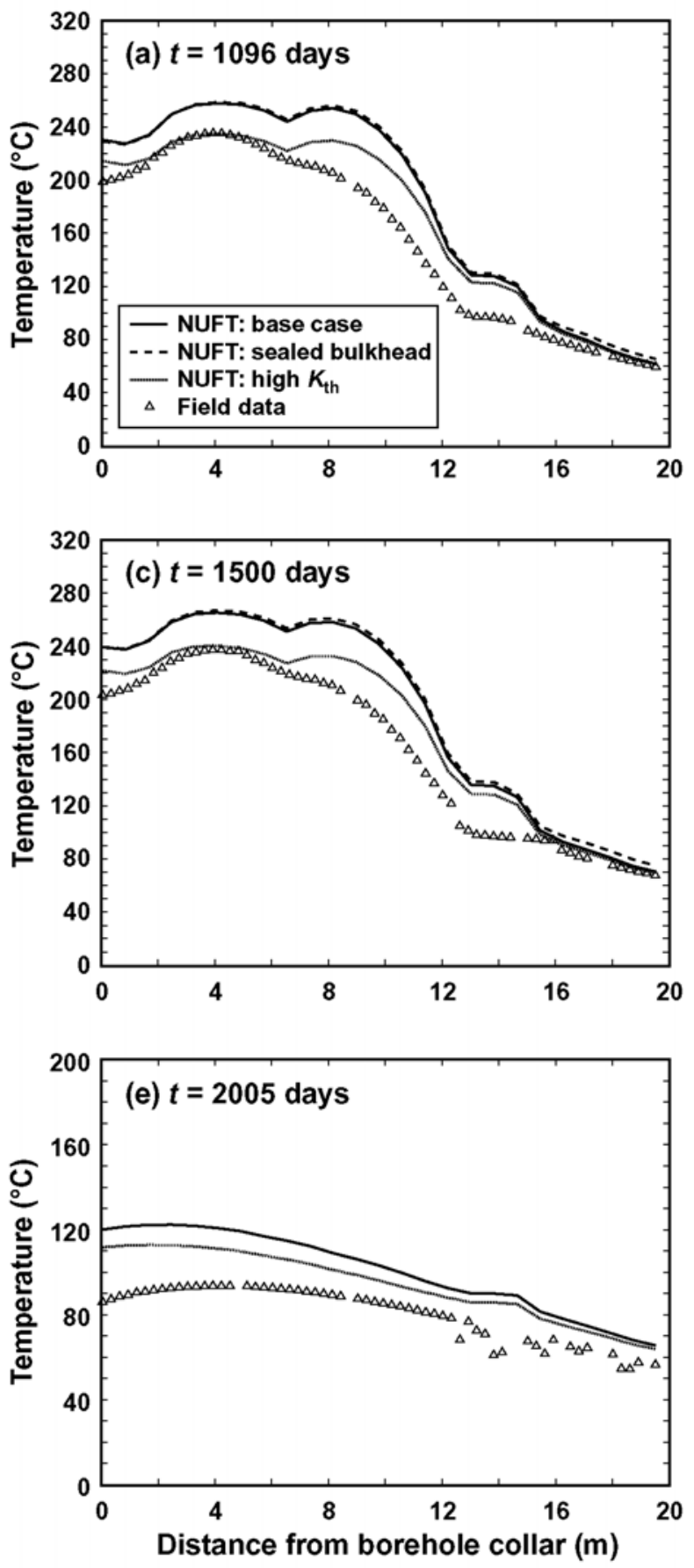

Borehole 143
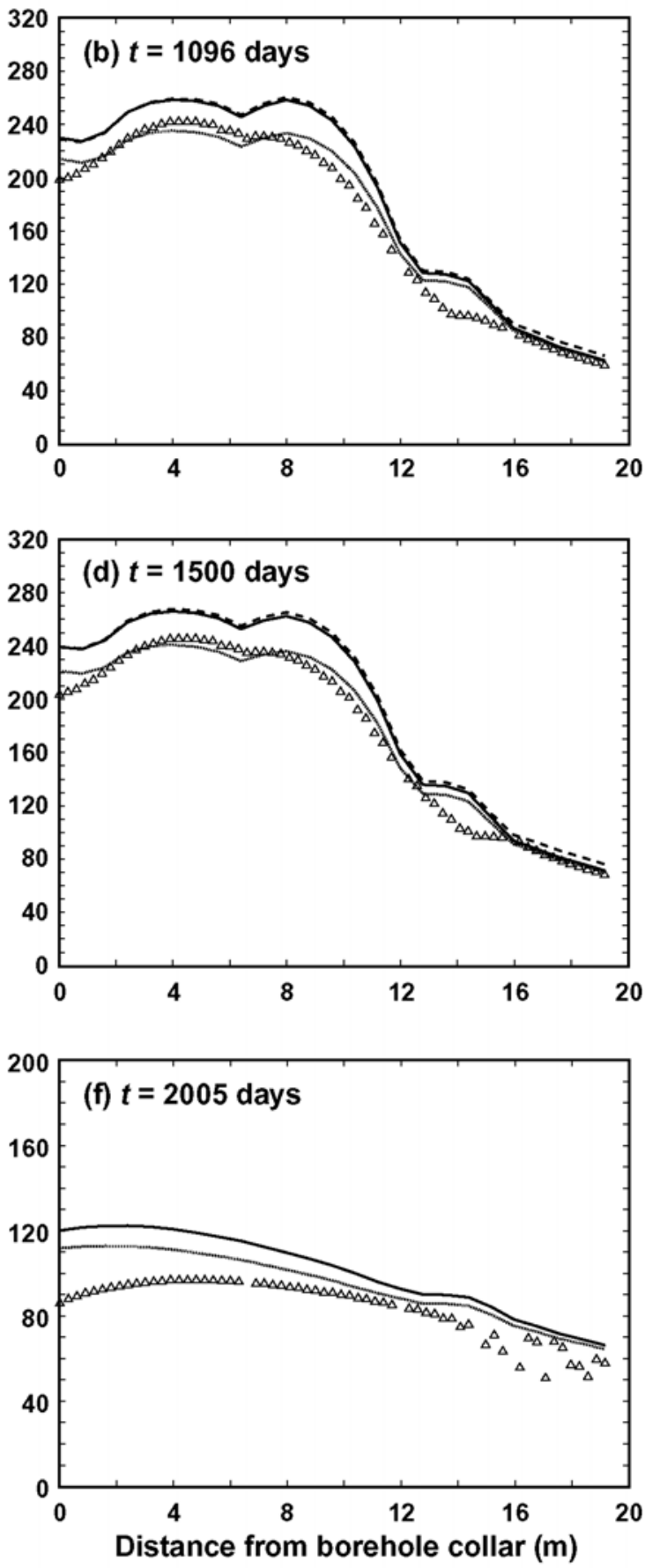

139-143 1096-2005d

Source: See Table XIII-1.

NOTE: The NUFT simulations are for the three indicated cases. The base case represents gas leakage through the bulkhead, while the sealed-bulkhead case does not allow gas leakage through the bulkhead. The high- $K_{\text {th }}$ case is the same as the base case except with the host-rock thermal conductivity $K_{\text {th }}$ being one standard deviation higher than the mean. Note that the heaters are turned off at 1,503 days.

Figure 7.4-10. NUFT-Simulated and Measured Temperatures Compared along Borehole $139(\mathrm{a}, \mathrm{c}, \mathrm{e})$ and Borehole 143 (b, d, f) at 1,096, 1,500, and 2,005 Days 
Borehole 79
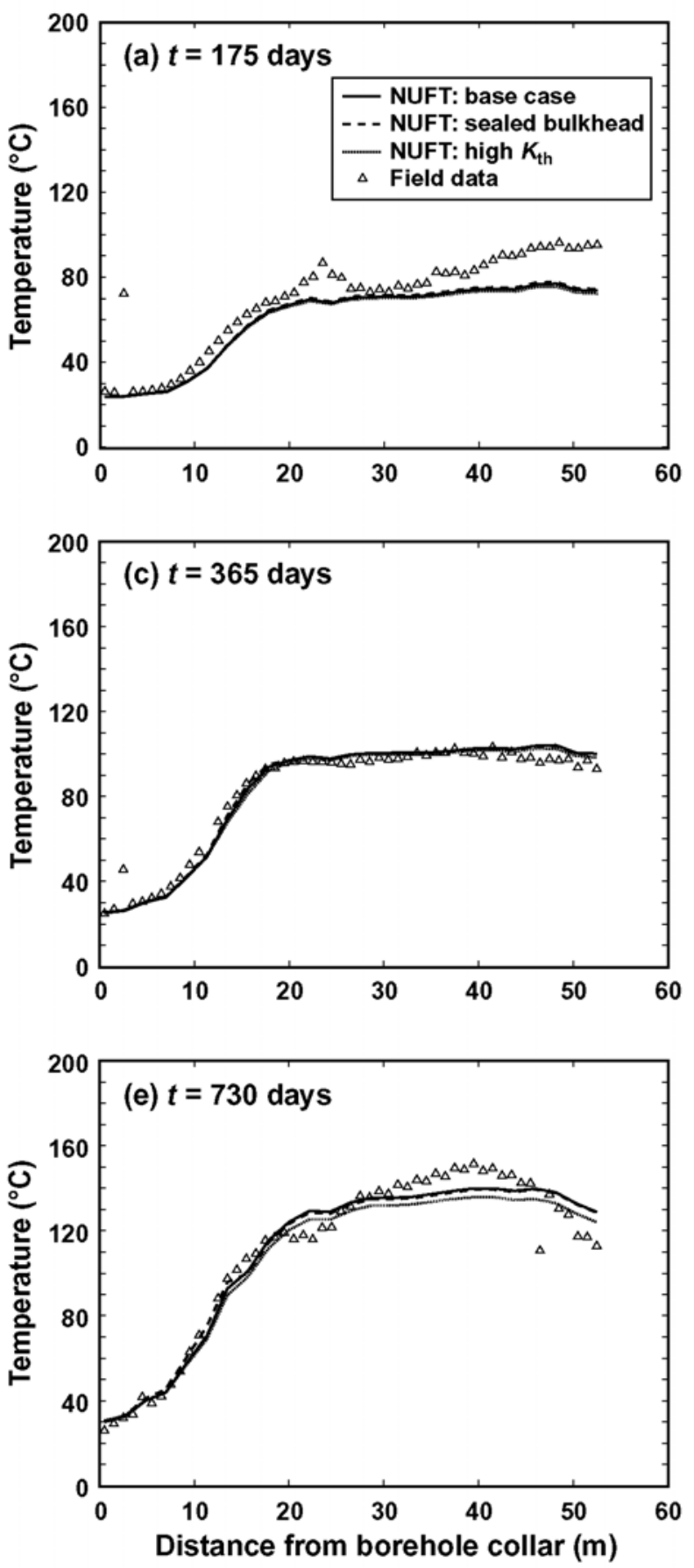

Borehole 80
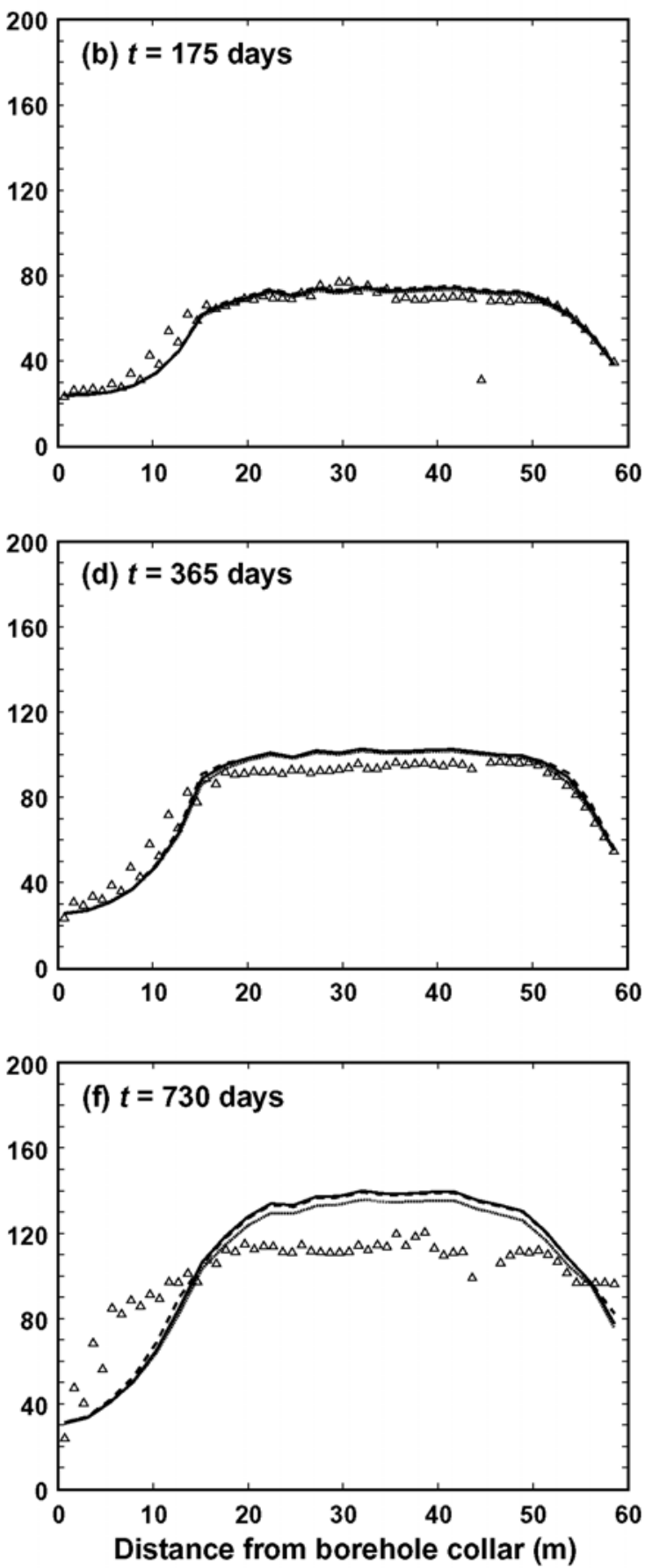

ss-79-80_175-730d

Source: See Table XIII-1.

NOTE: The NUFT simulations are for the three indicated cases. The base case represents gas leakage through the bulkhead, while the sealed-bulkhead case does not allow gas leakage through the bulkhead. The high- $K_{\text {th }}$ case is the same as the base case except with the host-rock thermal conductivity $K_{\text {th }}$ being one standard deviation higher than the mean.

Figure 7.4-11. NUFT-Simulated and Measured Temperatures Compared along Borehole $79(\mathrm{a}, \mathrm{c}, \mathrm{e})$ and Borehole 80 (b, d, f) at 175, 365, and 730 Days 
Borehole 79
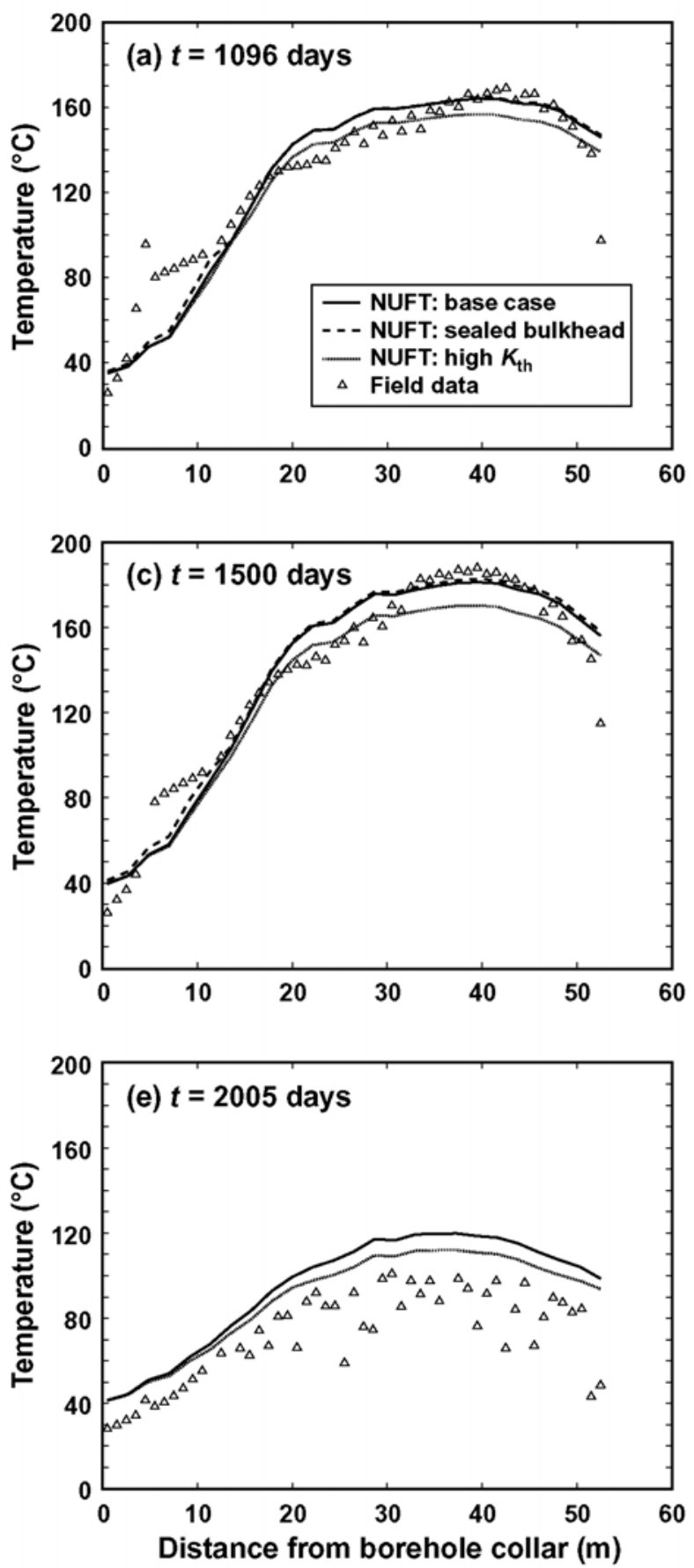

Borehole 80
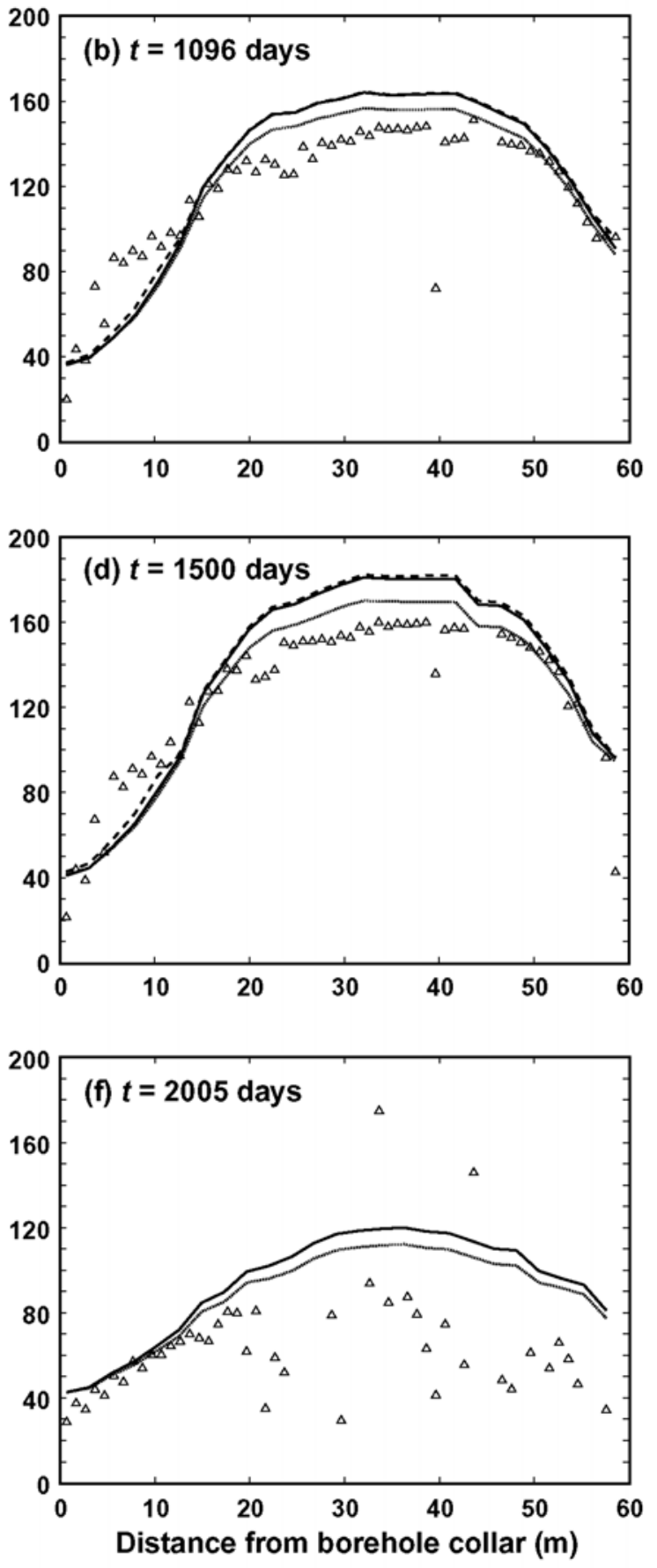

ss-79-80_1096-2005d

Source: See Table XIII-1.

NOTE: The NUFT simulations are for the three indicated cases. The base case represents gas leakage through the bulkhead, while the sealed-bulkhead case does not allow gas leakage through the bulkhead. The high- $K_{\text {th }}$ case is the same as the base case except with the host-rock thermal conductivity $K_{\text {th }}$ being one standard deviation higher than the mean. Note that the heaters are turned off at 1,503 days.

Figure 7.4-12. NUFT-Simulated and Measured Temperatures Compared along Borehole $79(\mathrm{a}, \mathrm{c}, \mathrm{e})$ and Borehole 80 (b, d, f) at 1,096, 1,500, and 2,005 Days 

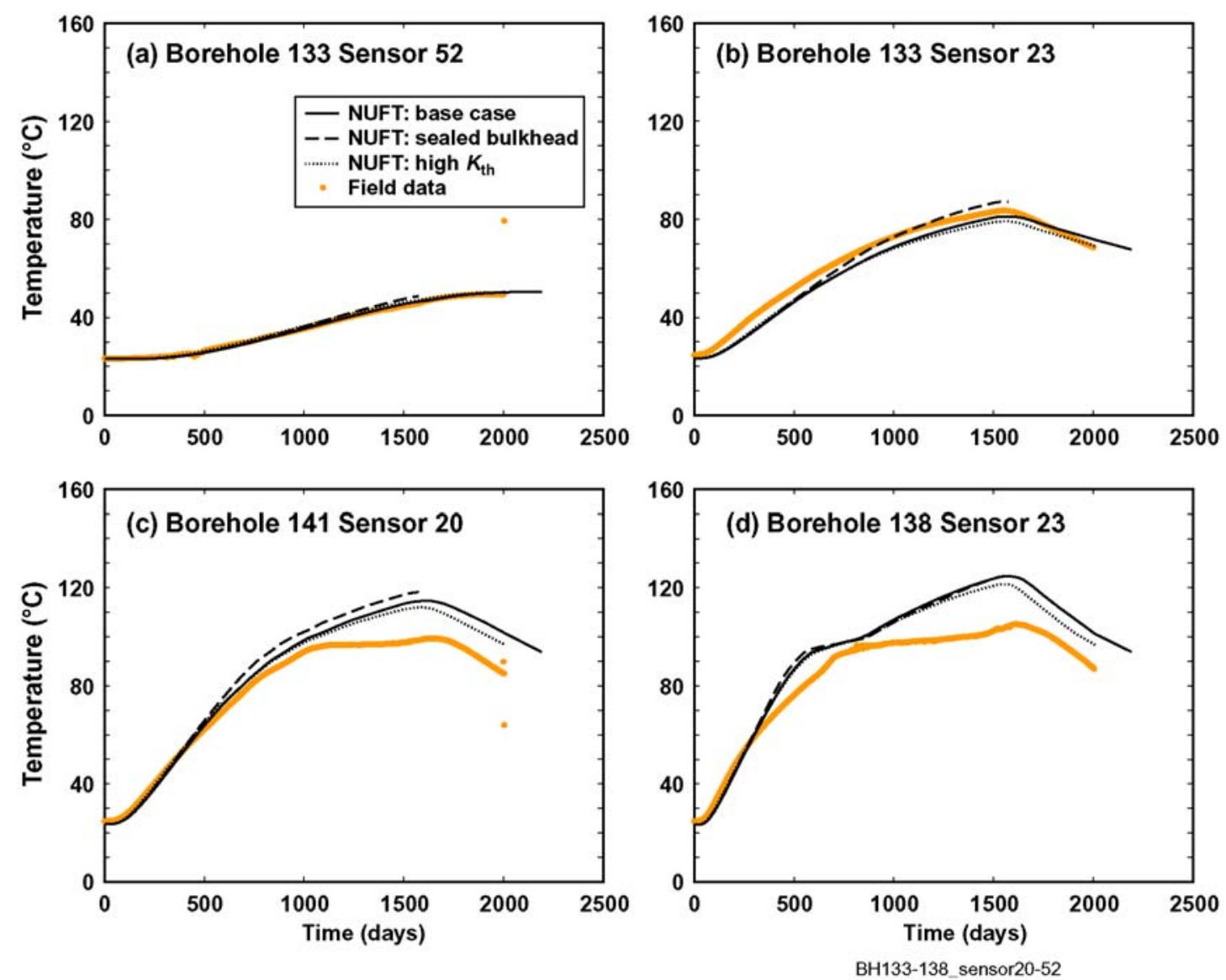

Source: See Table XIII-1.

NOTE: The NUFT simulations are for the three indicated cases. The base case represents gas leakage through the bulkhead, while the sealed-bulkhead case does not allow gas leakage through the bulkhead. The high- $K_{\text {th }}$ case is the same as the base case except with the host-rock thermal conductivity $K_{\text {th }}$ being one standard deviation higher than the mean. Note that the heaters are turned off at 1,503 days.

Figure 7.4-13. NUFT-Simulated and Measured Temperature Histories Compared at Borehole 133: Sensor 52 (a) and Sensor 23 (b), Borehole 141: Sensor 20 (c), and Borehole 138: Sensor 23 (d) 

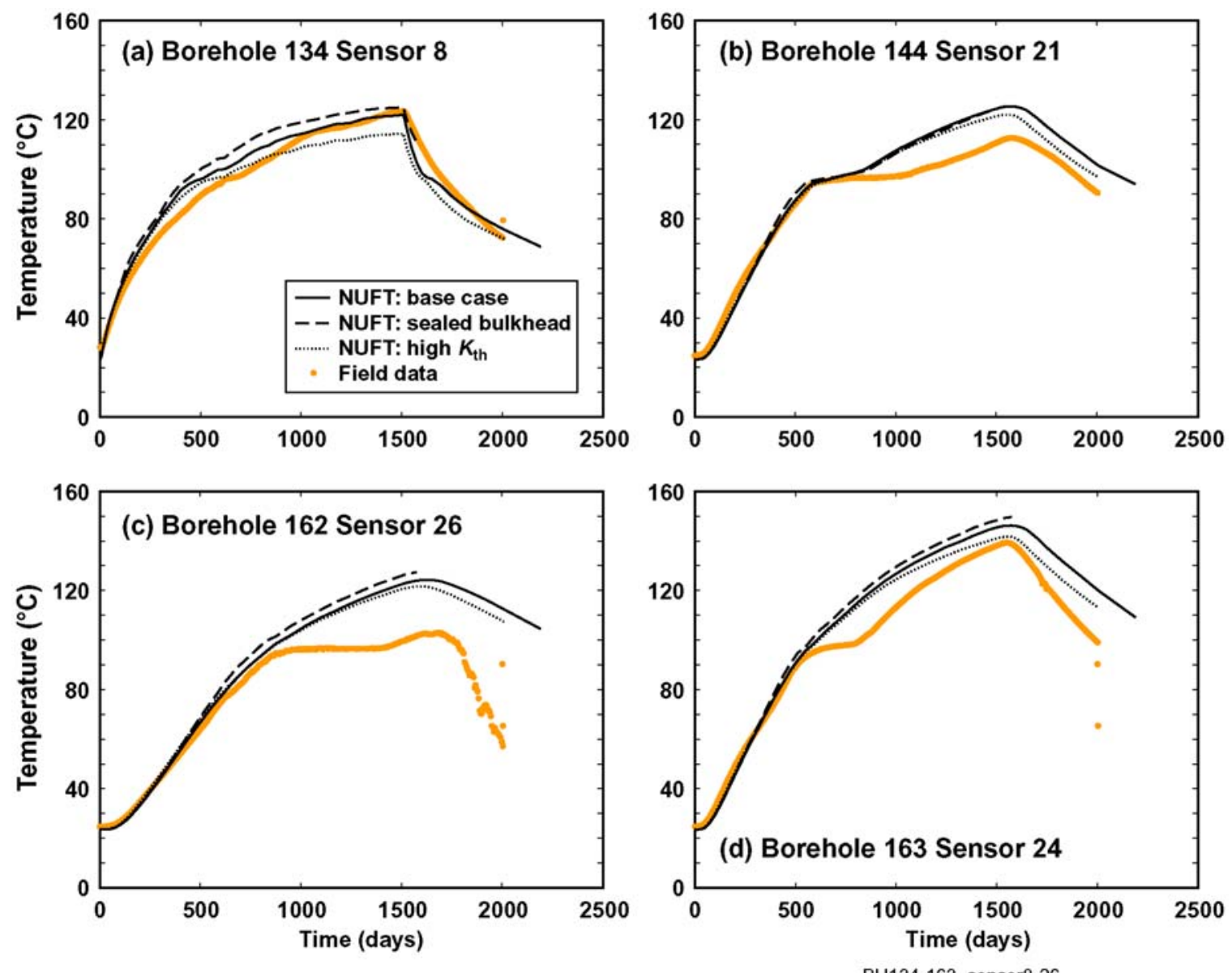

Source: See Table XIII-1.

NOTE: The NUFT simulations are for the three indicated cases. The base case represents gas leakage through the bulkhead, while the sealed-bulkhead case does not allow gas leakage through the bulkhead. The high- $K_{\text {th }}$ case is the same as the base case except with the host-rock thermal conductivity $K_{\text {th }}$ being one standard deviation higher than the mean. Note that the heaters are turned off at 1,503 days.

Figure 7.4-14. NUFT-Simulated and Measured Temperature Histories Compared at Borehole 134: Sensor 8 (a), Borehole 144: Sensor 21 (b), Borehole 162: Sensor 26 (c), and Borehole 163: Sensor $24(d)$ 

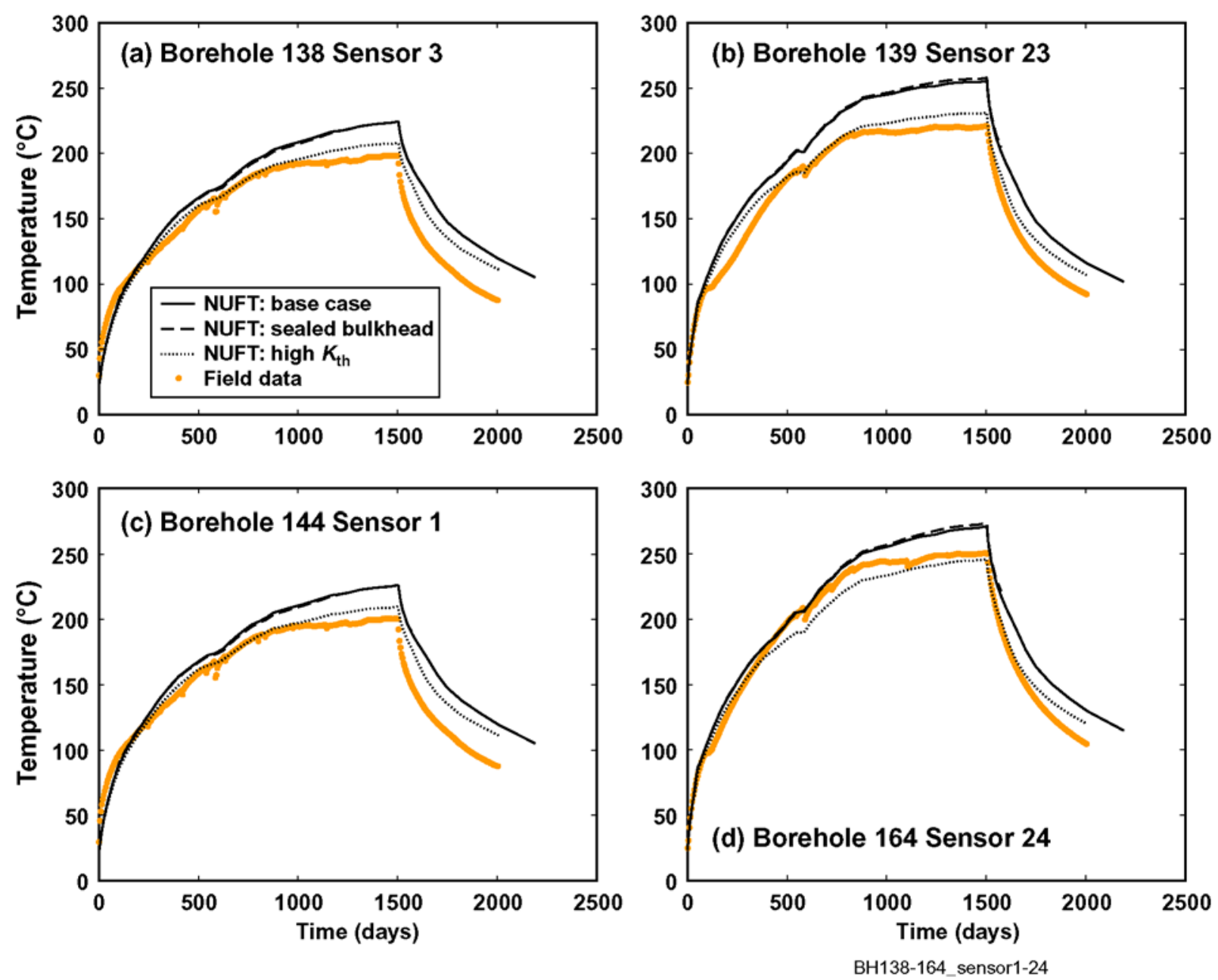

Source: See Table XIII-1.

NOTE: The NUFT simulations are for the three indicated cases. The base case represents gas leakage through the bulkhead, while the sealed-bulkhead case does not allow gas leakage through the bulkhead. The high- $K_{\text {th }}$ case is the same as the base case except with the host-rock thermal conductivity $K_{\text {th }}$ being one standard deviation higher than the mean. Note that the heaters are turned off at 1,503 days.

Figure 7.4-15. NUFT-Simulated and Measured Temperature Histories Compared at Borehole 138: Sensor 3 (a), Borehole 139: Sensor 23 (b), Borehole 144: Sensor 1 (c), and Borehole 164: Sensor 24 (d)

\subsubsection{Comparison of Simulated and Field-Measured Liquid-Phase Saturations in the Matrix}

The source DTNs for all field measurements of liquid-phase saturations in the DST are listed in Table 4.4-2. Note that all of the liquid-phase saturations discussed in this section apply to the matrix, rather than to the fractures; thus, they are called matrix liquid-phase saturations. Figure 7.4-16 shows the matrix liquid-phase saturation contours near the end of the heating phase $(1,500$ days) in plan view through a plane at the elevation of the wing-heater array and for a vertical cross-section midway along the length of the Heated Drift. Note that the heaters are turned off at 1,503 days. The maximum spatial extent of rock dryout occurs at the end of the heating phase. The dryout zones have coalesced between the wing-heater arrays and the Heated Drift. Also, 
rock dryout is vertically symmetrical about the heater horizon, indicating that condensate shedding is occurring efficiently around the edges of the boiling/rock-dryout zone.

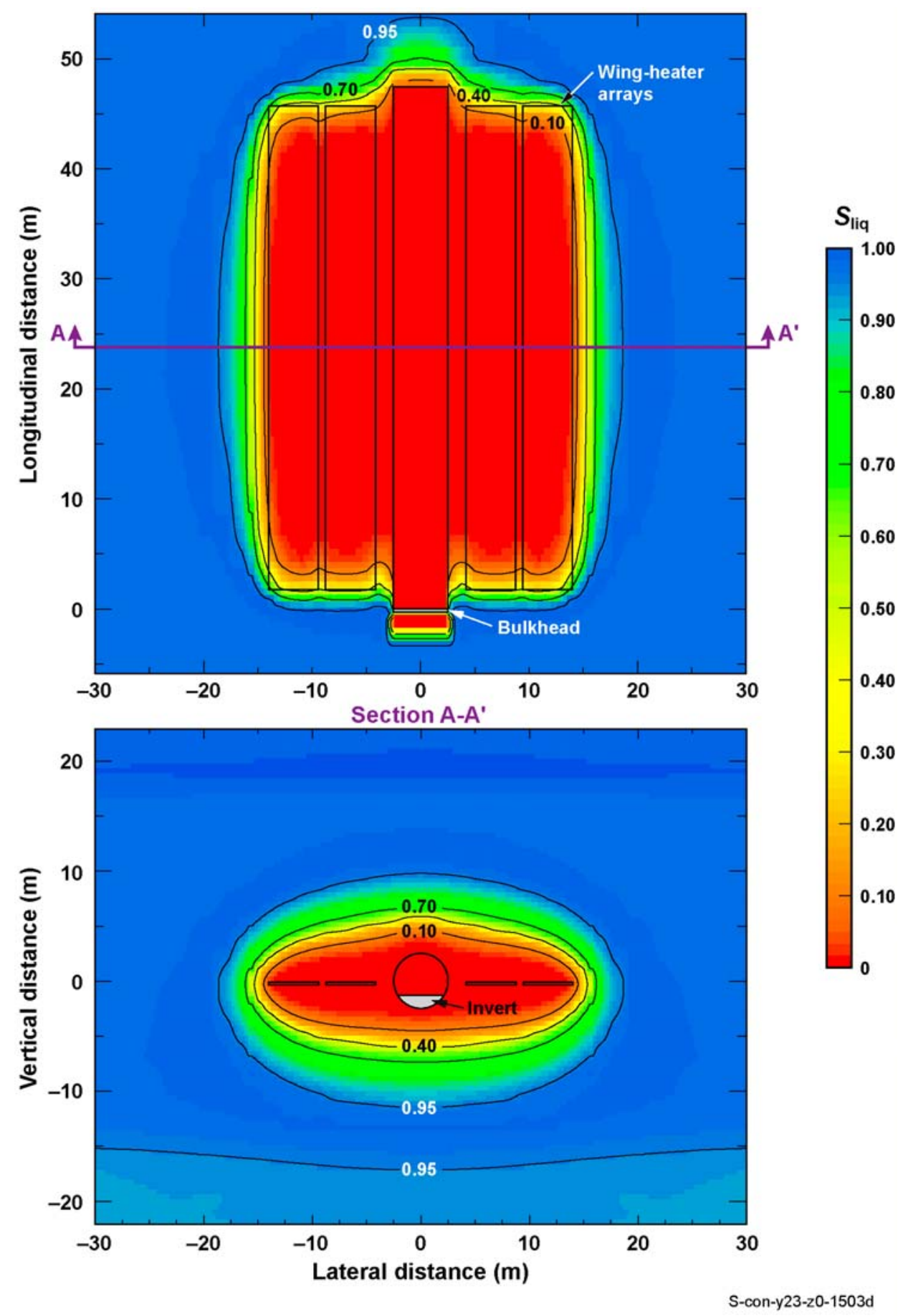

Source: See Table XIII-1.

NOTE: Heaters are turned off at 1,503 days, ending the heating phase.

Figure 7.4-16 Contours of Liquid-Phase Saturation (for the Base Case) in the Matrix at the End of the Heating Phase, Plotted in (a) Plan View Through a Horizontal Plane at the Elevation of the Wing-Heater Array and (b) for a Vertical Cross-Section Midway along the Heated Drift $(y=22.9 \mathrm{~m})$ 
Figures 7.4-17 through 7.4-19 compare NUFT-simulated and measured matrix liquid-phase saturation profiles along the Neutron Probe boreholes. Boreholes 79 and 80 are described in Table 7.4-1, while Borehole 68 is an inclined borehole passing below the Heated Drift, as is shown in Figure 7.2.2-3 of Drift-Scale Coupled Processes (DST and TH Seepage) Models (BSC 2004 [DIRS 170338]). All of the comparisons of matrix liquid-phase saturation profiles clearly indicate that the NUFT-simulated rock dryout lags far behind the dryout measured in the field. Figure 7.4-20 shows the NUFT-simulated time histories of temperature, liquid-phase saturation, and gas-phase pressure in the matrix at two locations: 20 and $27 \mathrm{~m}$ from the collar in Borehole 68. An inspection of Table 7.4-3, which summarizes NUFT-simulated temperature, liquid-phase saturation, and gas-phase pressure in the matrix at those locations, indicates that high gas-phase pressure is throttling vaporization and delaying rock dryout (indicated by the NUFT-simulated matrix liquid-phase saturation) compared to the observed dryout rate in the DST (indicated by field measurements of matrix liquid-phase saturation). The implication is that the use of a larger value of matrix permeability in the NUFT thermal-hydrologic model would result in less of a delay in NUFT-simulated rock dryout compared to the observed dryout rate in the DST. This conclusion is supported by the comparison of NUFT-simulated and observed rock dryout for the Large Block Test (Figure 7.3-2), which showed that the use of a larger value of matrix permeability resulted in a larger dryout zone. As discussed earlier, this is also consistent with the discussion in Section 7.4.4 of Drift-Scale Coupled Processes (DST and TH Seepage) Models (BSC 2004 [DIRS 170338]).

Table 7.4-3. NUFT-Simulated (Base-Case) Temperature, Liquid-Phase Saturation, and Gas-Phase Pressure in the Matrix Summarized at 20 and $27 \mathrm{~m}$ from the Collar of Borehole 68.

\begin{tabular}{|c|c|c|c|c|c|}
\hline $\begin{array}{c}\text { Distance (m) } \\
\text { From Collar of } \\
\text { Borehole 68 }\end{array}$ & $\begin{array}{c}\text { Time } \\
\text { (days) }\end{array}$ & $\begin{array}{c}\text { Temperature } \\
\left({ }^{\circ} \mathbf{C}\right)\end{array}$ & $\begin{array}{c}\text { Liquid-Phase } \\
\text { Saturation }\end{array}$ & $\begin{array}{c}\text { Gas-Phase } \\
\text { Pressure in } \\
\text { Matrix (atm) }\end{array}$ & $\begin{array}{c}\text { Saturation } \\
\text { Temperature from } \\
\text { Steam Tables }\left({ }^{\circ} \mathbf{C}\right)\end{array}$ \\
\hline 20 & 877 & 128.7 & 0.806 & 2.600 & 128.7 \\
\hline 20 & 1,242 & 143.9 & 0.684 & 4.032 & 143.9 \\
\hline 20 & 1,500 & 150.9 & 0.560 & 4.864 & 150.9 \\
\hline 20 & 1,917 & 118.2 & 0.376 & 1.946 & 118.2 \\
\hline 27 & 877 & 121.8 & 0.847 & 2.100 & 121.8 \\
\hline 27 & 1,242 & 139.7 & 0.721 & 3.582 & 139.7 \\
\hline 27 & 1,500 & 147.8 & 0.632 & 4.476 & 147.8 \\
\hline 27 & 1,917 & 128.0 & 0.462 & 2.562 & 128.0 \\
\hline
\end{tabular}

NOTE: $\quad$ These values are based on data plotted in Figure 6.3-20.

The underlying cause for the NUFT-simulated dryout behavior lagging behind the dryout behavior observed in the DST is the low value of matrix permeability in the Tptpmn (tsw34) in the modified-mean infiltration-flux hydrologic property set, which results in a large gas-phase pressure buildup in the matrix. This gas-phase pressure buildup throttles (i.e., restricts) the rate of vaporization and delays dryout of the host rock in the DST. Eventually, the spatial extent of the NUFT-simulated dryout zones approaches that of the measured dryout zones. The cause of the throttled dryout is consistent with the discussion in Section 7.4.4.2 of Drift-Scale Coupled Processes (DST and TH Seepage) Models (BSC 2004 [DIRS 170338]). The influence of matrix permeability on dryout is evident by comparing Figure 7.4.4.2.1a (which used the calibrated hydrologic property set, which is the same as the modified-mean infiltration-flux hydrologic property set in the Tptpmn, Tptpll, and Tptpln units) with Figure 7.4.4.2.1b (which used the site-specific property set), both of which are from BSC (2004 [DIRS 170338]). The site-specific 
property set, which has a larger value of matrix permeability, results in a larger simulated rock dryout zone than that simulated with a smaller value of matrix permeability (Figures 7.4.4.2.1a and 7.4.4.2.1b from BSC 2004 [DIRS 170338]).

A comparison of the measured matrix liquid-phase saturation profiles at 1,510 days (approximately when heating ceased) and 1,917 days shows that the dryout zone continues to expand during the cooldown phase. Thus, the DST measurements indicate that no rewetting has commenced prior to 1,917 days. Similarly, the NUFT-simulated matrix liquid-phase saturations continue to decrease during the cooldown phase. Thus, the NUFT thermal-hydrologic model agrees with the field measurements of rewetting behavior in the DST.

The lag in simulated dryout for the DST is a transient effect. As noted earlier, heating conditions for the DST result in an accelerated temperature rise and rock dryout, compared to those predicted for repository heating conditions. Although the comparison of NUFT-simulated dryout with the DST-observed dryout shows that NUFT-simulated dryout lags behind the DST-observed dryout, this is not important to the application of the MSTHM for post-closure repository predictions. This is because rock dryout predicted for repository heating conditions is much slower, occurring over much longer time frames than occurred during the DST. Within four years, the DST-observed rock dryout approaches the NUFT-simulated dryout. Under repository heating conditions, predicted rock dryout occurs over a much longer timeframe (hundreds to thousands of years as shown in Figure 6.3-22c) than was applicable to the DST. This conclusion is consistent with the discussion in Section 7.4.4.2 of Drift-Scale Coupled Processes (DST and TH Seepage) Models (BSC 2004 [DIRS 170338]). Summarizing, compared to the typical duration of rock dryout predicted for repository heating conditions, the duration of the DST-observed lag in rock dryout is insignificant. 


\section{Borehole 68}
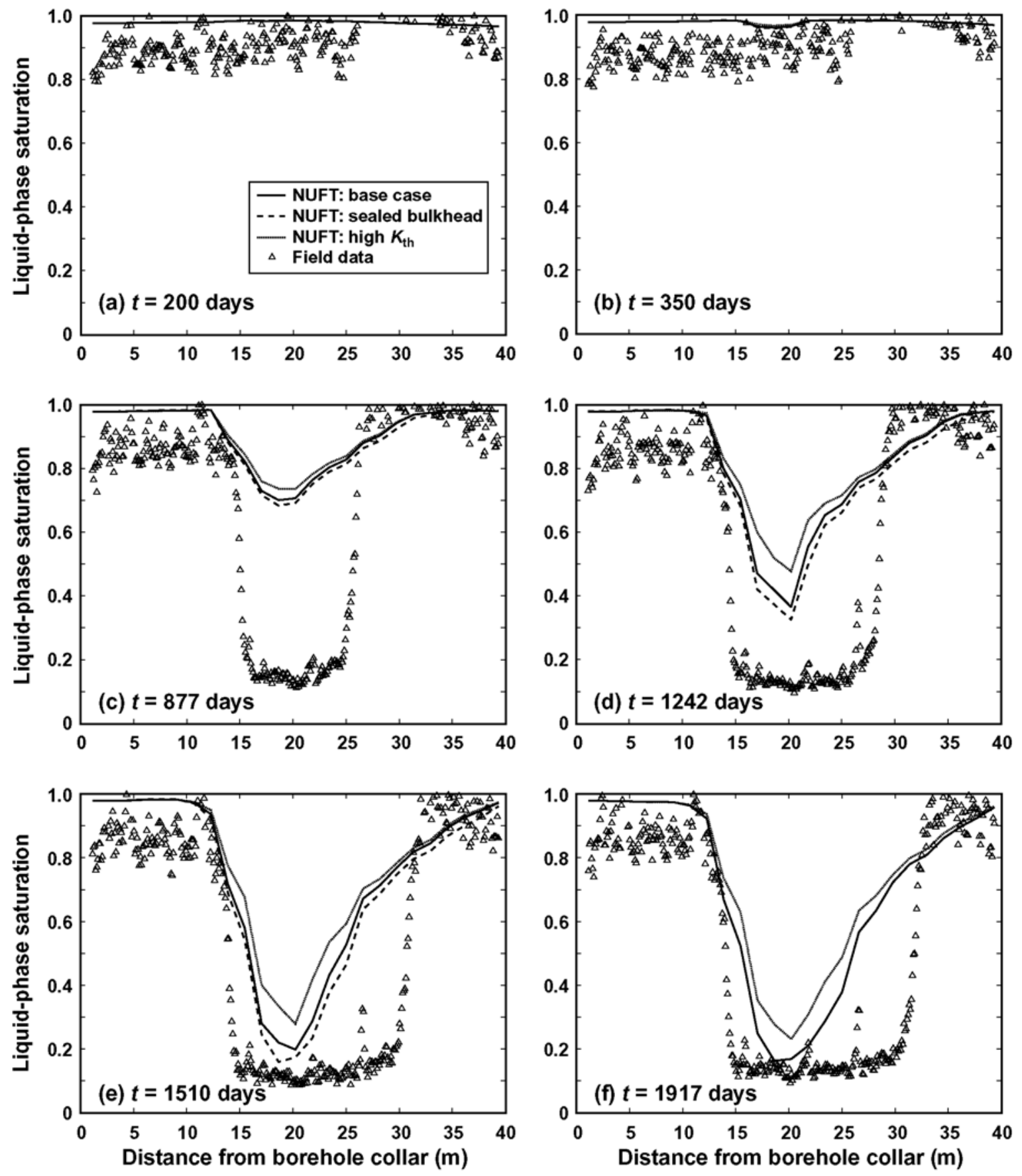

ss-S-68_200-1917d

Source: See Table XIII-1.

NOTE: The NUFT simulations are for the three indicated cases. The base case represents gas leakage through the bulkhead, while the sealed-bulkhead case does not allow gas leakage through the bulkhead. The high- $K_{\text {th }}$ case is the same as the base case except with the host-rock thermal conductivity $K_{\text {th }}$ being one standard deviation higher than the mean. Note that the heaters are turned off at 1,503 days.

Figure 7.4-17. NUFT-Simulated and Measured Liquid-Phase Saturations in the Matrix Compared along Borehole 68 at (a) 200 Days, (b) 350 Days, (c) 877 Days, (d) 1,242 Days, (e) 1,510 Days, and (f) 1,917 Days 


\section{Borehole 79}
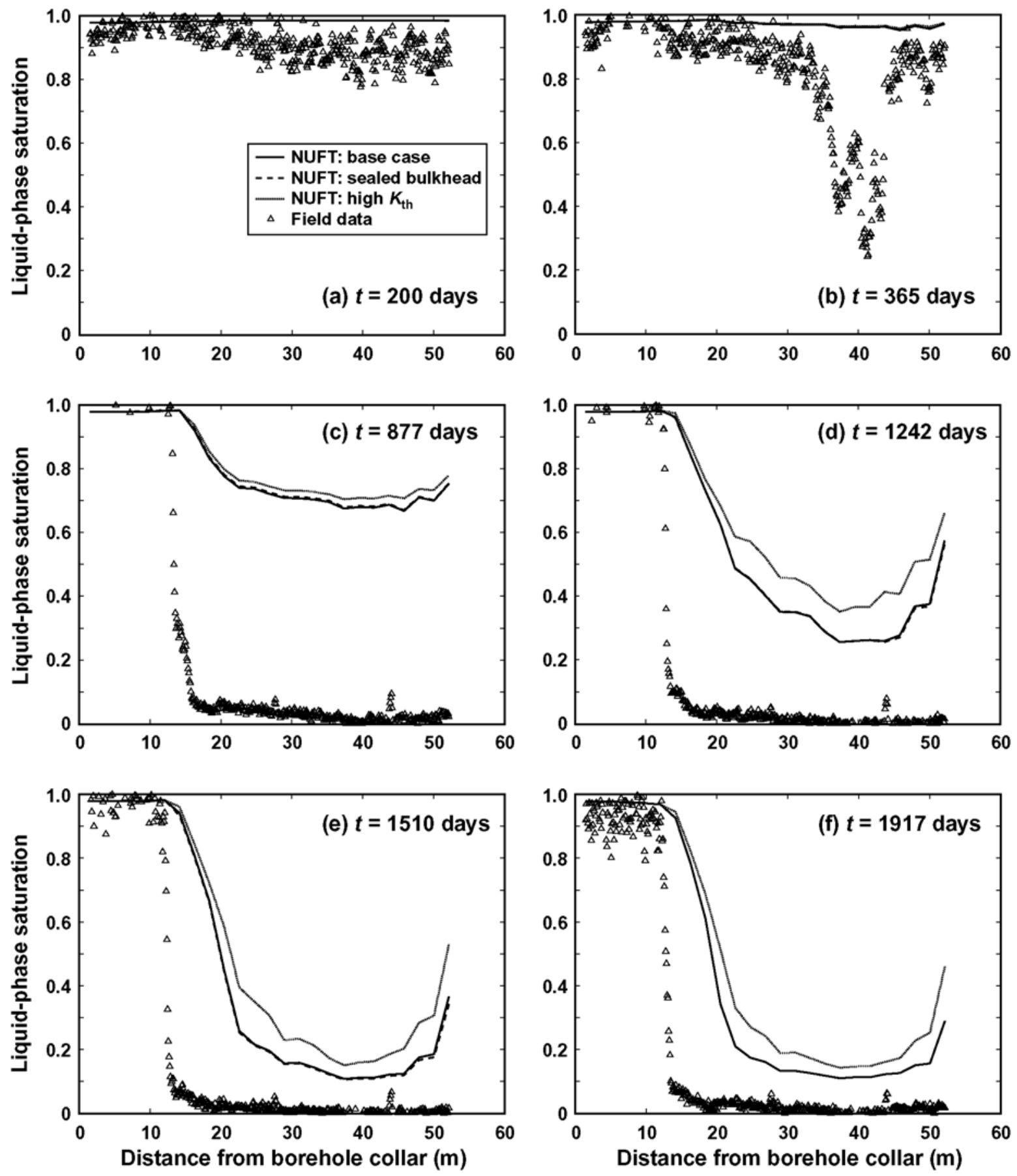

ss-S-79_200-1917d

Source: See Table XIII-1.

NOTE: The NUFT simulations are for the three indicated cases. The base case represents gas leakage through the bulkhead, while the sealed-bulkhead case does not allow gas leakage through the bulkhead. The high- $K_{\text {th }}$ case is the same as the base case except with the host-rock thermal conductivity $K_{\text {th }}$ being one standard deviation higher than the mean. Note that the heaters are turned off at 1,503 days.

Figure 7.4-18. NUFT-Simulated and Measured Liquid-Phase Saturations in the Matrix Compared along Borehole 79 at (a) 200 Days, (b) 365 Days, (c) 877 Days, (d) 1,242 Days, (e) 1,510 Days, and (f) 1,917 Days 


\section{Borehole 80}
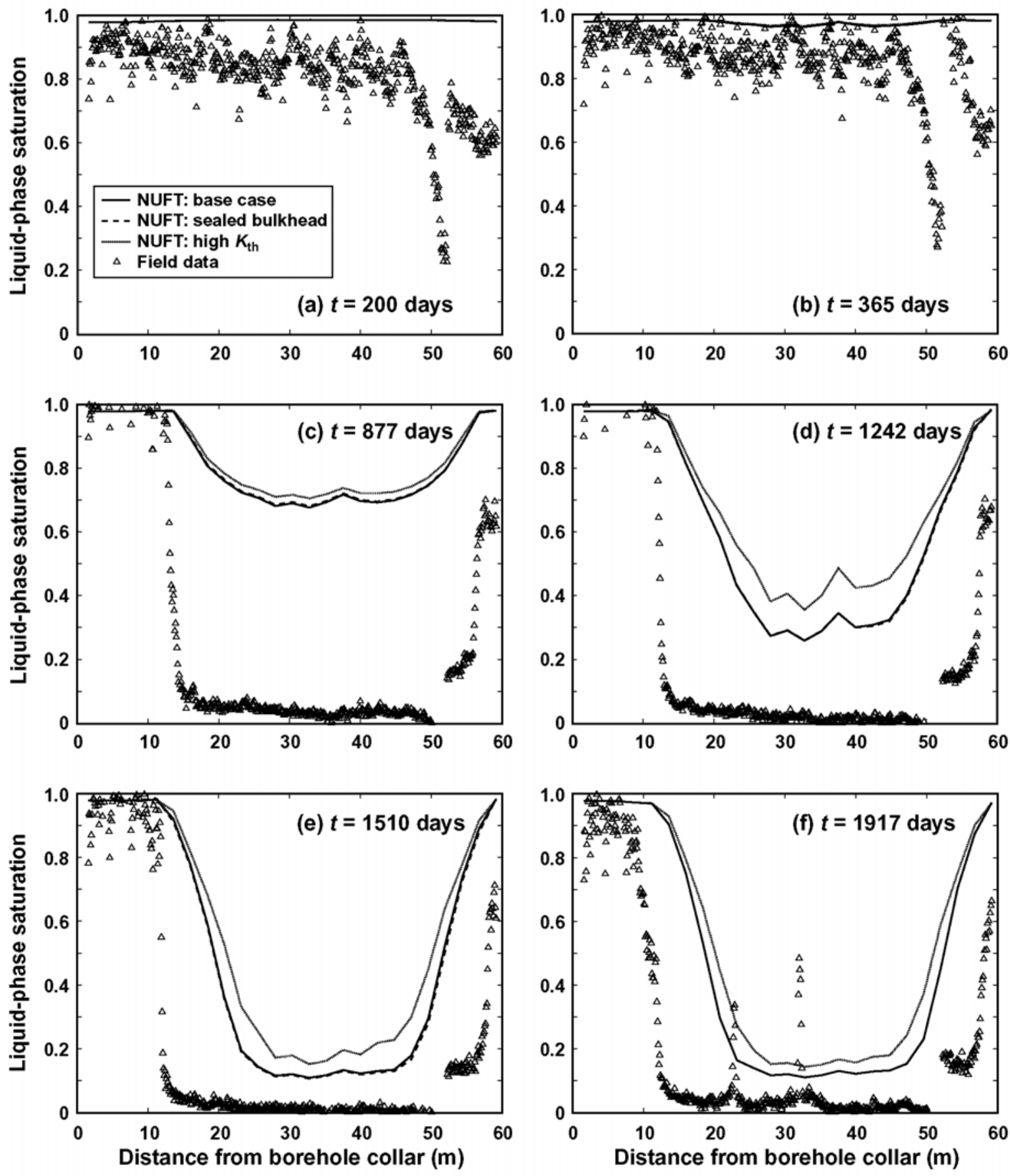

Ss-S-80_200-1917d

Source: See Table XIII-1.

NOTE: The NUFT simulations are for the three indicated cases. The base case represents gas leakage through the bulkhead, while the sealed-bulkhead case does not allow gas leakage through the bulkhead. The high- $K_{\text {th }}$ case is the same as the base case except with the host-rock thermal conductivity $K_{\text {th }}$ being one standard deviation higher than the mean. Note that the heaters are turned off at 1,503 days.

Figure 7.4-19. NUFT-Simulated and Measured Liquid-Phase Saturations in the Matrix Compared along Borehole 80 at (a) 200 Days, (b) 365 Days, (c) 877 Days, (d) 1,242 Days, (e) 1,510 Days, and (f) 1,917 Days 

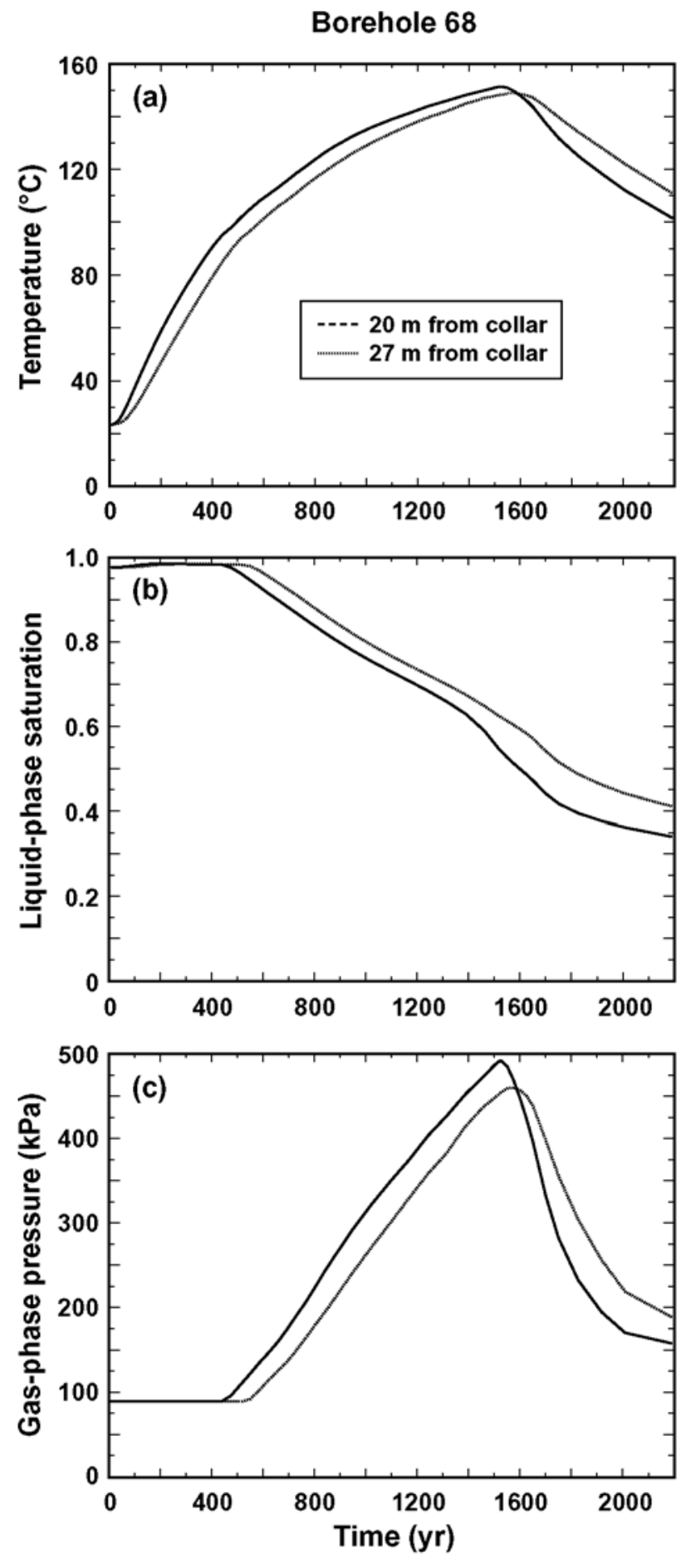

T-S-Pgas_BH68_20-27m

Source: See Table XIII-1.

Figure 7.4-20. NUFT-Simulated Time Histories of (a) Temperature, (b) Liquid-Phase Saturation, and (c) Gas-Phase Pressure in the Matrix, Plotted at Distances of $20 \mathrm{~m}$ and $27 \mathrm{~m}$ from the Collar of Borehole 68. 


\subsubsection{Summary of Model Validation Using DST Data}

The underlying cause for the absence of a NUFT-simulated temperature plateau $\left(\right.$ at $96^{\circ} \mathrm{C}$ ) is the low value of matrix permeability in the Tptpmn (tsw34) in the modified-mean infiltration-flux hydrologic property set, which results in a large gas-phase pressure buildup in the matrix, causing an increase in the saturation (boiling) temperature. The absence of a temperature plateau at $96^{\circ} \mathrm{C}$ causes the NUFT-simulated temperatures to be generally higher than field-measured temperatures for temperatures exceeding $96^{\circ} \mathrm{C}$. These observations are consistent with the discussion in Sections 7.4.3 and 7.4.4 of Drift-Scale Coupled Processes (DST and TH Seepage) Models (BSC 2004 [DIRS 170338]).

Another reason for NUFT-simulated temperatures being higher than measured temperatures is the uncertainty in host-rock thermal conductivity $K_{\text {th }}$ in the DST area. For the high- $K_{\text {th }}$ case (one standard deviation above the mean), NUFT-simulated temperatures were in better agreement with measured temperatures than the cases that used the mean $K_{\text {th }}$ values. Because percolation fluxes cannot be directly measured, uncertainty in local percolation flux in the DST area also contributes to differences between NUFT-simulated and measured temperatures. Section 6.3.4 discusses the influence of key parametric uncertainties on predicted thermohydrologic conditions in the repository. Table 6.3-30 shows that the combined influence of host-rock percolation-flux and thermal conductivity uncertainties results in peak drift-wall temperatures varying by 26.6 to $38.3^{\circ} \mathrm{C}$ for the four host-rock units. Note that the 30-percent validation criterion for temperature rise (above ambient), which is given in the TWP, is consistent with the magnitude of the influence of the parametric uncertainty of host-rock thermal conductivity and percolation flux on temperature. As shown in Table 6.3-30, the combined influence of host-rock thermal conductivity uncertainty and percolation-flux uncertainty causes the rise in peak drift-wall temperature (above ambient) to vary by about 30 percent.

For temperatures less than about $80^{\circ} \mathrm{C}$, NUFT-simulated and measured temperatures are in good agreement (within 30 percent as required by the TWP) for all three cases: (1) base case, (2) sealed bulkhead, and (3) high $K_{\text {th }}$. Overall, the comparison of NUFT-simulated and measured temperatures demonstrate that the NUFT thermohydrologic model provides a valid representation of heat flow in the DST. These observations are consistent with the discussion in Sections 7.4.3 and 7.4.4 of Drift-Scale Coupled Processes (DST and TH Seepage) Models (BSC 2004 [DIRS 170338]).

The underlying cause for the NUFT-simulated throttled (i.e., restricted) vaporization and delayed dryout (compared to dryout observed in the DST) is the large gas-phase pressure buildup in the matrix, which is caused by the low matrix permeability in the Tptpmn (tsw34) in the calibrated hydrologic property set. Thus, the cause of the difference between the NUFT-simulated and observed rock-dryout rate is well understood. Eventually, the spatial extent of the NUFT-simulated dryout zone approaches that of the dryout zone observed in the DST. Therefore, the ultimate spatial extent of rock dryout simulated by the NUFT thermohydrologic model agrees with that measured in the DST. From this it is concluded that the NUFT thermohydrologic model provides a valid representation of rock dryout in the DST. This conclusion is consistent with the discussion in Sections 7.4.3 and 7.4.4 of Drift-Scale Coupled Processes (DST and TH Seepage) Models (BSC 2004 [DIRS 170338]). To the extent that the observations of cooldown in the DST presently allow, the NUFT thermohydrologic model provides a valid representation of rewetting behavior in the DST. 
With a few exceptions, the differences between the NUFT-simulated and measured temperature changes from ambient temperatures are less than 30 percent. The exceptions are related to the above-mentioned large gas-phase pressure buildup that temporarily throttles (i.e., restricts) vaporization and rock dryout. It is important to note that this effect is transient that dissipates as the NUFT-simulated gas-phase pressure buildup declines. With the decline of the NUFT-simulated gas-phase pressure buildup, agreement between the NUFT-simulated and measured temperatures improves, and the differences between the NUFT-simulated and measured temperature changes from ambient temperatures are less than 30 percent. The NUFT-simulated rock dryout behavior (as measured by liquid-phase saturation in the matrix continuum versus time) agrees qualitatively with the measured dryout behavior. For the ultimate spatial extent of rock dryout, there is very good agreement between the NUFT-simulated and measured dryout. Overall, the comparisons of NUFT-simulated and measured temperatures and matrix liquid-phase saturations demonstrate that the NUFT thermohydrologic model provides a valid representation of heat flow, as well as dryout and rewetting of the host rock in the DST. These conclusions are consistent with the discussion in Sections 7.4.3 and 7.4.4 of Drift-Scale Coupled Processes (DST and TH Seepage) Models (BSC 2004 [DIRS 170338]).

Another conclusion from the DST model validation study is that the sealed-bulkhead case results in slightly higher NUFT-simulated temperatures than the base case (which had a leaky bulkhead). The influence of the leaky bulkhead on simulated temperatures is much less than that resulting from a one standard-deviation range in thermal conductivity. This conclusion is useful with respect to the potential significance of whether the ends of the emplacement drifts are sealed with bulkheads or simply backfilled with highly permeable crushed tuff. The conclusion of the insensitivity of the DST thermohydrologic simulations to the treatment of the bulkhead (leaky versus sealed) suggests that the MSTHM representation of thermohydrologic behavior in the emplacement drifts will not be significantly affected by whether the ends of the emplacement drifts are sealed.

\subsection{COMPARISON OF THE MSTHM RESULTS AGAINST A MONOLITHIC THREE-DIMENSIONAL THERMAL-HYDROLOGIC MODEL}

This model validation test case is similar to that conducted by Buscheck et al. (2003 [DIRS 164638]). Using a scaled-down three-drift repository as a model validation test case, the MSTHM is applied along with a corresponding monolithic three-dimensional thermal-hydrologic model for calculating drift-scale thermal-hydrologic conditions. The monolithic thermal-hydrologic model, which is called a Discrete-/Line-Averaged-Heat-Source Mountain-Scale Thermal-Hydrologic (D/LMTH) model (Table 1-2), uses a nested mesh to represent detailed thermal-hydrologic behavior in the vicinity of the emplacement drifts as well as mountain-scale thermal-hydrologic behavior. Both the MSTHM and the corresponding monolithic three-dimensional thermal-hydrologic model discretely represent eight individual waste packages down to the surface of the drip shield. Results from these two models are compared at the drift wall, drip shield, and invert. This comparison is the basis for the validation of the MSTHM methodology.

\subsubsection{Description of the MSTHM Validation Test Case}

The test case used to validate the MSTHM approach represents a scaled-down repository, consisting of three 243-m long drifts (Figure 7.5-1 and Table 7.5-1). The total heat output from 
these three drifts is $986.6 \mathrm{~kW}$, representing approximately 143 average waste packages (Buscheck et al. 2003 [DIRS 164638]). This heat output is modeled in the three drifts as a line-averaged heat source everywhere except at the center of Drift \#2 where 15 discrete waste packages are modeled: 7 at the center of Drift \#2 and 4 at either end of Drift \#2. Because the test case is symmetric, the 15 discrete waste packages can be modeled as the 7.5 discrete waste packages described in Table 7.5-2. The thermal-operating parameters of the three-drift repository test case are equivalent to those being considered for the TSPA-LA except for the total inventory of waste packages. The waste packages are spaced end to end along the drift with a gap of $10.6 \mathrm{~cm}$, which is similar to 10 $\mathrm{cm}$ gap that is being considered for the TSPA-LA (Table 4.1-2). Preclosure ventilation of the drifts is assumed to remove 70 percent of the heat generated during the 50 -year ventilation period. Note that at the time this validation test case was developed, a heat-removal efficiency of 70 percent was being used in the MSTHM calculations in support of FY 01 Supplemental Science and Performance Analyses, Volume 1: Scientific Bases and Analyses (BSC 2001 [DIRS 155950]). The initial heat output is $986.6 \mathrm{~kW}$ for the entire three-drift system, which is equivalent to about 1.18 percent of the 63,000 -MTU thermal load $(83,346 \mathrm{~kW})$ for the repository (Canori and Leitner 2003 [DIRS 166275], p. 3-95). Note that the total repository thermal load is obtained by multiplying the initial linear power density of $1.45 \mathrm{~kW} / \mathrm{m}$ (Table $4.1-1$ ) by $57,480 \mathrm{~m}$ of heated emplacement drift (Table 6.2-1). Four different types of waste packages are represented in the test case and are described in Table 7.5-2.

Table 7.5-1. Design and Operating Parameters Used in MSTHM Validation Test Case

\begin{tabular}{|l|l|}
\hline \multicolumn{1}{|c|}{ Parameter } & \multicolumn{1}{c|}{ Parameter Value } \\
\hline Drift spacing & $81 \mathrm{~m}$ \\
\hline Drift length & $243 \mathrm{~m}$ \\
\hline Drift diameter & $5.5 \mathrm{~m}$ \\
\hline Drip-shield diameter & $2.512 \mathrm{~m}$ \\
\hline Areal Mass Loading (AML) & $54.5 \mathrm{MTU} / \mathrm{acre}^{\mathrm{a}}$ \\
\hline Heated repository footprint & $59,049 \mathrm{~m}^{2}$ \\
\hline Lineal Power Density & $1.3534 \mathrm{~kW} / \mathrm{m}$ \\
\hline Total heat output & $986.6 \mathrm{~kW}$ \\
\hline $\begin{array}{l}\text { Approximate number of waste packages } \\
\text { represented in entire three-drift model }\end{array}$ & 143 \\
\hline Heat removal by ventilation & $70 \%$ for 50 years \\
\hline Waste package configuration and spacing & Line load with10.6-cm gaps \\
\hline
\end{tabular}

Source: Buscheck et al. 2003 [DIRS 164638], Table 4.

${ }^{a}$ Note that this value is rounded to 55 MTU/acre elsewhere in Section 7.5.

Table 7.5-2. Waste Package Types Used in the MSTHM Validation Test Case

\begin{tabular}{|c|c|c|c|c|}
\hline $\begin{array}{c}\text { Waste } \\
\text { Package Type }\end{array}$ & $\begin{array}{c}\text { Waste Package } \\
\text { Description }\end{array}$ & $\begin{array}{c}\text { Number of Waste } \\
\text { Packages }^{\text {a }}\end{array}$ & $\begin{array}{l}\text { Length } \\
\text { (m) }\end{array}$ & $\begin{array}{l}\text { Initial Heat } \\
\text { Output (kW) }\end{array}$ \\
\hline PWR1 & Average 21-PWR CSNF & 1.5 & 5.17 & 11.53 \\
\hline DHLW & Long DHLW & 2 & 5.22 & 0.282 \\
\hline PWR2 & Design-Basis 21-PWR CSNF & 2 & 5.17 & 11.80 \\
\hline BWR & Average 44-BWR CSNF & 2 & 5.17 & 7.377 \\
\hline
\end{tabular}

Source: Buscheck et al. 2003 [DIRS 164638].

a The number of discrete waste packages in the quarter-symmetry element test case (Figure 7.5-1). 


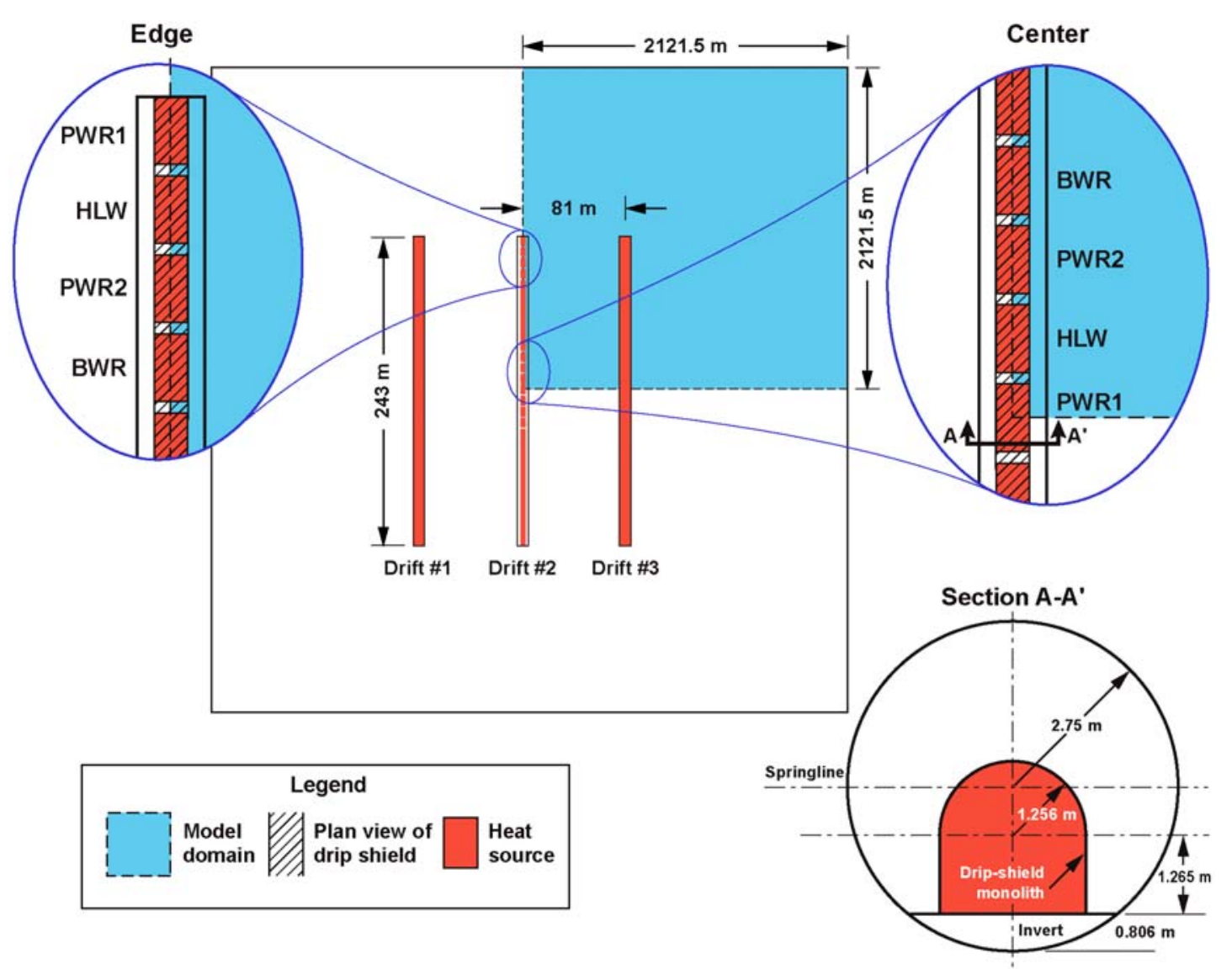

NOTE: To the upper left is the plan view of the three-drift repository test case; highlighted in blue is the zone of symmetry. To the upper right is a close-up of the Drift \#2 waste package sequencing. To the bottom right is the vertical cross-section of the modeled drift with the drip shield and waste package lumped together as a heat source.

Figure 7.5-1. Drift-Scale Conceptual Schematic Shown for the Model Validation Test Case

The validation test case focuses on two locations: at the center and edge of the repository. At the center of the repository, four waste package types are discretely represented (Figure 7.5-1) in Drift \#2, which is the central drift. At the edge of the repository, the same four waste package types are discretely represented; these four waste packages are also in Drift \#2. In this test case, the waste packages are not represented distinctly from the drip shield. Instead, the waste package and drip shield are lumped together and treated as a monolithic heat source. The remainder of Drift \#2, beyond the discretely represented waste package locations, has a line-averaged heat source within the drip-shield/waste package monolith (Figure 7.5-1). For Drifts \#1 and \#3, the heat-source representation is a line-averaged heat source distributed over the entire 5.5-m diameter cross section of the drift. Because heat is delivered directly to the host rock (with a line-averaged heat source) in Drifts \#1 and \#3, the contribution of thermal radiation and convection inside of those drifts is irrelevant. Within Drift \#2, thermal radiation and natural convection are approximated with a time-dependent effective thermal conductivity for the drift cavity between the drip shield and the drift wall (CRWMS M\&O 2001 [DIRS 153410]). Note that this approximation is different from that being used in the MSTHM calculations in support of the TSPA-LA (Section 6.3). However, for the purpose of the MSTHM validation problem it is only necessary that the MSTHM and the corresponding D/LMTH model both use the same approximation for thermal radiation and convection in the drift. Permeability in the drift cavity 
of Drift \#2 (which is the central drift in Figure $7.5-1$ ) is $1.0 \times 10^{-8} \mathrm{~m}^{2}$ in all three principal directions. Because advective and diffusive transport of gas can occur in the longitudinal direction along the drift axis (also called the axial direction), this model allows the cold-trap effect to occur. This D/LMTH model also allows liquid-phase flow in the invert to occur in the longitudinal direction along the drift axis. Note that in the MSTHM calculations in support of the TSPA-LA (Section 6.3) the permeability in the drift is $1.0 \times 10^{-8} \mathrm{~m}^{2}$ in the vertical and lateral directions. However, the MSTHM calculations in support of the TSPA-LA assume that gas- and liquid-phase flow in the axial direction along the drift is insignificant (Section 5.7). This assumption is equivalent to assuming that the cold-trap effect is insignificant. A sealed bulkhead is placed at the very end of the heated portion of Drift \#2 in the D/LMTH model. However, this sealed bulkhead is not impermeable, because it is assigned the same bulk permeability as that of the adjoining host rock (Section 5.3.1.6).

A second set of D/LMTH model calculations was conducted in which the permeability in the drift cavity and in the invert of Drift \#2 is set to zero in the axial direction. Because this D/LMTH model prevents the cold-trap effect from occurring, it corresponds to the assumption in the MSTHM calculations in support of the TSPA-LA. The differences in thermal-hydrologic behavior in the drift between the D/LMTH model, which allows gas-phase and liquid-phase flow in the axial direction along the drift, and the D/LMTH model, which does not allow this axial flow, quantify the relative influence of the cold-trap effect in this three-drift repository test case.

The D/LMTH model assumes the stratigraphy and boundary conditions, including infiltration flux, that pertain to the center of the repository modeled in supplemental analyses (BSC 2001 [DIRS 155950]; BSC 2001 [DIRS 158204]) in the MSTHM. The stratigraphic information and boundary conditions are derived from DTN: LB991201233129.001 [DIRS 146894], while the percolation fluxes for the present-day, monsoonal, and glacial climates are derived from GS000308311221.005 [DIRS 147613], according to Section 4.1.12 of Multiscale Thermohydrologic Model (BSC 2001 [DIRS 158204]). The assumption in this test case is that the conditions at this location apply to the entire model domain, that is, there is no lateral variation of stratigraphy in the test model. At this location, the repository is $372.9 \mathrm{~m}$ below the ground surface and $344.7 \mathrm{~m}$ above the water table. The host-rock unit at this location is the Tptpll (tsw35) unit. The Tptpll unit, which is the host-rock unit for the majority of the repository area, is modeled with a matrix porosity of 0.131 , a matrix permeability of $3.04 \times 10^{-17} \mathrm{~m}^{2}$, a fracture porosity of 0.018 and a fracture permeability of $2.38 \times 10^{-11} \mathrm{~m}^{2}$. Thermal parameters for the Tptpll unit are modeled using $900 \mathrm{~J} / \mathrm{kg}^{\circ} \mathrm{C}$ for specific heat capacity, and 1.84 and 1.25 $\mathrm{W} / \mathrm{m} /{ }^{\circ} \mathrm{C}$ for wet and dry thermal conductivity, respectively. The time-dependent infiltration rates at this location, the " $14 \mathrm{C} 3$ " location, are $5.7 \mathrm{~mm} / \mathrm{yr}$ for the present-day climate (0 to 600 years), $15.1 \mathrm{~mm} / \mathrm{yr}$ for the monsoonal climate (600 to 2,000 years), and $23.2 \mathrm{~mm} / \mathrm{yr}$ for the glacial-transition climate (beyond 2,000 years) (Flint et al. 2001 [DIRS 156351]; BSC 2001 [DIRS 158204]). Parameter values used here are the same as those used for FY 01 Supplemental Science and Performance Analyses, Volume 1: Scientific Bases and Analyses (BSC 2001 [DIRS 155950]).

The numerical mesh in the D/LMTH model includes four nested regions: (1) the very-fine-gridded inner nest surrounding Drift \#2 with grid-block dimensions of approximately $0.2 \mathrm{~m}$ in the horizontal and the vertical directions; (2) the fine-gridded intermediate mesh, surrounding the inner nest, with grid-block dimensions of approximately $1 \mathrm{~m}$ in the horizontal and the vertical directions; (3) the medium-gridded intermediate nest 
surrounding the fine-gridded intermediate nest, as well as Drifts \#1 and \#3, with grid-block dimensions of approximately $5 \mathrm{~m}$ in the horizontal and the vertical directions; and (4) the coarse-gridded mountain-scale mesh, surrounding the medium-gridded intermediate nest with grid-block dimensions of approximately $50 \mathrm{~m}$ in the horizontal direction and approximately $20 \mathrm{~m}$ in the vertical direction, and which extends $2 \mathrm{~km}$ laterally to the model boundaries. Because of symmetry, it is only necessary to explicitly model one-quarter of the model domain (Figure 7.5-1).

All of the MSTHM submodels used in the model validation test case used the same stratigraphy and boundary conditions as in the D/LMTH model. The SMT submodel has a heated repository footprint of $59,049 \mathrm{~m}^{2}$ and the same total initial heat output (986.6 kW or $829 \mathrm{MTU}$ ) as in the D/LMTH model (Buscheck et al. 2003 [DIRS 164638], p. 434, Table 4). MSTHM calculations for TSPA-LA involved running the LDTH and SDT submodels at four different AMLs. Because of the smaller heated footprint in this example, the influence of the edge-cooling effect occurs faster and with greater magnitude so that the LDTH-SDT submodel pairs are run at six different AMLs, rather than four. The DDT submodels are also run for the same six AMLs.

An important distinction between the MSTHM and the D/LMTH model concerns the treatment of air and vapor flow along the emplacement drift. The MSTHM effectively sets the axial permeability along the emplacement drift to zero, preventing axial air and vapor flow along the drift. For the D/LMTH model, the axial permeability is the same as that in the lateral and vertical directions $\left(1 \times 10^{-8} \mathrm{~m}^{2}\right.$, which is about three orders of magnitude greater than the bulk permeability of the host rock). Consequently, axial vapor flow (and the resulting moisture redistribution or cold-trap effect) occurs in the D/LMTH model, but does not occur in the MSTHM. The comparison of the MSTHM-simulated thermal-hydrologic behavior with that of the D/LMTH model is useful in determining the relative importance of axial vapor flow on thermal-hydrologic behavior in the emplacement drifts.

\subsubsection{Results of the MSTHM Validation Test Case}

The results of the nested-mesh D/LMTH model and the MSTHM are compared at the four waste package locations at the center and at the edge of the three-drift repository test case. For the center of the repository (Sections 7.5.2.1, 7.5.2.2, and 7.5.2.3), the results from the D/LMTH model are shown for two cases: (1) the case with axial gas- and liquid-phase flow along the drift, a sealed bulkhead at the edge of the drift, and small gas-phase dispersivity in the drift and (2) the case without that axial flow. Note that the small gas-phase dispersion coefficient accounts for binary diffusion of water vapor, but does not account for the influence of natural-convective mixing. For the repository edge (Sections 7.5.2.4, 7.5.2.5, 7.5.2.6, and 7.5.2.7), D/LMTH-model results are given for three cases, including one case without axial gas- and liquid-phase flow along the drift and two with axial flow along the drift. The two cases with axial flow include one with a sealed bulkhead at the end of the drift and small gas-phase dispersivity in the drift and a case with no bulkhead and large gas-phase dispersivity in the drift. The large gas-phase dispersion coefficient in the second case is used to account for the influence of turbulent naturalconvection mixing. The second case also accounts for the open unheated section of drift (called the turnout area) beyond the last outermost waste package, and it includes the effects of rock dryout during the ventilation period. Of the D/LMTH-model cases, the case with no bulkhead and a large gas-phase dispersion coefficient in the drift is most realistic. Differences between 
that case and the D/LMTH case with no axial gas- and liquid-phase flow quantify the influence of the cold-trap effect.

\subsubsection{Temperature at the Center of the Three-Drift Repository Test Case}

Drift-wall and drip-shield temperatures that are predicted by the D/LMTH model and the MSTHM are in good agreement at all four waste package locations at the center of Drift \#2 (Figure 7.5-2). Axial gas- and liquid-phase flows along the drift are seen to have an insignificant influence on temperatures at the center of the three-drift repository test case. Table-7.5-3 summarizes the peak drift-wall and drip-shield temperatures predicted by the MSTHM and the $\mathrm{D} / \mathrm{LMTH}$ model at the center of the three-drift repository test case. Differences in peak drift-wall temperature between the MSTHM and the D/LMTH model with axial gas- and liquid-phase flow along the drift axis range from $0.5^{\circ} \mathrm{C}$ to $2.3^{\circ} \mathrm{C}$; differences in peak drip-shield temperature range from $-1.7^{\circ} \mathrm{C}$ to $2.7^{\circ} \mathrm{C}$. Table $7.5-4$ summarizes the time when boiling at the drift wall ceases; differences between the two models are insignificant (generally 3 percent or less).

There is similar good agreement in temperature at other reference locations, such as in the invert. The D/LMTH-predicted temperatures tend to be slightly lower than the MSTHM-predicted temperatures. This is most likely because the MSTHM does not consider mountain-scale buoyant gas-phase convection, nor does it consider vapor (and latent heat) flow along the axis of the drift from the center to the edge of the repository and beyond. The D/LMTH model considers both of these cooling mechanisms and therefore predicts slightly cooler temperature histories than the MSTHM.

Table 7.5-3. Summary of Peak Temperatures for the Four Waste Package Locations at the Center of the Three-Drift Repository Test Case

\begin{tabular}{|l|c|c|c|c|c|c|}
\hline \multirow{2}{*}{$\begin{array}{c}\text { Waste } \\
\text { package }\end{array}$} & \multicolumn{3}{|c|}{ Peak Drift-Wall Temperature $\left({ }^{\circ} \mathbf{C}\right)$} & \multicolumn{3}{c|}{ Peak Drip Shield Temperature $\left({ }^{\circ} \mathbf{C}\right)$} \\
\cline { 2 - 7 } & MSTHM & D/LMTH model & Difference & MSTHM & D/LMTH model & Difference \\
\hline PWR1 & 140.4 & $138.8(139.3)$ & $1.6(1.1)$ & 160.0 & $160.5(160.9)$ & $-0.5(-0.9)$ \\
\hline DHLW & 135.5 & $133.2(133.8)$ & $2.3(1.7)$ & 145.1 & $142.4(142.9)$ & $2.7(2.2)$ \\
\hline PWR2 & 146.4 & $145.9(146.3)$ & $0.5(0.1)$ & 168.0 & $169.7(170.1)$ & $-1.7(-2.1)$ \\
\hline BWR & 145.5 & $144.9(145.3)$ & $0.6(0.2)$ & 163.1 & $163.1(164.4)$ & $0.0(-1.3)$ \\
\hline NOTE:
\end{tabular}
The D/LMTH-model results are for the cases with and without axial gas- and liquid-phase
flow along the drift; the latter case is given in the parentheses. These values are based

\subsubsection{Relative Humidity at the Center of the Three-Drift Repository Test Case}

Drift-wall relative humidity predicted by the D/LMTH model and the MSTHM are in good agreement at all four center waste package locations. Figure 7.5-3 shows drift-wall relative humidity for the four waste packages. The agreement is closest up until the very end of the rock dryout period when the MSTHM predicts slightly lower relative humidity at the drift wall. The agreement in the predicted drip-shield relative humidity between the two models is best for the PWR2 and BWR waste package (Figure 7.5-3f and h). The MSTHM predicts slightly lower relative humidity than the D/LMTH model for the relatively cool DHLW waste package (Figure 7.5-3d). It is noted that the DHLW waste package location has temperature and relative humidity gradients within the drip shield in the axial direction (not shown). The DHLW waste 
package is warmer (and drier) at its end than at its center because it is being heated by its neighboring waste packages that generate more heat (Table 7.5-2). Axial gas- and liquid-phase flow along the drift are seen to have an insignificant influence on relative humidity at the center of the three-drift repository test case.

Table 7.5-4. Summary of Time When Boiling Ceases at the Drift Wall for the Four Waste Package Locations at the Center of the Three-Drift Repository Test Case

\begin{tabular}{|l|c|c|c|c|}
\hline \multirow{2}{*}{ Waste package } & \multicolumn{4}{|c|}{ Time When Boiling at Drift Wall Ceases (years) } \\
\cline { 2 - 5 } & MSTHM & D/LMTH model & Difference & Difference $^{\mathbf{a}}$ \\
\hline PWR1 & 291.2 & 283.1 & 8.1 & $2.82 \%$ \\
\hline DHLW & 269.7 & 259.6 & 10.1 & $3.82 \%$ \\
\hline PWR2 & 312.0 & 303.3 & 8.7 & $2.83 \%$ \\
\hline BWR & 304.0 & 294.4 & 9.6 & $3.21 \%$ \\
\hline
\end{tabular}

${ }^{a}$ The difference (\%) is the difference (years) divided by the average time when drift-wall boiling ceases [(shortest + longest)/2]. The D/LMTH-model results are for the case with axial gas- and liquid-phase flow along the drift. These values are based on data plotted in Figure 7.5-2.

\subsubsection{Liquid-Phase Saturation at the Center of the Three-Drift Repository Test Case}

Drift-wall liquid-phase saturation $S_{\mathrm{dw}, \mathrm{j}, \mathrm{DMTH}}$ predicted by the D/LMTH model and MSTHM are in good agreement at all four center waste package locations (Figure 7.5-4a, c, e, and g). This good agreement is obtained regardless of whether axial gas- and liquid-phase flow is allowed to occur along the drift in the D/LMTH model. The minimum $S_{\mathrm{dw}, \mathrm{j}, \mathrm{DMTH}}$, which occurs during the boiling period, is virtually identical for the two models. The MSTHM predicts a slightly longer duration of dryout for the PWR1, PWR2, and BWR waste packages; for the DHLW waste package, the two models predict virtually the same dryout duration (Figure 7.5-4c). Axial gasand liquid-phase flow along the drift are seen to have an insignificant influence on drift-wall liquid-phase saturation. The agreement between the MSTHM and the D/LMTH model for the invert liquid-phase saturation, $S_{\text {inv,j,DMTH}}$, is good for the CSNF waste packages (Figure 7.5-4b, f, and $\mathrm{h}$ ) and it is adequate for the relatively cool DHLW waste package (Figure 7.5-4d). The influence of the cold-trap effect is exhibited by the slightly higher values of $S_{\text {inv,j,DMTH }}$ for the DHLW waste package in the D/LMTH model with axial gas- and liquid-phase flow along the drift, compared to the D/LMTH model that does not allow that axial flow. The cold-trap effect causes the advection of water vapor from the relatively hot CNSF waste package locations to the relatively cool DHLW waste package location, where it condenses, causing an increase in $S_{\mathrm{in}, \mathrm{j}, \mathrm{DMTH}}$. The two hot CSNF waste packages next to the DHLW waste package have slightly reduced $S_{\mathrm{in,j,DMTH}}$ for the D/LMTH model with axial gas- and liquid-phase flow along the drift compared to the D/LMTH model that does not allow that axial flow. 

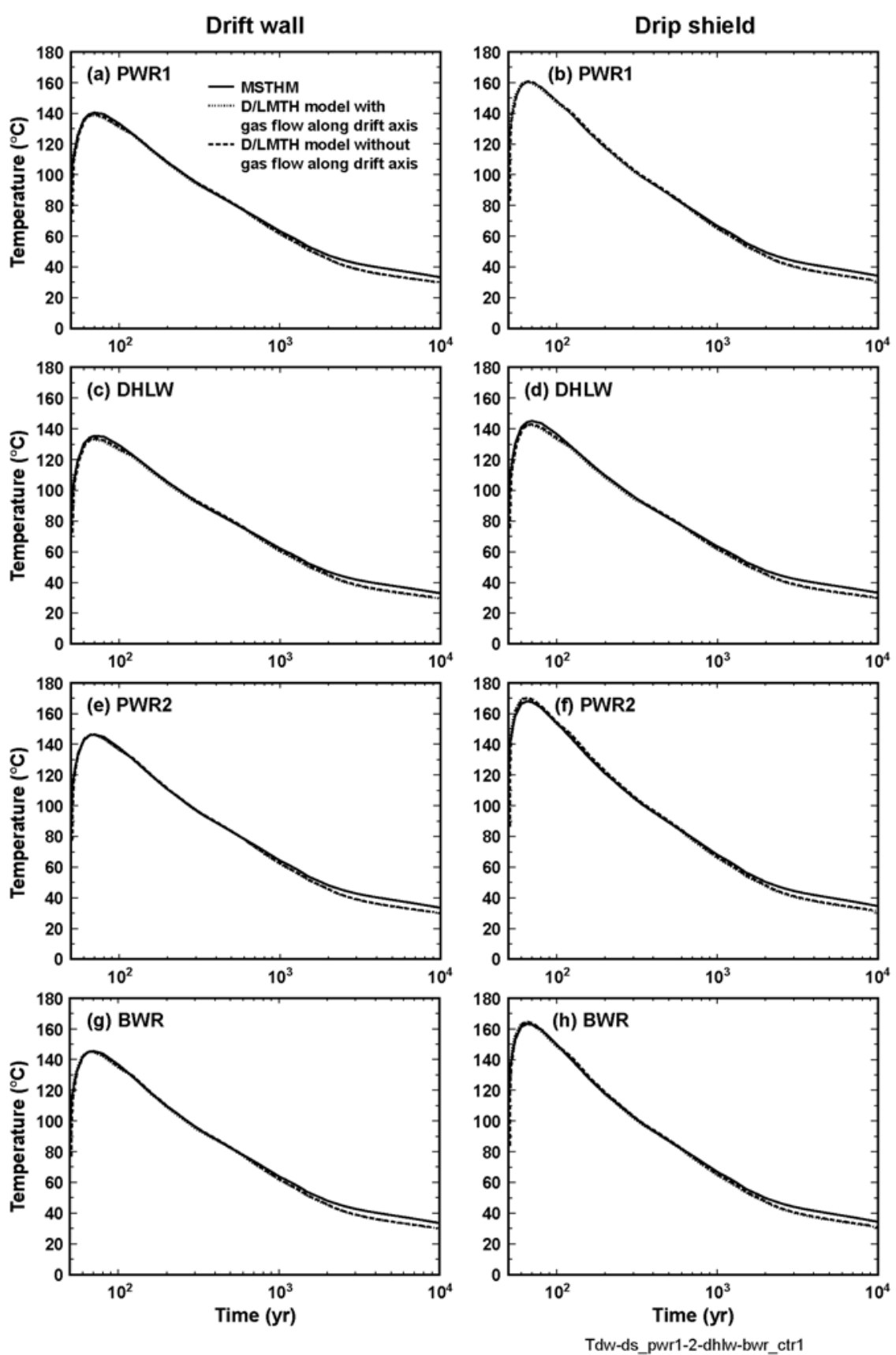

Source: See Table XIII-1.

NOTE: Drift-wall temperature ( $\left.T_{\mathrm{dw}, \mathrm{j}, \mathrm{DMTH}}\right)$ vs. time $(\mathrm{a}, \mathrm{c}, \mathrm{e}, \mathrm{g})$ and drip-shield temperature $\left(T_{\mathrm{ds}, \mathrm{D}, \mathrm{DMTH}}\right)$ vs. time $(\mathrm{b}, \mathrm{d}$, $\mathrm{f}, \mathrm{h}$ ) are determined by the MSTHM and the D/LMTH model. The D/LMTH-model results are given for the cases with and without axial gas- and liquid-phase flow along the drift.

Figure 7.5-2. Drift-Wall and Drip-Shield Temperature vs. Time for the (a,b) PWR1, (c,d) DHLW, (e, f) PWR2, and $(\mathrm{g}, \mathrm{h})$ BWR Waste Packages at the Center of the Three-Drift Repository Test Case 
Drift wall
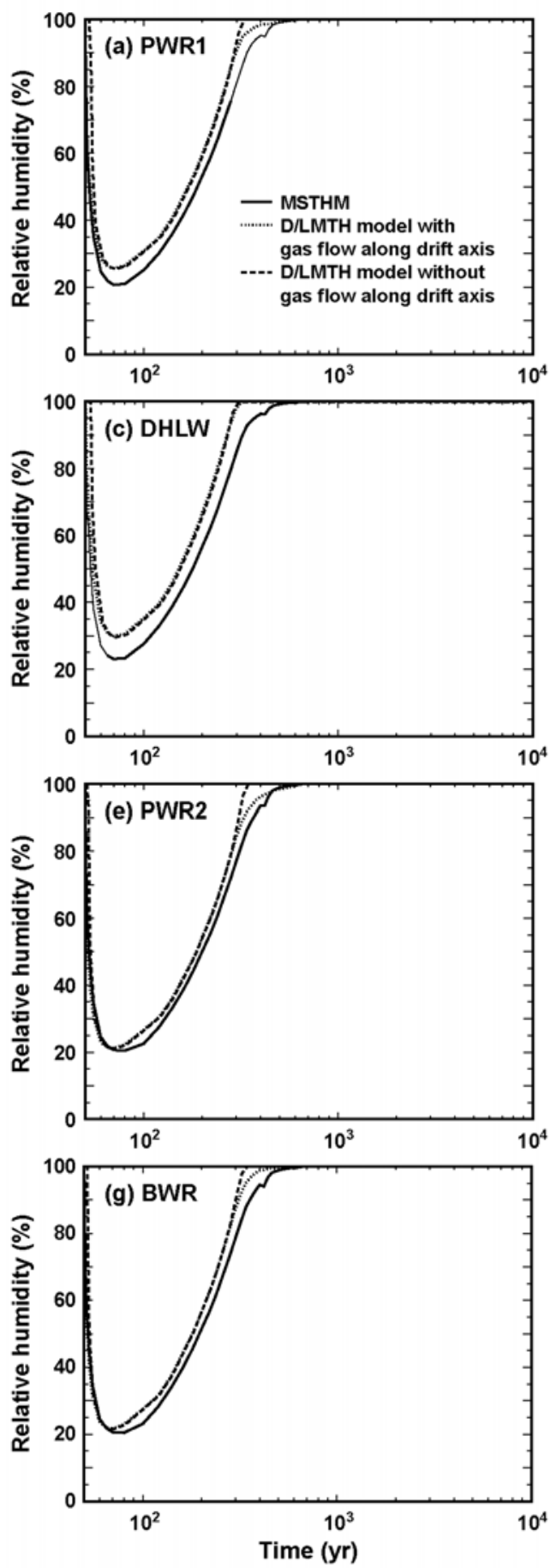

Drip shield
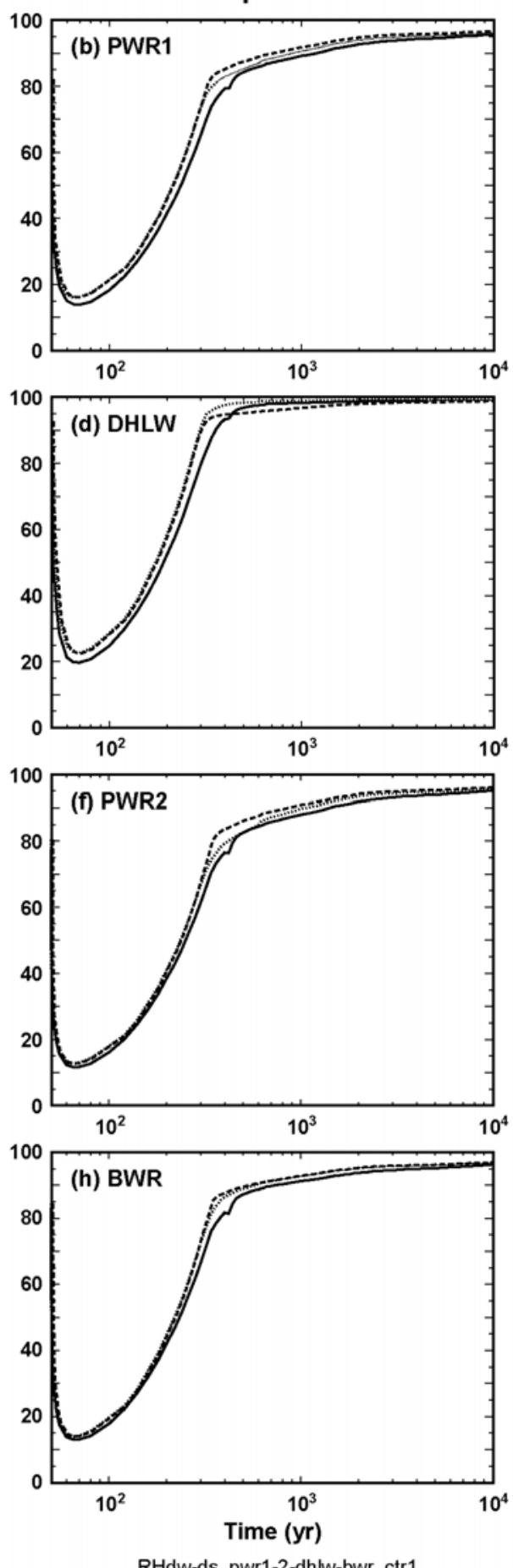

Source: See Table XIII-1.

NOTE: Drift-wall relative humidity $\left(R H_{\mathrm{dw}, \mathrm{j}, \mathrm{DMTH}}\right)$ vs. time $(\mathrm{a}, \mathrm{c}, \mathrm{e}, \mathrm{g})$ and drip-shield relative humidity $\left(R H_{\mathrm{ds}, \mathrm{j}, \mathrm{DMTH}}\right)$ vs. time $(b, d, f, h)$ are determined by the MSTHM and the D/LMTH model. The D/LMTH-model results are given for the cases with and without axial gas- and liquid-phase flow along the drift.

Figure 7.5-3. Drift-Wall and Drip-Shield Relative Humidity vs. Time for the (a,b) PWR1, (c,d) DHLW, (e, f) PWR2, and $(\mathrm{g}, \mathrm{h})$ BWR Waste Packages at the Center of the Three-Drift Repository Test Case 

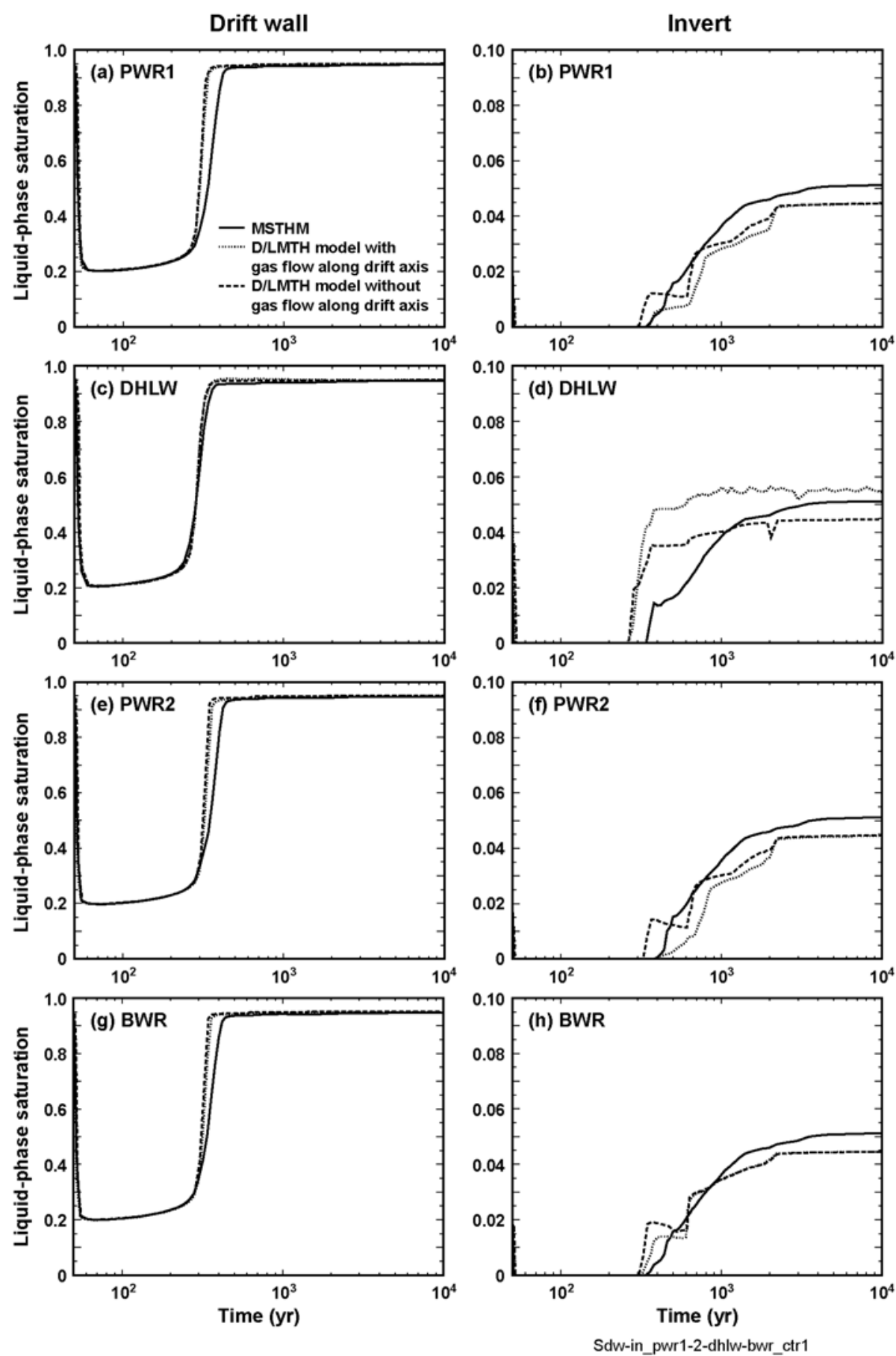

Source: See Table XIII-1.

NOTE: Drift-wall liquid-phase saturation $\left(S_{\mathrm{dw}, \mathrm{j}, \mathrm{DMTH}}\right)$ vs. time $(\mathrm{a}, \mathrm{c}, \mathrm{e}, \mathrm{g})$ and invert liquid-phase saturation $\left(S_{\text {in, ,DMTH }}\right)$ vs. time $(b, d, f, h)$ are determined by the MSTHM and the D/LMTH model. The D/LMTH-model results are given for the cases with and without axial gas- and liquid-phase flow along the drift.

Figure 7.5-4. Drift-Wall Liquid-Phase and Invert Liquid-Phase Saturation vs. Time for the (a, b) PWR1, (c, d) DHLW, (e, f) PWR2, and (g, h) BWR Waste Packages at the Center of the Three-Drift Repository Test Case 


\subsubsection{Temperature at the Edge of the Three-Drift Repository}

At the edge of the three-drift repository test case, the longitudinal waste package order from the end of the drift is the following: PWR1, DHLW, PWR2, BWR. The drift-wall temperatures predicted by the D/LMTH model and the MSTHM are in reasonably good agreement at the four waste package locations at the edge of Drift \#2 (Figure 7.5-5). This agreement is achieved regardless of whether axial gas- and liquid-phase flow along the drift is allowed to occur in the D/LMTH model. Tables 7.5-5 and 7.5-6 summarize the peak drift-wall and drip-shield temperatures predicted by the MSTHM and the D/LMTH model at the edge of the three-drift repository test case. A comparison of the D/LMTH-model temperatures (Figure 7.5-5 and Tables 7.5-5 and 7.5-6) clearly shows that the effect of axial transport of vapor and condensation on temperatures is small. When the MSTHM is compared with the D/LMTH model that allows axial gas- and liquid-phase flow along the drift (with no bulkhead and large gas-phase dispersivity in the drift), differences in peak drip-shield temperature range from $6.5^{\circ} \mathrm{C}$ for BWR package to $17.1^{\circ} \mathrm{C}$ for the PWR1 package (Table 7.5-6). The outermost two waste package locations, which have a temperature bias of about $17^{\circ} \mathrm{C}$, are representative of waste package locations that occupy only 1.6 percent of the repository area. The third and fourth waste package locations in from the repository edge, which have a temperature bias of about $7^{\circ} \mathrm{C}$ (Table $7.5-6$ ), are representative of waste packages that occupy only 1.6 percent of the repository area. These results indicate that for waste packages located more than $20 \mathrm{~m}$ from the repository edge, which encompasses about 97 percent of the repository area, the temperature overprediction by the MSTHM is less than about $7^{\circ} \mathrm{C}$. 

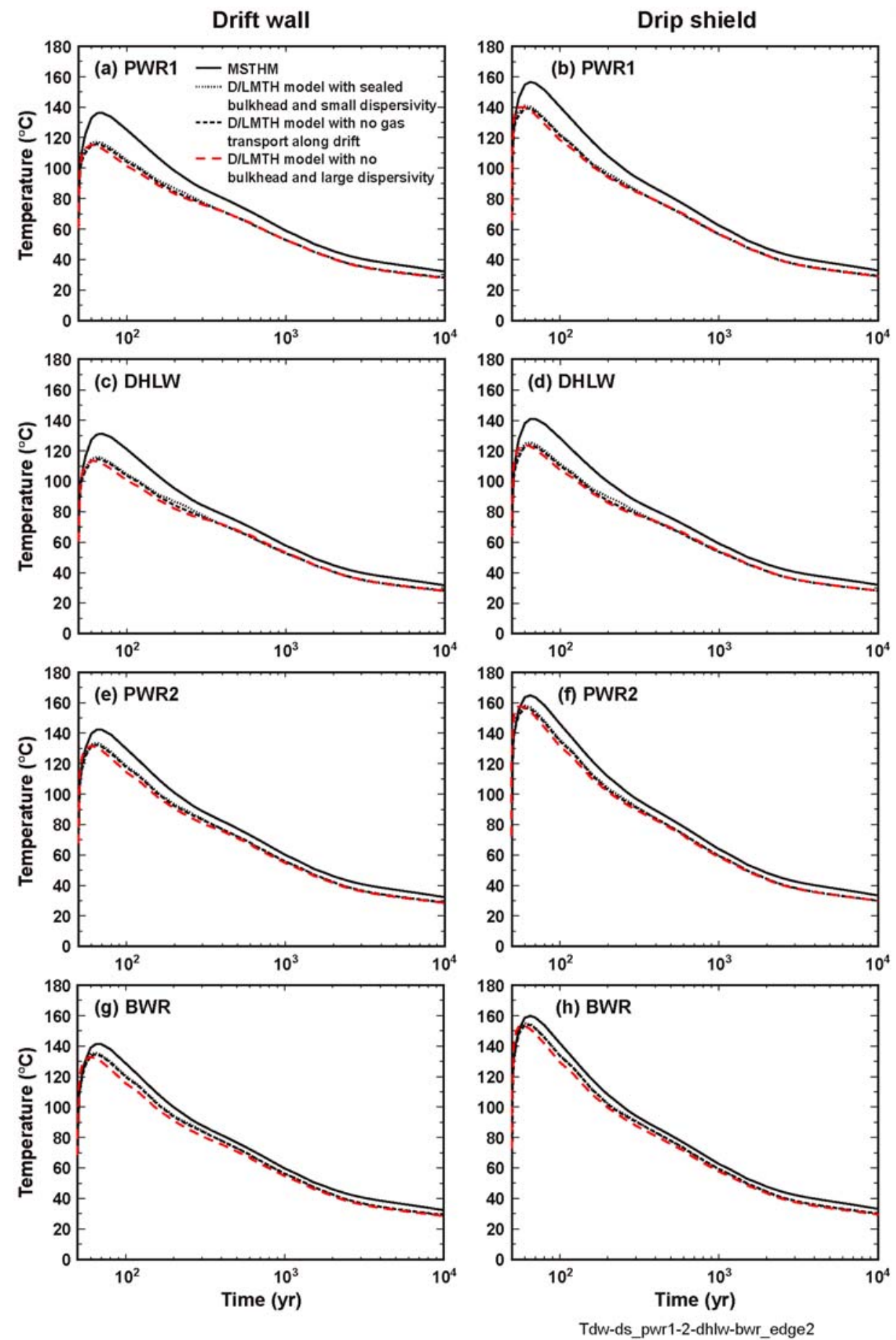

Source: See Table XIII-1.

NOTE: Drift-wall temperature ( $\left.T_{\mathrm{dw}, \mathrm{j}, \mathrm{DMTH}}\right)$ vs. time $(\mathrm{a}, \mathrm{c}, \mathrm{e}, \mathrm{g})$ and drip-shield temperature $\left(T_{\mathrm{ds}, \mathrm{j}, \mathrm{DMTH}}\right)$ vs. time $(\mathrm{b}, \mathrm{d}$, $\mathrm{f}, \mathrm{h}$ ) are determined by the MSTHM and the D/LMTH model. The D/LMTH-model results are given for a case without axial gas- and liquid-phase flow along the drift and for two cases with flow along the drift, including one with a sealed bulkhead and small gas-phase dispersivity in the drift and one with no bulkhead and large gas-phase dispersivity.

Figure 7.5-5. Drift-Wall and Drip-Shield Temperature vs. Time for the (a, b) PWR1, (c, d) DHLW, (e, f) PWR2, and $(\mathrm{g}, \mathrm{h})$ BWR Waste Packages at the Edge of the Three-Drift Repository Test Case 
Table 7.5-5. Peak Drift-Wall Temperatures Summarized for the Four Waste Package Locations at the Edge of the Three-Drift Repository Test Case

\begin{tabular}{|c|c|c|c|c|c|c|c|}
\hline \multirow{4}{*}{$\begin{array}{c}\text { Waste } \\
\text { Package }\end{array}$} & \multicolumn{7}{|c|}{ Peak Drift-Wall Temperature $\left({ }^{\circ} \mathrm{C}\right)$} \\
\hline & \multirow[t]{3}{*}{ MSTHM } & \multicolumn{3}{|c|}{ D/LMTH Model } & \multicolumn{3}{|c|}{ Difference (MSTHM - D/LMTH Model) } \\
\hline & & \multicolumn{2}{|c|}{$\begin{array}{l}\text { Axial gas- and liquid-phase } \\
\text { flow in drift }\end{array}$} & \multirow{2}{*}{$\begin{array}{l}\text { No axial gas- } \\
\text { \& liquid- } \\
\text { phase flow in } \\
\text { drift }\end{array}$} & \multicolumn{2}{|c|}{$\begin{array}{c}\text { Axial gas- and liquid-phase } \\
\text { flow in drift }\end{array}$} & \multirow{2}{*}{$\begin{array}{l}\text { No axial gas- } \\
\text { \& liquid- } \\
\text { phase flow in } \\
\text { drift }\end{array}$} \\
\hline & & $\begin{array}{l}\text { No bulkhead } \\
\& \text { large } \\
\text { dispersivity }\end{array}$ & $\begin{array}{c}\text { With } \\
\text { bulkhead \& } \\
\text { small } \\
\text { dispersivity } \\
\end{array}$ & & $\begin{array}{l}\text { No bulkhead } \\
\text { \& large } \\
\text { dispersivity }\end{array}$ & $\begin{array}{c}\text { With } \\
\text { bulkhead \& } \\
\text { small } \\
\text { dispersivity } \\
\end{array}$ & \\
\hline PWR1 & 136.3 & 115.4 & 117.5 & 115.8 & 20.9 & 18.8 & 20.5 \\
\hline DHLW & 131.3 & 113.5 & 115.8 & 114.3 & 17.8 & 15.5 & 17.0 \\
\hline PWR2 & 142.3 & 131.6 & 133.5 & 132.2 & 10.7 & 8.8 & 10.1 \\
\hline BWR & 141.4 & 133.0 & 135.5 & 134.5 & 8.4 & 5.9 & 6.9 \\
\hline
\end{tabular}

NOTE: $\quad$ These values are based on data plotted in Figure 7.5-5.

Table 7.5-6. Peak Drip-Shield Temperatures Summarized for the Four Waste Package Locations at the Edge of the Three-Drift Repository Test Case

\begin{tabular}{|c|c|c|c|c|c|c|c|}
\hline \multirow{4}{*}{$\begin{array}{c}\text { Waste } \\
\text { Package }\end{array}$} & \multicolumn{7}{|c|}{ Peak Drip-Shield Temperature $\left({ }^{\circ} \mathrm{C}\right)$} \\
\hline & \multirow[t]{3}{*}{ MSTHM } & \multicolumn{3}{|c|}{ D/LMTH Model } & \multicolumn{3}{|c|}{ Difference (MSTHM - D/LMTH Model) } \\
\hline & & \multicolumn{2}{|c|}{$\begin{array}{c}\text { Axial gas- and liquid-phase } \\
\text { flow in drift }\end{array}$} & \multirow{2}{*}{$\begin{array}{l}\text { No axial gas- } \\
\text { \& liquid- } \\
\text { phase flow in } \\
\text { drift }\end{array}$} & \multicolumn{2}{|c|}{$\begin{array}{c}\text { Axial gas- and liquid-phase } \\
\text { flow in drift }\end{array}$} & \multirow{2}{*}{$\begin{array}{l}\text { No axial gas- } \\
\& \text { liquid- } \\
\text { phase flow in } \\
\text { drift }\end{array}$} \\
\hline & & $\begin{array}{l}\text { No bulkhead } \\
\text { \& large } \\
\text { dispersivity }\end{array}$ & $\begin{array}{c}\text { With } \\
\text { bulkhead \& } \\
\text { small } \\
\text { dispersivity } \\
\end{array}$ & & $\begin{array}{c}\text { No bulkhead } \\
\& \text { large } \\
\text { dispersivity }\end{array}$ & $\begin{array}{c}\text { With } \\
\text { bulkhead \& } \\
\text { small } \\
\text { dispersivity } \\
\end{array}$ & \\
\hline PWR1 & 156.7 & 140.2 & 141.0 & 139.2 & 16.5 & 15.7 & 17.5 \\
\hline DHLW & 141.0 & 123.9 & 125.5 & 124.0 & 17.1 & 15.5 & 17.0 \\
\hline PWR2 & 164.7 & 156.9 & 158.0 & 156.6 & 7.8 & 6.7 & 8.1 \\
\hline BWR & 159.9 & 153.4 & 154.9 & 153.9 & 6.5 & 5.0 & 6.0 \\
\hline
\end{tabular}

NOTE: These values are based on data plotted in Figure 7.5-5.

As discussed above, the agreement between the two models improves with distance from the edge of the repository. There are two reasons for the increasing disagreement in temperature with proximity to the edge. The first is related to the gridblock discretization in the SMT submodel and the second is related to the dimensionality of the DDT submodel.

The current implementation of the MSTHM has an SMT submodel that discretizes the emplacement drifts into 20-m intervals (Section 6.2.5.1). Thus, the edge of the repository is represented by an SMT submodel temperature history that is $10 \mathrm{~m}$ from the repository edge. Finer gridding in the axial direction would result in finer representation of the rate of cooling for the outermost waste packages in the drift.

As discussed in Section 6.2.1, an underlying principle in the MSTHM concept is that the influence of three-dimensional mountain-scale heat flow on drift-scale thermal-hydrologic behavior can be approximated with the use of an effective drift spacing that is implemented in the LDTH submodels. This effective drift spacing gradually increases with time to approximate the increasing influence of the edge-cooling effect, which allows heat to migrate away from the heated footprint of the repository area. The principle of the effective drift spacing relies on heat flow immediately away from the emplacement drift (and into the adjoining host rock) occurring 
in a predominantly radial fashion. However, for the outermost two to three waste packages at the repository edge, heat flow can also have a substantial axial component. The use of a DDT submodel (Section 6.2.8) with an unheated portion in the axial direction (i.e., beyond the outermost waste package) would capture the influence of axial heat flow for the outermost two to three waste packages. The implementation of such a DDT submodel in the MSTHM methodology would likely result in closer agreement in temperatures predicted by the MSTHM and the D/LMTH model, and thereby reduce the small disagreement in temperatures for the outermost waste packages.

It is important to point out that even while the MSTHM overpredicts temperatures for packages near the end of the drift, these temperature differences between the MSTHM and D/LMTH model are well within the range of temperature differences resulting from parametric uncertainty (Tables 6.3-30 and 6.3-31). When the D/LMTH model that allows axial flow along the drift is compared with the D/LMTH model that does not, the small (insignificant) influence of the cold-trap effect on temperatures is evident (Tables 7.5-5 and 7.5-6).

A useful way of examining the differences between the MSTHM and D/LMTH models is to consider the center-to-edge temperature differences predicted by the two models (Table 7.5-7). Note that the MSTHM represents all four waste packages as having the same center-to-edge distance, whereas the D/LMTH-model representation has a progressively smaller center-to-edge distance with increasing distance from the repository edge. The MSTHM utilizes an SMT submodel that discretizes the emplacement drifts into 20-m intervals; thus, the outer $20 \mathrm{~m}$ of the MSTHM is treated in the same fashion insofar as the influence of the edge-cooling effect is concerned. Similarly, the four waste packages at the center of the three-drift repository are treated in the same fashion insofar as their proximity to the repository edge is concerned. In a sense, the MSTHM does not distinguish which of the four waste packages is actually the outermost waste package over the outermost $20 \mathrm{~m}$ of the emplacement drift. All four waste packages are treated as though their respective centers are located $10 \mathrm{~m}$ from the edge of the heated footprint of the repository. Similarly, all four waste packages at the center of the three-drift repository are treated as though their centers are located $111.5 \mathrm{~m}$ from the edge of the heated repository footprint. Consequently, all four waste packages have virtually the same center-to-edge temperature difference. Conversely, the D/LMTH model does distinguish the respective distances from the repository edge for each of the four waste packages. 
Table 7.5-7. Drip-Shield Temperature Difference Between the Center and Edge of the Three-Drift Repository Test Case, Compared for the D/LMTH Model and MSTHM

\begin{tabular}{|c|c|c|c|c|}
\hline \multirow{2}{*}{$\begin{array}{l}\text { Waste } \\
\text { Package }\end{array}$} & \multicolumn{2}{|c|}{$\begin{array}{l}\text { Center-to-Edge Distance } \\
(\mathrm{m})\end{array}$} & \multicolumn{2}{|c|}{$\begin{array}{c}\text { Center-to-Edge Drip } \\
\text { Shield Temperature } \\
\text { Difference }\left({ }^{\circ} \mathrm{C}\right)\end{array}$} \\
\hline & MSTHM & D/LMTH model & MSTHM & $\begin{array}{c}\text { D/LMTH } \\
\text { model }\end{array}$ \\
\hline PWR1 & 101.5 & 118.862 & 3.3 & 19.5 \\
\hline DHLW & 101.5 & 108.260 & 4.1 & 16.9 \\
\hline PWR2 & 101.5 & 97.658 & 3.3 & 11.7 \\
\hline BWR & 101.5 & 87.106 & 3.2 & 8.2 \\
\hline NOTE: & \multicolumn{4}{|c|}{$\begin{array}{l}\text { Temperature differences are based upon Tables } 7.5-6 \text { and } \\
7.5-5 \text {. The center-to-edge distances are based upon Figure } \\
\text { 7.5-1. The D/LMTH-model results are for the case with } \\
\text { longitudinal gas- and liquid-phase flow along the drift axis. } \\
\text { These values are based on data plotted in Figure } 7.5-5 \text {. }\end{array}$} \\
\hline
\end{tabular}

Table 7.5-7 indicates that the center-to-edge temperature difference in the D/LMTH model approaches that of the MSTHM for increasing distance from the repository edge. The reasons for the increasing agreement with increasing distance from the edge are discussed above. Tables 7.5-5 and 7.5-6 indicate that for waste packages located $20 \mathrm{~m}$ or more from the repository edge, the differences in temperature predicted by the MSTHM and D/LMTH model are small (less than $5^{\circ} \mathrm{C}$ for peak drip-shield temperatures). The MSTHM discretizes thermal-hydrologic behavior for 2,874 20-m intervals (Figure 6.2-3); of these intervals, only 92 are potentially affected by the axial vapor (and latent heat) loss at the edge of the repository, constituting only 3.2 percent of the repository area. Consequently, 96.8 percent of the repository should not be influenced by this effect at the outermost edge of the repository. For the outermost 3.2 percent of the repository, the small overprediction of MSTHM temperatures is well within the range of temperature differences resulting from parametric uncertainty (Tables 6.3-30 and 6.3-31).

Table 7.5-8 summarizes the time when boiling at the drift wall ceases; differences between the two models range from 17.3 to 44.9 percent. Again, the agreement between the two models improves with distance from the edge of the repository. Because the differences between the two models are within the range of differences arising from parametric uncertainty (Table 6.3-32), the impact of conceptual-model uncertainty is less than that of parametric uncertainty.

Table 7.5-8. Summary of Time When Boiling Ceases at the Drift Wall for the Four Waste Package Locations at the Edge of the Three-Drift Repository Test Case

\begin{tabular}{|l|c|c|c|c|}
\hline \multirow{2}{*}{ Waste Package } & \multicolumn{4}{|c|}{ Time When Boiling at Drift Wall Ceases (years) } \\
\cline { 2 - 5 } & MSTHM & D/LMTH Model & Difference & Difference $^{\mathbf{a}}$ \\
\hline PWR1 & 215.0 & 136.1 & 78.9 & $44.9 \%$ \\
\hline DHLW & 195.9 & 136.0 & 59.9 & $36.1 \%$ \\
\hline PWR2 & 233.2 & 184.2 & 49.0 & $23.5 \%$ \\
\hline BWR & 226.6 & 190.6 & 36.0 & $17.3 \%$ \\
\hline
\end{tabular}

a The difference (\%) is the difference (years) divided by the average time when drift-wall boiling ceases [(shortest + longest)/2]. The D/LMTH model results are for the case with longitudinal gas- and liquid-phase flow along the drift axis.

NOTE: $\quad$ These values are based on data plotted in Figure 7.5-5. 


\subsubsection{Relative Humidity at the Edge of the Three-Drift Repository Test Case}

Figure 7.5-6 gives the drift-wall relative humidity for the four waste packages at the edge of the repository. Drift-wall relative humidity predicted by the D/LMTH model and the MSTHM are in reasonable agreement at the four "edge” waste package locations. This agreement is achieved regardless of whether axial gas- and liquid-phase flow along the drift is allowed to occur in the D/LMTH model. However, the inclusion of axial vapor transport and the unheated part of the drift in the D/LMTH model (with no bulkhead and large gas-phase dispersivity) improves the agreement of predicted relative humidity (Figure 7.5-6) between the MSTHM and the D/LMTH model. Note also that the agreement between the two models improves with distance from the repository edge. The agreement in the predicted drift-wall relative humidity between the two models is best for the PWR2 and BWR waste package (Figure 7.5-6e and g). The agreement between the two models is better for drip-shield relative humidity (Figure 7.5-6b, d, f, and h) than it is for drift-wall relative humidity (Figure 7.5-6a, c, e, and g). The agreement is best during the postboiling period when relative humidity reduction resulting from rock dryout no longer plays a significant role in relative humidity reduction on the drip shield. During the boiling period, the agreement in drip-shield relative humidity improves with distance from the edge of the repository. The differences between the two models in drip-shield relative humidity are within the range of differences arising from parametric uncertainty (Section 6.3.2).

The influence of the cold-trap effect can be observed in Figure 7.5-6 by comparing the results from the D/LMTH model that allows axial gas- and liquid-phase flow along the drift with those from the D/LMTH model that does not allow that axial flow. The influence of the cold-trap effect is to reduce the drift-wall relative humidity, with the reduction being stronger for the three CSNF waste packages than it is for the DHLW waste package. This reduction results because some of the water vapor generated in the host rock flows radially inward into the drift and then axially along the drift beyond the outermost waste package, where it condenses and is imbibed into the host rock. This process results in a net reduction in moisture in the host rock, particularly adjacent to the CSNF waste packages. The drift-wall temperature adjacent to the DHLW waste package drops below the boiling point earlier than at the (relatively hotter) CSNF waste package locations. The earlier return to sub-boiling temperatures causes preferential condensation and imbibition into the host rock adjoining the DHLW waste package. The preferential condensation in the host rock adjacent to the DHLW waste package offsets some of the ongoing moisture loss from the host rock, decreasing the net reduction in liquid-phase saturation in the host rock. This smaller net reduction in liquid-phase saturation at the (relatively cooler) DHLW waste package location results in a smaller reduction in relative humidity than occurs for the (relatively hotter) CSNF waste packages. 
Drift wall
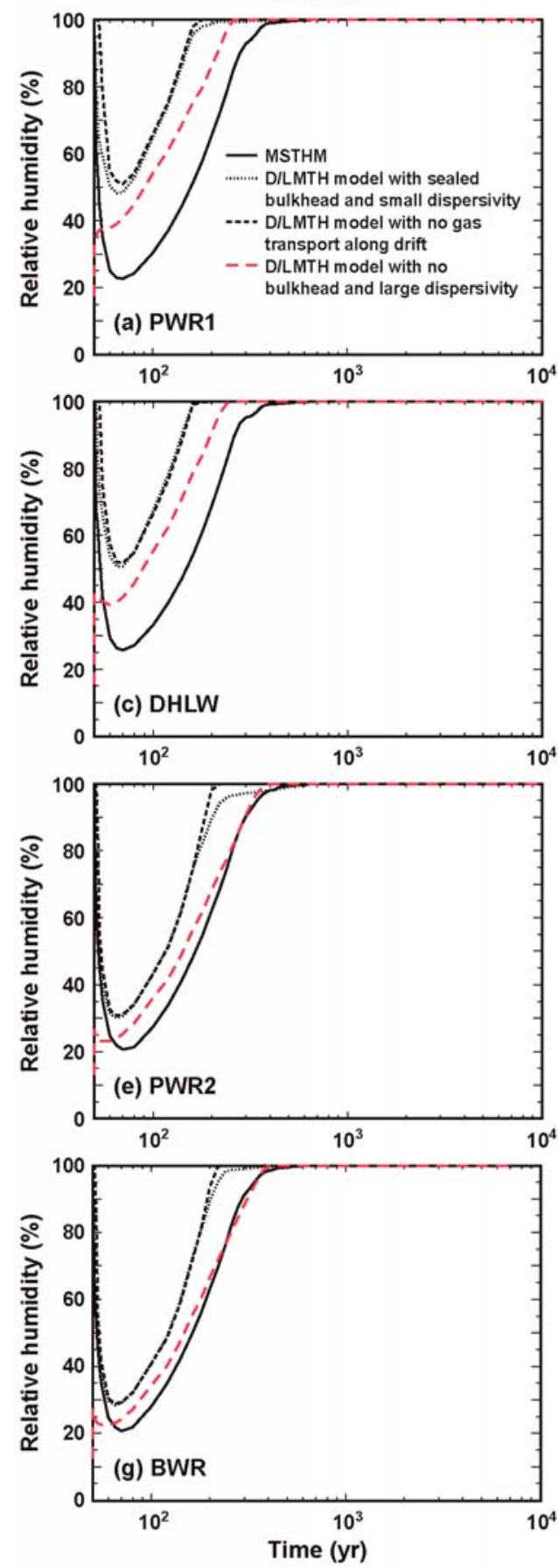

Drip shield
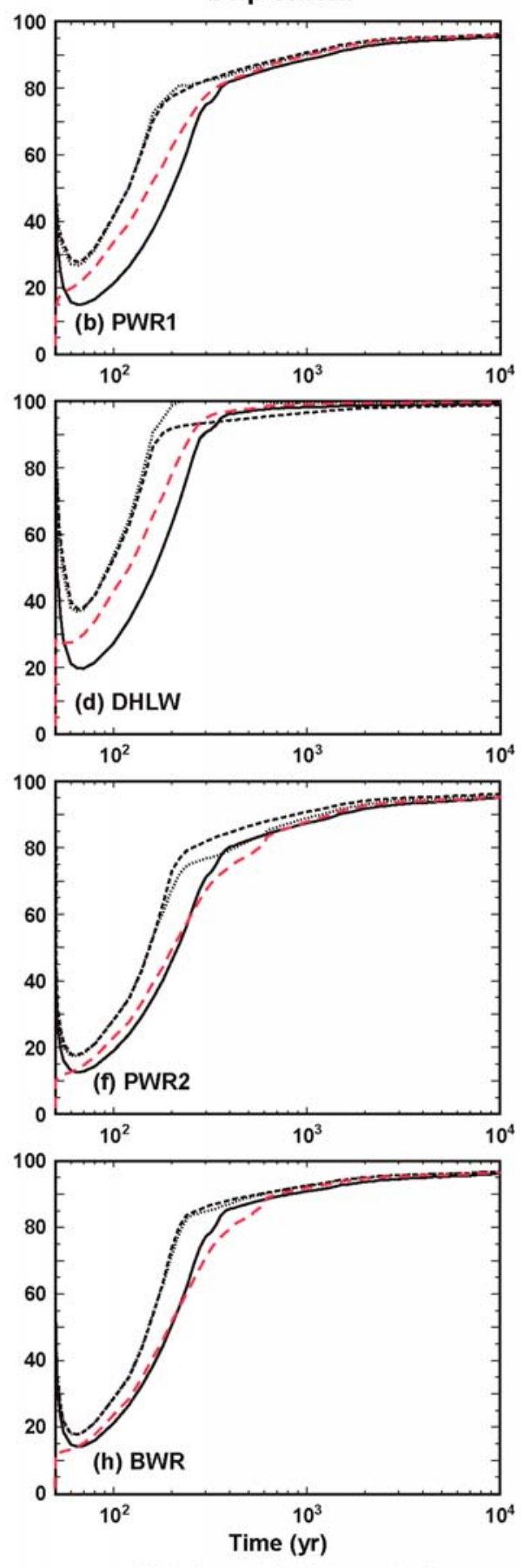

RHdw-ds_pwr1-2-dhlw-bwr_edge2

Source: See Table XIII-1.

NOTE: Drift-wall relative humidity $\left(R H_{\mathrm{dw}, \mathrm{j}, \mathrm{DMTH}}\right)$ vs. time $(\mathrm{a}, \mathrm{c}, \mathrm{e}, \mathrm{g})$ and drip-shield relative humidity $\left(R H_{\mathrm{ds}, \mathrm{j}, \mathrm{DMTH}}\right)$ vs. time $(b, d, f, h)$ are determined by the MSTHM and the D/LMTH model. The D/LMTH-model results are given for a case without axial gas- and liquid-phase flow along the drift and for two cases with flow along the drift, including one with a sealed bulkhead and small gas-phase dispersivity in the drift and one with no bulkhead and large gas-phase dispersivity.

Figure 7.5-6. Drift-Wall and Drip-Shield Relative Humidity vs. Time for the (a, b) PWR1, (c, d) DHLW, $(\mathrm{e}, \mathrm{f})$ PWR2, and $(\mathrm{g}, \mathrm{h})$ BWR Waste Packages at the Edge of the Three-Drift Repository Test Case 


\subsubsection{Liquid-Phase Saturation at the Edge of the Three-Drift Repository Test Case}

Drift-wall liquid-phase saturation $S_{\mathrm{dw}, \mathrm{j}, \mathrm{DMTH}}$ predicted by the D/LMTH model and MSTHM are in reasonable agreement at the four "edge" center waste package locations (Figure 7.5-7a, c, e, and $\mathrm{g}$ ). This agreement is achieved regardless of whether axial gas- and liquid-phase flow along the drift is allowed to occur in the D/LMTH model. However, the inclusion of axial vapor transport and the unheated part of the drift in the D/LMTH model (with no bulkhead and large gas-phase dispersivity) improves the agreement of predicted liquid-phase saturation (Figure 7.5-7) between the MSTHM and the D/LMTH model, with one exception, which is the invert liquid-phase saturation for the DHLW waste package (Figure 7.5-7d). Preferential condensation at the cold (DHLW waste package) location increases the invert liquid-phase saturation beneath that waste package. The cold-trap effect also results in a loss of moisture from the host rock adjoining all waste package locations (the hot CSNF waste packages in particular), which decreases the drift-wall liquid-phase saturation at those locations. The net reduction in liquid-phase saturation in the host rock at the cooler DHLW waste package location is reduced by virtue of preferential condensation occurring there after boiling ceases. The cold-trap effect also removes moisture from the invert liquid-phase saturation beneath the hot CSNF waste packages, which reduces the invert liquid-phase saturation at those locations. Preferential condensation beneath the (relatively cooler) DHLW waste package results in an increase in liquid-phase saturation in the invert (Figure 7.5-7d).

\subsubsection{Vapor and Condensate Fluxes at the Edge of the Three-Drift Repository Test Case}

Figure 7.5-8 shows the axial mass flux of water vapor in the gas phase along the central drift in the model, plotted for the upstream end of each of the four waste packages (the end closer to the repository center), and also at the repository edge (the downstream end of the outermost waste package, PWR1). Note that Figure 7.5-1 shows the waste package sequence. These results are for the most realistic D/LMTH case, which has no bulkhead and large gas-phase dispersivity in the drift. The curves are parallel, with the upstream value being less than the downstream value at a given waste package location, with the exception of the last two curves labeled PWR1 (the outermost waste package) and Repository Edge. The last two curves drop below the value of the respective upstream curves at approximately 300 years, signifying that condensation is occurring in the vicinity of the cooler DHLW waste package after about 300 years. 

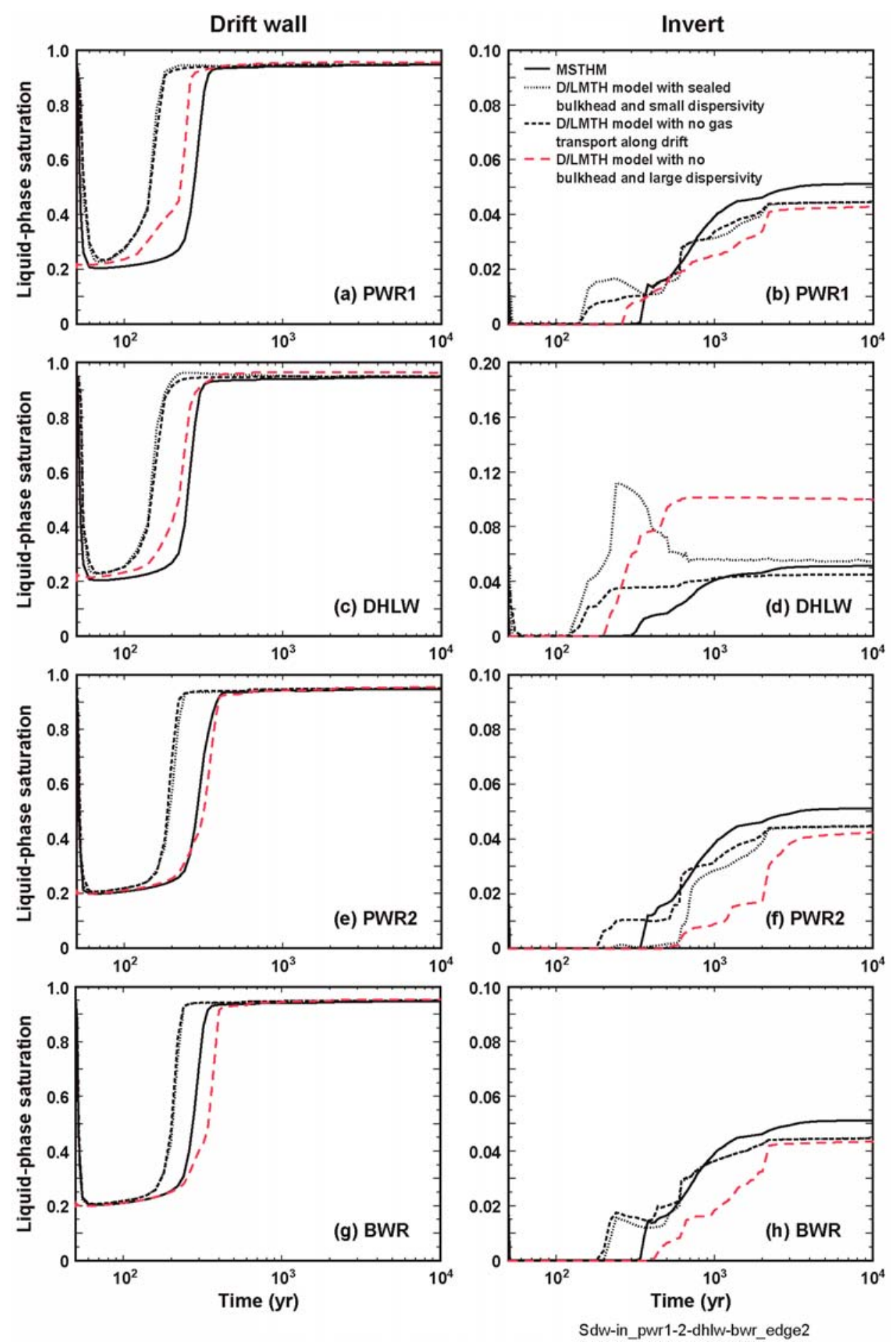

Source: See Table XIII-1.

NOTE: Drift-wall liquid-phase saturation $\left(S_{\mathrm{dw}, \mathrm{j}, \mathrm{DMTH}}\right)$ vs. time $(\mathrm{a}, \mathrm{c}, \mathrm{e}, \mathrm{g})$ and invert liquid-phase saturation $\left(S_{\text {in,j,DMTH }}\right)$ vs. time $(b, d, f, h)$ are determined by the MSTHM and the D/LMTH model. The D/LMTH-model results are given for a case without axial gas- and liquid-phase flow along the drift and for two cases with flow along the drift, including one with a sealed bulkhead and small gas-phase dispersivity in the drift and one with no bulkhead and large gas-phase dispersivity.

Figure 7.5-7. Drift-Wall Liquid-Phase and Invert Liquid-Phase Saturation vs. Time for the (a, b) PWR1, (c, d) DHLW, (e, f) PWR2, and (g, h) BWR Waste Packages at the Edge of the Three-Drift Repository Test Case 


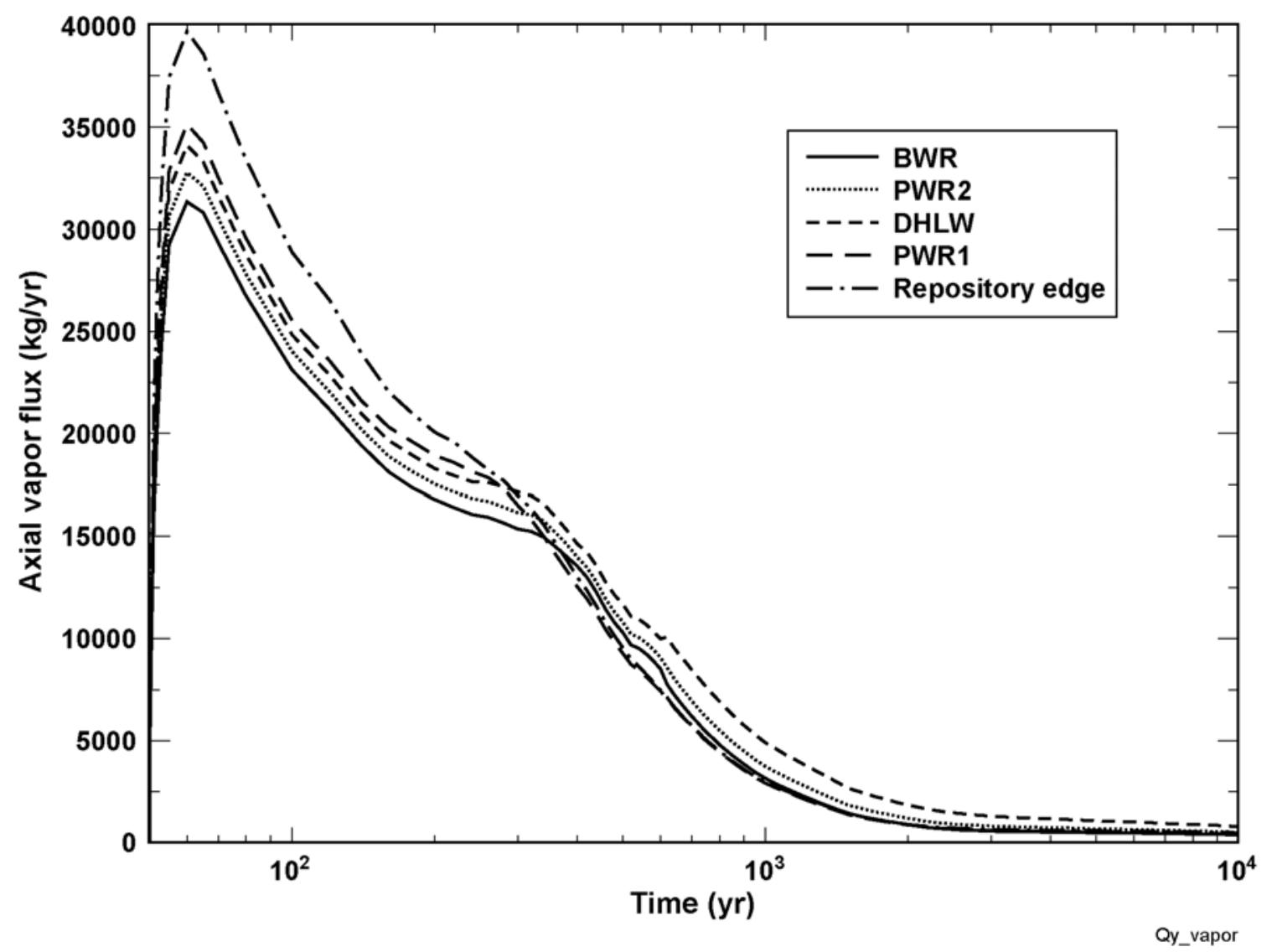

Source: See Table XIII-1.

NOTE: This figure corresponds to the D/LMTH-model case with no bulkhead and large gas-phase dispersivity. This case also includes the influence of host-rock dryout during the ventilation period. The waste package sequencing, starting from the edge, is PWR1, DHLW, PWR2, and BWR, as is shown in Figure 7.5-1. The upstream side of the waste package is the side closer to the repository center. The curve listed "repository edge" corresponds to the downstream side of the PWR1 waste package. The curve listed "PWR1"

corresponds to the upstream side of the PWR 1 waste package, and to the downstream side of the DHLW waste package. The curve listed "DHLW" corresponds to the upstream side of the DHLW waste package and to the downstream site of the PWR2 waste package. The curve listed "PWR2" corresponds to the upstream side of the PWR2 waste package and to the downstream side of the BWR waste package. The curve listed "BWR" corresponds to the upstream side of the BWR waste package.

Figure 7.5-8. Axial Vapor Flux on the Upstream Side of the Listed Waste Packages at the Edge of the Three-Drift Repository Test Case

Tables 7.5-9 to 7.5-12 show moisture balance results for each of the four outermost waste packages at the repository edge, from the D/LMTH model case with no bulkhead and large dispersivity (case 3). The phase change columns show where evaporation (positive values) and condensation (negative values) are occurring at each waste package location for several discrete times distributed over the regulatory period. Note that the delta axial vapor flux, which is the difference in axial vapor flux between the upstream and downstream sides of a waste package (see Figure 7.5-8), corresponds to the net condensation or evaporation occurring at a waste package location. The radial vapor flux corresponds to the phase change that occurs in the host rock. Thus, the sum of the radial vapor flux, the invert phase change, and the drift phase change is equal to the delta axial vapor flux. Of the four waste packages, the DOE high-level radioactive waste package (Table 7.5-10) is the coolest, and condensation occurs mainly there. A comparison of the delta axial vapor flux with the radial vapor flux shows that most of the 
condensation at the cooler waste package results from water vapor migration outward into cooler rock, where it condenses. This water is then diverted around the drift opening along with the ambient percolation flux.

Table 7.5-9. Summary of Moisture Balance for PWR1 Waste Package in Multiscale Thermal-Hydrologic Model Validation Test Case

\begin{tabular}{|c|c|c|c|c|c|c|}
\hline \multirow{2}{*}{$\begin{array}{c}\text { Time } \\
\text { (years) }\end{array}$} & \multicolumn{3}{|c|}{ Vapor Flux (kg/yr) } & \multicolumn{2}{c|}{ Phase Change (kg/yr) } \\
\cline { 2 - 7 } & $\begin{array}{c}\text { Axial } \\
\text { (upstream) }\end{array}$ & $\begin{array}{c}\text { Axial } \\
\text { (downstream) }\end{array}$ & Delta Axial & Radial & Invert & Drift \\
\hline 60 & $35,137.6$ & $39,680.5$ & $4,542.9$ & $4,300.3$ & 242.8 & 0.0 \\
\hline 100 & $25,530.0$ & $28,876.8$ & $3,346.8$ & $3,113.4$ & 233.3 & 0.0 \\
\hline 500 & $9,273.2$ & $9,554.1$ & 280.9 & 51.9 & 229.5 & -0.4 \\
\hline 1,000 & $2,928.7$ & $2,978.4$ & 49.7 & -59.4 & 109.1 & 0.0 \\
\hline 2,000 & 878.3 & 904.4 & 26.1 & -17.6 & 51.6 & -7.9 \\
\hline 5,000 & 547.5 & 603.6 & 56.1 & 19.3 & 36.8 & 0.0 \\
\hline 10,000 & 448.7 & 499.4 & 50.7 & 21.5 & 29.1 & 0.0 \\
\hline
\end{tabular}

Source: DTN: LL040703223122.050.

NOTE: The PWR1 waste package is located at the outer edge of the three-drift validation test case Figure 7.5-1) for the D/LMTH model with no bulkhead and a high gas-phase dispersion coefficient along the drift. Positive values of radial vapor flux correspond to vapor leaving the host rock and entering the drift (and invert); negative values correspond to vapor leaving the drift (and invert) and entering the host rock. Positive values of phase change correspond to evaporation; negative values correspond to condensation. The delta axial vapor flux, which is the difference in axial vapor flux between the upstream and downstream sides of a waste package (see Figure 7.5-8), corresponds to the net condensation or evaporation occurring at a waste package location. The radial vapor flux corresponds to the phase change that occurs in the host rock. Thus, the sum of the radial vapor flux, the invert phase change, and the drift phase change is equal to the delta axial vapor flux. 
Table 7.5-10. Summary of Moisture Balance for DOE High-Level Radioactive Waste Package in Multiscale Thermal-Hydrologic Model Validation Test Case

\begin{tabular}{|c|c|c|c|c|c|c|}
\hline \multirow[b]{2}{*}{$\begin{array}{c}\text { Time } \\
\text { (years) }\end{array}$} & \multicolumn{4}{|c|}{ Vapor Flux (kg/yr) } & \multicolumn{2}{|c|}{ Phase Change (kg/yr) } \\
\hline & $\begin{array}{c}\text { Axial } \\
\text { (upstream) }\end{array}$ & $\begin{array}{c}\text { Axial } \\
\text { (downstream) }\end{array}$ & Delta Axial & Radial & Invert & Drift \\
\hline 60 & $34,102.0$ & $35,138.0$ & $1,036.0$ & $1,036.0$ & 0.0 & 0.0 \\
\hline 100 & $24,835.0$ & $25,530.0$ & 695.0 & 695.0 & 0.0 & 0.0 \\
\hline 500 & $11,679.4$ & $9,273.2$ & $-2,406.2$ & $-2,381.4$ & -12.5 & -12.4 \\
\hline 1,000 & $4,902.1$ & $2,928.7$ & $-1,973.4$ & $-1,920.2$ & -30.4 & -22.8 \\
\hline 2,000 & $1,851.1$ & 878.3 & -972.8 & -925.7 & -19.1 & -28.0 \\
\hline 5,000 & $1,076.4$ & 547.5 & -528.8 & -495.0 & -10.4 & -23.4 \\
\hline 10,000 & 800.6 & 448.7 & -351.9 & -332.2 & -6.6 & -13.1 \\
\hline
\end{tabular}

Source: DTN: LL040703223122.050.

NOTE: The DOE high-level radioactive waste package is the second to the last waste package located at the outer edge of the three-drift validation test case (Figure 7.5-1) for the D/LMTH model with no bulkhead and a high gas-phase dispersion coefficient along the drift. Positive values of radial vapor flux correspond to vapor leaving the host rock and entering the drift (and invert); negative values correspond to vapor leaving the drift (and invert) and entering the host rock. Positive values of phase change correspond to evaporation; negative values correspond to condensation. The delta axial vapor flux, which is the difference in axial vapor flux between the upstream and downstream sides of a waste package (see Figure 7.5-8), corresponds to the net condensation or evaporation occurring at a waste package location. The radial vapor flux corresponds to the phase change that occurs in the host rock. Thus, the sum of the radial vapor flux, the invert phase change, and the drift phase change is equal to the delta axial vapor flux.

Table 7.5-11. Summary of Moisture Balance for PWR2 Waste Package in Multiscale Thermal-Hydrologic Model Validation Test Case

\begin{tabular}{|c|c|c|c|c|c|c|}
\hline \multirow{2}{*}{$\begin{array}{c}\text { Time } \\
\text { (years) }\end{array}$} & \multicolumn{4}{|c|}{ Vapor Flux (kg/yr) } & \multicolumn{2}{c|}{ Phase Change (kg/yr) } \\
\cline { 2 - 7 } & $\begin{array}{c}\text { Axial } \\
\text { upstream) }\end{array}$ & $\begin{array}{c}\text { Axial } \\
\text { (downstream) }\end{array}$ & Delta Axial & Radial & Invert & Drift \\
\hline 60 & $32,775.4$ & $34,102.0$ & $1,326.6$ & $1,326.9$ & 0.0 & 0.0 \\
\hline 100 & $24,014.0$ & $24,835.0$ & 821.0 & 821.0 & 0.0 & 0.0 \\
\hline 500 & $10,813.1$ & $11,679.4$ & 866.3 & 711.8 & 153.7 & 0.8 \\
\hline 1,000 & $3,744.8$ & $4,902.1$ & $1,157.3$ & $1,062.5$ & 94.8 & 0.0 \\
\hline 2,000 & $1,202.0$ & $1,851.1$ & 649.1 & 592.5 & 56.6 & 0.0 \\
\hline 5,000 & 678.6 & $1,076.4$ & 397.8 & 348.9 & 48.8 & 0.0 \\
\hline 10,000 & 524.7 & 800.6 & 275.9 & 238.2 & 37.7 & 0.0 \\
\hline
\end{tabular}

Source: DTN: LL040703223122.050.

NOTE: The PWR2 waste package is the third to the last waste package located at the outer edge of the three-drift validation test case (Figure 7.5-1) for the D/LMTH model with no bulkhead and a high gas-phase dispersion coefficient along the drift. Positive values of radial vapor flux correspond to vapor leaving the host rock and entering the drift (and invert); negative values correspond to vapor leaving the drift (and invert) and entering the host rock. Positive values of phase change correspond to evaporation; negative values correspond to condensation. The delta axial vapor flux, which is the difference in axial vapor flux between the upstream and downstream sides of a waste package (see Figure 7.5-8), corresponds to the net condensation or evaporation occurring at a waste package location. The radial vapor flux corresponds to the phase change that occurs in the host rock. Thus, the sum of the radial vapor flux, the invert phase change, and the drift phase change is equal to the delta axial vapor flux. 
Table 7.5-12. Summary of Moisture Balance for BWR Waste Package in Multiscale Thermal-Hydrologic Model Validation Test Case

\begin{tabular}{|c|c|c|c|c|c|c|}
\hline \multirow{2}{*}{$\begin{array}{c}\text { Time } \\
\text { (years) }\end{array}$} & \multicolumn{4}{|c|}{ Vapor Flux (kg/yr) } & \multicolumn{2}{c|}{ Phase Change (kg/yr) } \\
\cline { 2 - 6 } & $\begin{array}{c}\text { Axial } \\
\text { upstream) }\end{array}$ & $\begin{array}{c}\text { Axial } \\
\text { (downstream) }\end{array}$ & Delta Axial & Radial & Invert & Drift \\
\hline 60 & $31,340.2$ & $32,775.4$ & $1,435.2$ & $1,435.3$ & 0.0 & 0.0 \\
\hline 100 & $23,118.2$ & $24,014.0$ & 895.8 & 895.7 & 0.0 & 0.0 \\
\hline 500 & $10,292.6$ & $10,813.1$ & 520.5 & 389.3 & 130.2 & 1.0 \\
\hline 1,000 & $3,161.5$ & $3,744.8$ & 583.3 & 500.9 & 82.4 & 0.0 \\
\hline 2,000 & 889.2 & $1,202.0$ & 312.8 & 264.5 & 48.4 & 0.0 \\
\hline 5,000 & 489.6 & 678.6 & 189.0 & 155.7 & 33.4 & -0.1 \\
\hline 10,000 & 400.8 & 524.7 & 123.9 & 98.7 & 26.3 & -1.1 \\
\hline
\end{tabular}

Source: DTN: LL040703223122.050.

NOTE: The BWR waste package is the fourth to the last waste package located at the outer edge of the three-drift validation test case (Figure 7.5-1) for the D/LMTH model with no bulkhead and a high gas-phase dispersion coefficient along the drift. Positive values of radial vapor flux correspond to vapor leaving the host rock and entering the drift (and invert); negative values correspond to vapor leaving the drift (and invert) and entering the host rock. Positive values of phase change correspond to evaporation; negative values correspond to condensation. The delta axial vapor flux, which is the difference in axial vapor flux between the upstream and downstream sides of a waste package (see Figure 7.5-8), corresponds to the net condensation or evaporation occurring at a waste package location. The radial vapor flux corresponds to the phase change that occurs in the host rock. Thus, the sum of the radial vapor flux, the invert phase change, and the drift phase change is equal to the delta axial vapor flux.

\subsubsection{Summary of Three-Drift Repository Validation Test Case}

The MSTHM is also validated against a monolithic three-dimensional porous-medium model implemented using the NUFT code (Nitao 1998) for a three-drift test case, representing a scaled-down repository. Each simulated drift is $243 \mathrm{~m}$ long and uses a combination of line-averaged and discrete heat sources to represent the waste packages. The central drift uses a combination of a line-averaged heat source for most of the drift and four discrete sources (representing individual waste packages) at the center of the drift and four discrete sources at the outer end of the drift (Figure 7.5-1). The monolithic three-dimensional thermal-hydrologic model is called the discrete/line-averaged mountain-scale thermal-hydrologic (D/LMTH) model.

The D/LMTH model was run in three ways:

- Case 1: This case allows no axial vapor (or gas) transport along the drifts, corresponding to the MSTHM, which does not include vapor transport along the drift axis.

- Case 2: This case allows axial vapor transport, using a small value for the gas-phase dispersion coefficient to account for binary diffusion of water vapor but not for the influence of convective mixing. In addition, a bulkhead was located just beyond the outermost waste package at the end of each drift.

- Case 3: This case allows axial vapor transport, using the high value of the gas-phase dispersion coefficient to account for the influence of turbulent convective mixing. The third case has no bulkhead at the end of the drift, and includes the unheated section of 
the drift beyond the outermost waste package. The third case includes the effects of rock dryout during the ventilation period.

Of the three cases, the third is most realistic and is emphasized in the discussion below. Differences in the predicted thermal-hydrologic conditions for the drift and the adjoining host rock between cases 1 and 3 are used as quantitative indicators of the importance of the cold-trap effect, and moisture transport to the unheated part of each drift, with respect to MSTHM predictions. D/LMTH-model calculations were conducted for cases 1 and 2 for the four waste packages at the repository center. D/LMTH-model calculations were conducted for cases 1, 2, and 3 for the four waste packages at the repository edge.

For comparison, the MSTHM was configured for this same three-drift configuration and boundary conditions, so that results are directly comparable to the three-dimensional nested-grid thermal-hydrologic cases. The locations selected for direct comparisons are at the center and edge of the simplified repository.

Temperature differences between the MSTHM results and cases 1 through 3 are dominated by how the MSTHM methodology addresses three-dimensional heat losses. For waste packages located more than $20 \mathrm{~m}$ from the repository edge, which represents approximately $97 \%$ of the repository area, overprediction of peak drip shield temperature by the MSTHM is less than 6.5 $\mathrm{C}^{\circ}$. At the edge, comparison of the MSTHM with case 3 shows relatively small differences (6.5 to $17.1 \mathrm{C}^{\circ}$ ) in peak drip-shield temperature (Figure 7.5-6). These differences are smaller than the overall effect of parametric uncertainty of host-rock thermal conductivity and percolation flux (Section 6.3.5). Temperature differences are greatest for the last two waste packages at the edge, and are caused by the coarse spatial grid resolution of the SMT submodel used in the MSTHM framework.

The small differences in temperatures between cases 1 and 3 show the lack of influence of the cold-trap effect on temperatures for waste package locations at the repository edge. This result supports use of the MSTHM for predicting thermal-hydrologic conditions in the drifts and in the adjoining host rock for waste package locations near the repository edge.

For case 3, which includes axial vapor transport and the resulting cold-trap effect, the predicted in-drift relative humidity and host-rock liquid saturation conditions (Figures 7.5-6 and 7.5-7) agree more closely with the MSTHM results than the other cases. Importantly, the cold-trap effect causes net reduction in moisture (matrix liquid-phase saturation) in the host rock at all waste package locations, because water is evaporated and transported to unheated regions of the drift. The greatest moisture losses occur at the hotter spent-fuel waste packages, and smallest losses occur at the cooler DHLW waste packages that receive condensation when they cool below boiling $\left(96^{\circ} \mathrm{C}\right)$. Condensation at the drift wall, and within the near-field host rock adjacent to the DHLW waste package, offsets some (but not all) of the initial moisture loss. The smaller net moisture reduction at the cooler waste package locations results in smaller reduction in relative humidity than occurs for at hotter waste packages. Axial vapor transport is also predicted to cause net moisture reduction in the invert beneath the hotter waste package locations (Figure 7.5-7). Condensation in the invert beneath cooler waste packages increases the liquid-phase saturation there (Figure 7.5-7d). 
Because the MSTHM does not include axial vapor transport along the drift, it does not represent the net moisture reduction discussed above. However, the differences in predicted relative humidity and host-rock liquid saturation between the MSTHM results and case 3 are smaller than the overall effect of parametric uncertainty of host-rock thermal conductivity and percolation flux for the MSTHM of the repository (Section 6.3.5). Although the MSTHM does not directly account for the influences of the cold-trap effect or of rock dryout during the ventilation period, it does compare well with case 3, which includes both of these influences. Therefore, it is unnecessary to incorporate axial vapor transport and the resulting cold-trap effect into the MSTHM for TSPA-LA.

\subsection{VALIDATION SUMMARY}

The MSTHM has been validated by applying acceptance criteria, which are based on evaluation of the model's relative importance to the performance of the repository system. All validation requirements defined in the governing TWP (BSC 2004 [DIRS 170950], Section 2.2) have been fulfilled, including corroboration of model results with experimental data (Section 7.4) and corroboration with an alternative mathematical model (Section 7.5). Requirements for confidence building during model development have also been satisfied. The model development activities and post-development validation activities described in Section 7.1 of this report establish the scientific bases for the MSTHM. Based on this, the MSTHM is sufficiently accurate and adequate for the intended purpose, consistent with the level of confidence required by the model's relative importance to the performance of the repository system. 


\section{CONCLUSIONS}

\subsection{ANALYSIS AND MODELING CONCLUSIONS}

This model report documents the multiscale thermohydrologic model (MSTHM). An important phenomenological consideration for the licensing of the repository at Yucca Mountain is the generation of decay heat by the emplaced waste and the thermal-hydrologic consequences of this decay heat. A thermal-hydrologic modeling tool is developed and used to support the performance assessment of the engineered barrier system of the repository. This modeling tool simultaneously accounts for processes occurring at a scale of a few tens of centimeters around individual waste packages, for processes occurring around the emplacement drifts themselves, and for processes occurring at the mountain scale. Additionally, many other features are considered including nonisothermal, multiphase-flow in fractured porous rock of variable liquid-phase saturation and thermal radiation and convection in open cavities.

The MSTHM calculates the following thermal-hydrologic parameters: temperature, relative humidity, liquid-phase saturation, evaporation rate, air-mass fraction, gas-phase pressure, capillary pressure, and liquid- and gas-phase fluxes. The thermal-hydrologic parameters are determined as functions of position along each of the emplacement drifts in the repository and as functions of waste package type. These parameters are determined at various reference locations within the emplacement drifts, including the waste package and drip-shield surfaces and in the invert. They are also determined at various reference locations in the adjoining host rock; these parameters are determined every $20 \mathrm{~m}$ for each emplacement drift in the repository. Each emplacement drift is represented with its precise coordinate location, as well as each of the emplacement panels in the repository area (Figure 4-1). The MSTHM also accounts for ventilation during the preclosure period, including how heat-removal efficiency from drift ventilation varies as a function of time and distance along each of the emplacement drifts. The MSTHM accounts for three-dimensional drift-scale and mountain-scale heat flow. The MSTHM captures the influence of the key engineering-design parameters and natural system factors affecting thermal-hydrologic conditions in the emplacement drifts and adjoining host rock, including:

- Repository-scale variability of percolation flux above the repository

- Temporal variability of percolation flux (as influenced by climate change)

- Uncertainty in percolation flux (as addressed by the lower-bound, mean, and upper-bound infiltration-flux cases)

- Uncertainty in percolation flux (associated with infiltration estimates, flow focusing, and flow diversion by the rock layers overlying the repository)

- Stratigraphic variation of thermal conductivity

- Uncertainty in host-rock thermal conductivity of the host rock

- Stratigraphic variation of bulk rock density and specific heat

- Stratigraphic variation of hydrologic properties of the rock matrix

- Stratigraphic variation of hydrologic properties of fractures 
- Variability in overburden thickness

- Overall areal heat-generation density of the waste inventory, quantified by the Areal Mass Loading (AML, expressed in MTU/acre)

- Line-averaged thermal load along emplacement drifts, quantified by the Lineal Power Density (LPD, expressed in $\mathrm{kW} / \mathrm{m}$ )

- Distance between emplacement drifts (also called drift spacing)

- Age of spent-nuclear fuel at time of emplacement

- Repository footprint shape, which influences the evolution of the edge-cooling effect that increases with proximity to the repository edges

- Dimensions of the in-drift design (waste packages, drip shield, and invert)

- Properties of the in-drift engineered barrier system components

- Waste package spacing along the drift (line-load versus point-load spacing)

- Waste package sequencing (particularly with respect to the heat output from the respective waste package types)

- Time- and distance-dependent heat-removal efficiency of preclosure drift ventilation.

This report describes MSTHM calculations conducted to support the Total System Performance Assessment for the License Application (TSPA-LA). The MSTHM simulations are conducted for three infiltration-flux cases (lower-bound, mean, and upper-bound). The impact of parametric uncertainty of the key input parameters, percolation flux and host-rock thermal conductivity, is also addressed. Percolation flux and host-rock thermal conductivity are the two most important natural system parameters influencing peak temperatures and the time that the drift wall remains above the boiling point. It is found that the combined influence of percolation-flux uncertainty and host-rock thermal conductivity uncertainty on peak temperatures is represented by the sum of the individual contributions to peak-temperature uncertainty. It is also found that the combined influence of percolation-flux uncertainty and host-rock thermal conductivity on the duration of boiling at the drift wall is represented by the sum of the individual contributions to drift-wall-boiling-duration uncertainty. These conclusions are consistent with the approach used for abstraction of MSTHM results, with uncertainty, for TSPA-LA.

\subsection{MODEL VALIDATION, UNCERTAINTIES, AND LIMITATIONS}

This report documents decisions implemented during model development that build confidence and verify that a reasonable, credible technical approach using scientific and engineering principles was taken in order to:

- Evaluate and select inputs

- Formulate defensible assumptions

- Ensure consistency with physical principles 
- Represent important uncertainties

- Ensure that MSTHM predictions represent the range of possible outcomes, consistent with important processes, variabilities, and uncertainties.

For the purpose of confidence building and model validation, results from the MSTHM are compared against those from a mountain-scale thermohydrologic model, which is an alternative conceptual model (Section 6.4). Validation of the MSTHM is also supported by using results from field-scale thermal tests and using a monolithic thermohydrologic model of a three-drift repository test case, which is a scaled-down example of the actual repository (Section 7.5). The following discussion summarizes results using the Large Block Test (LBT) and Drift Scale Test (DST), and the three-drift repository test case.

Three-dimensional NUFT thermohydrologic-model simulations are compared with temperatures and liquid-phase saturations measured in the Large Block Test (LBT). The NUFT thermohydrologic model used in this confidence-building study is a three-dimensional equivalent to the two-dimensional LDTH submodels (Section 6.2.6) used in the MSTHM. The good agreement between the simulated and measured temperatures in the LBT builds confidence that the NUFT model provides a valid representation of heat flow in partially saturated fractured porous rock. Good agreement between the simulated and measured dryout and rewetting behavior in the LBT demonstrates that the NUFT thermohydrologic simulations provide valid representation of dryout and rewetting behavior in partially saturated fractured porous rock.

Three-dimensional NUFT thermohydrologic simulations are also compared with temperatures and liquid-phase saturations measured in the Drift Scale Test (DST). Note that the thermal-hydrologic model of the DST is a three-dimensional equivalent to the two-dimensional LDTH submodels (Section 6.2.6) used in the MSTHM. Overall agreement was achieved between simulated and measured temperatures. Simulated temperatures exhibit less of a distinctive plateau close to $96^{\circ} \mathrm{C}$ than the measured temperatures. This effect is associated with the use of the calibrated hydrologic property set and the low value of matrix permeability, which causes a large gas-phase pressure buildup in the matrix that increases the saturation (boiling) temperature and temporarily throttles (i.e., restricts) vaporization and delays rock dryout. Higher saturation (boiling) temperatures and lack of a temperature plateau close to $96^{\circ} \mathrm{C}$ cause simulated temperatures to be higher than measured temperatures for the above-boiling region. Results from Section 7.4.4 of Drift-Scale Coupled Processes (DST and TH Seepage) Models (BSC 2004 [DIRS 170338]) show that when the site-specific property set is used, this transient throttling effect does not occur and better agreement is obtained between simulated and measured temperatures in the above-boiling region.

Another reason for the NUFT-simulated temperatures being higher than measured temperatures is the uncertainty in host-rock thermal conductivity $K_{\text {th }}$ at the DST location. For the high- $K_{\text {th }}$ case (one standard deviation above the mean), simulated temperatures are in better agreement with the measured temperatures than the cases that used the mean $K_{\text {th }}$ values. Because percolation fluxes cannot be directly measured, uncertainty in the local percolation flux in the DST area also contributes to differences between simulated and measured temperatures. Section 6.3.4 discusses the influence of key parametric uncertainties on predicted thermohydrologic conditions in the repository. Table 6.3-30 shows that the combined influence of host-rock percolation-flux and thermal conductivity uncertainties results in peak drift-wall temperatures 
varying by 26.6 to $38.3^{\circ} \mathrm{C}$ for the four host-rock units. The 30-percent validation criterion for temperature rise (above ambient), which is given in the TWP, is consistent with the magnitude of the influence of the parametric uncertainty of host-rock thermal conductivity and percolation flux on temperature. As shown in Table 6.3-30, the combined influence of host-rock thermal conductivity uncertainty and percolation-flux uncertainty causes the rise in peak drift-wall temperature (above ambient) to vary by about 30 percent. For temperatures less than about $80^{\circ} \mathrm{C}$, simulated and measured temperatures are in good agreement for all three cases considered: (1) base case, (2) sealed bulkhead, and (3) high $K_{\text {th }}$.

With a few exceptions, the differences between the NUFT-simulated and measured temperature increases above ambient temperatures are less than 30 percent, thereby satisfying one part of the validation criterion for the DST comparison. The few exceptions are associated with the use of the calibrated hydrologic property set and the low value of matrix permeability, which results in a large gas-phase pressure buildup in the matrix that increases the saturation (boiling) temperature. It is important to note that this transient throttling effect dissipates as the NUFT-simulated gas-phase pressure buildup declines. Heating conditions for the DST result in an accelerated temperature increase, compared to that predicted for repository heating conditions. Thus, although matrix permeability is seen to have a noticeable affect on temperatures simulated for the DST, it does not significantly affect repository temperature evolution predicted by thermal-hydrologic models supporting TSPA-LA. Overall, the comparison of NUFT-simulated and measured temperatures demonstrates that the NUFT thermohydrologic model provides a valid representation of heat flow in the DST.

Although the NUFT-simulated dryout behavior (as measured by the liquid-phase saturation in the matrix continuum) lagged behind that observed in the DST, this is a transient effect. Heating conditions for the DST result in an accelerated temperature rise and dryout, compared to those predicted for repository heating conditions. Although the NUFT-simulated dryout lags behind the DST-observed dryout, this is not important to the application of the MSTHM for post-closure repository predictions. This is because predicted rock dryout for repository heating conditions is slower, occurring over much longer time frames than applicable to the DST. Within four years, the DST-observed rock dryout approaches the NUFT-simulated dryout, which satisfies the validation criterion for the DST comparison. Therefore, it can be concluded that the NUFT thermohydrologic model provides a valid representation of rock dryout in the DST and that the MSTHM provides valid predictions of post-closure dryout. To the extent that the observations in the DST allow, the NUFT thermohydrologic model provides a valid representation of rewetting behavior in the DST.

Another conclusion from the DST model validation study is that the sealed-bulkhead case results in slightly higher NUFT-simulated temperatures than the base case (which had a leaky bulkhead). The influence of the leaky bulkhead on simulated temperatures is less than that resulting from a one standard-deviation estimated range in thermal conductivity. This conclusion is useful with respect to the potential significance of whether the ends of the emplacement drifts are sealed with bulkheads or simply backfilled with highly permeable crushed tuff. The lack of sensitivity of the DST thermohydrologic simulations to the treatment of the bulkhead (leaky versus sealed) suggests that the MSTHM predictions of thermohydrologic response in the emplacement drifts is not significantly affected by whether the ends of the emplacement drifts are sealed. 
Validation of the MSTHM methodology itself involves a three-drift repository test case. This test case represents a scaled-down repository, consisting of three 243-m long drifts. A monolithic three-dimensional thermohydrologic model of this three-drift repository test case discretely represents 15 waste packages: 7 at the center of the central drift and 4 at either end of the central drift. The MSTHM and the monolithic thermohydrologic model predict almost identical thermohydrologic conditions at all waste package locations at the center of the three-drift repository test case. At the edge of the three-drift repository test case, the MSTHM and monolithic thermohydrologic model also predict similar conditions. Differences between the two models are largest for the last two waste packages at the edge, where the MSTHM predicts peak temperatures that are about $17^{\circ} \mathrm{C}$ higher than predicted in the monolithic thermal-hydrologic model. Note that the outermost two waste packages cover only 1.6 percent of the repository area. For the third and fourth waste package in from the repository edge, the MSTHM predicts peak temperatures that are about 6 to $8^{\circ} \mathrm{C}$ higher than predicted in the monolithic thermal-hydrologic model. For waste packages located more than $20 \mathrm{~m}$ from the repository edge, which encompasses 96.8 percent of the repository area, the bias in peak temperatures predicted by the MSTHM is less than about $6^{\circ} \mathrm{C}$. However, because all of the differences are within the range of those caused by parametric uncertainty (totaling about 30 to $40^{\circ} \mathrm{C}$, depending on the host-rock unit, as shown in Table 6.3-28), the MSTHM satisfies the validation criterion for this comparison and is suitable for predicting thermal-hydrologic conditions for all waste package locations.

The propagation of parametric uncertainty in the MSTHM addresses the two key natural system parameters: host-rock thermal conductivity and percolation flux. A sensitivity study of the influence of hydrologic-property uncertainty supports the conclusion that hydrologic-property uncertainty does not need to be propagated in the MSTHM calculations of in-drift temperature and relative humidity. Propagation of percolation-flux and host-rock thermal conductivity uncertainty in repository-wide MSTHM output is addressed with the following five (infiltration-flux host-rock thermal conductivity) cases:

- Lower-bound infiltration-flux case with low (mean minus one standard deviation) host-rock thermal conductivity

- Lower-bound infiltration-flux case with mean host-rock thermal conductivity

- Mean infiltration-flux case with mean host-rock thermal conductivity

- Upper-bound infiltration-flux case with mean host-rock thermal conductivity

- Upper-bound infiltration-flux case with high (mean plus one standard deviation) hostrock thermal conductivity

For these five cases, the range in peak drift-wall temperature is from $92^{\circ} \mathrm{C}$ to $175^{\circ} \mathrm{C}$, with a median drift-wall temperature of $133^{\circ} \mathrm{C}$; the range in peak waste package temperature is from $102^{\circ} \mathrm{C}$ to $203^{\circ} \mathrm{C}$, with a median waste package temperature of $153^{\circ} \mathrm{C}$ (Table 6.3-38). These five cases also result in a wide range of waste package relative-humidity histories as is shown in Figure 6.3-53. 
Another thermohydrologic parameter is the time when boiling ceases at the drift wall. For the five infiltration-flux host-rock thermal conductivity cases, the time when drift-wall boiling ceases ranges from no boiling to 2,177 years, with a median time of 721 years (Table 6.3-39). The percentage of waste packages that may experience no boiling at the drift wall is low $(0.1 \%$ of all waste packages).

Another thermohydrologic result of interest is the maximum lateral extent of the boiling zone relative to the centerline of the emplacement drifts because this indicates the likelihood of condensate and percolation flux drainage around emplacement drifts during the dryout period. For the five infiltration-flux host-rock thermal conductivity cases, the maximum lateral extent of boiling ranges from 4.1 to $27.9 \mathrm{~m}$, with a median maximum lateral extent of $7.9 \mathrm{~m}$ (Table 6.3-40). The lowest end of this range $(4.1 \mathrm{~m})$ pertains to the situation where boiling only occurs within the emplacement drift (i.e., not at the drift wall). For the majority of cases the lateral extent of boiling is much smaller than the half spacing between emplacement drifts. Therefore, the majority of the host rock between emplacement drifts always remains below the boiling point, thereby enabling condensate and percolation flux to continuously drain between emplacement drifts. Because of the continuous drainage of condensate around a dryout zone of limited extent, condensate above the emplacement drifts is limited.

\subsection{MODEL OUTPUTS}

The MSTHM results supplied to TSPA are summarized in Table 1-1. For each SMT submodel location (2,874 locations distributed over the repository area, which is shown in Figure 6.2-3), bin indices are calculated based on the rank order of the percolation flux associated with the location. Bin 1 includes the 5 percent of locations with the smallest percolation flux. Bin 2 includes locations with percolation fluxes in the 5th to 30th percentile. Bin 3 includes locations with percolation fluxes in the 30th to 70th percentile. Bin 4 includes locations with percolation fluxes in the 70th to 95th percentile. Bin 5 includes locations with percolation fluxes above the 95th percentile. Note that the binning is based solely on the percolation fluxes for the glacial-transition climate of the mean infiltration-flux case. Moreover, the lower- and upper-bound infiltration-flux cases share the same areal binning as that determined for the mean infiltration-flux case.

MSTHAC v7.0 calculations are performed at all 2,874 SMT submodel locations, and the output from these calculations are postprocessed and written in a format required to satisfy TSPA parameter requirements. Two sets of information are generated for the MSTHM output-parameter DTNs. The first set, which is called the "WAPDEG binning" set, includes limited output parameters at every SMT submodel location and for each of the two waste package groups, including commercial spent nuclear fuel (CSNF) and defense high-level waste (DHLW). The second set, which is called the "TSPA binning" set, includes complete output variable information for only typical bin locations and for typical waste packages (with respect to temperature and relative humidity histories) for each of the two waste package groups (CSNF and DHLW). Note that the waste package degradation (WAPDEG) model is a process model, which is downstream of the MSTHM (with respect to model-to-model parameter flow) and which directly uses MSTHM output parameters.

For seepage modeling and engineered barrier system performance assessment (Seepage and WAPDEG models), all SMT submodel locations and each of the eight waste package types 
(Table 6.3-13) are considered; therefore, there are 2,874 locations multiplied by 8 waste package types, which results in 22,992 waste package histories that are reported. For each SMT submodel location and waste package type, a single file is produced that reports $T_{\mathrm{wp}}, R H_{\mathrm{wp}}, T_{d w}$, $T_{\mathrm{ds}}$, and $R H_{\mathrm{ds}}$, where $T$ and $R H$ are temperature and relative humidity and wp, dw, and ds stand for waste package, drift wall, and drip shield, respectively. Two waste package groups-DHLW and CSNF-are also defined, and for each SMT submodel location, the most typical waste package in the grouping is selected and the same five parameters reported. The DHLW group includes waste packages dhlw-l1 and dhlw-s1. The CSNF group includes waste packages pwr1-1, pwr2-1, bwr1-1, bwr2-1, pwr1-2 and bwr1-2. Details of the determination of the typical waste package can be found in Appendix VIII.

Since the WAPDEG binning produces a large number of output files, the first set of files are concatenated using a UNIX shell script so that all locations falling within a bin and all waste packages of a given type (CSNF or DHLW) are included in a single file. This process creates 5 (the number of bins) multiplied by 2 (the number of waste package groups), which results in 10 output files. The second set of typical files is also concatenated so that there is one file for each bin and each waste package group. This produces another $5 \times 2=10$ files. Hence a total of 20 WAPDEG files are provided for each infiltration-flux case.

The second process (TSPA binning) involves determining the most typical location given a set of locations that define a "bin." For TSPA purposes, the focus is the most typical waste package (see below) in a group or bin; therefore, there are 5 bins $\times 2$ groups $=10$ typical waste packages reported. TSPA binning uses the same waste package group definitions used in WAPDEG binning. For each bin, two output files are created, one for the most typical CSNF package and one for the most typical DHLW package. There are 5 (the number of bins) multiplied by 2 (the number of waste package groups) files created for this type of processing. The process of determining the typical waste packages is described in Appendix VIII. The TSPA files include all MSTHM output parameters that are relevant to the modeled repository (43 in all) covering temperature, relative humidity, liquid-phase saturation, liquid-phase flux and other thermal-hydrologic parameters at reference locations within and adjacent to the emplacement drifts.

Table 8-1 is a list of data tracking numbers (DTNs) associated with the output produced by this report.

\subsection{YUCCA MOUNTAIN REVIEW PLAN CRITERIA ASSESSMENT}

This model report predicts results that directly pertain to the abstraction of the quantity and chemistry of water contacting engineered barriers and waste forms. This section summarizes the contents of this report as they apply to U.S. Nuclear Regulatory Commission's criteria for a detailed review of that abstraction. These are the relevant criteria from the Yucca Mountain Review Plan, Final Report (NRC 2003, Section 2.2.1.3.3.3 [DIRS 163274] which is from 10 CFR 63.114(a)-(c) and (e)-(g) [DIRS 156605]).

This report provides predictions of the evolution of thermal-hydrologic conditions in the repository emplacement drifts and in the adjoining host rock, but not predictions of seepage or in-drift condensation. These predictions provide the downstream process models and model abstraction with the thermal-hydrologic parameters (as functions of time) that influence the 
evolution of in-drift coupled flow and transport processes. Some aspects of the acceptance criteria (chemistry, seepage) are not addressed by this report.

\subsubsection{Acceptance Criterion 1-System Description and Model Integration are Adequate}

(1) Total system performance assessment adequately incorporates important design features, physical phenomena, and couplings, and uses consistent and appropriate assumptions throughout the quantity and chemistry of water contacting engineered barriers and waste forms abstraction process;

Table 4.1-1 lists the sources of input for design features and physical features. The design features that are inputs to the MSTHM calculations (including drip shield, invert, waste packages, drift design, and thermal loading) are in accordance with Interface Exchange Drawings (IEDs) (Section 4.1.1). Section 4.1.2 discusses the effects of small changes to the IEDs subsequent to the calculations documented in this report. Supplementary properties of the planned components are inputs from ASME standards and other justified sources (Section 4.1.1 and Appendix X). Simplifying assumptions about material properties are stated and justified (Section 5.3). The ventilation efficiency as a function of drift location and time is input from Ventilation Model and Analysis Report (BSC 2004 [DIRS 169862]).

Physical features of the unsaturated zone (stratigraphy) and some properties of the materials are input from Development of Numerical Grids for UZ Flow and Transport Modeling (BSC 2004 [DIRS 169855]). Other properties of the natural materials are input from Calibrated Properties Model (BSC 2004 [DIRS 169857]), Analysis of Hydrologic Properties Data (BSC 2004 [DIRS 170038]), Thermal Conductivity of Non-Repository Lithostratigraphic Layers (BSC 2004 [DIRS 170033]), Thermal Conductivity of the Potential Repository Horizon (BSC 2004 [DIRS 169854]), and other justified sources (Section 4.1). These sources assure consistency throughout the abstractions affecting the representation of the quantity and chemistry of water contacting engineered barriers and waste forms. Simplifying assumptions about material properties are stated and justified (Section 5.3).

The MSTHM represents the design features, physical phenomena, and couplings at the appropriate spatial scales. It incorporates a conceptual model for flow through unsaturated fractured porous rock at Yucca Mountain that is based on a dual-permeability representation of overlapping fracture and matrix continua (Section 6.2.2), which is consistent with all other hydrologic models, such as UZ Flow Models and Submodels (BSC 2004 [DIRS 169861], Drift-Scale Coupled Processes (DST and TH Seepage) Models (BSC 2004 [DIRS 170338]) and Mountain-Scale Coupled Processes (TH/THC/THM) (BSC 2004 [DIRS 169866]). The conceptual model for unsaturated-zone thermohydrology is implemented from standard form mass- and energy-balance equations (Sections 6.2.3.1, 6.2.3.2, and 6.2.3.6), including treatments of radiative heat transfer (Section 6.2.3.3) and thermal conduction (Section 6.2.3.4), with an active-fracture modification to the traditional dual-permeability approach (Section 6.2.3.5). The model does not address the chemistry of the water, but provides input to process models and abstractions that address chemical environments, waste package corrosion, and waste-form degradation.

The coupling of thermal and hydrologic processes is at the heart of the model presented in this report. The MSTHM couples the effects of processes at various spatial scales, from a few tens of 
centimeters around individual waste packages and emplacement drifts to the scale of the mountain (Section 6.2.1). The MSTHM accomplishes this with four submodel types of varying dimensionality (Section 6.2.4), using simplified assumptions that are stated and justified (Sections 5.2, 5.5, 5.6, and 5.7). The MSTHM is validated by comparing predictions from its key thermal-hydrological submodel (called the LDTH submodel) against field test data (Sections 7.3 and 7.4) and by comparing MSTHM predictions with predictions from a monolithic three-dimensional thermal-hydrological model (Section 7.5). Coupled processes that are not addressed in this report are considered, and their rationale for exclusion presented, in Engineered Barrier System Features, Events, And Processes (BSC 2004 [DIRS 169898]).

(2) The abstraction of the quantity and chemistry of water contacting engineered barriers and waste forms uses assumptions, technical bases, data, and models, that are appropriate and consistent with other related U.S. Department of Energy abstractions. For example, the assumptions used for the quantity and chemistry of water contacting engineered barriers and waste forms are consistent with the abstractions of “Degradation of Engineered Barriers” (Section 2.2.1.3.1); “Mechanical Disruption of Engineered Barriers (Section 2.2.1.3.2); "Radionuclide Release Rates and Solubility Limits" (Section 2.2.1.3.4); "Climate and Infiltration” (Section 2.2.1.3.5); and "Flow Paths in the Unsaturated Zone” (Section 2.2.1.3.6). The descriptions and technical bases provide transparent and traceable support for the abstraction of quantity and chemistry of water contacting engineered barriers and waste forms;

The MSTHM provides the basis for how long boiling conditions in the host rock adjacent to the drift wall prevent water from seeping into drifts. The MSTHM also determines temperature and relative humidity on the engineered barriers, quantities required for determining in-drift chemistry. The MSTHM has been validated for its intended purpose (Sections 7.1 and 7.2), using the results of field tests (Sections 7.3 and 7.4), and by comparing the MSTHM against an alternative model for the three-drift repository test case (Section 7.5). The magnitude of seepage during the post-boiling period and the chemistry of that seepage are not determined by the MSTHM nor in this report.

(3) Important design features, such as waste package design and material selection, backfill, drip shield, ground support, thermal loading strategy, and degradation processes, are adequate to determine the initial and boundary conditions for calculations of the quantity and chemistry of water contacting engineered barriers and waste forms;

Initial and boundary conditions for the MSTHM calculations of repository performance are based on inputs from other project documents (Section 4.1). Descriptions of design features are documented in IEDs (Section 4.1). Predicted heat-removal efficiency of the ventilation system is documented in Ventilation Model and Analysis Report (BSC 2004 [DIRS 169862]). The rationale for not directly representing ground support in the MSTHM is documented in Sections 5.3.1.10 and 5.3.2.7, and in Appendix VI. These inputs were sufficient to completely define the initial and boundary conditions for the MSTHM calculations.

(4) Spatial and temporal abstractions appropriately address physical couplings (thermalhydrologic-mechanical-chemical). For example, the U.S. Department of Energy 
evaluates the potential for focusing of water flow into drifts, caused by coupled thermal-hydrologic-mechanical-chemical processes;

The physics of coupled thermal-hydrological processes (Sections 6.1 and 6.2) are adequately incorporated into the MSTHM methodology (Section 6.2.4) and its submodels (Sections 6.2.5 through 6.2.11). Sensitivity analyses (Sections 6.3.9) on the influence of hydrologic property variability and uncertainty, demonstrate that the potential impact of mechanical and chemical coupling on the thermal-hydrological response in repository drifts (and in the adjacent host rock) are insignificant, compared to the influences of parametric uncertainty (Sections 6.3.2 and 6.3.4), which are addressed by the MSTHM and this report.

(5) Sufficient technical bases and justification are provided for total system performance assessment assumptions and approximations for modeling coupled thermalhydrologic-mechanical-chemical effects on seepage and flow, the waste package chemical environment, and the chemical environment for radionuclide release. The effects of distribution of flow on the amount of water contacting the engineered barriers and waste forms are consistently addressed, in all relevant abstractions;

The MSTHM addresses repository-scale variability and uncertainty of percolation flux that is based on the output (DTN: LB0302PTNTSW9I.001 [DIRS 162277]) from the UZ Flow Models and Submodels (BSC 2004 [DIRS 169861]). The MSTHM provides the basis for how long boiling conditions in the host rock adjacent to the drift wall prevent water from seeping into drifts. The magnitude of seepage during the post-boiling period and the chemistry of that seepage are not determined by the MSTHM nor in this report. However, the MSTHM determines temperature and relative humidity on the engineered barriers, quantities required for determining in-drift chemistry. The physics of coupled thermal-hydrological processes (Sections 6.1 and 6.2) are adequately incorporated into the MSTHM methodology (Section 6.2.4) and its submodels (Sections 6.2.5 through 6.2.11). Sensitivity analyses (Sections 6.3.9) on the influence of hydrologic property variability and uncertainty, demonstrate that the potential impact of mechanical and chemical coupling on the thermal-hydrological response in repository drifts (and in the adjacent host rock) is insignificant, compared to the influences of parametric uncertainty (Sections 6.3.2 and 6.3.4), which are addressed by the MSTHM and this report.

(6) The expected ranges of environmental conditions within the waste package emplacement drifts, inside the breached waste packages, and contacting the waste forms and their evolution with time are identified. These ranges may be developed to include: (i) the effects of the drip shield and backfill on the quantity and chemistry of waster (e.g., the potential for condensate formation and dripping from the underside of the shield); (ii) conditions that promote corrosion of engineered barriers and degradation of waste forms; (iii) irregular wet and dry cycles; (iv) gamma-radiolysis; and (v) size and distribution of penetrations of engineered barriers;

The MSTHM provides the basis for how long boiling conditions in the host rock adjacent to the drift wall prevent water from seeping into drifts. The magnitude of seepage during the postboiling period and the chemistry of that seepage are not determined by the MSTHM or in this report. However, the MSTHM determines temperature and relative humidity on the engineered barriers, quantities required for determining in-drift chemistry. 
(7) The model abstraction for quantity and chemistry of water contacting engineered barriers and waste forms is consistent with the detailed information on engineered barrier design and other engineered features. For example, consistency is demonstrated for: (i) dimensionality of the abstractions; (ii) various design features and site characteristics; and (iii) alternative conceptual approaches. Analyses are adequate to demonstrate that no deleterious effects are caused by design or site features that the U.S. Department of Energy does not take into account in this abstraction;

The MSTHM accounts for the three-dimensional geometry of the emplacement drift, drip shield, and invert (Section 6.2), including a discrete representation of each emplacement drift (Figure 6.2-3). The MSTHM also addresses the distribution of hydrostratigraphic units (and their respective thermal-hydrologic properties), based on Numerical Grids for UZ Flow and Transport Modeling (BSC 2004 [DIRS 169855]), Calibrated Properties Model (BSC 2004 [DIRS 169857]), Thermal Conductivity of the Potential Repository Horizon (BSC 2004 [DIRS 169854]), Thermal Conductivity of Non-Repository Lithostratigraphic Layers (BSC 2004 [DIRS 170033]), and Heat Capacity Analysis Report (BSC 2004 [DIRS 170003]). The MSTHM also addresses the distribution of percolation flux above the repository, based on UZ Flow Models and Submodels (BSC 2004 [DIRS 169861]).

(8) Adequate technical bases are provided, including activities such as independent modeling, laboratory or field data, or sensitivity studies, for inclusion of any thermalhydrologic-mechanical-chemical couplings and features, events, and processes;

This report lists ten features, events and processes (FEPs) that are included in the MSTHM model (Section 6.5). Table 6.5-1 provides, for each FEP, a cross-reference to the section that describes its disposition. Coupled processes that are not addressed in this report are considered, and their rationale for exclusion or inclusion elsewhere, is presented in Engineered Barrier System Features, Events, And Processes (BSC 2004 [DIRS 169898]).

(9) Performance-affecting processes that have been observed in thermal-hydrologic tests and experiments are included into the performance assessment. For example, the U.S. Department of Energy either demonstrates that liquid water will not reflux into the underground facility or incorporates refluxing water into the performance assessment calculation, and bounds the potential adverse effects of alteration of the hydraulic pathway that result from refluxing water;

The LDTH submodel of the MSTHM has been validated against the Large Block Test (Section 7.3) and the Drift Scale Test (Section 7.4). The LDTH submodel includes the influence of refluxing water in the host rock on the predicted thermal-hydrologic response in the drift and adjacent host rock. However, the LDTH-submodel results have never suggested the possibility of that refluxing water entering the emplacement drifts. Neither the results of the thermal-hydrological model simulations nor the measurements associated with the DST suggest the possibility of refluxing water entering emplacement drifts. Section 8.1 of Drift-Scale Coupled Processes (DST and TH Seepage) Models (BSC 2004 [DIRS 170338]) includes the following key conclusions: 
- For cases where thermal seepage takes place, it is predicted to begin several hundred to a few thousand years after rock temperature has returned below boiling, the delay caused by the slow saturation buildup in fractures; there is no seepage during the time period of above-boiling temperatures in the rock.

- Thermal-seepage percentages are always smaller than the respective ambient reference values, indicating that there is no enhanced seepage as a result of reflux of water.

Based on these conclusions, it is unnecessary to incorporate refluxing water in performance assessment calculations.

(12) Guidance in NUREG-1297 (Altman et al. 1988 [DIRS 103597]) and NUREG-1298 (Altman et al. 1988 [DIRS 103750]), or other acceptable approaches, is followed.

Inputs were selected and documented, and documents were checked and reviewed according to applicable BSC procedures, which comply with NUREG-1297 and 1298 (see Section 2).

\subsubsection{Acceptance Criterion 2 - Data Are Sufficient for Model Justification}

(1) Geological, hydrological, and geochemical values used in the license application are adequately justified. Adequate description of how the data were used, interpreted, and appropriately synthesized into the parameters is provided;

Geological and hydrological parameters and related information are input from Development of Numerical Grids for UZ Flow and Transport Modeling (BSC 2004 [DIRS 169855]), Calibrated Properties Model (BSC 2004 [DIRS 169857]), Analysis of Hydrologic Properties Data (BSC 2004 [DIRS 170038]), Thermal Conductivity of Non-Repository Lithostratigraphic Layers (BSC 2004 [DIRS 170033]), Thermal Conductivity of the Potential Repository Horizon (BSC 2004 [DIRS 169854], Section 4.1), and other justified sources. Descriptions of how the data were used, interpreted, and appropriately synthesized are provided in those documents.

(2) Sufficient data were collected on the characteristics of the natural system and engineered materials to establish initial and boundary conditions for conceptual models of thermal-hydrological-mechanical-chemical coupled processes, that affect seepage and flow and the engineered barrier chemical environment;

Initial and boundary conditions for the MSTHM calculations are documented in Mountain-Scale Coupled Processes (TH/THC/THM) (BSC 2004 [DIRS 169866]) and UZ Flow Models and Submodels (BSC 2004 [DIRS 169861]). Those reports describe the technical basis for establishing the initial and boundary conditions.

(3) Thermo-hydrologic tests were designed and conducted with the explicit objectives of observing thermal-hydrologic processes for the temperature ranges expected for repository conditions and making measurements for mathematical models. Data are sufficient to verify that thermal-hydrologic conceptual models address important thermal-hydrologic phenomena; 
The Large Block Test and the Drift Scale Test provided data for processes in the expected temperature range. These tests were used to validate the conceptual model underlying the LDTH submodels used in the MSTHM (Sections 7.3 and 7.4).

(4) Sufficient information to formulate the conceptual approach(es) for analyzing water contact with the drip shield, engineered barriers, and waste forms is provided.

The MSTHM provides the basis for how long boiling conditions in the host rock adjacent to the drift wall prevents water from seeping into drifts. The magnitude of seepage during the postboiling period and the chemistry of that seepage are not determined by the MSTHM or in this report. However, the MSTHM determines temperature and relative humidity on the engineered barriers, quantities required for determining in-drift chemistry. The MSTHM is validated by comparing predictions from its key thermal-hydrological submodel (called the LDTH submodel) against field test data (Sections 7.3 and 7.4) and by comparing MSTHM predictions with predictions from a monolithic three-dimensional thermal-hydrological model (Section 7.5), which is an alternative model.

\subsubsection{Acceptance Criterion 3-Data Uncertainty Is Characterized and Propagated Through the Model Abstraction}

(1) Models use parameter values, assumed ranges, probability distributions, and bounding assumptions that are technically defensible, reasonably account for uncertainties and variabilities, and do not result in an under-representation of the risk estimate;

The model parameter values were selected based on the characteristics of the input and are considered representative of the natural and engineered systems (Section 4.1). Design information is taken from Interface Exchange Drawings and qualified analyses. Boundary conditions, stratigraphy, and percolation fluxes are from UZ flow models, including uncertainties. Properties of the natural and engineered materials are based on measurements taken and documented in accordance with DOE quality requirements (Section 4.1 and Appendices IV and $\mathrm{X}$ ). When modeling decisions were necessary, the choices were made to preserve the variability of thermal-hydrologic responses (Sections 5.2.1, 5.2.2, and 6.2.1), thereby avoiding an under-representation of the risk estimate.

(2) Parameter values, assumed ranges, probability distributions, and bounding assumptions used in the total system performance assessment calculations of quantity and chemistry of water contacting engineered barriers and waste forms are technically defensible and reasonable, based on data from the Yucca Mountain region (e.g., results from large block and drift-scale heater and niche tests), and a combination of techniques that may include laboratory experiments, field measurements, natural analog research, and process-level modeling studies;

Sufficiently wide ranges of the key natural-system parameters are addressed to reasonably account for uncertainty (Section 6.3), and therefore do not result in an under-representation of the risk estimate. A sensitivity study (Section 6.3.9) justifies the decision not to propagate hydrologic-property uncertainty in the MSTHM. Sensitivity studies (Sections 6.3.10, 6.3.11, and 6.3.12) justify assumptions made in Section 5 concerning engineered-system parameter values. 
(3) Input values used in the total system performance assessment calculations of quantity and chemistry of water contacting engineered barriers (e.g., drip shield and waste package) are consistent with the initial and boundary conditions and the assumptions of the conceptual models and design concepts for the Yucca Mountain site. Correlations between input values are appropriately established in the U.S. Department of Energy total system performance assessment. Parameters used to define initial conditions, boundary conditions, and computational domain in sensitivity analyses involving coupled thermal-hydrologic-mechanical-chemical effects on seepage and flow, the waste package chemical environment, and the chemical environment for radionuclide release, are consistent with available data. Reasonable or conservative ranges of parameters or functional relations are established;

Parameters used to define initial conditions, boundary conditions, and computational domain of the MSTHM are consistent with available data. The MSTHM addresses the distribution of hydrostratigraphic units (and their respective thermal-hydrologic properties), based on Numerical Grids for UZ Flow and Transport Modeling (BSC 2004 [DIRS 169855]), Calibrated Properties Model (BSC 2004 [DIRS 169857]), Thermal Conductivity of the Potential Repository Horizon (BSC 2004 [DIRS 169854]), Thermal Conductivity of Non-Repository Lithostratigraphic Layers (BSC 2004 [DIRS 170033]), and Heat Capacity Analysis Report (BSC 2004 [DIRS 170003]). The MSTHM addresses the distribution of percolation flux above the repository, based on $U Z$ Flow Models and Submodels (BSC 2004 [DIRS 169861]).

(4) Adequate representation of uncertainties in the characteristics of the natural system and engineered materials is provided in parameter development for conceptual models, process-level models, and alternative conceptual models. The U.S. Department of Energy may constrain these uncertainties using sensitivity analyses or conservative limits. For example, the U.S. Department of Energy demonstrates how parameters used to describe flow through the engineered barrier system bound the effects of backfill and excavation-induced changes;

Previous studies have found that uncertainty in calculated thermohydrologic response is dominated by the uncertainty in host-rock thermal conductivity (Section 6.3.2). The sensitivity of thermohydrologic response to host-rock thermal conductivity uncertainty is addressed for plus and minus one standard deviation about the mean value (Section 6.3.2.2). Measurement statistics are used to determine the standard deviation for the wet and dry thermal conductivity values for each of the four host-rock units. Section 6.3.9 demonstrates that host-rock hydrologic property uncertainty has an insignificant influence on the thermal-hydrologic response. Section 6.3.11 demonstrates that invert hydrologic-property uncertainty has an insignificant influence on the thermal-hydrologic response. Sections 5.3.1.10 and 5.3.2.7 justify the assumption that ground support does not need to be incorporated in the MSTHM.

Previous studies have found that the contribution to uncertainty in calculated thermal-hydrologic conditions from the uncertainties in boundary values is dominated by the uncertainty in percolation flux (Section 6.3.2). The uncertainty in percolation flux at the repository horizon is addressed by way of lower-bound, mean, and upper-bound infiltration-flux cases, generated by UZ Flow Models and Submodels (BSC 2004 [DIRS 169861]) for each of three climate states: present-day, monsoonal, and glacial-transition (Section 6.3.2.1). The percolation-flux range 
from lower bound to upper bound for the present-day climate covers five orders of magnitude. Similar ranges apply to the monsoonal and glacial-transition climates.

In summary, the influence of parametric uncertainty of host-rock thermal conductivity and percolation flux on the predicted thermal-hydrologic response, which is represented in the MSTHM, is greater than differences in the predicted thermal-hydrologic response between the MSTHM and alternative conceptual models (Section 7.5).

\subsubsection{Acceptance Criterion 4-Model Uncertainty Is Characterized and Propagated Through the Model Abstraction}

(1) Alternative modeling approaches of features, events, and processes are considered and are consistent with available data and current scientific understanding, and the results and limitations are appropriately considered in the abstraction;

The validation of the MSTHM involved comparison with the results from a three-dimensional monolithic thermal-hydrologic model (Section 7.5), which is an alternative model. The differences in predicted thermal-hydrologic responses between the MSTHM and the alternative model are smaller than differences resulting from parametric uncertainty. Therefore, model uncertainty does not need to be propagated through the model abstraction.

(2) Alternative modeling approaches are considered and the selected modeling approach is consistent with available data and current scientific understanding. A description that includes a discussion of alternative modeling approaches not considered in the final analysis and the limitations and uncertainties of the chosen model is provided;

The validation of the MSTHM involved comparison with the results from a three-dimensional monolithic thermal-hydrologic model (Section 7.5), which is an alternative model. The differences in predicted thermal-hydrologic responses between the MSTHM and the alternative model are smaller than differences resulting from parametric uncertainty. Therefore, model uncertainty does not need to be propagated through the model abstraction. This report also considers a mountain-scale thermal-hydrologic model as an alternative to the MSTHM (Section 6.4). A calculation with the alternative model used (1) coarser grid discretization at the drift scale than the MSTHM, (2) a line-averaged approximation of the heat-generation-rate-versustime table (whereas the MSTHM represented the waste packages as discrete heat sources), and (3) a lumped heat source that filled the entire cross section of the emplacement drift. Because of limitations in the predictions provided from the alternative model, comparison is restricted to predictions of drift-wall temperatures. The differences are within the range of temperature differences resulting from parametric uncertainty. This report also contains a discussion of the limitations of the MSTHM (Section 1) and its uncertainties (Sections 6.3.9 through 6.3.13).

(3) Consideration of conceptual model uncertainty is consistent with available site characterization data, laboratory experiments, field measurements, natural analog information and process-level modeling studies; and the treatment of conceptual model uncertainty does not result in an under-representation of the risk estimate;

Comparison of the MSTHM with data from field tests (Sections 7.3 and 7.4) finds that the model uncertainty is within the range of parameter uncertainty. Comparison between the MSTHM and 
the 3-drift monolithic TH model for the three-drift repository test case (Section 7.5), finds that the model uncertainty is within the range of parameter uncertainty.

(4) Adequate consideration is given to effects of thermal-hydrologic-mechanical-chemical coupled processes in the assessment of alternative conceptual models. These effects may include: (i) thermal-hydrologic effects on gas, water, and mineral chemistry; (ii) effects of microbial processes on the engineered barrier chemical environment and the chemical environment for radionuclide release; (iii) changes in water chemistry that may result from the release of corrosion products from the engineered barriers and interactions between engineered materials and ground water; and (iv) changes in boundary conditions (e.g., drift shape and size) and hydrologic properties, relating to the response of the geomechanical system to thermal loading.

Sensitivity analyses (Sections 6.3.9) on the influence of hydrologic property variability and uncertainty, demonstrate that the potential impact of mechanical and chemical coupling on the thermal-hydrological response in repository drifts (and in the adjacent host rock) are insignificant, compared to the influences of parametric uncertainty (Sections 6.3.2 and 6.3.4), which are addressed by the MSTHM and this report. The influence of drift collapse on thermal-hydrologic response is addressed in Section 6.3.7.

Table 8-1. Data Tracking Numbers Associated with the Output Produced by This Report

\begin{tabular}{|c|c|}
\hline DTN & Title \\
\hline LL030602723122.027 & $\begin{array}{l}\text { Multiscale Thermohydrologic Model Output to TSPA and WAGDEG for Upper } \\
\text { Infiltration Case }\end{array}$ \\
\hline LL030608723122.028 & $\begin{array}{l}\text { Multiscale Thermohydrologic Model Output to TSPA and WAPDEG for the Lower } \\
\text { Infiltration Case }\end{array}$ \\
\hline LL030610323122.029 & $\begin{array}{l}\text { Multiscale Thermohydrologic Model Output to TSPA and WAPDEG for the Mean } \\
\text { Infiltration Case }\end{array}$ \\
\hline LL030704523122.030 & NUFT Input File Data Development to Support LA Multi-Scale Analyses \\
\hline LL030704623122.031 & NUFT Input File Data Development to Support LA Multi-Scale Analyses \\
\hline LL030804023122.034 & $\begin{array}{l}\text { Sensitivity Studies for Evaluating the Impact of Thermal Conductivity and Percolation } \\
\text { Rate on LA Multi-Scale Analyses }\end{array}$ \\
\hline LL030808523122.035 & $\begin{array}{l}\text { Input and Output Files Supporting MSTHM Micro-Abstractions for LA Multi-Scale } \\
\text { Analyses }\end{array}$ \\
\hline LL030808623122.036 & $\begin{array}{l}\text { Input and Output Files for NUFT MSTHM Submodels Supporting LA Multi-Scale } \\
\text { Analyses }\end{array}$ \\
\hline LL030808723122.037 & $\begin{array}{l}\text { Input and Output Files for the Creation of NUFT MSTHM Submodel Input Files } \\
\text { Supporting LA Multi-Scale Analyses }\end{array}$ \\
\hline LL030808823122.038 & $\begin{array}{l}\text { Input and Output Files for Building SMT, SDT, and LDTH Submodel Mesh Files in } \\
\text { Support of LA Multi-Scale Analyses }\end{array}$ \\
\hline LL030808923122.039 & $\begin{array}{l}\text { Input and Output Files Associated with the Large-Block and Drift Scale Tests in } \\
\text { Support of LA Multi-Scale Analyses }\end{array}$ \\
\hline LL030906131032.002 & $\begin{array}{l}\text { Output from the Multi-Scale AMR for the Lower Percolation Mean Thermal } \\
\text { Conductivity Case including Drift Wall Temperatures }\end{array}$ \\
\hline LL040102223122.042 & $\begin{array}{l}\text { Evaluation of the Sensitivity of In-Drift Temperature and Relative Humidity to } \\
\text { Hydrologic-Property Uncertainty }\end{array}$ \\
\hline LL031206723122.041 & $\begin{array}{l}\text { WAPDEG Output from the Multi-Scale AMR for the Mean Percolation Mean Thermal } \\
\text { Conductivity Case including Drift Wall Temperatures }\end{array}$ \\
\hline LL030906531032.005 & $\begin{array}{l}\text { Output from the Multi-Scale AMR for the Upper Percolation Mean Thermal } \\
\text { Conductivity Case including Drift Wall Temperatures }\end{array}$ \\
\hline
\end{tabular}


Table 8-1. Data Tracking Numbers Associated with the Output Produced by This Report (Continued)

\begin{tabular}{|c|c|}
\hline DTN & Title \\
\hline LL030905931032.001 & $\begin{array}{l}\text { Sensitivity Studies for Evaluating the Impact of Thermal Conductivity and Percolation } \\
\text { Rate on LA Multi-Scale Analyses. Lower Percolation Case, Low Thermal } \\
\text { Conductivity in Host Rock }\end{array}$ \\
\hline LL030906331032.004 & $\begin{array}{l}\text { Sensitivity Studies for Evaluating the Impact of Thermal Conductivity and Percolation } \\
\text { Rate on LA Multi-Scale Analyses. Upper Percolation Case, High Thermal } \\
\text { Conductivity in Host Rock }\end{array}$ \\
\hline LL040310323122.044 & $\begin{array}{l}\text { Input and Output files of the MSTHM Micro-Abstractions for the Collapsed-Drift cases } \\
\text { for the TSPA-LA Low-Probability-Seismic Scenario }\end{array}$ \\
\hline LL040404423122.045 & $\begin{array}{l}\text { Input and Output Files of the LDTH-Model Runs for the Focused-Seepage Sensitivity } \\
\text { Analysis for the Collapsed-Drift Cases Conducted in ANL-EBS-MD-000049 Rev } 1 \\
\text { ICN1 }\end{array}$ \\
\hline LL040501323122.046 & $\begin{array}{l}\text { Input and Output Files for the Sensitivity Studies for (1) Host-Rock Hydrologic } \\
\text { Properties, (2) Invert Intragranular Hydrologic Properties, and (3) Rubble Heat } \\
\text { Capacity for the Low-Probability-Seismic, Collapsed-Drift Cases }\end{array}$ \\
\hline LL040604823122.047 & $\begin{array}{l}\text { Input and Output Files for the Creation of NUFT MSTHM Submodel Input Files } \\
\text { Supporting LA Multi-Scale Analyses }\end{array}$ \\
\hline LL040703023122.048 & $\begin{array}{l}\text { Input and Output Files Associated with the Large-Block and Drift Scale Tests in } \\
\text { Support of LA Multi-Scale Analyses }\end{array}$ \\
\hline LL040703123122.049 & $\begin{array}{l}\text { Input and Output Files for the Sensitivity Studies for (1) Invert Intergranular } \\
\text { Hydrologic Properties, (2) Pseudo Permeability of the Gas-Filled Drift Cavity, and (3) } \\
\text { Ventilation Heat-Removal Efficiency }\end{array}$ \\
\hline LL040703223122.050 & $\begin{array}{l}\text { Validation of the Multiscale Thermal-Hydrologic Model Against a Corresponding } \\
\text { Three-Dimensional Monolithic Thermal-Hydrologic Model }\end{array}$ \\
\hline LL040704323122.051 & $\begin{array}{l}\text { Input and Output Files for the Comparison Study of Initial Liquid-Phase Saturation } \\
\text { and Capillary Pressure for the Mean and Modified-Mean Infiltration-Flux Property } \\
\text { Sets for the Lower-Bound, Mean, and Upper-Bound Infiltration-Flux Cases }\end{array}$ \\
\hline MO0307SPAVGSUM.000 & van Genuchten hydrologic parameters \\
\hline MO0406CDFINSMT.000 & $\begin{array}{l}\text { Area Weighted Cumulative Distribution Function (CDF) for PTN/TSW Infiltration } \\
\text { Rates Within SMT Area }\end{array}$ \\
\hline
\end{tabular}




\section{INTENTIONALLY LEFT BLANK}




\section{INPUTS AND REFERENCES}

\subsection{DOCUMENTS CITED}

Altman, W.D.; Donnelly, J.P.; and Kennedy, J.E. 1988. Qualification of Existing

103750

Data for High-Level Nuclear Waste Repositories: Generic Technical Position.

NUREG-1298. Washington, D.C.: U.S. Nuclear Regulatory Commission.

TIC: 200652.

Altman, W.D.; Donnelly, J.P.; and Kennedy, J.E. 1988. Peer Review for High-

103597

Level Nuclear Waste Repositories: Generic Technical Position. NUREG-1297.

Washington, D.C.: U.S. Nuclear Regulatory Commission. TIC: 200651.

Bandurraga, T.M. and Bodvarsson, G.S. 1999. “Calibrating Hydrogeologic

103949

Parameters for the 3-D Site-Scale Unsaturated Zone Model of Yucca Mountain, Nevada.” Journal of Contaminant Hydrology, 38, (1-3), 25-46. New York, New York: Elsevier. TIC: 244160.

Bear, J. 1972. Dynamics of Fluids in Porous Media. Environmental Science

Series. Biswas, A.K., ed. New York, New York: Elsevier. TIC: 217356.

Bird, R.B.; Stewart, W.E.; and Lightfoot, E.N. 1960. Transport Phenomena.

New York, New York: John Wiley \& Sons. TIC: 208957.

Brooks, R.H. and Corey, A.T. 1964. Hydraulic Properties of Porous Media. Hydrology Paper No. 3. Fort Collins, Colorado: Colorado State University. TIC: 217453.

BSC 2001. FY 01 Supplemental Science and Performance Analyses, Volume 1:

155950

Scientific Bases and Analyses. TDR-MGR-MD-000007 REV 00 ICN 01. Las

Vegas, Nevada: Bechtel SAIC Company. ACC: MOL.20010801.0404;

MOL.20010712.0062; MOL.20010815.0001.

BSC 2001. Multiscale Thermohydrologic Model. ANL-EBS-MD-000049 REV

158204 00 ICN 02. Las Vegas, Nevada: Bechtel SAIC Company.

ACC: MOL.20020123.0279.

BSC 2001. Thermal Tests Thermal-Hydrological Analyses/Model Report. ANL157330 NBS-TH-000001 REV 00 ICN 02. Las Vegas, Nevada: Bechtel SAIC Company. ACC: MOL.20011116.0025.

BSC 2002. The Enhanced Plan for Features, Events, and Processes (FEPs) at Yucca Mountain. TDR-WIS-PA-000005 REV 00. Las Vegas, Nevada: Bechtel SAIC Company. ACC: MOL.20020417.0385. 
BSC 2002. Guidelines for Developing and Documenting Alternative Conceptual

158794 Models, Model Abstractions, and Parameter Uncertainty in the Total System Performance Assessment for the License Application. TDR-WIS-PA-000008 REV 00, ICN 01. Las Vegas, Nevada: Bechtel SAIC Company.

ACC: MOL.20020904.0002.

BSC 2003. Advection Versus Diffusion in the Invert. ANL-EBS-MD-000063.

Las Vegas, Nevada: Bechtel SAIC Company. ACC: DOC.20040217.0004.

BSC 2003. Analysis of Infiltration Uncertainty. ANL-NBS-HS-000027 REV 01. Las Vegas, Nevada: Bechtel SAIC Company. ACC: DOC.20031030.0003.

BSC 2003. Design and Engineering, D\&E/PA/C IED Typical Waste Package Components Assembly 1 of 9. 800-IED-WIS0-00201-000-00C. Las Vegas, Nevada: Bechtel SAIC Company. ACC: ENG.20030917.0002.

BSC 2003. Interlocking Drip Shield. 000-MW0-TED0-00102-000-00A. Las Vegas, Nevada: Bechtel SAIC Company. ACC: ENG.20030205.0002.

BSC 2003. Longevity of Emplacement Drift Ground Support Materials for LA. 800-K0C-TEG0-01200-000-00A. Las Vegas, Nevada: Bechtel SAIC Company. ACC: ENG.20030922.0004.

BSC 2003. Repository Design Project, Repository/PA IED Emplacement Drift Committed Materials (2). 800-IED-WIS0-00302-000-00A. Las Vegas, Nevada: Bechtel SAIC Company. ACC: ENG.20030627.0004.

BSC 2003. Repository Design, Repository/PA IED Subsurface Facilities. 800161727 IED-EBS0-00402-000-00B. Las Vegas, Nevada: Bechtel SAIC Company. ACC: MOL.20030109.0146.

BSC 2004. Abstraction of Drift Seepage. MDL-NBS-HS-000019, Rev. 01. Las 169131 Vegas, Nevada: Bechtel SAIC Company.

BSC 2004. Analysis of Hydrologic Properties Data. ANL-NBS-HS-000042, 170038 Rev. 00. Las Vegas, Nevada: Bechtel SAIC Company.

BSC 2004. Calibrated Properties Model. MDL-NBS-HS-000003, Rev. 02. Las 169857 Vegas, Nevada: Bechtel SAIC Company.

BSC 2004. D\&E / PA/C IED Emplacement Drift Configuration. 800-IED167040 MGR0-00201-000-00A. Las Vegas, Nevada: Bechtel SAIC Company. ACC: ENG.20040113.0011.

BSC 2004. D\&E / PA/C IED Emplacement Drift Configuration and 168489 Environment. 800-IED-MGR0-00201-000-00B. Las Vegas, Nevada: Bechtel SAIC Company. ACC: ENG.20040326.0001. 
BSC 2004. D\&E / PA/C IED Interlocking Drip Shield and Emplacement Pallet. 169220 800-IED-WIS0-00401-000-00D. Las Vegas, Nevada: Bechtel SAIC Company. ACC: ENG.20040503.0018.

BSC 2004. D\&E / PA/C IED Subsurface Facilities. 800-IED-WIS0-00101-000-

164519 00A. Las Vegas, Nevada: Bechtel SAIC Company.

ACC: ENG.20040309.0026.

BSC 2004. D\&E / PA/C IED Subsurface Facilities. 800-IED-WIS0-00102-00000A. Las Vegas, Nevada: Bechtel SAIC Company.

ACC: ENG.20040309.0027.

BSC 2004. D\&E / PA/C IED Typical Waste Package Components Assembly. 167754 800-IED-WIS0-00203-000-00B. Las Vegas, Nevada: Bechtel SAIC Company. ACC: ENG.20040202.0011.

BSC 2004. D\&E / PA/C IED Typical Waste Package Components Assembly. 167369 800-IED-WIS0-00204-000-00B. Las Vegas, Nevada: Bechtel SAIC Company. ACC: ENG.20040202.0012.

BSC 2004. D\&E / PA/C IED Typical Waste Package Components Assembly. 800-IED-WIS0-00205-000-00D. Las Vegas, Nevada: Bechtel SAIC Company. ACC: ENG.20040518.0001.

BSC 2004. D\&E/PA/C IED Typical Waste Package Components Assembly. 800169472 IED-WIS0-00202-000-00C. Las Vegas, Nevada: Bechtel SAIC Company. ACC: ENG.20040517.0008.

BSC 2004. Data Qualification Plan, Qualification of DTN: MO0304MWDALACV.000 for Use in ANL-EBS-MD-000049 Rev02. Las Vegas, Nevada: Bechtel SAIC Company. ACC: MOL.20040722.0266.

BSC 2004. Design and Engineering, Interlocking Drip Shield Configuration. 168067 000-M00-SSE0-00102-000-00B. Las Vegas, Nevada: Bechtel SAIC Company. ACC: ENG.20040305.0021.

BSC 2004. Development of Numerical Grids for UZ Flow and Transport 169855 Modeling. ANL-NBS-HS-000015 REV 02. Las Vegas, Nevada: Bechtel SAIC Company. ACC: DOC.20040901.0001.

BSC 2004. Drift Degradation Analysis. ANL-EBS-MD-000027 REV. 03. Las 166107 Vegas, Nevada: Bechtel SAIC Company. ACC: MOL.20040915.0010.

BSC 2004. Drift-Scale Coupled Processes (DST and TH Seepage) Models. 170338 MDL-NBS-HS-000015, Rev. 01. Las Vegas, Nevada: Bechtel SAIC Company. ACC: DOC.20040930.0003. 
BSC 2004. Drift Scale THM Model. MDL-NBS-HS-000017, Rev. 01. Las

169864

Vegas, Nevada: Bechtel SAIC Company.

BSC 2004. Engineered Barrier System Features, Events, and Processes. ANL-

169898

WIS-PA-000002, Rev. 03. Las Vegas, Nevada: Bechtel SAIC Company.

BSC 2004. Evaluation of Features, Events, and Processes (FEP) for the

169826

Biosphere Model. ANL-MGR-MD-000011 Rev. 04. Las Vegas, Nevada:

Bechtel SAIC Company.

BSC 2004. Future Climate Analysis. ANL-NBS-GS-000008 REV 01. Las

Vegas, Nevada: Bechtel SAIC Company. ACC: DOC.20040908.0005.

BSC 2004. Ground Control for Emplacement Drifts for LA. 800-K0C-SSE0-

170292

00100-000-00A. Las Vegas, Nevada: Bechtel SAIC Company.

ACC: ENG.20040712.0019.

BSC 2004. Heat Capacity Analysis Report. ANL-NBS-GS-000013, Rev. 01.

Las Vegas, Nevada: Bechtel SAIC Company.

BSC 2004. In-Drift Natural Convection and Condensation. MDL-EBS-MD-

000001, Rev. 00. Las Vegas, Nevada: Bechtel SAIC Company.

BSC 2004. Mountain-Scale Coupled Processes (TH/THC/THM). MDL-NBS-

HS-000007 REV 02. Las Vegas, Nevada: Bechtel SAIC Company.

BSC 2004. Q-List. 000-30R-MGR0-00500-000-000 REV 00. Las Vegas,

168361

Nevada: Bechtel SAIC Company. ACC: ENG.20040721.0007.

BSC 2004. Repository Subsurface Emplacement Drifts Steel Invert Structure

169503

Plan \& Elevation. 800-SS0-SSE0-00101-000-00B. Las Vegas, Nevada: Bechtel

SAIC Company. ACC: ENG.20040520.0004.

BSC 2004. Technical Work Plan For: Near-Field Environment and Transport In-Drift Heat and Mass Transfer Model and Analysis Reports Integration. TWPMGR-PA-000018 REV 01. Las Vegas, Nevada: Bechtel SAIC Company.

ACC: DOC.20040729.0006.

BSC 2004. Thermal Conductivity of Non-Repository Lithostratigraphic Layers.

170033

MDL-NBS-GS-000006, Rev. 01. Las Vegas, Nevada: Bechtel SAIC Company.

BSC 2004. Thermal Conductivity of the Potential Repository Horizon. MDLNBS-GS-000005 REV 01. Las Vegas, Nevada: Bechtel SAIC Company.

ACC: DOC.20040928.0006.

BSC 2004. Total System Performance Assessment (TSPA) Model/Analysis for the 168504 License Application. MDL-WIS-PA-000004, Rev. 00. Las Vegas, Nevada: Bechtel SAIC Company. 
BSC 2004. UZ Flow Models and Submodels. MDL-NBS-HS-000006, Rev. 02.

169861

Las Vegas, Nevada: Bechtel SAIC Company.

BSC 2004. Ventilation Model and Analysis Report. ANL-EBS-MD-000030,

169862

Rev. 04. Las Vegas, Nevada: Bechtel SAIC Company.

Buscheck, T.A. 1999. Thermohydrologic Calculations for the Site

130078

Recommendation/License Application Design Selection, Phase 2. UCRL-ID133988. BB0000000-01717-0210-00009 REV 00. Livermore, California:

Lawrence Livermore National Laboratory. ACC: MOL.20000606.0193.

Buscheck, T.A. and Nitao, J.J. 1994. The Impact of Buoyant, Gas-Phase Flow

130561 and Heterogeneity on Thermo-Hydrological Behavior at Yucca Mountain. UCRL-JC-115351. Livermore, California: Lawrence Livermore National Laboratory. ACC: NNA.19940524.0012.

Buscheck, T.A. and Nitao, J.J. 1995. Thermal-Hydrological Analysis of Large-Scale Thermal Tests in the Exploratory Studies Facility at Yucca Mountain. UCRL-ID-121791. Livermore, California: Lawrence Livermore National Laboratory. ACC: MOL.19960501.0392.

Buscheck, T.A.; Gansemer, J.; DeLorenzo, T.H.; Nitao, J.J.; and Shaffer, R.J. 1998. Multiscale Thermohydrologic Model Sensitivity Analysis. UCRL-ID131489. Livermore, California: Lawrence Livermore National Laboratory. ACC: MOL.19980901.0245.

Buscheck, T.A.; Gansemer, J.; Nitao, J.J.; and Delorenzo, T.H. 1999. "Multi145972 Scale Near-Field Thermohydrologic Analysis of Alternative Designs for the Potential Repository at Yucca Mountain.” Scientific Basis for Nuclear Waste Management XXII, Symposium held November 30-December 4, 1998, Boston, Massachusetts, U.S.A. Wronkiewicz, D.J. and Lee, J.H., eds. 556, 615-622. Warrendale, Pennsylvania: Materials Research Society. TIC: 246426.

Buscheck, T.A.; Glascoe, L.G.; Lee, K.H.; Gansemer, J.; Sun, Y.; and Mansoor, K. 2003. "Validation of the Multiscale Thermohydrologic Model Used for Analysis of a Proposed Repository at Yucca Mountain.” Journal of Contaminant Hydrology, 62-63, 421-440. New York, New York: Elsevier. TIC: 254205.

Buscheck, T.A.; Rosenberg, N.D.; Gansemer, J.; and Sun, Y. 2002. 160749 "Thermohydrologic Behavior at an Underground Nuclear Waste Repository." Water Resources Research, 38, (3), 10-1 through 10-19. Washington, D.C.: American Geophysical Union. TIC: 253566.

Canori, G.F. and Leitner, M.M. 2003. Project Requirements Document. TER166275 MGR-MD-000001 REV 02. Las Vegas, Nevada: Bechtel SAIC Company. ACC: DOC.20031222.0006. 
Cho, Y.I.; Ganic, E.N.; Hartnett, J.P.; and Rohsenow, W.M. 1998. "Basic

160802

Concepts of Heat Transfer." Chapter 1 of Handbook of Heat Transfer. 3rd

Edition. Rohsenow, W.M.; Hartnett, J.P.; and Cho, Y.I., eds. New York, New

York: McGraw-Hill. TIC: 253612.

Crane, R.A.; Vachon, R.I.; and Khader, M.S. 1977. "Thermal Conductivity of

113426

Granular Materials - A Review.” Proceedings of the Seventh Symposium on

Thermophysical Properties, held at National Bureau of Standards, Gaithersburg, Maryland, May 10-12, 1977. Cezairliyan, A., ed. Pages 109-123. New York, New York: American Society of Mechanical Engineers. TIC: 246057.

CRWMS (Civilian Radioactive Waste Management System) M\&O (Management 111115 and Operating Contractor) 1998. Drift Scale Test As-Built Report. BAB00000001717-5700-00003 REV 01. Las Vegas, Nevada: CRWMS M\&O.

ACC: MOL.19990107.0223.

CRWMS M\&O 1998. Total System Performance Assessment-Viability

108000

Assessment (TSPA-VA) Analyses Technical Basis Document. Las Vegas, Nevada: CRWMS M\&O. ACC: MOL.19981008.0001; MOL.19981008.0002;

MOL.19981008.0003; MOL.19981008.0004; MOL.19981008.0005;

MOL.19981008.0006; MOL.19981008.0007; MOL.19981008.0008;

MOL.19981008.0009; MOL.19981008.0010; MOL.19981008.0011.

CRWMS M\&O 2000. Thermal Tests Thermal-Hydrological Analyses/Model

146921

Report. ANL-NBS-TH-000001 REV 00. Las Vegas, Nevada: CRWMS M\&O.

ACC: MOL.20000505.0231.

CRWMS M\&O 2000. Total System Performance Assessment for the Site

Recommendation. TDR-WIS-PA-000001 REV 00 ICN 01. Las Vegas, Nevada:

CRWMS M\&O. ACC: MOL.20001220.0045.

CRWMS M\&O 2001. Effective Thermal Conductivity for Drift-Scale Models

153410

Used in TSPA-SR. CAL-EBS-HS-000001 REV 00. Las Vegas, Nevada:

CRWMS M\&O. ACC: MOL.20010301.0252.

de Marsily, G. 1986. Quantitative Hydrogeology: Groundwater Hydrology for

100439

Engineers. San Diego, California: Academic Press. TIC: 208450.

DOE (U.S. Department of Energy) 2004. Quality Assurance Requirements and

Description. DOE/RW-0333P, Rev. 16. Washington, D.C.: U.S. Department of Energy, Office of Civilian Radioactive Waste Management.

ACC: DOC.20040907.0002.

Fetter, C.W. 1993. Contaminant Hydrogeology. Upper Saddle River, New

102009 Jersey: Prentice Hall. TIC: 240691. 
Flint, A.L.; Flint, L.E.; Bodvarsson, G.S.; Kwicklis, E.M.; and Fabryka-Martin, J. 2001. "Evolution of the Conceptual Model of Unsaturated Zone Hydrology at Yucca Mountain, Nevada.” Journal of Hydrology, 247, ([1-2]), 1-30. New York, New York: Elsevier. TIC: 250932.

Francis, N.D., Jr.; Webb, S.W.; Itamura, M.T.; and James, D.L. 2003. CFD 164602 Modeling of Natural Convection Heat Transfer and Fluid Flow in Yucca Mountain Project (YMP) Enclosures. SAND2002-4179. Albuquerque, New Mexico: Sandia National Laboratories. ACC: MOL.20030906.0165.

Freeze, G.A.; Brodsky, N.S.; and Swift, P.N. 2001. The Development of 154365 Information Catalogued in REV00 of the YMP FEP Database. TDR-WIS-MD000003 REV 00 ICN 01. Las Vegas, Nevada: Bechtel SAIC Company. ACC: MOL.20010301.0237.

Freeze, R.A. and Cherry, J.A. 1979. Groundwater. Englewood Cliffs, New 101173 Jersey: Prentice-Hall. TIC: 217571.

Hardin, E.L. 1998. Near-Field/Altered-Zone Models Report. UCRL-ID-129179 100350 DR. Livermore, California: Lawrence Livermore National Laboratory. ACC: MOL.19980504.0577.

Haukwa, C.; Wu, Y.S.; Hinds, J.J.; Zhang, W.; Ritcey, A.C.; Pan, L.H.; Simmons, 117826 A.M.; and Bodvarsson, G.S. 1998. Results of Sensitivity Studies of ThermoHydrologic Behavior Conducted on Hydrologic Parameter Sets. Milestone SP3CK5M4. Berkeley, California: Lawrence Berkeley National Laboratory. ACC: MOL.19980918.0001.

Hilf, J.W. 1975. “Compacted Fill.” Chapter 7 of Foundation Engineering 169699 Handbook. Winterkorn, H.F. and Fang, H.-Y., eds. New York, New York: Van Nostrand Reinhold. TIC: 248400.

Hillel, D. 1998. Environmental Soil Physics. San Diego, California: Academic Press. TIC: 254422.

Holman, J.P. 1990. Heat Transfer. 7th Edition. New York, New York:

106052 McGraw-Hill. TIC: 242477.

Incropera, F.P. and DeWitt, D.P. 1996. Fundamentals of Heat and Mass 108184 Transfer. 4th Edition. New York, New York: John Wiley \& Sons. TIC: 243950.

Incropera, F.P. and DeWitt, D.P. 2002. Fundamentals of Heat and Mass 163337 Transfer. 5th Edition. New York, New York: John Wiley \& Sons.

TIC: 254280. 
Irvine, T.F., Jr. 1998. “Thermophysical Properties.” Chapter 2 of Handbook of

170361

Heat Transfer. 3rd Edition. Rohsenow, W.M.; Hartnett, J.P.; and Cho, Y.I., eds.

New York, New York: McGraw-Hill. TIC: 253612.

Jury, W.A.; Gardner, W.R.; and Gardner, W.H. 1991. Soil Physics. 5th Edition.

102010

New York, New York: John Wiley \& Sons. TIC: 241000.

Kaviany, M. 1998. “Heat Transfer in Porous Media.” Chapter 9 of Handbook of 170520 Heat Transfer. 3rd Edition. Rohsenow, W.M.; Hartnett, J.P.; and Cho, Y.I., eds. New York, New York: McGraw-Hill. TIC: 253612.

Keenan, J.H.; Keyes, F.G.; Hill, P.G.; and Moore, J.G. 1969. Steam Tables, Thermodynamic Properties of Water Including Vapor, Liquid, and Solid Phases (English Units). New York, New York: John Wiley \& Sons. TIC: 246766.

Knudsen, J.G.; Bell, K.J.; Holt, A.D.; Hottel, H.C.; Sarofim, A.F.; Standiford, F.C.; Stuhlbarg, D.; and Uhl, V.W. 1984. "Heat Transmission.” Section 10 of Perry's Chemical Engineers' Handbook. 6th Edition. Perry, R.H.; Green, D.W.; and Maloney, J.O., eds. New York, New York: McGraw-Hill. TIC: 246473.

Kunii, D. and Smith, J.M. 1960. "Heat Transfer Characteristics of Porous 153166 Rocks.” American Institute of Chemical Engineers Journal, 6, (1), 71-78. New York, New York: American Institute of Chemical Engineers. TIC: 249321.

Leverett, M.C. 1941. "Capillary Behavior in Porous Solids.” AIME

100588

Transactions, Petroleum Development and Technology, Tulsa Meeting, October 1940. 142, 152-169. New York, New York: American Institute of Mining and Metallurgical Engineers. TIC: 240680.

Lichtner, P.C. and Walton, J.C. 1994. Near-Field Liquid-Vapor Transport in a Partially Saturated High-Level Nuclear Waste Repository. CNWRA 94-022. San Antonio, Texas: Center for Nuclear Waste Regulatory Analyses.

TIC: 216007.

Lide, D.R., ed. 1995. CRC Handbook of Chemistry and Physics. 76th Edition. Boca Raton, Florida: CRC Press. TIC: 216194.

Liley, P.E.; Reid, R.C.; and Buck, E. 1984. "Physical and Chemical Data." Section 3 of Perry's Chemical Engineers' Handbook. 6th Edition. Perry, R.H.; Green, D.W.; and Maloney, J.O., eds. New York, New York: McGraw-Hill. TIC: 246473.

Liu, H.H.; Doughty, C.; and Bodvarsson, G.S. 1998. "An Active Fracture Model 105729 for Unsaturated Flow and Transport in Fractured Rocks.” Water Resources Research, 34, (10), 2633-2646. Washington, D.C.: American Geophysical Union. TIC: 243012. 
LLNL (Lawrence Livermore National Laboratory) 2000. Validation Test Plan,

The Prediction of Thermohydrologic Behavior-NUFT 3.0.1s. Document

Number: 10130-VTP-3.0.1s-00. North Las Vegas, Nevada: U.S. Department of Energy, Yucca Mountain Site Characterization Office.

ACC: MOL.20010905.0180.

LLNL (Lawrence Livermore National Laboratory) 2002. Validation Test Plan,

The Prediction of Thermohydrologic Behavior-NUFT 3.0s, Rev 02. Software

Document Number: 10088-VTP-3.0s-02. North Las Vegas, Nevada: U.S.

Department of Energy, Yucca Mountain Site Characterization Office.

ACC: MOL.20031024.0397.

Manteufel, R.D.; Ahola, M.P.; Turner, D.R.; and Chowdhury, A.H. 1993. A

100776

Literature Review of Coupled Thermal-Hydrologic-Mechanical-Chemical

Processes Pertinent to the Proposed High-Level Nuclear Waste Repository at

Yucca Mountain. NUREG/CR-6021. Washington, D.C.: U.S. Nuclear

Regulatory Commission. TIC: 207771.

McAdams, W.H. 1954. Heat Transmission. 3rd Edition. New York, New York:

161435

McGraw-Hill. TIC: 242359.

Michel, H. 1999. “Bernold Sheets.” Letter from H. Michel (Bernold AG) to M.

Grigore (MK), July 2, 1999, with enclosures. ACC: MOL.20030506.0321.

Montazer, P. and Wilson, W.E. 1984. Conceptual Hydrologic Model of Flow in

100161 the Unsaturated Zone, Yucca Mountain, Nevada. Water-Resources Investigations Report 84-4345. Lakewood, Colorado: U.S. Geological Survey.

ACC: NNA.19890327.0051.

Mualem, Y. 1976. “A New Model for Predicting the Hydraulic Conductivity of

100599

Unsaturated Porous Media.” Water Resources Research, 12, (3), 513-522.

Washington, D.C.: American Geophysical Union. TIC: 217339.

Nitao, J.J. 1998. Reference Manual for the NUFT Flow and Transport Code, Version 2.0. UCRL-MA-130651. Livermore, California: Lawrence Livermore National Laboratory. ACC: MOL.19980810.0391.

Nitao, J.J. 2000. Documentation of the Thermal Energy Balance Equation Used 159883 in the USNT Module of the NUFT Flow and Transport Code. UCRL-ID-139836. Livermore, California: Lawrence Livermore National Laboratory.

ACC: MOL.20020711.0161.

NRC (U.S. Nuclear Regulatory Commission) 2003. Yucca Mountain Review Plan, Final Report. NUREG-1804, Rev. 2. Washington, D.C.: U.S. Nuclear Regulatory Commission, Office of Nuclear Material Safety and Safeguards. TIC: 254568. 
Perry, R.H.; Green, D.W.; and Maloney, J.O., eds. 1984. Perry's Chemical

Engineers' Handbook. 6th Edition. New York, New York: McGraw-Hill.

TIC: 246473.

Pollock, D.W. 1986. “Simulation of Fluid Flow and Energy Transport Processes

164747

Associated with High-Level Radioactive Waste Disposal in Unsaturated

Alluvium.” Water Resources Research, 22, (5), 765-775. Washington, D.C.:

American Geophysical Union. TIC: 253791.

Pruess, K.; Oldenburg, C.; and Moridis, G. 1999. TOUGH2 User's Guide,

160778

Version 2.0. LBNL-43134. Berkeley, California: Lawrence Berkeley National

Laboratory. TIC: 253038.

van Genuchten, M.T. 1980. “A Closed-Form Equation for Predicting the 100610 Hydraulic Conductivity of Unsaturated Soils.” Soil Science Society of America Journal, 44, (5), 892-898. Madison, Wisconsin: Soil Science Society of America. TIC: 217327.

Winterkorn, H.F. and Fang, H.-Y. 1975. "Soil Technology and Engineering 169700 Properties of Soils.” Chapter 2 of Foundation Engineering Handbook. Winterkorn, H.F. and Fang, H.-Y., eds. New York, New York: Van Nostrand Reinhold. TIC: 248400.

Yagi, S. and Kunii, D. 1957. "Studies on Effective Thermal Conductivities in 170330 Packed Beds.” AIChE Journal, 3, (3), 373-381. New York, New York:

American Institute of Chemical Engineers. TIC: 255847.

\subsection{CODES, STANDARDS, REGULATIONS, AND PROCEDURES}

10 CFR 63. Energy: Disposal of High-Level Radioactive Wastes in a Geologic 156605 Repository at Yucca Mountain, Nevada. Readily available.

AP-2.14Q, Rev. 3, ICN 0. Document Review. Washington, D.C.:

U.S. Department of Energy, Office of Civilian Radioactive Waste Management. ACC: DOC.20030827.0018.

AP-2.22Q, Rev. 1, ICN 1. Classification Analyses and Maintenance of the Q-List. Washington, D.C.: U.S. Department of Energy, Office of Civilian Radioactive Waste Management. ACC: DOC.20040714.0002

AP-2.27Q, Rev. 1, ICN 4. Planning for Science Activities. Washington, D.C.: U.S. Department of Energy, Office of Civilian Radioactive Waste Management. ACC: DOC.20040610.0006.

AP-3.15Q, Rev. 4, ICN 5. Managing Technical Product Inputs. Washington, D.C.: U.S. Department of Energy, Office of Civilian Radioactive Waste Management. ACC: DOC.20040812.0004. 
AP-SI.2Q, Rev. 0. Qualification of Level A Developed or Modified Software. Washington, D.C.: U.S. Department of Energy, Office of Civilian Radioactive Waste Management. ACC: MOL.20030113.0150.

AP-SIII.2Q, Rev. 1, ICN 2. Qualification of Unqualified Data. Washington, D.C.: U.S. Department of Energy, Office of Civilian Radioactive Waste Management. ACC: DOC.20040127.0008.

AP-SIII.10Q, Rev. 2, ICN 7. Models. Washington, D.C.: U.S. Department of Energy, Office of Civilian Radioactive Waste Management.

ACC: DOC.20040920.0002.

ASME (American Society of Mechanical Engineers) 1995. “Materials.” Section 108417 II of 1995 ASME Boiler and Pressure Vessel Code. New York, New York: American Society of Mechanical Engineers. TIC: 245287.

ASTM G 1-90 (Reapproved 1999). 1999. Standard Practice for Preparing, 103515 Cleaning, and Evaluating Corrosion Test Specimens. West Conshohocken, Pennsylvania: American Society for Testing and Materials. TIC: 238771.

LP-SI.11Q-BSC, Rev. 0, ICN 1. Software Management. Washington, D.C.: U.S. Department of Energy, Office of Civilian Radioactive Waste Management. ACC: DOC.20041005.0008.

\subsection{SOURCE DATA, LISTED BY DATA TRACKING NUMBER}

GS000308311221.005. Net Infiltration Modeling Results for 3 Climate Scenarios 147613 for FY99. Submittal date: 03/01/2000.

GS000483351030.003. Thermal Properties Measured 12/01/99 to 12/02/99 152932 Using the Thermolink Soil Multimeter and Thermal Properties Sensor on Selected Potential Candidate Backfill Materials Used in the Engineered Barrier System. Submittal date: 11/09/2000.

GS020183351030.001. Uncompacted Bulk Density for Analyses Performed 02/02/00 to 05/23/00 on Potential Backfill Materials Used in the Engineered Barrier System. Submittal date: 01/22/2002.

GS980808312242.015. Water Retention and Unsaturated Hydraulic Conductivity 119916 Measurements for Various Size Fractions of Crushed, Sieved, Welded Tuff Samples Measured Using a Centrifuge. Submittal date: 08/21/1998.

LB0205REVUZPRP.001. Fracture Properties for UZ Model Layers Developed 159525 from Field Data. Submittal date: 05/14/2002.

LB0208UZDSCPLI.002. Drift-Scale Calibrated Property Sets: Lower Infiltration Data Summary. Submittal date: 08/26/2002. 
LB0208UZDSCPMI.002. Drift-Scale Calibrated Property Sets: Mean

161243 Infiltration Data Summary. Submittal date: 08/26/2002.

LB03023DKMGRID.001. UZ 3-D Site Scale Model Grids. Submittal date:

162354 02/26/2003.

LB03023DSSCP9I.001. 3-D Site Scale UZ Flow Field Simulations for 9

163044

Infiltration Scenarios. Submittal date: 02/28/2003.

LB0302PTNTSW9I.001. PTN/TSW Interface Percolation Flux Maps for 9

162277 Infiltration Scenarios. Submittal date: 02/28/2003.

LB0302UZDSCPUI.002. Drift-Scale Calibrated Property Sets: Upper

161787

Infiltration Data Summary. Submittal date: 02/05/2003.

LB0310MTSCLTH3.001. Mountain Scale 3D TH Predictions: Simulations.

170270

Submittal date: 10/21/2003.

LB990701233129.001. 3-D UZ Model Grids for Calculation of Flow Fields for 106785 PA for AMR U0000, "Development of Numerical Grids for UZ Flow and Transport Modeling”. Submittal date: 09/24/1999.

LB990861233129.001. Drift Scale Calibrated 1-D Property Set, FY99.

110226

Submittal date: 08/06/1999.

LB991201233129.001. The Mountain-Scale Thermal-Hydrologic Model 146894 Simulations for AMR U0105, "Mountain-Scale Coupled Processes (TH) Models”. Submittal date: 03/11/2000.

LL020710223142.024. Moisture Content of Rock from Neutron Logging 159551 Activities in the Drift Scale Test (DST): August 1997 through May 2002. Submittal date: 08/20/2002.

LL030709023122.032. Moisture Content of Rock from Neutron Logging Activities in the Drift Scale Test (DST): January 2003 through May 2003. 165701

Submittal date: 07/24/2003.

LL980918904244.074. Temperature, Relative Humidity and Gas Pressure 135872 Results During the Large Block Test FY 98. Submittal date: 09/29/1998.

LL980919304244.075. Neutron Logging Activities at the Large Block Test 145099 (LBT). Submittal date: 09/30/1998.

MO0001SEPDSTPC.000. Drift Scale Test (DST) Temperature, Power, Current, 153836 and Voltage Data for June 1, 1999 through October 31, 1999. Submittal date: 01/12/2000. 
MO0002ABBLSLDS.000. As-Built Borehole Locations and Sensor Locations 147304 for the Drift Scale Test Given in Local (DST) Coordinates. Submittal date: 02/01/2000.

MO0003RIB00071.000. Physical and Chemical Characteristics of Alloy 22.

148850

Submittal date: 03/13/2000.

MO0007SEPDSTPC.001. Drift Scale Test (DST) Temperature, Power, Current, 153707 and Voltage Data for November 1, 1999 through May 31, 2000. Submittal date: 07/13/2000.

MO0012SEPDSTPC.002. Drift Scale Test (DST) Temperature, Power, Current, and Voltage Data for June 1, 2000 through November 30, 2000. Submittal date: $12 / 19 / 2000$.

MO0107SEPDSTPC.003. Drift Scale Test (DST) Temperature, Power, Current, and Voltage Data for December 1, 2000 through May 31, 2001. Submittal date: 07/06/2001.

MO0107TC239938.000. Hastelloy Alloy C-22, the Most Versatile Nickel169995 Chromium-Molybdenum Alloy Available Today with Improved Resistance to Both Uniform and Localized Corrosion as Well as a Variety of Mixed Industrial Chemicals. Submittal date: 07/23/2001.

MO0202SEPDSTTV.001. Drift Scale Test (DST) Temperature, Power, Current, and Voltage Data for June 1, 2001 through January 14, 2002. Submittal date: 02/28/2002.

MO0208SEPDSTTD.001. Drift Scale Test (DST) Temperature Data for January 15, 2002 through June 30, 2002. Submittal date: 08/29/2002.

161767

MO0303SEPDSTTM.000. Drift Scale Test (DST) Temperature Data for July 1, 2002 through December 31, 2002. Submittal date: 03/17/2003.

165698

MO0304MWDALACV.000. ANSYS-LA-Coarse Ventilation. Submittal date: 04/09/2003.

MO0306MWDASLCV.001. ANSYS-LA-Coarse Ventilation. Submittal date: 07/01/2003.

MO0307SEPDST31.000. Drift Scale Test (DST) Temperature Data for 165699 01/01/2003 through 06/30/2003. Submittal date: 07/07/2003.

MO0307SPAUSFPD.000. Brooks and Corey Unsaturated Flow Properties Data. 164436 Submittal date: 07/23/2003.

MO0312SEPQ1997.001. Meteorological Monitoring Data for 1997. Submittal date: $12 / 24 / 2003$. 
MO9807DSTSET01.000. Drift Scale Test (DST) Temperature, Power, Current,

Voltage Data for November 7, 1997 through May 31, 1998. Submittal date:

07/09/1998.

MO9810DSTSET02.000. Drift Scale Test (DST) Temperature, Power, Current,

113662

Voltage Data for June 1 through August 31, 1998. Submittal date: 10/09/1998.

MO98METDATA114.000. Validated Meteorological Data for Ambient Air

165702

Monitoring Report Period 27, January - March 1998. Submittal date:

04/30/1998.

MO98METDATA117.000. Validated Meteorological Data for Ambient Air

165705

Monitoring Report Period 28, April - June 1998. Submittal date: 08/11/1998.

MO98METDATA120.000. Validated Meteorological Data for Ambient Air

165706

Monitoring Report Period 29, July - September 1998. Submittal date:

10/30/1998.

MO9906DSTSET03.000. Drift Scale Test (DST) Temperature, Power, Current,

113673

Voltage Data for September 1, 1998 through May 31, 1999. Submittal date:

06/08/1999.

SN0303T0503102.008. Revised Thermal Conductivity of the Non-Repository

Layers of Yucca Mountain. Submittal date: 03/19/2003.

162401

SN0307T0510902.003. Updated Heat Capacity of Yucca Mountain Stratigraphic

164196

Units. Submittal date: 07/15/2003.

SN0404T0503102.011. Thermal Conductivity of the Potential Repository

169129

Horizon Rev 3. Submittal date: 04/27/2004.

\subsection{OUTPUT DATA, LISTED BY DATA TRACKING NUMBER}

LL030602723122.027. Multiscale Thermohydrologic Model Output to TSPA and WAGDEG for Upper Infiltration Case. Submittal date: 06/25/2003.

LL030608723122.028. Multiscale Thermohydrologic Model Output to TSPA and WAPDEG for the Lower Infiltration Case. Submittal date: 06/27/2003.

LL030610323122.029. Multiscale Thermohydrologic Model Output to TSPA and WAPDEG for the Mean Infiltration Case. Submittal date: 06/27/2003.

LL030704523122.030. NUFT Input File Data Development to Support LA Multi-Scale Analyses. Submittal date: 07/17/2003.

LL030704623122.031. NUFT Input File Data Development to Support LA Multi-Scale Analyses. Submittal date: 07/23/2003. 
LL030804023122.034. Sensitivity Studies for Evaluating the Impact of Thermal Conductivity and Percolation Rate on LA Multi-Scale Analyses. Submittal date: 09/11/2003.

LL030808523122.035. Input and Output Files Supporting MSTHM Micro-Abstractions for LA Multi-Scale Analyses. Submittal date: 09/11/2003.

LL030808623122.036. Input and Output Files for NUFT MSTHM Submodels Supporting LA Multi-Scale Analyses. Submittal date: 09/11/2003.

LL030808723122.037. Input and Output Files for the Creation of NUFT MSTHM Submodel Input Files Supporting LA Multi-Scale Analyses. Submittal date: 09/11/03.

LL030808823122.038. Input and Output Files for Building SMT, SDT, and LDTH Submodel Mesh Files in Support of LA Multi-Scale Analyses. Submittal date: 09/11/03.

LL030808923122.039. Input and Output Files Associated with the Large-Block and Drift Scale Tests in Support of LA Multi-Scale Analyses. Submittal date: 09/11/2003.

LL030906131032.002. Output from the Multi-Scale AMR for the Lower Percolation Mean Thermal Conductivity Case including Drift Wall Temperatures. Submittal date: 09/16/2003.

LL040102223122.042. Evaluation of the Sensitivity of In-Drift Temperature and Relative Humidity to Hydrologic-Property Uncertainty. Submittal date: 01/12/2004.

LL031206723122.041. WAPDEG Output from the Multi-Scale AMR for the Mean Percolation Mean Thermal Conductivity Case including Drift Wall Temperatures. Submittal date: 12/22/2003.

LL030906531032.005. Output from the Multi-Scale AMR for the Upper Percolation Mean Thermal Conductivity Case including Drift Wall Temperatures. Submittal date: 09/16/2003.

LL030905931032.001. Sensitivity Studies for Evaluating the Impact of Thermal Conductivity and Percolation Rate on LA Multi-Scale Analyses. Lower Percolation Case, Low Thermal Conductivity in Host Rock. Submittal date: 09/16/2003.

LL030906331032.004. Sensitivity Studies for Evaluating the Impact of Thermal Conductivity and Percolation Rate on LA Multi-Scale Analyses. Upper Percolation Case, High Thermal Conductivity in Host Rock. Submittal date: 09/16/2003.

LL040310323122.044. Input and Output files of the MSTHM Micro-Abstractions for the Collapsed-Drift cases for the TSPA-LA Low-Probability Seismic Scenario. Submittal date: 03/26/2004.

LL040404423122.045. Input and Output Files of the LDTH-Model Runs for the FocusedSeepage Sensitivity Analysis for the Collapsed-Drift Cases Conducted in ANL-EBS-MD-000049 Rev 1 ICN1. Submittal date: 04/21/2004. 
LL040501323122.046. Input and Output Files for the Sensitivity Studies for (1) Host-Rock Hydrologic Properties, (2) Invert Intragranular Hydrologic Properties, and (3) Rubble Heat Capacity for the Low-Probability-Seismic, Collapsed-Drift Cases. Submittal date: 05/19/2004.

LL040604823122.047. Input and Output Files for the Creation of NUFT MSTHM Submodel Input Files Supporting LA Multi-Scale Analyses. Submittal date: 07/12/2004.

LL040703023122.048. Input and Output Files Associated with the Large-Block and Drift Scale Tests in Support of LA Multi-Scale Analyses. Submittal date: 07/15/2004.

LL040703123122.049. Input and Output Files for the Sensitivity Studies for (1) Invert Intergranular Hydrologic Properties, (2) Pseudo Permeability of the Gas-Filled Drift Cavity, and (3) Ventilation Heat-Removal Efficiency. Submittal date: 07/14/2004.

LL040703223122.050. Validation of the Multiscale Thermal-Hydrologic Model Against a Corresponding Three-Dimensional Monolithic Thermal-Hydrologic Model. Submittal date: 07/14/2004.

LL040704323122.051. Input and Output Files for the Comparison Study of Initial Liquid-Phase Saturation and Capillary Pressure for the Mean and Modified-Mean Infiltration-Flux Property Sets for the Lower-Bound, Mean, and Upper-Bound Infiltration-Flux Cases. Submittal date: 07/16/2004.

MO0307SPAVGSUM.000. van Genuchten hydrologic parameters. Submittal date: 07/26/2003. MO0406CDFINSMT.000. Area Weighted Cumulative Distribution Function (CDF) for PTN/TSW Infiltration Rates Within SMT Area. Submittal date: 07/01/2004.

\subsection{SOFTWARE CODES}

boundary_conditions. V1.0. Sun, Sun OS 5.8. 11042-1.0-00.

164275

Chimney_interpolate. V1.0. Sun, Solaris 8. 11038-1.0-00.

164271

colCen. V1.0. Sun, Solaris 8. 11043-1.0-00.

164279

extractBlocks_EXT. V1.0. Sun, SUN O.S. 5.8. 11040-1.0-00.

164281

heatgen_ventTable_emplace. V1.0. Sun, Solaris 8. 11039-1.0-00.

164276

MSTHAC. V7.0. Sun, SUN O.S. 5.8. 10419-7.0-00.

164274

NUFT. V3.0.1s. Sun, SUN O.S. 5.8. 10130-3.0.1s-01.

166636

NUFT. V3.0s. SUN, Sun O.S. 5.8. 10088-3.0s-02.

164541

RADPRO. V4.0. Sun, SUN O.S. 5.8. 10204-4.0-00.

164273

readsUnits. V1.0. Sun, O.S. 5.5.1. 10602-1.0-00.

164542 
reformat_EXT_to_TSPA. V1.0. Sun, Sun OS 5.8. 11061-1.0-00. 164272

repository_percolation_calculator. V1.0. Sun, SUN O.S. 5.8. 11041-1.0-00. 164280

rme6. v1.2. SUN, SOLARIS 8. 10617-1.2-00. 163892

XTOOL V10.1. V10.1. Sun Ultra10. 10208-10.1-00. 148638

Xw. V1.0. Sun, Solaris 8. 11035-1.0-00. 164278

YMESH. v1.54. SUN, SOLARIS 8. 10172-1.54-00. 163894 


\section{INTENTIONALLY LEFT BLANK}




\section{APPENDIX I}

BUILDING NUFT SUBMODELS 
To build the NUFT submodels, the following 14 steps must be completed:

\section{Step 1 - Reformat the mesh from UZ Flow Models and Submodels (BSC 2004 [DIRS 169861]) using rme6 v1.2.}

The mesh of the three-dimensional site-scale UZ flow model requires some minor modifications in order to be usable as input to YMESH v1.54. Note that the term "World Grid," which is used in the following description, refers to the three-dimensional mountain-scale mesh that is required as input to YMESH v1.54. The software code rme6 v1.2 is used to read the element and vertices files in DTN: LB03023DKMGRID.001 [DIRS 162354] and to then create a single output file (called the World Grid), which contains the three-dimensional mountain-scale mesh in a format that can be read by YMESH v1.54. The software code rme6 v1.2 renames the UZ blocks such that the substring "Ze" in the block name is replaced by "z". Likewise, "VI" is replaced by "v", and all trailing "_" characters are removed.

The three-dimensional mountain-scale mesh (called the World Grid) is built by taking the element/connection and vertices files in DTN: LB03023DKMGRID.001 [DIRS 162354] and reformatting them into a YMESH-readable format using software code rme6 v1.2. Rename "* _" to "*”, rename "*Ze" to "*z", and rename "*VI" to "*v".

software code:

rme6

inputs:

1) Element/connection file (from DTN: LB03023DKMGRID.001 [DIRS 162354]) Grid_LA_3D.mesh

2) Vertices file (from DTN: LB03023DKMGRID.001 [DIRS 162354]) grid2002.grd

output:

1) World Grid

LBL2003-LA-YMESH (DTN: LL030808823122.038)

command line:

rme6 Grid_LA_3D.mesh grid2002.grd LBL2003-LA-YMESH

\section{Step 2 - Expand the reformatted mountain-scale mesh using xw v1.0.}

The three-dimensional mountain-scale mesh (file LBL2003-LA-YMESH, which is called the World Grid) created in the previous step needs to be expanded since it is not large enough to encompass the required SMT submodel mesh. The software code $\mathrm{xw}$ v1.0 reads the three-dimensional mountain-scale mesh (LBL2003-LA-YMESH) and expands it in the easting direction such that the grid begins at 166,000 m easting and ends at 177,000 $\mathrm{m}$ easting in the Nevada Central coordinate system.

software code:

$\mathrm{xW}$ v1.0

inputs: 
LBL2003-LA-YMESH (output from rme6 v1.2)

outputs:

1) Expanded World Grid

LBL2003-LA-YMESH-expand (DTN: LL030808823122.038)

command line:

xw LBL2003-LA-YMESH LBL2003-LA-YMESH-expand (DTN： LL030808823122.038)

\section{Step 3 - Create the SDT, LDTH, DDT submodel “.dat” files.}

The first step in building the NUFT LDTH, SDT, and DDT submodel (also called chimney submodels) input files is to create the files containing the vertical grid dimensions and associated UZ model layers at each LDTH/SDT submodel location. This process begins with a file that gives the easting, northing, and repository elevation in Nevada Central coordinates for each LDTH/SDT submodel location. There are two additional reference files (one for LDTH submodels and one for SDT submodels) that detail how the UZ model layers should be vertically discretized by YMESH v1.54. These files serve as a template for the "dat" files, which are constructed by taking the relevant template (SDT or LDTH) and inserting the Nevada Central coordinates for the specified LDTH/SDT submodel locations. These files are in the format specified by the YMESH v1.54 user's manual for extracting LDTH/SDT submodel (chimneysubmodel) stratigraphies from the expanded World Grid.

inputs:

a. SDT and LDTH submodel inputs:

chimneyLocation.dat (DTN: LL030808823122.038)

Contains name, easting, northing, and repository elevation for each "chimney"

LDTH/SDT submodel location.

b. SDT submodel inputs:

SDT_column_template_2003: Template for the SDT submodel .dat files. The template gives instructions to YMESH v1.54 about how to discretize the grid vertically by defining the vertical gridblock dimensions. This is essentially a complete dat file, except the easting, northing, and repository elevation for each LDTH/SDT submodel (i.e., chimney-submodel) location (e.g., P1R10C5) defined in the file "chimneyLocation.dat" have been inserted (by copying and pasting), which creates ".dat" files for each of the respective SDT submodel locations (DTN: LL030808823122.038).

c. LDTH submodel inputs:

LDTH_column_template_2003: Template for the LDTH .dat files. The template gives instructions to YMESH v1.54 about how to discretize the grid vertically by defining the vertical gridblock dimensions. This is essentially a complete dat file, except the easting, northing, and repository elevation for each chimney-submodel location (e.g., P1R10C5) defined in the file "chimneyLocation.dat" have been inserted (by copying and pasting), which creates ".dat" files for each of the respective LDTH submodel locations (DTN: LL030808823122.038).

Step 4 - Create the SDT, LDTH, DDT submodel “.col” and “.nft" files (software code YMESH v1.54). 
Once the ".dat" files have been created, YMESH v1.54 is used to create the "User Column Description" files that contain the vertical dimensions of the grid, along with the vertical distribution of UZ model layers. This file contains the definition of each gridblock layer including its thickness and material type (i.e., UZ model layer). To create these files, YMESH v1.54 is started and the expanded World Mesh is read. Next, a ".dat" file is opened and a ".col" file is saved by selecting the "User Column Description" save option in the YMESH File/Save menu. This process is repeated at each chimney-submodel location and for each of the SDT, LDTH, and DDT submodels.

The output ".nft" file is a NUFT genmsh table as defined in the NUFT user's manual (Nitao 1998 [DIRS 100474]). To create these files, YMESH v1.54 is started and the expanded World Mesh is read as input (using the "Open data file" command). Next, a ".dat" file is opened and a ".nft" file is saved by selecting the "User NUFT genmsh" save option in the YMESH v1.54 File/Save menu. This process is repeated at each chimney-submodel location and for each of the SDT, LDTH, and DDT submodels.

software code:

YMESH v1.54

inputs:

LBL2003-LA-YMESH-expand (output from xw v1.0) (DTN: LL030808823122.038)

".dat" files for each SDT submodel (chimney-submodel) location

(DTN: LL030808823122.038)

“.dat" files for each LDTH submodel (chimney-submodel) location

(DTN: LL030808823122.038)

outputs:

".col" file for each SDT submodel (chimney-submodel) location

(DTN: LL030808823122.038)

".nft" file for each SDT submodel (chimney-submodel) location

(DTN: LL030808823122.038)

".col" file for each LDTH submodel (chimney-submodel) location

(DTN: LL030808823122.038)

".nft" file for each LDTH submodel (chimney-submodel) location

(DTN: LL030808823122.038)

methodology:

1) Start YMESH v1.54

2) Open data file: World Grid (/LBL2003-LA-YMESH-expand)

3) Open data file: chimney.dat file ("*.dat")

4) Save data file: User NUFT genmsh file ("*.nft")

5) Save data file: User Column Description file (“*.col”)

6) Repeat Substeps 3 to 5 for all chimney-submodel locations and for each of the SDT, LDTH, and DDT submodels.

Step 5 - Create the SDT submodel files. 
Once the ".nft" files have been created for the SDT submodel "chimney-submodel" files (Step 4), the following substeps are carried out. For each chimney-submodel location, two output files are created. The first output file is a ".nft.dkm" file that adds the atm, wt, and wp blocks (for atmosphere, water table boundaries, and waste package, respectively) to the input NUFT gensmsh ".nft" file; this file is used for the SDT submodel runs with repository heating. A second file is also created that is a duplicate of the ".nft.dkm" file except there is no wp block present. The second file is called ".nft.dkm0"; this file is used for the SDT submodel initialization runs that have no repository heating. Note that because the file-naming convention is parallel with that used for the LDTH submodels (discussed below), the suffix "dkm" is used for the SDT submodels, as well as for the LDTH submodels. This naming convention does not mean that the SDT submodels use the DKM.

inputs (DTN: LL030808823122.038)

".nft" file for each SDT submodel (chimney-submodel) location

output files: (DTN: LL030808823122.038)

".nft.dkm" file: adds the atm, wt boundary gridblocks and wp gridblocks to the input ".nft" file for each chimney-submodel location

".nft.dkm0" file: adds the atm and wt blocks to the input ".nft" file for each chimneysubmodel location

\section{Step 6 - Create the LDTH submodel DKM files.}

Once the ".nft" files have been created, the DKM version of these files are created for each LDTH submodel (chimney-submodel) location. There are five output files created for each chimney-submodel location. The input files are modified to include the atmosphere and water table boundary gridblocks, to define the gridblocks within the emplacement drifts that represent the engineered barrier system components (e.g., invert), and to define the matrix and fracture continua. The specific elements added to each of the five types of output files are detailed below. Note that the files with the string " $\mathrm{dkm}$ " are used in the LDTH submodel runs with repository heating. The files with the string "dkm0" are used in the LDTH submodel initialization runs that have no repository heating.

inputs: (DTN: LL030808823122.038)

“.nft” file for each LDTH submodel (chimney-submodel) location

output files (a total of 5: for each chimney-submodel location): (DTN: LL030808823122.038)

"*.nft.msh.dkm0": adds the atm and wt boundary gridblocks to the input ".nft" file

"*.nft.msh.dkm0.f": adds the atm and wt fracture boundary gridblocks to the input ".nft" file. All blocks are prepended with "f-" to represent the fractures.

“*.nft.msh.dkm.f”: adds the atm, wt, drift, wp, invert, and hstrk fracture gridblocks to the input ".nft" file. All blocks are prepended with "f-" to represent the fractures. 
“*.nft.msh.dkm0.m": adds the atm and wt matrix boundary gridblocks to the input .nft file. All blocks are prepended with "m-" to represent the matrix.

“*.nft.msh.dkm.m”: adds the atm, wt, drift, wp, invert, and hstrk matrix gridblocks to the input .nft file. All blocks are prepended with "m-" to represent the matrix.

\section{Step 7 - Create DDT and LDTH submodel thermal-radiation connections.}

Radiative heat transfer is an important component in the DDT and LDTH heat transfer models. To accommodate this mechanism, NUFT requires a list of all thermal-radiation connections between surfaces inside the drifts that are separated by air. Typical thermal-radiation connections are found between the waste package and the drift wall, the waste package and the drip shield, the drip shield and the drift wall, and the drift wall and other drift wall elements. These connections are generated by hand and verified visually using RADPRO v4.0.

\section{Step 8 - Calculate LDTH submodel percolation flux values.}

1. Determine the "raw" percolation flux value for each LDTH submodel (chimneysubmodel) location

The LDTH submodel ".col" files created in Step 4 include the name of the grid column (e.g., g_9) from the three-dimensional site-scale UZ model grid (DTN: LB03023DKMGRID.001 [DIRS 162354]) that a given LDTH submodel resides within. For each of the respective LDTH submodel locations, the identity of the threedimensional site-scale UZ model grid column is recorded; note that this grid column is called the "World Column" by YMESH v1.54). Note that the identity of the World Column is given after the string "WORLD COLUMN" in the LDTH submodel input file. For each LDTH submodel location, the identity of the World Column is used to find the corresponding the present-day-, monsoonal- and glacial-transition-climate PTn-to-TSw percolation fluxes calculated by the three-dimensional site-scale UZ flow model (DTN: LB0302PTNTSW9I.001 [DIRS 162277]). This is repeated for the lower-bound, mean, and upper-bound infiltration flux cases. Note that there are nine percolation flux maps produced by the three-dimensional site-scale UZ flow model, corresponding to the three climate states and three infiltration flux cases.

i. For each LDTH submodel ".col" file generated above, grep for the string "WORLD COLUMN" and record the name of the World Column that the LDTH submodel resides within.

ii. From the three-dimensional site-scale UZ flow model (DTN: LB0302PTNTSW9I.001 [DIRS 162277]) and on the basis of the World Column that a given LDTH submodel resides within, find the PTn-to-TSw percolation flux values for the present-day, monsoonal, and glacial-transition climates and for the lower-bound, mean, and upper-bound infiltration flux cases.

\section{Determine the average percolation flux value for each repository panel}

The software code repository_percolation_calculator v1.0 is used, along with two input files to determine the repository-panel-averaged percolation flux for each 
repository panel (Panels 1, 2E, 2W, 3, and 5 in Figure 6.3-1). The first input file gives the coordinates of the vertices (i.e., corners) of a given repository panel. The second file is one of nine PTn-to-TSw percolation flux maps calculated by the threedimensional site-scale UZ flow model (DTN: LB0302PTNTSW9I.001 [DIRS 162277]). The output from repository_percolation_calculator v1.0 is a file that contains the percolation flux values for each of the World Columns (i.e., grid columns from the three-dimensional site-scale UZ flow model) that fall within the given repository panel footprint. The output file also contains the average percolation flux for that repository panel. This averaged panel flux is a simple arithmetic average of the percolation flux values falling within the repository-panel footprint. Because Panel 1 is relatively small, it was decided to group it with Panel $2 \mathrm{~W}$ and to treat Panels 1 and $2 \mathrm{~W}$ as a contiguous repository panel. Panels $2 \mathrm{E}, 3$, and 5 are treated individually according to the procedure described above.

software code:

repository_percolation_calculator v1.0: given a set of coordinates defining the footprint of a repository panel and a PTn-to-TSw percolation flux map from the three-dimensional site-scale UZ flow model (DTN: LB0302PTNTSW9I.001 [DIRS 162277]), determine which World Columns lie within the polygon and do a simple average of the corresponding percolation values to determine the average panel percolation.

input files: (DTN: LL030808723122.037) frameData1.dat: define the polygon for panel 1 frameData2e.dat: define the polygon for panel $2 \mathrm{E}$ frameData2w.dat:define the polygon for panel $2 \mathrm{~W}$ frameData3.dat: define the polygon for panel 3 frameData5.dat: define the polygon for panel 5

preq_la_ptn.dat: the present-day-climate lower-bound infiltration flux case PTn-to-TSw percolation flux map (DTN: LB0302PTNTSW9I.001 [DIRS 162277]) preq_ma_ptn.dat: the present-day-climate mean infiltration flux case PTn-to-TSw percolation flux map (DTN: LB0302PTNTSW9I.001 [DIRS 162277]) preq_ua_ptn.dat: the present-day-climate upper-bound infiltration flux case PTn-to-TSW percolation flux map (DTN: LB0302PTNTSW9I.001 [DIRS 162277])

monq_la_ptn.dat: the monsoonal-climate lower-bound infiltration flux case PTn-to-TSw percolation flux map (DTN: LB0302PTNTSW9I.001 [DIRS 162277]) monq_ma_ptn.dat: the monsoonal-climate mean infiltration flux case PTn-to-TSw percolation flux map (DTN: LB0302PTNTSW9I.001 [DIRS 162277]) 
monq_ua_ptn.dat: the monsoonal-climate upper-bound infiltration flux case PTn-to-TSw percolation flux map (DTN: LB0302PTNTSW9I.001

[DIRS 162277])

glaq_la_ptn.dat: the glacial-transition-climate lower-bound infiltration flux case PTn-to-TSw percolation flux map

(DTN: LB0302PTNTSW9I.001 [DIRS 162277])

glaq ma ptn.dat: the glacial-transition-climate mean infiltration flux case PTn-to-TSw percolation flux map (DTN: LB0302PTNTSW9I.001) glaq_ua_ptn.dat: the glacial-transition-climate upper-bound infiltration flux case PTn-to-TSw percolation flux map

(DTN: LB0302PTNTSW9I.001 [DIRS 162277])

command line

repository percolation calculator $<$ percolation map $><$ panel outline $>$ $<$ output file $>$

output files: (DTN: LL030808723122.037)

glacial_la_frameData1.dat glacial_la_frameData2e.dat glacial_la_frameData2w.dat glacial_la_frameData3.dat glacial_la_frameData5.dat modern_la_frameData1.dat modern_la_frameData2e.dat modern la frameData2w.dat modern_la_frameData3.dat modern_la_frameData5.dat monsoon_la_frameData1.dat monsoon_la_frameData2e.dat monsoon la frameData2w.dat monsoon_la_frameData3.dat monsoon_la_frameData5.dat

glacial_ma_frameData1.dat glacial_ma_frameData2e.dat glacial_ma_frameData2w.dat glacial_ma_frameData3.dat glacial_ma_frameData5.dat modern_ma_frameData1.dat modern_ma_frameData2e.dat modern ma frameData2w.dat modern_ma_frameData3.dat modern_ma_frameData5.dat monsoon_ma_frameData1.dat monsoon_ma_frameData2e.dat monsoon_ma_frameData $2 w$.dat monsoon_ma_frameData3.dat monsoon_ma_frameData5.dat 


$$
\begin{aligned}
& \text { glacial_ua_frameData1.dat } \\
& \text { glacial_ua_frameData2e.dat } \\
& \text { glacial_ua_frameData2w.dat } \\
& \text { glacial_ua_frameData3.dat } \\
& \text { glacial_ua_frameData5.dat } \\
& \text { modern_ua_frameData1.dat } \\
& \text { modern_ua_frameData2e.dat } \\
& \text { modern_ua_frameData2w.dat } \\
& \text { modern_ua_frameData3.dat } \\
& \text { modern_ua_frameData5.dat } \\
& \text { monsoon_ua_frameData1.dat } \\
& \text { monsoon_ua_frameData2e.dat } \\
& \text { monsoon_ua_frameData2w.dat } \\
& \text { monsoon_ua_frameData3.dat } \\
& \text { monsoon_ua_frameData5.dat }
\end{aligned}
$$

Note: These files contain the PTn-to-TSw percolation flux values falling within a given repository panel footprint and average value for that repository panel.

\section{Calculate panel averages for panels 1 and $2 w$}

Panels 1 and $2 \mathrm{~W}$ are grouped for the purpose of computing the LDTH submodel percolation fluxes. This is an area-weighted average, using the respective areas of Panels 1 and 2W.

\section{Calculate average percolation of all LDTH submodels falling within a repository panel}

A weighted average of the percolation flux values (Substep 2) for all LDTH submodel locations that fall inside of a particular panel footprint is calculated. The weighting factors, found in DTN: LL030808723122.037 (Microsoft Excel spreadsheets: scaled chimney percolation (base PTn) la.xls, scaled chimney percolation (base PTn)_ma.xls, and scaled chimney percolation (base PTn)_ua.xls), are determined by the following simple process. First, each of the SMT gridblocks in a given Panel is assigned to the closest LDTH submodel location. The weighting factors are equal to the number of SMT gridblocks assigned to a given LDTH submodel location divided by the total number of SMT gridblocks in that panel.

\section{Determine the scaled LDTH submodel percolation flux values from the "raw" LDTH submodel “chimney” percolation flux values}

The "raw" LDTH submodel (chimney-submodel) percolation values determined in Step 8, Substep 1 above are scaled so that the average "scaled" percolation flux of all LDTH submodels falling within a given repository panel is the same as the average percolation flux for that panel determined in Step 8, Substep 2 above. First, a simple arithmetic average of the "raw" LDTH submodel percolation flux values is calculated for a given repository panel. Then a scaling factor is computed for that panel, which is 
equal to the average percolation flux for that panel (determined in Step 8, Substep 2 above) divided by the average "raw" percolation flux of all LDTH submodels (determined in Step 8, Substep 4) within that panel. Finally, for each of the LDTH submodels within a repository panel, the "raw" percolation flux values are multiplied by the scaling factor for that panel to obtain the scaled percolation flux values for each of the LDTH submodels. This process is repeated for each repository panel, for each of the three climate states and for each of the three infiltration flux cases. These calculations are performed using Microsoft Excel spreadsheets in DTN: LL030808723122.037:

scaled chimney percolation (base PTn)_la.xls

scaled chimney percolation (base PTn)_ma.xls

scaled chimney percolation (base PTn)_ua.xls

\section{Create scaled SMT submodel repository-gridblock percolation-flux values}

Once the scaled percolation flux values have been calculated for each of the LDTH submodel locations, the corresponding percolation flux values for each of the SMT submodel gridblock locations can be calculated by interpolating the percolation fluxes between each of the LDTH submodel locations. Note that each of the LDTH/SDT submodel locations lies at the centers of SMT submodel repository gridblocks (see Figure 6.2-3). The LDTH and SDT submodel pairs are more or less equally spaced along drifts in the SMT submodel, and are always located at the ends of the emplacement drifts, and typically at one or two other locations along the central portion of the drift. Also, LDTH and SDT submodel pairs are typically located along every fourth drift. It is important to note that the gridblocks representing the emplacement drifts in the SMT submodel are regularly spaced, with $20-\mathrm{m}$ gridblock spacing along each drift and each drift being represented by a gridblock row that is 81$\mathrm{m}$ wide (which represents the drift spacing). Thus, intermediate locations along a drift (between LDTH/SDT submodel locations) can be linearly interpolated simply on the basis of the number of gridblocks separating that particular location from the pair of LDTH/SDT submodel locations that straddle it, and upon which the simple linear interpolation is based. Once the drifts that contain LDTH and SDT submodel pairs have been filled in with interpolated values, the drifts lying between these interpolated drifts can also be interpolated as well. The interpolation methodology interpolates linearly between drifts (north/south) such that the previously interpolated SMT submodel gridblock pairs are the same distance from the ventilation inlet as the target SMT submodel gridblock location. Again, because of the uniform gridblock spacing, the interpolation process is simply based upon the number of drifts between the drift for which the interpolation is being conducted and the previously interpolated emplacement drifts (which contain the LDTH-SDT submodel locations) that straddle the target drift.

Step 9 - Determine the identity of the world column (from the three-dimensional site-scale UZ flow model) for each LDTH-SDT submodel pair. 
The ".col" files created in Step 4 include the name of the world column into which an LDTH/SDT submodel pair falls. These world column names are recorded from the ".col" files for the LDTH and SDT submodels.

\section{Step 10 - Compute SMT, SDT, and LDTH submodel boundary conditions.}

The software code boundary_conditions v1.0 generates upper and lower boundary conditions for the LDTH, SMT, and SDT submodels of the MSTHM. The boundary conditions are derived from the three-dimensional site-scale UZ flow model. Data are extracted from the three-dimensional site-scale UZ flow model grid (DTN: LB03023DKMGRID.001 [DIRS 162354]) and from a file (DTN: LB991201233129.001 [DIRS 146894]) containing boundary conditions at the ground surface and at an elevation of $730 \mathrm{~m}$, which was the location of the (horizontal) water table in the three-dimensional site-scale UZ flow model grid used in the TSPA-SR (DTN: LB990701233129.001 [DIRS 106785]). Interpolation is used to determine the boundary conditions at the sloping water table in the three-dimensional site-scale UZ flow model. The software code boundary_conditions v1.0 reads input files containing the following information, respectively: (1) the SMT submodel grid, (2) the UZ model grid (File: MESH_rep.VF of DTN: LB991201233129.001 [DIRS 146894]) and (3) the initial conditions (File: INCON_thm_s32.dat of DTN: LB991201233129.001 [DIRS 146894]) from MountainScale Coupled Processes (TH/THC/THM) Models (BSC 2004 [DIRS 169866]), (4) the grid centers and ground-surface and water-table elevations of the World Columns in the threedimensional site-scale UZ flow model, (5) coordinates of the LDTH/SDT submodel locations, and (6) the values of wet thermal conductivity of the UZ model layers. Boundary conditions are generated at all World Columns (from the three-dimensional site-scale UZ flow model) and at all LDTH/SDT submodel locations. For the LDTH submodels, boundary_conditions v1.0 generates a table of boundary conditions at the ground surface, including temperature, gas-phase pressure, air mass fraction, and specific enthalpy of water at the ground-surface conditions in NUFT-input format. Also generated for LDTH submodels are boundary conditions at the water table, including temperature and gas-phase pressure in NUFT-input format. For the SMT and SDT submodels, boundary_conditions v1.0 generates ground-surface and water table temperatures in NUFT-input format. See Appendix II for details on the SMT submodel boundary condition construction.

Note that since the boundary conditions were determined for the SMT, SDT, and LDTH submodels, a new source of boundary condition has been made available from the MountainScale Coupled Processes (TH/THC/THM) Models (BSC 2004 [DIRS 169866]). The temperature and gas-phase-pressure boundary conditions can be extracted from the INCON block of file: th_v16.dat of DTN: LB0310MTSCLTH3.001 [DIRS 170270]. Compared to the use of file: INCON_thm_s32.dat of DTN: LB991201233129.001 [DIRS 146894], these updated boundary conditions result in negligible differences in temperatures and gas-phase pressures at both the upper boundary (the ground surface) and the lower boundary (the water table). Table I-1 gives the repository-wide averaged temperature at the upper and lower boundaries for the mountainscale TH model from Mountain-Scale Coupled Processes (TH/THC/THM) Models (BSC 2004 [DIRS 169866]) and for the MSTHM. Table I-2 gives the corresponding repository-wide averaged gas-phase pressure at the upper and lower boundaries for the respective models. 
Table I-1. Repository-Wide Averaged Temperature at the Upper and Lower Boundaries of the MountainScale TH Model and the MSTHM

\begin{tabular}{|c|c|c|c|c|}
\hline & \multicolumn{4}{|c|}{ Temperature $\left({ }^{\circ} \mathrm{C}\right)$} \\
\hline & $\begin{array}{c}\text { Mountain-Scale TH } \\
\text { Model }^{\mathrm{a}}\end{array}$ & MSTHM $^{b}$ & Mean Difference & $\begin{array}{c}\text { Root Mean Squared } \\
\text { Error }\end{array}$ \\
\hline Upper Boundary & 17.098 & 17.061 & -0.037 & 0.170 \\
\hline Lower Boundary & 30.097 & 30.117 & 0.021 & 0.157 \\
\hline
\end{tabular}

${ }^{\text {a }}$ Mountain Scale TH values based on DTN: LB0310MTSCLTH3.001 [DIRS 170270], INCON block of file: th_v16.dat.

${ }^{b}$ MS̄THM based on DTN: LB991201233129.001 [DIRS 146894], file INCON_thm_s32.dat.

NOTE: Repository-wide temperature and gas-phase pressures are determined for the heated repository footprint, plus the contingency area in the southern portion of Panel 2 (previously called Panel 5 in Figure 6.2.3).

Table I-2. Repository-Wide Averaged Gas-Phase Pressure at the Upper and Lower Boundaries of the Mountain-Scale TH Model and the MSTHM

\begin{tabular}{|c|c|c|c|c|}
\hline & \multicolumn{4}{|c|}{ Gas-Phase Pressure $(\mathrm{Pa})$} \\
\hline & $\begin{array}{c}\text { Mountain-Scale TH } \\
\text { Model }^{\mathrm{a}}\end{array}$ & MSTHM $^{b}$ & Mean Difference & $\begin{array}{c}\text { Root Mean Squared } \\
\text { Error }\end{array}$ \\
\hline Upper Boundary & 85,787 & 85,782 & -5 & 172 \\
\hline Lower Boundary & 91,810 & 91,805 & -5 & 18 \\
\hline
\end{tabular}

${ }^{\text {a }}$ Mountain Scale TH values based on DTN: LB0310MTSCLTH3.001 [DIRS 170270], INCON block of file: th_v16.dat.

${ }^{b}$ MS̄THM based on DTN: LB991201233129.001 [DIRS 146894], file INCON_thm_s32.dat.

NOTE: Repository-wide temperature and gas-phase pressures are determined for the heated repository footprint, plus the contingency area in the southern portion of Panel 2 (previously called Panel 5 in Figure 6.2.3).

Tables I-1 and I-2 also give the root mean square error in temperature and gas-phase pressure boundary conditions between the Mountain-Scale TH and the MSTHM. The differences between the two models are negligible. Therefore, obtaining the boundary conditions from DTN: LB991201233129.001 [DIRS 146894], file INCON_thm_s32.dat is reasonable and appropriate.

\section{Step 11 - Compute SMT, SDT, LDTH and DDT submodel heat-generation curves.}

Using a reference heat-generation-versus-time table, as well as a table of ventilation-heat-removal-efficiency as a function of time and distance from the ventilation inlet, heatgen_ventTable_emplace v1.0 produces files of heat-generation-versus-time tables in NUFTheatgen format. These heat-generation files have the influence of reduced heat-generation rates during the 50-year ventilation preclosure period and full-power heating during the postventilation postclosure period. See Appendix III for details on building the heat generation curves. See Appendix V for the assembly of NUFT input files.

\section{Step 12 - Compile natural- and engineered-system properties.}

Using several DTNs containing material-property values of the natural system and several Information Exchange Drawings containing material-property values of the engineered system, material-property files (called NUFT rocktab files) are constructed. These files are in the NUFT rocktab format; these files are read in as "include" file in the SMT, SDT, LDTH and DDT 
submodel NUFT input files. See Appendix IV for details on assembling the rocktab files that contain the material property values for the respective submodels.

\section{Step 13 - Compute effective thermal conductivity.}

To account for heat transfer by natural convection in the emplacement drift, correlations have been developed (Francis et al. 2003 [DIRS 164602], Table 6) for the relationship between drift wall, waste package, and drift air temperatures and an effective thermal conductivity $K_{\text {eff }}$ of the air in the emplacement drift cavity that represents the influence of heat transfer by natural convection. This process is conducted for the cavity between the drip shield and drift wall in the LDTH submodels and DDT submodels. This process is also conducted for the cavity between the waste package and drip shield in the DDT submodels.

It should be noted that the correlations for the in-drift effective thermal conductivity, which were obtained from Table 6 of Francis et al (2003 [DIRS 164602]), have been updated in In-Drift Natural Convection and Condensation (BSC 2004 [DIRS 164327], Table 6.4.7-3), resulting in very small changes to the coefficients. The small changes to the coefficients in the correlations are negligible, as shown in Figure I-1 for the effective thermal conductivity between the drip shield and drift wall at an average fluid temperature of $95^{\circ} \mathrm{C}$.

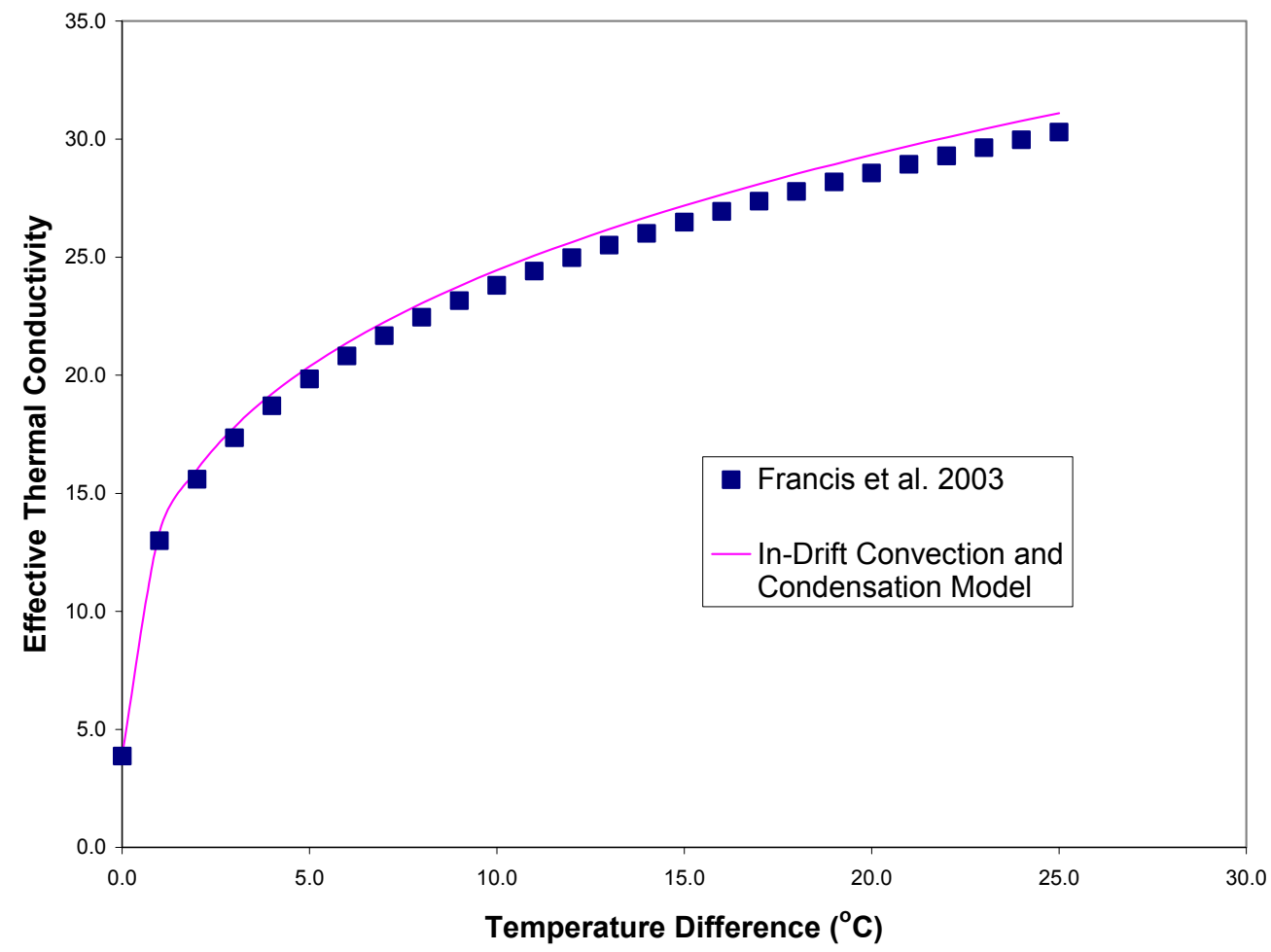

NOTE: The in-drift effective thermal conductivity between the drip shield and drift wall as a function of the temperature difference between those surfaces is plotted from the correlation in Table 6 of Francis et al. (2003 [DIRS 164602]) and in Table 6.4.7-3 of In-Drift Natural Convection and Condensation (BSC 2004 [DIRS 164327]).

Figure I-1. Plot of In-Drift Effective Thermal Conductivity Between the Drip Shield and Drift Wall as a Function of Temperature Difference 
The effective thermal conductivity $K_{\text {eff }}$ is determined by running a NUFT submodel (either LDTH or DDT) starting with an initial guess for $K_{\text {eff }}$ for the gas-filled cavities in the drift. The appropriate formula from Table 6 of CFD Modeling of Natural Convection Heat Transfer and Fluid Flow in Yucca Mountain Project (YMP) Enclosures (Francis et al. 2003 [DIRS 164602]) is used to compute $K_{\text {eff }}$ in the gas-filled cavities and the NUFT submodel is rerun with the new value of $K_{\text {eff. }}$ Each time a new NUFT-submodel run is completed, the value of $K_{\text {eff }}$ is computed and compared with the previous iteration. After the value of $K_{\text {eff }}$ has converged (between successive iterations), the iterative process is completed. The effective thermal conductivity $K_{\text {eff }}$ is a time-varying parameter and the formula in Table 6 of Frances et al. (2003 [DIRS 164602]) involves computing temperatures averaged over the gridblocks representing the gas-filled cavities in the emplacement drift. To carry out this iterative process, extractBlocks_EXT v1.0 is used. This software code takes a list of gridblocks, extracts the required information from the NUFT-submodel output, applies the appropriate formula from Table 6 of Frances et al. (2003 [DIRS 164602]), and produces a time history of calculated $K_{\text {eff. }}$.

software code:

extractBlocks_EXT v1.0

inputs:

The name of an input file that defines how to apply the formula from Table 6 of Frances et al. (2003 [DIRS 164602]) (DTN: LL030808723122.037)

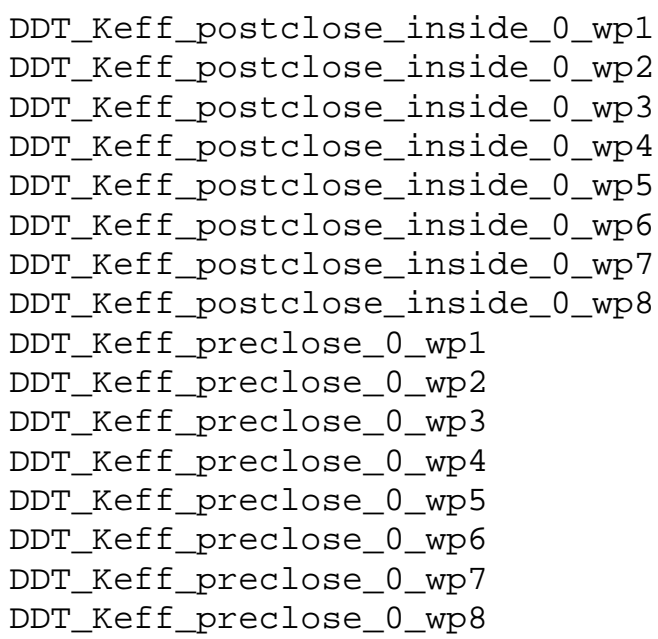

outputs:

A file with a time history of $K_{\text {eff }}$ calculated from the NUFT input (DTN: LL030808723122.037)

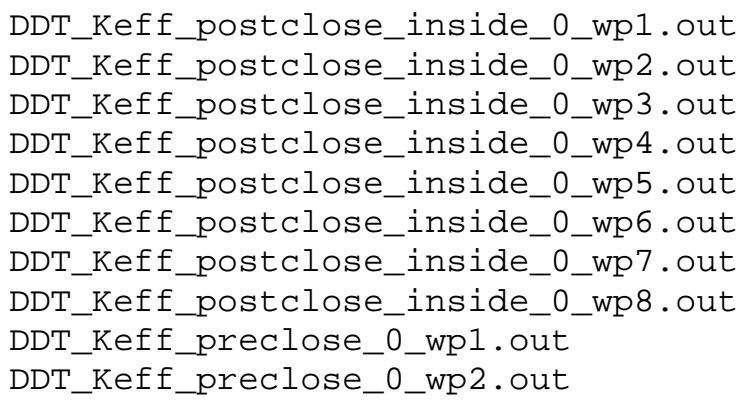




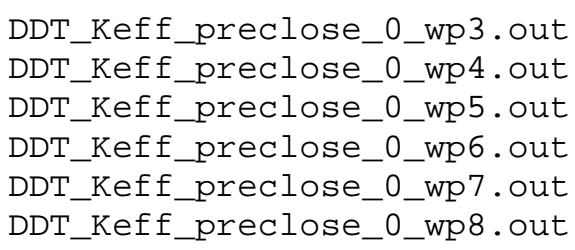

Step 14 - Create SMT submodel mesh.

To create the SMT submodel mesh used for the MSTHM calculations in this report, one must carefully perform the following steps. Note that one must be using the qualified version of YMESH v1.54 and Solaris OS 5.8 UNIX operating system.

a. Execute YMESH v1.54

ymesh

b. Pull down File tab on YMESH v1.54 to and Open the data file. In the Select Input File popup highlight the file "LBL2003-LA-YMESH-expand_qualified" (from NUFT-submodel Building Step 2) and click $O K$

c. Pull down Edit tab and highlight Extend World Columns. Make certain the Above tab is active. Enter the following:

Material atm

Thickness 200.

click $O K$ button

d. Remain in the Extended World Columns but now make the Below tab active. Enter the following:

Material sz1

Thickness 30.

click $O K$ button

Material sz2

Thickness 60.

click $O K$ button

Material sz3

Thickness 70.

click $O K$ button

Material sz4

Thickness 120.

click $O K$ button

Material $\quad$ sz5

Thickness 240.

click $O K$ button 


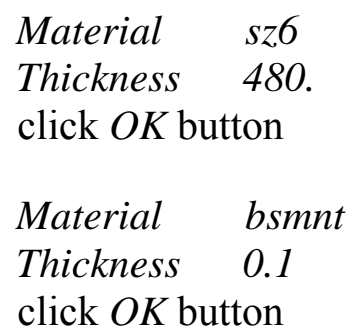

e. Click CLOSE button on Extend World Columns popup

f. Open File pulldown from YMESH v1.54 menu and select Open data file

g. In the Select Input File popup, select file "tspa03.grid03-150w" and click OK button

h. Highlight Options pulldown from YMESH v1.54 menu and select Trim Top Boundary

i. In Ending Conditions popup menu, enter the following:
Material atm
Thickness 0.1
click Apply button
click Close button

j. Highlight Edit pulldown from YMESH v1.54 menu and select Element Names

k. In Rename Elements popup window, follow these steps:

i. Select Material button and enter

$$
\begin{aligned}
& \text { Prefix atm } \\
& \begin{array}{l}
\text { Material atm } \\
\text { Click Apply button }
\end{array} \\
& \text { Prefix } \quad \text { bsm } \\
& \text { Material bsmnt } \\
& \text { Click Apply button }
\end{aligned}
$$

ii. Select PrefixIndexFile button

In the PrefixIndexRangeFile space enter heatBlockIndicesPanel1_2e_2w_3_5.data

Click Apply button

Click Close button

1. Highlight the File pulldown menu and select Save data file

In the Save File popup window type the Selection space enter "tspa03.mesh03-150w" Click $O K$ button

(Note that this saves the mesh) 
m. Return to a UNIX command prompt and type the following UNIX commands

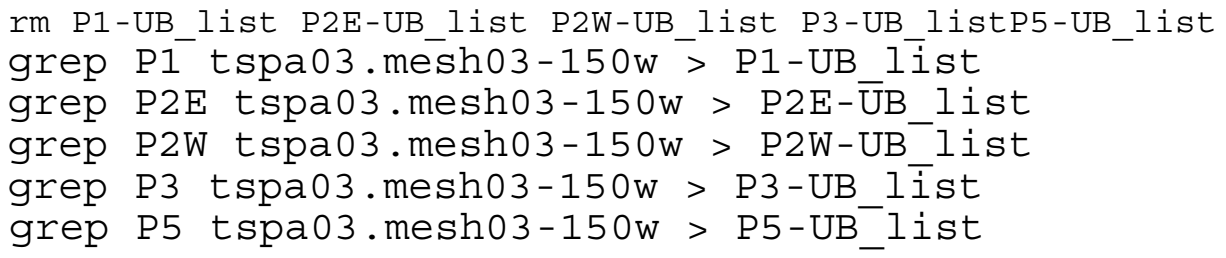

n. Using a text editor, open the five files just created: P1-UB_list, P2E-UB_list, P2WUB_list, P3-UB_list, and P5-UB_list (DTN: LL030808823122.038)

o. Edit the five files by removing all gridblock connections information (which is the last 70 percent of the file), saving only the element information (which is the first 30 percent of the file)

p. Save the five files with the above names

Note that any mistake made by the user in executing the YMESH v1.54 steps forces the user to return to the beginning and redo the YMESH v1.54 steps. 
APPENDIX II

BUILDING BOUNDARY CONDITIONS FOR SUBMODELS 
The software code boundary_conditions v1.0 generates upper and lower boundary conditions for the LDTH, SMT, and SDT submodels (see Step 10 of Appendix I). The boundary conditions are derived from Mountain-Scale Coupled Processes (TH/THC/THM) Models (BSC 2004 [DIRS 169866]) (DTN: LB991201233129.001 [DIRS 146894]). Data are extracted from the threedimensional site-scale UZ flow model grid being used in the TSPA-LA (DTN: LB03023DKMGRID.001 [DIRS 162354]), as well as from Mountain-Scale Coupled Processes (TH/THC/THM) Models (BSC 2004 [DIRS 169866]), including the boundary conditions (file INCON_thm_s32.dat in DTN: LB991201233129.001 [DIRS 146894]) and the corresponding three-dimensional mountain-scale grid (file $\mathrm{MESH}_{-}$rep.VF in DTN: LB991201233129.001 [DIRS 146894]). It should be noted that the three-dimensional mountain-scale grid used in Mountain-Scale Coupled Processes (TH/THC/THM) Models (BSC 2004 [DIRS 169866]) has a horizontal water table at an elevation of $730 \mathrm{~m}$, while the threedimensional site-scale UZ flow model grid used in the TSPA-LA (DTN: LB03023DKMGRID.001 [DIRS 162354]) has a sloping water table. The software code boundary_conditions v1.0 uses linear interpolation to determine the water-table boundary conditions at the sloping water-table surface in the three-dimensional site-scale UZ flow model grid used in the TSPA-LA (DTN: LB03023DKMGRID.001 [DIRS 162354]). The software code boundary_conditions v1.0 reads input files containing the following information, respectively: (1) the SMT submodel grid, (2) the UZ model grid and (3) initial conditions from Mountain-Scale Coupled Processes (TH/THC/THM) Models (BSC 2004 [DIRS 169866]), (4) the grid centers and ground-surface and water-table elevations of the World Columns in the three-dimensional site-scale UZ flow model, (5) coordinates of the LDTH/SDT submodel locations, and (6) the values of wet thermal conductivity of the UZ model layers.

For item (4) above, colCen v1.0 is used to determine the grid centers for all World Columns in the three-dimensional site-scale UZ flow model.

Boundary conditions are generated by boundary_conditions v1.0 at all World Columns (from the three-dimensional site-scale UZ flow model) and at all LDTH/SDT submodel locations. For the LDTH submodels, boundary_conditions v1.0 generates a table of boundary conditions at the ground surface, including temperature, gas-phase pressure, air mass fraction, and specific enthalpy of water at the ground-surface conditions in NUFT-input format. Also generated for LDTH submodels are boundary conditions at the water table, including temperature and gasphase pressure in NUFT-input format. For the SMT and SDT submodels, boundary_conditions generates ground-surface and water-table temperatures in NUFT-input format.

Prior to determining the boundary conditions, Steps 1 and 2 of Appendix I, which result in an expanded three-dimensional mountain-scale mesh (called the expanded World Grid for YMESH v1.54), must be executed. This expanded three-dimensional mountain-scale mesh (also called the expanded World Grid) is used as an input to boundary_conditions v1.0, which subsequently outputs all of the boundary condition files to be used for all of the submodels (see Appendix V for the assembly of NUFT input files).

\section{Create boundary condition files for all submodels.}

The software code boundary_conditions v1.0 was used to create the boundary conditions for all submodels. 
software code:

boundary_conditions

input files (DTN: LL030808723122.037)

smtMesh (SMT submodel mesh file in NUFT meshfile input format)

MESH_rep.VF of DTN: LB991201233129.001 [DIRS 146894] (Mesh file for Mountain-Scale Coupled Processes (TH/THC/THM) Models (BSC 2004 [DIRS 169866]))

INCON thm s32.dat of DTN: LB991201233129.001 (Initial conditions for Mountain-Scale Coupled Processes (TH/THC/THM) Models (BSC 2004 [DIRS 169866]))

grid_column_centers (Ground-surface and water-table elevations and coordinates of World Columns of the three-dimensional site-scale UZ flow model grid, which is the LBL2002-YMESH Expanded World Grid; this information is generated as output from colCen v1.0 - see above)

chimneyLocation (For each LDTH-SDT submodel pair this file locates the corresponding World Column in the LBL2002-YMESH Expanded World Grid)

tcond.dat (Thermal conductivity of UZ model layers)

output files (DTN: LL030808723122.037)

chimSurfBC.out (LDTH submodel surface boundary conditions: temperature, gas pressure, air mass fraction in gas phase, and specific enthalpy of water)

chimLowerBC.out (LDTH submodel water table boundary conditions: temperature and gas pressure)

smtUpperBC.out (Surface boundary temperature for SMT submodel in NUFT input format)

smtLowerBC.out (Lower boundary temperature for SMT submodel in NUFT input format)

worldColBC.out (LDTH/SDT submodel-type boundary conditions for all World Columns in the LBL2002-YMESH Expanded World Grid)

smtWorldBC (Summary of SMT submodel boundary conditions for columns in the LBL2002-YMESH Expanded World Grid)

execution process

To start, type:

boundary_conditions 
Enter output file extension:

out

Enter thermal cond. of material below water table, SMT submodel:

\section{2}

Enter value of added thickness below water table, SMT submodel:

1000

Enter name of SMT submodel mesh file:

Hit return with no entry to use default file, smtMesh

\section{SMTMESHTEST}

Enter name of the Mountain-Scale Coupled Process (TH/THC/THM) Models (BSC 2004 [DIRS 169866]) mesh file:

Hit return with no entry to use default file, MESH_rep.VF

\section{MESH_rep.VF}

Enter name of the Mountain-Scale Coupled Process (TH/THC/THM) Models (BSC 2004 [DIRS 169866]) file with init.cond.:

Hit return with no entry to use default file, INCON_thm_s32.dat

\section{INCON_thm_s32.dat}

Enter name of file with World Column data from the 3-D site-scale UZ flow model:

Hit return with no entry to use default file, grid_column_centers

\section{GRID_COLUMN_CENTERS}

Enter name of file with LDTH-/SDT submodel "chimney" locations:

Hit return with no entry to use default file, chimneyLocation

\section{CHIMNEYLOCATION}

Enter name of file with thermal cond. data:

Hit return with no entry to use default file, tcond.dat

TCOND.DAT 


\section{INTENTIONALLY LEFT BLANK}




\section{APPENDIX III}

HEAT GENERATION FOR SUBMODELS 
To produce the heat generation for the SMT, SDT, DDT, and LDTH submodels (Step 11 in Appendix I) the following instructions must be followed. The software code heatgen_ventTable_emplace v1.0 is used for this purpose.

The software code heatgen_ventTable_emplace v1.0 is used to incorporate the influence of ventilation heat-removal efficiency on the net heat generation available for heating the host rock. This is accomplished using a net-available-heat-generation fraction (Table III-1), which is equal to 1 minus the heat-removal-efficiency fraction, and which is given as a function of time and distance from the ventilation inlet. This code requires a control file that provides names of the locations (within the repository) at which heat generation files should be created along with the distance of that location from the ventilation inlet. The output of heatgen_ventTable_emplace v1.0 is a series of files of heat-generation-rate-versus-time tables that account for the heatremoval efficiency of forced-convection ventilation of the emplacement drifts during the preclosure period. The output files from heatgen_ventTable_emplace v1.0 are in NUFT heatgen format.

Table III-1. Net Available Heat-Generation Fraction as a Function of Time and Distance from the Ventilation Inlet Used in this Report

\begin{tabular}{|c|c|c|c|c|c|c|c|c|c|c|c|}
\hline \multirow{2}{*}{$\begin{array}{c}\text { Time } \\
\text { (yr) }\end{array}$} & \multicolumn{11}{|c|}{ Distance from Ventilation Inlet (m) } \\
\hline & 0 & 1 & 10 & 100 & 200 & 300 & 400 & 500 & 600 & 700 & 800 \\
\hline .000001 & 1 & 1 & 1 & 1 & & 1 & & & & & \\
\hline 00001 & 146308 & .142676 & 0.142563 & 0.140993 & 0.140799 & 0.140799 & 0.140799 & 0.140799 & 0.140799 & 0.140799 & 0.140799 \\
\hline 0.0001 & 0.217303 & 0.216986 & 0.227705 & 0.228043 & 0.227014 & 0.226996 & & 0.226996 & 0.226996 & & \\
\hline 0.001 & .476088 & 0.473018 & 0.481063 & 0.53203 & 0.523485 & 0.52025 & 0.520202 & 0.520168 & 0.520168 & 0.520168 & 0.520168 \\
\hline 0.002 & 0.292264 & 0.316736 & 0.339064 & 0.639182 & 0.629461 & 0.623959 & 0.623759 & 0.623744 & 0.623744 & 0.623744 & 0.623744 \\
\hline 0.005 & 0.280038 & 0.285626 & 0.299503 & 0.623057 & 0.63828 & 0.632743 & 0.625883 & 0.625394 & 0.625413 & 0.625413 & 0.625413 \\
\hline & 193758 & 0.208711 & 0.222313 & 0.342672 & 0.618228 & 62856 & 0.609709 & 0.607226 & 0.607041 & 041 & 0.6 \\
\hline 0.02 & 0.13269 & 0.147196 & 0.158759 & 0.269033 & 0.281053 & 0.620632 & 0.614217 & 0.601249 & 0.599502 & 0.599277 & 0.5 \\
\hline 0.05 & 0.098427 & 0.107858 & 0.117531 & 0.207132 & 0.270728 & 0.592514 & 0.600299 & 0.609218 & 0.624081 & 0.640142 & 0.621325 \\
\hline & .081837 & 0.090038 & 0.098317 & 0.179413 & 0.242904 & 0.301132 & 0.38071 & 0.447719 & 0.48086 & 0.561239 & 0.641619 \\
\hline 0.167 & .071587 & 0.07973 & 0.087446 & 0.161575 & 0.219363 & 0.276089 & 0.328697 & 0.372876 & 0.398714 & 0.457227 & 0.51574 \\
\hline 0.5 & 0.054689 & 0.061099 & 0.067563 & 0.12848 & 0.173734 & 0.216918 & 0.259313 & 0.300316 & 0.333768 & 0.364466 & 0.395163 \\
\hline 1 & 0.046744 & 0.051877 & 0.057946 & 0.111957 & & 0.191916 & 0.230384 & 0.269126 & 0.306335 & 0.340477 & \\
\hline 2 & 0.040779 & 0.043124 & 0.048668 & 0.098252 & 0.133631 & 0.168209 & 0.203015 & 0.237214 & 0.27068 & 0.30221 & 0.333407 \\
\hline 5 & 0.034946 & 0.028339 & 0.034312 & 0.07884 & 0.109622 & 0.139492 & 0.170165 & 0.20001 & 0.229961 & 0.257114 & 0.285117 \\
\hline 7 & 0.034075 & 0.032974 & 0.039111 & 0.07985 & 0.107428 & 0.135075 & 0.163945 & 0.191241 & 0.218936 & 0.245204 & 0.271005 \\
\hline 10 & 0.031507 & 0.027718 & 0.034033 & 0.072152 & 0.098795 & & 0.151777 & 0.178159 & 0.204479 & 0.229816 & \\
\hline 20 & 0.027692 & 0 & 0.008322 & 0.04327 & 0.068591 & 0.093648 & 0.117834 & 0.142747 & 0.166506 & 0.191557 & 0.213319 \\
\hline 30 & 0.026128 & 0.001645 & 0.010748 & 0.038894 & 0.060805 & 0.083288 & 0.103578 & 0.125227 & 0.145393 & 0.166498 & 0.186734 \\
\hline 50 & 0.021768 & 0 & 0 & 0.008813 & 0.026882 & 0.044891 & 0.064152 & 0.080771 & 0.099534 & 0.11707 & 0.134762 \\
\hline
\end{tabular}

SOURCE: These values are equal to 1 minus the heat-removal-efficiency fraction, which is given in DTN:

MO0304MWDALACV.000 [DIRS 164551], FILE: ANSYS-LA-coarse.xIs, "Efficiency Data" Worksheet. 
It is important to note that the source of the heat-removal efficiency versus time and distance table (DTN: MO0304MWDALACV.000 [DIRS 164551], FILE: ANSYS-LA-coarse.xls, "Efficiency Data" Worksheet) was superseded by DTN: MO0306MWDASLCV.001 [DIRS 165695], FILE: ANSYS-LA-coarse.xls, "Efficiency Data" Worksheet. Table III-2 gives the net available heat-generation fraction as a function of time and distance from the ventilation inlet, which is obtained from DTN: MO0306MWDASLCV.001 [DIRS 165695]. Appendix XIV documents the qualification of DTN: MO0304MWDALACV.000 for use in the MSTHM calculations reported in Section 6.3.

Table III-2. Net Available Heat-Generation Fraction as a Function of Time and Distance from the Ventilation Inlet from Updated Data Source

\begin{tabular}{|c|c|c|c|c|c|c|c|c|c|c|c|}
\hline \multirow{2}{*}{$\begin{array}{c}\text { Time } \\
\text { (yr) }\end{array}$} & \multicolumn{11}{|c|}{ Distance from Ventilation Inlet (m) } \\
\hline & 0 & 1 & 10 & 100 & 200 & 300 & 400 & 500 & 600 & 700 & 800 \\
\hline 0.000001 & 1 & 1 & 1 & 1 & 1 & 1 & 1 & 1 & & & \\
\hline 0.00001 & 0.135066 & 0.135098 & 0.134942 & 0.133348 & 0.133147 & 0.133147 & 0.133147 & 0.133147 & 0.133147 & 0.133147 & 0.133147 \\
\hline 0.0001 & 0.214621 & 0.215113 & 0.225830 & 0.219550 & 0.218889 & 0.218889 & 0.218889 & 0.218889 & 0.218889 & 0.218889 & 0.218889 \\
\hline 0.001 & 0.478338 & 0.475022 & 0.483168 & 0.524651 & 0.511303 & 0.509651 & 0.509610 & 0.509610 & 0.509610 & 0.509610 & 0.509610 \\
\hline 0.002 & 0.357323 & 0.341228 & 0.359332 & 0.637949 & 0.615778 & 0.613866 & 0.613771 & 0.613771 & 0.613771 & 0.613771 & 0.613771 \\
\hline 0.005 & 0.295914 & 0.298644 & 0.311384 & 0.626357 & 0.638665 & 0.618744 & 0.617352 & 0.617309 & 0.617309 & 0.617309 & 0.617309 \\
\hline 0.01 & 0.211570 & 0.220611 & 0.234199 & 0.344166 & 0.623465 & .608533 & 0.600455 & 0.599997 & 0.599962 & 0.599927 & \\
\hline 0.02 & 0.148423 & 0.156541 & 0.167830 & 0.277095 & 0.588253 & 0.597282 & 0.616473 & 0.596000 & 0.592972 & 0.592701 & 0.592664 \\
\hline 0.05 & 0.111385 & 0.113755 & 0.123993 & 0.213644 & 0.274106 & 0.347422 & 0.619900 & 0.623108 & 0.623445 & 0.612159 & 0.609106 \\
\hline 0.1 & 0.093342 & 0.094252 & 0.103040 & 0.184760 & 0.248296 & .300246 & 0.305689 & 0.627862 & 0.637413 & 0.647127 & 0.656842 \\
\hline 0.167 & 0.082390 & 0.083169 & 0.090779 & 0.165763 & 0.224567 & 0.282320 & 0.334485 & 0.365615 & 0.431550 & 0.553138 & 0.674726 \\
\hline 0.5 & 0.064291 & 0.063075 & 0.069602 & 0.130512 & 0.175606 & 0.219324 & 0.262088 & 0.302489 & 31269 & 09213 & 87158 \\
\hline 1 & 0.055766 & 0.053096 & 0.059301 & 0.113254 & 0.153850 & 0.192711 & 0.231531 & 0.269038 & 0.306778 & 0.340002 & 0.371565 \\
\hline 2 & 0.049463 & 0.043804 & 0.050139 & 0.098439 & 0.133850 & 0.167701 & 0.201723 & 0.235521 & 0.269083 & 0.300283 & 0.331118 \\
\hline 5 & 0.043663 & 0.028618 & 0.035436 & 0.078572 & 0.108016 & 0.138321 & 0.167566 & 0.197426 & 0.225970 & 0.252974 & 0.280183 \\
\hline 7 & 0.042880 & 0.033521 & 0.038796 & 0.078778 & 0.105996 & 0.133101 & 0.160787 & 0.188093 & 0.214863 & 0.240398 & 0.265608 \\
\hline 10 & 0.040675 & 0.028033 & 0.034276 & 0.071455 & 0.097638 & 0.123108 & 0.149386 & 0.174865 & 0.199773 & 0.224872 & 0.248124 \\
\hline 20 & 0.038559 & -0.001342 & 0.009525 & 0.042960 & 0.067913 & 0.092815 & 0.116884 & 0.140830 & 0.164491 & 0.187746 & 0.209693 \\
\hline 30 & 0.038599 & 0.003452 & 0.011231 & 0.040311 & 0.062029 & 0.083344 & 0.104132 & 0.125229 & 0.145945 & 0.166299 & 0.186499 \\
\hline 50 & 0.037744 & -0.022832 & -0.011204 & 0.010284 & 0.029428 & 0.048125 & 0.067176 & 0.085635 & 0.103205 & 0.120745 & 0.139413 \\
\hline
\end{tabular}

SOURCE: These values are equal to 1 minus the heat-removal-efficiency fraction, which is given in DTN: MO0306MWDASLCV.001 [DIRS 165695], FILE: ANSYS LA- Base Case.xIs, "Efficiency Data” Worksheet. 


\section{Creating Heat Generation Curves for the SDT and LDTH submodels}

software code

heatgen_ventTable_emplace v1.0

inputs: (DTN: LL030808723122.037)

SDT: string indicating to the software code that this is an SDT/LDTH submodel heatgen file

multi-package_7WP_Segment_Info_SDT_LDTH_TSPA03: default SDT/LDTH submodel heat-generation table with nominal loading and no ventilation

LA_ventilation_table_50yr.rfm: ventilation table with ventilation efficiency as a function of time and distance from the ventilation inlet.

ventilation time.reform: file giving the name and distance from the ventilation inlet for each LDTH-/SDT submodel "chimney" location.

outputs: (heatgen file) (DTN: LL030808723122.037)

P*_LDTH-SDT output heatgen file for each LDTH-/SDT submodel "chimney" location

\section{Creating Heat Generation Curves for the DDT submodels}

software code

heatgen_ventTable_emplace

inputs: (DTN: LL030808723122.037)

DDT: string indicating to the software code that this is a DDT heatgen file

DDT_TSPA03: default DDT heat generation table with nominal loading and no ventilation

LA_ventilation_table_50yr.rfm: ventilation table with ventilation efficiency as a function of time and distance from the ventilation inlet.

ventilation_time.reform: file giving the name and distance from the ventilation inlet for each LDTH-/SDTsubmodel "chimney" location.

outputs: (heatgen file) (DTN: LL030808723122.037)

P*_DDT output heatgen file for each LDTH-/SDT-submodel "chimney" location

\section{Creating Heat Generation Curves for the SMT submodel}

software code

heatgen_ventTable_emplace

inputs: (DTN: LL030808723122.037)

SMT:string indicating to the software code that this is an SMT submodel heatgen file SMT_TSPA03: default SMT submodel heat-generation-versus-time table with nominal loading and no ventilation

LA_ventilation_table_50yr.rfm: ventilation table with ventilation efficiency as a function of time and distance from the ventilation inlet. 
ventilation time.rfm: file giving the name and distance from the ventilation inlet for each LDTH-/SDT submodel "chimney" location.

outputs: (heatgen file) (DTN: LL030808723122.037)

SMT_TSPA03_P* output heatgen file for each SMT submodel location

The heatgen files are then used as inputs to the NUFT input files; see Appendix V for details on the assembly of NUFT input files. 


\section{APPENDIX IV}

BUILDING SUBMODEL MATERIAL PROPERTY FILES 


\section{LDTH - Submodel DKM Properties}

Hydrologic properties from DTN: LB0208UZDSCPMI.002 [DIRS 161243] are used for all three infiltration flux cases (Table IV-4), which are documented in Sections 6.3.1, 6.3.2, 6.3.3. Hydrologic properties from DTN: LB0208UZDSCPLI.002 [DIRS 161788] (Table IV-5) and from DTN: LB0302UZDSCPUI.002 [DIRS 161787] (Table IV-6) are used for the sensitivity study to hydrologic-property uncertainty, which is discussed in Section 6.3.2.4. From each of the three Microsoft Excel spreadsheet files contained in the respective DTNs, the following parameters are obtained: permeability (matrix and fracture), porosity (matrix and fracture), van Genuchten properties (matrix and fracture) and residual saturation (matrix and fracture).

The thermal properties are taken from files of the following sources: DTN: SN0303T0503102.008 [DIRS 162401], DTN: SN0307T0510902.003 [DIRS 164196], and Table 7-10 of DTN: SN0404T0503102.011 [DIRS 169129] (File: readme.doc). Bulk thermal conductivity $K_{\text {th }}$ (for both wet and dry conditions) and bulk density (average and 1 standard deviation above and below) of the nonrepository GFM2000 layers are contained in DTN: SN0303T0503102.008 [DIRS 162401]. The bulk thermal conductivity (for both wet and dry conditions) and bulk density $\rho_{\mathrm{b}}$ of the repository UZ model layers was obtained from Table 7-10 of DTN: SN0404T0503102.011 [DIRS 169129] (File: readme.doc); these data include mean values as well as one standard deviation above and below the mean. The specific heat capacity of the mineralogical model layers is taken from DTN: SN0307T0510902.003 [DIRS 164196]. The source input data for bulk density and bulk thermal-conductivity is summarized in Table IV-3a.

The following parameters were calculated by hand using parameters obtained in the files listed above: (1) grain density, (2) matrix density and fracture density, (3) matrix and fracture contact length factors, and (4) thermal conductivity relations for matrix and fracture. Table IV-3b shows the results of calculating the density and thermal conductivity for the matrix and fracture continua. It should be noted that the vitric units have no fractures, but in order for the DKM to work, values must be assigned to a pseudo-fracture continuum for vitric units. This is accomplished by simply assigning matrix properties to the fracture continuum for the vitric units $(\operatorname{tsw} 9 \mathrm{v}, \operatorname{ch} 1 \mathrm{v}, \operatorname{ch} 2 \mathrm{v}, \operatorname{ch} 3 \mathrm{v}, \operatorname{ch} 4 \mathrm{v}, \operatorname{ch} 5 \mathrm{v}$, and $\operatorname{ch} 6 \mathrm{v})$. The specific details of the hand calculations are listed below.

1. The grain density $\rho_{\mathrm{g}}$ is calculated as:

$$
\rho_{g}=\frac{\rho_{b}}{1-\phi_{m}}
$$

where $\phi_{\mathrm{m}}$ is matrix porosity and $\rho_{\mathrm{b}}$ is bulk density. 
2. The grain density $\rho_{\mathrm{g}}$ is partitioned to the matrix and fracture continuum according to the fracture porosity, $\phi_{f}$. The matrix and fracture densities, $\rho_{\mathrm{g}, \mathrm{m}}$ and $\rho_{\mathrm{g}, \mathrm{f}}$, are calculated as:

$$
\begin{aligned}
& \rho_{g, m}=\rho_{g}\left(1-\phi_{f}\right) \\
& \rho_{g, f}=\rho_{g} \phi_{f}
\end{aligned}
$$

Because the vitric units do not have fractures, the grain density for the fracture and matrix continuum is calculated slightly differently. The matrix porosity is portioned 50 percent to the matrix continuum and 50 percent to the "pseudo-fracture" continuum. The bulk density is portioned 50 percent to the matrix continuum and 50 percent to the pseudo-fracture continuum. Thus, the grain densities for the fracture and matrix continuum are calculated as:

$$
\rho_{\mathrm{g}, \mathrm{m}}=\rho_{\mathrm{g}, \mathrm{f}}=\frac{\rho_{\mathrm{b}}}{2\left(1-\frac{\phi_{\mathrm{m}}}{2}\right)}
$$

where $\phi_{m}$ is the total matrix porosity and $\rho_{\mathrm{b}}$ is the total bulk density. Table IV-3b shows the result of this hand calculation for the vitric units.

3. The matrix-contact-length factor is calculated as $1 /(6 \mathrm{~N})$ where $\mathrm{N}$ is the fracture frequency from DTN: LB0205REVUZPRP.001 [DIRS 159525] (Table IV-7) and 6 accounts for the distance between the center of the matrix block and the fractures for Type \#1 fractures as described in Development of Numerical Grids for UZ Flow and Transport Modeling (BSC 2004 [DIRS 169855], Equation 6-4). The fracture-contact-length factor is always 0, which is obtained from Equation 6-3 of Development of Numerical Grids for UZ Flow and Transport Modeling (BSC 2004 [DIRS 169855], Section 6.7). The matrix-contact-length factor and the fracture-contact-length factor affect disequilibrium between the matrix and fracture continuum in the LDTH submodels.

4. The thermal conductivity for the matrix $K_{\mathrm{th}, \mathrm{m}}$ and fracture $K_{\mathrm{th}, \mathrm{f}}$ (both dry and wet) are calculated as a function of fracture porosity $\phi_{f}$ for the given wet and dry bulk thermal conductivities $K_{\mathrm{th}}$ :

$$
\begin{aligned}
& K_{t h, m}^{d r y}=K_{t h}^{d r y}\left(1-\phi_{f}\right) \\
& K_{t h, f}^{d r y}=K_{t h}^{d r y} \phi_{f} \\
& K_{t h, m}^{w e t}=K_{t h}^{w e t}\left(1-\phi_{f}\right) \\
& K_{t h, f}^{w e t}=K_{t h}^{w e t} \phi_{f}
\end{aligned}
$$

These properties are written into a "rocktab" file (an example of which is listed at the bottom of this Appendix) for the NUFT input file (see Appendix V). All transport and partitioning parameters (e.g., $\mathrm{Kd}$ and $\mathrm{Kd}_{\text {Factor }}$ ) are set to zero because sorption is not considered for any of the calculations of this report. 
The uncertainty of the wet and dry thermal conductivity values of the repository UZ model layers was addressed with values from DTN: SN0303T0503102.008 [DIRS 162401] and from Table 7-10 of DTN: SN0404T0503102.011 [DIRS 169129] (File: readme.doc).

Note that de Marsily (1986 [DIRS 100439], p. 233) gives a range from 0.1 for clays to 0.7 for sands. The value of 0.2 for the matrix continuum is used because the pore sizes for matrix are closer to that of clays than to that of sands. A value of 0.7 is assumed for the fracture.

\section{LDTH Submodel In-Drift, DKM Properties}

\section{Invert Properties}

The invert properties for the matrix continuum (i.e., the intragranular porosity) are obtained from DTN: LB0208UZDSCPMI.002 [DIRS 161243] and for the fracture continuum (i.e., the intergranular porosity) are from Appendix X. Section 5.3.1.8 discusses the assumption about the intergranular permeability of the crushed-tuff invert material. The van Genuchten alpha for the fracture continuum from Table X-7 of Appendix X is $624 \mathrm{bar}^{-1}$, which converted to SI units, is equal to $6.24 \times 10^{-3} \mathrm{~Pa}^{-1}$. The input parameters that require hand calculations are: (1) intragranular porosity $\left(\phi_{\mathrm{m}}\right),(2)$ the thermal conductivity for the fracture and matrix continuum, and (3) the grain density of the matrix and of the fracture continuum. The thermal properties of the crushed-tuff invert are given in Tables IV-8 and IV-9.

\section{Invert Porosity}

The matrix porosity or intergranular porosity of the crushed-tuff grains in the invert, $\phi_{\mathrm{m}}$, is taken from DTN: LB0208UZDSCPMI.002 [DIRS 161243] and is equal to 0.131, which is the matrix porosity of the Tptpll (tsw35) unit. The intergranular porosity of the crushed-tuff invert material is obtained from Table X-7 of Appendix X and is equal to 0.45 . The porosity of the fracture continuum in the invert, $\phi_{\mathrm{f}}$, which is called the intergranular porosity, is a bulk quantity. Because the porosity of the matrix continuum in the invert, which is called the intragranular porosity, $\phi_{\mathrm{g}, \mathrm{m}}$, is also a bulk quantity, the intragranular porosity of the crushed-tuff invert material is given by:

$$
\phi_{\mathrm{g}, \mathrm{m}}=\phi_{\mathrm{m}}\left(1-\phi_{\mathrm{f}}\right)
$$

Thus, the intragranular porosity (or matrix-continuum porosity) of the crushed-tuff invert material used in the LDTH submodels is equal to 0.0721 .

\section{Invert Thermal Conductivity}

The bulk thermal conductivity of the crushed-tuff invert material is partitioned 99 percent to the matrix continuum and 1 percent to the fracture continuum, as follows:

$$
\begin{aligned}
& K_{\text {th,f }}=K_{\text {th }}(0.01) \\
& K_{\text {th,m }}=K_{\text {th }}(0.99)
\end{aligned}
$$

This partitioning is done because the majority of the thermal mass in the invert resides in the matrix continuum. 


\section{Invert Grain Density}

The bulk grain density of the crushed-tuff invert material is partitioned 99 percent to the matrix continuum and 1 percent to the fracture continuum, as follows:

$$
\begin{aligned}
\rho_{\mathrm{g}, \mathrm{m}} & =(0.99) \rho_{\mathrm{b}} /\left(1-\phi_{\mathrm{m}}\right) \\
\rho_{\mathrm{g}, \mathrm{f}} & =(0.01) \rho_{\mathrm{b}} /\left(1-\phi_{\mathrm{f}}\right)
\end{aligned}
$$

where $\rho_{\mathrm{g}, \mathrm{m}}$ is the grain density of the matrix continuum, $\rho_{\mathrm{g}, \mathrm{f}}$ is the grain density of the fracture continuum, $\rho_{\mathrm{b}}$ is the bulk density of the crushed-tuff invert material obtained from DTN: GS020183351030.001 [DIRS 163107] (rows 321-370) and given in Table IV-8, $\phi_{\mathrm{m}}$ is the matrix-continuum porosity of the crushed-tuff invert material, and $\phi_{\mathrm{f}}$ is the fracture-continuum porosity of the crushed-tuff invert. This partitioning is done because the majority of the thermal mass in the invert resides in the matrix continuum.

\section{Waste Package and Drip Shield Properties}

Due to grid resolution limitations in the drift, the geometry of the waste package and drip shield are lumped into a monolithic heat source in the LDTH submodels (see Figure 6.2-6). Waste package density, drip shield density, and thermal conductivity should be averaged into this lumped approximation. The half-area (called $\mathrm{A}_{1 / 2}$ ) of the waste package and drip shield as represented in the LDTH submodel as a group of finite difference blocks with an area calculated as:

$$
\mathrm{A}_{1 / 2}=0.242 \times 0.58+0.40 \times(0.58+0.37)+(0.759+0.760+0.425) \times(0.58+0.37+0.3025)=2.9552 \mathrm{~m}^{2}
$$

These dimensions are obtained from the gridblock spacings in the LDTH submodels (see Figure 6.2-6). Table 4-1 gives the nominal number of waste packages in the repository: (1) 4,299 21PWR AP waste packages, (2) 2,831 44-BWR AP waste packages, and (3) 11,184 total waste packages. Therefore, the majority of waste packages (64 percent) will be either 21-PWR AP waste packages or 44-BWR AP waste packages; both of these waste packages weigh 43,000 kg and are $5.165 \mathrm{~m}$ in length (Table 4-1). After adding $0.1 \mathrm{~m}$ for the waste-package spacing (Table 4-1) to the length of the waste package, the weight per unit length of the majority of waste packages is $43,000 \mathrm{~kg}$ divided by $5.265 \mathrm{~m}(5.165 \mathrm{~m}+0.1 \mathrm{~m})$, or $8,200 \mathrm{~kg} / \mathrm{m}$. This is taken to be representative of the average waste package in the repository. The lineal weight per unit length of drip shield is equal to the weight of the drip shield $(5,000 \mathrm{~kg}$, given in Table 4-1) divided by the drip-shield length $(6.105 \mathrm{~m}$, given in Table 4-1), which is equal to $820 \mathrm{~kg} / \mathrm{m}$.

The lineal weight per unit length of the average waste package and drip shield is $8,200 \mathrm{~kg} / \mathrm{m}$ and $820 \mathrm{~kg} / \mathrm{m}$, respectively, yielding a total lineal weight of $9,020 \mathrm{~kg} / \mathrm{m}$. The equivalent density, $\rho_{\text {equiv }}$, of the LDTH waste package and drip shield is calculated as:

$$
\rho_{\text {equiv }}=(9,020 \mathrm{~kg} / \mathrm{m}) /\left(2 \times \mathrm{A}_{1 / 2}\right)=1,526.1 \mathrm{~kg} / \mathrm{m}^{3}
$$


The thermal conductivity of the waste package and drip shield is the sum of the thermal conductivity values weighted by the relative weight of the respective materials:

$$
K_{\text {th,equiv }}=K_{\text {th,ds }} \times(820 / 9,020)+K_{\text {th,wp }} \times(8,200 / 9,020)
$$

\section{SDT/DDT Submodel Thermal Properties}

The thermal properties are taken from files of the following sources: DTN: SN0303T0503102.008 [DIRS 162401], DTN: SN0307T0510902.003 [DIRS 164196], and DTN: SN0404T0503102.011 [DIRS 169129] (Table 7-10, File: readme.doc). Bulk thermal conductivity and bulk density (average and 1 standard deviation above and below) of the GFM2000 nonrepository layers are contained in DTN: SN0303T0503102.008 [DIRS 162401]. Bulk thermal conductivity and bulk density variation (mean, and 1 standard deviation above and below) of the repository horizon UZ model layers are contained in Table 7-10 of DTN: SN0404T0503102.011 [DIRS 169129] (File: readme.doc). The specific heat capacity of the mineralogical model units was taken from DTN: SN0307T0510902.003 [DIRS 164196]. The input data from these DTNs are summarized in Table IV-3a. As discussed in the footnotes of Table IV-3a there are minor differences between the specific heat capacity used for several mineralogical model units and those given in the source DTN: SN0307T0510902.003 [DIRS 164196]. These differences are much smaller than the range of uncertainty for the affected layers (see column Z of the excel spreadsheet for DTN: SN0307T0510902.003 [DIRS 164196]). The affected mineralogical model units are well removed from the repository horizon; consequently, these small differences have no effect on thermal-hydrologic conditions within and adjacent to emplacement drifts. The SDT, DDT, and SMT submodels use the bulk density and bulk thermal conductivity values and do not require that these values be partitioned into the fracture and matrix continuum. Note that because NUFT uses the grain density (also called solid density), the matrix porosity, which is obtained from DTN: LB0208UZDSCPMI.002 [DIRS 161243], is also required as input to the input files for the SDT, DDT, and SMT submodels.

The only parameter requiring a hand calculation for the SDT and DDT submodel near-field properties is the grain density (or solid density) $\rho_{\mathrm{g}}$, which is calculated as:

$$
\rho_{g}=\frac{\rho_{b}}{1-\phi_{m}}
$$

\section{DDT Submodel In-drift Thermal Properties}

The material properties for the DDT submodel are the same as the corresponding bulk thermal properties in the drift for the LDTH submodel. There is a difference with how the waste package and drip shield are accounted for in the DDT submodel, however, as the DDT submodel represents each waste package separately and discretizes the drip shield.

\section{Waste Package and Drip Shield Thermal Properties}

For the DDT submodel the weights of each individual waste package are discretely represented, not lumped, into an average representation of the drip shield and waste package, as was done for 
the LDTH submodel. The mass density of each waste package type (21-PWR, 44-BWR, 5DHLW-long, and 5DHLW-short) is determined by taking volumetric average of the materials (outer barrier, inner vessel, internal cylinder):

$$
\rho_{\mathrm{WP}}=\left[\rho_{\text {outer }}\left(\mathrm{d}_{3}^{2}-\mathrm{d}_{2}^{2}\right)+\rho_{\text {inner }}\left(\mathrm{d}_{2}^{2}-\mathrm{d}_{1}^{2}\right)+\rho_{\text {internal }}\left(\mathrm{d}_{1}^{2}\right)\right] / \mathrm{d}_{3}^{2}
$$

where $d_{3}$ is the outermost diameter of the waste package, $d_{2}$ is the inner diameter of the "outer barrier," and $\mathrm{d}_{1}$ is the diameter of the internal cylinder obtained. The mass densities, $\rho_{\mathrm{WP}}, \rho_{\text {outer, }}$ $\rho_{\text {inner}}$, and $\rho_{\text {internal }}$ are, respectively, the weighted waste package mass density, the outer-barrier mass density, the inner-vessel mass density, and the internal cylinder density. These diameters were obtained from Design and Engineering, D\&E/PA/C IED Typical Waste Package Components Assembly 1 of 9 (BSC 2003 [DIRS 165406], Table 1). The density of the outer barrier (Alloy 22) was obtained from DTN: MO0003RIB00071.000 [DIRS 148850]; the density of the inner vessel (Stainless Steel Type 316) was obtained from Table XI of ASTM G 1-90; the density of the internal cylinder was obtained from Table 20 of D\&E / PA/C IED Typical Waste Package Components Assembly (BSC 2004 [DIRS 169990]).

The effective waste package specific heat, $C p_{W P}$, of the DDT submodel are calculated for each waste package using a volumetric average of the corresponding materials:

$$
C p_{\mathrm{WP}}=\left[C \mathrm{p}_{\text {outer }}\left(\mathrm{d}_{3}{ }^{2}-\mathrm{d}_{2}{ }^{2}\right)+C \mathrm{p}_{\text {inner }}\left(\mathrm{d}_{2}{ }^{2}-\mathrm{d}_{1}{ }^{2}\right)+C \mathrm{p}_{\text {internal }}\left(\mathrm{d}_{1}{ }^{2}\right)\right] / \mathrm{d}_{3}^{2}
$$

where $d_{3}$ is the outer diameter of the outer barrier, $d_{2}$ is the outer diameter of the inner vessel, and $\mathrm{d}_{1}$ is the inner diameter of the inner vessel; $C \mathrm{p}_{\text {outer }}$ is the specific heat of the outer barrier, $C p_{\text {inner }}$ is the specific heat of the inner vessel, and $C p_{\text {internal }}$ is the specific heat of the internal cylinder.

The effective waste package thermal conductivity, $K_{\text {th,WP, }}$ also uses a volumetric average:

$$
K_{\text {th,WP }}=\left[K_{\text {th,outer }}\left(\mathrm{d}_{3}^{2}-\mathrm{d}_{2}^{2}\right)+K_{\text {th,inner }}\left(\mathrm{d}_{2}^{2}-\mathrm{d}_{1}^{2}\right)+K_{\text {th,internal }}\left(\mathrm{d}_{1}^{2}\right)\right] / \mathrm{d}_{3}^{2}
$$

The waste package thermal conductivity only influences longitudinal heat flow along the axis of the drift in the DDT submodel. In other words, radial heat flow (from the center of the waste package to the outer surface) is not predicted in the DDT submodel. Therefore, only the axial component of $K_{\text {th,WP }}$ is required in the DDT submodel. Because the materials in the waste package are concentrically arranged, the volumetric average of $K_{\text {th,WP }}$ of the respective components of the waste package is the appropriate manner in which to determine the effective waste package thermal conductivity.

The thermal parameters for the drip shield (Table 4-1) were taken directly from Table TCD of 1995 ASME Boiler and Pressure Vessel Code (ASME 1995, Section II). The thermal parameters required in the NUFT submodels necessitate the calculations described below for titanium.

Due to limitations of grid resolution in the drift of the DDT submodels, all waste packages are modeled as though they have the same diameter even though the actual diameters are not the same (Table 4-1). An effective density $\rho_{\text {eff }}$ is calculated for each of the respective waste packages so that the mass of each waste package is properly represented in the DDT submodels. 
The effective density $\rho_{\text {eff }}$ is equal to the mass of the waste package (Table 4-1) divided by volume of the waste package as it is represented in the DDT submodel.

\section{Thermal Properties for Stainless Steel Type 316 and Titanium}

Several of the direct inputs available for determining waste package and drip shield thermal properties require interpolation (to a reference temperature) and/or require simple calculations to the input parameters required by the DDT submodel. The thermal conductivity of Stainless Steel Type 316, which is used in the inner cylinder of the waste packages, requires interpolation to $100^{\circ} \mathrm{C}$. Furthermore, the specific heat for Stainless Steel Type 316 should be calculated on the basis of thermal diffusivity and thermal conductivity, which are direct inputs. Similarly, the thermal conductivity of titanium, which is used in the drip shield, require interpolation to a temperature of $100^{\circ} \mathrm{C}$. Furthermore, the specific heat for titanium should be calculated on the basis of thermal diffusivity and thermal conductivity, which are direct inputs. The following steps were used to obtain the required parameter values.

1. Mass density of Stainless Steel Type 316

$7.98 \mathrm{~g} / \mathrm{cm}^{3}=7,980 \mathrm{~kg} / \mathrm{m}^{3}=498.175 \mathrm{lb} / \mathrm{ft}^{3}$

The bold value above is taken from Table XI of ASTM G 1-90.

2. Thermal conductivity of Stainless Steel Type $316\left(T=100^{\circ} \mathrm{C}\right)$

Table IV-1. Interpolation of Thermal Diffusivity and Thermal Conductivity Outlined for Stainless Steel Type 316.

\begin{tabular}{|c|c|c|c|c|}
\hline $\begin{array}{c}\text { Temperature } \\
\left({ }^{\circ} \mathrm{F}\right)\end{array}$ & $\begin{array}{c}\text { Temperature } \\
\left({ }^{\circ} \mathrm{C}\right)\end{array}$ & $\begin{array}{c}\text { Thermal } \\
\text { Diffusivity } \\
\left.\text { (ft }{ }^{2} / \mathrm{hr}\right)\end{array}$ & $\begin{array}{c}\text { Thermal } \\
\text { Conductivity } \\
\text { (BTU/hr-ft- }{ }^{\circ} \text { F) }\end{array}$ & $\begin{array}{c}\text { Thermal } \\
\text { Conductivity } \\
(\mathrm{W} / \mathrm{m} \cdot \mathrm{K})\end{array}$ \\
\hline 200 & 93.33 & 0.141 & 8.4 & 14.54 \\
\hline 250 & 121.11 & 0.143 & 8.7 & 15.06 \\
\hline 212 & 100.00 & 0.1415 & 8.472 & 14.665 \\
\hline Conversion Factor & & & 1.0 & 1.730734666 \\
\hline
\end{tabular}

NOTE: The conversion of these parameters from English units to SI units is also shown. The bold values are from Table TCD of 1995 ASME Boiler and Pressure Vessel Code (ASME 1995).

$0.1415=\mathbf{0 . 1 4 1}+(\mathbf{0 . 1 4 3}-\mathbf{0 . 1 4 1}) \times \frac{212-200}{250-200}$

$8.472=\mathbf{8 . 4}+(\mathbf{8 . 7}-\mathbf{8 . 4}) \times \frac{212-200}{250-200}$

$14.665=14.54+(15.06-14.54) \times \frac{212-200}{250-200}$

$14.663=1.730734666 \times 8.472$ 
3. Specific heat of Stainless Steel Type $316\left(T=100^{\circ} \mathrm{C}\right)$

$$
\begin{aligned}
\text { Specific Heat }\left(\mathrm{BTU} / \mathrm{lb}-{ }^{\circ} \mathrm{F}\right) & =\frac{\text { Thermal Conductivity }\left(\mathrm{BTU} / \mathrm{hr}-\mathrm{ft}-{ }^{\circ} \mathrm{F}\right)}{\text { Density }\left(\mathrm{lb} / \mathrm{ft}^{3}\right) \text { Thermal Diffusivity }\left(\mathrm{ft}{ }^{2} / \mathrm{hr}\right)} \\
& =\frac{8.472}{498.175 \times 0.1415}=0.1202\left(\mathrm{BTU} / \mathrm{lb}-{ }^{\circ} \mathrm{F}\right) \\
& =503.19\left(\mathrm{~J} / \mathrm{kg}^{\circ}{ }^{\circ} \mathrm{K}\right) .
\end{aligned}
$$

4. Density of titanium

$0.163 \mathrm{lb} / \mathrm{in}^{3}=4521 \mathrm{~kg} / \mathrm{m}^{3}=281.675 \mathrm{lb} / \mathrm{ft}^{3}$

The bold value above is taken from Section II, Table NF-2 of 1995 ASME Boiler and Pressure Vessel Code (ASME 1995).

5. Thermal conductivity of titanium $\left(T=100^{\circ} \mathrm{C}\right)$

Table IV-2. Interpolation of Thermal Diffusivity and Thermal Conductivity Outlined for Titanium

\begin{tabular}{|c|c|c|c|c|}
\hline $\begin{array}{c}\text { Temperature } \\
\left({ }^{\circ} \mathbf{F}\right)\end{array}$ & $\begin{array}{c}\text { Temperature } \\
\left({ }^{\circ} \mathbf{C}\right)\end{array}$ & $\begin{array}{c}\text { Thermal } \\
\text { Diffusivity } \\
\left(\mathbf{f t}^{2} / \mathbf{h r}\right)\end{array}$ & $\begin{array}{c}\text { Thermal } \\
\text { Conductivity } \\
\left(\text { BTU/h-ft- }{ }^{\circ} \text { F) }\right.\end{array}$ & $\begin{array}{c}\text { Thermal } \\
\text { Conductivity } \\
(\mathbf{W} / \mathbf{m} \cdot \mathbf{K})\end{array}$ \\
\hline 200 & 93.33 & $\mathbf{0 . 3 3 1}$ & $\mathbf{1 2 . 0 0}$ & 20.7688 \\
\hline 250 & 121.11 & $\mathbf{0 . 3 2 2}$ & $\mathbf{1 1 . 8 5}$ & 20.5092 \\
\hline 212 & 100.00 & 0.3288 & 11.964 & 20.7065 \\
\hline
\end{tabular}

NOTE: The conversion of these parameters from English units to SI units is also shown. The bold values are taken from Section II, Table NF-2 of 1995 ASME Boiler and Pressure Vessel Code (ASME 1995).

$$
\begin{aligned}
& 0.3288=\mathbf{0 . 3 3 1}+(\mathbf{0 . 3 2 2}-\mathbf{0 . 3 3 1}) \times \frac{212-200}{250-200} \\
& 11.964=\mathbf{1 2 . 0}+(\mathbf{1 1 . 8 5}-\mathbf{1 2 . 0}) \times \frac{212-200}{250-200}
\end{aligned}
$$

6. Specific heat of titanium $\left(T=100^{\circ} \mathrm{C}\right)$

$$
\begin{aligned}
\text { Specific Heat }\left(\mathrm{BTU} / \mathrm{lb}-{ }^{\circ} \mathrm{F}\right) & =\frac{\text { Thermal Conductivity }\left(\mathrm{BTU} / \mathrm{h}-\mathrm{ft}-{ }^{\circ} \mathrm{F}\right)}{\text { Density }\left(\mathrm{lb} / \mathrm{ft}^{3}\right) \text { Thermal Diffusivity }\left(\mathrm{ft}^{2} / \mathrm{h}\right)} \\
& =\frac{11.964}{281.675 \times 0.3288}=0.1292\left(\mathrm{BTU} / \mathrm{lb}-{ }^{\circ} \mathrm{F}\right) \\
& =540.85(\mathrm{~J} / \mathrm{kg}-\mathrm{K}) .
\end{aligned}
$$

These simple calculations used the following conversion factors:

1. Heat Capacity: $1.0 \mathrm{Btu} /\left(\mathrm{lb}-{ }^{\circ} \mathrm{F}\right)=4186.8 \mathrm{~J} /(\mathrm{kg} \cdot \mathrm{K})$

2. Thermal Conductivity $1.0 \mathrm{Btu} /\left(\mathrm{h}-\mathrm{ft}-{ }^{\circ} \mathrm{F}\right)=1.730734666 \mathrm{~W} /(\mathrm{m} \cdot \mathrm{K})$ 
3. Density $1.0 \mathrm{~g} / \mathrm{cm}^{3}=62.427960576 \mathrm{lb} / \mathrm{ft}^{3}$

4. $\quad 1.0 \mathrm{lb} / \mathrm{in}^{3}=27,679.904710203 \mathrm{~kg} / \mathrm{m}^{3}$

\section{Invert Thermal Properties}

For the DDT submodels, the invert has the same bulk thermal properties as the bulk thermal properties in the LDTH submodels. That is to say that the thermal conductivity, specific heat, and mass density in the DDT submodels are the same as the bulk thermal conductivity, specific heat capacity, and bulk mass density of the invert in the LDTH submodels.

\section{SMT-Submodel thermal properties}

Only fault and saturated zone thermal properties need to be specifically calculated for the SMT submodel thermal properties. Otherwise, the SMT submodel uses the same thermal properties as the SDT submodels.

\section{Fault-Zone Thermal Properties}

The density of the fault zone is simply the average of all of the units that make up the fault zone:

$$
\begin{aligned}
& \rho_{\text {tcwfl }}=\left(\rho_{\text {tcwl1 }}+\rho_{\text {tcwl2 }}+\rho_{\text {tcwl3 }}\right) / 3 \\
& \rho_{\text {ptnfl }}=\left(\rho_{\text {ptn21 }}+\rho_{\text {ptn22 }}+\rho_{\text {ptn23 }}+\rho_{\text {ptn24 }}+\rho_{\text {ptn25 }}+\rho_{\text {ptn26 }}\right) / 6 \\
& \rho_{\text {tsw }}=\left(\rho_{\text {tsw31 }}+\rho_{\text {tsw } 32}+\rho_{\text {tsw33 }}+\rho_{\text {tsw } 34}+\rho_{\text {tsw } 35}+\rho_{\text {tsw } 36}+\rho_{\text {tsw37 }}+\rho_{\text {tsw } 38}+\rho_{\text {tsw } 9 v}+\rho_{\text {tsw } 9 z}\right) / 10 \\
& \rho_{\text {chlfl }}=\left(\rho_{\text {chlv }}+\rho_{\text {ch1z }}\right) / 2 \text { (similar for ch2fl, ch3fl, ch4fl, ch5fl, ch6fl) } \\
& \rho_{\mathrm{pp} 4 \mathrm{fl}}=\rho_{\mathrm{pp} 4}(\text { similar for pp3, pp2, pp1, bf } 3, \mathrm{bf} 2, \operatorname{tr} 3, \operatorname{tr} 2)
\end{aligned}
$$

The same process is used to determine the fault-zone properties for thermal conductivity, specific heat and porosity.

\section{Saturated Zone Thermal Properties}

The saturated zone intersects $14 \mathrm{UZ}$ model layers (ch1z, ch2z, ch3z ch4z, ch5z, ch6z, pp4, pp3, $\mathrm{pp} 2, \mathrm{pp} 1, \mathrm{bf} 3, \mathrm{bf} 2, \operatorname{tr} 3$, and $\operatorname{tr} 2)$. The saturated-zone density, thermal conductivity, specific heat, and porosity are simply calculated as the sum of the properties for those units divided by 14 .

\section{Rocktab File Example}

Listed below is a part of an example rocktab file (dkm-afc-1Dds-mc-mi-03) that would be called in a NUFT input file (see Appendix V). Of note is that several material properties are listed each delineated by the line ";; End of the material". Specific details of the rocktab file properties are found in the NUFT user's manual (Nitao 1998 [DIRS 100474], p. 41).

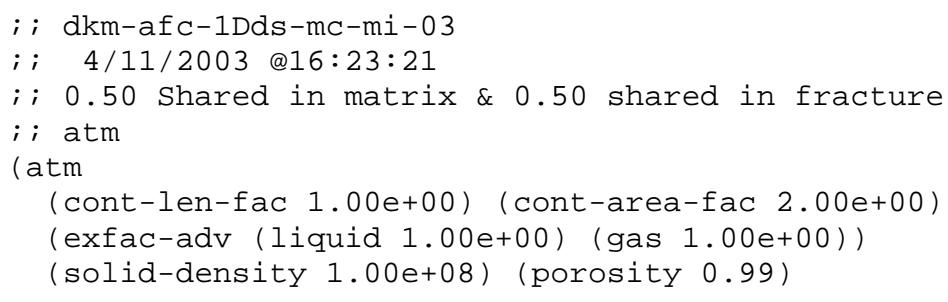




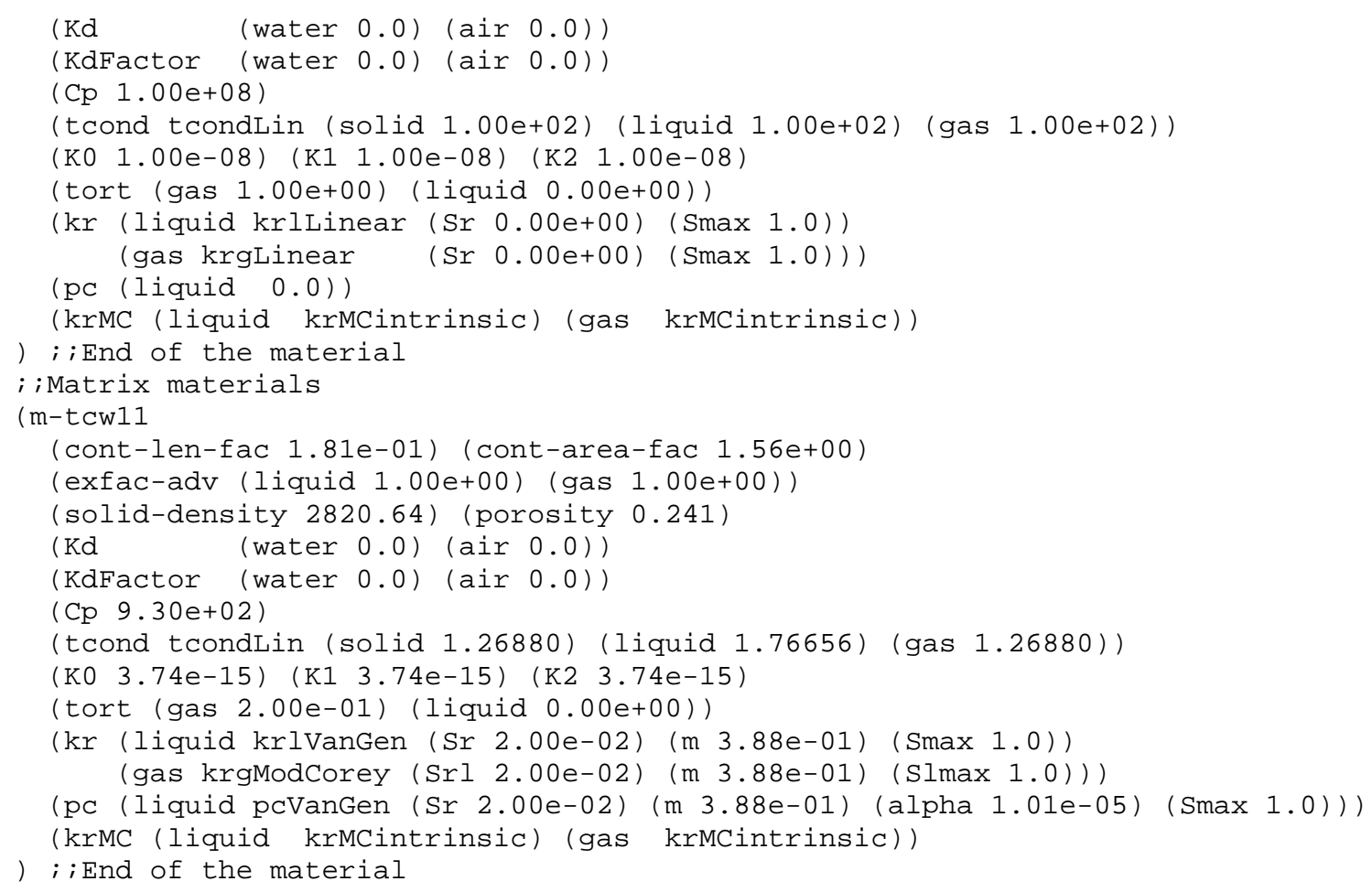

\section{[SECTION SKIP]}

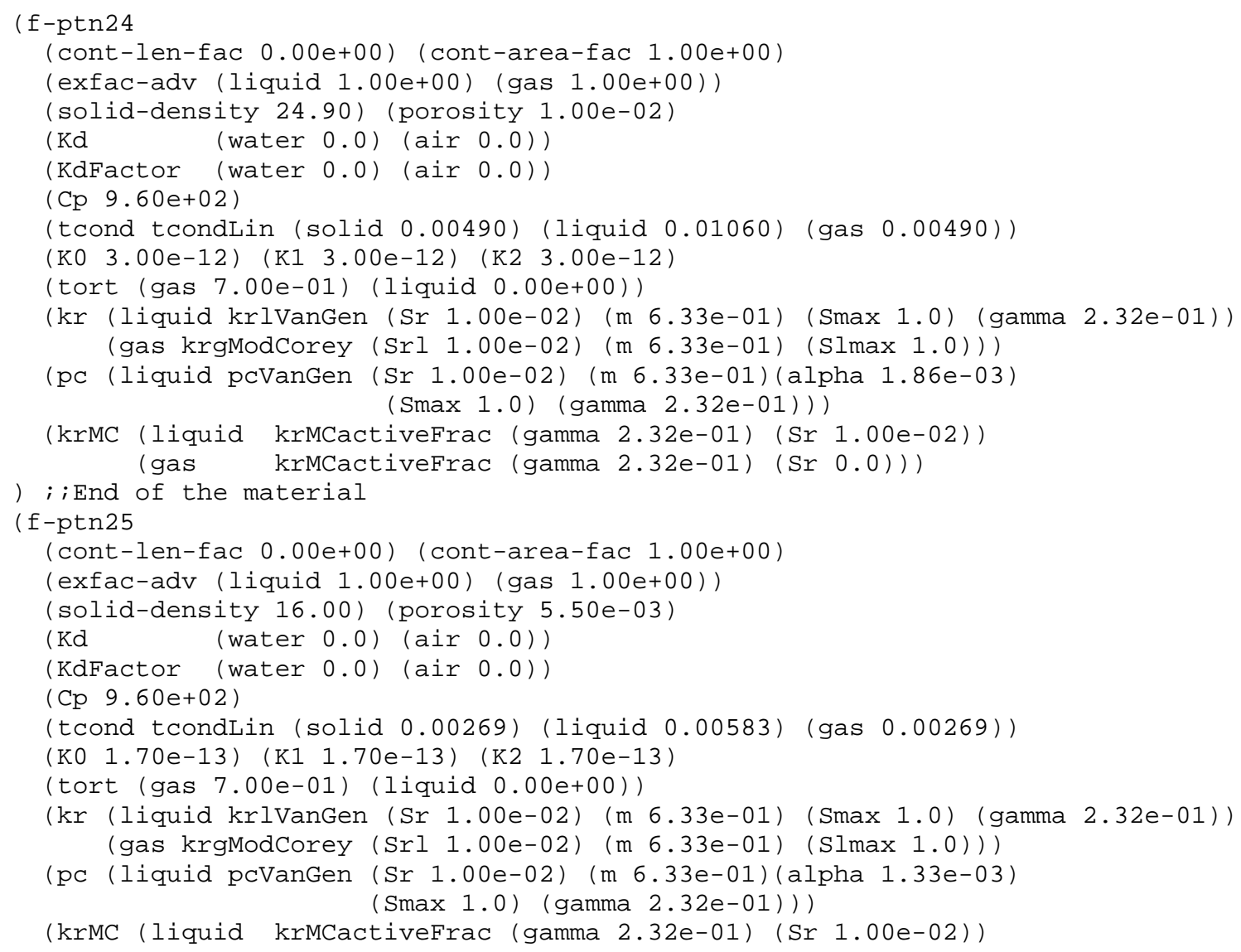


) ;; End of the material

\section{[SECTION SKIP]}

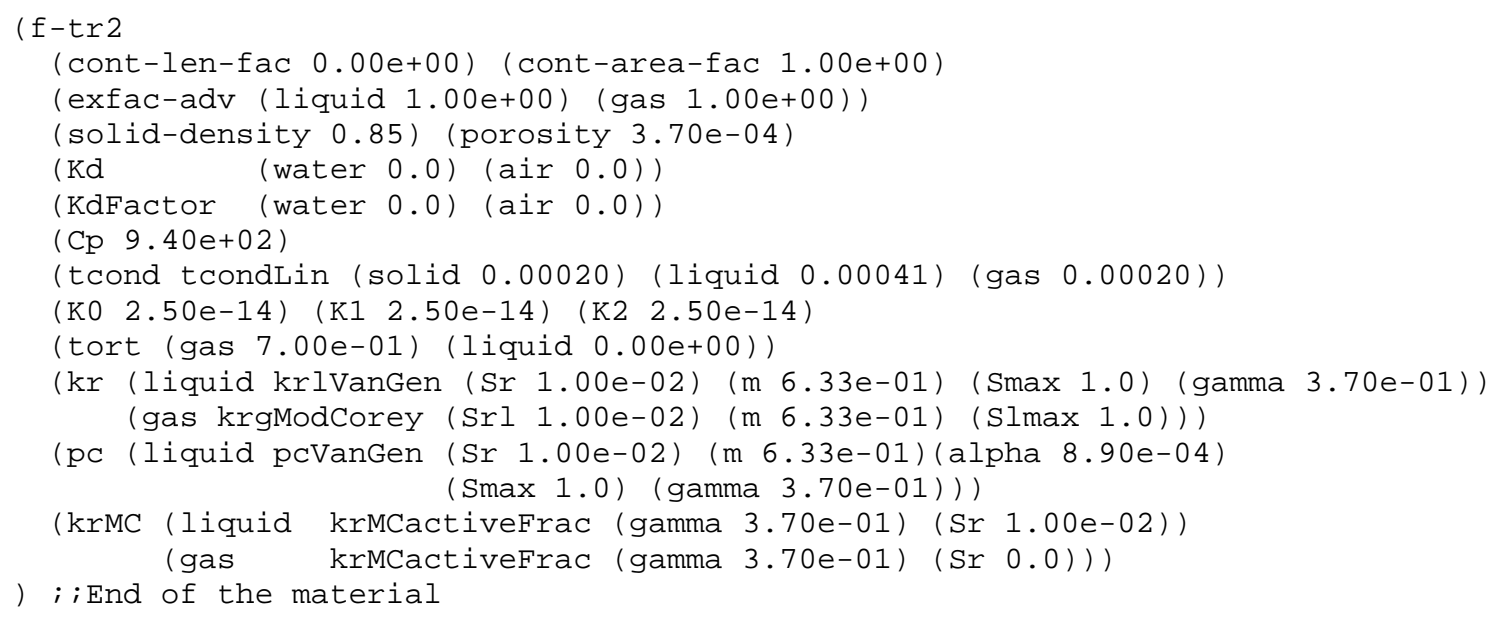


Table IV-3a. Specific Heat Capacity, Thermal Conductivity (Dry and Wet) and Bulk Density for the GFM2000 Units

\begin{tabular}{|c|c|c|c|c|c|c|}
\hline $\begin{array}{c}\text { Material } \\
\text { Name Used } \\
\text { in LDTH } \\
\text { Submodels } \\
\end{array}$ & $\begin{array}{c}\text { GFM2000 } \\
\text { Layer }\end{array}$ & $\begin{array}{l}\text { Mineralogic } \\
\text { Model Unit }\end{array}$ & $\begin{array}{c}\text { Bulk } \\
\text { Density } \\
\text { kg/m3 }\end{array}$ & $\begin{array}{c}\text { Thermal } \\
\text { Conductivity } \\
\text { Dry } \\
\text { W/m K } \\
\end{array}$ & $\begin{array}{c}\text { Thermal } \\
\text { Conductivity } \\
\text {, Wet } \\
\text { W/m K }\end{array}$ & $\begin{array}{c}\text { Specific } \\
\text { Heat } \\
\text { Capacity } \\
\mathrm{J} / \mathrm{g} \cdot \mathrm{K}\end{array}$ \\
\hline tcw11 & Tpcp & \multirow[t]{3}{*}{ Tpc_un } & 2,190 & 1.30 & 1.81 & 0.93 \\
\hline \multirow[t]{2}{*}{ tcw12 } & Tpcp & & 2,190 & 1.30 & 1.81 & 0.93 \\
\hline & TpcLD & & 2,190 & 1.30 & 1.81 & 0.93 \\
\hline \multirow[t]{2}{*}{ tcw13 } & Tpcpv3 & \multirow{2}{*}{$\begin{array}{l}\text { Tcppv3 - } \\
\text { Tpcpv2 }\end{array}$} & 2,310 & 0.688 & 0.796 & 0.95 \\
\hline & Tpcpv2 & & 1,460 & 0.490 & 1.06 & 0.95 \\
\hline ptn21 & Tpcpv1 & \multirow[t]{10}{*}{$\mathrm{PTn}^{\mathrm{f}}$} & 1,460 & 0.490 & 1.06 & 0.96 \\
\hline \multirow[t]{2}{*}{ ptn22 } & Tpbt4 & & 1,460 & 0.490 & 1.06 & 0.96 \\
\hline & Tpy (Yucca) & & 1,460 & 0.490 & 1.06 & 0.96 \\
\hline ptn23 & Tpbt3 & & 1,460 & 0.490 & 1.06 & 0.96 \\
\hline \multirow[t]{2}{*}{ ptn24 } & Tpy & & 1,460 & 0.490 & 1.06 & 0.96 \\
\hline & Tpbt3 & & 1,460 & 0.490 & 1.06 & 0.96 \\
\hline ptn25 & Tpp (Pah) & & 1,460 & 0.490 & 1.06 & 0.96 \\
\hline \multirow[t]{3}{*}{ ptn26 } & Tpbt2 & & 1,460 & 0.490 & 1.06 & 0.96 \\
\hline & Tptrv3 & & 1,460 & 0.490 & 1.06 & 0.96 \\
\hline & Tptrv2 & & 1,460 & 0.490 & 1.06 & 0.96 \\
\hline \multirow[t]{2}{*}{ tsw31 } & Tptrv1 & Tptrv1 & 2,310 & 0.688 & 0.796 & 0.95 \\
\hline & Tptrn & \multirow{3}{*}{$\begin{array}{l}\text { Tptrn - } \\
\text { Tptrl - } \\
\text { Tptf } \\
\end{array}$} & 2,190 & 1.30 & 1.81 & 0.93 \\
\hline tsw32 & Tptrn & & 2,190 & 1.30 & 1.81 & 0.93 \\
\hline \multirow[t]{2}{*}{ tsw33 } & Tptrl & & 2190 & 1.30 & 1.81 & 0.93 \\
\hline & Tptpul & Tptul & 1,830 & 1.1829 & 1.7749 & 0.93 \\
\hline tsw34 & Tptpmn & Tptpmn & 2,150 & 1.4189 & 2.0741 & 0.93 \\
\hline tsw35 & Tptpll & Tptpll & 1,980 & 1.2784 & 1.8895 & 0.93 \\
\hline tsw36 & Tptpln & \multirow[t]{2}{*}{ Tptpln } & 2,210 & 1.4900 & 2.1303 & 0.93 \\
\hline tsw37 & Tptpln & & 2,210 & 1.4900 & 2.1303 & 0.93 \\
\hline tsw38 & Tptpv3 & Tptpv3 & 2,310 & 0.688 & 0.796 & 0.98 \\
\hline tsw9v & Tptpv2 & \multirow[t]{2}{*}{ Tptpv2 } & 1,460 & 0.490 & 1.06 & $0.98^{\mathrm{a}}$ \\
\hline tsw9z & Tptpv2 & & 1,460 & 0.490 & 1.06 & 0.98 \\
\hline \multirow[t]{2}{*}{ ch1v } & Tptpv1 & \multirow{4}{*}{$\begin{array}{l}\text { Tptpv1 - } \\
\text { Tpbt1 }\end{array}$} & 1,460 & 0.490 & 1.06 & $1.08^{\mathrm{b}}$ \\
\hline & Tpbt1 & & 1,460 & 0.490 & 1.06 & $1.08^{\mathrm{b}}$ \\
\hline \multirow[t]{2}{*}{$\operatorname{ch} 1 \mathrm{z}$} & Tptpv1 & & 1,460 & 0.490 & 1.06 & 1.08 \\
\hline & Tpbt1 & & 1,460 & 0.490 & 1.06 & 1.08 \\
\hline $\operatorname{ch} 2 v$ & Tac (Calico) & \multirow{7}{*}{$\begin{array}{l}\text { Tac } \\
\text { (4 layers) }\end{array}$} & 1,670 & 0.595 & 1.26 & $1.07^{\mathrm{c}}$ \\
\hline $\operatorname{ch} 3 v$ & Tac (Calico) & & 1,670 & 0.595 & 1.26 & $1.07^{\mathrm{c}}$ \\
\hline $\operatorname{ch} 4 v$ & Tac (Calico) & & 1,670 & 0.595 & 1.26 & $1.07^{\mathrm{c}}$ \\
\hline $\operatorname{ch} 5 \mathrm{v}$ & Tac (Calico) & & 1,670 & 0.595 & 1.26 & $1.07^{\mathrm{C}}$ \\
\hline $\operatorname{ch} 2 z$ & Tac (Calico) & & 1,670 & 0.595 & 1.26 & 1.07 \\
\hline $\operatorname{ch} 3 z$ & Tac (Calico) & & 1,670 & 0.595 & 1.26 & 1.07 \\
\hline $\operatorname{ch} 4 z$ & Tac (Calico) & & 1,670 & 0.595 & 1.26 & 1.07 \\
\hline
\end{tabular}


Table IV-3a. Specific Heat Capacity, Thermal Conductivity (Dry and Wet) and Bulk Density for the GFM2000 Units (Continued)

\begin{tabular}{|c|c|c|c|c|c|c|}
\hline $\begin{array}{c}\text { Material } \\
\text { Name Used } \\
\text { in LDTH } \\
\text { Submodels } \\
\end{array}$ & $\begin{array}{c}\text { GFM2000 } \\
\text { Layer }\end{array}$ & $\begin{array}{c}\text { Mineralogic } \\
\text { Model Unit }\end{array}$ & $\begin{array}{c}\text { Bulk } \\
\text { Density } \\
\text { kg/m3 }\end{array}$ & $\begin{array}{c}\text { Thermal } \\
\text { Conductivity } \\
\text {, Dry } \\
\text { W/m K } \\
\end{array}$ & $\begin{array}{c}\text { Thermal } \\
\text { Conductivity } \\
\text {,Wet } \\
\text { W/m K }\end{array}$ & $\begin{array}{c}\text { Specific } \\
\text { Heat } \\
\text { Capacity } \\
\mathrm{J} / \mathrm{g} \cdot \mathrm{K}\end{array}$ \\
\hline $\operatorname{ch} 5 z$ & Tac (Calico) & Tac (Cont.) & 1,670 & 0.595 & 1.26 & 1.07 \\
\hline $\operatorname{ch} 6 \mathrm{v}$ & Tacbt (Calicobt) & \multirow[t]{2}{*}{ Tacbt } & 1,670 & 0.595 & 1.26 & $1.02 \mathrm{~d}$ \\
\hline $\operatorname{ch} 6 z$ & Tacbt (Calicobt) & & 1,670 & 0.595 & 1.26 & 1.02 \\
\hline pp4 & Tcpuv (Prowuv) & Tcpuv & 1,790 & 0.569 & 1.13 & 1.04 \\
\hline pp3 & Tcpuc (Prowuc) & \multirow{3}{*}{$\begin{array}{l}\text { Tcpuc - } \\
\text { Tcplc }\end{array}$} & 1,790 & 0.569 & 1.13 & 0.93 \\
\hline \multirow[t]{2}{*}{ pp2 } & Tcpmd (Prowmd) & & 2,070 & 1.06 & 1.63 & 0.93 \\
\hline & Tcplc (Prowlc) & & 1,790 & 0.569 & 1.13 & 0.93 \\
\hline \multirow[t]{3}{*}{ pp1 } & Tcplv (Prowlv) & \multirow{3}{*}{$\begin{array}{l}\text { Tcplv - } \\
\text { Tcbuv }\end{array}$} & 1,790 & 0.569 & 1.13 & $1.05 \mathrm{e}$ \\
\hline & Tcpbt (Prowbt) & & 1,790 & 0.569 & 1.13 & $1.05 \mathrm{e}$ \\
\hline & Tcbuv (Bullfroguv) & & 1,880 & 0.658 & 1.19 & $1.05 \mathrm{e}$ \\
\hline \multirow[t]{3}{*}{ bf3 } & Tcbuc (Bullfroguc) & \multirow{3}{*}{$\begin{array}{l}\text { Tcbuc - } \\
\text { Tcblc }\end{array}$} & 1,880 & 0.658 & 1.19 & 0.93 \\
\hline & Tcbmd (Bullfrogmd) & & 2,260 & 1.30 & 1.81 & 0.93 \\
\hline & Tcblc (Bullfroglc) & & 1,880 & 0.658 & 1.19 & 0.93 \\
\hline \multirow[t]{3}{*}{ bf2 } & Tcblv (Bullfroglv) & \multirow{3}{*}{$\begin{array}{l}\text { Tcblv - } \\
\text { Tctuv }\end{array}$} & 1,880 & 0.658 & 1.19 & 1.05 \\
\hline & Tcbbt (Bullfrogbt) & & 1,880 & 0.658 & 1.19 & 1.05 \\
\hline & Tctuv (Tramuv) & & 1,760 & 0.535 & 1.10 & 1.05 \\
\hline \multirow[t]{3}{*}{$\operatorname{tr} 3$} & Tctuc (Tramuc) & \multirow{3}{*}{$\begin{array}{l}\text { Tctuc - } \\
\text { Tctlc }\end{array}$} & 1,760 & 0.535 & 1.10 & 0.94 \\
\hline & Tctmd (Trammd) & & 2,140 & 1.06 & 1.63 & 0.94 \\
\hline & Tctlc (Tramlc) & & 1,760 & 0.535 & 1.10 & 0.94 \\
\hline \multirow[t]{2}{*}{$\operatorname{tr} 2$} & Tctlv (Tramlv) & \multirow{2}{*}{$\begin{array}{l}\text { Tctlv - } \\
\text { Tctbt }\end{array}$} & 1,760 & 0.535 & 1.10 & 0.94 \\
\hline & Tctbt (Trambt) & & 1,760 & 0.535 & 1.10 & 0.94 \\
\hline
\end{tabular}

${ }^{a}$ Zeolitic value of specific heat capacity $(0.98 \mathrm{~J} / \mathrm{g} \cdot \mathrm{K})$ is used rather than the vitric value $(0.96 \mathrm{~J} / \mathrm{g} \cdot \mathrm{K})$.

${ }^{\mathrm{b}}$ Zeolitic value of specific heat capacity $(1.08 \mathrm{~J} / \mathrm{g} \cdot \mathrm{K})$ is used rather than the vitric value $(0.96 \mathrm{~J} / \mathrm{g} \cdot \mathrm{K})$.

${ }^{c}$ Zeolitic value of specific heat capacity $(1.07 \mathrm{~J} / \mathrm{g} \cdot \mathrm{K})$ is used rather than the vitric value $(0.96 \mathrm{~J} / \mathrm{g} \cdot \mathrm{K})$.

${ }^{d}$ Zeolitic value of specific heat capacity $(1.02 \mathrm{~J} / \mathrm{g} \cdot \mathrm{K})$ is used rather than the vitric value $(0.97 \mathrm{~J} / \mathrm{g} \cdot \mathrm{K})$.

${ }^{\mathrm{e}}$ Specific heat capacity value for the Tcblv-Tctuv $(1.05 \mathrm{~J} / \mathrm{g} \cdot \mathrm{K})$ is used rather than for the Tcplv-Tcbuv (1.10 $\mathrm{J} / \mathrm{g} \cdot \mathrm{K})$.

f Ptn = Tpcpv1, Tpbt4, Tpy, Tpbt3, Tpp, Tpbt2, Tptrv3, Tptrv2

NOTE: The values for the nonrespository layers are from DTN: SN0303T0503102.008 [DIRS 162401]. The thermal conductivity and bulk density values for the repository layers (tsw33, tsw34, tsw35, tsw36, and tsw37) are from Table 7-10 of DTN: SN0404T0503102.011 [DIRS 169129] (File: readme.doc), with the density values rounded. The GFM2000 layers shown in italics pertain to data obtained from Table 7-10 of DTN: SN0404T0503102.011 [DIRS 169129] (File: readme.doc). The bulk density values from DTN: SN0404T0503102.011 [DIRS 169129] (File: readme.doc) have been slightly rounded to be consistent with the bulk density values from DTN: SN0303T0503102.008 [DIRS 162401]. Mineralogic model units are from Heat Capacity Analysis Report (BSC 2004 [DIRS 170003], Tables 6.1 and 6.7). The specific heat capacity for all layers is from DTN:

SN0307T0510902.003 [DIRS 164196] for the temperature range of 25 to $325^{\circ} \mathrm{C}$. The values of specific heat capacity, thermal conductivity, and bulk density for the layers with multiple GFM2000 layers (e.g., pp1) are the arithmetic average of the corresponding GFM2000-layer values. Table IV$3 \mathrm{~b}$ gives the result of this averaging for bulk density and bulk thermal conductivity. 
Table IV-3b. Thermal Properties for the UZ Model Layers.

\begin{tabular}{|c|c|c|c|c|c|c|c|c|c|c|c|c|}
\hline \multirow[b]{2}{*}{$\begin{array}{c}\text { Material } \\
\text { Name }\end{array}$} & \multicolumn{2}{|c|}{ Porosity } & \multicolumn{4}{|c|}{ Density } & \multicolumn{6}{|c|}{ Thermal Conductivity } \\
\hline & $\phi_{\mathrm{m}}$ & $\phi_{f}$ & $\underset{\mathrm{kg} / \mathrm{m}^{3}}{\rho_{\mathrm{b}}}$ & $\underset{\mathrm{kg} / \mathrm{m}^{3}}{\rho_{\mathrm{G}}}$ & $\begin{array}{c}\rho_{\mathrm{G}, \mathrm{m}} \\
\mathrm{kg} / \mathrm{m}^{3}\end{array}$ & $\underset{\mathrm{kg} / \mathrm{m}^{3}}{\rho_{\mathrm{G},}}$ & $\begin{array}{c}K_{\mathrm{th}, \mathrm{b}} \\
\text { wet } \\
\mathrm{W} / \mathrm{m}^{\circ} \mathrm{C}\end{array}$ & $\begin{array}{c}K_{\text {th,m }} \\
\text { wet } \\
W / m^{\circ} \mathrm{C}\end{array}$ & $\begin{array}{c}K_{\mathrm{th}, \mathrm{f}} \\
\text { wet } \\
\mathrm{W}^{\circ} / \mathrm{m}^{\circ} \mathrm{C}\end{array}$ & $\begin{array}{c}K_{\text {th,b }} \\
\text { dry } \\
\text { W/m } / \mathrm{m}^{\circ} \mathrm{C}\end{array}$ & $\begin{array}{c}K_{\text {th,m }} \\
\text { dry } \\
W / m^{\circ} \mathrm{C}\end{array}$ & $\begin{array}{c}K_{\mathrm{th}, \mathrm{f}} \\
\text { dry } \\
\mathrm{W} / \mathrm{m}^{\circ} \mathrm{C}\end{array}$ \\
\hline tcw11 & 0.241 & $2.40 \mathrm{E}-02$ & 2190 & 2890 & \begin{tabular}{|l|}
2820.64 \\
\end{tabular} & 69.36 & 1.81 & \begin{tabular}{|l|}
1.767 \\
\end{tabular} & 4.34E-02 & 1.30 & 1.269 & $3.12 \mathrm{E}-02$ \\
\hline tcw12 & 0.088 & $1.70 \mathrm{E}-02$ & 2190 & 2400 & 2359.20 & 40.80 & 1.81 & 1.779 & \begin{tabular}{|l|}
$3.08 \mathrm{E}-02$ \\
\end{tabular} & .30 & 1.278 & $2.21 \mathrm{E}-02$ \\
\hline tcw13 & 0.200 & $1.30 \mathrm{E}-02$ & 1890 & 2360 & 2329.32 & 30.68 & & 0.918 & & & .582 & \\
\hline ptn21 & 0.387 & $9.20 \mathrm{E}-03$ & 1460 & 2380 & 2358.10 & 21.90 & .06 & 1.050 & & & & \\
\hline ptn22 & 0.428 & $1.00 \mathrm{E}-02$ & 1460 & 2550 & 2524.50 & 25.50 & 1.06 & 1.049 & & & .485 & \\
\hline ptn23 & 0.233 & $2.10 \mathrm{E}-03$ & 1460 & 1900 & 1896.01 & 3.99 & 1.06 & 1.058 & & & & \\
\hline ptn24 & 0.413 & $1.00 \mathrm{E}-02$ & 1460 & 2490 & 2465.10 & 24.90 & & 1.049 & & ( & 0.485 & \\
\hline ptn25 & 0.498 & & 1460 & 2910 & & & & 1.054 & & & & \\
\hline ptn26 & 0.490 & & 1460 & 2860 & & & 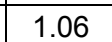 & 1.057 & & & & \\
\hline tsw31 & & & 2250 & 2380 & & & & 1.294 & & & & \\
\hline tsw32 & 0.15 & & 2190 & 2600 & 257 & & & 1.795 & & & & \\
\hline tsw33 & 0.155 & $5.80 \mathrm{E}-03$ & 2010 & 2380 & 2366.20 & 13.80 & 1.79 & 1.780 & & & 1.233 & \\
\hline tsw34 & & & 2150 & 2420 & & & & 2.052 & & & & \\
\hline sw35 & & & 1980 & 2280 & & & & 1.872 & & & & \\
\hline tsw36 & 0. & & 2210 & 2460 & & & & 2.102 & & & & \\
\hline tsw37 & & & 2210 & 2460 & & & & 2.102 & & & & \\
\hline tsw38 & 0.043 & $1.10 \mathrm{E}-02$ & 2310 & 2410 & & 26.51 & 0.80 & 0.791 & \begin{tabular}{|l|}
$8.80 \mathrm{E}-03$ \\
\end{tabular} & ( & 0.682 & $7.59 \mathrm{E}-03$ \\
\hline tsw9v & $0.115^{\mathrm{a}}$ & $115^{\mathrm{a}}$ & 1460 & $1890^{b}$ & & $824.39^{c}$ & & 1.060 & & & 0.490 & \\
\hline tsw9z & & & 1460 & 2010 & & & & 1.055 & & & & \\
\hline $\operatorname{ch1v}$ & $0.166^{a}$ & & 1460 & $2180^{b}$ & 87 & $874.78^{\mathrm{C}}$ & & 1.060 & & & 90 & \\
\hline $\operatorname{ch} 1 \mathrm{z}$ & 0.285 & -04 & 1460 & 2040 & & & & 1.060 & 1.70E-04 & & .490 & $8.00 \mathrm{E}-05$ \\
\hline $\operatorname{ch} 2 v$ & $0.173^{\mathrm{a}}$ & $0.173^{\mathrm{a}}$ & 1670 & $2550^{\mathrm{b}}$ & $1009.67^{c}$ & $1009.67^{c}$ & 1.26 & 1.260 & & 0.6 & 0.600 & $\mathrm{~N} / \mathrm{A}$ \\
\hline $\operatorname{ch} 3 v$ & $0.173^{\mathrm{a}}$ & $0.173^{\mathrm{a}}$ & 1670 & $2550^{\mathrm{b}}$ & $1009.67^{c}$ & $1009.67^{c}$ & 1.26 & 1.260 & & & 0.600 & $\mathrm{~N} / \mathrm{A}$ \\
\hline $\operatorname{ch} 4 v$ & $0.173^{\mathrm{a}}$ & & 1670 & $2550^{\mathrm{b}}$ & 100 & $1009.67^{c}$ & & & & & & \\
\hline $\operatorname{ch} 5 \mathrm{v}$ & $0.173^{\mathrm{a}}$ & $73^{\mathrm{a}}$ & 1670 & $2550^{\mathrm{b}}$ & $1009.67^{c}$ & $1009.67^{c}$ & & 1.260 & & & & \\
\hline $\operatorname{ch} 2 z$ & 0.322 & $3.70 \mathrm{E}-04$ & 1670 & 2460 & 245 & 0.91 & 1.2 & 1.260 & 4.70E-04 & 0.6 & 0.600 & \\
\hline $\operatorname{ch} 3 z$ & 0.322 & & 1670 & 2460 & 2459.09 & & & 1.260 & & & 0.600 & $E-04$ \\
\hline $\operatorname{ch} 4 z$ & 0.322 & $3.70 \mathrm{E}-04$ & 1670 & 2460 & 2459.09 & 0.91 & & 1.260 & 4.70E-04 & 0.6 & 0.600 & $2.20 \mathrm{E}-04$ \\
\hline $\operatorname{ch} 5 z$ & & & 1670 & 2460 & & & & 1.260 & 4.70 & & & $2.20 \mathrm{E}-04$ \\
\hline ch6v & $0.166^{\mathrm{a}}$ & & 1670 & $2550^{\mathrm{b}}$ & & $1000.60^{c}$ & & 1.260 & & & & \\
\hline ch6z & & & 1670 & 2290 & & & & 1.260 & & & 0.600 & \\
\hline pp4 & 0.32 & & 1790 & 2640 & & & & 1.130 & 4.20E-04 & 0.5 & 0.570 & $2.10 \mathrm{E}-04$ \\
\hline pp3 & & & 1790 & 2620 & 2617.46 & 2.54 & & 1.129 & 1.10E-03 & 0.57 & 0.569 & $5.50 \mathrm{E}-04$ \\
\hline pp2 & 0.221 & $9.70 \mathrm{E}-04$ & 1930 & 2480 & 2477.59 & 2.41 & 1.38 & 1.379 & $1.34 \mathrm{E}-03$ & 0.81 & 0.809 & $7.90 \mathrm{E}-04$ \\
\hline $\mathrm{pp} 1$ & 0.297 & $3.70 \mathrm{E}-04$ & 1820 & 2590 & 2589.04 & 0.96 & 1.15 & 1.150 & 4.30E-04 & 0.60 & & $2.20 \mathrm{E}-04$ \\
\hline bf3 & & & 2010 & 2440 & 2437.63 & & & 1.399 & & 0.87 & 0.869 & $8.40 \mathrm{E}-04$ \\
\hline bf2 & & & 1840 & 2400 & & & & 1.160 & & 0.62 & 0.620 & $2.30 \mathrm{E}-04$ \\
\hline tr3 & 0.175 & $9.70 \mathrm{E}-04$ & 1890 & 2290 & 2287.78 & 2.22 & 1.28 & 1.279 & $1.24 \mathrm{E}-03$ & 0.71 & 0.709 & $6.90 \mathrm{E}-04$ \\
\hline $\operatorname{tr} 2$ & 0.234 & $3.70 \mathrm{E}-04$ & 1760 & 2300 & 2299.15 & 0.85 & 1.10 & 1.100 & $4.10 \mathrm{E}-04$ & 0.54 & 0.540 & $2.00 \mathrm{E}-04$ \\
\hline
\end{tabular}

${ }^{\text {a }}$ Vitric units have matrix porosity partitioned $50 \%$ to the matrix continuum and $50 \%$ to the pseudo-fracture continuum.

${ }^{\mathrm{b}}$ Value not used in LDTH submodel.

${ }^{c}$ Vitric units have grain density partitioned $50 \%$ to the matrix continuum and $50 \%$ to the pseudo-fracture continuum.

NOTES: The subscripts $\mathrm{m}, \mathrm{f}, \mathrm{b}$, and $\mathrm{g}$ stand for matrix, fracture, bulk, and grain, respectively. The bulk density $\rho_{\beta}$ and bulk thermal conductivity $K_{\mathrm{th}, \mathrm{b}}$ (wet and dry) are obtained from Table IV-3a, with averaging applied to UZ model layers with multiple GFM2000 layers. The density and thermal-conductivity for the matrix and fracture continua are calculated by hand on the basis of fracture porosity.

Porosity values are derived from Table IV-4. 
Multiscale Thermohydrologic Model

Table IV-4. Matrix and Fracture Properties for the Mean Infiltration Flux One-Dimensional Drift-Scale Hydrologic Property Set

\begin{tabular}{|c|c|c|c|c|c|c|c|}
\hline $\begin{array}{c}\text { Material } \\
\text { name } \\
\text { from DTN } \\
\text { source }\end{array}$ & $\begin{array}{c}\text { Material } \\
\text { name used in } \\
\text { LDTH } \\
\text { submodels }\end{array}$ & $\begin{array}{c}\text { Permeability } \\
{\left[\mathrm{m}^{2}\right]}\end{array}$ & $\begin{array}{c}\text { Porosity } \\
{[-]}\end{array}$ & $\begin{array}{c}\text { Residual } \\
\text { saturation } \\
{[-]}\end{array}$ & $\begin{array}{c}\alpha \text { (alpha) } \\
{[1 / \mathrm{Pa}]}\end{array}$ & $\begin{array}{l}\mathbf{m} \\
{[-]}\end{array}$ & $\gamma \underset{[-]}{\gamma \text { (gamma) }}$ \\
\hline tcwM1 & m-tcw11 & $3.74 \mathrm{E}-15$ & 0.241 & 0.02 & 1.01E-05 & 0.388 & $N / A^{a}$ \\
\hline tcwM2 & m-tcw12 & $5.52 \mathrm{E}-20$ & 0.088 & 0.20 & $3.11 \mathrm{E}-06$ & 0.280 & $\mathrm{~N} / \mathrm{A}^{\mathrm{a}}$ \\
\hline tcwM3 & m-tcw13 & $5.65 \mathrm{E}-17$ & 0.200 & 0.31 & $3.26 \mathrm{E}-06$ & 0.259 & $\mathrm{~N} / \mathrm{A}^{\mathrm{a}}$ \\
\hline ptnM1 & m-ptn21 & $4.60 \mathrm{E}-15$ & 0.387 & 0.24 & 1.62E-04 & 0.245 & $\mathrm{~N} / \mathrm{A}^{\mathrm{a}}$ \\
\hline ptnM2 & m-ptn22 & $4.43 \mathrm{E}-12$ & 0.428 & 0.13 & 1.46E-04 & 0.219 & $\mathrm{~N} / \mathrm{A}^{\mathrm{a}}$ \\
\hline ptnM3 & m-ptn23 & $9.20 \mathrm{E}-15$ & 0.233 & 0.07 & 2.47E-05 & 0.247 & $\mathrm{~N} / \mathrm{A}^{\mathrm{a}}$ \\
\hline ptnM4 & m-ptn24 & $2.35 \mathrm{E}-12$ & 0.413 & 0.14 & 7.90E-04 & 0.182 & $\mathrm{~N} / \mathrm{A}^{\mathrm{a}}$ \\
\hline ptnM5 & m-ptn25 & $2.15 \mathrm{E}-13$ & 0.498 & 0.06 & 1.04E-04 & 0.300 & $\mathrm{~N} / \mathrm{A}^{\mathrm{a}}$ \\
\hline ptnM6 & m-ptn26 & $1.00 \mathrm{E}-11$ & 0.490 & 0.05 & 9.83E-04 & 0.126 & $N / A^{a}$ \\
\hline tswM1 & m-tsw31 & $2.95 \mathrm{E}-17$ & 0.054 & 0.21 & $8.70 \mathrm{E}-05$ & 0.218 & $\mathrm{~N} / \mathrm{A}^{\mathrm{a}}$ \\
\hline tswM2 & m-tsw32 & $2.23 \mathrm{E}-16$ & 0.157 & 0.07 & 1.14E-05 & 0.290 & $\mathrm{~N} / \mathrm{A}^{\mathrm{a}}$ \\
\hline tswM3 & m-tsw33 & $6.57 \mathrm{E}-18$ & 0.155 & 0.12 & $6.17 \mathrm{E}-06$ & 0.283 & $\mathrm{~N} / \mathrm{A}^{\mathrm{a}}$ \\
\hline tswM4 & m-tsw34 & 1.77E-19 & 0.111 & 0.19 & $8.45 \mathrm{E}-06$ & 0.317 & $\mathrm{~N} / \mathrm{A}^{\mathrm{a}}$ \\
\hline tswM5 & m-tsw35 & $4.48 \mathrm{E}-18$ & 0.131 & 0.12 & 1.08E-05 & 0.216 & $N / A^{a}$ \\
\hline tswM6 & m-tsw36 & 2.00E-19 & 0.103 & 0.20 & 8.32E-06 & 0.442 & $N / A^{a}$ \\
\hline tswM7 & m-tsw37 & $2.00 \mathrm{E}-19$ & 0.103 & 0.20 & $8.32 \mathrm{E}-06$ & 0.442 & $N / A^{a}$ \\
\hline tswM8 & m-tsw38 & $2.00 \mathrm{E}-18$ & 0.043 & 0.42 & 6.23E-06 & 0.286 & $\mathrm{~N} / \mathrm{A}^{\mathrm{a}}$ \\
\hline tswMv & m-tsw9v & 1.49E-13 & 0.229 & 0.13 & 4.86E-05 & 0.293 & $N / A^{a}$ \\
\hline tswMz & m-tsw9z & $3.5 \mathrm{E}-17$ & 0.275 & 0.36 & $4.61 \mathrm{E}-06$ & 0.059 & $\mathrm{~N} / \mathrm{A}^{\mathrm{a}}$ \\
\hline ch1Mv & m-ch1v & $6.65 \mathrm{E}-13$ & 0.331 & 0.06 & 8.73E-05 & 0.240 & $N / A^{a}$ \\
\hline $\operatorname{ch} 1 \mathrm{Mz}$ & m-ch1z & $3.5 \mathrm{E}-17$ & 0.285 & 0.38 & $2.12 \mathrm{E}-07$ & 0.349 & $\mathrm{~N} / \mathrm{A}^{\mathrm{a}}$ \\
\hline ch2Mv & m-ch2v & $2.97 \mathrm{E}-11$ & 0.346 & 0.06 & $2.59 \mathrm{E}-04$ & 0.158 & $\mathrm{~N} / \mathrm{A}^{\mathrm{a}}$ \\
\hline ch3Mv & m-ch3v & $2.97 \mathrm{E}-11$ & 0.346 & 0.06 & 2.59E-04 & 0.158 & $N / A^{a}$ \\
\hline ch4Mv & m-ch4v & 2.97E-11 & 0.346 & 0.06 & $2.59 \mathrm{E}-04$ & 0.158 & $N / A^{a}$ \\
\hline ch5Mv & m-ch5v & 2.97E-11 & 0.346 & 0.06 & $2.59 \mathrm{E}-04$ & 0.158 & $\mathrm{~N} / \mathrm{A}^{\mathrm{a}}$ \\
\hline ch2Mz & m-ch2z & $5.2 \mathrm{E}-18$ & 0.322 & 0.26 & $2.25 \mathrm{E}-06$ & 0.257 & $\mathrm{~N} / \mathrm{A}^{\mathrm{a}}$ \\
\hline ch3Mz & m-ch3z & $5.2 \mathrm{E}-18$ & 0.322 & 0.26 & $2.25 \mathrm{E}-06$ & 0.257 & $\mathrm{~N} / \mathrm{A}^{\mathrm{a}}$ \\
\hline ch4Mz & m-ch4z & $5.2 \mathrm{E}-18$ & 0.322 & 0.26 & $2.25 \mathrm{E}-06$ & 0.257 & $\mathrm{~N} / \mathrm{A}^{\mathrm{a}}$ \\
\hline ch5Mz & m-ch5z & $5.2 \mathrm{E}-18$ & 0.322 & 0.26 & $2.25 \mathrm{E}-06$ & 0.257 & $\mathrm{~N} / \mathrm{A}^{\mathrm{a}}$ \\
\hline ch6Mv & m-ch6v & $2.35 \mathrm{E}-13$ & 0.331 & 0.06 & 1.57E-05 & 0.147 & $\mathrm{~N} / \mathrm{A}^{\mathrm{a}}$ \\
\hline ch6Mz & m-ch6z & $8.2 \mathrm{E}-19$ & 0.271 & 0.36 & $1.56 \mathrm{E}-07$ & 0.499 & $\mathrm{~N} / \mathrm{A}^{\mathrm{a}}$ \\
\hline $\mathrm{pp} 4 \mathrm{Mz}$ & m-pp4 & $8.77 \mathrm{E}-17$ & 0.321 & 0.29 & 4.49E-07 & 0.474 & $\mathrm{~N} / \mathrm{A}^{\mathrm{a}}$ \\
\hline pp3Md & m-pp3 & $7.14 \mathrm{E}-14$ & 0.318 & 0.08 & 8.83E-06 & 0.407 & $\mathrm{~N} / \mathrm{A}^{\mathrm{a}}$ \\
\hline pp2Md & m-pp2 & $1.68 \mathrm{E}-15$ & 0.221 & 0.10 & $2.39 \mathrm{E}-06$ & 0.309 & $\mathrm{~N} / \mathrm{A}^{\mathrm{a}}$ \\
\hline $\mathrm{pp} 1 \mathrm{Mz}$ & m-pp1 & $2.35 \mathrm{E}-15$ & 0.297 & 0.30 & $9.19 \mathrm{E}-07$ & 0.272 & $\mathrm{~N} / \mathrm{A}^{\mathrm{a}}$ \\
\hline bf3Md & m-bf3 & $4.34 \mathrm{E}-13$ & 0.175 & 0.11 & 1.26E-05 & 0.193 & $\mathrm{~N} / \mathrm{A}^{\mathrm{a}}$ \\
\hline bf2Mz & m-bf2 & $8.1 \mathrm{E}-17$ & 0.234 & 0.21 & $1.18 \mathrm{E}-07$ & 0.617 & $\mathrm{~N} / \mathrm{A}^{\mathrm{a}}$ \\
\hline tr3Md & m-tr3 & $1.1 \mathrm{E}-15$ & 0.175 & 0.11 & 1.12E-05 & 0.193 & $\mathrm{~N} / \mathrm{A}^{\mathrm{a}}$ \\
\hline $\operatorname{tr} 2 \mathrm{Mz}$ & $m-\operatorname{tr} 2$ & $8.1 \mathrm{E}-17$ & 0.234 & 0.21 & 1.18E-07 & 0.617 & $\mathrm{~N} / \mathrm{A}^{\mathrm{a}}$ \\
\hline tcwF1 & f-tcw11 & $3.0 \mathrm{E}-11$ & $2.4 \mathrm{E}-02$ & 0.01 & 5.27E-03 & 0.633 & 0.587 \\
\hline tcwF2 & f-tcw12 & $5.3 \mathrm{E}-12$ & 1.7E-02 & 0.01 & 1.57E-03 & 0.633 & 0.587 \\
\hline tcwF3 & f-tcw13 & $4.5 \mathrm{E}-12$ & $1.3 \mathrm{E}-02$ & 0.01 & $1.24 \mathrm{E}-03$ & 0.633 & 0.587 \\
\hline
\end{tabular}


Table IV-4. Matrix and Fracture Properties for the Mean Infiltration Flux One-Dimensional Drift-Scale Hydrologic Property Set (Continued)

\begin{tabular}{|c|c|c|c|c|c|c|c|}
\hline $\begin{array}{l}\text { Material } \\
\text { name } \\
\text { from DTN } \\
\text { source }\end{array}$ & $\begin{array}{c}\text { Material } \\
\text { name used in } \\
\text { LDTH } \\
\text { submodels }\end{array}$ & $\begin{array}{c}\text { Permeability } \\
{\left[\mathrm{m}^{2}\right]}\end{array}$ & $\begin{array}{c}\text { Porosity } \\
{[-]}\end{array}$ & $\begin{array}{c}\text { Residual } \\
\text { saturation } \\
{[-]}\end{array}$ & $\begin{array}{c}\alpha \text { (alpha) } \\
{[1 / \mathrm{Pa}]}\end{array}$ & $\begin{array}{l}\mathbf{m} \\
{[-]}\end{array}$ & $\gamma \underset{[-]}{\gamma \text { (gamma) }}$ \\
\hline ptnF1 & $f-p t n 21$ & $3.2 \mathrm{E}-12$ & $9.2 \mathrm{E}-03$ & 0.01 & $8.70 \mathrm{E}-04$ & 0.633 & 0.232 \\
\hline ptnF2 & f-ptn22 & $3.0 \mathrm{E}-13$ & $1.0 \mathrm{E}-02$ & 0.01 & 1.57E-03 & 0.633 & 0.232 \\
\hline ptnF3 & f-ptn23 & $3.0 \mathrm{E}-13$ & 2.1E-03 & 0.01 & $5.18 \mathrm{E}-03$ & 0.633 & 0.232 \\
\hline ptnF4 & f-ptn24 & $3.0 \mathrm{E}-12$ & $1.0 \mathrm{E}-02$ & 0.01 & 1.86E-03 & 0.633 & 0.232 \\
\hline ptnF5 & f-ptn25 & $1.7 \mathrm{E}-13$ & $5.5 \mathrm{E}-03$ & 0.01 & 1.33E-03 & 0.633 & 0.232 \\
\hline ptnF6 & f-ptn26 & $2.2 \mathrm{E}-13$ & $3.1 \mathrm{E}-03$ & 0.01 & 1.34E-03 & 0.633 & 0.232 \\
\hline tswF1 & f-tsw31 & $8.1 \mathrm{E}-13$ & $5.0 \mathrm{E}-03$ & 0.01 & 1.60E-05 & 0.633 & 0.129 \\
\hline tswF2 & f-tsw32 & $7.1 \mathrm{E}-13$ & $8.3 \mathrm{E}-03$ & 0.01 & $1.00 \mathrm{E}-04$ & 0.633 & 0.600 \\
\hline tswF3 & f-tsw33 & $7.8 \mathrm{E}-13$ & $5.8 \mathrm{E}-03$ & 0.01 & $1.59 \mathrm{E}-03$ & 0.633 & 0.600 \\
\hline tswF4 & f-tsw34 & $3.3 \mathrm{E}-13$ & $8.5 \mathrm{E}-03$ & 0.01 & $1.04 \mathrm{E}-04$ & 0.633 & 0.569 \\
\hline tswF5 & f-tsw35 & $9.1 \mathrm{E}-13$ & $9.6 \mathrm{E}-03$ & 0.01 & 1.02E-04 & 0.633 & 0.569 \\
\hline tswF6 & f-tsw36 & $1.3 \mathrm{E}-12$ & $1.3 \mathrm{E}-02$ & 0.01 & 7.44E-04 & 0.633 & 0.569 \\
\hline tswF7 & f-tsw37 & $1.3 \mathrm{E}-12$ & $1.3 \mathrm{E}-02$ & 0.01 & 7.44E-04 & 0.633 & 0.569 \\
\hline tswF8 & f-tsw38 & $8.1 \mathrm{E}-13$ & $1.1 \mathrm{E}-02$ & 0.01 & $2.12 \mathrm{E}-03$ & 0.633 & 0.569 \\
\hline tswFv & f-tsw9v & $N / A^{b}$ & $\mathrm{~N} / \mathrm{A}^{\mathrm{b}}$ & $\mathrm{N} / \mathrm{A}^{\mathrm{b}}$ & $\mathrm{N} / \mathrm{A}^{\mathrm{b}}$ & $N / A^{b}$ & $N / A^{b}$ \\
\hline tswFz & f-tsw9z & $8.1 \mathrm{E}-13$ & 4.3E-03 & 0.01 & $1.5 \mathrm{E}-03$ & 0.633 & 0.370 \\
\hline ch1Fv & f-ch1v & $\mathrm{N} / \mathrm{A}^{\mathrm{b}}$ & $\mathrm{N} / \mathrm{A}^{\mathrm{b}}$ & $N / A^{b}$ & $N / A^{b}$ & $N / A^{b}$ & $N / A^{b}$ \\
\hline ch1Fz & f-ch1z & $2.5 \mathrm{E}-14$ & 1.6E-04 & 0.01 & $1.4 \mathrm{E}-03$ & 0.633 & 0.370 \\
\hline ch2Fv & f-ch2v & $\mathrm{N} / \mathrm{A}^{\mathrm{b}}$ & $N / A^{b}$ & $N / A^{b}$ & $\mathrm{~N} / \mathrm{A}^{\mathrm{b}}$ & $N / A^{b}$ & $\mathrm{~N} / \mathrm{A}^{\mathrm{b}}$ \\
\hline ch3Fv & $f-\operatorname{ch} 3 v$ & $\mathrm{~N} / \mathrm{A}^{\mathrm{b}}$ & $N / A^{b}$ & $N / A^{b}$ & $\mathrm{~N} / \mathrm{A}^{\mathrm{b}}$ & $\mathrm{N} / \mathrm{A}^{\mathrm{b}}$ & $\mathrm{N} / \mathrm{A}^{\mathrm{b}}$ \\
\hline ch4Fv & f-ch4v & $N / A^{b}$ & $N / A^{b}$ & $N / A^{b}$ & $N / A^{b}$ & $N / A^{b}$ & $\mathrm{~N} / \mathrm{A}^{\mathrm{b}}$ \\
\hline ch5Fv & f-ch5v & $\mathrm{N} / \mathrm{A}^{\mathrm{b}}$ & $\mathrm{N} / \mathrm{A}^{\mathrm{b}}$ & $N / A^{b}$ & $\mathrm{~N} / \mathrm{A}^{\mathrm{b}}$ & $\mathrm{N} / \mathrm{A}^{\mathrm{b}}$ & $\mathrm{N} / \mathrm{A}^{\mathrm{b}}$ \\
\hline ch2Fz & $f-\operatorname{ch} 2 z$ & $2.5 \mathrm{E}-14$ & $3.7 \mathrm{E}-04$ & 0.01 & $8.9 \mathrm{E}-04$ & 0.633 & 0.370 \\
\hline ch3Fz & f-ch3z & $2.5 \mathrm{E}-14$ & $3.7 \mathrm{E}-04$ & 0.01 & $8.9 \mathrm{E}-04$ & 0.633 & 0.370 \\
\hline $\operatorname{ch} 4 \mathrm{Fz}$ & $f-\operatorname{ch} 4 z$ & $2.5 \mathrm{E}-14$ & 3.7E-04 & 0.01 & $8.9 \mathrm{E}-04$ & 0.633 & 0.370 \\
\hline ch5Fz & $f-\operatorname{ch} 5 z$ & $2.5 \mathrm{E}-14$ & 3.7E-04 & 0.01 & $8.9 \mathrm{E}-04$ & 0.633 & 0.370 \\
\hline ch6Fv & f-ch6v & $\mathrm{N} / \mathrm{A}^{\mathrm{b}}$ & $\mathrm{N} / \mathrm{A}^{\mathrm{b}}$ & $\mathrm{N} / \mathrm{A}^{\mathrm{b}}$ & $N / A^{b}$ & $\mathrm{~N} / \mathrm{A}^{\mathrm{b}}$ & $N / A^{b}$ \\
\hline ch6Fz & $f-\operatorname{ch} 6 z$ & $2.5 \mathrm{E}-14$ & $1.6 \mathrm{E}-04$ & 0.01 & $1.4 \mathrm{E}-03$ & 0.633 & 0.370 \\
\hline $\mathrm{pp} 4 \mathrm{Fz}$ & f-pp4 & $2.5 \mathrm{E}-14$ & 3.7E-04 & 0.01 & 1.83E-03 & 0.633 & 0.370 \\
\hline pp3Fd & f-pp3 & $2.2 \mathrm{E}-13$ & 9.7E-04 & 0.01 & 2.47E-03 & 0.633 & 0.199 \\
\hline $\mathrm{pp} 2 \mathrm{Fd}$ & f-pp2 & $2.2 \mathrm{E}-13$ & $9.7 \mathrm{E}-04$ & 0.01 & $3.17 \mathrm{E}-03$ & 0.633 & 0.199 \\
\hline pp1Fz & f-pp1 & $2.5 \mathrm{E}-14$ & 3.7E-04 & 0.01 & 1.83E-03 & 0.633 & 0.370 \\
\hline bf3Fd & f-bf3 & $2.2 \mathrm{E}-13$ & $9.7 \mathrm{E}-04$ & 0.01 & 2.93E-03 & 0.633 & 0.199 \\
\hline bf2Fz & f-bf2 & $2.5 \mathrm{E}-14$ & 3.7E-04 & 0.01 & 8.9E-04 & 0.633 & 0.370 \\
\hline tr3Fd & f-tr3 & $2.2 \mathrm{E}-13$ & $9.7 \mathrm{E}-04$ & 0.01 & $1.6 \mathrm{E}-03$ & 0.633 & 0.199 \\
\hline $\operatorname{tr} 2 \mathrm{Fz}$ & f-tr2 & $2.5 \mathrm{E}-14$ & $3.7 \mathrm{E}-04$ & 0.01 & $8.9 \mathrm{E}-04$ & 0.633 & 0.370 \\
\hline
\end{tabular}

DTN: LB0208UZDSCPMI.002 [DIRS 161243].

a Gamma value does not apply to matrix continuum.

b Vitric units (those units ending with a " $v$ ") do not have fractures. The fracture continuum properties are the same as those of the matrix continuum for these units.

NOTE: The prefix " $m-$ " stands for matrix and "f-" stands for fracture. 
Table IV-5. Matrix and Fracture Properties for the Lower-Bound Infiltration Flux One-Dimensional DriftScale Hydrologic Property Set

\begin{tabular}{|c|c|c|c|c|c|c|c|}
\hline $\begin{array}{c}\text { Material } \\
\text { name from } \\
\text { DTN source }\end{array}$ & $\begin{array}{c}\text { Material } \\
\text { name used } \\
\text { in LDTH } \\
\text { submodels }\end{array}$ & $\begin{array}{c}\text { Permeability } \\
{\left[\mathrm{m}^{2}\right]}\end{array}$ & $\begin{array}{c}\text { Porosity } \\
{[-]}\end{array}$ & $\begin{array}{c}\text { Residual } \\
\text { saturation } \\
{[-]}\end{array}$ & $\begin{array}{c}\alpha \text { (alpha) } \\
{[1 / \mathrm{Pa}]}\end{array}$ & $\begin{array}{l}m \\
{[-]}\end{array}$ & $\begin{array}{c}\gamma \text { (gamma) } \\
{[-]}\end{array}$ \\
\hline tcwM1 & $\mathrm{m}$-tcw11 & $3.44 \mathrm{E}-15$ & 0.241 & 0.02 & 1.16E-05 & 0.388 & $N / A^{a}$ \\
\hline tcwM2 & m-tcw12 & 3.00E-20 & 0.088 & 0.20 & 2.67E-06 & 0.280 & $N / A^{a}$ \\
\hline tcwM3 & m-tcw13 & $3.96 \mathrm{E}-17$ & 0.200 & 0.31 & 1.64E-06 & 0.259 & $N / A^{a}$ \\
\hline ptnM1 & m-ptn21 & 5.55E-15 & 0.387 & 0.24 & 6.38E-05 & 0.245 & $N / A^{a}$ \\
\hline ptnM2 & m-ptn22 & $8.40 \mathrm{E}-12$ & 0.428 & 0.13 & 1.67E-04 & 0.219 & $N / A^{a}$ \\
\hline ptnM3 & m-ptn23 & $1.92 \mathrm{E}-14$ & 0.233 & 0.07 & 4.51E-05 & 0.247 & $N / A^{a}$ \\
\hline ptnM4 & m-ptn24 & $6.66 \mathrm{E}-13$ & 0.413 & 0.14 & $2.52 \mathrm{E}-03$ & 0.182 & $N / A^{a}$ \\
\hline ptnM5 & m-ptn25 & 1.96E-14 & 0.498 & 0.06 & 1.24E-04 & 0.300 & $N / A^{a}$ \\
\hline ptnM6 & m-ptn26 & 1.00E-11 & 0.490 & 0.05 & 1.63E-03 & 0.126 & $N / A^{a}$ \\
\hline tswM1 & m-tsw31 & 1.42E-17 & 0.054 & 0.21 & $8.02 \mathrm{E}-05$ & 0.218 & $N / A^{a}$ \\
\hline tswM2 & m-tsw32 & $3.96 \mathrm{E}-16$ & 0.157 & 0.07 & 9.46E-06 & 0.290 & $N / A^{a}$ \\
\hline tswM3 & m-tsw33 & 1.60E-18 & 0.155 & 0.12 & 4.25E-06 & 0.283 & $N / A^{a}$ \\
\hline tswM4 & m-tsw34 & $1.38 \mathrm{E}-19$ & 0.111 & 0.19 & 1.19E-06 & 0.317 & $N / A^{a}$ \\
\hline tswM5 & m-tsw35 & $2.33 E-18$ & 0.131 & 0.12 & 1.97E-06 & 0.216 & $N / A^{a}$ \\
\hline tswM6 & m-tsw36 & $5.58 \mathrm{E}-19$ & 0.103 & 0.20 & 4.22E-07 & 0.442 & $N / A^{a}$ \\
\hline tswM7 & m-tsw37 & $5.58 \mathrm{E}-19$ & 0.103 & 0.20 & 4.22E-07 & 0.442 & $N / A^{a}$ \\
\hline tswM8 & m-tsw38 & $2.93 E-18$ & 0.043 & 0.42 & 1.43E-06 & 0.286 & $N / A^{a}$ \\
\hline tswMv & m-tsw9v & $3.15 E-13$ & 0.229 & 0.13 & 1.86E-05 & 0.293 & $N / A^{a}$ \\
\hline tswMz & m-tsw9z & $3.5 \mathrm{E}-17$ & 0.275 & 0.36 & 4.61E-06 & 0.059 & $N / A^{a}$ \\
\hline ch1Mv & m-ch1v & $3.15 \mathrm{E}-14$ & 0.331 & 0.06 & 4.50E-05 & 0.240 & $N / A^{a}$ \\
\hline ch1Mz & m-ch1z & $3.5 \mathrm{E}-17$ & 0.285 & 0.38 & 2.12E-07 & 0.349 & $N / A^{a}$ \\
\hline ch2Mv & m-ch2v & $1.13 \mathrm{E}-11$ & 0.346 & 0.06 & $1.22 \mathrm{E}-04$ & 0.158 & $N / A^{a}$ \\
\hline ch3Mv & m-ch3v & $1.13 \mathrm{E}-11$ & 0.346 & 0.06 & 1.22E-04 & 0.158 & $N / A^{a}$ \\
\hline ch4Mv & m-ch4v & $1.13 \mathrm{E}-11$ & 0.346 & 0.06 & 1.22E-04 & 0.158 & $N / A^{a}$ \\
\hline ch5Mv & m-ch5v & $1.13 \mathrm{E}-11$ & 0.346 & 0.06 & $1.22 \mathrm{E}-04$ & 0.158 & $N / A^{a}$ \\
\hline ch2Mz & m-ch2z & $5.2 \mathrm{E}-18$ & 0.322 & 0.26 & $2.25 \mathrm{E}-06$ & 0.257 & $N / A^{a}$ \\
\hline ch3Mz & m-ch3z & $5.2 \mathrm{E}-18$ & 0.322 & 0.26 & $2.25 \mathrm{E}-06$ & 0.257 & $N / A^{a}$ \\
\hline ch4Mz & m-ch4z & $5.2 \mathrm{E}-18$ & 0.322 & 0.26 & $2.25 \mathrm{E}-06$ & 0.257 & $N / A^{a}$ \\
\hline ch5Mz & m-ch5z & $5.2 \mathrm{E}-18$ & 0.322 & 0.26 & $2.25 \mathrm{E}-06$ & 0.257 & $N / A^{a}$ \\
\hline ch6Mv & m-ch6v & $2.54 \mathrm{E}-13$ & 0.331 & 0.06 & 9.05E-06 & 0.147 & $N / A^{a}$ \\
\hline ch6Mz & m-ch6z & 8.2E-19 & 0.271 & 0.36 & $1.56 \mathrm{E}-07$ & 0.499 & $N / A^{a}$ \\
\hline pp4Mz & m-pp4 & $2.98 \mathrm{E}-16$ & 0.321 & 0.29 & 2.88E-07 & 0.474 & $N / A^{a}$ \\
\hline pp3Md & m-pp3 & $5.37 \mathrm{E}-14$ & 0.318 & 0.08 & 7.97E-06 & 0.407 & $N / A^{a}$ \\
\hline pp2Md & m-pp2 & 4.24E-16 & 0.221 & 0.10 & $2.41 \mathrm{E}-06$ & 0.309 & $N / A^{a}$ \\
\hline $\mathrm{pp} 1 \mathrm{Mz}$ & m-pp1 & $7.02 \mathrm{E}-16$ & 0.297 & 0.30 & 1.36E-06 & 0.272 & $N / A^{a}$ \\
\hline bf3Md & m-bf3 & $2.97 \mathrm{E}-14$ & 0.175 & 0.11 & 1.32E-05 & 0.193 & $N / A^{a}$ \\
\hline bf2Mz & m-bf2 & $8.1 \mathrm{E}-17$ & 0.234 & 0.21 & $1.18 \mathrm{E}-07$ & 0.617 & $N / A^{a}$ \\
\hline tr3Md & m-tr3 & 1.1E-15 & 0.175 & 0.11 & 1.12E-05 & 0.193 & $N / A^{a}$ \\
\hline $\operatorname{tr} 2 \mathrm{Mz}$ & m-tr2 & $8.1 \mathrm{E}-17$ & 0.234 & 0.21 & 1.18E-07 & 0.617 & $\mathrm{~N} / \mathrm{A}^{\mathrm{a}}$ \\
\hline tcwF1 & f-tcw11 & 3.0E-11 & $2.4 \mathrm{E}-02$ & 0.01 & $4.68 \mathrm{E}-03$ & 0.633 & 0.483 \\
\hline tcwF2 & f-tcw12 & $5.3 \mathrm{E}-12$ & 1.7E-02 & 0.01 & $3.20 \mathrm{E}-03$ & 0.633 & 0.483 \\
\hline tcwF3 & f-tcw13 & $4.5 \mathrm{E}-12$ & $1.3 \mathrm{E}-02$ & 0.01 & 2.13E-03 & 0.633 & 0.483 \\
\hline
\end{tabular}


Table IV-5. Matrix and Fracture Properties for the Lower-Bound Infiltration Flux One-Dimensional DriftScale Hydrologic Property Set (Continued)

\begin{tabular}{|c|c|c|c|c|c|c|c|}
\hline $\begin{array}{c}\text { Material } \\
\text { name from } \\
\text { DTN source }\end{array}$ & $\begin{array}{c}\text { Material } \\
\text { name used } \\
\text { in LDTH } \\
\text { submodels }\end{array}$ & $\begin{array}{c}\text { Permeability } \\
{\left[\mathrm{m}^{2}\right]}\end{array}$ & $\begin{array}{c}\text { Porosity } \\
{[-]}\end{array}$ & $\begin{array}{c}\text { Residual } \\
\text { saturation } \\
{[-]}\end{array}$ & $\begin{array}{c}\alpha \text { (alpha) } \\
{[1 / \mathrm{Pa}]}\end{array}$ & $\begin{array}{l}\mathbf{m} \\
{[-]}\end{array}$ & $\begin{array}{c}\gamma \text { (gamma) } \\
{[-]}\end{array}$ \\
\hline ptnF1 & f-ptn21 & $3.2 \mathrm{E}-12$ & $9.2 \mathrm{E}-03$ & 0.01 & 2.93E-03 & 0.633 & 0.065 \\
\hline ptnF2 & f-ptn22 & $3.0 \mathrm{E}-13$ & $1.0 \mathrm{E}-02$ & 0.01 & 6.76E-04 & 0.633 & 0.065 \\
\hline ptnF3 & f-ptn23 & $3.0 \mathrm{E}-13$ & $2.1 \mathrm{E}-03$ & 0.01 & $3.96 \mathrm{E}-03$ & 0.633 & 0.065 \\
\hline ptnF4 & $f-p \operatorname{tn} 24$ & 3.0E-12 & $1.0 \mathrm{E}-02$ & 0.01 & $2.51 \mathrm{E}-03$ & 0.633 & 0.065 \\
\hline ptnF5 & f-ptn25 & $1.7 \mathrm{E}-13$ & $5.5 \mathrm{E}-03$ & 0.01 & 1.53E-03 & 0.633 & 0.065 \\
\hline ptnF6 & f-ptn26 & $2.2 \mathrm{E}-13$ & $3.1 \mathrm{E}-03$ & 0.01 & $1.52 \mathrm{E}-03$ & 0.633 & 0.065 \\
\hline tswF1 & $f$-tsw31 & $8.1 \mathrm{E}-13$ & $5.0 \mathrm{E}-03$ & 0.01 & 1.58E-05 & 0.633 & 0.037 \\
\hline tswF2 & f-tsw32 & $7.1 \mathrm{E}-13$ & $8.3 \mathrm{E}-03$ & 0.01 & 1.31E-04 & 0.633 & 0.528 \\
\hline tswF3 & f-tsw33 & $7.8 \mathrm{E}-13$ & $5.8 \mathrm{E}-03$ & 0.01 & 1.94E-03 & 0.633 & 0.528 \\
\hline tswF4 & f-tsw34 & $3.3 \mathrm{E}-13$ & $8.5 \mathrm{E}-03$ & 0.01 & $6.55 \mathrm{E}-04$ & 0.633 & 0.476 \\
\hline tswF5 & f-tsw35 & $9.1 \mathrm{E}-13$ & $9.6 \mathrm{E}-03$ & 0.01 & 1.35E-03 & 0.633 & 0.476 \\
\hline tswF6 & f-tsw36 & $1.3 \mathrm{E}-12$ & $1.3 \mathrm{E}-02$ & 0.01 & 1.31E-03 & 0.633 & 0.476 \\
\hline tswF7 & f-tsw37 & $1.3 \mathrm{E}-12$ & $1.3 \mathrm{E}-02$ & 0.01 & 1.31E-03 & 0.633 & 0.476 \\
\hline tswF8 & f-tsw38 & $8.1 \mathrm{E}-13$ & 1.1E-02 & 0.01 & 1.75E-03 & 0.633 & 0.476 \\
\hline tswFv & f-tsw9v & $N / A^{b}$ & $N / A^{b}$ & $N / A^{b}$ & $N / A^{b}$ & $\mathrm{~N} / \mathrm{A}^{\mathrm{b}}$ & $\mathrm{N} / \mathrm{A}^{\mathrm{b}}$ \\
\hline tswFz & f-tsw9z & $8.1 \mathrm{E}-13$ & $4.3 \mathrm{E}-03$ & 0.01 & $1.5 \mathrm{E}-03$ & 0.633 & 0.276 \\
\hline ch1Fv & f-ch1v & $N / A^{b}$ & $N / A^{b}$ & $N / A^{b}$ & $N / A^{b}$ & $\mathrm{~N} / \mathrm{A}^{\mathrm{b}}$ & $N / A^{b}$ \\
\hline $\operatorname{ch} 1 \mathrm{Fz}$ & f-ch1z & $2.5 \mathrm{E}-14$ & $1.6 \mathrm{E}-04$ & 0.01 & 1.4E-03 & 0.633 & 0.276 \\
\hline ch2Fv & f-ch2v & $\mathrm{N} / \mathrm{A}^{\mathrm{b}}$ & $\mathrm{N} / \mathrm{A}^{\mathrm{b}}$ & $N / A^{b}$ & $\mathrm{~N} / \mathrm{A}^{\mathrm{b}}$ & $\mathrm{N} / \mathrm{A}^{\mathrm{b}}$ & $\mathrm{N} / \mathrm{A}^{\mathrm{b}}$ \\
\hline ch3Fv & f-ch3v & $N / A^{b}$ & $N / A^{b}$ & $N / A^{b}$ & $N / A^{b}$ & $N / A^{b}$ & $N / A^{b}$ \\
\hline ch4Fv & f-ch4v & $N / A^{b}$ & $N / A^{b}$ & $N / A^{b}$ & $N / A^{b}$ & $N / A^{b}$ & $N / A^{b}$ \\
\hline ch5Fv & f-ch5v & $N / A^{b}$ & $N / A^{b}$ & $N / A^{b}$ & $N / A^{b}$ & $N / A^{b}$ & $\mathrm{~N} / \mathrm{A}^{\mathrm{b}}$ \\
\hline $\operatorname{ch} 2 \mathrm{Fz}$ & f-ch2z & $2.5 \mathrm{E}-14$ & 3.7E-04 & 0.01 & $8.9 \mathrm{E}-04$ & 0.633 & 0.276 \\
\hline ch3Fz & f-ch3z & $2.5 \mathrm{E}-14$ & 3.7E-04 & 0.01 & $8.9 \mathrm{E}-04$ & 0.633 & 0.276 \\
\hline $\operatorname{ch} 4 \mathrm{Fz}$ & f-ch4z & $2.5 \mathrm{E}-14$ & $3.7 \mathrm{E}-04$ & 0.01 & $8.9 \mathrm{E}-04$ & 0.633 & 0.276 \\
\hline ch5Fz & $f-\operatorname{ch} 5 z$ & $2.5 \mathrm{E}-14$ & 3.7E-04 & 0.01 & $8.9 \mathrm{E}-04$ & 0.633 & 0.276 \\
\hline ch6Fv & f-ch6v & $\mathrm{N} / \mathrm{A}^{\mathrm{b}}$ & $\mathrm{N} / \mathrm{A}^{\mathrm{b}}$ & $N / A^{b}$ & $\mathrm{~N} / \mathrm{A}^{\mathrm{b}}$ & $\mathrm{N} / \mathrm{A}^{\mathrm{b}}$ & $N / A^{b}$ \\
\hline ch6Fz & $f-\operatorname{ch} 6 z$ & $2.5 \mathrm{E}-14$ & $1.6 \mathrm{E}-04$ & 0.01 & $1.4 \mathrm{E}-03$ & 0.633 & 0.276 \\
\hline pp4Fz & $\mathrm{f}-\mathrm{pp} 4$ & $2.5 \mathrm{E}-14$ & 3.7E-04 & 0.01 & $1.88 \mathrm{E}-03$ & 0.633 & 0.276 \\
\hline pp3Fd & f-pp3 & $2.2 \mathrm{E}-13$ & $9.7 \mathrm{E}-04$ & 0.01 & 1.32E-03 & 0.633 & 0.248 \\
\hline $\mathrm{pp} 2 \mathrm{Fd}$ & f-pp2 & $2.2 \mathrm{E}-13$ & $9.7 \mathrm{E}-04$ & 0.01 & 2.80E-03 & 0.633 & 0.248 \\
\hline pp1Fz & f-pp1 & $2.5 \mathrm{E}-14$ & 3.7E-04 & 0.01 & 6.39E-04 & 0.633 & 0.276 \\
\hline bf3Fd & f-bf3 & $2.2 \mathrm{E}-13$ & $9.7 \mathrm{E}-04$ & 0.01 & 1.91E-03 & 0.633 & 0.248 \\
\hline bf2Fz & $f-b f 2$ & $2.5 \mathrm{E}-14$ & $3.7 \mathrm{E}-04$ & 0.01 & 8.9E-04 & 0.633 & 0.276 \\
\hline tr3Fd & f-tr3 & $2.2 \mathrm{E}-13$ & $9.7 \mathrm{E}-04$ & 0.01 & 1.6E-03 & 0.633 & 0.248 \\
\hline $\operatorname{tr} 2 \mathrm{Fz}$ & $f$-tr2 & $2.5 \mathrm{E}-14$ & $3.7 \mathrm{E}-04$ & 0.01 & $8.9 \mathrm{E}-04$ & 0.633 & 0.276 \\
\hline
\end{tabular}

DTN: LB0208UZDSCPLI.002 [DIRS 161788].

${ }^{a}$ Gamma value does not apply to matrix continuum.

${ }^{b}$ Vitric units (those units ending with a " $v$ ") do not have fractures. The fracture continuum properties are the same as those of the matrix continuum for these units.

NOTE: The prefix "m-" stands for matrix and "f-" stands for fracture. 
Table IV-6. Matrix and Fracture Properties for the Upper-Bound Infiltration Flux One-Dimensional DriftScale Hydrologic Property Set

\begin{tabular}{|c|c|c|c|c|c|c|c|}
\hline $\begin{array}{c}\text { Material } \\
\text { name from } \\
\text { DTN source }\end{array}$ & $\begin{array}{c}\text { Material } \\
\text { name used in } \\
\text { LDTH } \\
\text { submodels }\end{array}$ & $\begin{array}{c}\text { Permeability } \\
{\left[\mathrm{m}^{2}\right]}\end{array}$ & $\begin{array}{c}\text { Porosity } \\
{[-]}\end{array}$ & $\begin{array}{c}\text { Residual } \\
\text { saturation } \\
{[-]}\end{array}$ & $\begin{array}{c}\alpha \text { (alpha) } \\
{[1 / \mathrm{Pa}]}\end{array}$ & $\begin{array}{l}m \\
{[-]}\end{array}$ & $\begin{array}{c}\gamma \text { (gamma) } \\
{[-]}\end{array}$ \\
\hline tcwM1 & m-tcw11 & $3.90 \mathrm{E}-15$ & 0.241 & 0.02 & 1.23E-05 & 0.388 & $N / A^{a}$ \\
\hline tcwM2 & m-tcw12 & 1.16E-19 & 0.088 & 0.20 & 3.39E-06 & 0.280 & $N / A^{a}$ \\
\hline tcwM3 & m-tcw13 & $4.41 \mathrm{E}-16$ & 0.200 & 0.31 & $3.25 \mathrm{E}-06$ & 0.259 & $N / A^{a}$ \\
\hline ptnM1 & m-ptn21 & $2.14 \mathrm{E}-14$ & 0.387 & 0.24 & $1.56 \mathrm{E}-04$ & 0.245 & $N / A^{a}$ \\
\hline ptnM2 & m-ptn22 & 1.29E-11 & 0.428 & 0.13 & 1.33E-04 & 0.219 & $N / A^{a}$ \\
\hline ptnM3 & m-ptn23 & 4.07E-14 & 0.233 & 0.07 & 2.39E-05 & 0.247 & $N / A^{a}$ \\
\hline ptnM4 & m-ptn24 & 4.27E-12 & 0.413 & 0.14 & 5.62E-04 & 0.182 & $N / A^{a}$ \\
\hline ptnM5 & m-ptn25 & 1.01E-12 & 0.498 & 0.06 & 9.48E-05 & 0.300 & $N / A^{a}$ \\
\hline ptnM6 & m-ptn26 & $1.00 \mathrm{E}-11$ & 0.490 & 0.05 & 5.23E-04 & 0.126 & $N / A^{a}$ \\
\hline tswM1 & m-tsw31 & 1.77E-17 & 0.054 & 0.21 & 4.85E-05 & 0.218 & $N / A^{a}$ \\
\hline tswM2 & m-tsw32 & $2.13 E-16$ & 0.157 & 0.07 & 1.96E-05 & 0.290 & $N / A^{a}$ \\
\hline tswM3 & m-tsw33 & $2.39 \mathrm{E}-17$ & 0.155 & 0.12 & $5.22 \mathrm{E}-06$ & 0.283 & $N / A^{a}$ \\
\hline tswM4 & m-tsw34 & 2.96E-19 & 0.111 & 0.19 & 1.65E-06 & 0.317 & $N / A^{a}$ \\
\hline tswM5 & m-tsw35 & $8.55 \mathrm{E}-18$ & 0.131 & 0.12 & 5.03E-06 & 0.216 & $N / A^{a}$ \\
\hline tswM6 & m-tsw36 & $7.41 \mathrm{E}-19$ & 0.103 & 0.20 & $1.08 \mathrm{E}-06$ & 0.442 & $N / A^{a}$ \\
\hline tswM7 & m-tsw37 & $7.41 \mathrm{E}-19$ & 0.103 & 0.20 & $1.08 \mathrm{E}-06$ & 0.442 & $N / A^{a}$ \\
\hline tswM8 & m-tsw38 & $7.40 \mathrm{E}-18$ & 0.043 & 0.42 & 5.58E-06 & 0.286 & $N / A^{a}$ \\
\hline tswMv & m-tsw9v & $2.24 \mathrm{E}-13$ & 0.229 & 0.13 & 4.86E-05 & 0.293 & $N / A^{a}$ \\
\hline tswMz & m-tsw9z & $3.5 \mathrm{E}-17$ & 0.275 & 0.36 & 4.61E-06 & 0.059 & $\mathrm{~N} / \mathrm{A}^{\mathrm{a}}$ \\
\hline ch1Mv & $\mathrm{m}-\mathrm{ch} 1 \mathrm{v}$ & $1.39 \mathrm{E}-12$ & 0.331 & 0.06 & $8.82 \mathrm{E}-05$ & 0.240 & $\mathrm{~N} / \mathrm{A}^{\mathrm{a}}$ \\
\hline $\operatorname{ch} 1 \mathrm{Mz}$ & m-ch1z & $3.5 \mathrm{E}-17$ & 0.285 & 0.38 & 2.12E-07 & 0.349 & $N / A^{a}$ \\
\hline ch2Mv & m-ch2v & 4.90E-11 & 0.346 & 0.06 & 2.73E-04 & 0.158 & $N / A^{a}$ \\
\hline ch3Mv & m-ch3v & $4.90 \mathrm{E}-11$ & 0.346 & 0.06 & 2.73E-04 & 0.158 & $N / A^{a}$ \\
\hline ch4Mv & m-ch4v & $4.90 \mathrm{E}-11$ & 0.346 & 0.06 & 2.73E-04 & 0.158 & $N / A^{a}$ \\
\hline ch5Mv & m-ch5v & $4.90 \mathrm{E}-11$ & 0.346 & 0.06 & 2.73E-04 & 0.158 & $N / A^{a}$ \\
\hline ch2Mz & m-ch2z & $5.2 \mathrm{E}-18$ & 0.322 & 0.26 & $2.25 \mathrm{E}-06$ & 0.257 & $N / A^{a}$ \\
\hline ch3Mz & m-ch3z & $5.2 \mathrm{E}-18$ & 0.322 & 0.26 & $2.25 \mathrm{E}-06$ & 0.257 & $N / A^{a}$ \\
\hline ch4Mz & m-ch4z & $5.2 \mathrm{E}-18$ & 0.322 & 0.26 & $2.25 \mathrm{E}-06$ & 0.257 & $N / A^{a}$ \\
\hline ch5Mz & m-ch5z & $5.2 \mathrm{E}-18$ & 0.322 & 0.26 & $2.25 \mathrm{E}-06$ & 0.257 & $\mathrm{~N} / \mathrm{A}^{\mathrm{a}}$ \\
\hline ch6Mv & m-ch6v & $2.72 \mathrm{E}-13$ & 0.331 & 0.06 & 1.67E-05 & 0.147 & $N / A^{a}$ \\
\hline ch6Mz & m-ch6z & $8.2 \mathrm{E}-19$ & 0.271 & 0.36 & $1.56 \mathrm{E}-07$ & 0.499 & $\mathrm{~N} / \mathrm{A}^{\mathrm{a}}$ \\
\hline $\mathrm{pp} 4 \mathrm{Mz}$ & m-pp4 & $1.02 \mathrm{E}-15$ & 0.321 & 0.29 & 4.57E-07 & 0.474 & $N / A^{a}$ \\
\hline pp3Md & m-pp3 & $1.26 \mathrm{E}-13$ & 0.318 & 0.08 & $9.50 \mathrm{E}-06$ & 0.407 & $\mathrm{~N} / \mathrm{A}^{\mathrm{a}}$ \\
\hline pp2Md & m-pp2 & $1.70 \mathrm{E}-15$ & 0.221 & 0.10 & $2.25 \mathrm{E}-06$ & 0.309 & $\mathrm{~N} / \mathrm{A}^{\mathrm{a}}$ \\
\hline $\mathrm{pp} 1 \mathrm{Mz}$ & m-pp1 & $2.57 \mathrm{E}-15$ & 0.297 & 0.30 & 8.77E-07 & 0.272 & $N / A^{a}$ \\
\hline bf3Md & m-bf3 & $3.55 \mathrm{E}-14$ & 0.175 & 0.11 & 3.48E-05 & 0.193 & $N / A^{a}$ \\
\hline bf2Mz & m-bf2 & 8.1E-17 & 0.234 & 0.21 & 1.18E-07 & 0.617 & $N / A^{a}$ \\
\hline tr3Md & m-tr3 & $1.1 \mathrm{E}-15$ & 0.175 & 0.11 & 1.12E-05 & 0.193 & $\mathrm{~N} / \mathrm{A}^{\mathrm{a}}$ \\
\hline $\operatorname{tr} 2 \mathrm{Mz}$ & m-tr2 & $8.1 \mathrm{E}-17$ & 0.234 & 0.21 & 1.18E-07 & 0.617 & $N / A^{a}$ \\
\hline tcwF1 & f-tcw11 & $3.0 \mathrm{E}-11$ & $2.4 \mathrm{E}-02$ & 0.01 & $5.01 \mathrm{E}-03$ & 0.633 & $5.00 \mathrm{E}-01$ \\
\hline tcwF2 & f-tcw12 & 5.3E-12 & 1.7E-02 & 0.01 & $2.19 \mathrm{E}-03$ & 0.633 & 5.00E-01 \\
\hline tcwF3 & f-tcw13 & $4.5 \mathrm{E}-12$ & 1.3E-02 & 0.01 & 1.86E-03 & 0.633 & 5.00E-01 \\
\hline ptnF1 & f-ptn21 & $3.2 \mathrm{E}-12$ & $9.2 \mathrm{E}-03$ & 0.01 & $2.69 \mathrm{E}-03$ & 0.633 & 1.00E-01 \\
\hline
\end{tabular}


Table IV-6. Matrix and Fracture Properties for the Upper-Bound Infiltration Flux One-Dimensional DriftScale Hydrologic Property Set (Continued)

\begin{tabular}{|c|c|c|c|c|c|c|c|}
\hline $\begin{array}{c}\text { Material } \\
\text { name from } \\
\text { DTN source }\end{array}$ & $\begin{array}{c}\text { Material } \\
\text { name used in } \\
\text { LDTH } \\
\text { submodels }\end{array}$ & $\begin{array}{c}\text { Permeability } \\
{\left[\mathrm{m}^{2}\right]}\end{array}$ & $\begin{array}{c}\text { Porosity } \\
{[-]}\end{array}$ & $\begin{array}{c}\text { Residual } \\
\text { saturation } \\
{[-]}\end{array}$ & $\begin{array}{c}\alpha \text { (alpha) } \\
{[1 / \mathrm{Pa}]}\end{array}$ & $\begin{array}{l}\mathbf{m} \\
{[-]}\end{array}$ & $\gamma \underset{[-]}{\gamma \text { (gamma) }}$ \\
\hline ptnF2 & f-ptn22 & $3.0 \mathrm{E}-13$ & $1.0 \mathrm{E}-02$ & 0.01 & 1.38E-03 & 0.633 & $1.00 \mathrm{E}-01$ \\
\hline ptnF3 & f-ptn23 & $3.0 \mathrm{E}-13$ & 2.1E-03 & 0.01 & 1.23E-03 & 0.633 & $1.00 \mathrm{E}-01$ \\
\hline ptnF4 & f-ptn24 & $3.0 \mathrm{E}-12$ & $1.0 \mathrm{E}-02$ & 0.01 & 2.95E-03 & 0.633 & 1.00E-01 \\
\hline ptnF5 & f-ptn25 & 1.7E-13 & $5.5 \mathrm{E}-03$ & 0.01 & 1.10E-03 & 0.633 & 1.00E-01 \\
\hline ptnF6 & f-ptn26 & $2.2 \mathrm{E}-13$ & $3.1 \mathrm{E}-03$ & 0.01 & 9.55E-04 & 0.633 & 1.00E-01 \\
\hline tswF1 & f-tsw31 & $8.1 \mathrm{E}-13$ & $5.0 \mathrm{E}-03$ & 0.01 & 1.58E-05 & 0.633 & 1.00E-01 \\
\hline tswF2 & f-tsw32 & $7.1 \mathrm{E}-13$ & 8.3E-03 & 0.01 & 1.00E-04 & 0.633 & 5.61E-01 \\
\hline tswF3 & f-tsw33 & $7.8 \mathrm{E}-13$ & $5.8 \mathrm{E}-03$ & 0.01 & 1.58E-03 & 0.633 & 5.61E-01 \\
\hline tswF4 & f-tsw34 & $3.3 \mathrm{E}-13$ & $8.5 \mathrm{E}-03$ & 0.01 & 1.00E-04 & 0.633 & 5.70E-01 \\
\hline tswF5 & f-tsw35 & $9.1 \mathrm{E}-13$ & $9.6 \mathrm{E}-03$ & 0.01 & 5.78E-04 & 0.633 & 5.70E-01 \\
\hline tswF6 & f-tsw36 & $1.3 \mathrm{E}-12$ & 1.3E-02 & 0.01 & 1.10E-03 & 0.633 & $5.70 \mathrm{E}-01$ \\
\hline tswF7 & f-tsw37 & $1.3 \mathrm{E}-12$ & 1.3E-02 & 0.01 & 1.10E-03 & 0.633 & 5.70E-01 \\
\hline tswF8 & f-tsw38 & $8.1 \mathrm{E}-13$ & $1.1 \mathrm{E}-02$ & 0.01 & $8.91 \mathrm{E}-04$ & 0.633 & $5.70 \mathrm{E}-01$ \\
\hline tswFv & f-tsw9v & $N / A^{b}$ & $N / A^{b}$ & $N / A^{b}$ & $N / A^{b}$ & $\mathrm{~N} / \mathrm{A}^{\mathrm{b}}$ & $\mathrm{N} / \mathrm{A}^{\mathrm{b}}$ \\
\hline tswFz & f-tsw9z & $8.1 \mathrm{E}-13$ & 4.3E-03 & 0.01 & $1.5 \mathrm{E}-03$ & 0.633 & $5.00 \mathrm{E}-01$ \\
\hline ch1Fv & f-ch1v & $N / A^{b}$ & $N / A^{b}$ & $N / A^{b}$ & $N / A^{b}$ & $N / A^{b}$ & $\mathrm{~N} / \mathrm{A}^{\mathrm{b}}$ \\
\hline ch1Fz & f-ch1z & $2.5 \mathrm{E}-14$ & $1.6 \mathrm{E}-04$ & 0.01 & $1.4 \mathrm{E}-03$ & 0.633 & $5.00 \mathrm{E}-01$ \\
\hline ch2Fv & $f-\operatorname{ch} 2 v$ & $N / A^{b}$ & $N / A^{b}$ & $N / A^{b}$ & $N / A^{b}$ & $\mathrm{~N} / \mathrm{A}^{\mathrm{b}}$ & $N / A^{b}$ \\
\hline ch3Fv & $f-\operatorname{ch} 3 v$ & $N / A^{b}$ & $N / A^{b}$ & $N / A^{b}$ & $N / A^{b}$ & $N / A^{b}$ & $\mathrm{~N} / \mathrm{A}^{\mathrm{b}}$ \\
\hline ch4Fv & f-ch4v & $N / A^{b}$ & $N / A^{b}$ & $N / A^{b}$ & $N / A^{b}$ & $N / A^{b}$ & $N / A^{b}$ \\
\hline ch5Fv & f-ch5v & $N / A^{b}$ & $N / A^{b}$ & $N / A^{b}$ & $N / A^{b}$ & $N / A^{b}$ & $N / A^{b}$ \\
\hline $\operatorname{ch} 2 \mathrm{Fz}$ & $f-\operatorname{ch} 2 z$ & $2.5 \mathrm{E}-14$ & 3.7E-04 & 0.01 & $8.9 \mathrm{E}-04$ & 0.633 & $5.00 \mathrm{E}-01$ \\
\hline ch3Fz & f-ch3z & $2.5 \mathrm{E}-14$ & 3.7E-04 & 0.01 & 8.9E-04 & 0.633 & 5.00E-01 \\
\hline ch4Fz & $f-\operatorname{ch} 4 z$ & $2.5 \mathrm{E}-14$ & 3.7E-04 & 0.01 & $8.9 \mathrm{E}-04$ & 0.633 & $5.00 \mathrm{E}-01$ \\
\hline ch5Fz & $f-\operatorname{ch} 5 z$ & $2.5 \mathrm{E}-14$ & 3.7E-04 & 0.01 & $8.9 \mathrm{E}-04$ & 0.633 & $5.00 \mathrm{E}-01$ \\
\hline ch6Fv & f-ch6v & $\mathrm{N} / \mathrm{A}^{\mathrm{b}}$ & $\mathrm{N} / \mathrm{A}^{\mathrm{b}}$ & $N / A^{b}$ & $\mathrm{~N} / \mathrm{A}^{\mathrm{b}}$ & $N / A^{b}$ & $N / A^{b}$ \\
\hline ch6Fz & $f-\operatorname{ch} 6 z$ & $2.5 \mathrm{E}-14$ & $1.6 \mathrm{E}-04$ & 0.01 & $1.4 \mathrm{E}-03$ & 0.633 & $5.00 \mathrm{E}-01$ \\
\hline pp4Fz & f-pp4 & $2.5 \mathrm{E}-12$ & 3.7E-04 & 0.01 & 8.91E-04 & 0.633 & $5.00 \mathrm{E}-01$ \\
\hline pp3Fd & f-pp3 & $2.2 \mathrm{E}-12$ & 9.7E-04 & 0.01 & 1.66E-03 & 0.633 & $5.00 \mathrm{E}-01$ \\
\hline $\mathrm{pp} 2 \mathrm{Fd}$ & f-pp2 & $2.2 \mathrm{E}-13$ & 9.7E-04 & 0.01 & 1.66E-03 & 0.633 & $5.00 \mathrm{E}-01$ \\
\hline pp1Fz & f-pp1 & $2.5 \mathrm{E}-14$ & 3.7E-04 & 0.01 & 8.91E-04 & 0.633 & $5.00 \mathrm{E}-01$ \\
\hline bf3Fd & f-bf3 & $2.2 \mathrm{E}-13$ & 9.7E-04 & 0.01 & 1.66E-03 & 0.633 & $5.00 \mathrm{E}-01$ \\
\hline bf2Fz & f-bf2 & $2.5 \mathrm{E}-14$ & 3.7E-04 & 0.01 & 8.9E-04 & 0.633 & 5.00E-01 \\
\hline tr3Fd & f-tr3 & $2.2 \mathrm{E}-13$ & 9.7E-04 & 0.01 & 1.6E-03 & 0.633 & 5.00E-01 \\
\hline $\operatorname{tr} 2 \mathrm{Fz}$ & f-tr2 & $2.5 \mathrm{E}-14$ & 3.7E-04 & 0.01 & $8.9 \mathrm{E}-04$ & 0.633 & $5.00 \mathrm{E}-01$ \\
\hline
\end{tabular}

DTN: LB0302UZDSCPUI.002 [DIRS 161787].

${ }^{a}$ Gamma value does not apply to matrix continuum.

b Vitric units (those units ending with a " $v$ ") do not have fractures. The fracture continuum properties are the same as those of the matrix continuum for these units.

NOTE: The prefix "m-" stands for matrix and "f-" stands for fracture. 
Table IV-7. Fracture Frequency and Fracture-to-Matrix Interface Area

\begin{tabular}{|c|c|c|}
\hline Material Name & $\begin{array}{l}\text { Fracture Frequency } \\
\qquad\left(\mathrm{m}^{-1}\right)\end{array}$ & $\begin{array}{c}\text { Interface Area } \\
{\left[\mathrm{m}^{2} / \mathrm{m}^{3}\right]}\end{array}$ \\
\hline tcw11 & 0.92 & 1.56 \\
\hline tcw12 & 1.91 & 13.39 \\
\hline tcw13 & 2.79 & 3.77 \\
\hline ptn21 & 0.67 & 1.00 \\
\hline ptn22 & 0.46 & 1.41 \\
\hline ptn23 & 0.57 & 1.75 \\
\hline ptn24 & 0.46 & 0.34 \\
\hline ptn25 & 0.52 & 1.09 \\
\hline ptn26 & 0.97 & 3.56 \\
\hline tsw31 & 2.17 & 3.86 \\
\hline tsw32 & 1.12 & 3.21 \\
\hline tsw33 & 0.81 & 4.44 \\
\hline tsw34 & 4.32 & 13.54 \\
\hline tsw35 & 3.16 & 9.68 \\
\hline tsw36 & 4.02 & 12.31 \\
\hline tsw37 & 4.02 & 12.31 \\
\hline tsw38 & 4.36 & 13.34 \\
\hline tsw39 (tsw9v) & $N A^{a}$ & $N A^{a}$ \\
\hline tsw39 (tsw9z) & 0.96 & 2.95 \\
\hline ch1VI (ch1v) & $N A^{a}$ & $N A^{a}$ \\
\hline ch1Ze (ch1z) & 0.04 & 0.11 \\
\hline ch2VI (ch2v) & $N A^{a}$ & $N A^{a}$ \\
\hline ch3VI (ch3v) & $N A^{a}$ & $N A^{a}$ \\
\hline ch4VI (ch4v) & $N A^{a}$ & $N A^{a}$ \\
\hline ch5VI (ch5v) & $N A^{a}$ & $N A^{a}$ \\
\hline ch2Ze (ch2z) & 0.14 & 0.43 \\
\hline ch3Ze (ch3z) & 0.14 & 0.43 \\
\hline ch4Ze (ch4z) & 0.14 & 0.43 \\
\hline ch5Ze (ch5z) & 0.14 & 0.43 \\
\hline ch6VI (ch6v) & $N A^{a}$ & $\mathrm{NA}^{\mathrm{a}}$ \\
\hline ch6 (ch6z) & 0.04 & 0.11 \\
\hline pp4 & 0.14 & 0.43 \\
\hline pp3 & 0.20 & 0.61 \\
\hline pp2 & 0.20 & 0.61 \\
\hline pp1 & 0.14 & 0.43 \\
\hline bf3 & 0.20 & 0.61 \\
\hline bf2 & 0.14 & 0.43 \\
\hline $\operatorname{tr} 3$ & 0.20 & 0.61 \\
\hline $\operatorname{tr} 2$ & 0.14 & 0.43 \\
\hline
\end{tabular}

DTN: LB0205REVUZPRP.001 [DIRS 159525]

a Vitric units (those units ending with a "VI" or a " $\mathrm{V}$ ") do not have fractures; therefore, fracture properties do not pertain to those units.

NOTE: In parentheses are the material names used in the LDTH submodels of this report. 
Table IV-8. Bulk Density of 4-10 Crushed Tuff

\begin{tabular}{|c|c|}
\hline Row number & Mass density $\left(\mathrm{gm} / \mathrm{cm}^{3}\right)$ \\
\hline 321 & 1.3 \\
\hline 322 & 1.2 \\
\hline 323 & 1.3 \\
\hline 324 & 1.3 \\
\hline 325 & 1.3 \\
\hline 326 & 1.2 \\
\hline 327 & 1.3 \\
\hline 328 & 1.2 \\
\hline 329 & 1.3 \\
\hline 330 & 1.2 \\
\hline 331 & 1.2 \\
\hline 332 & 1.2 \\
\hline 333 & 1.3 \\
\hline 334 & 1.3 \\
\hline 335 & 1.3 \\
\hline 336 & 1.3 \\
\hline 337 & 1.3 \\
\hline 338 & 1.2 \\
\hline 339 & 1.2 \\
\hline 340 & 1.2 \\
\hline 341 & 1.3 \\
\hline 342 & 1.3 \\
\hline 343 & 1.3 \\
\hline 344 & 1.3 \\
\hline 345 & 1.3 \\
\hline 346 & 1.3 \\
\hline 347 & 1.3 \\
\hline 348 & 1.3 \\
\hline 349 & 1.3 \\
\hline 350 & 1.2 \\
\hline 351 & 1.3 \\
\hline 352 & 1.3 \\
\hline 353 & 1.3 \\
\hline 354 & 1.2 \\
\hline 355 & 1.3 \\
\hline 356 & 1.3 \\
\hline 357 & 1.2 \\
\hline 358 & 1.2 \\
\hline 359 & 1.2 \\
\hline 360 & 1.3 \\
\hline 361 & 1.3 \\
\hline 362 & 1.3 \\
\hline 363 & 1.3 \\
\hline 364 & 1.2 \\
\hline 365 & 1.2 \\
\hline 366 & 1.2 \\
\hline 367 & 1.3 \\
\hline 368 & 1.3 \\
\hline 369 & 1.3 \\
\hline 370 & 1.3 \\
\hline
\end{tabular}

DTN: GS020183351030.001 [DIRS 163107], rows 321-370.

NOTE: The average mass density for the 50 samples is $1.27 \mathrm{gm} / \mathrm{cm}^{3}$, which is the value used for the crushed-tuff invert. 
Table IV-9. Specific heat and thermal conductivity of 4-10 crushed tuff

\begin{tabular}{|c|c|c|}
\hline Row number & $\begin{array}{c}\text { Specific heat } \\
\left(\mathbf{J}_{\mathbf{c m}}{ }^{\left.{ }^{\circ} \mathbf{C}\right)}\right.\end{array}$ & $\begin{array}{c}\text { Thermal conductivity } \\
\left(\mathbf{W} / \mathbf{m}{ }^{\circ} \mathbf{C}\right)\end{array}$ \\
\hline 1 & 0.82 & 0.17 \\
\hline 2 & 0.84 & 0.14 \\
\hline 3 & 0.98 & 0.17 \\
\hline 4 & 0.98 & 0.17 \\
\hline 5 & 0.99 & 0.17 \\
\hline 6 & 0.92 & 0.16 \\
\hline 7 & 0.96 & 0.17 \\
\hline 8 & 0.86 & 0.15 \\
\hline 9 & 0.88 & 0.16 \\
\hline 10 & 1.06 & 0.17 \\
\hline 11 & 0.94 & 0.17 \\
\hline
\end{tabular}

DTN: GS000483351030.003 [DIRS 152932], rows 1-11

NOTE: The average specific heat for the 11 samples is 0.93 $\mathrm{J} / \mathrm{cm}^{3}-{ }^{\circ} \mathrm{C}$, which is the value used for the crushed-tuff invert. The average thermal conductivity for the 11 samples is $0.2 \mathrm{~W} / \mathrm{m}^{-}{ }^{\circ} \mathrm{C}$, which is the averaged valued rounded up to the nearest "tenths"; this rounded averaged value is used for the crushed-tuff invert. 


\section{INTENTIONALLY LEFT BLANK}




\section{APPENDIX V}

BUILDING SUBMODEL INPUT FILES 


\section{SMT Submodel}

The SMT submodel has the following information in this order:

1. Time information (starttime, stoptime, timestepsize)

2. Material properties (in the form of a rocktab file; see Appendix IV)

3. Output information (for ".ext" time-history output; this is readable by XTOOL v10.1)

4. Heat generation information (in the form of a heatgen file; see Appendix III)

5. Restart file information

6. Boundary-conditions

7. Initial conditions

8. SMT submodel mesh file (in the form of an SMT submodel mesh file; see Appendix I)

9. Run control parameters

All parameter values are taken directly from inputs or calculations described in other Appendices. An example of an SMT submodel NUFT usnt-option input file follows below. For more information, see the NUFT documentation (Nitao 1998 [DIRS 100474]).

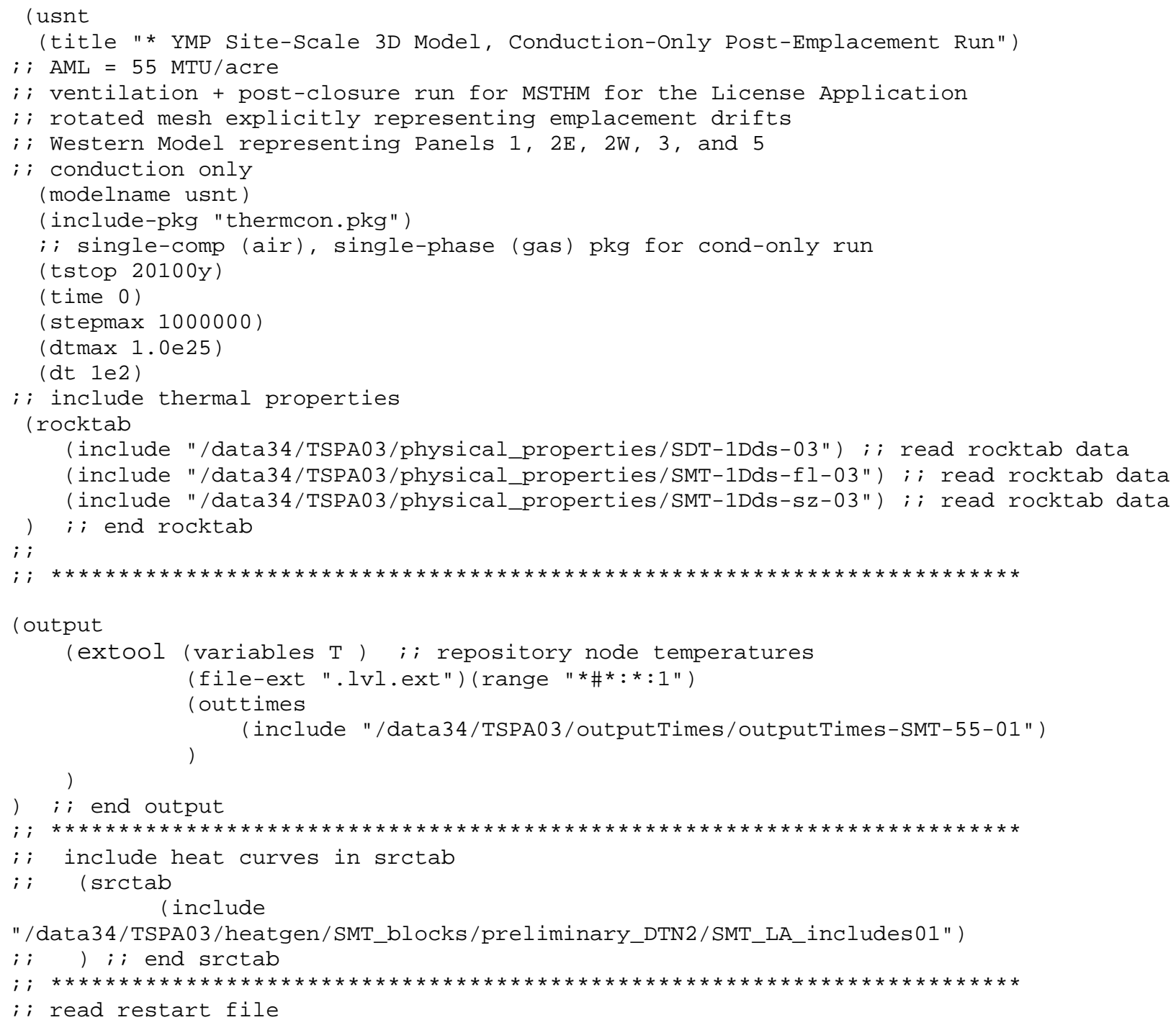




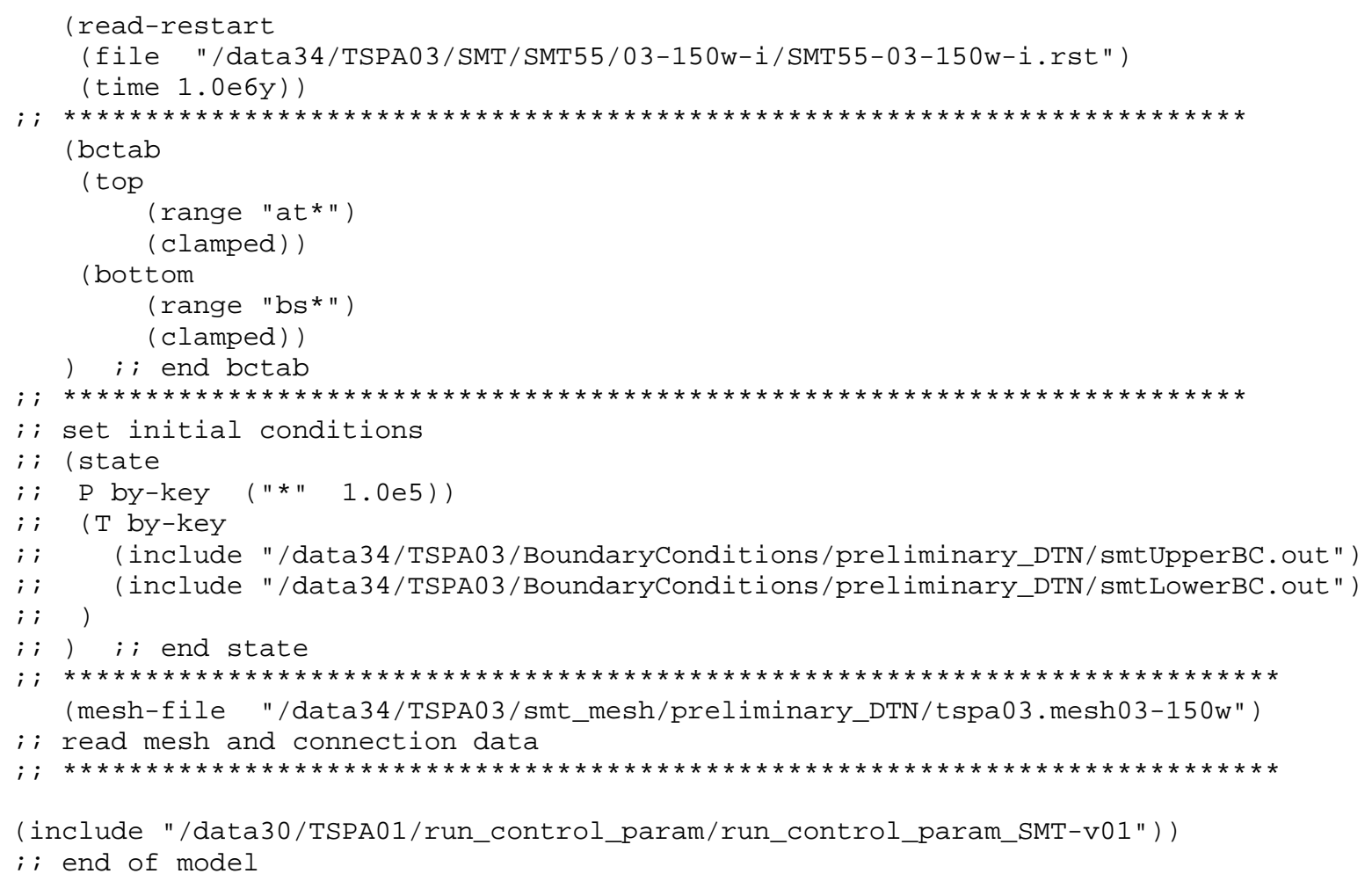

\section{LDTH submodel}

For the LDTH submodel input files, a calculation (in addition to those described in other Appendices) must be made to convert the percolation flux from $\mathrm{mm} / \mathrm{yr}$ to $\mathrm{kg} / \mathrm{m}^{2} / \mathrm{sec}$. An example of this calculation is:

\section{$\mathrm{J}=4.1884 \mathrm{~mm} / \mathrm{yr}(1$ day $/ 86,400 \mathrm{sec})(1 \mathrm{yr} / 365.25$ days $)(\mathrm{m} / 1,000 \mathrm{~mm})\left(1,000 \mathrm{~kg} / \mathrm{m}^{3}\right)=1.3274 \times 10^{-7} \mathrm{~kg} / \mathrm{m}^{2} / \mathrm{sec}$}

The LDTH submodel has the following information in this order:

1. Header information (lines preceded by a semicolon)

2. Time information (start time, stop time, timestepsize)

3. Convergence tolerance information

4. Output file (for ".ext” time-history output; this is readable by XTOOL v10.1)

5. Material properties (in the form of rocktab files; see Appendix IV)

6. Percolation flux information (see the flux conversion $\mathrm{mm} / \mathrm{yr}$ to $\mathrm{kg} / \mathrm{m}^{2} / \mathrm{sec}$ noted above)

7. Heat generation information (in the form of a heatgen file; see Appendix III)

8. Boundary-conditions

9. Restart conditions (optional)

10. Initial conditions (optional)

11. Mesh information for matrix continuum

12. Radcon information for matrix continuum (in the form of a file for doing thermalradiation connections, see Appendix VI)

13. Mesh information for fracture continuum

14. Run control parameters 
All parameter values are taken directly from inputs or calculations described in other appendices. An example of an DDT submodel NUFT usnt-option input file (P1R10C8-LDTH14-1Dds_mcmi-02.in) follows below. For more information, see the NUFT documentation (Nitao 1998 [DIRS 100474]). LDTH submodel input files follow the naming convention P(x)R(y)C(z)LDTH(aml)-1Dds_mc-(percolation)i-0(property set).in. For the three infiltration flux cases, there are 2,592 input files including 1,296 initialization runs and 1,296 postemplacement runs. These files are found in DTN: LL030808623122.036.

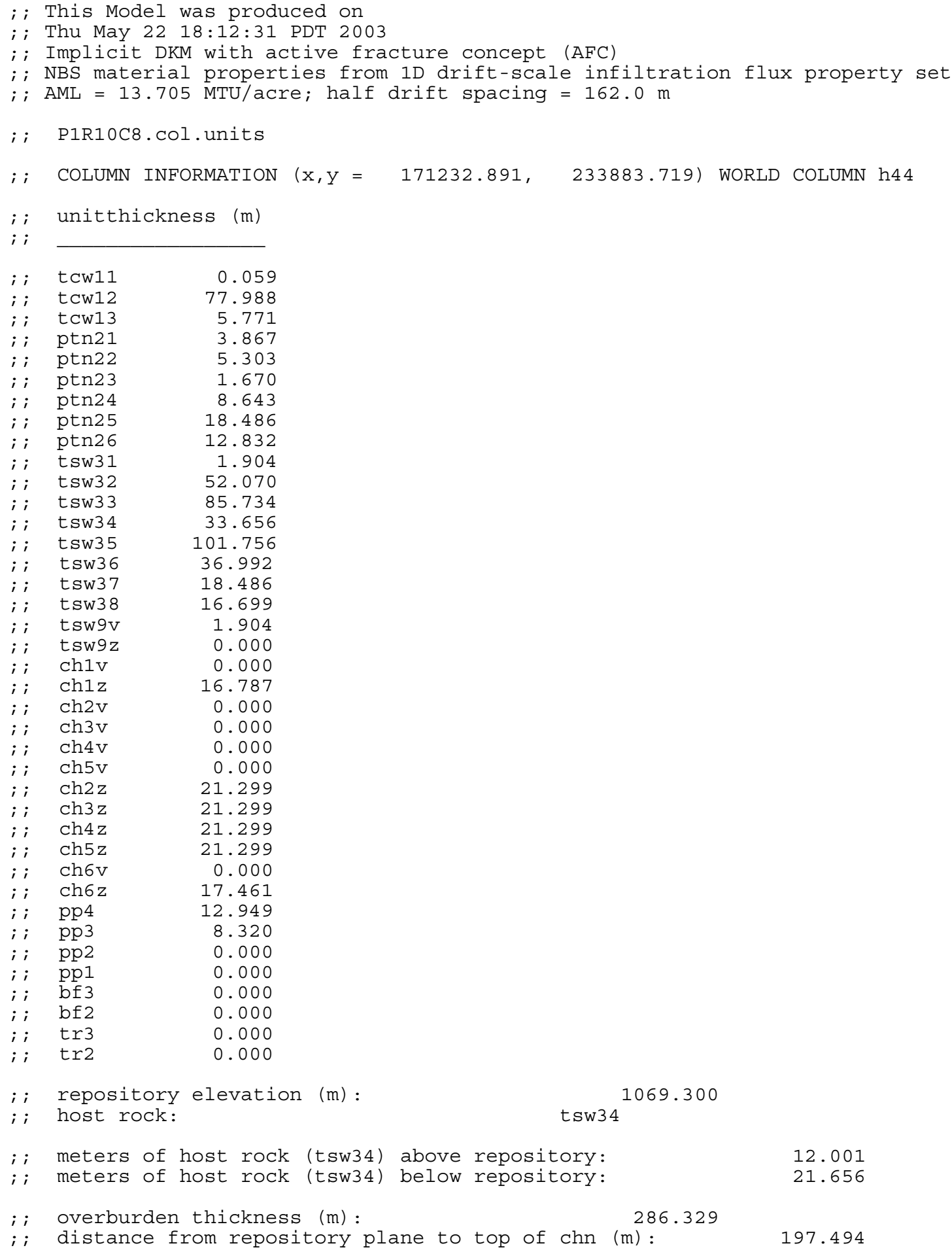


; i distance from repository plane to top of water table (m): 338.206

(usnt

(title "4.1883590e+00mm_yr,line-load,AML=14mtu_acre, LDTH14_1Dds_mc-mi")

(modelname usnt)

(tstop 20100y)

(time $0 y$ )

(stepmax 1000000)

$(\mathrm{dtmax} 1.000 \mathrm{e}+25)$

(dt $1 e 2)$

(tolerconv (P 5000.) (S 0.005) (X 0.005) ( $\mathrm{T} 0.5)$ )

; ; absolute NR conv. tolerance

(reltolerconv ( $\mathrm{P} 0.005)(\mathrm{S} 0.0)(\mathrm{X} 0.0)(\mathrm{T} 1 . \mathrm{e}-3))$

(tolerdt (P 2.e4) (S 0.35) (X 0.25$)(\mathrm{T}$ 10.) )

(reltolerdt (P 0.1$)\left(\begin{array}{ll}S & 0.0\end{array}\right)\left(\begin{array}{ll}X & 0.0\end{array}\right)\left(\begin{array}{ll}\mathrm{T} & 0.0\end{array}\right)$ )

i; trying with harmonic mean everywhere which means

; ; turning off the geometric before vtough.pkg gets called.

(diffusion-geo-mean off)

; ; for imp-DKM do not have this so that it will default to

; ; harmonic for fract-matrix interaction

i i (mult-cont-diff-harmonic off)

; ; following has to come after tolerances

(rmstolerconv 1e-4)

(include-pkg "vtough.pkg")

(check-mult-con off)

; ;

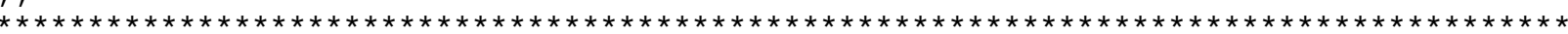

$* * * * * * * * * * * * *$

loutput

(extool (continuum f)

(variables T S.liquid X.air.gas RH PC.liquid P.gas qPhChg.water.gas QPhChg.water.gas q.liquid q.water.gas q.air.gas)

(file-ext ".f.EBS.ext") (range "*hstrk*.f*" "dr*.f*" "*in*.f*"

$" * w p * . f * ")$

(outtimes )

(include "/data34/TSPA03/outputTimes/outputTimes-LDTH-SDT-DDT-14-01")

)

(extool (continuum $\mathrm{m}$ )

(variables T S.liquid X.air.gas RH PC.liquid P.gas qPhChg.water.gas

QPhChg.water.gas q.liquid q.water.gas q.air.gas)

(file-ext ".m.EBS.ext") (range "*hstrk*.m*" "dr*.m*" "*in*.m*"

(outtimes

$" * w p * . m * ")$

(include "/data34/TSPA03/outputTimes/outputTimes-LDTH-SDT-DDT-14-01")

) $;$; end output

irocktab

(include "/data34/TSPA03/physical_properties/dkm-afC-EBS-mi-03")

) ; ; close rocktab

(include "/data34/TSPA03/physical properties/modpropTSPA03 0114 ")

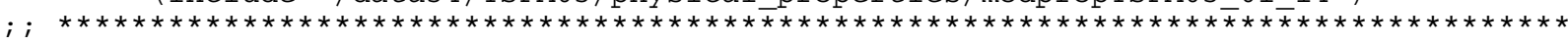

; i This srctab is adjusted to allocate percolation to just the fracture. (srctab

(compflux

(comp water)

(name infil)

(range $" * . f *: *: 2 "$ )

(mult-by-area z)

(allocate-by-element $(" * " 1.0))$

(table 0.0 $1.3274464 \mathrm{e}-07 \quad 600.00 \mathrm{y} \quad 1.3274464 \mathrm{e}-07 ; i 4.1883590 \mathrm{e}+00 \mathrm{~mm} / \mathrm{yr}$ $600.001 y 2.4720940 \mathrm{e}-07 \quad 2000.00 \mathrm{y} 2.4720940 \mathrm{e}-07 ; i 7.7999510 \mathrm{e}+00 \mathrm{~mm} / \mathrm{yr}$ 


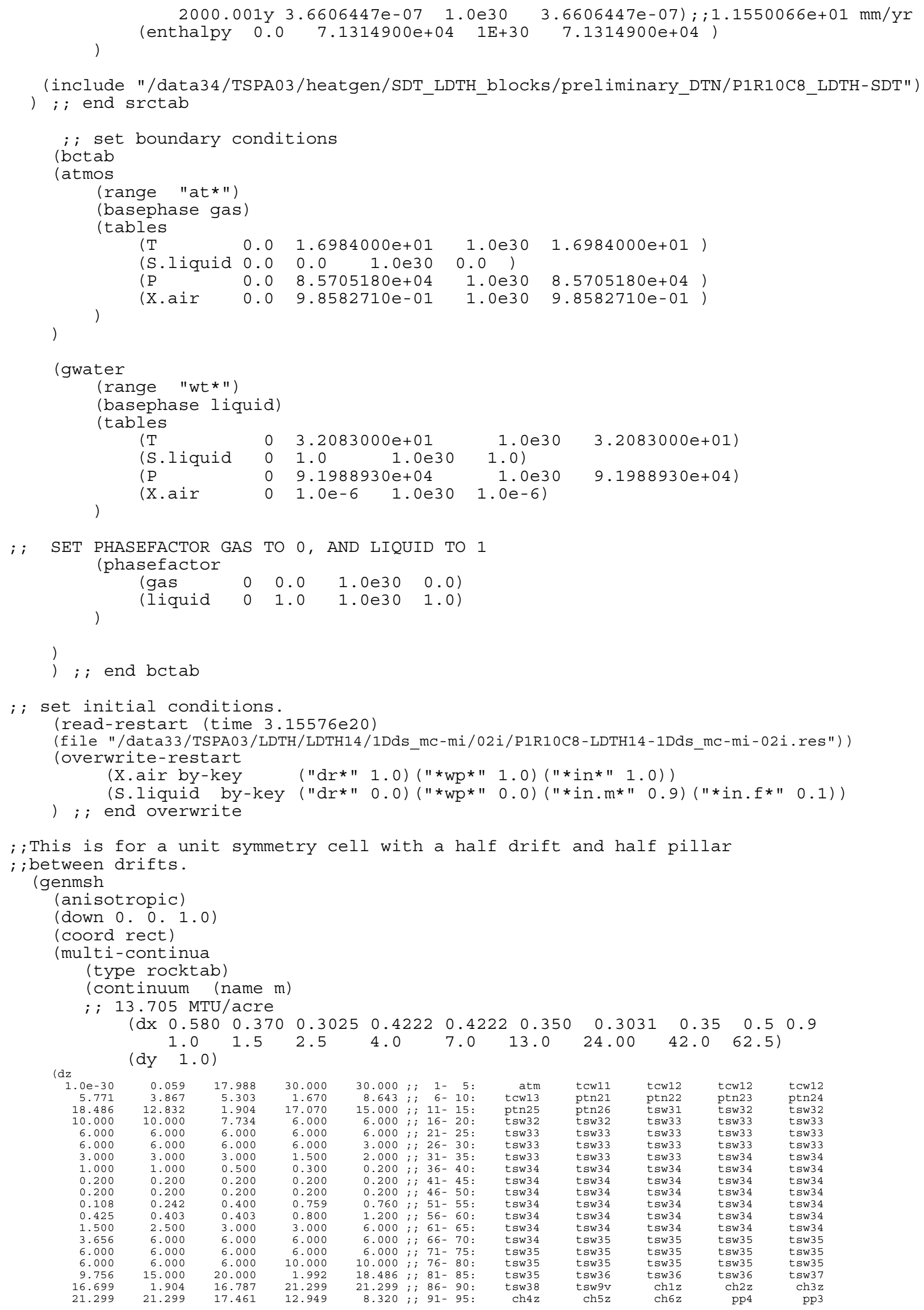


$i^{1.0 e-30}$

(atm

(tcw11

(tcw12

(tcw13

(ptn21

(ptn22

(ptn23

(ptn24

(ptn25

(ptn26

(tsw31

(tsw32

(tsw33

(tsw34

(tsw35

(tsw36

(tsw37

(tsw38

(tsw9v

(chlz

( $\operatorname{ch} 2 \mathrm{z}$

( $\operatorname{ch} 3 z$

(ch4 z

( ch5 $z$

(ch6z

(pp4

(pp3

(wt

(hstrk

(dr

(dr

(dr

(dr

(dr

(dr

(dr

(dr

(wp

(wp

(wp

i i invert

(in

)
; ; 96- 96: wt

atm

m-tcw11

$m-t c w 12$

$m-t c w 13$

$\mathrm{m}-\mathrm{ptn} 21$

$m-p \operatorname{tn} 22$

m-ptn23

m-ptn 24

m-ptn25

m-ptn26

m-tsw31

$\mathrm{m}-\mathrm{tsw} 32$

$m-t s w 33$

m-tsw34

m-tsw35

m-tsw36

m-tsw3 7

m-tsw38

m-tsw9v

$\mathrm{m}-\mathrm{ch} 1 \mathrm{z}$

$\mathrm{m}-\mathrm{ch} 2 \mathrm{z}$

$m-\operatorname{ch} 3 z$

$m-\operatorname{ch} 4 \mathrm{z}$

$\mathrm{m}-\operatorname{ch} 5 \mathrm{z}$

$\mathrm{m}-\mathrm{ch} 6 \mathrm{z}$

$\mathrm{m}-\mathrm{pp} 4$

m-pp3

m-pp3

m-tsw34

$m-d r$

$m-d r$

$m-d r$

$m-d r$

$m-d r$

$m-d r$

$m-d r$

$m-d r$

lsnf

lsnf

lsnf

m-invert 1

m-invert 2

\section{i) $96-96:-$}

$\begin{array}{llllll}1 & n x & 1 & n y & 1 & 1)\end{array}$

$\begin{array}{llllll}1 & n x & 1 & n y & 2 & 2\end{array}$

$1 \mathrm{nx} 1 \mathrm{ny} \quad 3 \quad 5$ )

$\begin{array}{llllll}1 & n x & 1 & n y & 6 & 6)\end{array}$

$\begin{array}{lllll}n x & 1 & n y & 7 & 7)\end{array}$

$\begin{array}{llllll}1 & n x & 1 & n y & 8 & 8\end{array}$

$1 \mathrm{nx} \quad 1$ ny 9 9)

$1 \mathrm{nx} 1 \mathrm{ny} 10$ 10)

$1 \mathrm{nx} 1 \mathrm{ny} 11$ 11)

$\begin{array}{lllll}n \times & 1 & n y & 12 & 12)\end{array}$

$1 \mathrm{nx} \quad 1$ ny 13 13)

$1 \mathrm{nx} 1 \mathrm{ny} 14$ 17)

$1 \mathrm{nx} \quad 1$ ny 18 33)

$1 \mathrm{nx} 1 \mathrm{ny} 34$ 66)

$\begin{array}{llllll}1 & n x & 1 & \text { ny } & 67 & 81\end{array}$

$1 \mathrm{nx} \quad 1$ ny $82 \quad 84$ )

$1 \mathrm{nx} \quad 1$ ny 85 85)

$1 \mathrm{nx} \quad 1$ ny $86 \quad 86$ )

$1 \mathrm{nx} \quad 1$ ny $87 \quad 87$ )

$1 \mathrm{nx} \quad 1$ ny 88 88)

$1 \mathrm{nx} 1$ ny 89 89)

$1 \mathrm{nx} \quad 1$ ny $90 \quad 90)$

$1 \mathrm{nx} 1$ ny 91 91)

$1 \mathrm{nx} \quad 1$ ny 92 92)

$1 \mathrm{nx} 1 \mathrm{ny} 93$ 93)

$\begin{array}{lllll}n \times & 1 & \text { ny } & 94 & 94)\end{array}$

$1 \mathrm{nx} 1$ ny 95 95)

$1 \mathrm{nx} \quad 1$ ny 96 96)

$\begin{array}{llllll}1 & n x & 1 & n y & 34 & 61\end{array}$

$\begin{array}{llllll}1 & 1 & 1 & \text { ny } & 41 & 41)\end{array}$

$\begin{array}{llllll}1 & 3 & 1 & \text { ny } & 42 & 42 \text { ) }\end{array}$

$\begin{array}{llllll}1 & 4 & 1 & \text { ny } & 43 & 44)\end{array}$

$\begin{array}{llllll}1 & 5 & 1 & \text { ny } & 45 & 46 \text { ) }\end{array}$

$\begin{array}{llllll}1 & 6 & 1 & \text { ny } & 47 & 49)\end{array}$

$\begin{array}{llllll}1 & 7 & 1 & \text { ny } & 50 & 54)\end{array}$

$\begin{array}{llllll}1 & 6 & 1 & \text { ny } & 55 & 55)\end{array}$

$\begin{array}{llllll}1 & 5 & 1 & \text { ny } & 56 & 56)\end{array}$

$\begin{array}{llllll}1 & 1 & 1 & \text { ny } & 52 & 52)\end{array}$

$\begin{array}{llllll}1 & 2 & 1 & \text { ny } & 53 & 53)\end{array}$

$\begin{array}{llllll}1 & 4 & 1 & \text { ny } & 57 & 57) \\ 1 & 2 & 1 & \text { ny } & 58 & 58)\end{array}$

(radcon

(surface-offset $\begin{array}{llll}0 & 0 & -3 \text { ) }\end{array}$

(include "/data34/TSPA03/radcon/LDTH/preliminary_DTN/ldth0_300m.radcon")

) i close radcon

) $;$; end continuum

(continuum (name $\mathrm{f}$ )

(flow-area-density $(" * . f * " 1.0))$

(Lenfirst $(" * . f * " 1.0)) \quad ;$; same as $\mathrm{Y}$-direction

$\begin{array}{ll}(\text { Len }(" * . f * " 1.0)) & ; ; \text { half-width of matrix } \\ & ; ; \text { same as y-direction }\end{array}$

; ; half-width of fracture

len-fac

; ; Lenfirst and Len values are doubled here since 50\% of cont-

i i $13.705 \mathrm{MTU} /$ acre

; i is used in rocktab file

$\left(\begin{array}{lllllllllll}\mathrm{dx} & 0.580 & 0.370 & 0.3025 & 0.4222 & 0.4222 & 0.350 & 0.3031 & 0.35 & 0.5 & 0.9\end{array}\right.$

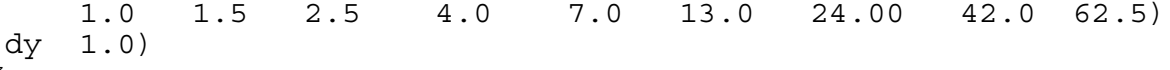

$\begin{array}{rrr}.0 \mathrm{e}-30 & 0.059 & 17.988 \\ 5.771 & 3.867 & 5.303 \\ 18.486 & 12.832 & 1.904 \\ 10.000 & 10.000 & 7.734 \\ 6.000 & 6.000 & 6.000 \\ 6.000 & 6.000 & 6.000 \\ 3.000 & 3.000 & 3.000 \\ 1.000 & 1.000 & 0.500 \\ 0.200 & 0.200 & 0.200\end{array}$

30.000
1.670
17.070
6.000
6.000
6.000
1.500
0.300
0.200

$30.000 ; ; \quad 1-5:$

8.643 i $1-5: \quad$ atm

atm
tcw13
ptn25

ptn21 tcw12

15.000 ; ; $11-15$ :

$6.000 ; ; 16-20:$

$6.000 ; ; 21-25:$

$2.000 ; ; 31-35: \quad$ tsw33

$0.200 ; ; 36-40: \quad \operatorname{tsw} 34$

tsw34 tsw34

tsw 34

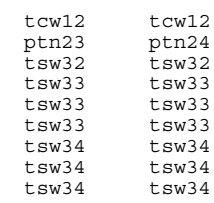




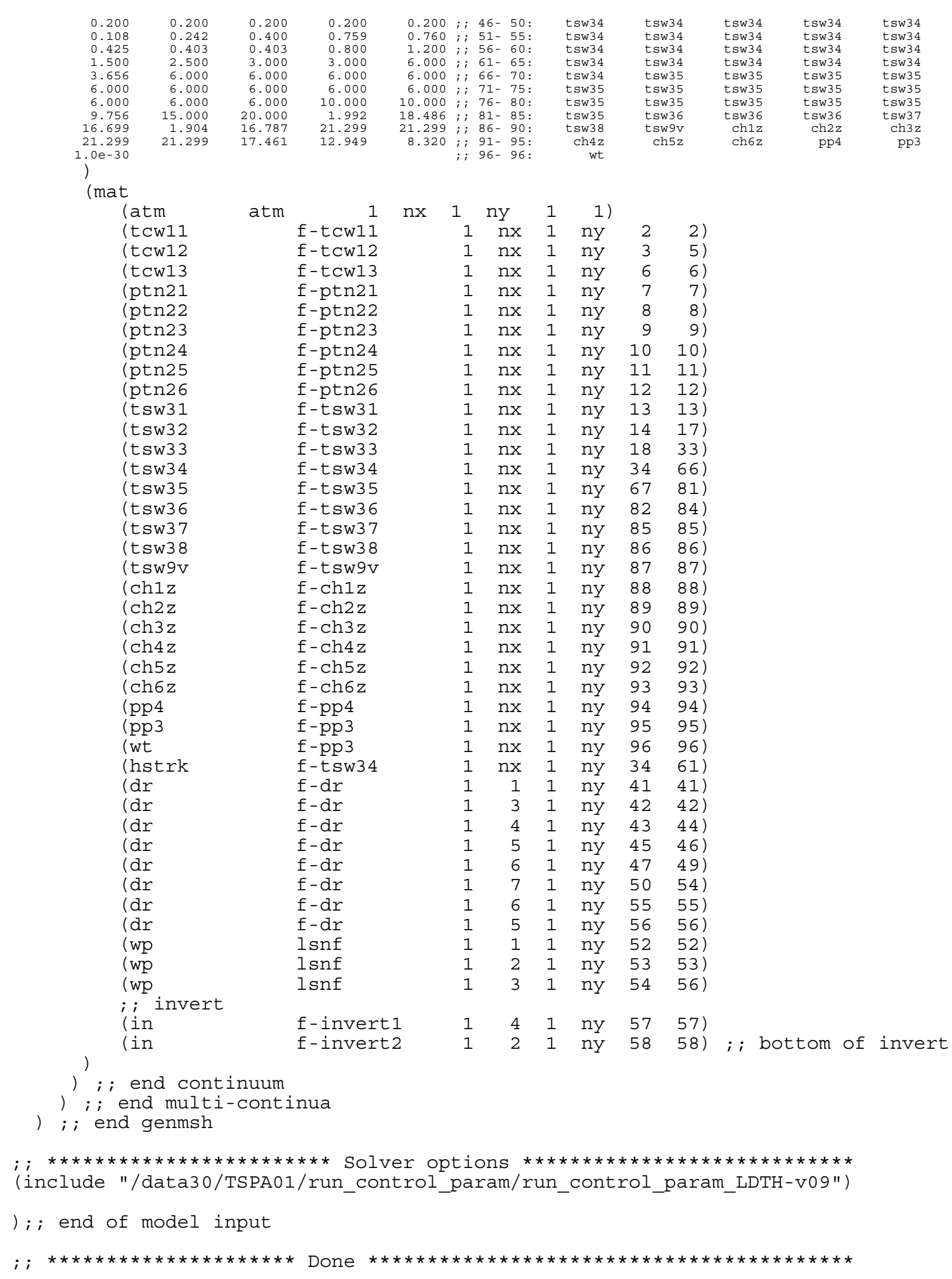




\section{SDT submodel}

The SDT submodel has the following information in this order:

1. Header information (lines preceded by a semicolon)

2. Time information (start time, stop time, timestepsize)

3. Output information (for ".ext" time-history output; this is a readable by XTOOL v10.1)

4. Material properties (in the form of a rocktab file, see Appendix IV)

5. Heat generation information (in the form of a heatgen file, see Appendix III)

6. Boundary-conditions

7. Initial conditions ("state" command)

8. SDT submodel mesh file (in the form of an SDT submodel mesh file, see Appendix I)

All parameter values are taken directly from inputs or calculations described in other appendices. An example of an SDT submodel NUFT input file (P5415C8-SDT27-00-01.in) follows. For more information, see the NUFT documentation (Nitao 1998 [DIRS 100474]). SDT submodel input files follow the naming convention $\mathrm{P}(\mathrm{x}) \mathrm{R}(\mathrm{y}) \mathrm{C}(\mathrm{z})-\mathrm{SDT}(\mathrm{aml})-00-01$.in. Note that only one set of SDT submodels to cover all three infiltration flux cases (lower-bound, mean, and upperbound), thus, there are 540 input files, which includes 108 initialization runs and 324 postemplacement runs. These files are found in DTN: LL030808623122.036.

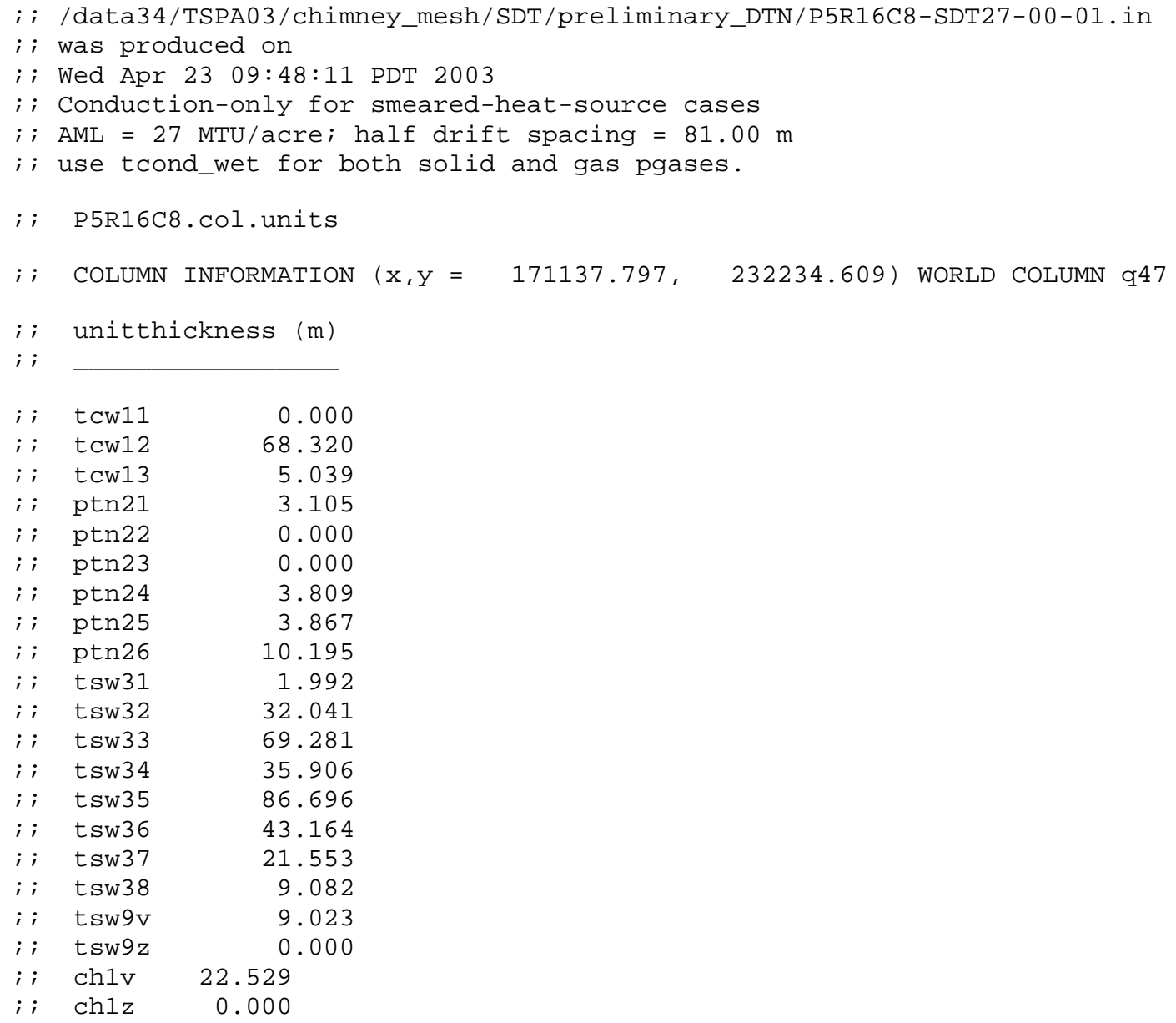




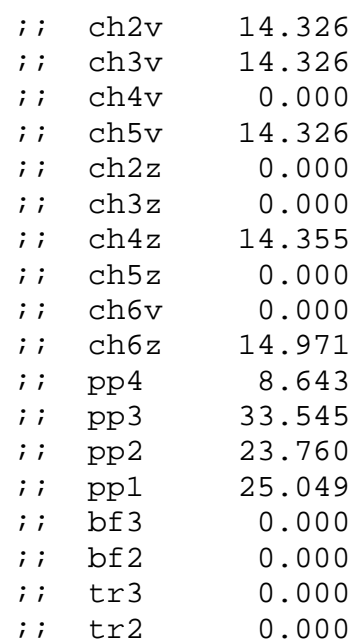

; ; repository elevation $(\mathrm{m})$ :

; ; host rock:

tsw34

$; ;$ meters of host rock (tsw34) above repository: $\quad 29.906$

;; meters of host rock (tsw34) below repository: $\quad 6.000$

$\begin{array}{lll}; ; & \text { overburden thickness }(\mathrm{m}): & 227.556 \\ ; ; & \text { distance from repository plane to top of chn }(\mathrm{m}): & 175.518\end{array}$

$; ;$ distance from repository plane to top of water table $(\mathrm{m}): \quad 361.347$

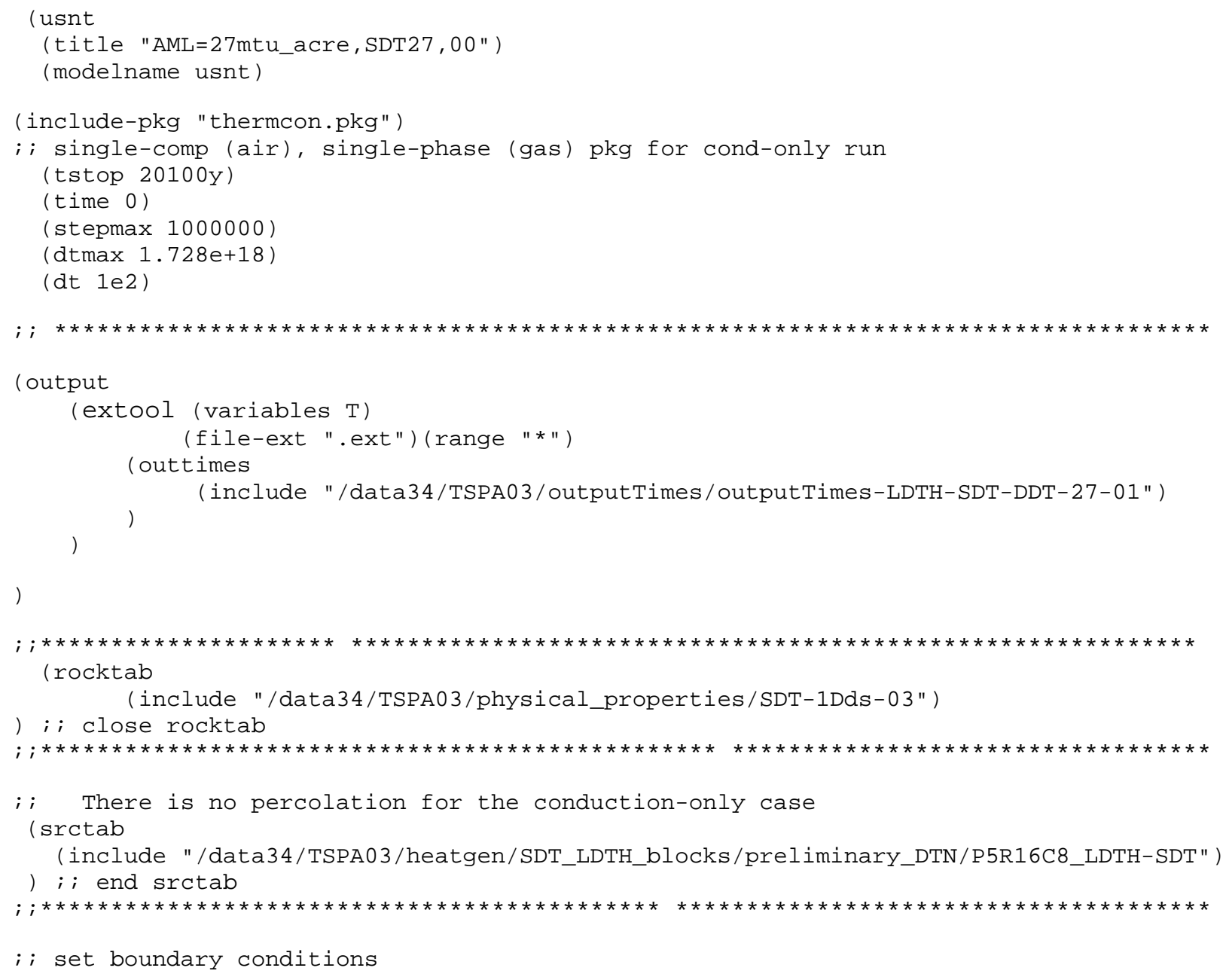




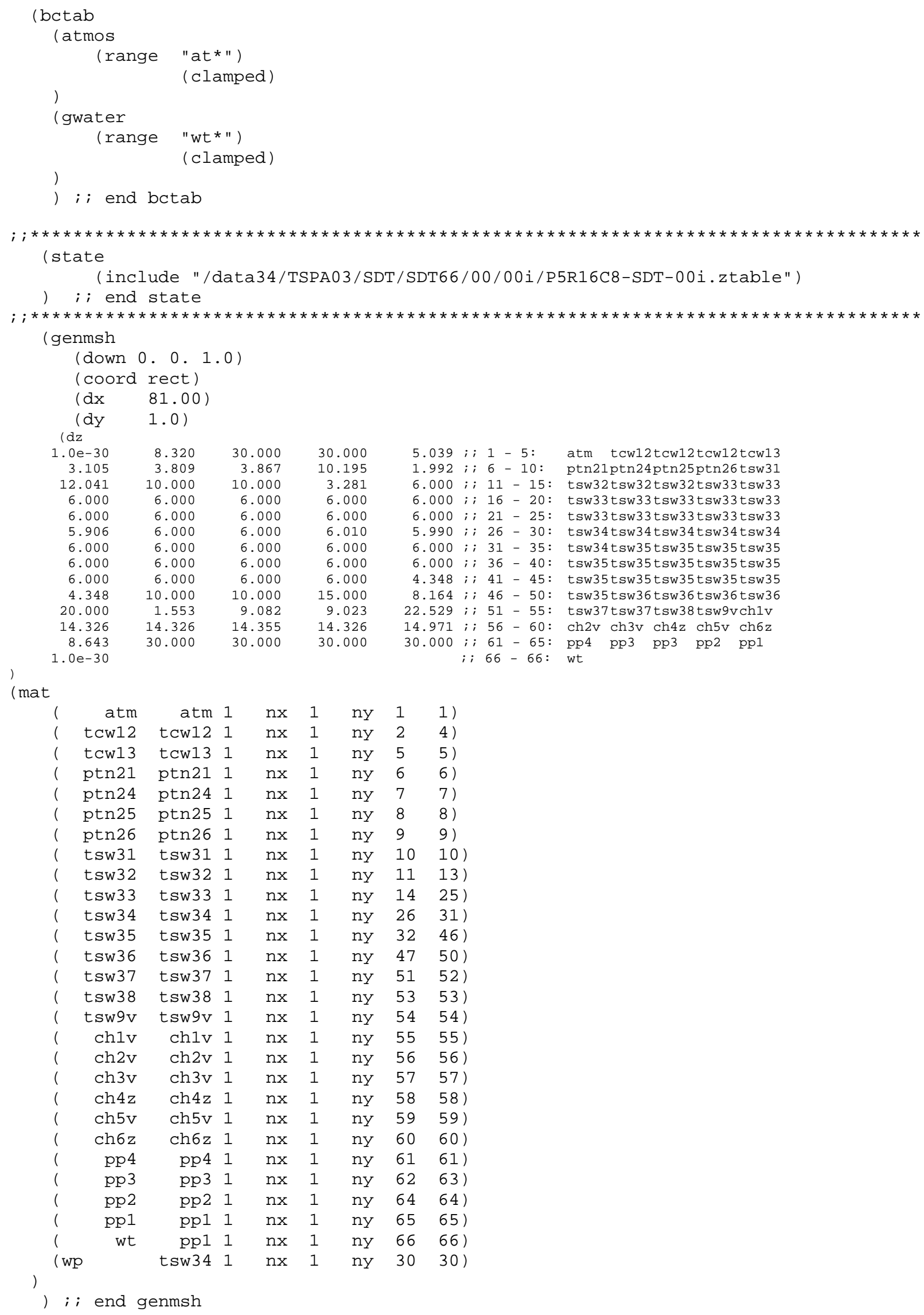




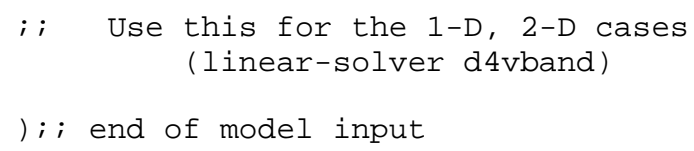

\section{DDT submodel}

The DDT submodel has the following information in this order:

1. header information (lines preceded by a semicolon)

2. time information (start time, stop time, timestepsize)

3. output information (for ".ext" time-history output this is a readable by XTOOL v10.1)

4. material properties (in the form of a rocktab file, see Appendix IV)

5. heat generation information (in the form of a heatgen file, see Appendix III)

6. boundary-conditions

7. restart file information

8. initial conditions

9. DDT mesh file

10. radcon information (in the form of a file for doing thermal-radiation connections, see Appendix VI)

11. run control parameters

All parameter values are taken directly from inputs or calculations described in other appendices. An example of an DDT submodel NUFT input file (P2WR5C10-DDT55-01-1e11.in) follows below. The interested reader is referred to the NUFT documentation (Nitao 1998 [DIRS 100474]) for specific details of this input file.

DDT submodel input files are found in DTN: LL030808623122.036. The names of these files are:

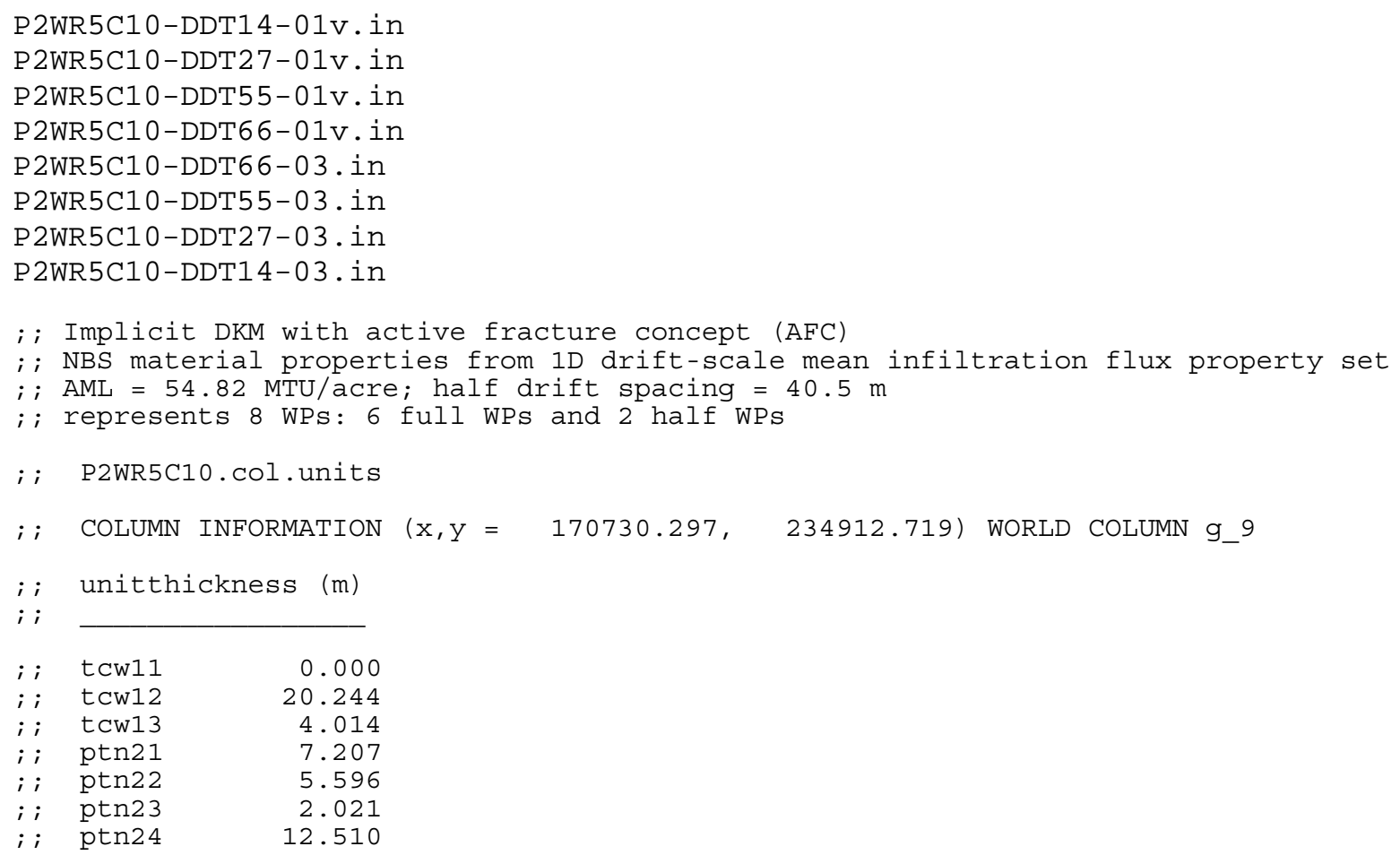




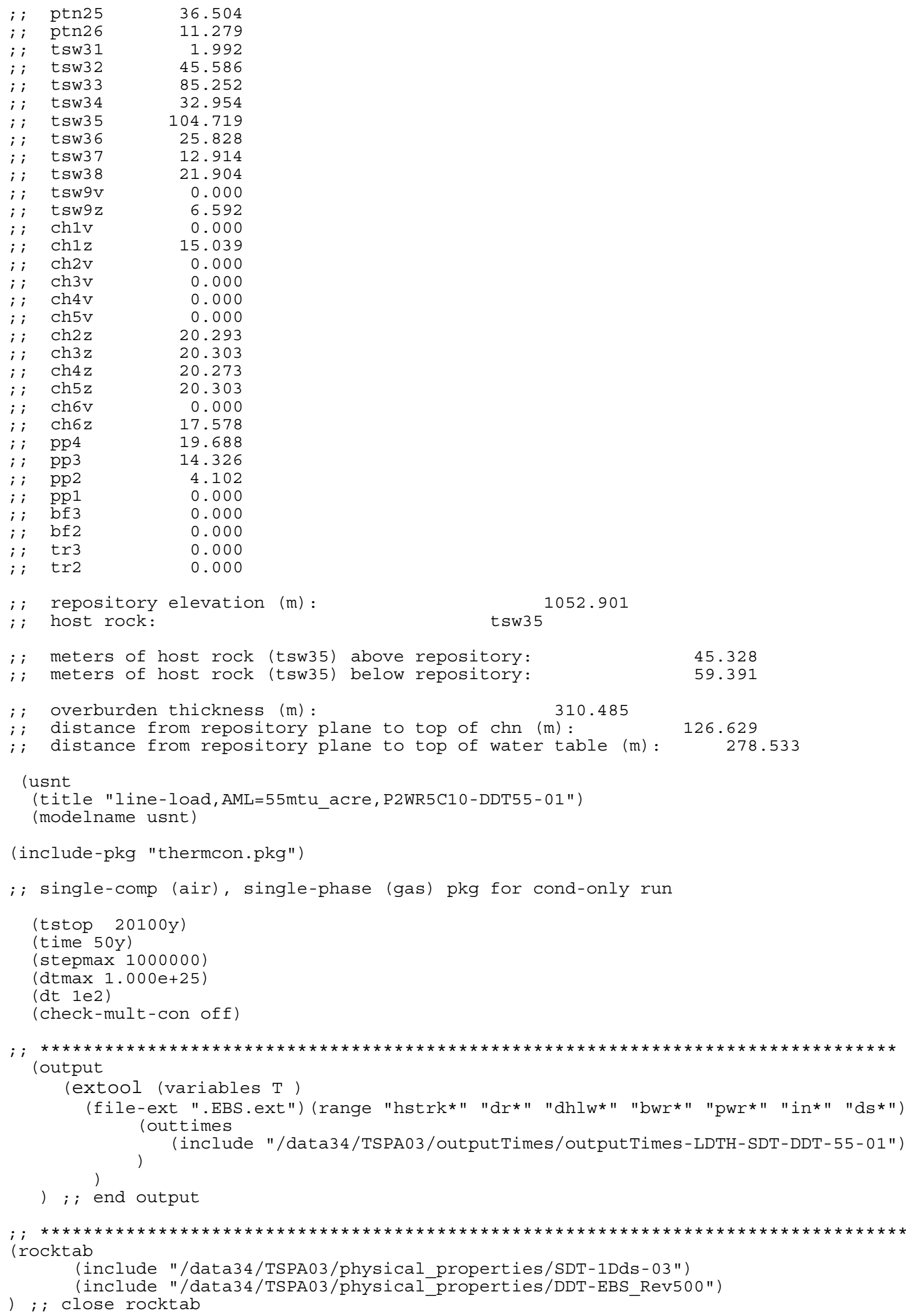




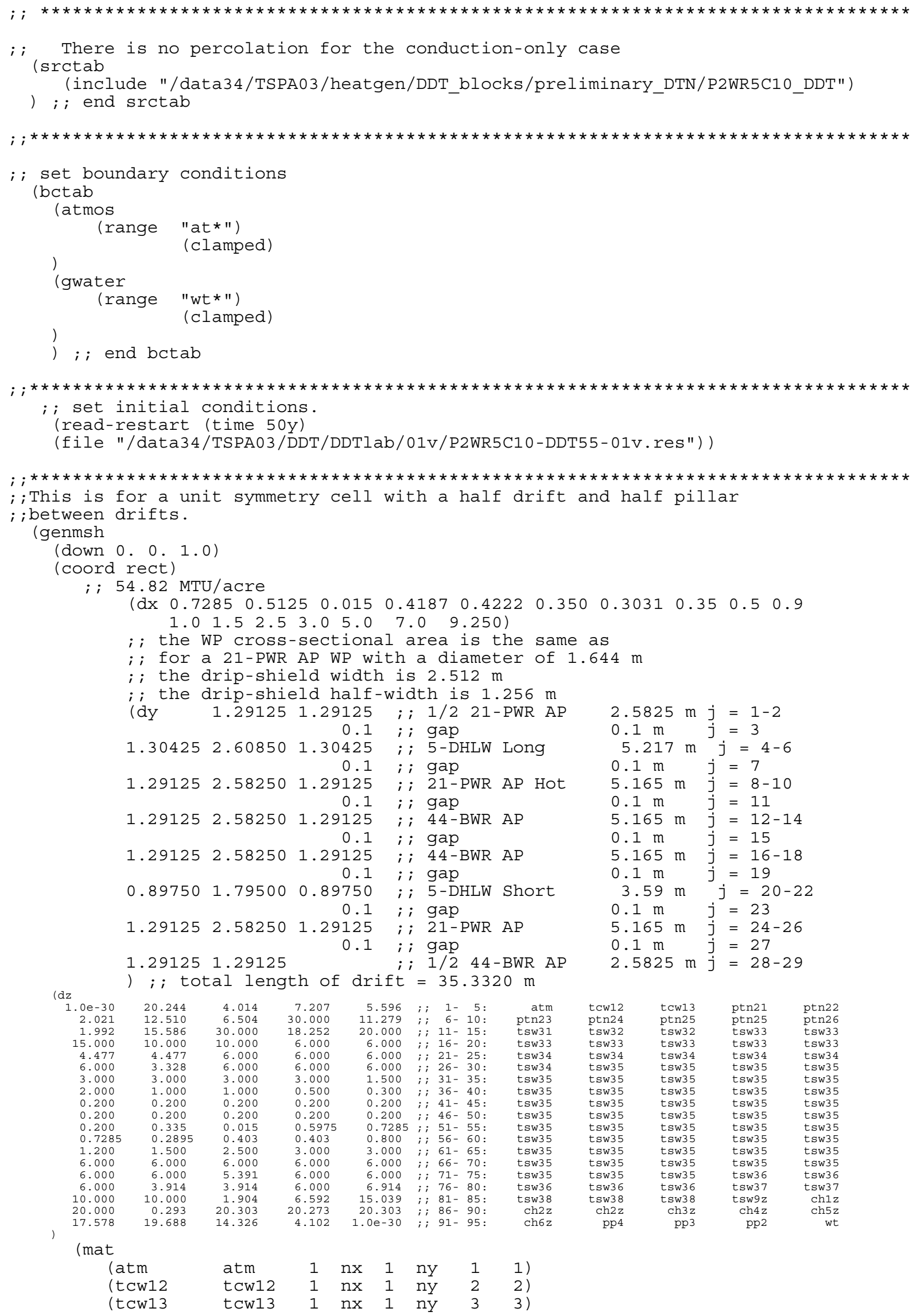




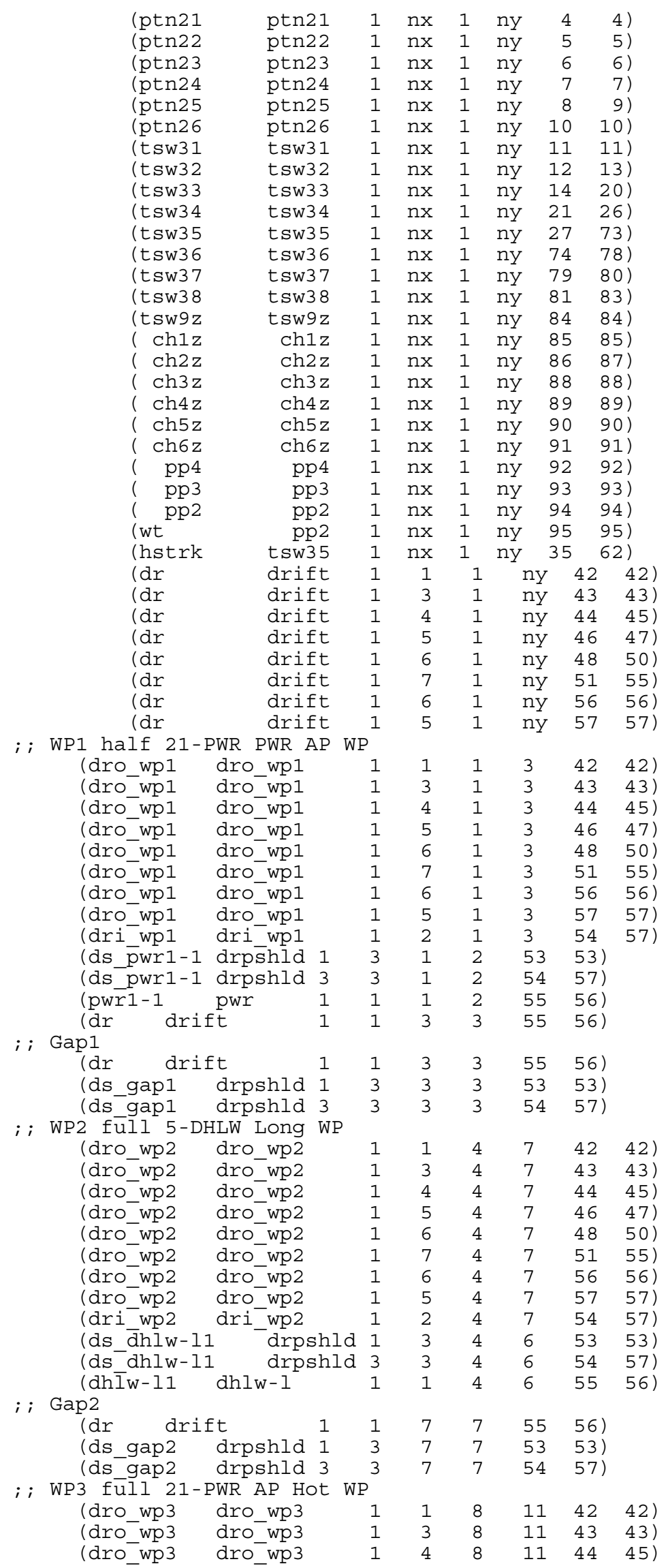




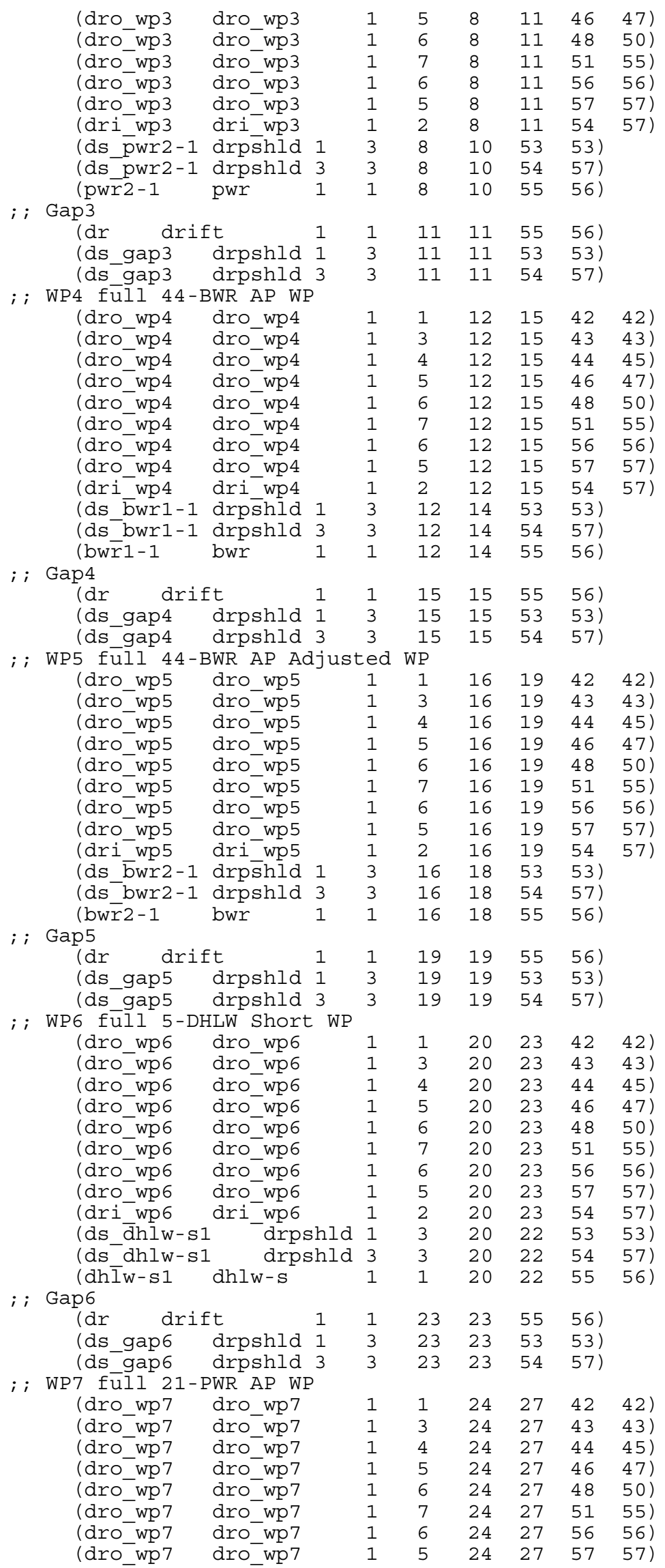




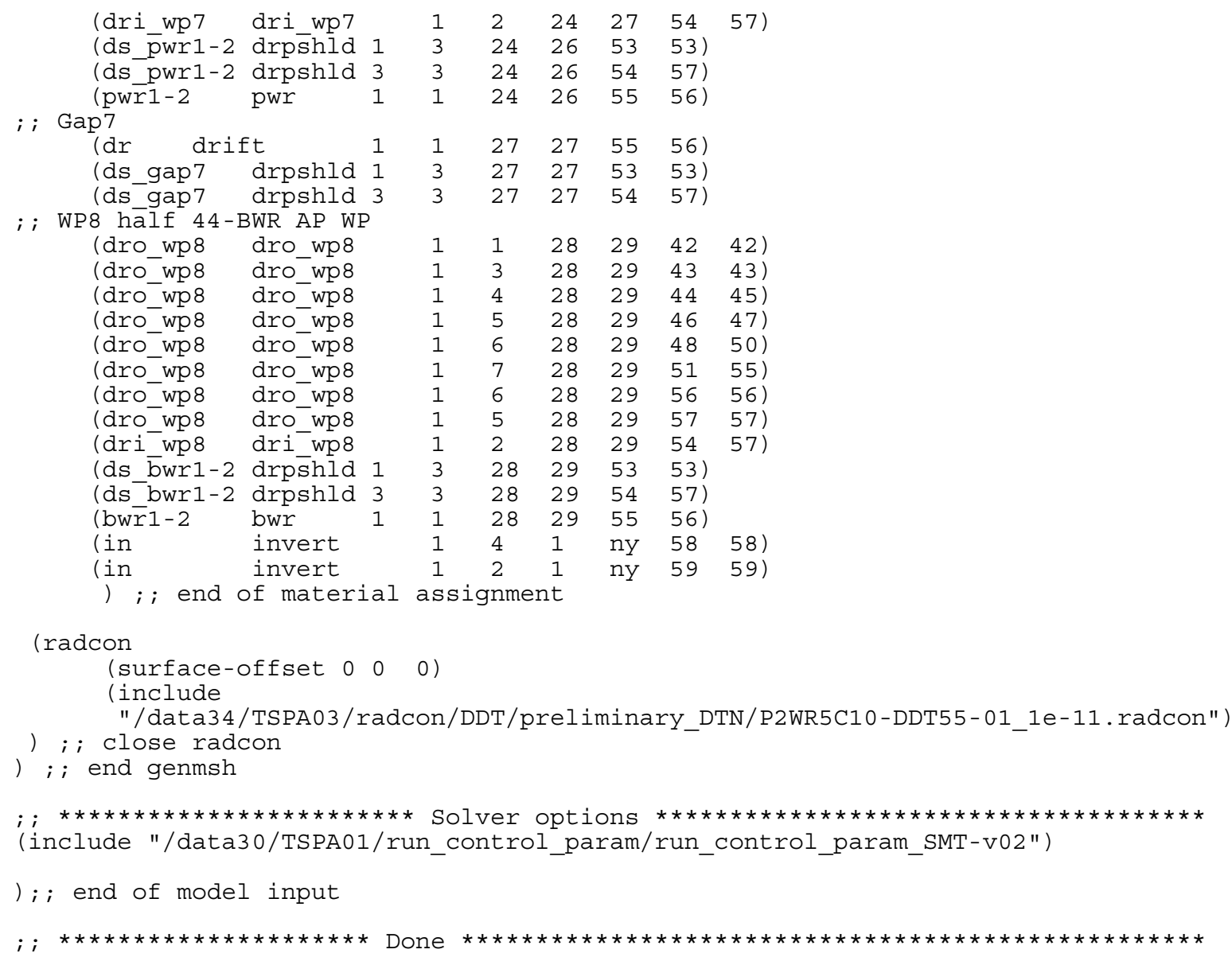


APPENDIX VI

LDTH AND DDT SUBMODEL THERMAL-RADIATION CONNECTION CALCULATION 
The LDTH and DDT submodels include heat transfer by thermal radiation inside the drift. The LDTH and DDT submodels represent thermal-radiative heat transfer between the drip shield, drift wall, and invert surfaces. The DDT submodels also represent thermal-radiative heat transfer between the waste package, drip shield, and invert surfaces beneath the drip shield. The determination of the thermal-radiation coefficients requires one direct input, which is the emissivity of the surfaces. The emissivity of the drift wall and invert surfaces is taken to be 0.9 , which is near the middle of the range given for rocks (0.88 to 0.95) in Table A.11 of Fundamentals of Heat and Mass Transfer (Incropera and DeWitt 1996 [DIRS 108184]). The process of determining thermal-radiation connections for the LDTH and the DDT submodels is done by hand following these steps:

1. Compile a list of model gridblocks that have at least 1 face contacting air within the drift

2. For each pair of gridblocks in this list

a. Determine if there is a clear path (line of sight between face centers) between the air contacting face of each block

b. If a clear path exists, calculate the thermal-radiation coefficient for that connection and write a "radcon" entry in NUFT format, which is given in Reference Manual for the NUFT Flow and Transport Code, Version 2.0 (Nitao 1998 [100474]). The coefficient $c$ used in Equations 9 and 10 of Section 6.2.3.3, and which is calculated by RADPRO v4.0 (Section 3.1.3), is determined as follows:

$$
c=\left(\sigma \varepsilon(\mathrm{N} 1 \times \mathrm{R})(-\mathrm{N} 2 \times \mathrm{R}) A_{1} A_{2}\right) / \pi|\mathrm{R}|^{4}
$$

where:

$$
\begin{aligned}
& \sigma=\text { Stefans Constant } \\
& \pi=\text { pi } \\
& \varepsilon=\text { emissivity } \\
& A_{1}=\text { area of grid block face } 1 \text { (radiating) } \\
& A_{2}=\text { area of grid block face } 2 \text { (connecting) } \\
& \mathrm{N} 1=\text { unit vector normal to face } 1 \\
& \mathrm{~N} 2=\text { unit vector normal to face } 2 \\
& \mathrm{R}=\text { distance from center of face } 1 \text { to center of face } 2
\end{aligned}
$$




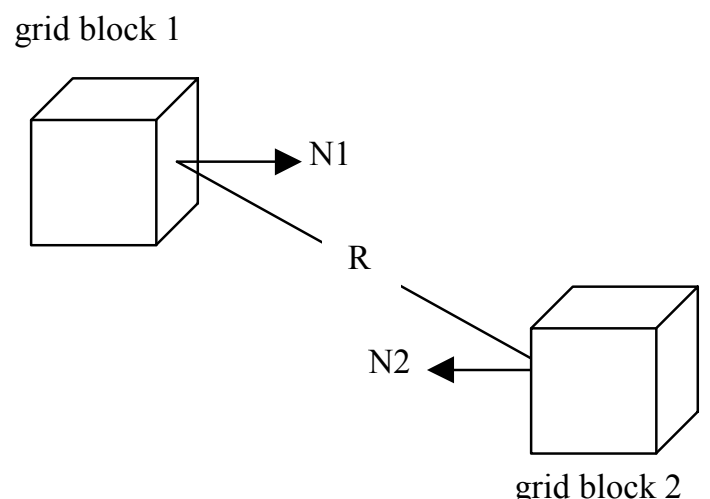

Radcon files are located in DTN: LL030808623122.036. The file names are:

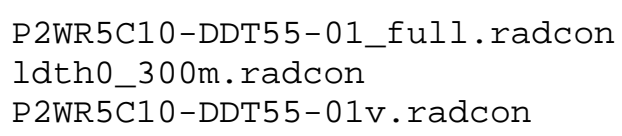

\section{Determining Effective Emissivity for RADPRO Radcon Files}

Equations 9 and 10 in Section 6.2.3.3 apply to gray-body-to-black-body thermal radiation, where the heat receiving surface $\left(A_{2}\right)$ is a perfect black body (i.e., $\varepsilon$ equal to 1$)$. The software routine RADPRO v4.0 (Section 3.1.3), which calculates the coefficient $c$ in Eq. VI-1, also pertains to gray-body-to-black-body thermal radiation. However, all surfaces within the emplacement drifts are gray bodies, with values of emissivity less than 1 . Therefore, the value of emissivity $\varepsilon$ taken as input for RADPRO v4.0 is actually an effective emissivity $\varepsilon_{\text {eff }}$, for the heat emitting surface, which accounts for the fact that the heat receiving surface is a gray body, rather than a black body. The value of effective emissivity $\varepsilon_{\mathrm{eff}}$ is determined by applying the solution of Bird et al. (1960 [DIRS 103524]) for radiative heat transfer between two long, gray coaxial cylinders by considering multiple reflections from the two sources:

$$
Q_{12}=\sigma\left(T_{1}{ }^{4}-T_{2}{ }^{4}\right) /\left[1 / A_{1} \varepsilon_{1}+\left(1 / A_{2}\right)\left(1 / \varepsilon_{2}-1\right)\right]
$$

Multiplying the numerator and denominator by $A_{1} \varepsilon_{1}$ results in the following expression:

$$
Q_{12}=A_{1} \varepsilon_{1} \sigma\left(T_{1}^{4}-T_{2}^{4}\right) /\left[1+\left(A_{1} \varepsilon_{1} / A_{2}\right)\left(1 / \varepsilon_{2}-1\right)\right]
$$

Using an effective emissivity $\varepsilon_{\text {eff }}$ results in the following expression:

$$
Q_{12}=A_{1} \varepsilon_{\text {eff }} \sigma\left(T_{1}^{4}-T_{2}^{4}\right)
$$

where $\varepsilon_{\text {eff }}$ is given by:

$$
\varepsilon_{\mathrm{eff}}=\varepsilon_{1} /\left[1+\left(A_{1} / A_{2}\right) \varepsilon_{1}\left(1 / \varepsilon_{2}-1\right)\right]
$$

The effective emissivity $\varepsilon_{\text {eff }}$ is simply $\varepsilon_{1}$, multiplied by a coefficient $C$ :

$$
\varepsilon_{\mathrm{eff}}=C \varepsilon_{1}
$$


where the coefficient $C$ is given by

$$
C=1 /\left[1+\left(A_{1} / A_{2}\right) \varepsilon_{1}\left(1 / \varepsilon_{2}-1\right)\right]
$$

For the LDTH submodels (Section 6.2.6) and DDT submodels (6.2.9), $A_{1}$ is taken to be equal to $A_{2}$, resulting in the following expression:

$$
C=1 /\left[1+\varepsilon_{1}\left(1 / \varepsilon_{2}-1\right)\right]
$$

Section 5.3.2.7 discusses the assumption concerning the emissivity at the drift-wall surface of emplacement drifts. The value of $\varepsilon_{\text {eff }}$ between the drip shield and drift-wall surface is determined for the LDTH and DDT submodels, using Equations VI-6 and VI-8 and the following values for emissivity on the drip shield $\left(\varepsilon_{1}\right)$ and for emissivity on the drift-wall (rock) surface $\left(\varepsilon_{2}\right)$ :

$$
\varepsilon_{1}=0.63 \text { (titanium from Lide } 1995 \text { [DIRS 101876], p. 10-298) }
$$

$\varepsilon_{2}=0.9$ (rock, in the range of 0.88 to 0.95 from Incropera and DeWitt 1996 [DIRS 108184])

This results in a value of 0.935 for the coefficient $C$. As discussed in Section 5.3.2.7, the driftwall surface is covered with Type 316 stainless steel liner, which has an emissivity of 0.52 to 0.66 (McAdams, Heat Transmission, 1954 [DIRS 161435]). Table VI-1 summarizes the value of the coefficent $C$ for different values of emissivity $\left(\varepsilon_{2}\right)$ at the drift wall.

Table VI-1. The Value of the Coefficient $C$ from Equation VI-7 Calculated for Different Values of Emissivity at the Drift Wall

\begin{tabular}{|c|c|c|}
\hline $\begin{array}{c}\text { Emissivity at Drift Wall } \\
\left(\varepsilon_{2}\right)\end{array}$ & $C$ & $C / C_{\text {orig }}{ }^{\mathrm{b}}$ \\
\hline 0.90 & $0.935^{\mathrm{a}}$ & 1.000 \\
\hline 0.90 & 0.969 & 1.037 \\
\hline 0.52 & 0.790 & 0.845 \\
\hline 0.59 & 0.833 & 0.892 \\
\hline 0.66 & 0.871 & 0.932 \\
\hline
\end{tabular}

NOTE: These values pertain to radiation between the drip shield and drift wall, where emissivity on the drip shield $\left(\varepsilon_{1}\right)$ is equal to 0.63 . ${ }^{\mathrm{a}} \mathrm{C}$ is calculated using Eq. VI-8. ${ }^{\mathrm{b}} \mathrm{C}_{\text {orig }}$ is the value of $C$ that was applied to determine $\varepsilon_{\text {eff }}$ from the drip shield to the drift wall for the LDTH and DDT submodels, which was calculated using Eq. $\mathrm{VI}-8$, and is equal to 0.935 .

For emissivity $\left(\varepsilon_{1}\right)$ on the drip shield equal to 0.63 , and emissivity $\left(\varepsilon_{2}\right)$ at the drift wall ranging from 0.52 to 0.66 , Eq. VI-7 gives values of $C$ ranging from 0.790 to 0.871 . As discussed above, for the LDTH and DDT submodels, a value of 0.935 was calculated (using Eq. VI-8) for the coefficient $C$ (called $C_{\text {orig }}$ in Table VI-1), which was used to determine the value $\varepsilon_{\text {eff }}$ from the drip shield to drift wall. The ratio $\mathrm{C} / C_{\text {orig }}$ is listed in Table VI-1 to illustrate the relative change in $\varepsilon_{\text {eff }}$ that would occur if this range of $\varepsilon_{2}$ were applied, compared to the value of $\varepsilon_{\text {eff }}$ used in the LDTH and DDT submodels. Thus, the value of $\varepsilon_{\text {eff }}$ would be reduced by 6.8 to 15.5 percent for the range of emissivities reported for Type 316 stainless steel. 
Because thermal radiation depends on the difference of the respective temperatures each raised to the fourth power (Eq. VI-4), the influence of a 6.8 to 15.5 percent reduction in the value of $\varepsilon_{\text {eff }}$ is small. An example illustrating this point is taken from Figure 6.3-23 in Section 6.3.2.1 of this report. At 70 years (20 years after closure), the temperature on the drip shield attains its peak value of $155.3^{\circ} \mathrm{C}$. (Note that the drip-shield temperature is not plotted in Figure 6.3-23.) At 70 years, the drift wall attains a peak temperature of $140.8^{\circ} \mathrm{C}$. When $\varepsilon_{\text {eff }}$ is reduced by 6.8 percent, the peak drip-shield temperature from Eq. VI-6 is calculated to be $156.2^{\circ} \mathrm{C}$. When $\varepsilon_{\text {eff }}$ is reduced by 10.8 percent (the average case in Table VI-1), the peak drip-shield temperature is calculated to be $156.8^{\circ} \mathrm{C}$. When $\varepsilon_{\text {eff }}$ is reduced by 15.5 percent, the peak drip-shield temperature is calculated to be $157.6^{\circ} \mathrm{C}$. Thus, reducing the value of $\varepsilon_{\text {eff }}$ by 6.8 to 15.5 percent results in a dripshield temperature increase of 0.9 to $2.3^{\circ} \mathrm{C}$, with an increase of $1.5^{\circ} \mathrm{C}$ for the average case. 


\section{APPENDIX VII}

EXTRACTION/MICRO-ABSTRACTION PROCESS FOR MSTHAC (BUILDING VIRTUAL LDTH AND SDT “CHIMNEY” SUBMODELS) 


\section{Extract MSTHAC v7.0 information from real LDTH and SDT “chimney” submodel output}

For the first stage of the multiscale thermohydrologic model abstraction process, MSTHAC v7.0 reads the NUFT output files for the SMT, SDT, LDTH, and DDT submodels, extracts the requested time histories, and saves them to a MSTHAC v7.0 "extraction" file. In order to perform the extraction, a MSTHAC v7.0 input file is created using the format defined in the MSTHAC 7.0 user's manual. A set of input files is created for each LDTH-/SDT submodel "chimney" location, with input files corresponding to each of the AMLs for which the LDTH and SDT submodels are run (e.g., AMLs of 66, 55, 27, and 14 MTU/acre). The resulting input files are run using MSTHAC 7.0.

\section{Interpolate extracted real LDTH and SDT “chimney" submodel output to the SMT submodel locations (virtual LDTH and SDT “chimney” submodel extraction files)}

Note that 108 out of 2874 of the SMT submodel repository-gridblock locations correspond to actual LDTH/SDT submodel locations. As discussed in Appendix I, these 108 locations generally occur for every fourth emplacement drift (see Figure 6.2-3). LDTH/SDT submodels are always placed at the ends of drifts and are usually placed at one or two locations along the central portion of those drifts. For the other locations that lie in between the $108 \mathrm{LDTH} / \mathrm{SDT}$ submodel locations, it is necessary to interpolate LDTH and SDT submodel results. These interpolated LDTH and SDT submodels are called "virtual" LDTH and SDT submodels.

The process of creating virtual LDTH and SDT "chimney" submodel extraction files is carried out with the use of chimney_interpolate v1.0. The software code chimney_interpolate v1.0 reads a control file that defines the following information: (1) name of a "real" chimney-submodel extraction file, (2) fractional weighting for this real chimney-submodel file (note that these weighting factors are the same as those used to interpolate percolation flux, as described in substep 6 of step 8 in Appendix I), (3) name of a second real chimney-submodel extraction file, (4) fractional weighting for this file and (5) the name of the virtual chimney-submodel extraction that will be created. Note that the two "real" chimney submodels straddle the target location where the interpolation occurs. The software code chimney_interpolate v1.0 does a simple linear interpolation between the two input files using the specified weights for each of the real chimney submodels.

The interpolation process is the same as that carried out for percolation flux (see substep 6 of step 8 of Appendix I). The interpolation process is two step: (1) "row-wise" interpolation along the drifts containing real chimney submodels and (2) "column-wise" interpolation to obtain virtual chimney submodels for the drifts lying between the drifts containing the real chimney submodels. First, "virtual" LDTH and SDT submodels are interpolated for all intermediate locations along the emplacement drifts that contain "real" LDTH and SDT submodels. Once these drifts have all of the virtual LDTH and SDT submodels created for the entire row of SMT submodel repository gridblocks, the "column-wise" interpolation process is conducted to create the virtual chimney submodels for the repository drifts lying between those with the real chimney submodels. The specified weighting factors for this linear interpolation process are the same as those used in interpolating the percolation flux for the SMT submodel repository gridblocks, as is described in Appendix I (see Substep 6 of Step 8). The output is a virtual chimney-submodel extraction file at each SMT submodel location and for each AML (e.g., 66, 55, 27, and 14 MTU/acre). This process is only conducted for the SDT and LDTH submodels. 
There are approximately 69,000 such files created. These files are found in DTN: LL030808523122.035. File names follow the conventions:

LDTH submodels: (panel \#)(i index):(j index)-LDTH(AML)-1Dds_mc-(percolation case)I-0(parameter case).m-f.EBS.ext.extract_LDTH_rev_14

SDT submodels: (panel \#)(i index):(j index)-SDT(AML)-00-01.ext.extract_SDT_rev_0

\section{Create *.in files for each virtual NUFT LDTH “chimney” submodel}

For the purposes of micro-abstraction, MSTHAC v7.0 requires the following: (1) the coordinates of the LDTH "chimney" submodels, (2) the real number for the AML (e.g., the real number for an AML of $66 \mathrm{MTU} / \mathrm{acre}$ is $65.784 \mathrm{MTU} / \mathrm{acre}$ ), and (3) the present-day-, monsoonal-, and glacial-transition-climate percolation fluxes for that LDTH submodel location. Note that 108 out of 2874 of the SMT submodel repository-gridblock locations correspond to actual LDTH submodel locations. For the other locations, interpolated LDTH and SDT submodel results are obtained; these interpolated LDTH and SDT submodels are called "virtual" LDTH and SDT submodels. To obtain this information, MSTHAC v7.0 reads a *.in file associated with each LDTH submodel. The format of the *.in file is specified by the NUFT user's manual (Nitao 1998 [DIRS 100474]) (see Appendix V), and the MSTHAC 7.0 user's manual specifies the required information for this file. A "virtual" LDTH submodel *.in file is created for each SMT submodel repository-gridblock location. Note that the only purpose for the virtual LDTH submodel *.in files is to supply MSTHAC v7.0 with the percolation flux for the glacial-transition climate for each of the SMT submodel repository gridblock locations. Although it is not required, the virtual LDTH submodel *.in files also contain the percolationflux values for the present-day and monsoonal climates as well. The percolation-flux values that were interpolated for each of the SMT submodel repository gridblock locations (see substep 6 of step 8 in Appendix I), along with the coordinates of that location, are edited into each of the virtual LDTH submodel *.in files with the use of scripts containing standard UNIX commands. There is a script for each of the three infiltration-flux cases: (1) create_virtual_in_SCRIPT_ma for the mean-infiltration-flux case, (2) create virtual in SCRIPT la for the lower-infiltrationflux case, and (3) create_virtual_in_SCRIPT_ua for the upper-infiltration-flux case. These three scripts, along with the instructions and control files for running these scripts, are found in DTN: LL030808523122.035 [DIRS 166419]. The names of these virtual LDTH submodel *.in files use the following convention:

(panel \#)(i index):(j index)-LDTH(AML)-1Dds_mc-(infiltration-flux case)i-0(parameter case).in

Note that the infiltration-flux-case labels are:

1. mi, which stands for mean infiltration flux

2. ui, which stands for upper infiltration flux

3. li, which stands for lower infiltration flux

Note also that the $\mathrm{i}$ and $\mathrm{j}$ indices are those from the SMT submodel and that the Panel numbers are P1, P2E, P2W, P3, and P5 (see Figure 6.2-3). The parameter case is 2, which is for the modified-mean-infiltration-flux property set. 
Run MSTHAC v7.0 at all SMT submodel locations using virtual SDT and LDTH "chimney" submodel extraction files, in conjunction with DDT and SMT submodel extraction files

Once the virtual SDT and LDTH submodel extraction files have been created and the virtual LDTH submodel *.in files have been created, MSTHAC v7.0 is run to generate the micro-abstraction output file at each SMT submodel location. This process also requires DDT submodel extraction files, as well as the SMT submodel extraction file. This process is carried out by first creating an abstraction MSTHAC v7.0 input file, as defined in the MSTHAC 7.0 user's manual. Once the input files are created, MSTHAC 7.0 is run with these files as input and the micro-abstraction output files are generated at each SMT submodel location. 


\section{INTENTIONALLY LEFT BLANK}


APPENDIX VIII

BINNING CALCULATIONS 


\section{Bin Indexes}

Bin indexes were calculated for each SMT submodel location based on the rank of the percolation flux associated with the location. The general calculation procedure is as follows:

1. Sort SMT submodel locations by ascending values of percolation flux

2. Calculate quantile values for each sorted point according to the rank of the point in the sorted data set

3. Assign bin indexes according to quantile intervals.

Binning was performed according to specifications provided by the Performance Assessment Department. Glacial-transition climate state (median case) was specified as the percolation flux source. Binning quantiles were as follows:

\begin{tabular}{|c|l|}
\hline Bin Index & \multicolumn{1}{|c|}{ Quantile Range } \\
\hline Bin 1 & less than 5 percent \\
\hline Bin 2 & $\begin{array}{l}\text { greater than or equal to 5 percent } \\
\text { less than 30 percent }\end{array}$ \\
\hline Bin 3 & $\begin{array}{l}\text { greater than or equal to 30 percent } \\
\text { less than 70 percent }\end{array}$ \\
\hline Bin 4 & $\begin{array}{l}\text { greater than or equal to 70 percent } \\
\text { less than 95 percent }\end{array}$ \\
\hline Bin 5 & greater than or equal to 95 percent \\
\hline
\end{tabular}

Bin indexes were calculated for each of the 2,874 SMT submodel locations.

\section{Bin the MSTHAC v7.0 output and reformat it for TSPA}

After all 2,874 MSTHAC v7.0 microabstractions have been created for a particular percolation case, the output is processed to produce the set of information required by TSPA. To facilitate their work, TSPA requires the micro-abstraction to be processed two different ways: "WAPDEG" binning and "TSPA" binning. Note that WAPDEG is a process model that uses MSTHM output. Because the WAPDEG model is downstream of the MSTHM (with respect to model-to-model parameter flow), WAPDEG does not produce any output required by the MSTHM. The total binned files are:

$$
22,992(\text { from WAPDEG) }+5,748(\text { from TSPA })=28,740
$$

\section{WAPDEG Binning}

The first processing (WAPDEG binning) involves reporting the T_wp, RH_wp, T_ds and RH_ds for each SMT submodel location and each waste package type. There are $\overline{8}$ waste package types which form two waste package groups:

Group1 : DHLW : dhlw-11, dhlw-s1 
Group2 : CSNF : pwr1-1, pwr2-1, bwr1-1, bwr2-1, pwr1-2, bwr1-2

For WAPDEG purposes, we are interested in each repository location and each waste package type, therefore, there are 2,874 locations $\times 8$ waste package type $=22,992$ typical waste packages reported.

Since the WAPDEG binning produces a large number of output files, the files are concatenated using a UNIX shell script so that all locations falling within a bin and all waste packages of a given type (CSNF or DHLW) are included in a single file. This process creates 5 (\# of bins) $\times 2$ (number of waste package groups) $=10$ output files for delivery. A second set of 10 files is provided in the WAPDEG format that only uses the "typical waste package" as explained below. Hence a total of 20 WAPDEG files are provided for each infiltration flux case.

\section{TSPA Binning}

The second process (TSPA binning) involves determining the most typical location given a set of locations that define a "bin." For TSPA purposes, this process is interested in the most typical waste package (see below) in a group / bin; therefore, there are 5 bins $\times 2$ groups $=10$ typical waste packages reported. A bin is a set of SMT submodel locations that have similar percolation values and is defined by the TSPA organization. For the purposes of processing, the waste packages are grouped into two waste package type groups (CSNF and DHLW). For each bin, two output files are created, one for the most typical CSNF package and one for the most typical DHLW package. There are 5 (\# of bins) $\times 2$ (waste package groups) files created for this type of processing. This results in an additional 2,874 locations $\times 2$ waste package groups $=5,748$ files.

The TSPA binning results of typical waste packages are concatenated using a UNIX shell so that all locations falling within a bin and all waste packages of a given type (CSNF or DHLW) are included in a single file. This process creates 5 (\# of bins) $\times 2$ (number of waste package groups) $=10$ output files for delivery.

\section{Typical Waste Package Determination}

The most typical package is selected by compiling for each waste package type and bin member, peak waste package temperature, and duration of boiling at the drift wall. These data are sorted from low to high, and a percentile assigned to each. For each waste package type and location in the list, the typical package is the one that is most median on the two parameter spaces.

To do this processing, reformat_EXT_to_TSPA v1.0 is used. The software code reformat_EXT_to_TSPA v1.0 takes the name of an input file as its only input. The format of this file is defined in the software code reformat_EXT_to_TSPA v1.0 user's manual.

Binning files are delivered as output from reformat_EXT_to_TSPA v1.0.

\section{Binning Algorithm}

For each location in a bin and waste package in a waste package group:

1. Calculate peak waste package temperature

2. Calculate boiling duration at the waste package 
3. Sort peak waste package temperature from high to low

4. Sort boiling duration from low to high

5. Assign percentile rank to each waste package temperature

6. Assign percentile rank to each boiling duration

For each included waste package type / location in the bin:

1. Calculate deviation of percentile rank from median $(50$ percent $)$ for peak waste package temperature

a. if current loc/waste package type is ranked 47 percent, deviation $=0.50-0.47=$ 0.03

2. Calculate deviation of percentile rank from median (50 percent) for boiling duration

b. if current loc/waste package type is ranked 54 percent, deviation $=0.50-0.54=$ $-0.04$

3. Calculate sum of squared deviations from Step 1 and 2

c. $0.03^{2}+0.04^{2}=0.0025$

For the current bin / waste package group, select the waste package/location with the smallest squared deviation (this is the most typical package). 


\section{INTENTIONALLY LEFT BLANK}


APPENDIX IX

MULTISCALE MODEL APPROACH TO THERMOHYDROLOGY AT YUCCA MOUNTAIN 


\section{MSTHM Concept}

The MSTHM approach breaks the solution of thermal-hydrologic modeling at Yucca Mountain into smaller pieces by varying dimensionality requirements (one-, two-, or three-dimensional) as needed for detail. The MSTHM approach subdivides the problem into thermal and thermal-hydrologic submodels. By subdividing the problem into more tractable pieces, more efficient thermal-conduction and thermal-radiation submodels are used to address the three-dimensional nature of the heated repository footprint and mountain-scale heat flow and the three-dimensional geometric details of the engineered components in the emplacement drifts, waste-package-to-waste-package heat-generation variability, and drift-scale heat flow. Two-dimensional thermal-hydrologic models, which are much more efficient than three-dimensional thermal-hydrologic models, are used to model all thermal-hydrologic variables in detail, within the emplacement drifts and in the adjoining host rock.

\section{MSTHM Spatial Scales}

Two spatial scales are considered for the MSTHM: (1) mountain scale (on the order of hundreds to thousands of meters) and (2) drift scale (on the order of fraction of meters). Drift-scale modeling includes the coupling of drift-scale processes both within the engineered barrier system and within the near field environment. Mountain-scale processes are needed to account for the influence of the ground surface, the water table, and most importantly, the influence of repository edge cooling effects. In addition to coupling the drift scale and mountain scale, the MSTHM also allows for consideration of the effect of different waste package types (e.g., different CSNF waste packages, co-disposal of DHLW) on the various performance measures.

\section{MSTHM Submodels}

The MSTHM simulates processes under a range of heat loading conditions to capture the edge effects within the repository and the discrete nature of waste packages. MSTHM simulates the $\mathrm{TH}$ response at various locations within the domain to account for variations in stratigraphy and infiltration. This is accomplished by simultaneously solving four "submodels" at different spatial scales. These four submodels comprising the MSTHM are categorized into four NUFT submodel types (SMT, SDT, DDT, and LDTH). The MSTHM also results in two MSTHAC v7.0 models (LMDH and DMTH). A consistent naming convention is used for these submodels. The first letter applies to the thermal loading where $S$ is the "smeared" area averaged heat loading, L is the "line" heat loading, and D is the "discrete" point heat loading. The second letter applies to the spatial scaling where M is the "mountain" scale and D is the "drift" scale. The last letters refer to the variables considered where $\mathrm{T}$ indicates that only "thermal conduction" variables are considered and where $\mathrm{TH}$ indicates that all "thermal-hydrologic" variables are considered.

The four different NUFT submodels (listed below) are solved simultaneously at different spatial scales:

- SMT Submodel - The three-dimensional smeared-source mountain-scale thermal-only submodel. 
- LDTH Submodel - The two-dimensional line-source drift-scale thermal-hydrology submodel.

- SDT Submodel - The one-dimensional smeared-source drift-scale thermal-only submodel.

- DDT Submodel - The three-dimensional discrete-source drift-scale thermal-only submodel.

The MSTHM processes the four NUFT submodels using MSTHAC v7.0 to produce the two following models:

- LMTH Model - The intermediary three-dimensional line-source mountain-scale thermal-hydrologic model.

- DMTH Model - The final three-dimensional discrete-source mountain-scale thermohydrology model.

Figure IX-1 illustrates the general conceptual relation between the four NUFT submodels (identified by red text) and the two MSTHAC v7.0 submodels (identified by blue text). The successive nature of the NUFT submodel execution followed by the MSTHAC v7.0 calculation for final output is illustrated in the flowchart of Figure IX-2.

The fundamental concept behind MSTHM is that two-dimensional representations of drift-scale thermal-hydrology (the LDTH submodels) can account for mountain-scale edge cooling processes by changing the horizontal distance of the adiabatic boundary in the drift-scale model. For locations within an infinite ( $\mathrm{x}$ and $\mathrm{y}$ ) expansive repository, the drift-scale model adiabatic boundary distance would be the half-way point between drifts. Edge effects within the model are accommodated by allowing the adiabatic boundaries to extend in time to mimic the cooling process. The distance to the adiabatic boundary is measured using the areal mass loading (AML) factor, which reports the heat input per unit area (reported in metric tonnes of uranium/acre, MTU/acre). As the distance to the adiabatic boundary increases, the AML decreases.

The relation between the time-varying AML at any given point in the repository is determined by interpolating the necessary width to the adiabatic boundary needed for an SDT submodel at the point to match the SMT submodel-predicted temperature. This is merely a superposition process justified by the linear nature of the conduction-only energy equation. Once this AML history is established, it is applied to the LDTH submodel, which introduces the dimensionality of the heat source (a waste package) and the hydrology of the system. The final component of MSTHM is the inclusion of thermal-radiative heat transfer with the DDT submodel. Here the temperature redistribution due to the variation between hotter waste packages, colder waste packages, and gaps between waste packages for one location in the repository is determined. This temperature difference is then applied to the two-dimensional thermal-hydrologic results to give complete thermal-hydrologic histories for all locations and all waste packages within the repository. 


\section{MSTHM Model Process}

The MSTHM methodology can be subdivided into the two specific "steps" illustrated in Figure IX-2. Step 1 is the simultaneous execution of the four NUFT submodels. Step 2 is the assembly of the NUFT submodel results into final MSTHM results through the use of MSTHAC v7.0. These processes are discussed in detail below.

\section{STEP 1: NUFT Submodel Execution}

A three-dimensional SMT submodel simulation determines the temperature history for a specific simulated repository life-cycle event. This three-dimensional conduction-only submodel has the total energy of the repository delivered over a smeared heat-source. Taking advantage of the fact that the transient conduction equation is linear and therefore super-positional, the temperature generated at any given location of the 3D SMT submodel at any given point in time can be simulated by a one-dimensional SDT conduction-only submodel of a certain heat input. This heat input can be characterized as the "emplaced heat input" divided by the lateral "width" of drift that the SDT submodel heating occurs, resulting in an areal mass loading AML. By superposing SDT submodels to create an SMT submodel temperature, an AML-varying history referred to as an $\mathrm{AML}_{\mathrm{hstrk}}$,eff is used to describe the heat-up and cool-down of that particular location of the repository. The MSTHM represents thermal-hydrologic processes, which includes the influences of hydrologic properties and percolation flux, by incorporating the results of two-dimensional LDTH submodels at each of the drift-scale-submodel locations. At each location, an AML curve is generated which describes the temperature history due to a specified heat input to the LDTH submodel.

The three-dimensional SMT and the one-dimensional SDT submodels solve for thermal conduction only and both share the same smeared-heat-source approximation and thermal-conduction representation of heat flow. The one-dimensional SDT submodels are executed at the same 108 locations and for the same AMLs as are the LDTH submodels providing a linkage between the SMT and the LDTH submodels. The common repository location of the SDT submodel and LDTH submodel drift wall temperatures allows for the SMT submodel temperature to be corrected for both the influence of thermal-hydrologic processes on temperature and for the influence of two-dimensional drift-scale dimensionality (orthogonal to the axis of the drift). This is accomplished by interpolating between AML histories. The SMT, SDT, and LDTH submodels share a blended heat-generation history of the entire waste package repository; hence, the heat-generation history is effectively that of an average waste package.

The three-dimensional DDT submodel is a drift-scale submodel, which includes individual waste packages with distinct heat-generation histories. The DDT submodel solves for thermal conduction and accounts for thermal radiation in addition to thermal conduction between the waste package and drift surfaces. The drift wall temperatures for an average waste package, calculated with the combined use of the LDTH, SMT, and SDT submodels, are then further modified to account for waste-package-specific deviations using the DDT submodel.

One complete MSTHM simulation requires multiple NUFT submodel executions to simulate the entire repository. Each MSTHM simulation includes the following NUFT submodel executions:

- 1 SMT submodel execution for the mountain 
- 1 DDT submodel $\times 4$ AMLs execution at one location in the repository

- N SDT submodel locations $\times 4$ AMLs

- N LDTH submodel locations $\times 4$ AMLs.

\section{STEP 2: MSTHM assembly process}

The use of MSTHAC v7.0 to assemble the execution results of the NUFT submodels into final output is the second part of MSTHM process (see Figure IX-2). MSTHAC v7.0 assembles the execution results from the submodels at the $\mathrm{N}$ locations within the repository creating time-varying AML curves.

The MSTHM assembly process can be broken into six calculation stages which center on the construction of two time-varying AMLs: an effective AML for the host rock ( $A M L_{\text {hstrk,eff }}$ ) and a specific $A M L\left(A M L_{\text {specific }}\right)$ for specific waste package locations along the drift. The $A M L_{\text {hstrk,eff }}$ varies spatially and temporally and is the interpolated AML that would be prescribed for an insulated heat submodel (SDT) to predict the temperature produced by a mountain-scale submodel (SMT). The $\mathrm{AML}_{\text {specific }}$ incorporates the discrete nature of the waste packages using the DDT submodel. Both AMLs are used to interpret LDTH submodel results to the LMTH and DMTH models. The six-stage process of MSTHM assembly is illustrated as an overview in Figure IX-2. Each stage is explained in detail below in conjunction with Figures IX-3 through IX-7.

\section{Assembly Stage 1: Assemble AML ${ }_{\mathrm{hstrk}, \text { eff }}$ (Figure IX-3)}

The SDT submodel temperature histories are plotted for each of the $\mathrm{N}$ spatial locations for a "family" of four AMLs $(66,55,27$, and 14 MTU/acre for this model report). For each spatial location, the plotted family of SDT submodel temperature histories is plotted against the time history of the temperature from the SMT submodel. The $\mathrm{AML}_{\text {hstrk, eff }}$ is interpolated by determining the AML needed for the SDT submodel to generate the SMT temperature at any given time.

\section{Assembly Stage 2: Interpolate LMTH (Figure IX-4)}

The LMTH results are determined by taking the thermal-hydrologic output from the LDTH submodels and plotting the time-history of the variables for each of the family of AMLs. First for each of the $\mathrm{N}$ locations, the thermal-hydrologic output history from the LDTH submodel is plotted for each of the four AMLs. Second, the thermal-hydrologic history for the LMTH at any given time $t^{*}$ is determined by interpolating the thermal-hydrologic value at $A M L_{\text {hstrk, fff }}\left(t^{*}\right)$ from the LDTH histories (note that the LDTH and DDT submodels include radiative heat transfer between the waste package, drip shield, and drift wall surfaces). As radiative heat transfer is proportional to the temperature difference between two surfaces raised to the fourth power, i.e., $\Delta \mathrm{T}^{4}$, linear interpolation between two bounding AML curves is not sufficient to accurately calculate a result. To address this issue, MSTHM submodels are run at a variety of AMLs. Hence, interpolations are performed over a small enough range that piecewise linear interpolation adequately characterizes the underlying nonlinear process of radiative heat transfer. 


\section{Assembly Stage 3: Calculate DMTH (Figure IX-5)}

The discrete thermal-hydrologic values are calculated from the LMTH submodel by incorporating the DDT submodel temperature results. Here, the temperature variation along the average temperature of the LMTH submodel accounts for differences in waste package loading. The temperature difference is calculated using the $A M L_{h s t r k, e f f}$ and the temperature from the DDT submodel. This difference is then superimposed on the LMTH submodel to yield DMTH submodel results.

\section{Assembly Stage 4: Assembling AMLspecific (Figure IX-6)}

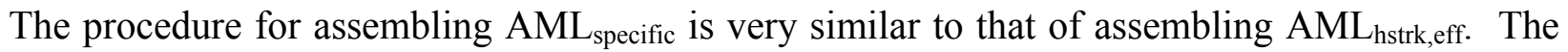
temperature history from the LDTH submodel is plotted for each of the $\mathrm{N}$ spatial locations for a "family" of four AMLs (66, 55, 27, and 14 MTU/acre). Along with the family of LDTH submodel temperature histories at each spatial location is plotted the time history of the temperature from the DMTH model. The $\mathrm{AML}_{\text {specific }}$ is interpolated by determining the AML needed for the LDTH submodel to generate the DMTH- model temperature at any given time.

\section{Assembly Stage 5: Interpolate Thermal-Hydrologic Variables for DMTH (Figure IX-7)}

The DMTH results are determined by taking the thermal-hydrologic output from the LDTH submodels and plotting the time-history of the variables for each of the family of AMLs. First for each of the $\mathrm{N}$ locations, the thermal-hydrologic output history from the LDTH submodel is plotted for each of the four AMLs. The thermal-hydrologic history for the DMTH at any given time $t^{*}$ is determined by interpolating the thermal-hydrologic value at $\operatorname{AML}_{\text {specific }}\left(t^{*}\right)$ from the LDTH histories.

\section{Assembly Stage 6: Determine Relative Humidity for the Waste Package and Drip Shield}

The relative humidity on top of the drip shield and on the waste package is calculated as a function of the saturated pressures in the drift. 


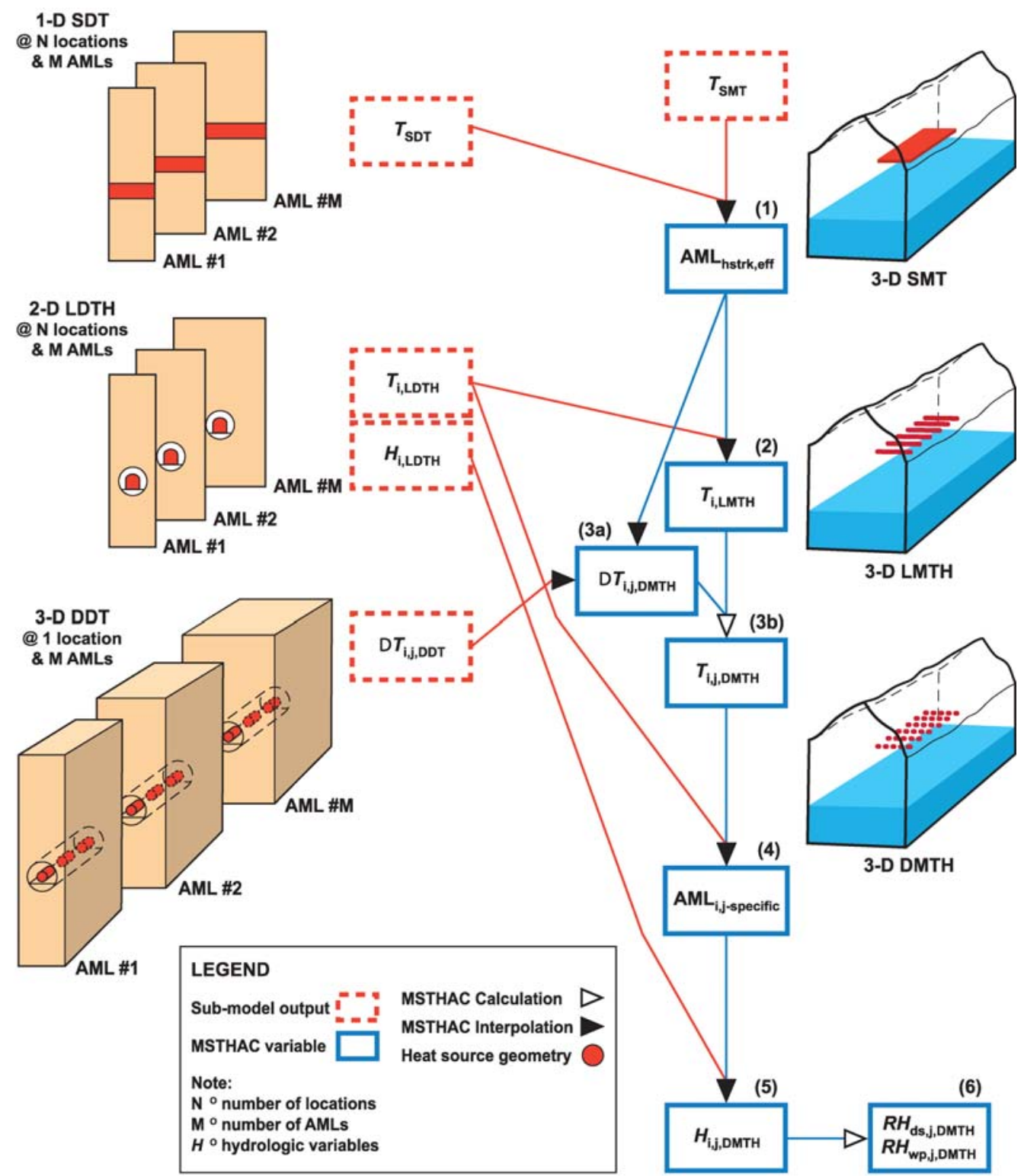

NOTE: SDT, LDTH, and DDT submodels are run a different AMLs (left side). SMT, LMTH, and DMTH models are the series of three-dimensional mountain-scale models of increasing complexity (right side). The six stages illustrate the process of constructing intermediate variables.

Figure IX-1. Six-Stage Flow Chart Diagram of the Multiscale Thermohydrologic Model (MSTHM) 


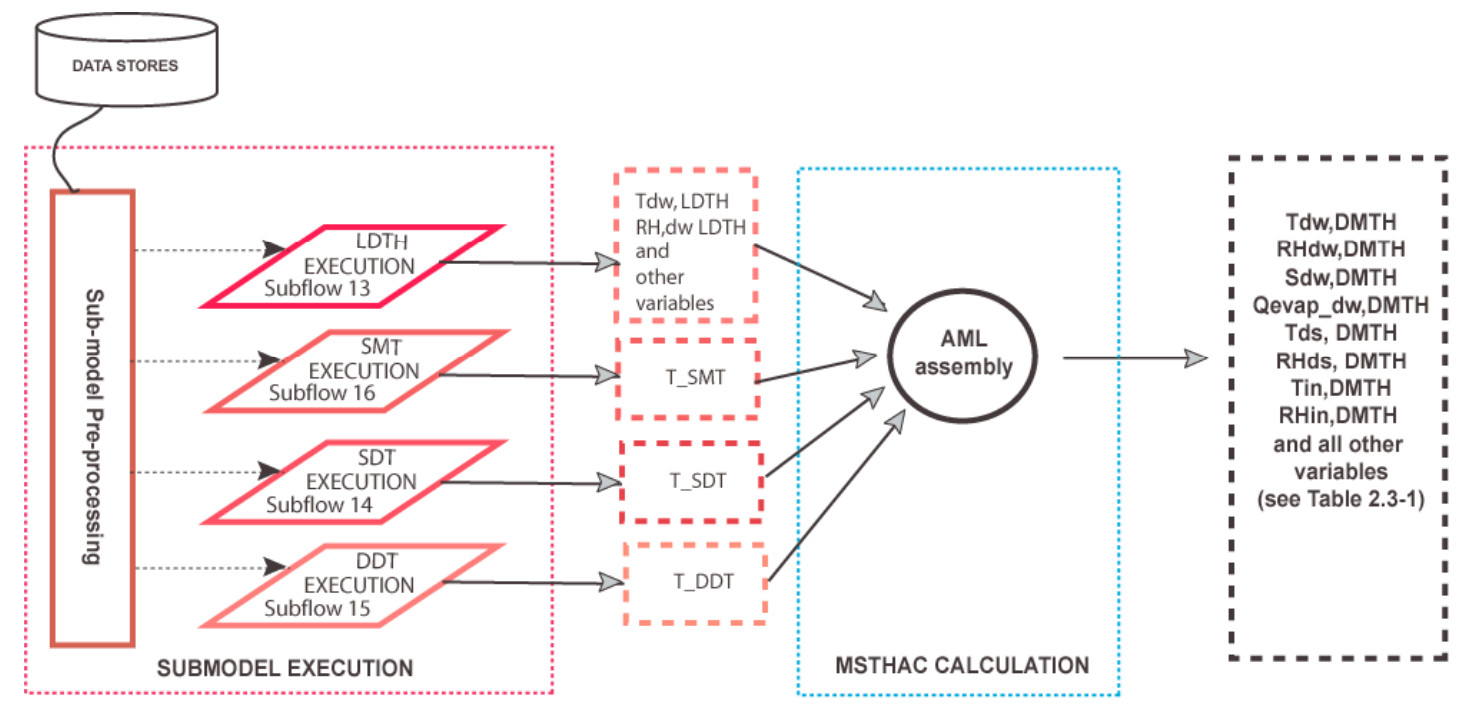

Figure IX-2. MSTHM Flowchart Shown in Two Steps: (1) NUFT Submodel Execution in Red, and (2) MSTHM Processing of Final Output Using MSTHAC v7.0 (Blue)

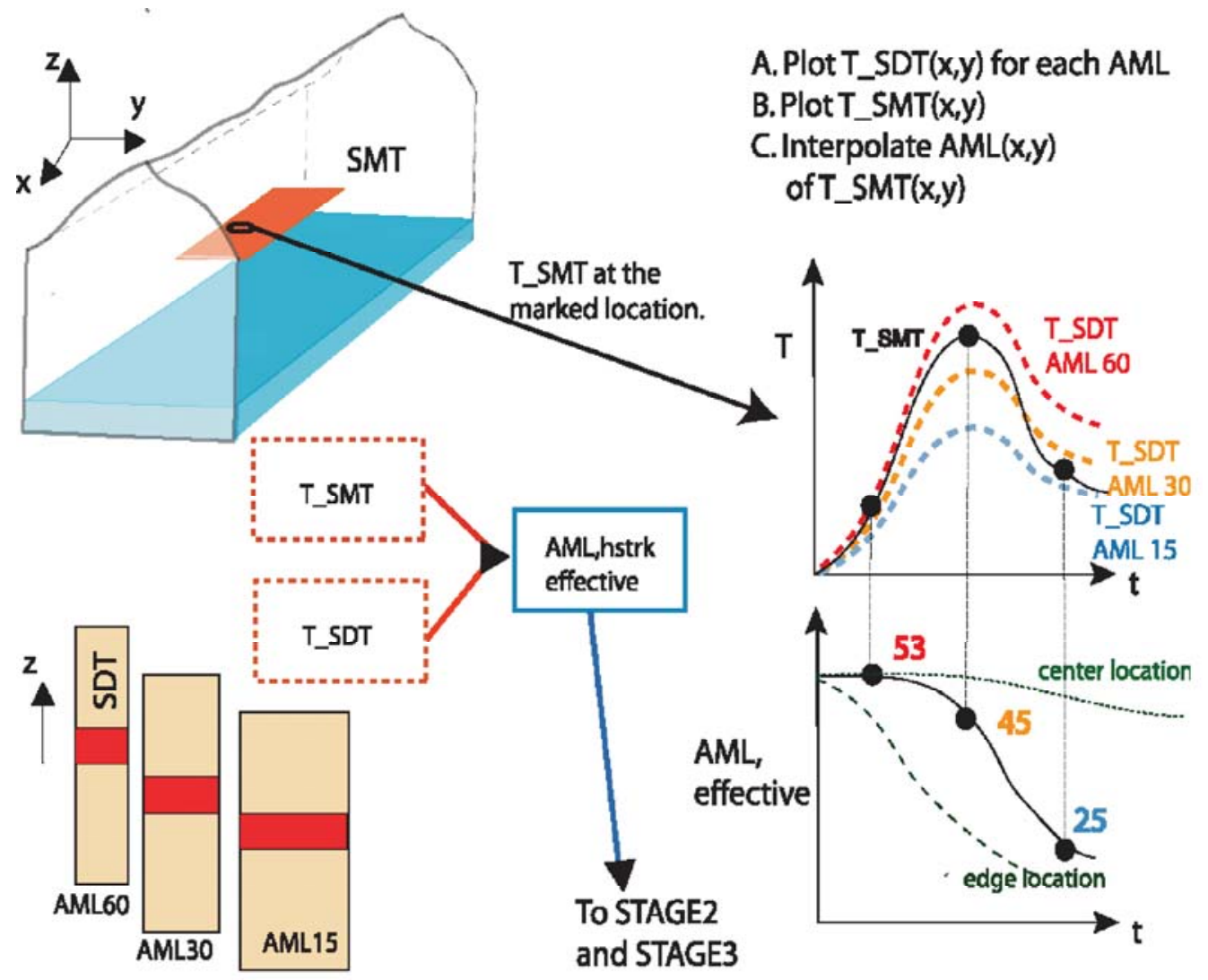

NOTE: Stage 1 involves the interpolation of the variable AML,effective from the SMT submodel temperature T_SMT and the family of SDT submodel temperatures T_SDT at three different AMLs.

Figure IX-3. MSTHM Stage 1 


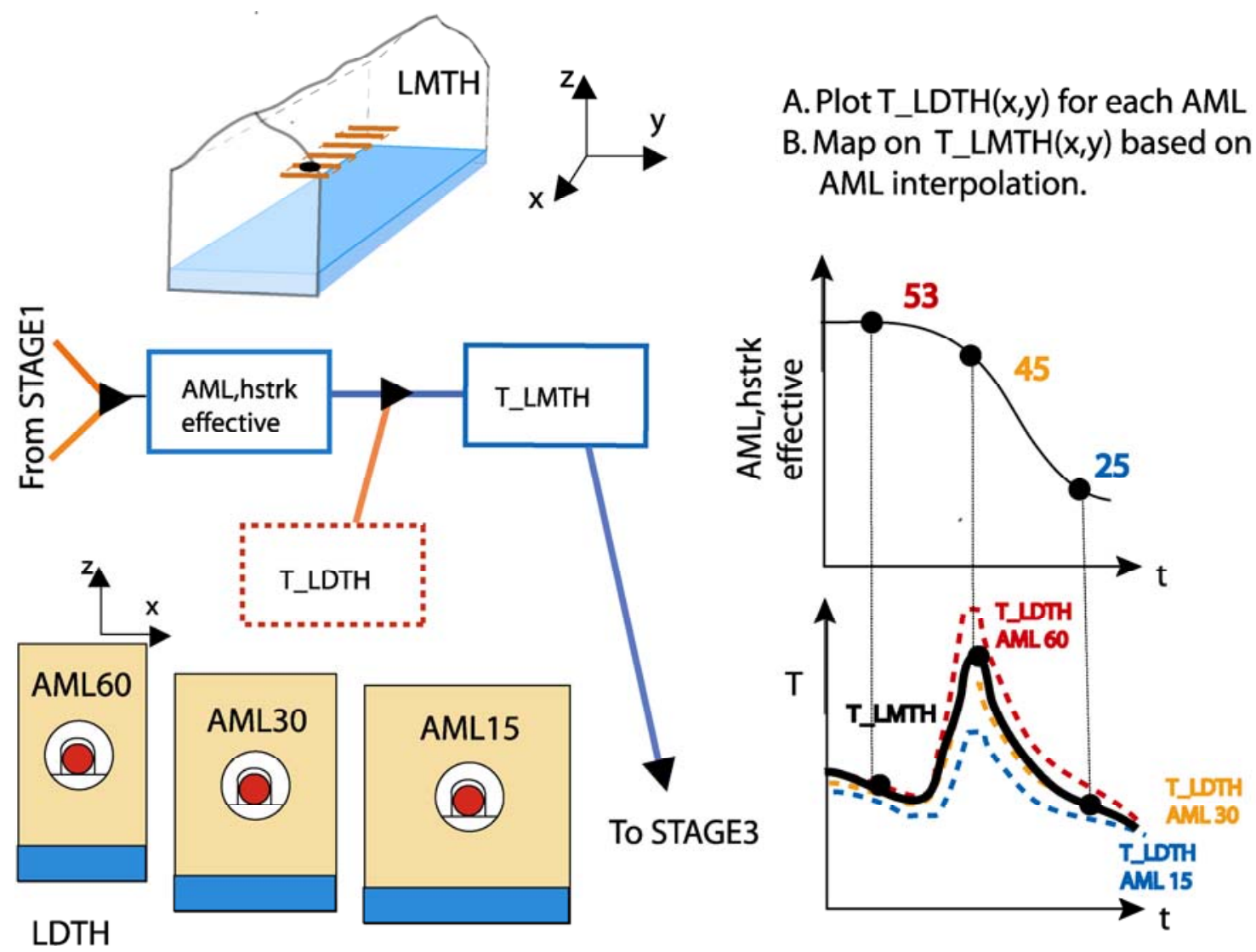

NOTE: Stage 2 involves the interpolation of the LMTH-model temperature T_LMTH from the variable AML,hstrk,effective and the family of LDTH submodel temperatures $\bar{T} \_$LDTH.

Figure IX-4. MSTHM Stage 2 

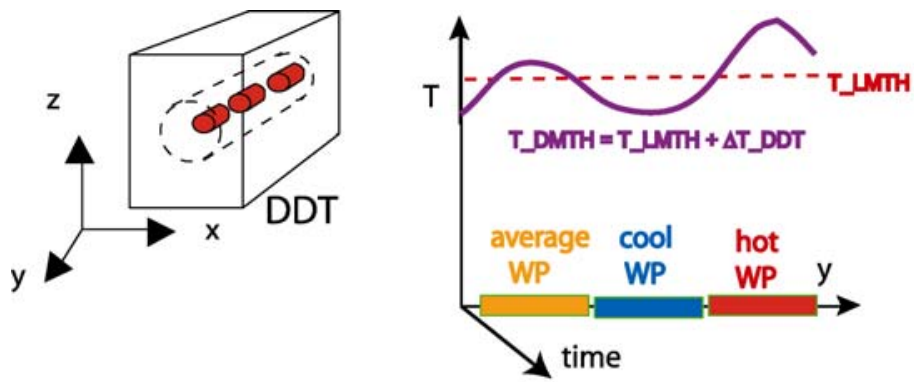

\section{A. Determine $\Delta \mathrm{T}+\mathrm{DDT}$ \\ B. Add $\Delta$ T_DDT to T_LMTH (from Step 2) to get \\ T_DMTH}

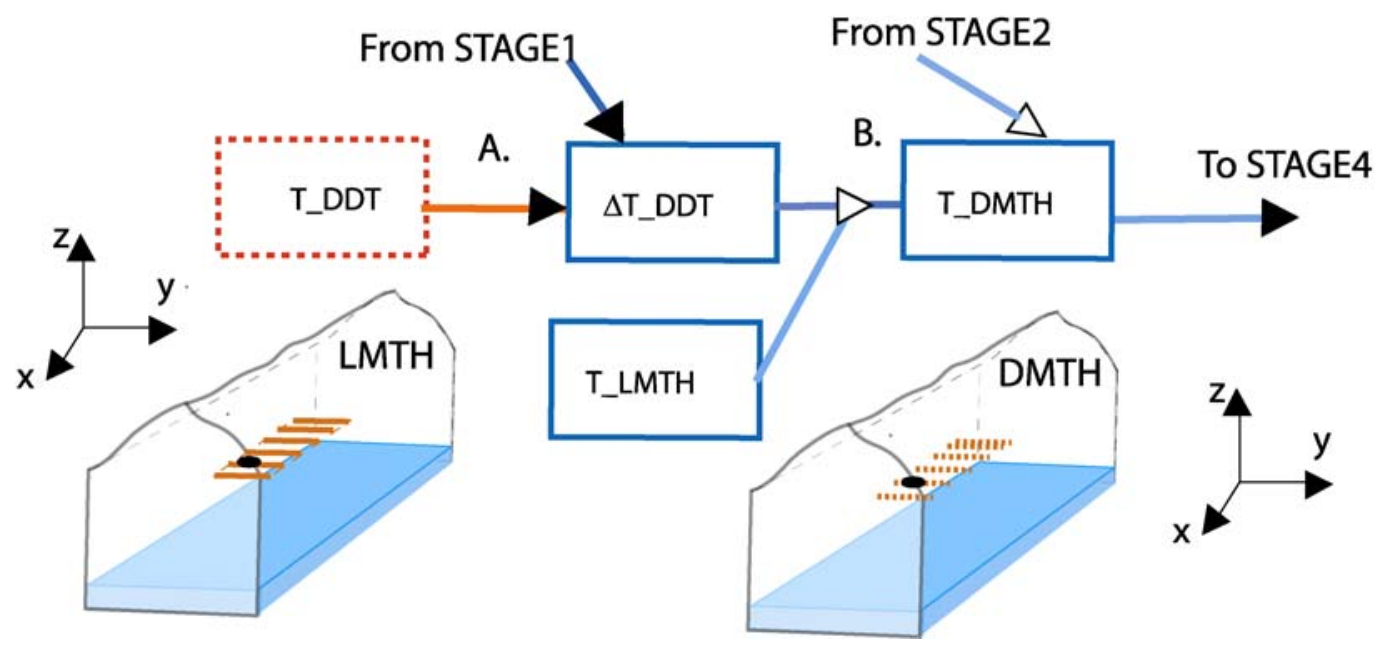

NOTE: Stage 3 involves the calculation of the DMTH-model temperature T_DMTH from the LMTH-model temperature T_LMTH and DDT submodel temperature T_DDT.

Figure IX-5. MSTHM Stage 3 


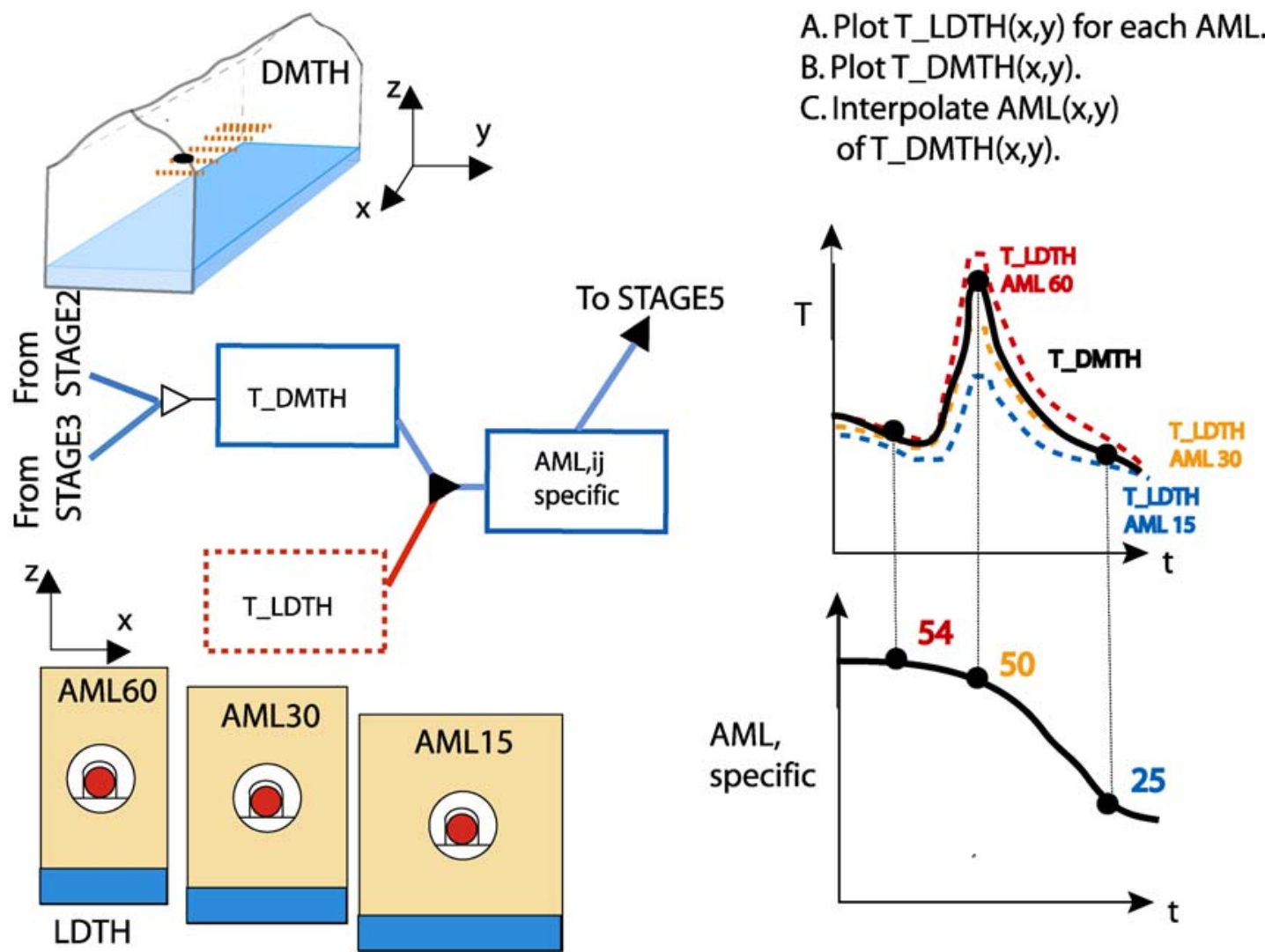

NOTE: Stage 4 involves the interpolation of the variable AMLspecific from the DMTH-model temperature T_DMTH and the family of LDTH submodel temperatures T_LDTH.

Figure IX-6. MSTHM Stage 4 

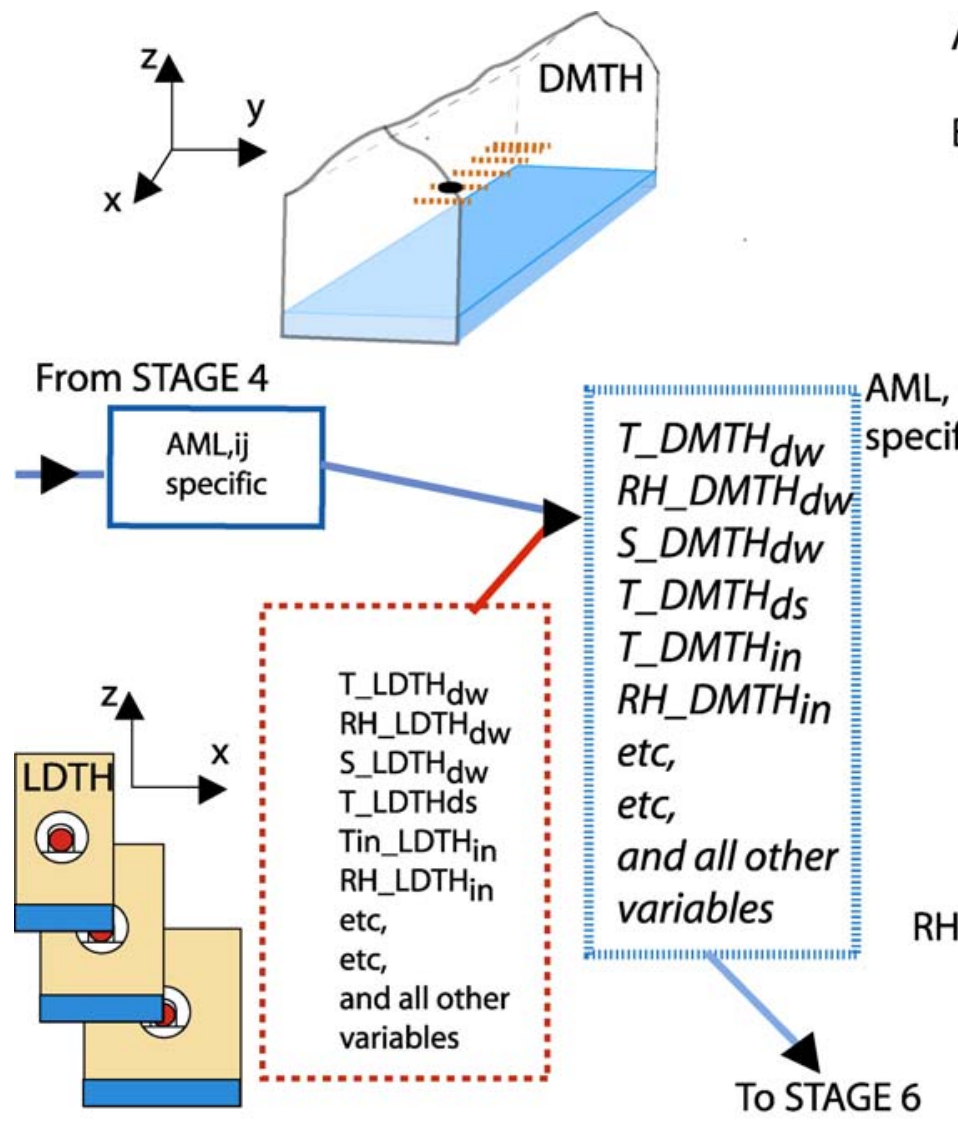

A Plot <variable>_LDTH $(\mathrm{x}, \mathrm{y})$ for each AML.

B Map on <variable>_DMTH $(x, y)$ based on $\mathrm{AML}$ interpolation.

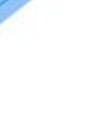

T_LDTH ${ }_{\text {dw }}$ $\mathrm{RH} \_$LDTH $\mathrm{dw}$ S_LDTH T_LDTHds Tin_LDTH RH_LDTH in $_{\text {in }}$ etc, and all other variables

NOTE: Stage 5 involves the determination of each hydrologic variable (e.g., $R H)$ using the variable AML,specific and the corresponding family of LDTH submodel hydrologic variable values.

Figure IX-7. MSTHM Stage 5 


\section{INTENTIONALLY LEFT BLANK}


APPENDIX X

HYDROLOGIC PROPERTIES FOR THE INTERGRANULAR POROSITY OF THE INVERT 
The multiscale thermohydrologic model requires an evaluation of the retention and hydraulic properties of the crushed tuff that comprises the invert. In this appendix, retention and hydraulic properties are estimated for the coarse pore space of the crushed tuff invert.

This appendix initially develops a nondimensionalized curve fit to the two-parameter van Genuchten retention relation for several materials that cover a wide range of particle sizes. The nondimensional curve fit is then applied to crushed tuff to develop moisture potential retention relations for various size particles ranging from $0.3 \mathrm{~mm}$ to $20 \mathrm{~mm}$. The relationship of unsaturated hydraulic conductivity to moisture potential is then developed on the basis of the van Genuchten curve-fit parameters. A summary of the hydrologic properties for the intergranular porosity of the invert is then presented.

Sections X.1 and X.2 develop water retention relationships for four unconsolidated materials, each representing a particular particle size. First, Section X.1 converts the retention data for a hydrocarbon fluid (DTN: MO0307PAUSFPD.000 [DIRS 164436]) into water retention data, using an estimate from Brooks and Corey (1964 [DIRS 156915]). Section X.1 also provides constants from Incropera and DeWitt (1996 [DIRS 108184]) that are needed to make relations nondimensional.

Next, for each of the four unconsolidated materials, Section X.2 demonstrates the development of a best-fit formula for the water retention relation, using the functional form of van Genuchten (1980 [DIRS 100610]). These are only examples; for further analysis, the appendix needs a form that incorporates information about particle size. To this end, and following a procedure suggested by Leverett (1941 [DIRS 100588], p. 159), Section X.2.5 develops a best fit to a formula that contains a nondimensional form of the intrinsic permeability (van Genuchten alpha), using the capillary rise as a surrogate for the particle size.

Sections X.3 and X.4 develop estimates of intrinsic permeability for possible crushed tuffs of differing particle size. Section X.3 begins by estimating an intergranular porosity applicable to all four crushed tuffs, taking the central value from a handbook range. Section X.4 determines the intrinsic permeability (as $(\mathrm{cm})^{-1}$ or (bars) ${ }^{-1}$ ) for each of the crushed tuffs, using the KozenyCarman equation (Bear 1972 [DIRS 156269], p. 166).

Unsaturated hydraulic conductivity is calculated within the qualified NUFT software, based on a relationship given by Fetter (1993 [DIRS 102009], p. 182). Section X.5 provides example results for each of the crushed tuffs.

\section{X.1 NON-DIMENSIONALIZED VAN GENUCHTEN RETENTION RELATION}

DTN: MO0307SPAUSFPD.000 [DIRS 164436] contains measured data on retention of a hydrocarbon fluid by four different particulate materials. These are measurements reported by Brooks and Corey (1964 [DIRS 156915]), as presented in Advection versus Diffusion in the Invert (BSC 2003 [DIRS 170881]). Figure X-1 presents the capillary rise of these unconsolidated samples. The Brooks and Corey moisture potential measurements include a range of particle sizes. A description of these data sets follows: 
- Volcanic Sand -This material originates from a wind-blown deposit along Crab Creek in Washington State. It consists of dark-colored aggregates that can be broken down into finer particles by applying pressure. It is not known to what degree these aggregates are themselves permeable, but they undoubtedly have some permeability. This sand has a degree of structure and has both primary and secondary porosity.

- Fine Sand -This sand was supplied by the Hanford Laboratories of General Electric Company at Richland, Washington, and apparently contains some volcanic minerals. This material contains a wide range of particle sizes, ranging down to silt size. Most of the particles are angular and not as rounded as most river bed sands.

- Glass Beads - This material is an example of media having a very narrow range of pore sizes. It is not much different in this respect, however, from many clean river sands.

- Touchet Silt Loam - This soil comes from the Columbia River basin and is also supplied by the Hanford Laboratory. It is extremely fine textured in that it contains practically no coarse sand, but it is somewhat unusual in that it contains a smaller amount of clay than would be expected in such a fine-textured soil. It is, in fact, nearly pure silt mixed with some extremely fine sand. It contains enough clay, however, to create a structure with secondary porosity.

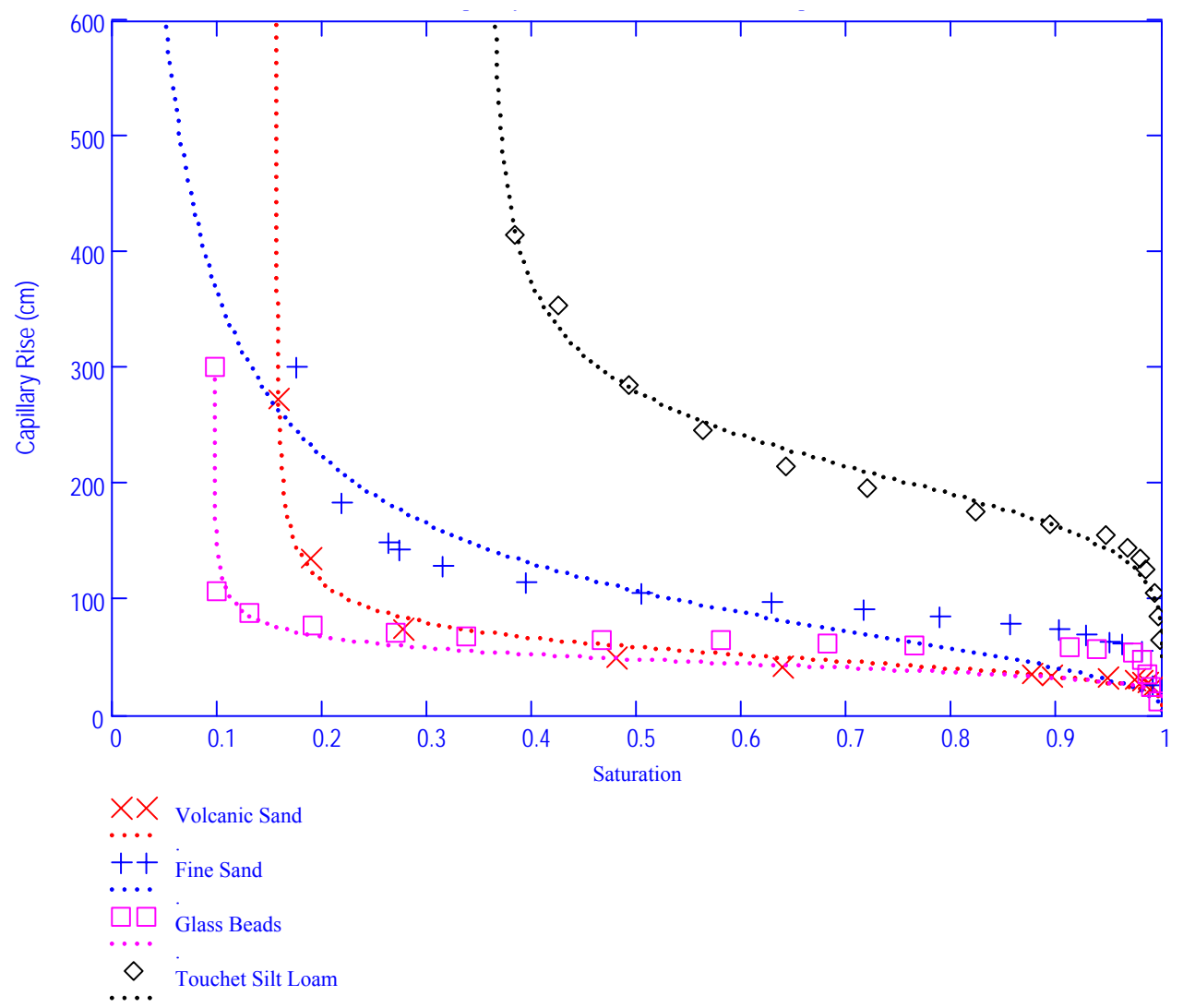

DTN: MO0307SPAUSFPD.000 [DIRS 164436].

Figure X-1. Capillary Rise of Unconsolidated Samples 
The dependence of the capillary pressure curve on particle diameter and porosity is analyzed in the same manner as Leverett (1941 [DIRS 100588], p.159). Leverett showed that capillary pressure data for various sands could be correlated using a non-dimensional group that included the mean particle diameter and the porosity. This approach is applied to the data of DTN: MO0307SPAUSFPD.000 [DIRS 164436] to produce a non-dimensional capillary pressure/saturation curve. This non-dimensional data is then fitted with the functional form posed by van Genuchten (1980 [DIRS 100610], Equation 21).

The relative permeability is based upon the work of Mualem, as reported by van Genuchten (1980 [DIRS 100610]). Mualem developed a semi-empirical relationship between the capillary pressure curve and the relative permeability curve. Mualem's correlation coefficient is combined with the fit of the non-dimensional capillary pressure to produce a liquid relative permeability curve appropriate for the invert interparticle porosity. The relative permeability of the gas phase is set to unity in anticipation of the very low interparticle saturation anticipated in the invert.

The Brooks and Corey data (DTN: MO0307SPAUSFPD.000 [DIRS 164436]) for unconsolidated particulate media are appropriate for the proposed invert configuration. Like the invert, all materials are composed of unconsolidated particles. Angularity of the particulate will be reflected in the data for sands. This, of course, presumes that the invert "rock" is "roughly" spherical, as opposed to a plate-like shape.

Input the properties for the four materials from DTN: MO0307SPAUSFPD.000 [DIRS 164436], Table 2:

Vs:=

\begin{tabular}{|l|l|l|}
\cline { 2 - 3 } \multicolumn{1}{c|}{} & \multicolumn{1}{c|}{0} & \multicolumn{1}{c|}{1} \\
\hline 0 & 12.000 & 0.990 \\
\hline 1 & 13.500 & 0.996 \\
\hline 2 & 14.500 & 0.980 \\
\hline 3 & 15.500 & 0.974 \\
\hline 4 & 16.000 & 0.948 \\
\hline 5 & 17.000 & 0.895 \\
\hline 6 & 17.200 & 0.875 \\
\cline { 2 - 3 }
\end{tabular}

$\mathrm{GB}:=$

\begin{tabular}{|l|r|r|}
\cline { 2 - 3 } \multicolumn{1}{c|}{} & \multicolumn{1}{c|}{0} & \multicolumn{1}{c|}{1} \\
\hline 0 & 5.900 & 0.995 \\
\hline 1 & 11.800 & 0.989 \\
\hline 2 & 17.800 & 0.985 \\
\hline 3 & 23.800 & 0.980 \\
\hline 4 & 26.900 & 0.971 \\
\hline 5 & 28.800 & 0.938 \\
\hline
\end{tabular}

FS :=

\begin{tabular}{|l|l|r|}
\cline { 2 - 3 } \multicolumn{1}{c|}{} & \multicolumn{1}{c|}{0} & \multicolumn{1}{c|}{1} \\
\hline 0 & 12.800 & 0.990 \\
\hline 1 & 27.800 & 0.980 \\
\hline 2 & 30.800 & 0.962 \\
\hline 3 & 31.800 & 0.950 \\
\hline 4 & 34.800 & 0.926 \\
\hline 5 & 36.800 & 0.901 \\
\hline 6 & 39.800 & 0.856 \\
\hline
\end{tabular}

TSL :=

\begin{tabular}{|l|l|l|}
\cline { 2 - 3 } \multicolumn{1}{c|}{} & \multicolumn{1}{c|}{0} & \multicolumn{1}{c|}{1} \\
\hline 0 & 32800 & 0.998 \\
\hline 1 & 42800 & 0.995 \\
\hline 2 & 52800 & 0.992 \\
\hline 3 & 62800 & 0.984 \\
\hline 4 & 67.900 & 0.978 \\
\hline 5 & 72500 & 0.967 \\
\hline
\end{tabular}

Note that only the first few values are printed out in the MathCad format. For a complete listing of the properties, the data are presented in DTN MO0307SPAUSFPD.000 [DIRS 164436]. 
Input the intrinsic permeability and porosity (DTN: MO0307SPAUSFPD.000 [DIRS 164436]).

$$
\left(\begin{array}{c}
\mathrm{k}_{\mathrm{VS}} \\
\mathrm{k}_{\mathrm{FS}} \\
\mathrm{k}_{\mathrm{FM}} \\
\mathrm{k}_{\mathrm{GB}} \\
\mathrm{k}_{\mathrm{TSL}} \\
\mathrm{k}_{\mathrm{FFH}}
\end{array}\right):\left(\begin{array}{c}
18 \\
2.5 \\
11.3 \\
6.3 \\
0.6 \\
30
\end{array}\right) \cdot\left(10^{-6} \cdot \mathrm{m}\right)^{2}
$$

The data have to be adjusted to account for the difference between water and the hydrocarbon fluid. According to Brooks and Corey (1964 [DIRS 156915], Equation 17, p. 9), the capillary rise of water was about twice that of the hydrocarbon used in the measurements. Van Genuchten (1980 [DIRS 100610]) used the same factor in his analysis.

$$
\left(\begin{array}{l}
\mathrm{VS}^{\langle 1\rangle} \\
\mathrm{FS}^{\langle 1\rangle} \\
\mathrm{FM}^{\langle 1\rangle} \\
\mathrm{GB}^{\langle 1\rangle} \\
\mathrm{TSL}^{\langle 1\rangle} \\
\mathrm{FFH}^{\langle 1\rangle}
\end{array}\right):\left(\begin{array}{l}
\mathrm{VS}^{\langle 1\rangle} \cdot 2 \\
\mathrm{FS}^{\langle 1\rangle} \cdot 2 \\
\mathrm{FM}^{\langle 1\rangle} \cdot 2 \\
\mathrm{~GB}^{\langle 1\rangle} \cdot 2 \\
\mathrm{TSL}^{\langle 1\rangle} \cdot 2 \\
\mathrm{FFH}^{\langle 1\rangle} \cdot 2
\end{array}\right)
$$

Because Brooks and Corey (1964 [DIRS 156915]) do not specify surface tension or temperature, they assume an ambient temperature to represent laboratory conditions. The surface tension of water equals 72 dynes $/ \mathrm{cm}$ at $25^{\circ} \mathrm{C}$. The water surface tension and density are (Incropera and DeWitt 1996 [DIRS 108184], p. 846):

$$
\begin{aligned}
\sigma_{w} & :=72 \cdot \frac{\text { dyne }}{\mathrm{cm}} \\
\rho & :=998 \cdot \frac{\mathrm{kg}}{\mathrm{m}^{3}}
\end{aligned}
$$

In accordance with the Brooks-Corey estimate of capillary rise, 


$$
\sigma_{H C}:=\frac{\sigma_{W}}{2}
$$

\section{X.2 DATA FITTING}

In the following analysis, curve fits are developed for the four materials separately for comparison to the measured retention data. A function representing the van Genuchten function is defined. Error functions are defined that for a set of van Genuchten parameters $\left(\alpha, n, S_{r}\right)$ provide a summation of the residuals squared between the predicted value for capillary pressure, and the measured capillary pressure. After defining the error function, the MathCad Minerr function is used to calculate the set of van Genuchten parameters $\left(\alpha, n, S_{r}\right)$ that minimizes the sum of the residuals squared. Define a vector of points for plotting purposes in MathCad. Note that the following function in MathCad defines a set of saturations that are then used to calculate corresponding capillary pressure or moisture potential that can then be used to generate a plot of moisture retention.

$$
f_{\text {plot }}:=\mid \begin{aligned}
& \text { for } \quad i \in 1 . .9999 \\
& s_{i} \leftarrow \frac{i}{10000} \\
& s
\end{aligned}
$$

The van Genuchten's fitting function (van Genuchten 1980 [DIRS 100610], Equation 21) is:

$$
\theta=\theta r+\frac{\theta_{s}-\theta r}{\left[1+(\psi \cdot \alpha)^{n}\right]^{m}}
$$

Van Genuchten includes the residual saturation in the fit. The van Genuchten $m$ parameter is defined in terms of n (van Genuchten 1980 [DIRS 100610], Equation 22):

$$
m=1-\frac{1}{n}
$$

Rewriting this Equation X.5 to solve for the exponent:

$$
\begin{aligned}
& \frac{1}{m}=\frac{n}{n-1} \\
& \frac{-1}{m}=\frac{n}{1-n}
\end{aligned}
$$

Substituting in the value of $\mathrm{m}$ into Equation X.4: 


$$
\theta=\theta_{r}+\frac{\left.\theta_{s}-\theta_{r}\right)}{\left[1+(\psi \cdot \alpha)^{n}\right]^{1-\frac{1}{n}}}
$$

Define the values for saturation

$$
\begin{aligned}
& \mathrm{S}_{\mathrm{s}}=\frac{\theta \mathrm{s}}{\theta_{\mathrm{s}}} \\
& \mathrm{S}_{\mathrm{s}}=1
\end{aligned}
$$

By definition, the value of Ss at saturation is one.

$$
\begin{gathered}
\theta=\mathrm{S} \cdot \theta_{\mathrm{S}} \\
\theta_{\mathrm{r}}=\mathrm{S}_{\mathrm{r}} \cdot \theta_{\mathrm{S}}
\end{gathered}
$$

Substitute these definitions into Equation X.8:

$$
\mathrm{S} \cdot \theta_{\mathrm{S}}=\mathrm{S}_{\mathrm{r}} \cdot \theta_{\mathrm{S}}+\frac{\left[-\theta_{\mathrm{S}} \cdot\left(-1+\mathrm{S}_{\mathrm{r}}\right]\right.}{\left[\left[1+(\psi \cdot \alpha)^{\mathrm{n}}\right]^{\left(1-\frac{1}{\mathrm{n}}\right)}\right]}
$$

Factor out $\theta_{\mathrm{s}}$ from both sides of the equation:

$$
S=S_{r}+\frac{\left[-1 \cdot\left(-1+S_{r}\right)\right]}{\left[\left[1+(\psi \cdot \alpha)^{n}\right]^{\left(1-\frac{1}{n}\right)}\right]}
$$

Restating the equation:

$$
\frac{\mathrm{S}-\mathrm{S}_{\mathrm{r}}}{1-\mathrm{S}_{\mathrm{r}}}=\frac{1}{\left[\left[1+(\psi \cdot \alpha)^{\mathrm{n}}\right]^{\left(1-\frac{1}{\mathrm{n}}\right)}\right]}
$$

Solve for the value of moisture potential as a function of saturation (S):

$$
\left[\left[1+(\psi \cdot \alpha)^{n}\right]^{\left(1-\frac{1}{n}\right)}\right]=\frac{\left(1-S_{r}\right)}{S-S_{r}}
$$




$$
\begin{aligned}
& {\left[\left[1+(\psi \cdot \alpha)^{\mathrm{n}}\right]^{\frac{\mathrm{n}-1}{\mathrm{n}}}\right]=\frac{\left(1-\mathrm{S}_{\mathrm{r}}\right)}{\mathrm{S}-\mathrm{S}_{\mathrm{r}}}} \\
& {\left[1+(\psi \cdot \alpha)^{\mathrm{n}}\right]=\left[\frac{\left(\mathrm{S}-\mathrm{S}_{\mathrm{r}}\right)}{1-\mathrm{S}_{\mathrm{r}}}\right]^{\frac{\mathrm{n}}{\mathrm{n}-1}}} \\
& (\psi \cdot \alpha)^{\mathrm{n}}=\left[\frac{\mathrm{S}-\mathrm{S}_{\mathrm{r}}}{1-\mathrm{S}_{\mathrm{r}}}\right]^{\frac{\mathrm{n}}{\mathrm{n}-1}}-1
\end{aligned}
$$

Solving for the moisture potential in terms of the saturation, and defining a function for the moisture potential:

$$
G\left(S, S_{r}, \alpha, n\right):=\frac{1}{\alpha} \cdot\left[\left(\frac{S-S_{r}}{1-S_{r}}\right)^{\frac{n}{1-n}}-1\right]^{\frac{1}{n}}
$$

\section{X.2.1 Volcanic Sand}

Define a function, in terms of the van Genuchten, parameters that represents the sum of the residuals squared between the measured capillary pressure and the predicted capillary pressure for the volcanic sand:

$$
\operatorname{error}(\mathrm{Sr}, \alpha, \mathrm{n}):=\sum_{\mathrm{i}=1}^{\operatorname{rows}(\mathrm{VS})}\left[\left(\mathrm{G}\left(\mathrm{VS}_{\mathrm{i}, 2}, \mathrm{Sr}, \alpha, \mathrm{n}\right)-\mathrm{VS}_{\mathrm{i}, 1}\right)^{2}\right]
$$

Define an initial estimate of the parameters:

$$
\left(\begin{array}{l}
\mathrm{Sr} \\
\alpha \mid:=\left(\begin{array}{c}
0.1 \\
\mathrm{n}
\end{array}\right) \\
0.02 \mid \\
6
\end{array}\right)
$$

Use the Minerr function to obtain the lease squares fit to the volcanic sand data:

$$
\begin{gathered}
\text { Given } \\
\operatorname{error}(\operatorname{Sr}, \alpha, n)=0
\end{gathered}
$$




$$
\begin{aligned}
& \left(\begin{array}{l}
\left.\operatorname{sr}_{\text {VS }}\right) \\
\alpha_{\text {VS }} \mid:=\operatorname{Minerr}(S r, \alpha, n) \\
\left.n_{\text {VS }}\right)
\end{array}\right. \\
& \left(\begin{array}{l}
s_{\text {Vs }} \\
\alpha_{\text {Vs }} \mid=\left(\begin{array}{l}
0.156 \\
n_{\text {VS }}
\end{array}\right) \\
0.021 \\
4.413
\end{array}\right)
\end{aligned}
$$

Output the sum of the residuals squared:

$$
\operatorname{error}\left(\mathrm{Sr}_{\mathrm{VS}}, \alpha_{\mathrm{VS}}, \mathrm{n}_{\mathrm{VS}}\right)=536.779
$$

Define a function for plotting purposes:

$$
\text { Splot } v:=\operatorname{Sr}_{V S}+\left(1-\mathrm{Sr}_{\mathrm{VS}}\right) \cdot \mathrm{f}_{\text {plot }}
$$

\section{X.2.2 Fine Sand}

Define a function, in terms of the van Genuchten parameters, that represents the sum of the residuals squared between the measured capillary pressure and the predicted capillary pressure for the fine sand:

$$
\operatorname{error}(\mathrm{Sr}, \alpha, \mathrm{n}):=\sum_{\mathrm{i}=1}^{\operatorname{rows}(\mathrm{FS})}\left[\left(\mathrm{G}\left(\mathrm{FS}_{\mathrm{i}, 2}, \mathrm{Sr}, \alpha, \mathrm{n}\right)-\mathrm{FS}_{\mathrm{i}, 1}\right)^{2}\right]
$$

Define an initial estimate of the parameters:

$$
\left(\begin{array}{l}
\mathrm{sr} \\
\alpha \\
\mathrm{n}
\end{array}\right):=\left(\begin{array}{c}
0.01 \\
0.1 \\
2
\end{array}\right)
$$

Use the Minerr function to obtain the lease squares fit to the fine sand data:

$$
\begin{gathered}
\text { Given } \\
\operatorname{error}(\operatorname{Sr}, \alpha, n)=0
\end{gathered}
$$




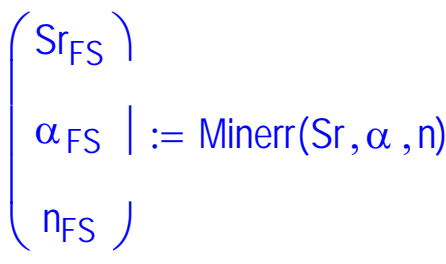

$$
\begin{aligned}
& \left(\begin{array}{l}
S_{F S} \\
\alpha_{F S} \mid=\left(\begin{array}{l}
0.170 \\
0.010 \\
n_{F S}
\end{array}\right) \\
5.664
\end{array}\right)
\end{aligned}
$$

Output the sum of the residuals squared:

$$
\operatorname{error}\left(\mathrm{Sr}_{\mathrm{FS}}, \alpha_{\mathrm{FS}}, \mathrm{n}_{\mathrm{FS}}\right)=675.283
$$

Define a function for plotting purposes:

$$
\operatorname{Splot}_{\mathrm{FS}}:=\mathrm{Sr}_{\mathrm{FS}}+\left(1-\mathrm{Sr}_{\mathrm{FS}}\right) \cdot \mathrm{f}_{\text {plot }}
$$

\section{X.2.3 Glass Beads}

Define a function, in terms of the van Genuchten parameters, that represents the sum of the residuals squared between the measured capillary pressure and the predicted capillary pressure for the glass beads:

$$
\operatorname{error}(\mathrm{Sr}, \alpha, \mathrm{n}):=\sum_{\mathrm{i}=1}^{\operatorname{rows}(\mathrm{GB})}\left[\left(\mathrm{G}\left(\mathrm{GB}_{\mathrm{i}, 2}, \mathrm{Sr}, \alpha, \mathrm{n}\right)-\mathrm{GB}_{\mathrm{i}, 1}\right)^{2}\right]
$$

Define an initial estimate of the parameters:

$$
\left(\begin{array}{l}
\mathrm{Sr} \\
\alpha \\
\mathrm{n}
\end{array}\right):\left(\begin{array}{c}
0.01 \\
0.03 \\
7
\end{array}\right)
$$

Use the Minerr function to obtain the lease squares fit to the glass beads data:

$$
\begin{gathered}
\text { Given } \\
\operatorname{error}(\operatorname{Sr}, \alpha, n)=0
\end{gathered}
$$




$$
\begin{aligned}
& \left(\begin{array}{l}
\left.\mathrm{Sr}_{G B}\right) \\
\alpha_{G B} \mid:=\operatorname{Minerr}(\operatorname{Sr}, \alpha, n) \\
n_{G B}
\end{array}\right) \\
& \left(\begin{array}{l}
\left.S_{G B}\right) \\
\alpha_{G B} \mid=\left(\begin{array}{l}
0.096991 \\
0.016780 \\
n_{G B}
\end{array}\right)
\end{array}\right.
\end{aligned}
$$

Output the sum of the residuals squared:

$$
\operatorname{error}\left(\mathrm{Sr}_{\mathrm{GB}}, \alpha_{\mathrm{GB}}, \mathrm{n}_{\mathrm{GB}}\right)=2.472 \times 10^{3}
$$

Define a function for plotting purposes:

$$
\text { Splot }_{G B}:=\operatorname{Sr}_{G B}+\left(1-\operatorname{Sr}_{G B}\right) \cdot f_{\text {plot }}
$$

\section{X.2.4 Touchet Silt Loam}

Define a function, in terms of the van Genuchten parameters, that represents the sum of the residuals squared between the measured capillary pressure and the predicted capillary pressure for the Touchet Silt Loam:

$$
\operatorname{error}(\mathrm{Sr}, \alpha, \mathrm{n}):=\sum_{\mathrm{i}=1}^{\operatorname{rows}(\mathrm{TSL})}\left[\left(\mathrm{G}\left(\mathrm{TSL}_{\mathrm{i}, 2}, \mathrm{Sr}, \alpha, \mathrm{n}\right)-\mathrm{TSL}_{\mathrm{i}, 1}\right)^{2}\right]
$$

Define an initial estimate of the parameters:

$$
\left(\begin{array}{l}
\mathrm{sr} \\
\alpha \\
n
\end{array}\right):=\left(\begin{array}{c}
0.001 \\
0.01 \\
3
\end{array}\right)
$$

Use the Minerr function to obtain the lease squares fit to the Touchet Silt Loam data:

$$
\begin{gathered}
\text { Given } \\
\operatorname{error}(\operatorname{Sr}, \alpha, n)=0
\end{gathered}
$$




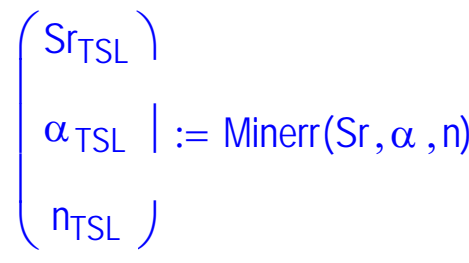

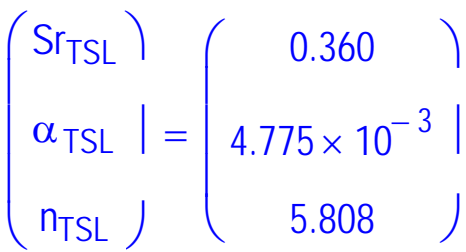

Output the sum of the residuals squared:

$$
\operatorname{error}\left(\mathrm{Sr}_{\mathrm{TSL}}, \alpha_{\mathrm{TSL}}, \mathrm{n}_{\mathrm{TSL}}\right)=1.872 \times 10^{3}
$$

Define a function for plotting purposes:

$$
\text { Splot }_{\mathrm{TSL}}:=\mathrm{Sr}_{\mathrm{TSL}}+\left(1-\mathrm{Sr}_{\mathrm{TSL}}\right) \cdot \mathrm{f}_{\text {plot }}
$$

The data sets have now been fitted individually. The residual saturation ( $\mathrm{Sr}$ ) for each set is inferred from the data. The results of the analysis are presented in Figure X-1.

\section{X.2.5 Nondimensional Capillary Pressure Correlation Using Leverett's Non-Dimensional Group}

The next analysis applies Leverett's nondimensional group (Leverett 1941 [DIRS 100588], p. 159) to the four data sets. It collapses the data reasonably well, with the volcanic sand providing the major deviation from the group. It compares favorably with Leverett's drainage curve for clean unconsolidated sands (Leverett 1941[DIRS 100588], Figure 4).

\section{Composite Set}

Define the function using the := notation for assigning a function.

$$
\mathrm{G} 2\left(\mathrm{~S}_{\mathrm{eff}}, \alpha, \mathrm{n}\right):=\frac{1}{\alpha} \cdot\left(\mathrm{S}_{\mathrm{eff}}^{\frac{\mathrm{n}}{1-\mathrm{n}}}-1\right)^{\frac{1}{\mathrm{n}}}
$$

Define the nondimensional parameter for analysis (Leverett 1941 [DIRS 100588], p. 159).

$$
\mathrm{G}_{2}=\frac{\mathrm{P}_{\mathrm{c}}}{\sigma_{\mathrm{w}}} \cdot \sqrt{\frac{\mathrm{k}}{\phi}}
$$


Define a function in terms of the dimensionless capillary pressure and the nondimensional van Genuchten parameters that represents the sum of the residuals squared between the measured dimensionless capillary pressure and the predicted dimensionless capillary pressure for all data sets:

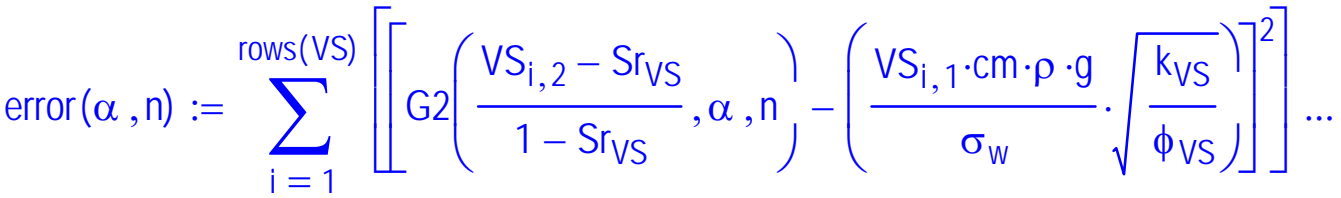

$$
\begin{aligned}
& +\sum_{i=1}^{\operatorname{rows}(\mathrm{FS})}\left[\left[\mathrm{G} 2\left(\frac{\mathrm{FS}_{\mathrm{i}, 2}-\mathrm{Sr}_{\mathrm{FS}}}{1-\mathrm{Sr}_{\mathrm{FS}}}, \alpha, \mathrm{n}\right)-\left(\frac{\mathrm{FS}_{\mathrm{i}, 1} \cdot \mathrm{cm} \cdot \rho \cdot \mathrm{g}}{\sigma_{\mathrm{W}}} \cdot \sqrt{\frac{\mathrm{k}_{\mathrm{FS}}}{\phi_{\mathrm{FS}}}}\right)\right]^{2}\right] \ldots \\
& +\sum_{i=1}^{\operatorname{rows}(\mathrm{GB})}\left[\left[\mathrm{G} 2\left(\frac{\mathrm{GB}_{\mathrm{i}, 2}-\mathrm{Sr}_{\mathrm{GB}}}{1-\mathrm{Sr}_{\mathrm{GB}}}, \alpha, \mathrm{n}\right)-\left(\frac{\mathrm{GB}_{\mathrm{i}, 1} \cdot \mathrm{cm} \cdot \rho \cdot g}{\sigma_{\mathrm{w}}} \cdot \sqrt{\frac{\mathrm{k}_{\mathrm{GB}}}{\phi_{\mathrm{GB}}}}\right)\right]^{2}\right] \ldots \\
& +\sum_{i=1}^{\operatorname{rows}(\mathrm{TSL})}\left[\left[\mathrm{G} 2\left(\frac{\mathrm{TSL}_{\mathrm{i}, 2}-\mathrm{Sr}_{\mathrm{TSL}}}{1-\mathrm{Sr}_{\mathrm{TSL}}}, \alpha, \mathrm{n}_{j}-\left(\frac{\mathrm{TSL}_{\mathrm{i}, 1} \cdot \mathrm{cm} \cdot \rho \cdot \mathrm{g}}{\sigma_{\mathrm{W}}} \cdot \sqrt{\frac{\mathrm{k}_{\mathrm{TSL}}}{\phi_{\mathrm{TSL}}}}\right)\right]^{2}\right]\right. \\
& i:=1 . . \operatorname{rows}(V S)
\end{aligned}
$$

Define an initial estimate of the parameters:

$$
\left(\begin{array}{l}
\alpha \\
n
\end{array}\right):=\left(\begin{array}{c}
4 \\
2.3
\end{array}\right)
$$

Use the Minerr function to obtain the lease squares fit to the volcanic sand data:

$$
\begin{gathered}
\text { Given } \\
\text { error }(\alpha, n)=0 \\
\left(\begin{array}{l}
\left.\alpha_{\text {comp }}\right) \\
\left.n_{\text {comp }}\right)
\end{array}=\operatorname{Minerr}(\alpha, n)\right. \\
\left(\begin{array}{l}
\left.\alpha_{\text {comp }}\right) \\
\left.n_{\text {comp }}\right)
\end{array}\right)=\left(\begin{array}{l}
2.455 \\
8.013
\end{array}\right)
\end{gathered}
$$

Output the sum of the residuals squared: 


$$
\begin{gathered}
j:=1 . . \operatorname{rows}(F S) \\
k:=1 . . \operatorname{rows}(G B) \\
\operatorname{error}\left(\alpha_{\text {comp }}, n_{\text {comp }}\right)=4.054
\end{gathered}
$$

Define a function for plotting purposes:

$$
\begin{aligned}
& \text { Splot }_{\text {comp }}:=\mathrm{f}_{\text {plot }} \\
& \mathrm{I}:=1 \text {.. rows (TSL) }
\end{aligned}
$$

The results of the analysis for normalized capillary rise for various materials are presented in Figure X-2.

Advection versus Diffusion in the Invert (BSC 2003 [DIRS 170881], Appendix VII) presents an independent verification using the Microsoft EXCEL equation solver. The analysis uses the same curve fitting procedure for volcanic sand, fine sand, glass beads, and Touchet Silt Loam individually, and then collectively by transforming the capillary rise data to a nondimensional capillary rise. Microsoft EXCEL is used to perform curve fitting to the van Genuchten retention relationship. The Solver is an add-in function in EXCEL. The Solver can minimize a target cell that involves multiple cell variables that might be subject to multiple constraints. The Solver is used specifically to solve for several variables under the constraint for a target value. In this case, the minimization of the least squares of the capillary rise is the target value for curve fitting. 


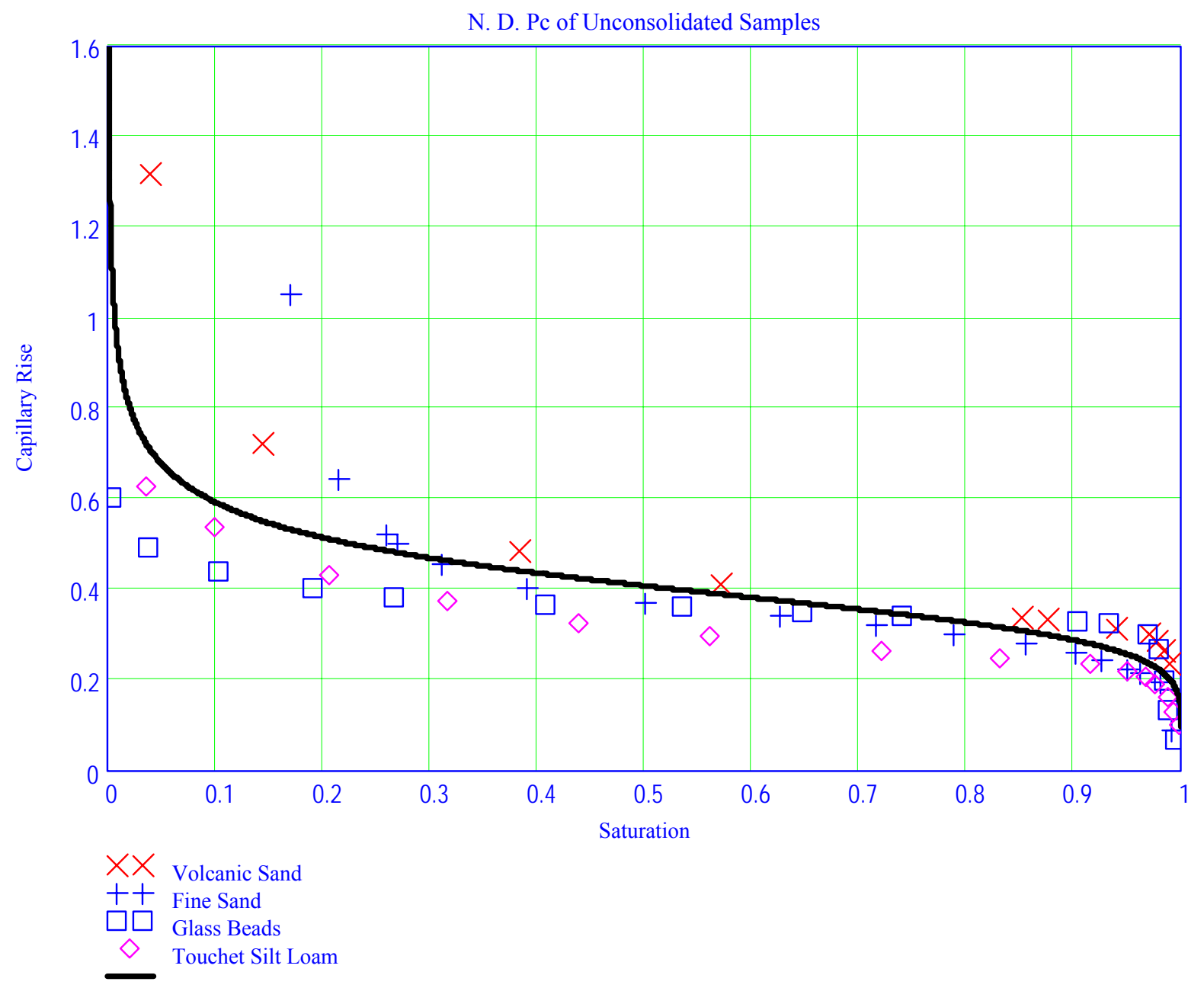

DTN MO0307SPAVGHYD.000

Figure X-2. Normalized Capillary Rise for Various Materials

\section{X.3 ASSESSMENT OF INTERGRANULAR POROSITY}

Hilf evaluated uniformly graded or poorly sorted sands and measured intergranular porosity ( $\left.\phi_{\text {matrix }}\right)$ ranges from 0.40 to about 0.48 when considering the maximum void ratio or porosity (Hilf 1975 [DIRS 169699], p. 257). For purposes of analysis, considering that crushed tuff may settle over time, a median value of 0.45 is adopted for the intergranular porosity ( $\left.\phi_{\text {intergrain }}\right)$.

Prior analyses reported in Advection versus Diffusion in the Invert (BSC 2003 [DIRS 170881], Section 6.3) have estimated the intragranular porosity ( $\phi_{\text {inatrix }}$ ) of crushed tuff to be 0.112 (BSC 2003 [DIRS 170881], Table 4-3). However, the total porosity includes both the intergranular porosity ( $\left.\phi_{\text {intergrain }}\right)$, related to the voids between the crushed tuff particles, as well as the intragranular porosity, related to the voids within the crushed tuff particles $\left(\phi_{\text {matrix }}\right)$. A total 
porosity of 0.545 has been calculated in Advection versus Diffusion in the Invert (BSC 2003 [DIRS 170881], Appendix XI) for sieved samples of crushed tuff ranging from 2 to $4.75 \mathrm{~mm}$.

Previous analysis in Advection versus Diffusion in the Invert (BSC 2003 [DIRS 170881], Section 6.3) estimated the intergranular porosity ( $\left.\phi_{\text {intergrain }}\right)$ that pertains to this coarse void space is equal to 0.49 .

Because the intergranular porosity value of 0.49 exceeds the range 0.40 to 0.48 , it suggests that the USGS values for measured bulk porosity (DTN GS980808312242.015 [DIRS 119916]) are consistent with a poorly graded sand in a loose state.

\section{X.4 MOISTURE POTENTIAL RETENTION RELATION FOR VARIOUS SIZE PARTICLES}

This section presents the calculations and plots of the retention curves for the nondimensionalized van Genuchten moisture potential retention relation for various size particles ranging from $0.317 \mathrm{~mm}$ to $20 \mathrm{~mm}$. The summary of the calculations of the air entry parameters is presented in Table X-1. The van Genuchten (n) value is 8.013 as discussed below.

Equation X.51 defines a nondimensional moisture potential parameter $\left(\Psi_{\mathrm{ND}}\right)$ for analysis, as suggested by Leverett (1941[DIRS 100588], p.159).

$$
\psi_{N D}=\psi \cdot \frac{\rho \cdot g}{\sigma_{W}} \cdot \sqrt{\frac{k}{\phi}}
$$

where

$$
\begin{aligned}
& \Psi_{N D}=\text { nondimensionalized moisture potential } \\
& \Psi=\text { moisture potential } \\
& \rho=\text { mass density of water }\left(\mathrm{kg} / \mathrm{m}^{3}\right) \\
& g=\text { acceleration due to gravity } \\
& k=\text { intrinsic permeability } \\
& \sigma_{w}=\text { interfacial tension between the pore water and mineral surface }(\text { dyne } / \mathrm{cm}) \\
& \phi=\text { porosity }
\end{aligned}
$$

The van Genuchten non-dimensional parameter (n) is calculated, where the van Genuchten dimensionless air entry parameter, $\alpha_{N D}=2.455$, such that $\mathrm{n}=8.01$ as presented above. For specific sized grains, the Kozeny-Carman equation expresses the relationship of the intrinsic permeability (k) to the porosity $(\phi)$ (Bear 1972 [DIRS 156269], p. 166):

$$
\text { Intrinsic permeability }=k=\frac{d_{m}{ }^{2}}{180} \cdot \frac{\phi^{3}}{(1-\phi)^{2}}
$$

where

$$
\begin{aligned}
& d_{m}=\text { mean particle diameter } \\
& \phi=\text { porosity }
\end{aligned}
$$


This equation is rearranged to obtain:

$$
\sqrt{\frac{k}{\phi}}=\frac{d_{m}}{\sqrt{180}} \cdot \frac{\phi}{(1-\phi)}
$$

The Leverett Equation as presented in Equation X.51 expresses the relationship of the nondimensional moisture potential $\left(\Psi_{N D}\right)$ to the dimensional moisture potential $(\Psi)$. Since the air-entry parameter $\alpha$ is inversely proportional to the moisture potential (See Equation X.4), the relationship of the nondimensional air-entry parameter as determined from the regression analysis for Equation X.4 is given by:

$$
\frac{1}{\alpha_{N D}}=\frac{1}{\alpha} \cdot \frac{\rho \cdot g}{\sigma_{w}} \cdot \sqrt{\frac{k}{\phi}}
$$

Solving for the air-entry parameter $\alpha$ in terms of the nondimensional air-entry parameter:

$$
\alpha=\alpha_{N D} \cdot \frac{\rho \cdot g}{\sigma_{w}} \cdot \sqrt{\frac{k}{\phi}}
$$

Substituting in Equation X.53 into Equation X.55 to express the air-entry parameter $\alpha$ in terms of the particle diameter $\left(\mathrm{d}_{\mathrm{m}}\right)$; the fluid density $(\rho)$; the surface tension $\left(\sigma_{\mathrm{w}}\right)$; the porosity $(\phi)$, the gravitational constant $(\mathrm{g})$; and the dimensionless air entry parameter $\left(\alpha_{N D}\right)$ as determined from the curve-fitting analysis:

$$
\alpha=\alpha_{N D} \cdot \frac{\rho \cdot g}{\sigma_{w}} \cdot \frac{d_{m}}{\sqrt{180}} \cdot \frac{\phi}{(1-\phi)}=2.455 \cdot \frac{\rho \cdot g}{\sigma_{w}} \cdot \frac{d_{m}}{\sqrt{180}} \cdot \frac{\phi}{(1-\phi)}
$$

Substituting in the value of $0.317 \mathrm{~mm}$ as a particle size with an intergranular porosity ( $\phi_{\text {intergrain }}$ ) of 0.45 , the calculated value for the van Genuchten air-entry parameter $(\alpha)$ in $\mathrm{cm}^{-1}$ for this size material is given in Equation X.55:

$$
\frac{\rho \cdot g}{\sigma_{w}} \sqrt{\frac{k}{\phi}} 2.455=\frac{\rho \cdot g}{\sigma_{w}} \frac{0.0317 \cdot \mathrm{cm}}{\sqrt{180}} \cdot \frac{0.45}{(1-0.45)} 2.455=0.0646 \cdot \mathrm{cm}^{-1}
$$

This analysis uses the following referenced properties for water: mass density, $\rho=1000 \mathrm{~kg} / \mathrm{m}^{3}$, $\sigma_{\mathrm{g}}$, geometric standard deviation, an interfacial tension between the pore water and mineral 
surface, $\sigma_{\mathrm{w}}=72$ dynes $/ \mathrm{cm}$ at ambient temperature, and gravity, $\mathrm{g}=9.81 \mathrm{~m} / \mathrm{sec}^{2}$ (Incropera and DeWitt 1996 [DIRS 108184], p. 846). Equation X.58 is used to calculate the value of the airentry parameter $(\alpha)$ in terms of (bars) ${ }^{-1}$ for a particle size of $0.3173 \mathrm{~mm}$ :

$$
\alpha=\frac{0.06466 \cdot \mathrm{cm}^{-1}}{1000 \cdot \frac{\mathrm{kg}}{\mathrm{m}^{3}} \cdot 9.81 \cdot \frac{\mathrm{m}}{\mathrm{sec}^{2}}}=65.9\left(\text { bars }^{-1}\right.
$$

Now consider the particle size of $3 \mathrm{~mm}$. The van Genuchten air-entry parameter $(\alpha)$ for this grain size from Equations X.55, is given as:

$$
\frac{\rho \cdot g}{\sigma_{w}} \sqrt{\frac{k}{\phi}} \cdot 2.455=\frac{\rho \cdot g}{\sigma_{w}} \frac{0.3 \cdot \mathrm{cm}}{\sqrt{180}} \cdot \frac{0.45}{(1-0.45)} \cdot 2.455=0.612 \cdot \mathrm{cm}^{-1}
$$

The value of the van Genuchten air-entry parameter $(\alpha)$ for the $3 \mathrm{~mm}$ diameter grain size in terms of bars ${ }^{-1}$ is calculated using Equation X.58 (bars) $)^{-1}$ :

$$
\alpha=\frac{0.611 \cdot \mathrm{cm}^{-1}}{1000 \cdot \frac{\mathrm{kg}}{\mathrm{m}^{3}} \cdot 9.81 \cdot \frac{\mathrm{m}}{\mathrm{sec}^{2}}}=624 . \text { bars }^{-1}
$$

The van Genuchten air entry parameter calculations are presented in Table $\mathrm{X}-1$. The individual retention curves with curve fits are presented in Tables X-2 through X-5 and are illustrated in Figures X-3 through X-6.

Table X-1. van Genuchten Air Entry Parameter $(\alpha)$ Calculations.

\begin{tabular}{|c|c|c|c|c|}
\hline \multirow{2}{*}{ Parameter } & \multicolumn{4}{|c|}{ Particle Diameter $\left(\mathbf{d}_{\mathbf{m}}\right)$} \\
\cline { 2 - 5 } & $\mathbf{0 . 3 1 7} \mathbf{~ m m}$ & $\mathbf{3} \mathbf{~ m m}$ & $\mathbf{1 0} \mathbf{~ m m}$ & $\mathbf{2 0} \mathbf{~ m m}$ \\
\hline van Genuchten air-entry parameter $(\alpha)(\mathrm{cm})^{-1}$ & $0.0646^{\mathrm{a}}$ & $0.612^{\mathrm{c}}$ & 2.05 & 4.09 \\
\hline van Genuchten air entry parameter(bars) $^{-1}$ & $65.9^{\mathrm{b}}$ & $624^{\mathrm{d}}$ & 2080 & 4160 \\
\hline
\end{tabular}

\footnotetext{
a See the calculation presented in Equation X.57.

b See the calculation presented in Equation X.58.

${ }^{c}$ See the calculation presented in Equation X.59.

d See the calculation presented in Equation X.60.
} 
Table X-2. Moisture Retention Data for $0.317 \mathrm{~mm}$ Crushed Tuff

\begin{tabular}{|c|c|c|c|c|}
\hline \multicolumn{5}{|c|}{ Van Genuchten Curve Parameters } \\
\hline Moisture Content at Saturation $(\theta \mathrm{s})$ & 0.45 & & & \\
\hline Residual Moisture Content $(\theta r)$ & 0.05 & & & \\
\hline Alpha $(\alpha)$ & 65.9 & bars $^{\wedge}-1$ & 0.0646 & $\mathrm{~cm}^{\wedge}-1$ \\
\hline $\mathrm{n}$ & 8.01 & & & \\
\hline $\mathrm{m}$ & 0.88 & & & \\
\hline
\end{tabular}

Retention Analysis

\begin{tabular}{|c|c|}
\hline \multicolumn{2}{|c|}{ Retention Analysis } \\
\hline & $\begin{array}{c}\text { Predicted } \\
\text { Moisture } \\
\text { Moisture Potential }\end{array}$ \\
Content
\end{tabular}
$\psi$ (bars)

( $\theta)$

\begin{tabular}{|r|r|}
\hline & \\
\hline 0.0001 & 0.450 \\
\hline 0.0002 & 0.450 \\
\hline 0.0005 & 0.450 \\
\hline 0.001 & 0.450 \\
\hline 0.002 & 0.450 \\
\hline 0.005 & 0.450 \\
\hline 0.01 & 0.438 \\
\hline 0.02 & 0.103 \\
\hline 0.05 & 0.050 \\
\hline 0.1 & 0.050 \\
\hline 0.2 & 0.050 \\
\hline 0.5 & 0.050 \\
\hline 1 & 0.050 \\
\hline 2 & 0.050 \\
\hline 5 & 0.050 \\
\hline 10 & 0.050 \\
\hline 20 & 0.050 \\
\hline 50 & 0.050 \\
\hline 100 & 0.050 \\
\hline 200 & 0.050 \\
\hline 500 & 0.050 \\
\hline 1000 & 0.050 \\
\hline
\end{tabular}

Predicted Moisture content obtained from Equation X.4 
Table X-3. Moisture Retention Data for 3.0 mm Crushed Tuff

\begin{tabular}{|c|c|c|c|c|}
\hline \multicolumn{5}{|c|}{ Van Genuchten Curve Parameters } \\
\hline Moisture Content at Saturation $(\theta \mathrm{s})$ & 0.45 & & & \\
\hline Residual Moisture Content $(\theta r)$ & 0.05 & & & \\
\hline Alpha $(\alpha)$ & 624 & bars $^{\wedge}-1$ & 0.612 & $\mathrm{~cm}^{\wedge}-1$ \\
\hline $\mathrm{n}$ & 8.01 & & & \\
\hline $\mathrm{m}$ & 0.88 & & & \\
\hline
\end{tabular}

\begin{tabular}{|c|c|}
\hline \multicolumn{2}{|c|}{ Retention Analysis } \\
\hline $\begin{array}{l}\text { Moisture Potential } \\
\qquad(\text { bars })\end{array}$ & $\begin{array}{c}\text { Predicted } \\
\text { Moisture } \\
\text { Content } \\
(\theta)\end{array}$ \\
\hline 0.0001 & 0.450 \\
\hline 0.0002 & 0.450 \\
\hline 0.0005 & 0.450 \\
\hline 0.001 & 0.442 \\
\hline 0.002 & 0.124 \\
\hline 0.005 & 0.050 \\
\hline 0.01 & 0.050 \\
\hline 0.02 & 0.050 \\
\hline 0.05 & 0.050 \\
\hline 0.1 & 0.050 \\
\hline 0.2 & 0.050 \\
\hline 0.5 & 0.050 \\
\hline 1 & 0.050 \\
\hline 2 & 0.050 \\
\hline 5 & 0.050 \\
\hline 10 & 0.050 \\
\hline 20 & 0.050 \\
\hline 50 & 0.050 \\
\hline 100 & 0.050 \\
\hline 200 & 0.050 \\
\hline 500 & 0.050 \\
\hline 1000 & 0.050 \\
\hline
\end{tabular}

Predicted Moisture content obtained from Equation X.4 
Table X-4. Moisture Retention Data for 10.0 mm Crushed Tuff

\begin{tabular}{|c|c|c|c|c|}
\hline \multicolumn{5}{|c|}{$\begin{array}{ll}\text { Van Genuchten Curve Parameters } \\
\end{array}$} \\
\hline Moisture Content at Saturation $(\theta \mathrm{s})$ & 0.45 & & & \\
\hline Residual Moisture Content $(\theta r)$ & 0.05 & & & \\
\hline Alpha $(\alpha)$ & 2080 & bars $^{\wedge}-1$ & 2.05 & $\mathrm{~cm}^{\wedge}-1$ \\
\hline $\mathrm{n}$ & 8.01 & & & \\
\hline $\mathrm{m}$ & 0.88 & & & \\
\hline
\end{tabular}

\begin{tabular}{|c|c|}
\hline \multicolumn{2}{|c|}{ Retention Analysis } \\
\hline $\begin{array}{c}\text { Moisture Potential } \\
\psi(\text { bars })\end{array}$ & $\begin{array}{c}\text { Predicted } \\
\text { Moisture } \\
\text { Content } \\
(\theta)\end{array}$ \\
\hline 0.0001 & 0.450 \\
\hline 0.0002 & 0.450 \\
\hline 0.0005 & 0.238 \\
\hline 0.001 & 0.052 \\
\hline 0.002 & 0.050 \\
\hline 0.005 & 0.050 \\
\hline 0.01 & 0.050 \\
\hline 0.02 & 0.050 \\
\hline 0.05 & 0.050 \\
\hline 0.1 & 0.050 \\
\hline 0.2 & 0.050 \\
\hline 0.5 & 0.050 \\
\hline 1 & 0.050 \\
\hline 2 & 0.050 \\
\hline 5 & 0.050 \\
\hline 10 & 0.050 \\
\hline 20 & 0.050 \\
\hline 50 & 0.050 \\
\hline 100 & 0.050 \\
\hline 200 & 0.050 \\
\hline 500 & 0.050 \\
\hline 1000 & 0.050 \\
\hline
\end{tabular}

Predicted Moisture content obtained from Equation X.4 
Table X-5. Moisture Retention Data for 20.0 mm Crushed Tuff

\begin{tabular}{|c|c|c|c|c|}
\hline \multicolumn{5}{|c|}{ van Genuchten Curve Parameters } \\
\hline Moisture Content at Saturation ( $\theta \mathrm{s})$ & 0.45 & & & \\
\hline Residual Moisture Content $(\theta r)$ & 0.05 & & & \\
\hline Alpha $(\alpha)$ & 4160 & bars $^{\wedge}-1$ & 4.09 & $\mathrm{~cm}^{\wedge}-1$ \\
\hline $\mathrm{n}$ & 8.01 & & & \\
\hline $\mathrm{m}$ & 0.88 & & & \\
\hline
\end{tabular}

\begin{tabular}{|c|c|}
\hline \multicolumn{2}{|c|}{ Retention Analysis } \\
\hline $\begin{array}{c}\text { Moisture Potential } \\
\qquad(\text { bars })\end{array}$ & $\begin{array}{c}\text { Predicted } \\
\text { Moisture } \\
\text { Content } \\
(\theta)\end{array}$ \\
\hline 0.00001 & 0.450 \\
\hline 0.0002 & 0.384 \\
\hline 0.0005 & 0.052 \\
\hline 0.001 & 0.050 \\
\hline 0.002 & 0.050 \\
\hline 0.005 & 0.050 \\
\hline 0.01 & 0.050 \\
\hline 0.02 & 0.050 \\
\hline 0.05 & 0.050 \\
\hline 0.1 & 0.050 \\
\hline 0.2 & 0.050 \\
\hline 0.5 & 0.050 \\
\hline 1 & 0.050 \\
\hline 2 & 0.050 \\
\hline 5 & 0.050 \\
\hline 10 & 0.050 \\
\hline 20 & 0.050 \\
\hline 50 & 0.050 \\
\hline 100 & 0.050 \\
\hline 200 & 0.050 \\
\hline 500 & 0.050 \\
\hline 1000 & 0.050 \\
\hline
\end{tabular}

Predicted Moisture content obtained from Equation X.4 


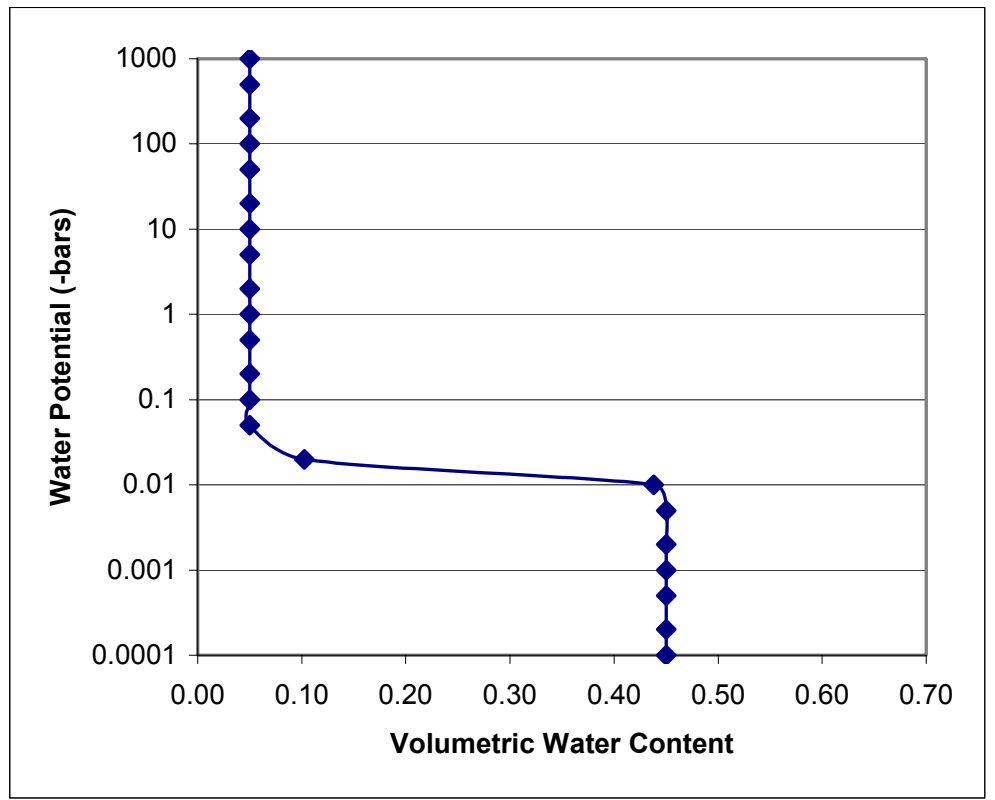

Figure X-3. Nondimensionalized Relationship for Mean Particle Diameter of $0.317 \mathrm{~mm}$

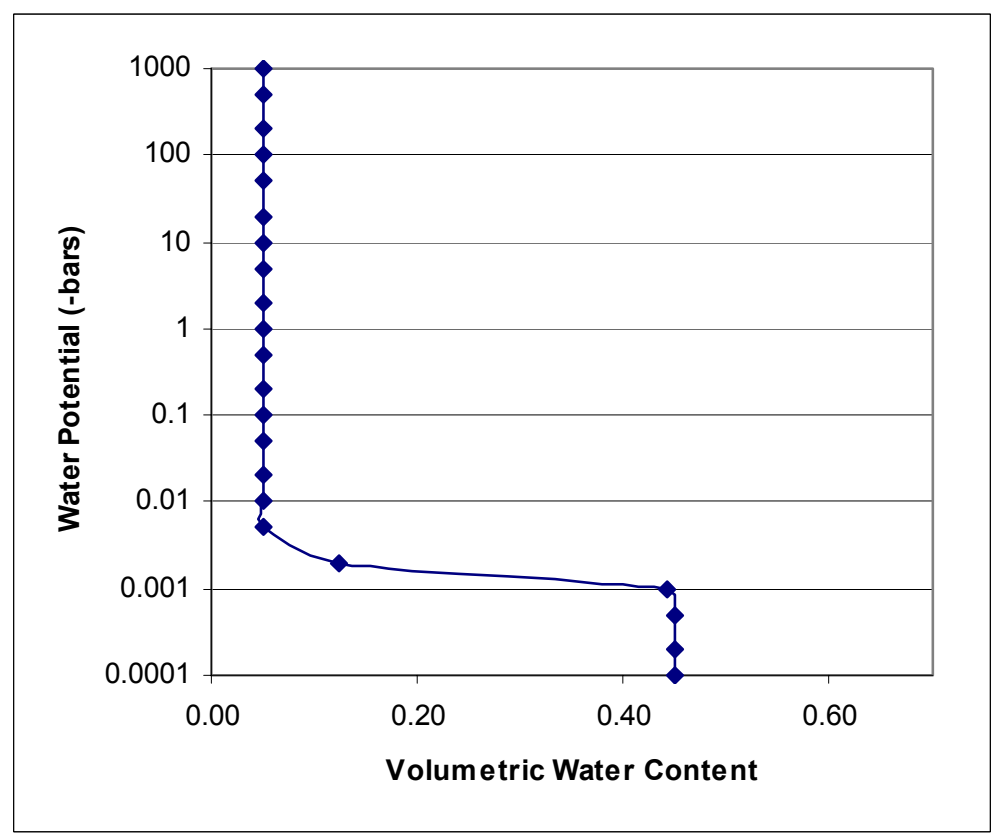

Figure X-4. Nondimensionalized Relationship for Mean Particle Diameter of $3.0 \mathrm{~mm}$ 


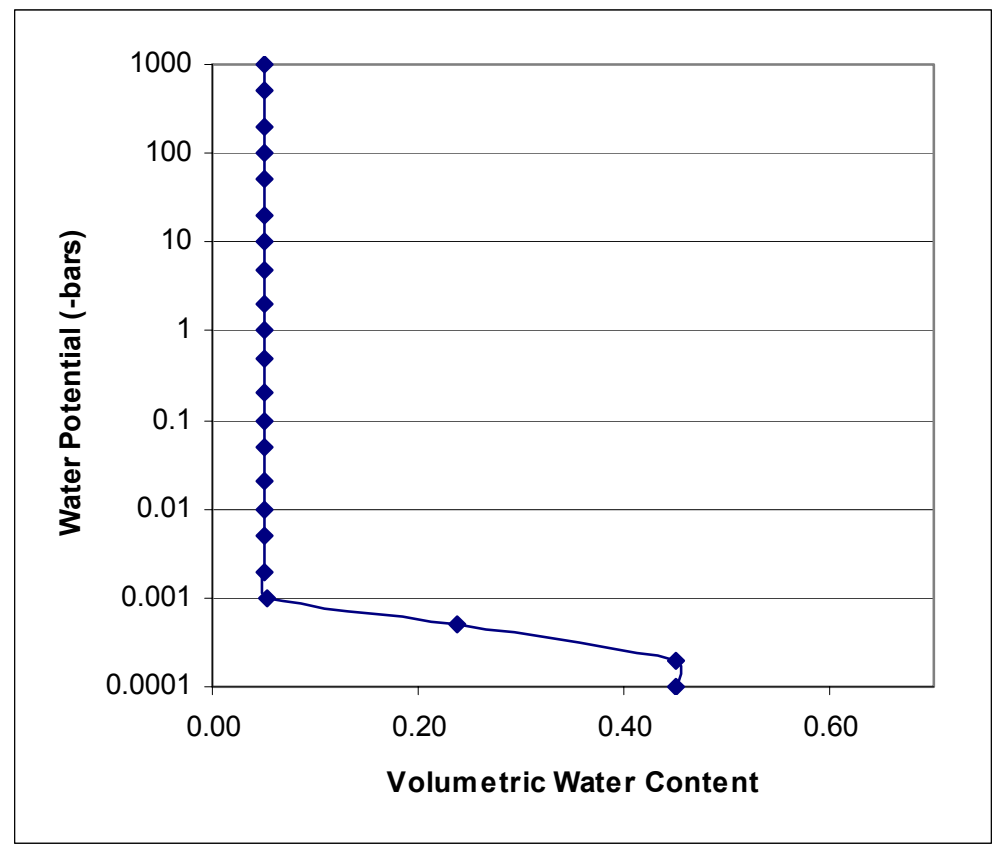

Figure X-5. Nondimensionalized Relationship for Mean Particle Diameter of $10.0 \mathrm{~mm}$

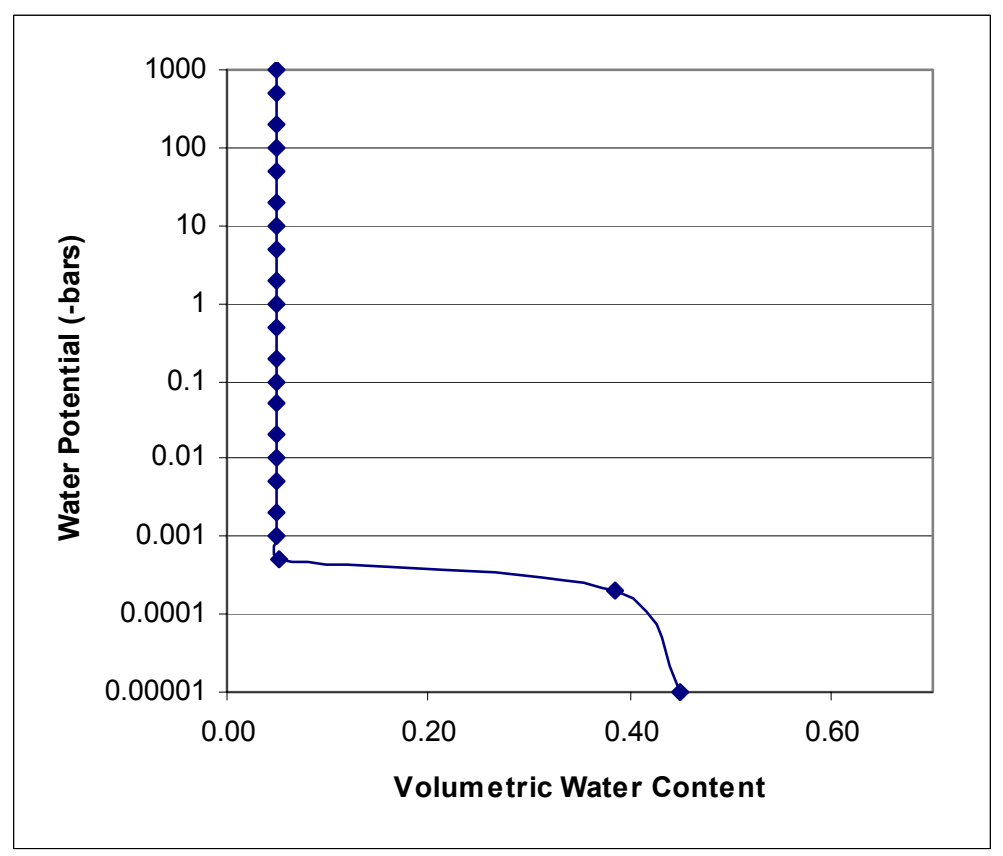

Figure X-6. Nondimensionalized Relationship for Mean Particle Diameter of $20.0 \mathrm{~mm}$ 


\section{X.5 UNSATURATED HYDRAULIC CONDUCTIVITY AND CAPILLARY PRESSURE FOR THE CRUSHED TUFF INVERT}

The following discussion presents the methodology and the analysis for determining the relationship between unsaturated hydraulic conductivity $\left(K_{u s}\right)$ and capillary pressure from the retention curve using the two-parameter nondimensional van Genuchten relationship and the size of the crushed tuff. The basis for the nondimensional retention relationship is a least squares curve fit for a series of retention measurements made on the materials presented above. The nondimensional van Genuchten air-entry parameter $(\alpha)$ is determined from a scaling relationship while the nondimensional (n) parameter is constant. The intrinsic permeability $(k)$ is determined from the Kozeny-Carman formula shown by Equation X.62 (Bear 1972 [DIRS 156269], p. 166) that relates intrinsic permeability $(k)$ to the grain size or pore diameter $\left(d_{m}\right)$ and porosity $(\phi)$. On the basis of the selected grain size, the saturated hydraulic conductivity $\left(K_{s}\right)$ and the van Genuchten relationship for relative permeability, the relationship of unsaturated hydraulic conductivity $\left(K_{u s}\right)$ relationship to moisture potential $(\psi)$ is determined.

A qualitative assessment is made over the range of moisture potentials ( $\psi)$ of interest ( 0.01 to 0.1 bars) as to whether significant intergranular liquid-phase advection in the coarse fraction of the crushed tuff would occur for a range of particle diameters. The analysis presented below is performed for grain size diameters of $0.317 \mathrm{~mm}, 3 \mathrm{~mm}, 10 \mathrm{~mm}$ and $20 \mathrm{~mm}$ for the intergranular porosity $\left(\phi_{\text {intergrain }}\right)$ respectively to cover a broad range of particle diameters.

The wetting-phase relative permeability as a function of moisture potential $(\psi)$ for van Genuchten curve fit is restated from Fetter (1993 [DIRS 102009], p. 182). The unsaturated hydraulic conductivity $\left(K_{u s}\right)$ (wetting-phase relative permeability times saturated hydraulic conductivity) as a function of moisture potential $(\psi)$ is derived using Equation X.61 (same as Eq. 4.17 of Fetter 1993 [DIRS 102009], with $n=1 /(1-m))$.

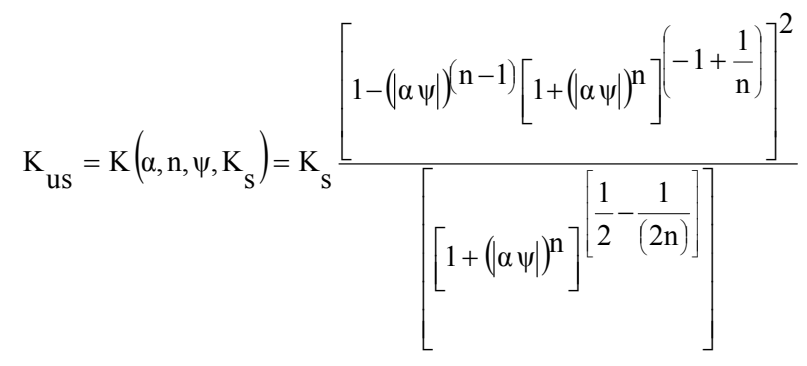

The intrinsic permeability $(\mathrm{k})$ corresponding to a grain size of $3 \mathrm{~mm}$ is calculated from Equation $\mathrm{X} .52$ as $1.51 \times 10^{-8} \mathrm{~m}^{2}$ :

$$
k=\frac{d_{m}^{2}}{180} \cdot \frac{\phi^{3}}{(1-\phi)^{2}}=1.51 \cdot 10^{-8} \cdot m^{2}
$$

Noting a conversion to saturated hydraulic conductivity from intrinsic permeability, the value for saturated conductivity is calculated for each of the particle sizes from 0.3 to $20 \mathrm{~mm}$ in diameter. 
The unsaturated hydraulic conductivity relationships are determined from the van Genuchten properties presented in Table X-1, and the saturated hydraulic conductivity. The calculations over a range of moisture potentials are presented in Table X-6, and are plotted in Figure X-7.

\section{Comparison of Conductivity Relationships}

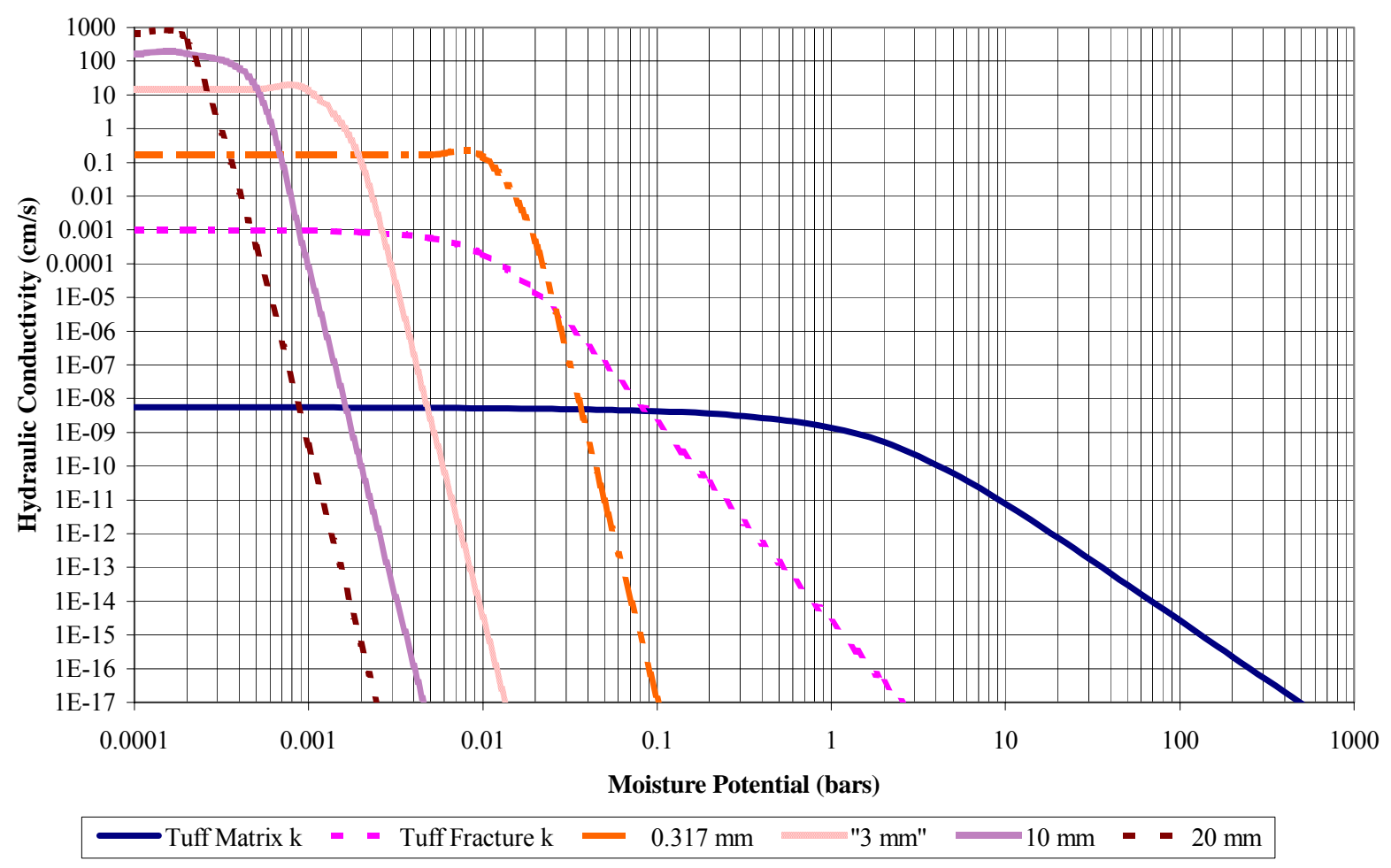

Figure X-7. Unsaturated Hydraulic Conductivity Relationships 
Table X-6. Unsaturated Hydraulic Conductivity (Kus) Calculations for the Non-Dimensionalized Moisture Potential $(\psi)$ Retention Relation

\begin{tabular}{|l|c|c|c|c|c|}
\hline \multirow{2}{*}{$\begin{array}{c}\text { Moisture } \\
\text { Potential } \\
(\psi)(\text { bars) }\end{array}$} & \multicolumn{5}{|c|}{ Unsaturated Hydraulic Conductivity $\left(\mathbf{K}_{\text {us }}\right)(\mathbf{c m} / \mathbf{s e c})$} \\
\cline { 2 - 6 } & Welded Tuff Matrix & $\mathbf{0 . 3 1 7} \mathbf{~ m m}$ & $\mathbf{3} \mathbf{~ m m}$ & $\mathbf{1 0} \mathbf{~ m m}$ & $\mathbf{2 0} \mathbf{~ m m}$ \\
\hline 0.0001 & $6.23 \mathrm{E}-09$ & $1.84 \mathrm{E}-01$ & $1.65 \mathrm{E}+01$ & $1.83 \mathrm{E}+02$ & $7.29 \mathrm{E}+02$ \\
\hline 0.0002 & $6.21 \mathrm{E}-09$ & $1.84 \mathrm{E}-01$ & $1.65 \mathrm{E}+01$ & $1.82 \mathrm{E}+02$ & $3.97 \mathrm{E}+02$ \\
\hline 0.001 & $6.15 \mathrm{E}-09$ & $1.84 \mathrm{E}-01$ & $1.52 \mathrm{E}+01$ & $8.60 \mathrm{E}-05$ & $4.56 \mathrm{E}-10$ \\
\hline 0.0015 & $6.13 \mathrm{E}-09$ & $1.84 \mathrm{E}-01$ & $4.54 \mathrm{E}+00$ & $3.15 \mathrm{E}-08$ & $1.66 \mathrm{E}-13$ \\
\hline 0.002 & $6.10 \mathrm{E}-09$ & $1.84 \mathrm{E}-01$ & $1.16 \mathrm{E}-01$ & $1.14 \mathrm{E}-10$ & $6.01 \mathrm{E}-16$ \\
\hline 0.005 & $5.99 \mathrm{E}-09$ & $1.84 \mathrm{E}-01$ & $2.81 \mathrm{E}-09$ & $1.93 \mathrm{E}-18$ & $1.01 \mathrm{E}-23$ \\
\hline 0.01 & $5.86 \mathrm{E}-09$ & $1.63 \mathrm{E}-01$ & $3.71 \mathrm{E}-15$ & $2.54 \mathrm{E}-24$ & $1.36 \mathrm{E}-29$ \\
\hline 0.02 & $5.66 \mathrm{E}-09$ & $5.02 \mathrm{E}-04$ & $4.89 \mathrm{E}-21$ & $3.41 \mathrm{E}-30$ & $2.02 \mathrm{E}-34$ \\
\hline 0.05 & $5.24 \mathrm{E}-09$ & $1.08 \mathrm{E}-11$ & $8.27 \mathrm{E}-29$ & $1.22 \mathrm{E}-35$ & $5.45 \mathrm{E}-36$ \\
\hline 0.1 & $4.74 \mathrm{E}-09$ & $1.42 \mathrm{E}-17$ & $1.57 \mathrm{E}-34$ & $1.36 \mathrm{E}-36$ & $5.92 \mathrm{E}-37$ \\
\hline 0.2 & $4.02 \mathrm{E}-09$ & $1.86 \mathrm{E}-23$ & $7.34 \mathrm{E}-37$ & $1.48 \mathrm{E}-37$ & $6.30 \mathrm{E}-38$ \\
\hline
\end{tabular}

DTN: MO0307SPAVGSUM.000

NOTE: The values for the saturated hydraulic conductivity $\left(\mathrm{K}_{\mathrm{s}}\right)(\mathrm{cm} / \mathrm{sec})$ as a function of the moisture potential $(\psi)$ are obtained by calculating the intrinsic permeability $(\mathrm{k})$ for a given set of van Genuchten parameters from Equation X.62 and then applying the conversion from intrinsic permeability $(\mathrm{k})$ to saturated hydraulic conductivity $\left(K_{s}\right)$ (Freeze and Cherry 1979 [DIRS 101173], p. 27):

$$
K_{s}=\frac{\rho \cdot g}{\mu} \cdot k
$$

The properties of water at ambient temperature are given by (Incropera and DeWitt 1996 [DIRS 108184], p. 846). The water density $(\rho)$ equals $1000 \mathrm{~kg} / \mathrm{m}^{3}$ and the absolute viscosity $(\mu)$ equals $8.935 \bullet 10^{-4}$ $\mathrm{N} \bullet \mathrm{s} /\left(\mathrm{m}^{2}\right)$. The values for the unsaturated hydraulic conductivity are then determined by scaling the saturated hydraulic conductivity relationship by the relative permeability relationship presented in Eq. IV.11 for a given moisture potential. 


\section{X.6 SUMMARY OF HYDROLOGIC PROPERTIES BASED ON THE NON- DIMENSIONALIZED MOISTURE POTENTIAL RETENTION RELATIONS}

The van Genuchten retention parameters as well as other hydrologic properties are summarized in Table X-7 over a range of particle sizes. These analyses show that the finer crushed tuff would have a greater tendency to retain water over the range of the moisture potentials in the repository.

Table X-7. Summary of Hydrologic Properties Based on the Non-Dimensionalized Moisture Potential Retention Relation

\begin{tabular}{|l|c|c|c|c|}
\hline \multirow{2}{*}{\multicolumn{1}{c|}{ Parameter }} & \multicolumn{3}{c|}{ Particle Size $\left(\mathbf{d}_{\mathrm{m}}\right)$} \\
\cline { 2 - 5 } & $\mathbf{0 . 3 1 7} \mathbf{~ m m}$ & $\mathbf{3 ~ \mathbf { ~ m }}$ & $\mathbf{1 0 ~ \mathbf { ~ m }}$ & $\mathbf{2 0} \mathbf{~ m m}$ \\
\hline Saturated Volumetric Moisture Content $\left(\theta_{\mathrm{s}}\right)^{\mathrm{a}}$ & 0.450 & 0.450 & 0.450 & 0.450 \\
\hline Residual Volumetric Moisture Content $\left(\theta_{\mathrm{r}}\right)$ & 0.050 & 0.050 & 0.050 & 0.050 \\
\hline van Genuchten Air-entry Parameter $\left(\mathrm{bars}^{-1}\right)(\alpha)^{\mathrm{b}}$ & 65.9 & 624. & 2080. & 4160. \\
\hline van Genuchten Air-entry Parameter $\left(\mathrm{cm}^{-1}\right)(\alpha)$ & 0.0647 & 0.612 & 2.04 & 4.08 \\
\hline van Genuchten n Value $(\mathrm{n})$ & 8.013 & 8.013 & 8.013 & 8.013 \\
\hline van Genuchten m Value $(\mathrm{m})^{\mathrm{c}}$ & 0.875 & 0.875 & 0.875 & 0.875 \\
\hline Saturated Intrinsic Permeability $\left(\mathrm{m}^{2}\right)(\mathrm{k})^{\mathrm{d}}$ & $1.68 \mathrm{E}-10$ & $1.51 \mathrm{E}-08$ & $1.67 \mathrm{E}-07$ & $6.69 \mathrm{E}-07$ \\
\hline Saturated Hydraulic Conductivity $(\mathrm{cm} / \mathrm{sec})\left(\mathrm{K}_{\mathrm{s}}\right)^{\mathrm{e}}$ & 0.184 & 16.48 & 183.1 & 732.5 \\
\hline
\end{tabular}

DTN: MO0307SPAVGSUM.000

${ }^{b}$ See text and Table X-1 for the calculation of the van Genuchten Air-Entry Parameter $(\alpha)$

a The saturated volumetric moisture $(\theta s)$ content equals the porosity $(\phi)$.

c The value of $n$ is given by 1/(1-m) (Fetter 1993 [DIRS 102009], p. 172).

d The intrinsic permeability ( $k$ ) is calculated from Equation X.62.

e The value of the saturated hydraulic conductivity (Ks) is obtained by the equation that converts an unsaturated intrinsic permeability (k) to a saturated hydraulic conductivity (Ks) (Freeze and Cherry 1979 [DIRS 101173], p. 27):

$$
K_{s}=\frac{\rho \cdot g}{\mu} \cdot k
$$

The properties of water at ambient temperature are given by (Incropera and DeWitt 1996 [DIRS 108184], p. 846). The water density $(\rho)$ equals $997 \mathrm{~kg} / \mathrm{m} 3$ and the absolute viscosity $(\mu)$ equals $8.935 \times 10-4 \mathrm{~N} \bullet \mathrm{s} /(\mathrm{m} 2)$. Note that these values compare well with the values for sands and gravels from Freeze and Cherry (1979 [DIRS 101173], p. 29). 


\section{INTENTIONALLY LEFT BLANK}




\section{APPENDIX XI}

THERMAL CONDUCTIVITY OF THE COLLAPSED DRIFT ZONE 
This appendix presents two EXCEL workbooks used to corroborate the thermal conductivity of the collapsed drift as a function of the void fraction within this zone. Section XI.1 presents the calculation of the void fraction determination from the bulking factor as determined in Drift Degradation Analysis (BSC 2004 [DIRS 166107], Section 6.4.2 and Appendix V). Section XI.2 presents the thermal conductivity calculation based upon the Kunii and Smith relationship (Kunii and Smith 1960 [DIRS 153166]).

\section{XI.1 ASSESSMENT OF THE VOID FRACTION WITHIN THE COLLAPSED DRIFT}

The intergranular porosity of collapsed drift material is a function of the bulking factor and lithophysal porosity. The lithophysal porosity is assumed to be added to the void volume after collapse. Consider that one cubic meter of drift collapses with a lithophysal porosity of $\phi$, and the bulking factor (a fraction) is B. Then the total void volume is $\phi+\mathrm{B}$, and the total volume of the one cubic meter is $1+\mathrm{B}$ as presented in the derivation below.

Derive the expression for the void fraction. Using the fundamental definition of lithophysal porosity:

$$
\phi_{L}=\frac{V_{\text {voids }}}{V_{\text {solids }}+V_{\text {voids }}}
$$

Where $V_{\text {voids }}$ is equal to the volume of the voids, and $V_{\text {solids }}$ is equal to the volume of the solids.

Note the following relationship:

$$
V_{\text {Total }}=V_{\text {solids }}+V_{\text {voids }}
$$

Where $V_{\text {total }}$ is equal to the total volume.

Now consider the new total volume is $V^{\prime}$ 'otal after bulking has occurred. Let $V_{\text {solids }}$ be equal to one, following the soil mechanics convention. Expressing the lithophysal porosity in terms of the volume of the voids:

$$
\phi_{L}=\frac{V_{\text {voids }}}{1+V_{\text {voids }}}
$$

Now expressing the change in total volume in terms of the bulking factor:

$$
V_{\text {Total }}^{\prime}=(1+B) V_{\text {Total }}
$$


Derive an expression for the volume of the voids before and after bulking. The volume of the voids after bulking:

$$
\begin{gathered}
V_{\text {voids }}^{\prime}=(1+B) \cdot V_{\text {Total }}-V_{\text {solids }} \\
V_{\text {voids }}^{\prime}=(1+B) \cdot V_{\text {Total }}-1
\end{gathered}
$$

Solving for the volume of the voids in terms of the lithophysal porosity:

$$
V_{\text {voids }}=\frac{\phi_{L}}{1-\phi_{L}}
$$

Expressing the total volume in terms of the lithophysal porosity, with the volume of solids set to one:

$$
V_{\text {Total }}=1+\frac{\phi_{L}}{1-\phi_{L}}
$$

The void fraction after bulking is defined as:

$$
\text { Void_Fraction }=\frac{V_{\text {voids }}^{\prime}}{V_{\text {Total }}^{\prime}}
$$

Substituting in the relationships for the void volume and the total volume:

$$
\text { Void_Fraction }=\frac{(1+B) \cdot V_{\text {Total }^{-1}}}{(1+B) V_{\text {Total }}}
$$




$$
\begin{gathered}
\text { Void_Fraction }=\frac{(1+B) \cdot\left(1+\frac{\phi_{L}}{1-\phi_{L}}\right)-1}{(1+B) \cdot\left(1+\frac{\phi_{L}}{1-\phi_{L}}\right)} \\
\text { Void_Fraction }=\frac{B+\phi_{L}}{1+B}
\end{gathered}
$$

(Eq. XI-11)

The calculations of the void fraction as a function of the lithophysal porosity, and of the bulking factor as given by Equation XI.11 are presented in the EXCEL workbook in Table XI-1. A range of lithophysal porosities are considered, $10 \%$ to $30 \%$, and a range of bulking factors, 0.1 to 0.4 . The lithophysal porosity of interest is $35 \%$ for a lithophysal rock mass category of 1 (BSC 2004 [DIRS 166107], Table 6-33). Category 1 and a bulking factor of 0.19 are chosen for analysis in Drift Degradation Analysis (BSC 2004 [DIRS 166107], Section 6.4.2.5).

\section{XI.2 SUMMARY OF THE EFFECTIVE THERMAL CONDUCTIVITY OF DRIFT- COLLAPSE MATERIAL}

Kunii and Smith (1960 [DIRS 153166]) describe a method for calculating the thermal conductivity of a porous medium with radiant heat transfer. The effective thermal conductivity is expressed by Kunii and Smith (1960 [DIRS 153166], Equation 8):

$$
k_{e}=k_{g} \cdot\left[\varepsilon \cdot\left(1+\beta \cdot \frac{h_{r v} \cdot D_{p}}{k_{g}}\right)+\frac{\beta \cdot(1-\varepsilon)}{\frac{1}{\frac{1}{\phi}+\frac{D_{p} \cdot h_{r s}}{k_{g}}}+\gamma \cdot \frac{k_{g}}{k_{s}}}\right]
$$

(Eq. XI- 12)

where

$D_{p} \quad$ Nominal or average diameter of packing $(m)$

$\mathrm{h}_{\mathrm{rv}}$ Heat transfer coefficient for radiation, void to void

$\mathrm{h}_{\mathrm{rs}}$ Heat transfer coefficient for radiation, solid to solid

$\mathrm{k}_{\mathrm{s}}$ Thermal conductivity of the solids $(\mathrm{W} /(\mathrm{m} \bullet \mathrm{K})$

$\mathrm{k}_{\mathrm{g}}$ Thermal conductivity of the fluid $(\mathrm{W} /(\mathrm{m} \bullet \mathrm{K})$

$\varepsilon \quad$ Void fraction 
$\beta \quad 1_{\mathrm{p}} / \mathrm{D}_{\mathrm{p}}$ which equals 1 as presented by Kunii and Smith (1960 [DIRS 153166], p. 72).

$\gamma \quad 1_{s} / D_{p}$ which equals $2 / 3$ as presented by Kunii and Smith (1960 [DIRS 153166], p. 72).

$\kappa$ Ratio of the solids thermal conductivity to the thermal conductivity of air.

The function $\phi\left(\kappa=\mathrm{k}_{\mathrm{s}} / \mathrm{k}_{\mathrm{g}}\right)$ is defined in Kunni and Smith (1960 [DIRS 153166], Equation 13) as:

$$
\phi(\kappa)=\phi\left(k_{s} / k_{g}\right)=\frac{1}{2} \cdot\left[\frac{\left(\frac{\kappa-1}{\kappa}\right)^{2} \cdot \sin (\theta)^{2}}{\ln (\kappa-(\kappa-1) \cdot \cos (\theta))-\frac{\kappa-1}{\kappa} \cdot(1-\cos (\theta))}\right]-\frac{2}{3} \cdot \frac{1}{\kappa}
$$

(Eq. XI-13)

where $\sin \left(\theta^{2}\right)=1 / \mathrm{n}$, and $\mathrm{n}$ is associated with the fraction of the total heat transfer associated with one contact point (of the solids). Kunii and Smith (1960 [DIRS 153166], p. 74) define $\mathrm{n} \approx 1.5$ for loose solids.

The radiant heat transfer coefficients need to be estimated. The radiant heat-transfer coefficients $\left(\mathrm{h}_{\mathrm{rs}}\right.$ and $\mathrm{h}_{\mathrm{rv}}$ ) are given by Yagi and Kunii (1957 [DIRS 170330], Equations 7 and 8):

$$
\begin{gathered}
h_{r s}=0.1952 \cdot\{p /(2-p)\} \cdot\{(t+273) / 100\}^{3} \\
h_{r v}=\left[0.1952 /\left\{1+\frac{\varepsilon}{2 \cdot(1-\varepsilon)} \cdot \frac{1-p}{p}\right\}\right] \cdot(t+273 / 100)^{3}
\end{gathered}
$$

(Eq. XI-15)

The lead coefficient of 0.1952 is derived from four times the Stephan Boltzmann constant in units of $\mathrm{kcal} /\left(\mathrm{m}^{2} \mathrm{~h} \mathrm{~K}{ }^{4}\right)$ (Perry et al. 1984 [DIRS 125806], p. 10-53).

The calculations are presented in Table XI-2. The calculations involve inputting the thermal parameters; estimating the thermal conductivity of the air as a function of absolute temperature using the relationship from Irvine (1998 [DIRS 170361]); estimating the $\phi$ function using the equation presented above; estimating the radiant heat transfer coefficients using the relationships presented above; and then substituting these values into the effective thermal conductivity relationship presented by Kunii and Smith (1960 [DIRS 153166], Equation 8).

The effective thermal conductivity of dry drift-collapse material is calculated to be 0.82 $\mathrm{W} /(\mathrm{m} \cdot \mathrm{K}), \pm 30 \%$, or ranges from 0.57 to $1.05 \mathrm{~W} /(\mathrm{m} \cdot \mathrm{K})$. The $0.82 \mathrm{~W} /(\mathrm{m} \cdot \mathrm{K})$ value cited here is based on the following independent variables: a temperature of $75^{\circ} \mathrm{C}$ (with radiant heat transfer being temperature dependent); a lithophysal porosity of $35 \%$ and a bulking factor of 0.19 , as noted previously; a dry rock thermal conductivity of $1.3998 \mathrm{~W} /(\mathrm{m} \cdot \mathrm{K})$ for stratigraphic unit Tptpll (DTN: SN0404T0503102.011 [DIRS 169129], Table 7-11); drift-collapse material (rock size) of 
10 centimeters (BSC 2004 [DIRS 166107], Section 6.4.2.5); and a rock emissivity of 0.92, which is the midpoint of the range in Table 4.1-1.

The uncertainty of $\pm 30 \%$ is based on a review of the literature by Crane et al. (1977 [DIRS 113426]). An estimate of a wet effective thermal conductivity is not provided because there has been no analysis to show that the flux of water vapor down the thermal gradient is resupplied at the energy source by an equal or greater amount of liquid water. If there is no resupply of liquid water to the energy source, the collapse material will be dry.

The effective thermal conductivity that contains a radiation component is a function of temperature. Consider that the base case described above at $75^{\circ} \mathrm{C}$ has an effective thermal conductivity of $0.76 \mathrm{~W} /(\mathrm{m} \cdot \mathrm{K})$ at $65^{\circ} \mathrm{C}$, and at $85^{\circ} \mathrm{C}$ this becomes $0.86 \mathrm{~W} /(\mathrm{m} \cdot \mathrm{K})$. 
Table XI-1. Workbook for Determining the Void Fraction in the Collapsed Drift

file: voidbulk.xls; 7/8/2004b

Purpose: Calculate the void fraction after drift collapse as a function of the bulking factor and lithophysal porosity. The lithophysal porosity is added to the void volume. Therefore the void volume in 1 cubic meter of rock becomes the bulking factor + the lithophysal porosity \%/100.

\begin{tabular}{|c|c|c|c|c|}
\hline Lithophysal & Bulking & \\
\hline Porosity & Factor & $\mathbf{0 . 1 9}$ & $\mathbf{0 . 4}$ & $\mathbf{0 . 2}$ \\
\hline \hline$\%$ & $\mathbf{0 . 1}$ & $\mathbf{0 . 1 9}$ & 0.36 & 0.25 \\
\hline $\mathbf{1 0}$ & 0.18 & 0.24 & 0.39 & 0.29 \\
\hline $\mathbf{1 5}$ & 0.23 & 0.29 & 0.43 & 0.33 \\
\hline $\mathbf{2 0}$ & 0.27 & 0.33 & 0.43 & 0.38 \\
\hline $\mathbf{2 5}$ & 0.32 & 0.37 & 0.46 & 0.40 \\
\hline $\mathbf{2 7 . 5}$ & 0.34 & 0.39 & 0.48 & 0.42 \\
\hline $\mathbf{3 0}$ & 0.36 & 0.41 & 0.50 & 0.46 \\
\hline $\mathbf{3 5}$ & 0.41 & 0.45 & 0.54 & \\
\hline \multicolumn{5}{|c|}{ Intergranular Void } \\
\hline
\end{tabular}

Obtain the lithophysal porosity from the drift degradation analysis, use 35\% (BSC 2004 [DIRS 166107], Table 6-33) for Category 1, (BSC 2004 [DIRS 166107], Sect. 6.4.2.5), and a bulking factor of of 19\% (BSC 2004 [DIRS 166107], Sec. 6.4.2.5). 
Table XI-2. Workbook for Calculation of the Collapsed Drift Thermal Conductivity

file: thermalk.xls; $7 / 8 / 2004 \mathrm{~b}$

Purpose: Calculate the effective thermal conductivity for loose solids, includes a contribution from radiant heat transfer. Refer to line 96 in this xls file for keff.

Reference: S. Yagi \& D. Kunii, AIChE J., 3(3), 373-381, 1957; refer to as Y\&K [DIRS 170330].

Reference: D. Kunii \& J.M. Smith, AIChE J., 6(1), 71-77, 1960; refer to as K\&S [DIRS 153166].

ENTER THE FOLLOWING:

Air thermal $\mathrm{k}=$

$0.030 \mathrm{~W}\left(\mathrm{~m}^{*} \mathrm{~K}\right)$, calculated from temperature entered below.

Rock thermal $\mathrm{k}=$

$1.3998 \mathrm{~W} /\left(\mathrm{m}^{*} \mathrm{~K}\right)$, wet $=2.0707$, or dry $=1.3998$.

Void fraction $=$

0.45

Rock size =

$10 \mathrm{~cm}$

Rock emissivity $=$

Temperature $=$

0.92 Ranges from 0.88 to 0.95 .

Temperature $=$

$75 \operatorname{deg} \mathrm{C}$, see note at end of this file.

Stephan-Boltzmann=

348 deg K

Beta $=$

$5.67 \mathrm{E}-08 \mathrm{~W} /\left(\mathrm{m}^{\wedge} 2 \mathrm{~K}^{\wedge} 4\right)$

Gamma $=$

1.00

see page 72 , right column K\&S

Uncertainty, \% =

0.67

see page 72 , right column K\&S

30 see notes

Air thermal k from Irvine (1998 [DIRS 170361], p. 2.4).

Void fraction from bulking factor \& lithophysal porosity, see spreadsheet voidbulk.xls in Table XI-1.

Rock thermal k from SN0404T0503102.011 ([DIRS 169129], file: Readme.doc).

Rock size from Drift Degradation Analysis (BSC 2004 [DIRS 166107], Sec. 6.1.4.1).

Rock emissivity is from Incropera \& DeWitt (2002 [DIRS 163337], Table A.11).

Stephan-Boltzmann constant from Cho, et al. (1998 [DIRS 160802], p.1.3).

Calculate phi1 and phi2 in K\&S, verify Figure 5, see plot on sheet2.

phi1 is for loose packing, phi2 is for close packing.

See K\&S, page 74, left column for $\mathrm{n} 1$ and $\mathrm{n} 2$.

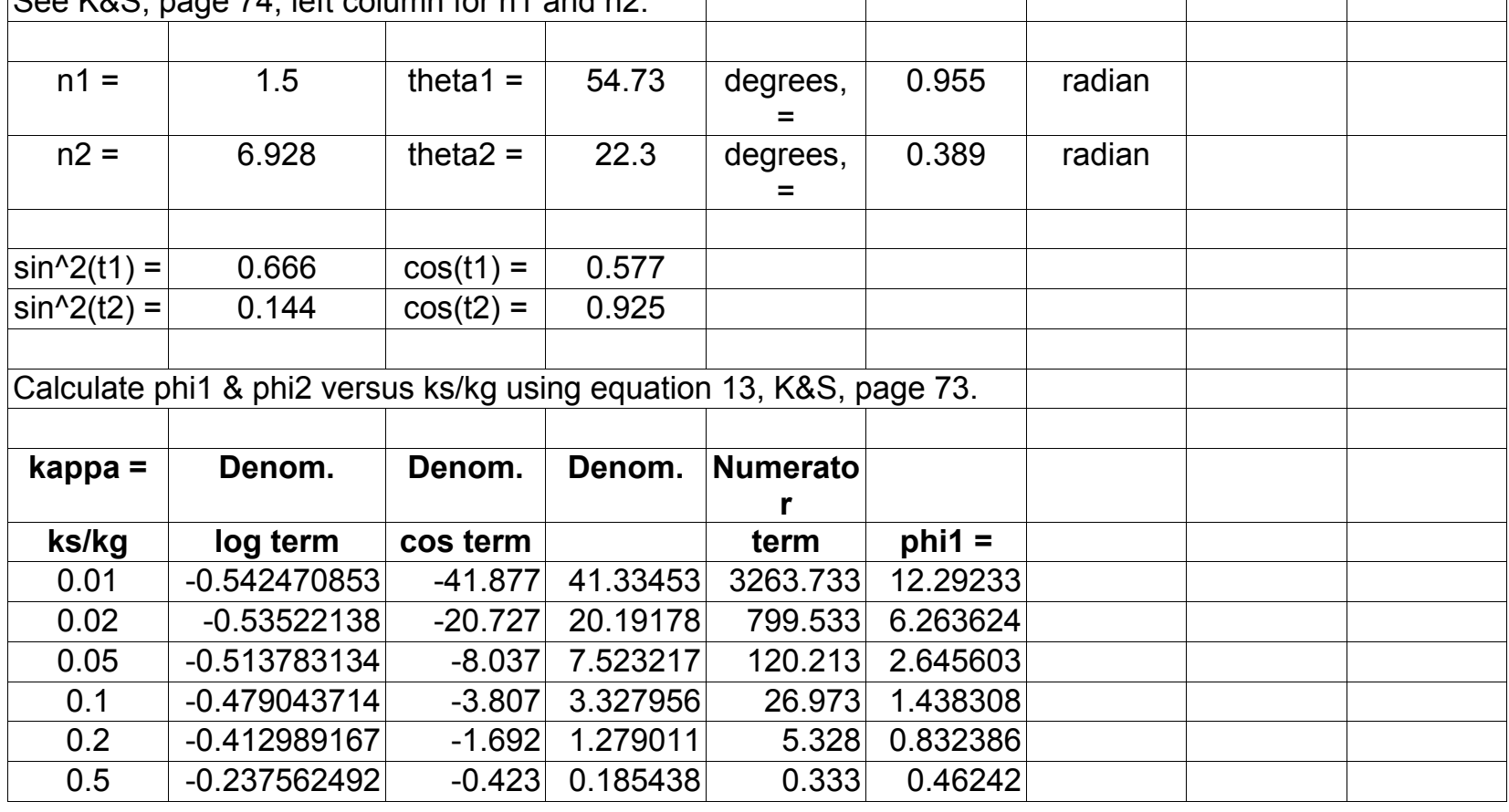


Table XI-2. Workbook for Calculation of the Collapsed Drift Thermal Conductivity (Continued)

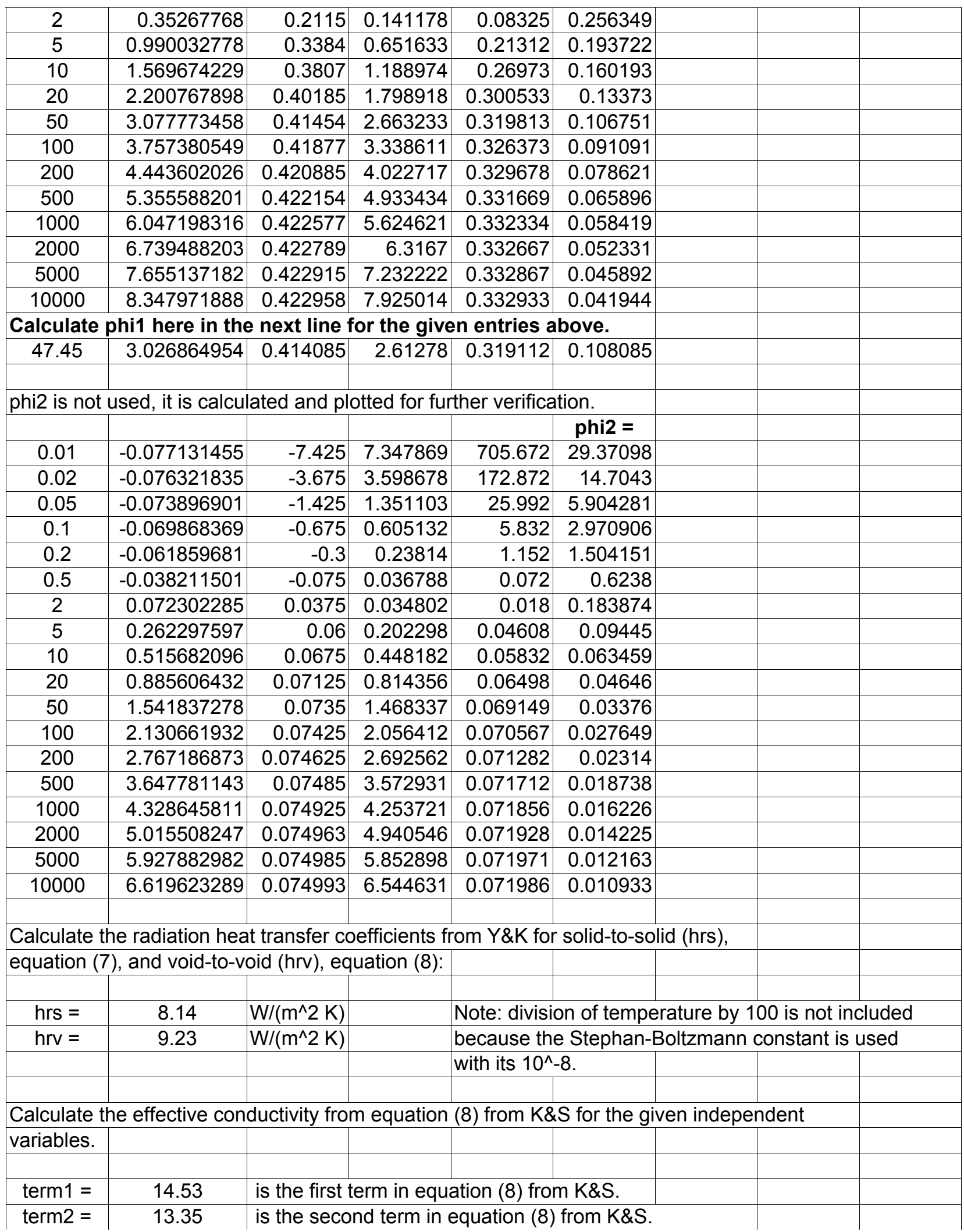


Table XI-2. Workbook for Calculation of the Collapsed Drift Thermal Conductivity (Continued)

\begin{tabular}{|c|c|c|c|c|c|c|c|}
\hline keff $=$ & 0.82 & \multicolumn{5}{|c|}{$\begin{array}{l}W /\left(m^{*} K\right) \text {, is the effective thermal conductivity, equation (8), } \\
K \& S \text {. }\end{array}$} & \\
\hline \multicolumn{3}{|c|}{ keff range based on input uncertainty $=$} & 0.58 & to & 1.07 & $W /\left(m^{*} K\right)$ & \\
\hline & & & & & & & \\
\hline \multirow{2}{*}{\multicolumn{8}{|c|}{$\begin{array}{l}\text { End of file note: The radiant heat transfer coefficients are temperature dependent. Therefore, the } \\
\text { use of any heat transfer coefficient with a radiant contribution becomes a trial-and-error heat transfer }\end{array}$}} \\
\hline & & & & & & & \\
\hline \multicolumn{7}{|c|}{ calculation. It is necessary to choose a temperature at which to perform the heat transfer } & \\
\hline
\end{tabular}




\section{INTENTIONALLY LEFT BLANK}


APPENDIX XII

COMPARISON OF PERCOLATION FLUXES 
This appendix compares percolation fluxes from UZ Flow Models and Submodels (BSC 2004 [DIRS 169861]) models with the corresponding fluxes implemented in the discretization used for calculations with the multiscale thermohydrologic model (MSTHM). The detailed comparisons are for the three climates (present-day, monsoonal and glacial) and for the lower, mean and upper-bound infiltration flux cases. The input DTNs are discussed and input to the analysis in Section XII.1 through XII.2. The sampling points are presented. Sections XII.3 through XII.7 develop the cumulative distribution functions. The cumulative distribution functions are developed for the respective cases and compared between the input DTN and its implementation in the MSTHM grid.

Figure XII-1 presents a flowchart showing how information for making the comparison is obtained from the Technical Data Management System (TDMS). The upper portion of the flowchart shows DTN: MO0406CDFINSMT.000 for the UZ flow model. This DTN contains a summary EXCEL workbook file T2_perc_data_and CDF.xls. The workbook contains nine worksheets that correspond to three climates and three cases. These represent cumulative distribution functions that are weighted according to grid areas. Each of these worksheets are used to define MathCad Column vectors that represent nine individual cumulative distribution functions (CDFs).

The lower portion of the flow chart shows the three output DTNs for the MSTHM model. These are DTNs: LL030608723122.028, LL030610323122.029, LL030602723122.027 for the lower, mean, and upper bounds respectively. These DTNs contain the following text files, all of which are used to define EXCEL components that are read into MathCad column vectors for purposes of plotting the distribution functions:

- Nevada_SMT_percolation_BIN_la.txt

- Nevada_SMT_percolation_BIN_ma.txt

- Nevada_SMT_percolation_BIN_ua.txt

The calculations presented in this appendix are performed in the MathCad File Cumulative Distribution Plots of Percolation.med. The data from the DTNs are input as EXCEL components in MathCad Professional 11. These DTNs are output from the multiscale thermohydrologic model.

EXCEL components in MathCad represent an efficient method for inputting the data from the input DTNs into MathCad. The EXCEL components presented below are input from EXCEL files that in turn are compiled from text files as discussed below. The inputs are generally column vectors from the EXCEL spreadsheet component as defined by the output property for each EXCEL component in MathCad. 


\section{Cumulative Distribution Functions for the UZ Flow Model}

TDMS
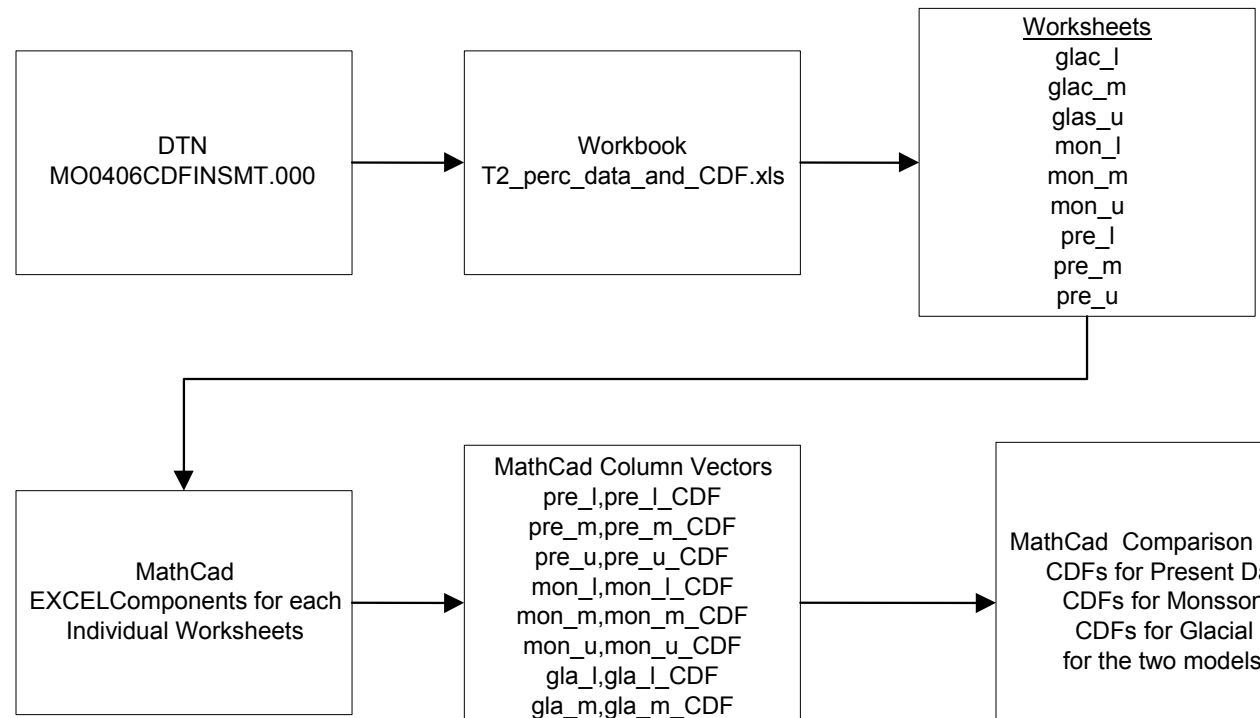

MathCad Column Vectors pre_I,pre_I_CDF pre_m,pre_m_CDF pre_u,pre_u_CDF mon I,mon I CDF mon_m,mon_m_CDF mon u,mon u CDF gla_I,gla_I_CDF gla_m,gla_m_CDF gla_u,gla_u_CDF

\section{Cumulative Distribution Functions for the MSTHM Model}

TDMS

Textfile

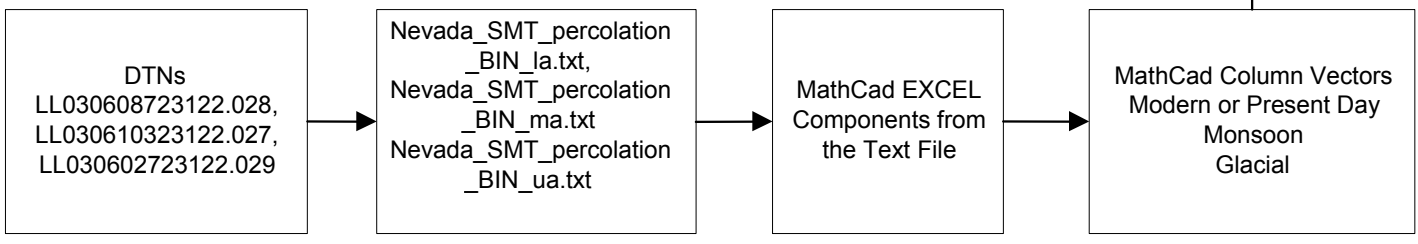

Figure XII-1. Flow Chart for Comparing Cumulative Distribution Functions 


\section{XII.1 INPUT DATA FROM THE 3-D SITE-SCALE UZ FLOW MODEL}

The DTN LB0302PTNTSW9I.001 [DIRS 162277] entitled "PTN/TSW Interface Percolation Flux Maps for 9 Infiltration Scenarios" and DTN LB03023DSSCP9I.001[DIRS 163044] entitled "3-D Site Scale UZ Flow Field Simulations for 9 Infiltration Scenarios" were used to develop the cumulative distribution function for the nine cases in DTN MO0406CDFINSMT.000. Input the coordinate data from DTN LB03023DSSCP9I.001[DIRS 163044] for purposes of developing a plot of sampling points of percolation for the UZ flow model. Note that any of the text files can be used since the coordinates are included in each file. Use the file monq_ma_ptn.q.

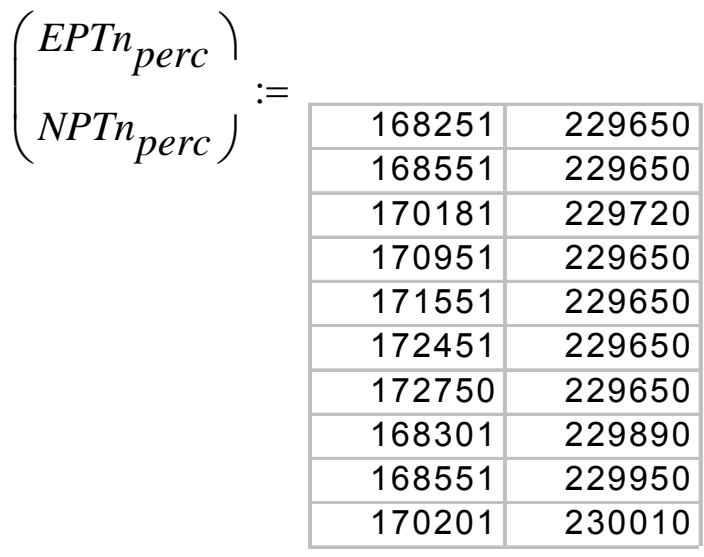

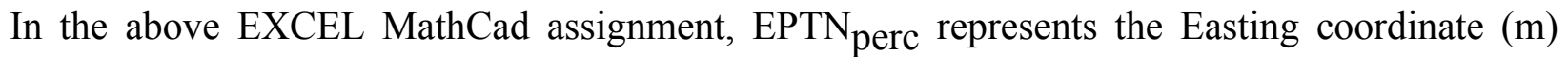
vector, and $\mathrm{NPTN}_{\text {perc }}$ represents the Northing coordinate (m) vector.

Determine the number of points using the row function:

$$
\operatorname{rows}\left(\operatorname{EPTn}_{\text {perc }}\right)=2.042 \times 10^{3}
$$

Rescale the data:

$$
\begin{aligned}
& j:=1 . .2042 \\
& \text { EPTn' }_{\text {perc }_{j}}:=\frac{\text { EPTn }_{\text {perc }}}{1000}-\frac{1.701 \times 10^{5}}{1000} \\
& \operatorname{NPTn}_{\text {perc }_{j}}:=\frac{\operatorname{NPTn}_{\text {perc }}}{1000}-\frac{2.319 \times 10^{5}}{1000}
\end{aligned}
$$


Figure XII-2 shows the sampling points for the 3-D Site-Scale UZ Flow Model.

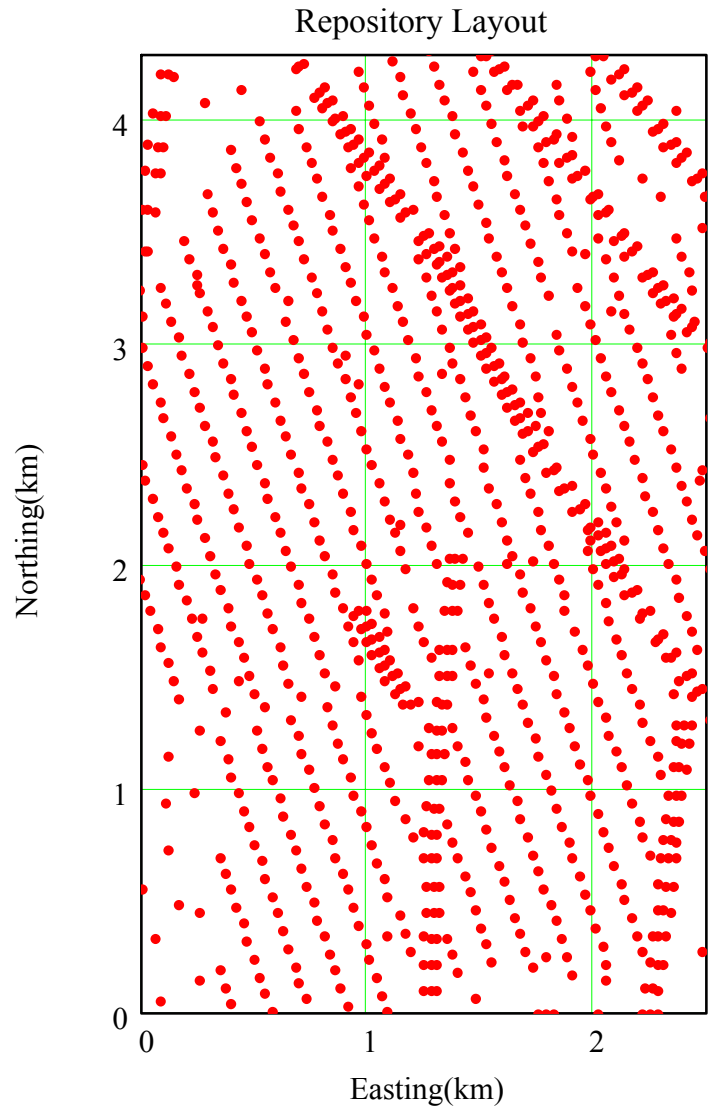

Figure XII-2. Sampling Points for the Tough2 PTn/TSw Model

Input the cumulative distribution functions from the EXCEL spreadsheet summarizing the results from DTN MO0406CDFINSMT.000. In this DTN, there is an EXCEL workbook entitled T2_perc_data_and_CDF.xls. This EXCEL workbook has 10 worksheets. The first worksheet is the combined data, and is not used in the analysis presented below. The next nine worksheets present cumulative distribution functions for the three climates and the three bounds as listed in Table XII-2. These are input to the MathCad program through the use of vectors using the properties tab for the EXCEL component. 
Table XII-1. Summary of EXCEL Worksheets in T2_perc_data_and_CDF.xls for DTN MO0406CDFINSMT.000

\begin{tabular}{|l|l|l|}
\hline Climate & Bound & Worksheet Name \\
\hline \hline Glacial & Lower & glac_I \\
\hline Glacial & Mean & glac_m \\
\hline Glacial & Upper & glac_u \\
\hline Monsoon & Lower & mon_I \\
\hline Monsoon & Mean & mon_m \\
\hline Monsoon & Upper & mon_u \\
\hline Present-Day & Lower & pre_l \\
\hline Present-Day & Mean & pre_m \\
\hline Present-Day & Upper & pre_u \\
\hline
\end{tabular}

Input the values for the present day climate for the lower case. These values are obtained from the worksheet pre_1 of T2_perc_data_and_CDF.xls. Note that only the first few rows are shown.

\begin{tabular}{|c|c|c|}
\hline \multirow[t]{8}{*}{ (pre_l_CDF) } & pre_l & pre_I_CDF \\
\hline & $0 . \overline{00}$ & $2.358330 \mathrm{E}-03$ \\
\hline & 0.00 & $4.716688 \mathrm{E}-03$ \\
\hline & 0.00 & 7.139175E-03 \\
\hline & 0.00 & $9.718286 \mathrm{E}-03$ \\
\hline & 0.00 & 1.208377E-02 \\
\hline & 0.00 & 1.416974E-02 \\
\hline & 0.00 & 1.644986E-02 \\
\hline
\end{tabular}

pre_1 represents the percolation flux in mm per year. pre_1_CDF represents the cumulative distribution pertaining to the percolation flux (dimensionless).

Input the values for the present day climate for the mean case. These values are obtained from the worksheet pre_m of T2_perc_data_and_CDF.xls

$$
\begin{aligned}
& \left(\begin{array}{c}
\text { pre_m } \\
\text { pre_m_CDF })
\end{array}\right)=\begin{array}{|r|r|}
\multicolumn{1}{l|}{\text { pre_m }} & \text { pre_m_CDF } \\
0.203114 & 0.00257911 \\
\hline 0.20648 & 0.00523494 \\
\hline 0.298709 & 0.0075933 \\
\hline 0.337577 & 0.00987342 \\
\hline 0.363078 & 0.01223175 \\
\hline 0.440667 & 0.01445095 \\
\hline 0.445001 & 0.01691418 \\
\hline 0.466575 & 0.01900016 \\
\hline 0.561075 & 0.02154509 \\
\hline
\end{array}
\end{aligned}
$$


pre_m represents the percolation flux in mm per year. pre_m_CDF represents the cumulative distribution pertaining to the percolation flux (dimensionless).

Input the values for the present day climate for the upper case. These values are obtained from the worksheet pre_u of T2_perc_data_and_CDF.xls.

$$
\begin{gathered}
\left(\begin{array}{c}
\text { pre_u } \\
\text { pre_u_CDF }
\end{array}\right):=\begin{array}{r|r|}
\multicolumn{1}{l|}{\text { pre_u }} & \text { pre_u_CDF } \\
\hline 0.872483 & 0.0022801 \\
1.014349 & 0.0049359 \\
\hline 1.275882 & 0.0063444 \\
\hline 1.460394 & 0.0084303 \\
\hline 1.486113 & 0.0110095 \\
\hline 1.573294 & 0.0114768 \\
\hline 1.634857 & 0.0126458 \\
\hline 1.69199 & 0.0138239 \\
\hline 1.827775 & 0.0144066 \\
\hline 1.9445 & 0.0153848 \\
\hline
\end{array}
\end{gathered}
$$

pre_u represents the percolation flux in mm per year. pre_u_CDF represents the cumulative distribution pertaining to the percolation flux (dimensionless).

Input the values for the monsoon climate for the lower case. These values are obtained from the worksheet mon_1 of T2_perc_data_and_CDF.xls.

$$
\begin{aligned}
& \left(\begin{array}{c}
\text { mon_l } \\
\text { mon_l_CDF }
\end{array}\right):=\begin{array}{|r|l|}
\multicolumn{1}{l|}{\text { mon_I }} & \text { mon_I_CDF } \\
\hline 0.1104 & 0.00265583 \\
\hline 0.113641 & 0.00304332 \\
\hline 0.149631 & 0.00562243 \\
\hline 0.201519 & 0.00790255 \\
\hline 0.315411 & 0.01026091 \\
\hline 0.339742 & 0.01234688 \\
\hline 0.460166 & 0.01269943 \\
\hline 0.49525 & 0.01387761 \\
\hline 0.496857 & 0.01504657 \\
\end{array}
\end{aligned}
$$

mon_1 represents the percolation flux in mm per year. mon_1_CDF represents the cumulative distribution pertaining to the percolation flux (dimensionless). 
Input the values for the monsoon climate for the mean case. These values are obtained from the worksheet mon_m of T2_perc_data_and_CDF.xls.

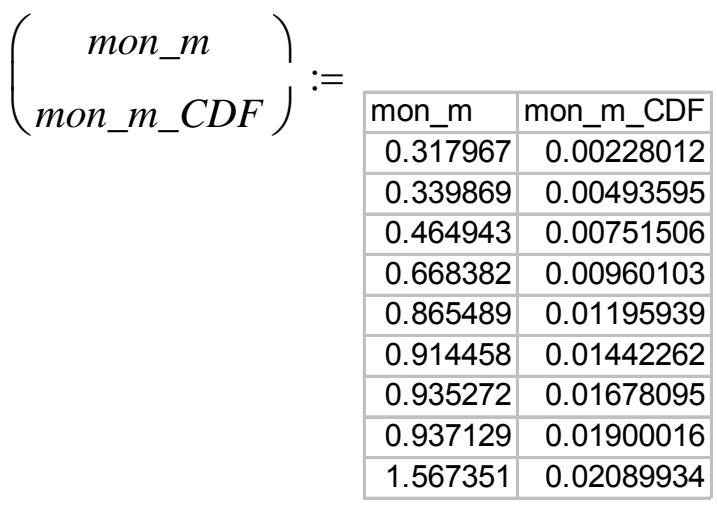

mon_m represents the percolation flux in mm per year. mon_m_CDF represents the cumulative distribution pertaining to the percolation flux (dimensionless).

Input the values for the monsoon climate for the upper case. These values are obtained from the worksheet mon_u of T2_perc_data_and_CDF.xls.

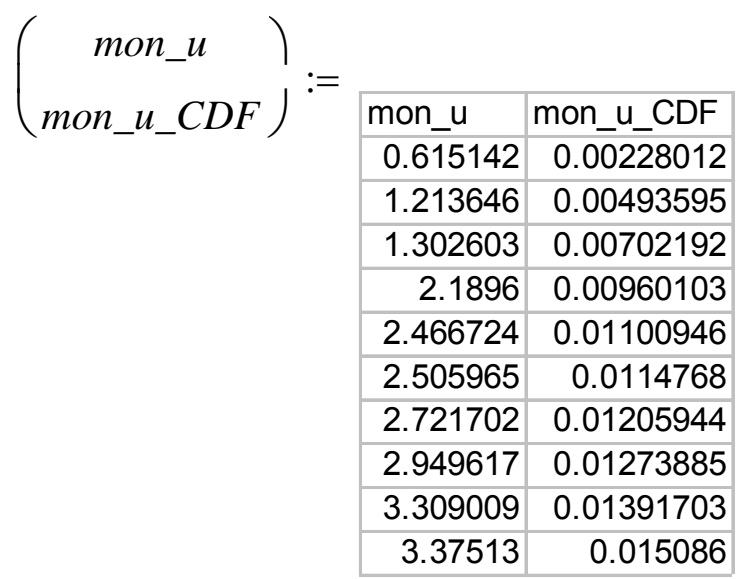

mon_u represents the percolation flux in mm per year. mon_u_CDF represents the cumulative distribution pertaining to the percolation flux (dimensionless). 
Input the values for the glacial climate for the lower case. These values are obtained from the worksheet glac_1 of T2_perc_data_and_CDF.xls.

$$
\begin{aligned}
& \left(\begin{array}{c}
\text { glac_l } \\
\text { glac_l_CDF }
\end{array}\right):=\frac{}{\text { glac_I }} \text { glac_I_CDF } \\
& 0.0021010 .00236548 \\
& \begin{array}{|l|l|}
0.007418 & 0.00502132 \\
\hline
\end{array} \\
& \begin{array}{|l|l|}
\hline 0.007655 & 0.00710729 \\
\hline
\end{array} \\
& \begin{array}{|l|l|}
\hline 0.010456 & 0.00938741
\end{array} \\
& \begin{array}{|l|l|}
0.017005 & 0.0097749 \\
\hline
\end{array} \\
& \begin{array}{|l|l|}
0.017178 & 0.01235401
\end{array} \\
& \begin{array}{r|r|}
0.021309 & 0.01270911
\end{array} \\
& \begin{array}{|l|l|}
0.0608 & 0.01306165 \\
\hline
\end{array} \\
& \begin{array}{lll}
0.067621 & 0.01552488
\end{array}
\end{aligned}
$$

glac_1 represents the percolation flux in mm per year. glac_1_CDF represents the cumulative distribution pertaining to the percolation flux (dimensionless).

Input the values for the glacial climate for the mean case. These values are obtained from the worksheet glac_m of T2_perc_data_and_CDF.xls.

$$
\begin{gathered}
\left(\begin{array}{c}
\text { glac_m } \\
\text { glac_m_CDF }
\end{array}\right):=\begin{array}{|r|r|}
\multicolumn{1}{|l}{\text { glac_m }} & \text { glac_m_CDF } \\
\hline 0.604386 & 0.00265583 \\
\hline 0.772607 & 0.00493595 \\
\hline 0.827256 & 0.00751506 \\
\hline 1.086087 & 0.00997829 \\
\hline 1.222658 & 0.01219749 \\
\hline 1.312919 & 0.01428347 \\
\hline 1.757234 & 0.0166418 \\
\hline 1.942364 & 0.01900016 \\
\hline 2.488503 & 0.02136434 \\
\hline
\end{array}
\end{gathered}
$$

glac_m represents the percolation flux in mm per year. glac_m_CDF represents the cumulative distribution pertaining to the percolation flux (dimensionless). 
Input the values for the glacial climate for the upper case. These values are obtained from the worksheet glac_u of T2_perc_data_and_CDF.xls.

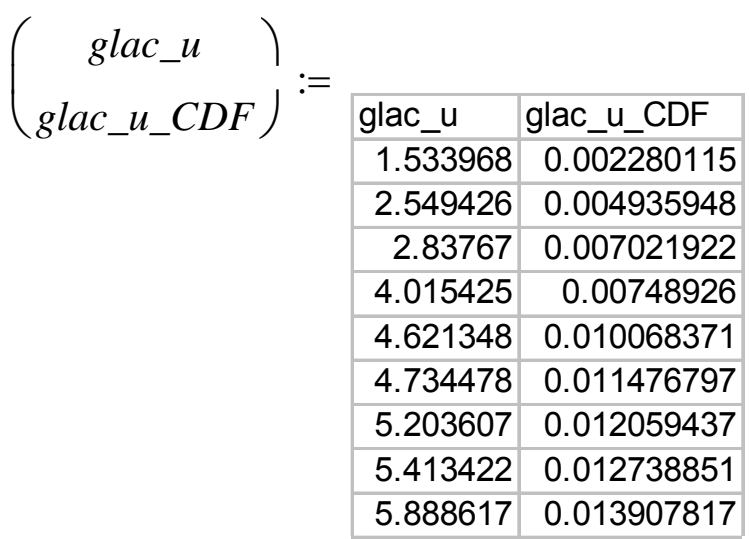

glac_u represents the percolation flux in mm per year. glac_u_CDF represents the cumulative distribution pertaining to the percolation flux (dimensionless).

\section{XII.2 INPUT DATA FROM THE MSTHM}

Consider the output DTNs containing the percolation flux boundary conditions for the MSTHM.

These DTNs are summarized below:

Table XII-1 Output DTNs for MSTHM model

\begin{tabular}{|l|l|}
\hline Lower Percolation Rate & DTN: LL030608723122.028 \\
\hline Mean Percolation Rate & DTN: LL030610323122.029 \\
\hline Upper Percolation Rate & DTN: LL030602723122.027 \\
\hline
\end{tabular}

Input the properties for the mean case. Note that the data are organized for the three climates for the lower, mean, and upper percolation rates presented above. The data are obtained from the text file Nevada_SMT_percolation_BIN_ma.txt of DTN: LL030610323122.029. Note that only the first few rows of the EXCEL component derived from the textfile are shown below. 


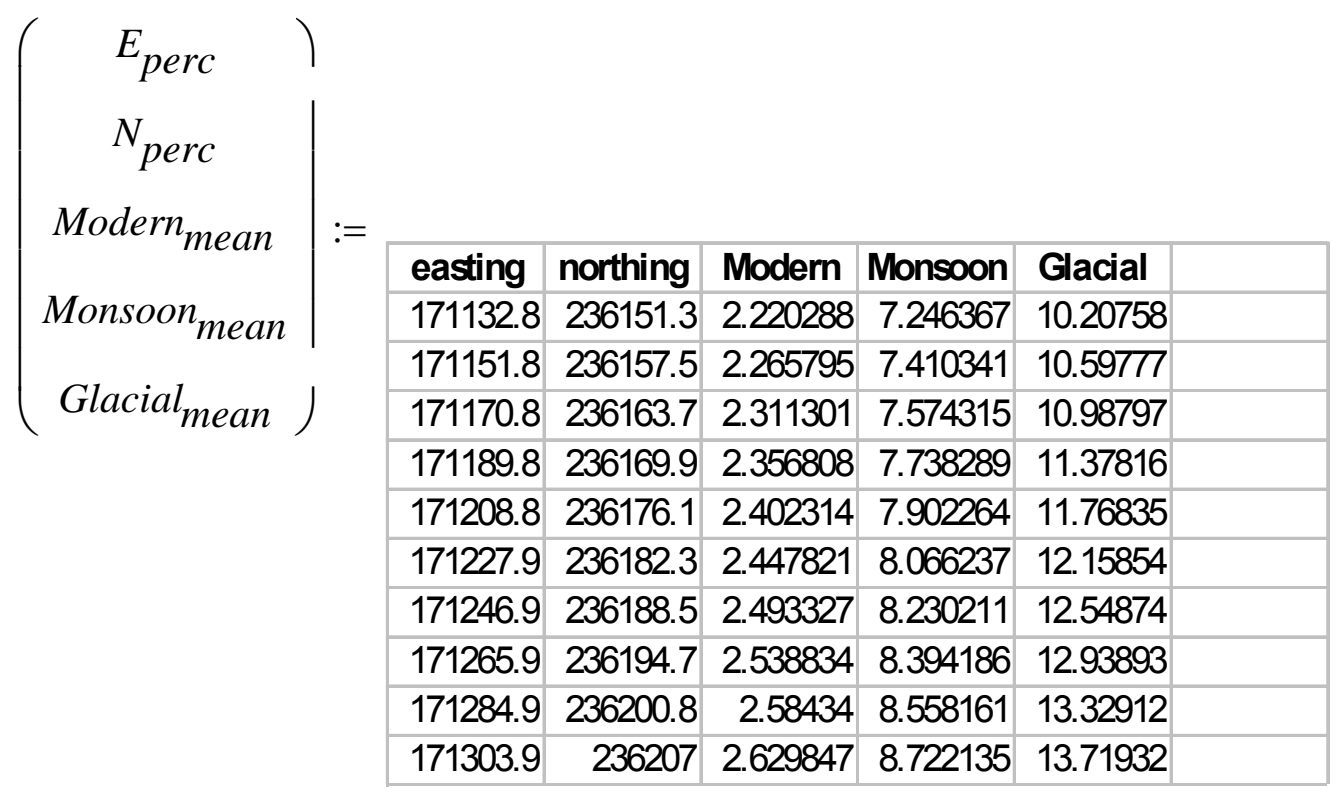

Modern $_{\text {mean }}$ represents the percolation flux vector $(\mathrm{mm} / \mathrm{yr})$ for the mean bound for the present

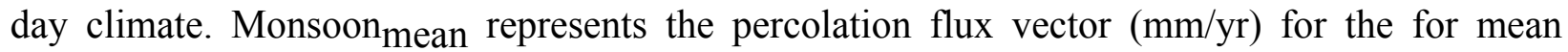
bound for the monsoon climate. Glacialmean represents the percolation flux vector ( $\mathrm{mm} / \mathrm{yr}$ ) for the for mean bound for the glacial climate. $E_{\text {perc }}$ represents the easting coordinate vector $(\mathrm{m})$. $\mathrm{N}_{\text {perc }}$ represents the northing coordinate vector.

Input the percolation fluxes for the lower bound case. The data that are read into the EXCEL component presented below are obtained from the text file Nevada_SMT_percolation_BIN_la.txt of from DTN: LL030608723122.028.

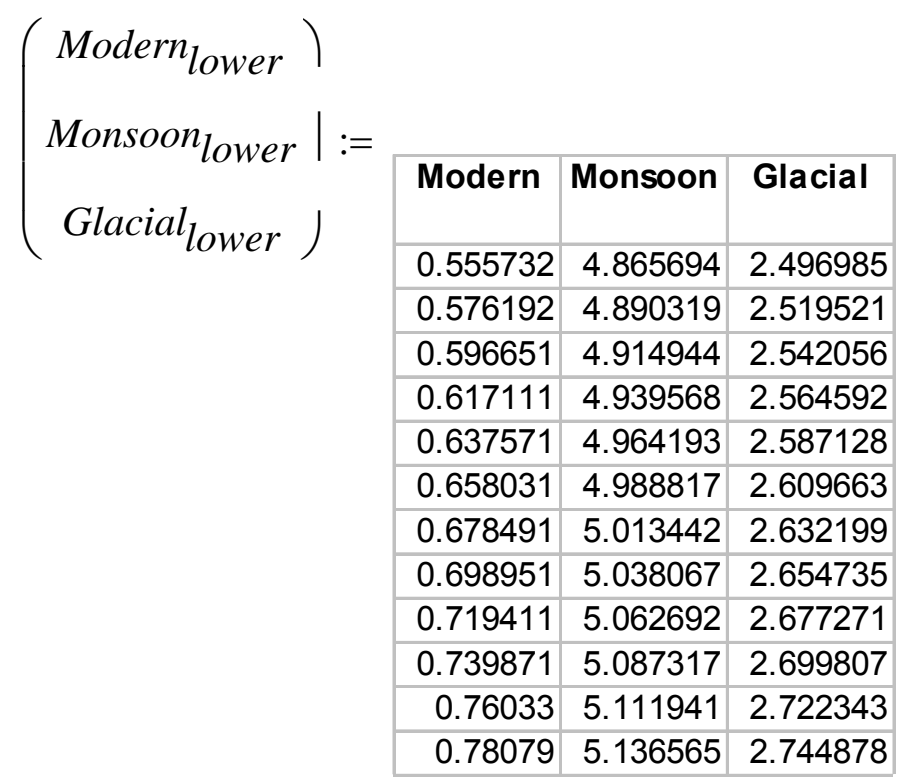


Modern lower represents the percolation flux vector $(\mathrm{mm} / \mathrm{yr})$ for the lower bound for the present

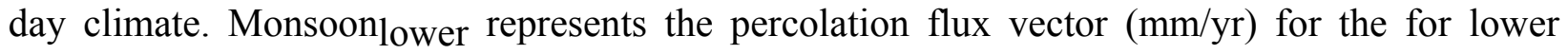
bound for the monsoon climate. Glacial lower represents the percolation flux vector $(\mathrm{mm} / \mathrm{yr})$ for the for lower bound for the glacial climate.

Input the percolation fluxes for the upper bound case. The data that are read into the EXCEL component presented below are obtained from the text file Nevada_SMT_percolation_BIN_ua.txt of from DTN: LL030602723122.027.

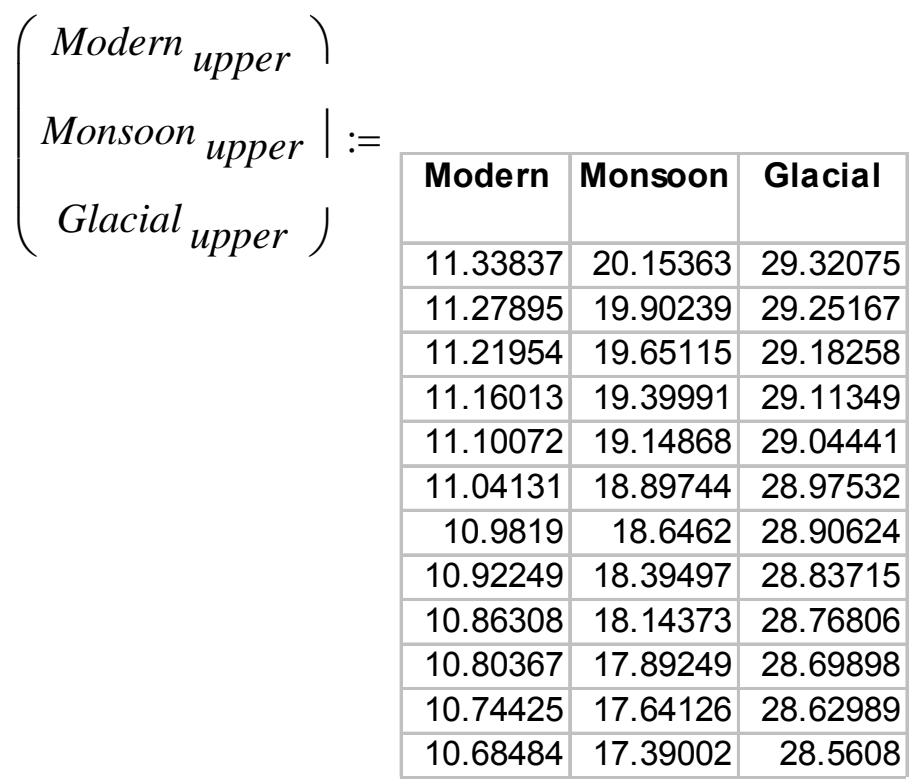

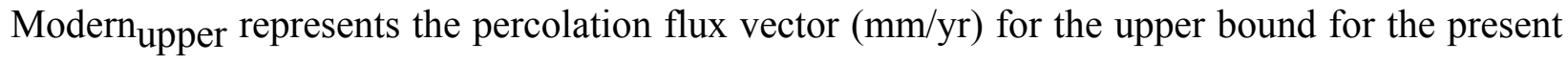
day climate. Monsoon ${ }_{\text {upper }}$ represents the percolation flux vector $(\mathrm{mm} / \mathrm{yr})$ for the for upper

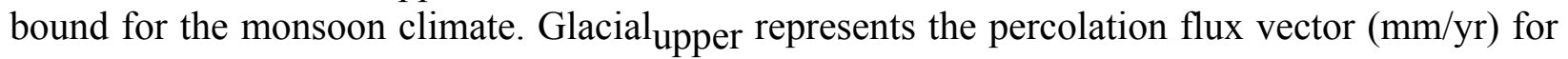
the for upper bound for the glacial climate.

Rescale the plots to $\mathrm{km}$.

$$
\begin{array}{ll}
\dot{d}_{\text {in }}:=1 . . \text { rows }\left(E_{\text {perc }}\right) & \min \left(E_{\text {perc }}\right)=1.701 \times 10^{5} \\
E_{\text {perc }_{j}}^{\prime}:=\frac{E_{\text {perc }}}{1000}-\frac{\min \left(E_{\text {perc }}\right)}{1000} & \min \left(N_{\text {perc }}\right)=2.319 \times 10^{5} \\
N_{\text {perc }_{j}}^{\prime}:=\frac{N_{\text {perc }}}{1000}-\frac{\min \left(N_{\text {perc }}\right)}{1000} &
\end{array}
$$


Figure XII-2 shows the SMT sampling locations.

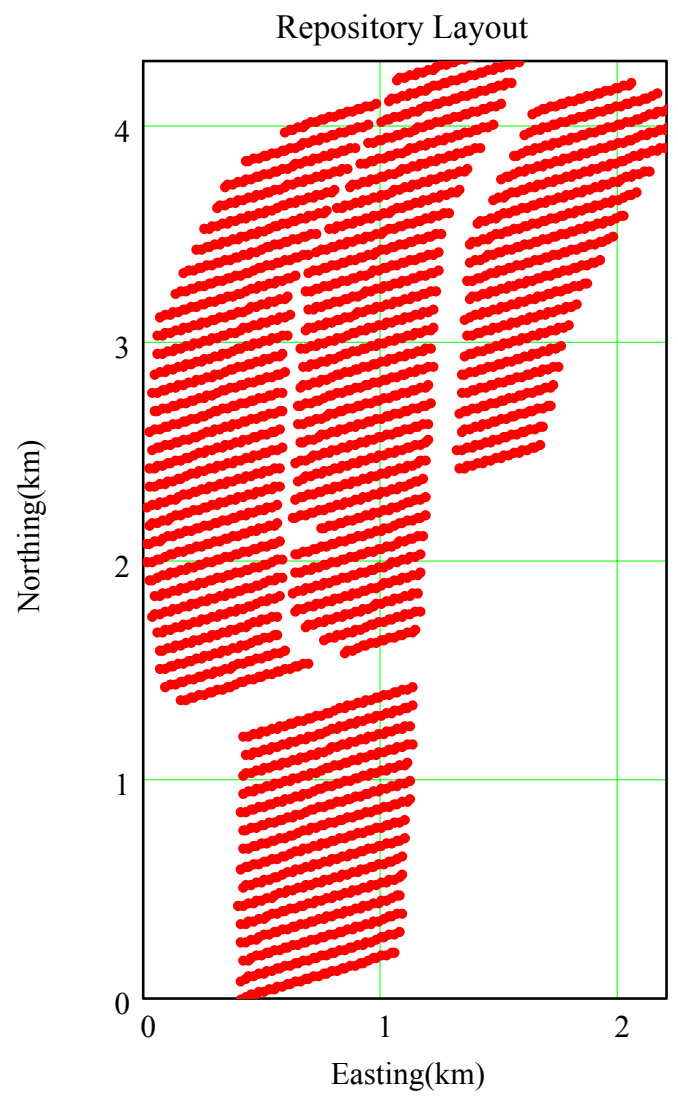

Figure XII-3. Sampling Points for the MSTHM Model

\section{XII.3 COMPARISONS FOR THE PRESENT-DAY CLIMATE}

The data for the present-day climate from the MSTHM calculations have equal weightings. In order to develop the CDF for the MSTHM model, sort the data in ascending order. Note that since the percolation values are for areas that are equal weighting, the CDF is determined directly by sorting the data in MathCad, and plotting the sorted data against the rank order expressed as a percentile. Output the first 16 values in $\mathrm{mm} / \mathrm{yr}$ Modern lower for purposes of illustration: 


\begin{tabular}{|c|r|}
\hline & 1 \\
\cline { 2 - 3 } Modern $_{\text {lower }}=$ & 0.556 \\
\hline 2 & 0.576 \\
\hline 2 & 0.597 \\
\hline 3 & 0.617 \\
\hline 4 & 0.638 \\
\hline 5 & 0.658 \\
\hline 6 & 0.678 \\
\hline 7 & 0.699 \\
\hline 8 & 0.719 \\
\hline 9 & 0.74 \\
\hline 10 & 0.76 \\
\hline 11 & 0.781 \\
\hline 12 & 0.801 \\
\hline 13 & 0.822 \\
\hline 14 & 0.892 \\
\hline 15 & 0.961 \\
\hline
\end{tabular}

Determine the number of rows in the column vector:

$$
\operatorname{rows}\left(\text { Modern }_{\text {lower }}\right)=2.874 \times 10^{3}
$$

Now use the sort function in MathCad to sort the values in ascending order:

$$
\text { Modern }_{\text {lower }}:=\operatorname{sort}\left(\text { Modern }_{\text {lower }}\right)
$$

Output the first values to show that MathCad sorted the values in ascending order:

\begin{tabular}{|c|r|}
\hline & \multicolumn{1}{|c|}{1} \\
\hline Modern $_{\text {lower }}=$ & $2.8 \cdot 10^{-5}$ \\
\hline 1 & $3.8 \cdot 10^{-5}$ \\
\hline 2 & $4.4 \cdot 10^{-5}$ \\
\hline 3 & $4.7 \cdot 10^{-5}$ \\
\hline 4 & $4.9 \cdot 10^{-5}$ \\
\hline 5 & $5 \cdot 10^{-5}$ \\
\hline 6 & $5.6 \cdot 10^{-5}$ \\
\hline 7 & $5.9 \cdot 10^{-5}$ \\
\hline 8 & $6 \cdot 10^{-5}$ \\
\hline 9 & $6.1 \cdot 10^{-5}$ \\
\hline 10 & $6.2 \cdot 10^{-5}$ \\
\hline 11 & $6.3 \cdot 10^{-5}$ \\
\hline 12 & $6.4 \cdot 10^{-5}$ \\
\hline 13 & $6.6 \cdot 10^{-5}$ \\
\hline 14 & $6.7 \cdot 10^{-5}$ \\
\hline 14 & $7 \cdot 10^{-5}$ \\
\hline
\end{tabular}

Now sort the other cases having demonstrating the results for the lower case: 


$$
\begin{aligned}
& \text { Modern }_{\text {mean }}:=\operatorname{sort}\left(\text { Modern }_{\text {mean }}\right) \\
& \text { Modern }_{\text {upper }}:=\operatorname{sort}\left(\text { Modern }_{\text {upper }}\right)
\end{aligned}
$$

Develop the CDF by plotting the rank order against the sorted values for mean, lower and upper percolation cases. The results are shown in Figure XII-3 for the modern or present case. The figure shows the $.05,0.30,0.70$, and 0.95 percentiles for the CDF.

Perform the analysis for the other cases. These are presented in Figures XII-4 through XII-6.

$$
j j:=1 . . \operatorname{rows}\left(\text { Modern }_{\text {lower }}\right)
$$

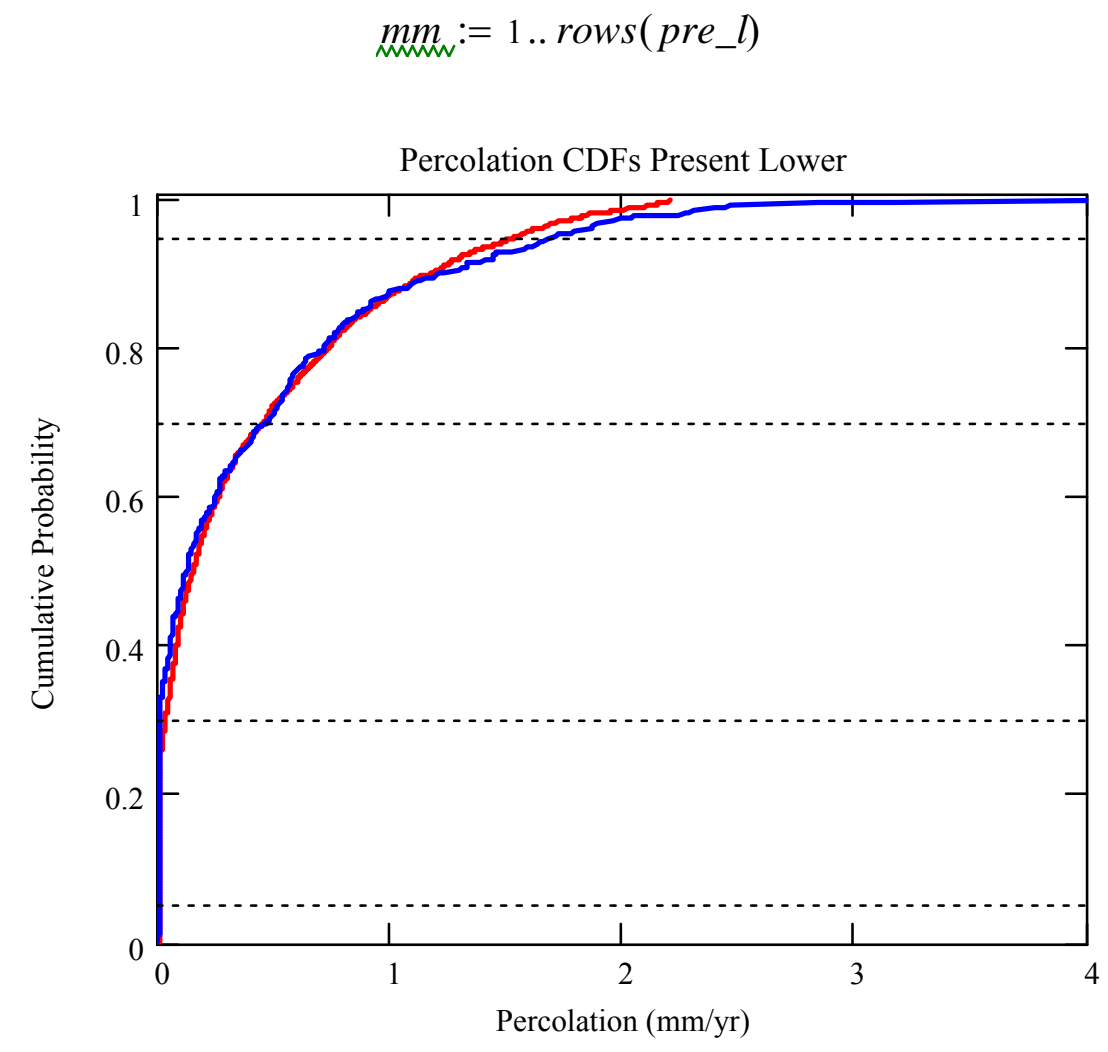

NOTE: $\quad$ Red line = MSTHM model; blue line = UZ flow model.

Figure XII-4. Cumulative Distribution Function Comparison for the Present Day Lower Case 


$$
j j:=1 . . \operatorname{rows}\left(\text { Modern }_{\text {mean }}\right)
$$
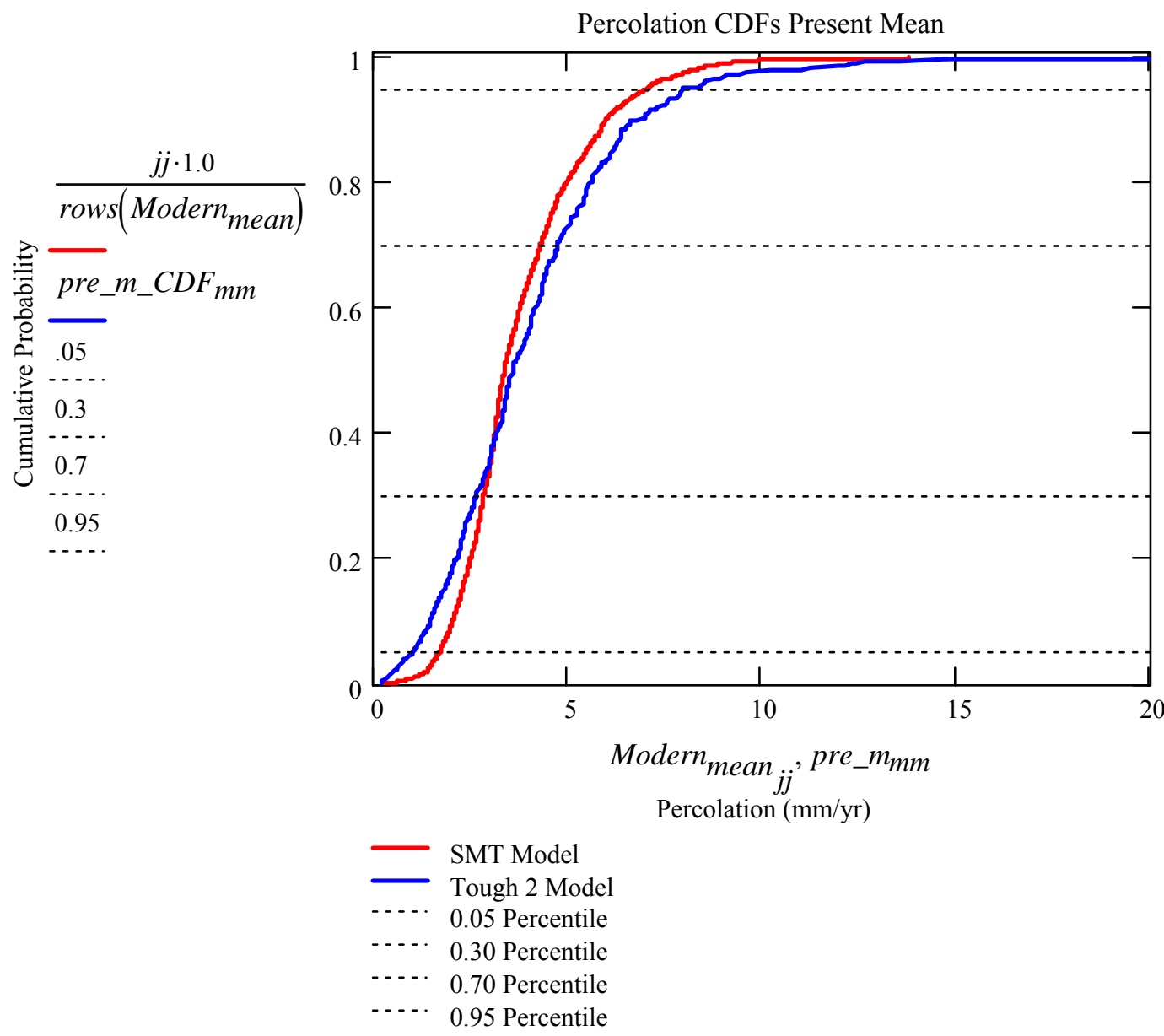

NOTE: $\quad$ Red line = MSTHM model; blue line = UZ flow model.

Figure XII-5. Cumulative Distribution Function Comparison for the Present-Day Mean Infiltration-Flux Case 


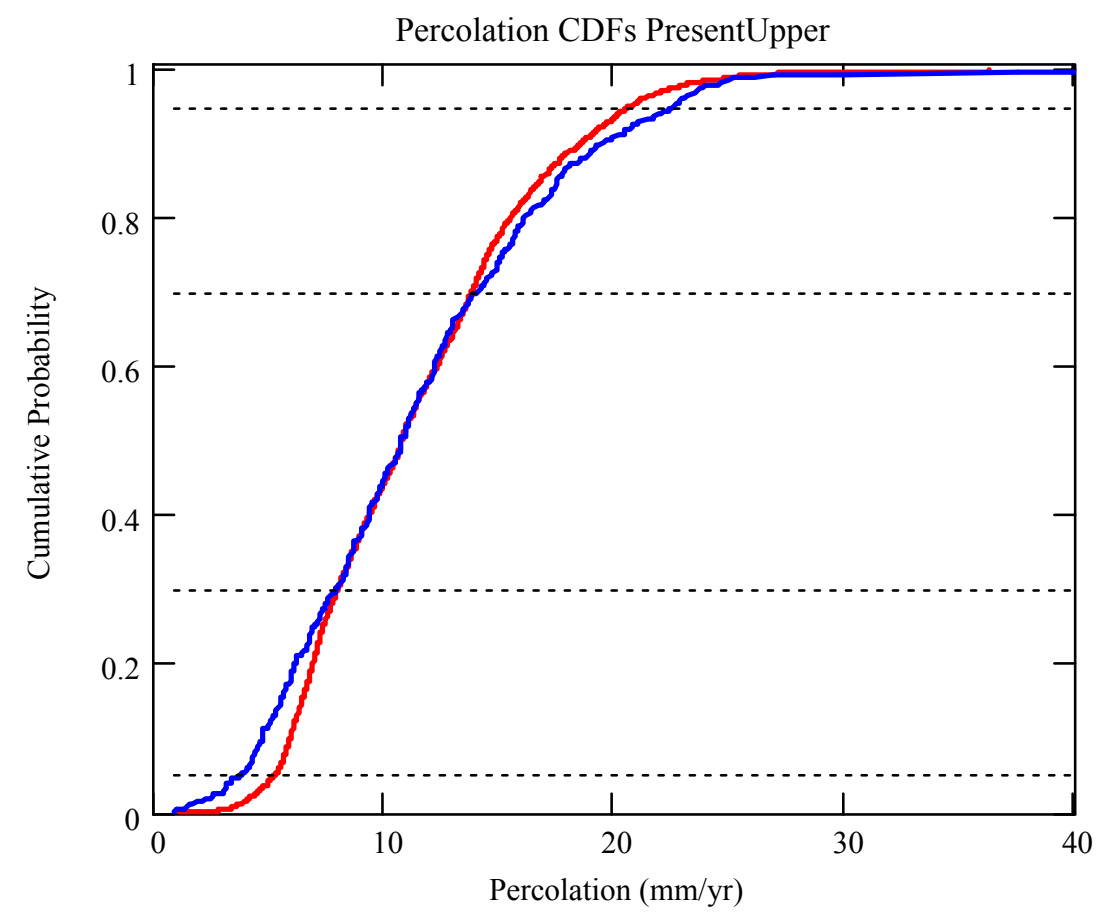

NOTE: $\quad$ Red line = MSTHM model; blue line = UZ flow model.

Figure XII-6. Cumulative Distribution Function Comparison for the Present Day Upper Case

\section{XII.4 COMPARISONS FOR THE MONSOONAL CLIMATE}

The data for the monsoonal climate from the MSTHM calculations have equal weightings. In order to develop the CDF for the MSTHM, sort the data in ascending order.

$$
\begin{aligned}
& \text { Monsoon }_{\text {lower }}:=\operatorname{sort}\left(\text { Monsoon }_{\text {lower }}\right) \\
& \text { Monsoon }_{\text {mean }}:=\operatorname{sort}\left(\text { Monsoon }_{\text {mean }}\right) \\
& \text { Monsoon }_{\text {upper }}:=\operatorname{sort}\left(\text { Monsoon }_{\text {upper }}\right)
\end{aligned}
$$

Develop the CDF by plotting the rank order against the sorted values for lower-, mean, and upper-bound infiltration-flux cases. Figures XII-7 through XII-9 show these cases for the monsoonal climate. 


$$
i \dot{H}_{\mathrm{w}}:=1 . . \operatorname{rows}\left(\text { Monsoon }_{\text {lower }}\right)
$$

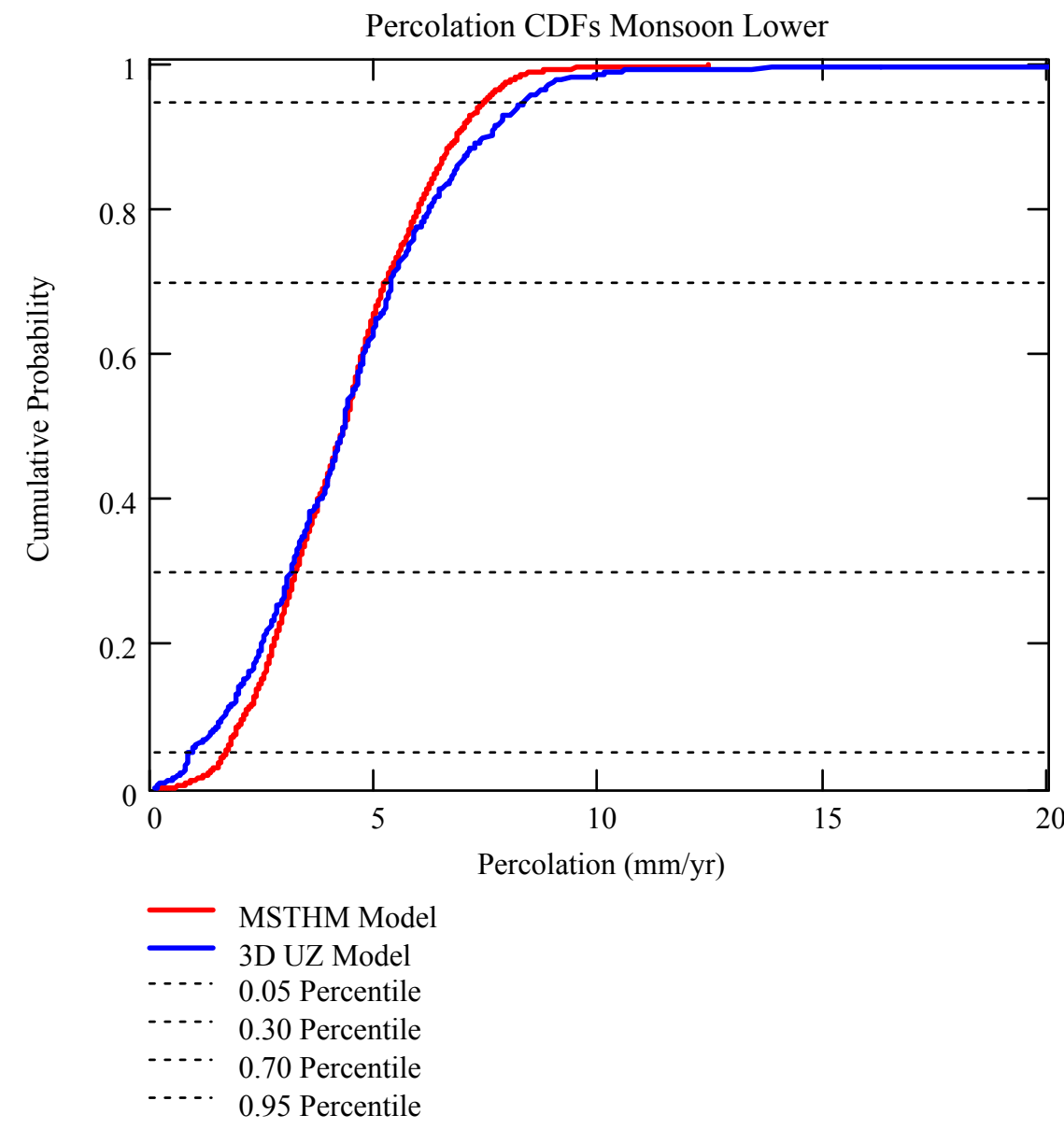

NOTE: $\quad$ Red line $=$ MSTHM model; blue line $=$ UZ flow model.

Figure XII-7. Cumulative Distribution Function Comparison for the Monsoonal-Climate Lower-Bound Infiltration-Flux Case 


$$
\begin{gathered}
m i{ }_{w}:=1 . \text { rows }\left(\text { Monsoon }_{\text {mean }}\right) \\
\underset{\mathrm{mm}}{\mathrm{m}}:=1 . . \operatorname{rows}(\text { mon_m })
\end{gathered}
$$

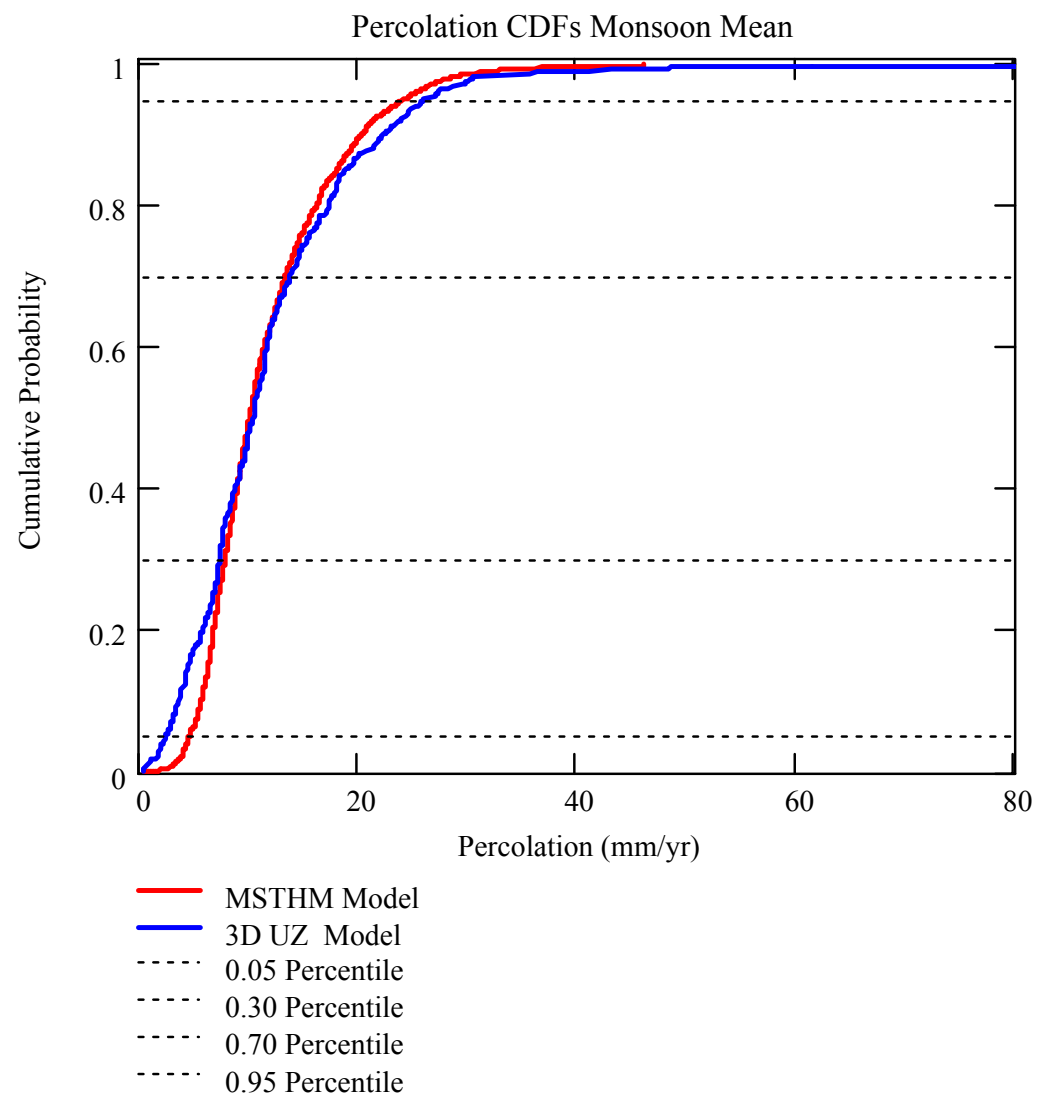

NOTE: $\quad$ Red line = MSTHM model; blue line = UZ flow model.

Figure XII-8. Cumulative Distribution Function Comparison for the Monsoonal-Climate Mean InfiltrationFlux Case 


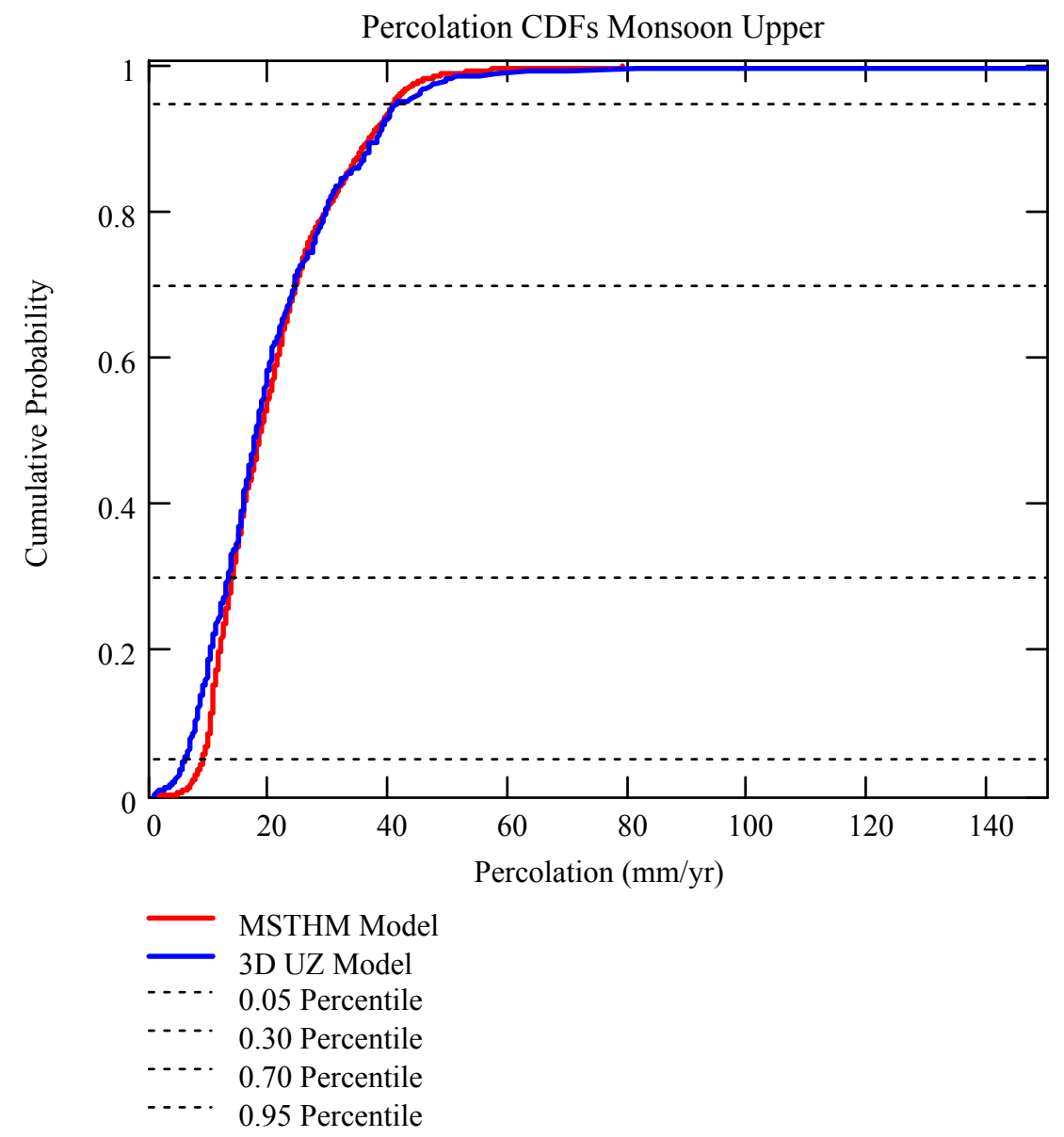

NOTE: $\quad$ Red line $=$ MSTHM model; blue line $=$ UZ flow model.

Figure XII-9. Cumulative Distribution Function Comparison for the Monsoonal-Climate Upper-Bound Infiltration-Flux Case 


\section{XII.5 COMPARISONS FOR THE GLACIAL CLIMATE}

The data for the glacial climate from the MSTHM calculations have equal weightings. In order to develop the CDF for the MSTHM, sort the data in ascending order.

$$
\begin{aligned}
& \text { Glacial }_{\text {lower }}:=\operatorname{sort}\left(\text { Glacial }_{\text {lower }}\right) \\
& \text { Glacial }_{\text {mean }}:=\operatorname{sort}\left(\text { Glacial }_{\text {mean }}\right) \\
& \text { Glacial }_{\text {upper }}:=\operatorname{sort}\left(\text { Glacial }_{\text {upper }}\right)
\end{aligned}
$$

Develop the CDF by plotting the rank order against the sorted values for lower-, mean, and upper-bound infiltration-flux cases. Figures XII-10 through XII-12 show these cases for the glacial climate.

$$
\mathrm{il}_{\mathrm{w}}:=1 . . \operatorname{rows}\left(\text { Glacial }_{\text {lower }}\right)
$$

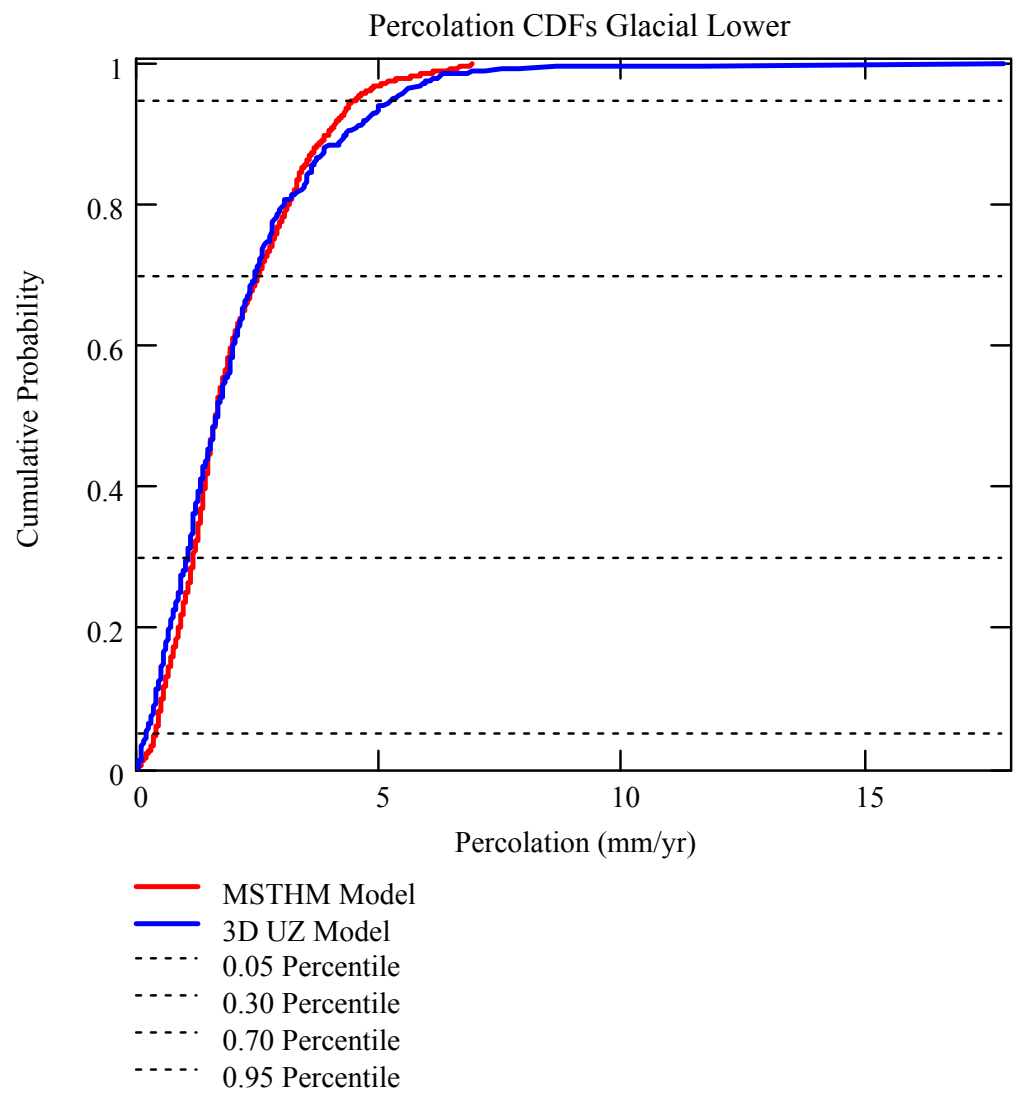

NOTE: $\quad$ Red line $=$ MSTHM model; blue line $=$ UZ flow model.

Figure XII-10. Cumulative Distribution Function Comparison for the Glacial-Climate Lower-Bound Infiltration-Flux Case 


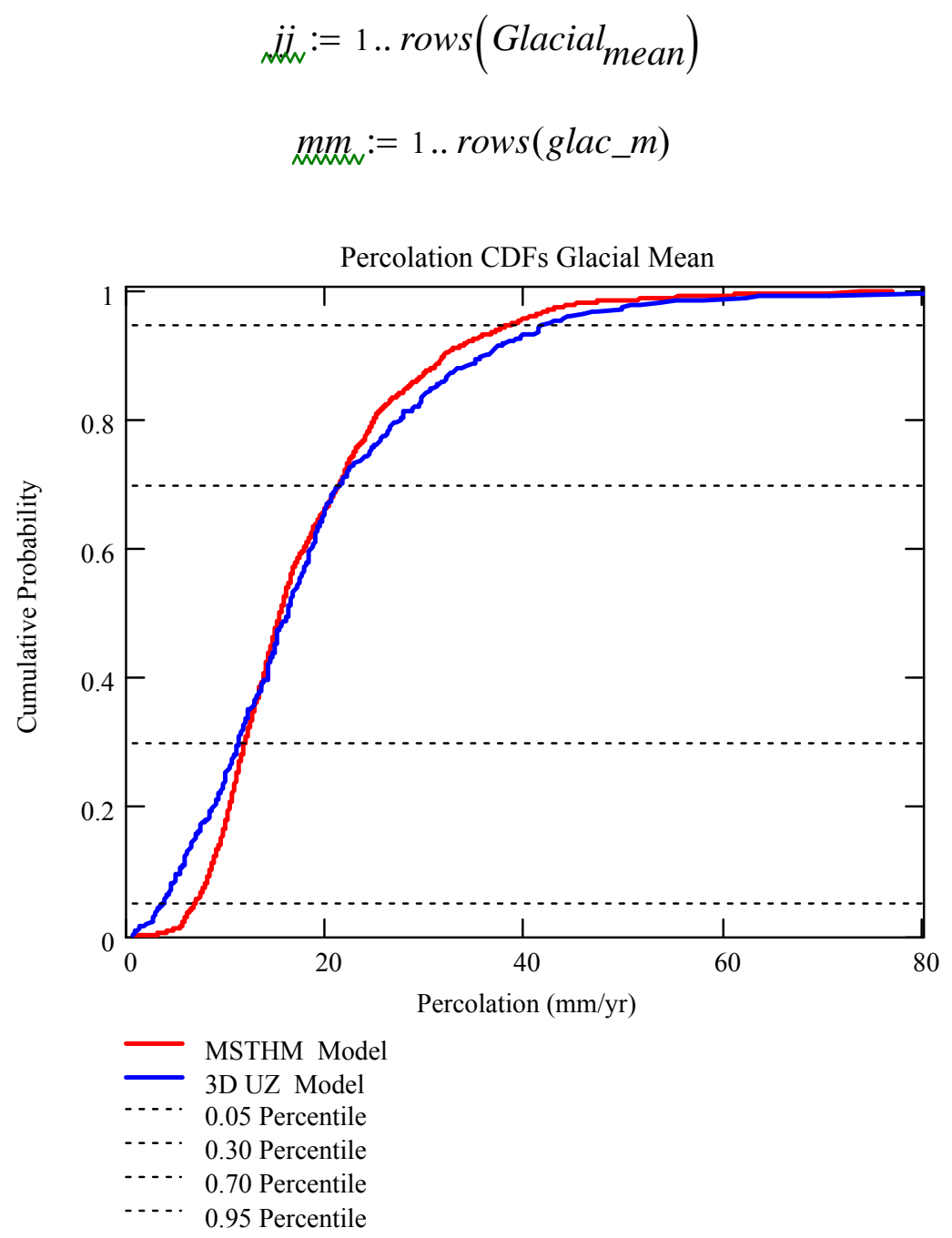

NOTE: $\quad$ Red line = MSTHM model; blue line $=$ UZ flow model.

Figure XII-11. Cumulative Distribution Function Comparison for the Glacial-Climate Mean Infiltration-Flux Case 


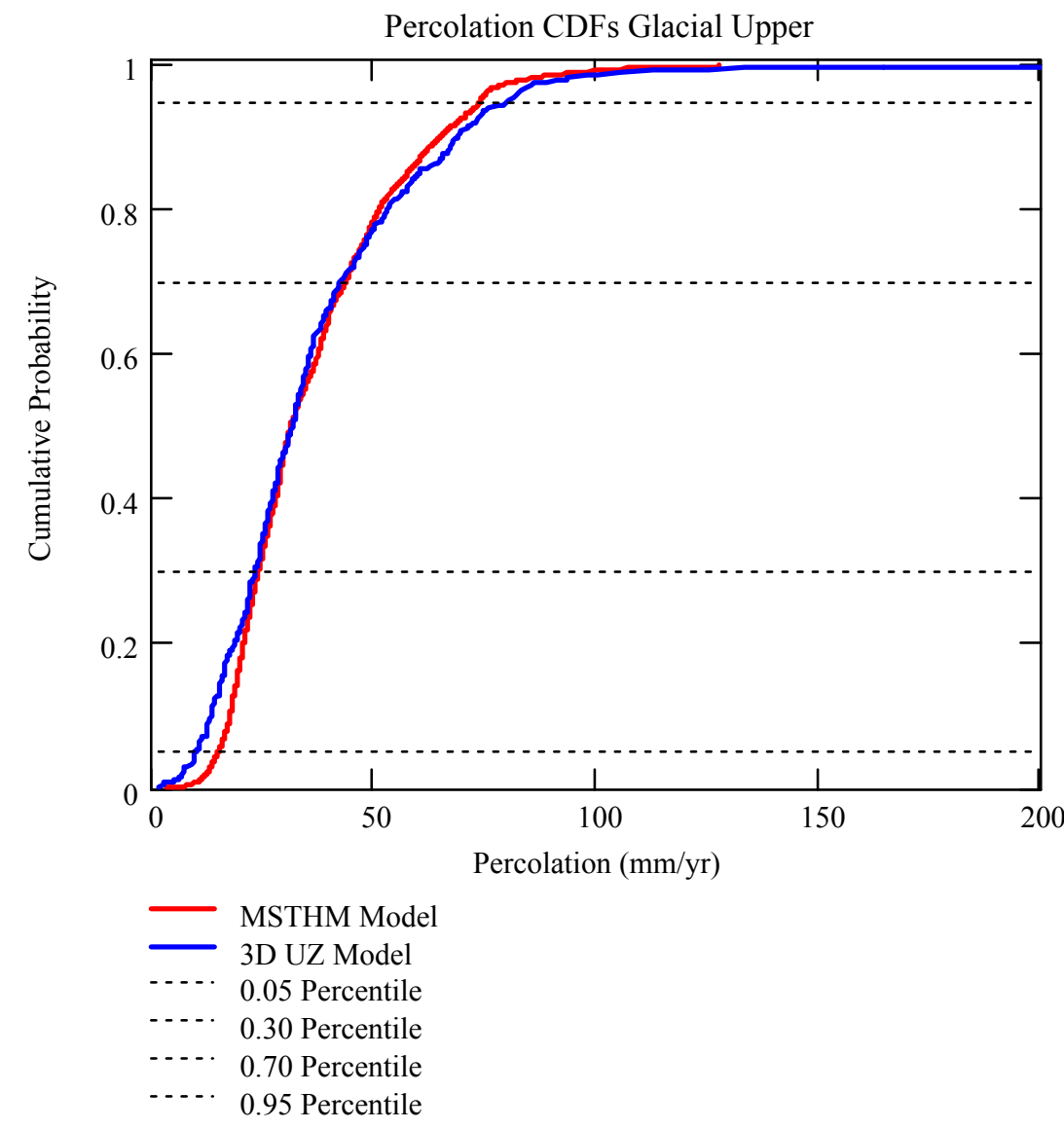

NOTE: $\quad$ Red line = MSTHM model; blue line = UZ flow model.

Figure XII-12. Cumulative Distribution Function Comparison for the Glacial-Climate Upper-Bound Infiltration-Flux Case

\section{XII.8 SUMMARY OF RESULTS}

Comparisons between the two models have been conducted. The comparisons of the cumulative distribution functions (CDF) show good agreement for the nine cases considered in the analysis with minor differences attributable to differences in gridding, sampling locations, and the areas tributary to sampling locations. 
APPENDIX XIII

LIST OF DATA SOURCES FOR FIGURES AND TABLES 
Table XIII-1. List of Data Sources for Figures

\begin{tabular}{|c|c|c|c|c|}
\hline $\begin{array}{c}\text { Figure } \\
\text { No. }\end{array}$ & Data Source & File Name & $\begin{array}{l}\text { Plotting } \\
\text { Software }\end{array}$ & Notes \\
\hline $4-1$ & LL030808623122.036 & INPUT/main_runs/SMT/tspa03.mesh03-150w & $\begin{array}{l}\text { MATLAB } \\
\text { v6.1.0.450 } \\
\text { (R12.1) }\end{array}$ & \\
\hline $4-2$ & LL040703123122.049 & $\begin{array}{l}\text { percolation_flux_files/ccdf_modern_perc_new-old-layouts.pltsc } \\
\text { percolation_flux_files/ccdf_monsoonal_perc_new-old-layouts.pltsc } \\
\text { percolation_flux_files/ccdf_glacial_perc_new-old-layouts.pltsc }\end{array}$ & XTOOL v10.1 & \\
\hline $6.2-3$ & LL030808623122.036 & INPUT/main_runs/SMT/tspa03.mesh03-150w & $\begin{array}{l}\text { MATLAB } \\
\text { v6.1.0.450 } \\
(\mathrm{R} 12.1)\end{array}$ & \\
\hline $6.2-6$ & LL030808623122.036 & INPUT/main_runs/LDTH/mi/LDTH55/P2WR5C10-LDTH55-1Dds_mc-mi-01.in & RADPRO v4.0 & \\
\hline $6.2-7$ & LL030808623122.036 & INPUT/initialization_runs/DDT/DDT55/P2WR5C10-DDT55-01v.in & RADPRO v4.0 & \\
\hline $6.2-12$ & LL040310323122.044 & Submodel_input_files/P2WR5C10-DDT55_nat-bkfl-11.in & RADPRO v4.0 & \\
\hline 6.3-1 & LL030808623122.036 & INPUT/main_runs/SMT/tspa03.mesh03-150w & $\begin{array}{l}\text { MATLAB } \\
\text { v6.1.0.450 } \\
\text { (R12.1) }\end{array}$ & \\
\hline $6.3-2$ & LL030808523122.035 & 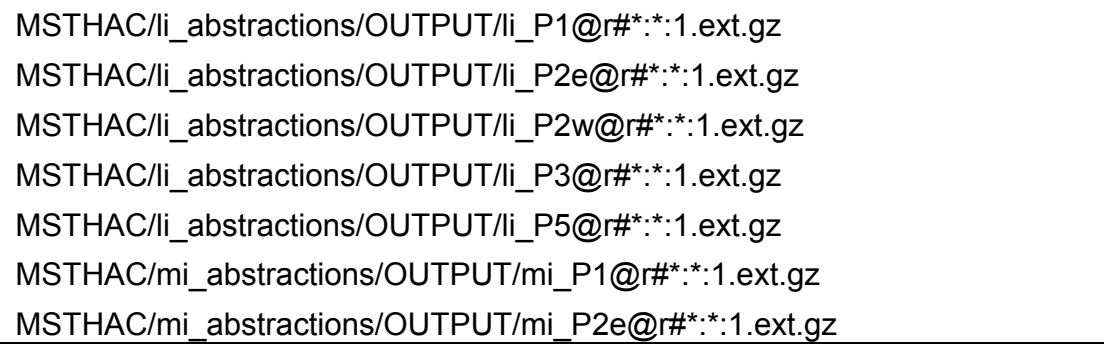 & XTOOL v10.1 & \\
\hline
\end{tabular}




\begin{tabular}{|c|c|c|c|c|}
\hline $\begin{array}{c}\text { Figure } \\
\text { No. }\end{array}$ & Data Source & File Name & $\begin{array}{l}\text { Plotting } \\
\text { Software }\end{array}$ & Notes \\
\hline & & 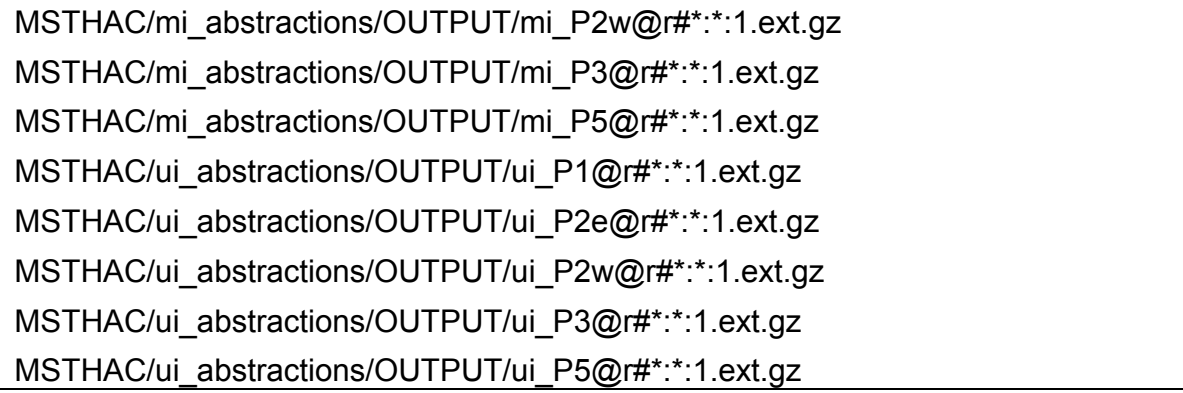 & & \\
\hline $6.3-3$ & LL030808523122.035 & 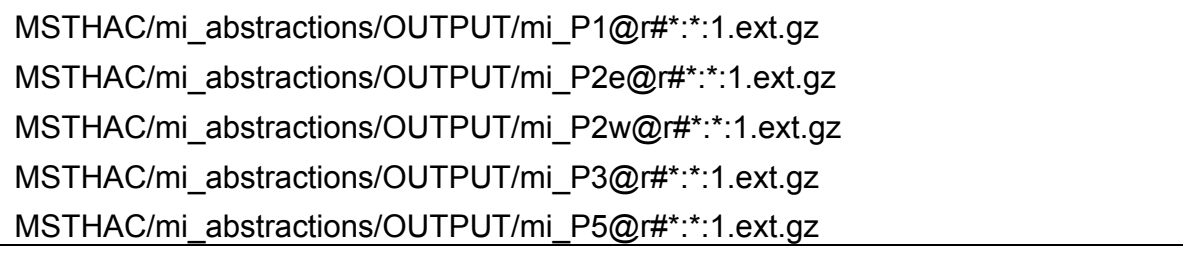 & $\begin{array}{l}\text { Tecplot v9.2- } \\
0-3 \text { (09-16- } \\
2002)\end{array}$ & \\
\hline $6.3-4$ & LL030808523122.035 & 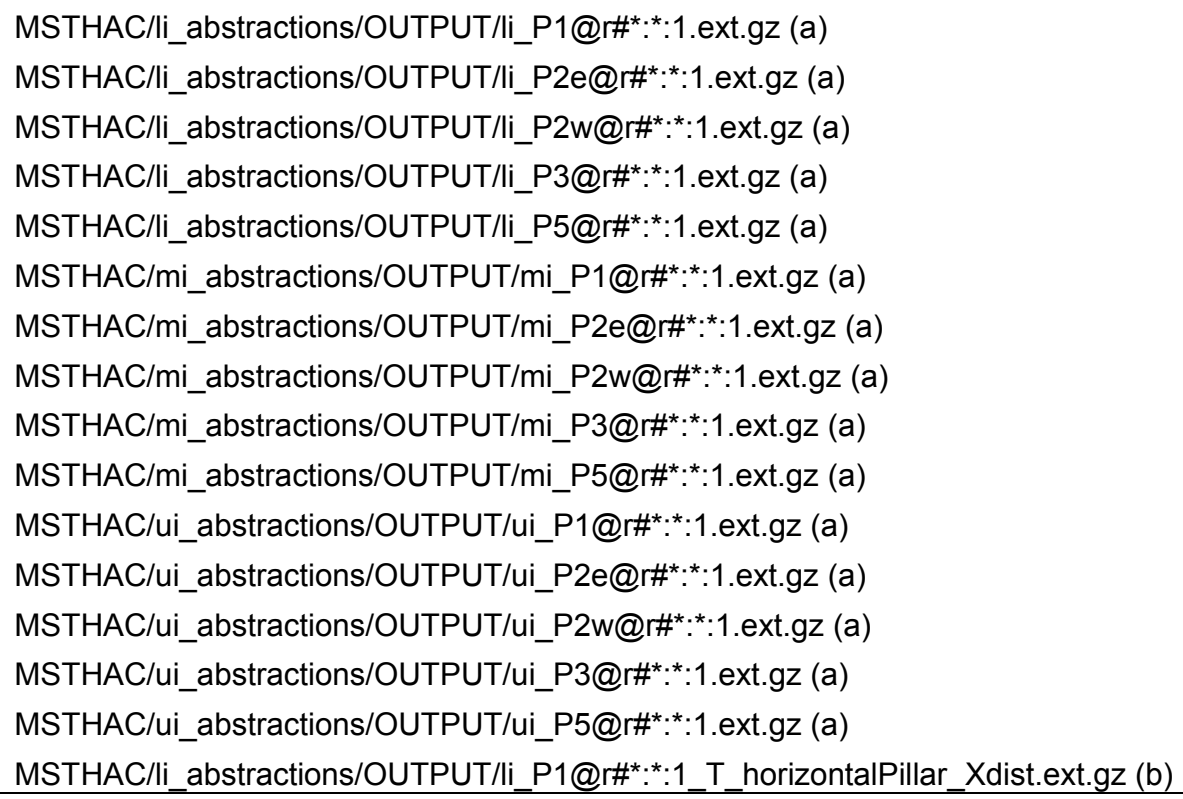 & XTOOL v10.1 & \\
\hline
\end{tabular}




\begin{tabular}{|c|c|c|c|c|}
\hline $\begin{array}{c}\text { Figure } \\
\text { No. }\end{array}$ & Data Source & File Name & $\begin{array}{c}\text { Plotting } \\
\text { Software }\end{array}$ & Notes \\
\hline & & 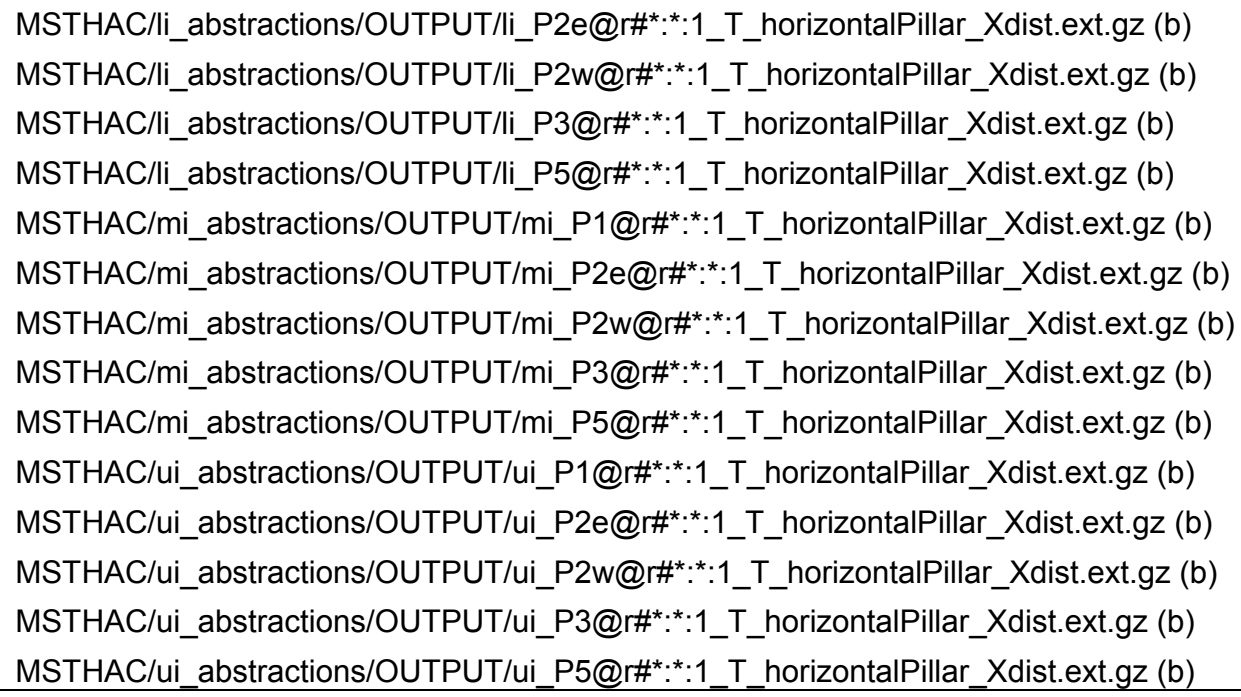 & & \\
\hline $6.3-5$ & LL030808523122.035 & 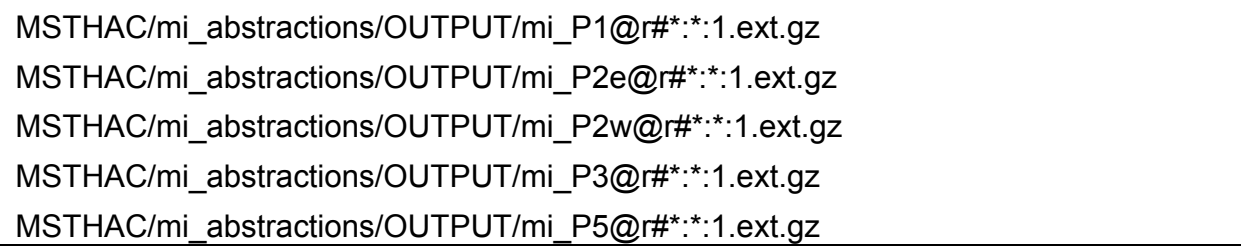 & $\begin{array}{l}\text { Tecplot v9.2- } \\
0-3(09-16- \\
2002)\end{array}$ & \\
\hline $6.3-6$ & LL030808523122.035 & $\begin{array}{l}\text { MSTHAC/mi_abstractions/OUTPUT/mi_P1@r\#*:*1_T_horizontalPillar_Xdist.ext.gz } \\
\text { MSTHAC/mi_abstractions/OUTPUT/mi_P2e@r\#*:*:1_T_horizontalPillar_Xdist.ext.gz } \\
\text { MSTHAC/mi_abstractions/OUTPUT/mi_P2w@r\#*:*1_T_horizontalPillar_Xdist.ext.gz } \\
\text { MSTHAC/mi_abstractions/OUTPUT/mi_P3@r\#*:*:1_T_horizontalPillar_Xdist.ext.gz } \\
\text { MSTHAC/mi_abstractions/OUTPUT/mi_P5@r**:*1_T_horizontalPillar_Xdist.ext.gz }\end{array}$ & $\begin{array}{l}\text { Tecplot v9.2- } \\
0-3(09-16- \\
2002)\end{array}$ & \\
\hline $6.3-7$ & LL030808523122.035 & $\begin{array}{l}\text { MSTHAC/li_abstractions/OUTPUT/li_P2e@r\#111:46:1.ext.gz } \\
\text { MSTHAC/mi_abstractions/OUTPUT/mi_P2e@r\#111:46:1.ext.gz } \\
\text { MSTHAC/ui_abstractions/OUTPUT/ui_P2e@r\#111:46:1.ext.gz }\end{array}$ & XTOOL v10.1 & \\
\hline
\end{tabular}


Table XIII-1. List of Data Sources for Figures (Continued)

\begin{tabular}{|c|c|c|c|c|}
\hline $\begin{array}{l}\text { Figure } \\
\text { No. }\end{array}$ & Data Source & File Name & $\begin{array}{l}\text { Plotting } \\
\text { Software }\end{array}$ & Notes \\
\hline $6.3-8$ & LL030808523122.035 & $\begin{array}{l}\text { MSTHAC/li_abstractions/OUTPUT/li_P2w@r\#94:46:1.ext.gz } \\
\text { MSTHAC/mi_abstractions/OUTPUT/mi_P2w@r\#94:46:1.ext.gz } \\
\text { MSTHAC/ui_abstractions/OUTPUT/ui_P2w@r\#94:46:1.ext.gz }\end{array}$ & XTOOL v10.1 & \\
\hline $6.3-9$ & LL030808523122.035 & $\begin{array}{l}\text { MSTHAC/li_abstractions/OUTPUT/li_P2w@r\#79:55:1.ext.gz } \\
\text { MSTHAC/mi_abstractions/OUTPUT/mi_P2w@r\#79:55:1.ext.gz } \\
\text { MSTHAC/ui_abstractions/OUTPUT/ui_P2w@r\#79:55:1.ext.gz }\end{array}$ & XTOOL v10.1 & \\
\hline $6.3-11$ & LL030808523122.035 & $\begin{array}{l}\text { MSTHAC/li_abstractions/OUTPUT/li_P3@r\#33:46:1.ext.gz } \\
\text { MSTHAC/mi_abstractions/OUTPUT/mi_P3@r\#33:46:1.ext.gz } \\
\text { MSTHAC/ui_abstractions/OUTPUT/ui_P3@r\#33:46:1.ext.gz }\end{array}$ & XTOOL v10.1 & \\
\hline $6.3-12$ & LL030808523122.035 & MSTHAC/mi_abstractions/OUTPUT/mi_P2e@r\#111:46:1.ext.gz & XTOOL v10.1 & \\
\hline $6.3-16$ & LL030808523122.035 & MSTHAC/mi_abstractions/OUTPUT/mi_P3@r\#33:46:1.ext.gz & XTOOL v10.1 & \\
\hline $6.3-17$ & LL030804023122.034 & $\begin{array}{l}\text { mi-mkt/P2ER8C6/mi-mkt-P2ER8C6.ext.gz } \\
\text { mi-mkt/P2ER8C6_EXT/mi-mkt-P2ER8C6.ext.gz }\end{array}$ & XTOOL v10.1 & \\
\hline $6.3-18$ & LL030804023122.034 & $\begin{array}{l}\text { mi-mkt/P2WR8C8/mi-mkt-P2WR8C8.ext.gz } \\
\text { mi-mkt/P2WR8C8_EXT/mi-mkt-P2WR8C8.ext.gz }\end{array}$ & XTOOL v10.1 & \\
\hline $6.3-19$ & LL030804023122.034 & $\begin{array}{l}\text { mi-mkt/P2WR5C10/mi-mkt-P2WR5C10.ext.gz } \\
\text { mi-mkt/P2WR5C10_EXT/mi-mkt-P2WR5C10.ext.gz }\end{array}$ & XTOOL v10.1 & \\
\hline $6.3-20$ & LL030804023122.034 & $\begin{array}{l}\text { mi-mkt/P3R8C13/mi-mkt-P3R8C13.ext.gz } \\
\text { mi-mkt/P3R8C13_EXT/mi-mkt-P3R8C13.ext.gz }\end{array}$ & XTOOL v10.1 & \\
\hline
\end{tabular}


Table XIII-1. List of Data Sources for Figures (Continued)

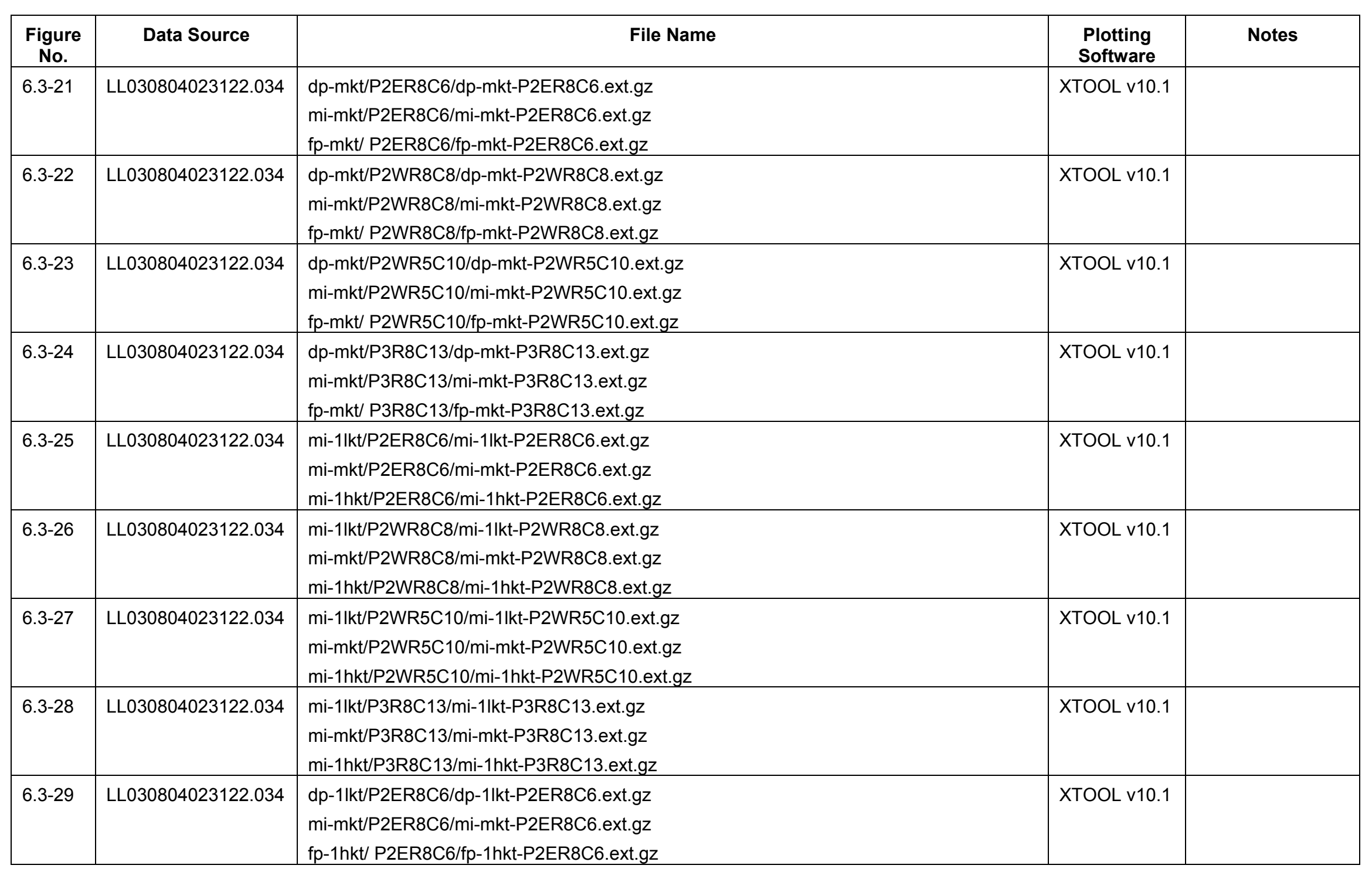


Table XIII-1. List of Data Sources for Figures (Continued)

\begin{tabular}{|c|c|c|c|c|}
\hline $\begin{array}{c}\text { Figure } \\
\text { No. }\end{array}$ & Data Source & File Name & $\begin{array}{l}\text { Plotting } \\
\text { Software }\end{array}$ & Notes \\
\hline $6.3-30$ & LL030804023122.034 & $\begin{array}{l}\text { dp-1lkt/P2WR8C8/dp-1lkt-P2WR8C8.ext.gz } \\
\text { mi-mkt/P2WR8C8/mi-mkt-P2WR8C8.ext.gz } \\
\text { fp-1hkt/ P2WR8C8/fp-1hkt-P2WR8C8.ext.gz }\end{array}$ & XTOOL v10.1 & \\
\hline $6.3-31$ & LL030804023122.034 & $\begin{array}{l}\text { dp-1lkt/P2WR5C10/dp-1lkt-P2WR5C10.ext.gz } \\
\text { mi-mkt/P2WR5C10/mi-mkt-P2WR5C10.ext.gz } \\
\text { fp-1hkt/ P2WR5C10/fp-1hkt-P2WR5C10.ext.gz }\end{array}$ & XTOOL v10.1 & \\
\hline $6.3-32$ & LL030804023122.034 & $\begin{array}{l}\text { dp-1lkt/P3R8C13/dp-1lkt-P3R8C13.ext.gz } \\
\text { mi-mkt/P3R8C13/mi-mkt-P3R8C13.ext.gz } \\
\text { fp-1hkt/ P3R8C13/fp-1hkt-P3R8C13.ext.gz }\end{array}$ & XTOOL v10.1 & \\
\hline $6.3-33$ & LL040102223122.042 & $\begin{array}{l}\text { 01/P2ER8C6-LDTH55-1Dds_mc-li-01.m.EBS.ext (a) } \\
\text { 01/P2ER8C6-LDTH55-1Dds_mc-li-01.f.EBS.ext (c) } \\
\text { 02/P2ER8C6-LDTH55-1Dds_mc-li-02.m.EBS.ext (a) } \\
\text { 02/P2ER8C6-LDTH55-1Dds_mc-li-02.f.EBS.ext (c) } \\
\text { 01/P2ER8C6-LDTH55-1Dds_mc-ui-01.m.EBS.ext (b) } \\
\text { 01/P2ER8C6-LDTH55-1Dds_mc-ui-01.f.EBS.ext (d) } \\
\text { 02/P2ER8C6-LDTH55-1Dds_mc-ui-02.m.EBS.ext (b) } \\
\text { 02/P2ER8C6-LDTH55-1Dds_mc-ui-02.f.EBS.ext (d) }\end{array}$ & XTOOL v10.1 & $\begin{array}{l}T \text { ds at upper drip- } \\
\text { shield gridblock } \\
R H_{\text {ds }} \text { at drift block } \\
\text { above upper drip- } \\
\text { shield block }\end{array}$ \\
\hline $6.3-34$ & LL040102223122.042 & $\begin{array}{l}\text { 01/P2WR8C8-LDTH55-1Dds_mc-li-01.m.EBS.ext (a) } \\
\text { 01/P2WR8C8-LDTH55-1Dds_mc-li-01.f.EBS.ext (c) } \\
\text { 02/P2WR8C8-LDTH55-1Dds_mc-li-02.m.EBS.ext (a) } \\
\text { 02/P2WR8C8-LDTH55-1Dds_mc-li-02.f.EBS.ext (c) } \\
\text { 01/P2WR8C8-LDTH55-1Dds_mc-ui-01.m.EBS.ext (b) } \\
\text { 01/P2WR8C8-LDTH55-1Dds_mc-ui-01.f.EBS.ext (d) } \\
\text { 02/P2WR8C8-LDTH55-1Dds_mc-li-02.m.EBS.ext (b) } \\
\text { 02/P2WR8C8-LDTH55-1Dds_mc-li-02.f.EBS.ext (d) }\end{array}$ & XTOOL v10.1 & $\begin{array}{l}T \text { ds at upper drip- } \\
\text { shield gridblock } \\
R H_{\text {ds }} \text { at drift block } \\
\text { above upper drip- } \\
\text { shield block }\end{array}$ \\
\hline
\end{tabular}




\begin{tabular}{|c|c|c|c|c|}
\hline $\begin{array}{c}\text { Figure } \\
\text { No. }\end{array}$ & Data Source & File Name & $\begin{array}{l}\text { Plotting } \\
\text { Software }\end{array}$ & Notes \\
\hline $6.3-35$ & LL040102223122.042 & $\begin{array}{l}\text { 01/P2WR5C10-LDTH55-1Dds_mc-li-01.m.EBS.ext (a) } \\
\text { 01/P2WR5C10-LDTH55-1Dds_mc-li-01.f.EBS.ext (c) } \\
\text { 02/P2WR5C10-LDTH55-1Dds_mc-li-02.m.EBS.ext (a) } \\
\text { 02/P2WR5C10-LDTH55-1Dds_mc-li-02.f.EBS.ext (c) } \\
\text { 01/P2WR5C10-LDTH55-1Dds_mc-ui-01.m.EBS.ext (b) } \\
\text { 01/P2WR5C10-LDTH55-1Dds_mc-ui-01.f.EBS.ext (d) } \\
\text { 02/P2WR5C10-LDTH55-1Dds_mc-ui-02.m.EBS.ext (b) } \\
\text { 02/P2WR5C10-LDTH55-1Dds_mc-ui-02.f.EBS.ext (d) }\end{array}$ & XTOOL v10.1 & $\begin{array}{l}T \text { ds at upper drip- } \\
\text { shield gridblock } \\
R H_{\text {ds }} \text { at drift block } \\
\text { above upper drip- } \\
\text { shield block }\end{array}$ \\
\hline $6.3-36$ & LL040102223122.042 & $\begin{array}{l}\text { 01/P3R8C13-LDTH55-1Dds_mc-li-01.m.EBS.ext (a) } \\
\text { 01/P3R8C13-LDTH55-1Dds_mc-li-01.f.EBS.ext (c) } \\
\text { 02/P3R8C13-LDTH55-1Dds_mc-li-02.m.EBS.ext (a) } \\
\text { 02/P3R8C13-LDTH55-1Dds_mc-li-02.f.EBS.ext (c) } \\
\text { 01/P3R8C13-LDTH55-1Dds_mc-ui-01.m.EBS.ext (b) } \\
\text { 01/P3R8C13-LDTH55-1Dds_mc-ui-01.f.EBS.ext (d) } \\
\text { 02/P3R8C13-LDTH55-1Dds_mc-ui-02.m.EBS.ext (b) } \\
\text { 02/P3R8C13-LDTH55-1Dds_mc-ui-02.f.EBS.ext (d) }\end{array}$ & XTOOL v10.1 & $\begin{array}{l}T \text { ds at upper drip- } \\
\text { shield gridblock } \\
R H_{\text {ds }} \text { at drift block } \\
\text { above upper drip- } \\
\text { shield block }\end{array}$ \\
\hline $6.3-37$ & LL040703123122.049 & $\begin{array}{l}\text { base-case_output/P2ER8C6-LDTH55-mi-mkt-02Q.m.EBS.ex.gz (matrix) } \\
\text { base-case_output/P2ER8C6-LDTH55-mi-mkt-02Q.f.EBS.ext.gz (fracture) }\end{array}$ & $\begin{array}{l}\text { MATLAB } \\
\text { v6.1.0.450 } \\
(\mathrm{R} 12.1)\end{array}$ & \\
\hline $6.3-38$ & LL040703123122.049 & $\begin{array}{l}\text { base-case_output/P2ER8C6-LDTH55-mi-mkt-02Q.m.EBS.ext.gz (matrix) } \\
\text { base-case_output/P2ER8C6-LDTH55-mi-mkt-02Q.f.EBS.ext.gz (fracture) }\end{array}$ & $\begin{array}{l}\text { MATLAB } \\
\text { v6.1.0.450 } \\
\text { (R12.1) }\end{array}$ & \\
\hline $6.3-39$ & LL040703123122.049 & $\begin{array}{l}\text { base-case_output/P2WR8C8-LDTH55-mi-mkt-02Q.m.EBS.ext.gz (matrix) } \\
\text { base-case_output/P2WR8C8-LDTH55-mi-mkt-02Q.f.EBS.ext.gz (fracture) }\end{array}$ & $\begin{array}{l}\text { MATLAB } \\
\text { v6.1.0.450 } \\
(\mathrm{R} 12.1)\end{array}$ & \\
\hline $6.3-40$ & LL040703123122.049 & $\begin{array}{l}\text { base-case_output/P2WR8C8-LDTH55-mi-mkt-02Q.m.EBS.ext.gz (matrix) } \\
\text { base-case_output/P2WR8C8-LDTH55-mi-mkt-02Q.f.EBS.ext.gz (fracture) }\end{array}$ & $\begin{array}{l}\text { MATLAB } \\
\text { v6.1.0.450 } \\
(\mathrm{R} 12.1)\end{array}$ & \\
\hline
\end{tabular}


Table XIII-1. List of Data Sources for Figures (Continued)

\begin{tabular}{|c|c|c|c|c|}
\hline $\begin{array}{l}\text { Figure } \\
\text { No. }\end{array}$ & Data Source & File Name & $\begin{array}{l}\text { Plotting } \\
\text { Software }\end{array}$ & Notes \\
\hline $6.3-41$ & LL040703123122.049 & $\begin{array}{l}\text { base-case_output/P2WR5C10-LDTH55-mi-mkt-02Q.m.EBS.ext.gz (matrix) } \\
\text { base-case_output/P2WR5C10-LDTH55-mi-mkt-02Q.f.EBS.ext.gz (fracture) }\end{array}$ & $\begin{array}{l}\text { MATLAB } \\
\text { v6.1.0.450 } \\
\text { (R12.1) }\end{array}$ & \\
\hline $6.3-42$ & LL040703123122.049 & $\begin{array}{l}\text { base-case_output/P2WR5C10-LDTH55-mi-mkt-02Q.m.EBS.ext.gz (matrix) } \\
\text { base-case_output/P2WR5C10-LDTH55-mi-mkt-02Q.f.EBS.ext.gz (fracture) }\end{array}$ & $\begin{array}{l}\text { MATLAB } \\
\text { v6.1.0.450 } \\
\text { (R12.1) }\end{array}$ & \\
\hline $6.3-43$ & LL040703123122.049 & $\begin{array}{l}\text { base-case_output/P3R8C13-LDTH55-mi-mkt-02Q.m.EBS.ext.gz (matrix) } \\
\text { base-case_output/P3R8C13-LDTH55-mi-mkt-02Q.f.EBS.ext.gz (fracture) }\end{array}$ & $\begin{array}{l}\text { MATLAB } \\
\text { v6.1.0.450 } \\
\text { (R12.1) }\end{array}$ & \\
\hline $6.3-44$ & LL040703123122.049 & $\begin{array}{l}\text { base-case_output/P3R8C13-LDTH55-mi-mkt-02Q.m.EBS.ext.gz (matrix) } \\
\text { base-case_output/P3R8C13-LDTH55-mi-mkt-02Q.f.EBS.ext.gz (fracture) }\end{array}$ & $\begin{array}{l}\text { MATLAB } \\
\text { v6.1.0.450 } \\
\text { (R12.1) }\end{array}$ & \\
\hline $6.3-45$ & LL040703123122.049 & $\begin{array}{l}\text { base-case_output/P2ER8C6-LDTH55-mi-mkt-02Q.m.EBS.ext.gz (matrix) } \\
\text { base-case_output/P2ER8C6-LDTH55-mi-mkt-02Q.f.EBS.ext.gz (fracture) } \\
\text { base-case_output/P2WR8C8-LDTH55-mi-mkt-02Q.m.EBS.ext.gz (matrix) } \\
\text { base-case_output/P2WR8C8-LDTH55-mi-mkt-02Q.f.EBS.ext.gz (fracture) } \\
\text { base-case_output/P2WR5C10-LDTH55-mi-mkt-02Q.m.EBS.ext.gz (matrix) } \\
\text { base-case_output/P2WR5C10-LDTH55-mi-mkt-02Q.f.EBS.ext.gz (fracture) } \\
\text { base-case_output/P3R8C13-LDTH55-mi-mkt-02Q.m.EBS.ext.gz (matrix) } \\
\text { base-case_output/P3R8C13-LDTH55-mi-mkt-02Q.f.EBS.ext.gz (fracture) }\end{array}$ & $\begin{array}{l}\text { MATLAB } \\
\text { v6.1.0.450 } \\
\text { (R12.1) }\end{array}$ & \\
\hline $6.3-46$ & LL040703123122.049 & $\begin{array}{l}\text { base-case_output/P2ER8C6-LDTH55-mi-mkt-02Q.m.EBS.ext.gz (matrix) } \\
\text { base-case_output/P2ER8C6-LDTH55-mi-mkt-02Q.f.EBS.ext.gz (fracture) }\end{array}$ & $\begin{array}{l}\text { MATLAB } \\
\text { v6.1.0.450 } \\
\text { (R12.1) }\end{array}$ & \\
\hline $6.3-47$ & LL040703123122.049 & $\begin{array}{l}\text { base-case_output/P2WR8C8-LDTH55-mi-mkt-02Q.m.EBS.ext.gz (matrix) } \\
\text { base-case_output/P2WR8C8-LDTH55-mi-mkt-02Q.f.EBS.ext.gz (fracture) }\end{array}$ & $\begin{array}{l}\text { MATLAB } \\
\text { v6.1.0.450 } \\
\text { (R12.1) }\end{array}$ & \\
\hline $6.3-48$ & LL040703123122.049 & $\begin{array}{l}\text { base-case_output/P2WR5C10-LDTH55-mi-mkt-02Q.m.EBS.ext.gz (matrix) } \\
\text { base-case_output/P2WR5C10-LDTH55-mi-mkt-02Q.f.EBS.ext.gz (fracture) }\end{array}$ & $\begin{array}{l}\text { MATLAB } \\
\text { v6.1.0.450 } \\
(R 12.1)\end{array}$ & \\
\hline $6.3-49$ & LL040703123122.049 & $\begin{array}{l}\text { base-case_output/P3R8C13-LDTH55-mi-mkt-02Q.m.EBS.ext.gz (matrix) } \\
\text { base-case_output/P3R8C13-LDTH55-mi-mkt-02Q.f.EBS.ext.gz (fracture) }\end{array}$ & $\begin{array}{l}\text { MATLAB } \\
\text { v6.1.0.450 } \\
\text { (R12.1) }\end{array}$ & \\
\hline
\end{tabular}




\begin{tabular}{|c|c|c|c|c|}
\hline $\begin{array}{c}\text { Figure } \\
\text { No. }\end{array}$ & Data Source & File Name & $\begin{array}{l}\text { Plotting } \\
\text { Software }\end{array}$ & Notes \\
\hline \multirow[t]{26}{*}{$6.3-51$} & LL030808523122.035 & From LL030808523122.035: & XTOOL v10.1 & \\
\hline & LL030905931032.001 & MSTHAC/li_abstractions/OUTPUT/li_P1@»\#"::1.ext.gz & & \\
\hline & LL030906331032.004 & MSTHAC/li_abstractions/OUTPUT/li_P2e@»\#*:*1.ext.gz & & \\
\hline & & MSTHAC/li_abstractions/OUTPUT/li_P2w@r\#*:*1.ext.gz & & \\
\hline & & MSTHAC/li_abstractions/OUTPUT/li_P3@r\#*:*1.ext.gz & & \\
\hline & & MSTHAC/li_abstractions/OUTPUT/li_P5@@\#*:*:1.ext.gz & & \\
\hline & & MSTHAC/mi_abstractions/OUTPUT/mi_P1@r\#":*1.ext.gz & & \\
\hline & & MSTHAC/mi_abstractions/OUTPUT/mi_P2e@@»*::*1.ext.gz & & \\
\hline & & MSTHAC/mi_abstractions/OUTPUT/mi_P2w@r»*::*1.ext.gz & & \\
\hline & & MSTHAC/mi_abstractions/OUTPUT/mi_P3@r\#*:*1.ext.gz & & \\
\hline & & MSTHAC/mi_abstractions/OUTPUT/mi_P5@r\#*:*:1.ext.gz & & \\
\hline & & MSTHAC/ui_abstractions/OUTPUT/ui_P1@r\#\#:*:1.ext.gz & & \\
\hline & & MSTHAC/ui_abstractions/OUTPUT/ui_P2e@r\#*:*1.ext.gz & & \\
\hline & & MSTHAC/ui_abstractions/OUTPUT/ui_P2w@r\#:::1.ext.gz & & \\
\hline & & MSTHAC/ui_abstractions/OUTPUT/ui_P3@@\#*:*:1.ext.gz & & \\
\hline & & MSTHAC/ui_abstractions/OUTPUT/ui_P5@r\#*:*1.ext.gz & & \\
\hline & & From LL030905931032.001: & & \\
\hline & & /post_process/createCCDFS/LII-lkt_CCDF.txt & & \\
\hline & & MSTHAC_abstraction/MSTHAC_output/LI-Ikt_P1@®\#":*:1.ext.gz & & \\
\hline & & MSTHAC_abstraction/MSTHAC_output/LI-Ikt_P2e@@"\#*:*:1.ext.gz & & \\
\hline & & MSTHAC_abstraction/MSTHAC_output/LI-Ikt_P2w@r\#*:*:1.ext.gz & & \\
\hline & & MSTHAC_abstraction/MSTHAC_output/LIIIkt_P3@@\#\#::1.ext.gz & & \\
\hline & & MSTHAC_abstraction/MSTHAC_output/LI-Ikt_P5@r॥*::*1.ext.gz & & \\
\hline & & From LL030906331032.004. & & \\
\hline & & /post_process/createCCDFS/UI-hkt_CCDF.txt & & \\
\hline & & MSTHAC_abstraction/MSTHAC_output/UI-hkt_P1@@\#":*:1.ext.gz & & \\
\hline
\end{tabular}




\begin{tabular}{|c|c|c|c|c|}
\hline $\begin{array}{c}\text { Figure } \\
\text { No. }\end{array}$ & Data Source & File Name & $\begin{array}{l}\text { Plotting } \\
\text { Software }\end{array}$ & Notes \\
\hline & & $\begin{array}{l}\text { MSTHAC_abstraction/MSTHAC_output/UI-hkt_P2e@@\#*:*:1.ext.gz } \\
\text { MSTHAC_abstraction/MSTHAC_output/UI-hkt_P2w@r\#*:*1.ext.gz } \\
\text { MSTHAC_abstraction/MSTHAC_output/UI-hkt_P3@»\#*:*1.ext.gz } \\
\text { MSTHAC_abstraction/MSTHAC_output/UI-hkt_P5@@\#\#:: :1.ext.gz }\end{array}$ & & \\
\hline 6.3-52 & LL030808523122.035 & From LL030808523122.035: & XTOOL v10.1 & \\
\hline & LL030905931032.001 & MSTHAC/li_abstractions/OUTPUT/li_P1@r\#*:*1.ext.gz (a) & & \\
\hline & LL030906331032.004 & MSTHAC/li_abstractions/OUTPUT/li_P2e@r\#\#:*:1.ext.gz (a) & & \\
\hline & & MSTHAC/li_abstractions/OUTPUT/li_P2w@r\#\#:*:1.ext.gz (a) & & \\
\hline & & MSTHAC/li_abstractions/OUTPUT/li_P3@@\#\#::1.ext.gz (a) & & \\
\hline & & MSTHAC/i_abstractions/OUTPUT/li_P5@@\#\#::1.ext.gz (a) & & \\
\hline & & MSTHAC/mi_abstractions/OUTPUT/mi_P1@r\#**:1.ext.gz (a) & & \\
\hline & & MSTHAC/mi_abstractions/OUTPUT/mi_P2e@@\#*:*:1.ext.gz (a) & & \\
\hline & & MSTHAC/mi_abstractions/OUTPUT/mi_P2w@r\#*:*:1.ext.gz (a) & & \\
\hline & & MSTHAC/mi_abstractions/OUTPUT/mi_P3@!\#*:*1.ext.gz (a) & & \\
\hline & & MSTHAC/mi_abstractions/OUTPUT/mi_P5@r\#*:*:1.ext.gz (a) & & \\
\hline & & MSTHAC/ui_abstractions/OUTPUT/ui_P1@r\#*:*:1.ext.gz (a) & & \\
\hline & & MSTHAC/ui_abstractions/OUTPUT/ui_P2e@r\#*:*1.ext.gz (a) & & \\
\hline & & MSTHAC/ui_abstractions/OUTPUT/ui_P2w@r\#*:*:1.ext.gz (a) & & \\
\hline & & MSTHAC/ui_abstractions/OUTPUT/ui_P3@r\#\#:*:1.ext.gz (a) & & \\
\hline & & MSTHAC/ui_abstractions/OUTPUT/ui_P5@»\#*:*1.ext.gz (a) & & \\
\hline & & From LL030905931032.001: & & \\
\hline & & /post_process/createCCDFS/LI-Ikt_CCDF.txt & & \\
\hline & & MSTHAC_abstraction/MSTHAC_output/LIIIkt_P1@r\#*:*1.ext.gz (a) & & \\
\hline & & MSTHAC_abstraction/MSTHAC_output/LI-Ikt_P2e@@\#*:*:1.ext.gz (a) & & \\
\hline & & MSTHAC_abstraction/MSTHAC_output/LI-lkt_P2w@ @\#:*:1.ext.gz (a) & & \\
\hline & & MSTHAC_abstraction/MSTHAC_output/LI-Ikt_P3@r\#*:*1.ext.gz (a) & & \\
\hline & & MSTHAC_abstraction/MSTHAC_output/LI-Ikt_P5@r\#*:*:1.ext.gz (a) & & \\
\hline
\end{tabular}




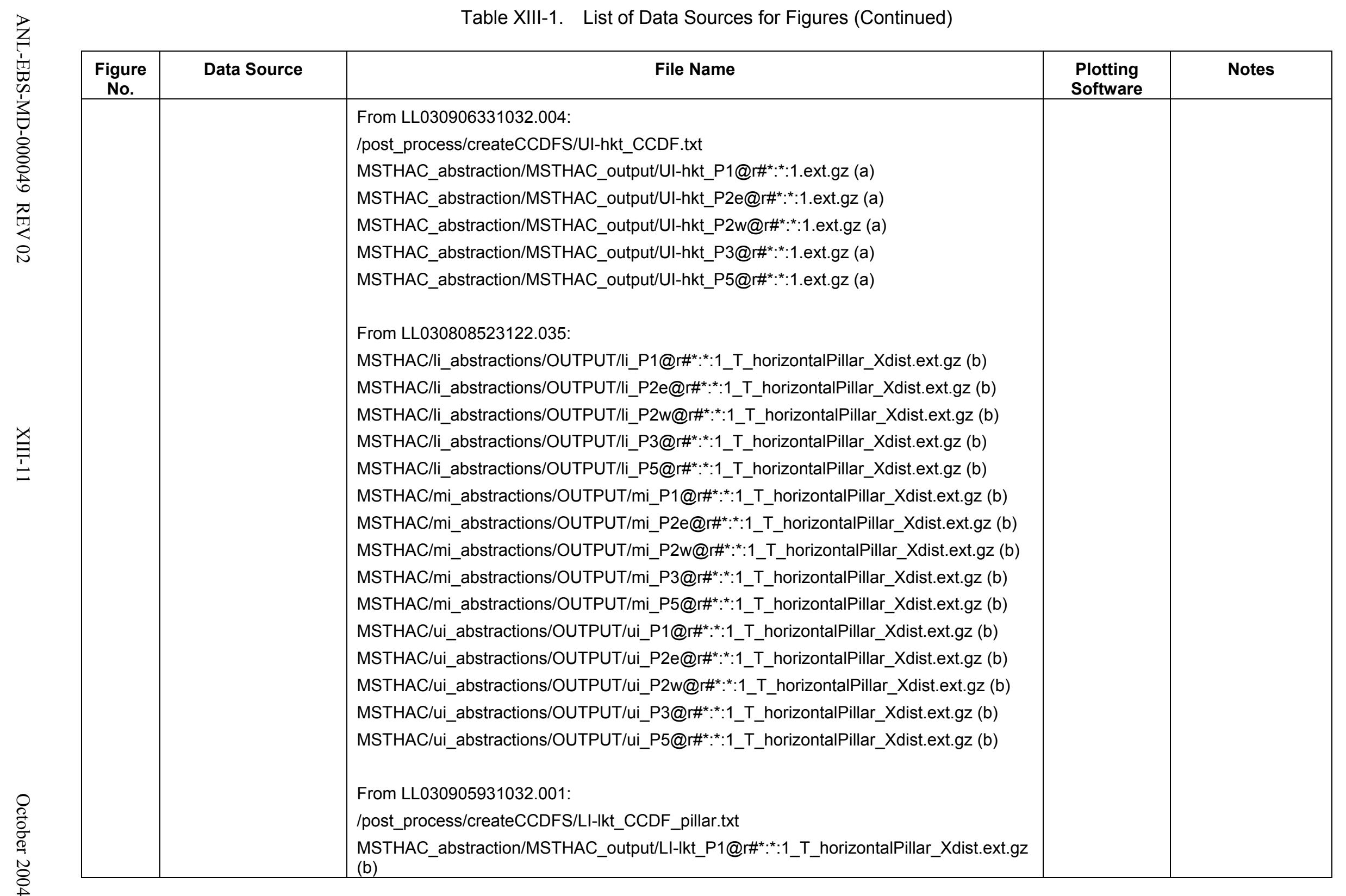




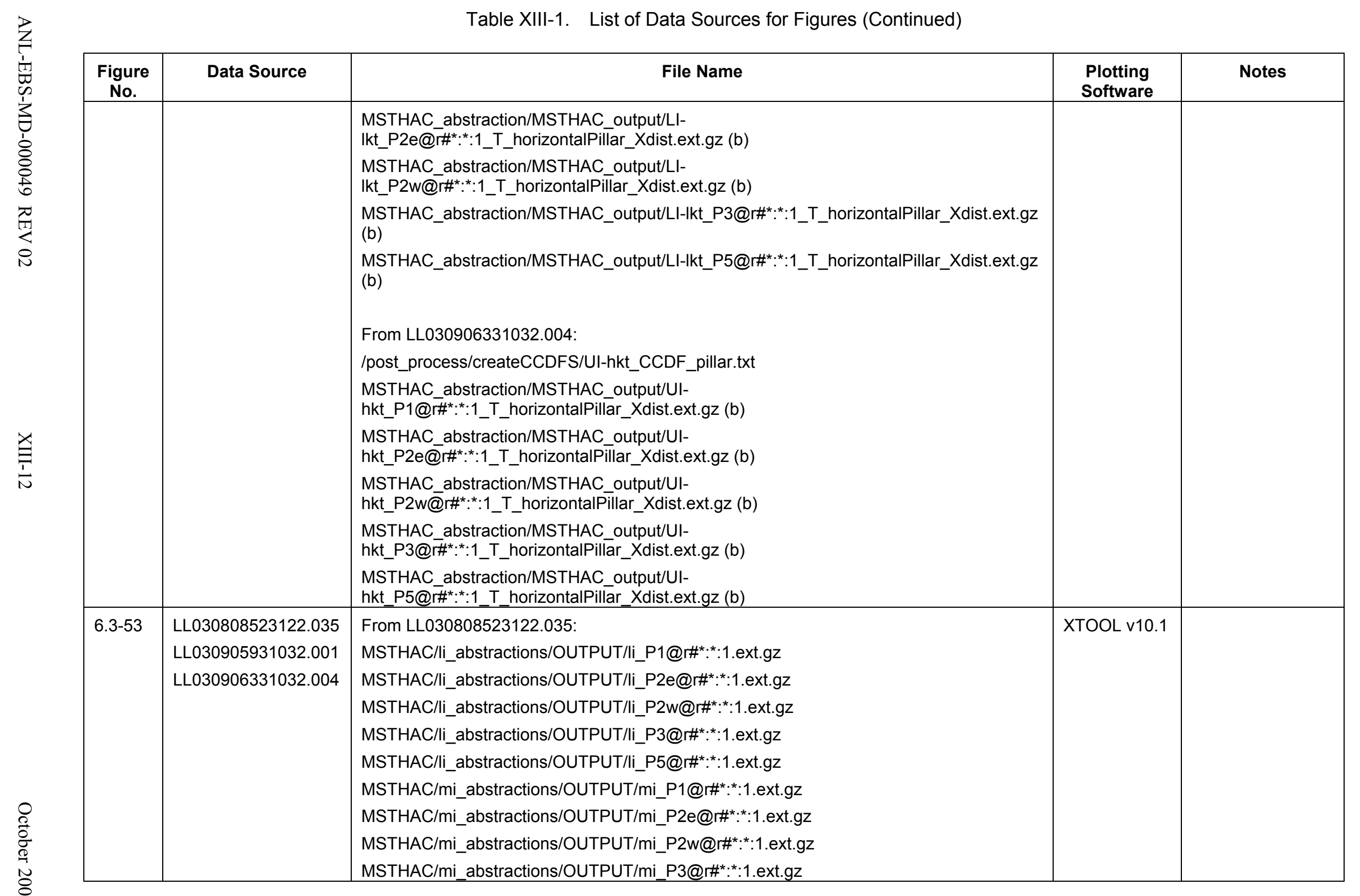




\begin{tabular}{|c|c|c|c|c|}
\hline $\begin{array}{c}\text { Figure } \\
\text { No. }\end{array}$ & Data Source & File Name & $\begin{array}{l}\text { Plotting } \\
\text { Software }\end{array}$ & Notes \\
\hline & & 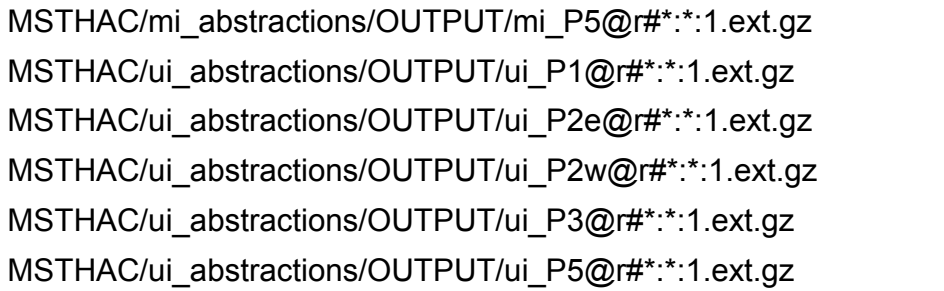 & & \\
\hline & & 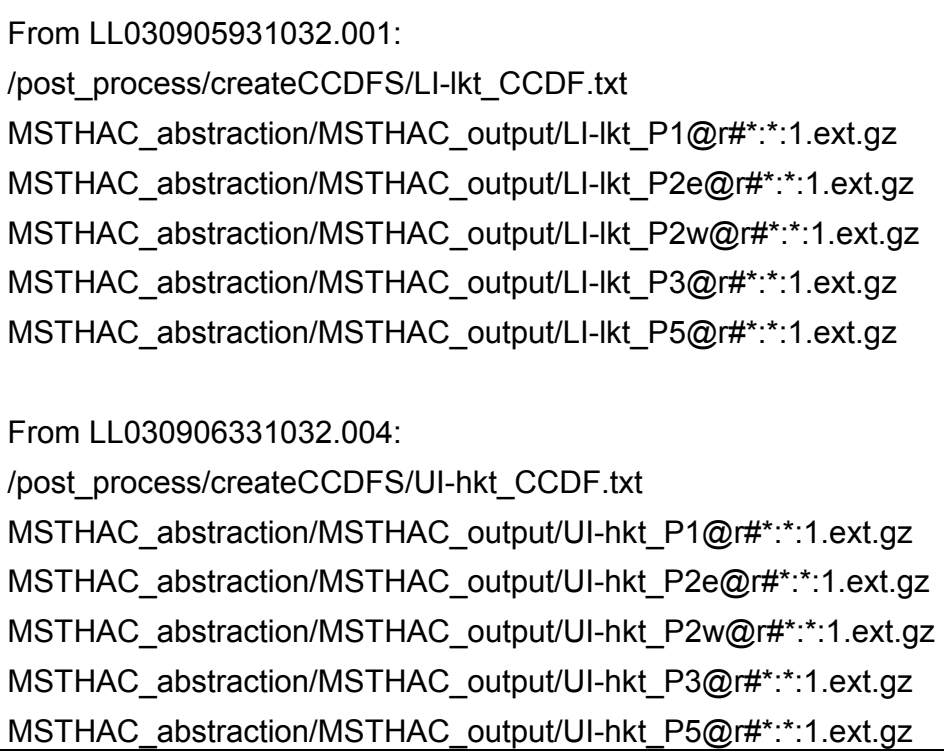 & & \\
\hline $6.3-54$ & $\begin{array}{l}\text { LL030808523122.035 } \\
\text { LL030905931032.001 } \\
\text { LL030906331032.004 }\end{array}$ & 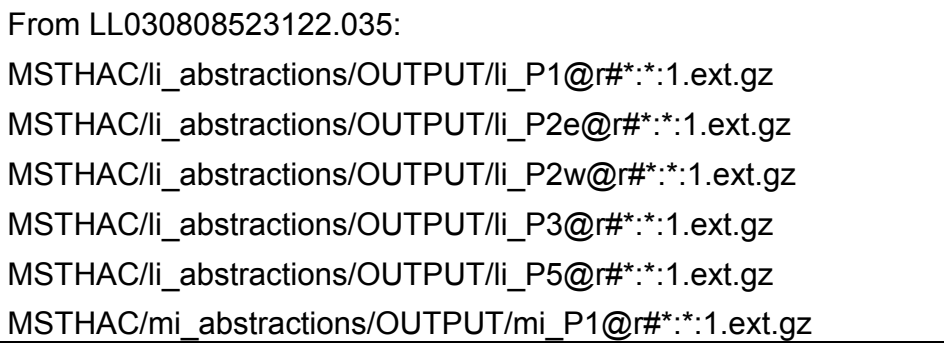 & XTOOL v10.1 & \\
\hline
\end{tabular}




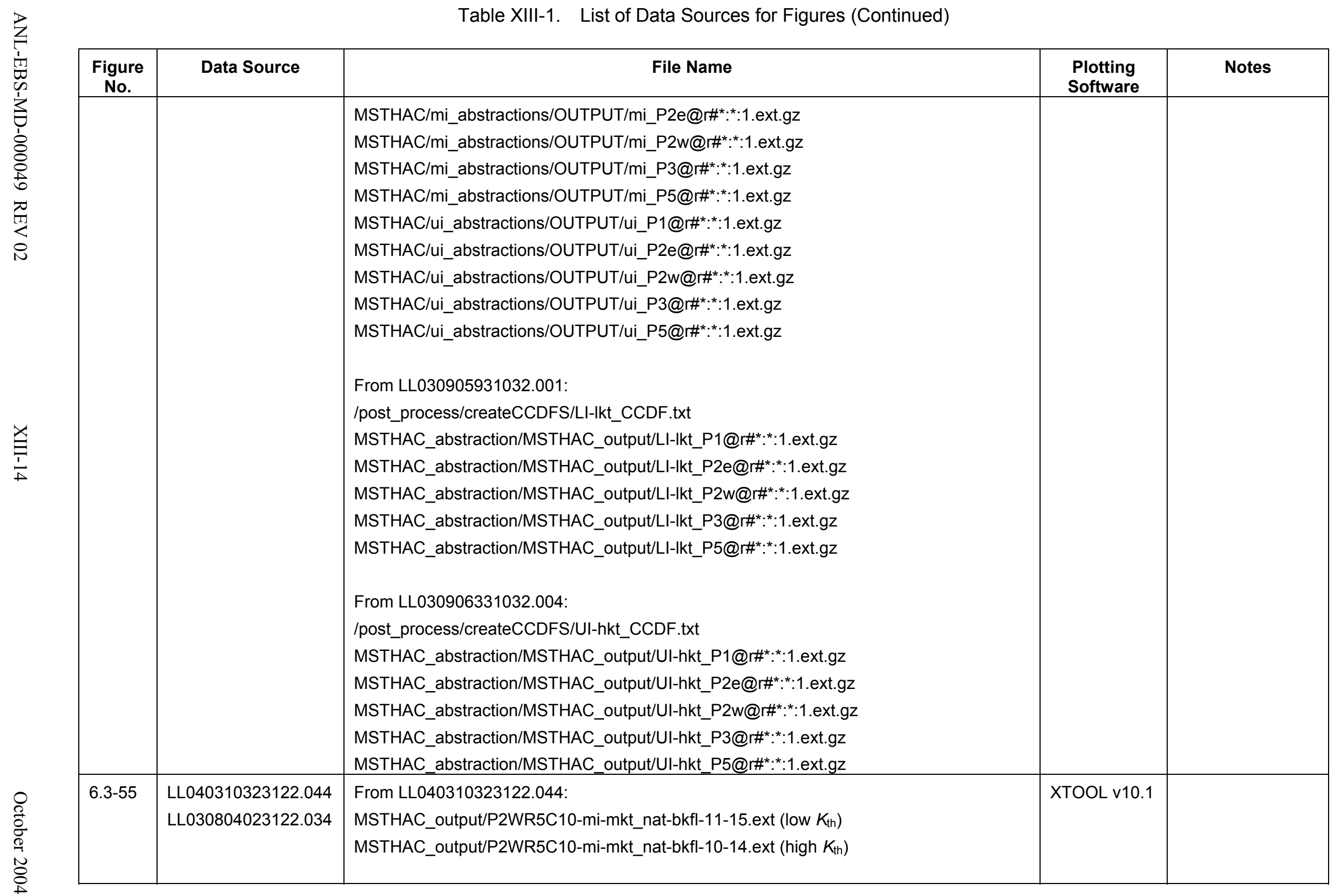


Table XIII-1. List of Data Sources for Figures (Continued)

\begin{tabular}{|c|c|c|c|c|}
\hline $\begin{array}{l}\text { Figure } \\
\text { No. }\end{array}$ & Data Source & File Name & $\begin{array}{l}\text { Plotting } \\
\text { Software }\end{array}$ & Notes \\
\hline & & $\begin{array}{l}\text { From LL030804023122.034 } \\
\text { mi-mkt/P2WR5C10/mi-mkt-P2WR5C10.ext.gz (Intact drift) }\end{array}$ & & \\
\hline $6.3-56$ & $\begin{array}{l}\text { LL040310323122.044 } \\
\text { LL030804023122.034 }\end{array}$ & $\begin{array}{l}\text { From LL040310323122.044: } \\
\left.\text { MSTHAC_output/P2WR5C10-mi-mkt_nat-bkfl-11-15.ext (low } K_{\text {th }}\right) \\
\left.\text { MSTHAC_output/P2WR5C10-mi-mkt_nat-bkfl-10-14.ext (high } K_{\text {th }}\right) \\
\text { From LL030804023122.034: } \\
\text { mi-mkt/P2WR5C10/mi-mkt-P2WR5C10.ext.gz (Intact drift) }\end{array}$ & XTOOL v10.1 & \\
\hline $6.3-57$ & $\begin{array}{l}\text { LL040310323122.044 } \\
\text { LL030804023122.034 }\end{array}$ & $\begin{array}{l}\text { From LL040310323122.044: } \\
\left.\text { MSTHAC_output/P2WR5C10-mi-mkt_nat-bkfl-11-15.ext (low } K_{\text {th }}\right) \\
\text { MSTHAC_output/P2WR5C10-mi-mkt_nat-bkfl-10-14.ext (high } K_{\text {th }} \text { ) } \\
\text { From LL030804023122.034: } \\
\text { mi-mkt/P2WR5C10/mi-mkt-P2WR5C10.ext.gz (Intact drift) }\end{array}$ & XTOOL v10.1 & \\
\hline $6.3-58$ & LL040501323122.046 & $\begin{array}{l}\text { The following files are found in file: rubble_heat-capacity output files.zip: } \\
\text { P2WR5C10-LDTH55-mi-mkt-15.m.EBS.ext (a) } \\
\text { P2WR5C10-LDTH55-mi-mkt-17.m.EBS.ext (a) } \\
\text { P2WR5C10-LDTH55-mi-mkt-15.f.EBS.ext (b) } \\
\text { P2WR5C10-LDTH55-mi-mkt-17.f.EBS.ext (b) }\end{array}$ & XTOOL v10.1 & \\
\hline $6.3-59$ & LL030808523122.035 & MSTHAC/mi_abstractions/OUTPUT/mi_P3@r\#51:49:1.ext.gz & XTOOL v10.1 & \\
\hline $6.3-60$ & LL040501323122.046 & $\begin{array}{l}\text { host-rock_study output_files/P2WR5C10-LDTH55-mi-tsw33-e2-09.m.EBS.ext (a,b) } \\
\text { host-rock_study output_files/P2WR5C10-LDTH55-mi-tsw34-e2-09.m.EBS.ext (a,b) } \\
\text { host-rock_study output_files/P2WR5C10-LDTH55-mi-tsw35-e2-09.m.EBS.ext (a,b) } \\
\text { host-rock_study output_files/P2WR5C10-LDTH55-mi-tsw36-e2-09.m.EBS.ext (a,b) } \\
\text { host-rock_study output_files/P2WR5C10-LDTH55-mi-tsw33-e1-09.m.EBS.ext (c,d) } \\
\text { host-rock_study output_files/P2WR5C10-LDTH55-mi-tsw34-e1-09.m.EBS.ext (c,d) } \\
\text { host-rock_study output_files/P2WR5C10-LDTH55-mi-tsw35-e1-09.m.EBS.ext (c,d) } \\
\text { host-rock_study output_files/P2WR5C10-LDTH55-mi-tsw36-e1-09.m.EBS.ext (c,d) } \\
\text { host-rock_study output_files/P2WR5C10-LDTH55-mi-tsw33-e-1-09.m.EBS.ext (e,f) } \\
\text { host-rock_study output_files/P2WR5C10-LDTH55-mi-tsw34-e-1-09.m.EBS.ext (e,f) }\end{array}$ & $\begin{array}{l}\text { MATLAB } \\
\text { v6.1.0.450 } \\
\text { (R12.1) }\end{array}$ & $\begin{array}{l}T_{\mathrm{dw}} \text { is the grid- } \\
\text { block-volume- } \\
\text { weighted average } \\
\text { for host-rock } \\
\text { gridblocks around } \\
\text { drift perimeter } \\
T_{\mathrm{ds}} \text { is the grid- } \\
\text { block-volume- } \\
\text { weighted average } \\
\text { around drip-shield } \\
\text { perimeter }\end{array}$ \\
\hline
\end{tabular}




\begin{tabular}{|c|c|c|c|c|}
\hline $\begin{array}{c}\text { Figure } \\
\text { No. }\end{array}$ & Data Source & File Name & $\begin{array}{l}\text { Plotting } \\
\text { Software }\end{array}$ & Notes \\
\hline & & $\begin{array}{l}\text { host-rock_study output_files/P2WR5C10-LDTH55-mi-tsw35-e-1-09.m.EBS.ext (e,f) } \\
\text { host-rock_study output_files/P2WR5C10-LDTH55-mi-tsw36-e-1-09.m.EBS.ext (e,f) } \\
\text { host-rock_study output_files/P2WR5C10-LDTH55-mi-tsw33-e-2-09.m.EBS.ext (g,h) } \\
\text { host-rock_study output_files/P2WR5C10-LDTH55-mi-tsw34-e-2-09.m.EBS.ext (g,h) } \\
\text { host-rock_study output_files/P2WR5C10-LDTH55-mi-tsw35-e-2-09.m.EBS.ext (g,h) } \\
\text { host-rock_study output_files/P2WR5C10-LDTH55-mi-tsw36-e-2-09.m.EBS.ext (g,h) }\end{array}$ & & \\
\hline $6.3-61$ & LL040501323122.046 & $\begin{array}{l}\text { host-rock_study output_files/P2WR5C10-LDTH55-mi-tsw33-e2-09.f.EBS.ext (a,b) } \\
\text { host-rock_study output_files/P2WR5C10-LDTH55-mi-tsw34-e2-09.f.EBS.ext (a,b) } \\
\text { host-rock_study output_files/P2WR5C10-LDTH55-mi-tsw35-e2-09.f.EBS.ext (a,b) } \\
\text { host-rock_study output_files/P2WR5C10-LDTH55-mi-tsw36-e2-09.f.EBS.ext (a,b) } \\
\text { host-rock_study output_files/P2WR5C10-LDTH55-mi-tsw33-e1-09.f.EBS.ext (c,d) } \\
\text { host-rock_study output_files/P2WR5C10-LDTH55-mi-tsw34-e1-09.f.EBS.ext (c,d) } \\
\text { host-rock_study output_files/P2WR5C10-LDTH55-mi-tsw35-e1-09.f.EBS.ext (c,d) } \\
\text { host-rock_study output_files/P2WR5C10-LDTH55-mi-tsw36-e1-09.f.EBS.ext (c,d) } \\
\text { host-rock_study output_files/P2WR5C10-LDTH55-mi-tsw33-e-1-09.f.EBS.ext (e,f) } \\
\text { host-rock_study output_files/P2WR5C10-LDTH55-mi-tsw34-e-1-09.f.EBS.ext (e,f) } \\
\text { host-rock_study output_files/P2WR5C10-LDTH55-mi-tsw35-e-1-09.f.EBS.ext (e,f) } \\
\text { host-rock_study output_files/P2WR5C10-LDTH55-mi-tsw36-e-1-09.f.EBS.ext (e,f) } \\
\text { host-rock_study output_files/P2WR5C10-LDTH55-mi-tsw33-e-2-09.f.EBS.ext (g,h) } \\
\text { host-rock_study output_files/P2WR5C10-LDTH55-mi-tsw34-e-2-09.f.EBS.ext (g,h) } \\
\text { host-rock_study output_files/P2WR5C10-LDTH55-mi-tsw35-e-2-09.f.EBS.ext (g,h) } \\
\text { host-rock_study output_files/P2WR5C10-LDTH55-mi-tsw36-e-2-09.f.EBS.ext (g,h) }\end{array}$ & $\begin{array}{l}\text { MATLAB } \\
\text { v6.1.0.450 } \\
\text { (R12.1) }\end{array}$ & $\begin{array}{l}R H_{\text {dw }} \text { is the grid- } \\
\text { block-volume- } \\
\text { weighted average } \\
\text { for host-rock } \\
\text { gridblocks around } \\
\text { drift perimeter } \\
R H_{\text {ds }} \text { is the grid- } \\
\text { block-volume- } \\
\text { weighted average } \\
\text { for drift gridblocks } \\
\text { around drip-shield } \\
\text { perimeter }\end{array}$ \\
\hline $6.3-62$ & LL040703123122.049 & $\begin{array}{l}\text { base-case_output/P2WR5C10-LDTH55-mi-mkt-02Q.m.EBS.ext.gz (a) } \\
\text { base-case_output/P2WR5C10-LDTH55-mi-mkt-02Q.f.EBS.ext.gz (b) } \\
\text { pseudo-kb_ouput/P2WR5C10-LDTH55-mi-mkt-kbe-12-02.m.EBS.ext.gz (a) } \\
\text { pseudo-kb_output/P2WR5C10-LDTH55-mi-mkt-kbe-12-02.f.EBS.ext.gz (b) } \\
\text { pseudo-kb_output/P2WR5C10-LDTH55-mi-mkt-kbe-10-02.m.EBS.ext.gz (a) } \\
\text { pseudo-kb_output/P2WR5C10-LDTH55-mi-mkt-kbe-10-02.f.EBS.ext.gz (b) } \\
\text { pseudo-kb_output/P2WR5C10-LDTH55-mi-mkt-kbe-9-02.m.EBS.ext.gz (a) }\end{array}$ & XTOOL v10.1 & $\begin{array}{l}T \text { ds at upper drip- } \\
\text { shield gridblock } \\
R H_{\text {ds }} \text { at drift block } \\
\text { above upper drip- } \\
\text { shield block }\end{array}$ \\
\hline
\end{tabular}




\begin{tabular}{|c|c|c|c|c|}
\hline $\begin{array}{c}\text { Figure } \\
\text { No. }\end{array}$ & Data Source & File Name & $\begin{array}{l}\text { Plotting } \\
\text { Software }\end{array}$ & Notes \\
\hline & & $\begin{array}{l}\text { pseudo-kb_output/P2WR5C10-LDTH55-mi-mkt-kbe-9-02.f.EBS.ext.gz (b) } \\
\text { pseudo-kb_output/P2WR5C10-LDTH55-mi-mkt-kbe-7-02.m.EBS.ext.gz (a) } \\
\text { pseudo-kb_output/P2WR5C10-LDTH55-mi-mkt-kbe-7-02.f.EBS.ext.gz (b) } \\
\text { pseudo-kb_output/P2WR5C10-LDTH55-mi-mkt-kbe-6-02.m.EBS.ext.gz (a) } \\
\text { pseudo-kb_output/P2WR5C10-LDTH55-mi-mkt-kbe-6-02.f.EBS.ext.gz (b) }\end{array}$ & & \\
\hline $6.3-63$ & LL040501323122.046 & $\begin{array}{l}\text { invert_study output_files/P2WR5C10-LDTH55-mi-mkt_tsw33inv-02.f.EBS.ext (a) } \\
\text { invert_study output_files/P2WR5C10-LDTH55-mi-mkt_tsw33inv-02.m.EBS.ext (b) } \\
\text { invert_study output_files/P2WR5C10-LDTH55-mi-mkt_tsw34inv-02.f.EBS.ext (a) } \\
\text { invert_study output_files/P2WR5C10-LDTH55-mi-mkt_tsw34inv-02.m.EBS.ext (b) } \\
\text { invert_study output_files/P2WR5C10-LDTH55-mi-mkt_tsw35inv-02.f.EBS.ext (a) } \\
\text { invert_study output_files/P2WR5C10-LDTH55-mi-mkt_tsw35inv-02.m.EBS.ext (b) } \\
\text { invert_study output_files/P2WR5C10-LDTH55-mi-mkt_tsw36inv-02.f.EBS.ext (a) } \\
\text { invert_study output_files/P2WR5C10-LDTH55-mi-mkt_tsw36inv-02.m.EBS.ext (b) }\end{array}$ & XTOOL v10.1 & $\begin{array}{l}\text { Sliq,inv is the grid- } \\
\text { block-volume- } \\
\text { weighted average } \\
\text { for the invert } \\
\text { gridblocks } \\
T_{\text {inv is the grid- }} \\
\text { block-volume- } \\
\text { weighted average } \\
\text { for the invert } \\
\text { gridblocks }\end{array}$ \\
\hline $6.3-64$ & LL040703123122.049 & $\begin{array}{l}\text { invert_study_output/P2WR5C10-LDTH55-mi-mkt_tsw33inv-02fninv.m.EBS.ext.gz (a) } \\
\text { invert_study_output/P2WR5C10-LDTH55-mi-mkt_tsw33inv-02fninv.f.EBS.ext.gz (b) } \\
\text { invert_study_output/P2WR5C10-LDTH55-mi-mkt_tsw34inv-02fninv.m.EBS.ext.gz (c) } \\
\text { invert_study_output/P2WR5C10-LDTH55-mi-mkt_tsw34inv-02fninv.f.EBS.ext.gz (d) } \\
\text { invert_study_output/P2WR5C10-LDTH55-mi-mkt_tsw35inv-02fninv.m.EBS.ext.gz (e) } \\
\text { invert_study_output/P2WR5C10-LDTH55-mi-mkt_tsw35inv-02fninv.f.EBS.ext.gz (f) } \\
\text { invert_study_output/P2WR5C10-LDTH55-mi-mkt_tsw36inv-02fninv.m.EBS.ext.gz (g) } \\
\text { invert_study_output/P2WR5C10-LDTH55-mi-mkt_tsw36inv-02fninv.f.EBS.ext.gz (h) }\end{array}$ & XTOOL v10.1 & $\begin{array}{l}T \text { and } R H \\
\text { obtained for } \\
\text { center gridblock at } \\
\text { upper invert layer } \\
\text { below drip shield }\end{array}$ \\
\hline $6.3-65$ & LL040703123122.049 & $\begin{array}{l}\text { invert_study_output/P2WR5C10-LDTH55-mi-mkt_tsw35inv-02fninv.m.EBS.ext.gz (a,b; } \\
\text { base case) } \\
\text { invert_study_output/P2WR5C10-LDTH55-mi-mkt_case1-02.m.EBS.ext.gz (a,b) } \\
\text { invert_study_output/P2WR5C10-LDTH55-mi-mkt_case2-02.m.EBS.ext.gz (a,b) } \\
\text { invert_study_output/P2WR5C10-LDTH55-mi-mkt_case3-02.m.EBS.ext.gz (a,b) } \\
\text { invert_study_output/P2WR5C10-LDTH55-mi-mkt_case4-02.m.EBS.ext.gz (a,b) } \\
\text { invert_study_output/P2WR5C10-LDTH55-mi-mkt_tsw35inv-02fninv.f.EBS.ext.gz (c; base } \\
\text { case) }\end{array}$ & XTOOL v10.1 & $\begin{array}{l}T \text { and } R H \\
\text { obtained for } \\
\text { center gridblock at } \\
\text { indicated locations }\end{array}$ \\
\hline
\end{tabular}




\begin{tabular}{|c|c|c|c|c|}
\hline $\begin{array}{c}\text { Figure } \\
\text { No. }\end{array}$ & Data Source & File Name & $\begin{array}{l}\text { Plotting } \\
\text { Software }\end{array}$ & Notes \\
\hline & & $\begin{array}{l}\text { invert_study_output/P2WR5C10-LDTH55-mi-mkt_case1-02.f.EBS.ext.gz (c) } \\
\text { invert_study_output/P2WR5C10-LDTH55-mi-mkt_case2-02.f.EBS.ext.gz (c) } \\
\text { invert_study_output/P2WR5C10-LDTH55-mi-mkt_case3-02.f.EBS.ext.gz (c) } \\
\text { invert_study_output/P2WR5C10-LDTH55-mi-mkt_case4-02.f.EBS.ext.gz (c) }\end{array}$ & & \\
\hline $6.3-66$ & LL040703123122.049 & $\begin{array}{l}\text { base-case_output/P2WR5C10-LDTH55-mi-mkt-02Q.m.EBS.ext.gz (a) } \\
\text { base-case_output/P2WR5C10-LDTH55-mi-mkt-02Q.f.EBS.ext.gz (b) } \\
\text { vent_study_output/P2WR5C10-LDTH55-mi-mkt-02.in-70p.m.EBS.ext.gz (a) } \\
\text { vent_study_output/P2WR5C10-LDTH55-mi-mkt-02.in-70p.f.EBS.ext.gz (b) } \\
\text { vent_study_output/P2WR5C10-LDTH55-mi-mkt-02.in-80p.m.EBS.ext.gz (a) } \\
\text { vent_study_output/P2WR5C10-LDTH55-mi-mkt-02.in-80p.f.EBS.ext.gz (b) } \\
\text { vent_study_output/P2WR5C10-LDTH55-mi-mkt-02.in-90p.m.EBS.ext.gz (a) } \\
\text { vent_study_output/P2WR5C10-LDTH55-mi-mkt-02.in-90p.f.EBS.ext.gz (b) } \\
\text { vent_study_output/P2WR5C10-LDTH55-mi-mkt-02.in-100p.m.EBS.ext.gz (a) } \\
\text { vent_study_output/P2WR5C10-LDTH55-mi-mkt-02.in-100p.f.EBS.ext.gz (b) }\end{array}$ & XTOOL v10.1 & $\begin{array}{l}T \text { ds at upper drip- } \\
\text { shield gridblock } \\
R H_{\text {ds }} \text { at drift block } \\
\text { above upper drip- } \\
\text { shield block }\end{array}$ \\
\hline $6.3-67$ & $\begin{array}{l}\text { LL030808523122.035 } \\
\text { LL030905931032.001 } \\
\text { LL030906331032.004 }\end{array}$ & 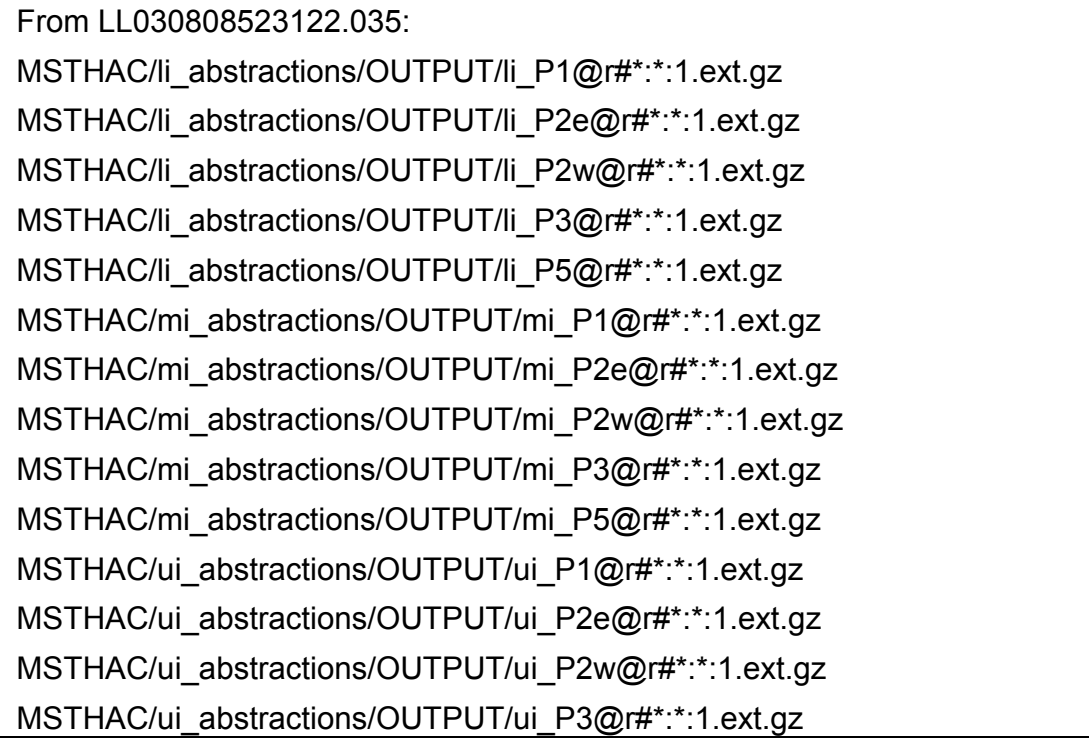 & $\begin{array}{l}\text { MATLAB } \\
\text { v6.1.0.450 } \\
\text { (R12.1) }\end{array}$ & \\
\hline
\end{tabular}




\begin{tabular}{|c|c|c|c|c|}
\hline $\begin{array}{c}\text { Figure } \\
\text { No. }\end{array}$ & Data Source & File Name & $\begin{array}{l}\text { Plotting } \\
\text { Software }\end{array}$ & Notes \\
\hline & & 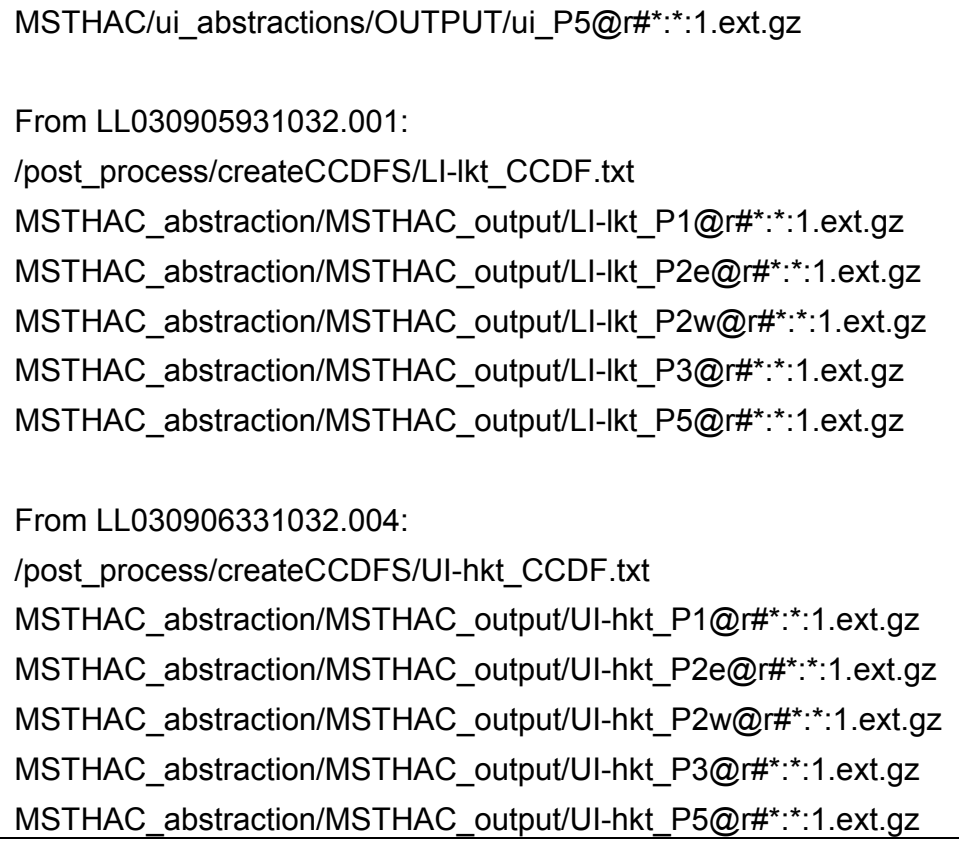 & & \\
\hline 6.3-68 & $\begin{array}{l}\text { LL030808523122.035 } \\
\text { LL030905931032.001 } \\
\text { LL030906331032.004 }\end{array}$ & 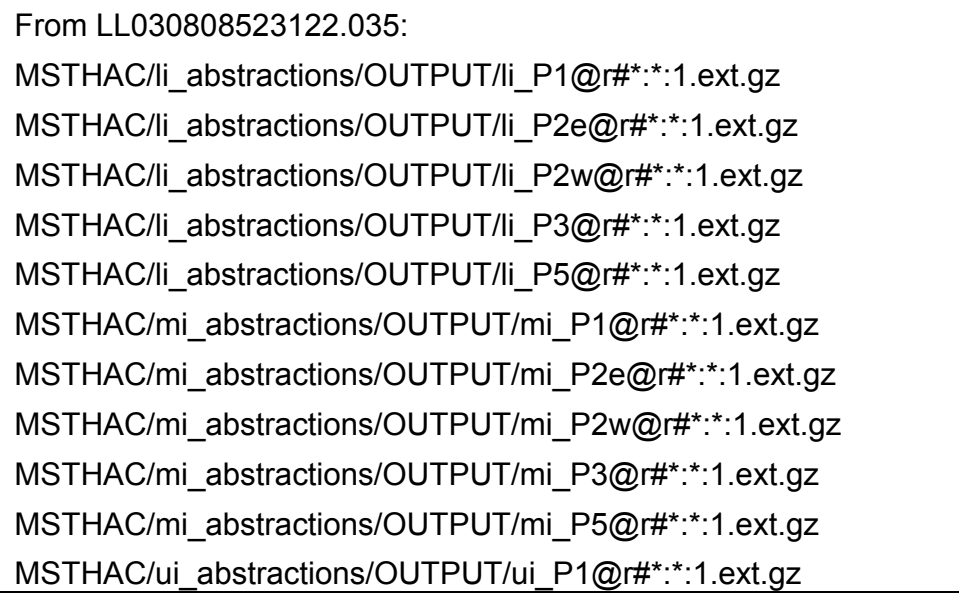 & $\begin{array}{l}\text { MATLAB } \\
\text { v6.1.0.450 } \\
\text { (R12.1) }\end{array}$ & \\
\hline
\end{tabular}




\begin{tabular}{|c|c|c|c|c|}
\hline $\begin{array}{c}\text { Figure } \\
\text { No. }\end{array}$ & Data Source & File Name & $\begin{array}{l}\text { Plotting } \\
\text { Software }\end{array}$ & Notes \\
\hline & & 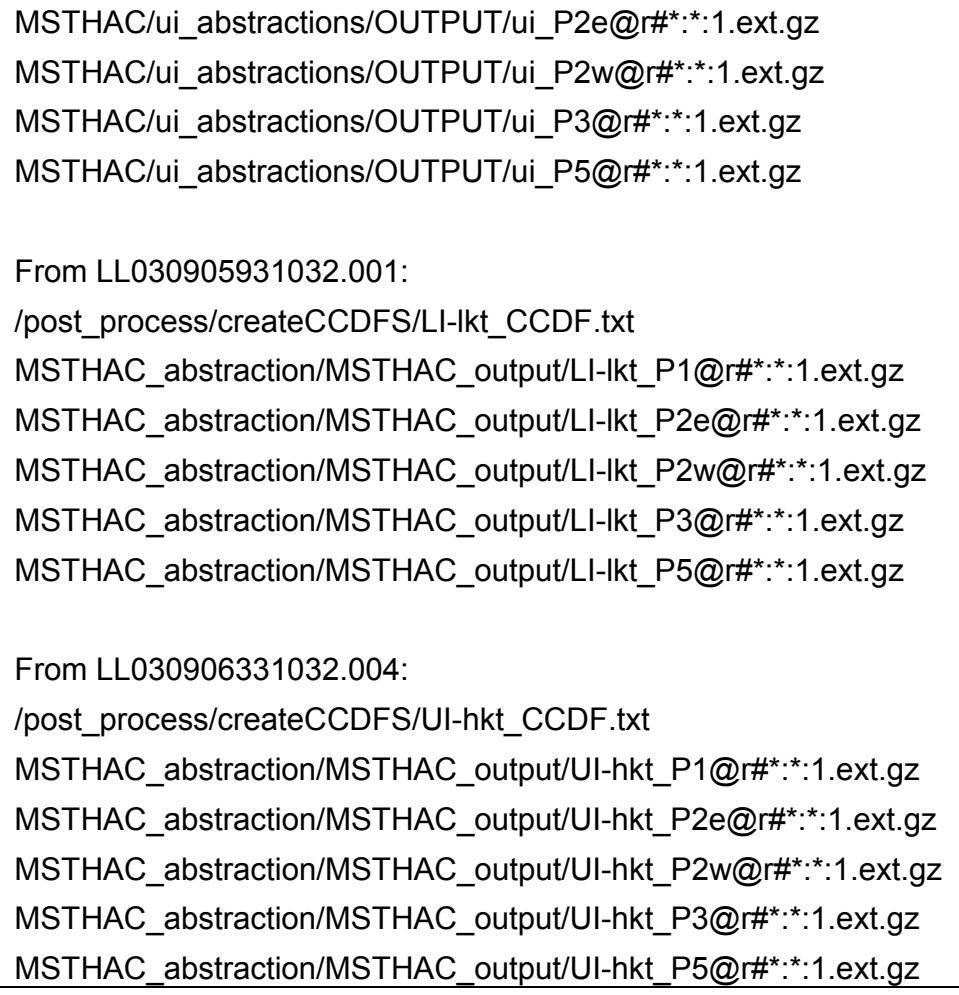 & & \\
\hline $6.3-69$ & $\begin{array}{l}\text { LL030808523122.035 } \\
\text { LL030905931032.001 } \\
\text { LL030906331032.004 }\end{array}$ & 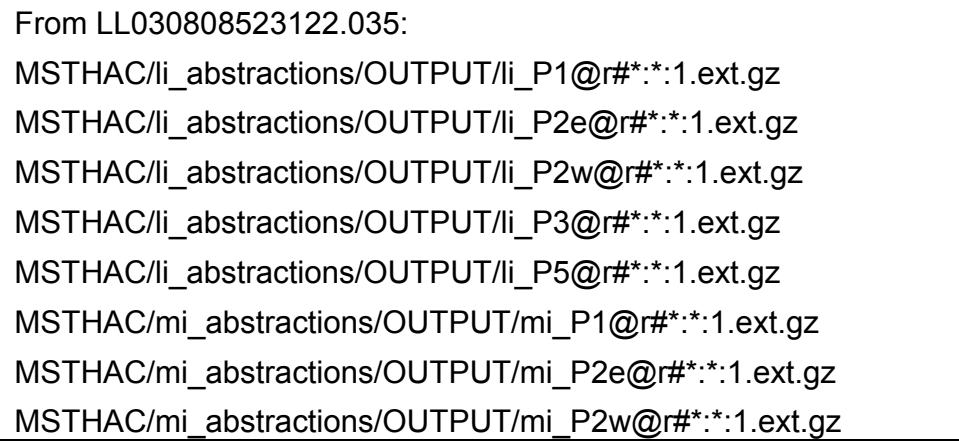 & $\begin{array}{l}\text { MATLAB } \\
\text { v6.1.0.450 } \\
\text { (R12.1) }\end{array}$ & \\
\hline
\end{tabular}


Table XIII-1. List of Data Sources for Figures (Continued)

\begin{tabular}{|c|c|c|c|c|}
\hline $\begin{array}{c}\text { Figure } \\
\text { No. }\end{array}$ & Data Source & File Name & $\begin{array}{l}\text { Plotting } \\
\text { Software }\end{array}$ & Notes \\
\hline & & 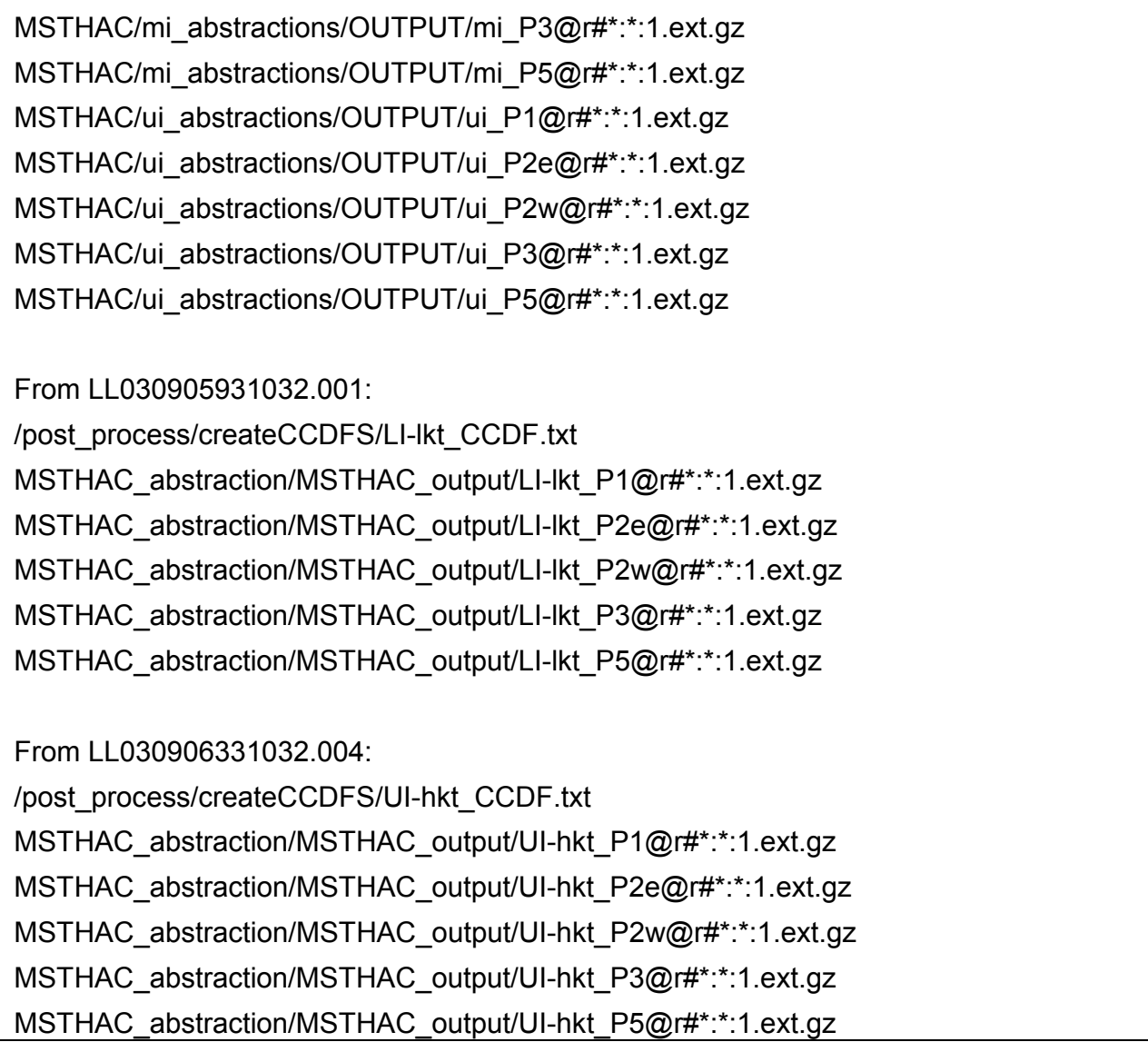 & & \\
\hline 7.3-1 & LL040703023122.048 & OUTPUTS/ms-valid-LBT-02.ST.m.ext.gz & XTOOL v10.1 & \\
\hline 7.3-2 & LL040703023122.048 & $\begin{array}{l}\text { OUTPUTS/ms-valid-LBT-02.ST.m.ext.gz } \\
\text { OUTPUTS/ms-valid-LBT-02.m.P.ext.gz }\end{array}$ & XTOOL v10.1 & \\
\hline 7.4-2 & LL030808923122.039 & MSTHM_large_block/DST/MAIN_RUN/OUTPUTS/ ms-valid-DST-03.m.ext (base case) & XTOOL v10.1 & \\
\hline $7.4-3$ & LL030808923122.039 & $\begin{array}{l}\text { MSTHM_large_block/DST/MAIN_RUN/OUTPUTS/ ms-valid-DST-03.m.xyz.T (base case) } \\
\text { MSTHM_large_block/DST/BH_SEAL/OUTPUTS/ ms-valid-DST-03-bhSeal.m.xyz.T }\end{array}$ & XTOOL v10.1 & \\
\hline
\end{tabular}




\begin{tabular}{|c|c|c|c|c|}
\hline $\begin{array}{c}\text { Figure } \\
\text { No. }\end{array}$ & Data Source & File Name & $\begin{array}{l}\text { Plotting } \\
\text { Software }\end{array}$ & Notes \\
\hline & & $\begin{array}{l}\text { (sealed bulkhead) } \\
\text { MSTHM_large_block/DST/SENSITIV/OUTPUTS/ ms-valid-DST-sensit-1htk.m.xyz.T (high } \\
K_{\text {th }} \text { ) } \\
\text { MSTHM_large_block/DST/SENSITIV_R/OUTPUTS/ ms-valid-DST-sensit-1htkr.m.xyz.T } \\
\text { (high } K_{\text {th }} \text {, restart run) }\end{array}$ & & \\
\hline $7.4-4$ & LL030808923122.039 & $\begin{array}{l}\text { MSTHM_large_block/DST/MAIN_RUN/OUTPUTS/ ms-valid-DST-03.m.xyz.T (base case) } \\
\text { MSTHM_large_block/DST/BH_SEAL/OUTPUTS/ ms-valid-DST-03-bhSeal.m.xyz.T } \\
\text { (sealed bulkhead) } \\
\text { MSTHM_large_block/DST/SENSITIV/OUTPUTS/ ms-valid-DST-sensit-1htk.m.xyz.T (high } \\
K_{\text {th }} \text { ) } \\
\text { MSTHM_large_block/DST/SENSITIV_R/OUTPUTS/ ms-valid-DST-sensit-1htkr.m.xyz.T } \\
\text { (high } K_{\text {th }} \text {, restart run) }\end{array}$ & XTOOL v10.1 & \\
\hline 7.4-5 & LL030808923122.039 & $\begin{array}{l}\text { MSTHM_large_block/DST/MAIN_RUN/OUTPUTS/ ms-valid-DST-03.m.xyz.T (base case) } \\
\text { MSTHM_large_block/DST/BH_SEAL/OUTPUTS/ ms-valid-DST-03-bhSeal.m.xyz.T } \\
\text { (sealed bulkhead) } \\
\text { MSTHM_large_block/DST/SENSITIV/OUTPUTS/ ms-valid-DST-sensit-1htk.m.xyz.T (high } \\
K_{\text {th }} \text { ) } \\
\text { MSTHM_large_block/DST/SENSITIV_R/OUTPUTS/ ms-valid-DST-sensit-1htkr.m.xyz.T } \\
\text { (high } K_{\text {th }} \text {, restart run) }\end{array}$ & XTOOL v10.1 & \\
\hline $7.4-6$ & LL030808923122.039 & $\begin{array}{l}\text { MSTHM_large_block/DST/MAIN_RUN/OUTPUTS/ ms-valid-DST-03.m.xyz.T (base case) } \\
\text { MSTHM_large_block/DST/BH_SEAL/OUTPUTS/ ms-valid-DST-03-bhSeal.m.xyz.T } \\
\text { (sealed bulkhead) } \\
\text { MSTHM_large_block/DST/SENSITIV/OUTPUTS/ ms-valid-DST-sensit-1htk.m.xyz.T (high } \\
K_{\text {th }} \text { ) } \\
\text { MSTHM_large_block/DST/SENSITIV_R/OUTPUTS/ ms-valid-DST-sensit-1htkr.m.xyz.T } \\
\text { (high } K_{\text {th }} \text {, restart run) }\end{array}$ & XTOOL v10.1 & \\
\hline 7.4-7 & LL030808923122.039 & $\begin{array}{l}\text { MSTHM_large_block/DST/MAIN_RUN/OUTPUTS/ ms-valid-DST-03.m.xyz.T (base case) } \\
\text { MSTHM_large_block/DST/BH_SEAL/OUTPUTS/ ms-valid-DST-03-bhSeal.m.xyz.T } \\
\text { (sealed bulkhead) } \\
\text { MSTHM_large_block/DST/SENSITIV/OUTPUTS/ ms-valid-DST-sensit-1htk.m.xyz.T (high } \\
K_{\text {th }} \text { ) } \\
\text { MSTHM_large_block/DST/SENSITIV_R/OUTPUTS/ ms-valid-DST-sensit-1htkr.m.xyz.T } \\
\text { (high } K_{\text {th }} \text {, restart run) }\end{array}$ & XTOOL v10.1 & \\
\hline
\end{tabular}


Table XIII-1. List of Data Sources for Figures (Continued)

\begin{tabular}{|c|c|c|c|c|}
\hline $\begin{array}{c}\text { Figure } \\
\text { No. }\end{array}$ & Data Source & File Name & $\begin{array}{l}\text { Plotting } \\
\text { Software }\end{array}$ & Notes \\
\hline $7.4-8$ & LL030808923122.039 & $\begin{array}{l}\text { MSTHM_large_block/DST/MAIN_RUN/OUTPUTS/ ms-valid-DST-03.m.xyz.T (base case) } \\
\text { MSTHM_large_block/DST/BH_SEAL/OUTPUTS/ ms-valid-DST-03-bhSeal.m.xyz.T } \\
\text { (sealed bulkhead) } \\
\text { MSTHM_large_block/DST/SENSITIV/OUTPUTS/ ms-valid-DST-sensit-1htk.m.xyz.T (high } \\
K_{\text {th) }} \\
\text { MSTHM_large_block/DST/SENSITIV_R/OUTPUTS/ ms-valid-DST-sensit-1htkr.m.xyz.T } \\
\text { (high } K_{\text {th }} \text {, restart run) }\end{array}$ & XTOOL v10.1 & \\
\hline $7.4-9$ & LL030808923122.039 & $\begin{array}{l}\text { MSTHM_large_block/DST/MAIN_RUN/OUTPUTS/ ms-valid-DST-03.m.xyz.T (base case) } \\
\text { MSTHM_large_block/DST/BH_SEAL/OUTPUTS/ ms-valid-DST-03-bhSeal.m.xyz.T } \\
\text { (sealed bulkhead) } \\
\text { MSTHM_large_block/DST/SENSITIV/OUTPUTS/ ms-valid-DST-sensit-1htk.m.xyz.T (high } \\
K_{\text {th }} \text { ) } \\
\text { MSTHM_large_block/DST/SENSITIV_R/OUTPUTS/ ms-valid-DST-sensit-1htkr.m.xyz.T } \\
\text { (high } K_{\text {th }} \text {, restart run) }\end{array}$ & XTOOL v10.1 & \\
\hline 7.4-10 & LL030808923122.039 & $\begin{array}{l}\text { MSTHM_large_block/DST/MAIN_RUN/OUTPUTS/ ms-valid-DST-03.m.xyz.T (base case) } \\
\text { MSTHM_large_block/DST/BH_SEAL/OUTPUTS/ ms-valid-DST-03-bhSeal.m.xyz.T } \\
\text { (sealed bulkhead) } \\
\text { MSTHM_large_block/DST/SENSITIV/OUTPUTS/ ms-valid-DST-sensit-1htk.m.xyz.T (high } \\
K_{\text {th) }} \\
\text { MSTHM_large_block/DST/SENSITIV_R/OUTPUTS/ ms-valid-DST-sensit-1htkr.m.xyz.T } \\
\text { (high } K_{\text {th }} \text {, restart run) }\end{array}$ & XTOOL v10.1 & \\
\hline 7.4-11 & LL030808923122.039 & $\begin{array}{l}\text { MSTHM_large_block/DST/MAIN_RUN/OUTPUTS/ ms-valid-DST-03.m.xyz.T (base case) } \\
\text { MSTHM_large_block/DST/BH_SEAL/OUTPUTS/ ms-valid-DST-03-bhSeal.m.xyz.T } \\
\text { (sealed bulkhead) } \\
\text { MSTHM_large_block/DST/SENSITIV/OUTPUTS/ ms-valid-DST-sensit-1htk.m.xyz.T (high } \\
K_{\text {th) }} \\
\text { MSTHM_large_block/DST/SENSITIV_R/OUTPUTS/ ms-valid-DST-sensit-1htkr.m.xyz.T } \\
\text { (high } K_{\text {th }} \text {, restart run) }\end{array}$ & XTOOL v10.1 & \\
\hline 7.4-12 & LL030808923122.039 & $\begin{array}{l}\text { MSTHM_large_block/DST/MAIN_RUN/OUTPUTS/ ms-valid-DST-03.m.xyz.T (base case) } \\
\text { MSTHM_large_block/DST/BH__SEAL/OUTPUTS/ ms-valid-DST-03-bhSeal.m.xyz.T } \\
\text { (sealed bulkhead) } \\
\text { MSTHM_large_block/DST/SENSITIV/OUTPUTS/ ms-valid-DST-sensit-1htk.m.xyz.T (high }\end{array}$ & XTOOL v10.1 & \\
\hline
\end{tabular}




\begin{tabular}{|c|c|c|c|c|}
\hline $\begin{array}{c}\text { Figure } \\
\text { No. }\end{array}$ & Data Source & File Name & $\begin{array}{l}\text { Plotting } \\
\text { Software }\end{array}$ & Notes \\
\hline & & $\begin{array}{l}\left.K_{\text {th }}\right) \\
\text { MSTHM_large_block/DST/SENSITIV_R/OUTPUTS/ ms-valid-DST-sensit-1htkr.m.xyz.T } \\
\text { (high } K_{\text {th }} \text {, restart run) }\end{array}$ & & \\
\hline $7.4-13$ & LL030808923122.039 & $\begin{array}{l}\text { MSTHM_large_block/DST/MAIN_RUN/OUTPUTS/ ms-valid-DST-03.m.xyz.T (base case) } \\
\text { MSTHM_large_block/DST/BH_SEAL/OUTPUTS/ ms-valid-DST-03-bhSeal.m.xyz.T } \\
\text { (sealed bulkhead) } \\
\text { MSTHM_large_block/DST/SENSITIV/OUTPUTS/ ms-valid-DST-sensit-1htk.m.xyz.T (high } \\
K_{\text {th }} \text { ) } \\
\text { MSTHM_large_block/DST/SENSITIV_R/OUTPUTS/ ms-valid-DST-sensit-1htkr.m.xyz.T } \\
\text { (high } K_{\text {th }} \text {, restart run) }\end{array}$ & XTOOL v10.1 & \\
\hline 7.4-14 & LL030808923122.039 & $\begin{array}{l}\text { MSTHM_large_block/DST/MAIN_RUN/OUTPUTS/ ms-valid-DST-03.m.xyz.T (base case) } \\
\text { MSTHM_large_block/DST/BH_SEAL/OUTPUTS/ ms-valid-DST-03-bhSeal.m.xyz.T } \\
\text { (sealed bulkhead) } \\
\text { MSTHM_large_block/DST/SENSITIV/OUTPUTS/ ms-valid-DST-sensit-1htk.m.xyz.T (high } \\
K_{\text {th) }} \\
\text { MSTHM_large_block/DST/SENSITIV_R/OUTPUTS/ ms-valid-DST-sensit-1htkr.m.xyz.T } \\
\text { (high } K_{\text {th }} \text {, restart run) }\end{array}$ & XTOOL v10.1 & \\
\hline 7.4-15 & LL030808923122.039 & $\begin{array}{l}\text { MSTHM_large_block/DST/MAIN_RUN/OUTPUTS/ ms-valid-DST-03.m.xyz.T (base case) } \\
\text { MSTHM_large_block/DST/BH_SEAL/OUTPUTS/ ms-valid-DST-03-bhSeal.m.xyz.T } \\
\text { (sealed bulkhead) } \\
\text { MSTHM_large_block/DST/SENSITIV/OUTPUTS/ ms-valid-DST-sensit-1htk.m.xyz.T (high } \\
K_{\text {th }} \text { ) } \\
\text { MSTHM_large_block/DST/SENSITIV_R/OUTPUTS/ ms-valid-DST-sensit-1htkr.m.xyz.T } \\
\text { (high } K_{\text {th }} \text {, restart run) }\end{array}$ & XTOOL v10.1 & \\
\hline 7.4-16 & LL030808923122.039 & MSTHM_large_block/DST/MAIN_RUN/OUTPUTS/ ms-valid-DST-03.m.ext (base case) & XTOOL v10.1 & \\
\hline $7.4-17$ & LL030808923122.039 & $\begin{array}{l}\text { MSTHM_large_block/DST/MAIN_RUN/OUTPUTS/ ms-valid-DST-03.m.xyz.S (base case) } \\
\text { MSTHM_large_block/DST/BH_SEAL/OUTPUTS/ ms-valid-DST-03-bhSeal.m.xyz.S } \\
\text { (sealed bulkhead) } \\
\text { MSTHM_large_block/DST/SENSITIV/OUTPUTS/ ms-valid-DST-sensit-1htk.m.xyz.S (high } \\
K_{\text {th }} \text { ) } \\
\text { MSTHM_large_block/DST/SENSITIV_R/OUTPUTS/ ms-valid-DST-sensit-1htkr.m.xyz.S } \\
\text { (high } K_{\text {th }} \text {, restart run) }\end{array}$ & XTOOL v10.1 & \\
\hline
\end{tabular}




\begin{tabular}{|c|c|c|c|c|}
\hline $\begin{array}{c}\text { Figure } \\
\text { No. }\end{array}$ & Data Source & File Name & $\begin{array}{c}\text { Plotting } \\
\text { Software }\end{array}$ & Notes \\
\hline $7.4-18$ & LL030808923122.039 & $\begin{array}{l}\text { MSTHM_large_block/DST/MAIN_RUN/OUTPUTS/ ms-valid-DST-03.m.xyz.S (base case) } \\
\text { MSTHM_large_block/DST/BH_SEAL/OUTPUTS/ ms-valid-DST-03-bhSeal.m.xyz.S } \\
\text { (sealed bulkhead) } \\
\text { MSTHM_large_block/DST/SENSITIV/OUTPUTS/ ms-valid-DST-sensit-1htk.m.xyz.S (high } \\
K_{\text {th }} \text { ) } \\
\text { MSTHM_large_block/DST/SENSITIV_R/OUTPUTS/ ms-valid-DST-sensit-1htkr.m.xyz.S } \\
\text { (high } K_{\text {th }} \text {, restart run) }\end{array}$ & XTOOL v10.1 & \\
\hline 7.4-19 & LL030808923122.039 & $\begin{array}{l}\text { MSTHM_large_block/DST/MAIN_RUN/OUTPUTS/ ms-valid-DST-03.m.xyz.S (base case) } \\
\text { MSTHM_large_block/DST/BH_SEAL/OUTPUTS/ ms-valid-DST-03-bhSeal.m.xyz.S } \\
\text { (sealed bulkhead) } \\
\text { MSTHM_large_block/DST/SENSITIV/OUTPUTS/ ms-valid-DST-sensit-1htk.m.xyz.S (high } \\
K_{\text {th }} \text { ) } \\
\text { MSTHM_large_block/DST/SENSITIV_R/OUTPUTS/ ms-valid-DST-sensit-1htkr.m.xyz.S } \\
\text { (high } K_{\text {th }} \text {, restart run) }\end{array}$ & XTOOL v10.1 & \\
\hline $7.4-20$ & LL030808923122.039 & MSTHM_large_block/DST/MAIN_RUN/OUTPUTS/ms-valid-DST-03.m.ext (base case) & XTOOL v10.1 & \\
\hline $7.5-2$ & LL040703223122.050 & $\begin{array}{l}\text { MSTHAC_center_output: } \\
\text { center_MSTHAC7_T_ds.ext.gz } \\
\text { center_MSTHAC7_T_dw.ext.gz } \\
\text { DLMTH_center_output: } \\
\text { ms-valid-anisot-cen-01r.m.T.EBS.ext.gz (no gas transport along drift) } \\
\text { ms-valid-anisot-cen-01rb.m.T.EBS.ext.gz (no gas transport along drift, restart) } \\
\text { ms-valid-anisot-cen-01rc.m.T.EBS.ext.gz (no gas transport along drift, restart) } \\
\text { ms-valid-anisot-cen-01rd.m.T.EBS.ext.gz (no gas transport along drift, restart) } \\
\text { ms-valid-anisot-cen-01re.m.T.EBS.ext.gz (no gas transport along drift, restart) } \\
\text { ms-valid-anisot-cen-01rf.m.T.EBS.ext.gz (no gas transport along drift, restart) } \\
\text { ms-valid-mixed-cen-01r.m.T.EBS.ext.gz (with sealed bulkhead) }\end{array}$ & XTOOL v10.1 & $\begin{array}{l}\text { D/LMDTH model: } \\
T_{\text {dw }} \text { is the grid- } \\
\text { block-volume- } \\
\text { weighted average } \\
\text { for host-rock } \\
\text { gridblocks around } \\
\text { drift perimeter } \\
T_{\text {ds }} \text { is the grid- } \\
\text { block-volume- } \\
\text { weighted average } \\
\text { around drip-shield } \\
\text { perimeter }\end{array}$ \\
\hline $7.5-3$ & LL040703223122.050 & $\begin{array}{l}\text { MSTHAC_center_output: } \\
\text { center_MSTHAC7_RH_ds.ext.gz } \\
\text { center_MSTHAC7_RH_dw.ext.gz }\end{array}$ & XTOOL v10.1 & $\begin{array}{l}\text { D/LMTH model: } \\
R H_{\text {dw }} \text { is the grid- } \\
\text { block-volume- } \\
\text { weighted average }\end{array}$ \\
\hline
\end{tabular}


Table XIII-1. List of Data Sources for Figures (Continued)

\begin{tabular}{|c|c|c|c|c|}
\hline $\begin{array}{c}\text { Figure } \\
\text { No. }\end{array}$ & Data Source & File Name & $\begin{array}{l}\text { Plotting } \\
\text { Software }\end{array}$ & Notes \\
\hline & & $\begin{array}{l}\text { DLMTH_center_output: } \\
\text { ms-valid-anisot-cen-01r.f.RH.EBS.ext.gz (no gas transport along drift) } \\
\text { ms-valid-anisot-cen-01rb.f.RH.EBS.ext.gz (no gas transport along drift, restart) } \\
\text { ms-valid-anisot-cen-01rc.f.RH.EBS.ext.gz (no gas transport along drift, restart) } \\
\text { ms-valid-anisot-cen-01rd.f.RH.EBS.ext.gz (no gas transport along drift, restart) } \\
\text { ms-valid-anisot-cen-01re.f.RH.EBS.ext.gz (no gas transport along drift, restart) } \\
\text { ms-valid-anisot-cen-01rf.f.RH.EBS.ext.gz (no gas transport along drift, restart) } \\
\text { ms-valid-mixed-cen-01r.f.RH.EBS.ext.gz (with sealed bulkhead) }\end{array}$ & & $\begin{array}{l}\text { for host-rock } \\
\text { gridblocks around } \\
\text { drift perimeter } \\
R H_{\text {ds }} \text { is the grid- } \\
\text { block-volume- } \\
\text { weighted average } \\
\text { for drift gridblocks } \\
\text { around drip-shield } \\
\text { perimeter }\end{array}$ \\
\hline $7.5-4$ & LL040703223122.050 & $\begin{array}{l}\text { MSTHAC_center_output: } \\
\text { center_MSTHAC7_S.liq_dw.ext.gz } \\
\text { center_MSTHAC7_S.liq_invert.ext.gz } \\
\text { DLMTH_center_output: } \\
\text { ms-valid-anisot-cen-01r.m.S.EBS.ext.gz (no gas transport along drift) } \\
\text { ms-valid-anisot-cen-01rb.m.S.EBS.ext.gz (no gas transport along drift, restart) } \\
\text { ms-valid-anisot-cen-01rc.m.S.EBS.ext.gz (no gas transport along drift, restart) } \\
\text { ms-valid-anisot-cen-01rd.m.S.EBS.ext.gz (no gas transport along drift, restart) } \\
\text { ms-valid-anisot-cen-01re.m.S.EBS.ext.gz (no gas transport along drift, restart) } \\
\text { ms-valid-anisot-cen-01rf.m.S.EBS.ext.gz (no gas transport along drift, restart) } \\
\text { ms-valid-mixed-cen-01r.m.S.EBS.ext.gz (with sealed bulkhead) }\end{array}$ & XTOOL v10.1 & $\begin{array}{l}\text { D/LMTH model: } \\
\text { Sliq,dw }_{\text {is the grid- }} \\
\text { block-volume- } \\
\text { weighted average } \\
\text { for host-rock } \\
\text { gridblocks around } \\
\text { drift perimeter } \\
\text { Sliq,inv is the grid- }_{\text {block-volume- }} \\
\text { weighted average } \\
\text { for the invert } \\
\text { gridblocks }\end{array}$ \\
\hline $7.5-5$ & LL040703223122.050 & $\begin{array}{l}\text { MSTHAC_edge_output: } \\
\text { edge_MSTHAC7_T_ds.ext.gz } \\
\text { edge_MSTHAC7_T_dw.ext.gz } \\
\text { DLMTH_edge_output: } \\
\text { ms-valid-anisot-edge-01r.m.T.EBS.ext.gz (no gas transport along drift) } \\
\text { ms-valid-mixed-edge-01r.m.T.EBS.ext.gz (with sealed bulkhead) } \\
\text { ms-valid-mixed-edge-01rb.m.EBS.T.ext.gz (with sealed bulkhead, restart) } \\
\text { ms-valid-mixed-edge-19.m.T.ext.gz (no bulkhead) } \\
\text { ms-valid-mixed-edge-19b.m.T.ext.gz (no bulkhead, restart) }\end{array}$ & XTOOL v10.1 & $\begin{array}{l}\text { D/LMDTH model: } \\
T_{\text {dw }} \text { is the grid- } \\
\text { block-volume- } \\
\text { weighted average } \\
\text { for host-rock } \\
\text { gridblocks around } \\
\text { drift perimeter } \\
T_{\text {ds is the grid- }} \\
\text { block-volume- } \\
\text { weighted average } \\
\text { around drip-shield } \\
\text { perimeter }\end{array}$ \\
\hline
\end{tabular}


Table XIII-1. List of Data Sources for Figures (Continued)

\begin{tabular}{|c|c|c|c|c|}
\hline $\begin{array}{c}\text { Figure } \\
\text { No. }\end{array}$ & Data Source & File Name & $\begin{array}{l}\text { Plotting } \\
\text { Software }\end{array}$ & Notes \\
\hline $7.5-6$ & LL040703223122.050 & $\begin{array}{l}\text { MSTHAC_edge_output: } \\
\text { edge_MSTHAC7_RH_ds.ext.gz } \\
\text { edge_MSTHAC7_RH_dw.ext.gz } \\
\text { DLMTH_edge_output: } \\
\text { ms-valid-anisot-edge-01r.f.RH.EBS.ext.gz (no gas transport along drift) } \\
\text { ms-valid-mixed-edge-01r.f.RH.EBS.ext.gz (with sealed bulkhead) } \\
\text { ms-valid-mixed-edge-01rb.f.RH.EBS.ext.gz (with sealed bulkhead, restart) } \\
\text { ms-valid-mixed-edge-19.f.RH.EBS.EBS.ext.gz (no bulkhead) } \\
\text { ms-valid-mixed-edge-19b.f.RH.EBS.EBS.ext.gz (no bulkhead, restart) }\end{array}$ & XTOOL v10.1 & $\begin{array}{l}\text { D/LMTH model: } \\
R H_{\text {dw }} \text { is the grid- } \\
\text { block-volume- } \\
\text { weighted average } \\
\text { for host-rock } \\
\text { gridblocks around } \\
\text { drift perimeter } \\
R H_{\text {ds }} \text { is the grid- } \\
\text { block-volume- } \\
\text { weighted average } \\
\text { for drift gridblocks } \\
\text { around drip-shield } \\
\text { perimeter }\end{array}$ \\
\hline $7.5-7$ & LL040703223122.050 & $\begin{array}{l}\text { MSTHAC_edge_output: } \\
\text { edge_MSTHAC7_S.liq_dw.ext.gz } \\
\text { edge_MSTHAC7_S.liq_invert.ext.gz } \\
\text { DLMTH_edge_output: } \\
\text { ms-valid-anisot-edge-01r.m.S.ext.gz (no gas transport along drift) } \\
\text { ms-valid-mixed-edge-01r.m.S.ext.gz (with sealed bulkhead) } \\
\text { ms-valid-mixed-edge-01rb.m.S.ext.gz (with sealed bulkhead, restart) } \\
\text { ms-valid-mixed-edge-19.m.S.ext.gz (no bulkhead) } \\
\text { ms-valid-mixed-edge-19b.m.S.ext.gz (no bulkhead, restart) }\end{array}$ & XTOOL v10.1 & $\begin{array}{l}\text { D/LMTH model: } \\
\text { Sliq,dw is the grid- }_{\text {block-volume- }} \\
\text { weighted average } \\
\text { for host-rock } \\
\text { gridblocks around } \\
\text { drift perimeter } \\
\text { Sliq,inv is the grid- }_{\text {block-volume- }} \\
\text { weighted average } \\
\text { for the invert } \\
\text { gridblocks }\end{array}$ \\
\hline
\end{tabular}


Table XIII-2. List of Data Sources for Tables

\begin{tabular}{|c|c|c|c|c|}
\hline $\begin{array}{c}\text { Table } \\
\text { No. }\end{array}$ & Data Source & File Name & $\begin{array}{l}\text { Plotting } \\
\text { Software }\end{array}$ & Notes \\
\hline $6.3-1$ & 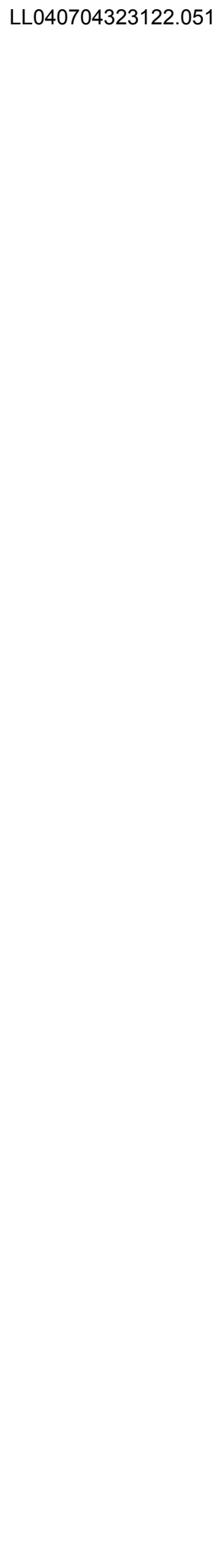 & 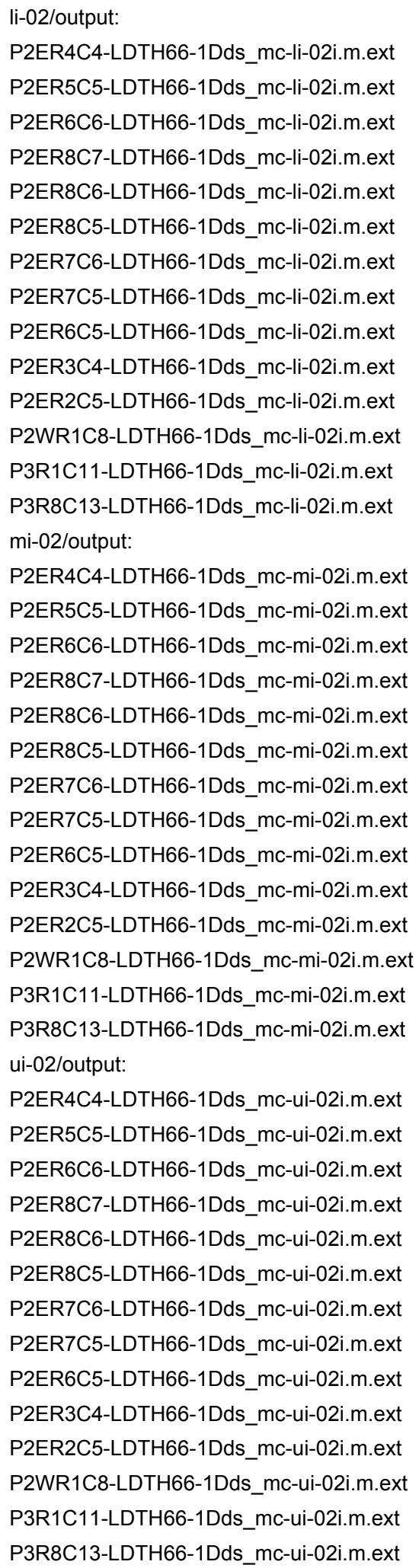 & $\begin{array}{l}\text { XTOOL } \\
\text { v10.1 }\end{array}$ & \\
\hline
\end{tabular}


Table XIII-2. List of Data Sources for Tables (Continued)

\begin{tabular}{|c|c|c|c|c|}
\hline $\begin{array}{c}\text { Table } \\
\text { No. }\end{array}$ & Data Source & File Name & $\begin{array}{l}\text { Plotting } \\
\text { Software }\end{array}$ & Notes \\
\hline $6.3-2$ & LL040704323122.051 & 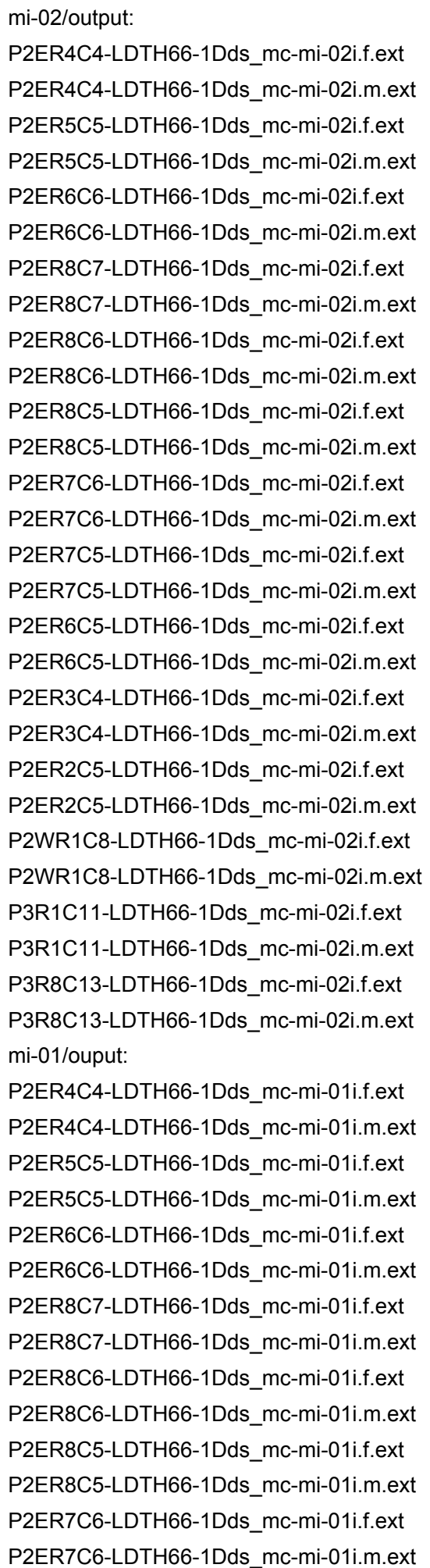 & $\begin{array}{l}\text { XTOOL } \\
\text { v10.1 }\end{array}$ & \\
\hline
\end{tabular}


Table XIII-2. List of Data Sources for Tables (Continued)

\begin{tabular}{|c|c|c|c|c|}
\hline $\begin{array}{c}\text { Table } \\
\text { No. }\end{array}$ & Data Source & File Name & $\begin{array}{l}\text { Plotting } \\
\text { Software }\end{array}$ & Notes \\
\hline & & $\begin{array}{l}\text { P2ER7C5-LDTH66-1Dds_mc-mi-01i.f.ext } \\
\text { P2ER7C5-LDTH66-1Dds_mc-mi-01i.m.ext } \\
\text { P2ER6C5-LDTH66-1Dds_mc-mi-01i.f.ext } \\
\text { P2ER6C5-LDTH66-1Dds_mc-mi-01i.m.ext } \\
\text { P2ER3C4-LDTH66-1Dds_mc-mi-01i.f.ext } \\
\text { P2ER3C4-LDTH66-1Dds_mc-mi-01i.m.ext } \\
\text { P2ER2C5-LDTH66-1Dds_mc-mi-01i.f.ext } \\
\text { P2ER2C5-LDTH66-1Dds_mc-mi-01i.m.ext } \\
\text { P2WR1C8-LDTH66-1Dds_mc-mi-01i.f.ext } \\
\text { P2WR1C8-LDTH66-1Dds_mc-mi-01i.m.ext } \\
\text { P3R1C11-LDTH66-1Dds_mc-mi-01i.f.ext } \\
\text { P3R1C11-LDTH66-1Dds_mc-mi-01i.m.ext } \\
\text { P3R8C13-LDTH66-1Dds_mc-mi-01i.f.ext } \\
\text { P3R8C13-LDTH66-1Dds_mc-mi-01i.m.ext }\end{array}$ & & \\
\hline
\end{tabular}




\section{APPENDIX XIV \\ QUALIFICATION OF UNQUALIFIED PROJECT DATA}


This appendix presents the results of the documentation of a data qualification task. The checking, reviewing, and documentation of the results of the data qualification activity are performed according to AP-SIII.2Q, Rev. 1 ICN 2, dated June 27, 2004. The following discussion addresses point by point the data qualification:

\section{Data Set for Qualification:}

The data set for qualification is DTN: MO0304MWDALACV.000 [DIRS 164551].

\section{Methods of Qualification Selected:}

The method selected for qualification is through the use of corroborating data. The data sets for ventilation efficiencies or heat generation fractions from the qualified source are compared to the source requiring qualification both spatially and temporally to determine if the comparisons satisfy the quantitative evaluation criteria. The rationale for this method is that if the heat mass fractions are in agreement to within the range of uncertainty, then the temperatures predicted at the drift wall from the average waste package line loading will be in agreement over the postclosure period that is analyzed in the multiscale thermohydrologic model.

\section{Evaluation Criteria:}

Appendix III presents the heat generation fractions derived from ventilation efficiencies for the various submodels used in this report. The DTN for ventilation efficiency (DTN: MO0304MWDALACV.000 [DIRS 164551]) requires qualification according to the data qualification plan (BSC 2004 [DIRS 170747]). This plan requires a comparison of the heat generation fraction (ventilation efficiencies) at times of 10,20,30, and 50 years at distances of $100,200,300,400,500,600,700$, and 800 meters from the ventilation inlet from DTN: MO0304MWDALACV.000 [DIRS 164551] with the qualified source from DTN: MO0306MWDASLCV.001 [DIRS 165695]. The criterion for data qualification is that the difference in heat generation fraction or ventilation efficiency from these two sources is less than 0.02 , or $2 \%$. This difference represents an estimate in the uncertainty in the data.

\section{Evaluation of the Technical Correctness of the Data, as Applicable:}

As documented in Ventilation Model and Analysis Report (BSC 2004 [DIRS 169862]), both analytical and finite element methods were developed for assessing spatial and temporal variations in ventilation efficiencies for use in repository preclosure analysis. These calculations show that for the selected repository design parameters, and existing thermal properties of the rock mass surrounding the emplacement drift at the repository horizon, a high ventilation efficiency is achievable over a range of conditions as predicted by either analytical or finiteelement methods and that the ventilation efficiency is insensitive to variations in rock thermal properties. The ventilation model was validated against measured data in Ventilation Model and Analysis Report (BSC 2004 [DIRS 169862]). Therefore, since the ventilation model is validated, correct ventilation efficiencies or heat mass fractions are calculated from the qualified source. 


\section{Data Generated by the Evaluation}

Table XIV-1 presents the heat generation fraction or ventilation efficiencies (rounded to three decimal places) at the times and locations from the source DTNs reproduced from Table III-1 and III-2, and the absolute value of the differences in these values that constitutes the data generated by this evaluation. The difference in heat generation fraction is equal to the difference in ventilation efficiency. The table shows that the criterion for data qualification from the plan is satisfied, with the maximum difference being 0.006 or $0.6 \%$.

Table XIV-1 Qualification of Heat Removal Fraction or Ventilation Efficiency

\begin{tabular}{|c|c|c|c|c|c|c|c|c|}
\hline \multirow{2}{*}{$\begin{array}{c}\text { Time } \\
\text { (yr) }\end{array}$} & \multicolumn{8}{|c|}{ Distance from Ventilation Inlet (m) } \\
\hline & 100 & 200 & 300 & 400 & 500 & 600 & 700 & 800 \\
\hline \multicolumn{9}{|c|}{ Net Available Heat Generation Fraction used in this Report from Table III-1. } \\
\hline 10 & 0.072 & 0.099 & 0.125 & 0.152 & 0.178 & 0.204 & 0.230 & 0.254 \\
\hline 20 & 0.043 & 0.069 & 0.094 & 0.118 & 0.143 & 0.167 & 0.192 & 0.213 \\
\hline 30 & 0.039 & 0.061 & 0.083 & 0.104 & 0.125 & 0.145 & 0.166 & 0.187 \\
\hline 50 & 0.009 & 0.027 & 0.045 & 0.064 & 0.081 & 0.100 & 0.117 & 0.135 \\
\hline \multicolumn{9}{|c|}{ Net Available Heat Generation Fraction from the Updated Data Source from Table III-2. } \\
\hline 10 & 0.071 & 0.098 & 0.123 & 0.149 & 0.175 & 0.200 & 0.225 & 0.248 \\
\hline 20 & 0.043 & 0.068 & 0.093 & 0.117 & 0.141 & 0.164 & 0.188 & 0.210 \\
\hline 30 & 0.040 & 0.062 & 0.083 & 0.104 & 0.125 & 0.146 & 0.166 & 0.186 \\
\hline 50 & 0.010 & 0.029 & 0.048 & 0.067 & 0.086 & 0.103 & 0.121 & 0.139 \\
\hline \multicolumn{9}{|c|}{ Difference between the Sources } \\
\hline 10 & 0.001 & 0.001 & 0.002 & 0.003 & 0.003 & 0.004 & 0.005 & 0.006 \\
\hline 20 & 0.000 & 0.001 & 0.001 & 0.001 & 0.002 & 0.003 & 0.004 & 0.003 \\
\hline 30 & 0.001 & 0.001 & 0.000 & 0.000 & 0.000 & 0.001 & 0.000 & 0.001 \\
\hline 50 & 0.001 & 0.002 & 0.003 & 0.003 & 0.005 & 0.003 & 0.004 & 0.004 \\
\hline
\end{tabular}

NOTE: Values presented in this table from Tables III-1 and III-2 are rounded to the third decimal place.

\section{EVALUATION RESULTS:}

Based upon the comparisons made above, and based upon the experience of the data qualification team, the data are qualified for use in the calculations reported in Section 6.3.

\section{Rationale for Abandoning any Qualification Methods, if Appropriate:}

Note that a single method was specified in the data qualification plan, and that there were no deviations from this plan. Therefore this item does not apply to the data qualification effort.

\section{Limits or Caveats Considered by Potential Users of the Data:}

The ventilation efficiency or heat mass fraction as presented in DTN: MO0304MWDALACV.000 [DIRS 164551] is based upon the current repository design involving an emplacement drift diameter of $5.5 \mathrm{~m}$; an emplacement drift spacing of $81 \mathrm{~m}$; an emplacement drift length varying from $600 \mathrm{~m}$ to $800 \mathrm{~m}$; a ventilation air flow rate of $15 \mathrm{~m}^{3} / \mathrm{sec}$; and a ventilation preclosure period of 50 years. The heat mass fraction from these DTNs is 
limited to this repository design. Any change in these design parameters would require a new analysis of heat mass fraction with the technical method of analysis presented in Ventilation Model and Analysis Report (BSC 2004 [DIRS 169862]).

\section{Identification of Any Supporting Information Used in the Qualification Effort:}

Note that the qualification is a direct comparison, and requires no supporting information other than the source DTN, and the method of analysis as presented in Ventilation Model and Analysis Report (BSC 2004 [DIRS 169862]).

\section{Data Qualification Plan:}

The data are qualified according to Data Qualification Plan, Qualification of DTN: MO0304MWDALACV.000 for Use in ANL-EBS-MD-000049 Rev02 (BSC 2004 [DIRS 170747]). 


\section{INTENTIONALLY LEFT BLANK}




\section{APPENDIX XV}

PREDICTION OF RH IN THE INVERT 
This appendix presents a method for the calculation of the relative humidity in the invert from the temperature and saturation time histories obtained from the multiscale thermohydrologic analysis. The method is being implemented in the total system performance assessment because of a problem in the method that MSTHAC Version 7.0 uses to calculate the invert relative humidity. The calculation presented in this appendix can be used to verify the calculation method used in the total system performance assessment. The saturation and temperature histories are obtained for P2WR5C10 as discussed below. The data for this prediction are obtained from DTN: LL040703123122.049, entitled Input and Output Files for the Sensitivity Studies for (1) Invert Intergranular Hydrologic Properties, (2) Pseudo Permeability of the GasFilled Drift Cavity, and (3) Ventilation Heat-Removal Efficiency, dated 14 July 2004.

Section XV.1 presents a partial list of basic thermophysical properties of water in Table XV-1 as obtained from Incropera and DeWitt (2002 [DIRS 163337], Table A.6 , pp. 924-925). Section XV.2 then defines three column vectors for the time, temperature, and matrix saturation histories over the time period from emplacement to 20,000 years after emplacement (from DTN: LL040703123122.049, PZWR5C10-LDTH55-mi-mkt-02Q.m.ebs.ext). A partial list of these column vectors is presented in Table XV-2. Section XV.3 then presents the governing relationships and Van Genuchten retention properties for the lower lithophysal unit. Also, this section defines the retention properties for the governing relationships. Section XV.4 then presents hand calculations that verify the MathCad 11 capillary pressure functions. Section XV.5 presents the governing relationships for the relative humidity calculation in the invert. Section XV.6 then presents the hand calculation for verification of the invert relative humidity calculation. Section XV.7 presents the MathCad 11 functions and the verification of these functions for relative humidity. Section XV.8 presents the comparison of relative humidity predictions from the MathCad 11 calculation with the multiscale thermohydrologic model. Section XV.9 presents the conclusions to the analysis.

The analyses presented in this appendix use MathCad 11 and EXCEL 97 for performing calculations and illustrating graphical output. The calculations have been performed using standard functions for this software, and the results illustrated are not dependent on the use of this software as evidenced by the independent verification of MathCad 11 functions by independent hand calculation in Section XV.4 and XV.6. The software does not need to follow LP-SI.11Q-BSC, Software Management, under Sections 2.1.2, and 2.1.6 of that procedure, because this standard industrial software is exempt.

The translation of information from DTN: LL040703123122.049 is shown in Figure XV-1. Note that in this figure an EXCEL workbook refers to the EXCEL file. The EXCEL workbook consists of several worksheets that refer to individual spreadsheets. The saturation, temperature, capillary pressure, and relative humidity information is downloaded through the following steps:

1. Access the technical data management system (TDMS) and locate DTN: LL040703123122.049 in the trace window. The trace type is "Get TDIF." In this window, click on the link on the upper right hand of the web page that you use to access the Model Warehouse Datatset.

2. Click button to download files. Note that at this stage, the address is ftp://sol.ymp.gov/pub11/LL040703123122.049/LDTH_Sensitivity_Studies/. 
3. Open the zip file LL040703123122_049.zip with Winzip and specify a directory for receipt of the data. Note that the zip file that is downloaded from the above site is large (over 200 megabytes). Now after downloading to the personal computer, Winzip can be used to extract (uncompress) the files. The extraction process generates a subfolder that contains other subfolders.

4. Locate directory base-case_output folder.

5. Locate and extract the file P2WR5C10-LDTH55-mi-mkt-02Q.m.ebs.ext. Note that the file is again a compressed file that needs to be extracted. This file represents the file datafile that is used by XTOOL Version 10.1 .

6. Note that XTOOL v10.1 works on a Sun workstation. The file then needs to be sent to a workstation with the current version of XTOOL v10.1.

7. Open the .ext file with File/Open.

8. Press "extraction" from the data menu.

9. Input the element name (in\#1:1:58) where the history data will be plotted.

10. Highlight $\mathrm{T}$ to save the temperature history into the buffer window. Highlight $\mathrm{S}$ to save the saturation history into the buffer window. The other variables are placed into the buffer window accordingly. Each of these histories is exported as text files entitled S_vs_t_P2WRC10_55_58.PLTSC, and T_vs_t_P2WR5C10_55_58.PLTSC to the EXCEL Inputs to the Prediction of the Invert.xls workbook; and Pcap_vs_t_P2WR5C10_55_58.PLTSC; and RH_vs_t_P2WR5C10_55_58.PLTSC to the EXCEL Outputs to the Prediction of the Invert.xls accordingly.

11. These files are placed in the workbook entitled Inputs to the Prediction of the Invert.xls in worksheets with the titles for the files respectively. The saturation, and temperature time histories are input to MathCad 11 as column vectors as Time, Temperature, and Saturation. The predicted capillary pressure and relative humidity is then exported with the Preout.prn textfile to EXCEL for comparison with the capillary pressure and relative humidity predicted by NUFT. Note that MathCad 11 uses a function entitled WRITEPRN(filename):= array to export data (capillary pressure and relative humidity time histories) that are then read on the worksheet MathCad in the Outputs to the Prediction of the Invert.xls.

12. The completion of steps 10 and 11 then allow for a comparison of the MathCad 11 calculation to data in the DTN. 


\section{Prediction of Relative Humidity(RH) in the Invert}

TDMS

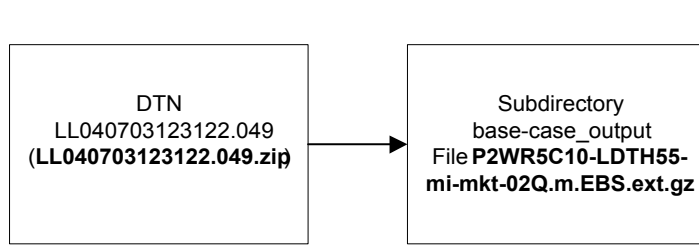

XTOOL v10.1

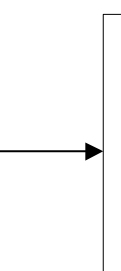

S_vs_t_P2WR5C10_55_58.PLTSC

T_vs_t_P2WR5C10_55_58.PLTSC

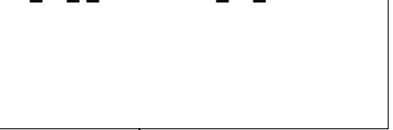

EXCEL INPUTS
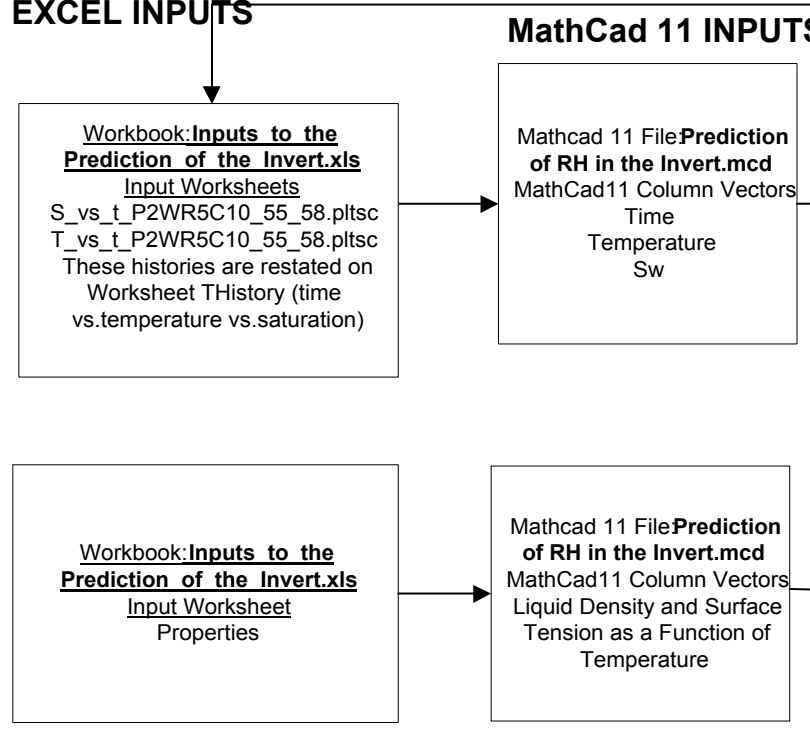

EXCEL OUTPUT

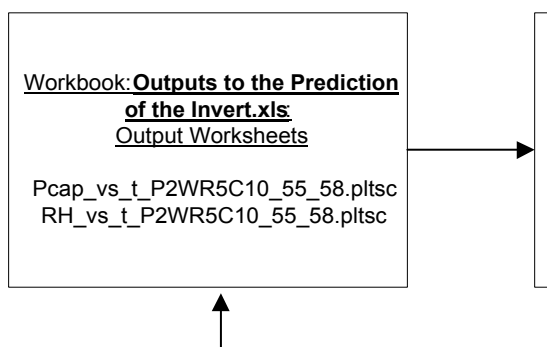

MathCad 11 Calculation

Mathcad 11 FilePrediction of RH in the Invert.mcd

MathCad11 Prediction of

Capillary Pressure versus Time and $\mathrm{RH}$ versus Time
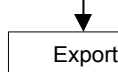
textfile Preout.prn

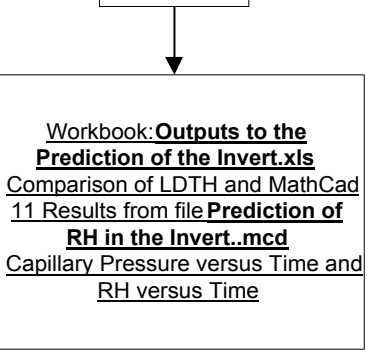

Note: Files shown in Bold.

Figure XV-1. Flow of Information for Extracting Invert Data

As shown in the figure, after the input and output histories are downloaded from the TDMS, the data are placed on the EXCEL worksheets in the workbook entitled Inputs_to_the_Prediction_of_the_Invert.xls. The thermophysical properties of water are also placed on the "Properties" worksheet. MathCad 11 then references these inputs as EXCEL 
components. After the calculations are processed in MathCad 11, the calculations are output to the EXCEL file Outputs_to_the_Prediction_of_the_Invert.xls on the "MathCad 11" worksheet for plotting purposes and for comparison to the $\bar{N}$ UFT calculations.

\section{XV.1 THERMOPHYSICAL PROPERTIES OF WATER}

Read in the properties of water vapor used to estimate the vapor pressure, the mass density, and the surface tension properties of the water as a function of temperature (Incropera and DeWitt, 2002 [DIRS 163337], pp. 924-925, Table A.6). The properties are used in the capillary pressure and relative humidity calculations from invert saturation. Table XV-1 is a partial list of these properties used in the calculations in subsequent sections. 
Table XV-1. Thermophysical Properties of Water

\begin{tabular}{|c|c|c|c|}
\hline \begin{tabular}{|c|} 
\\
Temperature $(\mathrm{K})$ \\
\end{tabular} & \begin{tabular}{|l|} 
Saturated \\
Vapor \\
Pressure \\
(Bars) \\
\end{tabular} & \begin{tabular}{|l|} 
Specific \\
Volume \\
$(\mathrm{m} 3 / \mathrm{kg})^{\star} 10^{\wedge}$ \\
3 \\
\end{tabular} & \begin{tabular}{|l|} 
Surface \\
Tension \\
$(\mathrm{N} / \mathrm{m})$ \\
$* 10^{\wedge} 3$ \\
\end{tabular} \\
\hline 273.15 & 0.00611 & 1 & 75.5 \\
\hline 275 & 0.00697 & 1 & 75.3 \\
\hline 280 & 0.0099 & 1 & 74.8 \\
\hline 285 & 0.01387 & 1 & 74.3 \\
\hline 290 & 0.01917 & 1.001 & 73.7 \\
\hline 295 & 0.02617 & 1.002 & 72.7 \\
\hline 300 & 0.03531 & 1.003 & 71.7 \\
\hline 305 & 0.04712 & 1.005 & 70.9 \\
\hline 310 & 0.06221 & 1.007 & 70 \\
\hline 315 & 0.08132 & 1.009 & 69.2 \\
\hline 320 & 0.1053 & 1.011 & 68.3 \\
\hline 325 & 0.1351 & 1.013 & 67.5 \\
\hline 330 & 0.1719 & 1.016 & 66.6 \\
\hline 335 & 0.2167 & 1.018 & 65.8 \\
\hline 340 & 0.2713 & 1.021 & 64.9 \\
\hline 345 & 0.3372 & 1.024 & \begin{tabular}{|l|}
64.1 \\
\end{tabular} \\
\hline 350 & 0.4163 & 1.027 & 63.2 \\
\hline 355 & 0.51 & 1.03 & \begin{tabular}{|l|}
62.3 \\
\end{tabular} \\
\hline 360 & 0.6209 & 1.034 & 61.4 \\
\hline 365 & 0.7514 & 1.038 & 60.5 \\
\hline 370 & 0.904 & 1.041 & 59.5 \\
\hline 373.15 & 1.0133 & 1.044 & 58.9 \\
\hline 375 & 1.0815 & 1.045 & 58.6 \\
\hline 380 & 1.2869 & 1.049 & 57.6 \\
\hline 385 & 1.5233 & 1.053 & 56.6 \\
\hline 390 & 1.794 & 1.058 & 55.6 \\
\hline 400 & 2.455 & 1.067 & 53.6 \\
\hline 410 & 3.302 & 1.077 & 51.5 \\
\hline 420 & 4.37 & 1.088 & 49.4 \\
\hline 430 & 5.699 & 1.099 & 47.2 \\
\hline 440 & 7.333 & 1.11 & 45.1 \\
\hline 450 & 9.319 & 1.123 & 42.9 \\
\hline 460 & 11.71 & 1.137 & \begin{tabular}{|l|}
40.7 \\
\end{tabular} \\
\hline 470 & 14.55 & 1.152 & 38.5 \\
\hline 480 & 17.9 & 1.167 & 36.2 \\
\hline 490 & 21.83 & 1.184 & 33.9 \\
\hline 500 & 26.4 & 1.203 & 31.6 \\
\hline 510 & 31.66 & 1.222 & 29.3 \\
\hline 520 & 37.7 & 1.244 & 26.9 \\
\hline
\end{tabular}

These properties are read from the workbook Inputs_to_the_Prediction_of_the_Invert.xls from worksheet Properties. Note that not all values are shown for the EXCEL component. The underlying worksheet does show all the values in the interpolation table.

Define the unit bar for expressing pressure results. 


$$
\begin{gathered}
\text { bar }:=10^{5} \cdot P a \\
P_{\text {sat }}(T):=\operatorname{linterp}\left[\left({ }_{B}^{\langle 0\rangle}\right), B^{\langle 1\rangle}, \frac{T}{K}\right] \cdot b a r \\
P_{\text {sat }}(342 \cdot K)=0.298 \mathrm{bar} \\
P_{\text {sat }}(342 \cdot K)=0.294 \mathrm{~atm}
\end{gathered}
$$

Define an interpolation function for the surface tension of the liquid water.

$$
\begin{gathered}
\sigma_{f}(T):=\operatorname{linterp}\left[\left(B^{\langle 0\rangle}\right), B^{\langle 3\rangle}, \frac{T}{K}\right] \cdot 10^{-3} \cdot \frac{N}{m} \\
\sigma_{f}(342 \cdot K)=0.06458 \frac{N}{m}
\end{gathered}
$$

Define the specific volume and density functions.

$$
\begin{gathered}
\operatorname{spev}(T):=\left[\operatorname{linterp}\left[\left(B^{\langle 0\rangle}\right), B^{\langle 2\rangle}, \frac{T}{K}\right]\right] \cdot \frac{\mathrm{cm}^{3}}{\mathrm{gm}} \\
\rho(T):=\frac{1}{\operatorname{spev}(T)} \\
\rho(300 \cdot K)=997.009 \frac{\mathrm{kg}}{\mathrm{m}^{3}}
\end{gathered}
$$

Note that these MathCad linear interpolation functions are verified in Section XV.4.

\section{XV.2 TEMPERATURE HISTORIES FROM THERMOHYDROLOGIC MODELING AND ANALYSIS}

Input the temperature and saturation $(\mathrm{Sw})$ histories for $\mathrm{P} 2 \mathrm{WR} 5 \mathrm{C} 10$. The data for this prediction are obtained from DTN: LL040703123122.049, entitled Input and Output Files for the Sensitivity Studies for (1) Invert Intergranular Hydrologic Properties, (2) Pseudo Permeability of the Gas-Filled Drift Cavity, and (3) Ventilation Heat-Removal Efficiency, dated 14 July 2004. 
Table XV-2. Invert Temperature and Saturation Time Histories for the P2WR5C10 Column

\begin{tabular}{|c|c|c|c|}
\hline Sw & $\begin{array}{r}\text { Time } \\
\text { (yrs) }\end{array}$ & $\begin{array}{c}\text { Temperature } \\
\text { C } \\
\end{array}$ & $\begin{array}{c}\text { Saturation } \\
(-)\end{array}$ \\
\hline & $\begin{array}{l}0.01 \\
\end{array}$ & 22.43 & 0.94 \\
\hline & 0.10 & 63.37 & 0.96 \\
\hline & 1.00 & 76.23 & 0.27 \\
\hline & 2.00 & 78.72 & 0.27 \\
\hline & 5.00 & 77.85 & 0.28 \\
\hline & 10.00 & 74.32 & 0.29 \\
\hline & 15.00 & 70.61 & 0.29 \\
\hline & 20.00 & 65.54 & 0.30 \\
\hline & 25.00 & 62.21 & 0.31 \\
\hline & 30.00 & 58.80 & 0.33 \\
\hline & 40.00 & 53.46 & 0.35 \\
\hline & 50.00 & 48.86 & 0.39 \\
\hline & 50.10 & 76.66 & 0.27 \\
\hline & 51.00 & 107.83 & 0.24 \\
\hline & 52.00 & 120.89 & 0.23 \\
\hline & 55.00 & 135.04 & 0.21 \\
\hline & 60.00 & 145.78 & 0.21 \\
\hline & 65.00 & 149.81 & 0.21 \\
\hline & 70.00 & 150.94 & 0.21 \\
\hline & 75.00 & 150.55 & 0.21 \\
\hline & 80.00 & 149.40 & 0.21 \\
\hline & 90.00 & 146.55 & 0.21 \\
\hline & 100.00 & 143.43 & 0.21 \\
\hline & 120.00 & 137.94 & 0.21 \\
\hline & 140.00 & 133.15 & 0.21 \\
\hline & 160.00 & 129.41 & 0.22 \\
\hline & 180.00 & 126.61 & 0.22 \\
\hline & 200.00 & 124.27 & 0.22 \\
\hline & 220.00 & 122.89 & 0.22 \\
\hline & 240.00 & 121.47 & 0.22 \\
\hline & 260.00 & 120.28 & 0.23 \\
\hline
\end{tabular}

These time histories are read from the workbook Inputs_to_the_Prediction_of_the_Invert.xls from worksheet THistory. Note that not all values are shown for the EXCEL component. Note that the Temperature and Saturation Histories are restated from the worksheets T_vs_t_P2WR5C10_55_58.pltsc and S_vs_t_P2WR5C10_55_58.pltsc, respectively. Note also that not all the data are shown in MathCad 11 for this EXCEL component. These time histories are restated on a single worksheet THistory that is derived from data on worksheets T_vs_t_P2WR5C10_55_58.pltsc and S_vs_t_P2WR5C10_55_58.pltsc. The data on THistory is then read into MathCad as an EXCEL component.

Figures $\mathrm{XV}-2$ and $\mathrm{XV}-3$ present the temperature and saturation ( $\mathrm{Sw}$ ) relationships as a function of time. Note that data plotting in these figures is performed in MathCad 11 and is considered qualified for graphical display of information. 


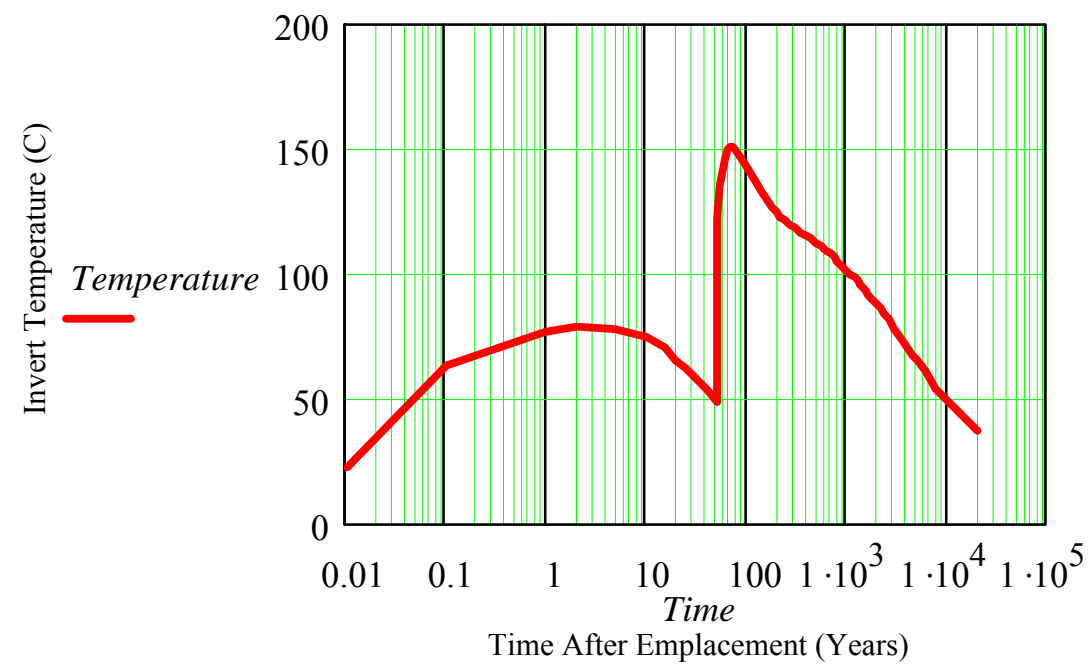

DTN: LL040703123122.049.

Figure XV-2. Invert Temperature History as a Function of Time (from Time versus Temperature on the Worksheet Thistory)

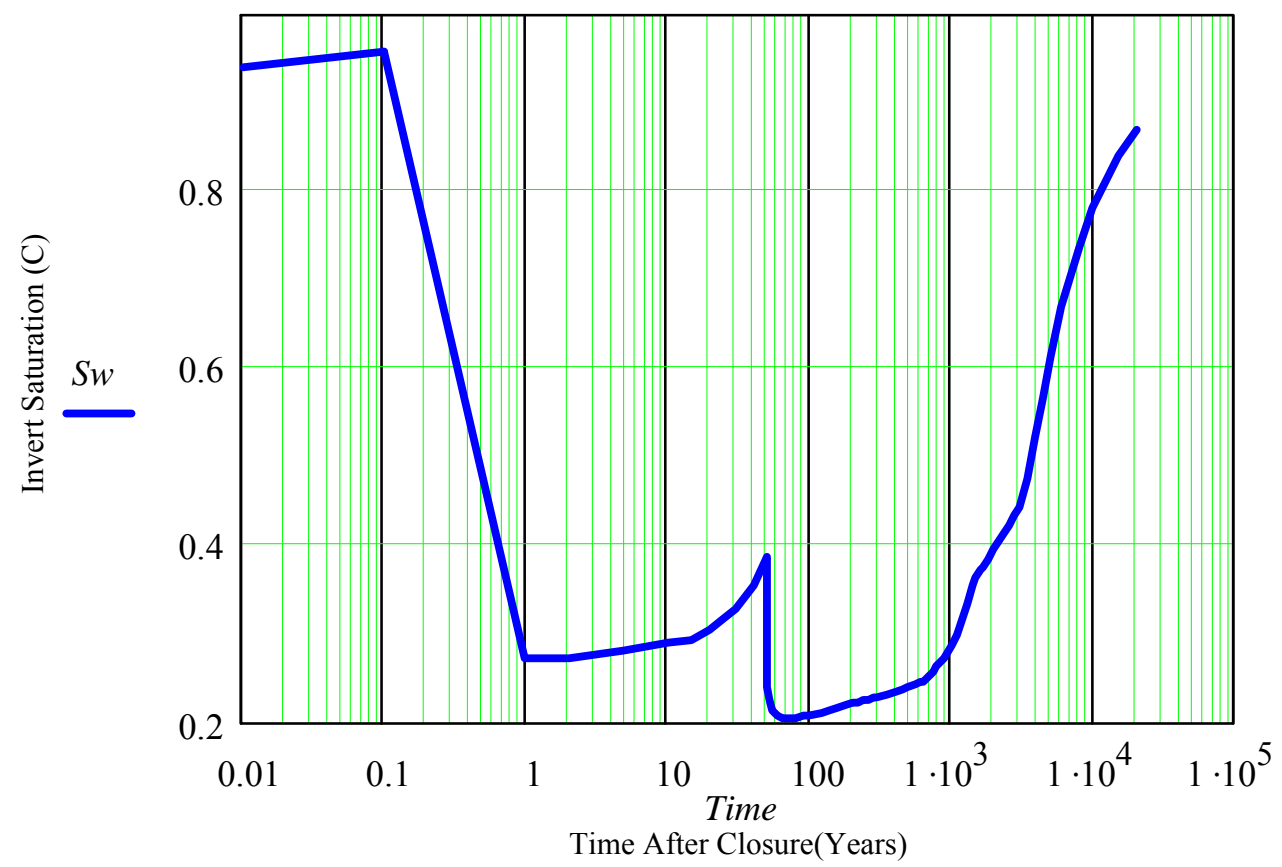

DTN: LL040703123122.049.

Figure XV-3. Invert Matrix Saturation History as a Function of Time (from Time versus Saturation on the Worksheet Thistory) 


\section{XV.3 GOVERNING RELATIONSHIPS AND VAN GENUCHTEN RETENTION PROPERTIES FOR THE LOWER LITHOPHYSAL UNIT}

This section presents the governing relationships and then presents the van Genuchten retention properties for the lower lithophysal unit used in the analysis.

The prediction of the moisture potential can be performed through the van Genuchten retention relationship for the tuff matrix (Fetter 1993 [DIRS 102009], p. 172):

$$
\theta\left(\psi_{m}\right)=\theta_{r}+\frac{\left(\theta_{s}-\theta_{r}\right)}{\left[1+\left|\alpha \psi_{m}{ }^{n}\right|\right]^{m}}
$$

where

$\begin{array}{ll}\theta & \text { Volumetric moisture content (-) } \\ \theta_{\mathrm{r}} & \text { Residual volumetric moisture content (-) } \\ \theta_{\mathrm{S}} & \text { Saturated volumetric moisture content (-) } \\ \psi_{\mathrm{m}} & \text { Moisture potential (bars or Pa)) } \\ \alpha & \text { Van Genuchten air entry parameter }\left(\mathrm{bar}^{-1} \text { or }^{\mathrm{Pa}^{-1}}\right) \\ \mathrm{n} & \text { Van Genuchten curve-fit parameter }(-) \text {, and } \\ \mathrm{m} & \text { Van Genuchten curve-fit parameter (-) }\end{array}$

Note that in NUFT, the moisture potential is expressed as a capillary pressure in which it is understood that the air entry parameter $\alpha$ is expressed in $(\mathrm{Pa})^{-1}$. Also, Fetter (1993 [DIRS 102009], p. 172) designates the (m) parameter for the van Genuchten relationship as: $m=1-1 / \mathrm{n}$. This value of " $\mathrm{m}$ " can be substituted into Equation XV-4 to derive the volumetric moisture content $(\theta)$ along with the notation:

$$
\theta\left(P_{c}\right)=\theta_{r}+\frac{\left(\theta_{s}-\theta_{r}\right)}{\left[1+\left(\left|P_{c} \alpha\right|\right)^{n}\right]^{\left(1-\frac{1}{n}\right)}}
$$

where

$$
\mathrm{P}_{\mathrm{c}}(\text { Capillary Pressure expressed in bars })=\psi_{\mathrm{m}}(\text { expressed in bars })
$$

In Equation XV-5, the moisture potential can be solved for in terms of the volumetric moisture content: 


$$
P_{c}(\theta)=\frac{\left[\left[\frac{\theta_{s}-\theta_{r}}{\theta-\theta_{r}}\right]^{\frac{1}{m}}-1\right]^{\frac{1}{n}}}{\alpha}
$$

The van Genuchten capillary pressure relationship for the tuff matrix (Fetter 1993 [DIRS 102009], p. 172) is for ambient temperature. Note that a correction for surface tension effects is necessary since surface tension is a function of temperature. Note that, as discussed by Hillel (1998 [DIRS 165404], pp38-44), the height of capillary rise or capillary pressure is a function of surface tension that in turn is a function of temperature. Therefore to calculate the correct capillary pressure, multiply the ambient capillary pressure by the ratio of the surface tension at elevated temperature to that at ambient temperature (set at 25 degrees Centigrade). The following calculation is performed in MathCad 11:

$$
P_{C}^{\prime}(\theta, T)=P_{C}(\theta) \cdot \frac{\sigma_{f}(T+273.15 \cdot K)}{\sigma_{f}(25 \cdot K+273.15 \cdot K)}
$$

where

$$
\mathrm{P}^{\prime} \mathrm{c}(\theta, \mathrm{T}) \text { is the capillary pressure corrected for surface tension effects }
$$

The moisture retention properties for the tuff matrix from the Tptpll unit (TSw35) are taken from Table IV-4 under the row heading tswM5 that corresponds to the material name m-tsw35 in the LDTH submodel. It should also be noted that the ratio $\left(\theta_{\mathrm{S}}-\theta_{\mathrm{r}}\right) /\left(\theta-\theta_{\mathrm{r}}\right)$ is equivalent to the ratio (1$\left.\mathrm{S}_{\mathrm{r}}\right) /\left(\mathrm{S}-\mathrm{S}_{\mathrm{r}}\right)$ that is used in NUFT.

$$
\begin{aligned}
& \theta_{S}:=0.131 \quad \theta_{r}:=0.12 \cdot \theta_{S} \quad \alpha:=1.08 \cdot{ }^{-5} \cdot \mathrm{Pa}^{-1} \quad \mathrm{~m}^{\prime}:=0.216 \\
& n:=\frac{1}{1-m^{\prime}}
\end{aligned}
$$

Input the universal gas constant and the molecular weight of water.

$$
\begin{array}{ll}
M:=18.016 \cdot \frac{\mathrm{gm}}{\mathrm{mole}} & R:=8.315 \cdot \frac{\mathrm{J}}{\mathrm{mole} \cdot \mathrm{K}} \\
\frac{\theta_{r}}{\theta_{S}}=0.12 & \theta_{r}=0.01572
\end{array}
$$

(Eq. XV-8) 


$$
\alpha=1.08 \times 10^{-5} \frac{1}{P a}
$$

Solve for $\theta$ as a function of Sw. Note that in the following equation, index notation is used to define the corresponding volumetric moisture content $(\Theta)$ for the saturation $(\mathrm{Sw})$. The index range is established by the statement $i:=0 \ldots \operatorname{rows}(\mathrm{S} w)-1$.

$$
i:=0 . . \operatorname{rows}(S w)-1 \quad \Theta_{i}:=\theta_{S} \cdot S w_{i}
$$

(Eq. XV-9)

Output the results of the calculation. The following table shows the relationship of volumetric

\begin{tabular}{|c|c|}
\hline \multirow{2}{*}{ Time $i=$} & $\Theta_{i}=$ \\
\hline & \begin{tabular}{|l}
0.123 \\
\end{tabular} \\
\hline \begin{tabular}{|r|}
0.01 \\
\end{tabular} & 0.125 \\
\hline 0.1 & 0.036 \\
\hline 1 & 0.035 \\
\hline 2 & 0.037 \\
\hline $\begin{array}{r}5 \\
10\end{array}$ & 0.038 \\
\hline$\frac{10}{15}$ & 0.038 \\
\hline 20 & 0.04 \\
\hline 25 & 0.041 \\
\hline 30 & 0.043 \\
\hline 40 & 0.046 \\
\hline 50 & 0.051 \\
\hline 50.1 & 0.035 \\
\hline 51 & 0.031 \\
\hline 52 & 0.03 \\
\hline 55 & 0.028 \\
\hline 60 & 0.027 \\
\hline 65 & 0.027 \\
\hline 70 & 0.027 \\
\hline 75 & 0.027 \\
\hline 80 & 0.027 \\
\hline 90 & 0.027 \\
\hline 100 & 0.027 \\
\hline 120 & 0.028 \\
\hline & 0.028 \\
\hline
\end{tabular}
moisture content as a function of time as derived from Equation XV-9.

Note that this is a partial listing of the data. The complete listing of the data are presented on Worksheet "Thistory" of the workbook Input to the Prediction of the Invert.xls.

Plot the invert volumetric moisture content as a function of time. 


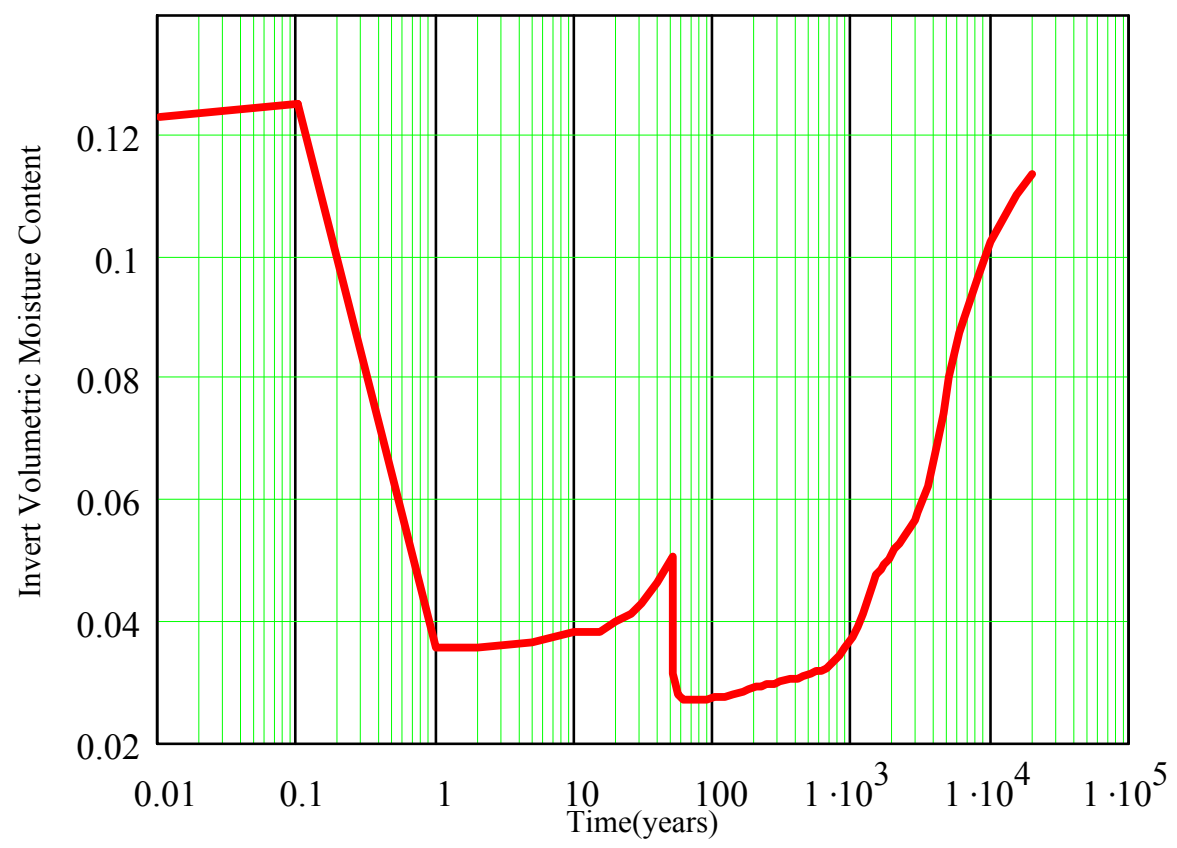

Figure XV-4. Invert Volumetric Moisture Content as a Function of Time

\section{XV.4 HAND CALCULATIONS FOR VERIFICATION OF MATHCAD FUNCTIONS}

Develop a hand calculation for verification of the relative humidity function. At 4,000 years the temperature of the invert is 70.5 degrees centigrade with a saturation of 0.52163 . Calculate the moisture potential in bars. From Equation XV-4:

$$
\begin{aligned}
& \theta=\theta_{r}+\frac{\left(\theta_{S}-\theta_{r}\right)}{\left[1+(\alpha \cdot \psi)^{n}\right]^{m}} \\
& S_{r}:=0.12 \quad S_{S}:=1
\end{aligned}
$$

Rewriting Equation XV-10:

$$
\frac{\theta-\theta_{r}}{\theta_{S}-\theta_{r}}=\frac{1}{\left[1+(\alpha \cdot \psi)^{n}\right]^{m}}
$$

or rewriting in terms of saturation: 


$$
\frac{S-S_{r}}{1-S_{r}}=\frac{1}{\left[1+\left(\alpha \cdot P_{C}\right)^{n}\right]^{m}}
$$

Substituting in the saturation:

$$
\begin{aligned}
& \frac{0.5216-0.12}{1-0.12}=\frac{1}{\left[1+\left(\alpha \cdot P_{C}\right)^{n}\right]^{m}} \\
& .4563=\frac{1}{\left[1+\left(\alpha \cdot P_{C}\right)^{n}\right]^{m}} \\
& {\left[1+\left(\alpha \cdot P_{C}\right)^{n}\right]^{m}=\frac{1}{.4563}} \\
& {\left[1+\left(\alpha \cdot P_{C}\right)^{n}\right]^{m}=2.191} \\
& 1+\left(\alpha \cdot P_{C}\right)^{n}=2.191^{\left(\frac{1}{0.216}\right)} \\
& 1+\left(\alpha \cdot P_{C}\right)^{n}=2.191^{4.6296} \\
& 1+\left(\alpha \cdot P_{C}\right)^{n}=37.760 \\
& \left(\alpha \cdot P_{C}\right)^{n}=37.760-1 \\
& \left(\alpha \cdot P_{C}\right)^{n}=36.760 \\
& \alpha \cdot P_{C}=36.760^{\frac{1}{1.276}} \\
& \alpha \cdot P_{C}=16.857
\end{aligned}
$$




$$
\begin{gathered}
P_{C}=\frac{16.857}{1.08 \cdot 10^{-5} \cdot \frac{1}{P a}} \\
P_{C}=1560833 \cdot P a
\end{gathered}
$$

or 15.60 Bars at a temperature of 70.5 degrees $\mathrm{C}$ at $4,000 \mathrm{yrs}$ and a saturation of 0.5216 .

Now consider the surface tension effects $\left(\sigma_{f}\right)$ and correct the capillary pressure function for surface tension effects. From Incropera and DeWitt (2002 [DIRS 163337], p. 924, Table A.6) and as reproduced in Table XV-1:

$$
\begin{aligned}
& \begin{array}{lll}
340 & 64.9 * 10^{-3} & 70.5 \cdot K+273.15 \cdot K=343.65 K
\end{array} \\
& \text { of }=\left[\frac{343.65-340}{345-340} \cdot(64.1-64.9)+64.9\right] \cdot 10^{-3} \cdot \frac{N}{m} \\
& \sigma f=64.3 \cdot 10^{-3} \cdot \frac{N}{m} \quad \text { for a temperature of } 70.5 \mathrm{C}
\end{aligned}
$$

Now calculate the surface tension at ambient temperature ( 25 degrees $C)$ :

$$
\begin{gathered}
273.15 \cdot K+25 \cdot K=298.15 \mathrm{~K} \\
295 \quad 72.7 * 10-3 \\
300 \quad 71.7 * 10-3 \\
\sigma f=\left[\frac{298.15-295}{300-295} \cdot(71.7-72.7)+72.7\right] \cdot 10^{-3} \cdot \frac{N}{m} \\
\text { of }=72.07 \cdot 10^{-3} \cdot \frac{N}{m}
\end{gathered}
$$

for a temperature of $25 \mathrm{C}$. 
Provide a capillary pressure correction based upon the ratio of the surface tension $(0.07207 \mathrm{~N} / \mathrm{m})$ at 25 degrees $\mathrm{C}$ and 70.5 degrees $\mathrm{C}$ :

$$
P_{C}^{\prime}=\left[\begin{array}{c}
1560833 . P a \cdot \frac{\left(64.3 \cdot 10^{-3} \cdot \frac{N}{m}\right)}{\left(72.07 \cdot 10^{-3} \cdot \frac{N}{m}\right)} \\
P_{C}^{\prime}=1392556 \cdot P a
\end{array}\right.
$$

Now calculate the density of water at this temperature. From Incropera and DeWitt (2002 [DIRS 163337], p. 924, Table A.6) and as reproduced in Table XV-1:

$$
\begin{aligned}
& 3401.021 * 10^{-3} \\
& 3451.024 * 10^{-3} \\
& {\left[\frac{343.65-340}{345-340} \cdot\left(1.024 \cdot 10^{-3}-1.021 \cdot 10^{-3}\right)+1.021 \cdot 10^{-3}\right] \cdot \frac{\mathrm{m}^{3}}{\mathrm{~kg}}} \\
& 977.3 \cdot \frac{\mathrm{kg}}{\mathrm{m}^{3}}
\end{aligned}
$$

(Eq. XV-34)

\section{XV.5 GOVERNING RELATIONSHIPS FOR RELATIVE HUMIDITY CALCULATION IN THE INVERT}

The relative humidity, $\mathrm{RH}\left(P_{\mathrm{c}}\right)$, in the invert can be expressed as a function of the moisture potential expressed as the capillary pressure through the soil-psychrometer relation (Kelvin equation) presented by Jury et al. (1991 [DIRS 102010], p. 60):

$$
R H\left(P_{C}\right)=P_{v} / P_{v}^{*}=\exp \left(\frac{M_{w} \cdot P_{c}^{\prime}}{\rho_{w} \cdot R \cdot T_{w}}\right)
$$

where

$\mathrm{P}^{\prime}{ }_{\mathrm{c}} \quad$ Capillary Pressure $(\mathrm{Pa})$ with surface tension correction

$\mathrm{M}_{\mathrm{w}} \quad$ Molecular weight of water $(\mathrm{kg} / \mathrm{mole})$,

$\rho_{\mathrm{w}} \quad$ Mass Density of Water $(\mathrm{kg} / \mathrm{m} 3)$

$\mathrm{T}_{\mathrm{w}} \quad$ Absolute temperature $(\mathrm{K})$

$\mathrm{P}_{\mathrm{V}} \quad$ Partial pressure of water $(\mathrm{Pa})$

$\mathrm{P}_{\mathrm{V}}^{*} \quad$ Saturated vapor pressure of water $(\mathrm{Pa})$

$\mathrm{R} \quad$ Universal Gas Constant $\left(8.315 \mathrm{~J} /\left(\right.\right.$ mole* $\left.\left.^{*}\right)\right)$ 


\section{XV.6 HAND CALCULATIONS FOR VERIFICATION OF THE MATHCAD FUNCTION FOR INVERT RELATIVE HUMIDITY}

The hand calculation for the corrected capillary pressure in Equation XV-32 is $1.393 * 10^{6} \mathrm{~Pa}$. Now substitute values into the Kelvin equation (Equation XV-35) to calculate the relative humidity. The hand calculation produces:

$$
\exp \left(M \cdot \psi \cdot \frac{1}{\rho(343.65 \cdot \mathrm{K}) \cdot R \cdot T}\right) \quad R=8.315 \frac{\mathrm{kgm}^{2}}{\mathrm{~s}^{2} \mathrm{~K} \mathrm{~mol}} \quad M=0.018016 \frac{\mathrm{kg}}{\mathrm{mol}}
$$

(Eq. XV-36)

$$
\begin{gathered}
\exp \left[\begin{array}{c}
18.016 \cdot \frac{\mathrm{gm}}{\mathrm{mole}} \cdot\left[-\left(1.395 \times 10^{6} \mathrm{~Pa}\right)\right] \cdot \frac{1}{977.3 \frac{\mathrm{kg}}{\mathrm{m}^{3}} \cdot\left(8.315 \frac{\left.\mathrm{kgm}^{2}\right)}{\mathrm{s}^{2} \mathrm{~K} \mathrm{~mol}}\right)} \cdot 343.65 \cdot \mathrm{K}
\end{array}\right] \\
=0.99104
\end{gathered}
$$

(Eq. XV-37)

Note that before the adjustment for surface tension, the capillary pressure was $1.56 * 10^{6} \mathrm{~Pa}$ as presented above. Therefore the capillary tension correction is about 11 percent.

\section{XV.7 MATHCAD FUNCTIONS AND VERIFICATION}

Note that in the relative humidity function presented below requires the moisture potential as a function of the volumetric moisture content. Define the inverse van Genuchten Moisture Retention Function. Note that in MathCad a := is equivalent to an assignment statement. Note also that the MathCad calculations in this Appendix are found in file Prediction of the RH in the Invert.mcd.

$$
\begin{gathered}
P_{C}(\theta):=\frac{\left.\left[\frac{\left(\theta_{S}-\theta_{r}\right)}{\left(\theta-\theta_{r}\right)}\right]^{\frac{1}{m^{\prime}}}-1\right]^{\frac{1}{n}}}{\alpha} \\
P_{C}^{\prime}(T, \theta):=P_{C}(\theta) \cdot \frac{\sigma_{f}(T+273.15 \cdot K)}{\sigma_{f}(25 \cdot K+273.15 \cdot K)}
\end{gathered}
$$


Define the relative humidity function on the basis of temperature, and volumetric moisture content.

$$
R E L 2(T, \theta):=\exp \left[\frac{-P_{C}^{\prime}(T, \theta)}{\rho(T+273.15 \cdot K)} \cdot \frac{1 \cdot M}{R \cdot(T+273.15 \cdot K)}\right]
$$

(Eq. XV-40)

The MathCad 11 functions presented above produce the following results that are in agreement with the hand calculations presented in Sections XV.4 and XV.6. The functions are therefore verified.

$$
\begin{gathered}
P_{C}\left(0.5216 \cdot \theta_{S}\right)=1.56321 \times 10^{6} \mathrm{~Pa} \\
\sigma_{f}(343.65 \cdot K)=0.064 \frac{\mathrm{N}}{\mathrm{m}} \\
\rho(343.65 \cdot K)=977.336 \frac{\mathrm{kg}}{\mathrm{m}^{3}} \\
-P_{C}\left(0.52163 \cdot \theta_{S}\right) \cdot \frac{\sigma_{f}(70.5 \cdot K+273.15 \cdot K)}{\sigma_{f}(25 \cdot K+273.15 \cdot K)}=-1.395 \times 10^{6} \mathrm{~Pa} \\
R E L 2\left(70.5 \cdot K, 0.52163 \cdot \theta_{S}\right)=0.99104
\end{gathered}
$$

Now develop the capillary pressure relationship (after surface tension correction) as a function of time. The data are output in the following arrays and Figure XV-5 presents a plot of the data. 


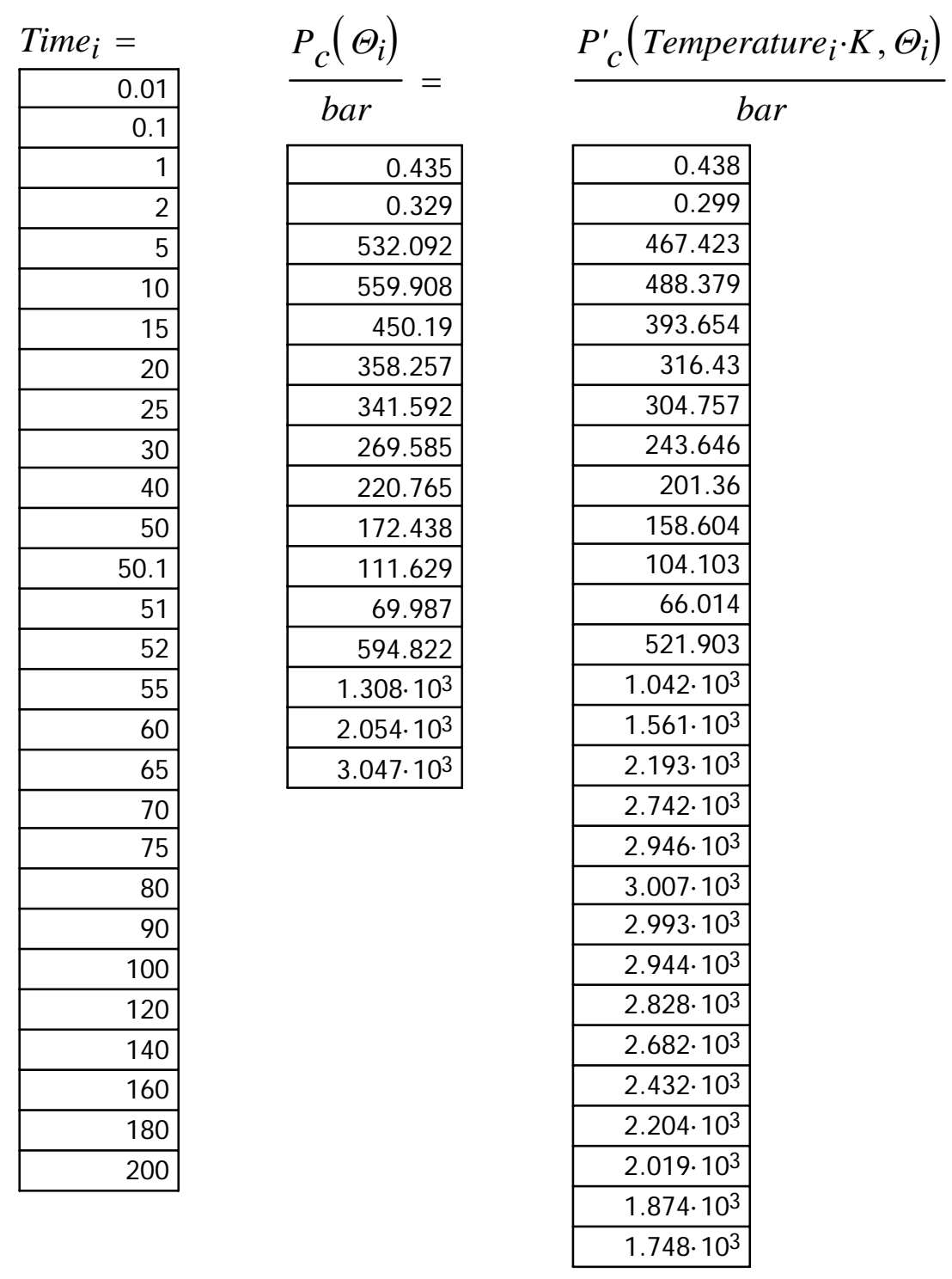

Note that MathCad 11 illustrates a portion of the results. The results are exported to the EXCEL workbook entitled Output_to_the_Prediction_of_Invert.xls on the MathCad 11 worksheet. 


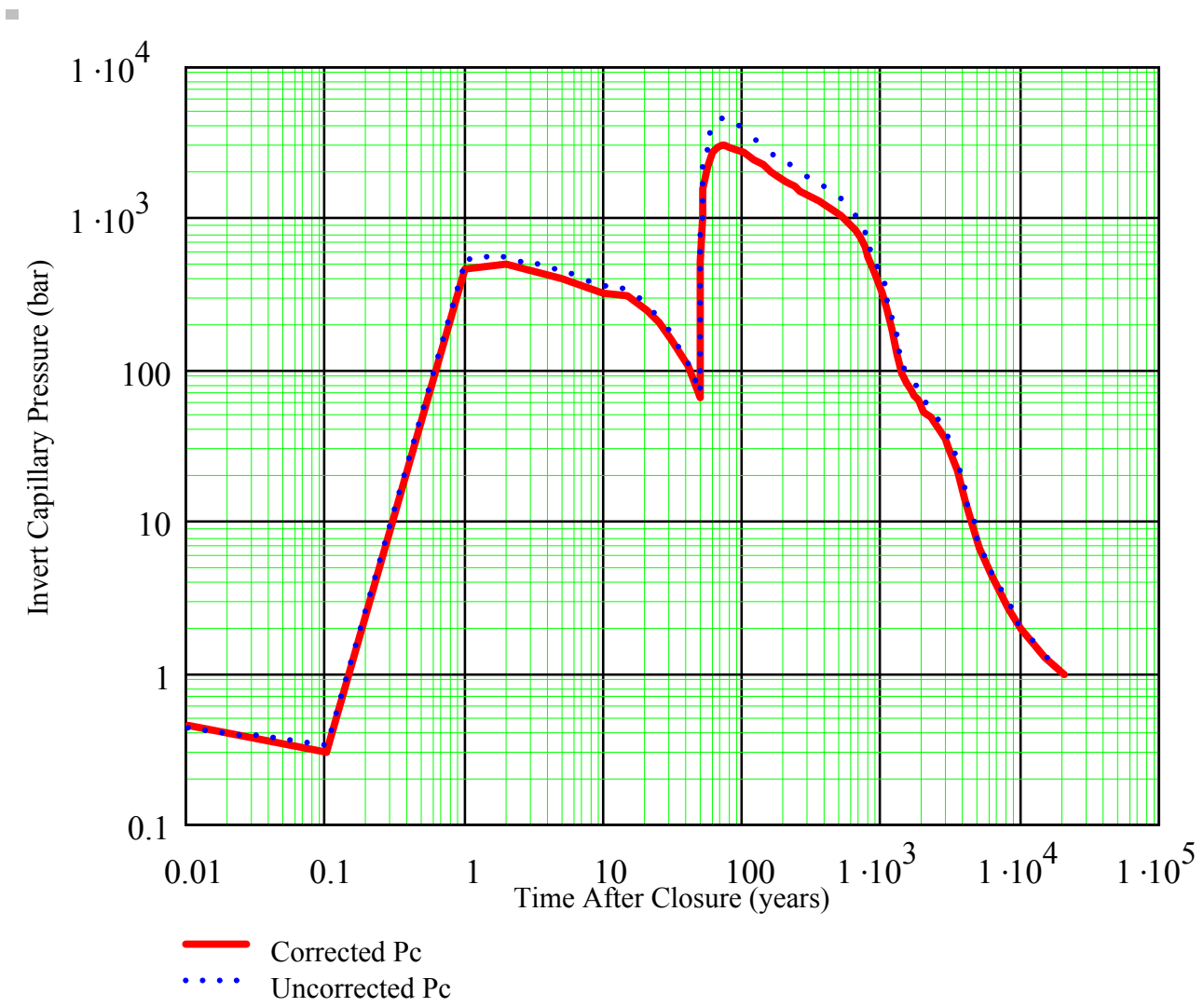

Figure XV-5. Invert Capillary Pressure and Corrected Capillary Pressure as a Function of Time

Note that MathCad 11 illustrates a portion of the results. The results are exported to the EXCEL workbook entitled Output_to_the_Prediction_of_Invert.xls on the MathCad 11 worksheet. 


\begin{tabular}{|c|c|}
\hline Time $_{i}=$ & $\operatorname{REL}\left(\right.$ Temperature $\left._{i} \cdot K, \Theta_{i}\right)$ \\
\hline 0.01 & \begin{tabular}{|l|}
0.99968 \\
\end{tabular} \\
\hline 0.1 & 0.9998 \\
\hline 1 & 0.74261 \\
\hline 2 & 0.73405 \\
\hline 5 & 0.77903 \\
\hline 10 & 0.81682 \\
\hline 15 & 0.82156 \\
\hline 20 & 0.85298 \\
\hline 25 & 0.87593 \\
\hline 30 & 0.90009 \\
\hline 40 & 0.93237 \\
\hline 50 & 0.95605 \\
\hline 50.1 & 0.71752 \\
\hline 51 & 0.53676 \\
\hline 52 & 0.40195 \\
\hline 55 & 0.286 \\
\hline 60 & 0.21409 \\
\hline 65 & 0.19263 \\
\hline 70 & 0.18668 \\
\hline 75 & 0.18797 \\
\hline 80 & 0.19268 \\
\hline 90 & 0.20436 \\
\hline 100 & 0.22038 \\
\hline 120 & 0.25106 \\
\hline 140 & 0.2832 \\
\hline 160 & 0.31273 \\
\hline 180 & 0.33837 \\
\hline 200 & 0.36249 \\
\hline 220 & 0.37956 \\
\hline 240 & 0.39727 \\
\hline
\end{tabular}

Note that MathCad 11 plots presented in Figures XV-6 and XV-7 are exported to the EXCEL workbook entitled Output_to_the_Prediction_of_Invert.xls on the MathCad 11 worksheet. A complete listing of the data is presented. 


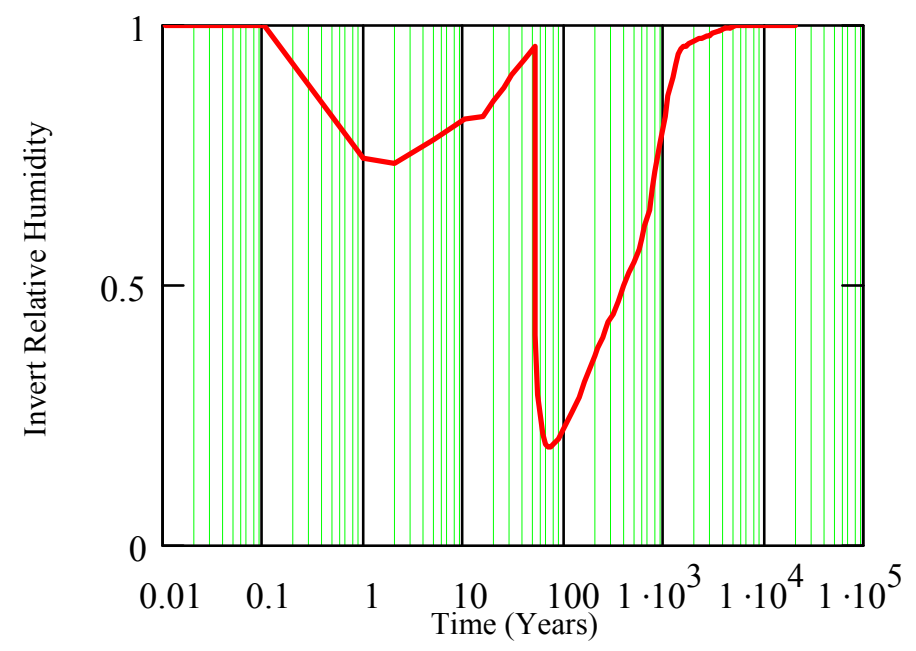

Figure XV-6. Relationship of Invert Relative Humidity to Time

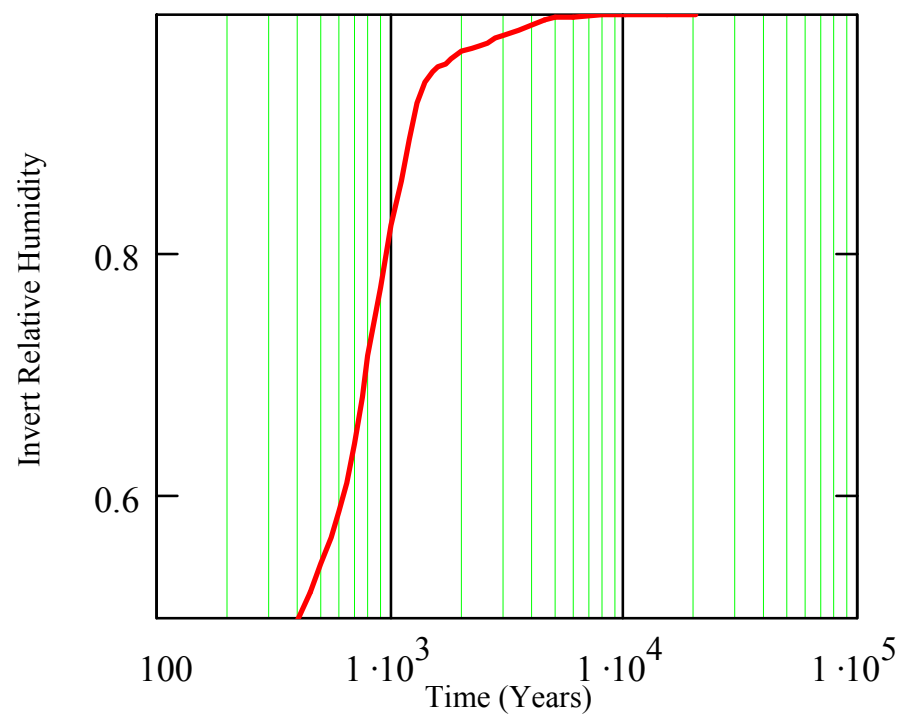

Figure XV-7. Relationship of Invert Relative Humidity over the Range from 0.50 to 1.0 After 100 Years 
Write the MathCad 11 results to an output file for comparing results to the LDTH model. These results are then placed on the worksheet MathCad 11 of the workbook Output_to_the_Prediction_of_Invert.xls. The EXCEL worksheet presents a complete listing of the output.

$$
\begin{aligned}
& A^{A R H_{i}, 0}:=\text { Time }_{i} \\
& \text { ARH }_{i, 1}:=\text { REL2 }\left(\text { Temperature }_{i} \cdot K, \Theta_{i}\right) \\
& \text { ARH }_{i, 2}:=\frac{P_{C}^{\prime}\left(\text { Temperature }_{i} \cdot K, \Theta_{i}\right)}{\text { bar }} \\
& \text { WRITEPRN("Preout') }:=A R H
\end{aligned}
$$

\section{XV.8 COMPARISON OF RELATIVE HUMIDITY PREDICTIONS FROM THE MATHCAD 11 CALCULATION WITH THE MULTISCALE THERMOHYDROLOGIC MODEL}

The tabulated relative humidity and capillary pressure results along with the results generated from the MathCad 11 File Prediction of the RH in the Invert Rev01 for P2WR5C10 are presented in the EXCEL workbook Output_to_the_Prediction_of_Invert.xls. Figures XV-8 through XV-9 present the comparisons between the two calculations. The calculations are in close agreement. 


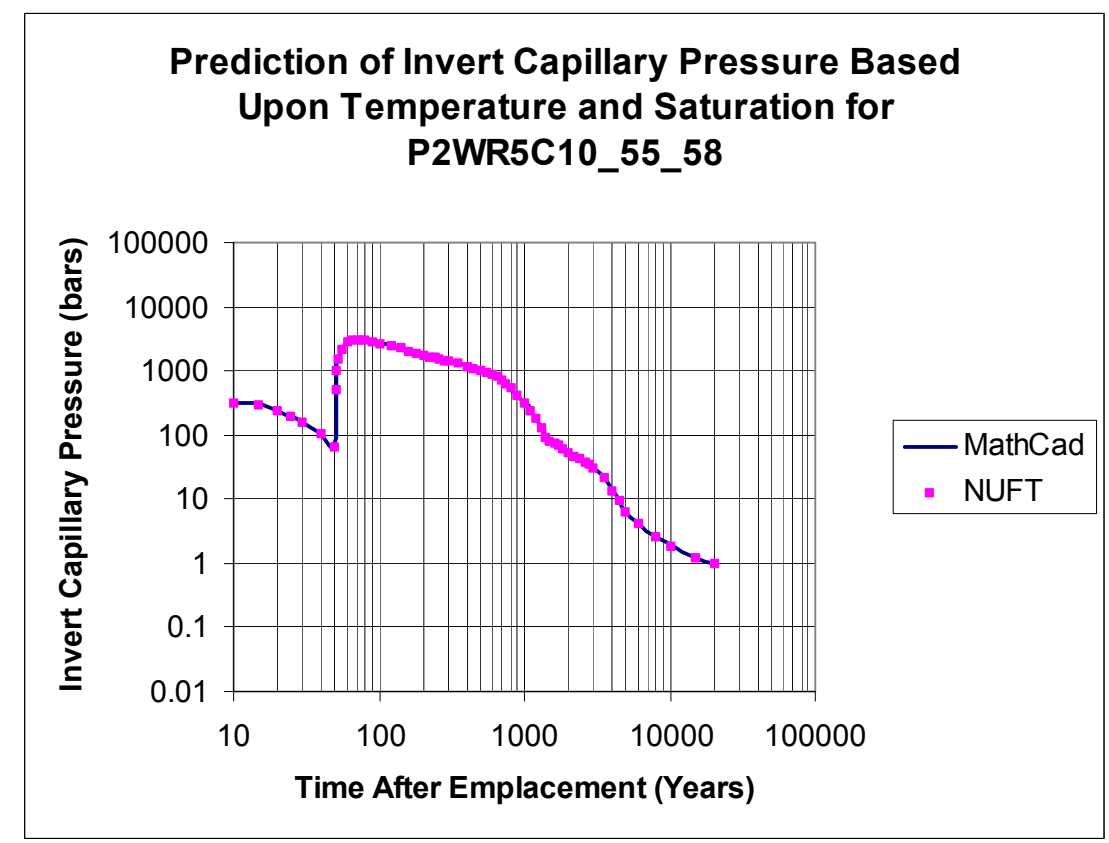

Figure XV-8. Comparison of Invert Capillary Pressure Between the MathCad 11 and Multiscale Calculations

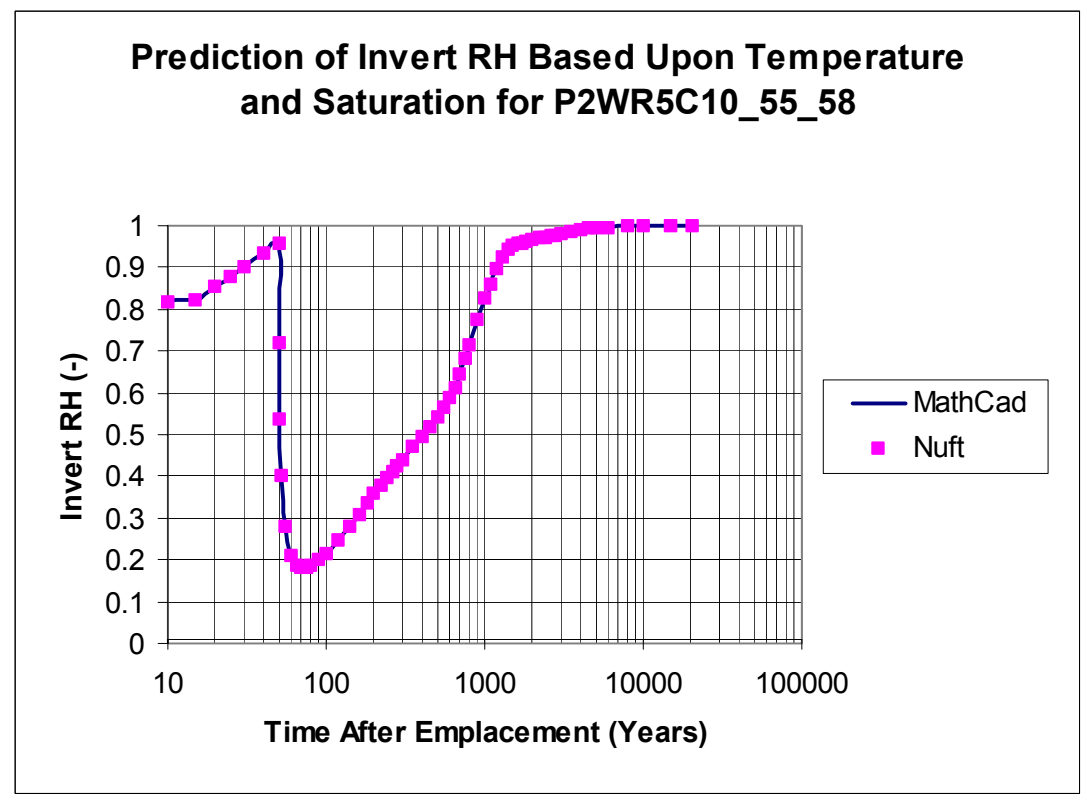

NOTE: The data for this plot are presented in the Workbook Outputs to the Prediction of the Invert.xls on worksheet RH_vs_t_P2WR5C10_55_58.pltsc and worksheet Math11. A complete listing of the data is presented on that worksheet.

Figure XV-9. Comparison of Invert Relative Humidity Between the MathCad 11 and Multiscale LDTH Calculations 


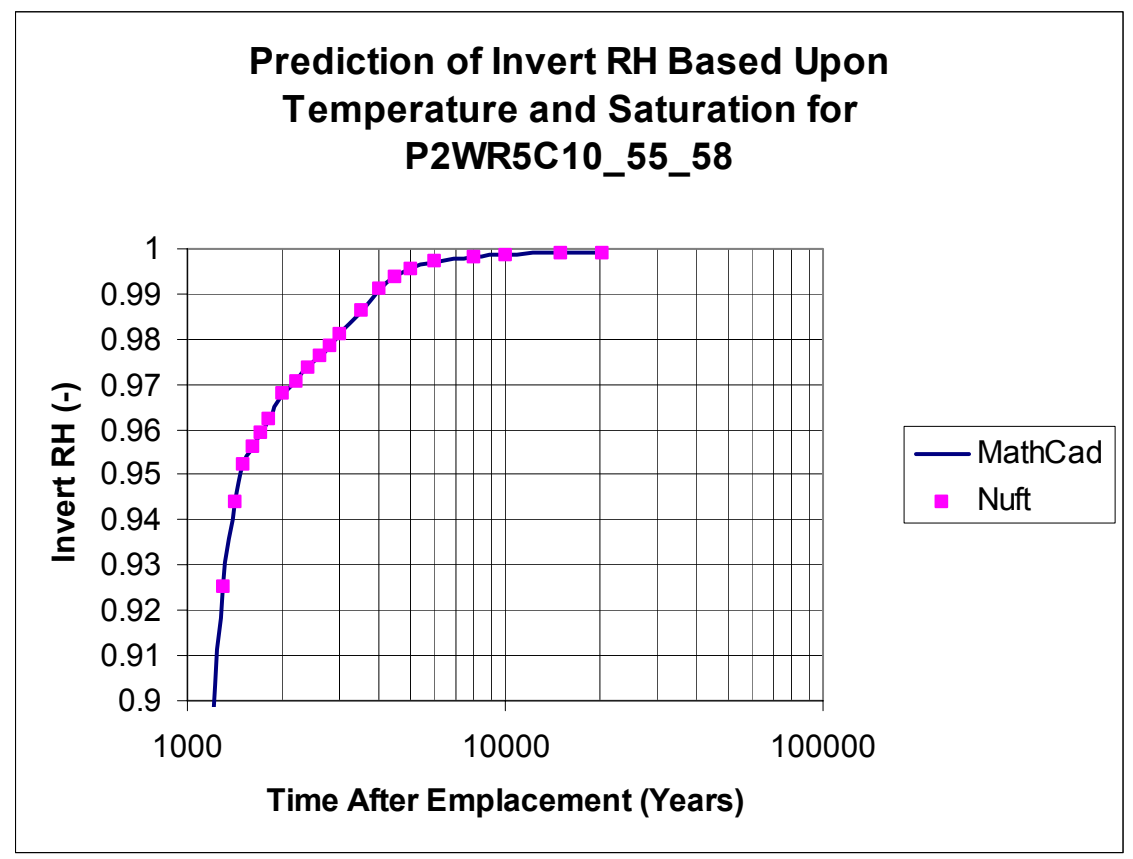

NOTE: the data for this plot are presented in the Workbook Outputs to the Prediction of the Invert.xls on worksheet RH_vs_t_P2WR5C10_55_58.pltsc and worksheet Math11. A complete listing of the data are presented on that worksheet.

Figure XV-10. Comparison of Invert Relative Humidity Between the MathCad 11 and Multiscale Calculations Near 100 Percent Relative Humidity

\section{XV.9 CONCLUSIONS}

The relative humidity is a smooth function based upon the Kelvin equation, the van Genuchten equation, and the temperature saturation from the multiscale thermohydrologic model. The results of the two calculations are in agreement. 